

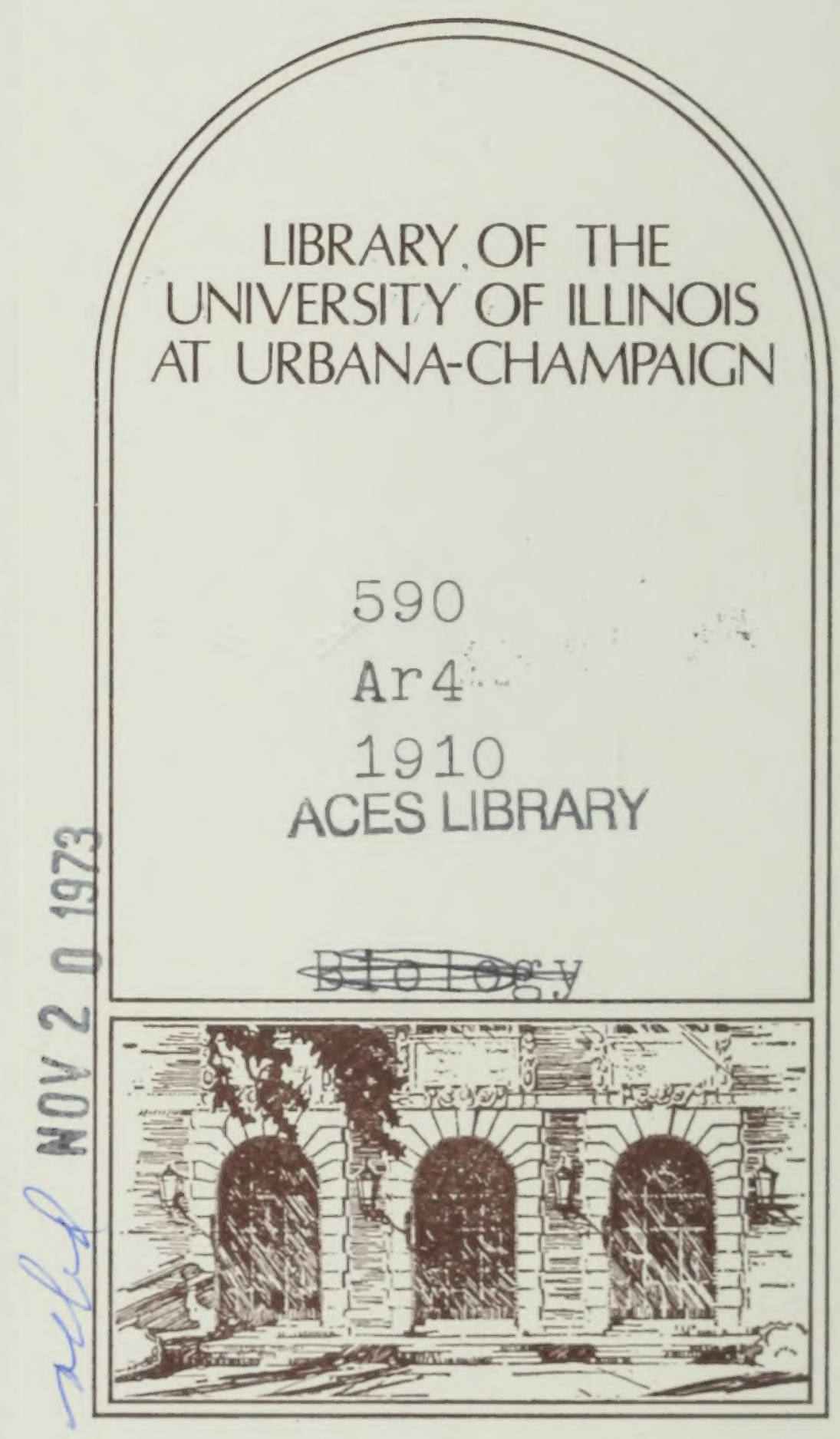


The person charging this material is responsible for its return to the library from which it was withdrawn on or before the Latest Date stamped below.

Theft, mutilation, and underlining of books are reasons for disciplinary action and may result in dismissal from the University.

UNIVERSITY OF ILLINOIS LIBRARY AT URBANA-CHAMPAIGN

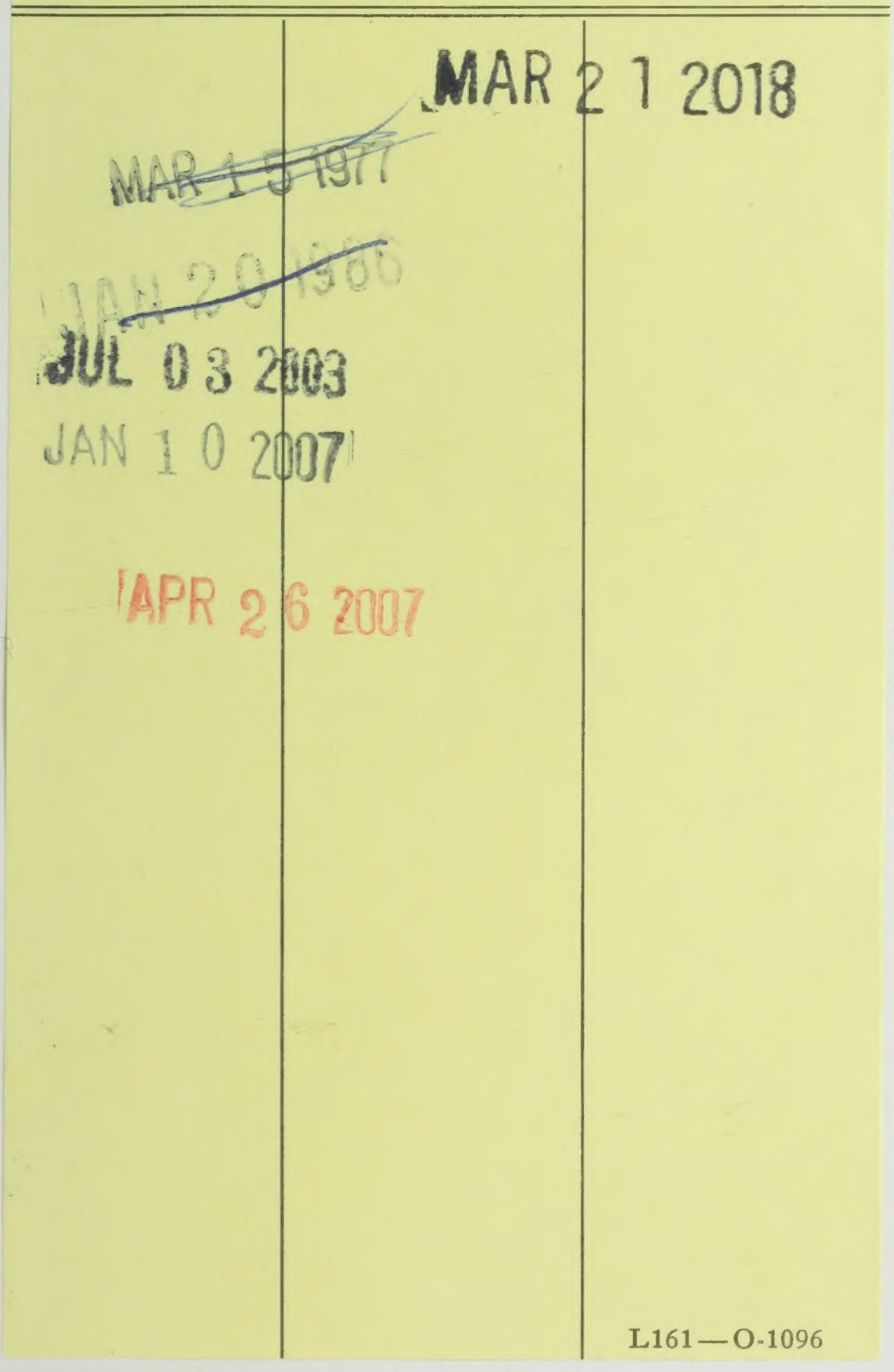


Digitized by the Internet Archive in 2018 with funding from

University of Illinois Urbana-Champaign Alternates 


\section{THE}

\section{WORKS OF ARISTOTLE}

TRANSLATED INTO ENGLISH

UNDER THE EDITORSHIP

OF

J. A. SMITH M.A.

WAYNFLETE PROFESSOR OF MORAL AND METAPHYSICAL PHILOSOPHY FELLOW OF MAGDALEN COLLEGE

W. D. ROSS M.A.

FELLOW OF ORIEL COLLEGE

VOLUME IV

\section{HISTORIA ANIMALIUM}

BV

D'ARCY WENTWORTH THOMPSON

OXFORD

AT THE CLARENDON PRESS 



\section{0 \\ Ar4 \\ 1910}

ACES LIBRARY

\section{PREFACE}

IT was the desire of the late Master of Balliol, Dr. Benjamin Jowett, as formulated in his will, that the proceeds from the sale of his works, the copyright in which he bequeathed to Balliol College, should be used to promote the study of Greek Literature, especially by the publication of new translations and editions of Greek authors. In a codicil to his will he expressed the hope that the translation of Aristotle's works begun by his own translation of the Politics should be proceeded with as speedily as possible. The College resolved that the funds thus accruing to them should, in memory of his services to the College and to Greek letters, be applied to the subvention of a series of translations of the works of Aristotle. Through the co-operation, financial and other, of the Delegates of the University Press it has now become possible to begin the realization of this design. By agreement between the College and the Delegates of the Press the present editors were appointed to superintend the carrying out of the scheme. The series is published at the joint expense and risk of the College and the Delegates of the Press.

The editors have secured the co-operation of various scholars in the task of translation. The translations make no claim to finality, but aim at being such as a scholar might construct in preparation for a critical edition and commentary. Wherever new readings are proposed the fact will be indicated, but notes justificatory of conjectural emendations or defensive of novel interpretations will, where admitted, be reduced to the smallest compass. 
The editors, while retaining a general right of revision and annotation, will leave the responsibility for each translation to its author.

$$
\begin{aligned}
& \text { J. A. S. } \\
& \text { W. D. R. }
\end{aligned}
$$

This book has been compiled at various times and at long intervals during very many years. The translation, which owes much to my father's helping hand in years long gone by, is based upon the text of Bekker; but in subsequent revisions I have included all that seemed to me most useful and appropriate from the texts or textual annotations of Schneider, Aubert and Wimmer, Piccolos, and Dittmeyer. To the emendations proposed by these commentators I have added some few of my own, which will be found brought together in a brief appendix. Many of these suggestions of mine are admittedly venturesome, and but very few of them have been adopted in my translation; but they all relate to passages where the text as it at present stands is in my opinion faulty, and where conjecture may be a help towards further consideration and ultimate emendation.

The so-called Tenth Book of the Historia Animalium has not been translated. It is spurious beyond question, and its contents have neither general nor particular interest.

My editors have been liberal in allowing me greater scope of annotation than was contemplated in the outset for the volumes of this series; but nevertheless I have felt constrained to omit much that I had written, especially on the zoological side of my commentary. To annotate, illustrate, and criticize Aristotle's knowledge of natural history is a task without an end.

Many friends and colleagues have given me abundantly of their knowledge and advice, and my editors have been assiduous in all manner of help and counsel.

D. W. T. 


\title{
HISTORIA ANIMALIUM
}

\author{
BY
}

D'ARCY WENTWORTH THOMPSON M.A., C.B. PROFESSOR OF NATURAL HISTORY IN UNIVERSITY COLLEGE, DUNDEE 


\author{
HENRICO JACKSON \\ PHILOSOPHI \\ DISCIPVLO CONDISCIPVLVS \\ PHILOSOPHIAE \\ TIRVNCVLVS PRIMIPILARI
}




\section{PREFATORY NOTE}

Is the following notes I have taken little account of matters of geography, but it seems worth while to call attention to the frequent reference in this book, and in certain other Aristotelian writings, to the island of Lesbos and to places in and near it (cf. Strabo xiii. 2).

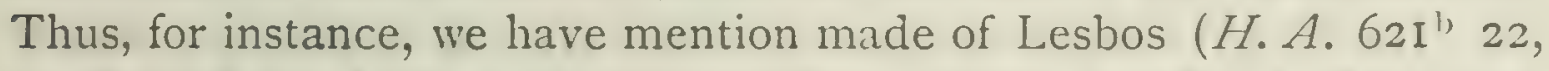
G. A. $763^{\mathrm{b}}$ I), Antissa (Probl. $1303^{\mathrm{a}} 34$, Oecon。 I $347^{\mathrm{a}}$ 25), Arginussa

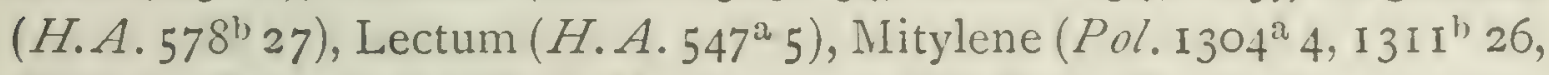

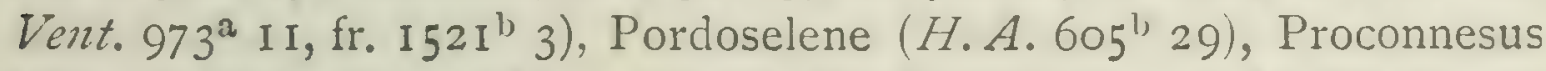
(Vent. $973^{\mathrm{a}}$ 20, fr. 152 I $^{\mathrm{b}}$ 1 3 ), Pyrrha $\left(G \cdot A \cdot 763^{\mathrm{b}}\right.$ 1), and the Pyrrhaean

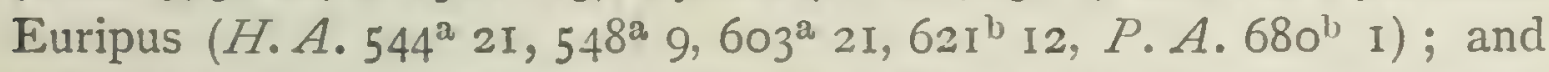
I think it, further, not improbable that $M a \lambda \epsilon_{n}\left(H \cdot A \cdot 548^{\mathrm{b}} 25\right)$ should be Madia, the south-eastern promontory of Lesbos.

We know that Aristotle spent two years in Mitylene, when he was about forty years old: that is to say, some three years after the death of Plato, just after his sojourn with Hermias of Atarneus, just prior to his residence at the court of Philip, and some ten years before he returned to Athens to begin teaching in the Lyceum (Dion. Hal. Ep.I ad Ammaeum, p. 727 R). Throughout the Natural History references to places in Greece are few, while they are comparatively frequent to places in Macedonia and to places on the coast of Asia Minor, all the way from the Bosphorus to the Carian coast. I think it can be shown that Aristotle's natural history studies were carried on, or mainly carried on, in his middle age, between his two periods of residence in Athens; that the calm, landlocked lagoon at Pyrrha was one of his favourite hunting-grounds; and that his short stay in Euboea, during the last days of his life, has left little if any impress on his zoological writings.

Then it would appear that Aristotle's work in natural history was antecedent to his more strictly philosophical work, and it would follow that we might proceed legitimately to interpret the latter in the light of the former. And remembering that Speusippus also was a naturalist (to whose writings on fish and shellfish Athenaeus bears abundant testimony), we might permit ourselves to surmise that inquiries into natural history were in no small degree to be reckoned with as a cause of the modification of Plato's doctrine, alike, though not identically, at the hands of Aristotle and of the later Academy. 



\section{ERRATA}

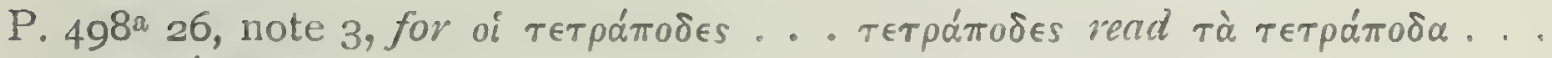
$\tau \in \tau \rho \alpha ́ \pi 0 \delta \alpha$.

P. $525^{\mathrm{b}} 30$, figure, transpose the numbers I, 2.

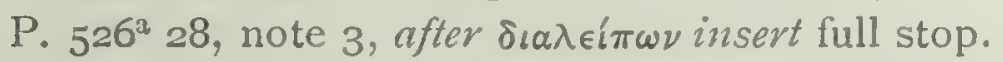

P. $59 \mathrm{I}^{\mathrm{a}} \mathrm{I} 7$, note I, for Epinephilus read Epincphelus.

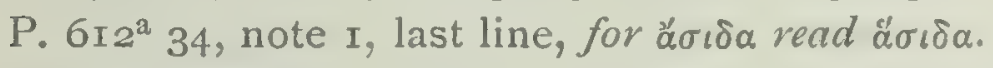

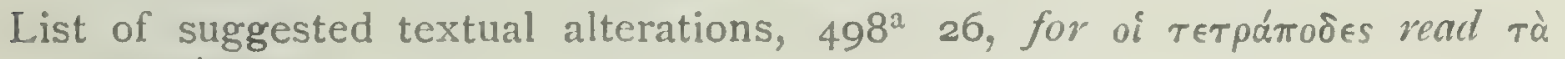
$\tau \in \tau \rho a ́ \pi v \delta \alpha$. 



\section{CONTENTS}

$\mathrm{CH}$.

\section{BOOK I.}

I. Of parts, simple and composite; of species and genera; and of differences in form, character, and habits.

2. Of the organs of alimentation and of excretion.

3. Of the organs of the male and female; of the sense of touch.

4. Of the moisture in animals; of blood and vein.

5. Of animals viviparous, oviparous, and vermiparous; of organs of locomotion, feet, fins, and wings.

6. Of the genera of animals, such as birds, fishes, serpents, cetaceans, testaceans, crustaceans, molluscs; and of isolated species, such as man.

7. Of the parts of the body; of the skull and its sutures.

8. Of the face and forehead.

9, Io. Of eyes and eyebrows.

II. Of ears, nose, and tongue.

I2. Of the neck and thorax.

I3, I4. Of the belly and navel; and of the private parts.

I5. Of the trunk and limbs.

I6. Of the brain; of the lungs and windpipe; of the gullet and stomach.

I7. Of the heart and other viscera.

BOOK II.

I. Of the limbs and their movements: of the huckle-bone; of wild cattle, elephants, camels, and of the martichore; and of other matters.

$2,3,4,5$. Of the teeth of dogs, of horses, of man, and of the elephant.

6. Of the elephant's tongue.

7. Of the mouth; and of the Egyptian hippopotamus.

8, 9. Of apes and monkeys.

Io. Of the crocodile.

II. Of the chameleon.

I2. Of the characters of birds; and of the Yunx or wryneck.

33. Of fishes; and of the dolphin.

14. Of serpents and of sea-serpents; and of the fish Echeneis.

I5. Of the chief genera of viviparous animals, and of their viscera; of maggots in the stag's head; of the gall-bladder.

16. Of the kidneys and bladder.

17. Of the heart and liver; of the stomach in ruminants, in the elcphant, in birds, and in fishes; of the anatomy of serpents; of the eyes of serpents and of swallow-chicks. 


\section{CONTENTS}

$\mathrm{CH}$.

\section{BOOK III.}

1. Of the organs of generation: in fishes, birds, and serpents; and in viviparous animals.

2. Of the veins, according to Syennesis and Dingenes of Apollonia.

3, 4. Of the same according to Polybus; and of the true system of the veins or blood-vessels.

5. Of sinews.

6. Of fibre, and of the clot of blood.

7. Of the bones.

8. Of cartilage, or gristle.

9. Of horns, nails, and hooves.

IO, I I. Of hair and skin; of baldness and of grey hair.

12. Of feathers; and of the influence of climate and season on the colour of feathers and of hair.

13. Of the membranes of the bones and of the brain.

14, 15 . Of membranous parts : of the omentum or caul, and of the bladder. I6. Of flesh.

17. Of fat and suet.

18. Of the pupil of the eye.

19. Of blood in health and disease.

20. Of marrow and of milk.

2I. Of milk; of the sheep and oxen of İpirus; of rennet and cheese.

22. Of the seed of animals.

BOOK IV.

1. Of the several genera of bloodless animals; of the poulpe or octopus. and of other molluscs or cuttlefishes.

2, 3. Of crustaceans.

4. Of testaceans.

5. Of sea-urchins.

6. Of tethya or ascidians; and of sea-nettles or sea-anemones.

7. Of insects; and of certain anomalous marine animals.

8. Of the senses: of the mole's eye; of hearing. smell and taste in fishes. and in bloodless animals.

9. Of voice and sound : in fishes, birds, and certain other animals.

10. Of sleep and waking : of the catching of fish asleep; of dreaming.

I1. Of the nature of male and female; of the eel; and of the fishes called capon-fish.

\section{BOOK $\mathrm{V}$.}

1. Of generation, spontaneous and hereditary.

2. Of pairing and copulation: in birds and in viviparous quadrupecis.

3. Of the same in oviparous quadrupeds.

4. Of the same in serpents and other animals of long bodies.

5. Of the same in fishes; and on the anomalous generation of the partridge. 


\section{CONTENTS}

CH.

6. Of pairing and copulation in molluscs or cuttlefishes.

7. Of the same in crustaceans.

8. Of the pairing of insects; of the season of pairing; and of the bird called halcyon.

9. Of the season of pairing: in birds, in insects, and in fishes.

10, 11. Of the same in fishes.

12. Of the same in molluscs or cuttlefishes, and in testaceans.

13. Of the same in birds, both wild and domesticated.

14. Of the signs of age and of maturity, and of the pairing seasons: in man and quadrupeds.

I5. Of the generation of the purple murex and other testaceans; and of the starfish and of the hermit crab.

i6. Of the spontaneous growth of the sea-nettle and of sponges.

17. Of the breeding habits of crustaceans.

18. Of the breeding habits of molluscs.

19. Of the breeding habits of insects; of creatures that live on snow and in fire; and of the ephemera.

20. Of the breeding habits of the hunter-wasp or ichneumon.

21 . Of the breeding habits of bees.

22. Of the varieties of bees; and of honey.

23. Of the breeding habits of wasps.

24 . Of the breeding habits of the humble-bee.

25. Of the breeding habits of ants.

26. Of the breeding habits of the scorpion.

27 . Of the breeding habits of spiders.

28,29 . Of the breeding habits of grasshoppers and locusts.

30. Of the breeding habits of the cicada, or tettix.

3I. Of insects spontaneously generated: of fleas and of lice; of the parasites of fishes.

32. Of the clothes-moth; of the grub called 'faggot-bearer'; of the figwasp, and of the device of caprification.

33. Of the generation of the tortoise, the lizard and the crocodile.

34. Of the generation of serpents, and of the viper.

\section{BOOK VI.}

I. Of the pairing and nesting of birds.

2. Of egrss, their colour, shape, structure, and maturation; of wind-eggs; of the pairing-habits of pigeons.

3. Of the structure of the hen's egg, and of the development of the chick therein; of twin-eggs.

4. Of the breeding habits of pigeons.

5. Of the vulture; and of swallow-chicks.

6. Of eagles; and of their treatment of their young.

7. Of the cuckoo; and of its laying in an alien nest.

8. Of the brooding of pigeons, crows, and partridges. 


\section{CONTENTS}

Cis.

c. Of the habits of pea-fowl.

10. Of the generation of cartilaginous fishes; of the embryo and its membranes in the smooth dog-fishes.

11. Of the breeding of cartilasinous tishes continued; of the fish called Rhinobatus.

12. Of the dolphin and other cetaceans, and of the seal; and of their generation and parturition.

I 3. Of the generation of oviparous fishes.

14. Of the carp and sheat-fish, and some other fishes of fresh-water.

15. Of the spontaneous generation of certain fishes.

16. Of the anomalous generation of eels.

17. Of the spawning season in fishes; of the pipe-fish; and of the tunny and mackerel.

IS. ()i the phenomena of pairing and conception in viviparous animals, as camels, elephants, horses, kine, and swine.

1). The same of sheep and goats.

20. The same of dogs.

21. The same, with further particulars, of cattle.

22. The same of horses; and of the substance called Hippomanes.

23. The same of asses.

24. Of mules; and of the Syrophocnician mules that pair and breed: of an old mule at Athens.

25. Of the signs of age in quadrupeds.

26. Of camels.

27. Of elephants.

28 . Of wild swine.

2\%. Of deer.

3c. Of bears.

31. Of lions.

32. Of the hyaena; and of its fabled ambiguity of sex.

33. Of hares.

34. Of the fox.

35. Of the wolf, the weasel, the ichneumon and the thos or civet.

36. Of the Syrian mules.

37. Of mice and of their prodigious fecundity; of the mice in Persia and in Egypt.

\section{BOOK VII.}

1. Of the signs of puberty in man and woman.

2. Of the so-called catamenia.

3. Of the signs of conception; of effluxion and abortion.

4. Of pregnancy; of twins and of multiple births.

5. Of lactation; and of the period of child-bearing.

6. Of the duration of fecundity; of individual differences in regard to procreation and child-bearing; of the inheritance of deformity; and of resemblance to parents. 


\section{CONTENTS}

CH.

7. Of impregnation; and of development within the womb.

8. Of the embryo.

9. Of labour or parturition.

10. Of delivery; and of the infant.

I I. Of milk; and of ailments of the breast.

I2. Of infantile convulsions and other maladies.

\section{BOOK VIII.}

I. Of the psychology of animals; of the principle of continuity in the scale of organisms; and of the definition of plant and animal.

2. Of terrestrial and aquatic animals, and of various aspects of this distinction; of the dolphin; of the effect upon development of minute changes in the embryo; of the habits and diet of various marine animals ; of eels and eel-fishing.

3. Of the diet and habits of birds.

4. The same of lizards and of serpents.

5. The same of wild quadrupeds.

6. Of drinking; and of the diet and fattening of swine.

7. Of the feeding and fattening of cattle; of the Pyrrhic or Epirote cattle.

8. Of the feeding of horses, mules, and asses; and of the watering of domestic animals.

9. Of the diet of the elephant; and of the length of life of elephants and of camels.

IO. Of the diet of sheep and of goats.

II. Of the food of insects.

12. Of the migration of birds.

13. Of the habitat and migration of fishes.

14. Of the winter-sleep or hibernation of insects.

I5. The same of fishes.

16. The same of birds.

17. The same of quadrupeds; and of the renewal of youth by sloughing or casting the skin in serpents, insects, and crustaceans.

I 8. Of season and weather, and of drought and moisture, in relation to birds and other animals.

19. The same of fishes; of parasites of fishes.

20. Of maladies peculiar to certain fishes; of lice in the sea; of devices for catching fish by poison and otherwise; of rain and drought, and heat and cold, in relation to shell-fish.

21 . Of the diseases of swine.

22. The same of dogs, and of the camel and elephant.

23. The same of cattle.

24. The same of horses.

25. The same of the ass.

26. The same of the elephant.

27. Of insects; of the parasitic enemies of the bee. 


\section{CONTENTS}

Cir.

28. Of cliversity of local habitation; and of climate as affecting the forms of animals.

29. Of the same as affecting their habits; and of venomous creatures in certain countries.

30. Of the condition of fishes and other marine animals in respect of season.

\section{BOOK IX.}

I. Of the psychology of animals; of the psychological differentiation of the sexes; of the sympathy and antipathy of various animals one to another; and of the habits of the elephant.

2. Of fishes that swim in shoals; and of fishes that are hostile to one another.

3. Of the habits and intelligence of sheep and goats.

4. The same of cattle and of horses.

5. The same of the stag and hind.

6. Of the habits of various animals; of the natural remedies that they employ; of the cunning of the hedgehog; and of the Ictis or marten.

7. Of the nesting of the swallow; and of the habits of pigeons and of partridges in regard to pairing, brooding, and rearing of the young.

8. The same continued.

9. Of woodpeckers.

IO. Of the intelligence of cranes; and of pelicans.

11. Of eagles and vultures; and of the wren and other birds.

12. Of swans and of the swan's song; of the chalcis or cymindis; and of other birds.

i 3. Of the jay; of the filial love of the stork and of the bee-eater; and of the cinnamon-bird.

14. Of the halcyon and its nest.

15. Of the hoopoe and other birds.

I6. Of the reed-warbler.

17. Of the crake; of the sitta or nut-hatch; and of the tree-creeper.

I8. Of herons.

I0. Of owsels; of the white owzels of Cyllene; and of the laius or blucthrush.

20. Of thrushes.

21. Of the blue-bird or wall-creeper.

22. Of the oriole.

23. Of the birds called pardalus and coljyrion; and of crows and ravens.

24. Of daws and choughs.

25. Of larks.

26. Of the woodenck.

27. Of the Egyptian ibis.

28 . Of the little ho:ned owls. 


\section{CONTENTS}

$\mathrm{CH}$.

29. Of the cuckoo.

30. Of the bird called cypselus; and of the goat-sucker.

31. Of ravens.

32. Of eagles.

33. Of a great bird in Scythia.

34. Of the phene or lammergeyer.

35. Of the petrel.

36. Of hawks; of hawking in Thrace ; and of the wolves by Lake Moeotis.

37. Of the habits of the fishing-frog, of the torpedo, and of other fishes; and of the sepia and the argonaut.

38. Of industrious insects; of the ant.

39. Of spiders and of the spider's web.

40. Of the whole economy of bees.

41. Of wasps.

42. Of the wasps called anthrenae.

43. Of humble-bees.

44. Of the temper and disposition of the lion and other animals.

45. Of the bison on Mount Messapium.

46. Of elephants.

47. Of camels; and of the King of Scythia's mare.

48. Of the affectionate disposition of the dolphin.

49. Of hens that assume the plumage of the cock.

50. Of the effects of castration or mutilation; of rumination or chewing the cud.

49 B. Of change of plumage, or metamorphosis, in birds; of the hoopoe; of birds bathing in water or in dust. 



\section{BOOK I}

I OF the parts of animals some are simple: to wit, all such $486^{\mathrm{a}} 5$ as divide into parts uniform with themselves, as flesh into flesh; others are composite, such as divicle into parts not uniform with themselves, as, for instance, the hand does not divide into hands nor the face into faces. ${ }^{1}$

${ }^{1}$ Cf. P.A. ii. I and 2 ; Theophr. H.Pl.i.2; Ps.-Arist. de Pl.i. 2 and 3. A treatise might be written on the intention and the history of the distinction here drawn by Aristotle, who had derived it from Anaxagoras (cf. Lucret. i. 830 ; Serv. ad Aen. iv. 625; Cic. Q. Acad.iv. 57 ; Galen, de Dogm. Hipp. v. 450, 673, ed. Kühn, \&c.). 'The subject is treated more fully in the de Purtibus (ii. I, \& c.), where A. distinguishes three degrees of composition or synthesis. The first is composition out of

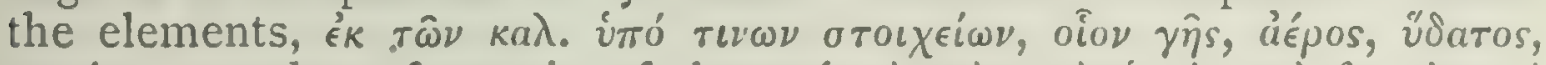

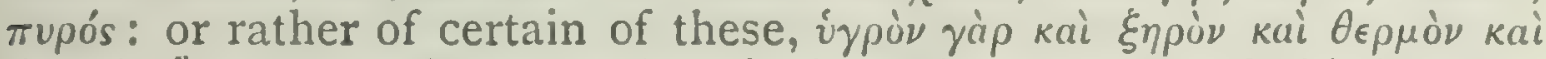

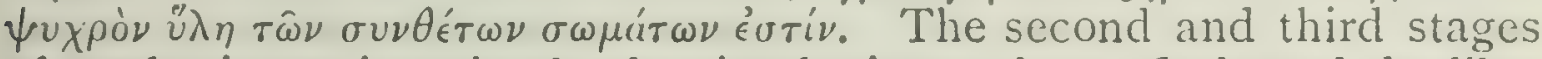
of synthesis are, in animals, the simple tissues, bone, flesh, and the like, and the organs that are built up of these (cf. Galen, xv. $7 \mathrm{~K}$.).

In Meteor. iv. Io the simple and composite parts of plants and animals are compared with the like categories of inanimate things, the former with such o $\mu о \iota \rho \mu \rho \hat{\eta}$ as gold and silver, tin and iron, kai ós $a$ ék

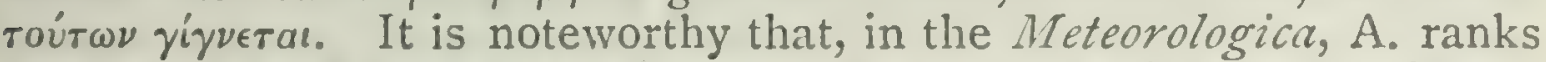

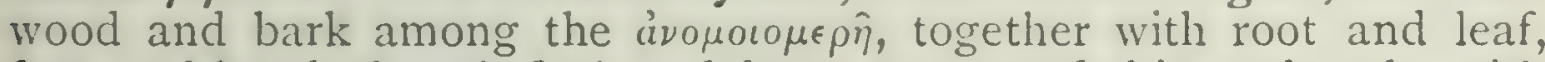
face and hand, though flesh and bone, nerve and skin rank only, with fibre and muscle, among the $\delta \mu \circ о \mu \epsilon \rho \hat{\eta}$; in other words, the histological analysis is carried somewhat further on the botanical than on the zoological side. As to sap and juice and fibre and vessel and flesh, these are elementary things, so far as biology conducts us: aip xai yiip

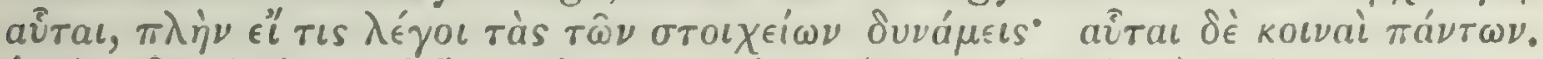

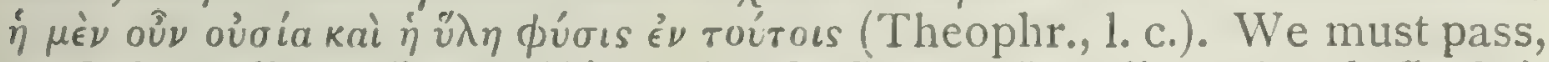
as Galen tells us (i. $487 \mathrm{~K}$.), to the de Gen.et Corr. ii, or the de Caelo i, for a discussion of the elements, and of the relation to these of the influences of wet and dry, hot and cold, \&c. As Aristotle's account of the elements remained the groundwork of the mediaeval conception of matter, so the older naturalists retained unaltered his distinction of simple and composite parts in the fabric of living things. The

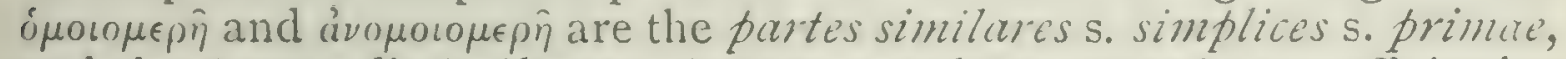
and the partes dissimilart's s. instrumcntales s. organicae' s. officinale's, of the naturalists. Wotton, for instance (de Diff. Amim.i. 4; 1552), gives a very fair epitome of the tissues as follows: 'Similares numerantur hac, os, cartilago, vena, arteria, nervus, ligamentum, tendo, membrana, caro, adeps, unguis, cutis; his adduntur humores, ut sangruis, et qui in oculo sunt, cristallinus et vitreus humor.' The division into tissues and organs of Bichat (Anat. générale', 1801) was thus quite on old lines.

AR. H.A. 
And of such as these, some are called not parts merely; but limbs or members. Such are those parts that, while cntire in themselves, have within themselves other diverse ro parts: as, for instance, the head, foot, hand, the arm as a whole, the chest; for these are all in themselves entire parts, and there are other diverse parts belonging to them. ${ }^{1}$

All those parts that do not subdivide into parts uniform with themselves are composed of parts that do so subdivide, for instance, hand is composed of flesh, sinews, and bones.

$I_{5}$ Of animals, some resemble one another in all their parts, while others have parts wherein they differ. ${ }^{2}$ Sometimes the parts are identical in form or species, as, for instance, one man's nose or eye rescmbles another man's nose or cyc, flesh flesh, and bone bone; and in like manner with a horse,

${ }^{1}$ P. A. i. 5. $645^{\mathrm{b}} 35$.

${ }^{2} \breve{\epsilon}^{\prime} \chi \epsilon \iota \delta \hat{\epsilon} \tau \hat{\omega} \nu \zeta \omega \hat{\omega} \nu$. The succeeding passage is not easy to translate, but its meaning scems to me to be exquisitely clear, and its statements to be ordered with an admirable logic. Of animals, some have all their parts alike, each to other, alike in one horse and in another horse, in one man and in another man. Such animals are alike in form or species, and differ only as individuals. Sume, again, liave the same parts, but the properties or accidents there of are contrary or opposite. or at least differ in degree. Such animals are alike in kind, or genus, as fishes are or birds, but differ specifically. Moresver, in certain cases, some part altogether new may supervene in one species though lacking in others, like the cock's comb, which is something singular and unmatched among birds; but we must not unduly estimate the importance of such minor accretions, which leave the totality of the organism insignificantly changed. Thirdly, we may have animals under observation whose parts neither are identical nor differ only by accident or in degree; but which, on the contrary, have an essential unlikeness, and only risemble one another in the way of analogy : for analogy might be described as the likeness between things essentially different, or as being no more than that resemblance which is conferred by similarity of place, use, or greneral sirnificance. For instance, a bird's feather is not the same thing as a fish's scale, nor is the difference one of accident or of degree; but they are separate things, inciuded under no single concept, and such rescmblance as they possess one to another is best clescribed as an analogy: and the creatures that bear them are not of the same genus, but of different genera. While these matters are of chief importance, there is a sort of difference not to be altogether overlooked, the difference of position, in parts that are still manifestly the same: as in the case of teats, that are pectoral in one animal and inguinal in another. Iastly, passing from animals in their integrity to the tissues of which they are composed, these may be classified according to the simpler classifications of elementary things, which fall into such simple categories as solid and fluid, or hard and soft, or wet and dry. Of sucli simple contrasts, flesh and bone, or blood and artery, are simple instances. 
and with all other animals which we reckon to be of one and the same species: for as the whole is to the whole, so 20 each to each are the parts severally. In other cases the parts are identical, save only for a difference in the way of excess or defect, as is the case in such animals as are of one and the same genus." By 'genus' I mean, for instance, Bird or Fish, for each of these is subject to difference in respect of its genus, ${ }^{2}$ and there are many species of fishes and of birds.

Within the limits of genera, most of the parts as a rule exhibit differences through contrast of the property $\mathrm{Or}^{\cdot} 486^{\mathrm{b}}$ : accident, such as colour and shape, to which they are subject: in that some are more and some in a less degree the subject of the same property or accident; and also in the way of multitude or fewness, magnitude or parvitude, in short in the way of excess or defect. Thus in some the texture of the flesh is soft, in others firm; some have a long bill, ${ }^{4}$ others a short one; some have 10 abundance of feathers, others have only a small quantity. It happens further that some have parts that others have not: for instance, some have spurs and others not, some have crests and others not; but as a gencral rule, most parts and those that go to make up the bulk of the body 5 are either identical with one another, or differ from one another in the way of contrast and of excess and dcfect. For 'the more' and 'the less' may be represented as 'excess' or 'defect'.

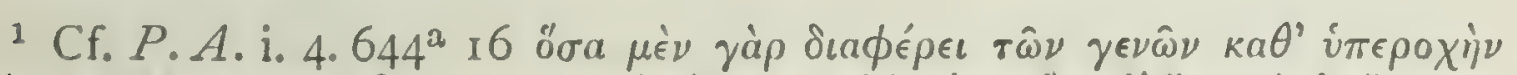

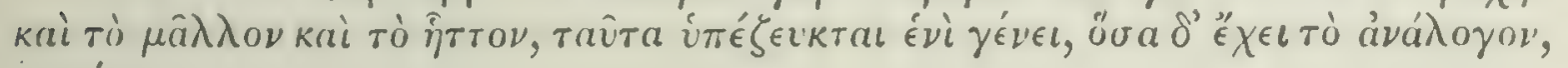
¿wpís.

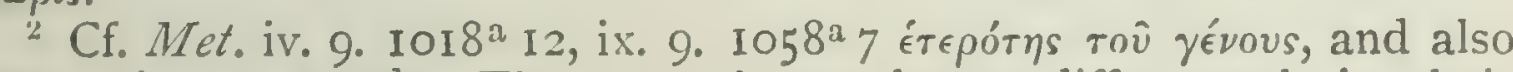
Met. vi. 12. $1037^{\mathrm{b}}$. The several translators differ much in their rendering of this passage, and in the text which they follow. Scaliger reads 'Horum enim utrumque differt tum in genere, tum si ad genus referantur' ; and Schneider 'tum in (suo) genere, tum si ad (alterum)

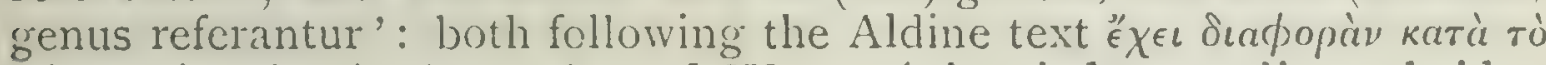

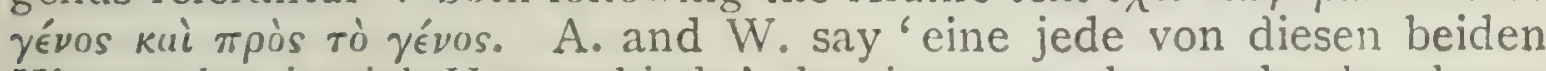
Klassen hat in sich Unterschiede', that is to say, they make the phrase of the same import as the succeeding and more expanded clause.

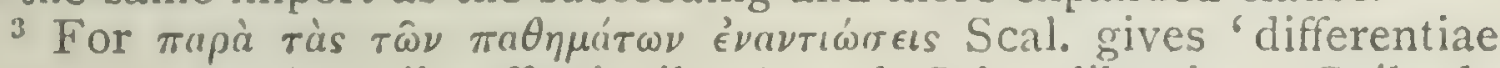
sumuntur a contrariis affectionibus', and Schn. likewisc: Guil. de Moerbeke, on the other hand, 'inter se ipsa praeter,' which rendering

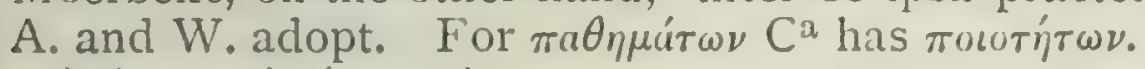

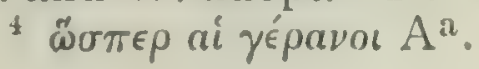


Once again, we may have to clo with animals whose parts are neither identical in form nor yet identical save for differences in the way of excess or defect: ${ }^{1}$ but they are the same only in the way of analogy, as, for instance, bone is 20 only analogous to fish-bonc, nail to hoof, hand to claw, and scale to feather; for what the feather is in a bird, the scale is in a fish.

The parts, then, which animals severally possess are diverse from, or identical with, one another in the fashion above described. And they are so furthermore in the way of local disposition: for many animals have identical organs that differ in position; for instance, some have teats in the $487^{\mathrm{a}}$ breast, others close to the thighs.

Of the substances that are composed of parts uniform (or homogeneous) with themselves, some are soft and moist, others are dry and solid. The soft and moist are such either absolutely or so long as they are in their natural conditions. as, for instance, blood, serum, lard, suet, marrow; sperm. gall, milk in such as have it, flesh and the like; and also, 5 in a different way, the superfluitics, ${ }^{2}$ as phlegm and the excretions of the belly and the bladder. The dry and solid are such as sinew, skin, vein, hair, bone, gristle, nail, horn (a term which as applicd to the part involves an ambiguity, since the whole also by virtue of its form is dero signated horn), ${ }^{3}$ and such parts as present an analogy to these.

1 i.e. we may have to do with animals neither specifically nor generically identical.

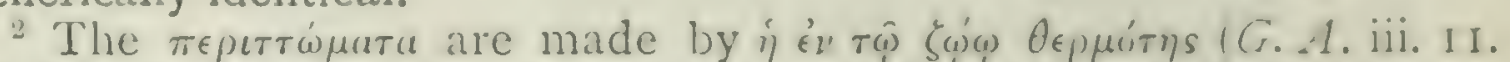

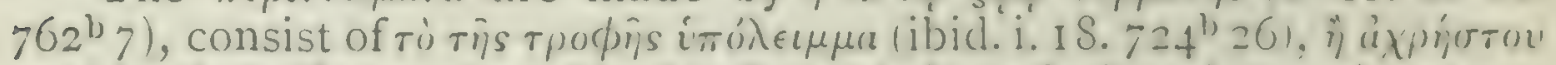

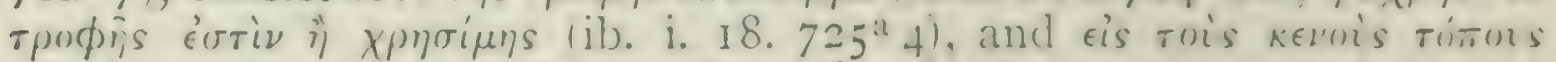

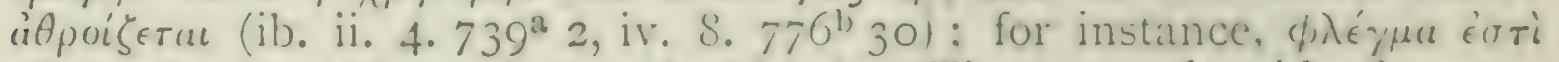

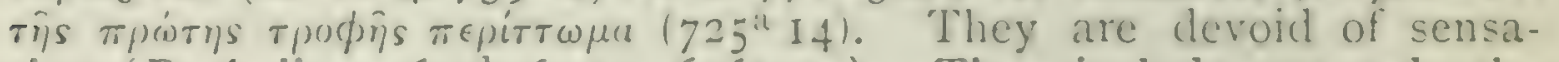
tion (P.A. ii. 7. 652 b, 10. $\left.656^{\mathrm{a}} 24\right)$. They include not only the excretions of bladder and intestine, but also blood, lard, sperm, gall, milk (though in the present passage these are apparently excluded), and even the eggs of birds. From the $\pi \epsilon \iota \tau \tau \dot{\omega} \mu a \tau \imath$ are formed bone, sinew, hair, nails, teeth and such like. They seem to be, in A.'s mind, the not-living constituents of the body, the 'formed material', as we say. For reff. see Bonitz, s. $\%$.

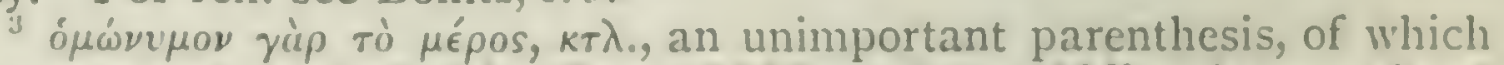
the true text is doubtful. Some MSS. and the Aldine have rpous to

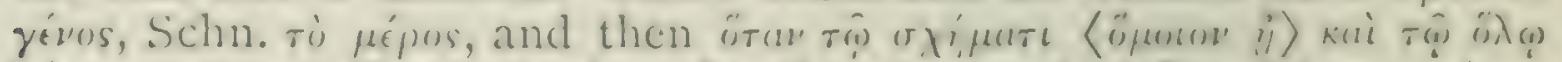

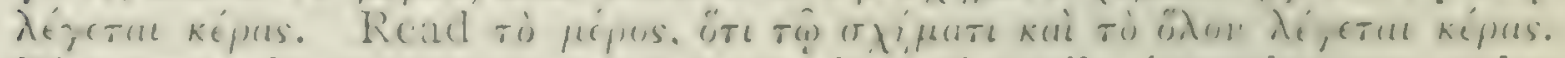
The sense is according to the version of Guil., 'aequivocum enim cum totum pars et figura dicatur cornu.' 
Animals differ from one another in their modes of subsistence, in their actions, in their habits, and in their parts. Concerning these differences we shall first speak in broad and general terms, and subsequently we shall treat of the same with close reference to each particular genus.

Differences are manifested in modes of subsistence, in habits, in actions performed. For instance, some I $_{5}$ animals live in water and others on land. ${ }^{1}$ And of those that live in water some do so in one way, and some in another: that is to say, some live and feed in the water, take in and emit water, and cannot live if deprived of water, as is the case with the great majority of fishes ${ }^{2}$ others get their food and spend their days in the 20 water, but do not take in water but air, nor do they bring forth in the water. Many of these creatures are furnished with feet, as the otter, the beaver, and the crocodile; some are furnished with wings, as the diver and the grebe; some are destitute of feet, as the water-snake. Some creatures get their living in the water and cannot exist outside it: but for all that do not take in either air or water, as, for 25 instance, the sea-nettle and the oyster. And of creatures that live in the water some live in the sea, some in rivers, some in lakes, and some in marshes, as the frog and the newt. ${ }^{3}$

Of animals that live on dry land some take in air and emit it, which phenomena are termed 'inhalation' and 'cxhalation'; as, for instance, man and all such land 30 animals as are furnished with lungs. Others, again, do not inhale air, yet live and find their sustenance on dry land; as, for instance, the wasp, the bee, and all other insects. And by 'insects' I mean such creaturcs as have nicks or notches on their bodies, either on their bellies or on both backs and bellies. ${ }^{4}$

And of land animals many, as has been said, derive their $487^{\text {b }}$ subsistence from the watcr; but of creatures that live in

1 H. A. viii. 2. $589^{2}$.

2 Eels can crawl on dry ground, P.A. iv. I3. $696^{a} 5$. Cf. also

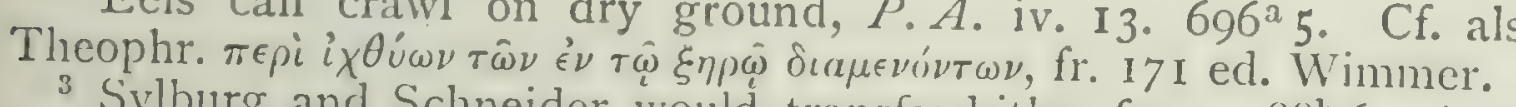

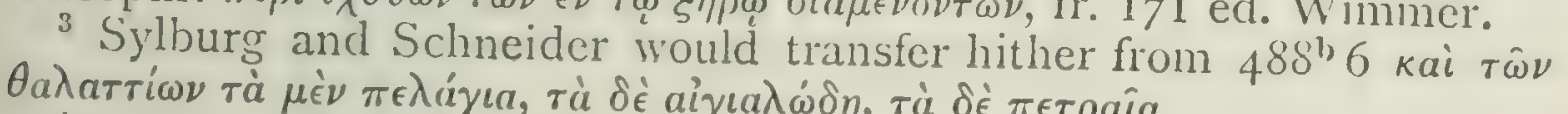
${ }^{4}$ H. A. iv. I. $523^{\mathrm{b}}$ I 5 .
. 
and inhale water not a single one derives its subsistence from dry land.

Some animals at first live in water, and by and by change their shape and live out of water, as is the case with 5 river worms, ${ }^{1}$ for out of these the gadfly ${ }^{2}$ develops.

Furthermore, some animals are stationary, and some are crratic. Stationary animals are found in water, but no such creature is found on dry land. In the water are many creatures that live in close adhesion to an external object, as is the case with sercral kinds of oyster. And, by the way, the sponge appears to be cndowed with a certain ro scnsibility: as a proof of which it is alleged ${ }^{3}$ that the difficulty in detaching it from its moorings is increased if the movement to detach it be not covertly applied.

Other creatures adhere at one time to an object and detach themselves from it at other times, as is the case with a species of the so-called sea-nettle; for some of these creatures seek their food in the night-time loose and unattached.

Many creatures are unattached but motionless, as is the is case with oysters and the so-called holothuria. ${ }^{4}$ Some can swim, as, for instance, fishes, molluscs, ${ }^{5}$ and crustaceans, such as the crawfish. But some of these last move by walking. as the crab, for it is the nature of the creature. though it lives in water, to move by walking.

Of land animals some are furnished with wings, such as birds and bees, and these are so furnished in different ways 20 one from another; others are furnished with feet. Of the animals that are furnished with fect some walk, some crecp, and some wriggle. ${ }^{6}$ But no creature is able only to move by flying, as the fish is able only to swim. for the animals with leathern wings can walk; the bat has foct and the scal has imperfect feet. ${ }^{7}$

Some bircls have fect of little power, and are therefore

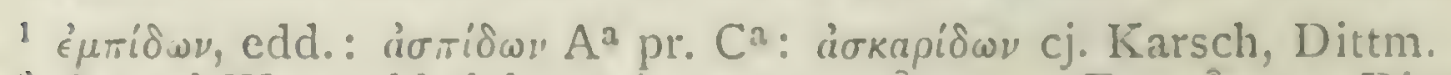

2 A. and W. would delete yiverat... oíorpos. For oîtpos Dittm.

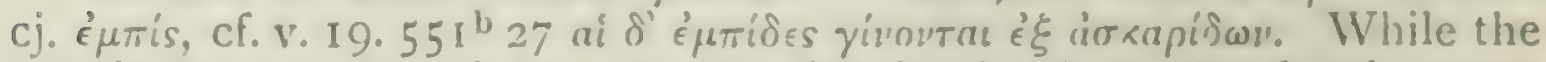
text is more or less faulty, the allusion is clearly to the development

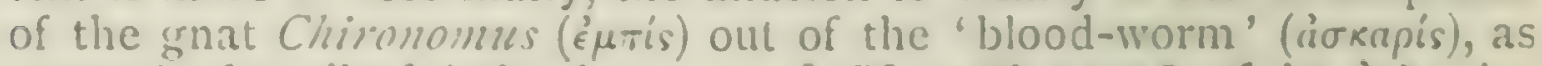

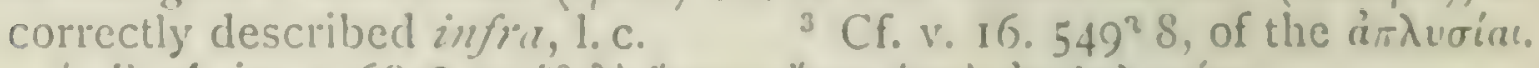

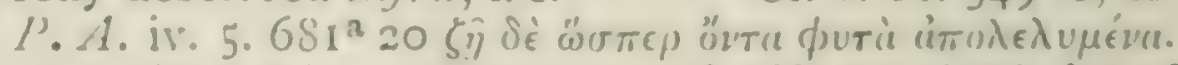

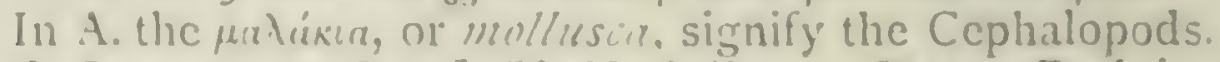

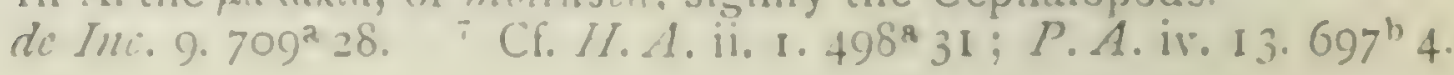


called Apodes. ${ }^{1}$ This little bird is powerful on the wing; 25 and, as a rule, birds that resemble it are weak-footed and strong-winged, such as the swallow and the drepanis or (?) Alpine swift; for all these birds resemble one another in their habits and in their plumage, ${ }^{2}$ and may easily be mistaken one for another. (The apus is to be seen at all seasons, but the drepanis only after rainy weather inso summer; for this is the time when it is seen and captured, though, as a general rule, it is a rare bird.)

Again, some animals move by walking on the ground as well as by swimming in water.

Furthermore, the following differences are manifest in their modes of living and in their actions. Some are gregarious, some are solitary, whether they be furnished $488^{a}$ with feet or wings or be fitted for a life in the water; and some partake of both characters, the solitary and the gregarious. And of the gregarious, ${ }^{3}$ some are disposed to combine for social purposes, others to live each for its own self.

Gregarious creatures are, among birds, such as the pigeon, the crane, and the swan; and, by the way, no bird furnished with crooked talons is gregarious. Of creatures that 5 live in water many kinds of fishes are gregarious, such as the so-called migrants, the tunny, the pelamys, and the bonito.

Man, by the way, presents a mixture of the two characters, the gregarious and the solitary.

Social creatures are such as have some one common object in view; and this property is not common to all creatures that are gregarious. Such social creatures are man, the bee, the wasp, the ant, and the crane.

Again, of these social creatures some submit to a ruler,

1 H. A. ix. 30. 6r $8^{a} 31$; Plin. H.N. x. 39, xi. 47. “̈movs may be the swift, or perhaps the cliff-martin or sand-martin; $\delta \rho \in \pi(t)$ is, lit. ' sicklewing', is, alternatively, either the large alpine, or the common swift; cf. Gl. of Gk. Birds, p. 34 .

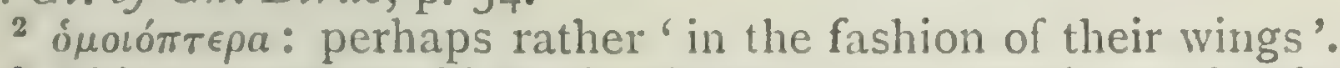

3 This passage would be simple and clear were it not for the words

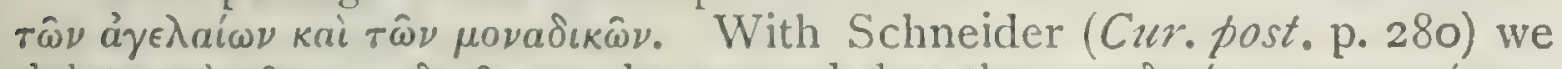

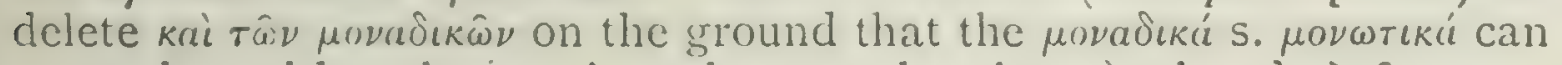

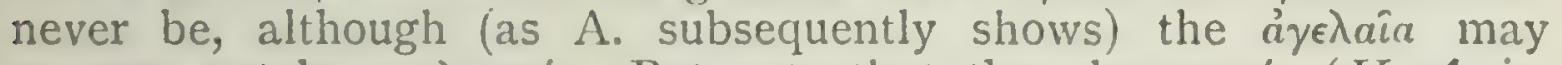

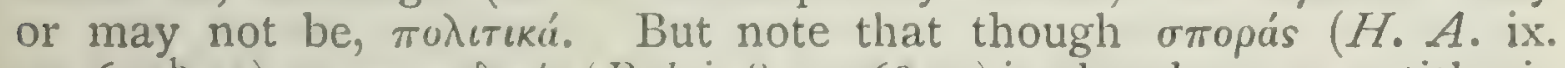
25. $617^{\mathrm{b}} 2 \mathrm{I}$ ) or $\sigma \pi$ opuoikís (Pol. i. S. $1256^{\mathrm{a}} 23$ ) is elsewhere an antithesis

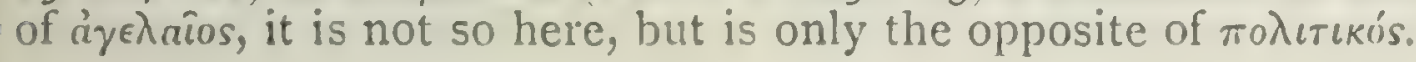


others are subject to no governance: as, for instance, the cranc and the several sorts of bee submit to a ruler, whereas ants ${ }^{1}$ and numerous other creatures ${ }^{2}$ are every one his own master.

And again, both of gregarious and of solitary animals, some are attached to a fixed home and others are erratic or nomad.

I5 Also, some are carnivorous, some graminivorous, some omnirorous: whilst some fecd on a peculiar dict, as for instance the bees and the spiders, for the bee lives on honcy and certain other sweets, and the spider lives by catching flics; and some creatures live on fish. Again, some creatures catch their food, others treasure it up: 20 whereas others do not so.

Some creatures provide themselves with a dwelling, others go without one: of the former kind are the mole, the mouse, the ant, the bee; of the latter kind are many insects and quadrupeds. Further, in respect to locality of dwelling-place, some creatures dwell under ground, as the lizard and the snake; others live on the surface of the ground, as the horse and the dog. [Some make to 25 themselves holes, others do not so.] ${ }^{3}$

Some are nocturnal, as the owl and the bat; others live in the daylight.

Morcorer, some creatures are tame and some are wild: some are at all times tame, as man ${ }^{4}$ and the mule; others are at all times savage, as the leopard and the wolf; and some creatures can be rapidly tamed, as the clephant.

Again, we may regard animals in another light. For, 30 whenever a race of animals is found domesticated, the same is always to be found in a wild ${ }^{5}$ condition; as we find to be the case with horses, line, swinc, [men.] sheep, goats, and clogs.

1 Cf. Pror. vi. 7.

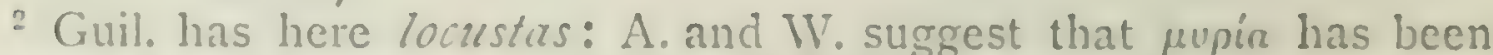

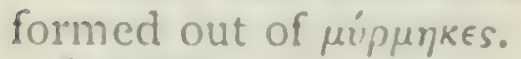
${ }^{3}$ [ ] Dittm.

$488^{2} 27$, Dittm. cj. oinv yivuos, where all MSS. and edd. have niov "iv $\theta$ pwros; a more plausible conjecture, following the ductus litterrmum, would perhaps be oiov öнos, îmos. In the next sentence, where perhaps

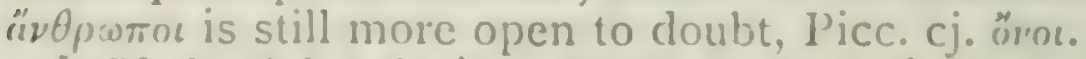

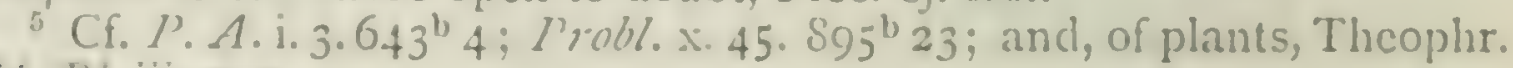
11. Ti.ii. 2. 2 . 
Further, some animals cmit sound while others are mute, and some are endowed with voice: of these latter some have articulate speech, ${ }^{1}$ while others are inarticulate; some are given to continual chirping and twittering, some are prone to silence; some are musical, and some unmusical; but all animals without exception exercise their power of singing $488^{\mathrm{b}}$ or chattering chiefly in connexion with the intercourse of the sexes.

Again, some creatures live in the fields, as the cushat; some on the mountains, as the hoopoe; some frequent the abodes of men, as the pigeon.

Some, again, are peculiarly salacious, as the partridge, ${ }^{2}$ the barn-door cock and their congeners; others are inclined to chastity, as the whole tribe of crows, for birds of this $a$ kind indulge but rarely in sexual intercourse. ${ }^{3}$

Of marine animals, again, some live in the open seas, some near the shore, some on rocks. ${ }^{4}$

Furthermore, some are combative under offence; others are provident for defence. Of the former kind are such as act as aggressors upon others or retaliate when subjected to ill usage, and of the latter kind are such as ro merely have some means of guarding themselves against attack.

Animals also differ from one another in regard to character in the following respects. Some are good-tempered, sluggish, and little prone to ferocity, as the ox; others are quick-tempered, ferocious and unteachable, as the wild boar; some are intelligent and timid, as the stag and the is hare; others are mean and treachcrous, as the snake; others are noble and couragcous and high-bred, as the lion; other's are thorough-bred and wild and treacherous, as the wolf: for, by the way, an animal is high-bred" if it come from a noble stock, and an animal is thorough-bred if it does not deflect from its racial characteristics.

1 H.A.iv. 9. $535^{\mathrm{a}} ;$ Poet. 20. $1456^{\mathrm{b}}$.

${ }^{2}$ G. A. ii. $7 \cdot 746^{\mathrm{b}} \mathrm{I} ;$ Ael. iv. I, \&c.

${ }^{3}$ Cf. G. A. iii. 6. $756^{\mathrm{b}}$ I9.

4 See note, $487^{a} 27$.

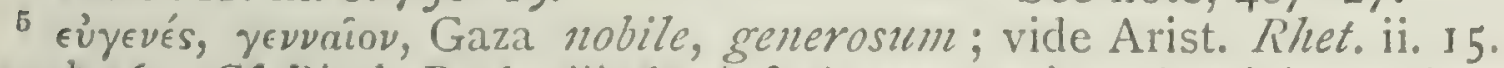

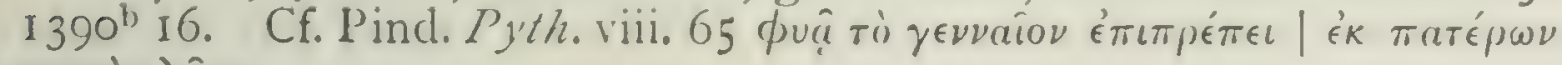

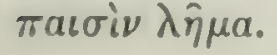


20 Further, some are crafty and mischievous, as the fox; some are spirited ${ }^{1}$ and affectionate and fawning, as the dog; others are easy-tempered and casily domcsticated, as the elephant; others are cautious and watchful, as the goose ; others are jealous and self-conceited, as the peacock. But of all animals man alone is capable of deliberation.

25 Many animals have memory, ${ }^{2}$ and are capable of instruction; but no other creature except man can recall the past at will.

With regard to the several gencra of animals, particulars as to their habits of life and modes of existence will be discussed more fully by and by.

${ }^{3}$ Common to all animals are the organs whereby they 30 take food and the organs whereinto they take it; ${ }^{4}$ and these are either identical with one another, or are diverse in the ways above specified: to wit, either identical in form, or varying in respect of excess or defect, or resembling one another analogically, or differing in position.

Furthermore, the great majority of animals have other organs besides these in common, whereby they discharge the residum of their food: I say, the great majority, for

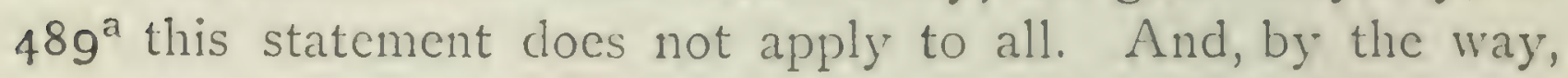
the organ whereby food is taken in is called the mouth, and the organ whereinto it is taken, the belly; the remainder of the alimentary system has a great variety of names.

Now the residuum of food is twofold in kind, wet and dry, and such creatures as have organs receptive of wet residum are invariably found with organs receptive of dry residuum; ; but such as have organs receptive of clry resi-

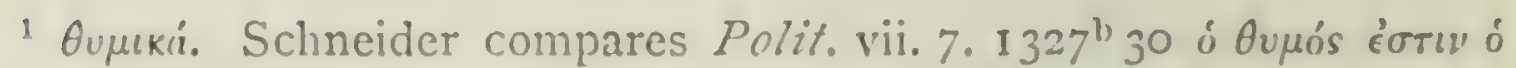

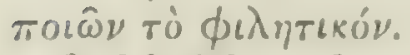

${ }^{2}$ Cf. Metapinys.i. I.

3 A. begins here to refer to function, and to speak of organs in relation to their particular function: this subject is discussed much more fully in $P^{\prime}$. 1. i. 5 and other portions of the same work.

P. A. ii. 10. $655^{\mathrm{b}} 30$.

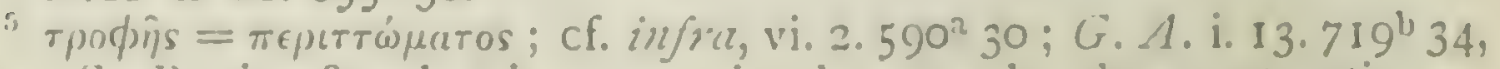
Sc. So bonitz, \&c., but it seems simpler to take the construction as 
cluum need not possess organs receptive of wet residuum. In other words, an animal has a bowel or intestine ${ }^{1}$ if it 5 have a bladder; but an animal may have a bowel and be without a bladder. And, by the way, I may here remark that the organ receptive of wet residuum is termed 'bladder', and the organ receptive of dry residuum 'intestine or bowel'.

3 Of animals otherwise, ${ }^{2}$ a great many have, besides the organs above-mentioned, an organ for excretion of the sperm: and of animals capable of generation one secretes io into another, and the other into itself. ${ }^{3}$ The latter is termed 'female', and the former 'male'; but some animals have neither male nor female. Consequently, the organs connected with this function differ in form, for some animals have a womb and others an organ analogous thereto.

The above-mentioned organs, then, are the most indis- 15 pensable parts of animals; and with some of them all animals without exception, and with others animals for the most part, must needs be provided.

One sense, and one alone, is common to all animalsthe sense of touch. ${ }^{4}$ Consequently, there is no special name for the organ in which it has its seat; for in some groups of animals the organ is identical, in others it is only analogous.

4 Every animal is supplied with moisture, and, if the 20 animal be deprived of the same by natural causes or artificial means, death ensues: further, every animal has another part in which the moisture is contained. These parts are blood and vein, and in other animals there is

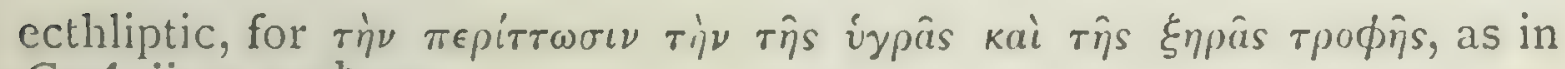
G. A. ii. $4 \cdot 737^{\mathrm{b}} 34$.

1 For the various meanings of koı ía cf. Bonitz, s.

$2 \tau \hat{\omega} \nu \delta \dot{\epsilon} \lambda o \iota \pi \hat{\omega} \nu$. 'Reliqua dicit animalia respiciens ad reliqua membra et partes communes vel singulares animalium,' Schneider.

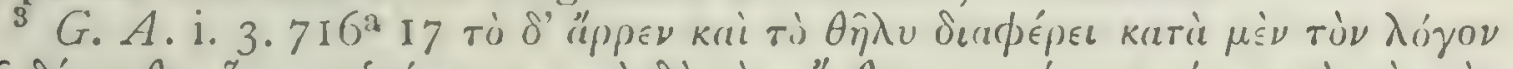

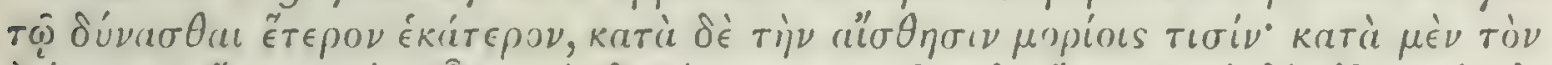

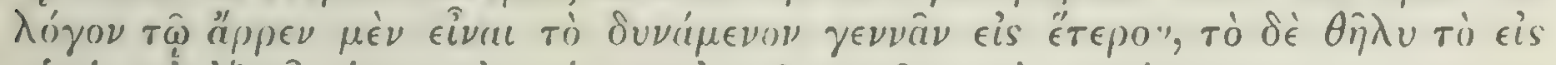

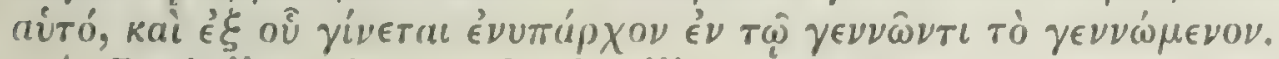

I P.A. ii. 1. $647^{\mathrm{a}}$; de An. iii. 13. $435^{\mathrm{a}}$. 
something to correspond ; ${ }^{1}$ but in these latter the parts are imperfect, being merely fibre and scrum or lymph.²

Touch has its scat in a part uniform and homogeneous, as in the flesh or something of the kind," and generally, 25 with animals supplied with blood, in the parts charged with blood. In other animals it has its seat in parts analogous to the parts charged with blood; but in all cases it is scated in parts that in their texture are homogeneous.

The active faculties, ${ }^{4}$ on the contrary, are seated in the parts that are heterogencous: as; for instance, the business of preparing the food is seated in the mouth, and the office of locomotion in the fect, the wings, or in organs to correspond.

30 Again, some animals are supplied with blood, as man, the horse, and all such animals as are, when full-grown, cither destitute of feet, or two-footed, or four-footed; other animals are bloodless, such as the bee and the wasp, and, of marine animals, the cuttle-fish, the crawfish, and all such animals as have more than four feet.

Again, some animals are viviparous, others oviparous, 5 others vermiparous or 'grub-bcaring'. Some are vivi$489^{\mathrm{b}}$ parous, such as man, the horse, the seal, and all other animals that are hair-coated, and, of marine animals, the cctaccans, as the doiphin, and the so-called Sclachia. (Of these latter animals, some have a tubular air-passage and no gills, as the dolphin and the whale: ${ }^{5}$ the dolphin with the air-passage going through its back, the whale with the

1 H. A. iii. 4. 5 I $5^{\mathrm{a}} 23$.

2 That ixwp takes the place of blood in beings without the latter, we know from $11 . \mathrm{v} \cdot 340$, with which Schn. appositely compares Anacreont.

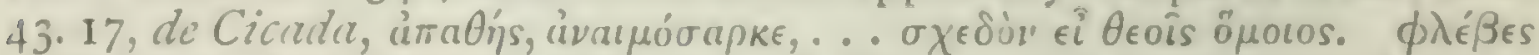

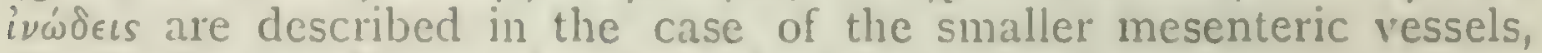
H. A. iii. $4.514^{\mathrm{b}}$ : see also the end of the same chapter.

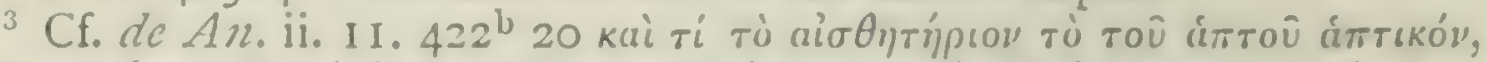

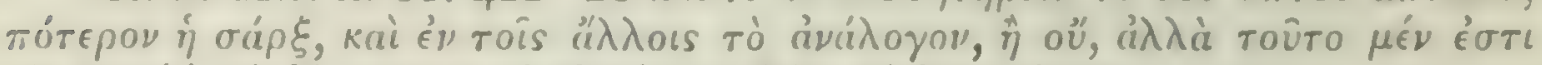

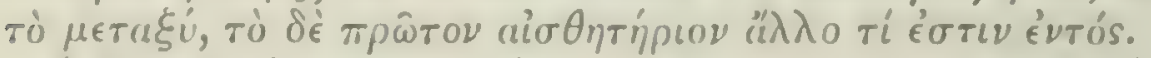

${ }^{4}$ The main contrast is with the senses, not excluding other functions such as the supply of moisture or of air. We should probably say "The more mechanical operations are performed', \&c.

${ }^{6}$ Plin. ix. 7.

'Si̊̀ rov v'́rov, which, according to Schneider, 'spatium inter caput et

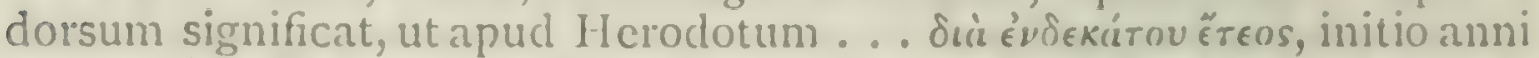
undecimi.' 'The corresponding passages in P.A. iv. 13. $697^{3} 25$, dc

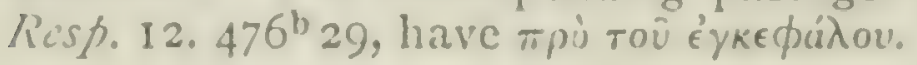


air-passage in its forehead; others have uncovered gills, 5 as the Selachia, the sharks and rays. ${ }^{1}$ )

What we term an egg is a certain completed result of conception out of which the animal that is to be develops, and in such a way that in respect to its primitive germ it comes from part only of the egg, while the rest serves for food as the germ develops."- A 'grub' on the other hand is a thing out of which in its entirety the animal in its entirety develops, by differentiation and growth of the embryo.

Of viviparous animals, some hatch eggs in their own interior, as creatures of the shark kind; others engender in their interior a live foetus, as man and the horse. When the result of conception is perfected, with some animals a living creature is brought forth, with others an egg is brought to light, with others a grub. Of the eggs, some have egg-shells and are of two different colours within, such as birds' eggs; others are soft-slinned and of uniform colour, as 15 the eggs of animals of the shark kind. Of the grubs, some are from the first capable of movement, others are motionless. ${ }^{3}$ However, with regard to these phenomena we shall speak precisely hereafter when we come to treat of Generation.

Furthermore, some animals have feet and some are destitute thereof. ${ }^{4}$ Of such as have feet, some animals have 20 two, as is the case with men and birds, and with men and birds only; some have four, as the lizard and the dog; some have more, as the centipede and the bee; but allsoever that have feet have an even number of them.

Of swimming creatures that are destitute of feet, some have winglets or fins, as fishes: and of these some have four fins, two above on the back, two below on the belly," 25

1 P. A. iv. I $3.696^{\mathrm{b}}$ Io.

2 Cf. G. A. iii. 9. 758 , \&c.

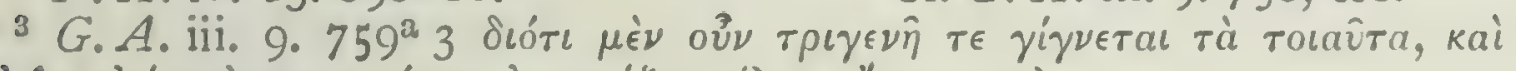

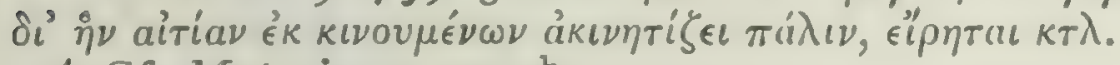

${ }^{4}$ Cf. Met. vi. 12. $1037^{b}$.

5 It is plain that A. is only referring to the paired fins, those, that is to say, that are truly comparable to the limbs of other vertebrates. The terms 'on the back' and 'on the belly' seem scarcely accurate, but they are inserted more for nomenclature than description, as we speak of the hinder pair as the ventral fins, though they may be jugular or

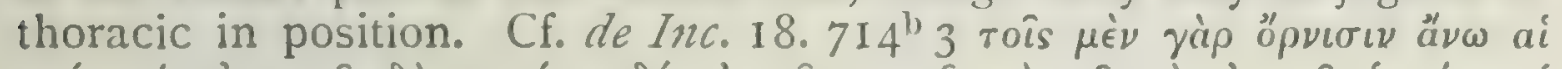

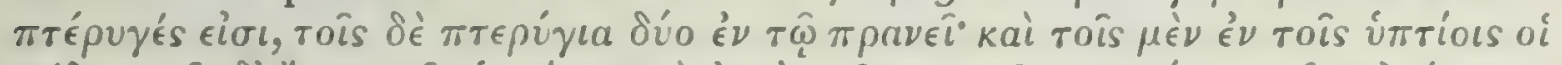

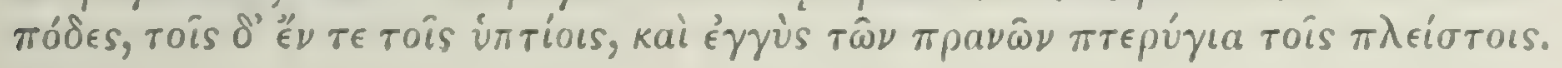


as the gilt-head and the basse: ${ }^{1}$ some have two only, - to wit, such as are excecdingly long and smooth, as the eel and the conger; some have none at all, as the muraena, but use the sea just as snalies use dry ground-and by the way, snakes swim in water in just the same way. ${ }^{2}$ Of the 3. shark-kind some have no fins, such as those that are flat and long-tailed, as the ray and the sting-ray, but these fishes swim actually by the undulatory motion of their flat bodics; the fishing frog; however, has fins, and so likewise have all such fishes as have not their flat surfaces thinned off to a sharp edge."

Of those swimming creatures that appear to have fect, as is the case with the molluscs, these creatures swim by the aid of their fect and their fins as well, and they swim most rapidly backwards in the direction of the trunk, ${ }^{4}$ as is the case with the cuttle-fish or sepia and the calamary: and, by the way, ncither of these latter can walk as the $490^{2}$ poulpe or octopus can.

The hard-skinned or crustaceous animals, like the crawfish, swim by the instrumentality of their tail-parts: and they swim most rapidly tail foremost, by the aid of the fins developed upon that member. The newt swims by means of its feet and tail; and its tail resembles that of the sheat5 fish, to compare little with great.

Of animals that can fly some are furnished with feathered wings, as the eagle and the hawk; some are furnished with membranous wings, ${ }^{\circ}$ as the bee and the cockchafer: others are furnished with leathern wings, as the flying fox ${ }^{6}$ and the bat. All flying creatures possessed of blood have feathered wings or leathern wings; the bloodless creatures have membranous wings, as insects. The creatures that have ro feathered wings or leathern wings have cither two feet ${ }^{\top}$

1 Chrysophrys auratues and Labrax lupus.

2 de Inc. 8. 708a I; Plin. ix. 73.

= P.A.iv. 13. $695^{\mathrm{l}} 22$.

- H.A. iv. I. $524^{\mathrm{a}} \mathrm{I} 3$.

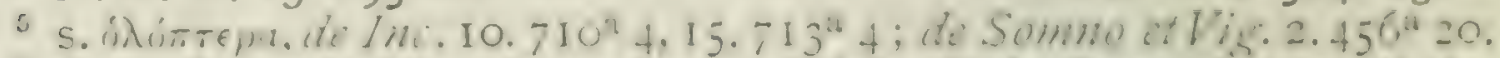

- itiñmg: probably a large bat ; of. "the litule foxes thist spuil the grapes', which were probably the Egyptian fruit-bat, Cymony'teris aregrptiata.

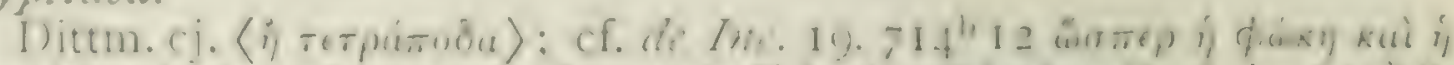

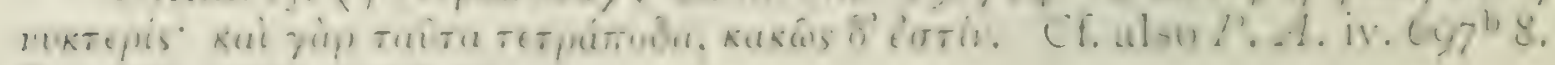
liut sce infiu, $490^{2} 2 S$. 
or no feet at all: for there are said to be certain flying serpents in Ethiopia ${ }^{1}$ that are destitute of feet.

Creatures that have feathered wings are classed as a genus under the name of 'bird'; the other two genera, the leathern-winged and membrane-winged, are as yet without a generic title.

Of creatures that can fly and are bloodless some are coleopterous or sheath-winged, for they have their wings in a sheath or shard, like the cockchafer and the dung- is beetle; others are sheathless, and of these latter some are dipterous and some tetrapterous: tetrapterous, such as are comparatively large or have their stings in the tail, dipterous, such as are comparatively small or have their stings in front. The coleoptera are, without exception, devoid of stings; the diptera have the sting in front, as the fly, the 20 horsefly, the gadfly, and the gnat."

Bloodless animals as a gencral rule are inferior in point of size to blooded animals; though, by the way, there are found in the sea some few bloodless creatures of abnormal size, as in the case of ccrtain molluscs." And of these bloodless genera, those are the largest that dwell in milder climates, and those that inhabit the sea are larger than 25 those living on dry land or in fresh water.

All creatures that are capable of motion move with four or more points of motion ; ${ }^{4}$ the blooded animals with four only: as, for instance, man with two hands and two feet, birds with two wings and two feet, quadrupeds and fishes severally with four feet and four fins. Creatures that have 30 two winglets or fins, or that have none at all like serpents, move all the same with not less than four points of motion; for there are four bends in their bodies as they move, or two bends together with their fins. Bloodless and manyfooted animals, whether furnished with wings or fect, move with more than four points of motion; as, for instance, the dayfly moves with four feet and four wings:" and, I may $490^{b}$ observe in passing, this creature is exceptional not only

1 Herod. ii. $75,76$.

\&. H. A. iv. 1. $524^{2} 26$.

${ }^{2} H \cdot A \cdot$ iv. $7 \cdot 53^{a} 9$.

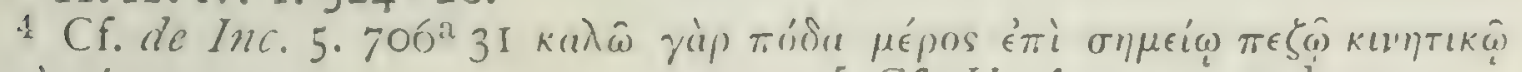

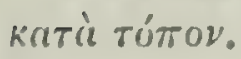

${ }^{5}$ Cf. $H . A$. v. $19.552^{\mathrm{b}} 2 \mathrm{I}$. 
in regard to the duration of its existence, whence it receives its name, but also because though a quadruped it has wings also.

All animals move alike, four-footed and many-footed; 5 in other words, they all move cross-corner-wise. And animals in general have two feet in advance; the crab alone has four. ${ }^{1}$

Very cxtensive genera of animals, ${ }^{2}$ into which other 6 subdivisions fall, are the following: one, of birds; one, of fishes; and another, of cetaccans. Now all these creatures are blooded.

There is another genus of the hard-shell kind, which is so called oyster; ${ }^{3}$ another of the soft-shell kind, not as yet designated by a single term; such as the spiny crawfish and the various kinds of crabs and lobsters; and another of molluscs, as the two kinds of calamary and the cuttle-fish; that of insects is different. All these latter creatures are bloodless, and such of them as have fect have a goodly I5 number of them; and of the insects some have wings as well as feet.

Of the other animals the genera are not extensive. ${ }^{4}$ For in them one species does not comprehend many species;

1 A. seems to take the crab as waiking strictly sideways : cf. de Ini. 17. $713^{\mathrm{b}} 32$.

2 The object of this chapter, as Scaliger clearly points out, is not to define genera, but, where possible, to denominate them : to show how certain familiar terms correspond to real generic groups, while on the other hand for many groups or genera susceptible of definition language has no names to correspond. The modern naturalist devises a new name for each new group that he defines; for . Distotle the definition was enough.

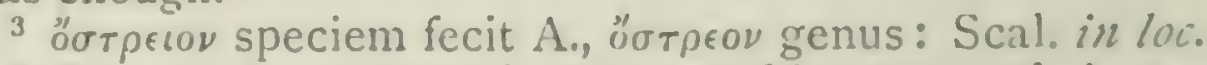

- The whole passage is very troublesome, and A. secms to juggle

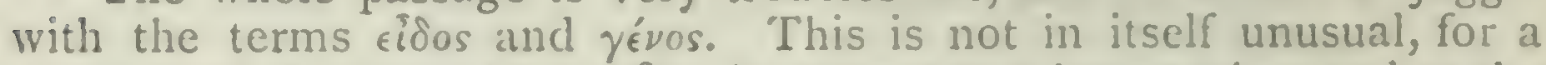
group may of course be an $\epsilon^{3} \delta$ os in respect to a larger yévos, and at the same time a yévos in respect to smaller e"io $\delta$. A. seems to me to be trying to show: (I) that the other large genera comparable to bircl. fish, \&.c., are not generally recognized, and are difficult to define; though 12 the does succed in arriving at, e.g., the genus of viviparous quadrupeds $\left(490^{\circ} 31\right) ;(3)$ that sometimes a genus has many specics, but under no common appellation: for, white this crab and that crab

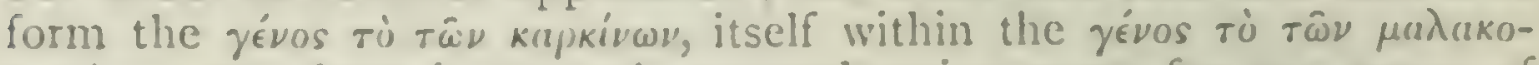

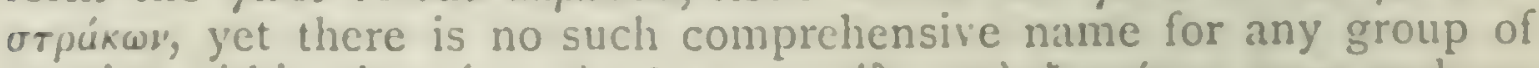

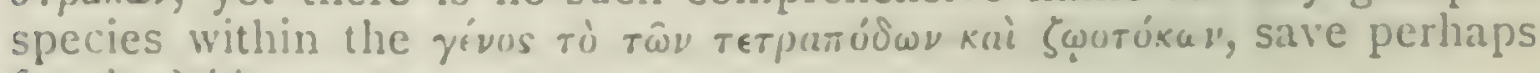
for the nódoupot.

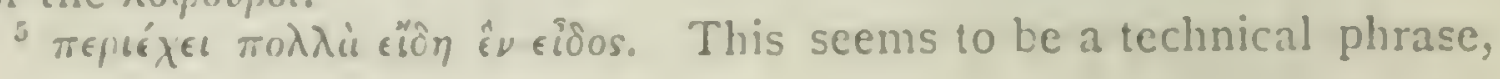


but in one case, as man, the species is simple, admitting of no differentiation, while other cases admit of differentiation, but the forms lack particular designations.

So, for instance, creatures that are quadrupedal and unprovided with wings are blooded without exception, ${ }^{1}$ but 20 somc of them are viviparous, and some oviparous. Such as are viviparous arc hair-coated, and such as are oviparous are covered with a kind of tessellated hard substance; and the tessellated bits of this substance are, as it were, similar in regard to position to a scale. ${ }^{2}$

An animal that is blooded and capable of movement on dry land, but is naturally unprovided with fect, belongs to the serpent genus; and animals of this genus are coated with the tessellated horny substance. Serpents in general are oviparous; the adder, an exceptional case, is viviparous: ${ }^{3} 25$ for not all viviparous animals are hair-coated, and some fishes also are viviparous.

All animals, however, that are hair-coated are viviparous. For, by the way, one must regard as a kind of hair such prickly hairs as hedgchogs and porcupines carry; for these spines perform the office of hair, and not of feet as is the 30 case with similar parts in sea-urchins. ${ }^{4}$

In the genus that combines all viviparous quadrupeds are many species, but under no common appellation. They are only named as it were one by one, as we say man, lion, stag, horse, dog, and so on ; though, by the way, there is a sort of genus "that embraces all creatures that have bushy manes and bushy tails, ${ }^{\prime}$ such as the horse, the ass, $49 \mathrm{I}^{\mathrm{a}}$ the mule, the jennet, and the animals that are called

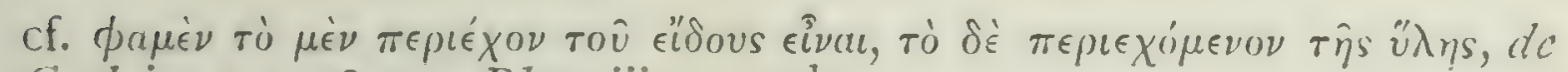
Cacl. iv. $4.312^{\mathrm{a}} 12$; Phys. iii. $7.207^{\mathrm{b}} \mathrm{I}$.

1 Schn. and Bekk. read oủ $\pi a ́ v t a$.

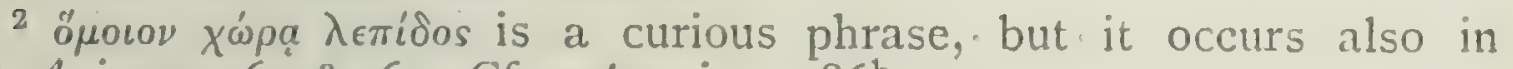
I'. A. iv. 11.69i $\mathrm{I}^{\mathrm{a}}$ 16. Cf. supra, i. I. $486^{\mathrm{b}} 2 \mathrm{I}$.

3 Here again, such information as this is not introduced to teach us such and such facts about serpents, but to illustrate the methods and the difficulties of defining the group to which they belong.

4 Horat. Canidia, 'Horret capillis ut marinus asperis Echinus.'

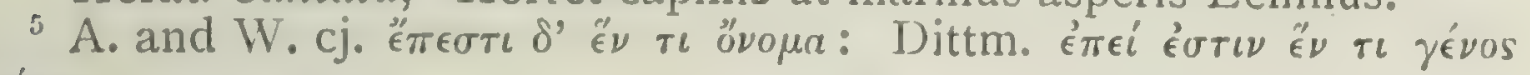

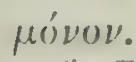

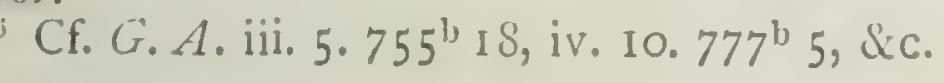

AR. H.A. 
IIcmioni ${ }^{1}$ in Syria,-from their externally resembling mules, though they are not strictly of the same species. And that they are not so is proved by the fact that they mate with and breed from one another.

5 For all these reasons, we must take animals species by species, and discuss their peculiarities severally.

These preceding statements, then, have been put forward thus in a general way, as a kind of foretaste of the number of subjects and of the properties that we have to consider in order that we may first get a clear notion of distinctive character and common propertics. $13 y$ and by wC shall discuss these matters with greater minuteness.

10 After this we shall pass on to the discussion of causes. For to do this when the investigation of the details is complete is the proper and natural method, and that whereby the subjects and the premisses of our argument will afterwards be rendered plain.

In the first place we must look to the constituent parts I5 of animals. ${ }^{2}$ For it is in a way relative to these parts, first and forcmost, that animals in their entirety difer from one another: either in the fact that some have this or that, while they have not that or this; or by peculiaritics of position or of arrangement; or by the differences that have been previously mentioned, depending upon diversity of form, on excess or defect in this or that particular, on analogy, or on contrasts of the accidental qualitics.

To begin with, we must take into consideration the 20 parts of Man. For, just as each nation is wont to reclion by that monetary standard with which it is most familiar, so must we do in other matters. And, of course, man is the animal with which we are all of us the most familiar.

Now the parts are obvious cnough to physical perception. Ilowever, with the view of observing due order and sequence and of combining rational notions with physical perception,

1 Equus hemionus or E. ontrger; cf. II. A. vi. $36.580^{a} 1$; Theophr. ap. Plin. viii. 69.

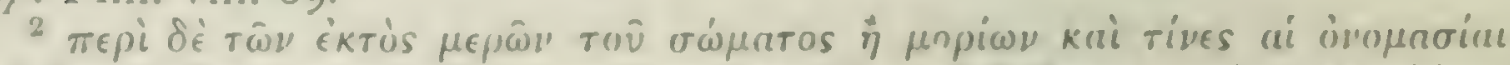

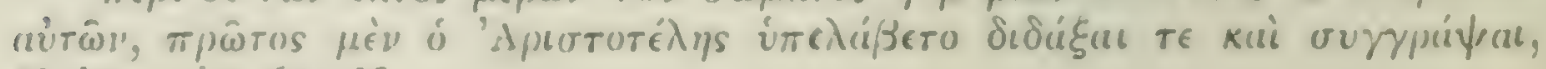
Galen, xiv. $699 \mathrm{~K}$. 
we shall proceed to enumerate the parts: firstly, the organic, ${ }^{1} 25$ and afterwards the simple or non-composite.

7 The chief parts into which the body as a whole is subdivided, ${ }^{2}$ are the head, the neck, the trunk (extending from the neck to the privy parts), which is called the thorax, two arms and two legs. ${ }^{3}$

Of the parts of which the head is composed the hair- 30 covered portion is called the 'skull'. The front portion of it is termed 'bregma' or 'sinciput', developed after birthfor it is the last of all the bones in the body to acquire solidity, ${ }^{4}$ - the hinder part is termed the 'occiput', and the part intervening between the sinciput and the occiput is the 'crown'. The brain lies underneath the sinciput; the occiput is hollow. ${ }^{5}$ The skull consists entirely of thin ${ }^{\circ} 49 \mathrm{I}^{\mathrm{b}}$ bone, rounded in shape, and contained within a wrapper of fleshless skin.

The skull has sutures: one, of circular form, in the case of women; in the case of men, as a general rule, three meeting at a point. ${ }^{7}$ Instances have been known of a man's skull devoid of suture altogether. In the skull the 5

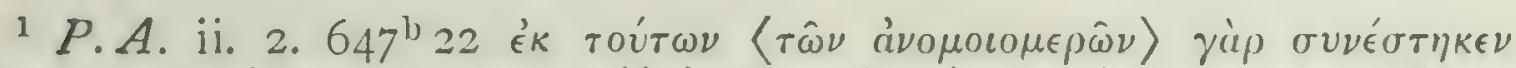

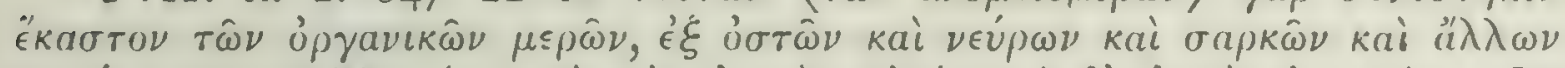

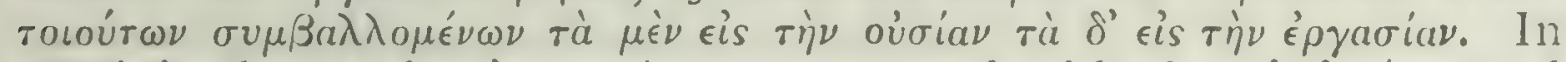

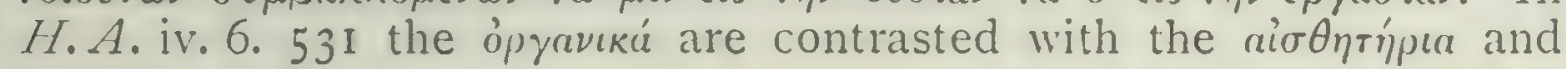

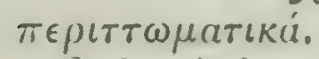

2 P.A. iv. 10. $685^{\mathrm{b}} 29$.

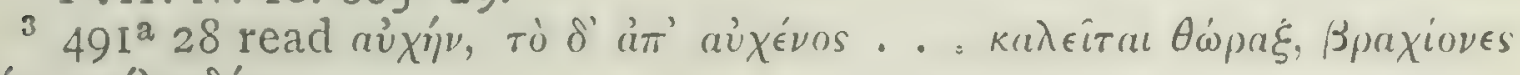

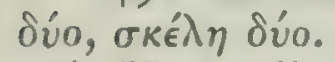

${ }^{4} H$. A. vii. 10. $587^{\text {b }}$ 13; P.A. ii. $7.653^{\mathrm{a}} 35 ; G$. A. ii. $5 \cdot 774^{\mathrm{a}} 24$.

5 That the back of the skull was empty is a vulgar error, arising, I think, in the following way: firstly, from a belief that hearing was associated with the element air, as is indicated in this connexion in

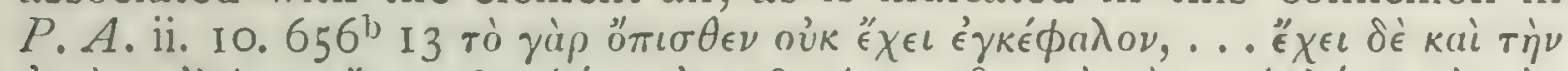

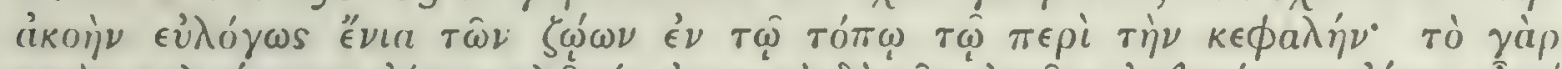

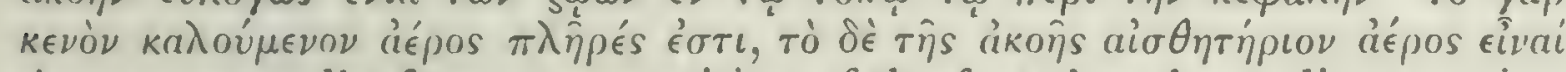
$\phi a \mu \epsilon \nu$ : secondly, from a recognition of the fact that the auditory region of the skull does contain air-spaces, as we may discover, without dissection, by tapping the mastoid process immediately behind the ear. Cf. also Hippocr. ii. p. 2 I 5 K, vii. p. Io L, \&c. See also Sonnenburg, \%ool. Frit. Bemert. zu Aristoteles, Bonn, 1857, p. 12.

6 apruóv may mean porous, hollow ; cf. Hippocr. ii. p. $218 \mathrm{~K}$, \&c.

${ }^{7} \mathrm{Cf} . H . A$. iii. $7.516^{\mathrm{a}}$ I9 (and note), $P$. A. ii. 10. $656^{\mathrm{b}}$ I4. I imagine that this singular misstatement dates from a belief that the sutures of the skull coincided with the margin and the partings of the hairy scalp. 
midtle line, where the hair parts, is called the crown or vertex. In some cases the parting is clouble; that is to say, some men are double-crowned, not in regard to the bony skull, but in consequence of the clouble fall or set of the hair. ${ }^{2}$

The part that lies under the skull is called the 'face': 8 10 but in the case of man only, for the term is not applied to a fish or to an ox. In the face the part below the sinciput and between the eyes is termed the forehead. When men have large forcheads, they are slow to move; when they have small ones, they are fickle; when they have broad ones, they are apt to be distraught; when they. have foreheads rounded or bulging out, they are quicktempcred. 3

Underneath the forchead are two eycbrows. Straight 9 s sycbrows are a sign of softness of disposition; such as curve in towards the nose, of harshness; such as curve out towards the temples, of humour and dissimulation; such as are drawn in towards one another, of jealousy. ${ }^{4}$

Under the cyebrows come the cyes. These are naturally. two in number. Fach of them has an upper and a lower cyclid, and the hairs on the edges of these are termed 20 'cyelashes'. The central part of the cyc includes the moist part whereby vision is effected, termed the "pupil', and the part surrounding it called the 'black': the part outside this is the 'white'. A part common to the upper and lower eyelid is a pair of nicks or corners, one in the direction of the nose, and the other in the direction of

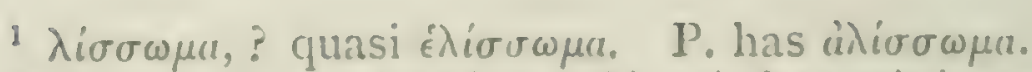

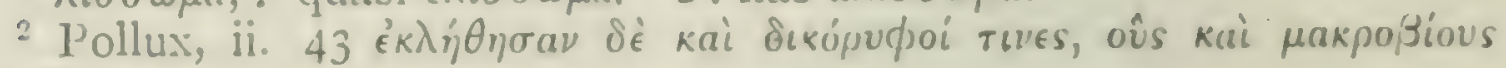
mpiḡoers.

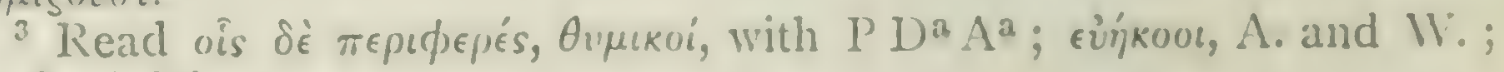
єنेंधккоі, Dittm.

"Trogus, ap. 1'in. xi.114; Antig. Mirab. I14; Arist. de Plissiogn. $6.812^{\mathrm{b}} 26$; Gialen, iv. $796 \mathrm{~K}$, who, for $\mu \omega \kappa o v$, humour or mockery, has $\mu \dot{\omega} \mu o v$, shame or disgrace.

de Sinsu, 12. $437^{b} 1$; Probl. xxxi. 7. 958n 14; Hippocr. de C $11 \% 17$ (i. p. $439 \mathrm{~K}$; viii. P. $606 \mathrm{~L}$ ). Hippocrates' description is much better:

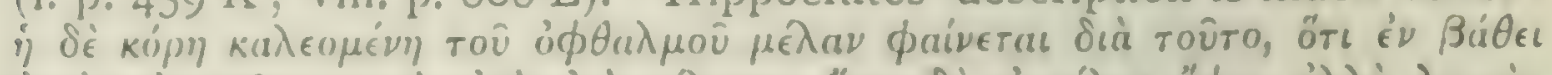

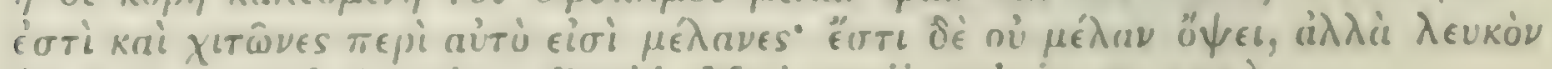

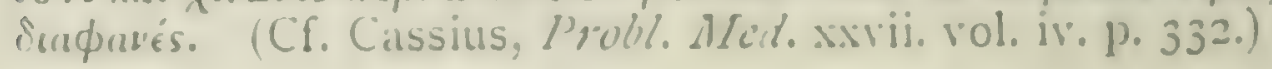


the temples. When these are long they are a sign of bad disposition; if the side toward the nostril be fleshy and 25 comb-like, ${ }^{1}$ they are a sign of dishonesty.

All animals, as a general rule, are provided with eyes, cxcepting the ostracoderms and other imperfect creatures; at all events, all viviparous animals have eyes, with the exception of the mole. And yet one might assert that, though the mole has not eyes in the full sense, yet it has eyes in a kind of a way. For in point of absolute fact it cannot see, and has no eyes visible externally; but when 30 the outer skin is removed, it is found to have the place where eyes are usually situated, and the black parts of the cyes rightly situated, and all the place that is usually devoted on the outside to eyes: showing that the parts are stunted in development. and the skin allowed to grow over. $^{2}$

Io Of the eye ${ }^{3}$ the white is pretty much the same in all $492^{\text {a }}$ creatures; but what is called the black differs in various animals. ${ }^{*}$ Some have the rim black, some distinctly blue, some greyish-blue, some greenish;" and this last colour is the sign of an excellent disposition, and is particularly well adapted for sharpness of vision.

1 By the $x \rho \epsilon \hat{\omega} \delta \in s$ is plainly meant the carmucula at the inner angle of the eye, which represents the third eyelid or nictitating membrane of the bird, especially well seen in hawks, owls, and many other large birds $\left(P . A\right.$. ii. I $3.657^{\text {b }}$ I6). It is very tempting to read oiov iktives, for oiov kTéves, with the Cod. Canis., Alb. Magnus (who renders sicut accidit oculis milvi) and Piccolos, and also with the version of De Moerbeke according to a MS. quoted by Camus (Notit. vi. p. 440; Schn. iii. p. 30). The structure in question is properly called $\epsilon^{\prime} \gamma k a \nu \theta i$, Galen, iv. 796 K. ; P. Aegin. iii, \&c. Trogus, ap. Plin. xi. I 14, literally translating A., has 'Qui carnosos a naribus angulos habent, malitiae notam praebent', and Antig. Mircb. (126) II4, has in like manner

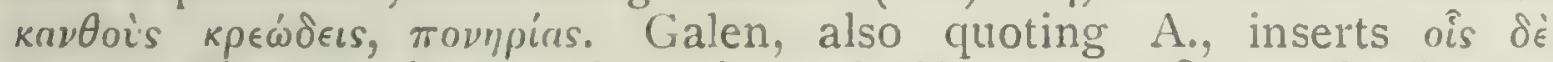

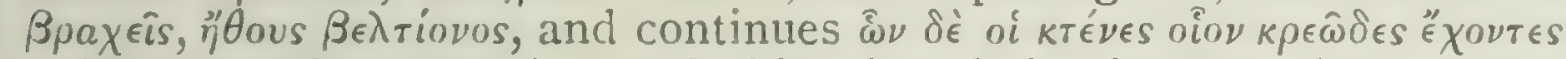

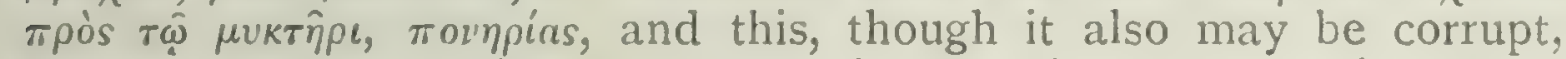
prevents tis meanwhile from departing far from the received text. The use of $k \tau \eta \delta$ óves, Ruf. Epl. 55, for the same part is also in favour of retaining $k T^{\prime} \boldsymbol{v}^{\prime} \in \mathrm{s}$.

${ }_{2}$ True of Talpa caeca of S. Europe; the eyes of our common T. enropea are rudimentary but distinctly visible. Cf. de An. iii. I.

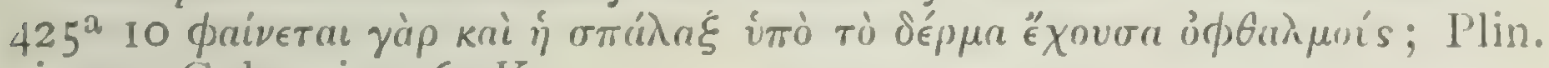
xi. 52 ; Galen, iv. I60 K.

${ }^{3}$ Cf. Galen, i. 329, xvii A., 723 K. ${ }^{4}$ G. A. V. I. $779^{\text {b }}$ I5.

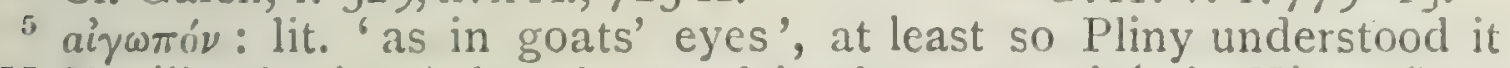
(H.N. viii. 76, xi. $5 \mathrm{I}$ ), but the word is obscure; aiyis; in Hipp. Conc. 
5 Man is the only; or nearly the only, creature, that has eyes of diverse colours. Animals, as a rule, have eyes of one colour only. Some horses have blue eyes. ${ }^{1}$

Of cyes, some are large, some small, some medium-sized; of these, the medium-sized are the best. Moreover, cyes sometimes protrude, sometimes recede, sometimes are neither protruding nor receding. Of these, the receding eyc is in all animals the most acute; but the last kind are the sign ro of the best disposition." Again, cyes are sometimes inclined to wink under observation, sometimes to remain open and staring, and sometimes are disposed neither to wink nor stare. The last kind are the sign of the best nature, and of the others, the latter lind indicates impudence, and the former indecision.

Furthermore, there is a portion of the head, whereby an II animal hears, a part incapable of breathing, the 'ear'. I say 'incapable of breathing', for Alcmacon is mistaken when he says that goats inspire through their ears. ${ }^{3}$ Of If the car one part is unnamed, the other part is called the 'lobe'; ${ }^{4}$ and it is entirely composed of gristle and flesh. The ear is constructed internally like the trumpet-shell, and the innermost bone is like the ear itsclf, and into it at the cnd the sound makes its way, as into the bottom of a jar. This receptacle does not communicate by any passage with 20 the brain, but does so with the palate, and a vein extends from the brain towards it. The eyes also are connected with the brain, and each of them lies at the cnd of a little vein. Of animals possessed of ears man is the only one that cannot move this organ. Of creatures possessed of hearing, some have cars, whilst others have none, but merely

214 (i. p. $267 \mathrm{~K}$, v. p. $322 \mathrm{~L}$ ), means a speck in the eye. Cf. G. A. v.

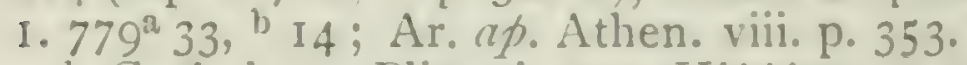

${ }_{1}$ G. A. 1. c.; Plin. xi. 53; Hippiatr. p. 53; Geopon. xri. 2. Schn.

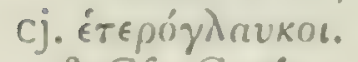

${ }^{2}$ Cf. G. A.v. 1. $780^{\text {l) }} 36$; of horses, Xen. de Re Eq. i. 9.

${ }^{3}$ Ael. i. 53 ; Opp. Cyn. ii. 340 ; Varro, R.R. ii. 3.5 , Sc.

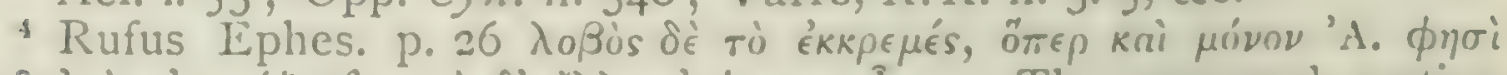

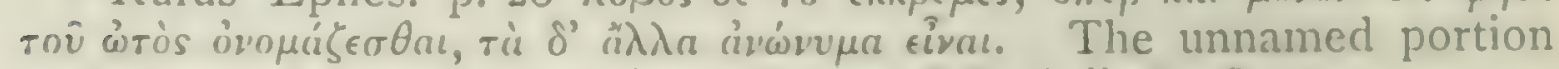

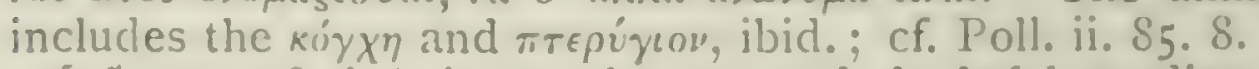

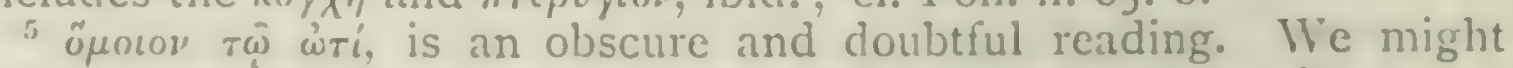

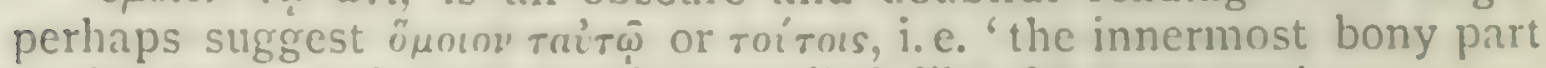
is also trumpet-shaped or spirally coiled, like the outer ear.' 
have the passages for cars visible, as, for cxample, fenthered 25 animals or animals coated with horny tessellates.

Viviparous animals, with the exception of the seal, the dolphin, and those others which after a similar fashion to these are cetaceans, ${ }^{1}$ are all provided with ears; for, by the way, the shark-kind are also viviparous. Now, the seal has the passages visible whereby it hears $;^{2}$ but the dolphin can hear, but has no ears, nor yet any passages visible. ${ }^{30}$ But man alone is unable to move his ears, and all other animals can move them. ${ }^{*}$ And the ears lie, with man, in the same horizontal plane with the eyes, and not in a plane above them as is the case with some quadrupeds." Of ears, some are fine, some are coarse, and some are of medium texture; the last kind are best for hearing, but they serve in no way to indicate character. Some cars are large, some small, some medium-sized; again, some stand out far, some lie in close and tight, and some take up a medium position ; $492^{\mathrm{b}}$ of these such as are of medium size and of medium position are indications of the best disposition, while the large and outstanding ${ }^{6}$ ones indicate a tendency to irrelevant talk or chattering. The part intercepted between the eyc, the ear, and the crown is termed the 'temple'.

Again, there is a part of the countenance that serves as 5 a passage for the breath, the 'nose'. For a man inhales and exhales by this organ, and sneezing is effected by its means: which last is an outward rush of collected breath, and is the only mode of breath used as an omen and regarded as supernatural. ${ }^{7}$ Both inhalation and exhalation go right on from the nose towards the chest $;^{8}$ and with the

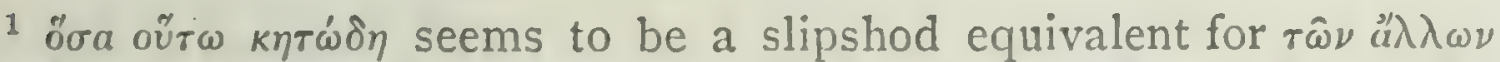

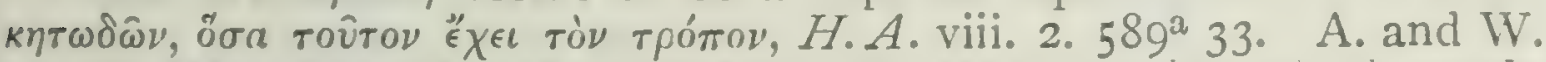

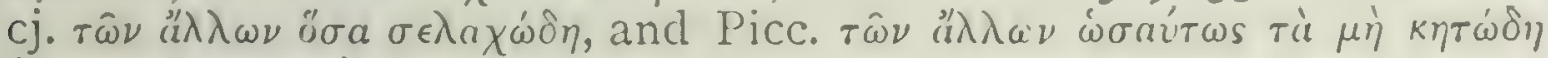

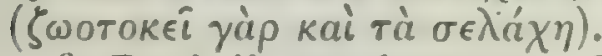

${ }^{2}$ P.A. ii. I2. $657^{\mathrm{a}} 22 ; G . A \cdot \mathrm{v} \cdot 2.78 \mathrm{I}^{\mathrm{b}} 23$.

3 H. A. iv. 8. $533^{\mathrm{b}}$ 14; Plin. xi. 50.

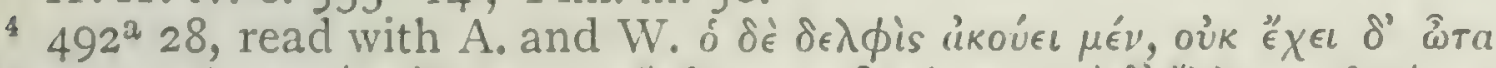

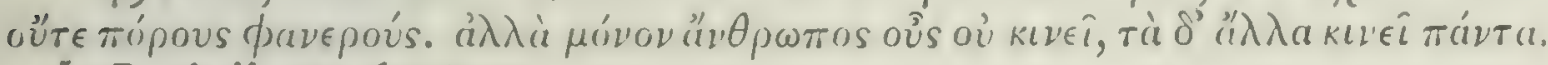

5 P.A. ii. II. $657^{2}$ I3.

- Galen, iv. $797 \mathrm{~K}$.; Antig. Mirat. I I4.

7 Od. xvii. 541; Ar. Ran.647, A\%.720; Athen. 66 C; Arist. Probl. ix. $54.897^{\mathrm{a}}$ I I, \&c.

8 ile Resp. $7.474^{a}$ I9. 
ro nostrils alone and separately it is impossible to inhale or exhale, owing to the fact that the inspiration and respiration take place from the chest along the windpipe, and not by any portion connected with the head; and indeed it is possible for a creature to live without using ${ }^{1}$ this process of nasal respiration.

Again, smelling takes place by means of the nose, ${ }^{2}$ - smelling, or the sensible discrimination of odour. And the nostril admits of easy motion, and is not, like the ear, intrinI5 sically immovable. A part of it, composed of gristle, constitutes a septum or partition, and part is an open passage; for the nostril consists of two separate channels. The nostril (or nose) of the elephant" is long and strong, and the animal uses it like a hand; for by means of this organ it draws objects towards it, and takes hold of them, and 20 introduces its food into its mouth, whether liquid or dry food, and it is the only living creature that does so.

Furthermore, there are two jaws; the front part of them constitutes the chin, and the hinder part the cheek. All animals move the lower jaw, with the exception of the rivercrocodile; this creature moves the upper jaw only. ${ }^{4}$

25 Next after the nose come two lips, composed of flesh, and facile of motion. The mouth lies inside the jaws and lips. Parts of the mouth are the roof or palate and the pharynx.

The part that is sensible of taste is the tonguc. The scnsation has its seat at the tip of the tongue; if the object to be tasted" be placed on the flat surface of the organ, the taste is less sensibly experienced. The tongue is sensitive in all other ways wherein flesh in general is so: 30 that is, it can appreciate hardness. or warmth and cold, in any part of it, just as it can appreciate taste." The tongue is conctimes broad, sometimes narrow, and sometimes of

But cf. de Resp. 1. $470^{b}$ 9, 9. $475^{a} 29$.

2 P.A. ii. $10.656^{\prime \prime} 31$.

3 P.A. ii. 16. $65^{\mathrm{b}} 33$.

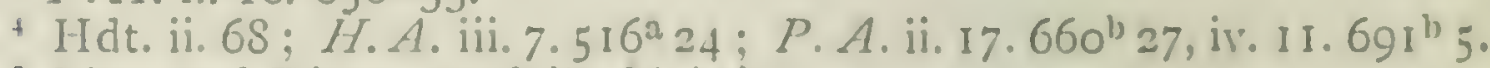

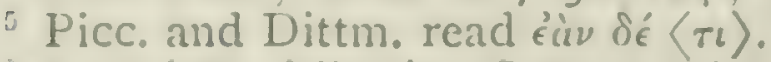

'A. and W., following Camus, point out that the text is unsatisfactory, inasmuch as taste has been expressly localized in a particular part of

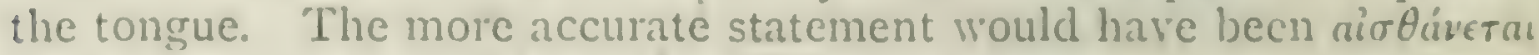

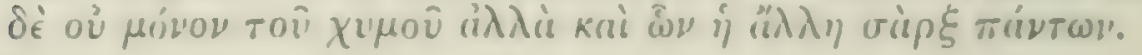


medium width; the last kind is the best and the clearest in its discrimination of taste. ${ }^{1}$ Moreover, the tongue is sometimes loosely hung, and sometimes fastened: ${ }^{2}$ as in the case of those who mumble and who lisp. ${ }^{3}$

The tongue consists of flesh, soft and spongy, and the so-called 'epiglottis' is a part of this organ.

That part of the mouth that splits into two bits is called the 'tonsils'; that part that splits into many bits, $493^{\mathrm{a}}$ the 'gums'. Both the tonsils and the gums are composed of flesh. In the gums are teeth, composed of bone.

Inside the mouth is another part, shaped like a bunch of grapes, ${ }^{4}$ a pillar streaked with veins." If this pillar gets relaxed" and inflamed it is called "uvula' or "bunch of grapes', and it then has a tendency to bring about suffocation. ${ }^{7}$

I2 The neck ${ }^{8}$ is the part between the face and the trunk. Of 5 this the front part is the larynx [and the back part the gullet]. $\quad$ The front part, composed of gristle, through which respiration and speech is effected, is termed the 'wind-pipe'; the part that is fleshy is the oesophagus, inside just in front of the chine. The part to the back of the neck is the epomis, or 'shoulder-point'. ${ }^{10}$

1 Perhaps, as most commentators have taken it, 'the best adapted for distinct articulation'; but the subject under discussion here is

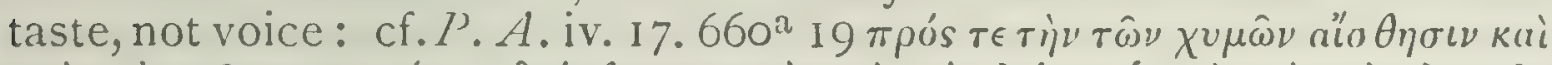

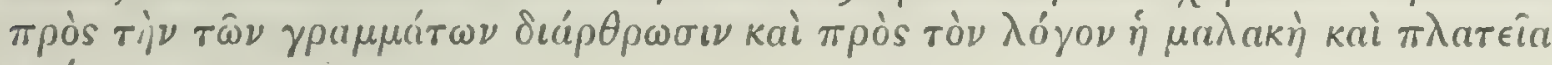

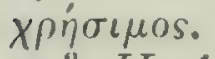

${ }_{2} H . A$. iv. 9. $5 j^{6} 6^{b} ; P . A$. ii. $17.660^{a} 2$.

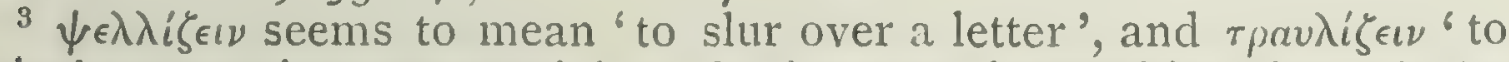
misplace or mispronounce it', as for instance in speaking through the

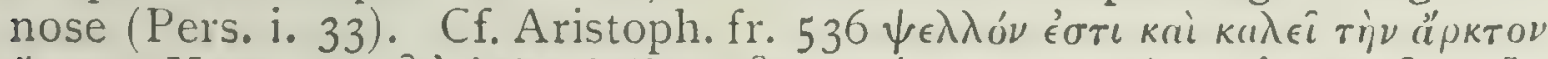

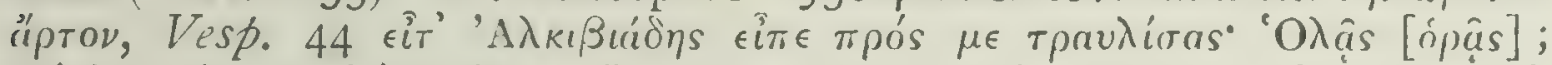

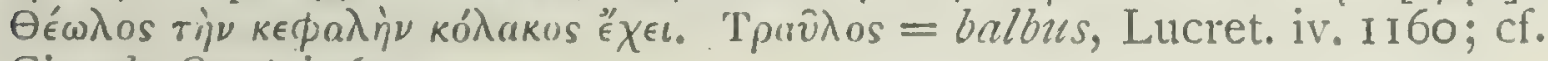
Cic. de Orat. i. 6 I.

4 Hippocr. de Morb. ii. Io (ii. p. $220 \mathrm{~K}$; vii. p. I8 L).

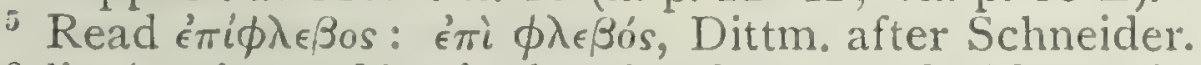

6 lit. 'moistened', viz. by the descent of phlegm from the brain,

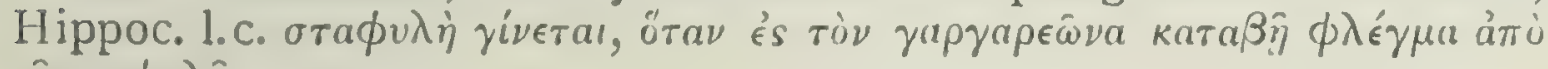
$\tau \hat{\eta} s \in \in \phi a \lambda \hat{\eta} s$.

7 Ruf. Ephes. p. $28^{a}$; Poll. ii. 99.

8 P.A. iii. 3. $664^{a}$.

${ }^{9}[]$ Dittm.

${ }_{10}$ The $\epsilon$ tr $\omega$ is is the region of the deltoid muscle, Galen, de Off. Part.

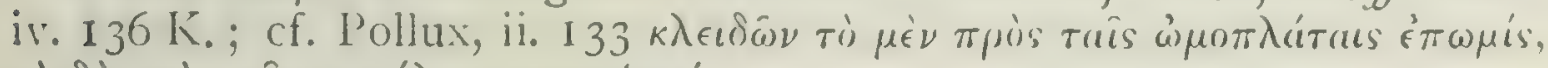

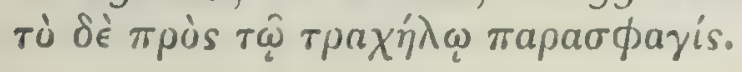


10

These then are the parts to be met with before you come to the thorax.

To the trunk there is a front part and a back part. Next after the neck in the front part is the chest, with a pair of breasts. To each of the breasts is attached a teat or nipple, through which in the case of females the milk percolates; and the breast is of a spongy texture. Milk, by the way, is found at times in the male; but with the male I5 the flesh of the breast is tough, with the female it is soft and porous.

Next after the thorax and in front comes the 'belly', and I3 its root ${ }^{1}$ the 'navel'. Underncath this root the bilateral part is the 'flank': the undivided ${ }^{2}$ part below the navel, the 'abdomen', the cxtremity of which is the region 20 of the 'pubes'; and above the navel the 'hypochondrium'; the cavity common to the hypochondrium and the flank is the gut-cavity.

Serving as a brace-girdle to the hinder parts is the

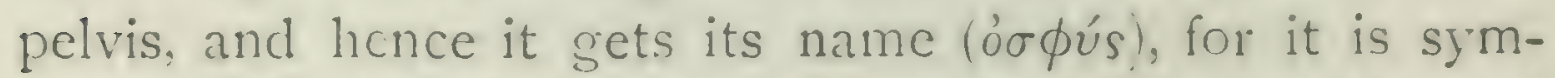

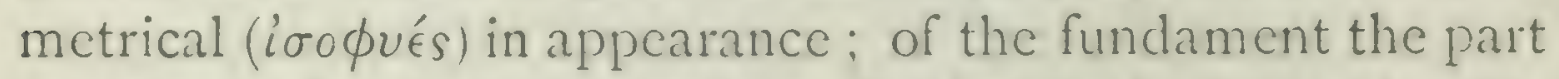
for resting on is termed the 'rump', and the part whercon the thigh pivots is termed the 'socket ' (or acetabulum).

The 'womb' is a part peculiar to the female; and the 25 'penis' is peculiar to the male. This latter organ is external and situated at the extremity of the trunk; it is composed of two separate parts: of which the extreme part is fleshy, does not alter in size, ${ }^{3}$ and is called the glans; and round about it is a skin devoid of any specific title, ${ }^{4}$ which integument if it be cut asunder never grows together again, any more than does the jaw or the cyelid." And the connexion between the latter and the glans is

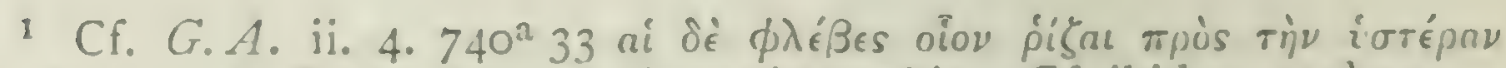

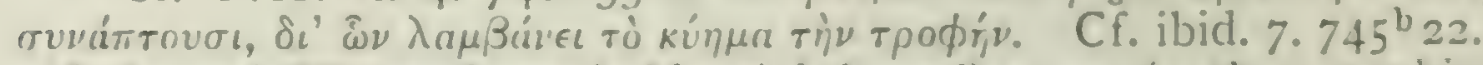

2. 1. and 11. read, probably rightly, kovilum kouril, thus combining the alternative readiners of the liss., and following (iaza carmm commune'.

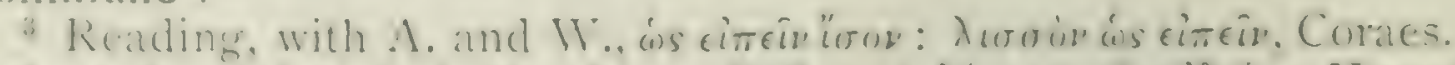

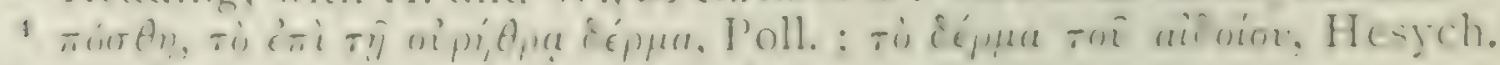
Cf. also Ruf. Ephes. i. p. 3 I, cit. Schn.

"H.A. iii.11.51S I; P.A. ii. 13. $657^{\text {b }} 3$; Hippocr. Afh. vi. I9. 
called the frenum. The remaining part of the penis is 30 composed of gristle; it is easily susceptible of enlargement; and it protrudes and recedes in the reverse directions to what is obscrvable in the identical organ in cats. ${ }^{1}$ Underneath the penis are two 'testicles', and the integument of these is a skin that is termed the 'scrotum'.

Testicles are not identical with flesh, and are not altogether diverse from it. But by and by we shall treat in an $493^{\text {b }}$ exhaustive way regarding all such parts.

4 The privy part of the female is in character opposite to that of the male. In other words, the part under the pubes is hollow or receding, and not, like the male organ, protruding. Further, there is an 'urethra' outside the womb ; (which organ serves as a passage for the sperm of the male, 5 and as an outlet for liquid excretion to both sexes). ${ }^{2}$

The part common to the neck and chest is the 'throat'; the 'armpit' is common to side, arm, and shoulder; and the 'groin' is common to thigh and abdomen. The part inside the thigh and buttocks is the 'perineum', and the part outside the thigh and buttocks is the 'hypoglutis'.

The front parts of the trunk have now been enumerated. The part behind the chest is termed the 'back'.

5 Parts of the back are a pair of 'shoulder-blades', the 'back-bone', and, underneath on a level with the belly in the trunk," the "loins'. Common to the upper and lower part of the trunk are the 'ribs', eight on either side, for' as to the so-called seven-ribbed Ligyans we have not received 15 any trustworthy evidence.

Man, then, has an upper and a lower part, a front and a back part, a right and a left side. Now the right and the left side are pretty well alike in their parts and identical

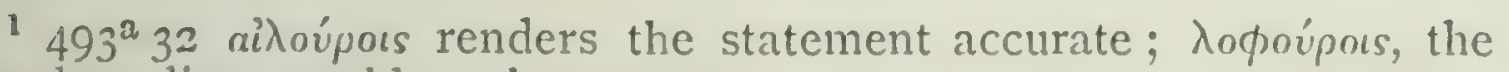
usual reading, would not be correct.

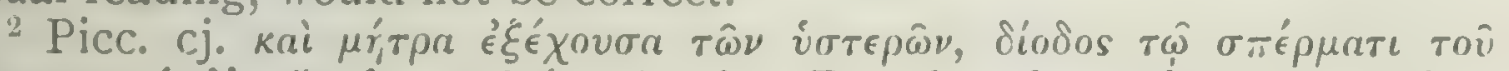

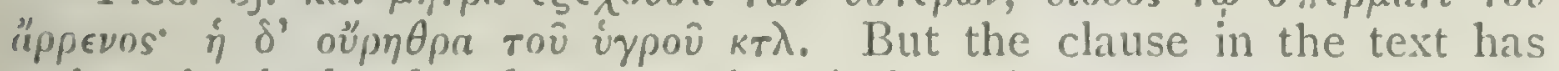
rather the look of a footnote, descriptive of the urethra in general terms: we therefore treat it as a parenthesis.

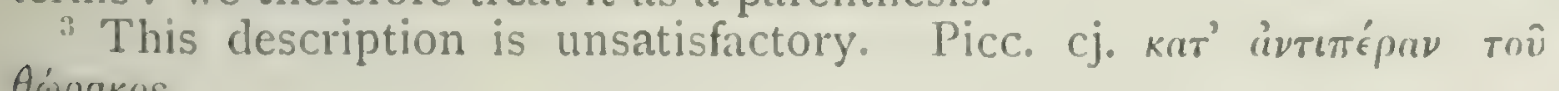
$\theta \dot{\omega}$ pakos. 
20 throughnut. except that the left side is the weaker of the two; but the back parts do not resemble the front ones, neither do the lower ones the upper: only that these upper and lower parts may be said to resemble one another thus. far, that, if the face be plump or meagre, the abdomen is plump or meagre to correspond; and that the legs correspond to the arms, and where the upper arm is short the thigh is 25 usually short also, and where the feet are small the hands are small correspondingly.

Of the limbs, one set, forming a pair, is 'arms'. To the arm belong the 'shoulder', 'upper-arm', 'clbow', 'forearm', and 'hand'. To the hand belong the 'palm', and the five 'fingers'. The part of the finger that bends is termed 'knuckle', the part that is inflexible is termed the 'phalanx'. The big finger or thumb is single-jointed, the zo other fingers are double-jointed. The bending both of the arm and of the finger takes place from without inwards in all cases; and the arm bends at the elbow. The inner part of the hand is termed the 'palm', and is fleshy and divided by joints or lines: in the case of long-lived people by one $494^{\mathrm{a}}$ or two extending right across, in the case of the short-lived by two, not so extending. ${ }^{1}$ The joint between hand and arm is termed the 'wrist'. The outside or back of the hand is sinewy, and has no specific designation.

There is another duplicate limb, the 'leg'. Of this limb the double-knobbed part is termed the 'thigh-bone', the s sliding part the ' knee-cap', the double-boned part the 'leg'; the front part of this latter is termed the 'shin'. and the part behind it the 'calf'. wherein the nesh is sinewy and venous, in some cases drawn upwards towards the hollow behind the knee, as in the cisc of people with litrge hips, and in other cases drawn downwards. The lower extremity of ro the shin is the 'ankle', duplicate in either leg. The part of the limb that contains a multiplicity of bones is the 'foot'. The hinder part of the foot is the 'heel'; at the front of it the divided part consists of 'toes', five in number; the fleshy part undcrneath is the 'ball'; 2 the upper

1 Arist. Probl. ix. 49.896a 35, xiv. 10. $964^{a} 33$; Plin. xi. I 4.

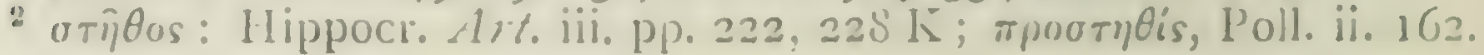


part or back of the foot is sinewy and has no particular appellation; of the toe, one portion is the 'nail' and another the 'joint', and the nail is in all cases at the extremity; 15 and toes are without exception single-jointed. Men that have the inside or sole of the foot clumsy and not arched, that is, that walk resting on the entire under-surface of their feet, ${ }^{1}$ are prone to roguery. The joint common to thigh and shin is the 'lknee'.

These, then, are the parts common to the male and the female sex. The relative position of the parts as to up and down, or to front and back, or to right and left, all 20 this as regards externals might safely be left to mere ordinary perception. But for all that, we must treat of them for the same reason as the one previously brought forward; that is to say, we must refer to them in order that a due and regular sequence may be observed in our cxposition, and in order that by the enumeration of these obvious facts due attention may be subsequently given to 25 those parts in men and other animals that are diverse in any way from one another.

In man, above all other animals, the terms 'upper' and 'lower' are used in harmony with their natural positions; for in him, upper and lower have the same meaning as when they are applied to the universe as a whole." In like manner the terms, 'in front', 'behind', 'right' and 'left', are 30 used in accordance with their natural sense. But in regard to other animals, in some cases these distinctions do not exist, and in others they do so, but in a vague way. For instance, the head with all animals is up and above in respect to their bodies; but man alone, as has been said, has, in maturity, this part uppermost in respect to the $494^{\circ}$ material universe.

Next after the head comes the neck, and then the chest and the back: the one in front and the other behind. Next after these come the belly, the loins, the sexual parts, and the haunches; then the thigh and shin; and, lastly. the feet.

1 Lat. plancus; cf. Plin. xi. 105.

"De Iuv. ct Sencet. I. $468^{\mathrm{a}} 5$; P. A. ii, 10. 656" 10. 
The legs bend frontwards, in the direction of actual progression, and frontwards also lics that part of the foot 5 which is the most effective of motion, and the flexure of that part; but the heel lies at the back, and the anklebones lie laterally, earwise. ${ }^{1}$ The arms are situated to right and left, and bend inwards: so that the convexities so formed by bent arms and legs are practically face to face with one another in the case of man. ${ }^{2}$

As for the senses and for the organs of sensation, the eyes, the nostrils, and the tongue, all alike are situated frontwarcls; the sense of hearing, and the organ of hearing; the car, is situated sideways, on the same horizontal plane 15 with the eyes. The eycs in man are, in proportion to his sizc, nearer to one another than in any other animal.

Of the senses man has the sense of touch more refined than any animal, and so also, but in less degree, the scnse of taste; in the development of the other senses he is surpassed by a great number of animals.

The parts, then, that are externally visible are arranged $\mathbf{I} 6$ 20 in the way above stated, and as a rule have their special designations, and from use and wont are known familiarly to all; but this is not the case with the inner parts. For the fact is that the inner parts of man are to a very great extent unknown: and the consequence is that we must have recourse to an examination of the inner parts of other animals whose nature in any way resembles that of man.

25 In the first place then, the brain lies in the front part of the head." And this holds alike with all animals possessed of a brain: and all blooded animals are possessed thereof,

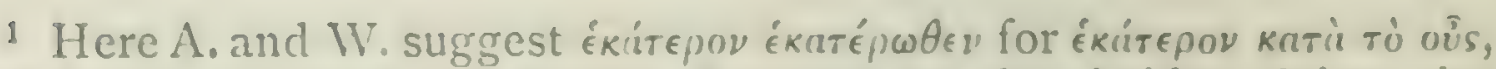
and translate 'jeder der beiden Knöchel an den beiden Seiten des I'usses'. The passage is perhaps corrupt, but it would seem that the general reference is to direction of flexure and not to position of parts; this, together with the manifestly awkward position of krii in kim $\mu$ is in the preceding line, slygests sone sul Treading as the following, kui in

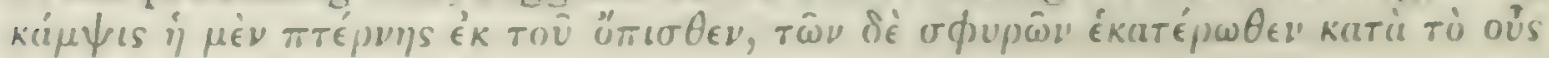
(cf. 1. It inf $\mathrm{rrt}$ ).

2 II. A. ii. I. $49^{8^{2}} 3$; ac Inc. 12-14. $711^{a}-712^{13}$.

"Hippocr. di Morb. ii. S (ii. p. 210 K; vii. p. 16 L). 
and, by the way, molluscs as well. But, taking size for size of animal, the largest brain, ${ }^{1}$ and the moistest, is that of man. Two membranes enclose it: the stronger one" nearer the bone of the skull; the inner one," round the 30 brain itself, is finer. The brain in all cases is bilateral. ${ }^{4}$ Behind this, right at the back, comes what is termed the 'cerebellum', differing in form from the brain as we may both feel and see.

The back of the head is with all animals cmpty and hollow, whatever be its size in the different animals. ${ }^{5}$ For $495^{a}$ some creatures have big heads while the face below is small in proportion, as is the case with round-faced animals; some have little heads and long jaws, as is the case, without cxception, among animals of the mane-and-tail species.

The brain in all animals is bloodless, ${ }^{6}$ devoid of vcins, 5 and naturally cold to the touch; ${ }^{-}$in the great majority of animals it has a small hollow in its centre. The brain-caul around it is reticulated with veins; and this brain-caul is that skin-like membrane which closely surrounds the brain. Above the brain is the thinnest and weakest bone of the head, which is termed 'bregma' Or' ro 'sinciput'.8

From the eye there go thrce ducts to the brain: the largest and the medium-sized to the cerebellum, the least to the brain itself; and the least is the one situated nearest to the nostril. The two largest ones, then, run side by side and do not meet; the medium-sized ones meet-and 15 this is particularly visible in fishes,-for they lie nearer than the large ones to the brain; the smallest pair are the most widely separate from one another, and do not meet.

Inside the neck is what is termed the 'oesophagus'

I P.A. ii. $14.65^{\mathrm{b}} 7$.

2 The dura mater; cf. Hippocr. de loc. in Hom. 2 (vi. p. 280 L); I1. A. iii. $13.519^{i \text {. }}$

${ }^{3}$ The pia mater, the $\mu \hat{\eta} \nu \iota \xi$ or 'brain-caul' of the sequel.

${ }^{4}$ Hippocr. de Morb. Sacr. 3 (i. p. $595 \mathrm{~K}$; vi. p. $366 \mathrm{~L}$ ); I.A. iii. 7. $669^{13} 22$.

5. $495^{\text {a }}$ I omit $\mu \epsilon \operatorname{t} \rho a$.

7 de Somno et Vig. 3. $457^{\text {ls }} 30$.

${ }^{6}$ P.A. ii. $7.652^{\mathrm{a}} 35$.

8 Hippocr. de Capil. Vuln. 2 (iii. p. $348 \mathrm{~K}$; ii. p. I88 L); P. A. ii. 7. $653^{\mathrm{a}} 35 ; H$. . vii. 10. $587^{\mathrm{b}} 13$. 
20 (whose other name ${ }^{1}$ is derived from its length and narrowness), and the windpipe. The windpipe is situated in front of the ocsophagus in all animals that have a windpipe, and all animals have one that are furnished with lungs. The windpipe is made up of gristle, is sparingly supplied with blood, and is streaked all round with numerous 25 minute veins; it is situated, in its upper part, near the mouth, below the aperture formed by the nostrils into the mouth - an aperture through which, when men, in drinking, inhale any of the liquid, this liquid finds its way out through the nostrils. In betwixt the two openings comes the so-called epiglottis, ${ }^{2}$ an organ capable of being drawn over and covering the orifice of the windpipe communiso cating with the mouth; the end of the tongue is attached to the epiglottis. In the other direction the windpipe extends to the interval between the lungs, and hereupon bifurcates into each of the two divisions of the lung: for the lung in all animals possessed of the organ has a tencency to be clouble. In viviparous animals, however, the $495^{\mathrm{b}}$ duplication is not so plainly discernible as in other species, and the duplication is least discernible in man. And in man the organ is not split into many parts, as is the case with some vivipara, neither is it smooth, but its surface is uneven.

In the case of the oripara, such as birds and oviparous quadrupeds, the two parts of the organ are separated to a distance from one another, so that the creatures appear 5 to be furnished with a pair of lungs; and from the windpipe; itself single, there branch off two separate parts extending to cach of the two divisions of the lung. It is attached also to the great rein and to what is clesignated the aorta'. When the windpipe is charged with air, the air passes on to the hollow parts of the lung. These parts have divisions, 10 composed of gristle, which meet at an acute angle; from the divisions run passages through the cntire lung, griving off smaller and smaller ramifications. The heart also is attached to the windpipe, by comnexions of fat,

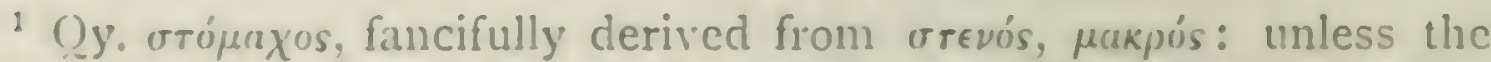
parenthes be a later interpolation. when we might rather conjecture

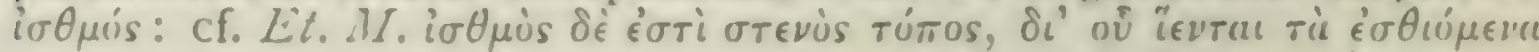
кrai $\pi \iota \nu i \mu \in \nu(8$.

P.A. iii. 3. $654^{\mathrm{b}} 21$. 
gristle, and sinew; and at the point of juncture there is a hollow. When the windpipe is charged with air, the entrance of the air into the heart, though imperceptible in some animals, is perceptible enough in the larger ones. I5 Such are the properties of the windpipe, and it takes in and throws out air only, and takes in nothing else either dry or liquid, or else it causes you pain until you shall have coughed up whatever may have gone down.

The oesophagus communicates at the top with the mouth, close to the winclpipe, and is attached to the back-20 bone and the windpipe by membranous ligaments, and at last finds its way through the midriff into the belly. It is composed of flesh-like substance, and is elastic both lengthways and breadthways.

The stomach of man resembles that of a dog; for it is not much bigger than the bowel, but is somewhat like 25 a bowel of more than usual width; then comes the bowel, single, convoluted, moderately wide. The lower part of the gut is like that of a pig; for it is broad, and the part from it to the buttocks is thick and short. The caul, ${ }^{1}$ or great omentum, is attached to the middle of the stomach, and consists of a fatty membrane, as is the case with all 30 other animals whose stomachs are single and which have teeth ${ }^{2}$ in both jaws.

The mesentery is over the bowels; this also is membranous and broad, and turns to fat. It is attached to the great vein and the aorta, and there run through it a number of veins closely packed together, extending towards the $496^{\mathrm{a}}$ region of the bowels, beginning above and ending below.

So much for the properties of the oesophagus, the windpipe, and the stomach.

The heart ${ }^{3}$ has three cavities, and is situated above the lung at the division of the windpipe, and is provided with 5 a fatty and thick membrane where it fastens on to the great vein and the aorta. It lies with its tapering portion

1P. A. iv. 3. $677^{a} 17 . \quad{ }^{2}$ i. e. incisors. Cf. infra, ii. I. $499^{a} 23$.

${ }^{3}$ See the fuller account of the heart and vessels in iii. $3-4 ; I^{\prime}$. A. iii. 4 . $666^{\mathrm{b}}$, \&c. 
upon the aorta, and this portion is similarly situated ${ }^{1}$ in relation to the chest in all animals that have a chest. In all animals alike, in those that have a chest and in those so that have none, the apex of the heart points forwards, although this fact might possibly escape notice by a change of position under dissection. The rounded end of the heart is at the top. The apex is to a great extent fleshy and close in texture, and in the cavities of the heart are sinews. As a rule the heart is situated in the middle of the chest in I5 animals that have a chest, and. in man it is situated a little to the left-hand side, leaning a little way from the division of the breasts towards the left breast in the upper part of the chest. ${ }^{2}$

The heart is not large, and in its gencral shape it is not clongated; in fact, it is somewhat round in form: only, be it remembered, it is sharp-pointed at the bottom. It has 20 threc cavities, as has been said: the right-hand one the largest of the three, the left-hand one the least, and the middle one intermediate in size. ${ }^{3}$ All these cavities, even the two small ones, are connected by passages with the lung, ${ }^{4}$ and this fact is rendered quite plain in one of the 25 cavitics. And below, at the point of attachment, in the largest cavity there is a connexion with the great vein ${ }^{5}$ [near which the mesentery lies]; ${ }^{6}$ and in the middle one there is a connexion with the aorta.

Canals lead from the heart into the lung, ${ }^{7}$ and branch off just as the windpipe does, rumning all over the lung parallel 30 with the passages from the windpipe. The canals from the heart are uppermost; and there is no common passage, but the passages through their having a common wall receive

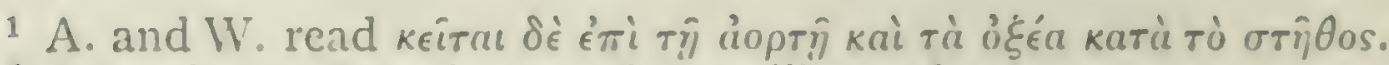

2 Plin. xi. 69; Cels. iv. I : cf. Juv. iii. 7. 160.

" The ascription of three cavitics to the heart was probably innluenced by tradition or mysticism, in much the same way as Plato's notion of the three corporeal faculties. For an attempted interpretation, see infra, iii. $3.513^{a}$.

4 . A. iii. $3 \cdot 513^{\mathrm{a}} 35$.

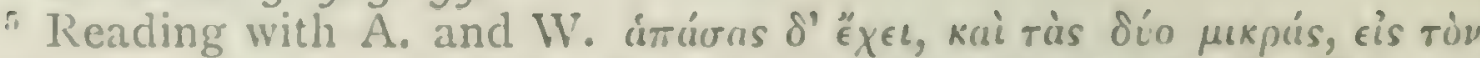

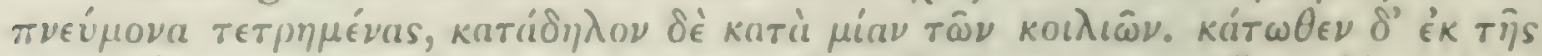

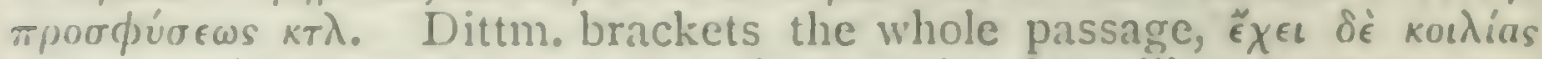

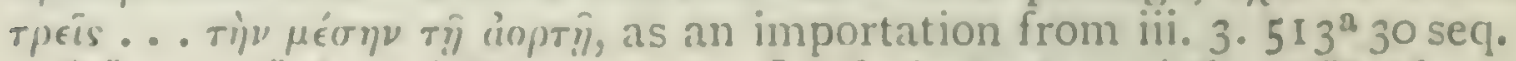
[ ] $\mathrm{L}$. and $\mathrm{W}$.
7 Cf. de liesp. 22 (16). 47 g $^{a} 26$. 
the breath and pass it on to the heart; and one of the passages conveys it to the right cavity, and the other to the left.

With regard to the great vein and the aorta we shall, by and by, treat of them together in a discussion devoted to them and to them alone.

In all animals that are furnished with a lung, and $496^{\mathrm{b}}$ that are both internally and externally viviparous, ${ }^{1}$ the lung is of all organs the most richly supplied with blood; for the lung is throughout spongy in texture, and along by every single pore in it go branches from the great vein. Those who imagine it to be empty are alto- 5 gether mistaken; and they are led into their error by their observation of lungs removed from animals under dissection, out of which organs the blood has all escaped immediately after death.

Of the other internal organs the heart alone contains blood. And the lung has blood not in itself but in its veins, but the heart has blood in itself; for in each of its three cavities it has blood, but the thinnest blood is what so it has in its central cavity.

Under the lung comes the thoracic diaphragm ${ }^{2}$ or midriff, attached to the ribs, the hypochondria and the backbone, with a thin membrane in the middle of it. It has veins running through it; and the diaphragm ${ }^{3}$ in the case of 15 man is thicker in proportion to the size of his frame than in other animals.

Under the diaphragm on the right-hand side lies the 'liver', and on the left-hand side the 'spleen', alike in all animals that are provided with these organs in an ordinary and not preternatural way; for, be it observed, in some quadrupeds these organs have been found in a transposed position.t These organs are connected with the stomach 20 by the caul.

To outward view the spleen of man is narrow and long; rescmbling the self-same organ in the pig. The liver in

1 i.e. the mammalia, as opposed to the ovipara and ovovivipara (cf. P. A. ii. 9. $655^{\mathrm{a}} 5$, iv. I. $676^{\mathrm{b}} 3, \& \mathrm{c}$.).

${ }^{2}$ Cf. P.A. iii. Io. $672^{b}$ Io.

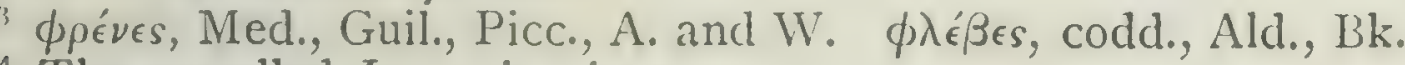

4 The so-called Inversio viscerum. 
the great majority of animals is not provided with a "gallbladder'; but the latter is present in some. " The liver of a man is round-shaped, and resembles the same organ in the ox. And, by the way, the absence above referred to of a 25 gall-bladder is at times met with in the practice of augury. For instance, in a certain district of the Chalcidic settlement in Euboea the sheep are devoid of gall-bladders; and in Naxos nearly all the quadrupeds have one so large that foreigners when they offer sacrifice with such victims are bewildered with fright, under the impression that the phenomenon is not due to natural causes, but bodes some mischief to the individual offercrs of the sacrifice. ${ }^{2}$

.30 Again, the liver is attached to the great vein, but it has no communication with the aorta; for the vein that goes off from the great vein goes right through the liver, at a point where are the so-called 'portals' of the liver. The spleen also is connected only with the great vein, for a vein extends to the spleen off from it.

After these organs come the 'kidneys': and these are placed close to the backbone, and resemble in character

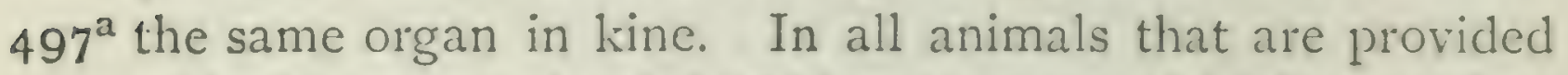
with this organ, the right kidney is situated higher up than the other. It has also less fatty substance than the lefthand one ${ }^{3}$ and is less moist. And this phenomenon also is observable in all the other animals alike.

Furthermore, passages or ducts lead into the kidneys 5 both from the great vein and from the aorta, only not into the cavity. For, by the way, there is a cavity in the middle of the kidney, bigger in some creatures and less in others; but there is none in the case of the seal." This latter animal has kidneys resembling in shape the identical organ in kine, but in its case the organs are more solid than in any other known creature. The ducts that lead into the kidneys lose themselves in the substance of the kidney's ro themsclves; and the proof that they extend no farther

1 The statement here would seem to be the opposite of the truth;

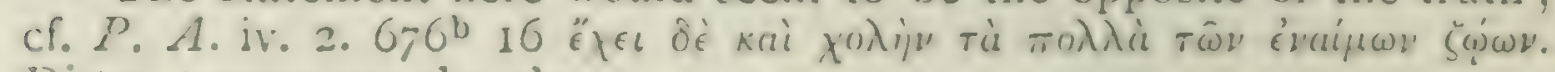
Dittm. transposes the ouk.

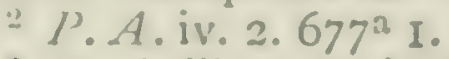

${ }^{3}$ P.A. iii. $9.671^{b} 28,672^{a}=3$.

$P . A$. iii. $9.671^{\mathrm{b}} 3$. 
rests on the fact that they ${ }^{1}$ contain no blood, nor is any clot found therein. The kidneys, however, have, as has been said, a small cavity. From this cavity in the kidney there lead two considerable ducts or ureters into the bladder; and others spring from the aorta, strong and continuous." And to the middle of each of the two kidneys is attached a hollow sinewy vein, stretching right along the spine is through the narrows; by and by these veins are lost in either loin, and again become visible extending to the flank. And these off-branchings of the veins terminate in the bladder. For the bladder lies at the extremity, and is held in position by the ducts stretching from the kidneys, along the stalk that extends to the urethra; and pretty 20 well all round it is fastened by fine sinewy membranes, that resemble to some extent the thoracic diaphragm. The bladder in man is, proportionately to his size, tolerably large.

To the stalk of the bladder the private part is attached, the external orifices coalescing; ${ }^{3}$ but a little lower down, 25 one of the openings communicates with the testicles and the other with the bladder. The penis is gristly and sinewy in its texture. With it are connected the testicles in male animals, and the properties of these organs we shall discuss in our general account of the said organ. ${ }^{t}$

All these organs are similar in the female; for there is 30 no difference in regard to the internal organs, except in respect to the womb, and with reference to the appearance of this organ I must refer the reader to diagrams in my 'Anatomy'. The womb, however, is situated over the bowel, and the bladder lies over the womb. But we must treat by and by in our pages of the womb of all female animals viewed generally. For the wombs of all female animals are not identical, neither do their local dispositions coincide.

These are the organs, internal and extcrnal, of man, and $497^{\mathrm{b}}$ such is their nature and such their local disposition.

${ }^{1}$ Here Dittm. inserts $\langle$ ri koi $\lambda a\rangle$, which interpretation gives the right sense, but is hardly necessary. Cf. iii. $4.514^{\mathrm{b}} 32, I^{\prime} \cdot A$. iii. $9.67 \mathrm{I}^{\mathrm{b}}{ }^{1} \mathrm{3}$. 2 The iliac arteries, not as seen in man, but, as in a quadruped, with
their origins higher up.

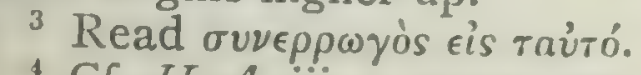

${ }^{4}$ Cf. H. A. iii. I. 509 et seq., G. A. i. I2. $718^{a}$. 


\section{BOOK II}

$497^{\circ} \quad$ With regard to animals in general, some parts or organs I 5 are common to all, as has been said, and some are common only to particular genera: ${ }^{1}$ the parts, moreover, are identical with or different from one another on the lines already repeatedly laid down. For as a general rule all animals 10 that are generically distinct have the majority of their parts or organs different in form or species; and some of them they have only analogically similar ${ }^{2}$ and diverse in kind or genus, while they have others that are alike in kind but specifically diverse; and many parts or organs exist in some animals, but not in others.

For instance, viviparous quadrupeds have all a head and Is a neck, and all the parts or organs of the head, but they differ each from other in the shapes of the parts. The lion has its neck composed of one single bone instead of vertebrac; "but, when dissected, the animal is found in all internal characters to resemble the dog.

The quadrupedal vivipara instead of arms have forclegs. ${ }^{4}$ This is true of all quadrupeds, but such of them as have 20 toes have, practically speaking, organs analogous to hands; at all cvents, they use these fore-limbs for many purposes as hands. And they have the limbs on the left-hand side less distinct from those on the right than man."

1 The main subject of this Book is to define the great genera of sanguincous animals, the viviparous and oriparous quadrupeds, the birds and fishes, though many instances of specific diversity are introduced parenthetically. In the opening sentences, which must be read together with those of Book I, brevity leads to a certain ap)earance of confusion: we are reminded that a generic difference between two animals carries with it generic difference between certain parts as well as specific differences between many others; but it now roes without saying that in animals which are specifically identical the parts are also specifically identical, and that in animals which are akin generically but diverse specifically the parts also are generically alike but are more or less specifically diverse.

"H.A.i. I. 486" I9, S.c.

3 P.A. iv. 10. 686a 21 ; Ael. iv. 34; cf. Wiegmann, Obs. irit., p. 3.

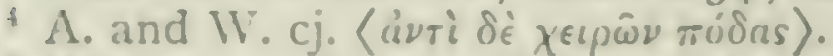

"Wiegmam, Picc, and Dittm. bracket this sentence, which is at 
but not similar to his; for the chest in man is broad, but that of all other animals is narrow.' Moreover, no other animal but man has breasts in front; ${ }^{2}$ the elephant,

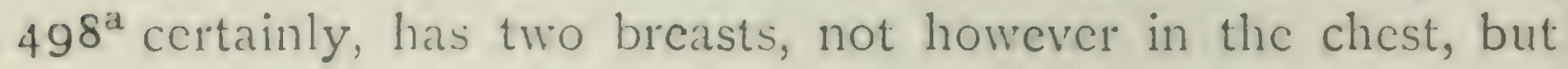
near it.

Moreover, also, animals have the flexions of their fore and hind limbs in directions opposite to one another, and in directions the reverse of those observed in the arms and legs of man; with the exception of the elephant." In s other words, with the viviparous quadrupeds the front legs bend forwards and the hind ones backwards; and the concavities $^{4}$ of the two pairs of limbs thus face onc another.

The elephant does not sleep standing, as some were wont to assert, but it bends its legs and settles down; only that ro in consequence of its weight it cannot bend its legs on both sides simultancously, but falls into a recumbent position on one side or the other, and in this position it goes to sleep." And it bends its hind legs just as a man bends his legs."

In the case of the ovipara, as the crocodile and the lizard 15 and the like, both pairs of legs, fore and hind, bend forwards, with a slight swerve to one side. ${ }^{7}$ The flexion is similar in the case of the multipeds; only that the legs in between the extreme ends always move in a manner intermediate between that of those in front and those behind, and accordingly bend sideways rather than backwards or forwards. ${ }^{\text {B }}$ But man bends his arms and his legs towards zo the same point, and therefore in opposite ways: that is to

${ }^{1} P . A$. iv. 10. $688^{\mathrm{a}} \mathrm{I} 3$.

2 Infra, $500^{a} 13 ; P . A$. iv. 1o. 685a 13 ; Ael. iv. 31.

3 de Inc. 9. $709^{a} 10 ; 12.712^{a} 11$.

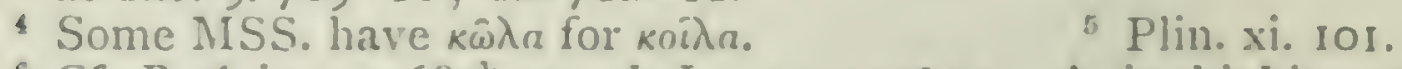

${ }^{6}$ Cf. P.A.iv. I0. $687^{b} 25$; de Inc. 13. $712^{a}$ II. A. is thinking of the elbow and knee in the elephant, as also in man: but of the wrist and ankle (knce and hock) of such an animal as the horse.

' This is at variance with fact, and with the statements in the de Incessu (e.g. 13. $712^{a}$ ) that no quadruped flexes its fore and hind limbs in the same direction: hence Wiegmann and Picoolos insert fis

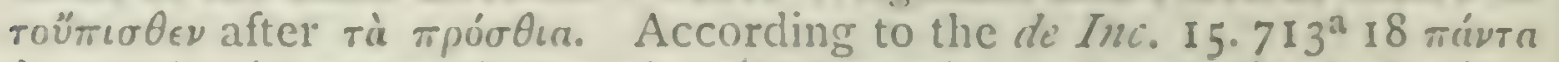

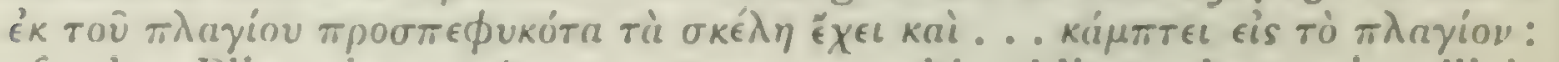
cf. also Plin. xi. 102 'sunt autem crura his obliqua, humani pollicis modo'.

${ }^{8}$ P'lin. xi. 35 (29). 
say, he bends his arms backwards, with just a slight inclination inwards, ${ }^{1}$ and his legs frontwards. No animal bends both its forc-limbs and hind-limbs backwards; but in the case of all animals the flexion of the shoulders is in the opposite direction to that of the elbows or the joints of the forelegs, and the flexure in the hips 2 : to that of the knees of the hind-legs: " so that since man differs from other animals in flexion, those animals that possess such parts as these move them contrariwise to man. ${ }^{3}$

Birds have the flexions of their limbs like those of the quadrupeds; for, although bipeds, they bend their legs backwards, and instead of arms or front legs have wings 30 which bend frontwards. ${ }^{4}$

The seal is a kind of imperfect or crippled quadruped; 5 for just behind the shoulder-blade its front feet are placed, resembling hands, like the front paws of the bear; for they are furnished with five toes, and each of the toes has three $498^{\mathrm{b}}$ flexions and a nail of inconsiderable size. The hind feet are also furnished with five toes; in their flexions and nails they resemble the front feet, and in shape they resemble a fish's tail.

The movements of animals, quadruped and multiped, are crosswise, or in diagonals, and their equilibrium in standing posture is maintained crosswise; and it is always the limb on the right-hand side that is the first to move. ${ }^{6}$ The lion, however, and the two species of camel, both the Bactrian

1 A. and W. cj. 〈Kai ékTós〉.

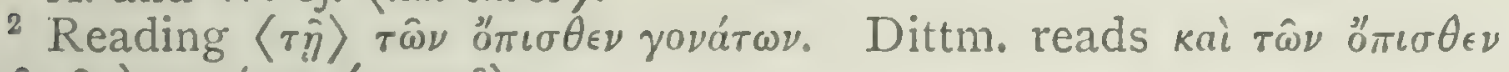

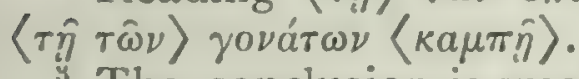

The conclusion is weak, the translation doubtful, and the text in all probability at fault. Dittm. reads $\tau \dot{\alpha} \tau a v \tau^{3} "{ }^{\prime} \chi o \nu \tau^{2} \dot{\epsilon}^{\prime} \nu \alpha \nu \tau i \omega s$, and

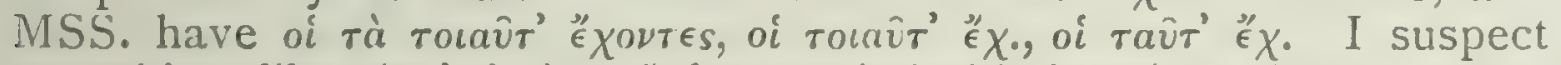

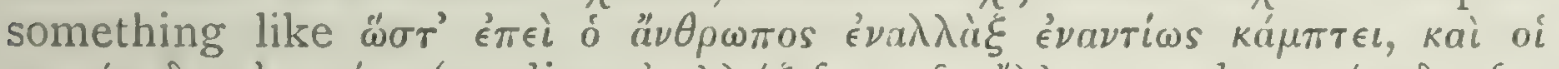

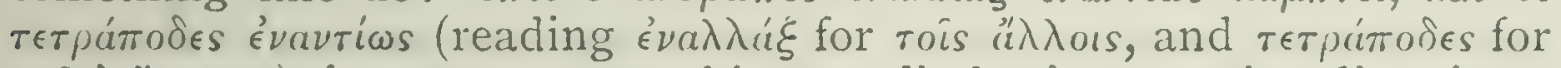

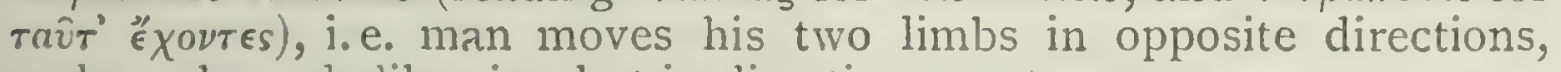
and quadrupeds likewise, but in directions contrary to man.

${ }^{4} P$. A. iv. 12. $693^{\mathrm{b}} 3$; de Inc. 12. $7 \mathrm{II}^{\mathrm{a}} \mathrm{16}, \mathrm{I} 3.712^{\mathrm{a}} 22$.

${ }^{5}$ H.A. i. I. $487^{b} 23 ;$ P.A. ii. $2.657^{\mathrm{a}} 22$, iv. 13. $697^{\mathrm{b}} 4$; de Inc. I9. $714^{\mathrm{b}}$ I2.

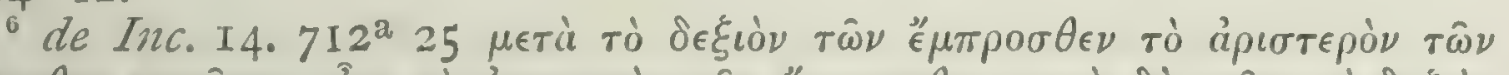

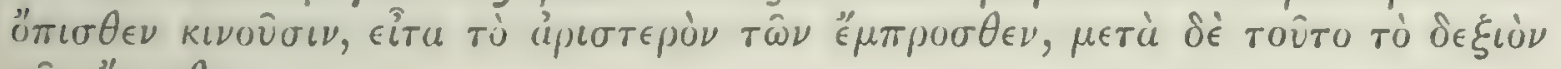
$\tau \hat{\omega} \nu$ oै $\pi \iota \tau \theta \epsilon \nu$. 
and the Arabian, progress by an amble; and the action so called is when the animal never overpasses the right foot Io with the left, but always follows close upon it. ${ }^{1}$

Whatever parts men have in front, these parts quadrupeds have below, in or on the belly; and whatever parts men have behind, these parts quadrupeds have above on their backs. Nost quadrupeds have a tail; for even the seal has a tiny one resembling that of the stag. Regarding the I 5 tails of the pithecoids we must give their distinctive properties by and by. ${ }^{2}$

All viviparous quadrupeds are hair-coated, whereas man has only a few short hairs excepting on the head, ${ }^{3}$ but, so far as the head is concerned, he is hairicr than any other animal. ${ }^{4}$ Further, of hair-coated animals, the back is 20 hairier than the belly, which latter is either comparatively void of hair or smooth and void of hair altogether." With man the reverse is the case.

Man also has upper and lower eyclashes, and hair under the armpits and on the pubes. No other animal has hair in cither of these localities, or has an under eyclash; though 25 in the case of some animals a few straggling hairs grow under the eyelid. ${ }^{6}$

Of hair-coated quadrupeds some are hairy all over the body, as the pig, the bear, and the dog; others ${ }^{\top}$ are especially hairy on the neck and all round about it, as is the case with animals that have a shaggy mane, such as the lion; others again are especially hairy on the upper surface of the 30 neck from the head as far as the withers, namely, such as have a crested mane, as is the case with the horse, the

1 Plin. (xi. 105) translates literally 'pecham, hoc est ut sinister pes non transeat dextrum sed subsequatur'. The passage is very obscure. An amble is, properly speaking, the mode of progression in which both legs of one sicle follow both legs of the other, insteat of moving criss-cross, and this indeed appears to be the gait of the camel. If this be what is meant here, we might conjecture the

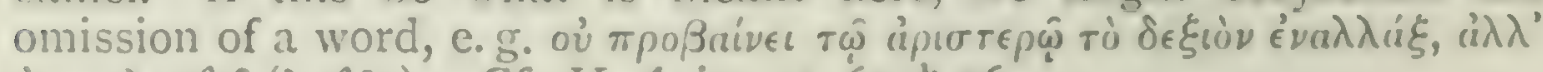

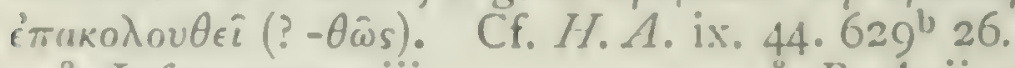

2 Infra, cap. viii. $\quad$ P.A. ii. 14. 655 15 ; Plin. xi. 47.

i Probl.x.62. $898^{n} 20$.

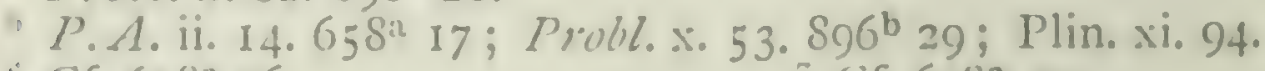

C. C. $65^{\mathrm{a}} 26$.

S Of the boar, Uit. xix. 446 . 
mule, and, among the undomesticated horned animals, the bison.

The so-called hippelaphus ${ }^{1}$ also has a mane on its withers, and the animal called pardion, ${ }^{2}$ in either case a thin mane extending from the head to the withers; the hippelaphus has, exceptionally, a beard by the larynx. Both these $499^{\text {a }}$ animals ${ }^{3}$ have horns and are cloven-footed; the female, however, of the hippelaphus has no horns. This latter animal resembles the stag in size; it is found in the territory of the Arachotae, ${ }^{4}$ where the wild cattle also are found.

Wild cattle ${ }^{5}$ differ from their domesticated congeners 5 just as the wild boar differs from the domesticated one. That is to say they are black, strong looking, with a hook-nosed muzzle, and with horns lying more over the back. The horns of the hippelaphus resemble those of the gazelle.

The elephant, by the way, is the least hairy of all quadrupeds. With animals, as a general rule, the tail ro corresponds with the body as regards thickness or thinness of hair-coating; that is, with animals that have long tails, for some creatures have tails of altogether insignificant size.

Camels ${ }^{6}$ have an exceptional organ wherein they differ from all other animals, and that is the so-called 'hump' on their back. The Bactrian camel differs from the Arabian; ${ }^{7}$ for the former has two humps and the latter only one, 15 though it has, by the way, a kind of a hump below like the one above, on which, when it kneels, the weight of the whole body rests. The camel has four teats like the cow, a tail like that of an ass, and the privy parts of the male are directed backwards. It has one knee in each leg, and the flexures of the limb are not manifold, as some say, 20 although they appear to be so from the constricted shape of the region of the belly. ${ }^{3}$ It has a huckle-bone like that

1 Cf. Tragelaphus, Plin. viii. 50 (33). Probably the Nylghau, Portax (Antilope) picta; cf. Wiegmann, Obs. crit., p. 2 I.

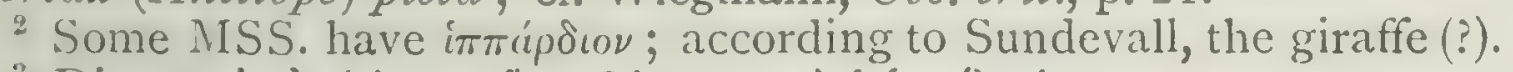

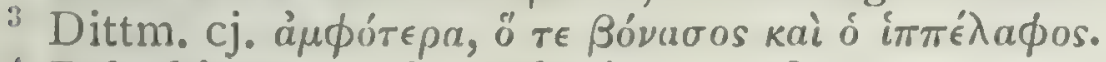

4 Beluchistan. Cf. Strabo ix. 8. 9, \&c.

${ }^{6}$ Cf. v. I 4, vi. 26 , ix. $47.630^{\mathrm{b}}$.

8 H.A. ii. I. $500^{\mathrm{b}} 29$; P.A. iv. Io. $688^{\mathrm{b}} 23$.

5 i.e. buffaloes.

7 Plin. viii. 26.

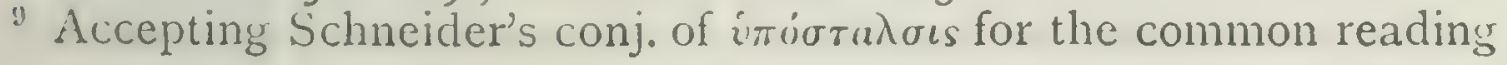


of kine, but meagre and small in proportion to its bulk. ${ }^{1}$ It is cloven-footed, and has not got tecth in both jaws; ${ }^{2}$ and it is cloven-footed in the following way: at the back there is a slight cleft extending as far up as the second 25 joint of the toes; and in front there are small hooves on the tip of the first joint of the tocs; ${ }^{3}$ and a sort of web passes across the cleft, as in geese. The foot is fleshy underneath, like that of the bear; so that, when the animal goes to $30 \mathrm{war}$, they protect its fect, when they get sore, with sandals. ${ }^{4}$ The legs of all quadrupeds are bony, sinewy, and fleshless; and in point of fact such is the case with all animals $499^{b}$ that are furnished with fect, with the exception of man. ${ }^{5}$ They are also unfurnished with buttocks; and this last point is plain in an especial degree in birds. It is the reverse with man; for there is scarcely any part of the body in which man is so fleshy as in the buttock, the thigh, 5 and the calf; "for the part of the leg called gastrocnemia or 'calf' is fleshy.'

Of blooded and viviparous quadrupeds some have the foot cloven into many parts, as is the case with the hands and feet of man (for some animals, by the way, are many-toed, as the lion, the dog, and the pard); others have fect cloven in twain, and instead of nails have hooves, as the sheep, the o goat, the deer, and the hippopotamus; " others are uncloven of foot, such for instance as the solid-hooved animals, the

iniorures; the latter would seem to be meaningless here (cf. Hippoct. Art. 806). With the general statement cf. Herod. iii. IO 3 ki $\mu \eta \lambda$ os 'v

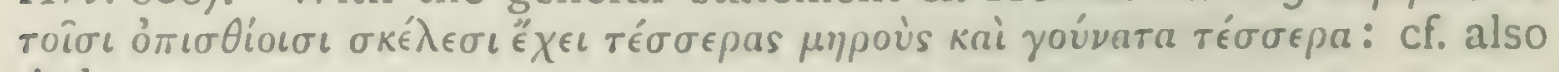
Acl. x. 3 .

1 Plin. xi. 105.

$2 " \ddot{\mu} \phi \omega \delta$ ov and its converse always refer only to the front or incisor teeth. The camel has three lower incisors on each side and one upper one, which is large and tusk-like, resembling a canine. Cf. P.A. iii. 14. $674^{a} 32$.

${ }^{3}$ I have followed, not without hesitation, A. and WV's conjectural

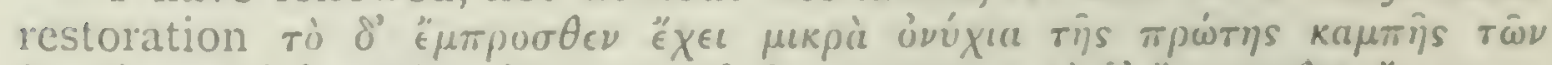

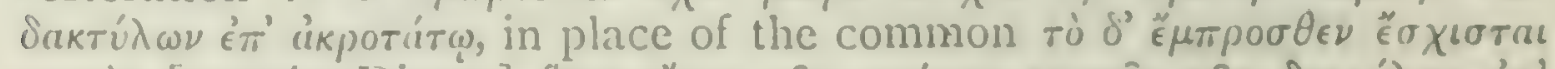

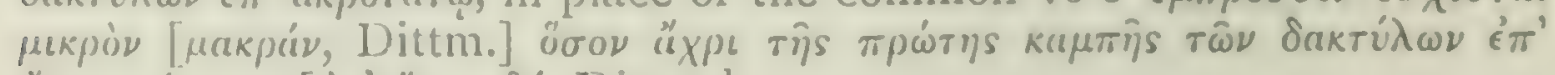
(в)

"

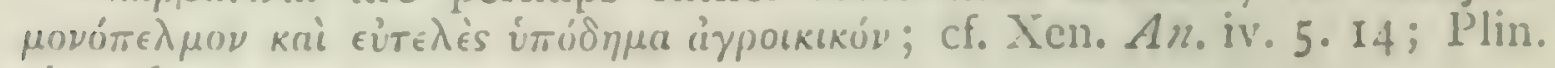
xi. 106.

Jlin. xi. 10弓.

7 Picc. would delete $\sigma a p \kappa \omega \dot{\omega} \in \iota s$.

'P. 1. iv. 10. 686' 7 .

8 "The hippopotamus has four toes. 
horse and the mule. Swine are cither cloven-footed or uncloren-footed; for there are in Illyria and in Paconia and elsewhere solid-hooved swine. ${ }^{1}$ The cloven-footed animals have two clefts behind; ${ }^{2}$ in the solid-hooved this part is continuous and undivided.

Furthermore, of animals some are horned, and some are I: not so. The great majority of the horned animals are cloven-footed, as the ox, the stag, the goat; and a solidhooved animal with a pair of horns has never yct been met with. But a few animals are known to be single-horned and single-hooved, as the Indian ass $;^{3}$ and one, to wit the ory ${ }^{4}{ }^{4}$ is single-horned and cloven-hooved.

Of all solid-hooved animals the Indian ass alone has an 20 astragalus or huckle-bone; for the pig, as was said above, is either solid-hooved or cloven-footed, and consequently has no well-formed huckle-bone. ${ }^{5}$ Of the cloven-footed many are provided with a huckle-bone. ${ }^{6}$ Of the manyfingered or many-toed, no single one has been observed to have a huckle-bone, ${ }^{7}$ none of the others any more than man. The lynx, however, has something like a hemiastragal, and the lion something resembling the sculptor's 25 'labyrinth'.8 All the animals that have a huckle-bone.

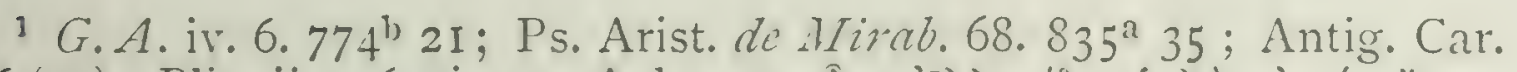

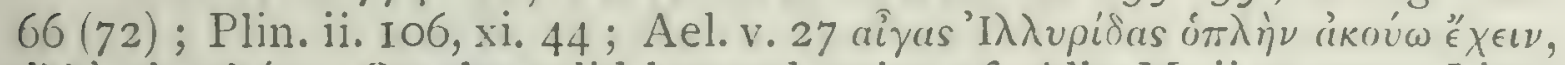
$i \lambda \lambda^{\prime}$ ou $\chi \eta \lambda \eta \dot{\eta}$. On the solid-hooved swine cf. Alb. M. ii.p. Ioo; Linn. Syst. Nat. 1740, p. 49, Amoen. Acurt.v. p. 46I ; Bateson's Virriation, I 894, p. 387 , \&c.

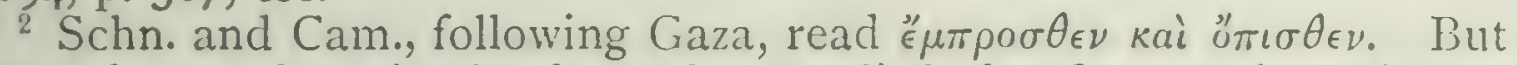
the reference here is clearly to the two little hooflets, or lateral toes, at the back of the foot.

${ }^{3}$ Doubtless the rhinoceros; this animal has three toes, indistinctly separate. On the rhinoceros cf. $P . A$. iii. 2. $663^{\text {a }} 23$; Ael. iv. 52; Ctes. ap. Phot. Bibl. lxxiv. p. I 53 .

${ }^{4}$ Cf. P. A. iii. 2. $663^{2} 23$. Probably Oryx (Antilope) lencoryx of $N$. Africa, or O.beisa of Abyssinia, as represented on Egyptian frescos. Cf. Plin. viii. (53) 214, and ii. (40) 107.
5 Plin. xi. 106.
${ }^{6} P . A$. iv. $10.690^{a} 21$.

7 A. means, of course, a huckle-bone suitable for playing with, and probably only then recognized it as a 'huckle-bone'.

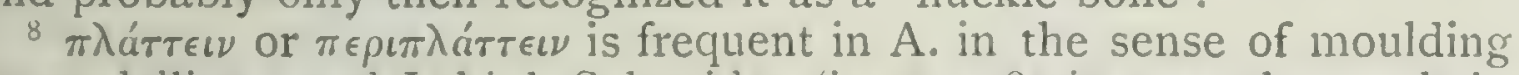
or modelling; and I think Schneider (iv. p. 29S) is near the mark in suggesting ' Fortasse $\pi \lambda$ át columnarum lapidearum capitulis cochlearum figuras incudebant ct

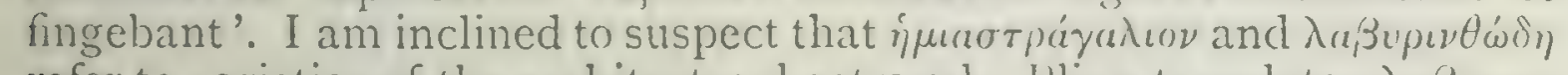
refer to varieties of the architectural astragal. I'liny translates $\lambda_{\alpha} \beta \mu_{\mu} \mu \nu$ Áwin, 'tortuosius,' and the lion's astragalus has actually a spiral twist. 
have it in the hinder legs. They have also the bone placed straight up in the joint; the upper part, outside; the lower part, inside; the sides called $\mathrm{Coa}^{1}$ turned towards one another, the sides called Chia ${ }^{1}$ outside, and the keraiac or 30 'horns' on the top. This, then, is the position of the huckle-bone in the case of all animals provided with the part.

Some animals are, at one and the same time, furnished with a mane and furnished also with a pair of horns bent $500^{a}$ in towards one another, as is the bison (or aurochs), which is found in Paconia and Maedica." But all animals that are horned are quadrupedal, except in cases where a creature is said metaphorically, or by a figure of specch, to have horns; just as the Egyptians describe the scrpents ${ }^{4}$ found in the neighbourhood of Thebes, while in point of $s$ fact the creatures have merely protuberances on the head sufficiently large to suggest such an epithet.

Of horned animals the deer alone has a horn, or antler, hard and solid throughout." The horns of other animals are hollow for a certain distance, and solid towards the extremity. The hollow part is derived from the skin," but the core round which ${ }^{7}$ this is wrapped-the hard part-is derived from the bones; as is the case with the horns of ro oxen. The deer is the only animal that sheds its homs, and it does so annually, after reaching the age of two years, and again renews them. All other animals retain their horns permanently, unless the horns be damaged by accident.

Again, with regard to the breasts and the generative organs, animals differ widely from one another and from I: man. For instance, the breasts of some animals are situated in front, either in the chest or near to it, and there

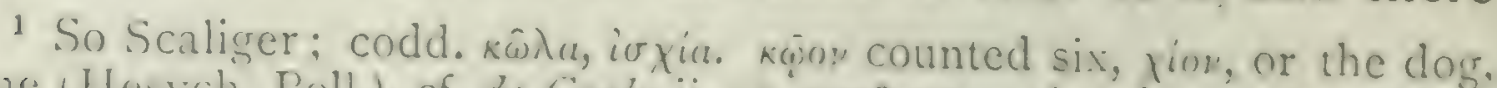

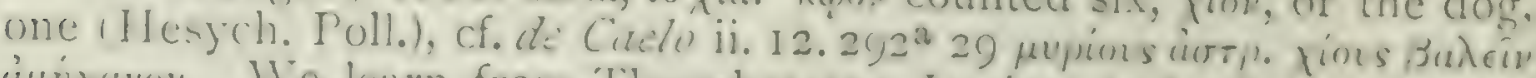
rimilarov. We learn from Theophrastus, Lucian, and others, that the huckle-bones of the gazelle were especially prized.

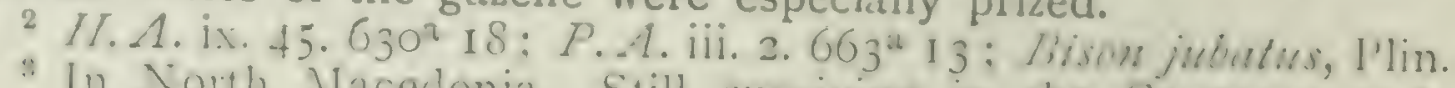
Lithuania.

In North Macedonia. Still surviving in the Caucasus and in

Cerastes aegyptiacus. Cf. Herod. ii. 74.

P.A. iii. $2.663^{\mathrm{b}} 12$; cf. H.A. ix. $5.61^{\mathrm{b}}$ I 3 .

H. A. iii. 9. $517^{a} 21$.

7 ü om. Bekk. 
are in such cases two breasts and two teats, as is the case with man and the elephant, ${ }^{1}$ as previously stated. ${ }^{2}$ For the elephant has two breasts in the region of the axillae; and the female elephant has two breasts insignificant in size and in no way proportionate to the bulk of the entire 20 frame, in fact, so insignificant as to be invisible in a sideways view; the males also have breasts, like the females, exceedingly small. The she-bear has four breasts. Some animals have two breasts, but situated near the thighs, and teats, likewise two in number, as the sheep; others have four teats, as the cow. Some have breasts neither in the 25 chest nor at the thighs, but in the belly, as the dog and pig; and they have a considerable number of breasts or dugs, but not all of equal size. Thus the she-pard has four dugs in the belly, the lioness two, and others more. The she-camel, also, has two dugs and four teats, like the cow. 30 Of solid-hooved animals the males have no dugs, cxcepting in the case of males that take after the mother, which phenomenon is observable in horses. ${ }^{3}$

Of male animals the genitals ${ }^{4}$ of some are external, as is the case with man, the horse, and most other creatures; some are internal, as with the dolphin. With those that $500^{\mathrm{b}}$ have the organ externally placed, the organ in some cases is situated in front, as in the cases already mentioned, and of these some have the organ detached, both penis and testicles, as man; others have penis and testicles closely attached to the belly, some more closely, some less; for 5 this organ is not detached in the wild boar nor in the horse.

The penis of the elephant resembles that of the horse; compared with the size of the animal it is disproportionately small ; the testicles are not visible, but are concealed inside in the vicinity of the kidneys; and for this reason the male speedily gives over in the act of intercourse.) The genitals of 10

1 Also the Libyan goats, Arist. $a p$. Ael. xvi. 33.

2 Supra, $497^{\mathrm{b}} 35$; cf. P.A. iv. 10. 688a 18 ; Plin. xi. 95.

3 P.A. iv. Io. 688 33 ; Galen, de usu Part. iii. $607 \mathrm{~K}$.

4 Cf. Plin. x. 83, xi. I09, I Io.

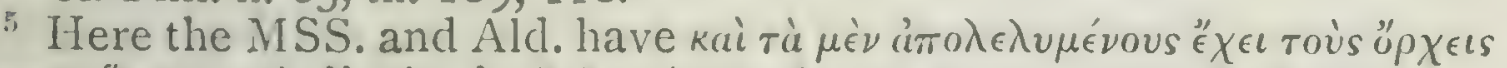

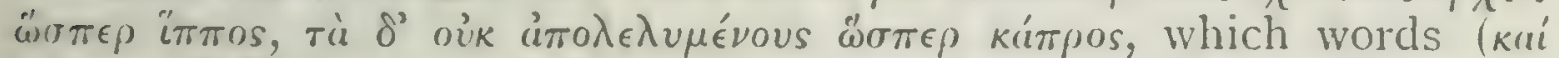

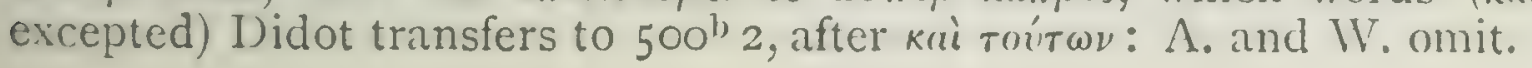


the female are situated where the udder is in sheep; when she is in heat, she draws the organ back and exposes it externally; to facilitate the act of intercourse for the male; and the organ opens out to a considerable extent.

With most animals the genitals have the position above I5 assigned; but some animals discharge their urine backwards, ${ }^{1}$ as the lynx, the lion, the camel, and the hare. Male animals differ from one another, as has been said, in this particular, but all female animals are retromingent: even the female elephant like other animals; though she has ${ }^{2}$ the privy part below the thighs.

20 In the male organ itself there is a great diversity. For in some cases the organ is composed of flesh and gristle, ${ }^{3}$ as in man; in such cases, the fleshy part docs not become inflated, ${ }^{4}$ but the gristly part is subject to enlargement. In other cases, the organ is composed of fibrous tissue, as with the camel and the deer ; in other cases it is bony, as with the fox, the wolf, the marten, and the weasel; for this organ 25 in the weasel has a bone.

When man has arrived at maturity, his upper part is smaller than the lower one," but with all other blooded animals the reverse holds good. By the 'upper' part we mean all extending from the head down to the parts used for excretion of residuum, and by the 'lower' part all clsc. 3. With animals that have feet the hind legs are to be rated as the lower part in our comparison of magnitudes, and with animals devoid of feet, the tail, ${ }^{i}$ and the like.

When animals arrive at maturity, their propertics are as above stated; but they differ greatly from one another in their growth towards maturity. For instance, man, when young, has his upper part larger than the lower, but in $50 r^{a}$ course of growth he comes to reverse this condition; and it is owing to this circumstance that-an exceptional instance.

1 Cf. P.A. iv. 10. $689^{\text {ab }} 31$.

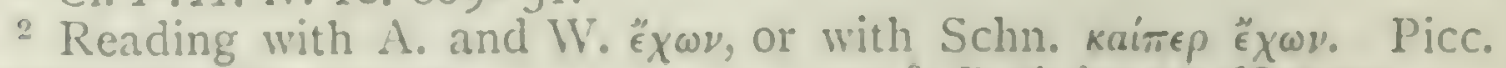
stigmatizes the clause.

${ }^{3}$ I. A. iv. 10. $689^{2} 29$.

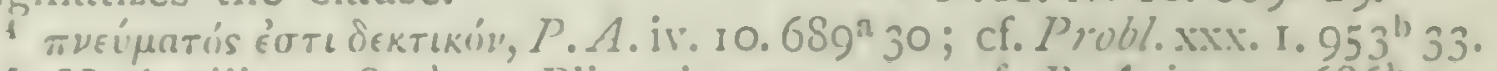

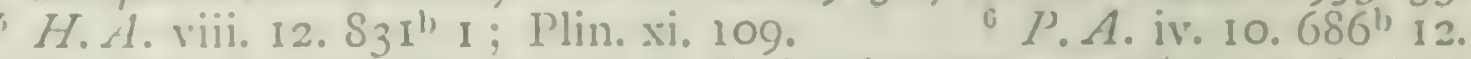

i It seems impossible to draw a distinction between ḱf save that $\kappa_{0}$ is never used of a very short tail, like the rump or uropygium of birds; cf. Bonitz, s. a'tic., Schn. iii. p. 74, \&.c. 
by the way-he does not progress in carly life as he does at maturity, but in infancy creeps on all fours; but some animals, in growth, retain the relative proportion of the parts, as the dog. Some animals at first have the upper part smaller and the lower part larger, and in course of growth the upper part gets to be the larger, as is the case 5 with the bushy-tailed animals such as the horse; for in their case there is never, subsequently to birth, any increase in the part extending from the hoof to the haunch. ${ }^{1}$

Again, in respect to the teeth, ${ }^{2}$ animals differ greatly both from one another and from man. All animals that are quadrupedal, blooded, and viviparous, are furnished 10 with teeth; but, to begin with, some are double-toothed (or fully furnished with teeth in both jaws), and some are not. For instance, horned quadrupeds are not doubletoothed; for they have not got the front teeth in the upper jaw; and some hornless animals, also, are not doubletoothed, as the camel. Some animals have tusks, like the 15 boar, ${ }^{3}$ and some have not. Further, some animals are sawtoothed, such as the lion, the pard, and the dog; and some have teeth that do not interlock but have flat opposing crowns, as the horse and the ox; and by 'saw-toothed' we mean such animals as interlock the sharp-pointed teeth in one jaw between the sharp-pointed ones in the other. No animal is there that possesses both tusks and horns, nor yet do either of these structures exist in any animal pos- 20 sessed of 'saw-teeth'.4 The front teeth are usually sharp, and the back ones blunt. The scal is saw-toothed throughout," inasmuch as he is a sort of link with the class of fishes; for fishes are almost all saw-toothed.

No animal of these genera is provided with double rows of tecth. There is, however, an animal of the sort, if we are to believe Ctesias. He assures us that the Indian wild beast 25 called the 'martichoras' "has a triple row of teeth in both

1 Xen. Eq. i. 16; Plin. xi. 108.

${ }^{2}$ P.A. iii. I ; G.A.v. 8.

${ }^{3} H . A$. iv. I I. $53^{8 \mathrm{~b}}$ I I ; Plin. xi. 6r.

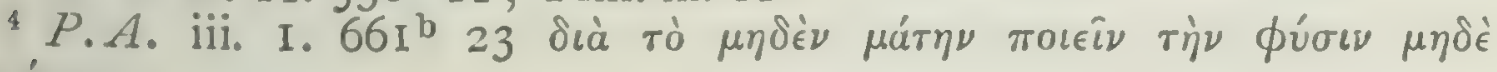
$\pi \epsilon \rho i \epsilon \rho \gamma \propto \nu$.

5.A.iv. I3. $697^{\mathrm{b}} 6$.

O. Pers. martijuqara, lit.' manslayer', the tiger. Cf. Ctes. Ind. af. AR. HaA. 
upper and lower jaw; that it is as big as a lion and equally hairy, and that its feet rescmble those of the lion ; that it rescmbles man in its face and cars; that its eyes so are blue, and its colour vermilion; that its tail is like that of the land-scorpion; that it has a sting in the tail, and has the faculty of shooting off arrow-wise ${ }^{1}$ the spines that are attached to the tail ; that the sound of its voice is a something between the sound of a pan-pipe and that of a trumpet; that it can run as swiftly" as a deer, and that it is savage $50 \mathrm{I}^{\mathrm{b}}$ and a man-eater. ${ }^{3}$

Man sheds his teeth, and so do other animals, as the horse, the mule, and the ass. And man sheds his front tceth; but there is no instance of an animal that sheds its molars. ${ }^{4}$ The pig sheds none of its teeth at all.

5 With regard to dogs some doubts are entertained, as 2 some contend that they shed no teeth whatever, and others - that they shed the canines, but those alone; "the fact being, that they do shed their tecth like man, but that the circumstance escapes obscrvation, owing to the fact that they never shed them until cquivalent tecth have grown within the gums to take the place of the shed ones. We shall be justified in supposing that the case is similar with wild 12 beasts in general; for they are said to shed their canines only. Dogs can be distinguished from one another, the young from the old, by their tecth; for the tecth in young dogs are white and sharp-pointed; in old dogs, black and blunt.

In this particular, the horse differs entirely from animals 3 15 in general: for, generally speaking, as animals grow older

Phot. Bibl. p. 67; Ael. iv. 21; Pausan. ix. 2r. 4; Plin. viii. (2 I) 30 ;

Philostr. v. Ap. iii. 45 ; cf. Otto Keller, Thicre des Altertums, p. 139.

1 The root of 'tiger' is said to signify 'sharp', 'swift', or 'an arrow'; cf. Varro, L. L. v. 100 'Vocabulum e lingua Armenia ; nam ibi et sagitta et quod vehementissimum flumen dicitur 'Tigris'.

2 'Animal relocitatis tremendac, Plin. viii. 66.

3 . and W. bracket this passage $\left(50 \mathrm{I}^{\mathrm{a}} 25^{-\mathrm{b}} \mathrm{I}\right)$ as an interpolation.

'G.A.v. S. $788^{\text {b }} 7$; Plin. xi. 63.

is the lion also is said to do: H.A.vi. 3 I. $579^{\mathrm{b}} 43 ; G . A .788^{\mathrm{b}} 17$; Plin. 1. c. 
their teeth get blacker, but the horse's teeth grow whiter with age.

The so-called 'canines' come in between the sharp teeth and the broad or blunt ones, partaking of the form of both kinds; for they are broad at the base and sharp at the tip.

Males have more teeth than females in the case of men, 20 sheep, goats, and swine; in the case of other animals observations have not yet been made: but the more teeth they have the more long-lived are they, as a rule, while those are short-lived in proportion that have teeth fewer in number and thinly set.?

The last teeth to come in man are molars called 'wisdomteeth ', ${ }^{2}$ which come at the age of twenty years, in the case 25 of both sexes. ${ }^{3}$ Cases have been known in women upwards of eighty years old where at the very close of life the wisdom-teeth have come up, causing great pain in their coming; and cascs have been known of the like phenomenon in men too. This happens, when it does happen, in the case of people where the wisdom-teeth have not come up in early years.

The elephant has four teeth on either side, by which it 30 munches its food, grinding it like so much barley-meal, and, quite apart from these, it has its great teeth, or tusks, two in number. In the male these tusks are comparatively large and curved upwards; in the female, they are comparatively small and point in the opposite direction; that $502^{\mathrm{a}}$ is, they look downwards towards the ground. The elephant is furnished with teeth at birth, but the tusks are not then visible.

The tongue of the elephant ${ }^{5}$ is exceedingly small, and situated far back in the mouth, ${ }^{6}$ so that it is difficult to get a sight of it.

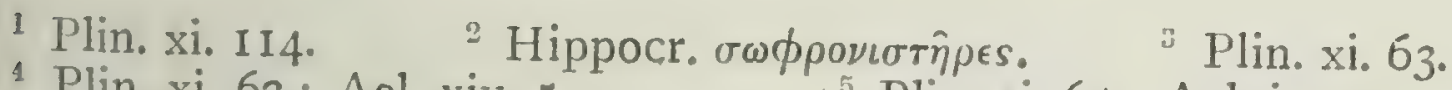

1 Plin. xi. 62; Ael. xiv. 5. 5 Plin. xi. 65; Ael. iv. 3 I.

${ }^{6}$ Plin. 1. c. 'lata elephanto praecipue', where Camper (Descr. p. 47) suspects alta s. latens. 
$5 \quad$ Furthermore, animals differ from one another in the 7 relative size of their mouths. In some animals the mouth opens wide, as is the case with the dog, the lion, and with all the saw-toothed animals; other animals have small mouths, as man; and others have mouths of medium capacity, as the pig and his congeners.

[The Egyptian hippopotamus ${ }^{1}$ has a mane like a horse, 10 is cloven-footed like an ox, and is snub-nosed. It has a huckle-bone like cloven-footed animals, and tusks just visible; it has the tail of a pig, the neigh of a horse, ${ }^{2}$ and the dimensions of an ass. The hide is so thick that spears are made out of it. In its internal organs it resembles the 15 horse and the ass.]

Some animals share the properties of man and the 8 quadrupeds, as the ape, the monkey, and the baboon. The monkey is a tailed ape. The baboon" resembles the ape 20 in form, only that it is bigger and stronger, more like a dog in face, and is more savage in its habits, and its tecth are more dog-like and more powerful.

Apes are hairy on the back in kecping with their guadrupedal nature, and hairy on the belly in leeping with their human form-for, as was said above, this characteristic 25 is reversed in man and the quadruped ${ }^{4}$-. only that the hair is coarse, so "that the ape is thickly coated both on the belly and on the back. Its face resembles that of man in many respects; in other words, it has similar nostrils and 30 cars, and tecth like those of man, both front tecth and molars. Further: whereas quadrupeds in general are not furnished with lashes on one of the two eyelids, this creature has them on both, only very thinly set, especially the under ones; in fact they are very insignificant indeed. And we

I Herod. ii. 7I ; Plin. viii. (25) 39, xi. (39) 113; Ael.v. 53. This description follows that of Herodotus closely, with slight exceptions:

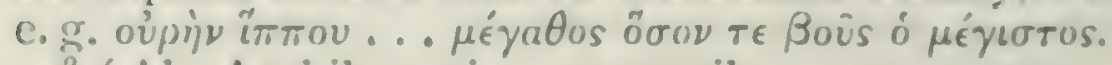

2 ' $\mathrm{Ab}$ Arabibus cius curatoribus percunctatus sum quam vocem edere soleret. Unus respondit equinam, alter mulinam. Verum nationi bifrate nihil credens. Illius aures paulo gravius rellere coepl; sed nullam vocem elicere potui (!), P. Gellius, ed. Hamburg, I614, p. 26; cit. Schneider, Hist. Piscium, 1789, p. 317.

${ }^{3}$ Plin. viii. So. 11. A. ii. I. $498^{1}$ I7; Plin. xi. (44) 100. $\ddot{\omega} \sigma \tau \epsilon \mathrm{cj}$. Dittm. 
must bear in mind that all other quadrupeds have no under eyelash at all. ${ }^{1}$

The ape has also in its chest two teats upon poorly developed breasts. It has also arms like man, only covered with hair, and it bends these legs like man, with the $502^{\mathrm{b}}$ convexities of both limbs facing one another. ${ }^{2}$ In addition, it has hands and fingers and nails like man, only that all these parts are somewhat more beast-like in appearance. Its feet are exceptional in kind. That is, they are like large 5 hands, and the toes are like fingers, with the middle one the longest of all, and the under part of the foot is like a hand except for its length, ${ }^{3}$ and stretches out towards the extremities like the palm of the hand; and this palm at the after end is unusually hard, and in a clumsy obscure kind of way resembles a heel. The creature uses its feet ro either as hands or feet, and doubles them up as one doubles a fist. Its upper-arm and thigh are short in proportion to the forearm and the shin. It has no projecting navel, but only a hardness in the ordinary locality of the navel. Its upper part is much larger than its lower part, as is the case is with quadrupeds; in fact, the proportion of the former to the latter is about as five to three. Owing to this circumstance and to the fact that its feet resemble hands and are composed in a manner of hand and of foot: of foot in the heel extremity, of the hand in all else-for even the toes have what is called a 'palm':-for these reasons the animal 20 is oftener to be found on all fours than upright. It has neither hips, inasmuch as it is a quadruped, ${ }^{4}$ nor yet a tail, inasmuch as it is a biped, except by the way that it has a tail as small as small can be, just a sort of indication of a tail. The genitals of the female resemble those of the female in the human species; those of the male are more like those of a dog than are those of a man.

The monkey, as has been observed, is furnished with 25

1 P.A. ii. 14. $658^{a}$ I 5 .

2 Cf. supra, I. $498^{\text {a }}$ I9; Plin. xi. Io2.

3 The construction is obscure; the best reading seems to be $\epsilon \pi t-$

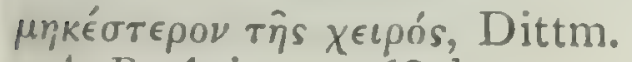

P.A. iv. I0. $689^{\mathrm{b}} 32$. 
a tail. In all such creatures the internal organs are found under dissection to correspond to those of man.

So much then for the propertics of the organs of such animals as bring forth their young into the world alive. ${ }^{1}$

Oviparous and blooded quadrupeds-and, by the way, Ic no terrestrial ${ }^{2}$ blooded animal is oviparous unless it is so quadrupedal or is devoid of fect altogether-are furnished with a head, a neck, a back, upper and under parts, the front legs and hind legs, and the part analogous to the chest, all as in the case of viviparous quadrupeds, and with a tail, usually large, in exceptional cases small. And all these creatures are many-toed, and the scveral toes are cloven apart. Furthermore, they all have the ordinary organs of sensation, including a tongue, with the exception $503^{a}$ of the Egyptian crocodile. ${ }^{3}$

This latter animal, by the way, resembles certain fishes. For, as a general rule, fishes have a prickly tongue, ${ }^{4}$ not free in its movements; though there are some fishes that present a smooth undifferentiated surface where the tongue should be, until you open their mouths "wide and make a close inspection.

Again, oviparous blooded quadrupeds are unprovided 5 with cars, but possess only the passage for hearing; neither have they breasts, nor a copulatory organ, nor cxtcrnal testicles, but internal ones only; neither are they hair-coated. but are in all cases covered with scaly plates. Noreover. they are without exception saw-toothed.

River crocodiles have pigs' eyes, large tecth and tusks, ro and strong nails, and an impenetrable skin composed of

${ }^{2}$ Schn. tr. 'quae animal pariunt, parte's extimas ad hunc habent modum "; and $A$. and WV. in like manner "die Resthaffenheit der mod aussen liegenden Theile der L.ebendiggebarenden'; in both cases

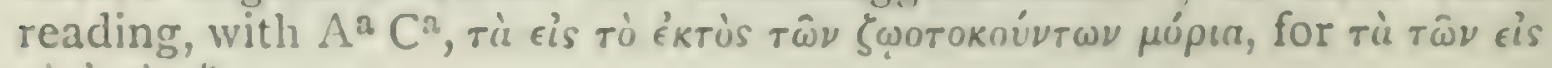

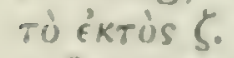

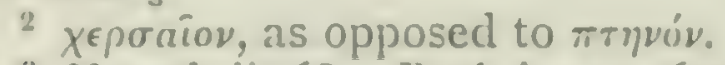

3 Herod. ii. 68 ; P.A. iv. II. 690" 20; Plin. viii. 37 (25), xi. 65.

P.A. ii. $17.66 \mathrm{I}^{2} 2$.

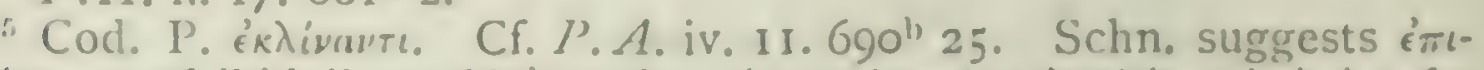

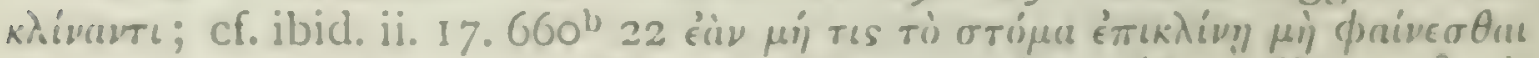

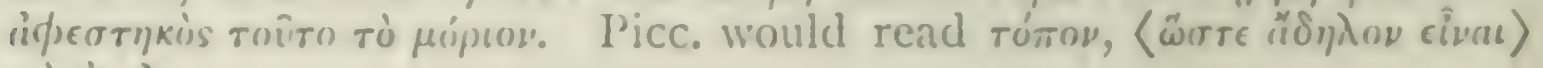
$\mu \dot{\eta} \dot{\epsilon}^{\prime} \gamma \kappa$. 
scaly plates. They see but poorly under water, but above the surfacc of it with remarkable acuteness. As a rule, they pass the day-time on land and the night-time in the water; for the temperature of the water is at night-time more genial than that of the open air.

The chameleon ${ }^{1}$ resembles the lizard in the general ${ }_{5}$ configuration of its body, but the ribs stretch downwards and meet together under the belly as is the case with fishes, and the spine sticks.up as with the fish. Its face resembles that of the baboon. ${ }^{2}$ Its tail is exceedingly long, terminates in a sharp point, and is for the most part coiled up, like 20 a strap of leather. It stands higher off the ground than the lizard, but the flexure of the legs is the same in both creatures. Each of its fect is divided into two parts, which bear the same relation to one another that the thumb and the rest of the hand bear to one another in man. Each of 25 these parts is for a short distance divided after a fashion into toes; on the front feet the inside part is divided into three and the outside into two, on the hind feet the inside part into two and the outside into three; it has claws also on these parts resembling those of birds of prey. Its body zo is rough all over, like that of the crocodile. Its eyes are situated in a hollow recess, and are very large and round, and are enveloped in a skin resembling that which covers the entire body $;^{3}$ and in the middle a slight aperture is left for vision, through which the animal sees, for it never covers up this aperture with the cutaneous envelope. It keeps twisting its eyes round and shifting its line of vision $503^{\mathrm{b}}$ in every direction, and thus contrives to get a sight of any object that it wants to see. The change in its colour ${ }^{4}$ takes place when it is inflated with air ; it is then black, not unlike the crocodile, or green like the lizard but black-spotted 5 like the pard. This change of colour takes place over the

1 Plin. viii. $5 \mathrm{I}$.

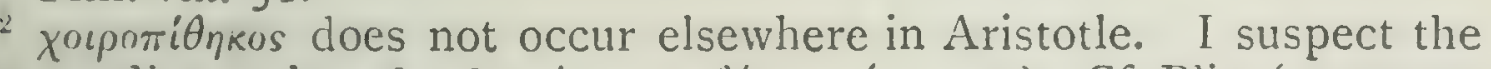
true reading to be $\tau \hat{\omega}$ r

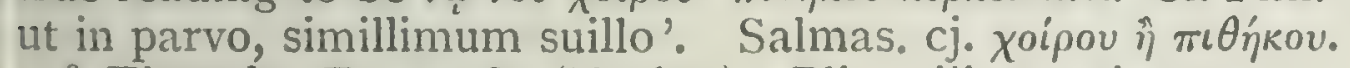

3 Theophr. Fr. p. 189 (Teubn.); Plin. viii. 5 I, xi. 55.

* Theophr. 1. c.; Antig. Mirab. 25; Ael. ii. I4; Ovid, Met.xv. 412 ; Plin. xxviii. 29, \&c. 
whole body alike, for the eyes and the tail come alike under its influence. In its movements it is very sluggish, like the ro tortoise. It assumes a greenish hue in dying; and retains this huc after death. It resembles the lizard in the position of the ocsophagus and the windpipe. It has no flesh anywhere except a fow scraps of flesh on the head and on the jaws and near to the root of the tail. It has blood only Is round about the heart, the eyes, the region above the heart, and in all the veins extending from these parts; and in all these there is but little blood after all. ${ }^{1}$ The brain is situated a little above the eycs, but connected with them. When the outer skin is drawn aside from off the cye, 20 a something is found surrounding the cyc, that gleams through like a thin ring of copper. ${ }^{2}$ Membrancs ${ }^{3}$ extend wellnigh over its entire frame, numerous and strong, and surpassing in respect of number and relative strength those found in any other animal. After being cut open along its entire length it continues to breathe for a considerable time; ${ }^{4}$ a very slight motion goes on in the region of the ${ }_{25}$ heart, and, while contraction is especially manifested in the neighbourhood of the ribs, a similar motion is more or less discernible orer the whole body. It has no splecn visible. It hibernates, like the lizard.

Bircls "also in some parts resemble the above-mentioned $\mathbf{I}$ 30 animals; that is to say, they have in all cases a head, a neck, a back, a belly, and what is analogous to the chest. The bird is remarkable among animals as having two feet, like man; only, by the way, it bends them backwards as quadrupeds bend their hind legs, as was noticed previously." It has neither hands nor front fect, but wings-an exceptional structure as compared with other animals. Its

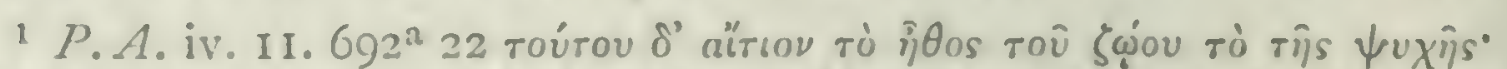

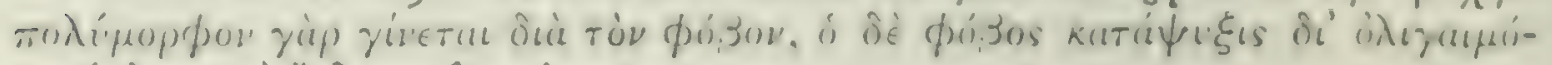

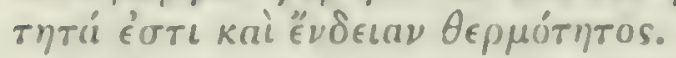

"Valentin, Theatr. Anatom., 1720, p. I96 'pupilla quasi parvo auren circulo circumdata'. Cf. Theoph. fr. p. 189 (Teubn.). See also A. and W.'s note.

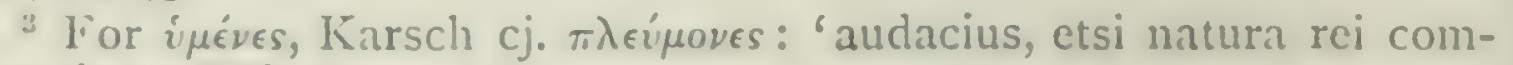
mendatur,' Dittm.

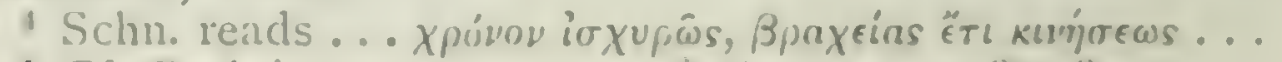

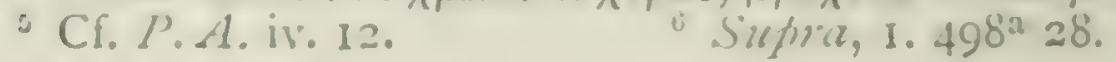


haunch-bone is long, like a thigh, and is attached to the body $504^{\mathrm{a}}$ as far as the middle of the belly; ${ }^{1}$ so like to a thigh is it that when viewed separately it looks like a real one, while the real thigh is a separate structure betwixt it ${ }^{2}$ and the shin. Of all birds those that have crooked talons have the biggest thighs and the strongest breasts. All birds are furnished with many claws, ${ }^{3}$ and all have the toes scparated 5 more or less asunder; that is to say, in the greater part the toes are clearly distinct from one another, for cven the swimming birds, although they are web-footed, have still their claws fully articulated and distinctly differentiated from one another. Birds that fly high in air are in all cases four-toed: that is, the greater part have three toes in front ro and one behind in place of a heel; some few have two in front and two behind, as the wryneck.

This latter bird is somewhat bigger than the chaffinch, and is mottled in appearance. It is peculiar in the arrangement of its toes, ${ }^{4}$ and resembles the snake in the structure of its tongue; for the creature can protrude its tongue to the cxtent of four finger-breadths, and then draw it back again. Is Moreover, it can twist its head backwards while keeping all the rest of its body still, like the serpent. It has big claws, somewhat resembling those of the woodpecker. ${ }^{5}$ Its note is a shrill chirp. ${ }^{6}$

Birds are furnished with a mouth, but with an exceptional one, for they have neither lips nor teeth, but a beak. 20 Neither have they ears nor a nose, but only passages for the sensations connected with these organs: that for the nostrils in the beak, and that for hearing in the head. Like all other animals they all have two eyes, and these are devoid of lashes. The heavy-bodied (or gallinaceous)

1 de Inc. II. $710^{b} 21$.

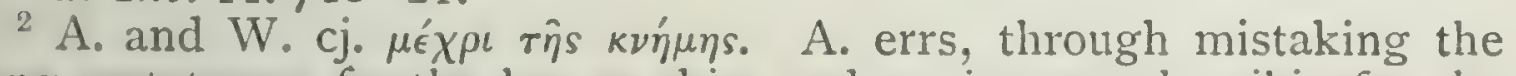
long metatarsus for the leg or shin, and so, in turn, the tibia for the thigh and the femur for the haunch-bone. The error is corrected by Fridericus II, de Arte venandi, p. 44, cit. Schn. iv. p. 304.

3 Plin. xi. 107.

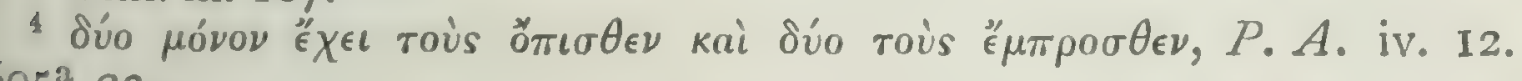
$695^{\mathrm{a}} 23$.

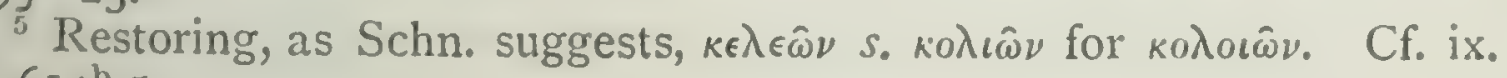
9. $614^{\mathrm{b}} 5$.

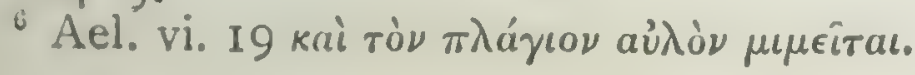


25 birds close the cyc by means of the lower lid, and all birds blink by means of a skin extending over the eye from the inner corner; the owl and its congeners also close the eye by means of the upper lic. ${ }^{1}$ The same phenomenon is observable in the animals that are protected by horny scutes, as in the lizard and its congeners; for they all without exception close the eye with the lower licl, but they do not blink like birds."

:o Further, birds have neither scutes nor hair, but feathers : and the feathers are invariably furnished with quills. They have no tail, but a rump' with tail-feathers, short in such as are long-legged and web-footed, large in others. These latter kinds of birds fly with their feet tucked up close to the belly; but the small-rumped or short-tailed birds fly with their legs stretched out at full length. All are furnished with a tongue, but the $504^{\text {b }}$ organ is variable, being long in some bircls and broad in others. Certain species of bircls above all other animals, and next after man, possess the faculty of uttering articulate sounds; and this faculty is chicfly developed in broadtongued birds." No oviparous creature has an epiglottis ${ }^{6}$ over the windpipe, but these animals so manage the open5 ing and shutting of the windpipe as not to allow any solid substance to get down into the lung.

Some species of birds are furnished additionally with spurs, but no bird with croolied talons is found so provided. The birds with talons are among those that fly wcll, but those that have spurs are among the heavy-bodied.

io Again, some bircls have a crest. As a general rule the crest sticks up, and is composed of feathers only: but the crest of the barn-door cock is exceptional in kind, for, whereas it is not just exactly flesh, at the same time it is not casy to say what else it is.

I.A. ii. 13. $657^{\mathrm{a}} 28$; Plin. xi. 57.

IP. A. iv. II. $691^{\mathrm{a}} 20$.

${ }^{3} G \cdot A \cdot v \cdot 3 \cdot 782^{a} 17$.

4 It seems plain that ouporíyıv means here not the rump only, but the whole tail of the bird: cf. P. A. iv. I3. 697" II oúden d' "Ex

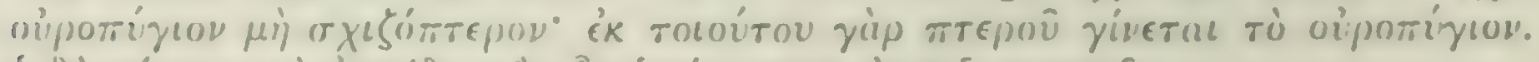

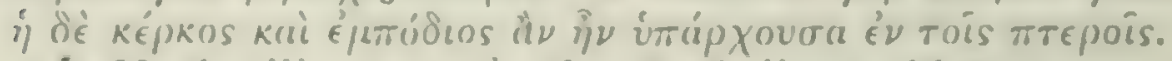

SH. A. viii. 12. $597^{\prime \prime} 26$; P. A. ii. $17.660^{2} 23$.

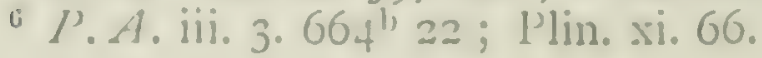


I3 Of water animals the genus of fishes constitutes a single group apart from the rest, and including many diverse forms. ${ }^{1}$

In the first place, the fish has a head, a back, a belly, in is the neighbourhood of which last are placed the stomach and viscera; and behind it has a tail of continuous, undivided shape, but not, by the way, in all cases alikc. No fish has a neck, or any limb, or testicles ${ }^{2}$ at all, within or without, or breasts. But, by the way, this absence of breasts may be predicated of all non-viviparous animals; and in 20 point of fact viviparous animals arc not in all cases provided with the organ, excepting such as are directly viviparous without being first oviparous. Thus the dolphin is clirectly viviparous, and accordingly we find it furnished with two breasts, ${ }^{3}$ not situated high up, but in the neighbourhood of the genitals. And this creature is not provided, likc quadrupeds, with visible teats, but has two vents, one on each flank, from which the milk flows; and its young have 25 to follow after it to get suckled, and this phenomenon has been actually witnessed.

Fishes, then, as has been observed, have no breasts and no passage for the genitals visible externally. But they have an exceptional organ in the gills, whereby, after taking the water in by the mouth, they discharge it again; and in the fins, of which the greater part have four, and the 30 lanky ones two, as, for instance, the eel, and these two situated near to the gills. ${ }^{4}$ In like manner the grey mulletas, for instance, the mullet found in the lake at Siphae "have only two fins; and the same is the case with the fish called Ribbon-fish." ${ }^{6} \quad$ Some of the lanky fishes have no fins

1 ió́a, frequent in A. of a logical species, is not used of the species of animals or plants. It may here mean the sensille species, and thus be all but identical with $\mu$ op pi, cf. Schn. 'piscium genus solum ab aliis multarum ambitu formarum distinctum est'.

${ }^{2}$ Cf. H.A. v. 5. $540^{b} 28$, \&c.

3 H.A. iii. 20. $52 \mathrm{I}^{\mathrm{b}} 23$; Plin. xi. 95 .

${ }^{4}$ H. A. i. 5. $489^{\mathrm{b}} 23$; P.A. iv. 13. $69^{\mathrm{a}} 4$; de Inc. $7.707^{\mathrm{b}} 28$; Plin. ix. 37 .

Tipha, on the south coast of Boeotia, near Thespiae; cf. Pausan. ix. 32. 3 (Sylburg). Cf. P.A. iv. 13.696 5 ; de Inc. $7.708^{a} 5$.

raivra, an unidentified fish. Cepola taenia, L. and Cobitis taenia, L. have two pair of fins. Speusippus (cit. Ath. $329 \mathrm{f}$ ) compares it 
at all, such as the muraena, nor gills articulated ${ }^{1}$ like those of other fish.

And of those fish that are provided with gills, some have $505^{a}$ coverings for this organ, whereas all the selachians have the organ unprotected by a cover. And those fishes that have coverings or opercula for the gills have in all cases their gills placed sideways; whereas, among selachians, the broad ones have the gills down below on the belly, as the torpedo and the ray, while the lanky ones have the 5 organ placed sideways, as is the case in all the dog-fish.

The fishing-frog has gills placed sideways, and covered not with a spiny operculum, as in all but the selachian fishes, but with one of skin.

Morever, with fishes furnished with gills, ${ }^{2}$ the gills in some cases are simple in others duplicate; and the last gill in the direction of the body is always simple. And, again, some 10 fishes have few gills, and others hare a great number; but all alike have the same number on both sides. Those that have the least number have one gill on either side, and this one cluplicate, like the boar-fish; others have two on cither side, one simple and the other duplicate, like the conger and the scarus; ${ }^{3}$ others have four on either side, I5 simple, as the elops, ${ }^{4}$ the synagris, ${ }^{5}$ the muracna, and the cel ; others have four, all, with the exception of the hindmost one, in clouble rows, as the wrasse," the perch, the sheat-fish, and the carp. The dog-fish have all their gills double, five on a side; and the sword-fish has eight ${ }^{i}$

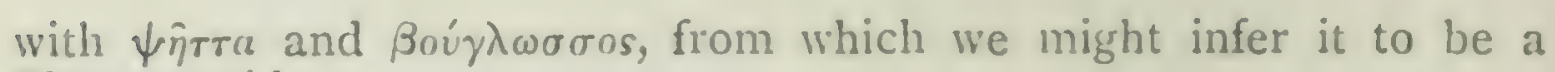
Pleuronectid.

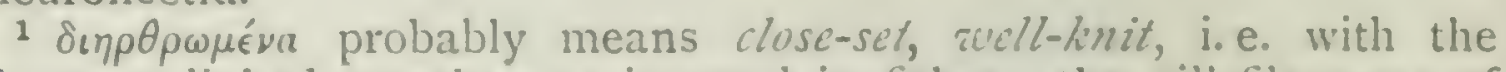
flaments linked together, as is usual in fishes; the gill-filaments of the muraena are loose and float apart.

2 Plin. ix. 32.

3 Scarus cretensis, the parrot-wrasse; mod. Gk. okip'ss.

4 The identification was disputed by the ancients; cf. Plin. ix. 27. xxxii. 54; Athen. vii. 364 , viii. 294; Ael. viii.28. Perhaps the sturgeon, perhaps a large tunny (cf. footnote, vi. $17 \cdot 570^{\mathrm{b}} 20$ ).

"In mod. Cik. ouvarpion is Dentex a'ulguris, but the statements here and in $15.506^{\text {b }} 16$ do not help the identification.

In mod. Gk. kixda is Ctemilabrus rostratus (Heldreich), and the various wrasses are known throughout the Mediterranean as lom(n), tourdum, srian, dic.

7 i. e. four on each side. 
double gills. ${ }^{1}$ So much for the number of gills as found in fishes.

Again, fishes differ from other animals in more ways than 20 as regards the gills. For they are not covered with hairs as are viviparous land animals, nor, as is the case with certain oviparous quadrupeds, with tessellated scutes, nor, like birds, with feathers; but for the most part they are covered with scales. Some few are rough-skinned, while 25 the smooth-skinned are very few indeed. Of the Selachia some are rough-skinned and some smooth-skinned; ${ }^{2}$ and among the smooth-skinned fishes are included the conger, the eel, and the tunny.

All fishes are saw-toothed excepting the scarus; ${ }^{3}$ and the teeth in all cases are sharp and set in many rows, and in some cases are placed on the tongue. ${ }^{4}$ The tongue is hard and spiny, and so firmly attached that fishes in many 30 instances seem to be devoid of the organ altogether. The mouth in some cases ${ }^{5}$ is wide-stretched, as it is with some viviparous quadrupeds....

With regard to organs of sense, all save eyes, fishes possess none of them, neither the organs nor their passages, neither ears nor nostrils; but all fishes are furnished with eyes, and the eyes devoid of lids, though the eyes are not hard; ${ }^{6}$ with regard to the organs connected with the other senses, hearing and smell, they are devoid alike of the organs themselves and of passages indicative of them.

Fishes without exception are supplied with blood. Some $505^{\mathrm{b}}$ of them are oviparous, and some viviparous; scaly fish are invariably oviparous, but cartilaginous fishes are all viviparous, with the single exception of the fishing-frog.

1 This passage is referred to, $P$. A. iv. $13.696^{1}$. 15 .

P.A.iv. 13. $697^{\mathrm{a}} 4$.

P.A. iii. I. $662^{a} 7$.

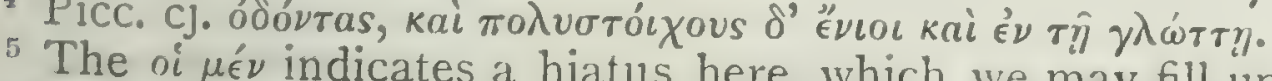

corresponding indicates a hiatus here, which we may fill up from the

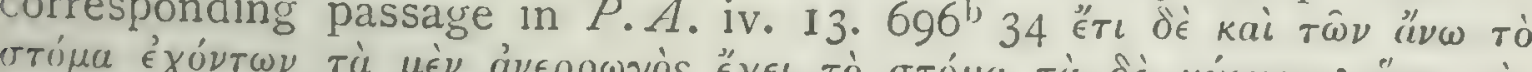

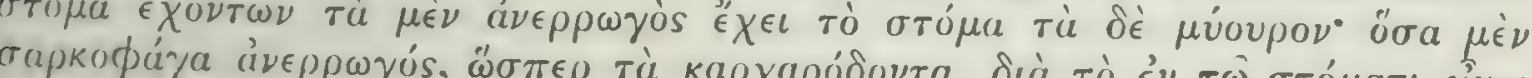
Tois roluvitoss

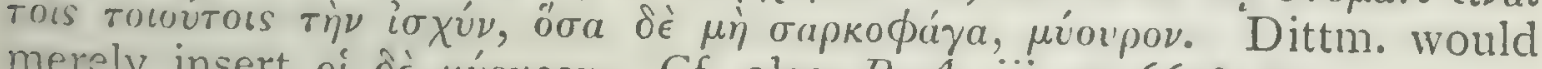

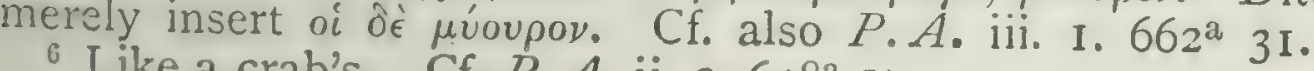

Like a crab's. Cf. P. A. ii. 2. $648^{a}$ I 7.

? G. A. iii. 3. $754^{2} 25$. 
5 Of blooded animals there now remains the serpent genus. I4 This genus is common to both elements, for, while most species comprehended therein are land animals, a small minority, to wit the aquatic species, pass their lives in fresh water. There are also sea-serpents, ${ }^{1}$ in shape to a great extent resembling their congeners of the land, with this exception that the head in their case is somewhat 10 like the head of the conger; and there are several kinds of sca-scrpent, and the different kinds differ in colour; these animals are not found in very decp water. Serpents, like fish, are devoid of fect.

There are also sea-scolopendras, ${ }^{2}$ rescmbling in shape their land congeners, but somewhat less in regard to masnitude. These creatures are found in the neighbourIs hood of rocks; as compared with their land congeners they are redder in colour, are furnished with fect in greater numbers and with less of more delicate structure. And the same renarli applies to them as to the sea-serpents, that they are not found in very decp water.

Of fishes whose habitat is in the vicinity of rocks there is a finy one, which some call the Iichencis," or 'ship-holder', and which is by some people used as a charm to bring luck zo in affairs of law and love. The creature is unfit for eating. Some people assert that it has fect, but this is not the case : it appears, however, to be furnished with feet from the fact that its fins rescmble those organs.

So much, then, for the external parts of blooded animals, as regards their numbers, their propertics, and their relative diversities.

25 As for the properties of the internal organs, these we 15 must first discuss in the case of the animals that are supplied with blood. For the principal genera difier from the rest of

1 H. A. ix. 37. 62 I 2 ; Plin. ix. 67.

"Annelid worms, e.g. Nercis. 11. 1. jx. 37. 621 6 ; de Inc. 7 . $707^{\text {il }} 30$; Plin. ix. 67 (43); Opp. Hal. ii. 424 ; Ael. vii. 35 .

3 Plin. ix. 41, xxii. I; Opp. Ilat. i. 213 ; Ael. xii. 45; Bartol. Romano, Nintice d/editcrance, Roma, 1607. The myth of the 'shipholder' has been elegintly explained by V. W. Lkman, 'On Dead Water, in the Repurts of Nansti's Norh l'olar Expedition, Christiania, 1004. 
animals, in that the former are supplied with blood and the latter are not; and the former include man, viviparous and oviparous quadrupeds, birds, fishes, cetaceans, and all the others that come under no general designation by reason 30 of their not forming genera, but groups of which simply the specific name is predicable, ${ }^{1}$ as when we say 'the serpent', 'the crocodile'.

All viviparous quadrupeds, then, are furnished with an oesophagus and a windpipe, situated as in man; the same statement is applicable to oviparous quadrupeds and to birds, only that the latter present diversities in the shape:s of these organs. As a general rule, all animals that take $5^{0} 6^{\mathrm{a}}$ up air and breathe it in and out are furnished with a lung, a windpipe, and an oesophagus, with the windpipe and oesophagus not admitting of diversity in situation but admitting of diversity in properties, and with the lung admitting of diversity in both these respects. Further, all blooded animals have a heart and a diaphragm or midriff ; 5 but in small animals the existence of the latter organ is not so obvious owing to its delicacy and minute size.

In regard to the heart 2 there is an exceptional phenomenon observable in oxen. In other words, there is one species of ox where, though not in all cases, a bone is found inside the heart. ${ }^{3}$ And, by the way, the horse's heart also io has a bone inside it.

The genera referred to above are not in all cases furnished with a lung: for instance, the fish is devoid of the organ, as is also every animal furnished with gills. All blooded animals are furnished with a liver. As a general rule blooded animals are furnished with a spleen; but with the great majority of non-viviparous but oviparous animals

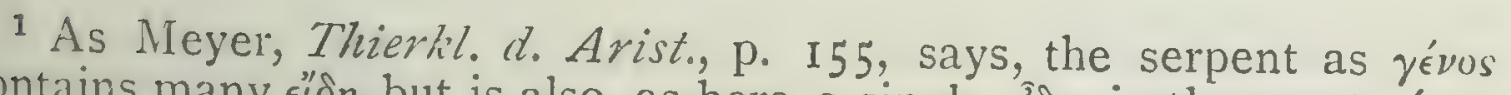

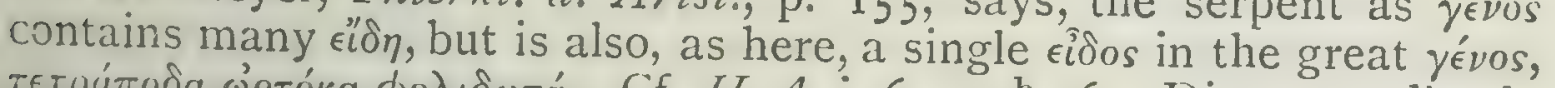

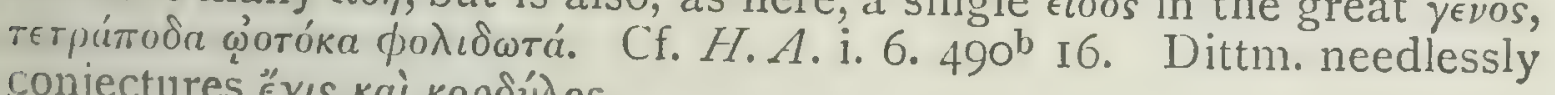

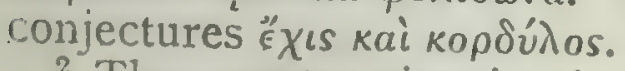

2 The construction is obscure, and suggests either a lacuna or an interpolation. I follow Schn., who, following Albertus, reads $\pi \lambda \dot{\eta} \nu$ ö

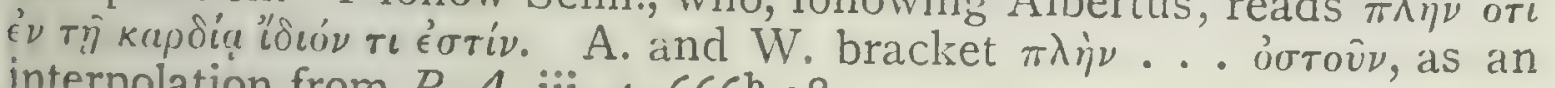
interpolation from $P . A$. iii. $4.666^{\mathrm{b}}$ is.

${ }^{3} P . A$. iii. $4 \cdot 666^{\mathrm{b}}$ I $8 ; G \cdot A \cdot$ v. $7 \cdot 787^{\mathrm{b}}$ I8. 
I5 the splecn is so small as all but to escape observation; ${ }^{1}$ and this is the case with almost all birds, as with the pigeon, the kite, the falcon, the owl: in point of fact, the aegocephalus ${ }^{2}$ is devoid of the organ altogether. With oviparous quadrupeds the case is much the same as with the viviparous; that is to say, they also have the spleen exceedingly minute, as the tortoise, the freshwater tortoise, the toad, 20 the lizard, the crocodile, and the frog.

Some animals have a gall-bladder close to the liver, and others have not. Of viviparous quadrupeds the deer is without the organ, ${ }^{3}$ as also the roe, the horse, the mule, the ass, the seal, and some kinds of pigs. ${ }^{4}$ Of deer those that are called Achainae ${ }^{5}$ appear to have gall in their tail, but 25 what is so called does resemble gall in colour, though it is not so completely fluid, and the organ internally ${ }^{6}$ resembles a spleen.

However, without any exception, stags are found to have maggots living inside the head, ${ }^{i}$ and the habitat of these creatures is in the hollow underneath the root of the tongue and in the neighbourhood of the vertebra to which the head is attached. These creatures are as large as the largest 3o grubs; they grow all together in a cluster, and they are usually about twenty in number. ${ }^{8}$

Deer then, as has been observed, are without a gallbladder; their gut, however, is so bitter that even hounds refuse to cat it unless the animal is exceptionally fat. ${ }^{3}$ With $506^{\mathrm{b}}$ the elephant also the liver is unfurnished with a gallbladder, but when the animal is cut in the region where the organ is found in animals furnished with it, there oozes out a fluid resembling gall, in greater or less quantitics. Of animals that talie in sea-watcr and are furnished with a

1 P. A. iii. $7.670^{a} 32$.

"Unidentified; perhaps one of the horned owls.

${ }^{3}$ P. A. iv. 2. $676^{\mathrm{b}} 27 .{ }^{4} \mu{ }^{\prime} \omega \nu^{\prime}$, Bekk, ; but cf. $P$. A. 1. c.

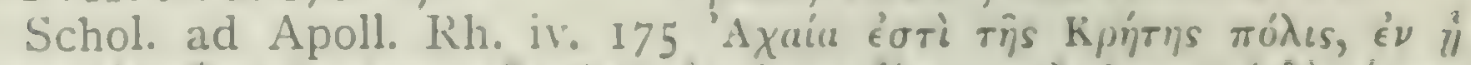

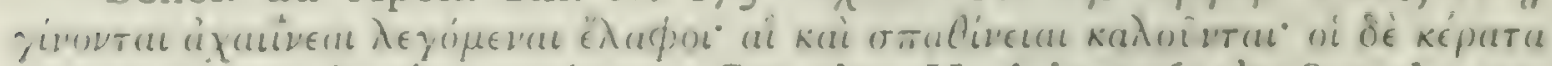

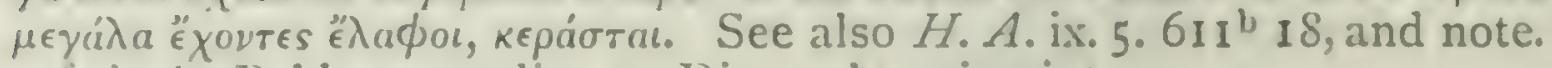
ékтós, Bekk, according to Dittm., by misprint.

7 Larvae of a gadfly, Oestrues sp., esp. Oe. mufburbis, Meig.; of Sundevall, p. 67. Cf. Plin. xi. 49.

${ }^{8}$ Dittm., following 13. St. Hilaire, brackets the paragraph.

- Plin. xi. 74. Nemes. de Nat. Hom。 iv. p. II6. 
lung, the dolphin is unprovided with a gall-bladder. Birds 5 and fishes all have the organ, ${ }^{1}$ as also oviparous quadrupeds, all to a greater or a lesser extent. But of fishes some have the organ close to the liver, as the dog-fishes, the sheat-fish, the rhine or angel-fish, the smooth skate, the torpedo, and, of the lanky fishes, the eel, the pipe-fish, ${ }^{2}$ and the hammer-headed shark. The callionymus," also, has the so gall-bladder close to the liver, and in no other fish does the organ attain so great a relative size. ${ }^{4}$ Other fishes have the organ close to the gut, attached to the liver by certain extremely fine ducts. The bonito has the gall-bladder stretched alongside the gut and equalling it in length, and often a double fold of it. Others have the organ in the 15 region of the gut; in some cases far off, in others near; as the fishing-frog, the elops, the synagris, the muraena, and the sword-fish. Often animals of the same species show this diversity of position; as, for instance, some congers are found with the organ attached close to the liver, and others with it detached from and below it. The case is much the same with birds: that is, some have the gall-bladder 20 close to the stomach, and others close to the gut, as the pigeon, the raven, the quail, the swallow, and the sparrow; some have it near at once to the liver and to the stomach as the aegocephalus; others have it near at once to the liver and the gut, as the falcon and the kite.

\section{Again, all viviparous quadrupeds are furnished with} kidneys and a bladder. 5 Of the ovipara that are not quad- 25 rupedal there is no instance known of an animal, whether fish or bird, provided with these organs. Of the ovipara

1 C. $P . A$. iv. 2.

${ }^{2}$ Syngnathus sp., cf. $H$. $A$. vi. I $3.567^{\mathrm{b}}$ I $8 ; G . A$. iii. $4 \cdot 755^{\mathrm{a}} 33$.

3 According to Cuvier, Uranoscopus scaber; but according to Dorio

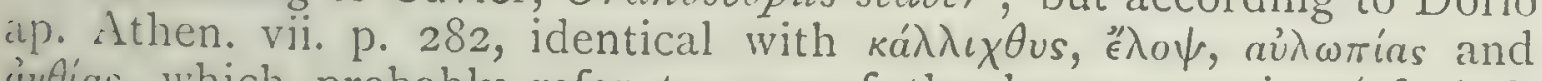
iivias, which probably refer to one of the larger tunnies (cf. Acl.
xiii. I7).

4 Menand., Anaxipp., \&c., ap. Ael. xiii. 4 ; Plin. xxxii. 7 ; Arist. fr.

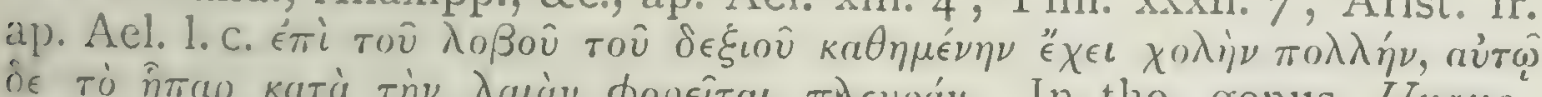

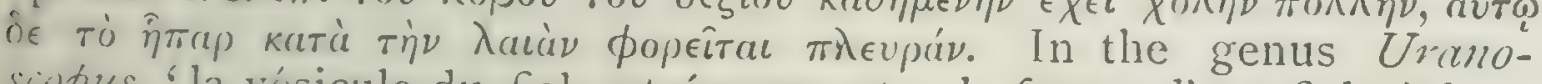
scopus, "la vésicule du fiel est énorme et a la forme d'une fiole à long con, suspendue ì un canal cholédoque aussi gros que le duodénum,' Cuvier, iii. p. 296.

${ }^{5}$ C. $P$. A. iii. 9 . 
that are quadrupedal, the turtle alone is provided with these organs ${ }^{1}$ of a magnitude to correspond with the other organs of the animal. In the turtle the kidney resembles the same organ in the ox; that is to say, it looks like one 30 single organ composed of a number of small ones. [The bison also resembles the ox in all its internal parts.]

With all animals that are furnished with these parts, the $\mathbf{r}_{\text {; }}$ parts are similarly situated, and with the exception of man, the heart is in the middle; in man, however, as has $507^{a}$ been observed, the heart is placed a little to the left-hand side." In all animals the pointed end of the heart turns frontwards; only in fish it would at first sight scem otherwise, for the pointed end is turned not towards the breast, but towards the head and the mouth. ${ }^{3}$ And (in fish) the 5 apex is attached to a tube ${ }^{4}$ just where the right and left gills meet together. There are other clucts cxtending from the heart to each of the gills, greater in the greater fish, lesser in the lesser; but in the large fishes the duct at the pointed end of the heart is a tube, white-coloured and exceedingly thick.

10 Fishes in some few cases have an oesophagus, as the conger and the eel; and in these the organ is small.

In fishes that are furnished with an undivided liver, the organ lies entirely on the right side; where the liver is cloven from the root, the larger half of the organ is on the right sicle: for in some fishes the two parts are detached from one 15 another, without any coalescence at the root, as is the case with the ${ }^{\prime}$ - - fish. And there is also a species of hare ${ }^{5}$ in what is named the lig district, near Lake Bolbe," and elsewhere,

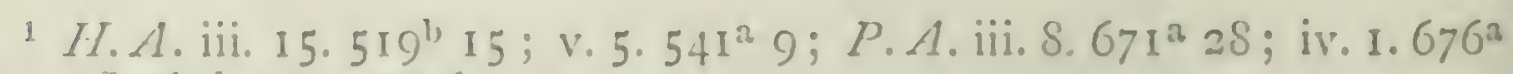
$29 ; G \cdot 1$. i. $13 \cdot 720^{2} 6$.

H. A. i. $17.496^{\mathrm{a}} 15$.

3 Plin. xi. 69.

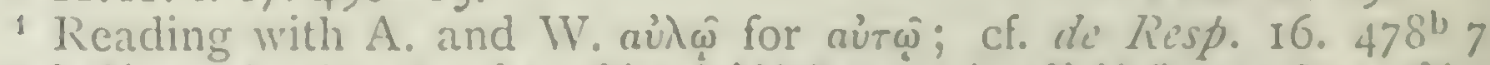

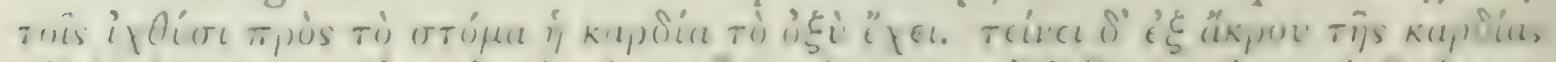

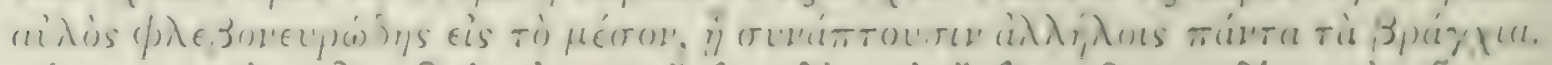

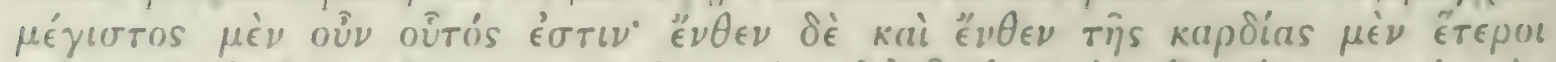

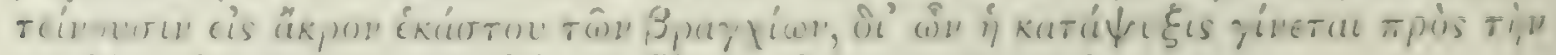

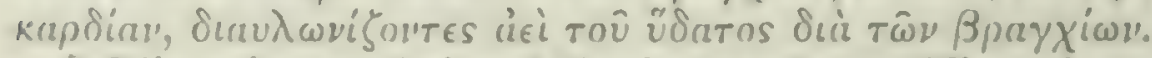

S Plin. xi.73; Arist. Mirab. 122. 842a; Theophr. ap. Athen. is. 401 ; Acl. v. 27 , xi. II.

In Macedonia, on the left bank of the Axios (Schn.); cf. Aesch. Persuc, 4) 4, 'Thuc. i. 58. 
which animal might be taken to have two livers owing to the length of the connecting ducts, ${ }^{1}$ similar to the structure in the lung of birds.

The spleen in all cases, when normally placed, is on the left-hand side, and the kidneys also lic in the same position 20 in all creatures that possess them. ${ }^{2}$ There have been known instances of quadrupeds under dissection, where the spleen was on the right hand and the liver on the left; but all such cases are regarded as supernatural.

In all animals the wind-pipe extends to the lung, and the manner how, we shall discuss hereafter; and the oeso- 25 phagus, ${ }^{3}$ in all that have the organ, extends through the midriff into the stomach. For, by the way, as has been observed, most fishes have no ocsophagus, but the stomach is united directly with the mouth, so that in some cases when big fish are pursuing little ones, the stomach ${ }^{t}$ tumbles forward into the mouth.

All the afore-mentioned animals have a stomach, and zo one similarly situated, that is to say, situated directly under the midriff; and they have a gut connected therewith and closing at the outlet of the residuum and at what is termed the 'rectum'. However, animals present diversities in the structure of their stomachs." In the first place, of the viviparous quadrupeds, such of the horned animals as are not equally furnished with teeth in both jaws are furnished 35 with four such chambers." These animals, by the way, are those that are said to chew the cud. ${ }^{7}$ In these animals the oesophagus extends from the mouth downwards along the lung, from the midriff to the big stomach (or paunch); $507^{\mathrm{b}}$ and this stomach is rough inside and semi-partitioned. ${ }^{8}$

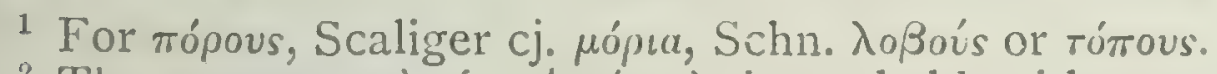

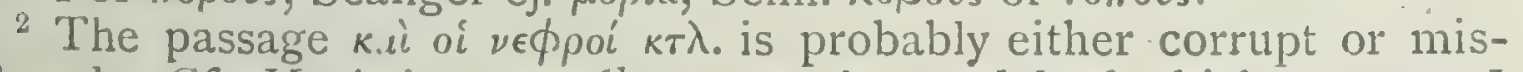
placed. Cf. $H . A$. i. 17. $496^{b}$ I7, on the model of which passage I

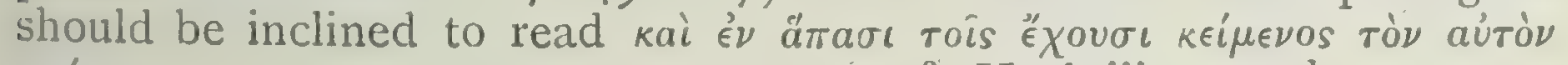
тро́тоу.

${ }^{3}$ H. A. iii. $3.513^{\mathrm{b}} 23$.

${ }^{4}$ Not the stomach, but the air-bladder, which often everts when a fish is brought up quickly from deep water.

5 C. $P . A$. iii. I4.

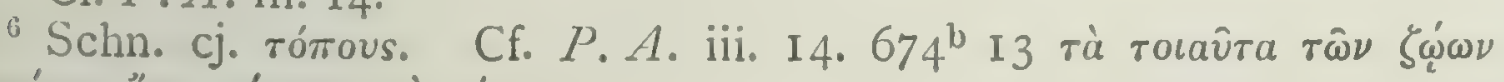

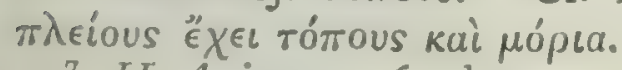

H.A.ix. 50. $632^{\mathrm{b}}$ I.

$8 \delta \iota \epsilon \lambda \eta \mu \mu \epsilon \ln$, loculis disseptus, Schn. A kink in the puunch appears internally as a prominent fold or partial dissepiment. 
And connected with it near to the entry of the ocsophagus is what from its appearance is termed the 'reticulum' (or honeycomb bag); for outside it is like the stomach, but 5 inside it resembles a netted cap; and the reticulum is a great deal smaller than the stomach. Connected with this is the 'cchinus' (or many-plies), rough inside and laminated, and of about the same size as the reticulum. Next after this comes what is called the 'enystrum' (or abomasum), ro larger and longer than the echinus, furnished inside with numerous folds or ridges, large and smooth. After all this comes the gut.

Such is the stomach of those quadrupeds that are horned and have an unsymmetrical dentition; and these animals differ one from another in the shape and size of the parts, and in the fact of the ocsophagus reaching the stomach 15 centralwise in some cases and sideways in others. Animals that are furnished equally with teeth in both jaws have one stomach; as man, the pig, the dog: the bear, the lion, the wolf. [The Thos, ${ }^{1}$ by the by, has all its internal organs similar to the wolf's.]

All these, then have a single ${ }^{2}$ stomach, and after that the gut; but the stomach in some is comparatively large. 20 as in the pig and bear, and the stomach of the pig has a few smooth folds or ridges; others have a much smaller stomach, not much bigger than the gut, as the lion, the dog. and man. In the other animals the shape of the stomach varies in the direction of one or other of those already mentioned; that is, the stomach in some animals resembles that of the pig; in others that of the clog. alike with the larger animals and the smaller ones. In all these animals 25 diversitics occur in regard to the size, the shape, the thickness or the thinness of the stomach, and also in regard to the place ${ }^{3}$ where the oesophagus opens into it.

There is also a difference in structure in the gut of the two groups of animals above mentioned (those with unsym-

1 l'robably Viacrer cinettu, or allied species. Cf. Jlin. viii. 52 (3t).

"A. and $\mathrm{V} V$. delete $\mu$ iru as incorrect in respect to the ruminants; or

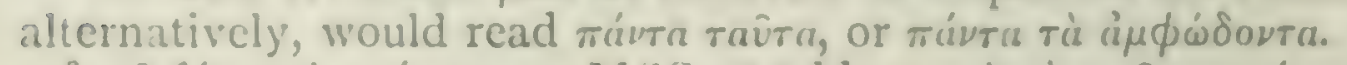

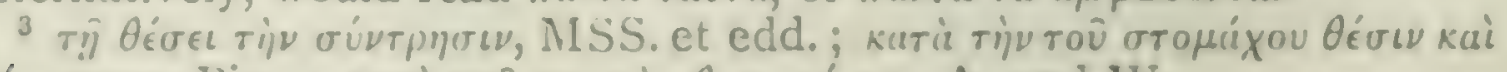

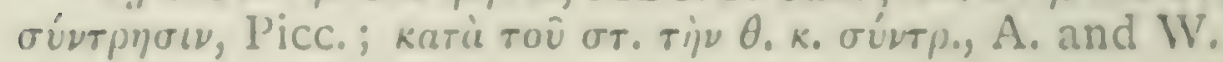


metrical and those with symmetrical dentitionj in size, in thickness, and in foldings.

The intestines in those animals whose jaws are unequally furnished with teeth arc in all cases the larger, for the animals themselves are larger than those in the other category; for very few of them are small, and no single one of the horned animals is very small. And some possess appendages (or caeca) to the gut, but no animal that has not incisors in both jaws has a straight gut.

The elephant has a gut constricted into chambers, ${ }^{1}$ so 35 constructed that the animal appears to have four stomachs; in it the food is found, but there is no distinct and separate receptacle. Its viscera resemble those of the pig, only that the liver is four times the size of that of the ox, and $508^{a}$ the other viscera in like proportion, while the spleen is comparatively small.

Much the same may be predicated of the properties of the stomach and the gut in oviparous quadrupeds, as in the land tortoise, the turtle, the lizard, both crocodiles, ${ }^{2}$ and, 5 in fact, in all animals of the like kind; that is to say, their stomach is one and simple, resembling in some cases that of the pig, and in other cases that of the dog.

The serpent genus is similar and in almost all respects furnished similarly to the saurians among oviparous land animals, if one could only imagine these saurians to be ro increased in length and to be devoid of lcgs. That is to say, the serpent is coated with tessellated scutes, and resembles the saurian in its back and belly; only, by the way, it has no testicles, but, like fishes, has two ducts conrerging into one, and an ovary long and bifurcate. The rest of its internal organs are iclentical with those of the saurians, except that, owing to the narrowness and length $5_{5}$ of the animal, the viscera are correspondingly narrow and clongated, so that they are apt to escape recognition from the similarities in shape. Thus, the windpipe of the creature is exceptionally long, and the ocsophagus is longer still,

1 Plin. xi. 79.

2 i.e. land and water, the former being a large lizard, e.g. Varamus or Stellio: cf. fr. $320,1532^{a} 25$. 
and the windpipe commences so close to the mouth that the tongue appears to be underneath it; and the windpipe 20 sccms to project orer the tongue, owing to the fact that the tongue draws back into a sheath and does not remain in its place as in other animals. The tongue, moreover, is thin and long and black, and can be protruded to a great distance. And both scrpents and samians have this altosether exceptional property in the tonguc, that it is forked 25 at the outer extremity, and this property is the morc marked in the serpent, for the tips of his tongue are as thin as hairs. The seal, also, by the way, has a split tongue. ${ }^{2}$

The stomach of the serpent is like a more spacious gut, resembling the stomach of the dog; then comes the gut, long, narrow, and single to the end. The heart is so situated close to the pharynx, small " and kidney-shaped; and for this reason the organ might in some cases ${ }^{4}$ appear not to hare the pointed end turned towards the breast. Then comes the lung; single, and articulated with a membranous passage, very long, and guite detached from the heart. The liver is long and simple; the spleen is short and round: as is the case in both respects with the 35 saurians. Its gall resembles that of the fish; the watcr$508^{\mathrm{b}}$ snakes have it beside the liver, and the other snakes have it usually beside the gut. These creatures are all sawtoothed. Their ribs are as numerous as the days of the month; in other words, they are thirty in number.

Some affirm that the same phenomenon is observable 5 with serpents as with swallow-chiclis; in other words, they say that if you prick out a serpent's eyes they will grow again." And further, the tails of saurians and of serpents, if they be cut off, will grow again.

With fishes the properties of the gut and stomach are similar; that is, they have a stomach single and simple:

I.A. ii. $17.606^{\text {l) } 6 .}$

$=P \cdot A \cdot$ iv. II. 69I $S$.

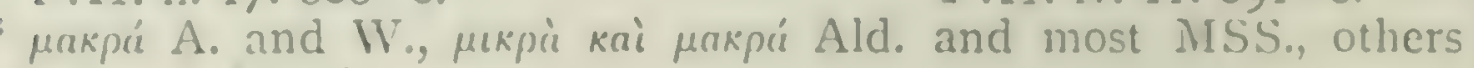

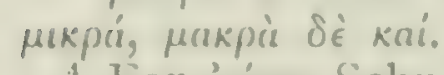

For ébiote Schn. cj. év zoírnıs, 'in these creatures.'

H. A. vi. 5. $563^{\mathrm{a}}$ 14: (3. A. iv. 6. $774^{\mathrm{b}} 31$; Plin. viii. 41 ; Antig. H. Himab.72, 95; Ael. xvii. 20. 
but variable in shape according to species. For in some ro cases the stomach is gut-shaped, ${ }^{\prime}$ as with the scarus, or parrot-fish; which fish, by the way, appears to be the only fish that chews the cud. ${ }^{2}$ And the whole length of the gut is simple, and if it have a reduplication or kink it loosens out again into a simple form. ${ }^{3}$

An exceptional property in fishes and in birds for the most part is the being furnished with gut-appendages or caeca. Birds have them low down and few in number. Is Fishes have them high up about the stomach, and sometimes numerous, as in the goby, the galeos, ${ }^{4}$ the perch, the scorpaena, the citharus, the red mullet, and the sparus ; the cestreus or grey mullet has several of them on one side of the belly, and on the other side only one. Some fish possess these appendages but only in small numbers, as the hepatus and the glaucus; and, by the way, they are 20 few also in the dorado. ${ }^{6}$ These fishes differ also from one another within the same species, for in the dorado one individual has many and another few. Some fishes are entirely without the part, as the majority of the selachians. As for all the rest, ${ }^{7}$ some of them have a ferv and some a great many. And in all cases where the gut-appendages are found in fish, they are found close up to the stomach. 25

In regard to their internal parts birds differ from other animals and from one another. Some birds, for instance, have a crop in front of the stomach, ${ }^{8}$ as the barn-door cock, the cushat, the pigeon, and the partridge; and the crop consists of a large hollow skin, into which the food first enters

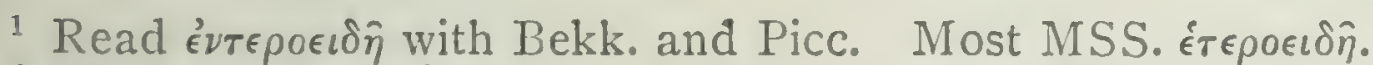

${ }^{2} H$. A. viii. 2. 591 ${ }^{\mathrm{b}} 22 ; P$. A. iii. I4. $675^{\mathrm{a}} 4$; Ael. ii. 54 ; Plin. ix. 29; Ovid, Hal. II9; Opp. Hal. i. I34.

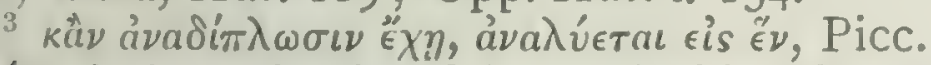

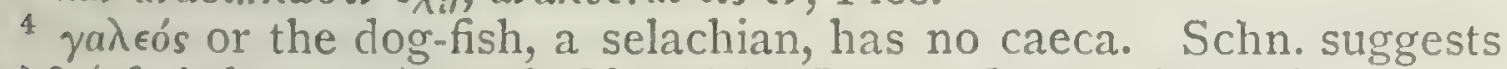

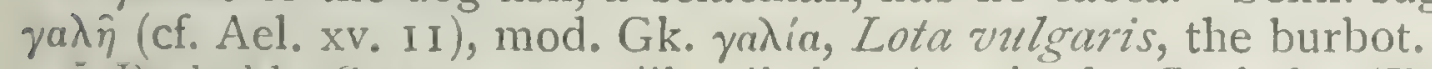

"I'robably. Sargzus sp., still called $\sigma \pi$ ripos in the Cyclades (Erhard, p. 88).

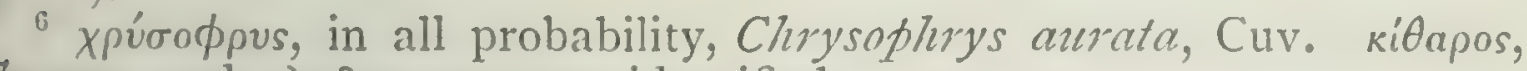

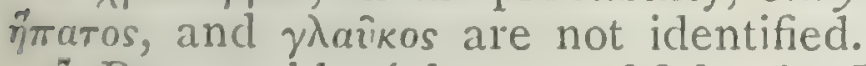

7 Presumably, 'the rest of fishes.' P.A. iii. I4. $675^{2}$ II oi $\delta \dot{\epsilon} \pi 0 \lambda \lambda \circ$ i

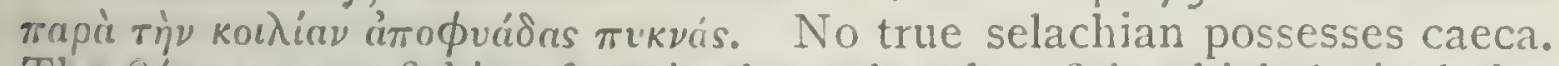
The Búrpaxos or fishing-frog is the only other fish which $\mathrm{A}$. includes among the Selachia, and it has two.

${ }^{8}$ P.A. iii. 14. $674^{\mathrm{b}} 22$. 
30 and where it lies undigested. Just where the crop leaves the oesophagus it is somewhat narrow; by and by it broadens out, but where it communicates with the stomach it narrows down again. The stomach (or gizzard) in most bircls is fleshy and hard, and inside is a strong skin which comes 35 away from the fleshy part. Other bircls have no crop, but instead of it an oesophagus wide and roomy, either all the $509^{a}$ way or in the part leading to the stomach, as with the daw: the raven, and the carrion-crow. The quail also has the oesophagus widened out at the lower extremity, and in the aegocephalus and the owl the organ is slightly broader at the bottom than at the top. The duck, the goose, the gull, the catarrhactes, and the great bustarcl have the ocsophagus wide

5 and roomy from one end to the other, and the same applics to a great many other bircls. In some birds there is a portion of the stomach ${ }^{1}$ that resembles a crop, as in the kestrel. In the case of small birds like the swallow and the sparrow neither the ocsophagus nor the crop is wide, but the stomach is long. Some few have neither a crop nor a dilated ro ocsophagus, but the latter is exceclingly long, as in longnecked birds, such as the porphyrio," and, by the way, in the case of all these birds the excrement is unusually moist. ${ }^{3}$ The quail is exceptional in regard to these organs, as compared with other birds; in other words, it has a crop, and at the same time its ocsophagus is wide and spacious in I5 front of the stomach, and the crop is at some distance, rclatively to its size, from the ocsophagus at that part.

Further, in most birds, the gut is thin, and simple when loosened out. ${ }^{4}$ The gut-appendages or caeca in birds, as has been observed, are few in number, and are not situated high up, as in fishes, but low down towards the extremity 20 of the gut. Birds, then. have cacea-not all, but the greater

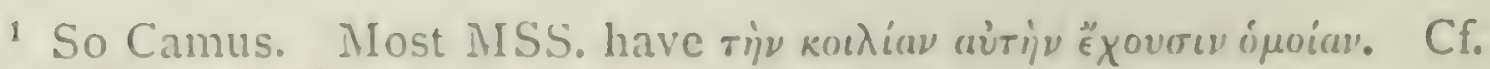

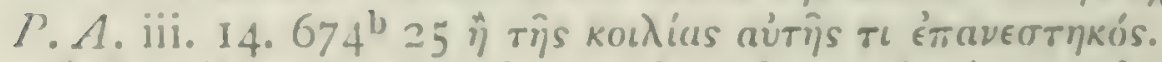

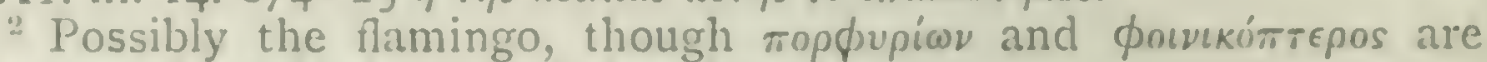
mentioned as distinct by Aristophanes.

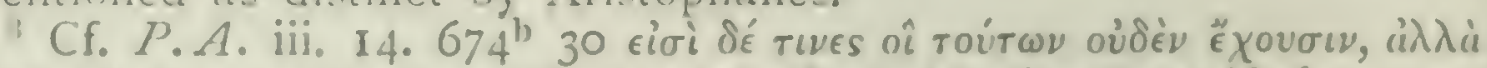

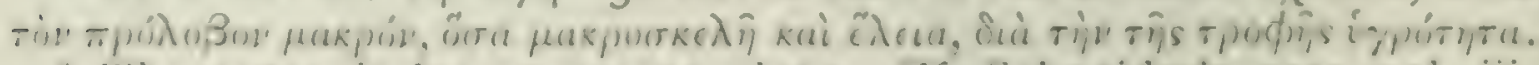

"The sence is hy no means rleatr. Cf. Schneider's note, vol. iii. p. 313 . 
part of them, such as the barn-door cock, the partridge, the duck, the night-raven, [the localus, ${ }^{1}$ ] the ascalaphus, ${ }^{2}$ the goose, the swan, the great bustard, and the owl. Some of the little birds also have these appendages; but the caeca in their case are exceedingly minute, as in the sparrow.

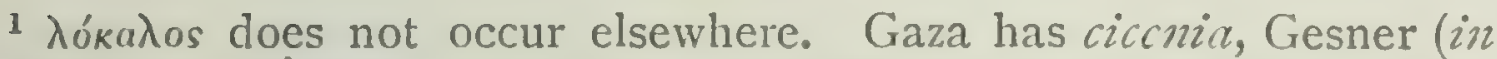
Alucone, p. 94) says ' hoc nomen Italicum esse avis nocturnae [aluco, aloco, alúcolo], ab aliquo forte adscriptum, ut vocem ascalaphum interpretaretur, et a librariis postea insertum' (J. G. S.).

${ }_{2}$ Perhaps an owl; cf. Ov. Met. v. 539. 


\section{BOOK III}

$509^{a}$ Now that we have stated the magnitudes, the properties, I and the relative differences of the other internal organs, it remains for us to treat of the organs that contribute to

30 generation. These organs in the female are in all cases internal; in the male they present numerous diversities.

In the blooded animals some males are altogether clevoid of testicles, ${ }^{1}$ and some have the organ but situated internally; and of those males that have the organ internally situated, some hare it close to the loin in the neighbourhood of the kidney and others close to the belly. Other

3. malcs have the organ situated externally. In the case of these last, the penis is in some cases attached to the belly, $509^{b}$ whilst in others it is loosely suspencled, as is the case also with the testicles; and, in the cases where the penis is attached to the belly, the attachment varies accordingly as the animal is emprosthuretic or opisthuretic.

No fish is furnished with testicles, nor any other creature that has gills, nor any scrpent whatever: nor, in short, any 5 animal devoid of feet, save such only as are viviparous within themselves. ${ }^{2}$ Birds are furnished with testicles, but these are internally situated, close to the loin. The case is similar with oriparous quadrupeds, such as the lizard, the tortoise and the crocodile; and among the viviparous animals this peculiarity is found in the hedgehog." Others among those creatures that have the organ internally situated have it close to the belly, as is the case with the

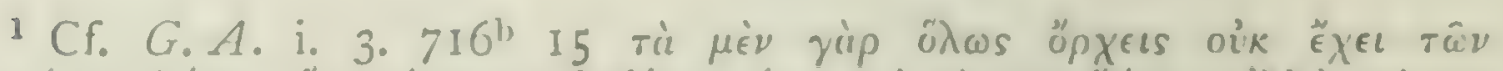

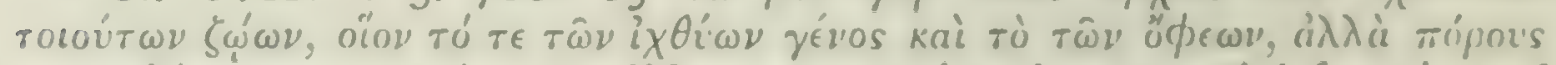

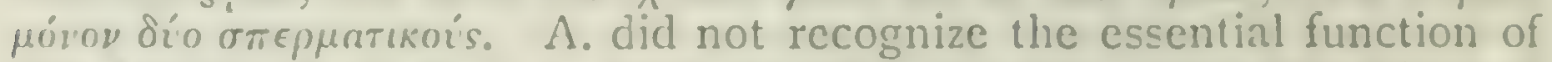

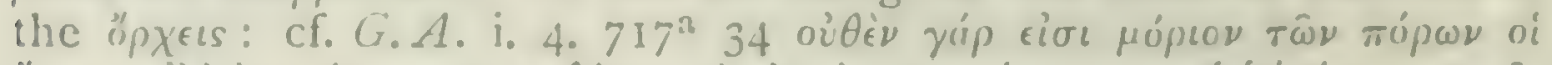

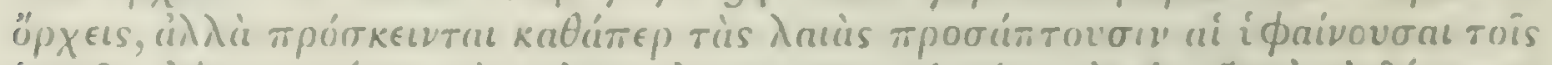

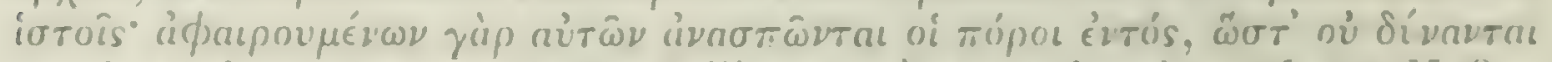

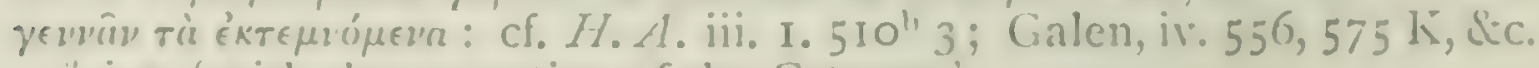

i. e. 'with the exception of the Cetacea.'

${ }^{3}$ G.A. i. 5.717' 27; 12.719' 16. 
dolphin amongst animals devoid of feet, and with the ro clephant among viviparous quadrupeds. ${ }^{1}$ In other cases these organs are externally conspicuous.

We have already ${ }^{2}$ alluded to the diversities observed in the attachment of these organs to the belly and the adjacent region; in other words, we have stated that in some cases the testicles are tightly fastencd back," as in the pig and its allies, and that in others they are freely suspended, as in man.

Fishes, then, are devoid of testicles, as has bcen stated, and serpents also. ${ }^{4}$ They are furnished, however, with two ducts connected with the midriff and running on to either side of the backbone, coalescing into a single duct above the outlet of the residuum, and by 'abore' the outlet I mean the region near to the spine. These ducts in the 20 rutting season get filled with the genital fluid, and, if the ducts be squeezed, the sperm oozes out white in colour. As to the differences observed in male fishes of diverse species, the reader should consult my treatise on Anatomy," and the subject will be hereafter more fully discussed when we describe the specific character in each case. ${ }^{6}$

The males of oviparous animals, whether biped or quadruped, are in all cases furnished with testicles close to the ${ }^{25}$ loin underneath the midriff. With some animals the organ is whitish, in others somewhat of a sallow hue; in all cases it is cntirely cnveloped with minute and delicate veins. From each of the two testicles extends a duct, and, as in the case of fishes, the two ducts coalesce into one above

1 Plin. xi. I Io 'delphino (testes) praelongi ultima conduntur alvo, et elephanto occulti'. Cf. G. A. i. 3. 71 $6^{\mathrm{b}} 27$; $12.719^{\mathrm{b}} 9$, \&c.

2 ii. I. $500^{\mathrm{b}} 3$.

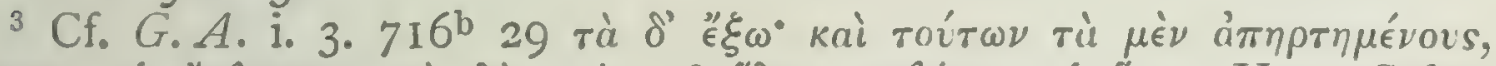

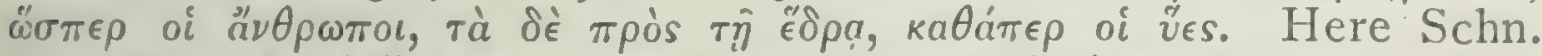

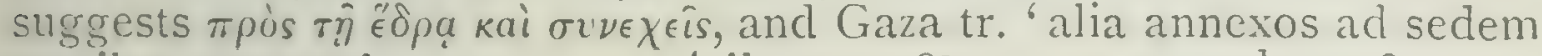
sessiles, ut sues.' $\quad$ 'ii. $17 \cdot 5^{2} 8^{\mathrm{a}}$ I2 ; v. $5 \cdot 54 \mathrm{O}^{\mathrm{b}} 30$, \& c.

5 The frequent references to ai àvaropai seem mostly to point to the lost treatise, but it sometimes is an open question whether we should not simply translate 'anatomy' or 'dissection'. The passages have becn collated and discussed by Höffner, Heitz, \&c. (cf. note on iv. I. $525^{\text {a }}$ 8). It is not impossible that the treatise may still exist in an Arabic version; cf. Dschemaluddin ap. Wenrich, de Autor. Gr. versicnarab. $\& c_{0}, 1842$, p. 148.

H.A. . 5. 
the outlet of the residuum. ${ }^{1}$ This constitutes the penis, 30 which organ in the case of small ovipara is inconspicuous; but in the case of the larger oripara, as in the goose and the like, the organ becomes quite visible just after copulation.

The ducts in the case of fishes and in biped and quadruped ovipara are attached to the loin under the stomach and the gut, in betwixt them ${ }^{2}$ and the great vein, from which ducts or blood-vessels extend, one to cach of the two 35 testicles. And just as with fishes the male sperm is found $510^{a}$ in the seminal ducts, and the ducts become plainly visible at the rutting season and in some instances become invisible after the scason is passed, so also is it with the testicles of bircls; before the breeding scason the organ is small in some birds and quite invisible in others, but cluring the season the organ in all cases is greatly enlarged."

5 This phenomenon is remarkably illustrated in the ring-dove and the partridge, so much so that some people are actually of opinion that these birds are devoid of the organ in the winter-time.

Of male animals that have their testicles placed frontwards, some have them inside, close to the belly; as the dolphin; some have them outside, exposed to view, close ro to the lower extremity of the belly. These animals resemble one another thus far in respect to this organ; but they differ from one another in this fact, that some of them have their testicles situated separately by themsclves, while others, which have the organ situated externally, have them enveloped in what is termed the scrotum. ${ }^{4}$

Again, in all viviparous animals furnished with feet the following propertics are obscrued in the te-ticles themselves. From the arta there extend vein-like ducts to the $i_{5}$ head of cach of the testicles, and another two from the kidneys; ${ }^{5}$ these two from the kidneys are supplicd with

H. A. $\because \cdot 3 \cdot 540^{3} 30$.

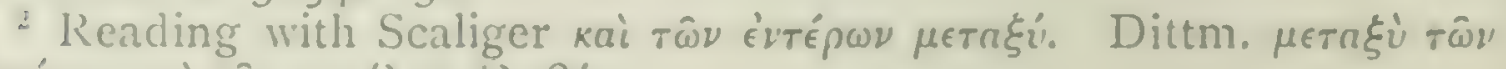

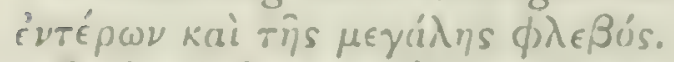

G. A. i. $4.717^{\text {b }}$; ; H. A. vi. 9. $564^{\text {b }}$ Io.

- Dittm. stigmatizes the whole paragraph. Cf. G. 1. i. 12.719) 4.

5 The spermatic arteries and veins. 
blood, ${ }^{1}$ while the two from the aorta are devoid of it. From the head of the testicle alongside of the testicle itself is a duct, thicker and more sinewy than the other just alluded to - a duct that bends back again at the end of the testicle ${ }^{2}$ to its head; and from the head of each of the 20 two testicles the two ducts extend until they coalesce in front at the penis. The duct that bends back again and that which is in contact with the testicle are enveloped in one and the same membrane, ${ }^{3}$ so that, until you draw aside the membrane, they present all the appearance of being a single undifferentiated duct. Further, the duct in contact with the testicle has its moist content qualified by blood, but to a comparatively less extent than in the case of the ducts higher up which are connected with the aorta; in 25 the ducts that bend back towards the tube of the penis, the liquid is white-coloured. There also runs a duct from the bladder, opening into the upper part of the canal, around which lies, sheath-wise, what is called the 'penis'.

All these descriptive particulars may be regarded by the light of the accompanying diagram; wherein the letter $A$ zo marks the starting-point of the ducts that extend from the aorta; the letters $K K$ mark the heads of the testicles and the ducts descending thereunto; the ducts extending from these along the testicles are marked $\Omega \Omega$; the ducts turning back, in which is the white fluid, are marked $B B$; the penis $\Delta$; the bladder $E$; and the testicles $\Psi \Psi$.

[By the way, when the testicles are cut off or removed, the ducts draw upwards by contraction. ${ }^{4}$ Moreover, when $510^{\text {b }}$ male aninals are young, their owner sometimes destroys the organ ${ }^{5}$ in them by attrition; sometimes they castrate them at a later period. And I may here add, that a bull has been known to serve a cow immediately after castration, and actually to impregnate her. $]^{6}$

1 The left spermatic rein falls into the renal vein close to the kidney, the right into the inferior vena cava near to the renal vein.

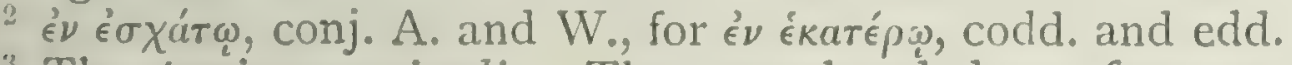

3 The tunica vaginalis. The convoluted ducts form an Éravaoi$\pi \lambda \omega \sigma i s\left(G . A\right.$. i. 4. 7I $7^{\text {a }} 33$ ), which is the epididymis of later authors.

${ }^{4}$ Cf. supra, p. $509^{a} 32$, footnote. $\quad H . A$. ix. $50.632^{a} 15$.

[ ] A. and W. 
$A$

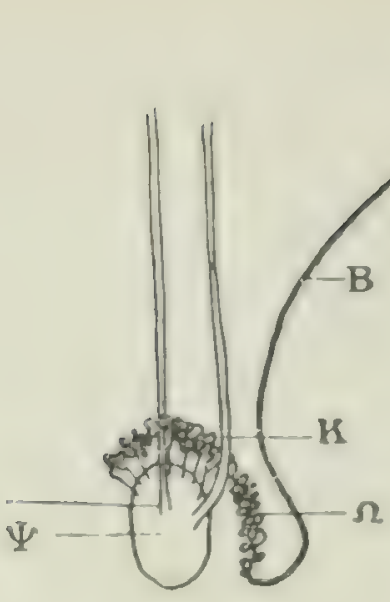

E kúrtıs.

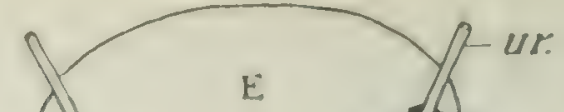

E
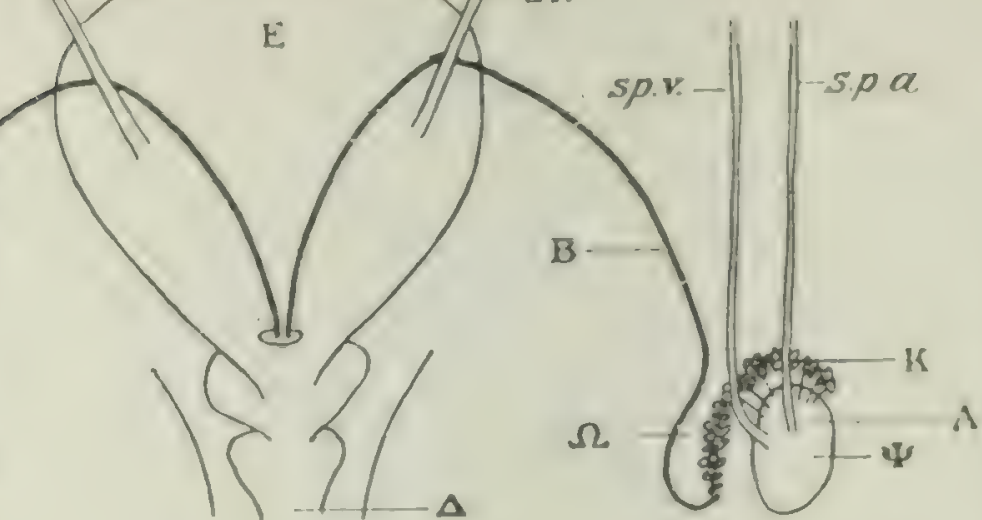

$\Psi \Psi$ ópXels.

$\Delta$ aíōô.

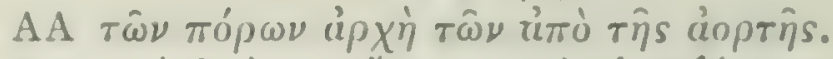

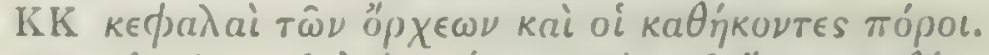

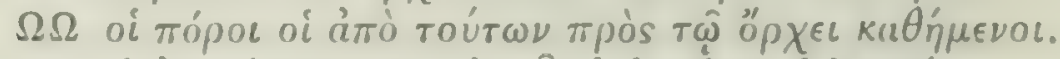

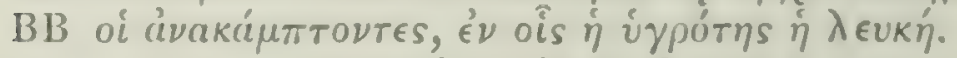

$[s p . v . s p . a$. spermatic vein and artery : ur. ureters.

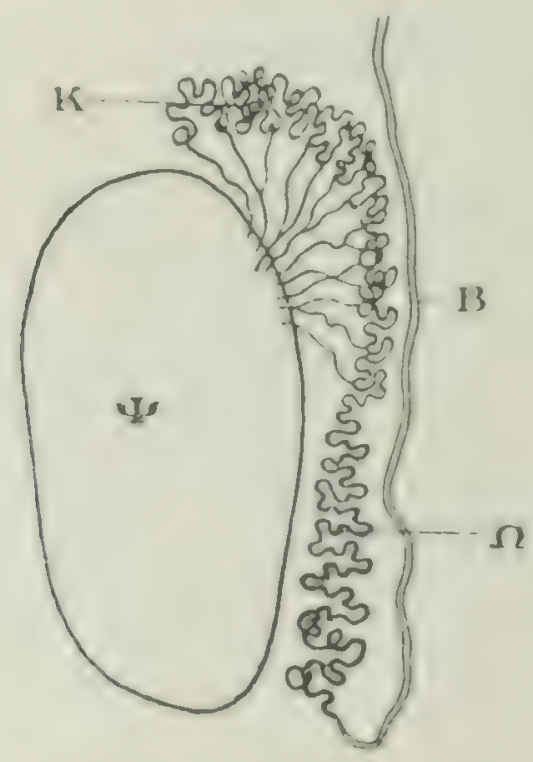

$\Psi$ testis.

$\Omega$ corpus epididymis.

$\mathrm{K}$ caput epididymis.

$B$ vas deferens.

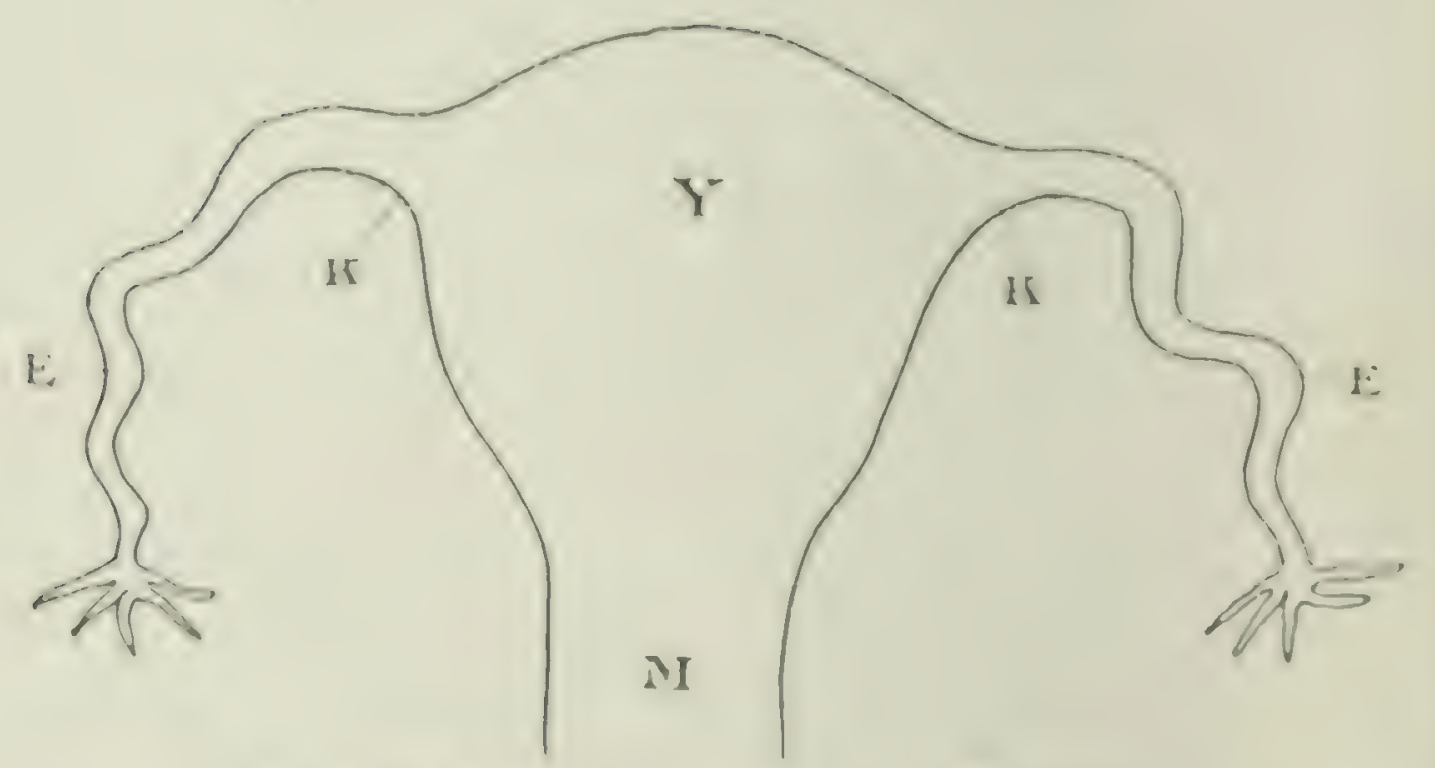

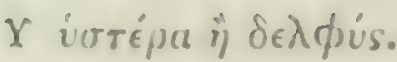

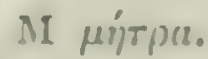

kili kepuitiç.

EL é $\lambda$ เ 
So much then for the propertics of testicles in male 5 animals.

In female animals furnished with a womb, the womb is not in all cases the same in form or endowed with the same properties, but both in the vivipara and the ovipara great diversitics present themselves. In all creatures that have the womb close to the genitals, the womb is two-horned, and one horn lies to the right-hand side and the other to to the left; ${ }^{1}$ its commencement, however, is single, and so is the orifice, resembling in the case of the most numerous and largest animals a tube composed of much flesh and gristle. Of these parts one is termed the hystera or delphys, whence is derived the word $\dot{\alpha} \delta \in \lambda \phi o ́ s$, and the other part, the tube or orifice, is termed metre. In all biped or quadruped is vivipara the womb is in all cases below the midriff, ${ }^{2}$ as in man, the dog, the pig, the horse, and the ox; the same is the case also in all horned animals. At the extremity of the so-called ceratic, or horns, the wombs of most animals have a twist or convolution.

In the case of those ovipara that lay eggs cxternally, the 20 wombs are not in all cases similarly situated. Thus the wombs of birds are close to the midriff, and the wombs of fishes down below, just like the wombs of biped and quadruped vivipara, only that, in the case of the fish, the wombs are delicately formed, mombranous, and clongated; so much so that in extremely small fish, each of the two bifurcated parts looks like a single egg, and those fishes 25 whose cgg is described as crumbling ${ }^{3}$ would appear to have insicle them a pair of eggs, whereas in reality each of the two sides consists not of one but of many eggs, and this accounts for their breaking up into so many particles.

The womb of birds has the lower and tubular portion fleshy and firn, and the part close to the midriff membranous and excecdingly thin and fine: so thin and fine 30 that the eggs might seem to be outsicle the womb altogether. In the larger birds the membrane is more

${ }^{1}$ G. A. i. $3.716^{\mathrm{b}} 32$.

2 Plin. xi. 84 'ova generantium annexa praecordiis'.

'i. e. is designated a 'roe'. 
distinctly visible, and, if inflated through the tube, lifts and swells out; in the smaller birds all these parts are more indistinct.

The propertics of the womb are similar in oviparous 35 quadrupeds, as the tortoise, the lizard, the frog and the 511 ${ }^{\mathrm{a}}$ like; for the tube below is single and fleshy, and the cleft portion with the eggs is at the top close to the midriff. With animals devoid of feet that are internally oviparous and viviparous externally, as is the case with the dogfish 5 and the other so-called Selachians (and by this title we designate such creatures destitute of feet and furnished with gills as are viviparous), with these animals the womb is bifurcate, and beginning down below ${ }^{1}$ it cxtends as far as the midriff, as in the case of birds. There is also a narrow part between the two horns running up as far as the midriff," and the eggs are engendered here and above at 1o the origin of the midriff; afterwards they pass into the wider space and turn from cgss into young animals. However, the differences in respect to the wombs of these fishes as compared with others of their own species or with fishes in general, would be more satisfactorily studied in their various forms in specimens under dissection.

The members of the serpent genus also present divergencies cither when compared with the above-mentioned 15 creatures or with one another. Serpents as a rule are oviparous, the viper being the only viviparous member of the genus." The viper is, previously to external partu-

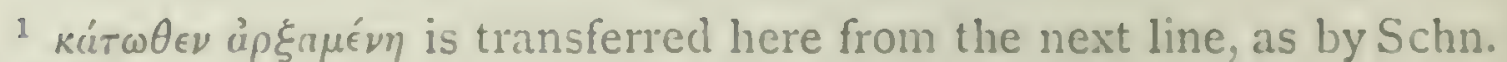
and Picc.

2 'The received text is plainly at fault. We translate, after Piccolos,

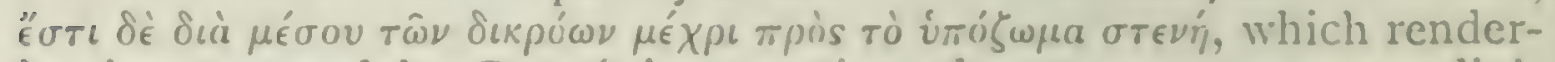
ing is supported by Gaza 'sinus arctior ad septum usque pertendit', and tampers but little with the text of the MSS. I suspect, however, that this emendation is inadequate. The subject-matter of the cliuse was doubtless the fact that in selachians, but not in birds, the ovmies lie between the "oviducts" or horns of the uterus, and this fact is elsewhere simply and clearly stated; c.g. H.A. vi. Io. $564^{\prime \prime}=0$

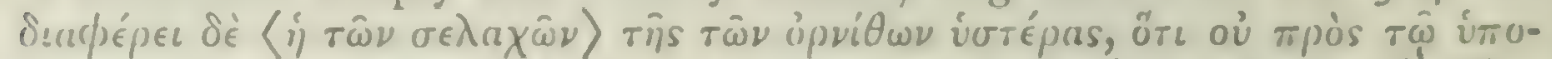

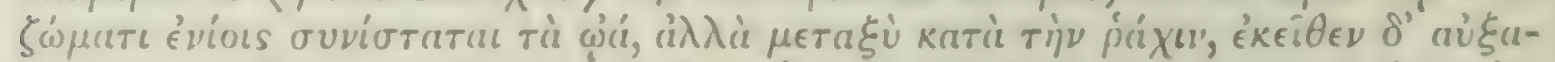

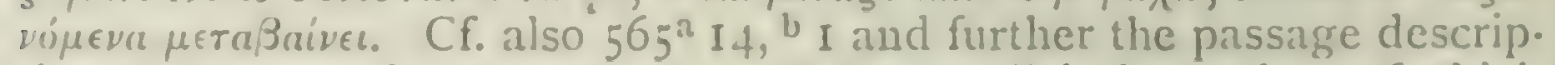
tive of the ovary in serpents, $5 I^{: 3}$ IS, the parallel phrascology of which may have helped to confuse the prescnt reading.

${ }^{3}$ H.A. . 34. $555^{\text {an } 25}$; Plin. X. S2, \&ic. 
${ }^{7}$ In sanguincous animals the homogeneous or uniform 2 part most unirersally found is the blood, and its habitat the rein; next in degree of universality, their analogues, lymph and fibre, and, that which chiefly constitutes the frame of 5 animals, flesh and whatsocver in the several parts is analogous to flesh; then bone, and parts that are analogous to bone, as fish-bone and gristle; and then, again, skin, membrane, sincw, hair, nails, and whaterer corresponds to these; and, furthermore, fat, suet, and the excretions: and ro the excretions are dung, phlegm, yellow bile, and black bile.

Now, as the nature of blood and the nature of the veins have all the appearance of being primitive, ${ }^{2}$ we must discuss their properties first of all, and all the more as some previous writers have treated them very unsatisfactorily. And the cause of the ignorance thus manifested is the extreme difficulty experienced in the way of observation. For in the dead bodics of animals the nature of the chief Is reins is undiscoverable, owing to the fact that they collapse at once when the blood leaves them; for the blood pours out of them in a stream, like liquid out of a ressel, since there is no blood separately situated by itself, except a little in the heart, ${ }^{3}$ but it is all lodged in the reins. In living animals it is impossible to inspect these parts, for of their 20 very nature they are situated inside the body and out of sight. For this reason anatomists who have carried on their investigations on dead bodies in the dissecting-room have failed to discorer the chief roots of the veins, while those who have narowly inspected bodies of living men reduced to extreme attenuation "have arrived at conclusions

1 The rest of this Book is devoted to a consideration of the $\mu \epsilon^{\prime} \eta \eta \dot{\mathrm{s}}$ ifunue, m. tlie simple parts or "tissues", the constituents or components of the organs. The foregoing chapter is rather a continuation of the Second than a beginning of the Third Book.

2 cip $x \eta$. Lit. a beginning, i.c. an efficient cause of development and

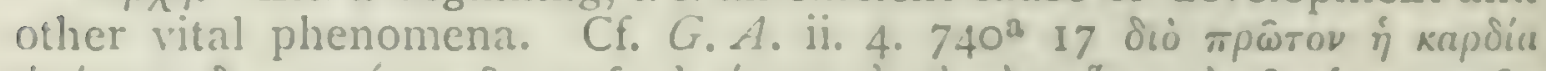

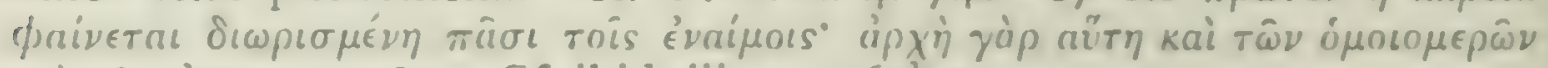

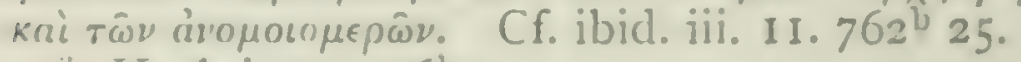

H. A. i. $17.496^{\mathrm{b}} 7$.

- The same method of investigation is alluded to by Galen, ii.

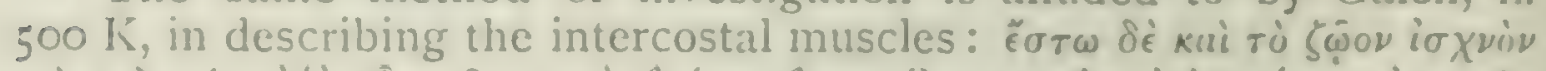

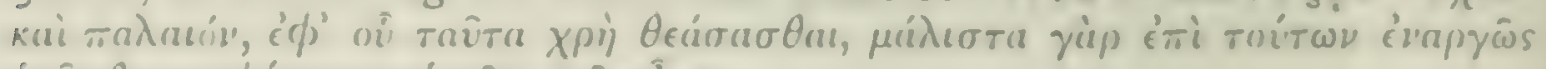

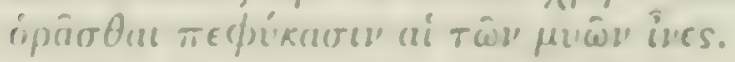


regarding the origin of the reins from the manifcstations visible externally. Of these investigators, Syennesis, the physician of Cyprus, writes as follows :-

'The big veins run thus ${ }^{1}$ :- from the navel across the 25 loins, ${ }^{2}$ along the back, past the lung, in under the breasts; one from right to left, and the other from left to right; that from the left, through the liver to the kidney and the testicle, that from the right, to the spleen and kidney and testicle, and from thence to the penis.'

Diogenes of Apollonia ${ }^{3}$ writes thus :-

'The veins in man are as follows:- There arc two veins pre-eminent in magnitude. These extend through the belly along the backbone, one to right, one to left; either one to the leg on its own side, and upwards to the head, past the collar bones, through the throat. From these, veins extend all over the body, from that on the right hand $51^{a}$ to the right side and from that on the left hand to the left side; the most important ones, two in number, to the heart in the region of the backbone; other two a little higher up through the chest in underneath the armpit, ${ }^{*}$ each to the hand on its own side: of these two, one being termed the vein 5 splenitis, and the other the vein hepatitis. Each of the pair splits at its extremity; the one branches in the direction of the thumb and the other in the direction of the palm; and from these run off a number of minute veins branching off to the fingers and to all parts of the hand. Other veins, more minute, extend from the main veins; from that on the ro right towards the liver, from that on the left towards the

1 Ps. Hippocr. de nat. ossimm, ix. p. I74 (Littré); i. p. 507 (Kühn).

2 In spite of the divided testimony of the codices, against the judgement of Bekker and of Piccolos, and in opposition to the Hippocratic text of Kuihn and Littré, I cannot think but that ék rov $\partial \mu \phi a \lambda o \hat{v} \pi a p \dot{u}$ $\tau \dot{\eta} \nu$ o $\sigma \phi \dot{v} \nu$ is the ancient and correct reading. It is supported by Plin. xi. 89 'venarum in umbilico nodus ac coitus', it is in harmony with the citation from Diogenes of Apollonia, and it is intelligible in the light of actual fact. Schneider, who adopted in his text the now

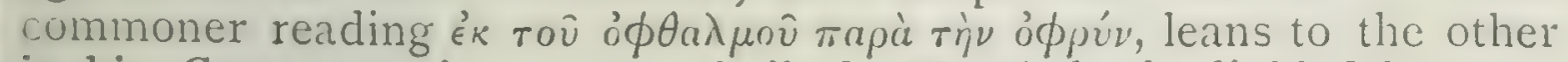
in his Curae post.iv. p. 322. Guil. de Moerbeke is divided between the two readings, 'ab umbilico iuxta supercilium.' From the point of view of cmbryology it is not inappropriate to call the umbilicus the origin of the veins.

3 Cf. Littré, i. p. 220 , ix. p. 163.

4 Subclavian or axillary. 
spleen and the kidneys. ${ }^{1}$ The veins that run to the legs ${ }^{2}$ split at the juncture" of the legs with the trunk and cxtend right down the thigh. The largest of these ${ }^{4}$ goes down the thigh at the back of it, and can be discerned and traced as a big one; the second one" runs inside the thigh, not Is quite as big as the one just mentionecl. After this they pass on along the linee to the shin and the foot (as the upper veins were described as passing towards the hands), ${ }^{6}$ and arrive at the sole of the foot, and from thence continue to the tocs. Norcover, many delicate veins scparate off from the great veins towards the stomach and towards the ribs.

20 'The veins that run through the throat to the head ' can be discerned and traced in the neck as large ones; and from each one of the two, where it terminates, there branch off a number of veins to the head; some from the right side towards the left. and some from the left side towards the right; and the two veins terminate near to each of the two ears. There is another pair of veins ${ }^{s}$ in the neck 25 running along the big vein on cither sicle, slightly less in size than the pair just spolien of, and with these the greater part of the veins in the head are connected. This other pair runs through the throat inside; and from cither one of the two there extend veins in underneath the shoulder blade ${ }^{0}$ and towards the hands ; ${ }^{10}$ and these appear along30 side the veins splenitis and hepatitis as another pair of reins smaller in size. ${ }^{11}$ When there is a pain near the surface of the body, the physician lances ${ }^{12}$ these two latter reins; ${ }^{10}$ but when the pain is within and in the region of the stomach

1 It is unreasonable to assume that D. meant 'and from both to the kidneys'.

2 iliacs.

3 A. and W. suggest that $\pi$ pó $\phi v \sigma r y$ is possibly a misreading for iodiv. Alb.tr. 'a radicibus coxae sive a iuncturis coxarum.'

The femoral.

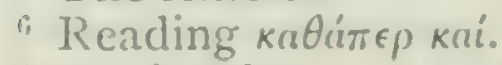

8 ext. jugular. 9 suprascapular. $10 \mathrm{v}$. cephalicac.

5) The int. saphenous.

11 The passage is difficult ; I adopt Dittmeyer's punctuation.

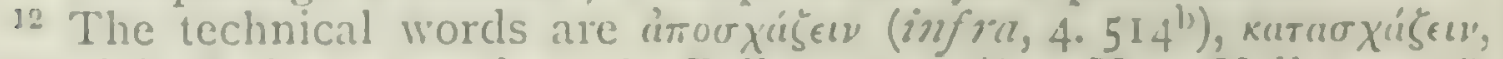

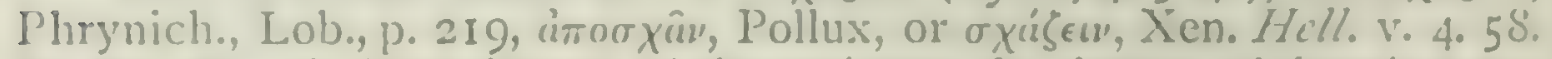

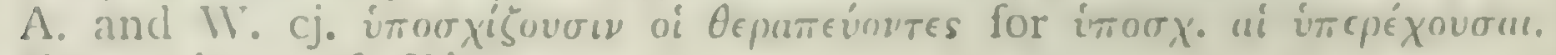
For variants cf, Dittm. 
he lances the veins splenitis and hepatitis. And from these, other veins depart to run below the breasts.

'There is also another pair running on each side through $5 \mathbf{I 2}^{\mathrm{b}}$ the spinal marrow to the testicles, thin and delicate. There is, further, a pair running a little underneath the cuticle through the flesh to the kidneys, and these with men terminate at the testicle, and with women at the womb. These 5 veins are termed the spermatic veins. ${ }^{2}$ The veins that leave the stomach are comparatively broad just as they leave; but they become gradually thinner, until they change over from right to left and from left to right.

'Blood is thickest when it is imbibed" by the fleshy parts; when it is transmitted to the organs above-mentioned, it ro becomes thin, warm, and frothy.'

3 Such are the accounts given by Syennesis and Diogenes. Polybus ${ }^{4}$ writes to the following effect:-

'There are four pairs of veins. The first extends from the back of the head, through the neck on the outside, past the backbone on either side, until it reaches the loins and is passes on to the legs, after which it goes on through the shins to the outer side of the ankles and on to the feet. And it is on this account that surgeons, for pains in the back and loin, bleed in ${ }^{5}$ the ham and in the outer side of the ankle. Another pair of vcins runs from the head, past the ears, through the neck; which veins are termed 20 the jugular veins. This pair goes on inside along the backbone, past the muscles of the loins, on to the testicles,

1 Venae basilicae.

2 I have transposed this clause from the end of the following sentence.

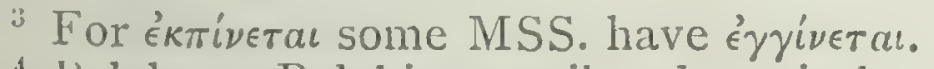

4 P'olybus s. Polybius, pupil and son-in-law of Hippocrates (cf. Epist. Hippocr., Kühn, iii. p. 842, Littré, ix. p. 418). The following quotation appears in the treatise de Nat. Honn. (vi. p. 58 L, i. p. 364 K), which treatise is accordingly ascribed to Polybus (cf. K. i. p. cxlvii), and in the composite treatise de Nat. Oss. (ix. p. I74 L, i. p. 506 K), cf. Littré, ix. p. 162. 'The essential point is the opinion that the bloodvessels originate in the head (cf. Littré, i, p. 217, but see also note, infra, p. $\left.513^{a} 22\right)$. According to Galen (in lib. Hippocr. de nat. human. cimmincint. XV. II K), P. taught the genuine doctrines of Hippocrates,

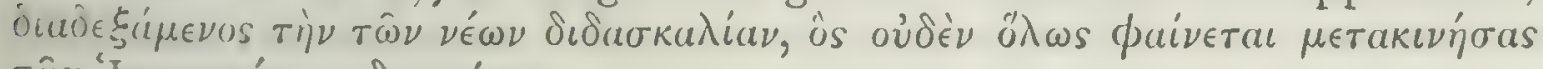
$\tau \hat{\omega} \nu$ 'I

${ }^{5}$ Dittm. cj. $\mu \in \tau a \dot{\xi} u$, 'between.' 
and onwards to the thighs, and through the inside of the hams and through the shins down to the inside of the ankles and to the fect; and for this reason, surgeons, for pains in 25 the muscles of the loins and in the testicles, bleed on the hams and the inner side ${ }^{1}$ of the ankles. The third pair extends from the temples, through the neck, in underneath the shoulder-blacles, into the lung; those from right to left going in underneath the breast and on to the splecn and the kidncy; those from left to right running from the lung 30 in underneath the breast and into the liver ${ }^{2}$ and the kidney; and both terminate in the fundament. The fourth pair extend from the front part of the head and the eyes in $5^{1} 3^{\text {a }}$ underneath the neck and the collar-bones; from thence they stretch on through the upper part of the upper arms to the elbows" and then through the fore-arms on to the wrists and the jointings of the fingers, and also through the lower part of the upper-arms to the armpits, and so on, 5 keeping above the ribs: ${ }^{4}$ until one of the pair reaches the spleen and the other reaches the liver; and after this they both pass over the stomach and terminate at the penis.'

The above (quotations sum up pretty well the statements of all previous writers. ${ }^{6}$ Furthermore, there are some writers on Natural History who have not ventured to lay 10 down the law in such precise terms as regards the veins, but who all alike agree in assigning the head and the brain ${ }^{7}$ as the starting-point of the reins. And in this opinion they are mistaken.

1 єौ $\sigma \omega \theta \epsilon \nu$, Dittm., from l's. Hippocr.

2 eis rò îjap, Picc., from P's. Hippocr.

3 Ps. Hippocr. (i. pp. $365,509 \mathrm{~K}$ ) has $\sigma u \gamma \kappa a \mu \pi a ́ s$ for $\kappa a \mu \pi \dot{s}$ and

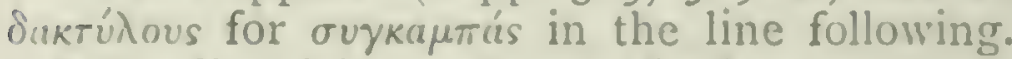

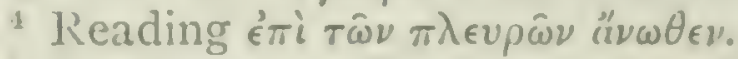

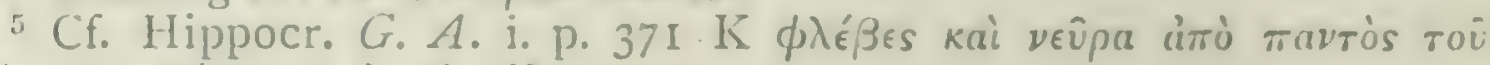

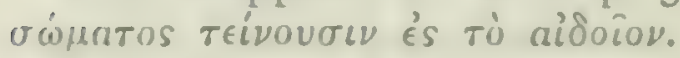

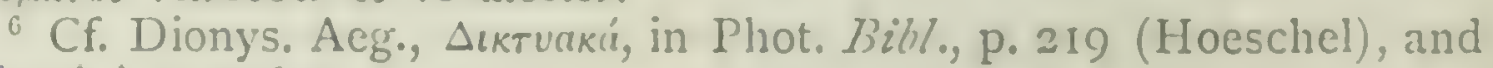
Littré, j. p. 216 ct seq.

7 'These words form an obvious difficulty in the way of accepting

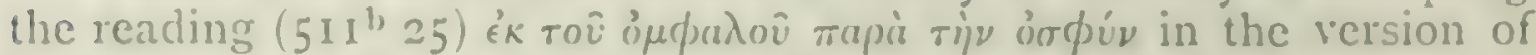
Syennesis; but it is also obvious that they are equally incompatible with the account given of the views of Diogenes of Apollonia. Neither do they apply to the Platonic theory, which was identical with Aristotle's; but they probably refer to a common tenet of the Hippocratic school. C.f. note, p. $5 I^{1} 25$. 
The investigation of such a subject, as has been remarked, is one fraught with difficulties; but, if any one be kecnly interested in the matter, his best plan will be to allow his animals to starve to cmaciation, then to strangle them on a sudden, and thereupon to prosecute his investigations.

IVe now proceed to give particulars regarding the $\mathrm{i}_{5}$ properties and functions of the veins. ${ }^{1}$ There are two blood-vessels in the thorax by the backbone, and lying to its inner side; and of these two the larger one is situated to the front, and the lesser one is to the rear of it ; and the arger is situated rather to the right-hand side of the body, and the lesser one to the left; and by some this vein is 20 termed the 'aorta', from the fact that even in dead bodies part of it is observed to be full of air. ${ }^{2}$ These blood-vessels have their origins in the heart, ${ }^{3}$ for they traverse the other visccra, in whatever direction they happen to run, without in any way losing their distinctive characteristic as bloodressels, whereas the heart is as it were a part of them (and that too more in respect to the frontward and larger one of 25 the two), ${ }^{4}$ owing to the fact that these two veins are above and below, with the heart lying midway.

The heart in all animals has cavities inside it. ${ }^{5}$ In the case of the smaller animals even the largest of the chambers is scarcely discernible; the second larger is scarcely discernible in animals of medium size; but in the largest animals 30

${ }^{1}$ It is plain that $\phi \lambda \epsilon \dot{\psi}$ is used indiscriminately of vein and artery, whence (not without hesitation) we translate it more often 'bloodvessel'. Only in the spurious treatise de Spiritu are the arteries clistinguished as airtnpiar. They were clearly distinguished, however, by the Hippocratics.

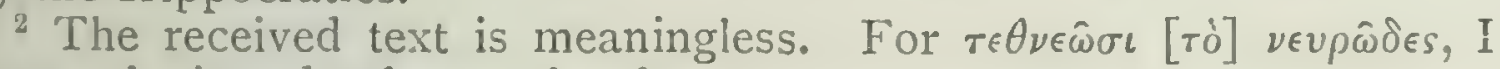
have substituted $\tau \epsilon \theta \nu \in \hat{\omega} \sigma \iota \nu \dot{\alpha} \epsilon \rho \hat{\omega} \delta \in s$.

${ }^{3}$ P.A. iii. 4. $665^{\mathrm{b}} 16,666^{\mathrm{b}} 25,5 \cdot 667^{\mathrm{b}}$ I 5, de Resp. I4 (8). $474^{\mathrm{b}} 7$, \&c.

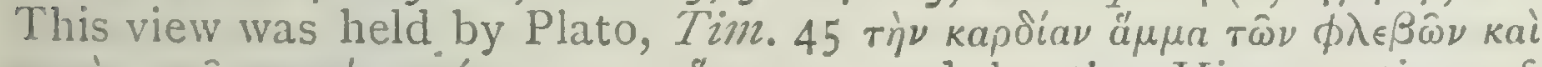

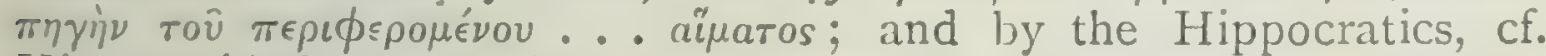

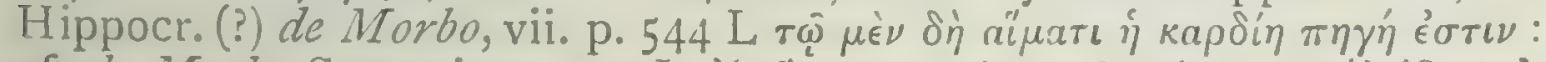

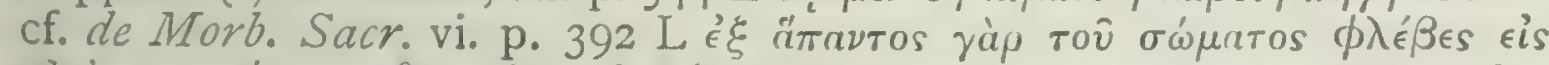

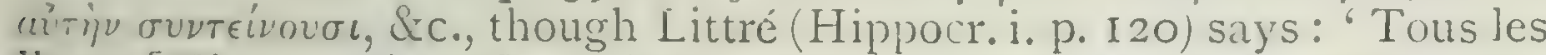
livres [Hippocratiques], où l'origine des raisseaux sanguins est placée dans le ccur, appartiennent à une époque postérieure à l'enseignement d'Aristote.'

4 i.e. the vena cava.

${ }^{5}$ Cf. H. A. i. I7. 496a 4; P.A. iii. 4. 666 2 I; Galen, de Usu. Part. iii. $480 \mathrm{~K}, \& \mathrm{c}$. 
all three chambers are distinctly scen. ${ }^{1}$ In the heart then (with its pointed end directed frontwards, as has been observed) the largest of the three chambers ${ }^{2}$ is on the right-hand side and highest up ; the least one is on the lefthand side; and the medium-sized one lies in betwixt the other two; and the largest one of the three chambers is 35 a great deal larger than either of the two others." All

1 Aristoph. Epit. H. An. (ed. Lambros, Berlin, I885) i. I I I roù

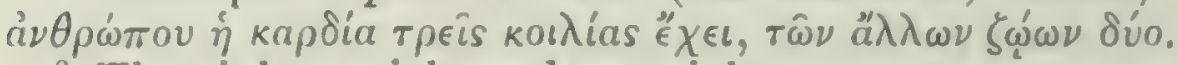

2 'The right auricle and ventricle.

3 The Aristotelian account of the iascular system is remarkable for its wealth of detail, for its great accuracy in many particulars, and for its extreme obscurity in others. It is so far true to nature that it is clear evidence of minute inquiry, but here and there so remote from fact as to sugsest that things once seen had been half-forgotten, or that superstition was in conflict with the results of observation. The account of the ressels connecting the left arm with the liver and the right with the spleen, an account embodied also in the obsolete and refuted versions of l'olybus, Diogenes, and (though obscurely) even of Syennesis, is a surviving cxample of mystical or superstitious belief. It is possible that the ascription of three chambers to the heart was also influenced by tradition or mysticism, much in the same way as l'lato's notion of the three corporeal faculties. The whole subject is discussed and variously interpreted by Galen, Haller, Hoffmann, Philippson ( Wimmer, Huxley, Pouchet, Ogle, and others.

$A$ chief cause of difficulty in interpreting the whole account is the lack of precise reference to the pulmonary artery. We should have expected the two great sinewy tubes of equal size, rumning side by side and leading one from one and one from the other side of the heart, to have been indicated clearly above all other lundmarks: but of the two great ressels connected with the heart, one is the 'aorta' and the other,

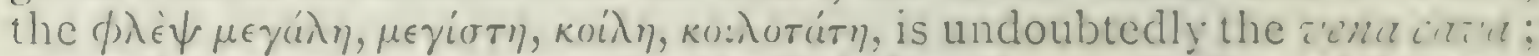
the pulmonary artery must be included uncler; or indicated in connexion with, one or other of these two.

We may on the one hand argue (as Huxley and others have done) that the pumonary artery, comnected as it is with the right side of the heart, was associated by $A$. with the veins that are likewise connected with that side; and so $\left(513^{\mathrm{b}} 1\right)$ that his 'great blood-vessel' corresponds to the superior and inferior venae cavare together with the right auricle, that the 'largest chamber' was the right ventricle, that it was in this ventricle that the blood 'broadens its channel as a river widening in a lake', and that the pulmonary artery was that 'by which the great blood-vessel comes out as blood-vessel again'. If we further accept the statement of $513^{b} 6,7$, that 'the great blood-vessel, passing through the heart, runs from the heart into the arorta', then (especially if we assume that it was the foetal heart which A. dissected) we may discern a reference to the ductus ar/eriosus, by which the pulmonary artery is connected with the aorta.

This rendering brings $A$.'s description into close agreement with the facts, but it is nevertheless difficult to accept, and for the following reasons: (I) it is hard to suppose that A. knew or believed the venac curduc and pulmonary artery to be in so close a connexion, or was 
aware that the venous circulation of the body was continued directly through the heart into the pulmonary circulation; (2) to include the pulmonary artery in A.'s enumeration of the veins is to lose the force of his well-marked distinction between the sinewy texture of artery and the membranous texture of vein; (3) the aorta is not 'much narrower' than the pulmonary artery, but as near as may be of the same size; (4) we are afterwards told that the aorta and its branches follow the whole course already ascribed to the veins, including therefore a distribution to the lungs; (5) it seems to me unlikely that the ductus arteriosus was ever dissected and recognized by Aristotle.

It seems to me much more likely that the pulmonary artery and aorta, both alike empty of blood in the dead subject and so similar in texture and appearance to one another and so plainly different from the veins, were together spoken of as 'the aorta', in other words as the arterial system: though this hypothesis would force us to admit that A. did not detect the simple fact of these two vessels communicating with opposite sides of the heart. This interpretation is supported

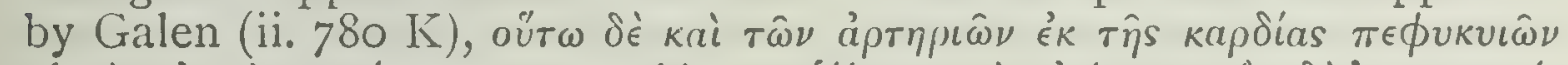

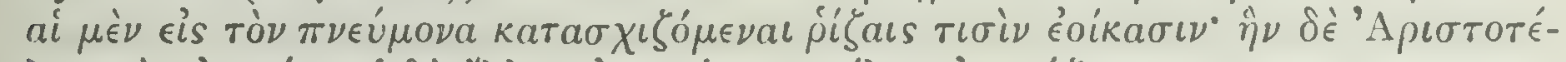

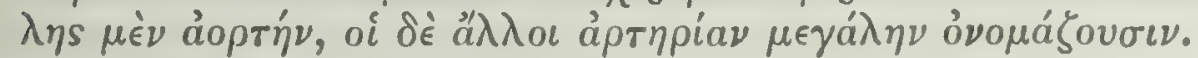

According to this view, the great vein which passes through the heart and is continued again is simply the rena carla, whose inferior and superior portions meet 'as in a reservoir' in the right auricle, and are thereby attached to the right ventricle, the largest of the cavities. The part of the great vein above the heart includes the pulmonary veins (their distinctness from the superior vena cava, and their communication with another auricle, being overlooked); and these veins stretch away to the lung and to the point of its attachment to the artery, while the other portion, that is to say the superior vena cava itself, goes on towards the backbone and splits into the two innominate veins from which come the jugular and subclavian branches. With all this system of veins an arterial system, the pulmonary artery and the branches of the aorta, runs parallel. The big vein that Antilochus cleft, smiting Thoön in the rear, was the whole venous trunk of the superior and inferior venae cavae. The courses of the aorta and inferior vena cava in the region below the heart are related with general accuracy.

In short, however we regard the account left us, there is one point of weakness, not to be reconciled with anatomical fact, the description of the heart itself and of its precise relation to the orifices of the great vessels: we may, as we please, ascribe the defect to imperfect dissection, to a corrupt or mutilated text, or possibly to the persistence of archaic and traditional views in regard to this central organ. ('Verum aut subtilis aliquis ordinis amor magno viro imposuit, aut loca ab Apellicone interpolata sunt, quae C. Hoffmanni est cxcusatio': Haller.)

The Hippocratics appear to have recognized, correctly, two cavities (cf. Hippocr. de Corde, i. $486 \mathrm{~K}$; Galen, ii. 62 I, iii. $442 \mathrm{~K}$; Aristoph. Epit. ii. 2I), and it was not till afterwards that the auricles were distinguished as appendages of these (cf. Galen, ii. 624 K).

Galen suggests that A.'s third or middle cavity was a portion of the

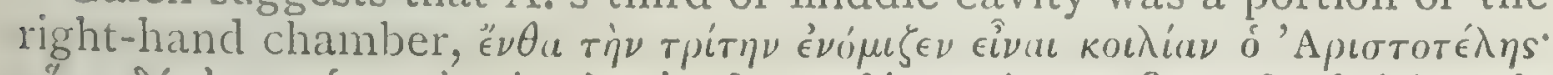

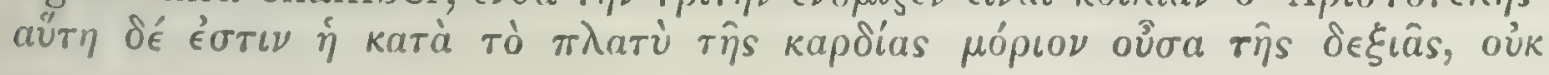


direction of the lung, but all these communications are indistinctly discernible by reason of their minuteness, except one. ${ }^{1}$

$5^{1} 3^{\text {b }}$ The great blood-vessel, then, is attached to the biggest of the three chambers, the one that lics uppermost ${ }^{2}$ and on the right-hand side; it then extends right through the chamber, coming out as blood-vessel again ; just as though the cavity of the heart were a part of the vessel, in which the blood broadens its channel as a river that widens out in a lake." The arta is attached to the middle chamber ; ${ }^{4}$ only, by the way; it is connected with it by a much narrower pipe.

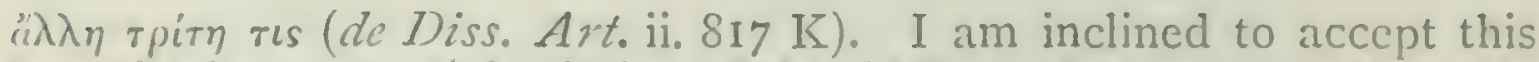
hypothesis as a partial solution of the riddle, and to suppose that this was the middle chamber in which ij óákpırıs took place, that part of the 'aorta' or arterial system now known as the pulmonary artery opening into it.

Plain to be seen as the aorta is elsewhere, it is concealed in the immediate neighbourhood of the heart by the pulmonary antery, which is there the most conspicuous of all vessels; and it is undoubtedly the pulmonary artery that is referred to in Aristoph. Epit. ii. 2 I pépovor

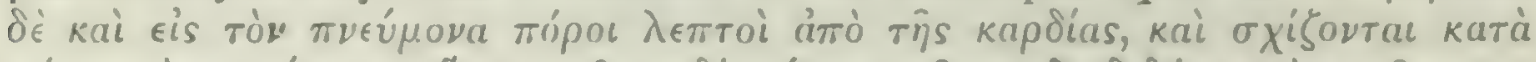

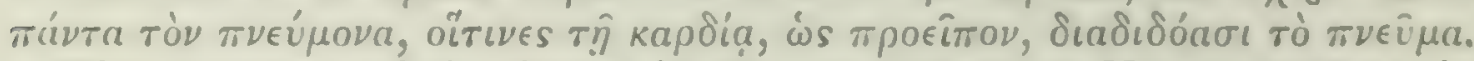

The account of the heart in the de Somn. et Vig. $3 \cdot 45^{\mathrm{a}} 15$ is of

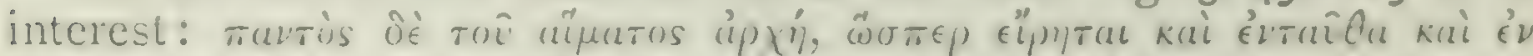

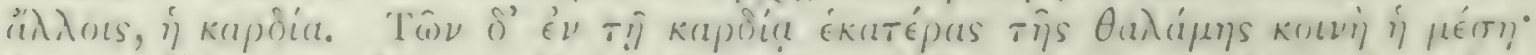

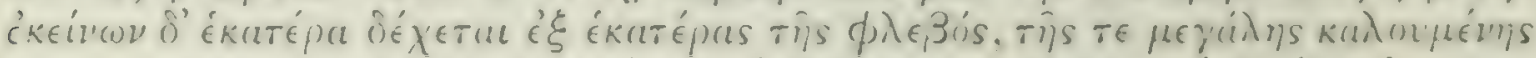

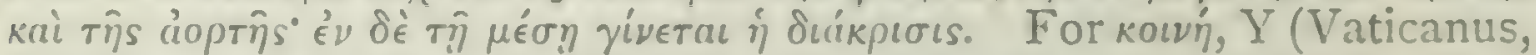
$26 \mathrm{I})$ has $\kappa \epsilon \nu \eta \dot{0}$. It is plain that the three chambers are not named or arranged here as in the other books, and also that one of the three, in this case the middle one, is recognized as being of very secondary anatomical importance.

If we take, in conclusion, the account of the veins in the Hippocratic treatise de Came, 5 (viii. p. $590 \mathrm{~L}$ ), an account closely comparable with Aritotle's, we again find no posible opportunity to suppose that the fulmonary artery was ever associated with the venous system: the

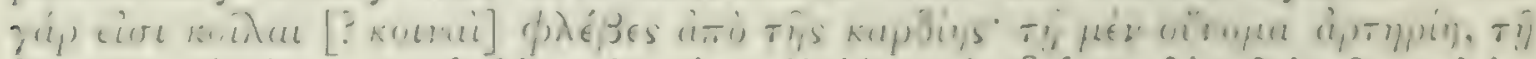

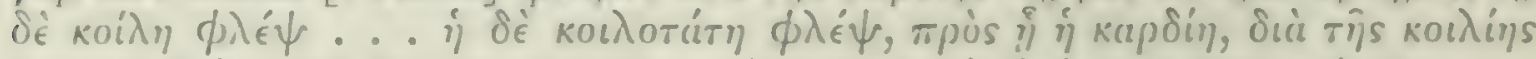

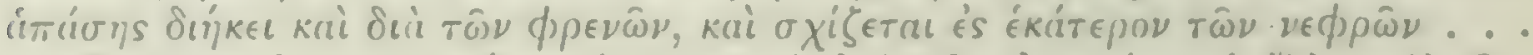

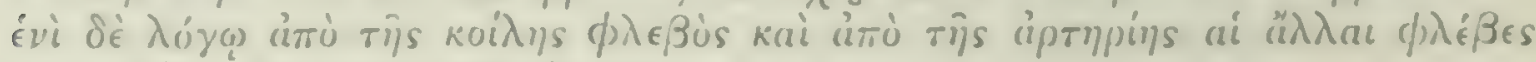

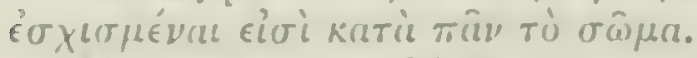

We may also add that were the pulmonary artery not as naturally associated with the aorta as the arteries are easy to distinguish from the veins, the view could never have arisen that the veins sprang from the liver and the arteries from the heart (cf. Hippocr. de Aliment. 3 I, ii. p. 22 K, ix. p. $110 \mathrm{~L}$, pił

1 The pulmonary artery.

: Uppermost, i.e. when the body is lying bupine under disection.

'Dante, 'nel lago del cor.'

i.e. the left ventricle. 
The great blood-vessel then passes through the heart [and runs from the heart into the aorta]. ${ }^{1}$ The great vessel looks as though made of membrane or skin, while the aorta is narrower than it, and is very sinewy; and as it stretches away to the head and to the lower parts it becomes ro exceedingly narrow and sinewy.

First of all, then, upwards from the heart there stretches a part of the great blood-vessel towards the lung and the attachment of the aorta, a part consisting of a large undivided vessel. But there split off from it two parts; one towards the lung and the other towards the backbone $1_{5}$ and the last vertebra of the neck. ${ }^{2}$

The vessel, then, that extends to the lung; as the lung itself is duplicate, divides at first into two; and then extends along by every pipe and every perforation, greater alons the greater ones, lesser along the less, so continuously that 20 it is impossible to discern a single part wherein there is not perforation and vein; for the extremitics are indistinguishable from their minuteness, and in point of fact the whole lung appears to be filled with blood. The branches of the blood-vessels lie above the tubes that extend from the windpipe. And that vessel ${ }^{3}$ which cxtends to the vertebra of the neck and the backbone, stretches back again 25 along the backbone; as Homer represents in the lines ${ }^{4}$ :-

〈Antilochus, as Thoön turned him round〉, Transpierc'd his back with a dishonest wound; The hollow vein that to the neck extends, Along the chine, the eager javelin rends.

1 See note, p. $513^{a} 35$. This passage has been a stumbling-block to all interpreters, and brings confusion into the whole Aristotelian account of the vascular system. The statement is contrary to fact, and even the construction invites suspicion. I have no doubt but that the reading is corrupt. Sylb., Schn., A. and W., and Picc. conj. ij $\delta^{\prime} a^{\prime} o \rho \tau \dot{\eta}$, i.e. 'and the aorta runs from the heart.' Dittm. inserts 〈 i. e. 'and a passage leads from the heart into the aorta.' Neither of these emendations is satisfactory. We have no clue to the restoration of the passage, but, indulging in surmise, I would suggest if $\delta$ a a pri $\epsilon$ is $\tau \dot{\eta} \nu$ ảpı

2 I translate literally, without attempting to force the text into precise agreement with the facts. I take it that $\mathrm{A}$. knew the lung to be supplied with blood somehow, but did not understand the real distribution of the veins.
${ }^{3}$ The vena cava.
1 Il. xiii. 546. 
From this vessel there extend small blood-vessels past each so rib and each vertebra; and at the vertebra above the kidneys the vessel bifurcates. And in the above way the parts branch off from the great blood-vessel.

I3ut up above all these, from that part which is connected with the heart, the entire vein branches off in two directions. 35 Fior its branches ${ }^{1}$ extend to the sides and to the collarbones, and then pass on, in men through the armpits to the
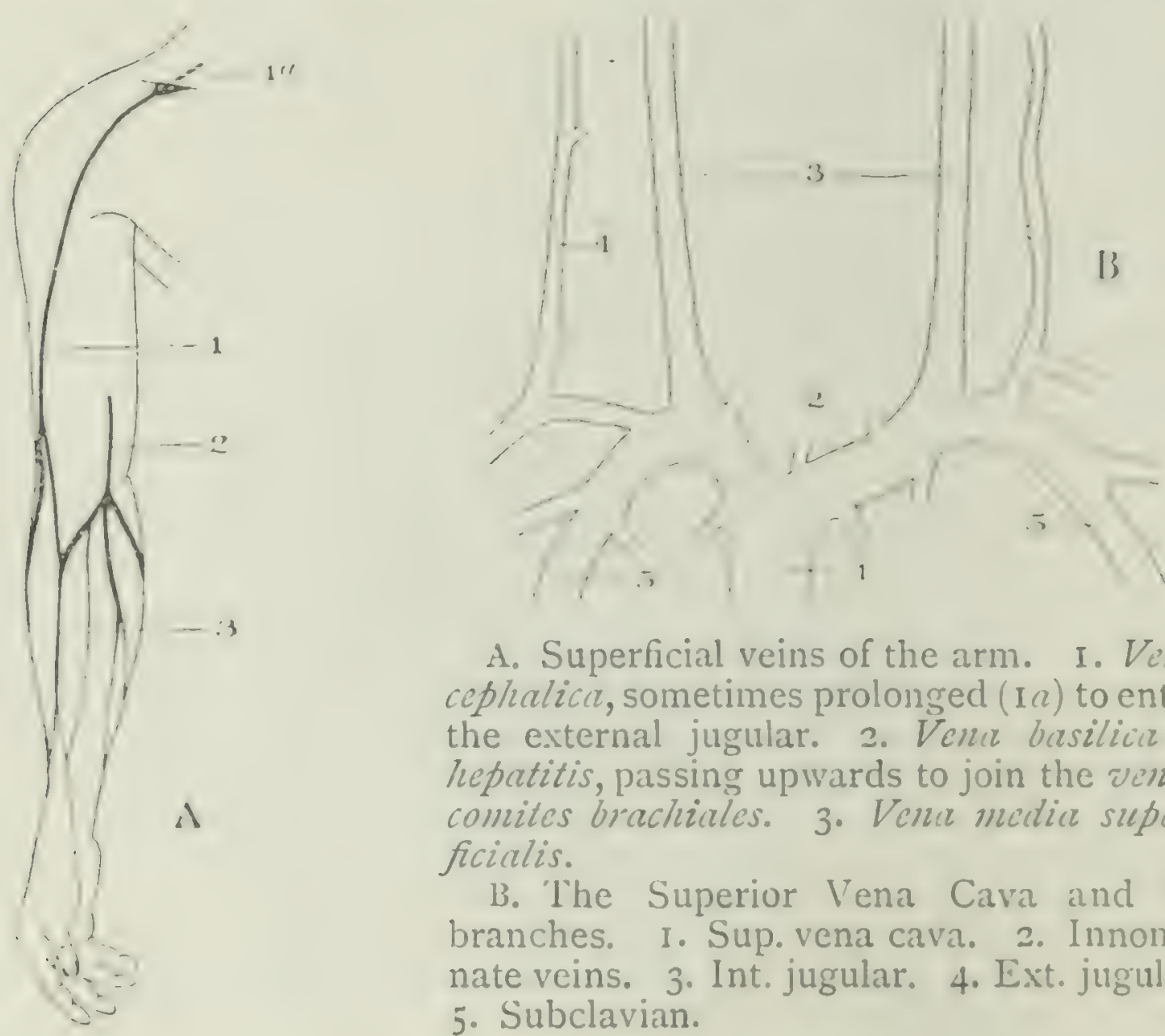

A. Superficial veins of the arm. I. Vena cephalica, sometimes prolonged $(\mathrm{I} a)$ to enter the external jugular. 2. Vencr basilici $s$. hepatitis, passing upwards to join the venae comites brachiales. 3. Venu mediu superficialis.

B. The Superior Vena Cava and its branches. I. Sup. vena cava. 2. Innominate veins. 3. Int. jugular. 4. Ext. jugular. 5. Subclavian.

$514^{\text {in }}$ arms, in quadrupeds to the foreless, in birds to the wings, and in fishes to the upper or pectoral fins. The trunks of these veins, where they first branch off, are called the 'jugular' veins ${ }^{2}$; and, where they branch off to the neck 5 [from the great icin]" they run alongside the windpipe: and, occasionally, if these reins are pressed cxternally, men,

1 The innominate and subclavian veins.

2 The internal jugular veins of modern anatomy; literally, perhaps, the 'cut-throat' veins. Cf. Celsus, 4. I 'dextra sinistraque circum guttur venae grandes quae opoyirioss nominantur, itemque arteriae quas kapwrióas vocant sursum precedentes ultra aures fertuntur'

3 Om. Gaza. 
though not actually choked, become insensible, shut their eyes, and fall flat on the ground. Extending in the way described and keeping the windpipe in betwixt them, they pass on until they reach the ears at the junction of the lower jaw with the skull. Hence again they branch off so into four veins, ${ }^{1}$ of which onc ${ }^{2}$ bends back and descends through the neck and the shoulder," and meets the previous branching off of the vein ${ }^{4}$ at the bend of the arm, whilc the rest of it terminates at the hand and fingers.

Each vein of the other ${ }^{5}$ pair stretches from the regrion of ${ }_{5} 5$ the ear to the brain," and branches off in a number of fine and delicate veins into the so-called meninx, or membrane, which surrounds the brain. The brain itself in all animals is destitute of blood, and no vein, great or small, holds its course therein. But of the remaining veins that branch off 20 from the last-mentioned vein some envelop the head, others close their courses in the organs of sense and at the roots of the teeth in veins exceedingly fine and minute.

4 And in like manner the parts of the lesser one of the two chief blood-vessels, designated the aorta, branch off, accompanying the branches from the big vein; only that, in 25 regard to the aorta, the passages are less in size, and the branches very considerably less than are those of the great rein. So much for the veins as observed in the regions above the heart.

The part of the great vein that lies underneath the heart ${ }^{7}$ cxtends, freely suspended, right through the midriff, and is 30 united both to the aorta and the backbone by slack membranous communications. From it one vein, short and

1 i. e. two on each side. The one branch doubtless includes the facial veins, and also the external jugular, whose independent entry into the subclavian is not described, A. supposing it to pass directly into the cephalic vein.

2 i. e. one on either side (the external jugular).

${ }^{3}$ i. e. as the cephalic vein. While this vein more commonly enters the axillary, it is not infrequently prolonged over the clavicle to join the external jugular.

${ }^{4} \mathrm{i}$.e. communicates with the brachial or subclavian by means of its anastomosis with the vena basilica.

5 internal jugular.

7 vena cava inferior.

6 As the lateral sinus, \&c. 
wide, extends through the liver, ${ }^{1}$ and from it a number of minute veins branch off into the liver and disappear. From 35 the vein that passes through the liver two branches separate off, of which one 2 terminates in the diaphragm or so-called $514^{\mathrm{b}}$ midriff, and the other runs up again through the armpit into the right arm ${ }^{3}$ and unites with the other veins at the inside of the hend of the arm; and it is in consequence of this local connexion that. when the surgeon opens this vein in the forcarm, the patient is relieved of certain pains in the liver; and from the left-hand side of it there extends a short but thick vein to the spleen and the little veins 5 branching off it disappear in that organ. Another part branches off from the left-hand side of the great vein, and ascends, by a course similar to the course recently described, into the left arm; ${ }^{4}$ only that the ascending rein in the one case is the rein that traverses "the liver, while in this case it is distinct from the vein that runs into the spleen.

ro Again, other veins branch off from the big rein; one to the omentum, and another to the pancreas, from which vein run a number of reins through the mesentery. All these veins coalesce in a single large vein, along the cntire gut and stomach to the oesophagus; about these parts there ${ }_{5} 5$ is a great ramification of branch veins. ${ }^{6}$

As far as the kidneys, each of the two remaining undivided, the aorta and the big rein extend; and here they get more closely attached to the backbone, and branch off, each of the two, into a $A$ shape, and the big vein gets 20 to the rear of the aorta. But the chicf attachment of the anorta to the backbone takes place in the region of the heart; and the attachment is effected by means of minute and sinewy vessels. The aorta, just as it draws off from the heart, is a tube of considerable rolume, but, as it advances

1 hepatic and portal veins.

2 inferior phrenic.

3 No such vein exists, but the account is probably based on imperfect knowledge of the vemu arygos, which $\mathrm{A}$. would seem to have supposed to communicate with the a'ena basiliea.

I' l'erhaps based, in like manner, on the left upper azygos.

5 Reading ì Sui.

" The general distribution of the mesenteric veins is fairly correct, but Aristotle is mnacquainted with their relation to the liver through the portal vein. C., howeve:, II. A. vii. $9.586^{\mathrm{b}}$ Is. 
in its course, it gets narrower and more sinewy. And from the aorta there extend veins to the mesentery ${ }^{1}$ just like the veins that extend thither from the big vein, only that 25 the branches in the case of the aorta are considerably less in magnitude; they are, indeed, narrow and fibrillar, and they end in delicate hollow ${ }^{2}$ fibre-like veinlets.

There is no vessel that runs from the aorta into the liver or the spleen.

From each of the two great blood-vessels there cxtend branches to each of the two flanks, ${ }^{3}$ and both branches fasten on to the bone. Vessels ${ }^{4}$ also extend to the kidneys , 0 from the big rein and the aorta; only that they do not open into the cavity of the organ, but their ramifications penetrate into its substancc. From the aorta ${ }^{5}$ run two other ducts to the bladder, firm and continuous; and there are other clucts from the hollow of the kidneys, in no way 35 communicating with the big vein. From the centre of each of the two kidneys springs a hollow sinewy vein, running along the backbone right through the loins ; by and by $515^{\mathrm{a}}$ each of the two veins first disappears in its own flank, and soon afterwards reappear's stretching in the direction of the flank. The extremities of these attach to the bladder, ${ }^{7}$ and also in the male to the penis and in the female to the womb. From the big vein no vein extends to the womb, 5 but the organ is connected with the aorta by veins numerous and closely packed.

Coeliac and mesenteric arteries.

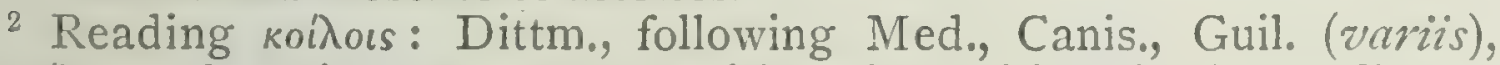

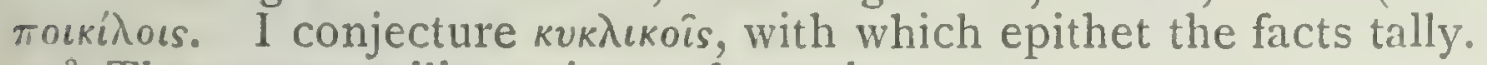

3 The common iliac veins and arteries.

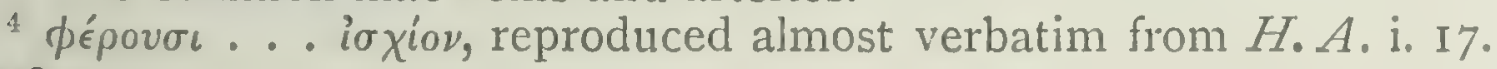
$497^{\mathrm{a}} 4$.

5 The ducts that are said to run from the aorta to the bladder (as also in i. I7) are not easily to be identified. They are, perhaps, the spermatic arteries, but $A$. and $W$. take them to be the ligamenta resicae lateralia.

${ }^{6} \phi \lambda \epsilon \beta \hat{\omega} \nu$, of the MSS., is unintelligible. Picc. reads (with $A^{a}$ )

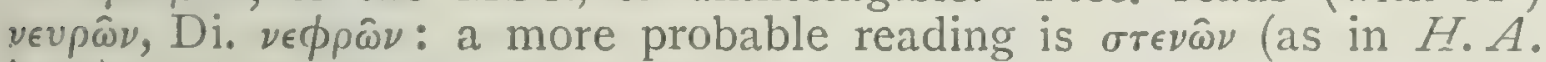
i. I7), and so Dittm., or possibly ó $\sigma \phi \dot{v} \omega \nu$. These ducts are undoubtedly the ureters, which are well described in $P . A$. iii. $9.67 \mathrm{I}^{\mathrm{b}} 16$. Cf. Celsius, 4. I 'a renibus singulae venae colore albae ad vesicam feruntur: oup $\eta \hat{\eta} \rho a$ Graeci vocant'. A. and W. bracket the whole

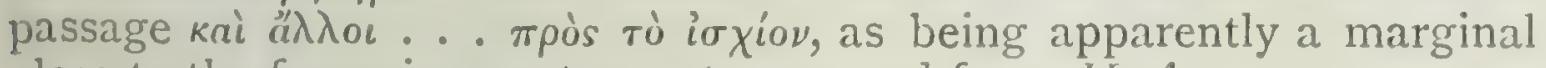
gloss to the foregoing sentence, transposed from $H . A$. I. I7.

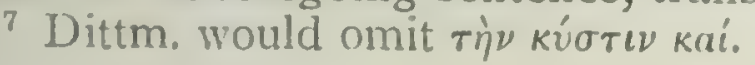


Furthermore, from the aorta and the great vein at the points of divarication there branch off other veins. Some of these run to the groins-large hollow veins ${ }^{1}$ - and then ro pass on dorrn through the legs and terminate in the fect and tocs. Anct, again, another set run through the groins and the thighs cross-garter fashion, from right to left and from left to right, and unite in the hams with the other veins. $^{2}$

In the above description we have thrown light upon the course of the veins and their points of departure.

15. In all sanguineous animals the case stands as here set forth in regard to the points of cleparture and the courses of the chicf veins. But the description docs not hold equally good for the entire vein-system in all these animals. For, in point of fact, the organs are not identically situated in them all; and, what is more, some animals are furnished with organs of which other animals are clestitute. At the same time, while the description so far holds good, the 20 proof of its accuracy is not equally casy in all cascs, but is casiest in the case of animals of considerable magnitude and supplied abundantly with blood. For in little animals and those scantily supplicd with blood, cither from natural and inherent causes or from a prevalence of fat in the body, thorough accuracy in investigation is not equally attainable; for in the latter of these creatures the passages get clogged, like water-channels choked with slush; ${ }^{2}$ and the others have a few minute fibres ${ }^{4}$ to serve instead of 25 veins. But in all cases the big vein is plainly discemible. cven in creatures of insignificant size.

The sincws of animals have the following propertics. 5 For these also the point of origin is the heart ${ }^{5}$; for the heart has sinews within itself in the largest of its three 30 chambers, and the aorta is a sinew-like rein; in fact, at its

1 The common iliacs, and their branches.

2 Probably the anastomoses of the saphenous veins.

3 Plat. I im. $77 \mathrm{G} ;$ P.A. iii. 5. 665: 14. 29; Galen. de Nat. Faic. ii. $210 \mathrm{~K}$.

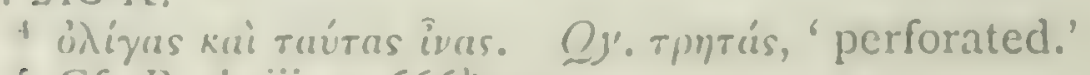

${ }^{5}$ C. P. A. iii. 4. 666' 17. 
head there is no sinew; but the head is held together by the sutures of the bones.

I5 Sincw is fissile lengthwise, but crosswise it is not easily broken, but admits of a considerable amount of hard tension. In connexion with sinews a liquid mucus is developed, white and glutinous, and the organ, in fact, is sustained by it and appears to be substantially composed of it. Now, vein may be submitted to the actual cautery, but sinew, when submitted to such action, shrivels up altogether; and, if sinews be cut asunder, the severed parts will not again 20 cohere. ${ }^{1} \Lambda$ fecling of numbness is incidental only to parts of the frame where sinew is situated. ${ }^{2}$

There is a very extensive system of sinews connected scverally with the feet, the hands, the ribs, the shoulderblades, the neck, and the arms.

All animals supplied with blood are furnished with sinews; but in the case of animals that have no flexures to their limbs, but are, in fact, destitute of either feet or hands, 25 the sinews are fine and inconspicuous; and so, as might have been anticipated, the sinews in the fish are chicfly discernible in connexion with the fin.

The ines ${ }^{3}$ (or fibrous connective tissue) are a something 6 intermediate between sinew and vein. Some of them are supplicd with fluid, the lymph; and they pass from sinew 30 to vein and from vein to sinew. ${ }^{4}$ There is another kind of ines or fibre that is found in blood, but not in the blood of all animals alike. If this fibre be left in the blood, the blood will coagulate; if it be removed or extracted, the blood is found to be incapable of coagulation. While, however, this fibrous matter is found in the blood of the great majority of animals, it is not found in all. For

1 Plin. xi. 88.

2 veipa in Ar. are sincws and ligaments, but with these he included and confused such nerves as he was acquainted with: cf. I'lin. xi. \&8 'neque ii [nervi] solichantur incisi: mirumque, vulneratis summus dolor, praesectis nullus'.

${ }^{3}$ C. P. P. A. ii. 4 .

' The meaning is uncertain. Scal. tr. 'differunt autem a nervis, yuantum ad venarum naturam vergunt, et a venis distant quantum ad nervorum inclinant rationem '. 
instance, we fail to find it in the blood of the deer, the roe, the antelope, ${ }^{2}$ and some other animals ; and, owing to this deficiency of the fibrous tissue, the blood of these animals does not coagulate to the extent observed in the blood of other animals. ${ }^{3}$ The blood of the deer coagulates to about $516^{a}$ the same extent as that of the hare: that is to say, the blood in either case coagulates, but not into a stiff or jellylike substance, like the blood of ordinary animals, but only into a flaccid consistency like that of milk which is not subjected to the action of rennet. The blood of the antelope admits of a firmer consistency in coagulation; for in this respect it resembles, or only comes a little short of, 5 the blood of sheep. Such are the properties of vein, sinew, and fibrous tissue.

The bones in animals are all connected with one single bone, ${ }^{4}$ and are interconnected, like the veins, in one unbroken sequence; and there is no instance of a bone standing apart by itself.

In all animals furnished with bones, the spine or back- Io bone is the point of origin for the entire osseous system. The spine is composed of vertebrae, and it extends from the head down to the loins. The vertebrae are all perforated, and, above, the bony portion of the head is connected with the topmost vertebrae, and is designated the 'skull'. And the serrated lines on the skull are termed 'sutures'.

The skull is not formed alike in all animals. In some 15 animals the skull consists of one single undivided bone, as in the case of the $\operatorname{dog} ;{ }^{5}$ in others it is composite in structure, as in man ; and in the human species the suture is circular in the female, while in the male it is made up

1 H. A. iii. 19. $520^{\mathrm{b}} 24$; P. A. ii. $4.650^{\mathrm{b}}$ I 5 ; Meteor. iv. $7 \cdot 384^{\mathrm{a}} 26$.

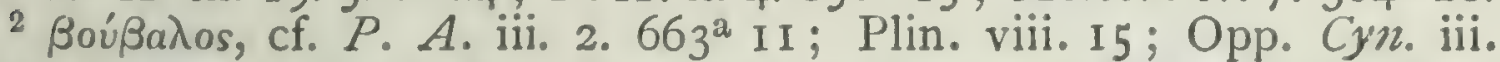
300 ; Strabo, xvii. 3. 4, \&c. ; identified by Cuvier with Antilope (Alcocephalus) bubalis, of N. Africa.

${ }^{3}$ Cf. Plin. xi. 9o. It is said that the blood of animals which have been coursed coagulates imperfectly: cf. John Hunter's Works, i. p. 239 ; also Hewson's do., edit. Gulliver, p. 25.

P.A. ii. $9.654^{\mathrm{b}} \mathrm{I2}$.

5 Ael. iv. 40. 
of three separate sutures, uniting above in three-corner fashion $;^{1}$ and instances have been known of a man's skull so being devoid of suture altogether. The sliull is composed not of four bones, but of six; two of these are in the region of the cars, small in comparison with the other four. From the skull extend the jaws, constituted of bone. [Animals in general move the lower jaw; the rivercrocodile ${ }^{2}$ is the only animal that moves the upper onc. ${ }^{3}$ ${ }_{25}$ In the jaws is the tooth-system; and the tceth are constituted of bone, and are half-way perforated; and the bone in question is the only kind of bone which it is found impossible to grave with a graving tool.

On the upper part of the course of the backbone ${ }^{4}$ are the collar-bones and the ribs. The chest rests on ribs; and these ribs ${ }^{5}$ meet together, whereas the others do not; for 30 no animal has bone in the region of the stomach. ${ }^{6}$ Then come the shoulder-bones, or blade-bones, and the armbones connected with these, and the bones in the hands connected with the bones of the arms. With animals that have forelegs, the osscous system of the foreleg resembles that of the arm in man.

35 Below the level of the backbone, after the haunch-bone, comes the hip-socket; then the leg-bones, those in the thighs and those in the shins, which are termed colenes or $516^{\mathrm{b}}$ limb-bones, a part of which is the ankle, while a part of the same is the so-called 'plectrum' in those creatures that

${ }^{1}$ Herod. ix. 83; H. A.i. $7.491^{\mathrm{b}} 2$; P.A. ii. $7.653^{\mathrm{b}}$ I ; Ruf. Ephes. p. 34. The alleged difference between the male and female skull is one of the puzzles of Aristotelian anatomy; I am inclined to think (with Harduin, ad Plin. xi. 48) that A. imagined the sutures to correspond with the partings of the hair, but see Ogle's note (I'arts of Anim.p. I68).

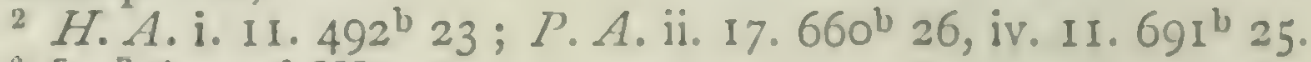

3 [ A. and W.

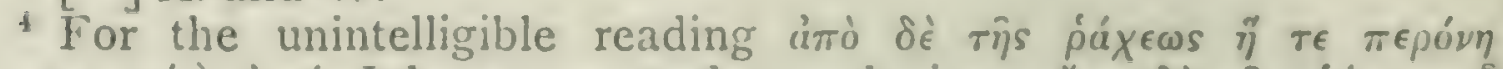

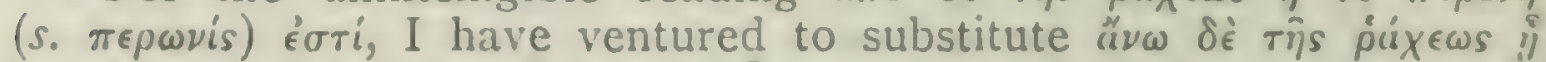

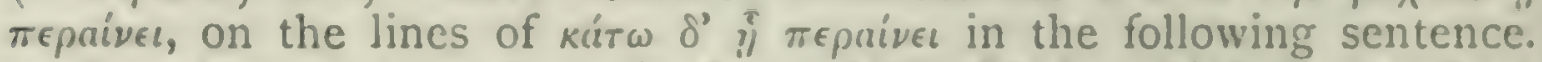
tepún never means a bone in A., and the fibula, which it elsewhere means, has no relation to the context. Tepuin(n), by the way; does not necessarily mean to end, but also to extend, to run its course.

b i. c. the upper ones.

i P.A. ii. $9.655^{\mathrm{a}} \mathrm{I}$. 
smaller ones, more or less spinous. But all sanguineous animals have a backbone of either one kind or other: that is, composed either of bone or of spine.

The other portions of the skeleton are found in some animals and not found in others, but the presence or the 25 absence of this and that part carrics with it, as a matter of course, the presence or the absence of the bones or the spines corresponding to this or that part. For animals that are destitute of arms and legs cannot be furnished with limb-bones: and in like manner with animals that have the same parts, but yet have them unlike in form; for in these animals the corresponding bones differ from one another in the way of relative excess or relative defect, or in the way of analogy taking the place of identity. So 30 much for the osseous or spinous systems in animals.

Gristle $^{1}$ is of the same nature as bone, but differs from it 8 in the way of relative excess or relative defect. And just like bone, cartilage also, if cut, does not grow again. In terrestrial viviparous sanguinea the gristle formations are 35 unperforated, and there is no marrow in them as there is in bones; in the selachia, however-for; be it observed, $5^{1} 7^{\text {a }}$ they are gristle-spined-there is found [in the case of the flat species $],{ }^{2}$ in the region of the backbone, a gristle-like substance analogous to bonc, and in this gristle-like substance there is a liquid resembling marrow. In viviparous animals furnished with fect, gristle formations are found in the region of the ears, in the nostrils, and around certain 5 extremities of the bones.

Furthermore, there are parts of other kinds, neither 9 identical with, nor altogether diverse from, the parts above cnumerated: such as nails, hooves, claws, and horns: and also, by the way, beaks, such as birds are fumished withall in the several animals that are furnished therewithal. 10 All these parts are flexible and fissile; but bone is neither flexible nor fissile, but frangible.

1 P. A. ii. 9. $655^{a} 32$; Plin. xi. 87 .

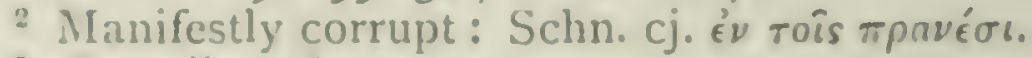

3 P. A. ii. 6. $652^{\mathrm{a}}$ I3. 
And the colours of horns and nails and claw and hoof follow the colour of the skin and the hair. ${ }^{1}$ For according as the skin of an animal is black, or white, or of medium hue, so are the horns, the claws, or the hooves, as the case r 5 may be, of hue to match. And it is the same with nails. The teeth, however, follow after the bones. Thus in black men, such as the Aethiopians and the like, the teeth and bones are white, but the nails are black, like the whole of the skin.

Horns in general are hollow at their point of attachment to the bone which juts out from the head inside the horn, but they have a solid portion at the tip, and they are simple and undivided in structure. In the case of the stag alone of all animals the horns are solid throughout, ${ }^{2}$ and ramify into branches (or antlers). And, whereas no other animal is known to shed its horns, the deer sheds its horns ${ }_{25}$ annually, unless it has been castrated; and with regard to the effects of castration in animals we shall have much to say hereafter. ${ }^{3}$ Horns attach rather to the skin than to the bone; which will account for the fact that there are found in Phrygia and elsewhere cattle that can move their horns as freely as their ears. ${ }^{4}$

Of animals furnished with nails-and, by the way, all zo animals have nails that have toes, and toes that have feet, except the elephant; and the elephant has toes undivided and slightly articulated, but has no nails whatsoever ${ }^{5}$ - of animals furnished with nails, some are straight-nailed, like man ; others are crooked-nailed, as the lion among animals $57^{\mathrm{b}}$ that walk, and the eagle among animals that fly.

${ }^{1}$ Cf. G. A. ii. 6. $745^{\mathrm{a}} 22$; v. $4.784^{\mathrm{a}} 42,5.785^{\mathrm{b}}$ 3.

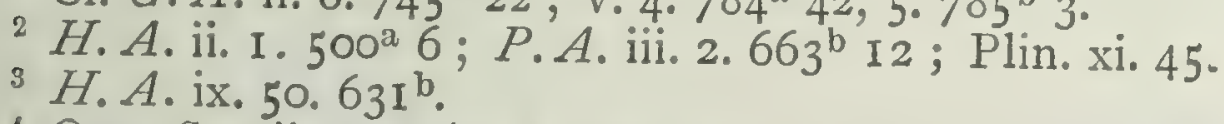

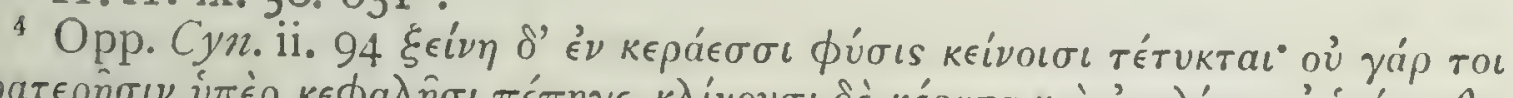

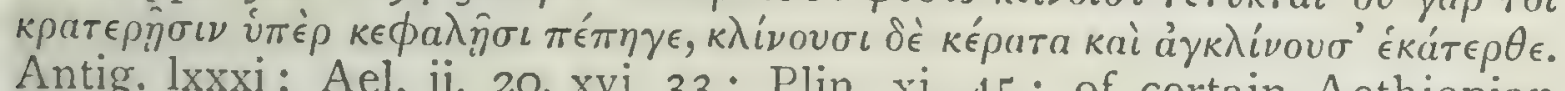
Antig. Ixxxi; Ael. ii. 20, xvi. 33 ; Plin. xi. 45; of certain Aethiopian cattle, Ael. xvii. 45, Diod. Sic. i. 20I, Agatharch. ap. Phot. p. I363. Schn, quotes (p. I47) from Lobus, Descr. de l'Abyssinie, i. p. $88^{\prime}$ 'ceuxlà n'ont point de cornes, ou s'ils en ont, elles sont si molles et si flexibles qu'elles leur pendent comme des bras rompus'; and refers also to Beckmann, Litteratur der ältesten Reisebeschreibungen, i. p. 566. Similar cattle are known from Madagascar; cf. Flacourt, Hist. de la grande île Madagascar, I66I.

${ }^{5}$ H.A. ii. I. $497^{\mathrm{b}} 23$, \&c. 
The following are the properties of hair and of parts ro analogous to hair, and of skin or hide. All viviparous animals furnished with feet have hair; ${ }^{1}$ all oviparous 5 animals furnished with feet have horn-like tessellates; fishes, and fishes only, have scales-that is, such oviparous fishes as have the crumbling egg or roc. For of the lanky fishes, the conger has no such egg, nor the muraena, and the eel has no egg at all. ${ }^{2}$

The hair differs in the way of thickness and fineness, ${ }^{3}$ and of length, according to the locality of the part in which Io it is found, and according to the quality of skin or hide on which it grows. For, as a general rule, the thicker the hide, the harder and the thicker is the hair; and the hair is inclined to grow in abundance and to a great length in localities of the bodics hollow and moist, if the localities be fitted for the growth of hair at all. The facts are similar in the case of animals whether coated with scales Is or with tesscllates. With soft-haired animals the hair gets harder with good feeding, and with hard-haired or bristly animals it gets softer and scantier from the same cause. Hair differs in quality also according to the relative heat or warmth of the locality: just as the hair in man is hard in 20 warm places and soft in cold ones. Again, straight hair is inclined to be soft, and curly hair to be bristly.

Hair is naturally fissile, and in this respect it differs in II degree in diverse animals. In some animals the hair goes on gradually hardening into bristle until it no longer re25 scmbles hair but spine, as in the case of the hedgehog. ${ }^{4}$ And in like manner with the nails; for in some animals the nail differs as regards solidity in no way from bone.

Of all animals man has the most delicate skin: that is, if we take into consideration his relative size." In the skin or hide of all animals there is a mucous liquid, scanty in some animals and plentiful in others, as, for instance, in 3. the hide of the ox; for men manufacture glue out of it.

1 Plin. xi. 94.

2H.A. vi. 13. $567^{\mathrm{a}} 20,16.570^{\mathrm{a}} 3$, Sic.

H.A.i.6. $490^{\mathrm{b}} 28 ; G . A$. v. $3.78 \mathrm{I}^{\mathrm{b}} 33$.

${ }^{5}$ G. A. v. $5.785^{\mathrm{b}} 8$.

${ }^{3} G \cdot A \cdot$ v. 3. $782^{n} \mathrm{I}$. 
(And, by the way, in some cases glue is manufactured from fishes also.) The skin, when cut, is in itself devoid of sensation ${ }^{1}$ and this is especially the case with the skin on the head, owing to there being no flesh between it and the skull. And wherever the skin is quite by itself, if it be cut $518^{a}$ asunder, it does not grow together again, as is seen in the thin part of the jaw, in the prepuce, and the eyelid. ${ }^{3}$ In all animals the skin is one of the parts that extends continuous and unbroken, ${ }^{4}$ and it comes to a stop only where the natural ducts pour out their contents, ${ }^{5}$ and at the mouth and nails.

All sanguineous animals, then, have skin; but not all 5 such animals have hair ${ }^{6}$ save only under the circumstances described above. The hair changes its colour ${ }^{7}$ as animals grow old, and in man it turns white or grey. ${ }^{8}$ With animals, in general, the change takes place, but not very obviously, or not so obviously as in the case of the horse. ${ }^{9}$ Hair turns grey from the point backwards to the roots. But, in the majority of cases, grey hairs are white from the ro beginning; and this is a proof that greyness of hair does not, as some believe to be the case, imply withering or decrepitude, for no part is brought into existence in a withered or decrepit condition.

In the eruptive malady called the white-sickness all the hairs get grey; and instances have been known where the hair became grey while the patients were ill of the malady, whereas the grey hairs shed off and black ones replaced them on their recovery, [Hair is more apt to $\mathbf{5}_{5}$ turn grey when it is kept covered than when exposed to the action of the outer air. $]^{10}$ In men, the hair over the temples is the first to turn grey, ${ }^{11}$ and the hair in the front

P.A. ii. I0. $65^{\mathrm{b}} 6$.

2 i. e. the cheek.

${ }^{3}$ H. A. i. I3. $493^{\mathrm{a}} 27$.

4 That is to say, the skin forms a connected system as do the bloodvessels, but not the sinews: vide supra.

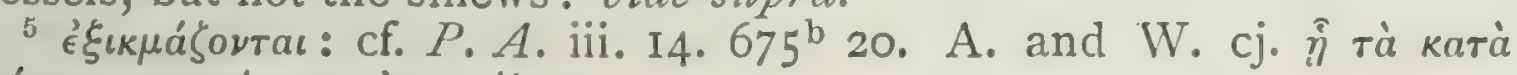

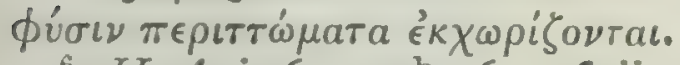

${ }^{6} H . A$. i. 6. $490^{\mathrm{b}} 26$; cf. ii. I. $498^{\mathrm{b}}$ I6.

7 G.A.v. 3-6; de Coloribus, 5, 6.

${ }^{9} G$. A. v. $5 \cdot 785^{\mathrm{a}}$ II.

11 C. Ar. Eq. 520.

${ }^{8}$ Probl.x. 63. 898 31.

${ }^{30}$ [ ] Dittm. 
grows grey sooner than the hair at the back; and the hair on the pubes is the last to change colour.

Some hairs are congenital, others grow after the maturity of the animal; but this occurs in man only. The congenital 20 hairs are on the head, the cyclids, and the eycbrows; of the later growths the hairs on the pubes are the first to come, then those under the armpits, and, thirdly, those on the chin; for, singularly enough, the regions where congenital growths and the subscquent growths are found are equal in number. The hair on the head grows scanty and 25 sheds out to a greater extent and sooner than all the rest. But this remark applics only to hair in front; for no man ever gets bald at the back of his head. Smoothness on the top of the head is termed 'baldness', but smoothness on the eyebrows is denoted by a spccial term which means 'forehead-baldness'; and neither of these conditions of baldness supervenes in a man until he shall have come so under the influence of sexual passion. For no boy ever gets bald, no woman, and no castrated man. ${ }^{1}$ In fact, if a man be castrated before reaching puberty; the later growths of hair never come at all; and, if the operation take place subsequently, the after-growths, and these only, shed off; or, rather, two of the growths shed off, but not that on the pubes.

Women do not grow hairs on the chin; cxcept that a scanty beard grows on some women after the monthly courses have stopped; and a similar phenomenon is obscrved 35 at times in priestesses in Caria, ${ }^{2}$ but these cases are looked upon as portentous with regard to coming events. The $5^{18^{\mathrm{b}}}$ other after-growths are found in women, but more scanty and sparse. Men and women are at times born constitutionally and congenitally incapable of the after-growths; and individuals that are destitute even of the growth upon the pubes are constitutionally impotent.

Hair as a rule grows more or less in length as the wearer

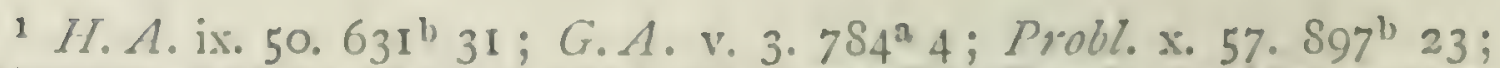
Hippocr. Aphovi. 28 (iv. p. 57 I L, iii. p. 753 K); P'orph. de Alst. p. 233 ; Plin. xi. 7. 47; Antig. 11. M1. 109, IIS.

2 Herod. i. 175, viii. 104. 
grows in age; chiefly the hair on the head, then that in the 5 beard, and fine hair grows longest of all. With some people as they grow old the eyebrows grow thicker, ${ }^{1}$ to such an extent that they have to be cut off; and this growth is owing to the fact that the eyebrows are situated at a conjuncture of bones, and these bones, as age comes on, draw apart and exude a gradual increase of moisture or rheum. The eyelashes do not grow in size, but they io shed when the wearer comes first under the influence of sexual feelings, and shed all the quicker as this influence is the more powerful; and these are the last hairs to grow grey.

Hairs if plucked out before maturity grow again; but they do not grow again if plucked out afterwards. Every hair is supplied with a mucous moisture at its root, and immediately after being plucked out it can lift light articles if it touch them with this mucus.

Animals that admit of diversity of colour in the hair admit of a similar diversity to start with in the skin and in the cuticle of the tongue. ${ }^{2}$

In some cases among men the upper lip and the chin is thickly covered with hair, and in other cases these parts are smooth and the cheeks are hairy; and, by the way, smooth-chinned men are less inclined than bearded men 20 to baldness.

The hair is inclined to grow in certain diseases, especially in consumption, and in old age, and after death; ${ }^{3}$ and under these circumstances the hair hardens concomitantly with its growth, and the same duplicate phenomenon is observable in respect of the nails.

In the case of men of strong sexual passions the congenital hairs shed the sooner, while the hairs of the after- 25

1 P.A. iii. I $5.65^{\mathrm{b}} 20$.

${ }^{2} H . A$. vi. 19. $574^{2}$ 5; G.A. v. 6. $786^{a} 2$ I. Cf. Verg. G. iii. 387 'Illum autem, quamvis aries sit candidus ipse, Nigra subest udo tantum cui lingua palato, Reice, ne maculis infuscet vellera pullis Nascentum'. Cf. Plin. viii. 72; Colum. vii. 3; Geopon. xviii. 6.

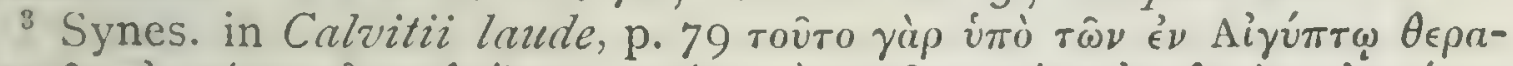

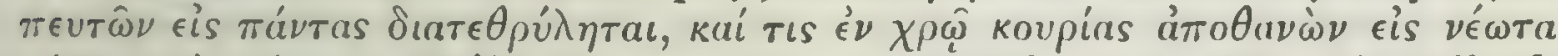

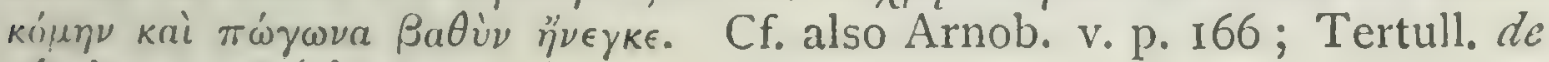
Anim. c. 5 I (cit. J. G.S.). 
growths are the quiclier to come. When men are afflicted with varicose veins ${ }^{1}$ they are less inclined to take on baldness; and if they be bald when they become thus afflicted, they have a tendency to get their hair again.

If a hair be cut, it does not grow at the point of section; but it gets longer by growing upward from below. In fishes the scales grow harder and thicker with age, ${ }^{2}$ and 30 when the animal gets emaciated or is growing old the scales grow harder. In quadrupeds as they grow old the hair in some and the wool in others gets decper but scantier in amount: and the hooves or claws get larger in size; and the same is the case with the beaks of birds. 35 The claws also increase in sizc, as do also the nails.

$519^{\text {a }}$ With regard to winged animals, such as birds, no 12 creature is liable to change of colour by reason of age, excepting the crane. ${ }^{3}$ The wings of this bird are ashcoloured at first, but as it grows old the wings get black. Again, owing to special climatic influences, as when unusual frost prevails, a change is sometimes observed to take place in birds whose plumage is of one uniform 5 colour $;{ }^{4}$ thus, birds that have dusky or downright black plumage turn white or grey, as the raven, the sparrow, and the swallow; but no case has erer yet been known of a change of colour from white to black. [Further, most birds change the colour of their plumage at different scasons of the year," so much so that a man ignorant of their habits might be mistaken as to their identity.]

ro Some animals change the colour of their hair with a change in their drinking-water, for in some countries the same species of animal is found white in one district and black in another. And in regard to the commerce of the sexes, water in many places is of such peculiar quality that rams, if they have intercourse with the female after drinking it, beget black lambs, as is the case with the water

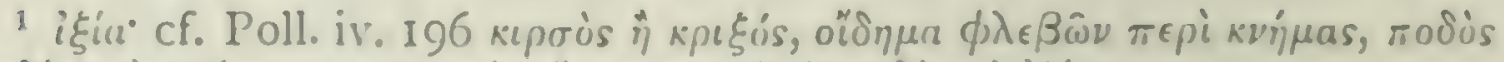

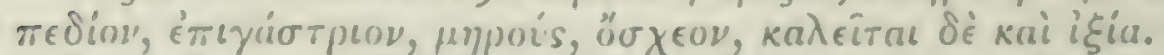

G. A.v. $3 \cdot 783^{\mathrm{b}} 6$.

1 Cf. de Coloribus, passim.

G. A.v. 5. $795^{\mathrm{a}} 21$; Plin. x. 42.

i Probl.x.7.891b 13 ; Plin. viii. 72 ; Varro, R. R. ii. 2.
} 
of the Psychrus (so-called from its coldness), a river in the district of Assyritis in the Chalcidic Peninsula, on the coast I5 of Thrace; and in Antandria there are two rivers of which one makes the lambs white and the other black. ${ }^{1}$ The river Scamander also has the reputation of making lambs yellow, and that is the reason, they say, why Homer designates it the 'Yellow River'.'

Animals as a general rule have no hair on their internal 20 surfaces, and, in regard to their extremities, they have hair on the upper, but not on the lower side.

The hare, or dasypod, is the only animal known to have hair inside its mouth and underneath its feet. ${ }^{3}$ Further, the so-called mouse-whale ${ }^{4}$ instead of teeth has hairs in its mouth resembling pigs' bristles.

Hairs after being cut grow at the bottom but not at 25 the top; if feathers be cut off, they grow neither at top nor bottom, but shed and fall out. Further, the bee's wing will not grow again after being plucked off, nor will the wing of any creature that has undivided wings. Neither will the sting grow again if the bee lose it, but the creature will die of the loss. ${ }^{5}$

I3 In all sanguineous animals membranes are found. And 30 membrane ${ }^{6}$ resembles a thin close-textured skin, but its qualities are different, as it admits neither of cleavage nor of extension. Membrane envelops each one of the bones and each one of the viscera, both in the larger and the smaller animals; though in the smaller animals the mem- 519 branes are indiscernible from their extreme tenuity and minuteness. The largest of all the membranes are the two that surround the brain, ${ }^{7}$ and of these two the one that lines the bony skull is stronger and thicker than the one

${ }^{1}$ Antig. H.M. 78 (84); Ael. viii. 21.

${ }^{2}$ Il. xx. 74. ${ }^{3}$ G. A. iv. $5.774^{a} 35$; Plin. xi. 94.

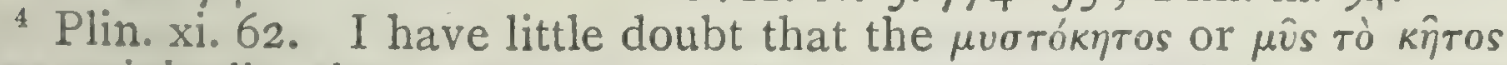

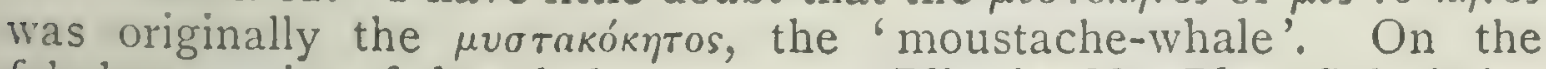
fabulous stories of the whale-mouse see Plin. ix. 88; Plut. Sol. Anim. p. 980; Opp. Hal. v. 7 I ; Ael. iii. I3; Claudian. Eutrop. ii. 425.

${ }_{5}^{5}$ Plin. xi. 19; H.A. ix. 40. 626a 17 ; Verg. G. iv. 237.

${ }^{6}$ P. A. iii. I1.673 ${ }^{\mathrm{b}}$. ${ }^{7}$ H. A. i. 16. $494^{\mathrm{b}} 29$. 
that envelops the brain ${ }^{1}$ next in order of magnitude comes the membrane that encloses the heart. If $m \mathrm{~cm}$ 5 brane be bared and cut asunder it will not grow together again, and the bone thus stripped of its membrane mortifies.

The omentum ${ }^{2}$ or caul, by the way, is membrane. All I4 sanguineous animals are furnished with this organ; but in some animals the organ is supplied with fat, and in others it is devoid of it. The omentum has both its starting-point ro and its attachment, with ambidental vivipara, in the centre of the stomach, where the stomach has a kind of suture; in non-ambidental vivipara it has its starting-point and attachment in the chief of the ruminating stomachs. ${ }^{3}$

The bladder also is of the nature of membrane, but of 15 membrane peculiar in kind, for it is extensile. The organ is not common to all animals, but, while it is found in all I5 the vivipara, the tortoise ${ }^{4}$ is the only oviparous animal that is furnished therewithal. The bladder, like ordinary membrane, if cut asunder will not grow together again, unless the section be just at the commencement of the urethra: except indeed in very rare cases, for instances of healing have been known to occur. After death, the organ passes no liquid excretion; but in life, in addition to the normal liquid excretion, it passes at times dry excretion also, which turns into stones in the case of sufferers from that 20 malady. Indeed, instances hare been known of concretions in the bladder so shaped as closely to rescmble cockleshells.

Such are the properties, then, of rein, sinew and skin, of fibre and membrane, of hair, nail, claw and hoof, of horns, of teeth, of beak, of gristle, of bones, and of parts that are 25 analogous to any of the parts here cnumerated.

1 The dura mater and pia mater.

2 P.A. iv. $3.677^{\mathrm{b}}$ I 4 ; Plin. xi. 80 .

${ }^{3}$ Cf. Cuvier, Leçons d'anat. comp.iv. pp. 87,89 . In the P.A. the terms povokoidu and modikoidu conespond to what are here called

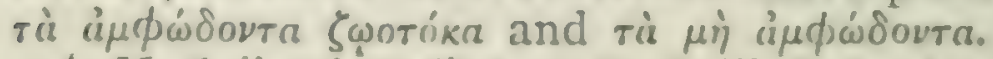

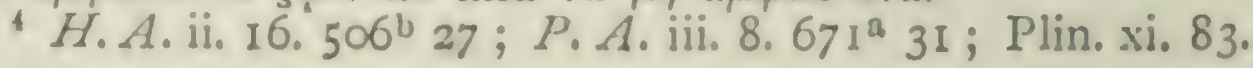


I6 Flesh, ${ }^{1}$ and that which is by nature akin to it in sanguineous animals, is in all cases situated in between the skin and the bone, or the substance analogous to bone; for just as spine is a counterpart of bone, so is the flesh-like substance of animals that are constructed on a spinous system the counterpart of the flesh of animals constructed $3^{\circ}$ on an osseous one.

Flesh can be divided asunder in any direction, not lengthwise only as is the case with sinew and vein. When animals are subjected to emaciation the flesh disappears, and the creatures become a mass of veins and fibres; ${ }^{2}$ when they are over fed, fat takes the place of flesh. ${ }^{3}$ Where the flesh is abundant in an animal, its veins arc $520^{\mathrm{a}}$ somewhat small and the blood abnormally red; the viscera also and the stomach are diminutive; whereas with animals whose veins are large the blood is somewhat black, the viscera and the stomach are large, and the flesh is somewhat scanty. And animals with small stomachs are disposed to take on flesh.

I7 Again, fat and suet differ from one another. ${ }^{4}$ Suet is frangible in all directions and congeals if subjected to extreme cold, whereas fat can melt but cannot freeze or congeal; and soups made of the flesh of animals supplied with fat do not congeal or coagulate, as is found with 10 horse-flesh and pork; but soups made from the flesh of animals supplied with suet do coagulate, as is seen with mutton and goat's flesh. Further, fat and suet differ as to their localities: for fat is found between the skin and flesh, but suet is found only at the limit of the fleshy parts. Also, in animals supplied with fat the omentum or caul is supplied with fat, and it is supplied with suet in animals supplied with suet. Moreover, ambidental animals are 15 supplied with fat, and non-ambidentals with suet.

Of the viscera the liver in some animals becomes fatty, as, among fishes, is the case with the selachia, by the
${ }^{1} P . A$. ii. 8.
${ }^{2}$ H.A. iii. $5.5 \mathrm{I} 5^{\mathrm{b}} \mathrm{I}$.

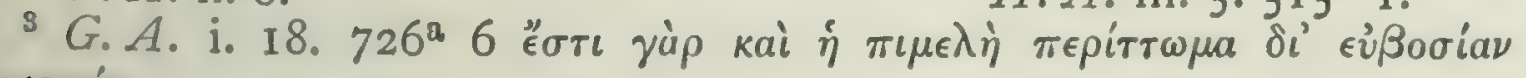

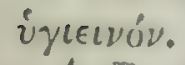

${ }^{4}$ P.A. ii. 5 ; Plin. xi. 85. 
melting of whose livers an oil is manufactured. These cartilaginous fish themselves have no free fat at all in 20 connexion with the flesh or with the stomach. The suet in fish is fatty, and does not solidify or congeal. All animals are furnished with fat, either intermingled with their flesh, or apart. Such as have no free or separate fat are less fat than others in stomach and omentum, as the cel; for it has only a scanty supply of suct about the 25 omentum. Most animals take on fat in the belly, especially such animals as are little in motion.

The brains of animals supplied with fat are oily, as in the pig; of animals supplied with suet, parched and dry. ${ }^{1}$ But it is about the kidneys ${ }^{2}$ more than any other viscera that animals are inclined to take on fat; and the right kidney is always less supplied with fat than the left kidney, 30 and, be the two kidneys ever so fat, there is always a space devoid of fat in between the two. Animals supplied with suet are specially apt to have it about the kidneys, and especially the shecp; for this animal is apt to dic from its kidneys being cntirely cnveloped. Fat or suct about the kidney is superinduced by overfeeding, as is found at $520^{\text {b }}$ Lcontini in Sicily; and consequently in this district they defer driving out sheep to pasture until the day is well on, with the view of limiting their food by curtailment of the hours of pasture.

The part around the pupil of the eye is fatty ${ }^{3}$ in all 18 animals, and this part resembles suet in all animals that 5 possess such a part and that are not furnished with hard eyes. ${ }^{4}$

Fat animals, whether male or female, are more or less unfitted for brecling purposes." Animals are disposed to

1 The corresponding statement in the $P . A$. is of the marrow, not of the brain.

${ }^{2}$ P.A. iii. 9. $672^{a} 2$; Plin. xi. Sr.

3 miov is A. and W.'s emendation for knєvóv; cf. de Sensu, 2. $438^{\text {n }} 20$

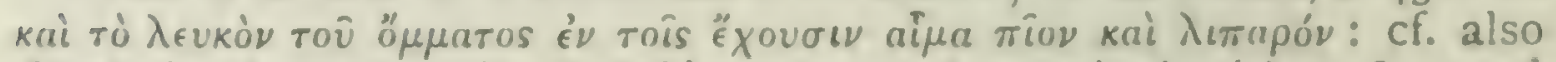

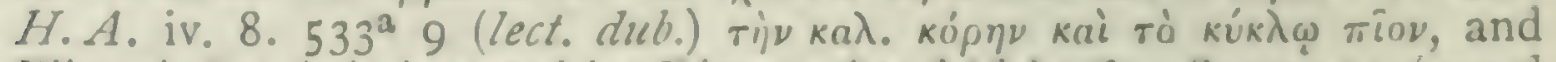
P'lin. xi. 85; it is inserted by Dittm. after iqqeaipuis. Scotus tr. "quod prope pupillam oculi est, in omnibus animalibus est multi sebi'.

i. e. like the crab.

${ }^{5}$ G. A. i. 18. $726^{a} 3$; I'lin. l.c., \&.c. 
take on fat more when old than when young, and especially when they have attained their full breadth and their full length and are beginning to grow depth-ways.

I9 And now to proceed to the consideration of the blood. ro In sanguineous animals blood is the most universal and the most indispensable part ; and it is not an acquired or adventitious part, but it is a consubstantial part of all animals that are not corrupt or moribund. ${ }^{1}$ All blood is contained in a vascular system, to wit, the veins, and is found nowhere else, excepting in the heart. Blood is not sensitive to touch is in any animal, ${ }^{2}$ any more than the excretions of the stomach; and the case is similar with the brain and the marrow. When flesh is lacerated, blood exudes, if the animal bc alive and unless the flesh be gangrened. Blood in a healthy condition is naturally sweet to the taste, ${ }^{3}$ and red in colour; 20 blood that deteriorates from natural decay or from disease

more or less black. Blood at its best, before it undergoes deterioration from either natural decay or from discase, is neither very thick nor very thin. In the living animal it is always liquid and warm, but, on issuing from the body, it coagulates in all cases except in the case of the deer, the roe, and the like animals; for, as a general rule, blood 25 coagulates unless the fibres be extracted. ${ }^{4}$ Bull's blood is the quickest to coagulate. ${ }^{5}$

Arimals that are internally and externally viviparous are more abundantly supplied with blood than the sanguineous ovipara. ${ }^{6}$ Animals that are in good condition, either from natural causes or from their health having been 30 attended to, have the blood neither too abundant-as creatures just after drinking have the liquid inside them in abundance-nor again very scanty, as is the case with animals when exccedingly fat. For animals in this condition have pure blood, but very little of it, and the fatter

1 Plin. xi. 90.

P.A. iv. 2. $677^{3} 20$.

${ }^{\circ}$. A. ii. $4.65 \mathrm{I}^{\mathrm{a}} \mathrm{I}$.

${ }^{2} P \cdot A \cdot$ ii. $3 \cdot 650^{\mathrm{b}} 4$.

${ }^{4}$ Cf. $515^{\mathrm{b}} 34$.

- A doubtful sentence, probably leaving a lacuna.

AR. II.A. 
an animal gets the less becomes its supply of blood; for whatsoever is fat is destitute of blood.

$521^{\mathrm{a}}$ A fat substance is incorruptible, but blood and all things containing it corrupt rapidly, and this property characterizes especially all parts connected with the bones. Blood is finest and purest in man; and thiclest and blackest in the bull and the ass, of all vivipara. ${ }^{1}$ In the lower and the ${ }_{5}$ higher parts of the body blood is thicker and blacker than in the central parts. ${ }^{2}$

Blood beats or palpitates in the veins of all animals alike all over their bodies, and blood is the only liquid that permeates the entire frames of living animals, without exception and at all times, as long as life lasts. Blood is developed first of all in the heart of animals ${ }^{3}$ before the ro body ${ }^{4}$ is differentiated as a whole. If blood be removed or if it escape in any considerable quantity, animals fali into a faint or swoon; if it be remored or if it escape in an exceedingly large quantity they die. If the blood get exceedingly liquid, animals fall sick; for the blood then turns into something like ichor, or a liquid so thin that it at times has been known to exude through the pores like sweat. In some cases blood, when issuing from the veins, I5 does not coagulate at all, or only here and there. Whilst animals are sleeping the blood is less abundantly supplied near the exterior surfaces, so that, if the sleeping creature be pricked with a pin, the blood does not issue as copiously as it would if the creature were awake. Blood is developed out of ichor by coction, and fat in like manner out of blood. If the blood get diseased, haemorhoids may ensue in the nostril or at the anus, or the reins may become varicose. $20 \mathrm{Blood}$, if it comupt in the body; has a tendency to turn into pus, and pus may turn into a solid concretion.

Blood in the female differs from that in the male, for, supposing the male and female to be on a par as regards agre and general health, the blood in the female is thicker and blacker than in the male; and with the female there is

1 Plin. xi. 90.

3 P.A. ii. 4. $666^{a} 7$, ' 24 , Sc.
${ }^{2}$ Cf. P. A. ii. $2.647^{\mathrm{b}} 34$.

- sc. of the embryo. 
a comparative superabundance of it in the interior. Of all 25 female animals the female in man is the most richly supplied with blood, ${ }^{1}$ and of all female animals the menstruous discharges are the most copious in woman. ${ }^{2}$ The blood of these discharges under disease turns into flux. Apart from the menstrual discharges, the female in the human species is less subject to diseases of the blood than the male.

Women are seldom afflicted with varicose veins, with haemorrhoids, or with bleeding at the nose, and, if any of 30 these maladies supervene, the menses are imperfectly discharged. ${ }^{3}$

Blood differs in quantity and appearance according to age; in very young animals it resembles ichor and is abundant, in the old it is thick and black and scarce, and in middle-aged animals its qualities are intermediate. In old animals the blood coagulates rapidly, even blood at the $5 \mathbf{2 1}^{\mathrm{b}}$ surface of the body; but this is not the case with young animals. Ichor is, in fact, nothing else but unconcocted blood: either blood that has not yet been concocted, or that has become fluid again.

20 We now proceed to discuss the properties of marrow; ${ }^{4}$ for this is one of the liquids found in certain sanguineous 5 animals. All the natural liquids of the body are contained in vessels: as blood in veins, marrow in bones [and other moistures in membranous structures of the skin or gut]. ${ }^{5}$

In young animals the marrow is exceedingly sanguineous, but, as animals grow old, it becomes fatty in animals supplied with fat, and suet-like in animals with suet. All bones, ro however, are not supplied with marrow, but only the hollow ones, and not all of these. For of the bones in the lion some contain no marrow at all, and some are only scantily supplied therewith; and that accounts, as was previously observed, ${ }^{6}$ for the statement made by certain writers that the lion is marrowless. In the bones of pigs it is found in $I_{5}$

1 G. A. iv. I. $765^{\text {b }}$ is.

${ }^{2}$ Cf. G. A. i. I9, \&c.

${ }^{3}$ Cf. H.A. vii. I1. $587^{\mathrm{b}} 33$; G. A. i. 19. $727^{\mathrm{a}}$ I2, \&c.

1 P.A. ii. 6 ; Plin. xi. 86.

5 del. A. and W., Dittm.

${ }^{6}$ Cf. $5^{16^{\mathrm{b}}} 7$. 
small quantities; and in the bones of certain animals of this species it is not found at all.

These liquicls, then, are nearly always congenital in animals, but milk and sperm come at a later time. Of these latter, that which, whensoever it is present, is secreted in all cases ready-made, is the milk; ${ }^{1}$ sperm, on the other 20 hand, is not secreted out in all cases, but in some only, as in the case of what are designated thori in fishes. ${ }^{2}$

Whatever animals have milk, have it in their breasts. ${ }^{3}$ All animals have breasts that are internally and externally viviparous, as for instance all animals that have hair, as man and the horse; and the cetaceans, as the dolphin, the porpoise, ${ }^{4}$ and the whale-for these animals have breasts and 25 are supplied with milk. Animals that are oviparous or only externally viviparous have neither breasts nor milk, as the fish and the bird. ${ }^{5}$

All milk is composed of a watery serum called 'whey', and a consistent substance called curd (or cheese); and the thicker the milk, the more abundant the curd. The milk, then, of non-ambidentals coagulates, ${ }^{6}$ and that is why cheese

30 is made of the milk of such animals under domestication; but the milk of ambidentals does not coagulate, nor their fat cither, and the milk is thin and sweet. Now the camel's milk is the thinnest, and that of the human species next after it, and that of the ass next again, but cow's milk is the thickest. Milk does not coagulate under the influence of cold, but

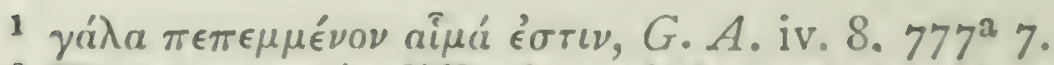

2 The passage is difficult, and the text not above suspicion. I accept Schneider's interpretation ( (ur. post. vol. iv. p. 333), 'Quemadmodum lac paratum et in mammis collectum adest, ita seme'n collectum et paratum ad coitum non adest in animalibus aut rase aliquo, relut lac mammis, continctur, practer genus piscium in quo oi topoi qui appellantur cum mammis feminarum comparari possunt.' Cf. $(i . A$. i. 5.

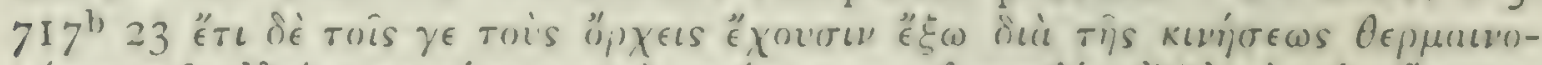

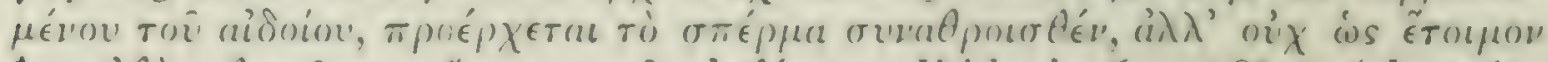

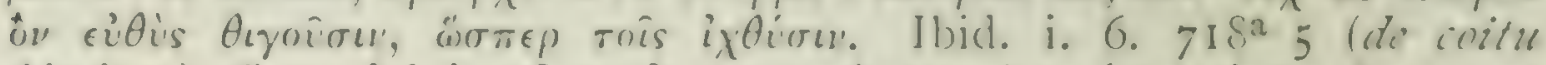

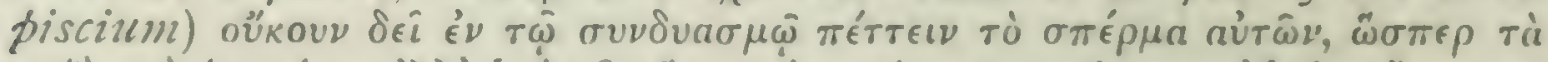

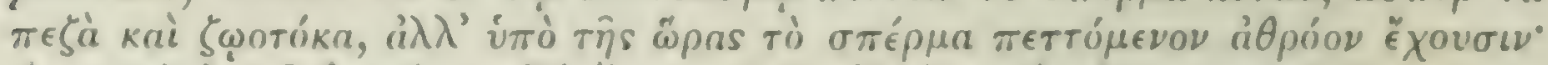

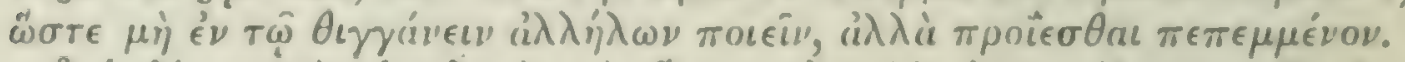

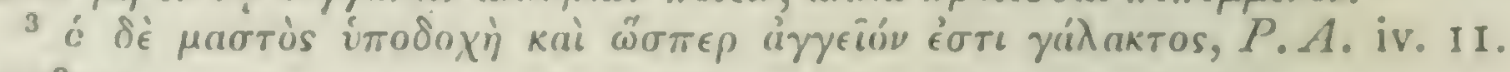
$692^{\mathrm{a}}$ II.

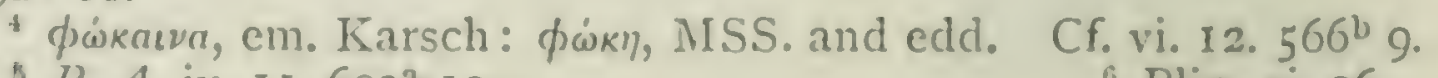

${ }^{5}$ P.A. iv. I1. $692^{\mathrm{a}}$ 10.

${ }^{6}$ Plin. xi. 96. 
rather runs to whey; but under the influence of heat it coagulates and thickens. ${ }^{1}$ As a general rule milk only comes to animals in pregnancy. When the animal is pregnant milk is found, but for a while it is unfit for use, ${ }^{2}$ and then after an interval of usefulness it becomes unfit for use again. In the case of female animals not pregnant a small quantity of milk has been procured by the employment of special food, and cases have been actually known where 5 women advanced in years on being submitted to the process of milking have produced milk, and in some cases have produced it in sufficient quantities to enable them to suckle an infant.

The people that live on and about Mount Oeta take such she-goats as decline the male and rub their udders hard with nettles to cause an irritation amounting to pain; hereupon they milk the animals, procuring at first a liquid resembling blood, then a liquid mixed with purulent to matter, and eventually milk, as freely as from females submitting to the male.

As a general rule, milk is not found in the male of man or of any other animal, though from time to time it has been found in a male; for instance, once in Lemnos a he-goat was milked by its dugs (for it has, by the way, two dugs close to the penis), and was milked to such effect that I5 cheese was made of the produce, and the same phenomenon was repeated in a male of its own begetting. ${ }^{3}$ Such occurrences, however, are regarded as supernatural and fraught with omen as to futurity, and in point of fact when the Lemnian owner of the animal inquired of the oracle, the god informed him that the portent foreshadowed the acquisition of a fortune. With some men, after puberty, milk

1 Galen, vi. $694 \mathrm{~K}$; Plin. l.c. Cf. G. A. iv. $4 \cdot 772^{\mathrm{a}} 22$.

2 This first milk, and not (as L. and S. have it) the $\pi v \in \tau^{\prime} a$ of $522^{\mathrm{b}} 3$, is known as 'beestings', lat. colostra: cf. Plin. xxviii. 33 'est autem colostra prima a partu spongiosa densitas lactis', also ibid. xi. 96 ; Martial. xiii. 38 'Surripuit pastor quae nondum stantibus haedis, De primo matrum lacte colostra damus'. See also Colum. vii. 3 ; Antig. Mirab. 26.

${ }^{3}$ Cf. Antig. Mirab. 26. The phenomenon has been reobserved; cf. Beckmann in loc. Antig. 'Quid quod in vicinia nostra vidimus olim hircum, qui magno cum lucro quotidie mulgebatur atque dux erat et maritus caprarum? 
zo can be produced by squeezing the breasts; cases have been known where on their being subjected to a prolonged milking process a considerable quantity of milk has been educed.

In milk there is a fatty element, which in clotted milk gets to resemble oil. 'Goat's milk is mixed with sheep's milk in Sicily, and wherever shecp's milk is abundant. ${ }^{2}$ The best milk for clotting is not only that where the cheese is most abundant, but that also where the cheese is driest. ${ }^{3}$

25 Now some animals produce not only enough milk to rear their young, but a superfluous amount for general use, for cheese-making and for storage. This is especially the case with the shcep and the goat, and next in degree with the cow. Mare's milk, by the way, and milk of the she-ass are mixed in with Phrygian cheese. And there is more cheese in cow's milk than in goat's milk; for grazicrs tell us that 30 from nine gallons of goat's milk they can get nineteen cheeses at an obol apiece, and from the same amount of cow's milk, thirty. Other animals give only enough of milk to rear their young withal, and no superfluous amount and none fitted for cheese-making, as is the case with all animals

$\mathbf{5 2 2}^{\mathrm{b}}$ that have more than two breasts or dugs; for with nonc of such animals is milk produced in superabundance or used for the manufacture of cheese.

The juice of the fig and rennet ${ }^{4}$ are employed to curdle milk. The fig-juice is first squeezed out into wool; the wool is then washed and rinsed, and the rinsing put into a little milk, and if this be mixed with other milk it curdles 5 it. Rennet is a kind of milk, for it is found in the stomach of the animal while it is yet suckling.

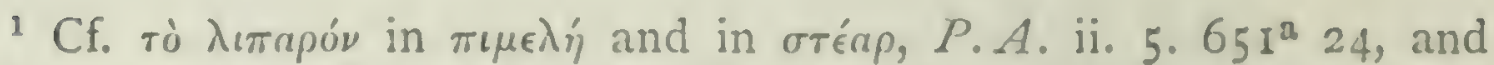

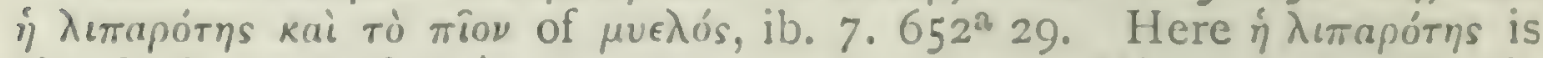

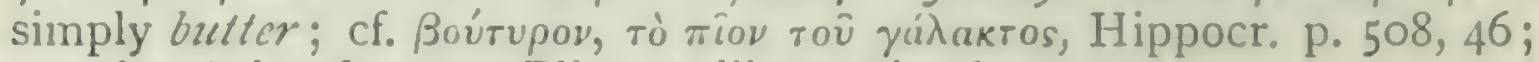
see also Arist. fr. 593; Plin. xxviii. 35, xi. 96.

2 Schn., Bk., and most MSS. read $\pi \lambda \epsilon i o v$, which, however, both

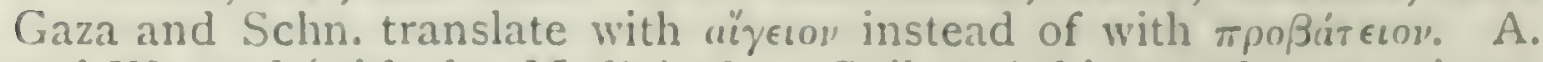
and W. read (with the Medic.) Tiov; Guil. tr. 'ubi coagulum caprinum miscent', as though he read mvov. Hence we might conjecture as a

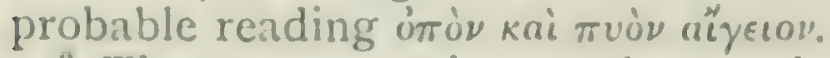

9 The statement is not clear. aúxumpurraton perhaps means 'least fatty', as it does when applied to the brain, supra, 17. $520^{2} 27$.

P.A. iii. I 5 . $676^{a} 6$. 
2I Rennet then consists of milk with an admixture of fire, ${ }^{1}$ which comes from the natural heat of the animal, as the milk is concocted. ${ }^{2}$ All ruminating animals produce rennet, and, of ambidentals, the hare. ${ }^{3}$ Rennet improves in quality the longer it is kept; and cow's rennet, after ro being kept a good while, and also hare's rennet, is good for diarrhoea, and the best of all rennet is that of the young deer.

In milk-producing animals the comparative amount of the yield varies with the size of the animal and the diversities of pasturage. For instance, there are in Phasis small cattle that in all cases give a copious supply of milk, and I $_{5}$ the large cows in Epirus ${ }^{4}$ yield each one daily some nine ${ }^{5}$ gallons of milk, and half of this from each pair of teats, ${ }^{6}$ and the milker has to stand erect, stooping forward a little, as otherwise, if he were seated, he would be unable to reach up to the teats. But, with the exception of the ass, all the quadrupeds in Epirus ${ }^{7}$ are of large size, and, relatively, the 20 cattle and the dogs are the largest. Now large animals require abundant pasture, and this country supplies just such pasturage, and also supplies diverse pasture grounds to suit the diverse seasons of the year. The cattle are particularly large, and likewise the sheep of the so-called Pyrrhic breed, the name being given in honour of King Pyrrhus.

Some pasture quenches milk, as Median grass or lucerne, ${ }^{8}$ and that especially in ruminants; other feeding renders it copious, as cytisus and vetch; only, by the way, cytisus in

1 A. and W. read (with Med. and Reg. marg.) Tupóv, '́k $\delta \dot{\epsilon} \tau \hat{\eta} s$, but the reading $\pi \hat{v} \rho$ ô $\epsilon^{\prime} \kappa \tau \hat{\eta} s$ is strengthened by $G$. $A$. ii. $4.739^{b} 22$ kai yà $\rho$

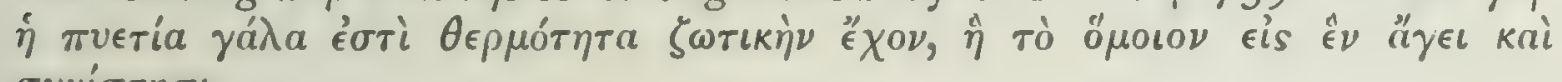

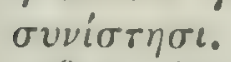

$2 \mathrm{sc}$. in its stomach.

3 Varro, R. R. ii. I ; Plin. l.c. \&c.

${ }_{4}$ H. A. viii. 7. 595 $5^{\mathrm{b}} 8$; Plin. viii. 70; Ael. iii. 33, xii. I I ; Ath. ix. 376 ; Varro, R. R. ii. 5 ; Colum. vi. I, \&c.

${ }_{5}$ Four gallons is a fair average yield; a very good cow may give seven.

'We should have expected ' at each of the two milkings' ; accord-

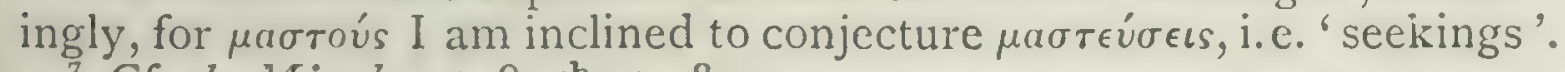

${ }_{7}$ C. de Mirab. 75. $835^{\mathrm{b}} 27$, \&c.

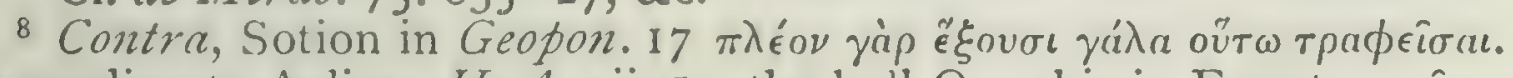

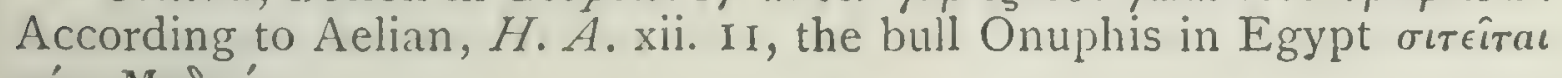

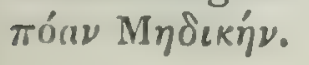


flower is not recommended, as it has burning properties, and vetch is not good for pregnant kine, as it causes increased 30 difficulty in parturition. ${ }^{1}$ However, beasts that have access to good feeding, as they are benefited thereby in regard to pregnancy, so also being well nourished produce milk in plenty. Some of the leguminous plants ${ }^{2}$ bring milk in abundance, as for instance, a large feed of beans with the ewe, the common she-goat, the cow, and the small she$5^{2} 3^{\mathrm{a}}$ goat; for this feeding makes them drop their udders. And, by the way, the pointing of the udder to the ground before parturition is a sign of there being plenty of milk a-coming.

Milk remains for a long time in the female, if she be kept from the male and be properly fed, and, of quadrupeds, this 5 is especially true of the ewe; for the ewe can be milked for eight months. As a general rule, ruminating animals give milk in abundance, and milk fitted for cheese manufacture. In the neighbourhood of Torone cows run dry for a few clays before calving, and have mill all the rest of the time. In women, milk of a livid colour is better than white for ro nursing purposes; and swarthy women give healthier milk than fair ones. Milk that is richest in cheese is the most nutritious, but milk with a scanty supply of cheese is the more wholesome for children.

All sanguincous animals eject sperm. ${ }^{3} \quad$ As to what, and 22 how, it contributes to generation, these questions will be discussed in another treatise. Taking the size of his body ${ }_{15}$ into account, man emits more sperm than any other animal. In hairy-coated animals the sperm is sticky, but in other animals it is not so. It is white in all cases, and Herodotus is under a misapprehension when he states that the Acthiopians eject black sperm. ${ }^{4}$

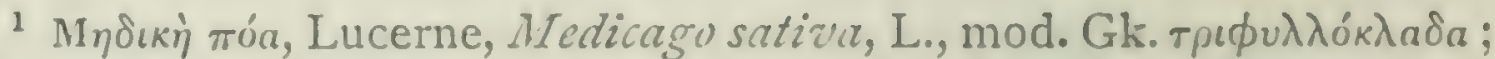
cf. Diosc. 2. I77, Plin. xviii. 43, Colum. ii. Io, Pallad. v. I, Varro, $R$. $R$. i. 42, Scc. kútıбos, Medicago arborea, L., Diosc. iv. 113, Plin. xiii. 47, Colum. ii. I I, Verg. Ecl. i. 79, G. ii. 430 ; cf. Paulet, Flore de Virg. p. 33 , S.c.; the chief of fodder-plants in antiquity. öpoßos, Vicia

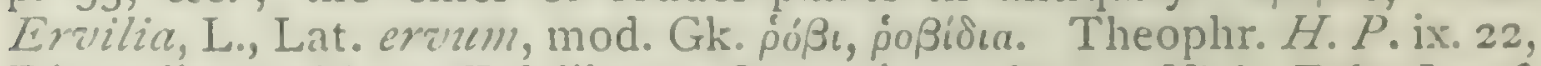

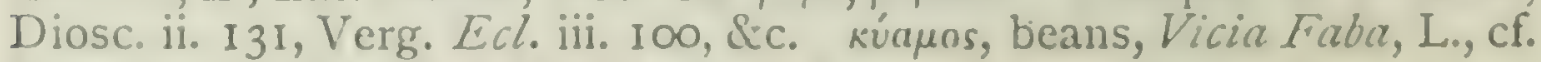
Theophr. H. P. viii. 3, Plin. xviii. 7, \&c.

$2 \mathrm{Or}$, as commonly translated, 'substances that induce flatulency.' See note, vii. 12. $588^{\text {a }} 8$. Cf. viii. $7.595^{\text {h }} 6$, Herod. iv. 2.
${ }^{y}$ G. A. ii. 2-4, Sic.
Herod. iii. IOI ; G. A. ii. $2.736^{2}$ Io. 
Sperm issues from the body white and consistent, if it be healthy, and after quitting the body becomes thin and 20 black. In frosty weather it does not coagulate, but gets exceedingly thin and watery both in colour and consistency; but it coagulates and thickens under the influence of heat. If it be long in the womb before issuing out, it comes more than usually thick; and sometimes it comes out dry and compact. Sperm capable of impregnating or of fructification sinks in water; sperm incapable of producing that 25 result dissolves away. But there is no truth in what Ctesias has written about the sperm of the elephant. ${ }^{1}$

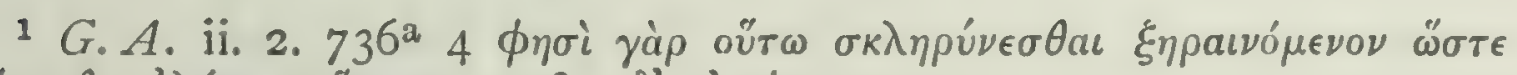

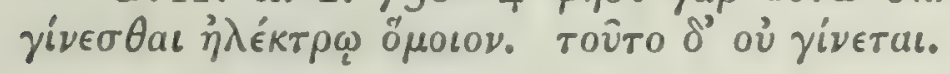




\section{BOOK IV}

$523^{\text {a }}$ We have now treated, in regard to blooded animals, of $\mathbf{I}$

$3^{r}$ the parts they have in common and of the parts peculiar to this genus or that, and of the parts both composite and $523^{\text {b }}$ simple, whether without or within. We now proceed to treat of animals devoid of blood. These animals are divided into several genera.

One genus consists of so-called 'molluscs'; and by the term 'mollusc' we mean an animal that, being devoid of blood, has its flesh-like substance outside, and any hard structure it may happen to have, inside-in this respect resembling the red-blooded animals,-such as the genus of the cuttle-fish.

5 Another genus is that of the malacostraca. These are animals that have their hard structure outside, and their soft or flesh-like substance inside, and the hard substance belonging to them has to be crushed rather than shattered; and to this genus belongs the crawfish and the crab.

A third genus is that of the ostracoderms or 'testaceans'. These are animals that have their hard substance outside io and their flesh-like substance within, and their hard substance can be shattered but not crushed; and to this genus belong the snail and the oyster.

The fourth genus is that of insects; and this genus comprehends numerous and dissimilar species. Insects are creatures that, as the name implies, have nicks either on the belly or on the back, or on both belly and back, and have If no one part distinctly osseous and no one part distinctly fleshy, but are throughout a something intermediate between bone and flesh; that is to say, their body is hard all through, inside and outside. Some insects are wingless, such as the iulus and the centipede; some are winged, as the bee, the cockchafer, and the wasp; and the same kind 
is in some cases both winged and wingless, ${ }^{1}$ as the ant and 20 the glow-worm.

In molluscs ${ }^{2}$ the external parts are as follows: in the first place, the so-called fcet; secondly, and attached to these, the head; thirdly, the mantle-sac, containing the internal parts, and incorrectly designated by some writers the head; ${ }^{3}$ and, fourthly, fins round about the sac. In all molluscs 25 the head is found to be between the feet and the belly. All molluscs are furnished with eight feet, and in all cases these feet are severally furnished with a double row of suckers, with the exception of one single species ${ }^{4}$ of poulpe or octopus. ${ }^{5} \quad$ The sepia, the small calamary and the large calamary have an exceptional organ in a pair of long arms 30 or tentacles, having at their extremities a portion rendered rough by the presence of two rows of suckers; ${ }^{6}$ and with these arms or tentacles they apprehend their food ${ }^{7}$ and draw it into their mouths, and in stormy weather they cling by them to a rock and sway about in the rough water like ships lying at anchor. ${ }^{8}$ They swim by the aid of the fins $524^{\mathrm{a}}$ that they have about the sac. In all cases their feet are furnished with suckers.

The octopus, by the way, uses his feelers either as feet or hands; with the two which stand over his mouth he draws in food, and the last $^{3}$ of his feelers he employs in the 5

${ }^{1}$ P. A. i. $3 \cdot 643^{\mathrm{b}} 2$.

2 i.e. in the Cephalopods; P.A. iv. 9, \&c.; G. A. i. 15 ; Plin. ix. 44 ; cf. Aubert, die Cephalopoden des Aristoteles, Leipzig, I 862 (Z.f. *u.Z. xii); Apostolides and Delage, Les Mollusques d'aprìs Aristote, Arch.zool. exp. et gén. ix. pp. 305-420, I88I.

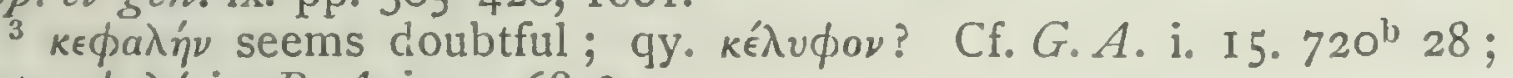
but $\kappa \in \phi a \lambda \dot{\eta}$ in $P$. A. iv. $9.685^{\text {a }} 5$.

${ }^{4}$ viz. the genus Eledone; cf. Leach, Zool. Misc., Cephalop. iii. p. 138, I817.

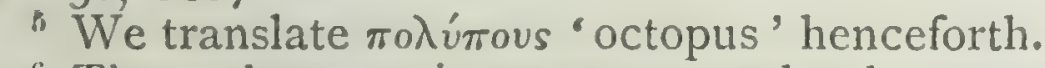

" The suckers are in two rows on the short arms, but more numerous

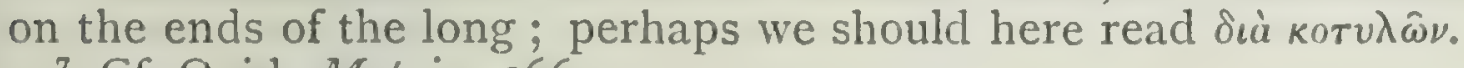

7 Cf. Ovid, Met. iv. 366.

8 P.A. jv. 9. $685^{\text {b }}$; Plin. ix. 28 ; Athen. vii. 9. 373. Hom. Od. v. 432 ; Phocyl. The observation is confirmed by Apostolides and Delage, l.c., p. 407.

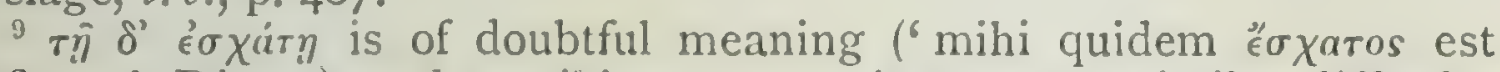
infimus', Dittm.), and possibly corrupt: it presents similar difficulty in a similar passage, still more certainly corrupt, in $P . A$. iv. 9. $685^{a}$ I6. 
act of copulation ${ }^{1}$ and this last one, by the way, is extremcly sharp, is exceptional as being of a whitish colour,

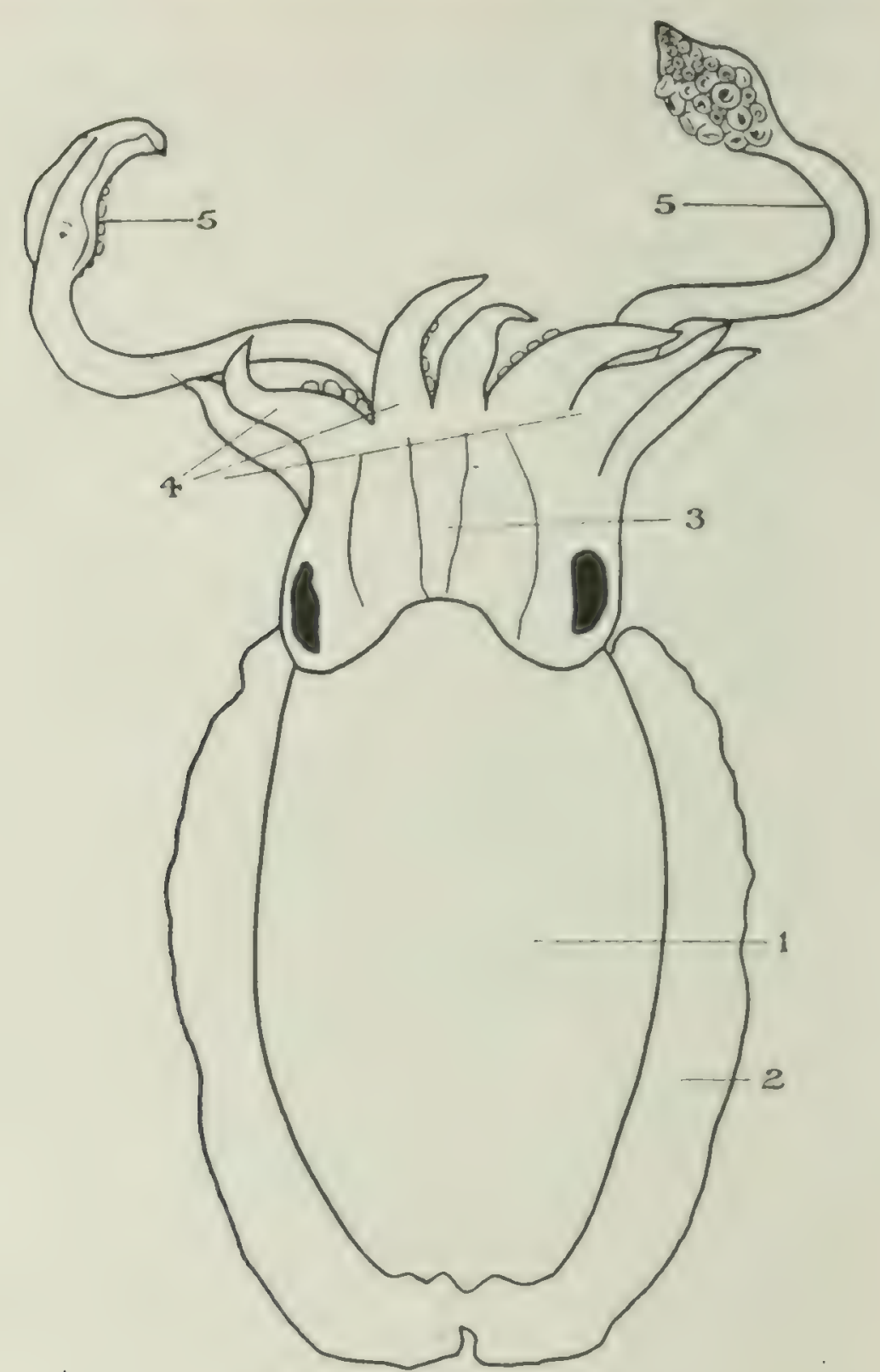

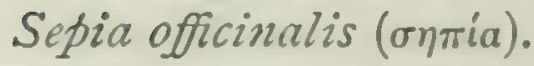

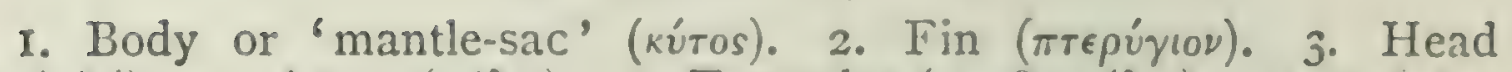

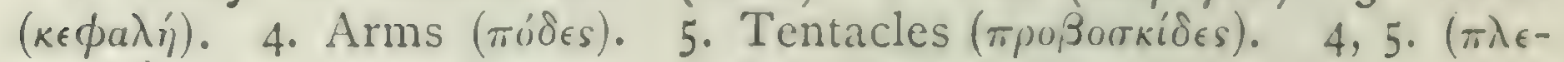
ктivar).

and at its extremity is bifurcate; that is to say, it has an additional something ${ }^{2}$ on the rachis, and by rachis is meant

${ }^{1}$ H. A.v. 6. $54 \mathrm{I}^{\mathrm{b}} \mathrm{I} ;$ G. A. i. I 5. $721^{\mathrm{a}}$ I 5, iii. 8. $757^{\mathrm{b}} 3 \mathrm{I}$; Plin. ix. 74.

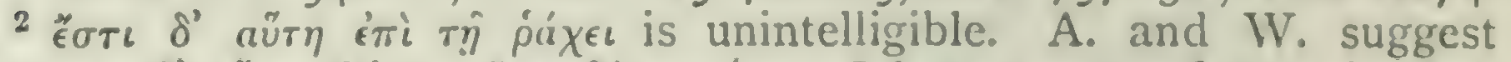

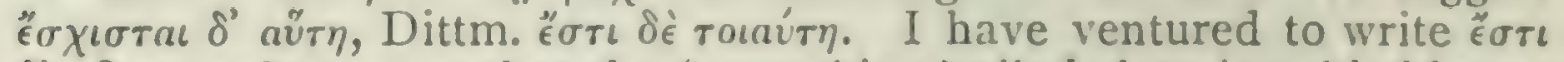
$\delta^{\prime} a v^{3} \tau \iota$, and suppose that the 'something' alluded to is a bladder or

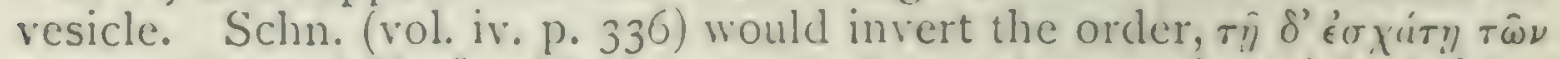

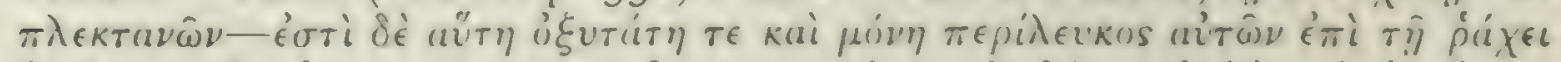

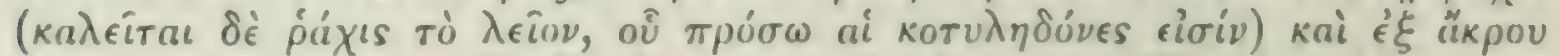

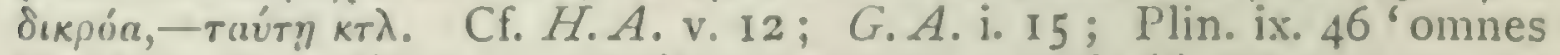
brachiis ut pedibus et manibus utuntur: cauda(?) vero, quae est bisulca et acuta, in coitu' (where we are tempted to read something like caliz'a una earum): ibid. 74 "polypi crine uno feminae naribus annexo coetunt'. That $\mathrm{A}$. described the 'hectocotylized' arm of an 
the smooth surface or edge of the arm on the far side from the suckers.

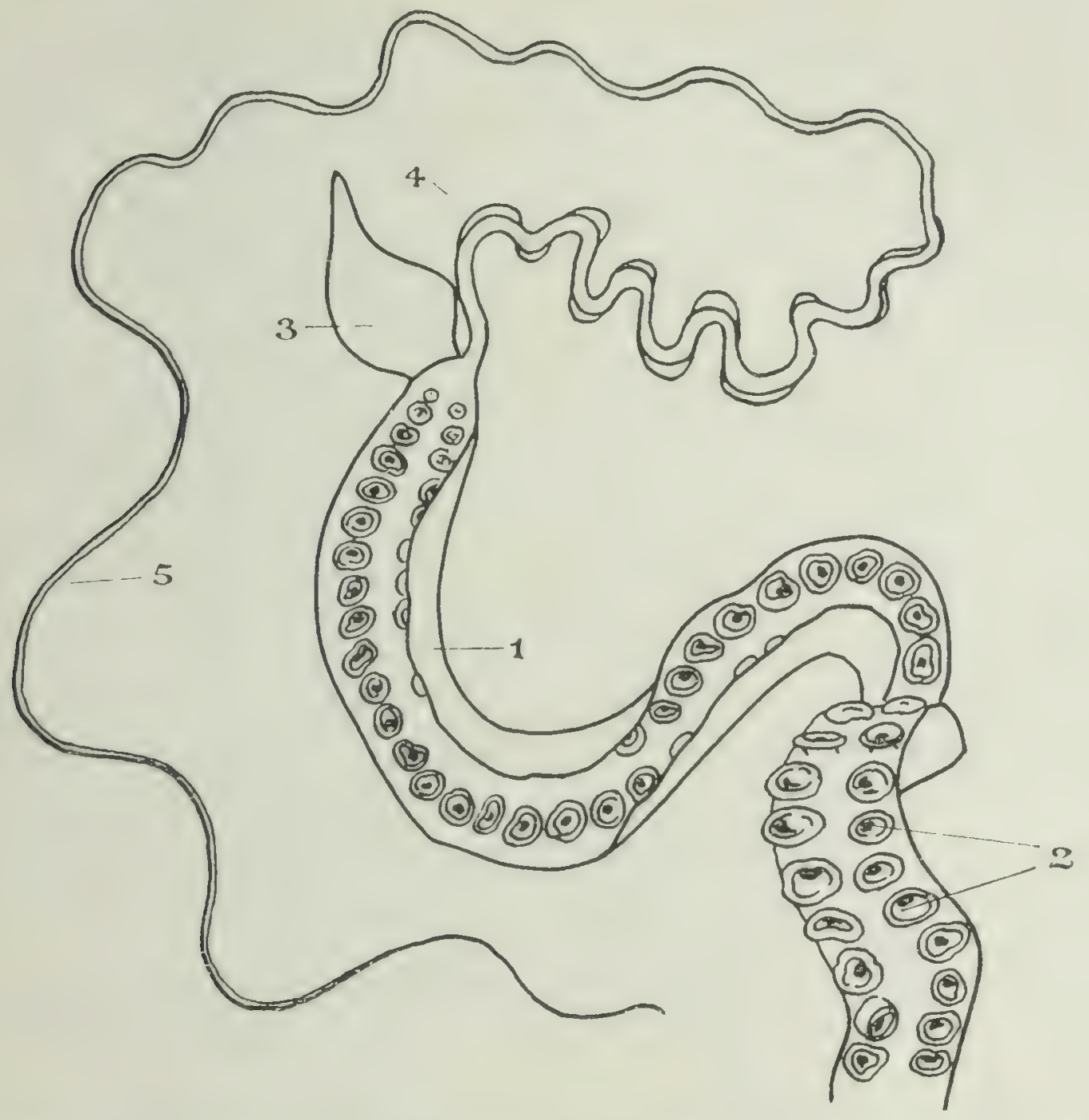

Hectocotylized arm of an Octopus (Philonexis catenulatus $=$ Ocythoe tuberculata).

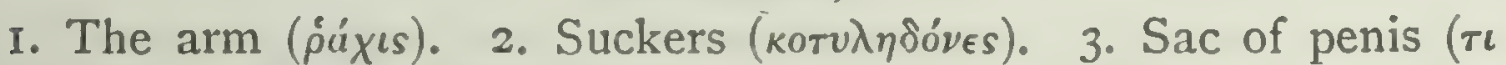

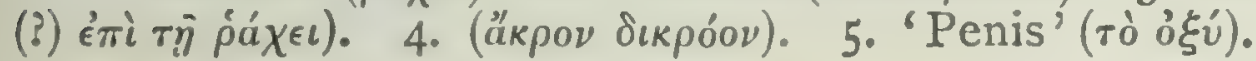

In front of the sac and over the feelers they have a hollow tube, by means of which they discharge any sea- Io water that they may have taken into the sac of the body

Octopod is clear, but to elucidate the details of his description is not easy ; indeed Aubert is inclined to think that A. had in mind some species not studied by modern naturalists. The arm is but slightly modified in the common Cctopus, typical hectocotylization being only found in Argonauta, Tremoctopus, and Philonexis. In these (and to one or other of them I take the description to refer) the arm, when freed from a special sac in which it is at first contained, has a long hollow terminal filament (the 'penis' of modern nomenclature, by which the spermatophores are transmitted), and at its base another sac, or the remains thereof, within which the filament had developed. Cf. Vérany, Ann.Sc. Nat. xvii.pp. 148-191, 1852; H. Müller, Z.f. w. Z. iv. 1852, pp. I-35, 346-59; Steenstrup, Arch. f. Naturg., 1856, p. 243, and especially Aubert, op. cit. 
in the act of recciving food by the mouth. ${ }^{3}$ They can shift the tube from side to side, and by means of it they clischarge the black liquid peculiar to the animal.

Stretching out its fect, it swims ${ }^{2}$ obliquely in the direction of the so-called head, ${ }^{3}$ and by this mode of swimming I5 it can see in front, for its cyes are at the top, and in this attitude it has its mouth at the rear. The 'head', while the creature is alive, is hard, and looks as though it were inflated. ${ }^{4}$ It apprehends and retains objects by means of the under-surface of its arms, and the membrane in between its fect is kept at full tension; if the animal get on to the sand it can no longer retain its hold.

There is a difference between the octopus and the other molluscs above mentioned: ${ }^{j}$ the body of the octopus is small, and his feet are long, whereas in the others the body is large and the feet short; so short, in fact, that they cannot walk on them. Compared with one another, the teuthis, or calamary, is long-shaped," and the sepia flat25 shaped; and of the calamaries the so-called teuthus is much bigger than the teuthis; for teuthi have been found as much as five ells long. ${ }^{7}$ Some sepiac attain a length of

1 A better description of this region in $G . A . \mathrm{i} .14 .720^{\mathrm{b}} 27^{\mathrm{e} \nu} \mathrm{\nu}$ toís

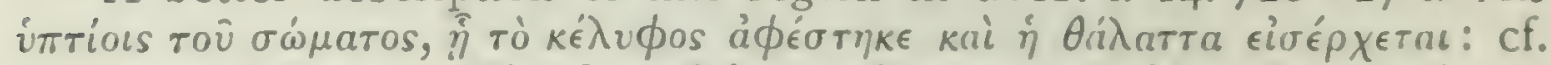
$P . A$. iv. 5. $679^{a} 3$. The funnel is on the ventral side of the animal, but in Octopus, which animal lies prone on its ventral face, the funnel is long enough to curve round one side or other of the head, and so to project dorsally.

${ }_{2} H$. A. i. 5. $489^{a} 35$; Plin. ix. 74 .

3 i.e. of the trunk.

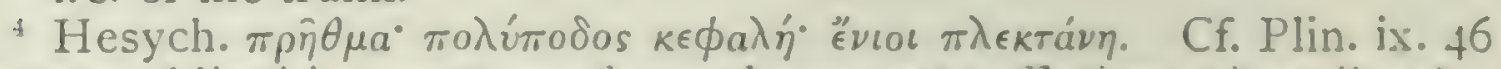
' natant obliqui in caput, quod pracdurum est sufflatione viventibus'.

5 Arist. ap. Athen. vii. p. 326, \&c.

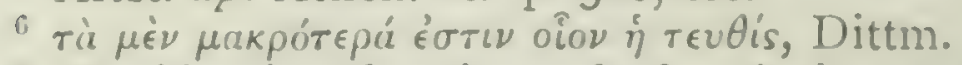

7 The identity of $\tau \in \bar{i} \theta$ os and of $\tau \in v \theta i$ is is not clear. I feel certain that Aubert is far astray in identifying the latter with Sepioteuthis, a small animal of excessive rarity. Leaving out Sepia and Octopus, we have two sorts of cuttlefish conspicuous and abundant in the markets of the Nediterranean, viz. Lolige culsuris and its immediate allies, and the various species of Ommastrephini ; of these latter, one very common species, Todarodes sagitutus (totaro of the Naples fishermen), grows to an immense size. I think that $\tau \in \bar{v} \theta$ os was Todarodes and its

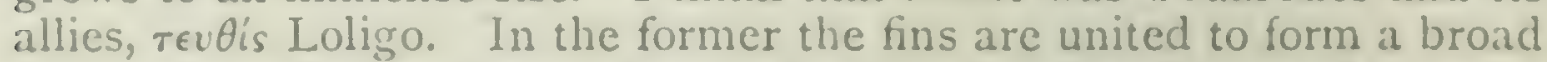
arrow-shaped, sometimes almost circular, fin stretching right across the body (hence calamaio sactia of the Italians); in the latter the fin is longer and divided into two lateral halves, not meeting across the midcle line nor forming one circular fin right across the body : iisi $\mu$ terou 
two ells, and the feelers of the octopus are sometimes as long, or even longer. The species teuthus is not a numerous one; the teuthus differs from the teuthis in shape ; that is, the sharp extremity of the teuthus is broader 30 than that of the other, and, further, the encircling fin goes all round the trunk, whereas it is in part lacking in the teuthis; both animals are pelagic.

In all cases the head comes after the feet, in the middle of the feet that are called arms or feelers. There is here $524^{\mathrm{b}}$ situated $^{1}$ a mouth, and two teeth ${ }^{2}$ in the mouth; and above these two large eyes, and betwixt the eyes a small cartilage enclosing a small brain; and within the mouth it has a minute organ of a fleshy nature, and this it uses as a tongue, for no other tongue does it possess. Next 5 after this, on the outside, is what looks like a sac; the flesh of which it is made is divisible, not in long straight strips, but in annular flakes; and all molluscs have a cuticle around this flesh. ${ }^{3}$ Next after or at the back of the mouth comes a long and narrow oesophagus, and close after that a crop or craw, large and spherical, ${ }^{4}$ like that of a bird; 10

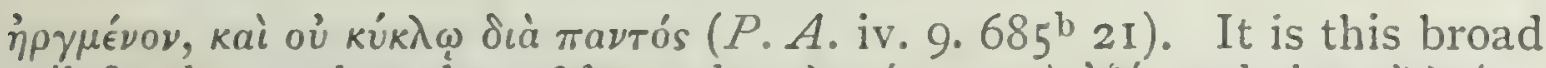
tail-fin that makes the $\tau \epsilon \hat{v} \theta$ os to be $\pi \lambda a \tau \dot{v} \tau \epsilon \rho$ os $\tau \dot{0} \dot{o}^{\xi} \dot{v}^{\prime}$, and that $\epsilon^{\prime} \lambda \lambda \epsilon i \pi \epsilon \iota$

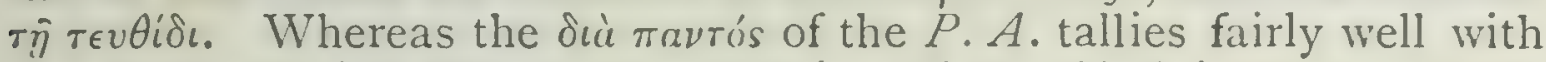

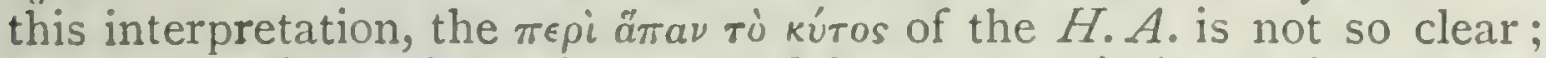
but in the light of the former and better description I do not feel

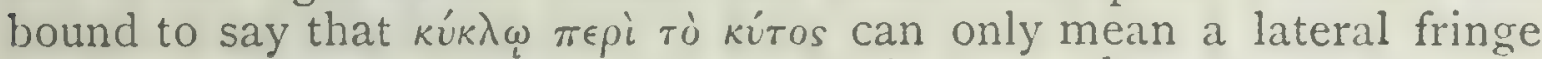
such as we have in Sepia. In $P . A$. iv. $5.678^{\mathrm{b}}$ we read that the alimentary canal is alike in Sepia and Octopus, but in the $\tau \epsilon v \theta i \delta \in s$ the two stomach-cavities resemble one another, and the one is not so like to a crop; this is accurately true of Loligo, whereas the forms which I am inclined to identify with $\tau \epsilon \hat{v} \theta 0 s$, unfortunately not mentioned in this passage, resemble Sepia and Octopus; cf. Cuvier, Mém. sur les

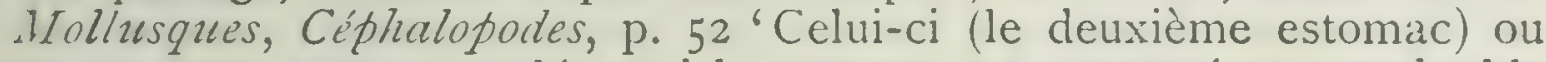
ce que nous avons appelé aussi le coecum, est ramassé en une double et courte spirale dans le calmar sagitté (Todarodes); mais dans le calmar commun (Loligo), il forme un longr sac à parois minces, qui descend jusques dans le fond de l'abdomen, et où l'on ne voit de restige de courbure et de sillons transverses que vers son origine. Le gézier est, comme dans la seiche, charnu et doublé d'une veloutée presque cornée.' An Aristotelian fragment in Athen. vii. p. 326 gives no further help. On a gigantic squid, see Plin. ix. 30 (48).

1 Cf. P.A. iv. 5. $678^{\mathrm{b}} 7,9.684^{\mathrm{b}}$ Io; Ar. $a p$. Athen. vii. p. 323 , \&c.

${ }^{2}$ For $\tau \dot{0} \mu \mu^{\prime} \nu \mathrm{A}$. and W. cj. $\tau \dot{0} \mu \epsilon^{\prime} \sigma o \nu, \mathrm{i}$. e. ' In the middle of the head there is a mouth'.

${ }^{3}$ P.A. ii. 8. $654^{\text {a }}$ I 3 ; Plin. xi. 37 (87).

$4 \pi \alpha \in \mu \phi \in \rho \hat{\eta} \mathrm{P} \mathrm{D}^{\mathrm{a}}$. 
then comes the stomach, like the fourth stomach in ruminants; ${ }^{1}$ and the shape of it resembles the spiral convolution in the trumpet-shell ${ }^{2}$ from the stomach there goes back again, in the direction of the mouth, a thin gut, and the gut is thicker ${ }^{3}$ than the oesophagus.

Molluscs have no viscera, but they have what is called I5 a mytis, ${ }^{4}$ and on it a vessel containing a thick black juice; ${ }^{5}$

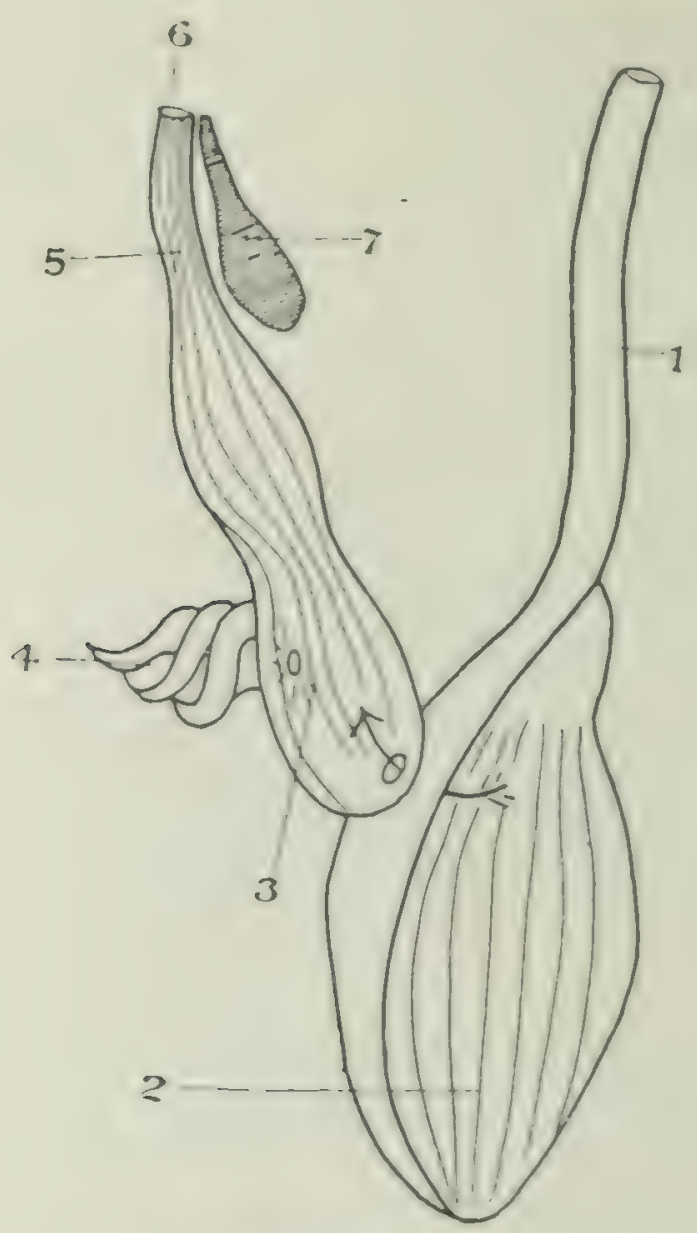

Alimentary canal of Todarodes sagittatus (? tevioos).

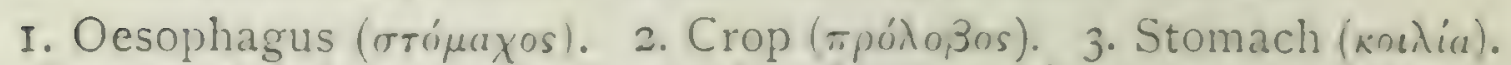

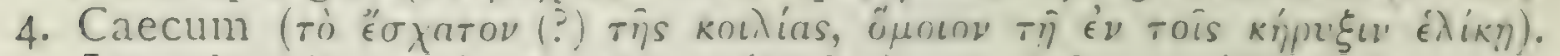

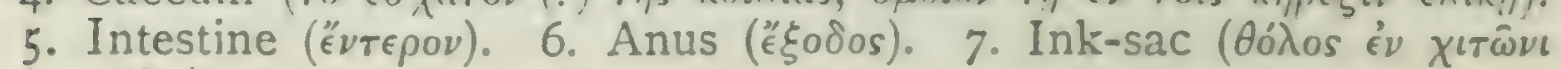
$\dot{v} \mu \in \nu \omega \dot{\delta} \epsilon \iota)$.

in the sepia or cuttle-fish this ressel is the largest, and this juice is most abundant. All molluscs, when frightened,

1 Ar. ap. Athen. l.c., cf. H. A. ii. 17. $507^{\mathrm{b}} 9$.

2 In $T$. sagittatus, Octopus and others, there is a spiral prolongation of the second stomach or caecum; what is here called the crop is nowadays termed the stomach icf. $524^{32} 26$, footnote). For to oxipua we

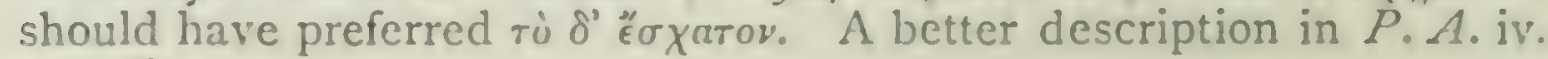
$5.678^{\mathrm{b}} 25$.

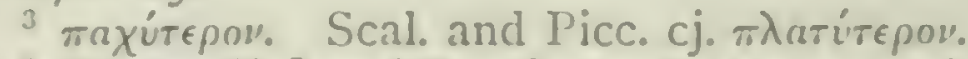

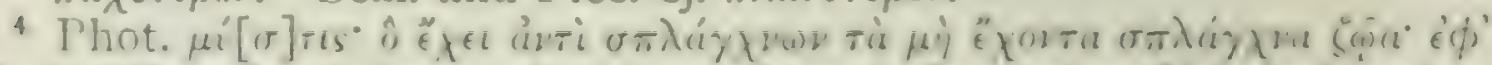

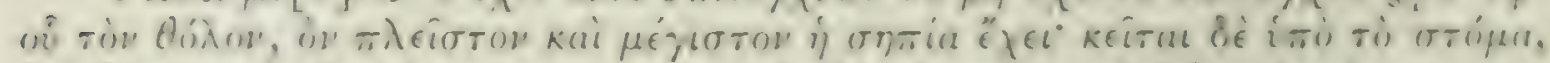

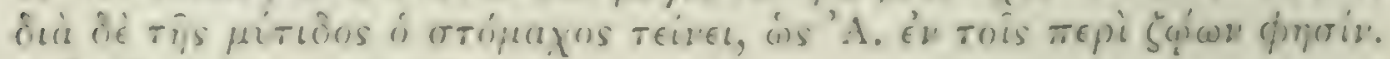

P. A. iv. 5.679 1 . 
discharge such a juice, but the discharge is most copious in the cuttle-fish. The mytis, then, is situated under the mouth, and the oesophagus runs through it; and down below at the point to which the gut extends ${ }^{1}$ is the vesicle of the black juice, and the animal has the vesicle and the gut enveloped in one and the same membrane, and by 20 the same orifice discharges both the black juice and the residuum. The animals have also certain hair-like or furry growths in their bodies. ${ }^{2}$

In the sepia, the teuthis, and the teuthus the hard parts are within, towards the back of the body; those parts are called in one the sepium, and in the other the 'sivord'." They differ from one another, for the sepium in the cuttlefish and teuthus is hard and flat, being a substance inter- 25 mediate between bone and fish-bone, with (in part) a crumbling, spongy texture, but in the teuthis the part is thin and somewhat gristly. These parts differ from one another in shape, as do also the bodies of the animals. The octopus has nothing hard of this kind in its interior, but it has a gristly substance round the head, which, if the animal grows old, becomes hard. ${ }^{4}$

The females differ from the males. The males have a duct in under the oesophagus, extending from the mantle-cavity ${ }^{5}$ to the lower portion of the sac, and there is an organ to which it attaches, resembling a breast; in the female there are two of these organs, situated higher $525^{a}$ up; with both sexes there are underneath these organs certain red formations. The egg ${ }^{b}$ of the octopus is single, uneven on its surface, and of large size; the fluid substance within is all uniform in colour, smooth, and in colour white; the size of the $\operatorname{egg}^{6}$ is so great as to fill a vessel larger than 5

1 sc. before turning back.

2 That these are the gills is rendered more than probable by $H . A$. iv. 4. $529^{\mathrm{a}} 30, \mathrm{ix} .37 .620^{\mathrm{b}} \mathrm{I} 7$, where the gills of the scallop and the crawfish are described under the same name or epithet.

${ }^{3} P$. A. ii. $8.654^{\mathrm{a}} 20$.

4. P.A. ii. 8. $654 ; G . A$. iii. $8.75^{a} 6$; cf. also Arist. ap. Athen. vii. 326.

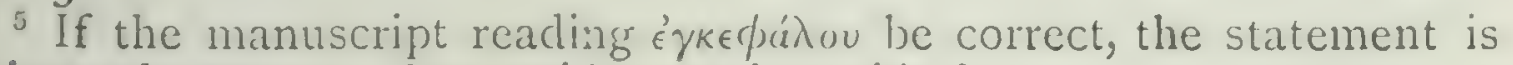
grievously wrong. Qy. $\kappa \in \lambda u ́ \phi o v$, or ẻv $\kappa \in \lambda u ́ \phi \omega ?$

B i.e. the egg-mass.

AR. H.A. 
the creaturc's head. ${ }^{1}$ The sepia has two sacs, and inside them a number of eggs, like in appearance to white hailstones. $^{2}$ For the disposition of these parts I must refer to my anatomical diagrams. ${ }^{3}$

The males of all these animals differ from the females 4 and the difference between the sexes is most marked in the ı sepia; for the back of the trunk, which is blacker than
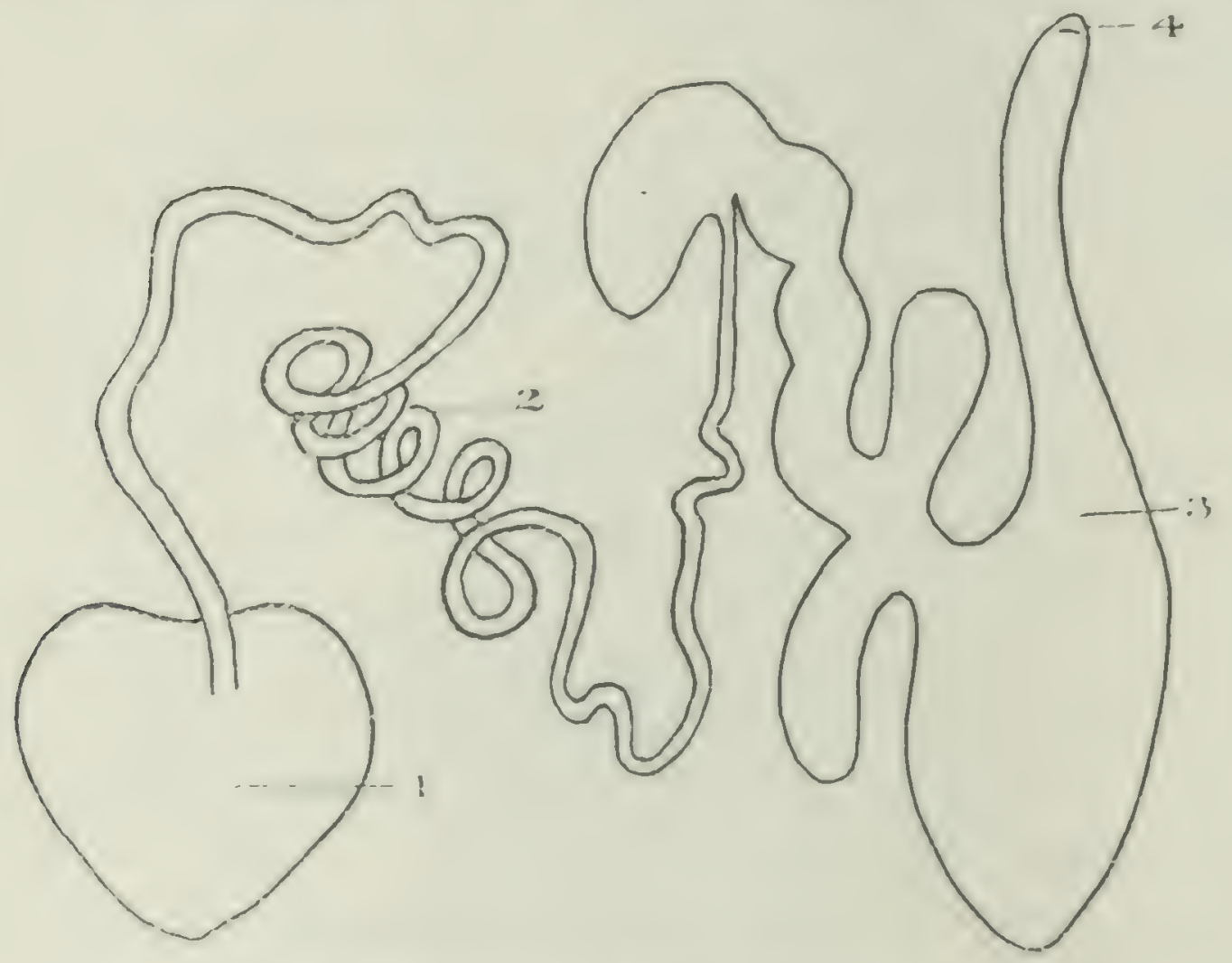

Male organs of Sepiu ofjucimalis.

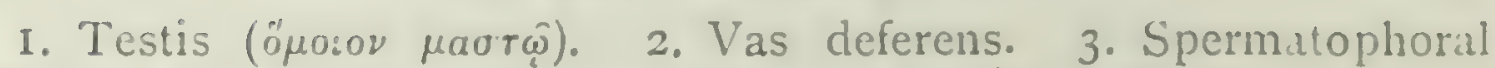

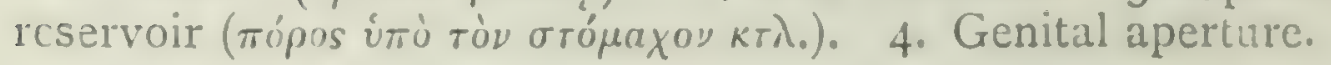

the belly, is rougher in the male than in the female, and in the male the back is striped, and the rump is more sharply pointed.

${ }^{1}$ Cf. Plin. ix. 5 I (74) 'Polypi hieme coeunt, pariunt vere ova tortili vibrata pampino tanta fecunditatc ut multitudinem ororum occisi non recipiant cavo capitis, quo praegnantes tulere'.

$2 \mathrm{FO}^{-1}$ better accounts of the female organs see $G . A \cdot \mathrm{i} .3 \cdot 7 \mathrm{I} 7^{2} 3$, i. $14.720^{\text {b) }} 21$, iii. $8.758^{a} 6$.

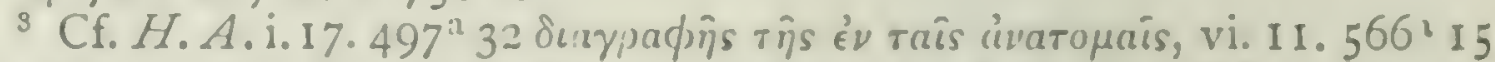

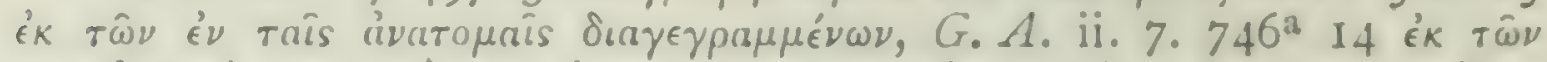

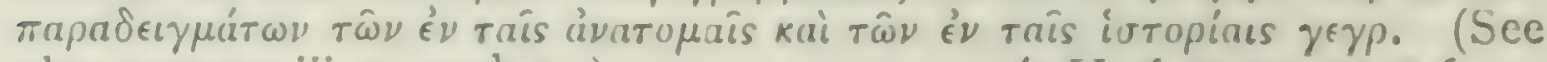
also note on iii. I. $509^{\mathrm{b}} 23$.)

4 . A. v. 12. $544^{\text {a }} 6$.

5 the sexes are casiy distinguishe 1 , but not by supericial differences of colour or form. Here one is tempted to suppose that two species are being compared, the darker and larger $S$. officinalis with the lighter-coloured S. orbigniana, the 'seccia culo appuntato' of the Neapolitan fishermen. C. Jattat, op. cit. p. $154^{\prime}$ 'Per distinguere 
There are several species of the octopus. One keeps close to the surface, and is the largest of them all, and near the shore the size is larger than in deep water; and there ${ }_{15}$ are others, small, variegated in colour, which are not articles of food. There are two others, ${ }^{1}$ one called the heledone, which differs from its congeners in the length of its legs and in having one row of suckers-all the rest of the molluscs having two,- and the other nicknamed variously the bolitaina or the 'onion,' and the osolis or the 'stinkard '. 2

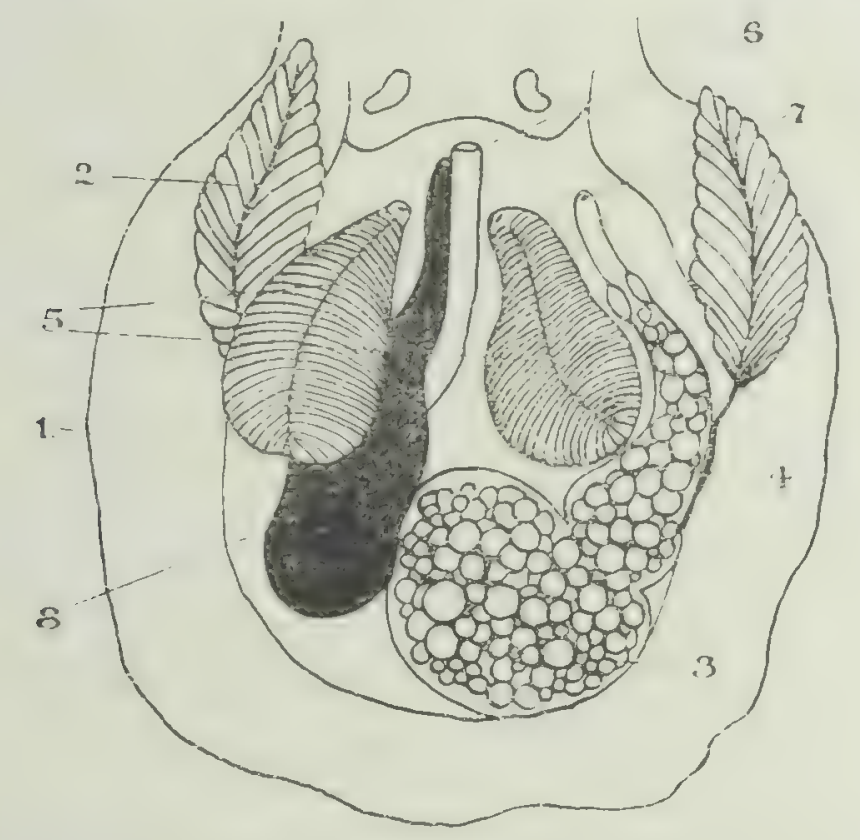

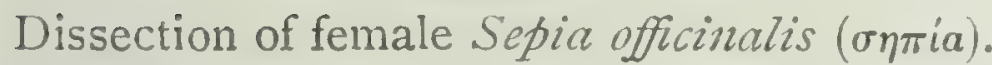

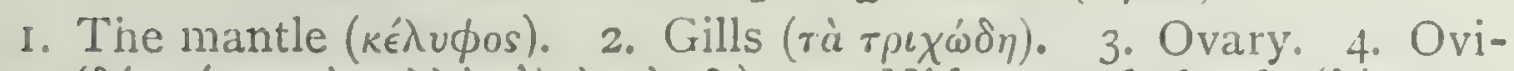

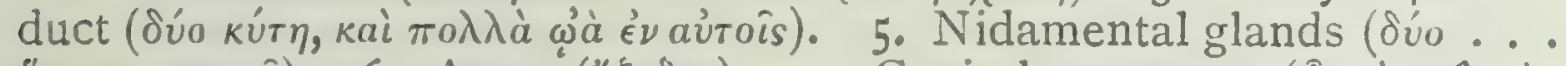

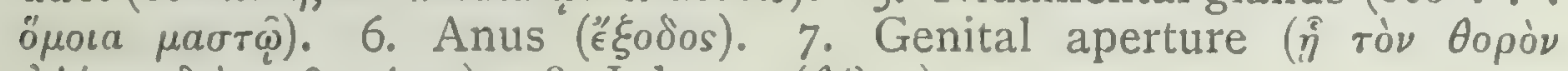

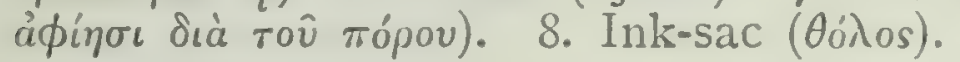

There are two others found in shells resembling those of 20 the testaceans. One of them is nicknamed by some persons

i sessi in questa specie ( $S$. officinalis) sono stati messi in evidenza altri caratteri, $i$ quali pero non reggono ad una critica accurata ; mentre alcuni sono molto difficili ad apprezzare, altri non sono veri caratteri sessuali, ma variazioni della specie'.

1 Plin. ix. $30(48)$.

2 It is precisely the common Eledone (purpo muscariello, moscardino,

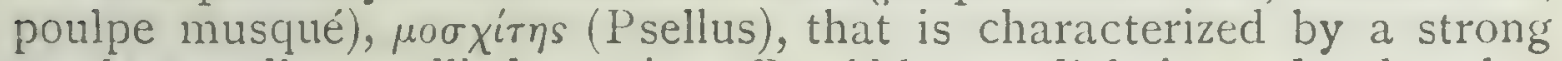
musky smell, an allied species, E. Aldrowandi, being odourless but nevertheless unpalatable. The text is therefore not clear, and $A$. and

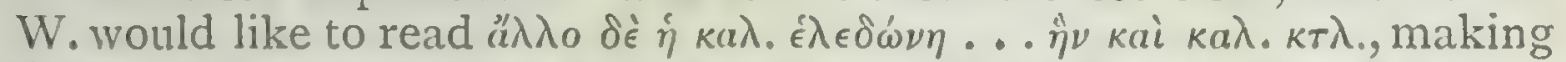

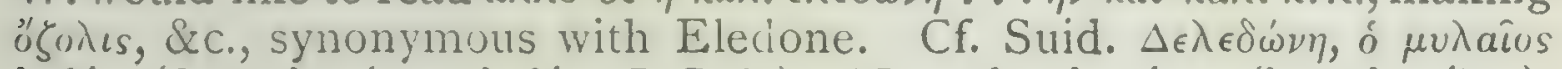

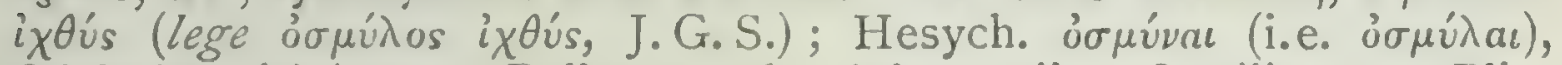

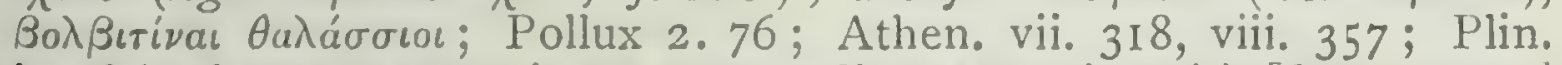
ix. 48 'polyporum generis est ozaena, dicta a gravi capitis [le'g' caepae]

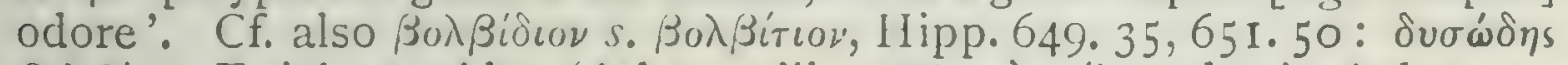

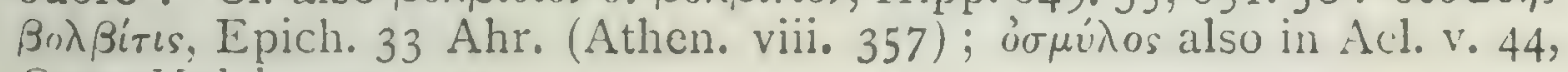
Opp. Hal. i. $307,310$. 
the nautilus or the pontilus, ${ }^{1}$ or by others the 'polypus' cgg'; ${ }^{2}$ and the shell of this creature is something like a separate valie of a deep scallop-shell. ${ }^{3}$ This polypus lives very often near to the shore, and is apt to be thrown up high and dry on the beach; under these circumstances it is found with its shell detached, and dies ${ }^{4}$ by and by on ${ }_{25}$ dry land. These polypods are small, and are shaped, as regards the form of their bodies, like the bolbidia. There is another polypus that is placed within a shell like a snail; it never comes out of the shell, but lives inside the shell like the snail, and from time to time protrudes its feelers." So much for molluscs.

3o IVith regard to the Malacostraca ${ }^{\top}$ or crustaceans, one species is that of the crawfish, and a second, resembling

1 Cf. Opp. Hal. i. 338-59; Athen. 317; Plin. ix. 47.

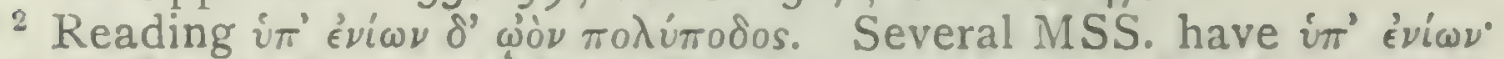

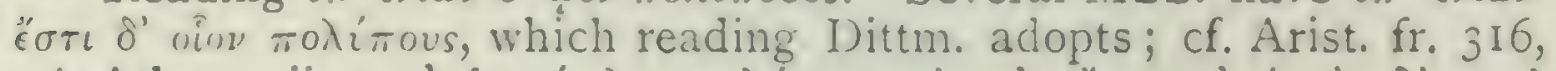

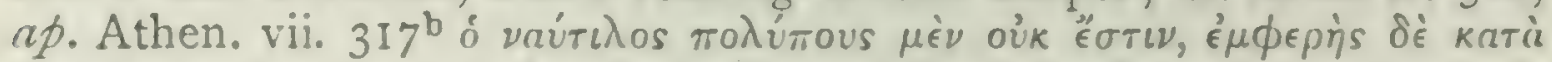
Tàs $\pi \lambda \epsilon k$ tívas. Schneider (vol. iii. p. 88) divined a connexion with Callimachus' celebrated Epigram (Athen. vii. $318^{\text {t) }}$ ), and I am not at

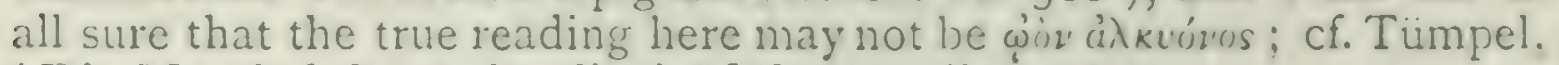
'Die Muschel der Aphrodite,' Philologus, li. 3, I892.

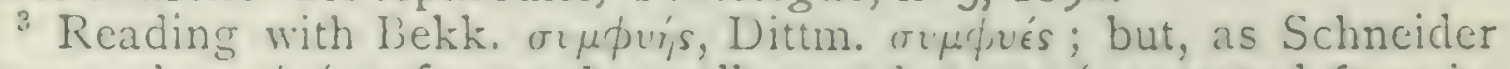
shows, wi $\sigma \cdot \mu$ w'r, refers to the scallop, and means 'separated from its

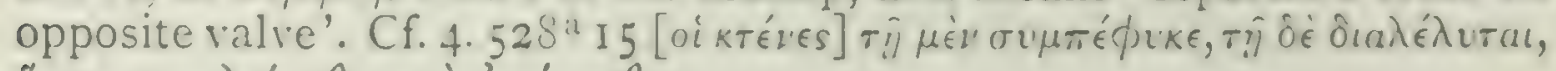

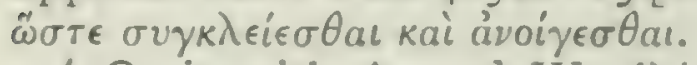

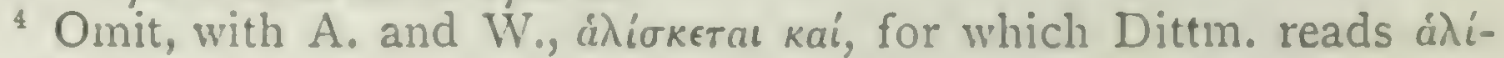
$\sigma \kappa \in \tau a \iota \ddot{\eta}^{\prime}$

${ }^{5}$ Vide infra, ix. 37.622a 32 ; Ath. vii. $317^{\mathrm{b}}$; Plin. 29 (47); Opp. Hal. i. 338 .

6 This allusion, nowhere else repeated, has seemed to many commentators to refer to Nautilus pompilius, L., in spite of the fact that Nautilus is not found in the Mediterranean (cf. Fér. et I): Orb. Hist. des Mollusques, p. 58; Apostol. and Delage, op.cit.p. 4I4, \&c.). I know no other clue, unless one lie in the following reference to Ocythoe tuberulata, an Octopod, in Jatta's monograph on the leshalopeds, p. 200. 'Il racconto dei pescatori nizzardi e genovesi, che si trova anche su la bocca dei nostri marinari. secondo il quale questo Cefalopodo sarebbe fornito di una conchiglia gelatinosa, che lascerebbe cadere quando è per essere catturato, è certamente frutto della fantasia sempre viva nella gente di mare." Though making light of the story, Jatta himself figures a male Ocythoe dwelling within the gelatinous test of a large Salpa, and reports that other naturalists have witnessed the same phenomenon.

7 Cf. Cavolini, Eraeugung der Fische und Krebse, 1792; Cuvier, 'Sur les écrevisses connues aux anciens,' $A n n$. du MIus. An x. xi. pp. 368-84; J. G. Schneider, Mag. Ges. Naturf. Fr. Berlin, I. P. $163-85,1807$; John Young, "Malacostraca of Aristotle; .inn. Mhas. N. H., I865, p. 261. 
the first, is that of the lobster; the lobster differing from the crawfish ${ }^{1}$ in having claws, and in a few other respects as well. Another species is that of the carid, and another is that of the crab, and there are many kinds both of carid and of crab.

Of carids there are the so-called cyphac, or " hunch-backs '," the crangons, or squillae, and the little kind, or shrimps, ${ }^{3}$ and the little kind do not develop into a larger kind.

Of the crab, the varieties are indefinite and incalculable. The largest of all crabs is one nicknamed Maia, ${ }^{4}$ a second variety is the pagurus ${ }^{5}$ and the crab of Heracleotis, and 5 a third variety is the fresh-water crab; ${ }^{6}$ the other varieties are smaller in size and destitute of special designations. In the neighbourhood of Phoenice there are found on the beach certain crabs that are nicknamed the 'horsemen', from their running with such speed that it is difficult to overtake them; these crabs, when opened, are usually found empty, and this emptiness may be put down to insufficiency of nutriment. [There is another variety, small ro like the crab, but resembling in shape the lobster.] ${ }^{8}$

All these animals, as has been stated, have their hard and shelly part outside, where the skin is in other animals, and the fleshy part inside; and the belly is more or less provided with lamellae, or little flaps, and the female here deposits her spawn.

1 I am inclined to read $k a \rho i \delta \omega \nu$ for $k a \rho i ́ \beta \omega \nu$, and to consider the clause as parenthetic or interpolated. The claws of the crawfish are described below, and elsewhere. Cf. also P. A. iv. 8. 684 15 ai $\delta \dot{\epsilon}$

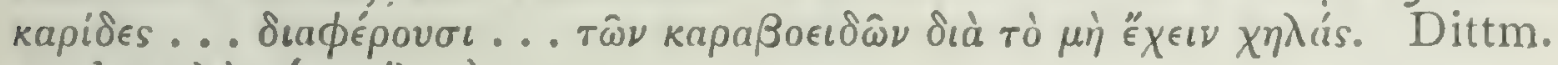

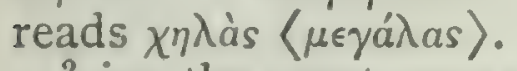

2 i.e. the great prawns, Palaemon sp.

3 e.g. Crangon vultgaris (L.).

4 i.e. 'grannie'. Plin. ix. (3I) 51. Probably Mara squinado (Herbst'.

${ }^{5}$ Probably the common edible crab, C. pagurus, L., mod. Gk. кaßoûpı.

'Thelphusa fluviatilis, Latr.

- Cancer cursor, Belon, Obs. de plusieurs singularités trouvées en Grèce, 1553, ii. p. I38; Ocypoda cursor (L.). Cf. Plin. ix. 5 I i sopial, Ael.vii. 24. The gill-chamber is very large, griving a look of emptiness

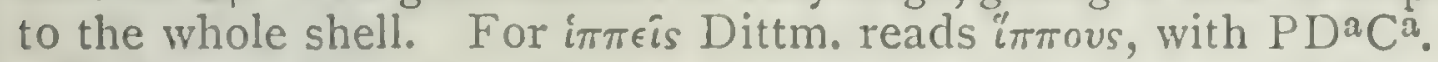

8 This and the preceding sentence are of the nature of footnotes, if not actually interpolations. I strongly suspect that zorípeov should follow, if not replace, $\mu$ ikpóv, and that the note is parenthetic to that on the fresh-water crab; cf. A. and W. in loc. 
I5 The crawfishes have five fect on either side, including the claws at the end; ${ }^{1}$ and in like manner the crabs have ten feet in all, inclucling the claws. Of the carids, the hunch-backed, or prawns, have five fect on either side, which are sharp-pointed-those towards the head; and five others on either side in the region of the belly, with their 20 extremities flat; they are devoid of flaps on the under side such as the crawfish has, but on the back they resemble the crawfish. ${ }^{2}$ It is very different with the crangon, or

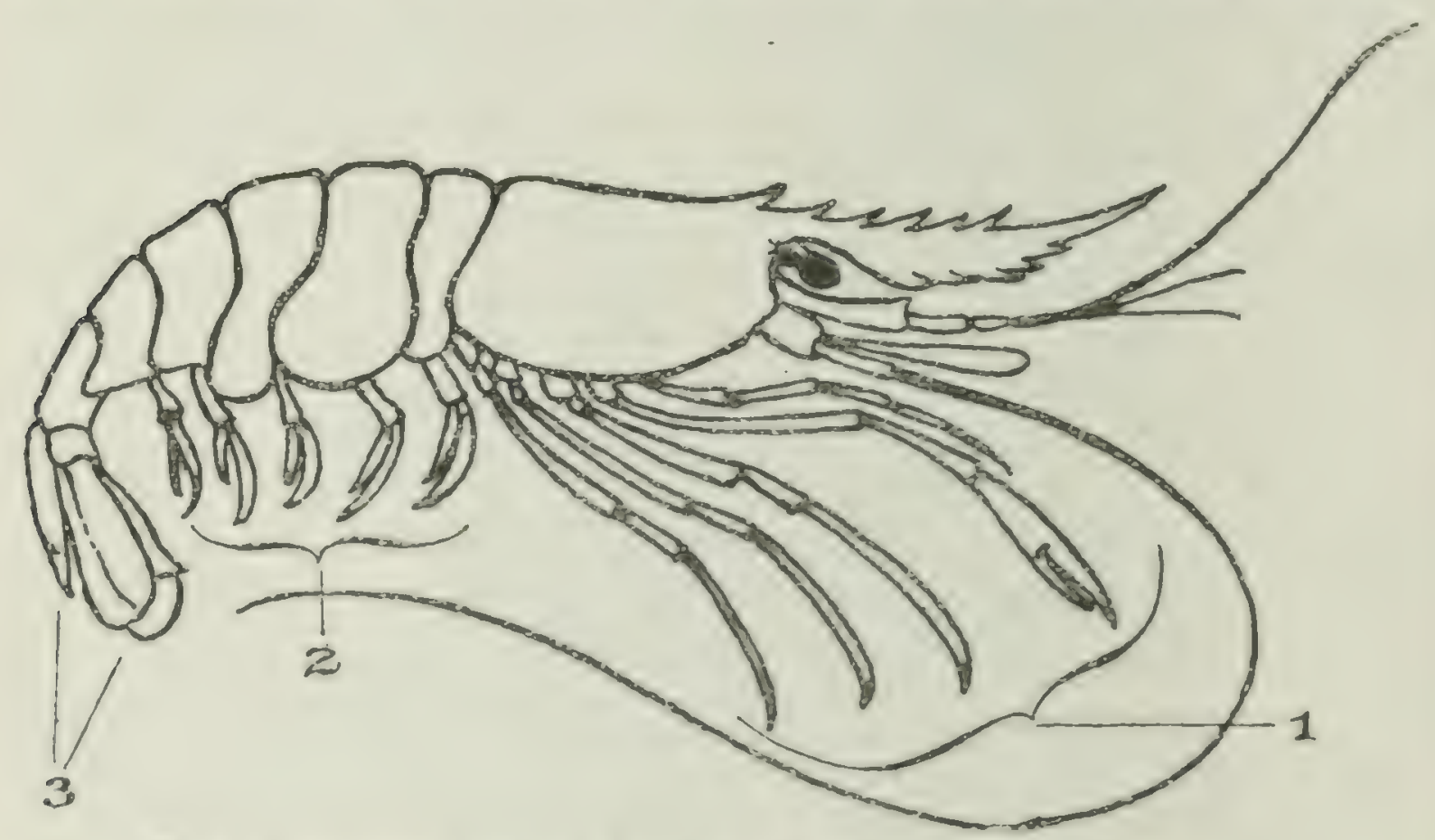

The Common Prawn, Palaemon serratus (kapis í kuфí).

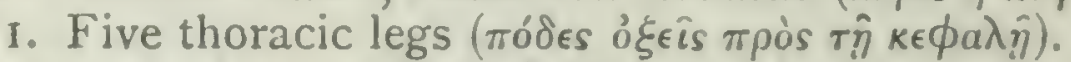

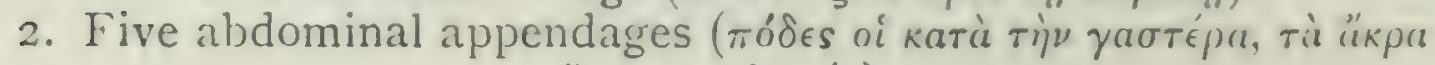

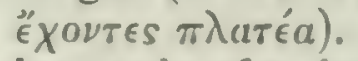

3. The 'telson' with the last pair of swimmerets (oủpò kai $\pi$ repúyı

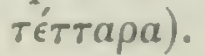

squilla ${ }^{3}$ it has four front $\operatorname{legs}{ }^{4}$ on either side, then three thin ones close behind on cither side, and the rest ${ }^{5}$ of the body is for the most part deroid of fect. Of all these animals

25 the fect bend out obliquely, as is the case with insects; and the claws, where claws are found, turn inwards.' The

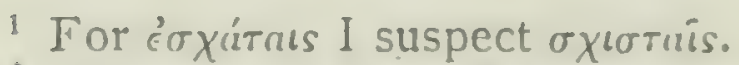

2 This describes such a species as Paluemon seratus. Penaeus indmote would suggest six legs, owing to the larger size of the third maxilliped; also the swimmerets are less leg-like and more flap-like.

3 Squilla mantis.

+ Schn. inserts tidateis, after Alb. M.

Titeiov appears doubtful.

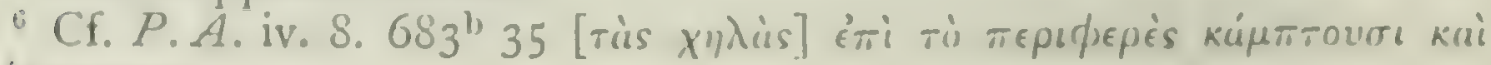
étisomitr. 
crawfish has a tail, and five fins on it; and the roundbacked carid has a tail ${ }^{1}$ and four fins; the squilla also has fins at the tail on either side. In the case of both the hump-backed carid and the squilla the middle part of the tail is spinous: only that in the squilla the part is flattened 30 and in the carid it is sharp-pointed. Of all animals of this genus the crab is the only one devoid of a rump; and,

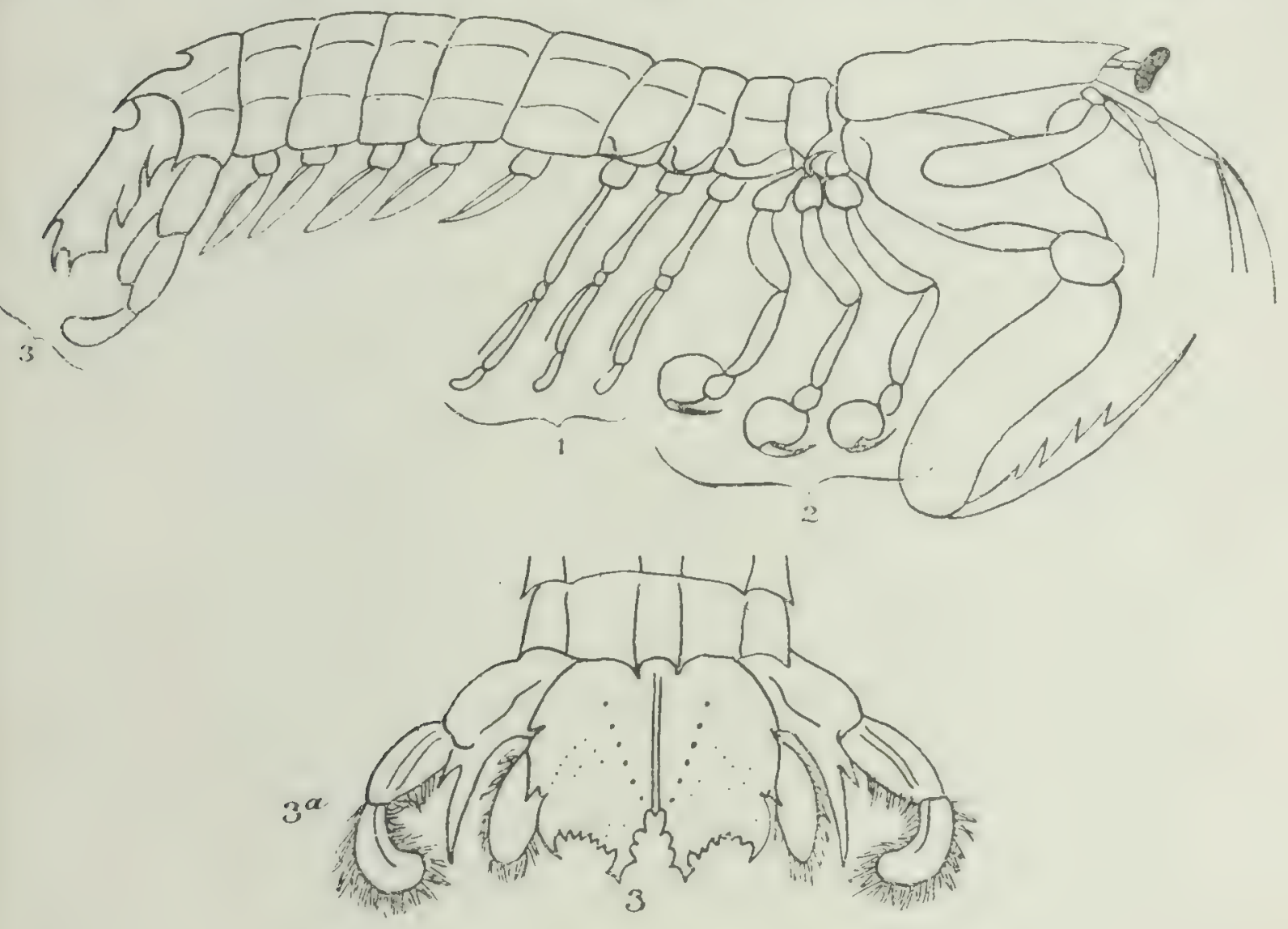

Squilla mantis ( $\kappa \rho а \gamma \gamma \dot{\omega} \nu)$.

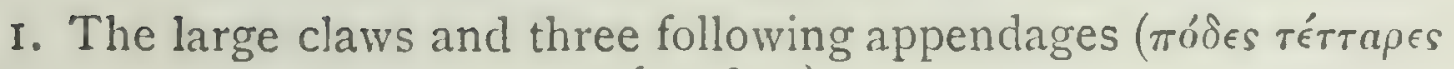
oi $\pi \rho \hat{\omega} \tau 0 \iota)$.

2. The last three thoracic limbs (ä $\lambda \lambda$ o $\tau \rho \in$ is $\lambda \epsilon \pi \tau \circ i)$.

3. The 'telson' and terminal swimmerets (oúpà kai тrepúyıa).

while the body of the carid and the crawfish is elongated, that of the crab is rotund. ${ }^{2}$

In the crawfish ${ }^{3}$ the male differs from the female: in the female the first foot ${ }^{4}$ is bifurcate, in the male it is undivided; $526^{a}$

${ }^{1}$ Dittm. suggests, I think needlessly, $\langle\mu \alpha \times$ aí $\rangle$.

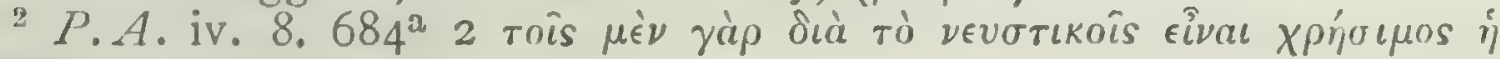
oípá.

${ }^{3}$ kápaßos, L. locusta (Plin. ix. 50, \&c.); Genoese alagousta, Fr. langouste; Palinumes vullgaris, Latr.

${ }_{4}^{4}$ i.e. reckoning from behind. This sexual difference has been very generally overlooked by naturalists, though it is mentioned by Ortmann in Bronn's Thierreich (Crustacea, p. II37); hence commentators, ignorant of the actual fact, have sought, and failed to find, the dism 
the belly-fins in the female are large and overlapping on the neck, ${ }^{1}$ while in the male they are smaller and do not overlap $;^{2}$ and, further, on the last fect of the male there are 5 spur-like projections, large and sharp, which projections in the female are small and smooth. Both male and female have two antennac in front of the cycs, large and rough, and other antennae underneath, small and smooth. The cyes of all these creatures are hard and beady, and can 10 move either to the inner or to the outer side. The eyes of most crabs have a similar facility of movement, or rather, in the crab this facility is developed in a higher degrec.

The lobster ${ }^{4}$ is all over grey-coloured, with a mottling of black. Its under or hinder feet, up to the big fect or claws, are cight in number; then come the big fect, far larger" and flatter at the tips than the same organs in the crawI5 fish; and these big fect or claws are exceptional in their structure, for the right claw has the extreme flat surface long and thin, while the lcft claw has the corresponding surface thick and round." Each of the two claws, divided at the end like a pair of jaws, has both below and above a set of tecth: only that in the right claw they are all small and saw-shaped, while in the lcft claw those at the apex are 20 saw-shaped and those within are molar-shaped, these latter being, in the under part of the cleft claw, four tecth close together, and in the upper part three tecth, not close together. Both right and left claws have the upper part mobile, and bring it to bear against the lower one, and

tinction alluded to in the foremost legs or great claws. It is not unnatural to reckon the legs in order from behind forwards when the animal is viewed from bclow, that is to say, in the direction in which they overlap.

1 i.e. the narrow part of the abdomen. Fr. 'col de l'écrevisse'.

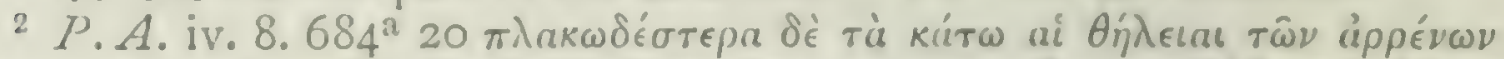

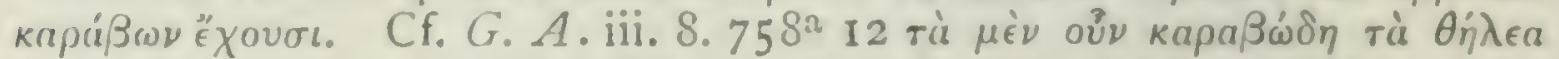

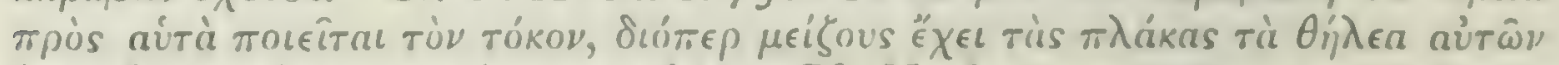

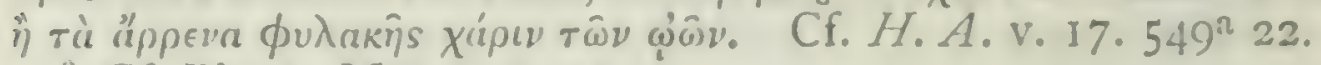

${ }^{3}$ Cf. Plaut. Men. v. 5.24.

- Astacus, Plin. ix. 5 I, elephantus, id. xxii. 53, Homarus aulgaris, L.

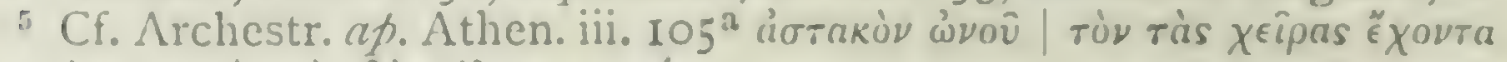

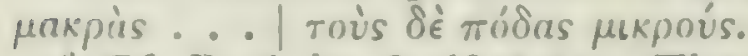

'Cf. P.A.iv. S. $684^{2} 32$. The 'crushing-claw' may be right or left, indifferently: cf. Herrick, in U.S. Fish. Comm. Rep. 1895; Stahr, Jen. Zitschr. xxxii. IS98; Przibram, Arch. F. Entrivilulungsmech. xix. 1905. 
both are curved like bandy-legs, being thereby naturally adapted for apprehension and constriction. Above the two ${ }^{25}$ large claws come two others, ${ }^{1}$ covered with hair, a little underneath the mouth; and undcrneath these the gill-like formations in the region of the mouth, hairy and numerous. ${ }^{2}$ These organs the animal keeps in perpetual motion; and the two hairy feet it bends and draws in "towards its mouth. The feet near the mouth are furnished also with delicate outgrowing appendages. ${ }^{4}$ Like the crawfish, the lobster :o has two teeth, or mandibles, and above these teeth are its antennae, long, but shorter and finer by far than those of the crawfish, and then four other antennae ${ }^{5}$ similar in shape, but shorter and finer than the others. Over these $5^{2} 6^{\mathrm{b}}$ antennae come the eyes, small and short, ${ }^{6}$ not large like the eyes of the crawfish. Over the eyes is a peaky rough projection like a forehead, ${ }^{7}$ larger than the samc part in the crawfish ; in fact, the frontal part is more pointed and the thorax is much broader in the lobster than in the craw- 5 fish, and the body in general is smoother and more full of flesh. Of the eight feet, four are bifurcate at the extremities, and four are undivided. The region of the so-called neck is outwardly divided into five divisions, and sixthly comes the flattened portion at the end, and this portion has five flaps, or tail-fins; and the inner or under parts, ro into which the female drops her spawn, ${ }^{8}$ are four in number and hairy, and on each of the aforesaid parts is a spine turned outwards, short and straight. The body in general and the region of the thorax in particular are smooth, not rough as in the crawfish; ${ }^{2}$ but on the large claws the outer portion has larger spines. There is no apparent $\mathrm{I}_{5}$ difference between the male and female, for they both have

1 i.e. the third maxillipeds.

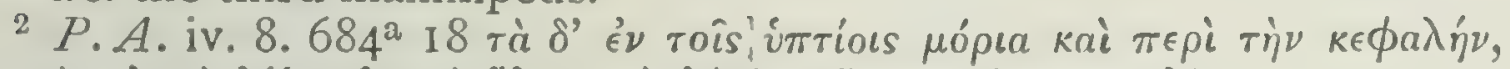

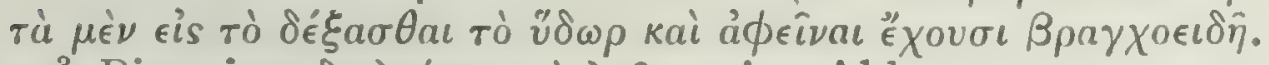

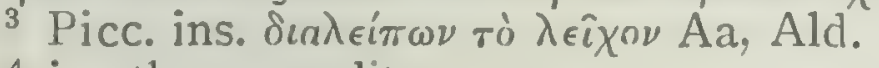

${ }^{4}$ i.e. the exopodites.

5i.e. the two bifurcate 'antennules'.

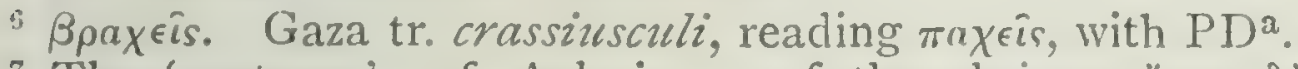

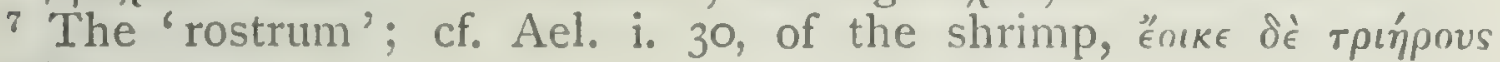
$\epsilon^{\prime} \mu \beta o ́ \lambda \omega$.

${ }_{8}$ Cf́. G. A. iii. 8. $75^{\mathrm{a}} \mathrm{I} 3$.

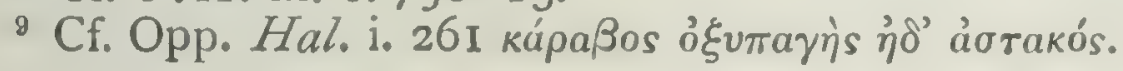


one claw, whicherer it may be, larger than the other, and neither male nor female is ever found with both claws of the same size. ${ }^{1}$

2 All crustaceans take in water close by the mouth. The crab discharges it, closing up, as it cloes so, a small portion 20 of the same. ${ }^{3}$ and the crawfish discharges it by way of the gills: and, by the way, the gill-shaped organs in the crawfish are very numerous.

The following properties arc common to all crustaceans: they have in all cases two tecth, or mandibles (for the front tecth in the crawfish are two in number): and in all cascs there is in the mouth a small fleshy structure scrving for a tongue; ${ }^{*}$ and the stomach is close to the mouth, only that 25 the crawfish has a little oesophagus in front of the stomach, and there is a straight gut attached to it. This gut, in the crawfish and its congeners, and in the carids, extends in a straight line to the tail, and terminates where the animal discharges the residuum, and where the female deposits ${ }^{5}$ her spawn; in the crab it terminates where the flap is situated, and in the centre of the flap. [And, by the way, in all 30 these animals the spawn is deposited outside.] Further. the female has the place for the spawn rumning along the gut. And, again, all these animals have, more or less, an organ termed the 'mytis', or ' poppy-juice'.

IVe must now proceed to review their several differentiac.

$527^{\mathrm{a}}$ The crawfish then. as has been saici, has two tecth, large and hollow. in which is contained a juice resembling the mytis, and in between the teeth is a fleshy substance, shaped like a tongue. After the mouth comes a short oesophagus, and then a membranous stomach attached to

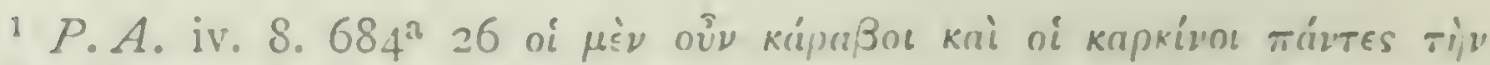

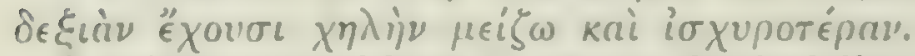

2 Dittm. considers 11. I $8-30$ doubtfully genuine.

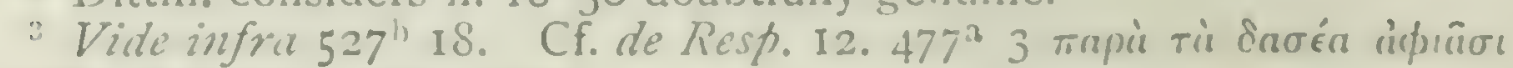

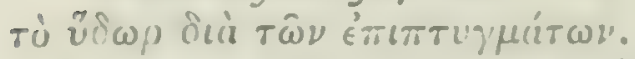

'Apparently the 'upper lip'.

5 An crror, exposed by Cavolini (p. I 40); unless deposition, strictly. speaking, rather than extrusion be meant.

"Omitting $\%$ The sentence is doubtless corrupt. A. and $\mathrm{W}$. cj.

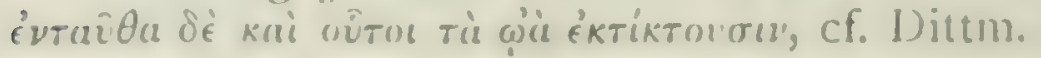


the oesophagus, and at the orifice of the stomach are three 5 teeth, two facing one another and a third standing by itself underneath. Coming off at a bend from the stomach is a gut, simple and of equal thickness throughout the entire length of the body until it reaches the anal vent.

These are all common properties of the crawfish, the carid, and the crab; for the crab, be it remembered, has ro two teeth. ${ }^{1}$

Again, the crawfish has a duct attached all the way from the chest to the anal vent ${ }^{2}$ and this duct is connected with the ovary in the female, and with the seminal ducts in the male. This passage is attached to the concave surface of the flesh in such a way that the flesh is in betwixt the duct and the gut; for the gut is related to the convexity is and this duct to the concavity, pretty much as is observed in quadrupeds. And the duct is identical in both the sexes; that is to say, the duct in both is thin and white, and charged with a sallow-coloured moisture, and is attached to the chest.

[The following are the properties of the egg and of the convolutes in the carid. $]^{3}$

The male, by the way, differs from the female in regard to its flesh, in having in connexion with the chest two separate and distinct white substances, resembling in colour and conformation the tentacles of the cuttle-fish, and they are convoluted like the 'poppy' or quasi-liver of the trumpet-shell. These organs have their starting-point in 'cotyledons' or papillae, which are situated under the ${ }_{25}$ hindmost feet; and hereabouts the flesh is red and blood. coloured, but is slippery to the touch and in so far unlike flesh. Off from the convolute ${ }^{4}$ organ at the chest branches

1 Dittm. brackets the whole sentence; cf. P.A. iv. $5 \cdot 679^{2} 36$.

2 Probably, as Cavolini suggested, the ventral nerve-cord. If so, to associate this with the reproductive system is an error in marked contrast to the accurate account of the latter which immediately follows.

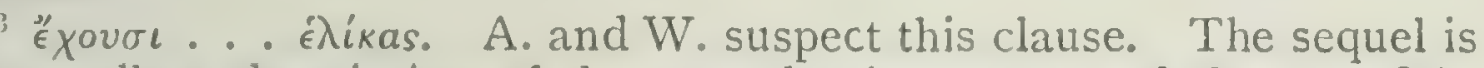
an excellent description of the reproductive organs of the crawfish,

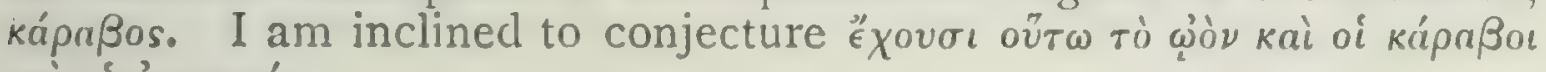
kai oi àr trakní.

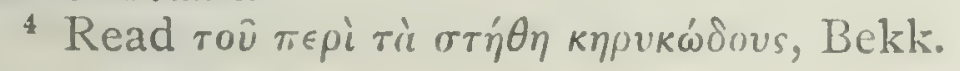


off another coil about as thick as ordinary twine; and underneath there are two granular seminal bodics in juxta30 position with the gut. These are the organs of the male. The female has red-coloured eggs, which are adjacent to the stomach and to each side of the gut all along to the fleshy parts, being enveloped in a thin membrane.

Such are the parts, internal and extcrnal, of the carid.

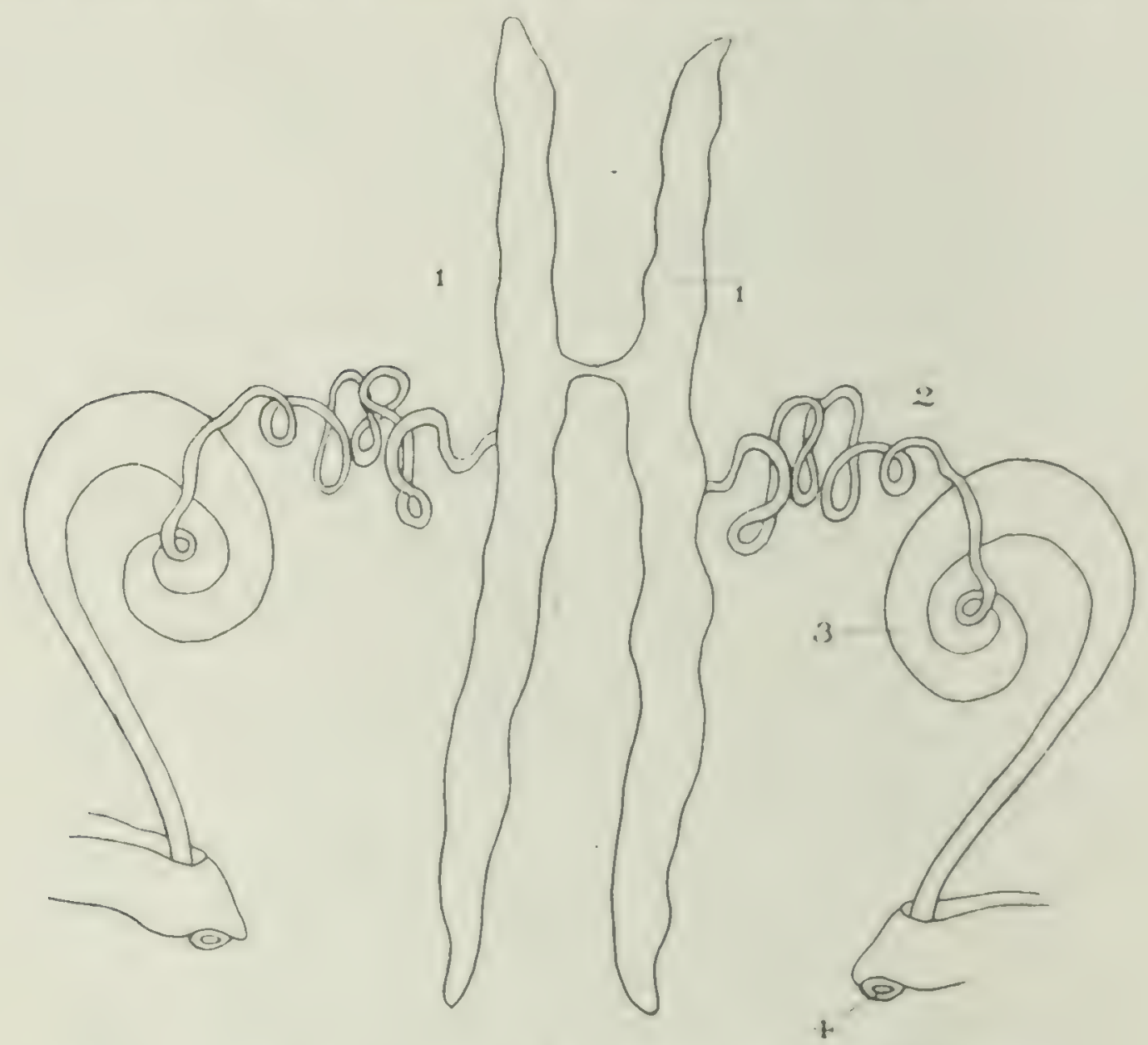

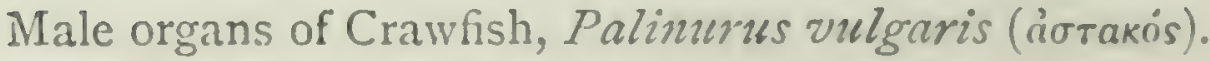

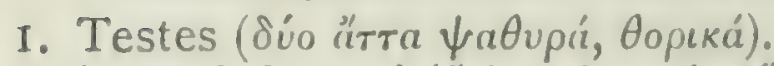

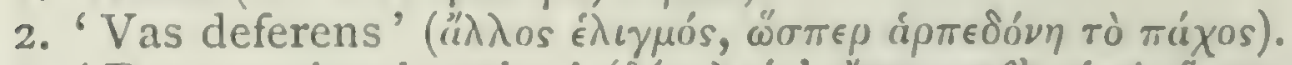

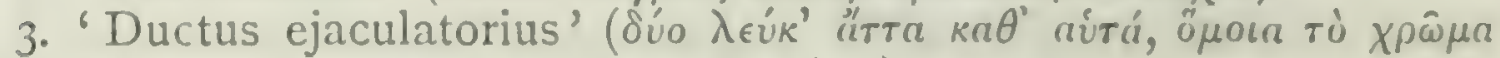

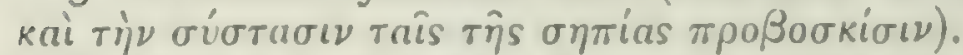

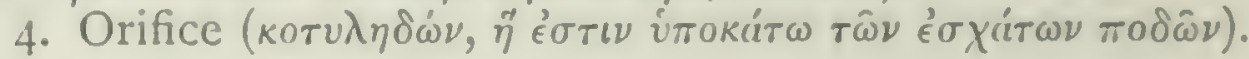

$527^{\mathrm{b}} \quad 1$ The inner organs of sanguincous animals happen to 3 have specific designations; for these animals have in all cases the inner viscera, but this is not the case with the bloodless animals, ${ }^{2}$ but what they have in common with red-blooded animals is the stomach, the ocsophagus, and the gut.

1 The greater part of this chapter recapitulates the foregoing: 'itaque su-picor caput hoc totum accessisse ex Epitome Hieroclis aut alin,' Schn.

${ }^{2}$ C.. P.A. iv. $5 \cdot 678^{a} 3$ I. 
With regard to the crab, it has already been stated that 5 it has claws and feet, and their position has been set forth ; furthermore, for the most part they have the right claw bigger and stronger than the left. It has also been stated ${ }^{1}$ that in general the eyes of the crab look sideways. Further, the trunk of the crab's body is single and undivided, including its head ${ }^{2}$ and any other part it may possess. Some ro crabs have eyes placed sideways on the upper part, immediately under the back, and standing a long way apart, and some have their eyes in the centre and close together, like the crabs of Heracleotis and the so-called 'grannies':" The mouth lies underneath the eyes, and inside it there are two teeth, as is the case with the crawfish, only that in the crab the teeth are not rounded but long; and over the teeth are two lids, ${ }^{4}$ and in betwixt ${ }_{5}$ them are structures such as the crawfish has besides its teeth. The crab takes in water near by the mouth, using the lids as a check to the inflow, ${ }^{5}$ and discharges the water by two passages above the mouth, closing by means of the lids the way by which it entered; and the two passage-ways are just underneath the eyes. When it has taken in water 20 it closes its mouth by means of both lids, and ejects the water in the way above described. ${ }^{6}$ Next after the teeth comes the oesophagus, very short, so short in fact that the stomach seems to come straightway after the mouth. Next after the oesophagus comes the stomach, two-horned, to the centre of which is attached a simple and delicate gut; 25 and the gut terminates outwards, at the ${ }^{7}$ operculum, as has been previously stated. [The crab has the parts in

${ }^{1}$ H. A. iv. 2. $526^{\mathrm{a}} 9$.

${ }^{2}$ Reading $\eta^{\prime \prime} \tau \epsilon \kappa \epsilon \phi a \lambda \dot{\eta}$.

3 Far apart, for instance, in Grapsus and Thelphusa, near together in Calappa.

${ }^{4}$ The last maxillipeds.

$5527^{\mathrm{b}}$ I 7 read $a \dot{a} \omega \theta \hat{\omega} \nu$ roîs $\epsilon \pi \imath k a \lambda \dot{v} \mu \mu a \tau \iota \nu$. Picc. cj. $\dot{a} \pi \eta \theta \hat{\omega} \nu$, i.e. straining or filtering. We might also suggest ämo $\theta \in \nu$.

${ }^{6}$ It is commonly denied that the crab or any other crustacean takes in water either at or near the mouth, the current entering the respiratory chamber at the sides of the carapace but issuing near the mouth in the manner described. According to Cavolini the water does enter by these anterior apertures, as well as at the sides of the carapace.

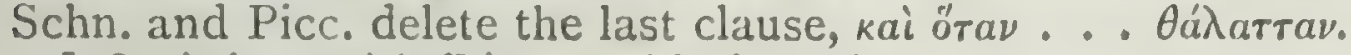

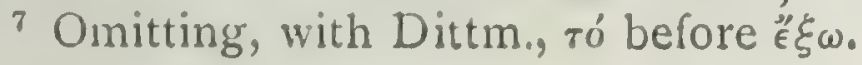


between the lids in the neighbourhood of the teeth similar to the same parts in the crawfish.] Inside the trunk is a sallow juice and some few little bodies, long and white, 30 and others spotted red.' The male differs from the female in size and breadth, and in respect of the ventral flap ; ${ }^{2}$ for this is larger in the female than in the male, and stands out further from the trunk, and is more hairy ${ }^{3}$ [as is the case also with the female in the crawfish].

So much, then. for the organs of the malacostraca or crustacea.

With the ostracoderma, or testaccans:" such as the land- 4 $528^{\text {a }}$ snails and the sca-snails, and all the 'oysters' so-called, and also with the sca-urchin genus, the fleshy part, in such as have flesh, is similarly situated to the fleshy part in the crustaccans; in other words, it is inside the animal, and the shell is outside, and there is no hard substance in the interior. As compared with one another the testaceans 5 present many diversitics, both in regard to their shells and to the flesh within. Some of them have no flesh at all, as the sea-urchin; others have flesh, but it is inside and wholly hidden, except the head, as in the land-snails, ${ }^{5}$ and the socalled cocalio," and, among pelagic animals, in the purple to murex, the ceryx or trumpet-shell, the sea-snail, and the

1 In contrast to the carefully described dissection of the crawfish, this seems to be but a crude statement of what is first seen on removing the carapace of a crab, viz. the white ridges of the body-wall, the gills lying upon them, and the soft mass of liver, \&c., within.

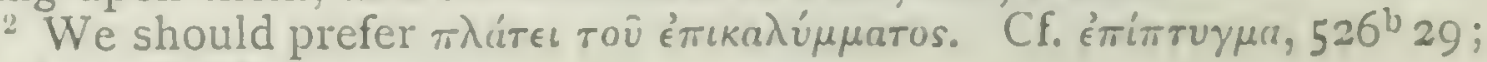
P.A.iv. $8.684^{\text {a } 22 .}$

${ }^{3}$ Cf. infra, v. 7. $541^{\text {b }} 30$.

${ }^{4}$ Cf. $P . A$. iv. $5.679^{\circ} 2$, \&. C. For identification of species see in particular E. von Martens. 'Dic dassischen Conchyliemanen,' J Whouh. a. Ver. f. vater\%. Naturk. in Wiurtemberg, 1860, pp. 175-264; also Locard, Hist. des mollusques dans l'antiquité, Lyon, 1884.

${ }^{5}$ Classical references to snails are elaborately discussed by Férussac, Hist. nat. des mollusques terr. ct fluviat., ii. p. 97, L.c.

- Apparently It. quecciolo, and meaning any small periwinkle-like shells.

kipp $v_{5}$ is usually interpreted to mean some such conspicuous species as Tritonium nodiferum or Ranella gigantea. Its modern derivatives are applied to very diverse spiral shells, e.g. carrygut in Venice and Trieste to Trochus and Cerithium vulgatum, carucolli in Sicily to C. mediterancum, caracol in Spain to Helix, Trochus, Turbo, \&c.; hence also Prov. csirrigron, Fr. cscargot ( 1 . Niartens, l.c. p. 215). Cf. 
spiral-shaped ${ }^{1}$ testaceans in general. Of the rest, some are bivalved and some univalved; and by 'bivalves' I mean such as are cnclosed within two shells, and by 'univalyed 'such as are enclosed within a single shell, and in these last the fleshy part is exposed, as in the case of the limpet. ${ }^{2}$ Of the bivalves, some can open out, like the scallop and the mussel; is for all such shells are grown together on one side and are separate on the other, so as to open and shut. ${ }^{3}$ Other bivalves are closed on both sides alike, like the solen or razor-fish. ${ }^{4}$ Some testaceans there are, that are entirely enveloped in shell and expose no portion of their flesh outside, as the tethya or ascidians.

Again, in regard to the shells themselves, the testaceans present differences when compared with one another. ${ }^{5}$ Some are smooth-shelled, like the solen, the mussel, and some clams, ${ }^{6}$ viz. those that are nicknamed 'milk-shells', 'while others are rough-shelled, such as the pool-oyster or edible oyster, the pinna, and certain species of cockles, and the trumpet-shells; and of these some are ribbed, ${ }^{8}$ such as the scallop and a certain kind of clam or cockle, and some 25 are devoid of ribs, as the pinna and another species of clam. Testaceans also differ from one another in regard also H.A. v. 12. $544^{\text {a }}$ 15, viii. I3. $599^{\text {a }}$ I2; P.A. iv. 5 ; Athen. iii. pp. 32,44 .

1 Cerithium vulgatum is known in the fish-market at Spalato as strombolo (Faber).

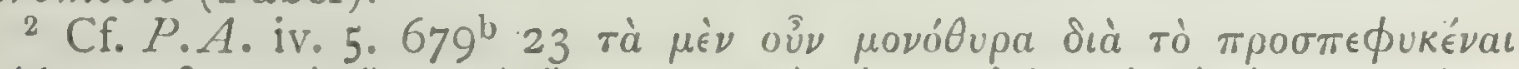

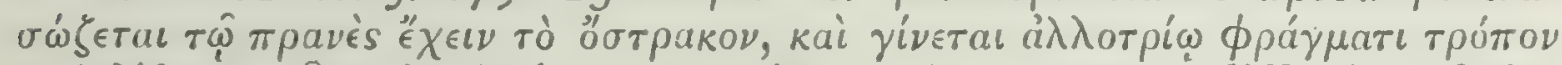

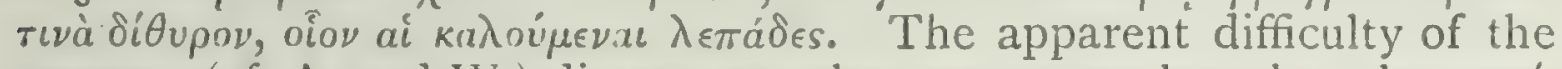
passage (cf. A. and W.) disappears when we remember that the $\mu$ ovó-

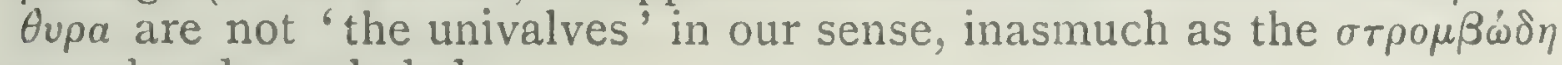
are already excluded.

${ }^{3}$ P. A. iv. $7.683^{\mathrm{b}} \mathrm{I} 6$.

${ }^{4}$ Doubtless the genus still so called, whose bivalved shell is prevented from opening by adhesion of the mantle-lobes. Cf. also Sophron ap. Athen. iii. p. 32, \&c. The same shell is the Donax of Pliny, a name perpetuated in the Adriatic cannello s. cannalichio, from canna.

${ }^{5}$ Cf. Plin. $33(52)$.

${ }^{6}$ Using 'clam', as in America, for various common (edible) bivalves, e.g. Mactra, Tapes, Mya, \&c. The ribbed kind is doubtless a cockle, Cardium.

${ }^{7}$ Very probably a Mactra, e.g. M. lactea, Poli (M. subtruncata, Mont.), It. madia candida.

${ }^{8}$ Elsewhere 'striped': cf. Diph. S. ap. Athen, iii. 90 kai oi $\mu \dot{\epsilon} \nu$

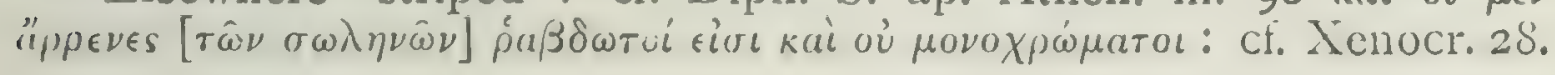


to the thickness or thinness of their shell, buth as regards the shell in its entirety and as regards specific parts of the shell, for instance, the lips; for some have thin-lipped shells, like the mussel, and others have thick-lipped shells, like the oyster. A property common to the above mentioned, and, in fact, to all testaccans, is the smoothness 30 of their shells inside. ${ }^{1}$ Some also are capable of motion, like the scallop, and indeed some aver that scallops can actually fly, owing to the circumstance that they often jump right out of the apparatus by means of which they are caught; " others are incapable of motion and are attached fast to some external object, as is the case with the pinna." All the spiral-shaped testaceans can move $528^{\mathrm{b}}$ and creep, and even the limpet ${ }^{4}$ relaxes its hold to go in quest of food. In the case of the univalves and the bivalves, the fleshy substance adheres to the shell so tenaciously that it can only be removed by an effort; in the 5 case of the stromboids, it is more loosely attached. And a peculiarity of all the stromboids is the spiral twist of the shell in the part farthest away from the head; they are also furnished from birth with an operculum. And, further, all stromboid testaceans have their shclls on the right-hand side, and move not in the direction of the spire, but the ro opposite way." Such are the diversities observed in the external parts of these animals.

The internal structure is almost the same in all these creatures, and in the stromboids especially; for it is in size that these latter differ from one another, and in accidents of the nature of excess or defect. And there is not much difference betreen most of the univalves and bivalves; Is but, while those that open and shut differ from one another

1 Transferring this clause, which $A$. and $I W$. delete, from $52 S^{\text {b }} 2$, accorcling to a suggestion of Dittmeyer's.

2 Plin. ix. $33(52)$.

3 Infra, viii. I. $588^{b}$ I 5 .

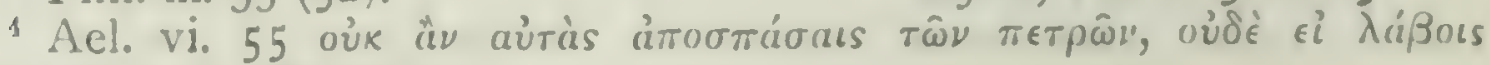

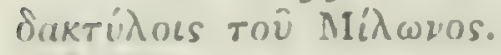

5 The sentence cannot be interpreted, as A. and IV. take it, to mean a right-handed spiral in our sense. It seems simply to mean that the morement must stat from the right, and that therefore the shell must be atsumed to be to the right-hand side since the animal is found $t)$ move in a direction opposite to the spire. Cf. de Inc. 5. 706: I2, from which the passage is perhaps derived (A. and IV.). 
but slightly, they differ considerably from such as are incapable of motion. And this will be illustrated more satisfactorily hereafter.

The spiral-shaped testaceans are all similarly constructed, but differ from one another, as has been said, in the way of excess or defect (for the larger specics have larger and more conspicuous organs, and the smaller have smaller 20 and less conspicuous), and, furthermore, in relative hardness or softness, and in other such accidents or properties. All the stromboids, for instance, have the flesh that extrudes from the mouth of the shell, hard and stiff; some more, and some less. From the middle of this protrudes the head and two horns, and these horns are large in the large species, but exceedingly minute in the smaller ones. The 25 head protrudes from them all in the same way; and, if the animal be alarmed, the head draws in again. Some of these creatures have a mouth and teeth, ${ }^{1}$ as the snail; teeth sharp, and small, and delicate. They have also a proboscis just like that of the fly; and the proboscis is tongueshaped. The ceryx and the purple murex have this organ 30 firm and solid; and just as ${ }^{2}$ the myops, or horse-fly, and the oestrus, or gadfly, can pierce the skin of a quadruped, so is this proboscis proportionately stronger in these testaceans; for they bore right through the shells of other shell-fish on which they prey. ${ }^{3}$ The stomach follows close $5 \mathbf{2} 9^{a}$ upon the mouth, and, by the way, this organ in the snail resembles a bird's crop. ${ }^{4}$ Underneath come two white firm formations, mastoid or papillary in form; and similar formations are found in the cuttle-fish also, only that they are of a firmer consistency in the cuttle-fish. After the stomach comes an oesophagus, simple and long, extend- 5 ing to the poppy or quasi-liver, which is in the innermost recess of the shell. All these statements may be verified in the case of the purple murex and the ceryx by observa-

I Or rather 'jaws'. Not, of course, the microscopic 'teeth' of the lingual ribbon: cf. $P . A$. iv. $5 \cdot 679^{b} 5$.

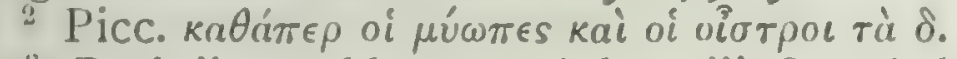

3 P.A. ii. 17.66 ${ }^{\text {a }} 21$; Athen. iii. 89; Ael.v. 34 ; Plin. ix. 60.

${ }^{4}$ Cf. H.A.iv. 5. $679^{6}$ 9. The description seems to be taken from a large snail, e.g. Helix pomatia. 
tion within the whorl of the shell. What comes next to the ocsopliagus is the gut; in fact, the gut is continuous with the oesophagus, ${ }^{1}$ and runs its whole length uncomplicated to the outlet of the residuum. The gut has its ro point of origin in the region of the coil of the mecon, or so-called 'poppy', and is wider hereabouts [for, remember, the mecon is for the most part a sort of excretion in all testaceans]; it then takes a bend and runs up again towards the fleshy part, and terminates by the sicle of the head, where the animal discharges its residuum; and this holds good in the case of all stromboid testaceans. whether I5 terrestrial or marine. From the stomach there is clrawn in a parallel direction with the oesophagus, in the larger snails, a long white duct ${ }^{2}$ enveloped in a membrane, resembling in colour the mastoid formations higher up; and in it are nicks or interruptions, as in the egg-mass of the crawfish, only, by the way, the duct of which we are treating is white 20 and the egg-mass of the crawfish is red. This formation has no outlet nor duct, but is enveloped in a thin membrane with a narrow cavity in its interior. And from the gut downward extend black and rough formations, in close connexion, something like the formations in the tortoise, only not so black. Marine snails, also, have these formations, and the white ones, only that the formations are 25 smaller in the smaller species.

The non-spiral univalves and bivalves are in some respects similar in construction, and in some respects dissimilar, to the spiral testaceans. They all have a head and horns, and a mouth, and the organ resembling a tongue; but these organs, in the smaller species, are indiscemible owing to the minuteness of these animals, and some are indiscrnible even in the larger species when lead, or when at rest and motionless. They all have the so mecon, or poppy, but not all in the same place, nor of equal size, nor similarly open to observation; thus, the limpets have this organ decp down in the bottom of the shell, and the bivalves at the hinge commecting the two

1 A. and W. and Dittm. bracket this clause.

"'The 'hermaphrodite duct '. 
valves. ${ }^{1}$ They also have in all cases the hairy growths or bcards, ${ }^{2}$ in a circular form, as in the scallops. And, with regard to the so-called 'egg', ${ }^{3}$ in those that have $529^{\text {b }}$ it, when they have it, it is situated in one of the semicircles of the periphery, as is the case with the white formation in the snail; for this white formation in the snail corresponds to the so-called $\mathrm{cgg}$ of which we are speaking. But all these organs, as has been stated, are 5 distinctly traceable in the larger species, while in the small ones they are in some cases almost, and in others altogether, indiscernible. Hence they are most plainly visible in the large scallops; and these are the bivalves that have one valve flat-shaped, like the lid of a pot. The outlet of the excretion is in all these animals (save for the exception to be afterwards related ${ }^{4}$ on one side; for there is a passage whereby the excretion passes out. [And, remember, the ro mecon or poppy, as has been stated, is an excretion in all these animals - an excretion enveloped in a membrane.] $]^{5}$ The so-called egg has no outlet in any of these creatures, but is merely an excrescence in the fleshy mass; and it is not situated in the same region with the gut, but the ' egg' is situated on the right-hand side, and the gut on the left." Such are the relations of the anal vent in most of these animals; but in the case of the wild ${ }^{7}$ limpet (called by some $\mathbf{r}_{5}$ the 'sea-ear'), the residuum issues beneath ${ }^{8}$ the shell, for the shell is perforated to give an outlet. In this particular limpet the stomach is seen coming after the mouth, and the

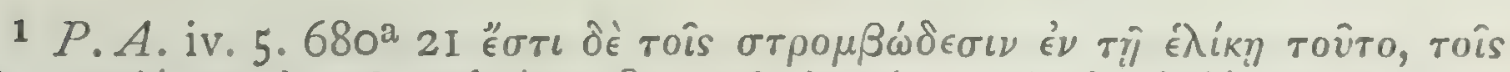

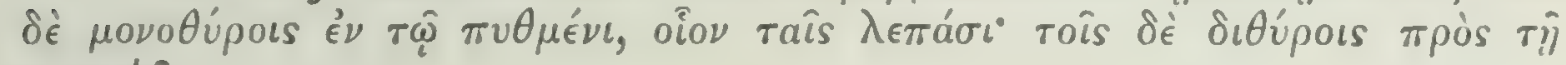

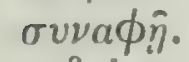

2 i. e. the gills. Cf. note on iv. I. $524^{\mathrm{b}} 20$.

3 Apparently the adductor muscle.

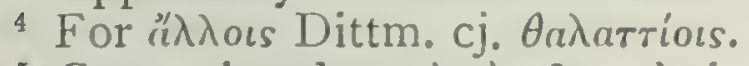

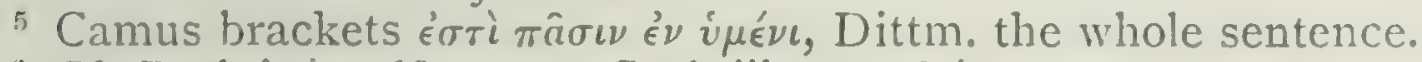

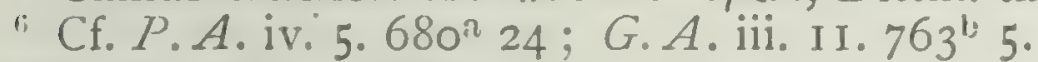

7 Commonly attributed to Fissurella graeca, but the epithet is unexplained. I suggest that it is corrupt, and conceals a forgotten

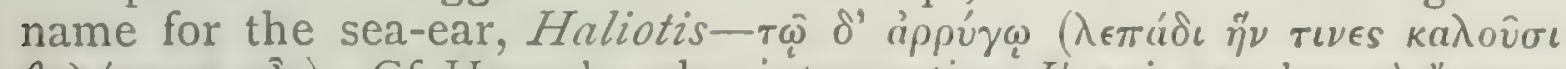

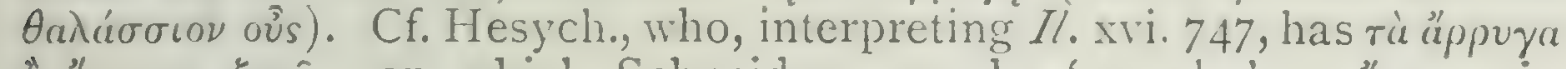

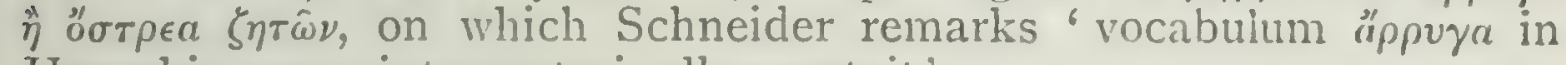
Hesychio nemo interpretari adhuc potuit'. MSS.

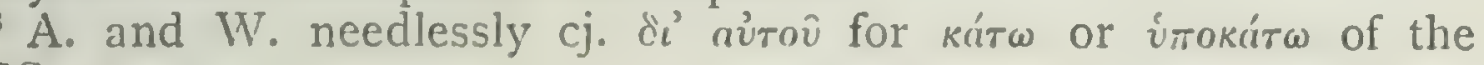


egg-shaped formations are discernible. But for the relative positions of these parts you are refered to my Treatise on Anatomy.

20 The so-called ${ }^{1}$ carcinium or hermit crab is in a way intermediate between the crustaccans and the testaceans. In its nature it resembles the crawfish kind, and it is born simple of itsclf." but by its habit of introducing itself into a shell and living there it resembles the testaceans, and so appears to partake of the characters of both kinds. In 25 shape, to give a simple illustration, it rescmbles a spicler, only that the part below the head and thorax is larger in this creature than in the spider. It has two thin red horns, and underneath these horns two long eyes, not retreating inwards, nor turning sideways like the eyes of the crab, but protruding straight out: and underneath these eycs the 30 mouth, and round about the mouth screral hair-like growths, and next after these two bifurcate legs or claws, whereby it draws in objects towards itsclf, and two other legs on either side, and a third" small one. All below the $530^{a}$ thorax is soft, and when opened in dissection is found to be sallow-coloured within. From the mouth there runs a single passage right on to the stomach, but the passage for the excretions is not discernible. The legs and the thorax are hard, but not so hard as the legs and the thorax of the 5 crab. It does not adhere to its shell like the purple murex and the ccryx, but can casily slip out of it. It is longer when found in the shell of the stromboids than when found in the shell of the neritae.

t And, by the way, the animal found in the shell of the neritae is a separate species, like to the other in most respects; but of its bifurcate fect or claws, the right-hand one is small and the left-hand one is large," and it proro gresses chicfly by the aid of this latter and larger one.

1 Cf. H.A.v. 15. 548" I4; kapkuris, Opp. Hal. i. 320-37; Ael. vii. $31, q .2 \%$

i. e. without a hard-shell coating.

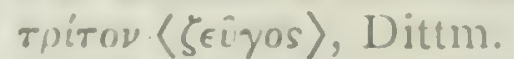

+ Dittm. stigmatizes the two following paragraphs.

"Milne-Edwards divides the hermit-crabs into Pagures dex/res (c.g. I'. hemhundus), simisties (c. g. P. diogenes), and acquimunes. 
In the shells of these animals, ${ }^{1}$ and in cortain others, ${ }^{2}$ there is found a parasite whose mode of attachment is similar. The particular one which we have just described is named the cyllarus.]"

The nerites has a smooth large round shell, ${ }^{+}$and resembles the ceryx in shape, only the poppy-juice is, in its case, not black but red. It clings with great force near the middle. ${ }^{5}$ I 5 In calm weather, then, they go free afield, but when the wind blows the carcinia take shelter against the rocks: the neritae themselves cling fast like limpets ; ${ }^{;}$and the same is the case with the haemorrhoid or aporrhaid and all others of the like kind. And, by the way, they cling to 20 the rock, when they turn back their operculum, for this operculum seems like a lid; in fact this structure represents the one part, in the stromboids, of that which in the bivalves is a duplicate shell. ${ }^{\circ}$ The interior of the animal is fleshy, and the mouth is inside. And it is the same with the haemorrhoid, the purple murex, and all suchlike as animals.

Such of the little crabs as have the left foot or claw the bigger of the two are found in the neritae, but not in the stromboids. [There are some snail-shells which have inside them creatures resembling those little crayfish that are also found in fresh water. These creatures, however, differ in having the part inside the shell soft.]" But as $3^{\circ}$

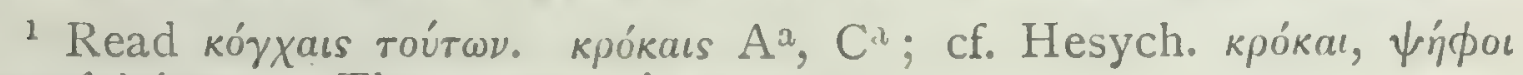

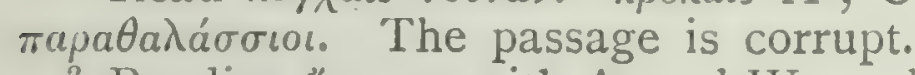

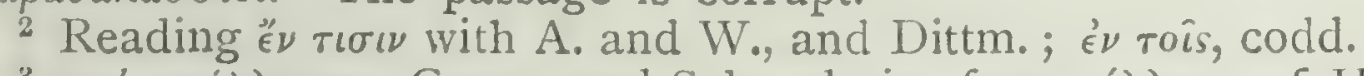

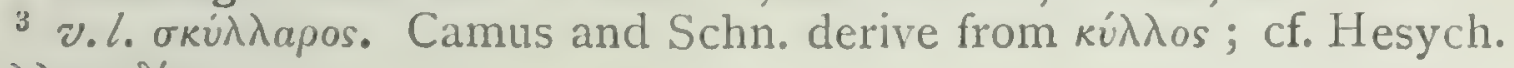
$\kappa v \lambda \lambda \circ \pi 0 \delta i \omega \nu$.

4 The description suggests Dolium galea, the 'rotunda in oleario

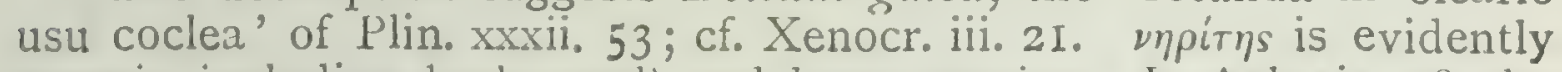
generic, including both small and large species. In Ael. xiv. 28, the

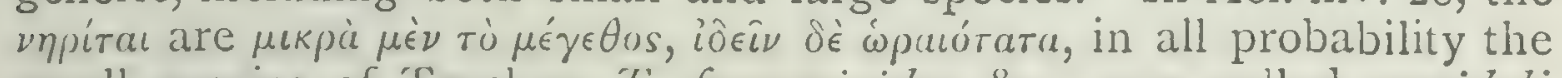
small species of Trochus, $T$. fragerrioides, \&c., now called naridoli in the Adriatic. The large, left-handed Pagurus striatus, 6-9 in. long, is common in Dolium, but like the other hermits does not restrict itself to the shell of any particular mollusc.

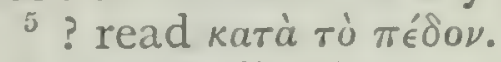

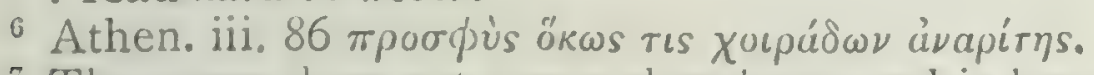

7 The name does not occur elsewhere, and is here variously written. It is usually ascribed to Aporracis pes-pelicani, the mod. Venetian name of which, zamarigola, is somewhat similar.

8 P.A.iv. 5.679" 17.

- Apparently an interpolation, or repetition. 
to their characters, you are referred to my Treatise on Anatomy.

${ }^{1}$ The urchins are devoid of flesh, and this is a character 5 peculiar to them; and while they are in all cases empty and deroid of any flesh within, ${ }^{2}$ they are in all cases furnished with the black formations. There are several species $530^{\mathrm{b}}$ of the urchin, and one of these is that which is made use of for food; " this is the kind in which are found the so-called eggs, ${ }^{4}$ large and edible, in the larger and smaller specimens alike; for even when as yet very small they are provided with them. There are two other species, the spatangus," 5 and the so-called bry'ssus; ${ }^{\prime}$ these animals are pelagic and scarce. Further, there are the cclinometrae, or "motherurchins', the largest in size of all the species. ${ }^{7}$ In addition to these there is another species, small in size, but furnished with large hard spines; it lives in the sea at a depth of several fathoms ${ }^{8}$ and is used by some people as a specific to for cases of strangury. In the neighbourhood of Torone ${ }^{10}$ there are sea-urchins of a white colour, shells, spines, eggs and all, and that are longer than the ordinary sea-urchin. The spine in this species is not large nor strong, but rather $\operatorname{limp}$; and the black formations in connexion with the mouth are more than usually numerous, and communicate with Is the external duct, but not with one another; in point of

1 Cf. throughout, P.A. iv. Io; Plin. 3I (51).

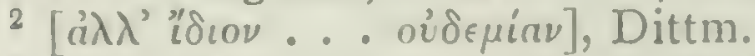

s Several species are used as food. The smaller include Sphaercchimus gramularis and Strongylocentrotus lividus, both very common, and known to the Adriatic fishermen as rizzo di mar, from the ricelike appearance of the eggs. According to Ed. Forbes (European Seas, p. 151) in Sicily the large Echinus esculcntus is called the ' King of Urchins', and the still 'larger E. melo is popularly considered to be

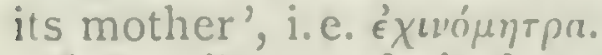

${ }^{4}$ A. will not admit that these are true ova, inasmuch as he denies the existence of ova in testaceans in general; cf. P.A.iv. $5.680^{a} 25$; Antig. 137 .

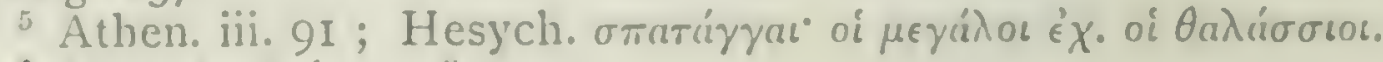

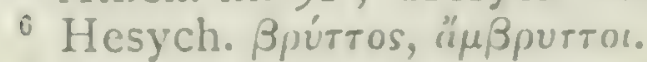

7 Plin. ix. 3 I (5I) 'echinometrae ... quorum longissimae spinae, colyces minimi : aplarently confusing with the next species: ci. note".

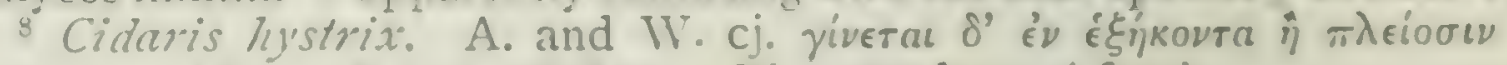

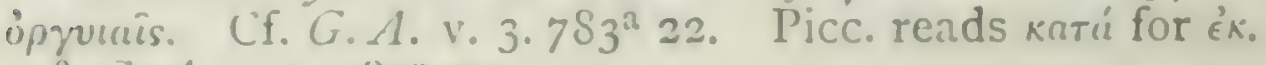

${ }^{3}$ G. $A \cdot$ v. $3 \cdot 783^{\text {il }} 20$.

${ }^{10}$ Cape Drepann, to the west of Athos. The sea-urchin referred to is evidently one of the 'irregular' urchins, or spatangoids. 
fact, the animal is in a manner divided up by them. The edible urchin moves with greatest freedom and most often ; and this is indicated by the fact that these urchins have always something or other ${ }^{1}$ on their spines.

All urchins are supplied with eggs, but in some of the species the eggs are exceedingly small and unfit for food. Singularly enough, the urchin has what we may call its head and its mouth down below, and a place for the issue of the so residuum up above; [and this same property is common to all stromboids and to limpets]. ${ }^{2}$ For the food on which the creature lives lies down below; consequently the mouth has a position well adapted for getting at the food, and the excretion is above, near to the back of the shell. The urchin has, also, five hollow teeth inside, and in the middle of these teeth a fleshy substance serving the office of a 25 tongue. Next to this comes the oesophagus, and then the stomach, divided into five parts, and filled with excretion, ${ }^{3}$ all the five parts uniting at the anal vent, where the shell is perforated for an outlet. Underneath the stomach, in another membrane, are the so-called eggs, identical in number in all cases, and that number is always an odd so number, to wit five. Up above, the black formations ${ }^{t}$ are attached to the starting-point of the teeth, and they are bitter to the taste, and unfit for food. A similar or at least an analogous formation is found in many animals; as, for instance, in the tortoise, the toad, the frog, the stromboids, and, generally, in the molluscs; but the formation varies $53^{\mathrm{I}^{\mathrm{a}}}$ here and there in colour, and in all cases is altogether uneatable, or more or less unpalatable. In reality the mouthapparatus ${ }^{5}$ of the urchin is continuous from one end to the

1 With some doubt I have followed $A$. and $W$. in reading $\langle 0 ̈ \tau \iota\rangle \dot{a} \in \dot{i}$ $\tau$, , on the ground of apparent parallelism with $P . A$. iv. $5.68 \mathrm{I}^{\mathrm{a}} 8$; $\mathrm{cf}_{\text {. }}$ Gaza, "cuius rei argumentum quod semper aliquid algae suis spinis implexum gerant.' On the other hand, Plin. ix. 5 I reads: 'ingredi est his in orbem volvi; itaque detritis saepe aculeis inveniuntur.' This suggests to me that some such word as $\tau \rho \dot{v} \chi o v \sigma \iota \nu$ underlies $\tau \iota$ "̈ Хov

${ }_{2}[]$, A. and W., Dittm.

${ }^{3}$ Cf. P.A. iv. 5. $680^{a}$ 8. A. seems to have taken the general bodycavity, with its fluid-contents, for the stomach.

"In this case the 'black formation' can only be the gut.

${ }^{\sigma} \sigma \dot{u}_{\mu \alpha}, \mathrm{A}$. and W., Dittm. So the Medicean; all other MSS. and 
other, but to outward appearance it is not so, but looks like 5 a horn lantern ${ }^{1}$ with the panes of horn left out. The urchin uses its spines as feet; for it rests its weight on these, and then moving shifts from place to place.

The so-called tethym or ascidian ${ }^{2}$ has of all these animals the most remarkable characteristics. ${ }^{3}$ It is the only mollusc that has its entire body concealed within its shell, ${ }^{4}$ and the 6 1o shell is a substance intermediate between hide and shell, so that it cuts like a piece of hard leather. It is attached to rocks by its shell, and is provided with two passages placed at a distance from one another, rery minute and hard to see, whereby it admits and discharges the sea-water; for it 15 has no visible excretion [whercas of shell fish in gencral some resemble the urchin in this matter of excretion, and others are provided with the so-called mecon, or poppyjuice].5 If the animal be opened, it is found to have, in the first place, a tendinous membrane running round inside the shell-like substance, ${ }^{6}$ and within this membrane is the flesh-like substance of the ascidian, not resembling that in other molluses; but this flesh, to which I now allude, is the same in all ascidia. And this substance is attached in two 20 places to the membrane and the skin, obliquely; and at the point of attachment the space is narrowed from side to side, where the fleshy substance stretches towards the passages that lead outwards through the shell; and here it discharges and admits food and liquid matter; just as it would if one of the passages were a mouth and the other an

cdd. have $\tau ; \sigma \hat{\omega} \mu a$; it cannot. be doubted that the allusion is to the whole oral mechanism now known as '. Mristotle's lantern', claborately described by Cuvier, Lefons d'anat. comp., ISo5, iii. pp. 329-35.

1 The 'lantern' with which the comparison is made is a lantern set on a lamp-post, and therefore having its lower end pointed and not flattened; the 'lantern' of the sea-urchin is uncommonly like that on the poop of a salleon in old Dutch sea-pieces.

2 It. tctinotti. The ascidian, by the way, like the sea-urchin, is a common article of food in the Mediterranean: cf. Il. xvi. 74; Athen. iii. $85,92$. As remedies, Xenocr. 29; Plin. xxiii. 30, 3 I, 39.

P.A.iv. 5.680:4. 4. Vide supra, iv. 4. 528 19.

[ ] A. and W.

- Perhaps we should read $\sigma a p \kappa \omega \delta \in$. So the Aldine; elsewhere

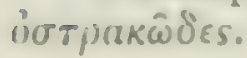


anal vent; and one of the passages is somewhat wider than the other one. Inside it has a pair of cavities, onc on either 25 side, a small partition separating them; and one of these two cavities contains the liquid. The creature has no other organ whether motor or sensory, nor, as was said in the case of the others, is it furnished with any organ connected with excretion, as other shell-fish are. The colour of the ascidian is in some cases sallow, and in other zo cases red. ${ }^{2}$

There is, furthermore, the genus of the sea-nettles, ${ }^{3}$ peculiar in its way. The sea-nettle, or sea-anemone, clings to rocks like certain of the testaceans, but at times relaxes its hold. It has no shell, but its entire body is fleshy. It $53^{\mathrm{I}}$ is sensitive to touch, ${ }^{4}$ and, if you put your hand to it, it will seize and cling to it, as the cuttle-fish would do with its feelers, and in such a way as to make the flesh of your hand swell up..$^{5}$ Its mouth is in the centre of its body, and it lives adhering to the rock as an oyster to its shell. If any 5 little fish ${ }^{6}$ come up against it it clings to it; in fact, just as I described it above as doing to your hand, so it does to anything edible that comes in its way; and it feeds upon sea-urchins and scallops. Another species of the sea-nettle roams freely abroad. ${ }^{\top}$ The sea-nettle appears to be deroid altogether of excretion," and in this respect it resembles a plant. Of sea-nettles there are two species, the lesser and ro more edible; and the large hard ones, such as are found in

1 Cf. $P . A$ iv. $5 \cdot 68 \mathrm{I}^{2} 28$. The two orifices are the mouth and the atrial aperture; the two cavities, the pharynx or branchial sac, and the atrium or cloacal chamber.

2 The red is doubtless Cynthia papiliosa, which is bright scarlet; the sallow includes Phallusia mammillata and other large and common Ascidians.

3 Cf. Plin. ix. 45 (68); H.A. v. I6. $548^{\mathrm{a}} 23$.

4 Cf. P.A.iv. 5. 68 $\mathrm{I}^{\mathrm{b}} 4$. On the text see Dittmeyer.

5 Plin. ix. 45 (68) "vis pruritu mordax'; cf. also Diph. ap. Athen. iii. 90 .

${ }^{6}$ Cf. $H . A$. viii. 2. $590^{a} 28$. On the text cf. Dittm.

${ }^{7}$ Cf. H.A.i. I. $487^{\text {b }}$ I 2 : but possibly the sea-nettle here referred to is a jelly-fish, or medusa; cf. H.A. v. I5. Cf. Cuv. in loc. Plin. 'Urtica marina errans, medusa, L. ; urtica fixa, actinia, L.'

${ }^{8}$ Cf. $H . A$. viii. 2. $590^{a} 29 ; P . A$. iv. $5.68 \mathrm{i}^{\text {a }} 8$.

9 Various anemones are eaten, fried, in the Mediterranean, e.g. Actinia viridis, Fr. ortie de mer. 
the neighbourhood of Chalcis. In winter time ${ }^{1}$ their flesh is firm, and accordingly they are sought after as articles of food, but in summer weather they are worthless, ${ }^{2}$ for they Is become thin and watery: and if you catch at them they break at once into bits, and cannot be taken off the rocks cntire; and being oppressed by the heat they tend to slip back into the crevices of the rocks. ${ }^{3}$

So much for the external and the internal organs of molluscs, crustaceans, and testaceans.

We now proced to treat of insects in like manner. This 7 genus comprises many species, and, though several kinds we clearly related to one another, these are not classified under one common designation, as in the case of the bec, the drone, the wasp, and all such insects, and again as in the case of those that have their wings in a sheath or shard, 25 like the cockichafer, the carabus or stag-beetle, the cantharis or blister-beetle, ${ }^{4}$ and the like.

Insects have three parts common to them all; the head, the trunk containing the stomach, and a third part in betwixt these two, corresponding to what in other creatures cmbraces chest and back. In the majority of insects this intermediate part is single: but in the long and multipedal insects it has practically the same number of segments as of nicks.

3o All insects when cut in two continue to live, excepting such as are naturally cold by nature, or such as from their minute size chill rapidly: though, by the way, wasps notwithstanding their small size continue living after severance. In conjunction with the middle portion either the head or $52^{\text {a }}$ the stomach can live, but the head cannot live by itself. Insects that are long in shape and many-footed can live for a long while after being cut in twain, and the severed portions can move in cither clirection, backwards or forwards; thus, the hinder portion, if cut off, can crawl cither in the

1 Ael. vii. 35 .

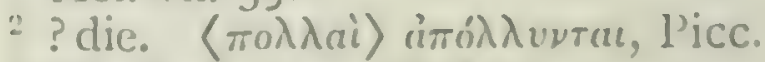

Cf. P. A. iv. 5. $680^{2} 2 \mathrm{~g}$.

Cintharis ie'sicintoriu, L. 
direction of the section or in the direction of the tail, as is observed in the scolopendra. ${ }^{1}$

All insects have eyes, but no other organ of sense discern- 5 ible, except that some insects have a kind of a tongue ${ }^{2}$ corresponding to a similar organ common to all testaceans; and by this organ such insects taste and imbibe ${ }^{3}$ their food. In some insects this organ is soft; in other insects it is firm; as it is, by the way, in the purple-fish, among testaceans. ${ }^{*}$ In the horsefly and the gadfly this organ is hard, and 10 indeed it is hard in most insects. In point of fact, such insects as have no sting in the rear use this organ as a weapon, ${ }^{5}$ (and, by the way, such insects as are provided with this organ are unprovided with teeth, with the exception of a few insects); the fly by a touch can draw blood with this organ, and the gnat can prick or sting with it.

Certain insects are furnished with prickers or stings. Some insects have the sting inside, as the bee and the ${ }_{5} 5$ wasp,${ }^{6}$ others outside, as the scorpion; and, by the way, this is the only insect furnished with a long tail. ${ }^{7}$ And, further, the scorpion is furnished with claws, as is also the creature resembling a scorpion ${ }^{8}$ found within the pages of books.

In addition to their other organs, flying insects are furnished with wings. Some insects are dipterous or 20 double-winged, as the fly; others are tetrapterous or furnished with four wings, as the bee; and, by the way, no insect with only two wings has a sting in the rear." Again, some winged insects have a sheath or shard for their wings, as the cockchafer; whereas in others the wings

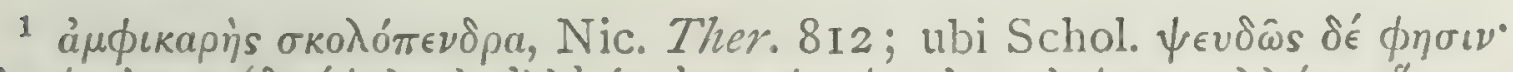

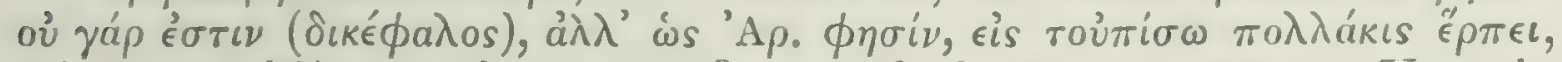

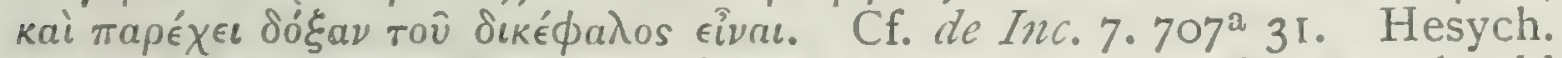

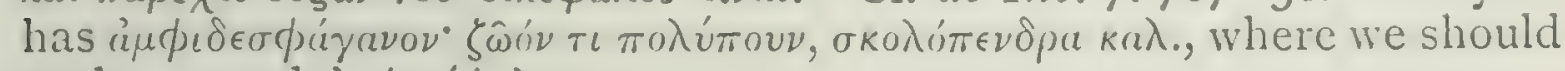

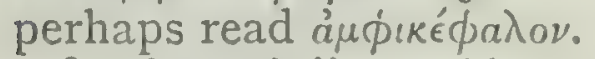

${ }^{2}$ Cf. P.A. ii. I7. 66 I $^{\mathrm{a}}$ I 5, iv. $5.678^{\mathrm{b}}$ I 3 .

${ }^{3}$ eis aurú, Picc., A. and W., Dittm.

4 A. and W. bracket this sentence.

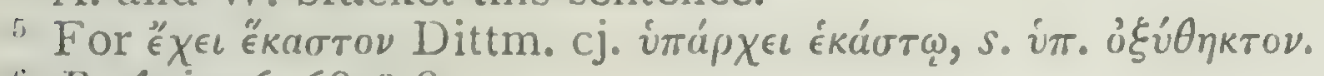

"P.A.iv. 6.683 8 .

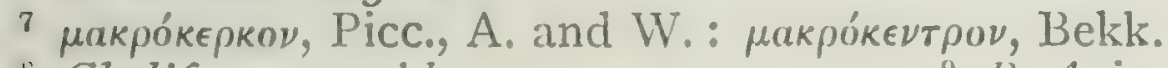

8 Chelifer cancroides. $P$. A. iv. 6.683it I3. 
are unsheathed, as in the bee. But in the case of all alike, 25 flight is in no way modificd by tail-stecrage: and the wing is devoid of quill-structure or division of any kind. ${ }^{1}$

Again, some insects have antennae in front of their eyes, as the butterfly and the horned-beetle. Such of them as have the power of jumping have the hinder legs the longer; and these long hind-legs whereby they jump ${ }^{2}$ bend backwards like the hind-legs of quadrupeds. All insects have 30 the belly different from the back; as, in fact, is the case with all animals. The flesh of an insect's body is neither shcll-like nor is it like the internal substance of shellcovered animals, nor is it like flesh ${ }^{3}$ in the ordinary sense of the term; but it is a something intermediate in quality. ${ }^{4}$ Therefore they have nor spine, nor bone, nor $532^{\text {b }}$ sepia-bone, nor enveloping shell; but their body by its hardness is its own protection and requires no extraneous support. However, insects have a skin; but the skin is exceedingly thin. These and such-like are the external organs of insects.

5 Internally, next after the mouth, comes a gut, in the majority of cases straight and simple down to the outlet of the residuum: but in a few cases the gut is coiled. ${ }^{5}$ No insect is provided with any viscera, or is supplied with fat; and these statements apply to all animals devoid of blood. Some have a stomach also: and attached to this the rest of the gut, either simple or convoluted as in the case of 1o the acris or grasshopper."

The tettix or cicada, ${ }^{\text {s }}$ alone of such creatures (and, in fact, alone of all creatures), is unprovicled with a mouth, but it is provided with the tongue-like formation found in

1 H. A. iii. 12. $519^{n} 28$.

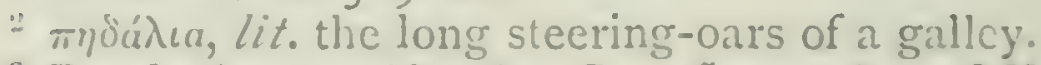

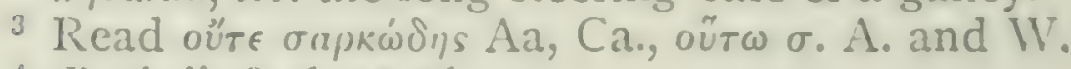

P.A. ii. $8.654^{\mathrm{a}} 26$.

5 Plin. xi. $3(4)$ 'nihil intus nisi admodum paucis intestinum implicatum'.

${ }^{6}$ P.A.iv. $5.682^{\mathrm{a}} 15$.

7 A. and W. point out that the gut is simple in the locusts, but much coiled in the cicadas. "They therefore suggest $i \vec{i}$ i $\pi \lambda_{0} \dot{\nu} \nu \tilde{\omega} \sigma \pi \epsilon \rho$ ai

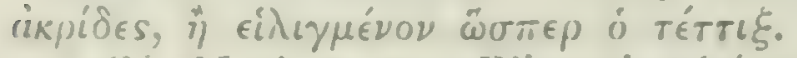

C. H.A.v. 3o; Plin. xi. 26 (32); Ael. i. 20.

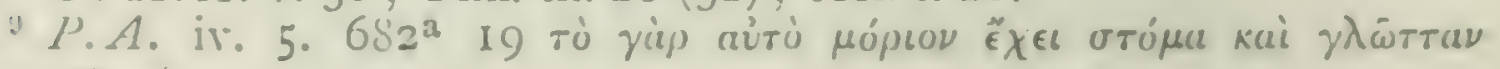
mprepinkis. 
insects furnished with frontward stings: ${ }^{1}$ and this formation in the cicada is long, continuous, and devoid of any split; and by the aid of this the creature feeds on dew, and on dew only, and in its stomach no excretion is ever found. Of the cicada there are several kinds, ${ }^{2}$ and they differ from one another in relative magnitude, and in this respect that ${ }_{5}$ the achetes ${ }^{3}$ or chirper is provided with a cleft or aperture under the hypozoma ${ }^{4}$ and has in it a membranc quite discernible, ${ }^{5}$ whilst the membrane is indiscernible in the tettigonia.

Furthermore, there are some strange creatures to be found in the sea, which from their rarity we are unable to classify. Experienced ${ }^{6}$ fishermen affirm, some that they have at 20 times seen in the sea animals like sticks, black, rounded, and of the same thickness throughout; others that they have seen creatures resembling shields, red in colour, and furnished with fins packed close together; and others that they have seen creatures resembling the male organ in shape and size, with a pair of fins in the placc of the 25 testicles, and they aver that on one occasion a creature of this description was brought up on the end of a nightline. ${ }^{7}$

So much then for the parts, external and internal, exceptional and common, of all animals.

8 We now proceed to treat of the scnses; for there are diversities in animals with regard to the senses, seeing that 30

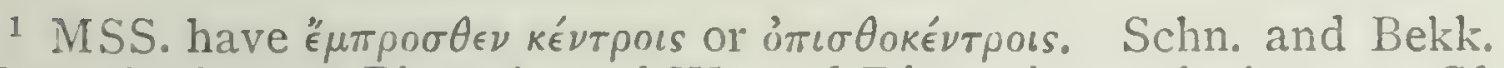

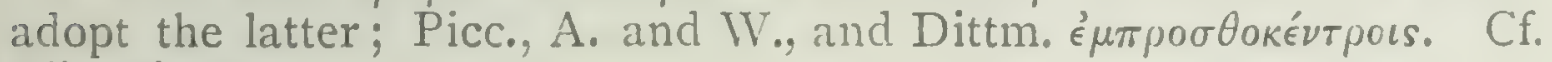
Plin. xi. 32.

2 Ael. x. 44.

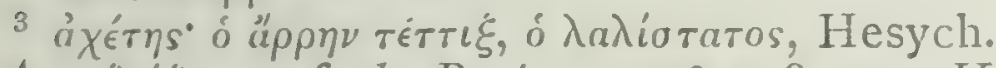

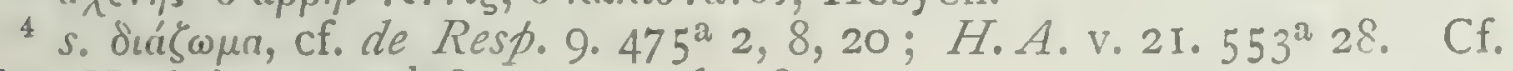
also $H . A$. iv. 9. $535^{\mathrm{b}} 8, \mathrm{v} \cdot 30 \cdot 55^{\mathrm{a}}$ I 8 .

5 This organ is peculiar to the male cicada; cf. Carus, Analekten, I828, p. I46; Landois, Tonapparate der Insekten, I867, p. 48. A pair of little drums on the first abdominal segment are set in vibration by muscles within; the abdomen filled with air acts as a resonator.

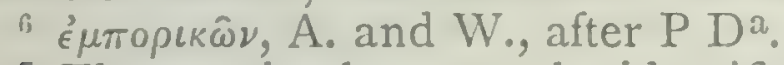

7 These animals cannot be identified, but I believe the last to be, in all probability, Gastrofteron meclelii. The second suggests Penn:1tula, though the comparison with a shield is obscure; Prof. Grute refers it to Idalia laciniosa, or some similar sea-slug. 
some animals have the use of all the senses, and others the use of a limited number of them. The total number of the senses (for we have no experience of any special sense not here included), is five: sight, hearing, smell, taste, and touch.

Man, then, and all vivipara that have feet, and, further, $533^{\text {a }}$ all red-blooded ovipara, ${ }^{1}$ appear to have the use of all the five scnses, except where some isolated species has been subjected to mutilation, as in the case of the mole. ${ }^{2}$ For this animal is deprived of sight; it has no cyes visible, but 5 if the skin-a thick one, by the way-be stripped off the head, about the place in the exterior where cyes usually are, the cyes are found inside in a stunted condition, furnished with all the parts found in ordinary eyes; that is to say, we find there the black rim, and the fatty part surrounding it;" but all these parts are smaller than the ro same parts in ordinary visible eyes. There is no external sign of the existence of these organs in the molc, owing to the thickness of the skin drawn over them, so that it would seem that the natural course of development were congenitally arrested; [for extending from the brain ${ }^{4}$ at its junction with the marrow are two strong sinewy ducts running past the sockets of the eycs, and terminating at the upper cycIs teeth]. All the other animals of the kinds above mentioned have a perception of colour "and of sound, and the senses of smell and taste; the fifth sense, that, namely; of touch. is common to all animals whatsoever.

In some animals the organs of sense are plainly dis-

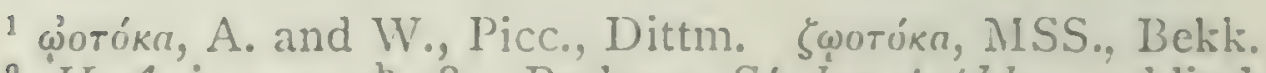

2 'H.A.i. 9. 49I' 28. Perhaps Spalax typhluss, a blind, mole-like rodent, abundant in the Cyclades, where, according to Erhard, the mole is not found. We have no information as to the distribution of the two in Greece.

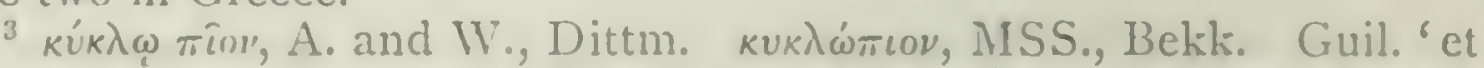
quod in circuitu pingue'. Cf. H. A. iii. IS. 520" 2 ; de Sensu, 2. $438^{\text {: }}$

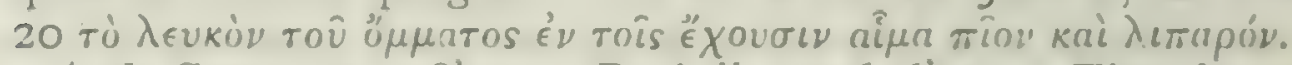

${ }^{1}$ de Sensu, 2. $43^{b} 27 ; P$. A. ii. 10.656 17 . The clause bracketed (by $A$. and IV.) apparently does not refer to the mole (which has no conspicuous eye-teeth, while Spalax has none at all), but is an interpolation of general import.

5 Colour is held to be that which we actually see: cf. de Sensu: 3 .

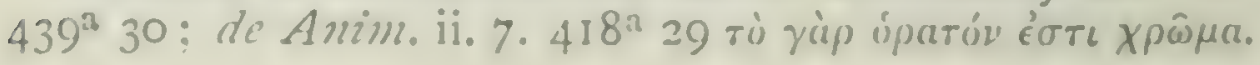


cernible; and this is especially the case with the eyes. ${ }^{1}$ For animals have a special locality for the cyes, and also 20 a special locality for hearing: that is to say, some animals have ears, while others have the passage for sound discernible. $^{2}$ It is the same with the sense of smell; that is to say, some animals have nostrils, and others have only the passages for smell, such as birds. It is the same also with the organ of taste, the tongue. Of aquatic red-blooded 25 animals, ${ }^{3}$ fishes possess the organ of taste, namely the tongue, but it is in an imperfect and amorphous form, ${ }^{4}$ in other words it is osseous and undetached. In some fish the palate ${ }^{5}$ is fleshy, as in the fresh-water carp, so that by an inattentive observer it might be mistaken for a tongue. ${ }^{6}$

There is no doubt but that fishes have the sense of taste, for a great number of them delight in special flavours; and fishes freely take the hook if it be baited with a piece of flesh from a tunny or from any fat fish, obviously enjoying the taste and the eating of food of this kind. Fishes have no visible organs for hearing or for smell ${ }^{7}$ for what might $533^{b}$ appear to indicate an organ for smell in the region of the nostril has no communication with the brain. These indications, in fact, in some cases lead nowhere, like blind alleys, and in other cases lead only to the gills; but for all this fishes undoubtedly hear and smell. For they are observed 5 to run away from any loud noise, such as would be made by the rowing of a galley, so as to become easy of capture in their holes; for, by the way, though a sound be very slight in the open air, it has a loud and alarming resonance to creatures that hear under water. ${ }^{8}$ And this is shown in the capture of the dolphin; for when the hunters have ro enclosed a shoal of thesc fishes with a ring of their canoes, they set up from inside the canoes a loud splashing in the

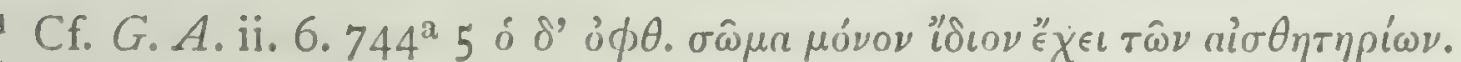

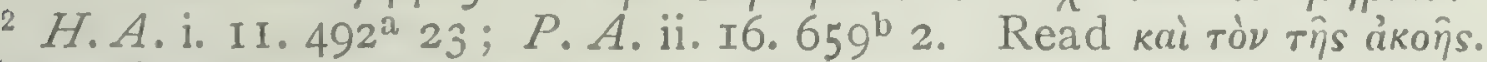

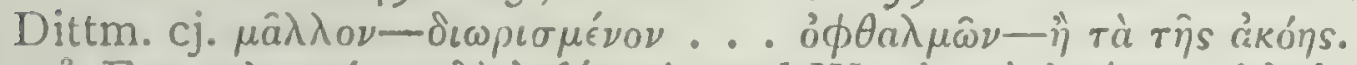

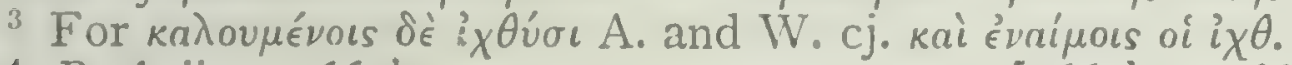

${ }^{4}$ P.A. ii. $17.660^{\mathrm{b}} \mathrm{r}$. ${ }^{\mathrm{g}} 66 \mathrm{O}^{\mathrm{b}} 34,66 \mathrm{I}^{\mathrm{a}} \mathrm{I}$.

6 Still known as 'carps' tongues', and esteemed as a delicacy.

('Vim augendae Veneris habet,'Aldrovandi.)

7 P.A. ii. 16. $659^{\mathrm{b}}$ I3.

8 A. and W. bracket kai ... $\pi \hat{a} \sigma \iota \nu$. 
water, and by so doing induce the creatures to run in a shoal high and dry up on the beach, and so capture them while stupefied with the noise. And yet, for all this, the dolphin has no organ of hearing discernible. ${ }^{2}$ Furthermore, 15 when engaged in their craft, fishermen are particularly careful to make no noise with oar or net; and after they have spied a shoal, they let down their nets at a spot so far off that they count upon no noise being likely to reach the shoal, occasioned cither by oar or by the surging of their 20 boats through the water ; and the crews are strictly enjoined to preserve silence until the shoal has been surrounded. And, at times, when they want the fish to crowd together, they adopt the stratagem of the dolphin-hunter; in other words they clatter stones together, that the fish may; in their fright, gather close into one spot, and so they envelop 25 them within their nets. [Before surrounding them, then, they prescrve silence, as was said; but, after hemming the shoal in, they call on every man to shout out aloud and make any kind of noise: for on hearing the noise and hubbub the fish are sure to tumble into the nets from sheer fright.] ${ }^{3}$ Further, when fishermen see a shoal of fish feeding at a :o distance, disporting themselves in calm bright weather on the surface of the water, if they are anxious to descry the size of the fish and to learn what kind of a fish it is, they may succeed in coming upon the shoal whilst yet basking at the surface if they sail up without the slightest noise, but if any man make a noise previously, the shoal will be seen to scurry away in alarm. Again, there is a small $534^{\text {a }}$ river-fish called the cottus ${ }^{4}$ or bull-head; this creature burrows under a rock, and frshers catch it by clattering stones against the rock, and the fish, bewildered at the noise, larts out of its hiding-place. From these facts it is : quite obrious that frshes can heir: and indecd some people,

1 A similar procedure is described by Apostolides (op. cit. p. 33) in the capture of ovvaypises, Dentex vulgaris. A hollow cone on a long handle is used for striking the water by Adriatic fishermen, and is

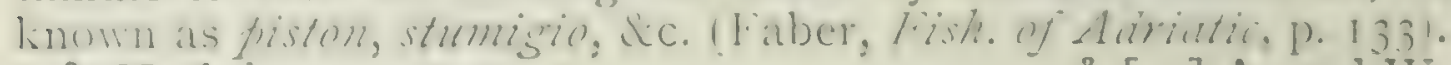

2 H.A. II. $402^{\mathrm{a}} 29^{\circ}$.

${ }^{3}[] \mathrm{A}$. and $W$.

* MISS. have Boiros and koítos. Sylburg restored kóstos, from Gaza. The traditional identification with Cothus gobio, L., has little value. 
from living near the sea and frequently witnessing such phenomena, affirm that of all living creatures the fish is the quickest of hearing. And, by the way, of all fishes the quickest of hearing are the cestreus or mullet, the cluremps, ${ }^{1}$ the labrax or basse, ${ }^{2}$ the salpe or saupe, ${ }^{3}$ the cliromis or sciaena, ${ }^{4}$ and such like. ${ }^{5}$ Other fishes are less quick of to hearing, and, as might be expected, are more apt to be found living at the bottom of the sea.

The case is similar in regard to the sense of smell. ${ }^{6}$ Thus, as a rule, fishes will not touch a bait that is not fresh, neither are they all caught by one and the same bait, but they are severally caught by baits suited to their several likings, and these baits they distinguish by their sense of smell $;^{7}$ and, by the way, some fishes are attracted by 15 malodorous baits, as the saupe, for instance, is attracted by excrement. Again, a number of fishes live in caves; and accordingly fishermen, when they want to entice them out, smear the mouth of a cave ${ }^{8}$ with strong-smelling pickles, and the fish are soon attracted to the smell. And the eel 20 is caught in a similar way; for the fisherman lays down an earthen pot that has held pickles, after inserting a 'weel' in the neck thereof. As a general rule, fishes are especially attracted by savoury smells. For this reason, fishermen roast the fleshy parts of the cuttle-fish and use it as bait on account of its smell, for fish arc peculiarly attracted by it ; they also bake the octopus and bait their fish-baskets $=5$ or weels with it, entirely, as they say, on account of its smell. Furthermore, gregarious fishes, ${ }^{9}$ if fish-washings or bilge-water be thrown overboard, are observed to scud off

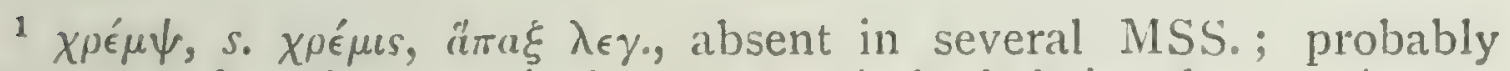
corrupt, and perhaps equivalent to $\chi p o \mu i s$, both being from $\chi \rho \epsilon \mu \omega$, to neigh; cf. infra.

${ }^{2}$ Labrax lupus; cf. Ar. ap. Athen. vii. $310^{b}$.

${ }^{3}$ Box salpa; cf. Athen. vii. $32 \mathrm{I}^{\mathrm{\theta}}$. Mod. Gk. $\sigma a ́ \lambda \pi a$, It. salpa, scroupi, \&c.

${ }^{4}$ xpouis. Sciuence aquila (or some closely allied fish): said to be still called chro in Genoa and Marseilles, Cuvier, Ann. Inst. Arilucul., 1842 , p. 73. See notes v. IO. $543^{\mathrm{b}} 2$, viii. $12.601^{\mathrm{b}} 30$.

\footnotetext{
5 Ael. ix. 7 ; Plin. x. 89. ${ }^{6}$ de Sensu, 5. $444^{\text {b }} 8$.

7 Cheese, for instance, is much used by Greek fishermen; similarly rogue or cod-roe by French sardine-fishers.

8 Plin. xi. 2 (3) : Opp. Hal.iv. 647.

(3) Ael. ix. 46.
} 
to a distance, from apparent dislike of the smell. And it is asserted that they can at once detect by smell the presence $534^{\text {b }}$ of their own blood ; and this faculty is manifested by their hurrying off to a great distance whencver fish-blood is spilt in the sea. And, as a general rule, if you bait your weel with a stinking bait, the fish refuse to enter the weel or even to draw near; but if you bait the weel with a fresh 5 and savoury bait, they come at once from long distances and swim into it. [And all this is particularly manifest in the dolphin; for, as was stated, it has no visible organ of hearing, and yet it is captured when stupefied with noisc; and so, while it has no visible organ for smell, it has the ro sense of smell remarkably kecn.] ${ }^{1}$ It is manifest, then, that the animals above mentioned are in possession of all the five senses.

All other animals may, with very few cxceptions, be comprehended within four genera: to wit, molluscs, crusta15 ceans, testaceans, and insects. Of thesc four genera, the mollusc, ${ }^{2}$ the crustacean, and the insect have all the senses: at all crents, they have sight," smell, and taste. As for insects, both winged and wingless, they can detect the presence of scented objects afar off, as for instance bees and cnipes ${ }^{4}$ detect the presence of honey at a distance; 20 and they do so recognizing it by smell. Many insects are killed by the smell of brimstone; "ants, if the apertures to their dwellings be smeared with powdered "origanum and brimstone, quit their nests; and most insects may be banished with burnt hart's horn, or better still by the 25 buming of the gum styrix. The cuttle-fish, the octopus, and the crawfish may be caught by bait.' The octopus, in fact, clings so tightly to the rocks that it cannot be

I [ ] A. and W.

2 Cf. de Sensul, 5. 444" 12.

$3 \mathrm{~A}$. and W. omit ö $\psi w$, holding that it and akoinv are unmentioned

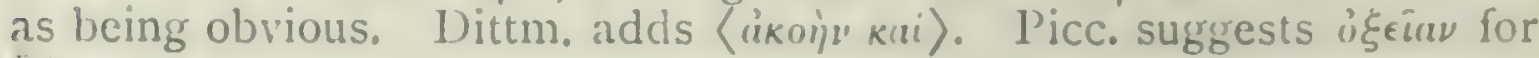
rivin.

1 I'lin. xi. 19, xxx. 53; cf. Theoph. de 1'\% iv. 17 ; de Sinsu, l.c.

"SC. кичоне́ vou.

${ }^{6} \lambda \in i \omega \nu$. Rejected as meaningless by $A$. and $W$. Dittm. quotes Scal., ' $\lambda \epsilon i \omega \nu$, frequens dictio Dioscoridi et Galeno subigere' uliquo liquore'; and continues, 'adde $\lambda \epsilon \iota \bar{u} v, i . c$. in pulverem conterere.'

${ }^{7}$ Plin. x. 90. 
pullcd off, but remains attached even when the lnife is employed to sever it; and yet, if you apply fleabane to the creature, it drops off at the very smell of it. ${ }^{1}$ The facts are similar in regard to taste. For the food that insects go in $535^{\text {at }}$ quest of is of diverse kinds, and they do not all delight in the same flavours: for instance, the bee ${ }^{2}$ never settles on a withered or wilted flower, but on fresh and sweet ones; and the conops or gnat ${ }^{3}$ settles only on acrid substances and not on sweet. The sense of touch, by the way, as has been remarked, is common to all animals. Testaceans 5 have the senses of smell and taste. With regard to their possession of the sense of smell, that is proved by the use of baits, e.g. in the case of the purple-fish; for this creature is enticed by baits of rancid meat, which it perceives and is attracted to from a great distance. The proof that it possesses a sense of taste hangs by the proof of its sense of 10 smell; for whenever an animal is attracted to a thing by perceiving its smell, it is sure to like the taste of it. Further, all animals furnished with a mouth derive pleasure or pain from the touch of sapid juices.

With regard to sight and hearing, we cannot make statements with thorough confidence or on irrefutable evidence. However, the solen or razor-fish, if you make a noise, appears to burrow in the sand, and to hide himself deeper is when he hears the approach of the iron rod ${ }^{4}$ (for the animal, be it observed, juts a little out of its hole, while the greater part of the body remains within),-and scallops, if you present your finger near their open valves, close them tight ${ }^{5}$ again as though they could see what you were doing. Furthermore, when fishermen are laying bait for neritae, 20

1 This procedure is still common in (ireece, either fleabane (Imula coryza) or tobacco being used; see Apostolides, La Pêche en Grèce, 1907, p. 50. Cf. Arch. zool. exp. et gén., 1881, p. 412.

${ }^{2}$ Cf. viii. I I. $596^{\mathrm{b}}$ I 5 ; cf. also ix. $40.625^{\mathrm{b}} 20$. See also Plin. xi. 8; Varro, R. R. iii. I6. 6.

3 A. and W. suggest here the vinegar-fly, Mosillus (Oinopota) cellarius.

${ }^{4}$ lit. 'iron'; probably an iron rod with a conical knob at the end, still used in the Adriatic for the capture of the cafie langle or razorfish; it is let down into the creature's burrow, between its valves which close upon it, and it is thus drawn up (Faber, Adriatic, p. Sg).

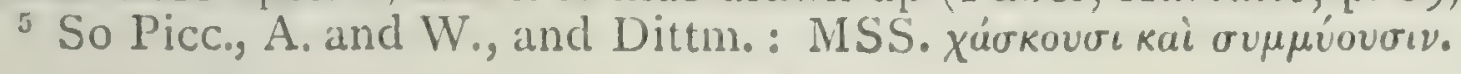


they always get to lecward of them, and never speak a word while so engaged, under the firm impression that the animal can smell and hear; and they assure us that, if any one speaks aloud, the creature makes efforts to escape. With regard to testaccans, of the walking or creeping species the urchin appears to have the least developed sense of smell; and, of the stationary specics, the ascidian 25 and the barnacle.

So much for the organs of sense in the general run of animals. We now proceed to treat of voice.

Voice and sound are different from one another; and $\mathbf{9}$ language differs from voice and sound. The fact is that no animal can give utterance to voice except by the action of the pharynx, ${ }^{1}$ and consequently such animals as are devoid of lung have no voice; and language is the 30 articulation of rocal sounds by the instrumentality of the tongue. Thus, the voice and larynx can emit vocal or vowel sounds; non-vocal or consonantal sounds are made $535^{\mathrm{b}}$ by the tongue and the lips; and out of these vocal and non-vocal sounds language is composed. Consequently: animals that have no tongue at all or that have a tongue not freely detached, have neither voice - nor language: although, by the way, they may be enabled to make noises or sounds by other organs than the tongue.

Insects, for instance, have no roice and no language, but they can emit sound by internal air or wind, though not by the emission of air or wind; for no insects are capable of respiration." But some of them make a humming noise. like the bee and the other winged insects; and others are said to sing, as the cicada.' And all these latter insects make their special noises by means of the membrane that is underncath the hypozomal - those insects, that is to say, whose body is thus divided ; ${ }^{5}$ as for instance: one

1 P.A. iii. $3.664^{\mathrm{a}} 3^{6}$.

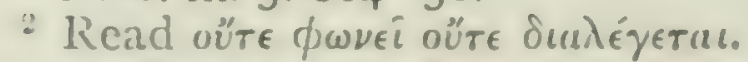

${ }^{3}$ Cf. Plin. xi. $2(3)$.

4 de liesp. 9. $475^{\mathrm{a}} 6$; de Somn. et Vig. $2.456^{3}$ 10, $20 ; H . \Lambda$. v. 30. $5500^{2} 20$.

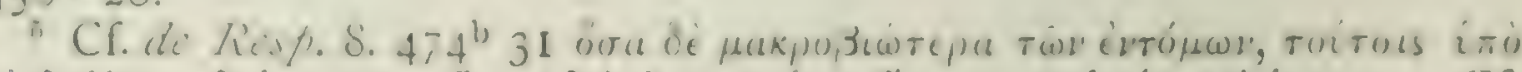

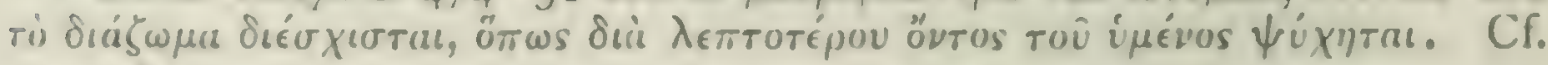
9. $475^{\mathrm{a}} 19$. 
species of cicada, which makes the sound by means of the friction of the air. ${ }^{1}$ Flies and bees, and the like, produce ro their special noise by opening and shutting their wings in the act of flying; for the noise made is by the friction of air between the wings when in motion. The noise made by grasshoppers is produced by rubbing or reverberating with their long hind-legs. ${ }^{2}$

No mollusc or crustacean can produce any natural voice or sound. Fishes can produce no voice, for they have no lungs, nor windpipe and pharynx; but they emit certain inar- 15 ticulate sounds and squeaks, which is what is called their 'voice', ${ }^{3}$ as the lyr $a^{4}$ or gurnard, and the sciaena ${ }^{5}$ (for these fishes make a grunting kind of noise) and the caprus or boar-fish in the river Achelous, ${ }^{6}$ and the chalcis ${ }^{7}$ and the cuckoo-fish ${ }^{4}$ for the chalcis makes a sort of piping sound, and the cuckoo-fish makes a sound greatly like the cry of 20 the cuckoo, and is nicknamed from the circumstance. The apparent voice in all these fishes is a sound caused in some cases by a rubbing motion of their gills, ${ }^{8}$ which by the way

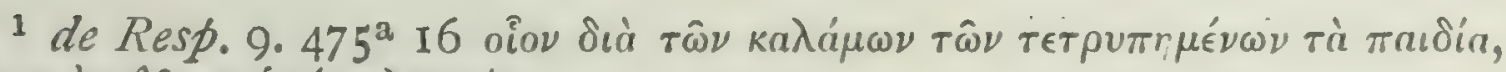

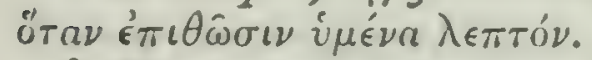

2 The sound is produced by a toothed bar rubbing against a ridged surface. Sometimes the hind-leg rubs against the elytron or forewing (Acridiidae), sometimes one elytron against the other (Gryllidal, Locustidae). Cf. (int. al.) Latreille, Mém. Mus. d'Hist. Nat. viii. I 822; Regen, Arb. zool. Inst. Univ. Wien, xiv (1903), pp. 359-422.

${ }^{3}$ Ael. x. II. Cf. Joh. Müller, 'Ueber die Fische welche Töne von sich geben,'Arch. f. Anat., I 857, p. 249; also Sörensen, Om Lydorganer hos Fiske, Copenhagen, 1884.

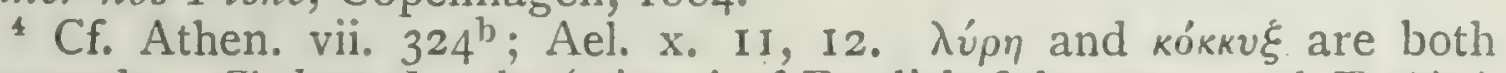
gurnards. 7 : Iyra, L., the 'piper' of English fishermen, and T. fini, Bloch (both called $T$. cuculus by Linnaeus), seem to be the 'cuckoofish', and are still so called in various Mediterranean dialects; the common gurnard, T. gurnardus, is a 'grunter', Fr. grondin, grognant, Germ. Knurrhahn, \&c.

${ }^{5}$ Cf. Cuv. et Valenciennes, iv. p. 4 I ; Day, British Fishes, i. p. I 5 I.

${ }^{6}$ de An. ii. 8. $420^{\mathrm{b}}$ I2; Ael. x. II ; Plin. xi. II2. This cannot be our boar-fish (Capros aper), which is marine. It is not impossible that it is another name for the $\gamma \lambda$ ávis or Silurus (see notes on vi. I3. $568^{\mathrm{a}} 23$, viii. $20.602^{\mathrm{b}} 22$ ), which belongs to a family remarkable for vocal powers.

7 Identified by many with the John Dory, Zeus faber. J. Müller would read here $\chi a \lambda k \in u$ is (cf. Opp. IFal. i. 133), which Athen. (3250) distinguishes from $\chi^{a \lambda k i s . ~ \chi a p a k i \delta a ~ i n ~ M o d . ~ C i k . ~ i s . ~ S a r g u s ~ a n t g a r i s . ~}$

${ }^{8}$ Or rather gill-covers; stridulation often occurs also at the base of the fin-spines. 
are prickly; ${ }^{\prime}$ or in other cases by internal parts about their bellies; for they all have air or wind inside them," by rubbing and moving which they produce the sounds." 25 Some cartilaginous fish seem to squeak.

But in these cases the term 'voice' is inappropriate; the more correct expression would be 'sound'. For the scallop, when it goes along supporting itself on the water, which is technically called 'flying', makes a whizzing sound; and so does the sen-swallow or flying-fish: ${ }^{4}$ for this fish flics in the air, clcan out of the water, being furnished with fins 30 broad and long. Just then as in the flight of birds the sound made by their wings is obriously not voice, so is it in the case of all these other creatures.

The dolphin, when taken out of the water, gives a squeak $53^{\mathrm{a}}$ and moans in the air, but these noises do not resemble those above mentioned. For this creature has a voice (and can therefore utter vocal or vowel sounds), for it is furnished with a lung and a windpipe; but its tonguc is not loose, nor has it lips, so as to gire utterance to an articulate sound 〈or a sound of rowel and consonant in combination〉.

Of animals which are furnished with tongue and lung,"

5 the oviparous quadrupeds produce a roice, but a fecble one; in some cases, a shrill piping sound, like the scrpent: in others, a thin faint cry ; ${ }^{6}$ in others, a low hiss, like the tortoise. The formation of the tongue in the frog is exceptional. The front part of the tongue, which in other animals is detached, is tightly fixed in the frog as it is in ro all fishes; but the part towards the pharynx is frecly detached, and may, so to speak, be spat outwards, and it

I. A. ii. $17.660^{\text {l) }} 25$.

2 Cf. Miuller, l.c., p. $26 \%$.

3 Noreau describes, in Trigla and Zeus, an annular diaphragm stretching across the cavity of the air-bladder and set in rapid vibration; C. R. Paris, lix. p. 436, 1864; Anm. Sc. Nat. (6) iv. 1876, p. 65.

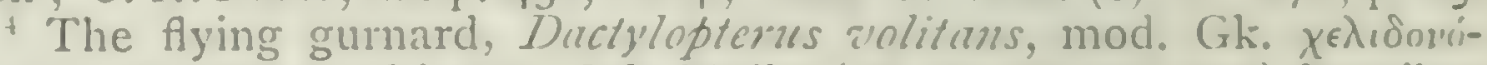

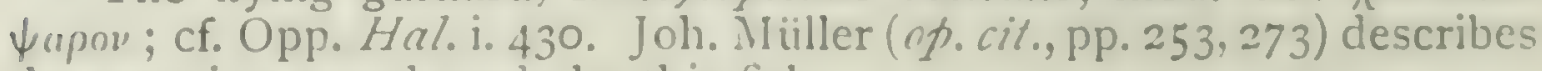
the grunting sound made by this fish.

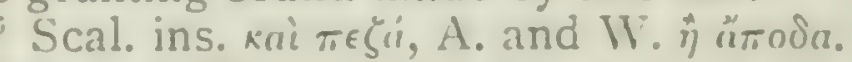

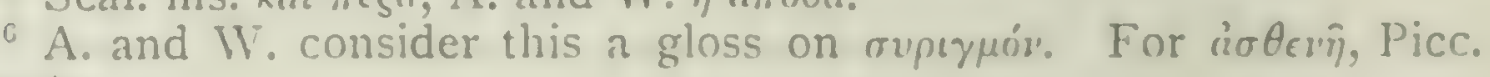
oteli,

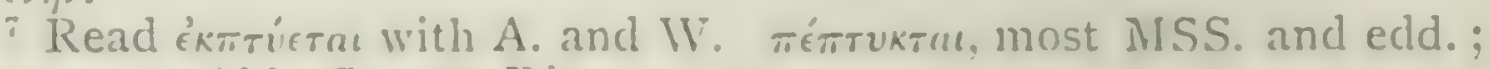

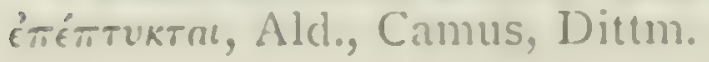


is with this that it makes its peculiar croak. The croakings that goes on in the marsh is the call of the males to the females at rutting time; ${ }^{1}$ and, by the way, all animals have a special cry for the like end at the like season, as is obscrved in the case of goats, swine, and sheep. [The I5 bull-frog makes its croaking noise by putting its under jaw on a level with the surface of the water and extending its upper jaw to its utmost capacity. The tension is so great that the upper jaw becomes transparent, and the animal's eyes shine through the jaw like lamps ; ${ }^{2}$ for, by the way, the commerce of the sexes takes place usually in the night time.]

Birds can utter vocal sounds; and such of them can 20 articulate best as have the tongue moderately flat, and also such as have thin delicate ${ }^{3}$ tongues. In some cascs, the male and the female utter the same note; in other cases, different notes. The smaller birds are more vocal and given to chirping than the larger ones; but in the pairing season every species of bird becomes particularly vocal. 25 Some of them call when fighting, as the quail, others cry or crow when challenging to combat, as the partridge, ${ }^{+}$or when victorious, as the barn-door cock. In some cases cock-birds and hens sing alike, as is observed in the nightingale, only that the hen stops singing when brooding or 30 rearing her young;" in other birds, the cocks sing more" than the hens; in fact, with barn-door fowls and quails, the cock sings and the hen does not.

Viviparous quadrupeds utter vocal sounds of different kinds, but they have no power of converse. In fact, this $53^{\mathrm{b}}$

1 Ael. ix. I3.

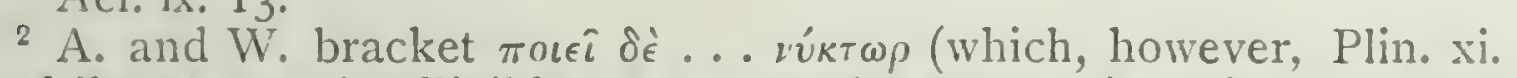
65 follows) as unintelligible. I suspect the passage is entirely corrupt,

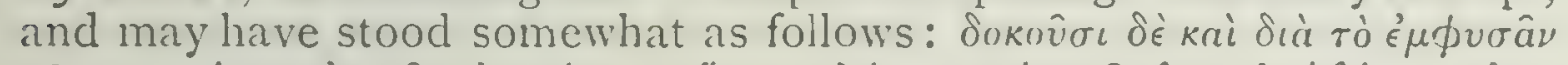

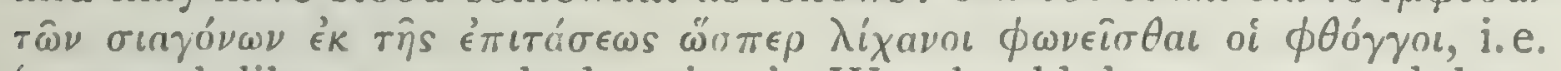
'resound like a stretched string.' We should have expected here some reference to the vocal sacs, as in Ov. Met. vi. 377 'inflataque colla tumescunt'; cf. Alb. M. xxvi. p. 253 'ideo vesicas duas inflatas facit a latere oris, et cum vocat inferius labrum in aquae tenet superficie, et superius super aquam'.

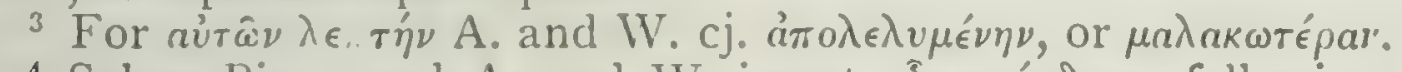

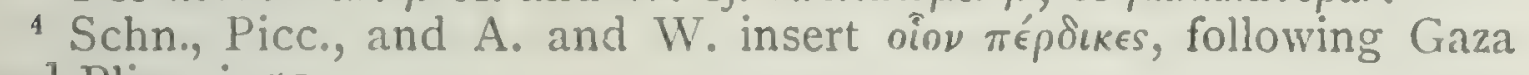
and Plin. xi. 5 I.

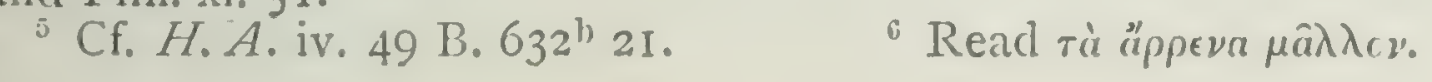


power, or language, is peculiar to man. For while the capability of talking implics the capability of uttering vocal sounds, the converse does not hold good. Men that are born deaf are in all cases also clumb; that is, they can 5 make vocal sounds, but they cannot speak. Children, just as they have no control over other parts, so have no control, at first, over the tongue; but it is so far imperfect, ${ }^{1}$ and only frees and detaches itself by degrees, so that in the interval children for the most part lisp and stutter. ${ }^{2}$

Vocal sounds and modes of language differ according to locality: Vocal sounds are characterized chiefly by their ro pitch, whether high or low, and the kinds of sound capable of being produced are identical within the limits of one and the same species; but articulate sound, that one might reasonably designate 'language', differs both in various animals, and also in the same species according to diversity of locality; as for instance, some partridges cackle, and some make a shrill twittering noise." Of little birds, some ${ }^{5}$ sing a different note from the parent birds, if they have been removed from the nest and have heard other birds singing; and a mother-nightingale has been observed to give lessons in singing to a young bird, ${ }^{4}$ from which spectacle we might obriously infer that the song of the bird was not equally congenital "with mere voice, but was something capable of modification and of improvement. ${ }^{6}$ Men have the same voice or vocal sounds, but they differ 20 from one another in speech or language.

The elephant makes a vocal sound of a wind-like sort by the mouth alone, unaided by the trunk, just like the sound of a man panting or sighing; i but, if it employ the trunk

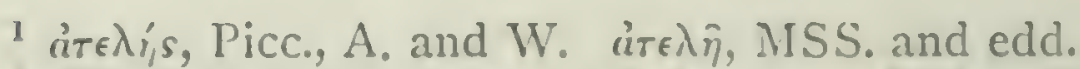

2 Cf. P.A. ii. 17. 6602 26 (cf. Aristoph. Nubes, 862, 1381).

"Theoph. p. I8I Teubner (ap. Athen. ix.390); Ael. iii. 35; Antig. de Mirab. vi. The difference is specific, between $P^{\prime}$. sracia and $P$. cineren.

+ Plut. Sol. An.973 A ; Ael. iii. 40 ; Dion. de Arit. i. 20.

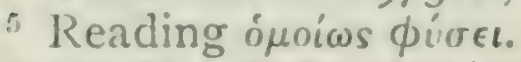

"Mr. Warde Fowler (Summer Studies) arguing, from the case of the ruckoo, against the theory that birds acquire their song under their parents' tutelage, seems to neglect the distinction herc drawn by Aristotle. The imnate and instinctive poriy of the cuclioo is a different thing from the modulated and skilled nutiderons of the singing bird.

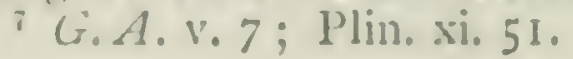


as well, the sound produced is like that of a hoarse trumpet.

Io With regard to the sleeping and waking of animals, all creatures that are red-blooded and provided with legs give 25 sensible proof that they go to sleep and that they waken up from sleep; ${ }^{1}$ for, as a matter of fact, all animals that are furnished with cyelids shut them up when they go to sleep. Furthermore, it would appear that not only do men dream, but horses also, and dogs, and oxen; aye, and sheep, and goats, and all viviparous quadrupeds; and dogs 30 show their dreaming by barking in their sleep. With regard to oviparous animals we cannot be sure that they dream, but most undoubtedly they sleep. And the same may be said of water animals, such as fishes, molluscs, crustaceans, to wit crawfish and the like. These animals $537^{\mathrm{a}}$ sleep without doubt, although their sleep is of very short duration. The proof of their sleeping cannot be got from the condition of their eyes-for none of these creatures are furnished with eyelids-but can be obtained only from their motionless repose.

2 Apart from the irritation caused by lice and what are 5 nicknamed fleas, ${ }^{3}$ fish are met with in a state so motionless that one might casily catch them by hand; and, as a matter of fact, these little creatures, if the fish remain long in one position, ${ }^{4}$ will attack them in myriads and devour them. For these parasites are found in the depths of the sea, and are so numerous that they devour any bait made of fish's flesh if it be left long on the ground at the bottom; io

\section{1 de Somno et Vig. I. $454^{\text {b }}$ I 5 ; Plin. x. 75.}

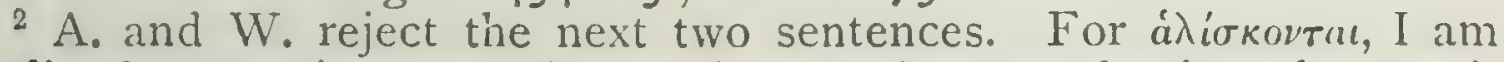

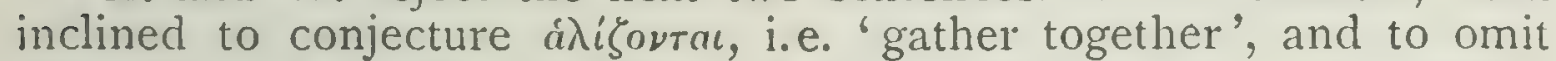

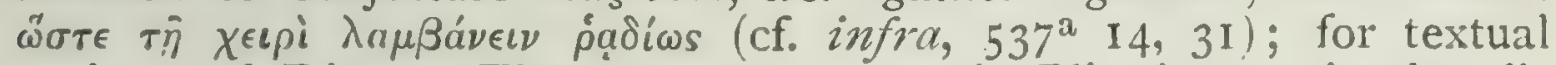
variants $\mathrm{cf}$. Dittm. The cognate passage in Plin. ix. 7I simply tells us that lice exist in the sea, and are supposed to disturb the fishes' slumbers: 'nihil non gignitur in mari; ut cauponarum (conopeorum, Scalig.) etiam aestiva animalia pernici molesta saltu, et quae capillus maxime celat, exsistant, et circumglobata escae saepe extrahantur: quae causa somnum piscium in mari noctibus infestare existimatur.'

${ }^{3}$ The 'fleas' are probably small Amphipods (Scoticé 'sandy loupers'); the Arabs call shrimps barghut-el-bahi, i. e. sea-fleas.

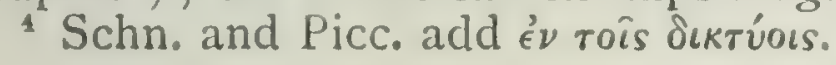


and fishermen often draw up a cluster of them, all clinging on to the bait. ${ }^{1}$

But it is from the following facts that we may more reasonably infer that fishes sleep. Very often it is possible to take a fish off its guard so far as to catch hold of it or is to give it a blow unawares; and all the while that you are preparing to catch or strike it, the fish is quite still but for a slight motion of the tail. And it is quite obrious that the animal is slecping; from its morcments if any disturbance be made during its repose; for it moves just as you would cxpect in a creature suddenly awakened. Further, owing to their being asleep, fish may be captured by torchlight." The watchmen in the tunny-fishery ${ }^{3}$ often take adrantage of the fish being aslcep to envelop them in a circle of nets: 20 and it is quite obvious that they were thus sleeping by their lying still and allowing the glistening under-parts of their bodics to become visible, while the capture is taking place. They sleep in the night-time more than during the day; and so soundly at night that you may cast the net without making them stir." Fish, as a gencral rule, slcep close to the ground, or to the sand or to a stone at the bottom, or after concealing themselves under a rock or the 25 ground. Flat fish go to sleep in the sand; and they can be distinguished by the outlines of their shapes in the sand, and are caught in this position by being speared with pronged instruments. The basse, the chrysophrys or gilthead, the mullet, and fish of the like sort are often caught in the claytime by the prong "owing to their having becn

1 Plin. ix. 47.

Scoticé, 'burning the watter.' Cf. Plat. Soph v.; Ael. xi. 43; Pollux, vii. I38, x. 133. See also Apostolides, p. 40, for an account of the practice in Greece at the present day, and Faber (Fisheries of the Adriatic, pp. 100, II 4, 137) for its use in the sardine-fisheries of the Adriatic.

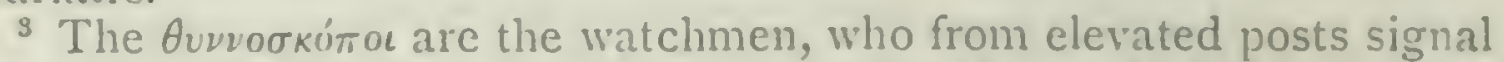
the movements of the shoals; they are the 'hooers' of the Cornish pilchard fishery; cf. Theocr. iii. 26; Opp. Hal. iv. 637. The present account seems to refer to the smaller fishery with the seine or circlenet, the tratta or palandaro di ton of the Adriatic: cf. Plin. x. 75, and see Apostolices, l.u l'ilhe in circic, 1). 32. On the great tumnyfishery by means of the maimgue or prote di ton see Ael. xiii. I6, xi. 5, 6; Strabo, 1. 2.6, 8, vii.6. 2, wii. 3. 16. See also P. Rhode,

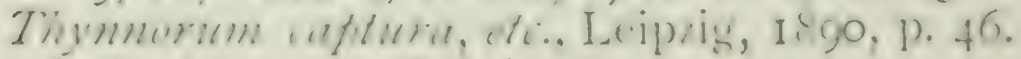

+ Cf. Orac. ap. Hdt. i. 62.

c Latt. fuscini, It. fuerim, by which the same lishes are still captured. 
surprised when sleeping; for it is scarcely probable that such fish could be pronged while awake. Cartilaginous 30 fish sleep at times so soundly that they may be caught by hand. The dolphin and the whale, and all such as arc furnished with a blow-hole, slcep with the blow-hole over $537^{\mathrm{b}}$ the surface of the water, and breathe through the blowhole while they keep up a quict flapping of their fins; indeed, some mariners assure us that they have actually heard the dolphin snoring. ${ }^{1}$

Molluscs slcep like fishes, and crustaceans also. It is : plain also that insects sleep; for there can be no mistaking their condition of motionless repose. In the bee " the fact of its being asleep is very obvious; for at night-time bees are at rest and cease to hum. But the fact that insects sleep may be very well seen in the case of common everyday creatures: for not only do they rest at night-time ro from dimness of vision (and, by the way, all haid-cyed creatures see but indistinctly), ${ }^{3}$ but even if a lighted candle be presented they continue sleeping quite as soundly. ${ }^{4}$

Of all animals man is most given to dreaming. Children and infants do not dream," but in most cases dreaming 15 comes on at the age of four or five years. Instances have bcen known of full-grown men and women that have never dreamed at all; ${ }^{6}$ in exceptional cases of this kind, it has been observed that when a dream occurs in advanced life it prognosticates either actual dissolution or a general break-up of the system.

So much then for sensation and for the phenomena of sleeping and of awakening.

II With regard to sex, some animals are divided into malc and female, but others are not so divided, but can only be said in a comparative way to bring forth young and to be

1. H.A. vi. 12. 566 I 5 ; Plut. Sol. An. p. 979; Plin. x. 75 ; Ael. xi. 22.

$2 H . A . \mathrm{ix} .40 .627^{2} 27$.

4 But cf. de Sommo et Vig. 1. $454^{\mathrm{b}} 20$.

$5 \mathrm{Cf}$. de Sommiis, 3. $46^{\mathrm{a}} 13,462^{\mathrm{b}} 5$; the contrary, H.A. vii. Io. $587^{\mathrm{b}}$ Io; cf. G. A. v. I. $779^{\mathrm{a}} 12$.

de Somniis, $3.462^{a}$ 3 ; Plin. x. 98. 
pregnant.' In animals that live confined to one spot there 25 is no duality of sex; nor is there such, in fact, in any testaccans. ${ }^{2}$ In molluscs and in crustaceans we find male and female: and, indecd, in all animals furnished with feet, ${ }^{3}$ biped or quadruped; in short, in all such as by copulation engender cither live young or egg or grub. In the several genera, with however certain exceptions, there cither absolutely is or absolutely is not a duality of sex. Thus, 30 in quadrupeds the duality is universal, while the absence of such duality is universal in testaccans, and of these creatures, as with plants, some individuals are fruitful and some $53^{\mathrm{a}}$ are not. ${ }^{4}$

But among insects and fishes, some cases are found ${ }^{5}$ wholly devoid of this duality of sex. For instance, the eel is neither male nor female, and can engender nothing. ${ }^{6}$ In fact, those who assert that eels are at times found with 5 hair-like or worm-like progeny attached, malic only. random assertions from not having carefully noticed the locality of such attachments. For no eel nor animal of this kind is ever viviparous unless previously oviparous; and no eel was ever yet seen with an egg. And animals that are viviparous have their young in the womb and closely attached, and not in the belly; for, if the embryo were kept 10 in the belly, it would be subjected to the process of digestion like ordinary food. When people rest duality of sex in the eel on the assertion that the head of the male is bigger and longer, and the head of the female smaller and more snubbed, they are taking diversity of species for diversity of $\operatorname{sex} .^{8}$

${ }^{1}$ G. A. i. I. $715^{\mathrm{a}} 20 . \quad$ a $G$. A. i. I $4 \cdot 720^{\mathrm{b}} 7,23 \cdot 731^{\mathrm{a}} 24$.

3 Dittm. inserts kui évaímoเs: cf. 10. $536^{\text {l }} 25$, I I. $538^{a} 23 ; G$. A. i. I. 7 I $5^{\mathrm{a}} 20$.

G. A. i. I. $715^{\mathrm{b}} 22$.

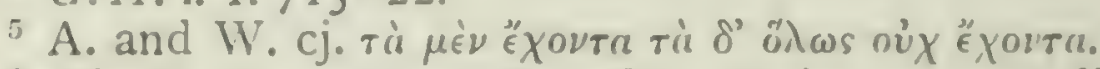

"Cf. H. A. v. I6. $570^{2} 3$, \&c. It is a recent discovery that eels spawn in the depths of the ocean, from which they never afterwards return.

7 . Read тробтєфико́т'.

${ }^{\circ}$ Cf. H.A. viii. 30. $\cos ^{a}$ 5. Yarrell, Giinther, and others, like A., have held the difference to be specific. We now know that the eels with large, broal, 'frog-mouthed' heads are females IC. J. G. Tetersen. Fiskeri-Beretninger, v. 1896, Copenhagen). 
There are certain fish that are nicknamed the cpitragiae, or capon-fish, and, by the way, fish of this description are found in fresh water, as the carp and the balagrus." This 15 sort of fish never has either roe or milt; but they are hard and fat all over, and are furnished with a small gut; and these fish are regarded as of super-excellent quality.

Again, just as in testaceans and in plants there is what bears and engenders, but not what impregnates, so is it, among fishes, with the psetta, the crytluinus, and the so channe; ${ }^{3}$ for these fish are in all cases found furnished with eggs. ${ }^{4}$

As a general rule, in red-blooded animals furnished with feet and not oviparous, the male is larger and longer-lived than the female (except with the mule, where the female is longer-lived and bigger than the male); whereas in ovi- 25 parous and vermiparous creatures, as in fishes and in insects, ${ }^{5}$ the female is larger than the male; as, for instance, with the serpent, the phalangim or venom-spider, the gecko, and the frog. The same difference in size of the sexes is found in fishes, as, for instance, in the smaller cartilaginous fishes, in the greater part of the gregarious species, and in all that live in and about rocks. The fact $3^{\circ}$ that the female is longer-lived than the male is inferred from the fact that female fishes are caught older than males. $53^{\mathrm{b}}$ Furthermore, in all animals the upper and front parts are

1 Plut. Thes. I 8 .

2 The Baidrypos is unidentified, but the word may be akin to bullere, a name for the carp in the Adriatic. It may be, as Rondelet takes it, the Crucian or Prussian carp, Carassius vulgaris.

3 That the genus Serranus is hermaphrodite was rediscovered by Cavolini. According to Erhard S. cabrilla is now known as xáveos, S. scriba as $\pi \dot{p} p k a$; but both species, according to Faber, are called

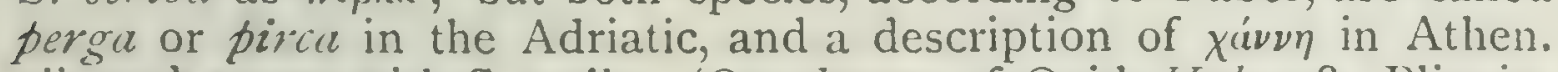
vii. $327^{\circ}$ agrees with $S$. scriba. (On channa cf. Ovid, Hal. I08; Plin. ix.

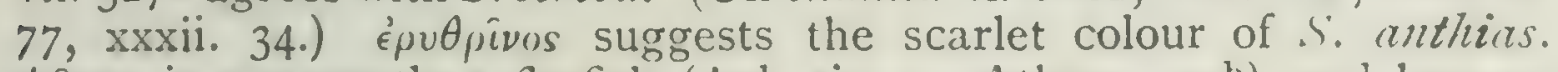

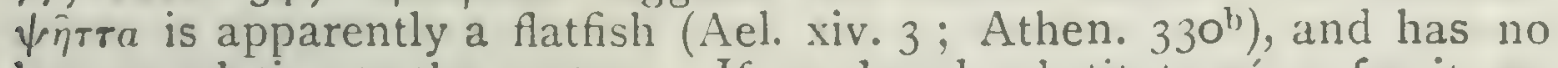
known relation to the context. If we dared substitute $\pi \epsilon \rho^{\prime} \varkappa$ for it, we should have here together the three species of the hermaphrodite seaperch. For a detailed list of hermaphrodite fishes cf. Max Weber, Tijdsch.d. Ned. Dicrk. Ver. (2) i. p. 128, 1885-87.

$H$. A. vi. 13. $567^{2} 27 ; G . A$. i. 5 , ii. $5, \&$ c.

${ }^{5}$ G. A. i. 16. $721^{2} 18$. 
better, stronger, and more thoroughly equipped ${ }^{1}$ in the male than in the female, whereas in the female those parts are the better that may be termed hinder-parts or under5 parts. ${ }^{2}$ And this statement is applicable to man and to all vivipara that have feet. Again, the female is less muscular and less compactly jointed, ${ }^{3}$ and more thin and delicate in the hair-that is, where hair is found; and, where there is no hair, less strongly furnished in some analogous substance. And the female is more flaccid in texture ro of flesh, and more knock-kneed, and the shin-bones are thinner; and the fect are more arched and hollow in such animals as are furnished with feet. And with regard to voice, the female in all animals that are vocal has a thinner and sharper voice than the male; ' except, by the way, with kine, for the lowing and bellowing of the cow has 15 a decper note than that of the bull." With regard to organs of defence and offence, such as teeth, tusks, homs, spurs, and the like, these in some species the male possesses and the female does not; as, for instance; the hind has no horns, and where the cock-birci has a spur the hen is 20 entirely destitute of the organ; ${ }^{6}$ and in like manner the sow is devoid of tusks. In other specics such organs are found in both sexes, but are more perfectly developed in the male; as; for instance, the horn of the bull is more powerful than the horn of the cow?

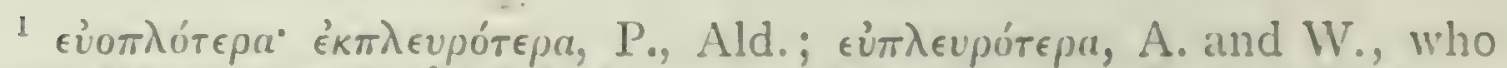

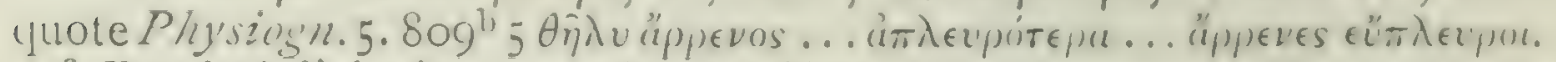

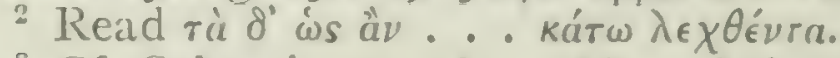

${ }^{3}$ Cf. Schn. iv. p. 385 . The whole passagre looks like an extract from a work on Physiognomy; cf. Ar. Phy'siogn. 6.810".

Probl. xi. 62.906a 3 .

${ }^{5}$ G. A. $1 \cdot 7 \cdot 786^{\mathrm{b}} 23,787^{\mathrm{l}} 9$.

${ }^{5}$ C. . H. A. ix. 49.631 12.

${ }^{7}$ Cf. I'robl. x. 57. $897^{b} 27$; l'lin. xi. 37 (45); Ael. xii. I9. 


\section{BOOK V}

I As to the parts internal and external that all animals are $53^{\mathrm{b}}$ furnished withal, and further as to the senses, to voice, and sleep, and the duality of sex, all these topics have now been 30 touched upon. It now remains for us to discuss, duly and $539^{\text {a }}$ in order, their several modes of propagation.

These modes are many and diverse, and in some respects are like, and in other respects are unlike to one another. As we carricd on our previous discussion genus by genus, so we must attempt to follow the same 5 divisions in our present argument; only that whereas in the former case we started with a consideration of the parts of man, in the present case it behoves us to treat of man last of all because he involves most discussion. ${ }^{1}$ Wre shall commence, then, with testaceans, and then proceed 10 to crustaceans, and then to the other genera in due order; and these other genera are, severally, molluscs, and insects, then fishes viviparous and fishes oviparous, and next birds; and afterwards we shall treat of animals provided with feet, both such as are oviparous and such as are viviparous; and "Ne may observe that some " quadrupeds are viviparous, but that the only viviparous biped is man.

"Now there is one property that animals are found to have in common with plants. ${ }^{4}$ For some plants are generated from the seed of plants, whilst other plants are self-generated through the formation of some elemental principle similar to a seed; and of these latter plants some derive their nutriment from the ground, whilst others grow inside other plants, as is mentioned, by the way, in my 20 treatise on Botany." So with animals, some spring from

${ }^{1}$ H. A. i. 6. $491^{\mathrm{a}} \mathrm{Ig}$.

${ }^{2}$ Dittm. would read $\pi v \lambda \lambda a^{\circ}$.

${ }^{3}$ We here enter on a long parenthesis, including much that is probably late and spurious, returning to the main question and to the promised order of treatment in C. I5.

G. A. i. I. $715^{\text {b) } 18 . ~}$

' Cf. Wimmer, liragmenta, p. 46 et seq. But èv roîs duroís où

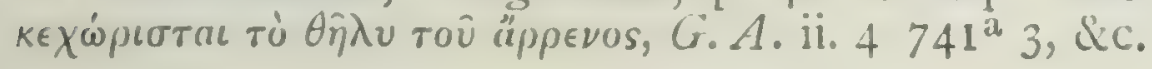


parent animals according to their kind, whilst others grow spontancously and not from kindred stock; and of these instances of spontaneous generation some come from putrefying carth or vegetable matter, ${ }^{1}$ as is the case with a number of insects, while others are spontaneously generated $2:$ in the inside of animals out of the secretions of their several organs.

In animals where generation goes by heredity, wherever there is duality of sex generation is due to copulation. In the group of fishes, however, there are some that are neither male nor female, and these, while they are identical generically with other fish, differ from them specifically;" but there are others that stand altogether isolated and apart by themselves. Other fishes there are that are always female 30 and never male, and from them are conceived ${ }^{4}$ what correspond to the wind-egrss in birds. Such eggs, by the way, in birds are all unfruitful; but it is their nature to be independently capable of generation up to the $539^{b}$ egg-stage," unless indeed there be some other mode than the one familiar to us of intercourse with the male; but concerning these topics we shall treat more precisely later on.' In the case of certain fishes, however, after they have spontaneously generated eggs, these eggs develop into living animals; only that in certain of these cases development is spontaneous, and in other's is not inde5 pendent of the male; and the method of proceeding in regard to these matters will be set forth by and by, for the method is somewhat like to the method followed in the case of birds.' But whensocver creatures are spontaneously generated. either in other animals. in the soil, or on plants, or in the parts of these, and when such are generated male and female, then from the copulation of such spontaneously

11.A.v.19. $551^{\text {a }}$ I ; G. A. i. 2. $715^{-1}, 27$.

e.g. кебтреis. Cf. infra, v. II. $543^{\text {b }} 17$, vi. $15.569^{3}$.

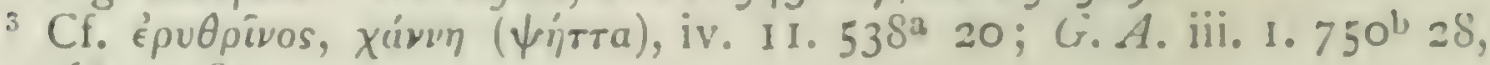
5. $756^{\text {is }}$ I 5 , \&.c.

A. and W. supply wiá.

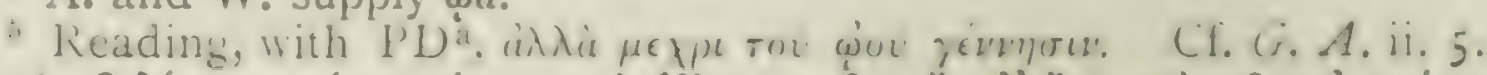

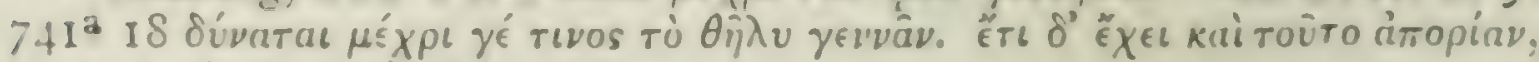

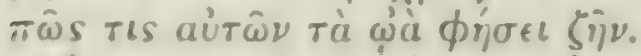

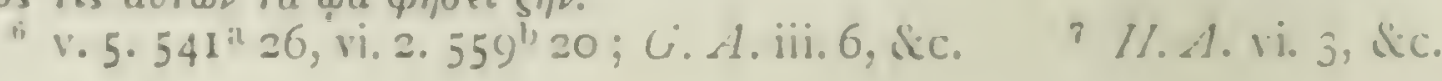


gencrated males and females there is generated a something io -a something never identical in shape with the parents, but a something imperfect. ${ }^{1}$ For instance, the issue of copulation in lice is nits; in flies, grubs; in fleas, ${ }^{2}$ grubs egg-like in shape; and from these issues the parent-species is never reproduced, nor is any animal produced at all, but the like nondescripts only. ${ }^{3}$

First, then, we must proceed to treat of 'covering' in regard to such animals as cover and are covered; and then after this to treat in due order of other matters, both the 5 exceptional and those of general occurrence.

2 Those animals, then, cover and are covered in which there is a duality of sex, and the modes of covering in such animals are not in all cases similar nor analogous. ${ }^{4}$ For the red-blooded animals that are riviparous and furnished with feet "have in all cases organs adapted for procreation, 20 but the sexes do not in all cases come together in like manner. Thus, opisthuretic animals copulate with a rearward presentment, as is the case with the lion, the hare, and the lynx; ${ }^{6}$ though, by the way, in the case of the hare, the female is often observed to cover the male.

The case is similar in most other such animals; that is to 25 say, the majority of quadrupeds copulate as best they can, the male mounting the female; and this is the only method of $\mathrm{co}-$ pulating adopted by birds, though there arecertain diversities of method observed even in birds. For in some cases the female squats on the ground and the male mounts on top 30 of her, as is the case with the cock and hen bustard, ${ }^{8}$ and the barn-door cock and hen; in other cases, the male mounts without the female squatting, as with the male and

1 G.A. i. I6. $721^{\mathrm{a}}, \mathrm{i} .18 .723^{\mathrm{b}} 5$, \&c.

2 Schn., Guil., Bckk. $\psi v \chi \chi_{\hat{\omega} \nu}$. Cf. G. A. i. 18. $721^{\mathrm{a}} 8,723^{\mathrm{b}}$ 5. But butterfies are not among the things 'spontaneously generated". Cf. also infra, c. 19. $551^{\mathrm{a}} 24,31.556^{\mathrm{b}} 24$; Athen. vii. 352 .

H.A.v. $31.55^{\text {b }}$, Athen. vii. $35^{2}$.

4 Plin. x. 83.

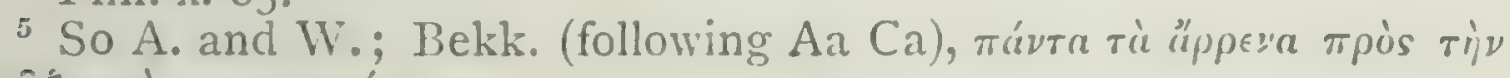

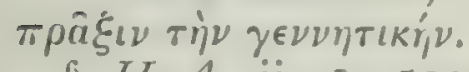

${ }^{6} H . A$. ii. I. $500^{\mathrm{b}}$ I 5 , vi. 3 I. $579^{\mathrm{a}} 3 \mathrm{I} ; P . A$. iv. Io. $689^{\mathrm{a}} 3 \mathrm{I}$. Cf. Acl. xiii. 12.

7 Plin. $x .73$.

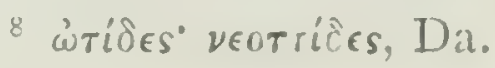

AR. H.A. 
female crane: ${ }^{1}$ for, with these birds, the male mounts on to the back of the female and covers her, and like the cocksparrow consumes but very little time in the operation. Of quadrupeds, bears perform the operation lying prone on $540^{2}$ one another, ${ }^{-}$in the same way as other quadrupeds do while standing up; that is to say, with the belly of the male pressed to the back of the female. Hedgehogs copulate erect, belly to belly:3

With regard to large-sized vivipara, the hind only very rarely sustains the mounting of the stag to the full conclu5 sion of the operation, and the same is the case with the cow as regards the bull, ${ }^{4}$ owing to the rigidity of the penis of the bull. In point of fact, the females of these animals elicit the sperm of the male in the act of withdrawing from underneath him; and, by the way, this phenomenon has been observed in the case of the stag and hind, domesticated, of course. Covering with the wolf is the same as 10 with the dog. Cats do not copulate with a rearward presentment on the part of the female, but the male stands erect and the female puts herself underneath him;" and, by the way, the female cat is peculiarly lccherous, and whecdles the male on to sexual commerce, and caterwauls during the operation. ${ }^{6}$ Camels copulate with the female in a sitting posture, and the male straddles over and covers her, not with the hinder presentment on the female's part 15 but like the other quadrupeds mentioned above, and they pass the whole day long in the operation; when thus engaged they retire to loncly spots, ${ }^{7}$ and none but their keeper dare approach them. And, be it obscried. the penis of the camel is so sinewy that bow-strings are 20 manufactured out of it. Elephants. also, copulate in lonely places, ${ }^{8}$ and especially by river-sides in their usual haunts; the female squats down, and straddles with her legs, and the male mounts and covers her. The seal covers like all

1 Plin. x. 73 'stante, ut in gruibus'.

H. A. vi. 30. $579^{a} 19$ катакєк

S H.A. vi.2. $540^{\mathrm{a}} 3$; G.A. i. 5. $717^{\mathrm{b}} 30$.

4. A. vi.29. $578^{\text {i }} 7$; Plin. x. 83 .

5 Plin...$c$.

"Amat miserrime, Linnaeus, in Sy'st. $\Lambda^{\prime} z t^{\prime}$

Cf. Ael. vi.6o. ' ${ }^{2}$ C. Ael. viii. 17; Plin. viii. 5; H. 4. ii. I. $500^{\prime \prime} 7$. 
opisthuretic animals, and in this species the copulation extends over a lengthened time, as is the case with the dog and bitch; and the penis in the male seal is excep- 25 tionally large.

3 Oviparous quadrupeds cover one another in the same way. That is to say, in some cases the male mounts the female precisely as in the viviparous animals, ${ }^{1}$ as is observed in both the land and the sea tortoise. . . . And these creatures have an organ in which the ducts converge, and 30 with which they perform the act of copulation, as is also observed in the toad, ${ }^{2}$ the frog, and all other animals of the same group.

4. Long animals devoid of fect, like serpents and muraenae: intertwine in coition, belly to belly." And, in fact, serpents $540^{\mathrm{b}}$ coil round one another so tightly as to present the appearance of a single serpent with a pair of heads. The same mode is followed by the saurians; that is to say, they coil round one another in the act of coition.

5 All fishes, with the exception of the flat selachians, lic down side by side, and copulate belly to belly. Fishes, ${ }^{t}$ however, that are flat and furnished with tails-as the ray, the trygon, ${ }^{5}$ and the like-copulate not only in this way, but also, where the tail from its thinness ${ }^{6}$ is no impediment, by mounting of the male upon the female, belly to back. io But the rhina or angel-fish, ${ }^{7}$ and other like fishes where the tail is large, copulate only by rubbing against one another sideways, belly to belly. Some men assure us that they have seen some of the selachia copulating hindways, like dog and bitch. In all the cartilaginous species the female ${ }_{15}$ is larger than the male; and the same is the case with other

1 Cf. Ael. xv. I9.

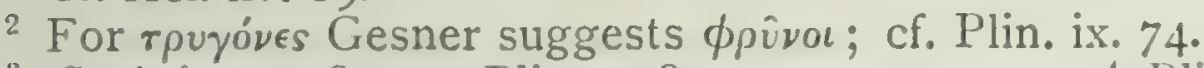

G.A.i.7.718 17 ; Plin.x. 82 .

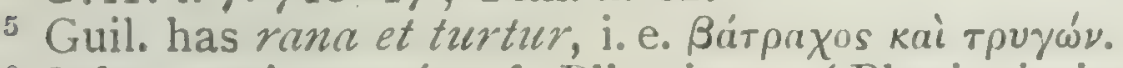

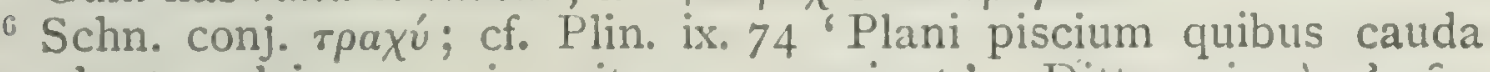
non obest aculeique . $\because$ in coitu superveniunt'. Dittm. cj. tó oủpaîov

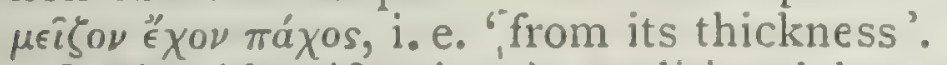

7 The identification is traditional but uncertain : fivm is probably either Rhina squatina or the allied Rhinobatus columnae; cf. vi. II, $566^{\circ} 27$. 
fishes for the most part. And among cartilaginous fishes are included, besides those already named, the bos, ${ }^{2}$ the lamia," the actos," the narce or torpedo, the fishing-frog, and all the galeodes or sharls and dogfish. ${ }^{5}$ Cartilaginous fishes, then, of all kinds, have in many instances becn 20 obscrved copulating in the way above mentioned; for, by the way, in viviparous animals the process of copulation is of longer duration than in the ovipara.

It is the same with the dolphin and with all cetaccans; ${ }^{6}$ that is to say; they come side by side, male and female, and copulate, and the act extends orer a time which is neither short nor very long.

Again, in cartilaginous fishes the male, in some specics, 25 differs from the female in the fact that he is furnished with two appendages hanging down from about the exit of the residuum, and that the female is not so furnished; and this distinction between the sexes is observed in all the species of the sharks and dog-fish.

'Now neither fishes nor any animals devoid of fect are 30 furnished with testicles, ${ }^{8}$ but male serpents and male fishes have a pair of ducts which fill with milt or sperm at the rutting season, and discharge in all cascs, a milk-like juicc. These ducts unite, as in birds: for birds, by the way, have $54 \mathrm{I}^{\mathrm{a}}$ their testicles in their interior, and so have all ovipara that are furnished with fect. And this union of the ducts is so far continued and of such extension as to enter the receptive organ in the female.

I H. A. iv. II. $53^{a} 27$.

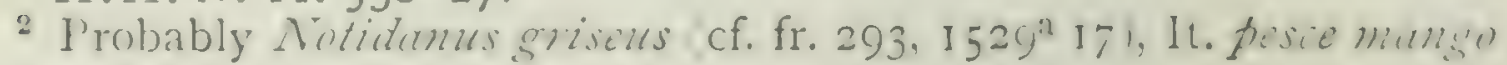
or 'ox-fish', from its great eye.

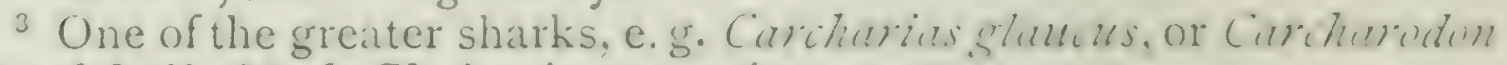

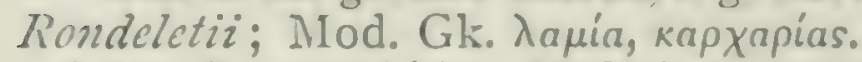

4 In all probability Myliobatis aquila or bovina, Mod. Gk. a'eris, It. aquila, aquilone. The characteristic feature of this fish is the great stinging spine at the base of the tail. I have little doubt that the original name, still prescrved in sicily, was fisci wula, or cistités : then by corruption in old seafaring polyglot, aquila and aiesós.

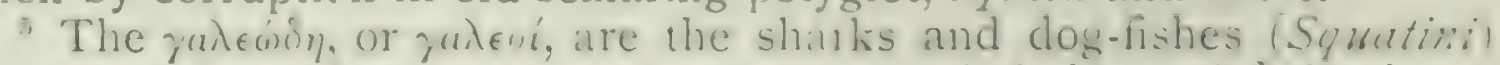
as opposed to the skates and rays; cf. H.A. i. $5 \cdot 489^{\text {h }} 6$, vi. Io. $565^{\mathrm{a}} 14$, \&C.

$G$. A. iii. $5 \cdot 765^{\mathrm{b}} \mathrm{I}$; Plin. ix. 74 .

7 A. and W. regard the next two paragraphs as an interpolation : cf. iii. 1. $509^{\text {b }} 3$, ii. 16. $506^{\text {b }} 24$.

"Il.A. ii. 17. 508a 12, iii. 1. 509"15; G.A.i. 3. 716"15. 
In viviparous animals furnished with feet there is outwardly one and the same duct for the sperm and the liquid residuum ${ }^{1}$ but there are separate ducts internally, as has 5 been observed in the differentiation of the organs. And with such animals as are not viviparous ${ }^{2}$ the same passage serves for the discharge also of the solid residuum; although, internally, there are two passages, ${ }^{3}$ separate but near to one another. And these remarks apply to both male and female; for these animals are unprovided with a bladder except in the case of the tortoise; and the she-tortoise, ${ }^{4}{ }_{10}$ though furnished with a bladder, has only one passage; and tortoises, by the way, belong to the ovipara.

In the case of oviparous fishes the process of coition is less open to observation. In point of fact, some are led by the want of actual observation to surmise that the female becomes impregnated by swallowing the seminal fluid of the male. And there can be no doubt that this proceeding on the part of the female is often witnessed; for at the rutting season the females follow the males and perform this opera- 15 tion, and strike the males with their mouths under the belly, and the males are thereby induced to part with the sperm sooner and more plentifully. And, further, at the spawning season the males go in pursuit of the females, and, as the female spawns, the males swallow the eggs; and the species is continued in existence by the sparn that survives this process. On the coast of Phoenicia they take advantage of these instinctive propensities of the two sexes to catch both one and the other: that is to say, by using the male of the grey mullet as a decoy they collect and net 20 the female, and by using the female, the male. ${ }^{6}$

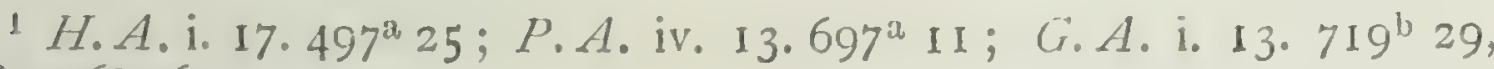
18. $726^{a}$ I6.

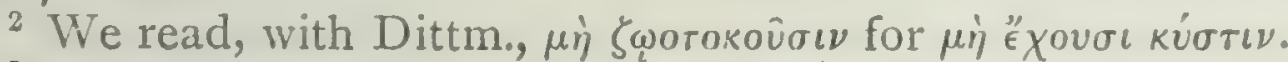

3 Schn., Picc., and Dittm. insert $\left\langle 8 \dot{v}^{\circ}\right\rangle$.

4 Schn. and Picc. cj. $\theta a \lambda a \tau \tau i a$ for $\theta \dot{\eta} \lambda \in \iota a$ : cf. H.A. iii. I5. $519^{\mathrm{b}} 15$, ii. $16.506^{\mathrm{b}} 27 ; P$. A. iii. $8.671^{\text {al }}$ I 5 .

H.A. vi. 13. $567^{2} 32 ; G . A$. iii. 5. $75^{\text {a }} 5$; Plin. ix. 74 ; Ael. ix. 63.

${ }^{6}$ Cf. Opp. Hal. iv. 120-45. This process is still in use, especially in Eilis (Apostolides, of. cit. p. 45). One fisher holds a female grey mullet with rod and line fastened to its operculum, while another casts a light net $(\pi \epsilon \zeta o ́ \beta \sigma \lambda o \nu)$ about the males which gather round. 'The scarus is caught in the same way, as also in Oppian's time (Hal. iv. 40-1 IO). 
The repeated obscrvation of this phenomenon has led to the notion that the process was equivalent to coition, but the fact is that a similar phenomenon is observable in quadrupeds. For at the rutting seasons both the males s: and the females take to running at their genitals, and the two sexes talie to smelling each other at those parts. ${ }^{1}$

[With partridges, ${ }^{2}$ by the way, if the female gets to leeward of the male, she becomes thereby impregnated. And often when they happen to be in heat she is affected in this wise by the roice of the male, or by his breathing down on her as he flies overhead; ${ }^{3}$ and, by the way, both the male and the female partridge keep the mouth wide 30 open and protrude the tongue in the process of coition. $]^{4}$

The actual process of copulation on the part of oviparous fishes is seldom accurately observed, owing to the fact that they very soon fall aside and slip asunder. But, for all that, the process has been observed to take place in the manner above described.

$54 \mathrm{I}^{\mathrm{b}}$ Molluscs, such as the octopus, the sepia, and the 6 calamary, have sexual intercourse all in the same way: ${ }^{5}$ that is to say, they unite at the mouth, by an interlacing of their tentacles. When, then, the octopus rests its so-called 5 head" against the ground and spreads abroad its tentacles, the other sex fits into the outspreading of these tentacles, and the two sexes then bring their suckers into mutual connexion.

Some assert that the male has a kind of penis in one of his tentacles, ${ }^{7}$ the one in which are the $[\text { two }]^{8}$ largest o suckers: and they further asscrt that the organ is ten-

${ }^{1}$ G. A. ii. 8. $748^{\mathrm{b}} 26$.

2 H. A.vi. 2. $560^{b}$ 13; G. A. iii. 15. $75^{\mathrm{a}} 13$; Plin. x. 5 r; Athen. ix. 389 ; Ael. xrii. I5; Antig. lxxxvii.

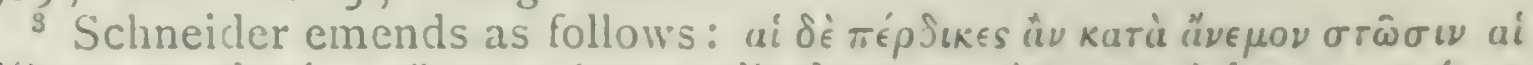

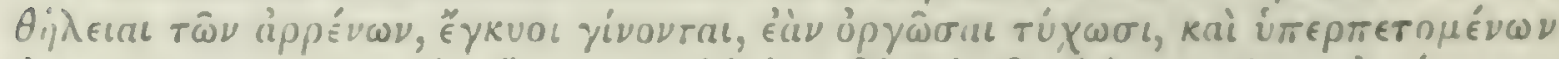

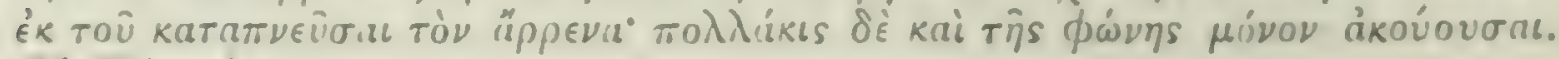
Cf. Plin. l.c.

- Probably an interpolation here (B. St. Hilaire, Dittm.).

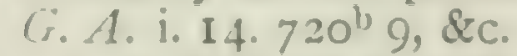

i. e. its body or mantle-sac; cf. iv. I. $523^{\text {b }} 24$.

H. A. iv. 1. 524:5; Athen. vii. 317 .

i. Súo is unintelligible, and duubtless corrupt. 
dinous ${ }^{1}$ in character, growing attached right up to the 10 middle of the tentacle, and that the latter enables it to enter the nostril or funnel ${ }^{2}$ of the female.

Now cuttle-fish and calamaries swim about closely intertwined, with mouths and tentacles facing one another and fitting closely together, and swim thus in opposite directions $;^{3}$ and they fit their so-called nostrils into one another, and the one sex swims backwards and the other frontwards during the operation. And the female lays its spawn by the so-called 'blow-hole'; ${ }^{4}$ and, by the way, 15 some declare that it is at this organ that the coition really takes place.

7 Crustaceans copulate," as the crawfish, the lobster, the carid and the like, just like the opisthuretic quadrupeds, 20 when the one animal turns up its tail and the other puts his tail on the other's tail. Copulation takes place in the early spring, near to the shore; and, in fact, the process has often been observed in the case of all these animals. ${ }^{6}$ Sometimes it takes place about the time when the figs begin to ripen. Lobsters and carids copulate in like ${ }_{25}$ manner.

Crabs copulate ${ }^{7}$ at the front parts of one another, belly to belly, throwing their overlapping ${ }^{8}$ opercula to meet one another: first the smaller crab moints the larger at the rear; after he has mounted, the larger one turns on one side. Now, the female differs ${ }^{9}$ in no respect from the 30 male except in the circumstance that its operculum is larger, more elevated, and more hairy, and into this operculum it spawns its eggs and in the same neighbourhood is the outlet of the residuum. In the copulative process of penis).

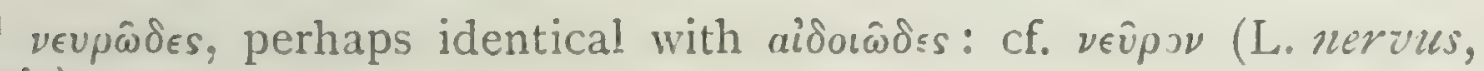

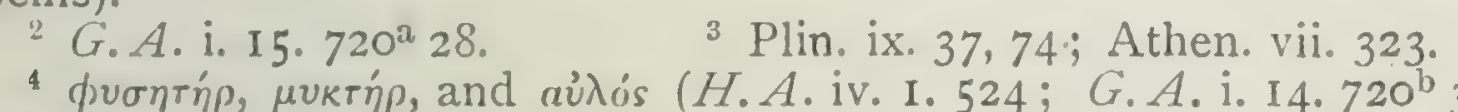

are all alike used of the 'funnel'.

5 Cf. G.A. i. I4. $720^{\mathrm{b}}$ 9. See also Lafresnaye, Rev. Zool., I848, pp. 279-82; Coste, Compt. rent. xlvi. pp. 432, 433, 1858.
Athen. iii. 105.
8 Or 'in folds or layers'.
H. A. iv. $3 \cdot 527^{\text {b }} 30$. 
these animals there is no protrusion of a member from one animal into the other.

Insects ${ }^{1}$ copulate at the hinder end, ${ }^{2}$ and the smaller 8 $542^{\text {a }}$ individuals mount the larger; and the smaller individual is the male. The female pushes from underneath her sexual organ into the body of the male above, this being the reverse of the operation obscrved in other creatures; ${ }^{3}$ and this organ in the case of some insects appears to be clisproportionately large when compared to the size of the body: 5 and that too in very minute creatures; in some insects the disproportion is not so striking. This phenomenon may be witnessed if any one will pull asunder flies that are copulating; and, by the way, these creatures are, under the circumstances, averse to separation; for the intercourse of the sexes in their case is of long duration, as may be observed ro with common cveryday insects, such as the fly and the cantharis. They all copulate in the manner above described, the fly; the cantharis, the sphondyle, ${ }^{4}$ [the phalangium spicler " and any others of the kind that copulate at all. The phalangia "--that is to say, such of the species as spin webs-perform the operation in the following way: the fomale takes hold of the suspended $w \mathrm{cb}$ at the middle and gives a pull, and the male gives a counter pull; this operaIs tion they repeat until they are drawn in together and interlaced at the hinder ends: for, by the way; this mode of copulation suits them in consequence of the rotundity of their stomachs. ${ }^{\top}$

So much for the modes of sexual intercourse in all animals; but, with regard to the same phenomenon, there are definite laws followed as regards the seaton of the ycar and the age of the animal.

so Animals in general eem naturally disposed to this inter-

$1 G \cdot A \cdot i \cdot 16.72 I^{\text {n }}$

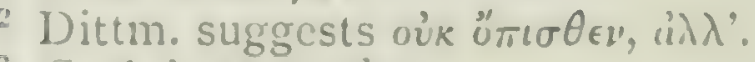

${ }^{3}$ G.A. i. $21.729^{\mathrm{b}} 22$.

${ }^{1}$ For reff. cf. Schneider, vol. iii. p. 275; Sundevall, Thiorrlen de's A\%. p. 237. The animal is unidentified.
1 ) ittm.
P'lin. xi. 29.
Cf. ix. 39. $622^{\mathrm{b}} 27$, dic. 
course at about the same period of the year, and that is when winter is changing into summer. And this is the season of spring, in which almost all things that fly or walk or swim take to pairing. Some animals pair and breed in autumn also and in winter, as is the case with cer- 25 tain aquatic animals and certain birds. Man pairs and breeds at all seasons, as is the case also with domesticated animals, owing to the shelter and good feeding they enjoy: that is to say, with those whose period of gestation is also comparatively brief, as the sow and the bitch, and with those birds that breed frequently. Many animals time the season 30 of intercourse with a view to the right nurture subsequently of their young. In the human species, the male is more under sexual excitement in winter, and the female in summer.

With birds the far greater part, as has been said, pair and breed during the spring and early summer, with the exception of the halcyon.

The halcyon ${ }^{1}$ breeds at the season of the winter solsticc. Accordingly, when this season is marked with calm 5 weather," the name of 'halcyon days' is given to the seven days preceding, and to as many following, the solstice; as Simonides the poet says :-

God lulls for fourteen days the winds to sleep

In winter; and this temperate interlude

Men call the Holy Season, when the deep

Cradles the mother Halcyon and her brood.

And these days are calm, when southerly winds prevail at the solstice, northerly ones having been the accompaniment of the Pleiads. The halcyon is said to take seren days for building her nest, and the other seven for laying and hatching her egrss. ${ }^{3}$ In our country there are not always halcyon days about the time of the winter solstice, but in I5 the Sicilian seas this scason of calm is almost periodical. The bird lays about five eggs.

'Cf. ix. 14.

${ }^{2}$ Theocr. vii. 57 ; Plin. x. 47, \&c. For reff. see Gl. of Gl. Birds, p. 30 .

${ }^{3}$ The number of the halcyon days varies according to different

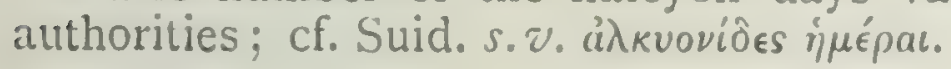


The aithyia, or diver, and the larus, or gull, lay their 9 cggs on rocks ${ }^{1}$ bordering on the sea, two or three at a time; but the gull lays in the summer, and the diver at the beginning of spring, just after the winter solsticc, and it 20 broods ${ }^{2}$ over its eggs as birds do in general. And neither of these birds resorts to a hiding-place. $]^{3}$

The halcyon is the most rarely seen of all birds. It is scen only about the time of the setting of the Pleiads and the winter solstice. When ships are lying at anchor in the roads, it will hover about a vessel and then disappear 25 in a moment, and Stesichorus in one of his poems alludes to this peculiarity. ${ }^{4}$ The nightingale also breeds at the beginning of summer, and lays five or six eggs; from autumn until spring it retires to a hiding-place.

Insects copulate and breed in winter also, that is when the weather is fine and south winds prevail; such, I mean, 30 as do not hibernate, as the fly and the ant. The greater part of wild animals bring forth once and once only in the year, except in the case of animals like the hare, where the female can become superfoctally impregnated.

"In like manner the great majority of fishes breed only $543^{\text {a }}$ once a year, ${ }^{6}$ like the shoal-fishes (or, in other words, such as are caught in nets), the tunny, the pelamys, the grey mullet, the chalcis, the mackercl, ${ }^{7}$ the sciaena, the psetta ${ }^{8}$ and the like, with the exception of the labrax or basse; for this fish (alone amongst those mentioned) breeds twice ${ }^{2}$ a year, and the second brood is the wealier of the two.

${ }^{1}$ Plin. x. 48 'Gaviae in petris nidificant'. Schn, quotes from Cetti (ii. p. 30I) that sea-gulls are still called grcriae in Sardinia, and $\lambda$ ápot $=\gamma \lambda a ́$ pot in Mod. Gk.

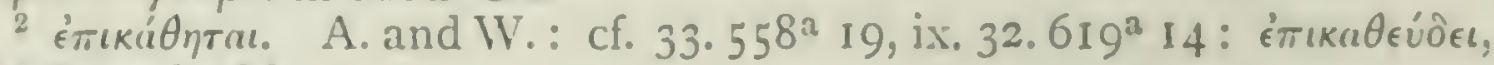
MSS. and edd.

${ }_{3}$ This sentence is either spurious or out of place.

${ }^{4}$ Cf. Pindar, fr. in Schol. Apoll. Rh. i. 1084. Schn. conjectures a reference to an Argonautic legend.

- The succeeding statements concerning fishes are confused, and often at variance with those in $H . A$. vi. 17 .

"Athen. vii. 329; Ael. x. 2.

7 koגias, Opp. Hal. i. $184 \sigma k o \lambda i ́ a s$, described by Arist. ap. Athen. vii.

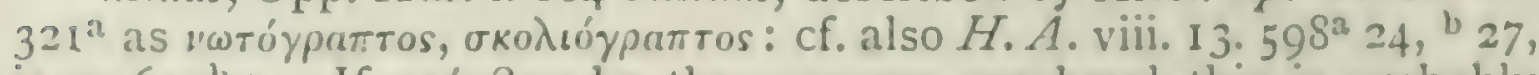
ix. $2.610^{1} \%$. If $\sigma \kappa \delta ́ \mu \beta$ pos be the common mackerel, this is probably Sc. colirs, L.

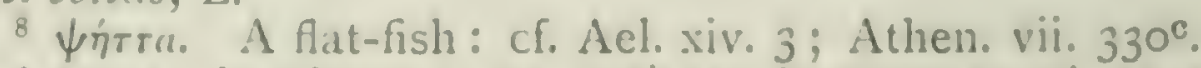

3 Once: in winter, v. I1. $543^{\prime \prime} 11$; in summer, vi. $17.570^{1,} 20$. 
The trichias ${ }^{1}$ and the rock-fishes breed twice a year; the red mullet breeds thrice a year, ${ }^{2}$ and is exceptional in this 5 respect. This conclusion in regard to the red mullet is inferred from the spawn; for the spawn of the fish may be seen in certain places at three different times of the year. $^{3}$ The scorpaena breeds tivice a year. ${ }^{4}$ The sargue breeds twice, in the spring and in the autumn." The saupe breeds once a year only, in the autumn. ${ }^{6}$ The female tunny breeds only once a year, but owing to the fact that the fish in some cases spawn early and in others late, it looks as though the fish bred twice over: ${ }^{7}$ The first spawning ro takes place in December before the solstice, and the latter spawning in the spring. The male tunny differs from the female in being unprovided with the fin beneath the belly which is called aphareus. ${ }^{8}$

Io Of cartilaginous fishes, the rhina or angel-fish is the only one that breeds twice; ${ }^{9}$ for it breeds at the beginning of autumn, and at the setting of the Pleiads: and, of the 15 two seasons, it is in better condition in the autumn. It engenders at a birth seven or eight young. Certain of the

1 reıxias: supposed by Cuvier to be the sardine.

2 In autumn only, vi. $17.570^{\mathrm{b}} 22$.

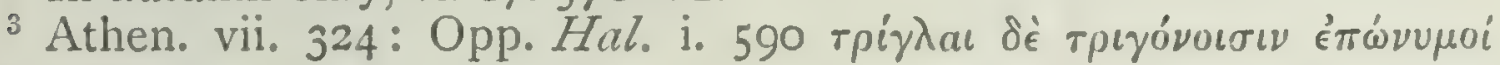

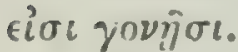

4 The identity of $\sigma \kappa о \rho \pi i s$ and $\sigma \kappa о \rho \pi i o s$ is discussed by Athen. vii. $320^{\mathrm{b}}$. The latter is red, éputpós, ibid. $282^{\mathrm{b}}, \pi v p p o ́ s, 320^{\mathrm{d}}$, the former dark, $\mu \in \lambda a v i \zeta \omega \nu, 320^{\prime \prime}$. $\sigma k o \rho \pi i o s$ is probably Scorpaenu scrofa, $\sigma \kappa o p \pi$ is the

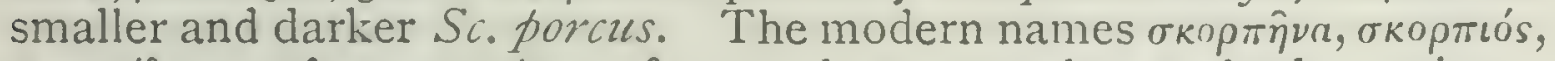
$\sigma \kappa о \rho \pi i \delta$, scorfana, scorpano, \&c., apply more or less to both species.

- Sargus Rondeletii, Mod. Gk. бípyos, Med. sargue, sargó, surague, \&c. Cf. Athen. vii. $321^{\mathrm{b}}$; Plin. ix. 74. Cf. H. A. v. II. $543^{\mathrm{b}}$ I5, vi. 17. $570^{2} 32$.

${ }^{6}$ Cf. II. $543^{b}$ 8, vi. I7. $570^{b}$ I $8.7^{7}$ Cf. II. $543^{b}$ II , vi. I7. 57 I $^{a}$ I3.

8 There is no such fin in the tunny, nor any other mark of sexual difference. The passage is doubtless corrupt, though Pliny (ix. I8), Athenaeus (vii. $303^{\mathrm{d}}$ ), and Hesychius read it as we do, save that the

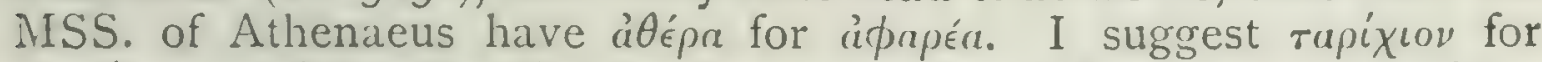
$\pi \tau \epsilon \rho \dot{\gamma} \gamma\llcorner o v$, and suppose that some preparation of the roe is referred to.

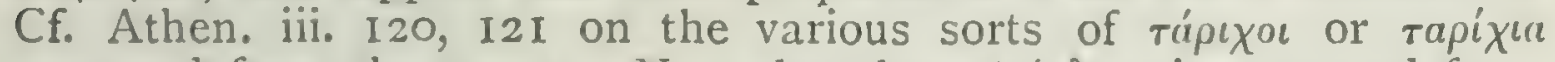
prepared from the tunny. Note that the $\mu \in \lambda(i \nu \delta \rho u s$ is prepared from the largest tumnics, which, according (e.g.) to Archestratus, $a p$. Athen. vii. $303^{\mathrm{d}}$, are the females. The imoyáatpla of this fish are especially recommended by many writers, vide Athen. vii. 302. With à

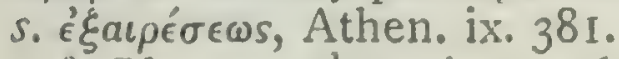

${ }^{9}$ Cf. II. $543^{b}$ 9, vi, I I. $566^{\text {a }}$ I8. 
dog-fishes, for cxample the spotted dog, seem to breed twice a month, and this results from the circumstance that the eggs do not all reach maturity at the same time.

Some fishes breed at all scasons, as the muracna. This 20 animal lays a great number of eggs at a time; and the young when hatched are very small but grow with great rapidity, like the young of the hippurus, for these fishes from being climinutive at the outset grow with exceptional rapidity to an exceptional size. ${ }^{1}$ [Be it observed that the muraena breeds at all seasons, but the hippurus only in the spring. The smyrus differs from the smyraena; for 25 the muraena is mottled and weakly, whereas the smyrus is strong and of one uniform colour, and the colour resembles that of the pine-tree, ${ }^{2}$ and the animal has tecth inside and out. $^{3}$ They say that in this case, as in other similar ones, the one is the male, and the other the female, of a single species. They come out on to the land, ${ }^{4}$ and are frequently caught. $]^{5}$

30 Fishes, then, as a sencral rulc, attain their full growth with great rapidity, but this is especially the case, among small fishes, with the coracine or crow-fish: ${ }^{6}$ it spawns, by $543^{\mathrm{b}}$ the way, near the shore, in weedy and tangled spots. The orphus also, or sca-perch, is small at first, and rapidly altains a great size. ${ }^{7}$ The pelamys and the tunny breed

1 Commonly iclentitied with Coryflume hiffurus the "dolphin': cf. Rondelet, de Pisc. p. $25^{\prime} \mathrm{Cum}$ enim Hispani piscatores parvos hippuros ceperint, nassis includunt, illicque crescere sintunt brevi tcmpore, utpote quorum incrementum indies conspiciatur'. According

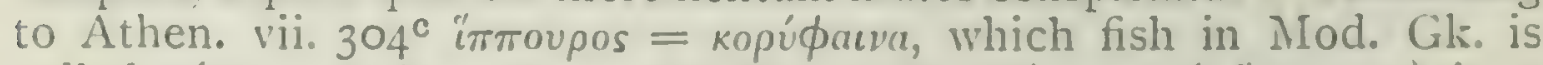

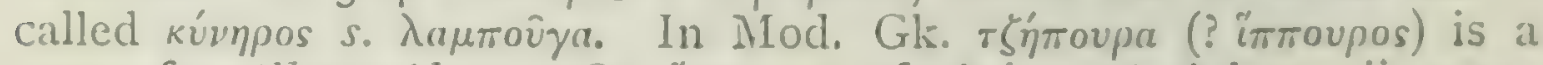
name for C\%rysophrys. On "itroupos cf. Arist. ap. Athen. vii. $312^{c}$; Plin. ix. 16; Ovid. Hal. 96 'celeres hippuros'.

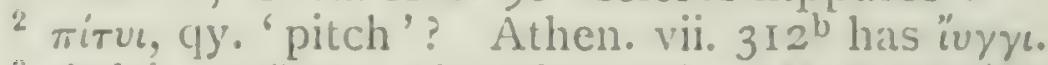

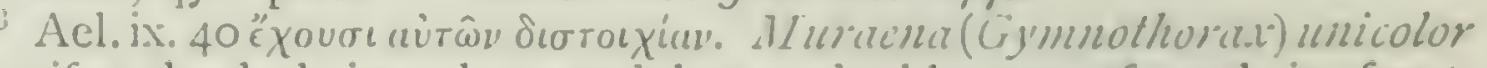
is uniformly dark in colour and has a double row of teeth in front. A specimen was shown to Hofmann in the market at. Athens as the male of the common Muracna ( $H$. and Jordan, p. 248).

P.A. iv. 13. $696^{\mathrm{b}} 20$.

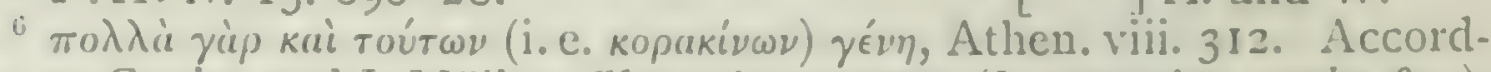
ing to Cuvier and J. Miuller, Chromis castanca (It. coracino, corbo, \&c.), the allied fish from the Nile (Athen. l.c.) being C.niloticus. Unbrina cirrhose and Corrina migra are known as corrit, and are said to spawn in hackish water, but these we identify with orinum or pripus.

7 Athen. vi. 315. Epincphelus gigers, the 'Nérou', according to

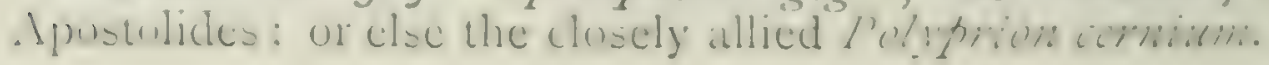


in the Euxine, and nowhere elsc. The cestreus or mullet, ${ }^{1}$ the chrysophrys or gilt-head, and the labrax or basse, breed best where rivers run into the sea. The orcys ${ }^{2}$ or large- 5 sized tunny, the scorpis, ${ }^{3}$ and many other specics spawn in the open sea.

II Fish for the most part breed some time or other during the three months between the middle of March and the middle of June. ${ }^{4}$ Some few breed in autumn: as, for instance, the saupe and the sargus, and such others of this sort as brecd shortly before the autumn cquinox; likervise the clectric ray and the angel-fish. Other fishes breed both in winter 1o and in summer, as was previously observed: as, for instance, in winter-time the basse, the grey mullet, and the belone or pipe-fish; and in summer-time, from the middle of June to the middle of July, the female tunny, about the time of the summer solstice; " and the tunny lays a sac-like cnclosure in which are contained a number of small eggs. ${ }^{6}$ The ryades or shoal-fishes breed in summer.

Of the grey mullets, ${ }^{7}$ the chelon ${ }^{8}$ begins to be in roe between the middle of November and the middle of $I_{5}$ December; as also the sargue, and the smyxon or myxon, and the cephalus; and their period of gestation is thirty days. And, by the way, some of the grey mullet species are

${ }^{1}$ Cf. Erhard, Fauna d. Cycladen, p. 8 (cit. A. and W.). Very abundant in the lagoons at Missolonghi (Apostolides).

${ }^{2} \mathrm{Cf}$. the o" $\rho$ киขо of Dorio $a p$. Athen. vii. $315^{\mathrm{b}}$, which come in from the Atlantic.

${ }^{3}$ I suspect that $\sigma \kappa o \mu \beta p i \delta \in s$ (Aa Ca), mackerel, is the correct reading. On $\sigma$ kopтis see above, $9.543^{\mathrm{a}} 7$.

${ }^{4}$ Cf. H.A. vi. I7. 570 ; Plin. ix. 74.

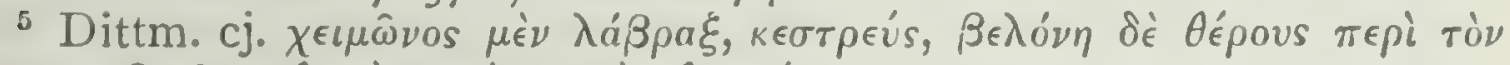

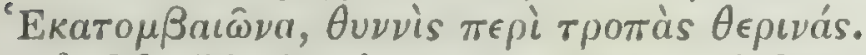

${ }^{6}$ Cf. H.A. vi. 17. $57 \mathrm{I}^{2}$ I4. Athen. vii. 303. In Auxis vulgaris, an allied species, Cuvier and Val. (viii. p. I44) state that the eggs are enveloppés d'un gluten roussâtre.

7 The grey mullets are very often referred to by A., and are of great importance in the Mediterranean. Ed. Forbes speaks of them as the commonest fish in the Constantinople market. The ké $\phi a \lambda$ os is also a kind of grey mullet; the name remains in Greek, and in the It. cievolo, cefalo. $\mu u \dot{\xi} \omega \nu$ is probably another species, which Cuvier refers, though with little certainty, to $M$. auratus.

8 Probably Mugil Chelo, the thick-lipped grey mullet; in Sicily shalone. H.A.vi. 17.570" 2 ; Athen. vii. 306. 
not produced from copulation, but grow spontancously from mud and sand. ${ }^{1}$

As a general rule, then, fishes are in roe in the springzo time; while some, as has been said, are so in summer, in autumn, or in winter. But whereas the impregnation in the spring-time follows a general law, impregnation in the other seasons docs not follow the same rule either throughout or within the limits of one genus; and, further, conception in these variant scasons is not so prolific. And, indeed, we must bear this in mind, that just as with plants 25 and quadrupeds diversity of locality has much to do not only with general physical health but also with the comparative frequency of sexual intercourse and generation, so also with regard to fishes locality of itself has much to do not only in regard to the size and vigour of the creature, but also in regard to its parturition and its copulations: 3.0 causing the same specics to breed oftener in one place and seldomer in another.

$544^{\mathrm{a}}$ The molluscs also breed in spring. Of the marine mol- 12 luscs one of the first to breed is the sepia. It spawns at all times of the day ${ }^{2}$ and its period of gestation is fiftecn days. ${ }^{3}$ After the female has laid her eggs, the male comes and discharges the milt ${ }^{4}$ orer the eggs, and the eggs thereupon harden. And the two sexes of this animal go about 5 in pairs, side by side; and the male is more mottled and more black on the back than the female. ${ }^{5}$

The octopus pairs in winter and breeds in spring, lying hidden for about two months. Its spawn is shaped like a vine-tendril," and resembles the fruit of the white poplar; the creature is extraordinarily prolific, for the ro number of individuals that come from the spawn is something incalculable. The male differs from the female in the fact that its head is longer, and that the organ called by

1 Athen. vii. 305.

2 For $\pi \hat{a} \sigma a \nu \tilde{\omega} \rho a \nu$ A. and IT. conjecture $\pi \lambda \dot{j} \theta$ os $\omega \dot{\omega} \nu$, cf. infra IS. $570^{2}$ I; Athen. vii. 323. But cf. 14. $546^{\mathrm{a}} 21$.

${ }^{3}$ Cf. Athen. vii. 323; Plin. ix. 74.

1 Reading Oopón. Most MSS, have Aodóv, Gaza, atramentum. For

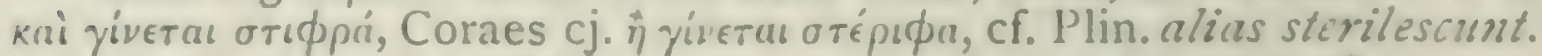

${ }^{5}$ Cf. $H . A$. iv. I. $525^{2} 9^{\circ}$

i C. $19.55 \mathrm{I}^{\mathrm{B}} \mathrm{IO}$. 
the fishermen its penis, in the tentacle, is white. ${ }^{1}$ The female, after laying her eggs, broods over them, and in consequence gets out of condition, by reason of not going in quest of food during the hatching period.

The purple murex breeds about spring-time, and the is ceryx at the close of the winter. And, as a general rule, the testaceans are found to be furnished with their so-called eggs ${ }^{2}$ in springtime and in autumn, with the exception of the edible urchin; for this animal has the so-called eggs in most abundance in these scasons, but at no season is unfurnished with them; and it is furnished with them in especial abundance in warm weather or when a full moon is 20 in the sky. ${ }^{3}$ Only, by the way, these remarks do not apply to the sea-urchin found in the Pyrrhaean Straits, ${ }^{4}$ for this urchin is at its best for table purposes in the winter; " and these urchins are small but full of eggs.

Snails are found by observations to become in all cases impregnated about the same season. ${ }^{6}$

I3 7 [Of birds the wild species, as has been stated, as a general 25 rule pair and breed only once a year. The swallow, howcver, and the blackbird breed twice. With regard to the b lackbird, however, its first brood is killed by inclemency of weather (for it is the earliest of all birds to breed), but the second brood it usually succeeds in rearing.

Birds that are domesticated or that are capable of domestication breed frequently, just as the common pigeon 30 breeds all through the summer, and as is seen in the barndoor hen; for the barn-door cock and hen have intercoursc, and the hen breeds, at all seasons alike: excepting, by the way, during the days about the winter solstice. ${ }^{8}$

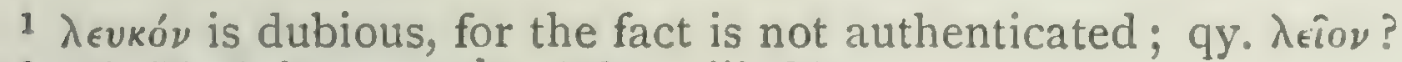

${ }^{2}$ Cf. H.A. iv. $4.529^{\mathrm{b}}$; Athen. iii. 88.

3 Edward Forbes says that the sea-urchin is in season in Sicily about the full moon of March. It is still a common belief in the Mediterranean that sea-urchins should be fished at the full of the moon.

${ }^{4}$ Guil. quae in nigro Ponto, i, e. Negroponte.

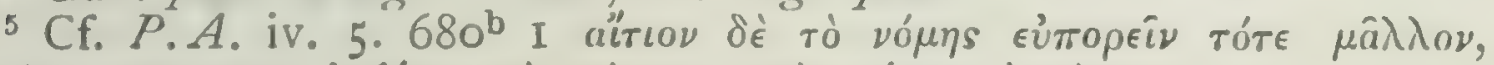

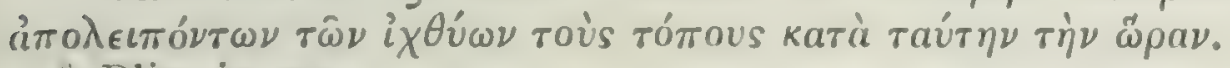

i Plin. ix. 74 .

7 This chapter, and especially that portion relating to the pigenn, is doubtfully authentic.

H. A. vi. I. $55^{\mathrm{b}} \mathrm{I}$. 
Of the pigcon family there are many dircrsitics : ${ }^{1}$ for the peristera or $\mathrm{common}$ pigeon is not idcntical with the peleias or reck-pigeon. In other words, the rock-pigeon is smaller than the common pigeon, and is less easily domesticated; it is also black, and small, red-footed and rough-footed; and in conscquence of these peculiarities it is neglected by 5 the pigeon fancicr. The largest of all the pigcon species is the phatta or ring-dove; and the next in size is the oenas or stock-dore; ${ }^{2}$ and the stock-dove is a little larger than the common pigcon. The smallest of all the species is the turtle-dove. Pigcons brecel and hatch at all scason:, if they are furnished with a sunny place and all requisites; unless they are so furnished, they breed only in the summer. 10 The spring brood is the best, or the autumn brood. At all erents, without doubt, the produce of the hot scason, the summer brood, is the poorest of the three.]

Further, animals cliffer from one another in regard to the I4 time of life that is best adapted for sexual intercourse.

To begin with, in most animals the secretion of the seminal fluid anci its generative capacity are not phenomena simultaneously manifestcd, but manifested successively: 15 Thus, in all animals, the earliest secretion of sperm is unfruitful," or if it be fruitful the issue is comparatively poor and small. And this phenomenon is especially observable in man, in viviparous quadrupeds, and in birds: for in the case of man and the quadruped the offspring is smaller, and in the case of the bird, the egg.

For animals that copulate, of one and the same species, 2o the age for maturity is in most species ${ }^{4}$ tolerably uniform, unless it occurs prematurcly by reacon of abnormality, or is postponed by physical injury.

In man, then, maturity is indicated by a change of the

${ }^{1}$ Cf. H. A. viii. 3. $593^{\text {a }}$ 12. $597^{\text {ln }}$ Athen. iii. $393^{\text {b }}$; Ael. V. H. I. I5, \&ic.

2 Identification with the stock-dove is doubtful, and oivcis has probably no connexion with oirns: cf. Gl. of Gli. Birds: p. I20.

G. A. ii. 4. $739^{2}$ 10.

'Dittmeyer's bracketing of $\mu \epsilon^{\prime}$ ' and insertion of ' ${ }^{\prime}$ scem tmnecessary. 
tone of voice, ${ }^{1}$ by an increase in size and an alteration in appcarance of the sexual organs, as also in an increase of size and alteration in appcarance of the breasts; and above all, in the hair-growth at the pubes. Man begins to possess 25 seminal fluid about the age of fourteen, and becomes generatively capable at about the age of twenty-one years.

In other animals there is no hair-growth at the pubes (for some animals have no hair at all, and others have none on the belly, or less on the belly than on the back), but still, in some animals the change of voice is quite obvious; 30 and in some animals other organs give indication of the commencing secretion of the sperm and the onset of generative capacity. As a general rule the female is sharper-toned in voice than the male, and the young animal than the elder ; ${ }^{2}$ for, by the way, the stag has $545^{2}$ a much deeper-toned bay than the hind. Moreover, the male cries chiefly at rutting time, and the female under terror and alarm; and the cry of the female is short, and that of the male prolonged. With dogs also, as they grow 5 old, the tone of the bark gets deeper.

There is a difference observable also in the neighings of horses. That is to say, the female foal has a thin small neigh, and the male foal a small neigh, yet bigger and deeper-toned than that of the female, and a louder one as time goes on. And when the young male and female are two years old and take to brecding, the neighing of the ro stallion becomes loud and deep, and that of the mare louder and shriller than heretofore; and this change goes on until they reach the age of about twenty years; and after this time the neighing in both sexes becomes weaker and weaker.

As a rule, then, as was stated, the voice of the male differs from the voice of the female, in animals where the 15 voice admits of a continuous and prolonged sound, in the fact that the note in the male voice is more deep and bass; not, however, in all animals, for the contrary holds good in

${ }^{2}$ G.A. v. 7. 786 14 ; Probl. xi. I4. $900^{\mathrm{a}} 32,24 \cdot 90 \mathrm{I}^{\mathrm{b}} 24$. 
the casc of some, as for instance in kine: for here the cow has a deeper note than the bull, and the calves a deeper note than the cattle. ${ }^{1}$ And we can thus understand the 20 change of voice in animals that undergo gelding; ${ }^{2}$ for male animals that undergo this process assume the characters of the female.

The following are the ages at which various animals become capacitated for sexual commerce. The ewe and the she-goat are sexually mature when one year old, and this statement is made more confidently in respect to the 25 she-goat than to the ewe; the ram and the he-goat are sexually mature at the same age. The progeny of very young individuals among these animals differs from that of other males: for the males improve in the course of the second year, when they become fully mature. ${ }^{3}$ The boar and the sow are capable of intercourse when eight months old, and the female brings forth when one year old, the difference corresponding to her period of gestation. The 30 boar is capable of generation when eight months old, but, with a sire under a year in age, the litter is apt to be a poor one. The ages, however, are not invariable; now and then $545^{\mathrm{b}}$ the boar and the sow are capable of intercourse when four months old, and are capable of producing a litter which can be reared when six months old; but at times the boar begins to be capable of intercourse when ten months. He continues sexually mature until he is three years old. The dog and the bitch are, as a rule, sexually capable and sexually receptive when a year old, and sometimes when 5 eight months old; ${ }^{4}$ but the priority in date is more common with the dog than with the bitch. The period of

${ }^{1}$ G. A.v. $7 \cdot 7 \$ 7^{\mathrm{a}} 3 \mathrm{I}$.

${ }^{2} H . A$. ix. 50. $632^{2} 5 ;$ G. A. v. 7. $787^{\text {b }}$ 19; Probl. xi. 34. $902^{2} 27$.

'A corrupt passage. Gaza tr. 'mares quoque in is ipsis generibus codem illo tempore ineunt: sed proles differt, quatenus praestantior ca est quam senescentes mares et feminae procrearint'. A. and W.

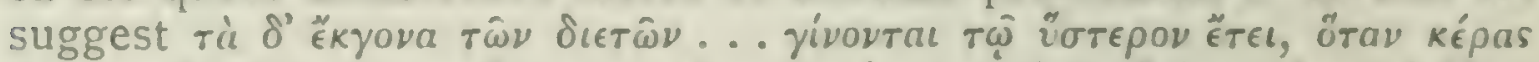

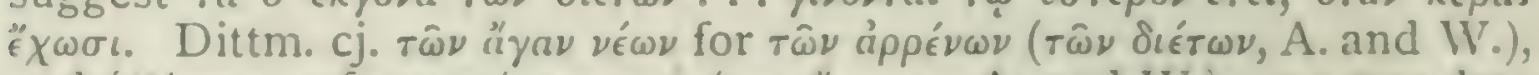

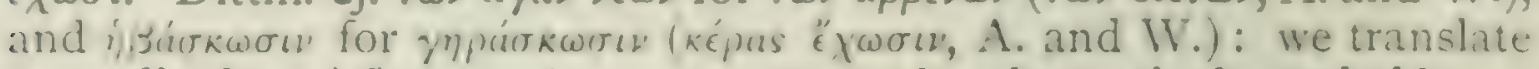
accordingly. iิ ơ

H. A. vi. 20. $574^{3} 16$. 
gestation with the bitch is sixty days, or sixty-one, or sixtytwo, or sixty-three at the utmost; the period is never under sixty days, or, if it is, the litter comes to no good. The bitch, after delivering a litter, submits to the male in six months, but not before. The horse and the mare are, at ro the earlicst, sexually capable and sexually mature when two ${ }^{1}$ years old; the issue, however, of parents of this age is small and poor. As a general rule these animals are sexually capable when three years old, and they grow better for breeding purposes until they reach twenty years. The s 5 stallion is sexually capable up to the age of thirty-three years, and the mare up to forty, ${ }^{2}$ so that, in point of fact, the animals are sexually capable all their lives long; for the stallion, as a rule, lives for about thirty-five years, and the mare for a little over forty ; although, by the way, a horse has been known to live to the age of seventy-five. 20 The ass and the she-ass are sexually capable when thirty months old; but, as a rule, they are not generatively mature until they are three years old, or three years and a half. An instance has been known of a she-ass bearing and bringing forth a foal when only a year old. A cow has been known to calve when only a year old, and the calf grew as big as might be expected, but no more. So much 25 for the dates in time at which these animals attain to generative capacity.

In the human species, the male is generative, at the longest, up to seventy years, and the female up to fifty; but such extended periods are rare. As a rule, the male is generative up to the age of sixty-five, and to the age of 30 forty-five the female is capable of conception.

The ewe bears up to eight years, and, if she be carefully tencled, up to eleven years; in fact, the ram and the ewe are sexually capable pretty well all their lives long. He- $546^{\text {a }}$ goats, if they be fat, are more or less unscrviceable for breeding ; ${ }^{*}$ and this, by the way, is the reason why country folk say of a vine when it stops bearing that it is 'running

1 H.A. vi. 22. $575^{\mathrm{b}} 22$; Ael. xv. 25.

2 Ael. xv. 25; Colum. R.R.vi. 37.9.

4 G. A. i. I8. $725^{\mathrm{b}} 34$; Theoph. C. P. i. 5.5 ; H.P. iv. I4. 6.

${ }^{3}$ Cf. vi. 22. $576^{\mathrm{a}} 26$.

$\mathrm{O} 2$ 
the goat'. However, if an over-fat he-goat be thinned down, he becomes scxually capable and generative.

Rams single out the oldest cwes for copulation, and 5 show no regard for the young oncs. And, as has becn stated, the issue of the younger ewes is poorer than that of the older ones.

The boar is good for brecling purposes until he is three ycars of age; ${ }^{2}$ but after that age his issue detcriorates, for after that age his rigour is on the decline. The boar is most capable after a good feed, and with the first sow it ro mounts; if poorly fed or put to many females, the copulation is abbreviated," and the litter is comparatively poor. The first litter of the sow is the fewest in number; at the second litter she is at her prime. The animal, as it grows old, continues to breed, but the sexual desire abates. When they reach fiftecn years, they become unproductive, and are Is getting old. If a sow be highly fed, it is all the more eager for scxual commerce, whether old or young; but, if it be orer-fattened in pregnancy, it gives the less milk after parturition. With regard to the age of the parents, the litter is the best when they are in their prime; but with regard to the seasons of the year, the litter is the best that comes at the beginning of winter; and the summer litter the poorest, consisting as it usually does of animals small 20 and thin and flaccid." The boar, if it be well fed, is sexually capable at all hours, night and day; but otherwise is peculiarly salacious carly in the morning. As it grows old the sexual passion dies away, as we have already remarked. Very often a boar, when more or less impotent from age or debility, fincling itself unable to accomplish the sexual commerce with clue speed, and growing fatigued 25 with the standing posture, will roll the sow over on the ground, and the pair will conclude the operation sicle by

1 i.c. running riot in over-luxuriance.

2 Plin. viii. 51; Varro, R.R. ii. 4. 8; Columella, vii. 9.

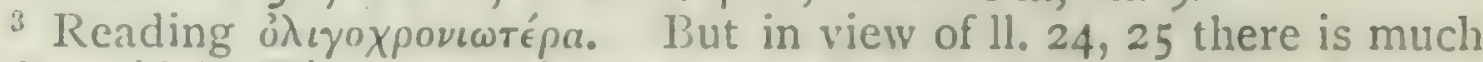

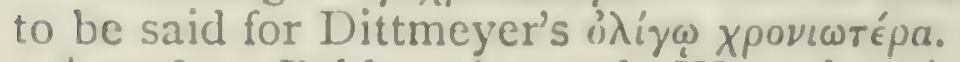

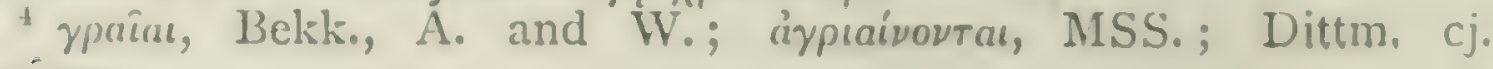
जтEір)

G But cf. Varro, R. R. ii. 4. I3. 
side of one another. The sow is sure of conception if it drops its lugs in rutting time $;^{1}$ if the ears do not thus drop, it may have to rut a second time before impregnation takes place.

Bitches do not submit to the male throughout their lives, ${ }^{2}$ but only until they reach a certain maturity of years. As a general rule, they are sexually receptive and conceptive until they are twelve years old; although, by the way, cases have been known where dogs and bitches 30 have been respectively procreative and conceptive to the ages of eighteen and even of twenty ycars. But, as a rule, age diminishes the capability of generation and of conception with these animals as with all others.

The female of the camel is opisthuretic, and submits to $546^{\mathrm{b}}$ the male in the way above described $;^{3}$ and the season for copulation in Arabia is about the month of October. Its period of gestation is twelve months $;^{4}$ and it is never delivered of more than one foal at a time. The female becomes sexually receptive and the male sexually capable 5 at the age of three years. After parturition, an interval of a year clapses before the female is again receptive to the male.

The female ${ }^{j}$ elephant becomes sexually receptive when ten years old at the youngest, and when fifteen at the oldest; ${ }^{6}$ and the male is sexually capable when five ycars old, or six. The season for intercourse is spring. The male allows an interval of three years to elapse after com-10 merce with a female: and, after it has once impregnated a female, it has no intercourse with her again. ${ }^{7}$ The period of gestation with the female is two years; and only one young animal is produced at a time, in other words it is uniparous. And the embryo is the size of a calf two or three months old. ${ }^{8}$

1 H. A. vi. 18. $573^{\text {b } 8 ; ~ P l i n . ~ v i i i . ~} 77$.

2 Plin.x. 83 ; contra, H. A. vi. $20.574^{\mathrm{b}} 27$.

3 H. A. v. 2. 5 IO $^{a} 8$; cf. vi. I 8.57 I $^{b} 24$, ix. $47.630^{b} 3$ I.

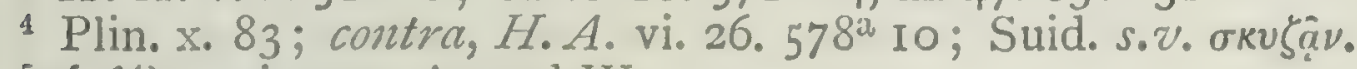

5 i $\theta \dot{\eta} \lambda \epsilon \iota a$, interp. A. and $\mathrm{W}$.

${ }^{6}$ Plin. viii. 5 ; cf. H. A. vi. $27.578^{a}$.

7 Ael. viii. I 7 .

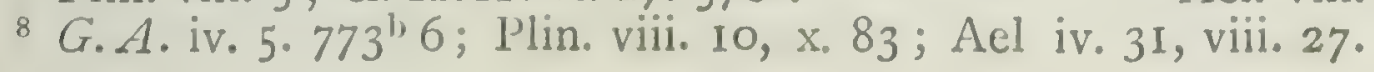


So much for the copulations of such animals as copulate. I5 15

We now proceed to treat of generation both with respect to copulating and non-copulating animals, and we shall commence with discussing the subject of generation in the case of the testaceans.

The testacean ${ }^{1}$ is almost the only genus that throughout all its species is non-copulative.

The porphyrae, or purple murices, gather together to some one place in the spring-time, and deposit the so-called 'honey-comb'.2 This substance resembles the comb, only 20 that it is not so neat and delicate; and looks as though a number of husks of white chick-peas were all stuck together. But none of these structures has any open passage, and the porphyra does not grow out of them, but these and all other testaceans grow out of mud and decaying matter. The substance, is, in fact, an excretion 25 of the porphyra and the ceryx; for it is deposited by the ceryx as well. Such, then, of the testaceans as deposit the honeycomb are generated spontaneously like all other testaceans, but they certainly come in greater abundance in places where their congeners have becn living previously. At the commencement of the process of depositing the honeycomb, they throw off a slippery mucus, and of this 30 the husklike formations are composed. These formations, then, all melt and deposit their contents ${ }^{4}$ on the ground, and at this spot therc arc found on the ground a number of minute porphyrae, and porphyrac are caught at times with these animalculac upon them, some of which are too $547^{\text {a }}$ small to be differentiated in form. If the porphyrac are caught before producing this honey-comb, they sometimes go through the process in fishing-crecls, not here and there in the baskets, but gathering to some one spot all together, just as they do in the sea; and owing to the narrowness of their new quarters they cluster together like a bunch of grapes.

${ }^{1}$ Cf. G. A. iii. $2.76 \mathrm{I}^{\mathrm{a}}$.

${ }^{2}$ G. A. iii. 2. $76 \mathrm{I}^{\mathrm{b}} 32$; Athen. iii. 88 ; Plut. Sol. Ar. 980.

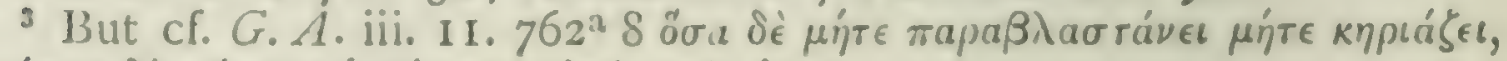

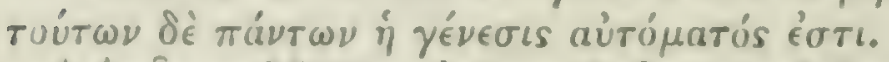

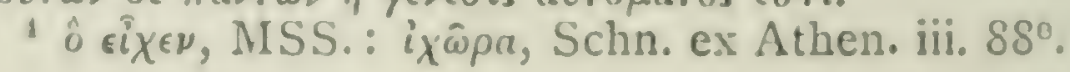


There are many species of the purple murex ${ }^{1}$ and some are large, as those found off Sigeum and Lectum; others 5 are small, as those found in the Euripus, and on the coast of Caria. And those that are found in bays are large and rough; in most of them the peculiar bloom from which their name is derived is dark to blackness, in others it is reddish and small in size; some of the large ones weigh upwards of a mina apiece. But the specimens that are found along the coast and on the rocks are small-sized, and ro the bloom in their case is of a reddish hue. Further, as a general rule, in northern waters the bloom is blackish, and in southern waters of a reddish hue. The murex is caught in the spring-time when engaged in the construction of the honeycomb; but it is not caught at any time about the rising of the dog-star, ${ }^{2}$ for at that period it does not feed, but conceals itself and burrows. The bloom of the animal is is situated between the mecon (or quasi-liver) and the neck, and the co-attachment of these is an intimate one. In colour it looks like a white membrane, and this is what people extract; and if it be removed and squeezed it stains your hand with the colour of the bloom. There is a kind of vein that runs through it, and this quasi-vein would appear to be in itself the bloom. And the qualities, by the way, of this organ are astringent. ${ }^{3}$ It is after the murex 20 has constructed the honey-comb that the bloom is at its worst. Small specimens they break in pieces, shells and all, for it is no easy matter to extract the organ; but in dealing with the larger ones they first strip off the shell and then abstract the bloom. For this purpose the neck and mecon are separated, for the bloom lies in between them, above the so-called stomach; hence the necessity of 25

${ }^{1}$ e.g. M. brandaris, M. trunculus, Purpura haemastoma, \&c. The first is still called at Tarento quecciolo a far la porpora (Costa). The great refuse-heaps of shells at Tarento consist of $1 /$. brinduris, at Tyre of $M$. trunculus. On the species of $\pi$ ó $\rho \phi v \rho a \mathrm{cf}$. Plin. ix. 6r, Athen. iii. 88; also Fabius Columna, de Purpura, I674; J. G. Schneider in Ulloa's Nachrichten won America, 1781, vol. ii. p. 377 ; Heusinger, de Purp. antiquorum, Würzburg, 1826; Martens, op. cit. p. 205; Lacaze Duthiers, 'Nat. Hist. of the Purple of the Ancients,' Pr. Roy. Soc. x. pp. 579-84, I860; also Mém. sur le pourpre, Lille, 1859, 28 pp., Arch. zool. exp. et gén., 1897, \&c.

${ }^{2}$ Plin. ix. 38.

3 Dittm. would reject. 
scparating them in abstracting the bloom. Fishermen are anxious always to break the animal in pieces while it is yet alive, ${ }^{1}$ for, if it die before the process is completed, it vomits out the bloom; and for this reason the fishermen keep the animals in creels, until they have collected a sufficient number and can attend to them at their leisure. Fishermen in past times used not to lower crecls or attach so them to the bait, so that very often the animal got dropped off in the pulling up; at present, howerer, they always attach a basket, ${ }^{2}$ so that if the animal fall off it is not lost. The animal is more inclined to slip off the bait if it be full inside; if it be empty it is difficult to shalie it off. Such $547^{\mathrm{b}}$ are the phenomena connected with the porphyra or murex.

The same phenomena are manifested by the ceryx or trumpet-shell; and the scasons are the same in which the phenomena are observable. ${ }^{3}$ Both animals, also, the murex and the ceryx, have their opercula similarly situated ${ }^{4}$-and, in fact, all the stromboids, and this is congenital with them 5 all; and they feed by protruding the so-called tongue underneath the operculum. The tongue of the murex is bigger than one's finger, and by means of it, it feeds, and perforates conchylia and the shells of its own kind." Both the murex and the ceryx are long-lived. The murex lives ro for about six years; and the yearly increase is indicated by a distinct interval in the spiral convolution of the shell."

The mussel also constructs a honey-comb. ${ }^{\top}$

With regard to the limnostreac, or lagoon oystcrs," wherever you have slimy mud there you are sure to find them beginning to grow: ${ }^{2}$ Cockles and clams and razor-

1 Cf. Ael. xvi. I.

2 Plin. ix. 37.

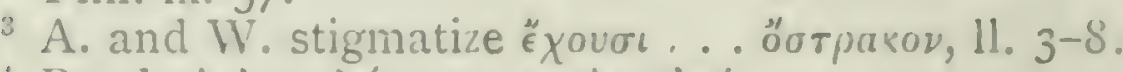

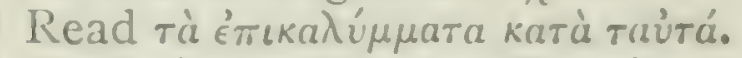

P.A. ii. $17.66 \mathrm{I}^{\mathrm{a}} 2 \mathrm{I}$; Plin. ix. 60.

Plin. ix. 6I ; cf. G. A. iii. 2. $763^{2} 20$; Athen. l.c.

G.A. iii. 2. $76 \mathrm{I}^{\mathrm{b}} 30$; Plin. xxii. 32. Here the reference is doubtless wo the crowiled 'spat"; for the mussel does not construct egs-capsules. A. and IV. delete the passage.

I Probably Ostrea cochlear, Poli ; ostrica di fango of the Neapolitans (Martens).

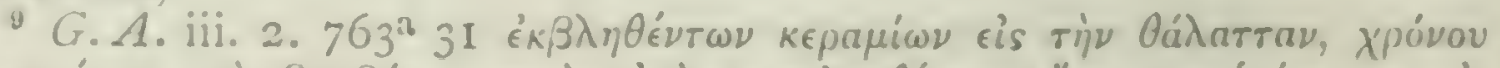

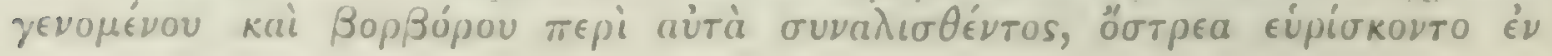


fishes and scallops grow spontancously in sandy places. The pinna grows straight up from its tuft of anchoring 15 fibres ${ }^{1}$ in sandy and slimy places; ${ }^{2}$ these creatures have inside them a parasite nicknamed the pinna-guard, ${ }^{3}$ in some cases a small carid ${ }^{4}$ and in other cases a little crab; ${ }^{5}$ if the pinna be deprived of this pinna-guard it soon dies.

As a general rule, then, all testaceans grow by spontaneous generation in mud, differing from one another according to the differences of the material; oysters growing in slime, and cockles and the other testaceans 20 above mentioned on sandy bottoms; and in the hollows of the rocks the ascidian and the barnacle, and common sorts, ${ }^{6}$ such as the limpet and the nerites. All these animals grow with great rapidity, especially the murex and the scallop; for the murex and the scallop attain their full growth in a year. In some of the testaceans white 25 crabs are found, very diminutive in size; they are most numerous in the trough-shaped ${ }^{\top}$ mussel. In the pinna also is found the so-called pinna-guard. They are found also in the scallop and in the oyster; these parasites never appear to grow in size. Fishermen declare that the para- 30 site is congenital with the larger animal. [Scallops burrow for a time in the sand, like the murex. $]^{\mathrm{s}}$

[Shell-fish, then, grow in the way above mentioned; and

aviois. On the cultivation of oysters cf. Plin. ix. 5I, Xenocr. de Aq. 26.

${ }^{1}$ It is a moot point whether to read '́k rov $\beta v \sigma \sigma o \hat{v}$, 'out of deep water', or 'ُ $k \tau i \hat{s} \beta\langle\dot{u} \sigma \sigma o v$, 'from its byssus, or tuft of anchoring fibres.' The latter is the characteristic feature of the Pinna, and it accords with Gaza's translation, ' pimnae erectae ex bysso, id est villo sive lana illa pinnali': the former with Athenaeus iii. 89 ' $k$ zov $\beta u \theta_{o} \hat{v}$. On the

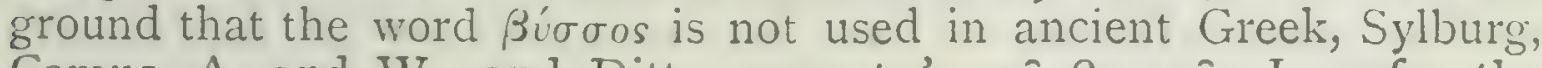
Camus, A. and W., and Dittm. accept '̇א $\tau 0 \hat{v} \beta v \sigma \sigma o \hat{v}$; I prefer the other alternative, chiefly on the ground that the pinna does grow 'straight up out of its byssus', but, though it lives in deep water, cannot be said to 'grow up out of it'. Cf. Bochart, Hieroz. ii. C. 45; A. Müller, in Wiegmann's Archiv, 1837, i. p. 2, \&c.

2 Plin. ix. 42.

${ }^{3}$ Aristoph.Vesp. I510; Athen. iii. 89; Plin. ix. $42 ; \Lambda$ el. iii. 29.

1 Pontonia tyrrhena, Latr.

5 Pinnotheres veterum, Bosc.

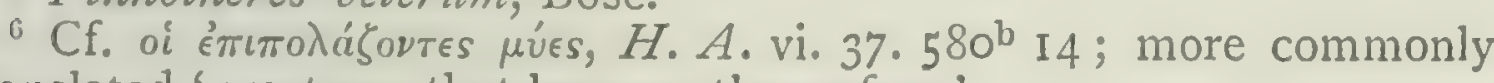
translated 'creatures that keep on the surface'.

7 Schn. $\pi \eta \lambda \dot{\omega} \delta \epsilon \iota \iota v$. The crab is Pinnotheres pisum, Fabr.

${ }^{8}[$ ] A. and W. 
some of them grow in shallow water, ${ }^{1}$ some on the seashore, some in rocky places, ${ }^{2}$ some on hard and stony ground, and some in sandy places.]" Some shift about from place to place, others remain permanent on one spot. Of those that keep to one spot the pinnae are rooted to 5 the ground; the razor-fish and the clam keep to the same locality, but are not so rooted; but still, if forcibly removed they die. ${ }^{4}$

[The star-fish is naturally so warm that whatever it lays hold of is found, when suddenly taken away from the animal, to have undergone a process like boiling. ${ }^{5}$ Fishermen say that the star-fish is a great pest in the Strait of ro Pyrrha. In shape it resembles a star as seen in an ordinary drawing. The so-called 'lungs' are generated spontaneously. The shells that painters use are a good deal thicker, and the bloom is outside the shell on the surface. These creatures are mostly found on the coast of Caria. $]^{6}$

I5 The hermit-crab ${ }^{i}$ grows spontancously out of soil and slime, and finds its way into untenanted shells. As it grows it shifts to a larger shell, as for instance into the shell of the nerites, or of the strombus or the like, and very often into the shell of the small ceryx. After entering a new 20 shell, it carries it about, and begins again to fecd, and, by and by, as it grows, it shifts again into another larger one.

Moreover, the animals that are unfurnished with shells 16 grow spontancously, like the testaceans, as, for instance, the sea-nettles and the sponges in rocky caves.

Of the sea-nettle, ${ }^{8}$ or sea-anemone, there are two species; 25 and of these one species lives in hollows and never loosens its hold upon the rocks, and the other lives on smooth flat reefs, free and detached, and shifts its position from time to

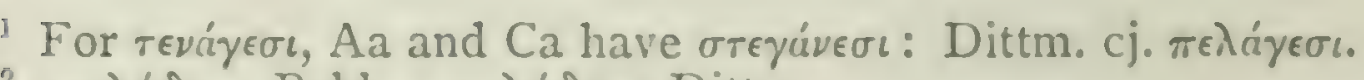

${ }^{2} \sigma \pi \iota \dot{\omega} \delta \epsilon \sigma \iota$, Bekk. : $\pi \eta \lambda \dot{\omega} \delta \epsilon \sigma \iota$, Dittm.

$s[] \mathrm{A}$. and W.

4. A. ix. i. $588^{\mathrm{L}}$ I 5 .

Plin. ix. 86; Antig. de Mirab. 88; cf. P.A. iv. 4. 6SI ${ }^{\mathrm{b}} 9$.

" $\left[\right.$ ] A. and W. All this chapter, from $547^{b} 32$ to the end, is of cloubtful authenticity, and contains several unusual words: ippijwros,

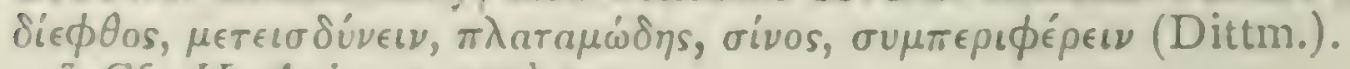

${ }^{7}$ Cf. H. A. iv. 4. $529^{\mathrm{b}} 20$.

${ }^{8}$ Cf. H. A. iv. 6. $531^{\mathrm{a}} 31$, viii. 2. $590^{\mathrm{a}} 27$. 
time. [Limpets also detach themselves, and shift from place to place. $]^{1}$

In the chambered cavities of sponges pinna-guards or parasites are found. ${ }^{2}$ And over the chambers there is a kind of spider's web, by the opening and closing of which they catch minute fishes; that is to say, they open the 30 web to let the fish get in, and close it again to entrap them. ${ }^{3}$

Of sponges there are three species; ${ }^{4}$ the first is of loose porous texture, the second is close-textured, the third, which is nicknamed 'the sponge of Achilles', is exception- 548 ally fine and close-textured and strong. This sponge is used as a lining to helmets and greaves, for the purpose of deadening the sound of the blow; and this is a very scarce species. Of the close-textured sponges such as are particularly hard and rough are nicknamed 'goats'.

Sponges grow spontaneously either attached to a rock or on sea-beaches, and they get their nutriment in slime: a proof of this statement is the fact that when they are first secured they are found to be full of slimc. This is characteristic of all living creatures that get their nutriment by close local attachment. And, by the way, the closetextured sponges are weaker than the more openly porous ones because their attachment cxtends over a smaller area.

It is said that the sponge is sensitive; and as a proof of this statement they say that if the sponge is made aware of an attempt being made to pluck it from its place of attachment it draws itself together, and it becomes a difficult task to detach it. It makes a similar contractile movement in windy and boisterous weather, obviously with the object of tightening its hold. Some persons express doubts as to

\section{1 [ ] Schn., Picc., A. and W., Dittm. Cf. viii. 2. $590^{2} 32$.}

2 Plut. Soll. Anim. 980; Ael. viii. I6. The crab is Typton spongicola, Costa.

3 Cf. Aristoph. H.A. Epit. i. 45.

4 Though the species of sponges are very numerous, zoologists refer all the commercial varieties to a single one. Three qualities are recognized in the Adriatic, spusne da bagno o learantino, de cavallo od equino, and zimocca. 
the truth of this assertion; as, for instance, the people of ${ }_{5}$ Torone.

The sponge brecls parasites, worms, and other creatures, on which, if they be detached, the rock-fishes prey, as they prey also on the remaining stumps of the sponge; ${ }^{1}$ but, if the sponge be broken off, it grows again from the remaining stump and the place is soon as well covered as before.

The largest of all sponges are the loose-textured ones, and these are peculiarly abundint on the coast of Lycia. 20 The softest are the close-textured sponges; for, by the way, the so-called sponges of Achilles are harder than these, $\Lambda$ s a general rule, sponges that are found in deep calm waters are the softest; for usually windy and stormy weather has a tendency to harden them (as it has to harden all similar growing things), and to arrest their growth. And this accounts for the fact that the sponges found in the Hellespont are rough and close-textured; 25 and, as a general rule, sponges found beyond or inside Cape Malca are, respectively, comparatively soft or comparatively hard. But, by the way; the habitat of the sponge should not be too sheltered and warm, for it has a tendency to decay, like all similar vegetable-like growths. And this accounts for the fact that the sponge is at its best when found in decp water close to shore; for owing to the depth of the water they enjoy shelter alike from stormy winds and from excessive heat.

Whilst they are still alive and before they are washed so and cleaned, they are blackish in colour. Their attachment is not made at one particular spot, nor is it made all over their boclies; for vacant pore-spaces intervenc. There is a kind of membrane stretched over the under parts; and in the under parts the points of attachment are the more $549^{\text {a }}$ numerous. On the top most of the pores are closed, but four or fre are open and visible; and we are told by some that it is through these pores that the animal takes its food.

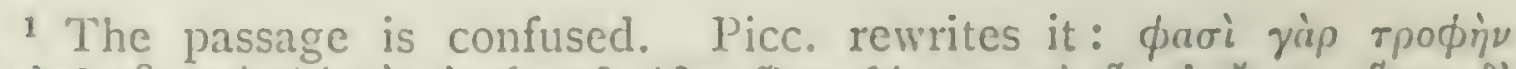

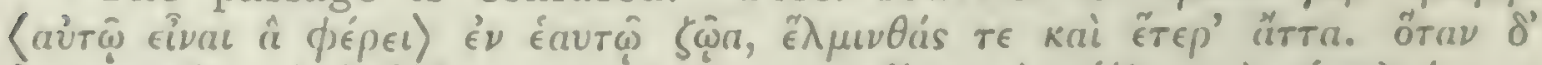

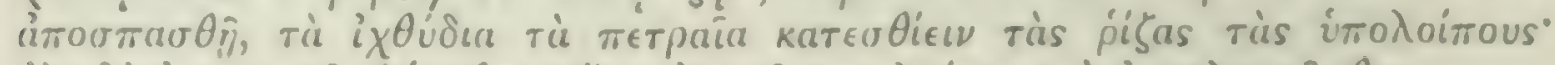

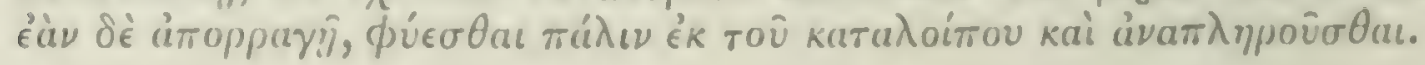


There is a particular species 'that is named the "aplysia". or the 'unwashable', from the circumstance that it cannot be cleaned. This species has the large open and visible $\tilde{5}$ pores, but all the rest of the body is close-textured; and, if it be dissected, it is found to be closer and more glutinous than the ordinary sponge, and, in a word, something lunglike in consistency. And, on all hands, it is allowed that this species is sensitive and long-lived. They are distinguished in the sea from ordinary sponges from the circum- ro stance that the ordinary sponges are white while the slime is in them, ${ }^{3}$ but that these sponges are under any circumstances black.

And so much with regard to sponges and to generation in the testaceans.

I7 Of crustaceans, the female crawfish after copulation conceives and retains its eggs for about three months, from I5 about the middle of May to about the middle of August; they then lay the eggs into the folds underneath the belly, and their eggs grow like grubs. This same phenomenon is observable in molluscs also, and in such fishes as are oviparous; for in all these cases the egg continues to grow. 20

The spawn of the crawfish ${ }^{4}$ is of a loose or granular consistency, and is divided into eight parts; for corresponding to each of the flaps on the side there is a gristly formation ${ }^{5}$ to which the spawn is attached, and the entire structure resembles a cluster of grapes; for each gristly formation is split into several parts. This is obvious enough if you draw the parts asunder; but at first sight the whole 25 appears to be one and indivisible. And the largest are not those nearest to the outlet but those in the middle, and the farthest off are the smallest. The size of the small eggs is that of a small seed in a fig; and they are not quite close to the outlet, but placed middleways; for at both ends, tailwards and trunkwards, there are two intcrvals devoid of so

1 On the species of sponges see also Plin. ix. 69, xxxi. 47.

2 Theoph. H. Pl. iv. 6. Io; Plin. l.c.

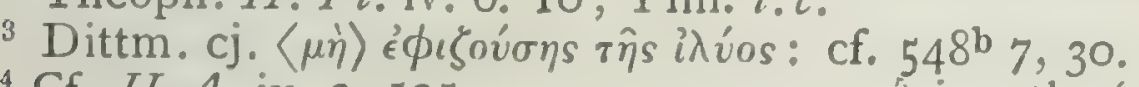

${ }^{4}$ Cf. H. A. iv. 2. 525 .

i.e. the 'swimmerets'. 
eggs; for it is thus that the flaps also grow. The side flaps, then, cannot close, but by placing the end flap on them the animal can close up all, and this end-flap serves $549^{\mathrm{b}}$ them for a lid. And in the act of laying its eggs it scems to bring them towards the gristly formations ${ }^{1}$ by curving the flap of its tail, and then, squeczing the eggs towards the said gristly formations ${ }^{2}$ and maintaining a bent posture, it performs the act of laying. The gristly formations at these seasons increase in size and become receptive of the eggs; 5 for the animal lays its eggs into these formations, just as the sepia lays its eggs among twigs and driftwood.

It lays its eggs, then, in this manner, and after hatching them for about twenty days it rids itself of them all in one solid lump, as is quite plain from outside. And out of these eggs crawfish form in about fifteen days, and these ro crawfish are caught at times less then a finger's breadth, or seven-tenths of an inch, in length. The animal, then, lays its eggs before the middle of September, and after the middle of that month throws off its eggs in a lump. With the humped carids or prawns the time for gestation is four months or thereabouts.

Crawfish are found in rough and rocky places, lobsters in smooth places, and neither crawfish nor lobsters are is found in muddy ones; and this accounts for the fact that lobsters are found in the Hellespont and on the coast of Thasos, and crawfish in the neighbourhood of Sigeum and Mount Athos. Fishermen, accordingly, when they want to catch these various creatures out at sea, take bearings on the beach and elsewhere that tell them where the ground at the bottom is stony and where soft with slime. In 20 winter and spring these animals kecp in near to land, in summer they keep in deep water; thus at various times seeking respectively for warmth or coolness.

The so-called arctus or bear-crab lays its eggs at about the same time as the crawfish; and consequently in winter and in the spring-time, before laying their eggs, they are at 25 their best, and after laying at their worst.

i. e. the abdominal appendages, or swimmerets, $=\pi \tau i x a 1,549^{4} 17$.

Reading, with $A$. and $W$., ékcivors for cübis kai. 
They cast their shell in the spring-time (just as serpents shed their so-called 'old-age' or slough), both directly after birth and in later life; this is true both of crabs and crawfish. And, by the way, all crawfish are longlived.

I8 Molluscs, after pairing and copulation, lay a white spawn; 30 and this spawn, as in the case of the testacean, gets granular in time. The octopus discharges into its hole, ${ }^{1}$ or into a potsherd or into any similar cavity, a structure resembling the tendrils of a young vine or the fruit of the white poplar, as has been previously observed. ${ }^{2}$ The eggs, whon the female has laid them, are clustered round the sides of the hole. They are so numerous that, if they be removed, $55^{\mathrm{a}}$ they suffice to fill a vessel much larger than the animal's body ${ }^{3}$ in which they were contained. Some fifty days later, the eggs burst and the little polypuses creep out, like little spiders, in great numbers ; the charac- 5 teristic form of their limbs is not yet to be discerned in detail, but their general outline is clear enough. And, by the way, they are so small and helpless that the greater number perish; it is a fact that they have been seen so extremely minute as to be absolutely without organization, but nevertheless when touched they moved. The eggs of the sepia ${ }^{4}$ look like big black myrtle-berries, and they are ro linked all together like a bunch of grapes, ${ }^{5}$ clustered round a centre, and are not easily sundered from one another: for the male exudes over them some moist glairy stuff, which constitutes the sticky gum. ${ }^{6}$ These eggs increase in size; and they are white at the outset, but black and larger I 5 after the sprinkling of the male seminal fluid.

When it has come into being the young sepia is first distinctly formed inside out of the white substance, and when the egg bursts ${ }^{7}$ it comes out. The inner part is formed as soon $a^{8}{ }^{8}$ the female lays the egg, something like

1 Athen. vii. 317.

$212.544^{a} 7$.

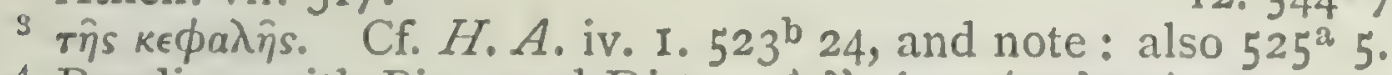

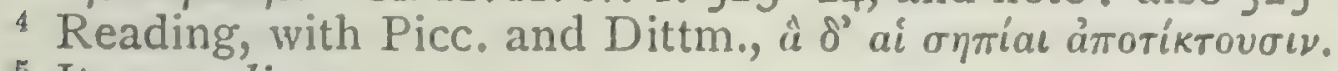

It. uva di mare.

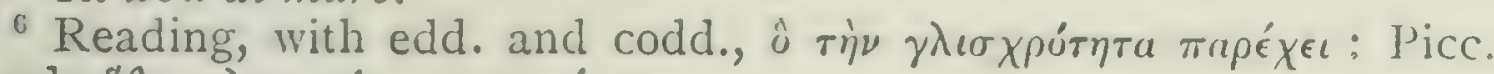

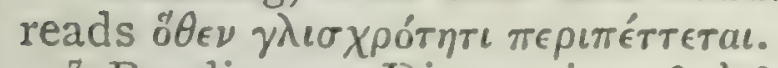

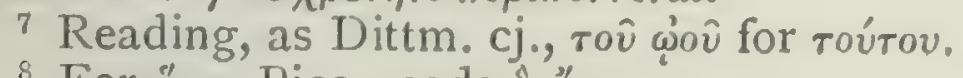

8 For ótav Picc, reads ò "iै 
a hail-stone ${ }^{1}$ and out of this substance the young scpia grows by a head-attachment, just as young birds grow by $20 \mathrm{a}$ belly-attachment. What is the cxact nature of the navel-attachment has not yet been observed, except that as the young sepia grows the white substance grows less and less in size, and at length, as happens with the yolk in the case of bircls, the white substance in the case of the young sepia clisappears. In the case of the young sepia, as in the
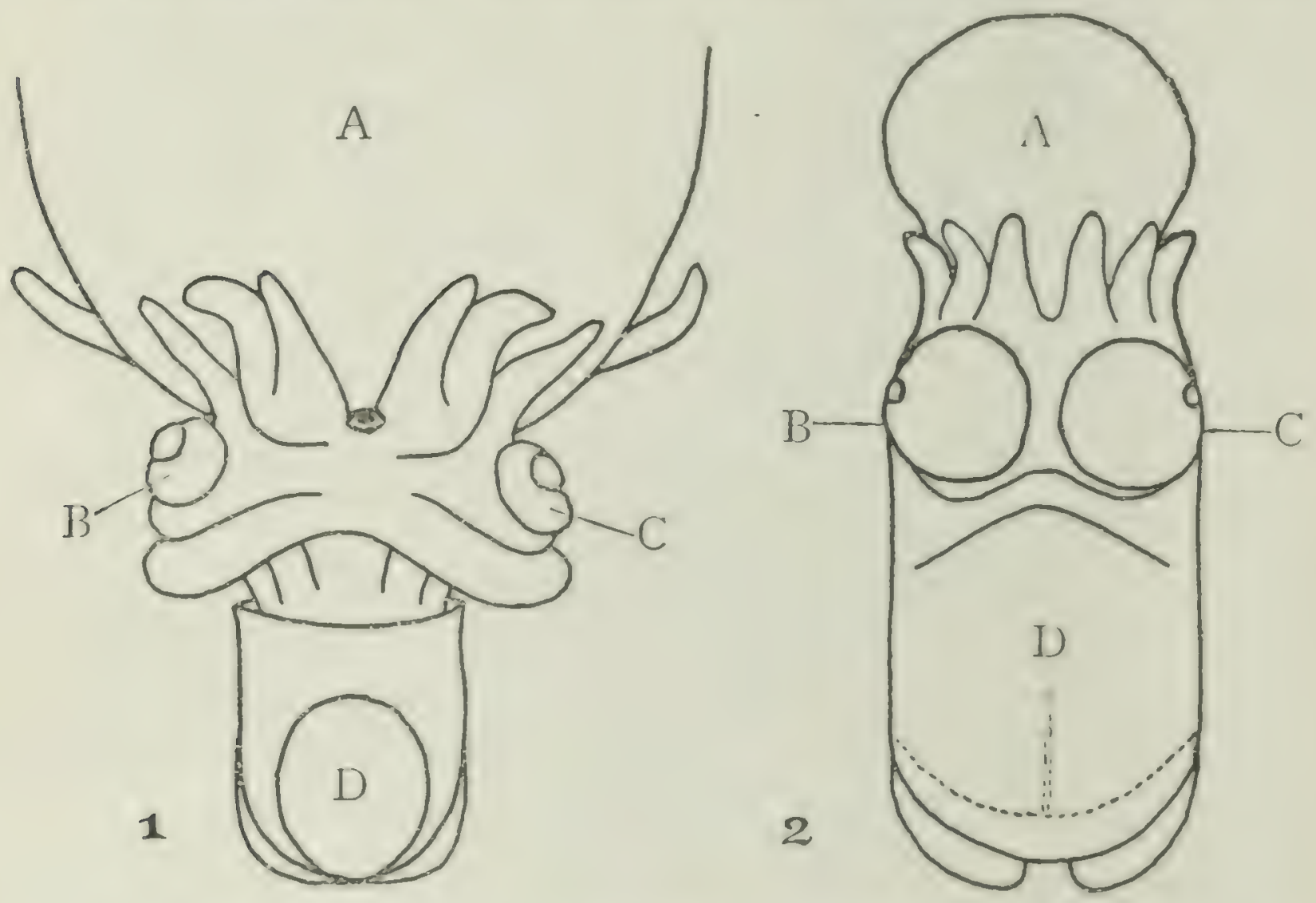

1. Younger, and 2, older, stages in the development of Sepia. A. 'Ovum,' or remains of the yolk-sac. B, C. Eyes. D. Tò $\sigma \eta \pi i \delta$ cov, or body of the little Sepia.

case of the young of most animals, the eyes at first scem 25 very large. To illustrate this by way of a figure, let $A$ represcnt the orum, Bind an the eyce, and in the sepidium, or body of the little sepia.

The female sepia goes pregnant in the spring-time, and lays its egros after fifteen clays of gestation; after the eggs are laid there comes in another fifteen days something like a bunch of grapes, and at the bursting of these the young sepiac issue forth. But if, when the young ones are fully 30 formed, you sever the outer covering a moment too soon,

1 On the xaidasu in a bird's egg cf. vi. $2.560^{2} 2 S$. 
the young creatures eject excrement, and their colour 30 changes from white to red in their alarm. ${ }^{1}$

Crustaceans, then, hatch their eggs by brooding over them as they carry them about beneath their bodies; but $550^{\mathrm{b}}$ the octopus, the sepia, and the like hatch their eggs without stirring from the spot where they may have laid them, and this statement is particularly applicable to the sepia; in fact, the nest ${ }^{2}$ of the female sepia is often seen exposed to view close in to shore. The female octopus at times sits brooding over her eggs, and at other times squats in front 5 of her hole, stretching out her tentacles on guard."

The sepia lays her spawn near to land in the neighbourhood of sea-weed or reeds or any off-sweepings such as brushwood, twigs, or stones; and fishermen place heaps of faggots here and there on purpose, and on to such heaps the female deposits a long continuous roe in shape like a to vine tendril.4 It lays or spirts out the spawn with an effort, as though there were difficulty in the process. The female calamary spawns at sea; and it emits the spawn, as does the sepia, in the mass.

The calamary and the cuttle-fish are short-lived, as, with few exceptions, they never see the year out; 5 and the 15 same statement is applicable to the octopus.

From one single egg comes one single sepia; and this is likewise true of the young calamary.

The male calamary differs from the female; for if its gill-region ${ }^{6}$ be dilated and examined there are found two

1 Cf. Theoph. fr. 173,188 (Wimmer).

2 I take ró kúros to mean $\delta$ kútrapos, the hive or nest. Cf. the double meaning of alveus.

${ }^{3}$ Athen, vii. $317^{\mathrm{f}}$.

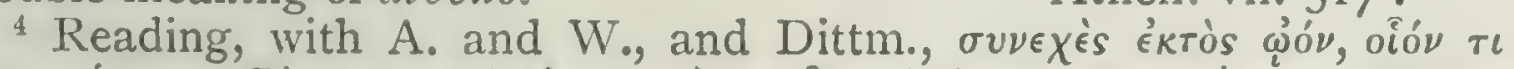

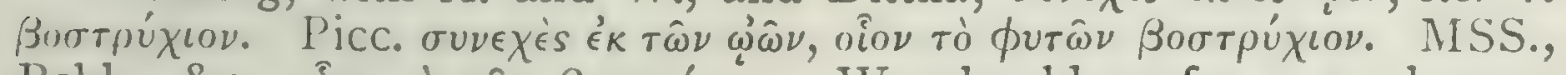
Bekk., \&c., oîo $\tau \dot{0} \tau \hat{\omega} \nu \nu \beta o \sigma \tau \rho \dot{\chi} \chi \dot{\omega} \omega \nu$. We should prefer a word more closely connected with ßorpús, one, that is to say, meaning a bunch of

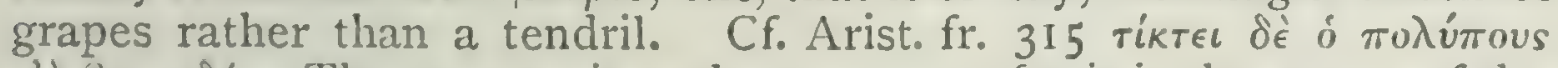
đà Botpvoóv. The passage is perhaps corrupt, for it is the spawn of the octopus that is tendril-like, as well described in $12.544^{2} \mathrm{9}, 18.549^{1} 33$, while that of the sepia is equally well described in $18.550^{\circ}$ IO.

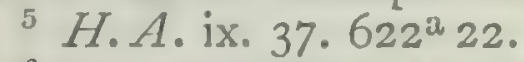

${ }^{6}$ kó $\mu \eta$, supposed by Schneider to refer to the gills, cf. тì rex $H . A$. iv. I. $524^{\mathrm{b}} 2 \mathrm{I}, 4.529^{\mathrm{a}} 32$. Scaliger bases on Gaza's version the

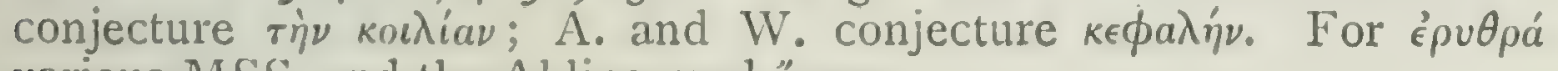
various MSS. and the Aldine read "̈vтєра. 
red formations resembling breasts, ${ }^{1}$ with which the male is unprovided. In the sepia, apart from this distinction in the 20 sexes, the male, as has becn stated, ${ }^{2}$ is more mottled than the female."

With regard to insects, that the male is less than the I9 female and that he mounts upon her back, and how he performs the act of copulation and the circumstance that he gives over reluctantly; all this has already been set forth ${ }^{4}$ $2 \vdots$ in most cases of insect copulation "this process is speedily followed up by parturition.

All insects engender grubs, with the exception of a species of butterfly; and the female of this species lays a hard egs: resembling the seed of the cnecus, ${ }^{6}$ with a juice inside it. But from the grub, the young animal does not grow out of a mere portion of it, as a young animal grows from a portion 30 only of an egg, but the grub entire grows and the animal becomes differentiated out of it. ${ }^{\top}$

And of insects some are derived from insect congeners, as the renom-spider ${ }^{8}$ and the common-spider from the venom-spider and the common-spider, and so with the attelabus or locust," the acris or grasshopper, and the tettix $55^{\mathrm{a}}$ or cicada. Other insects are not derired from living parentage, but are senerated spontancously : some out of dew falling on leaves, ordinarily in spring-time, but not seldom in winter when there has been a stretch of fair weather and southerly winds; others grow in decaying mud 5 or clung: others in timber, green or dry; some in the hair of animals: some in the flesh of animals: some in excrements: and some from excrement after it has becn voided. and some from excrement yet within the living animal, like the helminthes or intestinal worms. And of these intestinal worms there are three species: one named the flat-worm, anothe:

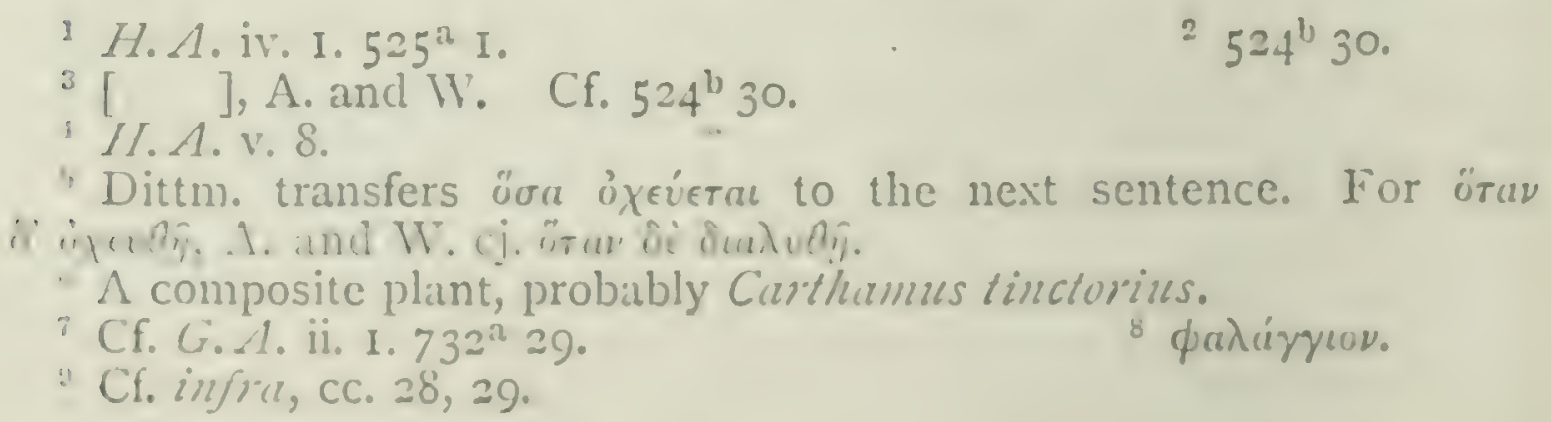

'Dittm. transfers üou óxєúєtal to the next sentence. For öruv

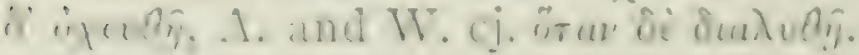

$\Lambda$ composite plant, probably Carthamms tinctorius.

C. G.A. ii. 1. $732^{\mathrm{a}} 29$.

Cf. infral, cc. $28,29$. 
the round worm, and the third the ascarid. These intestinal Io worms do not in any case propagate their kind. The flatworm, however, in an exceptional way, clings fast to the gut, and lays a thing like a melon-seed, ${ }^{1}$ by observing which indication the physician concludes that his patient is troubled with the worm.

The so-called psyche or butterfly" is generated from caterpillars ${ }^{3}$ which grow on green leaves, chicfly leaves of the raphanus, which some call crambe or cabbage. At 15 first it is less than a grain of millet; it then grows into a small grub; and in three ${ }^{4}$ days it is a tiny caterpillar. After this it grows on and on, and becomes quiescent and changes its shape, and is now called a chrysalis. The outer shell is hard, and the chrysalis moves if you touch it. 20 It attaches itself by cobweb-like filaments, and is unfurnished with mouth or any other apparent organ. After a little while the outer covering bursts asunder, and out flies the winged creature that we call the psyche or butterfly. At first, when it is a caterpillar, it feeds and ejects excrement; but when it turns into the chrysalis it neither feeds nor ejects excrement. 2

The same remarks are applicable to all such insects as are developed out of the grub, both such grubs as are derived from the copulation of living animals and such as are generated without copulation on the part of parents. For the grub of the bee, the anthrena, and the wasp, whilst it is young, takes food and voids excrement; but when it $55^{\mathrm{b}}$ has passed from the grub shape to its defined form and become what is termed a 'nympha', it ceases to takc food and to void excrement, and remains tightly wrapped up and motionless until it has reached its full size, when it brcaks the formation with which the cell is closed, and 5 issues forth. The insects named the hypera and the penia."

1 The 'proglottis' of the Taenia. Cf. Plin. xi. 38.

'The 'cabbage white' butterfly, $P$. brassicae, or allied species.

${ }^{3} \kappa \dot{\mu} \mu \pi \eta$. Cf. Colum. X. $324^{6}$ teneras audent erodere frondes Implicitus conchae limax hirsutaque campe?

${ }_{4}$ A. and W: suspect $\tau \iota \sigma \iota \nu$ for $\tau \rho \iota \sigma i \nu$.

$5 \pi \eta v^{\prime}, \nu$ (lit. spindle) and $\tilde{u} \pi \epsilon \rho_{0} \nu$ (pestle) are evidently chrysalids derived from the 'looper' caterpillars of the Geometridae; and the reference to colour is suggestive of the common currant-moth, Abraxus 
are derived from similar caterpillars, which move in an undulatory way, progressing with one part and then pulling up the hincler parts by a bend of the body. ${ }^{1}$ The developed insect in each case takes its peculiar colour from the parent caterpillar.

so From one particular large grub, which has as it were horns, and in other respects differs from grubs in general, there comes, by a metamorphosis of the grub, first a caterpillar, then the cocoon, ${ }^{2}$ then the necydalus; and the creature passes through all these transformations within six months. A class of women unwind and reel off the cocoons of these creatures, and afterwards weave a fabric 15 with the threads thus unwound; a Coan woman of the name of Pamphila, daughter of l'lateus, being credited with the first invention of the fabric. ${ }^{3}$ After the same fashion the carabus or stag-beetle ${ }^{4}$ comes from grubs that live in dry wood: at first the grub is motionless, but after a while the shell bursts and the stag-bectle issues forth.

From the cabbage is engendered the cabbage-worm, and 20 from the leek the prasocuris or leekbane ${ }^{5}$ this creature is

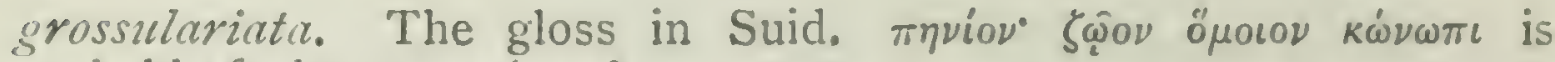
probably faulty; qy. кá $\mu \pi \eta$ ? $\kappa r \lambda$.

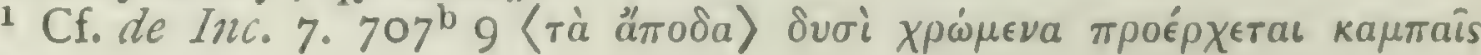

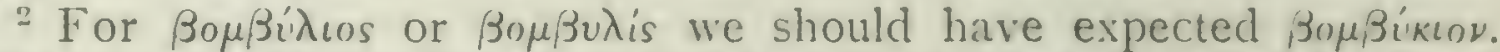
The passage is usually taken to be an inaccurate description of the silkworm, bomby mori; but the description of the caterpillar rather suggrests one of the large Saturniae, such as furnish the Tussore silk of India.

3 Cf. Plin. xi. 22, 23 for a fuller account. These passages have been much discussed. P'liny indicates that the invention came from Assyria. and Latreille, secking for an Indian locality similar in name to Cos, found it in the island Cosmin, near Rangoon. It is believed that neither the true silkworm, nor its true food-plant, Morus alka, came to Greece before Justinian's reign, about A.D. 550. See inter alin, Brotier, Mén. de l'Acul. des Inscr. xlvi. 1793.

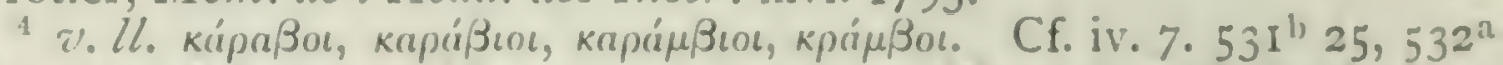
27 ; керripßu, , Anton. lib. xiii. A longicorn (Cerambycid) beetle, here translated freely 'stag-beetle', though that name is more strictly applied to Lucounus.

A faulty passage restored by Schn. from Ael. ix. 39. Cf. Theoph. H.P. vii. 5. Strattis also, ap. Athen. ii. 69, mentions the $\pi$ aro-

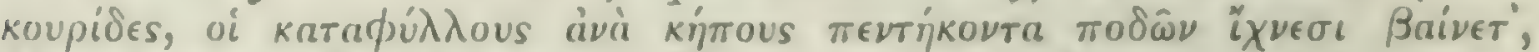

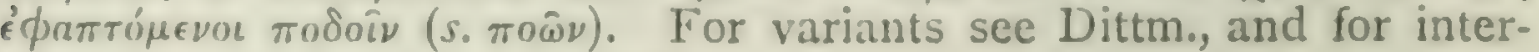
pretations cf. Sundevall, p. 236. 
also winged. From the flat animalcule that skims ${ }^{1}$ over the surface of rivers comes the ocstrus or gadfly; and this accounts for the fact that gadflies most abound in the neighbourhood of waters on whose surface these animalcules are observed. ${ }^{2}$ From a certain small, black and hairy caterpillar comes first a wingless glow-worm; ${ }^{3}$ and this creature again suffers a metamorphosis, and transforms 25 into a winged insect named the bostrychus (or hair-curl).

Gnats grow from ascarids; and ascarids are engendered in the slime of wells, or in places where there is a deposit left by the draining off of water. This slime decays, and first turns white, then black, and finally blood-red; and at $\mathbf{5 5}^{\mathrm{a}}$ this stage there originate in it, as it were, little tiny bits of red weed, ${ }^{4}$ which at first wriggle about all clinging together, and finally break loose and swim in the water, and are hereupon known as ascarids. After a few days they 5 stand straight up on the water motionless and hard, and by and by the husk breaks off and the gnats are seen sitting upon it, until the sun's heat or a puff of wind sets them in motion, when they fly away. ${ }^{5}$

With all grubs and all animals that break out from the grub state, generation ${ }^{6}$ is due primarily to the heat of the ro sun or to wind.

Ascarids are more likely to be found, and grow with unusual rapidity, in places where there is a deposit of a mixed and heterogeneous kind, as in kitchens ${ }^{7}$ and in

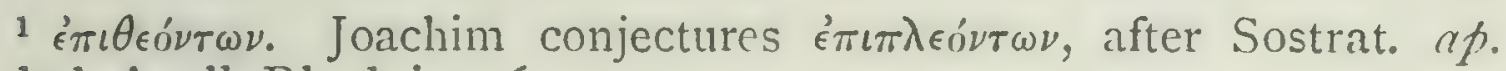
Schol. Apoll. Rhod. i. I265.

2 The flies are not true gadflies (Tabamus), but species of Syrphus or Strationys, whose larvae are aquatic; but the 'animalcules' seem to be small beetles of the genus Gyrimus, and are not the actual larvae.

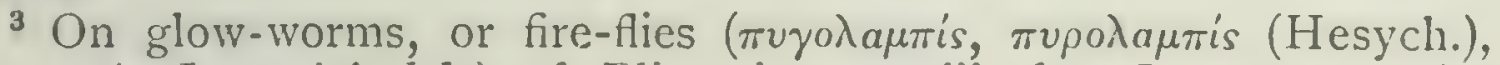
$\lambda a \mu \pi v$ pis, Lat. cicindela), cf. Plin. xi. 34, xviii. 67. In some species the female is apterous and much the more brilliant; in others (e.g. Luciola italica) the winged male is much the brighter, and the female is very rare.

4 A. and W. conjecture $\sigma \kappa \omega \lambda \eta \dot{\kappa} \iota$.

5 The description applies to the 'blood-worm', or larva of Chironomus, a common gnat. Cf. $H$. A. i. I. $487^{\mathrm{b}} 5$.

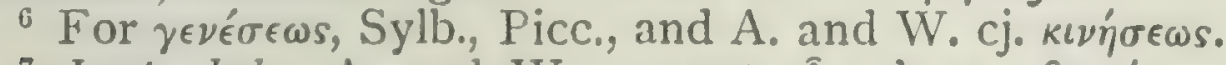

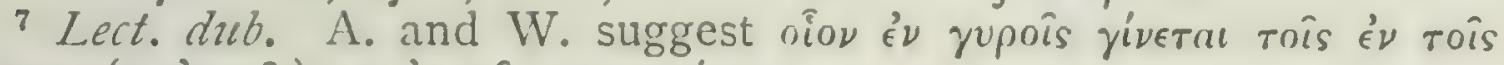

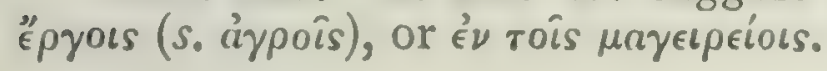


ploughed fields, for the contents of such places are disposed to rapid putrefaction. In autumn, also, owing to the drying up of moisture, they grow in unusual numbers.

i5 The tick is gencrated from couch-grass. The cockchafer comes from a grub that is generated in the dung of the cow or the ass. ${ }^{1}$ The cantharus or scarabcus rolls a piece of dung into a ball, lies hidden within it during the winter, and gives birth therein to small grubs, from which grubs come new canthari." Certain winged insects also come from the grubs that are found in pulse, in the same fashion 20 as in the cases described.

Flies grow from grubs in the dung that farmers have gathered up into heaps: for those who are engaged in this work assiduously gather up the compost, and this they technically term 'working-up' the manure." The grub is 25 cxccedingly minute ${ }^{4}$ to begin with; first-ercn at this stage-it assumes a reddish colour, and then from a quiescent state it takes on the power of motion, as though born to it; it then becomes a small motionless grub; it then moves again, and again relapses into immobility; it then comes out a perfect fly, and moves away under the influence of the sun's heat or of a puff of air. The myops ${ }^{5}$ 30 or horse-fly is engendered in timber. The orsodacna or budbane is a transformed grub ; and this grub is engendered $52^{2^{\mathrm{b}}}$ in cabbage-stalks. ${ }^{\circ}$ The cantharis ${ }^{\top}$ comes from the catcr-

$1 \mu \eta \lambda \circ \lambda \alpha_{\nu} \theta \eta$ is a cockchafer or 'rose-chafer', e.g. Cetonia aurata

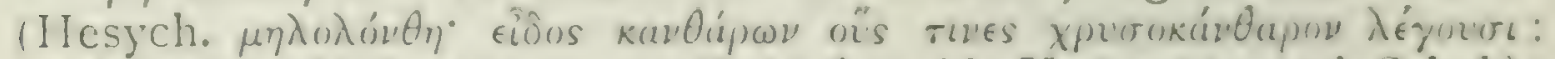

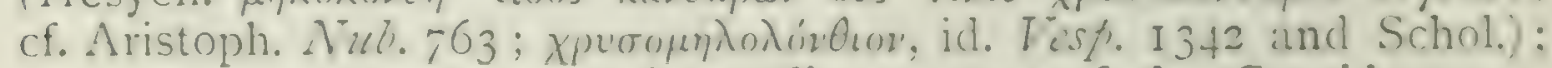
but the statement here made applies to one of the Copridae, e.g. Scarabaens.

Ael. x. I5, \&c. Cf. Horap. i. Io following whom, de Pauw would

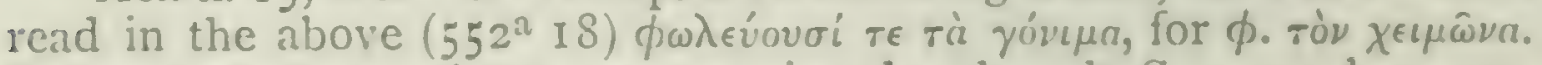
Fabre has shown that some species do, though $S$. sacer does not, survive the winter, together with their eggs and young.

This passage baffles translation, in spite of Schncider's explanation

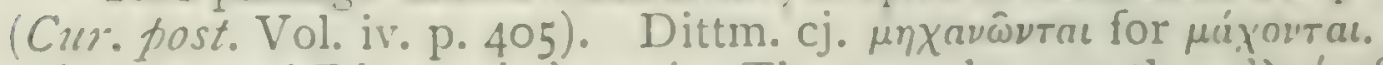

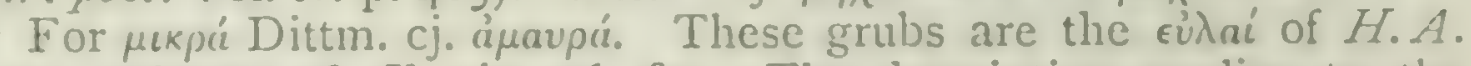
ii. 15. $506^{\mathrm{a}} 30$, cf. Il. xix. 26, \&c. The description applies to the common house-fly and its close allies.

5 Iabanus, Plin. xi. 38 ; cf. infra, 20. $553^{2}$ I 5. As a matter of fact, the Tabanid larvac (or many of them) live in decayed wood, in contrast to the parasitic larve of the Oestridac, or bots.

A curculionid beetle, probably Hellica oleracer.

Theoph. H.I'. viii. Io; Plin. xi. 4I, xviii. 44; Ael. ix. 39. 
pillars that are found on fig-trees or pear-trees or fir-treesfor on all these grubs are engendered-and also from caterpillars found on the dog-rose; and the cantharis takes eagerly to ill-scented substances, from the fact of its having been engendered in ill-scented woods. The conops comes from a grub that is engendered in the slime of vinegar. ${ }^{1} 5$

${ }^{2}$ And, by the way, living animals are found in substances that are usually supposed to be incapable of putrefaction; for instance, worms are found in long-lying snow; ${ }^{3}$ and snow of this description gets reddish in colour; and the grub that is engendered in it is red, as might have been expected, and it is also hairy. The grubs found in the snows of Media are large and white; and all such grubs are little disposed to motion. In Cyprus, in places where ro copper-ore is smelted, with heaps of the ore piled on day after day, an animal is engendered in the fire, ${ }^{,}$somewhat larger than a bluebottle fly, furnished with wings, which can hop or crawl through the fire. And the grubs and these latter animals perish when you keep the one away from the fire and the other from the snow. Now the is salamander "is a clear case in point, to show us that animals do actually exist that fire cannot destroy; for this creature, so the story goes, not only walks through the fire but puts it out in doing so.

On the river Hypanis in the Cimmerian Bosphorus, about the time of the summer solstice, there are brought down towards the sea by the stream what look like little sacks rather bigger than grapes, out of which at their 20

Probably a blister-beetle, Cantharis, Lytti or Mylabris sp., but the

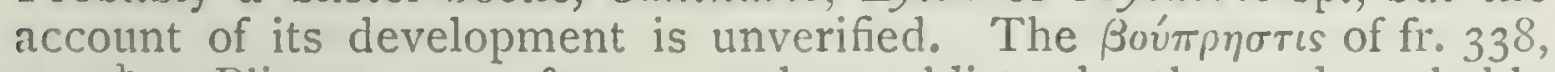
$1534^{\mathrm{b}} 9$, Plin. $\mathrm{xxx}$. 10, \&c.., was also a blister-beetle, and probably identical with that found by Belon on Mt. Athos, where it was still called Voupristi : cf. Kirby and Spence, i. p. I57, ed. I816.

1 The vinegar-fly, Oinopota cellaris: cf. Plin. l.c., Geopon. vi. I2.

$2 \mathrm{~A}$. and W. reject the rest of this chapter.

3 Cf. Plin. xi. 4I ; Senec. Q. Nat.v.6; Antig. Mirab. 9o; Ael. ii. 2. The well-known snow-fleas, snow-worms, or glacier-fleas (1'oduridae): cf. Löw, Verh.z. b. Ges. Wien, viii, 1858, p. 564 (cit. Camb. Nat. Hist.: Insects, Pt. i. p. I94), \&c.

${ }^{4}$ Plin. xi. 42; Ael. ii. 2. This insect is unknown: cf. Meteor. iv. 4.

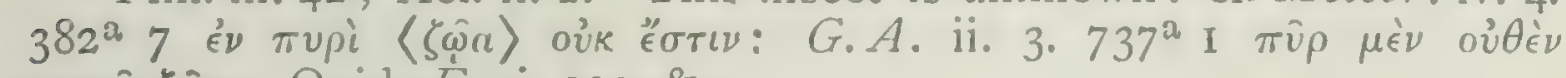

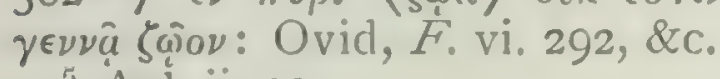

5 Ael. ii. 3I. 
bursting issues a winged quadruped. The insect lives and flies about until the evening, but as the sun goes down it pines away, and dics at sunset having lived just one day, from which circumstance it is called the ephemeron. ${ }^{1}$

As a rule, insects that come from caterpillars and grubs are held ${ }^{2}$ at first by filaments resembling the threads of ${ }_{25}$ a spider's web. ${ }^{3}$

Such is the mode of generation of the insects above enumerated.

The wasps that are nicknamed 'the ichneumons' (or 20 hunters), less in sizc, by the way, than the ordinary wasp, kill spiders and carry off the dead bodies to a wall or some such place with a hole in it; this hole they smear over with mud and lay their grubs inside it, and from the 30 grubs come the hunter-wasps. ${ }^{4}$ Some of the coleoptera and of the small and nameless insects make small holes or $553^{\mathrm{a}}$ cells of mud on a wall or on a grave-stone, and there deposit their grubs. ${ }^{5}$

${ }^{6}$ With insects, as a general rule, the time of generation from its commencement to its completion comprises three or four wecks. With grubs and grub-like creatures the time is usually three weeks, and in the oviparous insects ${ }^{7}$ as a rule four. But, in the case of oviparous insects, the $5 \mathrm{egg}$-formation comes at the close of seven days from copulation, and during the remaining three wecks the parent broods over and hatches its young; i. e. where this

1 Cf. Cic. Q. Tusc. i. 39 ; Plin. xi. 43; Ael. v. 43. (Hence Cicero's joke of the consul dialis.) A May-fly, probably raccording to Sundevall, p. I99) the large Efhener, longicunta, Oliv., very" common in S. Russia. In the Ephemeridae one pair of legs is usually smaller than the others: cf. H. A. i. 5. $490^{2} 34$.

2 A. and W. cj. $\pi \epsilon \rho i \epsilon \in \epsilon \tau \imath$, ' wrapped.'

${ }^{3}$ C. $551^{2} 20$.

4 The Sphegidac, which provision their nests with various insects: cf. H.A. ix. I. $609^{a} 5$; Plin. x. 95. The present account suggests I'ilopuius (sicliphron) spirifex, of S. Lurope, which builds mud-cells in nooks of walls, usually within peasants cottages, and stores them

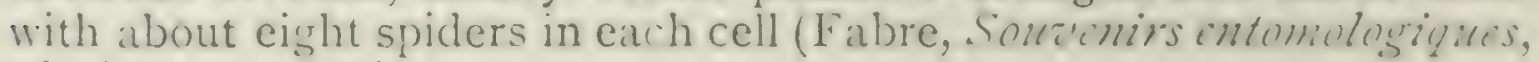
sér. iv. p. I, I89I).

Schneider suggests the little bectle Trichedes (Clems) alrerrius, which lays its eggs in the nests of mason-bees.

i $A$. and W. reject the rest of this chapter and the next.

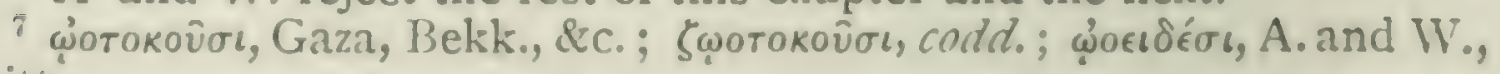
Dittm. 
is the result of copulation, as in the case of the spider and its congeners. As a rule, the transformations take place in intervals of three or four days, corresponding to the ro lengths of interval at which the crises recur in intermittent fevers.

So much for the generation of insects. Their death is due to the shrivelling ${ }^{\text {I }}$ of their organs, just as the larger animals die of old age. Winged insects die in autumn from the shrinking of their wings. The myops dies from 15 dropsy in the eyes. ${ }^{2}$

2I With regard to the generation of bees different hypotheses are in vogue. Some affirm that bees neither copulate nor give birth to young, but that they fetch their young. ${ }^{3}$ And some say that they fetch their young from the flower of the callyntrum ; ${ }^{*}$ others assert that they 20 bring them from the flower of the reed, others, from the flower of the olive. And in respect to the olive theory, it is stated as a proof that, when the olive harvest is most abundant, the swarms are most numerous." Others declare that they fetch the brood of the drones from such things as above mentioned, but that the working bees are engendered by the rulers of the hive.

Now of these rulers there are two kinds: ${ }^{6}$ the better kind is red in colour, the inferior kind is black and variegated; the ruler is double the size of the worling bee. These rulers have the abdomen or part below the waist half as large again, and they are called by some the 'mothers', from an idea that they bear or generate the

1 Or 'chilling'.

2 Plin. xi. 43. The smaller Tabanidae are supposed to be blind or short-sighted, whence Linn. Tirbanus caecuticns, Swed. blindknargs (Sundevall).

${ }^{3}$ Verg. G. iv. 200 ; Colum. ix. 2. 7 ; Plin. xi. I6; G. A. iii. Io. $760^{a}$ 29. Cf. Aubert und Wimmer, 'Die Parthenogenesis bei Aristoteles,' Zeitschr. f. wiss. Zool. ix. pp. 509-21, I858.

4 An unidentified plant: lit. 'broom'; qy. 'heather'.

"H.A. ix. 40.624 Io.

${ }^{6}$ Cf. $H . A$. ix. 40. $624^{\mathrm{b}} 2 \mathrm{I}$; Varro, R. R. iii. I6. I 8 ; Colum. ix. Io. The two kinds arc probably the Italian or Ligurian and the common bee.

${ }^{7}$ Cf. Xen. Oecon, 7. $32 \dot{\eta} \tau \hat{\omega} \nu \mu \epsilon \lambda \iota \sigma \sigma \omega \hat{\omega} \nu \dot{\eta} \gamma \epsilon \mu \dot{\omega} \nu$. 
30 bees; and, as a proof of this theory of their motherhood, they declare that the brood of the clrones appears cven when there is no ruler-bee in the hive, but that the bees do not appear in his absence. Others, again, assert that these

$553^{\mathrm{b}}$ insects copulate, and that the drones are male and the bees female.

The ordinary bee is generated in the cells of the comb, but the ruler-bees in cells down below attached to the comb, suspended from it, ${ }^{1}$ apart from the rest, six or seven in number, and growing in a way quite different from the mode of growth of the ordinary brood.

5 Bees ${ }^{2}$ are provided with a sting, but the drones are not so provided. The rulers" are provided with stings, but they never use them; and this latter circumstance will account for the belief of some people that they have no stings at all.

Of bees there are various species. ${ }^{4}$ The best kind is $\mathbf{2 2}$ a little round mottled insect; another is long, and resembles ro the anthrena; a third is black and flat-bellied, and is nicknamed the 'robber'; a fourth kind is the drone, the largest of all, but stingless and inactive." And this proportionate size of the drone explains why some bec-masters place a net-work in front of the hives; for the network is put to kecp the big drones out while it lets the little bees go in.

Of the king bees there are, as has becn stated, two kinds. I5 In every hive there are more kings than one; and a hive goes to ruin if there be too few kings, not because of anarchy thereby cnsuing, but, as we are told, because these creatures contribute in some way to the generation of the common bees. A hive will go also to ruin if there be too large a number of kings in it; for the members of the hives are thereby subdivided into too many separate factions.

20 Whenever the spring-time is late a-coming. and when

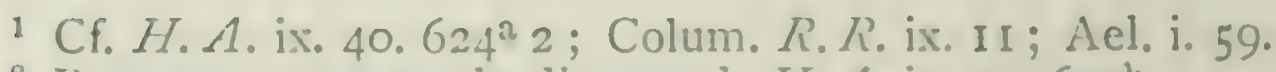

2 Bees are more amply discussed, $H$. A. ix. 40.623b.

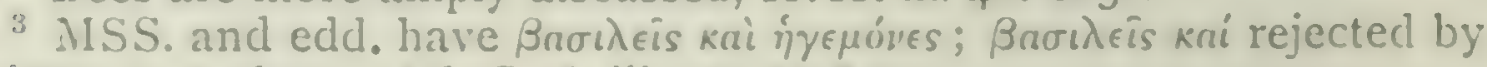
Dittm. as a gloss. Cf. G.A. iii. 10. $759^{\mathrm{a}} 21$.

"Ijetm. umecessarily adds $\left\langle\pi \lambda c(a)\right.$ from ix. $40.624^{k}=0$.

"Cf. H. A. ix. 40. 624" 25; Varro, K. R. iii. 16. 19; Plin. xi. I7. 
there is drought and mildew, then the progeny of the hive is small in number. ${ }^{1}$ But when the weather is dry they attend to the honey, and in rainy weather their attention is concentrated on the brood $;^{2}$ and this will account for the coincidence of rich olivc-harvests and abundant swarms.

The bees first work at the honeycomb, and then put the pupae in it: by the mouth, say those who hold the theory 25 of their bringing them from elsewhere. After putting in the pupae they put in the honey for subsistence, and this they do in the summer and autumn; and, by the way, the autumn honey is the better of the two.

The honeycomb is made from flowers, and the materials for the wax. they gather from the resinous gum of trees, while honey is distilled from dew, and is deposited chiefly at the risings of the constellations or when a rainbow is in 30 the sky: ${ }^{4}$ and as a general rule there is no honey before the rising of the Pleiads. [The bee, then, makes the wax from flowers. The honey, however, it does not make, but merely gathers what is deposited out of the atmosphere; $554^{\mathrm{a}}$ and as a proof of this statement we have the known fact that occasionally bee-keepers find the hives filled with honey within the space of two or three days. Furthermore, in autumn flowers are found, but honey, if it be withdrawn, is not replaced; now, after the withdrawal of the original honey, when no food or very little is in the hives, there 5 would be a fresh stock of honey, if the bees made it from flowers. ] ${ }^{6}$ Honey, if allowed to ripen and mature, gathers consistency; for at first it is like water and remains liquid for several days. ${ }^{7}$ If it be drawn off during these days it has no consistency; but it attains consistency in about

1 H. A. ix. $40.627^{\mathrm{b}} 20$; Plin. xi. I 8 .

2 Plin. xi. I4.

3 Oy., the substance for sealing up the cells.

4 Perhaps 'under the influence of the Dog-star': cf. Plin. xi. I2.30. $\mathrm{D}^{\mathrm{a}}$ has oiptos for $\dot{\eta}$ ipts. But cf. Probl. xii. $3 \cdot 906^{2} 37$.

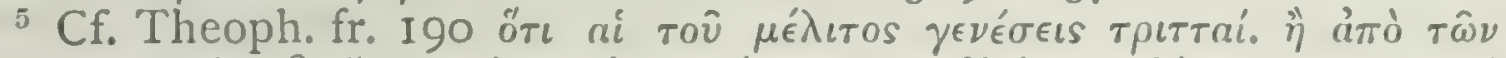

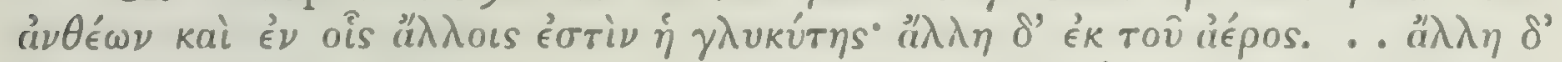

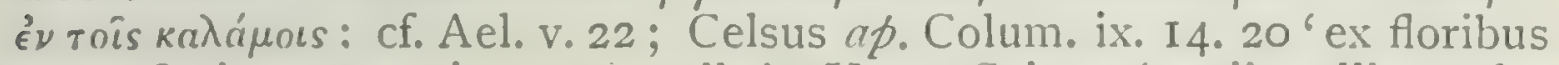
ceras fieri, ex matutino rore mella'; Verg. G. iv. I 'aerii mellis caelestia dona'.

${ }^{6}$ The passage is apparently spurious, and in conflict with $554^{\mathrm{a}} \mathrm{I} 3$, $554^{\mathrm{b}} 9$, \&c.

7 Plin. xi. I 3 . 
Io twenty days. The taste of thyme-honey ${ }^{1}$ is discernible at once, from its peculiar swectness and consistency.

The bee gathers from every flower that is furnished with a calyx or cup, and from all other flowers that are swecttasted, without doing injury to any fruit; and the juices of the flowers it takes up with the organ that resembles a tongue and carries off to the hive.

I5 Swarms are robbed of their honey on the appearance of the wild fig. ${ }^{2}$ They produce the best larvae at the time the honey is a-making. The bee carries wax and bees' bread round its legs, but vomits the honey into the cell. After depositing its young, it broods over it like a bird. The grub when it is small lies slantwise in the comb, but 20 by and by rises up straight by an effort of its own and takes food, and holds ${ }^{4}$ on so tightly to the honeycomb as actually to cling to it.

The young of bees and of drones is white, and from the young come the grubs; and the grubs grow into bees and drones. The egg of the king bee is reddish in colour, 25 and its substance is about as consistent as thick honey; and from the first it is about as big as the bee that is produced from it. From the young of the king bee there is no intermediate stage, it is said, of the grub, but the bee comes at once. ${ }^{5}$

Whenever the bee lays an egg in the comb there is always a drop of honey set against it. The larva of the bee gets fect and wings as soon as the cell has becn stopped up with wax, and when it arrives at its com-

$554^{\mathrm{b}}$ pleted form it breaks its membrane and flics away. It cjects excrement in the grub state, but not afterwards; that is, not until it has got out of the cncasing membrane, as we have already described. If you remove the heads from off the larvae before the coming of the wings, the bees will cat them up; and if you nip off the wings from

${ }^{1}$ So Picc., for $\chi u \mu o v$. Cf. H. A. is. 40. 626 20 ; Colum. is. 4, Sic.

Plin. xi. I 5 .

"Plin. xi. 16.

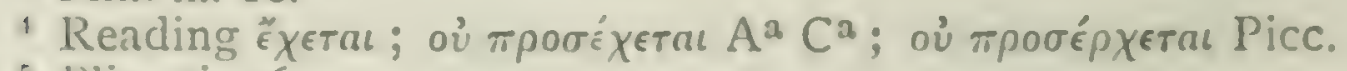

s Plin. xi. I6. 
a drone and let it go, the bees will spontaneously bite off 5 the wings from off all the remaining drones.

The bee lives for six years as a rule, as an exception for seven years. ${ }^{1}$ If a swarm lasts for nine years, or ten, great credit is considered due to its management.

In Pontus ${ }^{2}$ are found bees exceedingly white in colour, and these bees produce their honey twice a month. ${ }^{3}$ (The bees in Themiscyra, on the banks of the river Thermodon, 10 build honeycombs in the ground and in hives, and these honeycombs are furnished with very little wax but with honey of great consistency; and the honeycomb, by the way, is smooth and level.) But this is not always the case with these bees, but only in the winter season; for in Pontus the ivy is abundant, and it flowers at this time of the year, and it is from the ivy-flower that they derive their honey. A white and very consistent honey is brought down from ${ }_{5} 5$ the upper country to Amisus, which is deposited by bees on trees ${ }^{4}$ without the employment of honeycombs: ${ }^{5}$ and this kind of honey is produced in other districts in Pontus.

There are bees also that construct triple honeycombs in the ground; and these honeycombs supply honey but never contain grubs. $^{6}$ But the honeycombs in these places are 20 not all of this sort, nor do all the bees construct them.

\section{Anthrenae ${ }^{7}$ and wasps construct combs for their}

1 Virg. G. iv. 206; Plin. xi. 22.

2 On honey of various kinds, in various localities, cf. de Mirab. I6. $83^{\mathrm{I}^{\mathrm{b}}}$ I8 seq.; Plin. xxi. 45 .

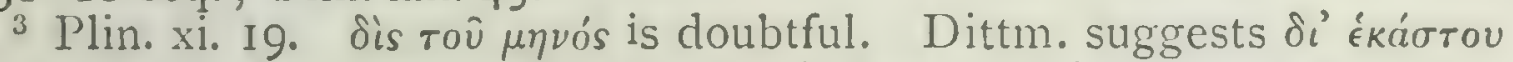

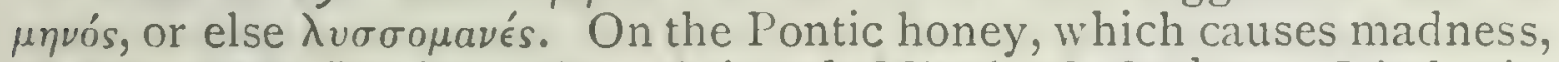
cf. Xen. Exp. Cyr. iv. s. fin.; Arist. de Hirab. I8. 83 I $^{\mathrm{b}} 23$; Diod. Sic. xiv. 29; Strabo, xii. 3 ; Ael. v. 42 ; Diosc. ii. I03, \&c. Cf. Beckmann, Arist. de Mirab. p. 44.
4 Plin. l.c.
5 De Mirab. 16. 83 I $^{\mathrm{b}} 20$; Ael. v. 42.

6 We may compare, perhaps, the 'honey-tubs' of Bombus.

7 à $\theta p \eta \dot{\nu \eta}$ is not to be identified, several different wasps appearing to be included under this name and that of $\sigma \phi \phi^{\prime} \xi$. Those that 'have no king' are either solitary wasps or those forming small colonies, e.g. Polistes. The elegant nest of the latter is perhaps that referred to as one of those made by à $\theta p \eta \dot{\nu \eta}$. The underground nests are such as those of $V$. rulgaris, germanica, and rufa, cf. $H 1$. A. ix. $42.629^{a} 7$, but see note in loc. The hornet, $V$. crabro, which usually builds in a hollow tree, is not mentioned here, but would seem to be the $\sigma \phi i \eta \xi$ ä $y$ pros of ix. $41.627^{\mathrm{b}} 23$. 
young. ${ }^{1}$ When they have no king, but are wandering about in search of one, the anthrene constructs its comb on some high place, and the wasp inside a hole. When the anthrene 25 and the wasp have a ling, they construct their combs underground. Their combs are in all cases hexagonal like the comb of the bee. They are composed, however, not of wax, but of a bark-like filamented ${ }^{2}$ fibre, and the comb of the anthrene is much neater than the comb of the wasp. Like the bee, they put their young just like a drop of $555^{\mathrm{a}}$ liquid on to the side of the cell, and the egg clings to the wall of the cell. But the eggis are not deposited in the cells simultaneously; on the contrary, in some cells are creatures big enough to $\mathrm{fly}$, in others are nymphae, and in others are mere grubs. As in the case of bees, excrement is observed only in the cells where the grubs are found. 5 As long as the creatures are in the nymph condition they are motionless, and the cell is cemented over. In the comb of the anthrene there is found in the cell of the young a drop of honey in front of it. The larvac of the anthrene and the wasp make their appearance not in the spring but in the autumn; and their growth is especially discernible in times of full moon. And, by the way, the ro egrgs and the grubs never rest at the bottom of the cells, but always cling on to the side wall.

There is a kind of humble-bee" that builds a cone-shaped 24 nest of clay against a stone or in some similar situation, besmearing the clay with something like spittle. ${ }^{4}$ And

$1 H . A$. ix. 40, 4 I; Plin. xi. 2 I.

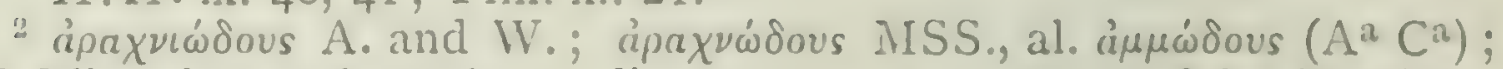
cf. Plin. xi. 24, where the reading arancosa was restored by Harduin, in place of cortice et arenc.

${ }^{3}$ Cf. H.A. ix. 43. The description applies accurately to the mason-bee, Chaticodoma muraria (Latr.), save for the word $\dot{\xi} \xi$ í. The mason-bee's nest is rounded, like half an orange. There is a solitary wasp, Eumenes courctutu, L., which builds a tiny, hard, one-celled nest of clay and spittle, conically pointed; but this insect does not resemble the humble-bee, nor has it any sort of 'honeycomb'.

voút $A$. and $W$., which is in accord with the facts. Schn. (Cur. post.) $\dot{\omega} \sigma \pi \epsilon \rho \epsilon i$ á $\lambda i$. Picc. $\dot{\omega} \sigma \pi \epsilon p \epsilon i$ cìòs $\sigma \tau i \lambda \beta \eta$. Cf. Plin. xi. $25^{\text {'nidos }}$ luto fingunt salis specie applicatos lapidi'. 
this nest or hive is exceedingly thick and hard; in point of fact, one can hardly break it open with a spike. ${ }^{1}$ Here ${ }^{15}$ the insects lay their eggs, and white grubs are produced wrapped in a black membrane. A part from the membrane there is found some wax ${ }^{2}$ in the honeycomb; and this wax is much sallower in hue than the wax in the honeycomb of the bee.

25 Ants copulate and engeiider grubs;" and these grubs attach themselves to nothing in particular, but grow on and 20 on from small and rounded shapes until they become elongated and defined in shape: and they are engendered in spring-time.

26 The land-scorpion also lays a number of egg-shaped grubs, ${ }^{4}$ and broods over them. When the hatching is completed, the parent animal, as happens with the parent spider, is ejected and put to death by the young ones; for 25 very often the young ones are about eleven in number.

27 Spiders ${ }^{5}$ in all cases copulate in the way above mentioned, and generate at first small grubs. ${ }^{6}$ And these grubs metamorphose in their entirety, and not partially, into spiders; for, by the way, the grubs are round-shaped at the outset. And the spider, when it lays its eggs, broods over them, and in three days the eggs or grubs $555^{\mathrm{b}}$ take definite shape.

All spiders lay their eggs in a web: but some spiders lay in a small and fine web, and others in a thick one; and some, as a rule, lay in a round-shaped case or capsule, and some are only partially enveloped in the web. The young grubs are not all developed at one and the same time into young spiders; but the moment the development takes place, the young spider makes a leap and begins to spin his 5

1 Lit. 'spear'; spiculis, Plin. xi. 25.

2 Schn. and A. W. read $\sigma \kappa \omega \lambda \dot{\eta} \kappa \iota a\langle\omega o \epsilon \iota \hat{\eta}\rangle$; cf. Plin. xi. 36.

3 Not 'wax', but a mixture of honey and pollen stored up for food for the young.

4 Plin. xi. 30.

5 For a fuller account of various species see $H . A$. ix. $38.622^{\mathrm{b}}$.

${ }^{6} H . A$. v. 8. $542^{\text {a }}$ I 3 ; G.A. iii. 9. $758^{\mathrm{b}} 9$; Plin. xi. 29. 
web. The juice of the grub, if you squeeze it, is the same as the juice found in the spider when young ; that is to say, it is thick and white.

The meadow spider ${ }^{1}$ lays its eggs into a web, one half of which is attached to itself ${ }^{2}$ and the other half is free; and on this the parent broods until the eggs are hatched. 10 The phalangia lay their eggs in a sort of strong basket which they have woven, and brood over it until the eggs are hatched. The smooth spider is much less prolific than the phalangium or hairy spider. These phalangia, when they grow to full size, very often envelop the mother phalangium and eject and kill her; and not seldom they kill the father-phalangium as well, if they catch him: for, by the way, he has the habit of co-operating with the Is mother in the hatching. The brood of a single phalangium is sometimes three hundred in number. The spider attains its full growth in about four weeks.

Grasshoppers (or locusts) copulate in the same way as 28 other insects; that is to say, with the lesser covering the zo larger, for the male is smaller than the female. The female:

1 Lycosa sp.

- \#pos aitais, or aitais, is not very intelligible, but the description scems somehow to refer to the gossamer webs which the field-spider shoots out, remains attached to, and is sometimes borne upon.

3 akpioss, Lat. locustac (Plin. xi. 35, \&.c.), are grasshoppers, including locusts, but precise identification is not possible, either of ikpis or artétaß̧os, or of the many other kindred names in Greek, many of them obviously foreign, e.g. äipakos (Diosc., cf. Talmud, Nipss),

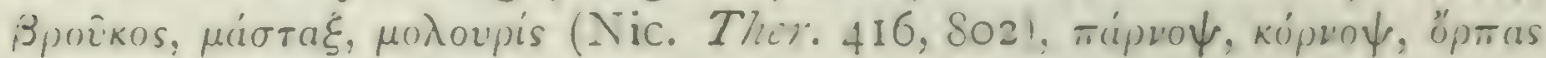
(Hesych., Arab. sure that $\dot{\tau} \tau \tau^{\prime} \lambda a \beta o s$ in cap. 29 is not an interpolation, for Pling's account of locusta (l.c.) seems to embody the substance of both

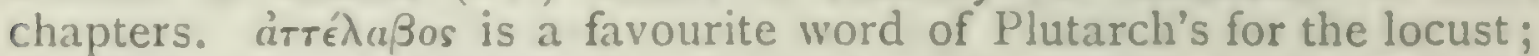

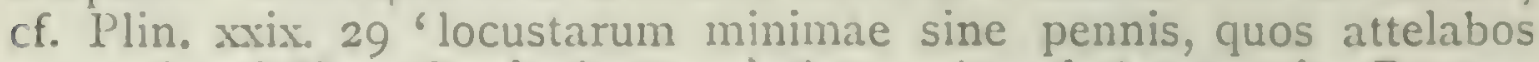

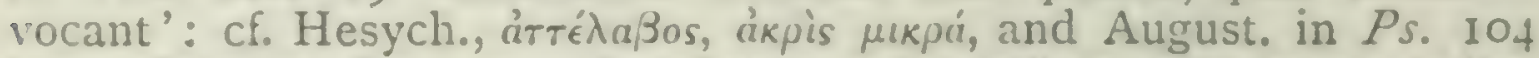
- umar plaga est locustia et bruchus, quoniam altera est parens et alter est foetus'. It is a fact that the wingless larvae are often as destructire as the perfect insect. Theoph. fr. I74 (Wimmer) does not help our

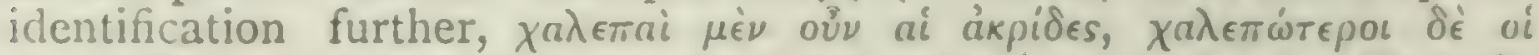

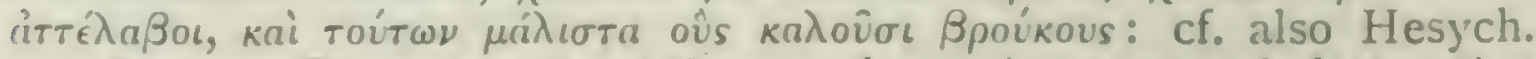
s. $1 . \beta_{1}$ mikns. There are about three or four migratory and destructive species in the Mediterranean countries. of which. Lomiam ferçrimum, the largest, is probably that of Exod. $x .4$; Pachytylus migratorius, $P$. cincruscins and Culoptenus itulicus are commoner in S. Europe. 
first insert the hollow tube, ${ }^{1}$ which they have at their tails, in the ground, and then lay their eggs: and the male, by the way, is not furnished with this tube. The females lay their eggs all in a lump together, and in one spot, so that the entire lump of eggs resembles a honeycomb. After they have laid their eggs, the eggs assume the shape of oval grubs that are enveloped by a sort of thin clay, like a membrane; in this membrane-like formation they grow 25 on to maturity. The larva is so soft that it collapses at a touch. The larva is not placed on the surface of the ground, but a little beneath the surface; and, when it reaches maturity, it comes out of its clayey investiture in the shape of a little black grasshopper; by and by, the skin integument strips off, ${ }^{2}$ and it grows larger and larger.

The grasshopper lays its eggs at the close of summer, and dies after laying them. The fact is that, at the time $556^{\mathrm{a}}$ of laying the eggs, grubs are engendered in the region of the mother grasshopper's neck; ${ }^{3}$ and the male grasshoppers die about the same time. In spring-time they come out of the ground; and, by the way, no grasshoppers are found in mountainous land or in poor land, but only in flat and loamy ${ }^{4}$ land, for the fact i:; they lay their eggs 5 in cracks of the soil. During the winter their cggs remain in the ground; and with the coming of summer the last year's larva develops into the perfect grasshopper. ${ }^{5}$

29 The attelabi " or locusts lay their eggs and die in like manner after laying them. Their eggs are subject to

3 It is doubtful whether we should read, with PDa, aùóv, or кuvidov with other MSS. and edd. The former is intrinsically probable, but Plin. (l.c.) has 'demisso spinae caule'. Either word suggests a long ovipositor such as is found in the 'green grasshoppers', e.g. Locusta rividissima, but not in the ordinary grasshoppers and locusts (Acridiidae): the latter insert the abdomen itself in the ground, making a hole by means of two little valvular appendages at its end, and the sexual difference is not obvious. While this particular observation may apply to one particular form, the rest of the chapter may well be of more general import.

${ }^{2}$ Cf. H.A. viii. $17.601^{a} 6$.

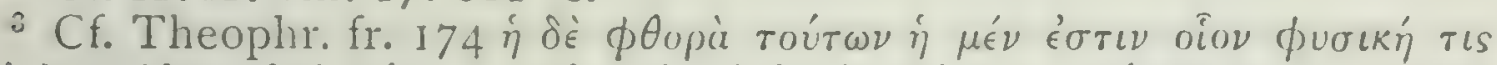

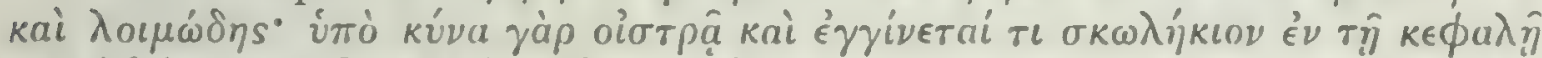
kai $\phi \theta \epsilon i p \in \tau a l:$ the grubs of some ichneumon or other parasitic insect.

${ }^{4}$ Lit. 'crumbly'.

A. and W. bracket $55^{\mathrm{a}} \mathrm{I}-7, \mathrm{D}$ ittm. 3-6. 'See note, p. $555^{\mathrm{b}}$ I 8 . $A R_{0} H_{0} A_{0}$ 
destruction by the autumn rains, when the rains are unro usually heavy; but in seasons of drought the locusts are cxceedingly numerous, from the absence of any destructive cause, since their destruction seems then to be a matter of accident and to depend on luck.

Of the cicada there are two kinds ; ${ }^{1}$ one, small in size, 30 15 the first to come and the last to disappear; the other, large, the singing one, that comes last and first disappears. Both in the small and the large species some are divided at the waist, to wit, the singing ones, and some are undivided; and these latter have no song. The large and singing cicada is by some designated the 'chirper', and the small cicada the 'tettigonium' or cicadelle. And, by the way, 20 such of the tettigonia as are divided at the waist can sing just a little.

The cicada is not found where there are no trees; and this accounts for the fact that in the district surrounding the city of Cyrene it is not found at all in the plain country, but is found in great numbers in the neighbourhood of the city, and especially where olive-trecs" are growing: for an olive grove is not thiclily shaded. And the cicada is not found in cold places, and consequently is not found in any grove that keeps out the sunlight. ${ }^{3}$

25 The large and the small cicada copulate alike, belly to belly. The male discharges sperm into the female ${ }^{4}$ as is the case with insects in general, and the female cicada has a cleft generative organ; and it is the female into which the male discharges the sperm.

1 Plin. xi. 32 ; H. A. iv. $7.532^{\mathrm{b}}$ II. Probably the two common Euro. pean cicadas, $C$. flletin, Scop., and $C$. omi. L..; the former, the larger, is black above, the latter greenish yellow with black spots. As to C.om, 'son chant est comme enroué et ne se fait pas entendre de loin!' Olivier, cit. Amyot et Séville, Hémiptères, Paris, IS43, p. 4SI. There are, however, other smaller species of $C$. in Southern Europe.

${ }^{2}$ Cf. H.A. viii. 17.601 7 ; Strabo vi. I.9.

"Vers. Eil.ii. 13 'Sole sub ardenti resonant arbusta cicadis'. Sone MSS. have oukious for církiots.

A. and IV. consider the whole passage corrupt, and rewrite as

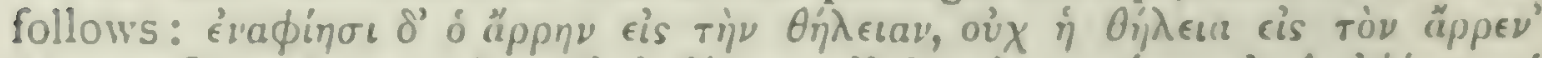

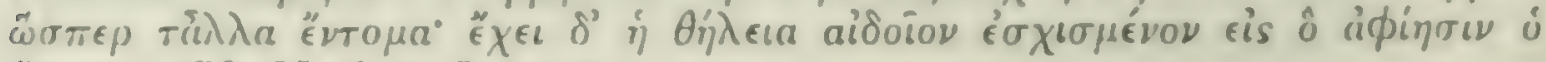

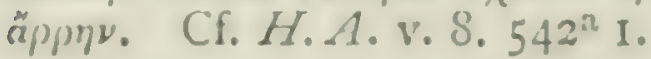


They lay their eggs in fallow lands, boring a hole with the pointed organ they carry in the rear, ${ }^{1}$ as do the locusts likcwise; for the locust lays its eggs in untilled $55^{\mathrm{b}}$ lands, and this fact may account for their numbers in the territory adjacent to the city of Cyrene. The cicadae also lay their eggs in the canes on which husbandmen prop vines, perforating the canes; and also in the stalks of the squill. This brood runs into the ground." And they are 5 most numerous in rainy weather. The grub, on attaining full size in the ground, becomes a tettigometra (or nymph), and the creature is sweetest to the taste ${ }^{3}$ at this stage before the husk is broken. When the summer solstice comes, the creature issues from the husk at night-time, and in a moment, as the husk breaks, the larva becomes the perfect cicada. ${ }^{4}$ The creature, also, at once turns black ${ }^{5}$ in colour 10 and harder and larger, and takes to singing. In both species, the larger and the smaller, it is the male that sings, and the female that is unvocal. ${ }^{6}$ At first, the males are the sweeter eating; but, after copulation, the females, as they are full then of white eggs.

If you make a sudden noise as they are flying overhead they let drop something like water. Country people, in 15 regard to this, say that they are voiding urine, i. e. that they have an excrement, and that they feed upon dew.

If you present your finger to a cicada and bend back the tip of it and then cxtend it again, it will endure the presentation more quietly than if you were to keep your finger outstretched altogether; and it will set to climbing your finger: ${ }^{8}$ for the creature is so weak-sighted that it will take

1 The female cicada has a long and powerful ovipositor; cf. note antea, 28. $555^{\mathrm{b}} 2 \mathrm{I}$.

2 The cicada lays its eggs in dead twigs: the larva, issuing in the following year, becomes a 'nymph', which burrows deep in the ground, and after another year issues from its envelope as the perfect insect.

${ }^{3}$ On cicadas as food cf. Ael. xii. 6.

* Cf. H. A. viii. 17. 601 9: Ar. Av. 1095; Lucr. iv. 56, v. 803 'Folliculos ut nunc tereteis aestate cicadae Linquunt sponte sua victum vitamque petenteis'.

5 Cf. Martial, i. I i6.

- Cf. Xenarch. in Aninol.

7 Theocr. iv. 16; Verg. Ecl.v. 77, \&c.

8 'Si on lui présente une canne, en continuant de siffler, cille s'y pose 
20 to climbing your finger as though that were a moving leaf.

Of insects that are not carnivorous but that live on the $3 \mathrm{r}$ juices of living flesh, such as lice and fleas and bugs, all, without exception, generate what are called 'nits', and these nits generate nothing.

25 Of these insects the flea is generated out of the slightest amount of putrefying matter; for wherever there is any dry excrement, a flea is sure to be found. Bugs are generated from the moisture of living animals, as it dries up outside their bodies. Lice are generated out of the flesh of animals.

When lice are coming there is a kind of small eruption visible, unaccompanied by any discharge of purulent matter; and, if you prick an animal when in this condition $557^{\mathrm{a}}$ at the spot of eruption, the lice jump out. In some men the appearance of lice is a discase, in cases where the body is surcharged with moisture; and, indeed, men have been known to succumb to this louse-discase, as Alcman the poet and the Syrian Pherecydes are said to have done." Moreover, in certain diseases lice appear in great abundance.

There is also a species of louse called the 'wild louse', 5 and this is harder than the ordinary louse, and there is exceptional difficulty in getting the skin rid of it. Boys heads are apt to be lousy, but men's in less degree; and women are more subject to lice than men. But, whenever pcople are troubled with lousy heads, they are less than 10 ordinarily troubled with headache. And lice are generated in other animals than man. For birds are infested with them; and pheasants, unless they clean themsclies in the clust, are actually destroyed by them. All other winged animals that are furnished with feathers are similarly inet redescend lentement encore à reculons; ... M. Boyer est parvenu ainsi à en faire placer une sur son nez.' Amyot et Séville, p. 480.

1 This refers to the very minute itch-mite, Surcoptes scabiei: cf. Sundevall, p. 229: generally stated to have been first discovered in the twelfth century by Avenzoar, a Mloorish physician of Seville.

${ }^{2}$ The morbus penticularis, or phthiriasis, due to the louse Phthirius incuinalis, and similar discases due to Aarri : cf. Antig. H. Mimb. xcv; Plin. xi. 39. 
fested, and all hair-coated creatures also, with the single exception of the ass, ${ }^{1}$ which is infested neither with lice nor with ticks.

Cattle suffer both from lice and from ticks. Sheep and 15 goats breed ticks, but do not breed lice. Pigs breed lice large and hard. In dogs are found the flea peculiar to the animal, the Cynoroestes." In all animals that are subject to lice, the latter originate from the animals themselves. Moreover, in animals that bathe at all, lice are more than usually abundant when they change the water in which 20 they bathe.

In the sea, lice are found on fishes, but they are gonerated not out of the fish but out of slime; and they resemble multipedal wood-lice, only that their tail is flat. Sea-lice are uniform in shape and universal in locality, and 25 are particularly numerous on the body of the red mullet." And all these insects are multipedal and devoid of blood.*

The parasite that feeds on the tunny is found in the region of the fins; it resembles a scorpion, and is about the size of a spider." In the seas between Cyrene and Egypt there is a fish that attends on the dolphin, which 30 is called the 'dolphin's louse'.' This fish gets exceedingly fat from enjoying an abundance of food while the dolphin is out in pursuit of its prey.

32 Other animalcules besides these are generated, as we $557^{\mathrm{b}}$ have already remarked, some in wool or in articles made of wool, as the ses or clothes-moth.' And these animalcules come in greater numbers if the woollen substances are dusty; and they come in especially large numbers if a spider ${ }^{8}$ be shut up in the cloth or wool, for the creature

1 Plin. xi. 39.

2 Od. xvii. 300. Doubtless the common tick, Ixodes ricines; cf. Plin. xi. 40.

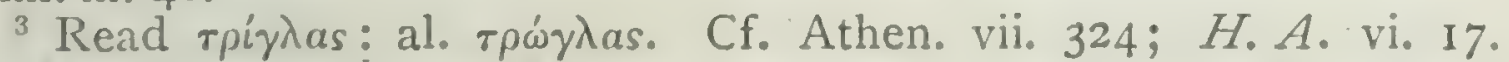

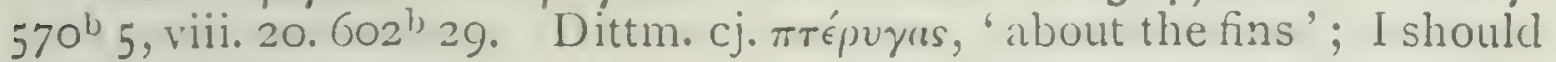
prefer $\beta$ páyx

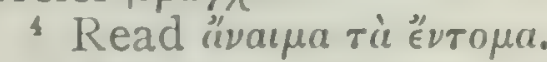

"Naucrates ductor: cf. Ael. ix. 7.

5 See note to viii. I9.

7 Tiner, and allied genera: cf. Plin. xi. 4 I.

8 A doubtful reading, though followed by Plin. l.c. For apá $\lambda^{\prime} \nu \eta{ }^{\prime}$

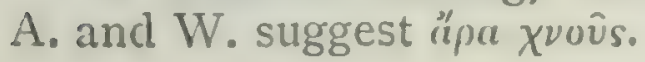


drinks up any moisture that may be there, and dries up 5 the woollen substance. This grub is found also in men's clothes.

A creature is also found in wax ${ }^{1}$ long laid by, just as in wood, and it is the smallest of animalcules and is white in colour, and is designated the acari or mite. In books also other animalcules are found, some resembling the grubs ro found in garments, and some resembling tailless scorpions, but very small. As a general rule we may state that such animalcules are found in practically anything, both in dry things that are becoming moist and in moist things that are drying, provided they contain the conditions of life.

There is a grub entitled the 'faggot-bearer', as strange a creature as is known. ${ }^{4}$ Its head projects outside its shell, I5 mottled in colour, and its feet are near the end or apex, as is the case with grubs in general ; but the rest of its body is cased in a tunic as it were of spider's web, and there are little dry twigs about it, that look as though they had stuck by accident to the creature as it went walking about. But these twig-like formations are naturally connected with the tunic, for just as the shell is with the body of the snail so is the whole superstructure with our grub; and they do not drop off, but can only be torn off, as though they were all 20 of a piece with him, and the removal of the tunic is as fatal to this grub as the removal of the shell would be to the snail. In course of time this grub becomes a chrysalis. as is the case with the silkworm, and lives in a motionless condition. But as yet it is not known into what winged 25 condition it is transformed.

The fruit of the wild fig contains the psen, or fig-wasp. This creature is a grub at first; but in due time the husk peels off and the psen leares the husk behind it and flies away, and enters into the fruit of the fig-trec through its orifice, and

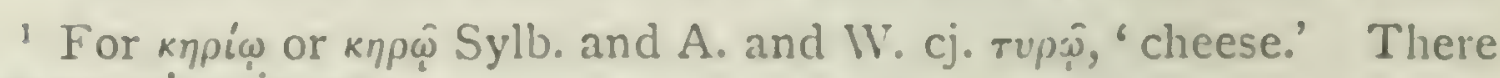
are no mites in wax.

2 The book-scorpion, Chelifer cuncroides; cf. H. A. iv. 17. $532^{2}$ IS.

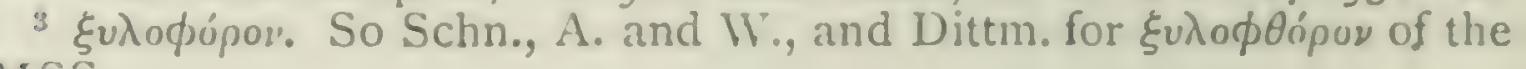
MSS.

"The creature is not our caddis-worm, but the 'basket-worm', or caterpillar of l'syche, a species of moth common in Southern Eumpe.

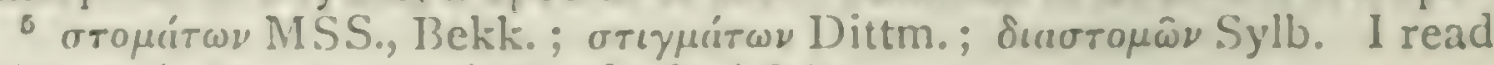

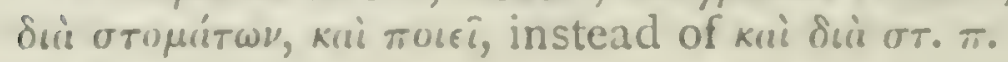


causes the fruit not to drop off; and with a view to this phenomenon, country folk are in the habit of tying wild 30 figs on to fig-trecs, and of planting wild fig-trees near domesticated oncs. ${ }^{1}$

33 In the case of animals that are quadrupeds and redblooded and oviparous, generation takes place in the spring, $55^{8^{\mathrm{a}}}$ but copulation does not take place in an uniform season. In some cases it takes place in the spring, in others in summer time, and in others in the autumn, according as the subsequent season may be favourable for the young.

The tortoise lays eggs with a hard shell and of two colours within, like birds' eggs, and after laying them burics s them in the ground and treads the ground hard over them; it then broods over the eggs on the surface of the ground, and hatches the eggs the next year. The hemys, or freshwater tortoise, ${ }^{2}$ leaves the water and lays its eggs. It digs a hole of a cask-like shape, and deposits therein the eggs; after rather less than thirty days it digs the eggs up again and hatches them with great rapidity, and leads its young 10 at once off to the water. The sea-turtle lays on the ground eggs just like the eggs of domesticated birds, buries the eggs in the ground, and broods over them in the night-time. It lays a very great number of eggs, amounting at times to one hundred.

Lizards and crocodiles, terrestrial and fluvial, lay eggs on 15 land. The eggs of lizards hatch spontaneously on land, for

1 The wild fig and the cultivated fig stand to one another in the relation of male and female. Cf. G. A. i. I. $715^{\mathrm{b}} 2 \mathrm{I}$ kai yà $\rho$ év roís

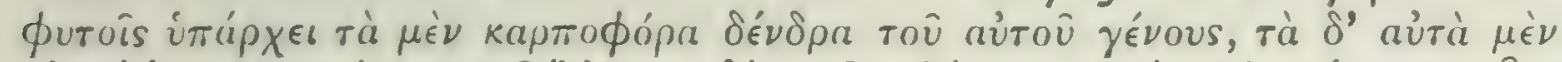

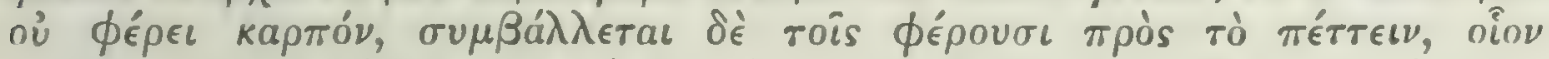

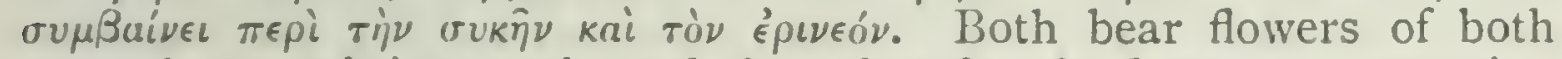
sexes, but one brings male and the other female flowers to maturity. Caprification, or artificial fertilization, consists in hanging ripe fruit of the Caprificus on fig-trees, whose figs are then in their female stage. Wasps (Cynips Psenes, L., Blastophaga grossmum, Grav.) hatched within the former, enter the latter, carrying pollen with them. The literature on caprification is very large; cf. (int. al.) Paul Mayer, Mitth.d. Zool. Stut. Neapel, iii.pp. 55I-7S, I 882; and, among classical references, Herod. i. 193 (cf. Athen. xiv. 65I); Theophr. H.P.ii. 8; C.P. ii. 9, iii. 18; Plin. xv. 19, xvii. 27, 44; Colum. R.R. xi. 2. 56 ; Pallad. iv. 10, vii. 6; Arnob. passim; Varro, L.L.V. 3 ; Suid. s. $\%$ (i) pincestus, \&ec.

${ }^{2}$ Plin. xxxii. 4. 
the lizard does not live on into the next year; in fact, the life of the animal is said not to exceed six months. The river-crocodile ${ }^{1}$ lays a number of eggs, sixty at the most, white in colour, and broods over them for sixty days: for, 20 by the way, the creature is very long-lived. And the disproportion is more marked in this animal than in any other between the smallness of the original egg and the huge size of the full-grown animal. ${ }^{2}$ For the egrs is not larger than that of the goose, and the young crocodile is small, answering to the egg in size, but the full-grown animal attains the length of twenty-six fect; in fact, it is actually stated that the animal goes on growing to the end of its days.

With regard to serpents or snakes, the viper is externally 34 viviparous, having been previously oviparous internally." The cgg, as with the egg of fishes, is uniform in colour and soft-skinned. The young serpent grows on the surface of the egg, and, like the young of fishes, has no shell-like envelopment. The young of the riper is born inside a membrane that bursts from off the young creature in three 30 day's; and at times the young viper eats its way out from the inside of the egg. The mother viper brings forth all its young in one day, twenty in number, and one at a time. $55^{8}$ The other serpents are externally oviparous, and their eggs are strung on to one another like a lady's necklace; after the dam has laid her eggs in the ground she broods over them, and hatches the eggs in the following year.

${ }^{3}$ Cf. Herod. ii. 68; Plin. viii. 37.

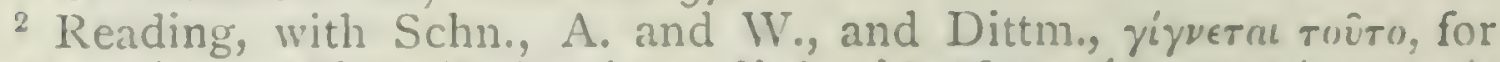

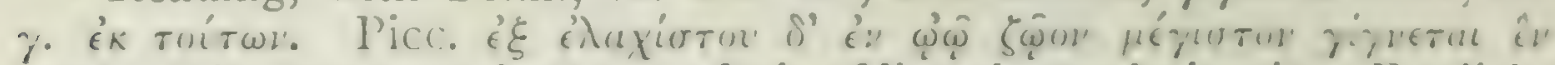
roîro. The sentence does not admit of literal translation into English.

${ }^{3}$ G.A. ii. I. $732^{\text {l }} 23$, iv. $3 \cdot 770^{: 1} 24 ; H . A$. iii. I. $511^{a}$ I6. 


\section{BOOK VI}

I So much for the generative processes in snakes and $55^{\mathrm{b}}$ insects, and also in oviparous quadrupeds.

Birds without exception lay eggs, but the pairing season Io and the times of parturition are not alike for all. ${ }^{1}$ Some birds couple and lay at almost any time in the year, as for instance the barn-door hen and the pigeon: the former of these coupling and laying during the entire year, with the exception of the month before and the month after the winter solstice. $^{2}$ Some hens, even in the high breeds, lay ${ }^{5}$ a large quantity of eggs before brooding, amounting to as many as sixty; and, by the way, the higher breeds are less prolific than the inferior ones. The Adrian hens ${ }^{3}$ are small-sized, but they lay every day; they are cross-tempered, and often kill their chickens; they are of all colours. Some domesticated hens lay twice a day; ${ }^{4}$ indeed, instances have 20 been known where hens, after exhibiting extreme fecundity, have died suddenly. Hens, then, lay eggs, as has becn stated, at all times indiscriminately; the pigeon, the ringdove, the turtle-dove, and the stock-dove lay twice a year," and the pigeon actually lays ten times a year. The great majority of birds lay during the spring-time. Some birds 25 are prolific, and prolific in either of two ways-either by laying often, as the pigeon, or by laying many eggs at a sitting, as the barn-door hen. All birds of prey, or birds with crooked talons, are unprolific, except the kestrel: this

Cf. $H . A$. ix. cc. $7-36$.

H.A. v. I3. $544^{\mathrm{b}} 33$; Plin. x. 74 .

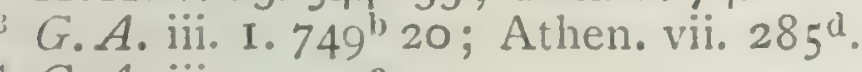

G.A. iii. I. $750^{2} 27$.

5 We translate with Plin. x. 74 'palumbi et turtures bis anno pariunt ' : so Schn., 'male Gaza vertit bina pariunt'. A. and W. trans-

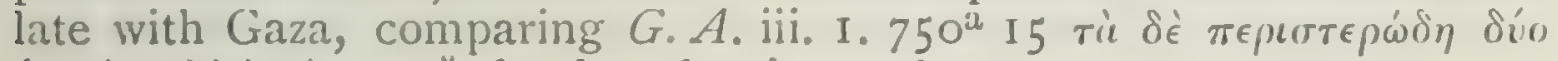

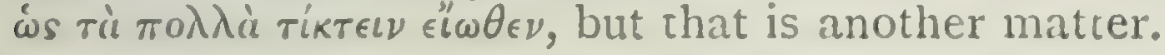


bird is the most prolific of birds of prey $;^{1}$ as many as four eggs have been observed in the nest, and occasionally it 30 lays even more.

Birds in general lay their eggs in nests, but such $559^{\text {a }}$ as are disqualified for flight, as the partridge and the quail, ${ }^{2}$ do not lay them in nests but on the ground, and cover them over with loose material. The same is the case with the lark and the tetrix. These birds hatch in sheltered places; but the bird called merops in Bocotia," alone of all birds, burrows into holes in the ground and hatches there.

5 Thrushes, like swallows, build nests of clay; on high trees, and build them in rows all close together, so that from their continuity the structure resembles a necklace of nests. ${ }^{4}$ Of all birds that hatch for themselves the hoopoe is the only one that builds no nest whatever; it gets into the ro hollow of the trunk of a tree, and lays its eggs there without making any sort of nest." The circus builds cither under a dwelling-roof or on cliffs. The tetrix, called ourax in Athens, builds neither on the ground nor on trees, but on low-lying shrubs.

15 The egg in the case of all birds alike is hard-shelled, if it 2 be the produce of copulation and be laid by a healthy hen - for some hens lay soft eggs. The interior of the egg

1 G. A. iii. I. $750^{a} 7$; Plin. x. 73.

${ }^{2}$ H.A. ix. 8. 61 $3^{\mathrm{b}}$ 6; Xen. Mem。 ii. I. 4.

${ }^{3}$ Read $\mu \epsilon \operatorname{co\pi a}$ (with $\mathrm{PD}^{\mathrm{a}}$ ), the bee-eater. H. A. ix. 13. 615 $5^{\mathrm{b}} 24$; Plin. X. 5 I.

${ }^{4}$ This description (with which cf. Plin. $x .74$ ) is not true of the thrush, nor is it known to be true as a whole of any other bird. That the thrush builds her nest of clay, or at least lines it therewith, is true, and this is all that we are told by Alex. Myndius: cf. Athen. ii. $65^{2}$. I am therefore inclined to think that the latter part of the sentence should refer to the swallow. On the swallow's nest cf. $H . A$. ix. 7. 612b 21 ; Plin. x. 49; Acl. iii. 24, 25, \&c:

${ }^{5}$ A different account in $H . A$. ix. 15. 616a 35 ; Ael. iv. 26. The phrase $к a \theta^{\prime}$ '́ution', as Scal, Schn., and others have shown, is difficult, nor is the sense made much clearer by substituting кn日' éavici. The contrast implied may be with the cuclioo, which neither builds nor hatches, and this reference is the less unlikely from the resemblance in note and connexion in story between the two bircls. Note the juxtaposition of "̈ $\pi \circ \psi$ and kipkos, as in the well-known myth. For

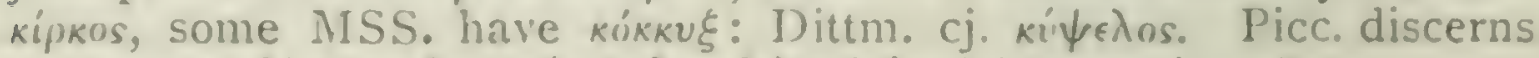

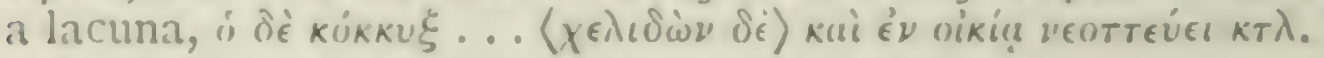


is of two colours, and the white part is outside and the yellow part within. ${ }^{1}$

The eggs of birds that frequent rivers and marshes differ from those of birds that live on dry land; that is to say, 20 the eggs of water-birds have comparatively more of the yellow or yolk and less of the white. Eggs vary in colour according to their kind. Some eggs are white, as those of the pigeon and of the partridge; others are yellowish, as the eggs of marsh birds; in some cases the eggs are mottled, as the eggs of the guinea-fowl and the pheasant; ${ }^{2}$ while the 25 eggs of the kestrel are red, like vermilion.

Eggs are not symmetrically shaped at both ends: in other words, one end is comparatively sharp, and the other end is comparatively blunt; and it is the latter end that protrudes first at the time of laying. Long and pointed eggs are female; those that are round, or more rounded at the narrow end, are male. ${ }^{3}$ Eggs are hatched by the incubation of the mother-bird. In some cases, as in Egypt, 559 they are hatched spontaneously in the ground, by being buried in dung heaps. ${ }^{4}$ A story is told of a toper in Syracuse, how he used to put eggs into the ground under his rush-mat and to keep on drinking until he hatched them." Instances have occurred of eggs being deposited in warm vessels and getting hatched spontaneously.

The sperm of birds, as of animals in general, is white. After the female has submitted to the male, she draws up ${ }^{6}$ the sperm to underneath her midriff. At first it is little in size and white in colour ; by and by it is red, the colour of blood; as it grows, it becomes palc and yellow all over. 10 When at length it is getting ripe for hatching, it is subject to differentiation of substance, and the yolk gathers together

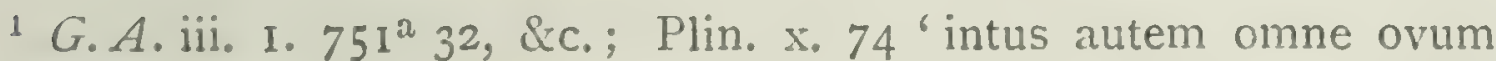
volucrum bicolor'.

${ }^{2}$ Plin. l.c. 'alia punctis distincta, ut meleagridi; alia rubri coloris, ut phasianis, cenchridi'.

${ }_{3}$ Plin. l.co, Colum. viii. 5, Antig. de Mirab. 103 all assert the converse.

4 Diod. Sic. i. 74; Geopon. xiv. I. I.

"Antig. de Mirab. 104; Plin. x. 75.

$6 \lambda a \mu \beta a ́ v \epsilon$. Gaza tr. 'Concipit ovum', but the phrase here seems to be descriptive rather than technical: cf. G. A. ii. $4 \cdot 739^{\text {b }} 8$. 
within and the white settles round it on the outside. When the full time is come, the egg detaches itself and protrudes, changing from soft to hard with such temporal exactitude that, whereas it is not hard during the process of pro15 trusion, it hardens immediately after the process is completed: ${ }^{1}$ that is if there be no concomitant pathological circumstances. Cases have occurred where substances resembling the cgs at a critical point of its growththat is, when it is yellow all over, as the yolk is subsequently - have been found in the cock when cut open, underneath his midriff, just where the hen has her egggs; and these are entirely yello: in appearance and of the same size as 20 ordinary eggs. Such phenomena are regarded as unnatural and portentous.

Such as affirm that wind-eggs are the residua of eggs previously begotten from copulation are mistaken in this assertion, for we have cases well authenticated where chickens of the common hen and goose have laid windeggs without ever having been subjected to copulation." 25: Wind-eggs are smaller, less palatable, and more liquid than true eggs, and are produced in greater numbers. When they are put under the mother bird, the liquid contents never coagulate, but both the yellow and the white remain as they were. Wind-eggs are laid by a number of birds: as for instance by the common hen, the hen partridge, the hen pigeon, the peahen, the goose, and the vulpanser." Eiggs are hatched under brooding

1 G.A. iii. I. $752^{\mathrm{a}} 35$; Plin. l.c.

2 G.A. iii. 1. $75^{\mathrm{a}} 9$, dic.; Plin. x. So.

3 The only characters that these birds seem to possess in common is that all are more or less sacred, mystical, or associated with supersti-

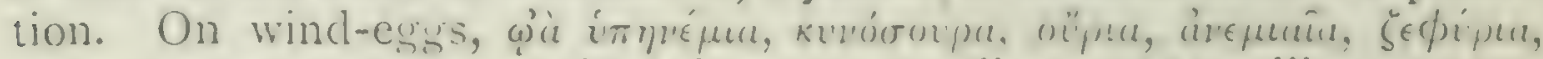
cf. supra, v. I. $539^{a} 31 ; G . A$. i. $21.730^{a} 4$, ii. $5 \cdot 741^{\text {a }}$ I7, iii. I. $749^{\text {a }}$ I, $750^{b} 3,751^{a} 9$, dic.; Athen. i. $57 \mathrm{C}$; Colum. 1i. 27, dec : and especially

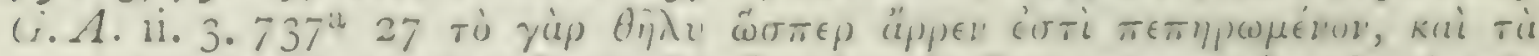

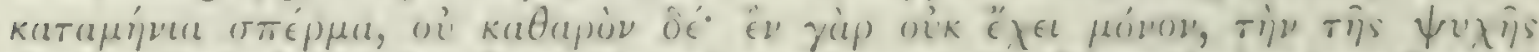

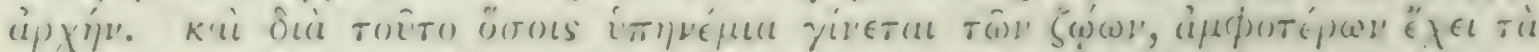

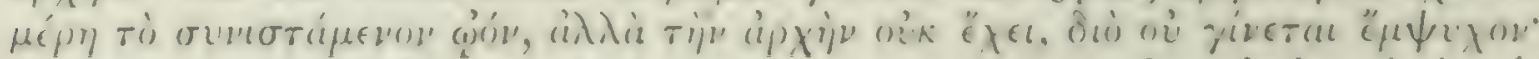

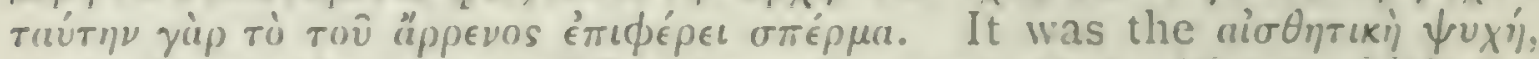
that wherein the animal clifers from the plant, that without which the: body would be but as a corpse, that the female cannot supply and that it is the sperial virtue of the mate to contribute (t).A. ii. 5. 7 t $^{3}$ 12).

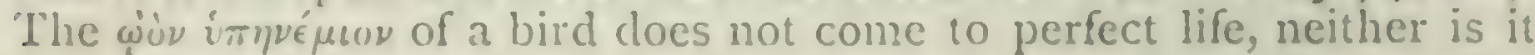


hens more rapidly in summer than in winter; that is to say, hens hatch in eighteen days in summer, but occasionally $560^{\text {a }}$ in winter take as many as twenty-five. ${ }^{1}$ And by the way for brooding purposes some birds make better mothers than others. If it thunders while a hen-bird is brooding, the eggs get addled. Wind-eggs that are called by some cynosura and uria are produced chiefly in summer. Wind- 5 eggs are called by some zephyr-eggs, because at springtime hen-birds are observed to inhale the breezes; they do the same if they be stroked in a peculiar way by hand. Wind-eggs can turn into fertile eggs, and eggs due to previous 10 copulation can change breed, if before the change of the yellow to the white the hen that contains wind-eggs or eggs begotten of copulation be trodden by another cock-bird. Under these circumstances the wind-cggs turn into fertile eggs, and the previously impregnated eggs follow the brecd of the impregnator; but if the latter impregnation takes place during the change of the yellow to the white, then no 15 change in the egg takes place: the wind-cgg does not become a true egg, and the true egg does not take on the breed of the latter impregnator." If when the egg-substance is small copulation be intermitted, the previously existing egg-substance exhibits no increase; but if the hen be again submitted to the male the incrcase in size proceeds with rapidity.

dead as a stick or a stone is clead: it manifestly possesses $\psi v \times \dot{\eta} \nu$ ruvu: but this is the last and lowest, $\dot{\eta} \theta \rho \in \pi \tau \iota \kappa \dot{\eta}$, that which plants also possess. Further development takes place if impregnation be at

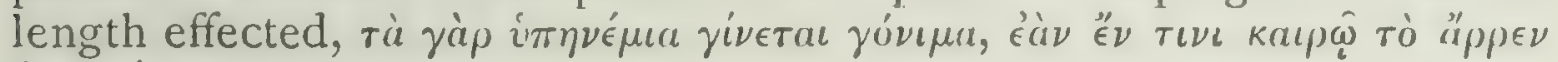

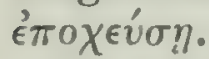

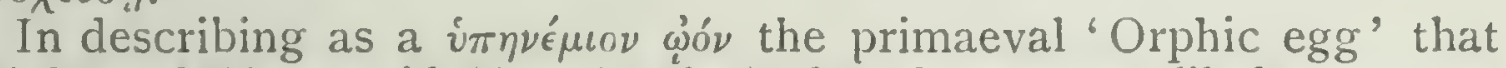
Night and Chaos laid (Ar. A\%.694), the phrase very likely suggests or embodies some special mystical significance, akin to which we have the story in Horap. i. I I of how the Vulture, as symbolizing the year,

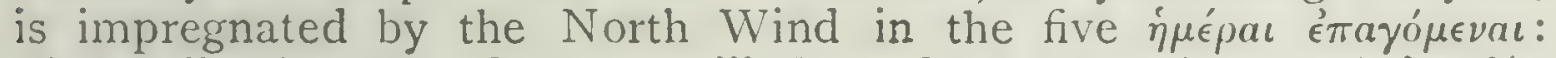

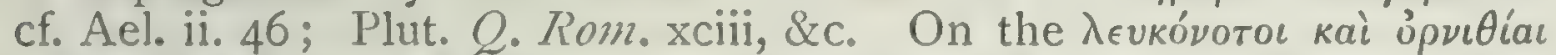
"ut $\mu \circ$, the Etesian winds, or genetubilis anra livoni, cf. Olympiod. in Arist. Meteor. ii. 5. $382^{a}$ I 4 ; Plin. xi. 47 , \&c. On fables of the similar conception of mares in Lusitania cf. Varro, $R$. R. ii. 2 ; Plin. xii. 42; Verg. G. iii. 275 ; Sil. It. iii. 381 ; Augustin. Civ. D. xxi. 5 (in Cappadocia); of sheep, Ael. vii. 27 ; of tigers, Opp. Cyn. iii. 355, \&c., \&c.

1 G.A. iii. 2. $753^{a} 17$; Plin. x. 75 .

$2 A$. and $W$. stigmatize the remainder of this paragraph and the next. 
The yolk and the white are diverse not only in colour but also in propertics. ${ }^{1}$ Thus, the yolk congeals under the influence of cold, whereas the white instead of congealing is inclined rather to liquefy. Again, the white stiffens under the influence of fire. whereas the yolk does not stiffen;

25 but, unless it be burnt through and through, it remains soft, and in point of fact is inclined to set or to harden more from the boiling than from the roasting of the egg." The yolk and the white are separated by a membrane from one another. The so-called 'hail-stones', or treadles, that are found at the extremity ${ }^{3}$ of the yellow in no way contribute towards gencration, as some crroncously suppose ${ }^{4}$ they 30 are two in number, one below and the other above. If you take out of the shells a number of yolks and a number $560^{\mathrm{b}}$ of whites and pour them into a saucepan and boil them slowly over a low fire, the yolks will gather into the centre and the whites will set all round them. ${ }^{5}$

Young hens are the first to lay, and they do so at the 5 beginning of spring and lay more eggs than the older hen.; but the egres of the younger hens are comparatively small." As a general rule, if hens get no brooding they pine and sicken. After copulation hens shiver and shake themselves, and often kick rubbish about all round them ${ }^{8}$ - and this, by the way, they do sometimes after laying-whereas pigeons trail

1 G. A. iii. 2. $753^{\mathrm{a}} 34$.

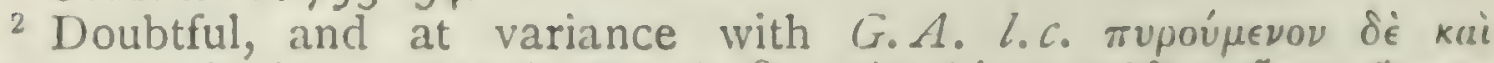

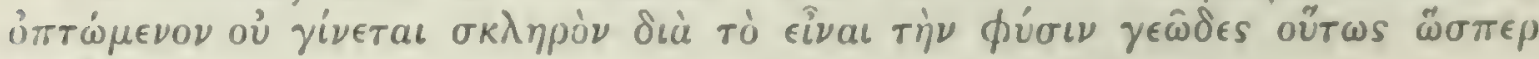
күро́s.

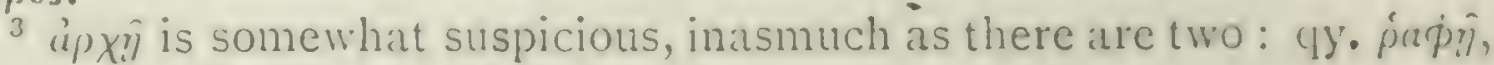

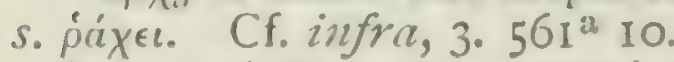

\& A. and W. quote appositely from C. F. Wolff, Bildungd. Darmlitmuls, Halle, 1812, p. \$7 '1) a ich mich zuerst mit der Untersuchung bebriteter lier beschiftigte, suchte ich den Embryo im Hagel des Eies (Chalazie), und noch jetzt hebe ich zum Andenten eine sehr sorgtaltige Zeichnum von einer Chalaze auf, wovon ich die Rudimente des Embryo gefunden zu haben glaubte. Nachher las ich mit Vergnügen im Intrey, diss Fabricius in denselluen Irrthum gerathen und sogar darin geblieben ist.'

${ }^{5}$ G. A. iii. 1. $752^{2} 4$.

- Plin. $l . c$.

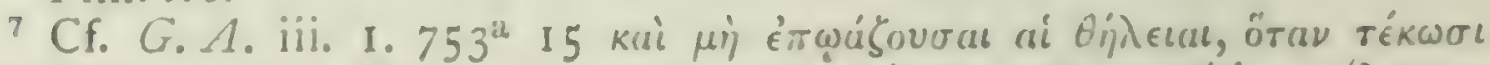

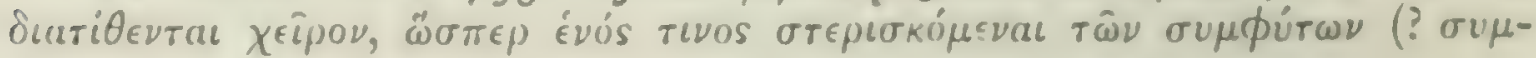
фópwv).

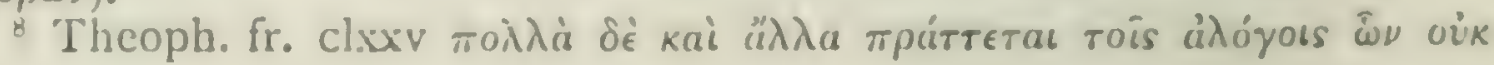


their rumps on the ground, and geese dive under the water. ${ }^{1}$ ro Conception of the true egg and conformation of the windegg take place rapidly with most birds; as for instance with the hen-partridge when in heat." The fact is that, when she stands to windward and within scent of the male, she conceives, ${ }^{3}$ and becomes useless for decoy purposes: for, by I 5 the way, the partridge appears to have a very acute sense of smell.

The generation of the egg after copulation and the generation of the chick from the subsequent hatching of the egg are not brought about within equal periods for all birds, but differ as to time according to the size of the parentbirds. The egg of the common hen after copulation sets and matures in ten days as a general rule; the egg of the 20 pigeon in a somewhat lesser period. ${ }^{4}$ Pigeons have the faculty of holding back the egg at the very moment of parturition; if a hen pigeon be put about by any one, for instance if it be disturbed on its nest, or have a feather plucked out, or sustain any other annoyance or disturbance, then even though she had made up her mind to lay she can keep the egg back in abeyance.

A singular phenomenon is observed in pigeons with re- 25 gard to pairing: that is, they kiss one another just when the male is on the point of mounting the female, ${ }^{5}$ and without this preliminary the male would decline to perform his

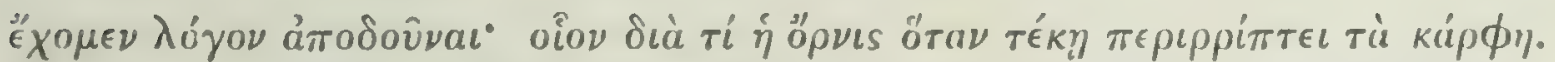

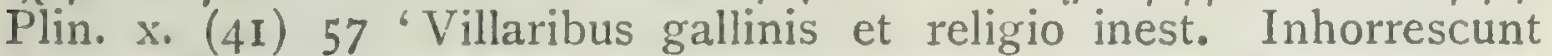
edito ovo, excutiuntque sese, et circumactae purificant, ac festuca aliqua

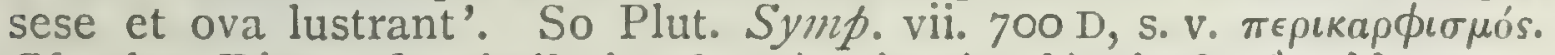

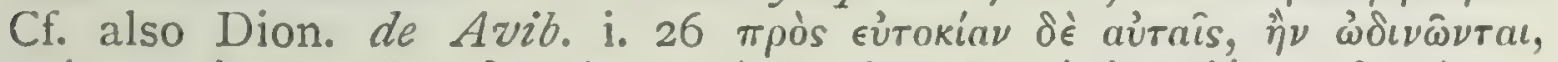

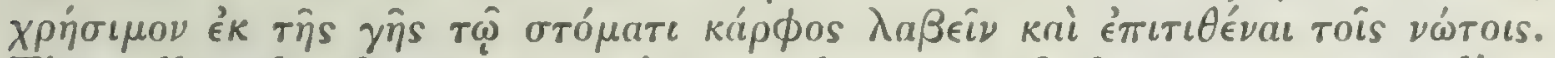
The alleged phenomenon is merely one of the many remedies, charms, or fascinationes, the use of which is attributed to particular animals.

1 Varro, R.R. iii. IO. 3 .

$2 H . A$. v. 5. $54^{\mathrm{a}} 26 ; G . A$. iii. I. $75^{\mathrm{a}} 15 ;$ Ael. H.A. xvii. I5; Antig. de Mirab.8I (87); Athen. ix. 390; Plin. x. 5 I.

3 This myth, probably Egyptian, is, like the similar one of the vulture, referred to frequently by the Fathers, e.g. Isid. xii. 7 ; Orig. vii: cf. note, p. $559^{\text {b }} 29$.

4 Plin. x. 74.

${ }^{5}$ G.A. iii. 6.756 23 ; Athen. ix. $394^{\text {d }}$; Ael. V.H. i. I5; Dion. de Avib. i. 25 ; Plin.x. 79 ; Ovid, Am. ii. 6. 56. 
function. ${ }^{1}$ With the older males the preliminary kiss is only given to begin with, and subsequently he mounts without previously kissing $;^{2}$ with younger males the preliminary is never omitted. Another singularity in these 30 birds is that the hens tread one another when a cock is not forthcoming, after kissing one another just as takes place in the normal pairing. Though they do not impreg$56 \mathrm{I}^{\mathrm{a}}$ nate one another they lay more eggs under these than under ordinary circumstances; no chicks, however, result therefrom, but all such eggs are wind-eggs.

Gencration from the egg proceeds in an identical manner 3 5 with all birds, but the full periods from conception to birth differ, as has been said. With the common hen after three days and three nights there is the first indication of the embryo; with larger birds the interval being longer, with smaller birds shorter. Neanwhile the yolk comes into being, 10 rising towards the sharp end, ${ }^{4}$ where the primal element of the egg is situated, and where the egg gets hatched; and

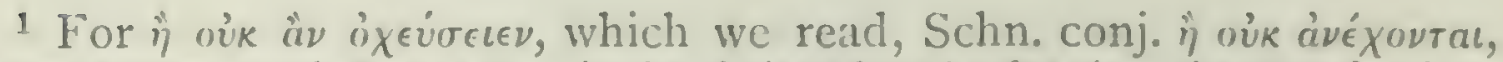

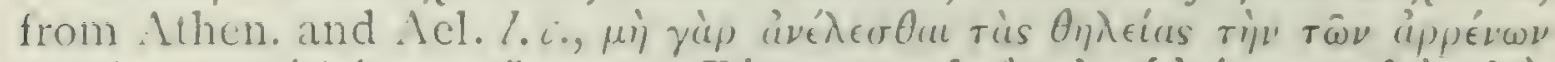

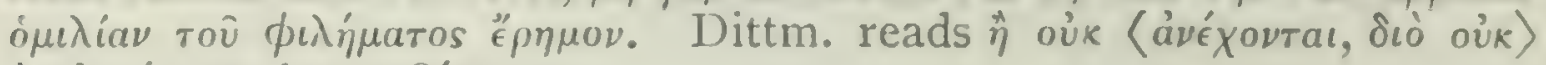

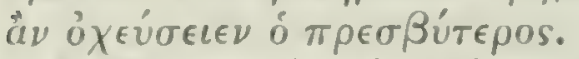

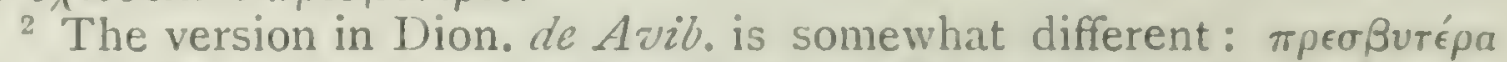

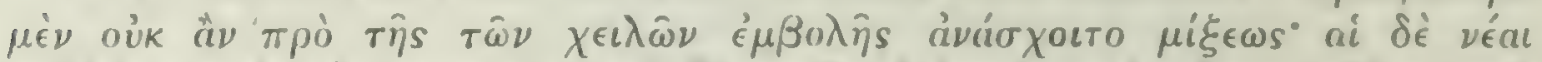

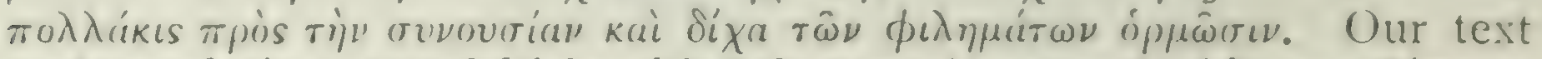

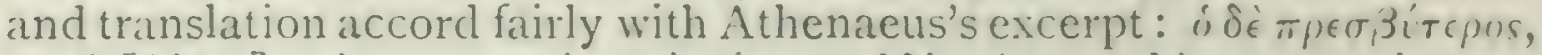

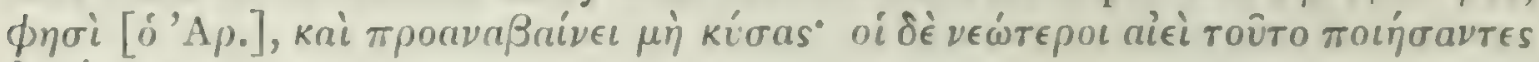
¿хєи́о口

${ }^{3}$ This chapter is in great part open to suspicion. The parts which I have bracketed as especially doubtful do not correspond precisely with those which Dittmeyer has bracketed.

${ }^{4}$ The fuller account in $\vec{G} \cdot A \cdot$ iii. $2.72^{2}$ is in part fanciful. The egg must not be spherical, but unsymmetrical in order that the part wherein lies the aip $x^{\prime}$ may be differentiated: the aip x'y is at the point of attachment of the egg to the parent, as of the seed to its pod, and the broad end being found to issue first from the parent, and further, the fact that in deformed eags an irregular outgrow th like an imperfect stalk is seen at the narrow end. determine the latter as the point of origin of the egg, the seat of the apxy. That being so, the head of the chicken, the nobler part. must ultimately be found here, and the eger is laid, so to speak, feet first, conversely to the birth of the vivipara. But this is a curious error, for it is easy to observe that in the ripened "'s's the chick's head is at the broitd end, and that there it breaks the shell; in the early stages the embryo floats uppermost, and confronts us at whatever point we open the egg. 
the heart appears, like a speck of blood, in the white of the egg. ${ }^{1}$ This point beats and moves as though endowed with life, and from it two vein-ducts with blood in them trend in a convoluted course [as the egg-substance goes on growing, towards each of the two circumjacent integuments] $;{ }^{2}$ and a membrane carrying bloody fibres now I $_{5}$ envelops the yolk, ${ }^{3}$ leading off from the vein-ducts. A little afterwards the body is differentiated, at first very small and white. The head is clearly distinguished, and in it the eyes, swollen out to a great extent. This condition of the eyes lasts on for a good while, as it is only by 20 degrees that they diminish in size and collapse. At the outset the under portion of the body appears insignificant in comparison with the upper portion. Of the two ducts that lead from the heart, the one proceeds towards the circumjacent integument, ${ }^{4}$ and the other, like a navel-string, towards the yolk. The life-element of the chick is in the white of the egg, and the nutriment comes through the 25 navel-string out of the yolk. ${ }^{5}$

When the egg is now ten days old the chick and all its parts are distinctly visible. The head is still larger than the rest of its body, and the eyes larger than the head, but still devoid of vision. The eyes, if removed about this time, are found to be larger than beans, and black; if the $3 \circ$ cuticle be peeled off them there is a white and cold liquid inside, quite glittering in the sunlight, but there is no hard substance whatsoever. Such is the condition of the head

1 Plin. x. 74.

2 Gaza tr. 'ad ambientem album liquorem'. We have no textual authority for this rendering, which is more correct in meaning than the text, and which suggests the omission of the words bracketed. What are afterwards described as the two integuments (allantois and yolk-sac) are not yet differentiated on the third day.

${ }^{3}$ I conjecture $\lambda_{\epsilon} \kappa_{\kappa} \ell \theta \nu$ in place of $\lambda \epsilon v \kappa o ́ \nu$.

4 Dittm. unnecessarily supplies $\left\langle\chi^{\prime} \rho \iota \iota^{\prime}\right\rangle$ : cf. G. A. iii. $2.753^{\mathrm{b}} 30$.

5 This statement is contrary to the view of the Hippocratic school. Cf.

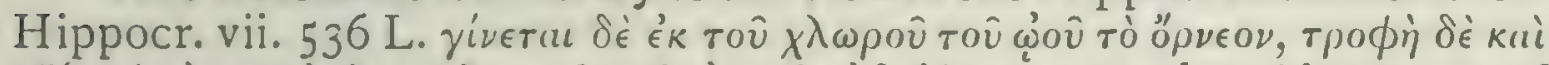

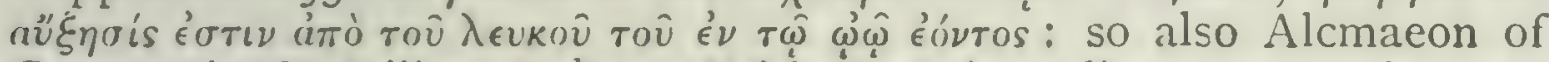
Croton, cit. G.A. iii. $2.752^{\mathrm{b}} 25$. With the Aristotelian account cf. Clear-

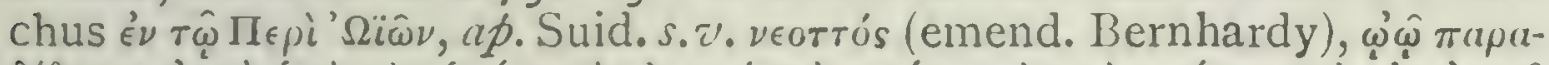

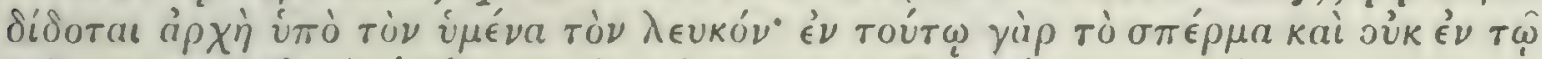

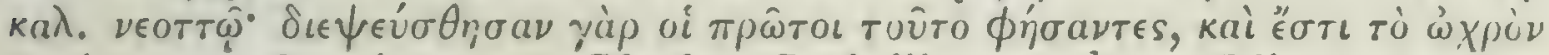

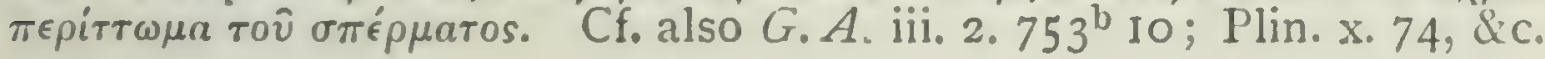


and eyes. At this time also the larger internal organs are visible, as also the stomach and the arrangement of the viscera; and the veins that secm to proceed from the heart 5 are now close to the navel. From the navel there stretch a pair of veins; one ${ }^{1}$ towards the membrane that envelops the yoke (and, by the way, the yolk is now liquid, or more so than is normal), and the other ${ }^{2}$ towards that membrane which envelops collectivcly the membrane wherein the chick lies, the membrane of the yolk, and the intervening ro liquid. [For, as the chick grows, little by little one part of the yolk goes upward, and another part downward, and the white liquid is hetween them; and the white of the egg is underneath the lower part of the yolk, as it was at the outset.] On the tenth day the white is at the extreme outer surface, reduced in amount, glutinous, firm in sub${ }_{5} 5$ stance, and sallow in colour.

The disposition of the several constituent parts is as follows. First and outermost comes the membrane of the egg, not that of the shell, but" underneath it. Inside this membrane ${ }^{4}$ is a white liquid; then comes the chick, and a membrane round about it, ". separating it off so as to keep) the chick free from the liquid; next after the chick comes 20 the yolk, into which one of the two veins was described as leading, the other one leading into the enveloping white substance. [A membrane ${ }^{4}$ with a liquid resembling serum envelops the entire structure. Then comes another membrane" right round the embryo, as has been described, separating it off against the liquid. Underneath this comes the yolk, enveloped in another membrane (into which yolk 25 proceeds the navel-string that leads from the heart and the big vein), so as to kecp the embryo frec of both liquids.]

About the twenticth day, if you open the egg and touch the chick, it moves inside and chirps; and it is already coming to be corered with down. when, after the twentieth

1 The vitelline vein and artery.

2 The allantoic vein and artery.

3 Picc. and Dittm., following Schneider, insert $\langle i\rangle$ : I think necdlessly.

- The allantois.

s The amnion. 
day is past, the chick begins to break the shell. ${ }^{1}$ The head is situated over the right leg close to the flank, and the 30 wing is placed over the head; and about this time is plain to be seen the membrane resembling an after-birth that comes next after the outermost membrane of the shell, into which membrane the one of the navel-strings was $5_{6} \mathbf{2}^{\mathbf{a}}$ described as leading (and, by the way, the chick in its entirety is now within it), and so also is the other membrane resembling an after-birth, namely that surrounding the yolk, into which ${ }^{2}$ the second navel-string was described as leading; and both of them were described as being connected with the heart and the big vein. At this conjuncture 5 the navel-string that leads to the outer after-birth collapses and becomes detached from the chick, and the membrane that leads into the yolk is fastened on to the thin gut of the creature, and by this time a considerable amount of the yolk is inside the chick and a yellow sediment is in its stomach. About this time it discharges residuum ${ }^{3}$ in the ro direction of the outer after-birth, and has residuum inside its stomach; and the outer residuum is white [and there comes a white substance inside]. ${ }^{4}$ By and by the yolk, diminishing gradually in size, at length becomes entirely used up and comprehended within the chick (so that, ten days after hatching, if you cut open the chick, a small is remnant of the yolk is still left in connexion with the gut), ${ }^{5}$ but it is detached from the navel, and there is nothing in the interval between, but it has been used up entirely. During the period above referred to the chick sleeps, wakes up, makes a move and looks up and chirps; and the heart and the navel together palpitate as though 20 the creature were respiring. So much as to generation from the egg in the case of birds. ${ }^{6}$

1 Plin. l.c.

2 i. e. the yolk, unless we should read on, in which case its antecedent would be $\dot{v} \mu \eta \dot{\nu}$.

${ }_{3}$ The urates of the allantoic fluid.

"Cf. Scalig. in loc. 'Hoc non caret mendi suspicione. Gaza vertit: "Excrementum ctiam album eodem tempore pullus emittit, et in alvo quiddam album consistit." Omisit igitur verba otiosa aut vitiosa.'

${ }^{3}$ G. A. iii. 2. $754^{a}$ II.

${ }^{6}$ This is probably the chief passage referred to in $G . A$. iii. 2. 
Birds lay some eggs that are unfruitful, even eggs that are the result of copulation, and no life comes from such eggs by incubation; and this phenomenon is observed especially with pigeons.

1 Twin eggs have two yolks. In some twin eggs a thin 25 partition of white intervenes to prevent the yolks mixing with each other, but some twin eggs are unprovicled with such partition. and the yoles run into one another. There are some hens that lay nothing but twin eggs, ${ }^{2}$ and in their case the phenomenon regarding the yolks has been observed. For instance, a hen has been known to lay 30 eighteen eggs, and to hatch twins out of them all, except those that were wind-eggs; the rest were fertile (though, $562^{b}$ by the way, one of the twins is always bigger than the other), but the eighteenth was abnormal or monstrous."

Birds of the pigeon kind, such as the ring-dove and the 4 turtle-dove, lay two eggs at a time; that is to say, they 5 do so as a general rule, and they never lay more than three. The pigeon, as has been said, lays at all seasons; the ring-dove and the turtle-dove lay in the spring-time, and they never lay more than twice in the same season. The hen-bird lays the sccond pair of eggs when the first pair happens to have been destroyed, for many of the henpigeons destroy the first brood. The hen-pigeon, as has been said, occasionally lays three eggs, but it never rears 10 more than two chicks, and sometimes rears only one; and the odd one is always a wind-egg. ${ }^{4}$

Very few birds propagate within their first year. All birds, after once they have begun laying, kecp on having

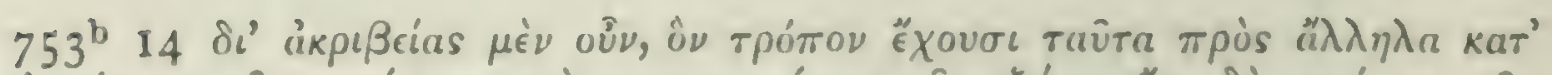

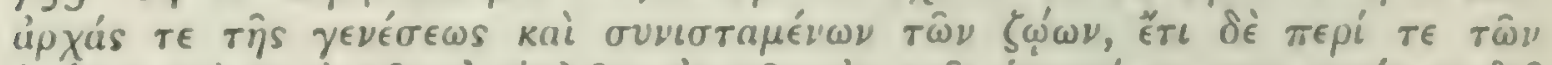

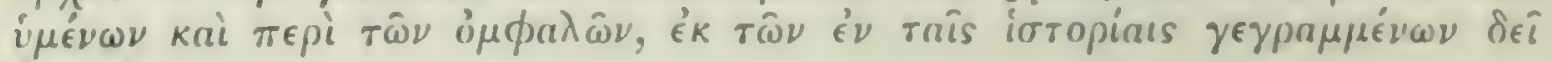
Oecopleir.

${ }^{1}$ Cf. G. A. iv. $4 \cdot 769^{\text {b }}$ 3o et seq.

- P'lin. x. 74' Quaedam gallinae omnia gemina ova pariunt, et geminos interdum excludunt, ut Corn. Celsus auctor est, alterum maiorem. Aliqui negant omnino geminos excludi.'

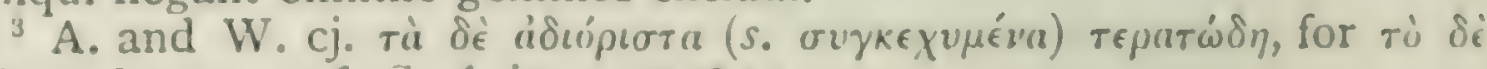

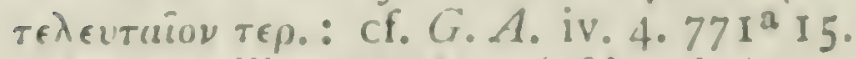

G.A. iii. 2. $753^{\text {a }} 30$ (of hawks). 
eggs, though in the case of some birds it is difficult to detect the fact from the minute size of the creature.

The pigeon, as a rule, lays a male and a female egg, and ${ }_{15}$ generally lays the male egg first; after laying it allows a day's interval to ensue and then lays the second egg. The male takes its turn of sitting during the daytime; the female sits during the night. The first-laid egg is hatched and brought to birth within twenty days; and the mother bird pecks a hole in the egg the day before she 20 hatches it out. The two parent birds brood for some time over the chicks in the way in which they brooded previously over the eggs. In all connected with the rearing of the young the female parent is more cross-tempered than the male, as is the case with most animals after parturition. The hens lay as many as ten times in the year $;^{1}$ occasional instances have been known of their laying eleven times, and 25 in Egypt they actually lay twelve times. The pigeon, male and female, couples within the year; in fact, it couples when only six months old. Some assert that ring-doves and turtle-doves pair and procreate when only three months old, and instance their superabundant numbers by way of proof of the assertion. The hen-pigeon carries her eggs fourteen days; for as many more days the parent 30 birds hatch the eggs; by the end of another fourteen days the chicks are so far capable of flight as to be overtaken $563^{\text {a }}$ with difficulty. [The ring-dove, according to all accounts, lives up to forty years. ${ }^{2}$ The partridge lives over sixteen.] ${ }^{3}$ [After one brood the pigeon is ready for another within thirty days. $]^{4}$

5 The vulture ${ }^{5}$ builds its nest on inaccessible cliffs ; ${ }^{6}$ for 5 which reason its nest and young are rarely seen. And therefore Herodorus, father of Bryson the Sophist, deciares that vultures belong to some foreign country unknown to us, stating as a proof of the assertion that no one has ever

1 Athen. ix. 394 ; Ael. V. H. i. I 5 ; Plin. x. 74.

${ }^{2} H . A . \mathrm{ix} .7 .613^{\mathrm{a}} 17 .{ }^{3}\left[{ }^{4} \mathrm{~A}\right.$. and W. ${ }^{4}$ Dittm.

5 H. A. ix. II. 61 $4^{\text {a }} 8$; Antig. Mirab. 42; Plin. x. 7; Plut Romul. ix, Q. Rom. 286 A.

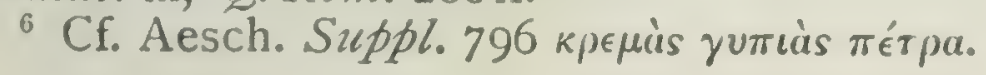


scen a vulture's nest, and also that vultures in great numbers 10 make a sudden appearance in the rear of armies. Howerer, difficult as it is to get a sight of it, a vulture's nest has becn seen. The vulture lays two eggs.

[Carnivorous birds in general are obscrved to lay but once a year. The swallow is the only carnivorous bird that builds a nest twice. ${ }^{1}$ If you prick out the eyes ${ }^{2}$ of swallow chicks while they are yet young, the birds will get 15 well again and will see by and by. $]^{3}$

The eagle ${ }^{4}$ lays three eggs and hatches two of them, as 6 it is said in the verses ascribed to Musacus:

That lays three, hatches two, and cares for onc.

This is the case in most instances, though occasionally 20 a brood of three has been observed. As the young ones grow, the mother becomes wearicd with feeding them and cxtrudes one of the pair from the nest. At the same time the bird is said to abstain from food," to avoid harrying the young of wild animals. That is to say, its wings blanch, and 25 for some days its talons get turned awry. It is in consequence about this time cross-tempered to its own young. The phene is said to rear the young one that has been expelled the nest. The eagle broods for about thirty days."

1 H.A. v. I3. $544^{\mathrm{a}} 26$.

${ }^{2}$ H.A. ii. 17. $508^{\mathrm{b}} 5$; G.A. iv. 6. $774^{\mathrm{b}} 3 \mathrm{I}$; Antig. Mirab. 72, 98 ; Ael. xvii. 20.

$3[$ A. and $\mathrm{W}$.

4 This portion of the book, and this chapter in particular, are interwoven with Egyptian myth. The eagle or vulture was a symbol of compassion : cf. Horap. ii. 99 in

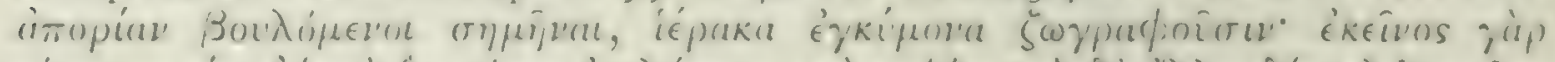

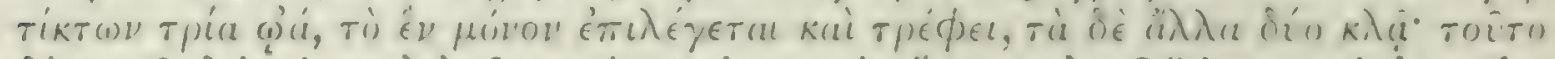

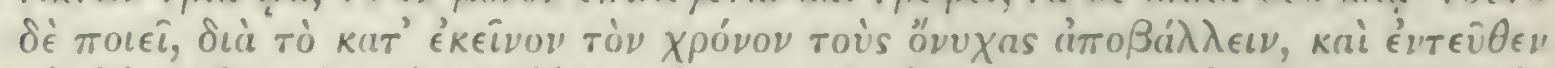

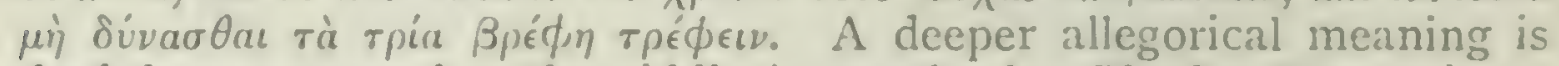
cloubtless present, but the riddle is unsolved. Cf. also Horap. i. II, Tretz. Chil. xii. 439, where the eagle is a symbol of the year.

"Reading äraбros: the reading is very dubious. Guil. tr. 'dicitur in tempore codem extra genus aquilae fieri, perhaps reading. with $\mathrm{C}^{\mathrm{a}}$. є̇тієтоs: cf. Gaza 'nam et degenerare ac hebescere aquila dicitur' : inureos, which, according to Dittm. Occurs in l'I)a was suggested by sylburg from l'lin. $x .+$ 'quippe co tempore ipsis cibum negavit

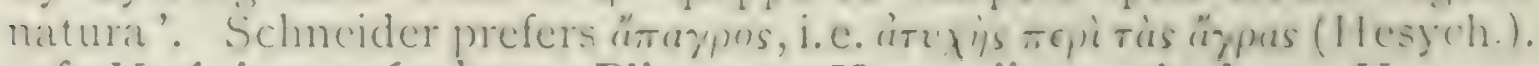

11. . ix. 34.619 25 ; Plin. ג. 4; Horap. ii. 99; Ambros. Hcxacm. v. 18. \&ec. 
The hatching period is about the same for the larger birds, such as the goose and the great bustard; for the middle-sized birds it extends over about twenty days, as in the case of the kite and the hawk. ${ }^{1}$ The kite in general 30 lays two eggs, but occasionally rears three young ones. The so-called aegolius at times rears four. It is not true that, as some aver, the raven lays only two eggs ; ${ }^{2}$ it lays a $563^{\text {b }}$ larger number. It broods for about twenty days and then cxtrudes its young. ${ }^{3}$ Other birds perform the same operation; at all events mother birds that lay several eggs often extrude one of their young.

Birds of the eagle species are not alike in the treatment 5 of their young. The white-tailed eagle is cross, the black eagle is affectionate in the feeding of the young; though, by the way, all birds of prey, when their brood is rather forward in being able to fly, beat and extrude them from the nest. ${ }^{4}$ The majority of birds other than birds of prey, as has been said, also act in this manner, and after fecding ro their young take no further care of them; but the crow is an exception. This bird for a considerable time takes charge of her young; for, even when her young can fly, she flies alongside of them and supplies them with food.

7 The cuckoo is said by some to be a hawk transformed, ${ }^{6}$ because at the time of the cuckoo's coming, the hawk, 15 which it resembles, ${ }^{7}$ is never seen; and indeed it is only

1 Plin. x. 74.

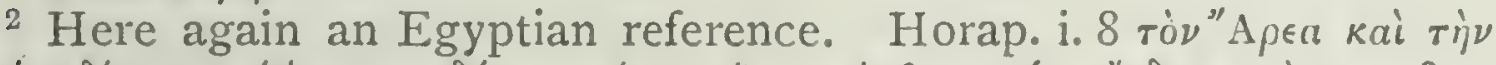

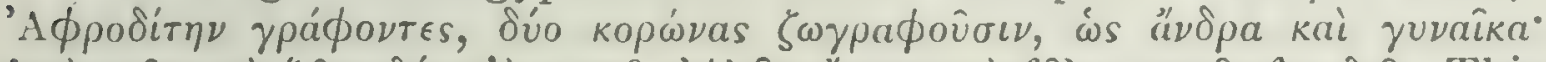

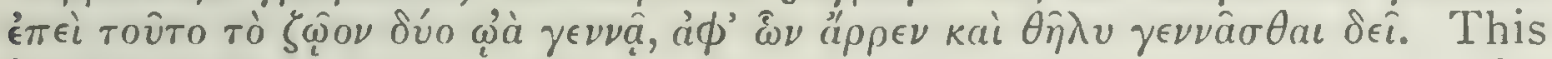
is the ovگuyia or Götterpaar, Isis and Nephthys:'cf. Brugsch, iv. p. I 559, s.v. terau; Lauth, Manetho, p. I47, \&c.

${ }^{3}$ H. A. ix. 31.6 $18^{b}$ Io; Plin. x. I 5 .

4 Plin. $x .3$.

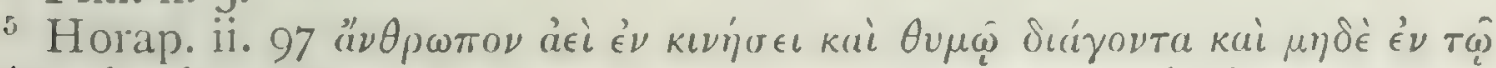

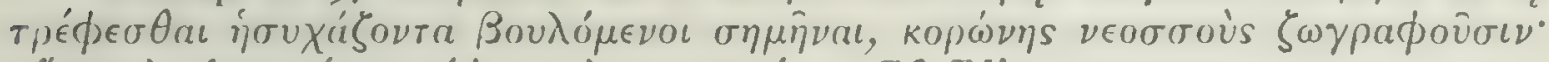

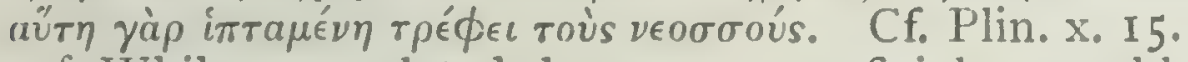

${ }^{6}$ While, as related here, a superficial resemblance does exist between the cuckoo and the hawk, the fabled metamorphosis lies deeper (cf. Aes. Fab. 198, ed. Halm, Plut. Arat. xxx, Tzetz. ad Lyc. 395, \&. .) ; it is connected with the confusion, based on similarity of note, between the cuckoo and the hoopoc (коúkouфor), and the mystical relation or metamorphosis of the latter with the hawk (kipkos), both solar emblems. Cf. H.A. ix. 49 B. $633^{a}$ I I ; Plin. x. II, \&c.

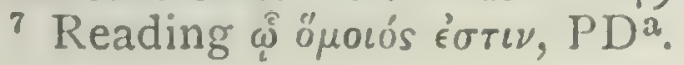


for a few days that you will see hawks about when the cuckoo's note sounds early in the season. The cuckoo appears only for a short time in summer, and in winter disappears. The hawk has crooked talons, which the cuckoo 20 has not; neither with regard to the head does the cuckoo resemble the hawk. In point of fact, both as regards the head and the claws it more resembles the pigeon. ${ }^{1}$ However, in colour and in colour alone it does resemble the hawk, only that the markings of the hawk are striped, and of the cuckoo mottled. And, by the way, in size and flight 25 it resembles the smallest of the hawk tribe, ${ }^{2}$ which bird disappears as a rule about the time of the appearance of the cuckoo, though the two have been seen simultancously. The cuckoo has been scen to be preyed on by the hawk; and this never happens between birds of the same species. ${ }^{3}$ They say no one has ever seen the young of the cuckoo. 30 The bird lays eggs, but does not build a nest. ${ }^{4}$ Sometimes it lays its eggs in the nest of a smaller bird after first devouring the eggs of this bird; it lays by preference in the $564^{a}$ nest of the ring-dove, after first devouring the eggs of the pigcon. (It occasionally lays two, but usually one.) It lays also in the nest of the hypolais," and the hypolais hatches and rears the brood. It is about this time that the bird becomes fat and palatable. [The young of hawks also get 5 palatable and fat. One species builds a nest in the wilderness and on sheer and inaccessible cliffs. ${ }^{6}$

With most birds, as has been said of the pigcon, the 8 hatching is carried on by the male and the female in turns: with some birds, however, the male only sits long enough to

1 In Chinese folklore both P'igeon and (uckoo metamorphose with the hawk: cf. Watters, Tr.R.As.Soc. (N. China Br.), IS67, p. 225.

2 The merlin, F. aesalon, a winter-migrant in Greece, Krüper, p. 160 .

3 A. and $W$. bracket the foregoing part of the chapter.

1 H.A. ix. 29. 61 8a 8; G.A. iii. I. 750 15; Arist. de Mirab. 3. $830^{b}$ II; Antig. Mirab. 109; Theophr. C: Pl. ii. 17.9.

According to Krüper (p. 184) the cuclioo in (ireece lays oftenest

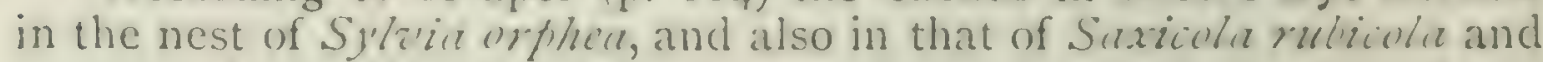

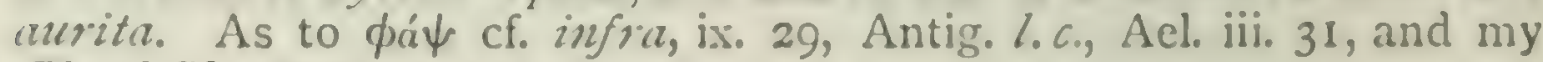
Gl. of Gl. Birds, p. 146.

i A clisjointed statement, regarding not the cuckoo but a hawk. 
allow the female to provide herself with food. In the goose tribe the female alone incubates, and after once sitting on ro the eggs shc continues brooding until they are hatched. ${ }^{1}$

The nests of all marsh-birds are built in districts fenny and well supplied with grass; consequently, the motherbird while sitting quiet on her eggs can provide herself with food without having to submit to absolute fasting.

With the crow also the female alone broods, and broods i 5 throughout the whole period; the male bird supports the female, bringing her food and feeding her. The female of the ring-dove begins to brood in the afternoon and broods through the entire night until breakfast-time of the following day; the male broods during the rest of the time. ${ }^{2} 20$ Partridges build a nest in two compartments; the male broods on the one and the female on the other. ${ }^{3}$ After hatching, each of the parent birds rears its brood. But the male, when he first takes his young out of the nest, treads them. ${ }^{4}$

9 Peafowl ${ }^{j}$ live for about twenty-five years, breed about 25 the third year, and at the same time take on their spangled plumage. They hatch their eggs within thirty days or rather more. The peahen lays but once a year, and lays twelve eggs, or may be a slightly lesser number : she does not lay all the eggs there and then one after the other, but at intervals of two or three days. Such as lay for the first zo time lay about eight eggs. The peahen lays wind-eggs. They pair in the spring; and laying begins immediately after pairing. The bird moults when the earliest trees are $564^{\mathrm{b}}$ shedding their leaves, and recovers its plumage when the same trees are recovering their foliage. ${ }^{6}$ Pcople that rear

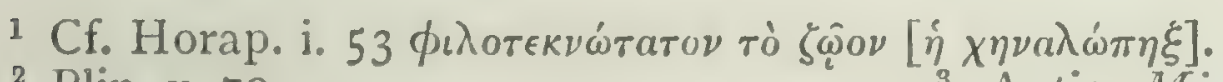

2 Plin. x. 79.

4 This is one of the many fables of the salacity and unnatural lust

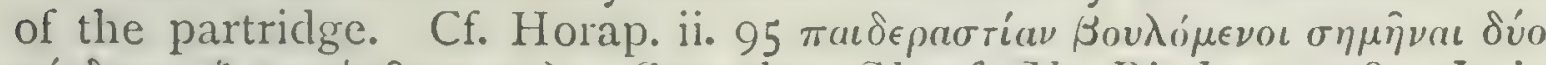

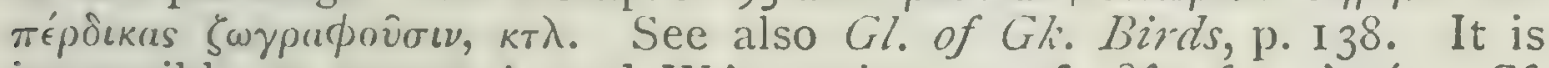
impossible to accept $A$. and W.'s conjecture of aủ $\theta$ is for aùtoús. Cf.

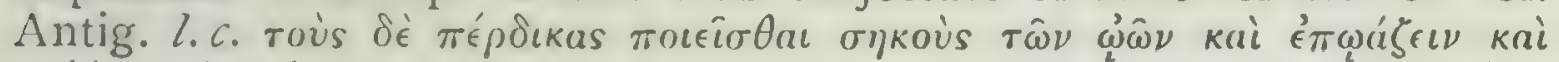

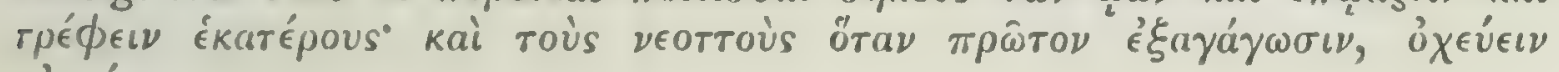
av̉ioús.

${ }^{5}$ Athen. ix. 379; Ael. v. 32 ; Varro, R.R. iii. 9; Plin. x. 79.

${ }^{6}$ Plin. $\mathrm{x} .22$. 
peafowl put the eggs under the barn-door hen, ${ }^{1}$ owing to the fact that when the peahen is brooding over them the 5 peacock attacks her and tries to trample on them; owing to this circumstance some birds of wild varicties run away from the males and lay their eggs and brood in solitude. Only two eggs are put under a barn-door hen, for she could not brood over and hatch a large number. They take cvery precaution, by supplying her with food, to prevent her going off the eggs and discontinuing the brooding.

10 With male birds about pairing time the testicles are obviously larger than at other times, and this is conspicuously the case with the more salacious birds, such as the barndoor cock and the cock partridge; the peculiarity is less conspicuous in such birds as are intermittent in regard to pairing. ${ }^{2}$

So much for the conception and gencration of birds.

15 It has been previously stated that fishes are not all oviparous. ${ }^{3}$ Fishes of the cartilaginous genus are viviparous; the rest are oviparous. And cartilaginous fishes are first oviparous internally and subsequently viviparous; ${ }^{4}$ they rear the embryos internally, the batrachus or fishing-frog being an exception. ${ }^{5}$

Fishes also, as was above stated, are provided with wombs, and wombs of diverse kinds. The oviparous

${ }^{1}$ Colum. viii. I I ; Pallad. i. 28, \&c.; Plin. x. 79.

${ }^{2}$ Probably corrupt. Cf. the explicit and accurate statement supra iii. I. $510^{a} 3 ; G . A$. i. $4.717^{b}$. The MSS. are discrepant; with

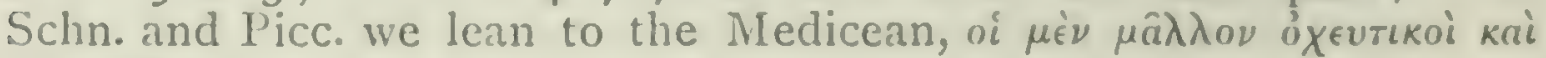

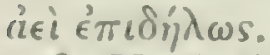

3 II. 1. iii. $15 \cdot 511^{26} 6$.

G. A. iii. 3. $754^{\mathrm{a}} 23$; Plin. ix. (24) 40 ; Ael. xiii. 5 , Sic.

5 The general statement explicitly made here and in $G \cdot A$. iii. 3 . $754^{\text {a }} 23$ is erroneous, the skates, rays, and several sharks being oviparous. There is perhaps, however, a misunderstanding. The descrip-

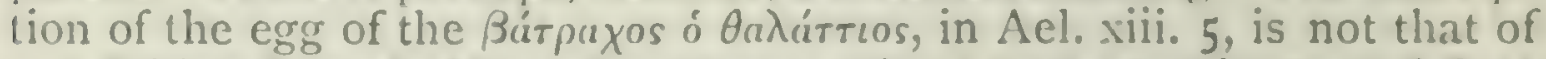
our fishing-frog, lophius frisutomius. whose eggs are minute. and fiout agglutinated in a long chain; they are very rarely seen. On the contrary, Aelian's account is apparently a poor description of the skate's egg; and again, in G.A. iii. $3 \cdot 754^{\mathrm{a}} 33$, it is probably the skate's egg that is referred to. The account in H.A.vi. 17.570 33 is again not true of the fishing-frog. In the whole matter it is impossible to disentangle zoological error from confusion of nomenclature, or from possible textual corruption of Britos for ßírpaxos. 
genera have wombs bifurcate in shape and low down in 20 position; the cartilaginous genus have wombs shaped like those of birds. ${ }^{1}$ The womb, however, in the cartilaginous fishes differs in this respect from the womb of birds, that with some cartilaginous fishes the eggs do not settle close to the diaphragm but middle-ways ${ }^{2}$ along the backbone, and as they grow they shift their position.

The egg with all fishes is not of two colours within but is of even hue; and the colour is nearer to white than to 25 yellow, and that both when the young is inside it and previously as well.

Development from the egg in fishes differs from that in birds in this respect, that it does not exhibit that one of the two navel-strings that "leads off to the membrane that lies close under the shell, while it does exhibit that one of the two that in the case of birds leads off to the yolk. ${ }^{4}$ In a general way the rest of the development from the egg 30 onwards is identical in birds and fishes. That is to say, development takes place at the upper part of the egg, and the veins extend in like manner, at first from the heart; and at first the head, the eyes, and the upper parts are largest; and as the creature grows the egg-substance $565^{\text {a }}$ decreases and eventually disappears, and becomes absorbed within the embryo, just as takes place with the yolk in birds.

The navel-string is attached a little way below the aperture of the belly. ${ }^{5}$ When the creatures are young the navelstring is long, but as they grow it diminishes in size; at length 5 it gets small and becomes incorporated, as was described in the case of birds. The embryo and the egg are enveloped by a common membrane, and just under this is another membrane that envelops the cmbryo by itself; and in between the two membranes is a liquid. The food inside to

${ }^{1} H$. A. iii. I. 5 II $^{\mathrm{a}} 6$; G.A. i. II. 7 I $^{\mathrm{b}}$ 2, \&c.

${ }^{2}$ Cf. $565^{2}$ I 5 .

${ }^{3}$ Reading $\partial \mu \phi a \lambda \dot{\nu} \nu\langle\tau \dot{\nu} \nu\rangle \tau \epsilon i \nu 0 \nu \tau a$, with Schn. and Picco, after G.A. iii. $3 \cdot 754^{\mathrm{b}} 5$.

${ }^{4}$ In other words, there is a yolk-sac, but no allantois.

5 As A. and W. point out, the statement would be correct if we read $\tau \eta \dot{\eta}$ yarrpi, i.e. 'attached to the belly, a little way below the mouth'. Dittm. cj. $\langle\dot{\epsilon} \pi i\rangle \tau \eta \hat{s}$ yaotpós. 
the stomach of the little fishes resembles that inside the stomach of young chicks, and is partly white and partly yellow.

As regards the shape of the womb, the reader is referred to my treatise on Anatomy. The womb, however, is diverse in diverse fishes, as for instance in the sharks as compared one with another or as compared with the skate. That is to say, in some sharks the eggs adhere in the 15 middle of the womb ${ }^{1}$ round about the backbone, as has been stated, and this is the case with the dog-fish ; ${ }^{2}$ as the cggs grow they shift their place; and since the womb is bifurcate and adheres to the midriff, as in the rest of similar creatures, the eggs pass into one or other of the two compartments. This womb and the womb of the other sharks 20 exhibit, as you go a little way off from the midriff, something resembling white breasts," which never make their appearance unless there be conception.

Dog-fish and skate have a kind of egg-shell, in the which is found an egg-like liquid. The shape of the egg-shell resembles the tongue of a bagpipe, ${ }^{\prime}$ and hair-like ducts are 25 attached to the shell. With the dos-fish which is called by some the 'dappled shark'," the young are born when the shell-formation breaks in pieces and falls out; with the ray, after it has laid the egg the shell-formation breaks up and the young move out. ${ }^{6}$ The spiny dog-fish has its eggs

1 i. e. 'between the horns of the womb'.

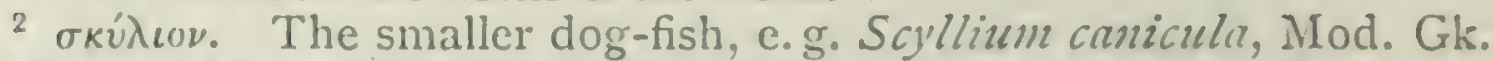
$\sigma \kappa \cup \lambda i, \sigma \kappa \nu \lambda o ́ \psi a \rho \circ$.

3 The 'oviducal glands', which secrete the egg-shell.

- We translate bagpipe rather than flute. The resemblance of such an egg-case as that of Scyllium (especially after it has split at one end for the escape of the young) to a 'split' reed such as that of the bagpipes is close and accurate. Theoph. H.P. iv. I I describes clearly how the cane is split and two pieces applied together to form the 'reed'. A. and IV. miss the point when they say that the comparison is with the stalk of the reed, and 'nicht sowohl auf die Figur als auf die Masse und deren äusseres Aussehen zu beziehen'.

5 veßpias. Probably Scyllium stellare, the 'spotted dog-fish', gatto pardo in the Adriatic.

- In both alike the embryo is developed after the egg is laid. In the viviparous Mustelus ( $y a \lambda \epsilon \operatorname{s}^{\circ}$ o $\lambda$ eios) there is, however, a thin and temporary egg-shell which breaks up at an carly stage; and it may be that $\nu \in \beta$ pias refers to some species intermediate in character of which we lack recent information. 
close to the midriff above the breast-like formations; when 30 the egg descends, as soon as it gets detached the young is born. The mode of generation is the same in the case of $565^{\mathrm{b}}$ the fox-shark.

The so-called smooth shark has its eggs in betwixt the wombs like the dog-fish; these eggs shift into each of the two horns of the womb and descend, and the young develop with the navel-string attached to the womb, so that, 5 as the egg-substance gets uscd up, the embryo is sustained to all appearance just as in the case of quadrupeds. ${ }^{1}$ The navel-string is long and adheres to the under part of the womb (each navel-string being attached as it were by a sucker), and also to the centre of the embryo in the place where the liver is situated. If the embryo be cut open, even though it has the egg-substance no longer, the food inside is egg-like in appearance. Each embryo, as in the ro case of quadrupeds, is provided with a chorion and separate membranes. When young the embryo has its head upwards, but downwards when it gets strong and is completed in form. Males are generated on the left-hand side of the womb, and females on the right-hand side, and males and females on the same side together." If the embryo be cut is open, then, as with quadrupeds, such internal organs as it is furnished with, as for instance the liver, are found to be large and supplied with blood.

All cartilaginous fishes have at one and the same time eggs above close to the midriff (some larger, some smaller), in considerable numbers: ${ }^{3}$ and also embryos lower down. 20 And this circumstance leads many to suppose that fishes of this species pair and bear young every month, inasmuch as they do not produce all their young at once, but now and again and over a lengthened period. But such eggs as have come down below within the womb are simultaneously ripened and completed in growth.

1 See Joh. Müller's classic memoir, 'Ueber d. glatten Hai des Aristoteles (Mustelus laeris),' Abh.d. Berlin. Akad., 1840. Cf. Plut. Soll. An. 982 A.

${ }_{2}$ i.e. males are not restricted to the right nor females to the left side, as Anaxagoras would have it, cf. G. A. iv. I. $763^{\mathrm{b}} 34$.

${ }^{3}$ A. and W. del. $\pi 0 \lambda \lambda a ́$. 
Dog-fish in sencral can extrude and talic in again their 25 young, ${ }^{1}$ as can also the angel-fish and the electric ray-and, by the way, a large electric ray has been seen with about eighty embryos inside it - but the spiny dog-fish ${ }^{2}$ is an exception to the rule, being prevented by the spine of the young fish from so cloing. Of the flat cartilaginous fish, the trygon and the ray cannot extrude and take in again in consequence of the roughness of the tails of the young. The batrachus ${ }^{3}$ or fishing-frog also is unable to take in its 30 young owing to the size of the head and the prickles; and, by the way, as was previously remarked, it is the only one of these fishes that is not viviparous.

$566^{\mathrm{a}}$ So much for the varieties of the cartilaginous species and for their modes of generation from the egg.

At the breeding scason the sperm-ducts of the male are II filled with sperm, so much so that if they be squeczed the sperm flows out spontaneously as a white fluid; the ducts s are bifurcate, and start from the midriff and the great vein. About this period the sperm-clucts of the male are quite distinct [from the womb of the female], ${ }^{4}$ but at any other than the actual brecding time ${ }^{5}$ their distinctness is not obvious to a non-cxpert. The fact is that in certain fishes at certain times these organs are imperceptible, as was stated regarding the testicles of birds. ${ }^{6}$

Among other distinctions observed between the thoric ducts and the womb-ducts is the circumstance that the thoric ducts are attached to the loins, while the wombducts move about freely and are attached by a thin membrane. The particulars regarding the thoric ducts may

1 A common belief; for many reff., classical and patristic, see Bochart, Hicroz. pp. 1033-5: 'maxima de nihilo nascitur historia.'

${ }^{2}$ Acanthias vulgaris, Mod. Gk. äkavtius, It. spinello, spinarolo, \&.c. The spine is in front of the dorsal fin.

${ }^{3}$ Gaza tr. rain, i.e. Báros: cf. note anter, p. 564 18.

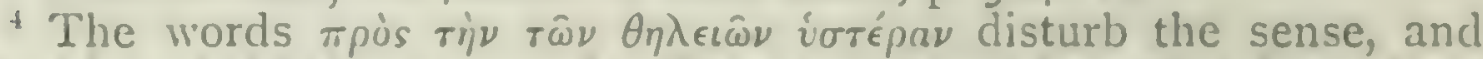
slould probably be cxpunged. They are absent from Cian's reading. 'patent eo tempore etiam imperitis, scilicet incremento seminis et turgentis fastu libidinis. Interdum enim ac nonnullis admodum incerti redduntur, ut de testiculis avium.?

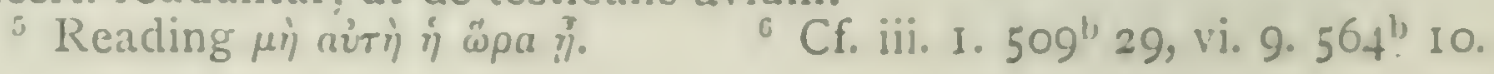


be studied by a reference to the diagrams in my treatise on Anatomy.

Cartilaginous fishes are capable of superfoetation, and is their period of gestation is six months at the longest. The so-called starry dog-fish bears young the most frequently; in other words it bears twice a month. ${ }^{1}$ The breedingseason is in the month of Maemacterion. ${ }^{2}$ The dog-fish as a general rule bear twice in the year, with the exception of 20 the little dog-fish, ${ }^{3}$ which bears only once a year. Some of them bring forth in the springtime. The rhine, or angelfish, bears its first brood in the springtime, and its second in the autumn, about the winter setting of the Pleiads; ${ }^{*}$ the second brood is the stronger of the two. The electric ray brings forth in the late autumn. ${ }^{5}$

Cartilaginous fishes come out from the main seas and deep waters towards the shore and there bring forth their young, and they do so for the sake of warmth and by way 25 of protection for their young.

Observations would lead to the general rule that no one variety of fish pairs with another variety. The angel-fish, however, and the batus or skate appear to pair with one another; for there is a fish called the rhinobatus, with the head and front parts of the skate and the after parts of the rhine or angel-fish, just as though it were made up of both 30 fishes together. ${ }^{6}$

Sharks then and their congeners, as the fox-shark ${ }^{i}$ and the dog-fish, and the flat fishes, such as the electric ray, the ray, the smooth skate, and the trygon, are first oviparous $566^{\mathrm{b}}$

${ }^{1}$ H.A. v. IO. $543^{\text {a }}$ I 7 .

2 September-October.

3 Galens canis and similar species.

4 About the end of December; cf. Ideler, i. p. 250.

5 Plin. ix. (5 I) 74 .

- pevoßatos is probably the modern genus Rhinobatus, the Squatinoraia of Willughby and other older writers, including $R$. Colummnat, and other species common in the Greek fish-markets. jivn is probably the angel-fish, Rhina squatina (Squatina laevis, Cuv.), which is itself somewhat intermediate in appearance between a shark and a skate. Cf. G. A. ii. $7.746^{\mathrm{b}} 5$; Plin. l.c.

"Probably Alopecius vulpes, which retains, among other names that of volpe, renard, \&c. 
and then viviparous in the way above mentioned, [as are also the saw-fish and the ox-ray]. ${ }^{1}$

The dolphin, the whale, and all the rest of the Cetacea, 12 all, that is to say, that are provided with a blow-hole instead of gills, are viviparous. ${ }^{2}$ That is to say, no one of all these fishes is ever scen to be supplied with eggs, but 5 directly with an embryo from whose differentiation comes the fish, just as in the case of mankind and the viviparous quadrupeds.

The dolphin bears one at a time generally, but occasionally two. ${ }^{3}$ The whale bears one or at the most two, generally two. The porpoise in this respect resembles the dolphin, and, by the way, it is in form like a little dolphin, and is Io found in the Euxine; ${ }^{4}$ it differs, however, from the dolphin as being less in size and broader in the back; its colour is leaden-black. Many people are of opinion that the porpoise is a variety of the dolphin.

All creatures that have a blow-hole respire and inspire, for they are provided with lungs." The dolphin has been I 5 seen asleep with his nose above water, and when asleep he snores. ${ }^{6}$

The dolphin and the porpoise are provided with milk, and suckle their young. ${ }^{7}$ They also take their young, when small, inside them. The young of the dolphin grows rapidly, being full-grown at $\operatorname{ten}^{8}$ years of age. 20 Its period of gestation is ten months. It brings forth its young in summer, and never at any other season; [and, singularly enough, under the Dog-star it disappears for about thirty days]. Its young accompany it for a con-

1 We have transferred these words, on Ditmeyer's suggestion, from the following sentence. On Bous cf. note to v. $5.540^{\mathrm{b}} \mathrm{I7}$.

2 Plin. ix. 15.

* H. A. viii. I $3.598^{\prime \prime}$ I.

3 Opp. Hal. i. 654.

H.A. iv. 10. $537^{b}$ I.

6 Perhaps an interpolation from iv. 10. $537^{2} 3 \mathrm{I}, \mathrm{A}$. and W.

7 Plin. ix. 7; Ael. v. 4; Opp. Hal. i. 656.

${ }^{3}$ A. and W. cj. $\delta$, i. e. four.

9 In this and some similar statements I am strongly inclined to look for an astronomical meaning; in other words, for a reference not to the animal itself but to its stellar namesake. The constellation of the Dolphin sets as the Dog-star rises, and therefore undergues its 
siderable period; and, in fact, the creature is remarkable for the strength of its parental affection. ${ }^{1} \quad$ It lives for many years; some are known to have lived for more than twenty-five, and some for thirty years; the fact is fisher- 25 men nick their tails sometimes and set them adrift again, and by this expedient their ages are ascertained.

The seal is an amphibious animal: that is to say, it cannot take in water, but breathes and sleeps and brings forth on dry land 2-only close to the shore-as being an animal furnished with feet; it spends, however, the greater part of its time in the sea and derives its food from it, so 30 that it must be classed in the category of marine animals. It is viviparous by immediate conception and brings forth its young alive, and exhibits an after-birth and all else just like a ewe. It bears one or two at a time, and three at $567^{a}$ the most. It has two teats, and suckles its young like a quadruped. Like the human species it brings forth at all seasons of the year, but especially at the time when the earliest kids are forthcoming. It conducts its young ones, when they are about twelve days old, over and over again 5 during the day down to the sea, accustoming them by slow degrees to the water. ${ }^{3}$ It slips down steep places instead of walking, from the fact that it cannot steady itself by its feet. It can contract and draw itself in, for it is fleshy and soft and its bones are gristly. ${ }^{4}$ Owing to the flabbiness of its body it is difficult to kill a seal by a blow, unless you ro strike it on the temple. It looks like a cow. The female in regard to its genital organs resembles the female of the ray; " in all other respects it resembles the female of the human species.

So much for the phenomena of generation and of parturi- 15 tion in animals that live in water and are viviparous either internally or externally.

period of occultation (or conjunction with the Sun) about the season when Sirius is rising at sunset, viz. in the beginning of the year.

1 Opp. Hal. i. 667 ; Ael.v. 6.

2 Plin. ix. I5; Ael. ix. 50.

s Opp. Hal. i. 69o; Ael. ix. 9.

4 Plin. xi. 87.

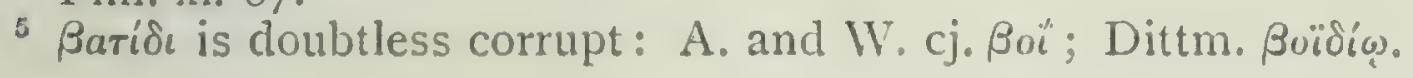
$A R, H, A$. 
Oviparous fishes have their womb bifurcate and placed 13 low down, as was said previously ${ }^{1}$-and, by the way, all scaly fish are oviparous, as the basse, the mullet, the grey 20 mullet, and the etelis, ${ }^{2}$ and all the so-called white-fish, and all the smooth or slippery fish except the eel ${ }^{3}$-and their roe is of a crumbling or granular substance. This appearance $^{4}$ is due to the fact that the whole womb of such fishes is full of eggs, so that in little fishes there seem to be only a couple of eggs there ; ${ }^{j}$ for in small fishes the womb is indistinguishable, from its diminutive size and thin contexture. The pairing of fishes has been discussed as previously. $^{6}$

Fishes for the most part are divided into males and females, but one is puzzled to account for the erythrinus and the channa, for specimens of these species are never caught except in a condition of pregnancy.

With such fish as pair, eggs are the result of copulation, but such fish have them also without copulation ; ${ }^{8}$ and this 30 is shown in the case of some river-fish, for the minnow? has eggs when quite small,-almost, one may say, as soon as it is born. These fishes shed "1" their eggs little by little. and, as is stated, the males swallow the greater part of them, ${ }^{11}$ and some portion of them goes to waste in the $567^{\mathrm{b}}$ water; but such of the eggs as the female deposits on the spawning beds are sarcd. ${ }^{22}$ If all the eggs were preserved,

1 H. A. iii. I. 5 IO $^{\mathrm{b}} 20$, vi. 10. $564^{\mathrm{b}}$ I9.

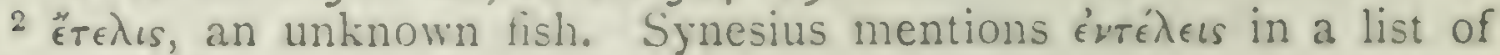
African fishes.

${ }^{3}$ H.A. iv. II. $538^{a} 3$.

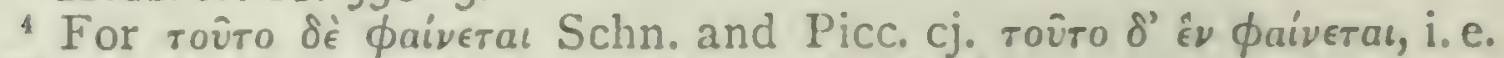
- This looks like one single egrs [on cach side]'.

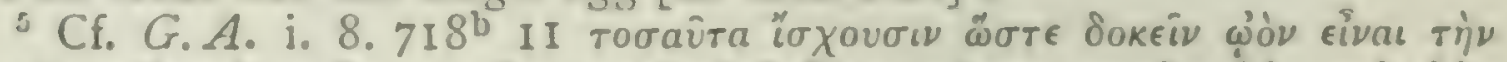

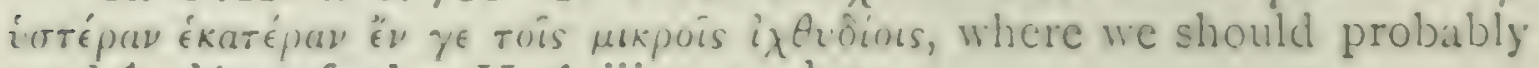
read $\hat{\epsilon} \nu \omega^{\circ} \nu$ : cf. also $H . \Lambda$. iii. I. $510^{11} 25$.

. H. A. v. 5 .

7 Serranidac, vide iv. I1. $538^{a} 20$; cf. G. A. iii. I. $750^{\text {b }} 30$, Sic.

${ }^{8}$ G. A. iii. 5. $756^{2} 17$, \&.c.

' to kivos' 'impossible à reconnaitre,' Cuv. and Val. xiii. p. 36S; usually identified with the minnow.

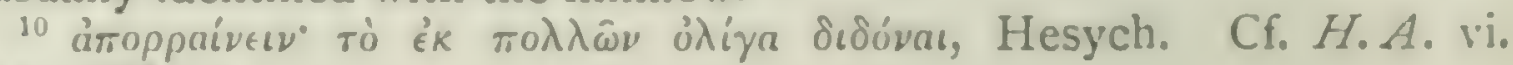
I4. $568^{3}$ I 3 .

11 Cf. Herod. ii. 93.

1: I have translated the MS. reading, but should rather expect

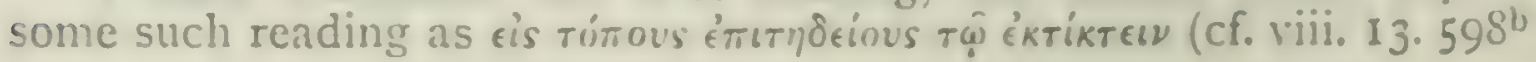


each species would be infinite in number. The greater number of these eggs so deposited are not productive, but only those over which the male sheds the milt or sperm; for when the female has laid her eggs, the male follows and sheds its sperm over them, and from all the eggs so 5 besprinkled young fishes proceed, while the rest are left to their fate. ${ }^{1}$

2 The same phenomenon is observed in the case of molluscs also; for in the case of the cuttlefish or sepia, after the female has deposited her eggs, the male besprinkles them. ${ }^{3}$ It is highly probable that a similar phenomenon takes place in regard to molluscs in general, though up to the 10 present time the phenomenon has been observed only in the case of the cuttlefish.

Fishes deposit their eggs close in to shore, the goby close to stones; and, by the way, the spawn of the goby is flat and crumbly. Fish in general so deposit their eggs; for the water close in to shore is warm and is better supplied with food than the outer sea, and serves as a protection to the spawn against the voracity of the larger fish. And it is I5 for this reason that in the Euxine most fishes spawn near the mouth of the river Thermodon, because the locality is sheltered, genial, and supplied with fresh water.

Oviparous fish as a rule spawn only once a year. The little phycis or black goby is an exception, as it spawns twice; the male of the black goby ${ }^{*}$ differs from the female 20 as being blacker and having larger scales.

Fishes then in general produce their young by copulation, and lay their eggs; but the pipe-fish, as some call it, when the time of parturition arrives, bursts in two, and the eggs

4), and from some such text Gaza and Albertus translate. Dittm. cj.

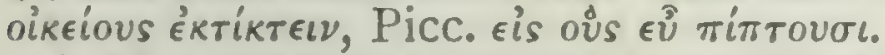

1 The meaning is doubtful, and the phrase probably does not mean much. We should be reluctant to read in it the assertion that unfertilized eggs sometimes do and sometimes do not develop, especially in view of the foregoing sentence, of $568^{\mathrm{b}} 8$, and of parallel passages in the $G . A$.; while on the other hand the Greek is somewhat strained by the rendering above given, which, however, I take to express the ideal that was present to the author's mind.

2 A. and W. bracket $567^{\mathrm{b}} 8-22$, Dittm. I2-22.

${ }^{3}$ G. A. iii. 8. $75^{\mathrm{a}}$ I5.

4 húkns, Gabius niger (Apostolides).

Cf. Arist. ap. Athen. vii. $319^{\circ}$. 
escape out. ${ }^{1}$ For the fish has a diaphysis or cloven growth 25 under the belly and abdomen (like the blind snakes), ${ }^{2}$ and, after it has spawned by the splitting of this diaphysis, the sides of the split ${ }^{3}$ grow together again.

Development from the egg takes place similarly with fishes that are oviparous internally and with fishes that are oviparous externally; that is to say, the embryo comes at the upper end of the egg and is enveloped in a membrane, 30 and the eyes, large and spherical, are the first organs visible. From this circumstance it is plain that the assertion is untenable which is made by some writers, to wit, that the young of oviparcus fishes are generated like the grubs of worms; for the opposite phenomena are observed in the case of these grubs, in that their lower extremitics are the larger at the outset, and that the eyes and the head appear later on. ${ }^{4}$

$568^{a}$ After the egg has been used up, the young fishes are like tadpoles ${ }^{5}$ in shape, and at first, without taking any nutriment, they grow by sustenance derived from the juice oozing from the egg; by and by, they are nourished up to full growth by the river-waters.

When the Euxine is 'purged' "6 a substance called phycus 5 is carried into the Hellespont, and this substance is of a pale yellow colour. Some writers aver that it is the flower of the phycus, from which rouge is made ; it comes at the

1 Cf. Cuvier. ad Plin. ix. 76 'Syngnatho acui, L., et generaliter omnibus syngnathis, post anum sub cauda fossa inest quam duplex valva claudit mobilis, in qua ova ponunt dum pariunt. Mox patentibus sponte valvis, erumpunt ova aut pisciculi. Unde creditum scisso tantum ventre iis edi ova aut fetus.' The fact was rediscovered by Cavolini, and establishes the identity of $\beta \in \lambda(i m \eta$, in this and similar passages, with the pipe-fish, Syngnathus. H. A. vi. $17.57^{2} 3:(i . A$. iii. $3.755^{a} 32$; Plin. ix. $76(52)$.

2 Probably Pseudopus pallasi; cf. Acl. viii. I 3 and Schneider's note.

- Plin. ix. 76 'a partu coalescit vulnus'. Hence Schn. cj. here

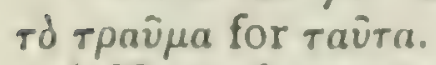

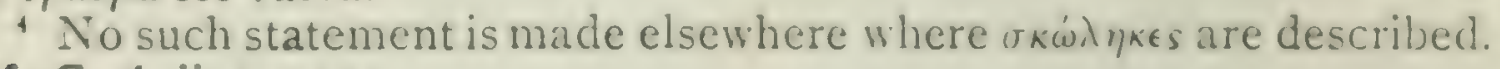
Cf. G. A. ii. I. 732 .

- yúpıvor, tadpoles, are not mentioned elsewhere by A., and the whole passage is open to suspicion.

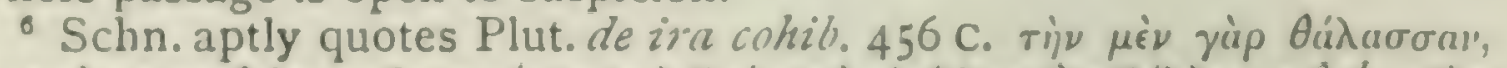

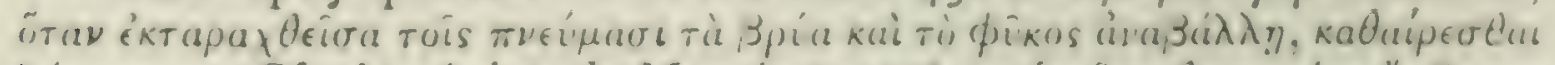

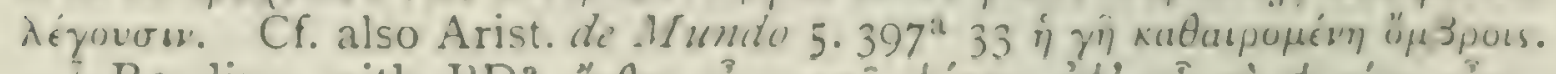

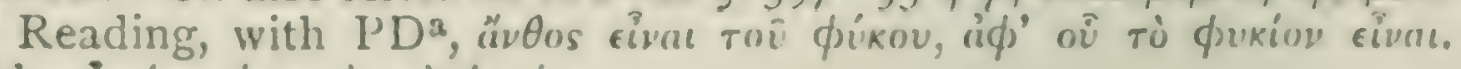

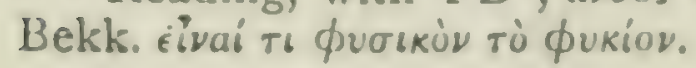


beginning of summer. Oysters and the small fish of these localities feed on this substance, and some of the inhabitants of these maritime districts say that the purple murex derives its peculiar colour from it. ${ }^{1}$

I4 Marsh-fishes and river-fishes conceive at the age of five months as a general rule, and deposit their spawn towards the close of the year without exception. ${ }^{2}$ And with these fishes, like as with the marine fishes, the female does not void all her eggs at one time, nor the male his sperm; but 15 they are at all times more or less provided, the female with eggs, and the male with sperm. The carp spawns as the seasons come round, five or six times, and follows in spawning the rising of the greater constellations." The chalcis spawns three times, and the other fishes once only in the year. They all spawn in pools left by the overflowing of 20 rivers, and near to reedy places in marshes; as for instance the phoxinus or minnow and the perch.

The glanis or sheat-fish ${ }^{4}$ and the perch deposit their spawn in one continuous string, like the frog; so continuous, in fact, is the convoluted spawn of the perch that," by reason of its smoothness, the fishermen in the marshes can unwind it off the reeds like threads off a reel. The 25 larger individuals of the sheat-fish spawn in deep waters, some in water of a fathom's depth, the smaller in shallower water, generally close to the roots of the willow or of some other tree, or close to reeds or to moss. At times

$1 \mathrm{~A}$. and W. bracket this paragraph; it may be out of place, but it is of no small interest and value. Phychs is mentioned as a sea-weed yielding a rouge or purple dye, Theoph. H.P. iv. 7 ; Plin. xiii. 25, \&c.

${ }^{2}$ Cf. viii. I5.

3 e.g. the Pleiads, Arcturus, and the Dog-star, Plin. xi. I4.

4 The common European Silurus glanis deposits its eggs in a hole, and leaves them after fertilization without further care. But there is another species in Greece, Purusilurus Aristotelis (Agassiz), and Agassiz and Cill argue that we learn from Aristotle the habits of this fish, habits which agree with those of its allies, the N. American catfishes. This fish is still called $\gamma \lambda a^{\prime} v o s, \gamma \lambda a^{\prime} v i \delta \iota, \& c_{0}$, and is common in the Achelous, the Peneus, and elsewhere. Cf. L. Agassiz, Proc. Am. Acad. of Arts and Sc. iii.pp. 325-34, I85; Th. Gill, Washington Univ. Bull. v. pp. 5-13, 1907.

5 The roe of the perch consists of a concatenation of little egrgs, like poppy-sceds, enveloped in at grelatinous meshwork; it has a considerable resemblance to frog-spawn. 
30 these fishes intertwine with one another, a big with a little one, and bring into juxtaposition the ducts-which some writers designate as navels - at the point where they emit $568^{\mathrm{b}}$ the gencrative products and discharge the egg in the case of the female and the milt in the case of the male. Such eggs as are besprinkled with the milt grow, in a day or thereabouts, whiter and larger, and in a little while afterwards the fish's eycs become visible, for these organs in 5 all fishes, as for that matter in all other animals, are carly conspicuous and secm disproportionatcly big. But such eggs as the milt fails to touch remain, as with marine fishes, useless and infertile. From the fertile eggs, as the little fish grow, a kind of sheath detaches itself; this is a so membrane that envelops the egg and the young fish. When the milt has mingled with the eggs, the resulting product becomes very sticky or viscous, and adheres to the roots of trees or wherever it may have been laid. The male keeps on guard at the principal spawning-place, and the female after spawning goes away.

1: In the case of the sheat-fish the growth from the eges is exceptionally slow, and, in consequence, the male has to kecp watch for forty or fifty days to prevent the spawn being devoured by such little fishes as chance to come by. ${ }^{1}$ N'cxt in point of slowness is the gencration of the carp. As with fishes in general, so even with these, the spawn thus protected disappears and gets lost rapidly. ${ }^{2}$

In the case of some of the smaller fishes " when they are only three days old young fishes are generated. liggs 20 touched by the male sperm take on increase both the same day and also later. The egg of the sheat-fish is as big as a vetch-seed; the egrg of the carp and of the carp-species as big as a millet-seed.

These fishes then spawn and generate in the way here described. The chalcis," however, spawns in deep water

Cf. ix. $37.621^{2} 25$.

2 The text and translation are alike doubtful. Dittm. tr. 'acque celeriter atque glani etiam cyprini exclusi diffugiunt'.

${ }^{3}$ Dittm. suggests the insertion of $\omega^{\prime} \omega \nu$ after $\tau \hat{\omega} \nu \delta^{\circ}$.

i The MSS. have also yauris. which sugrests a possible misteading

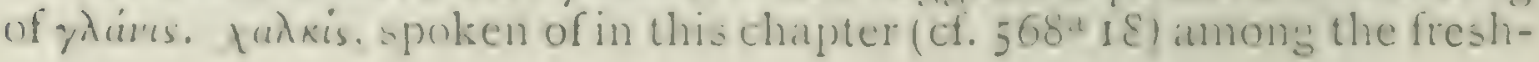


in dense shoals of fish $;^{1}$ and the so-called tilon ${ }^{2}$ spawns 25 near to beaches in sheltered spots in shoals likewise. The carp, the baleros, and fishes in general push eagerly into the shallows for the purpose of spawning, and very often thirteen or fourteen males are seen following a single female. When the female deposits her spawn and departs, zo the males follow on and shed the milt. The greater portion of the spawn gets wasted; because, owing to the fact that the female moves about while spawning, the spawn scatters, $569^{a}$ or so much of it as is caught in the stream and docs not get entangled with some rubbish. For, with the exception of the sheat-fish, no fish keeps on guard; unless, by the way, it be the carp, which is said to remain on guard, ${ }^{3}$ if it so happen that its spawn lies in a solid mass.

All male fishes are supplied with milt, excepting the 5 eel : ${ }^{4}$ with the eel, the male is devoid of milt, and the female of spawn. The mullet goes up from the sca to marshes and rivers; the eels, on the contrary, make their way down from the marshes and rivers to the sea.

I5 The great majority of fish, then, as has been stated, io proceed from eggs. However, there are some fish that proceed from mud and sand, even of those kinds that proceed also from pairing and the egg. This occurs in ponds here and there, and especially in a pond in the neighbourhood of Cnidos. This pond, it is said, at one time ran dry about the rising of the Dog-star, and the mud had all dried up; ${ }^{6}$ at the first fall of the ${ }_{5} 5$ rains $^{7}$ there was a show of water in the pond, and on the first appearance of the water shoals of tiny fish were found in the pond. The fish in question was

water fish, is elsewhere referred to as marine. Cf, iv. 9. $535^{\mathrm{b}} \mathrm{I} 8$, viii. $20.602^{\mathrm{b}} 28, \mathrm{ix} .37 .62 \mathrm{I}^{\mathrm{b}} 7$.

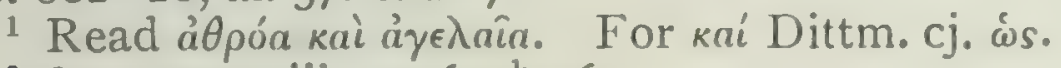

2 See note, viii. 20. $602^{\mathrm{b}} 26$.

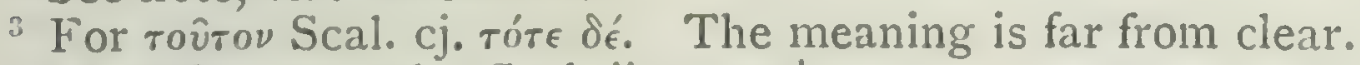

- Cf. infra, cap. I6; G. A. ii. 5. $74 \mathrm{I}^{\mathrm{b}} \mathrm{I}$.

5 B. St. Hilaire and Dittm. regard this chapter as spurious.

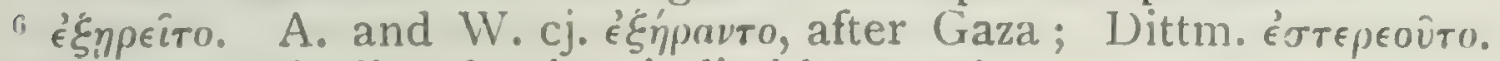
Scal. tr. 'ne quis dicat latuisse in limi humore'.

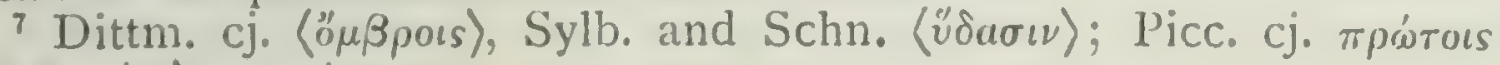

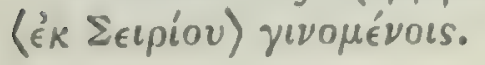


a kind of mullet, one which does not proceed from normal pairing, about the size of a small sprat: and not one of these fishes was provided with either spawn or milt. There are found also in Asia Minor, in rivers not communicating 20 with the sea, little fishes like whitebait. ${ }^{1}$ differing from the small fry found near Cnidos but found under similar circumstances. Some writers actually aver that mullet all grow spontaneously. ${ }^{2}$ In this assertion they are mistaken, for the female of the fish is found provided with spawn, and the male with milt. However, there is a species of mullct that grows spontaneously out of mud and sand.

2.5 From the facts above enumerated it is quite proved that certain fishes come spontaneously into existence, not being derived from eggs or from copulation. Such fish as are neither oviparous nor viviparous arise all from one of two sources, from mud, or from sand and from decayed matter that rises thence as a scum; for instance, the so-called froth of the small fry ${ }^{\circ}$ comes out of sandy ground. This so fry is incapable of growth and of propagating its lind; $569^{b}$ after living for a while it dies away and another creature takes its place, and so, with short intervals excepted, it may be said to last the whole ycar through. At all events; it lasts from the autumn rising of Arcturus ${ }^{4}$ up to the spring-time. As a proof that these fish occasionally come 5 out of the ground we have the fact that in cold weather they are not caught, and that they are caught in warm weather, obviously coming up out of the ground to catch the heat; also, when the fishermen use dredges and the ground is scraped up fairly often, the fishes appear in larger numbers and of superior quality. All other small fry are inferior in quality owing to rapidity of growth.

${ }^{2} \dot{\psi} \psi \eta \operatorname{ró}^{*}$ "Non est nomen piscis sed artis in genere piscium coquendo ad epulas,' Scal. Cf. Terent. Andr. ii. 2. 32 'pisciculos minutos ferre obolo in coenam seni', so translating Menander, tò

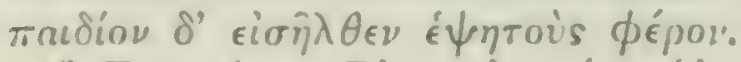

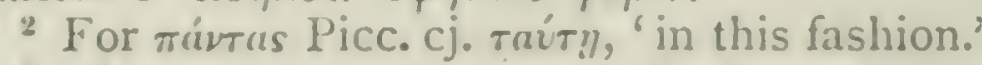

3 cipún. Young fry, especially those of the atherine or sand-smelt, are stull called nommoti in the Adriatic, nowmuts at Marseilles I Faber. The young atherines cling together in clense masses and in incredible numbers; they are sold chiefly to the poor, fried, baked in milk, or preserved in vil. Carus ascribes the name nom mati to Gobius pelluidus, Niurdo.

4 Middle of September. 
The fry are found in sheltered and marshy ${ }^{1}$ districts, 10 when after a spell of fine weather the ground is getting warmer, as, for instance, in the neighbourhood of Athens, at Salamis and near the tomb of Themistocles and at Marathon; for in these districts the froth is found. ${ }^{2}$ It appears, then, in such districts and during such weather, and occasionally appears after a heavy fall of rain in the 15 froth that is thrown up by the falling rain, from which circumstance the substance derives its specific name." Foam is occasionally brought in on the surface of the sca in fair weather. [And ${ }^{4}$ in this, where it has formed on the surface, the so-called froth collects, as grubs swarm in manure; for which reason this fry is often brought in from 20 the open sea. The fish is at its best in quality and quantity in moist warm weather.]

The ordinary fry is the normal issue of parent fishes: the so-called gudgeon-fry of small insignificant gudgeon-like fish that burrow under the ground. From the Phaleric fry comes the membras, ${ }^{5}$ from the membras the trichis, from 25 the trichis the trichias, and from one particular sort of fry, to wit from that found in the harbour of Athens, comes what is called the encrasicholus, or anchovy. ${ }^{6}$ There is another fry, derived from the maenis ${ }^{7}$ and the mullet.

The unfertile fry is watery and leeps only a short time, as has been stated, for at last only head and eyes are left. 30 However, the fishermen of late have hit upon a method of $570^{\text {a }}$

1 The reading a' $\lambda \epsilon \epsilon \iota \nu$ is, mild, warm, of $\mathrm{D}^{\mathrm{a}}$ and the Aldine, seems

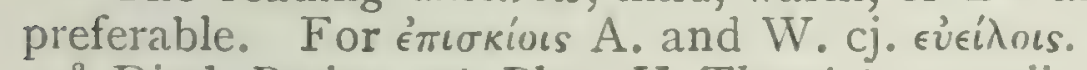

${ }^{2}$ Diod. Perieg. ap. Plut. V. Themist. c. xxxii; Paus. Attic. i. I.

3 i. e. àфpós, froth or foam.

4 The text is manifestly spurious, and the rendering here given is conjectural.

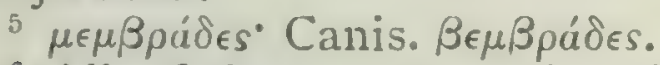

${ }^{6}$ All of these seem to be clupeoid fishes, but are otherwise unrecognizable. In M. Gk. Opiora, $\phi i^{\prime} \sigma \sigma a$ is applied to Sardinella

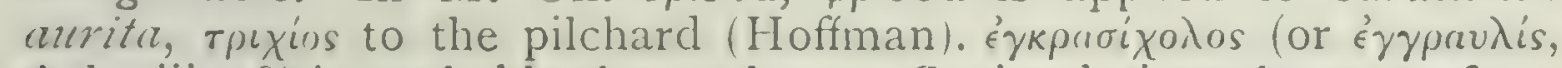
Ael. viii. 18) is probably the anchovy; Cuvier derives the name from $\dot{\epsilon} \nu$ kpari $\chi^{\prime}$ inos, in allusion to the method of gutting, by nipping off the head, to which the liver, \&c. remain attached.

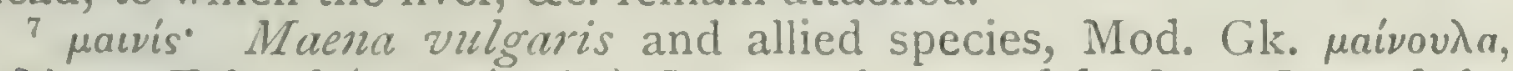

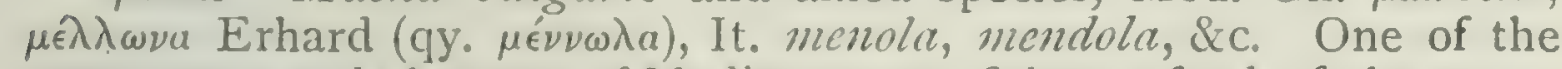
commonest and cheapest of Mediterranean fishes, a food of the poor; hence the Venetian byword mangia mendole: cf. Athen. vii. p. 3 I3. 
transporting it to a distance, as when salted it keeps for a considerable time.

Ecls are not the issue of pairing, neither are they ovi- I6 parous; nor was an eel ever found supplied with either milt or spawn, nor are they when cut open found to have 5 within them passages for spawn or for eggs. In point of fact, this entire ${ }^{1}$ species of blooded animals proceeds neither from pairing nor from the egg.

There can be no doubt that the case is so. For in some standing pools, after the water has been drained off and the mud has been dredged away, the eels appear again 10 after a fall of rain. In time of drought they do not appear even in stagnant ponds, for the simple reason that their existence and sustenance is derived from rain-water.

There is no doubt, then, that they proceed neither from pairing nor from an cgg. Some writers, however, are of opinion that they generate their kind, because in some cels little worms are found, from which they suppose that cels 15 are derived." But this opinion is not founded on fact. Eels are derived from the so-called 'carth's guts' that grow spontancously in mud and in humid ground;" in fact, cels have at times been seen to cmerge out of such earthworms, and on other occasions have been rendered visible when the earthworms were laid open by either scraping or cutting. Such earthworms are found both in the sea and in rivers: zo especially where there is decayed matter: in the sea in places where sea-weed abounds, and in rivers and marshes near to the edge; for it is near to the water's edge that sun-heat has its chief power and produces putrefaction. So much for the generation of the eel.

25 Fish do not all bring forth their young at the same 17 scason nor all in like manner, neither is the period of gestation for all of the same duration.

Before pairing the males and females gather together in shoals; at the time for copulation and parturition they

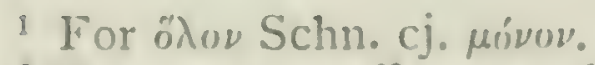

2 H. A.v. II. $538^{n} 4$.

3 For many reff. see Schneider at lui., in Hist. litt. l'iscium, pp. 35,323 . 
pair off. With some fishes the time of gestation ' is not longer than thirty days, with others it is a lesser period; but with all it extends over a number of days divisible by zo seven. The longest period of gestation is that of the species which some call a marimus. ${ }^{2}$

The sargue conceives during the month of Poseideon (or December), ${ }^{3}$ and carries its spawn for thirty days; and the $570^{b}$ species of mullet named by some the chelon, and the myxon, ${ }^{4}$ go with spawn at the same period and over the same length of time.

All fish suffer greatly during the period of gestation, and are in consequence very apt to be thrown up on shore at this time. In some cases they are driven frantic with pain 5 and throw themselves on land. At all events they are throughout this time continually in motion until parturition is over (this being especially true of the mullet), and after parturition they are in repose. With many fish the time for parturition terminates on the appearance of grubs within the belly; ${ }^{5}$ for small living grubs get generated there and eat up ${ }^{6}$ the spawn.

With shoal fishes parturition takes place in the spring, and indeed, with most fishes, about the time of the spring equinox ${ }^{7}$ with others it is at different times, in summer with some, and with others about the autumn equinox.

The first of shoal fishes to spawn is the atherine, ${ }^{8}$ and it spawns close to land; the last is the cephalus: and this is 15 inferred from the fact that the brood of the atherine appears first of all and the brood of the cephalus last. The

1 H. A. v. 9.

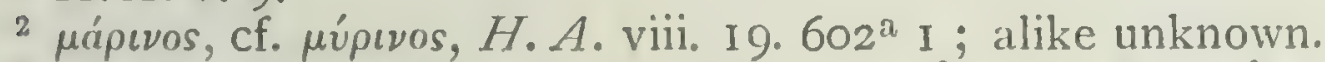

${ }^{3} H . A$. v. II. $543^{\mathrm{b}}$ I 4 : cf. v. $9 \cdot 543^{\mathrm{a}} 7$, b 8 , vi. $2.59 \mathrm{I}^{\mathrm{b}}$ I9, where apparently a different fish is referred to.

${ }^{4} \mu \dot{\xi} \xi \omega \nu$. Apparently another species of grey mullet. According to Apostolides ifugil salicns is called $\mu v \dot{\xi} \iota v(i p)$ at Missolonghi and at Chalcis.

5 Athen. vii. $324^{\mathrm{e}}$. Cf. Schn. H. Pisc. p. 89.

${ }^{6}$ I read $\epsilon^{\prime} \xi \epsilon \sigma \theta i \in \iota$ for $\epsilon^{\prime} \xi \in \lambda a v \dot{\nu} \epsilon$, as suggested by A. and W. C. Arist.

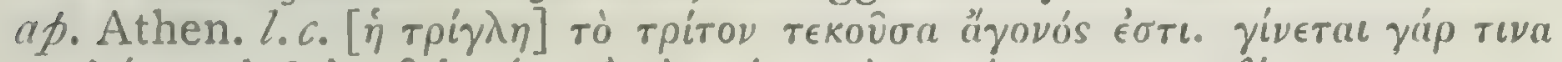

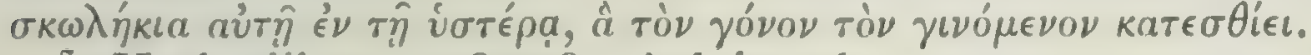

7 H. A. viii. 13. $598^{a} 28$; Ael. ix. 46.

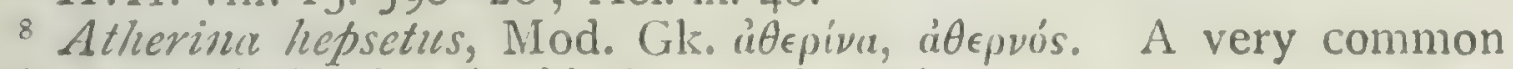

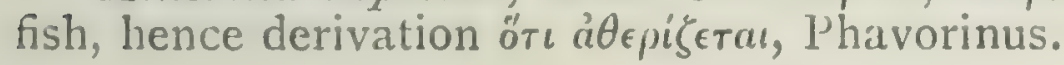


mullet also spawns early. ${ }^{1}$ The saupe spawns usually at the beginning of summer, but occasionally in the autumn. The aulopias, which some call the anthias, ${ }^{2}$ spawns in the 20 summer. Next in order of spawning comes the chrysophrys" or gilthead, the basse, ${ }^{4}$ the mormyrus," and in general such fish as are nicknamed 'runners'. ${ }^{6}$ Latest in order of the shoal fish come the red mullet ${ }^{7}$ and the coracine; these spawn in autumn. The red mullet spawns on mud, and consequently, as the mud continues cold for a long while, spawns late in the year. The coracine carrics its spawn for a long time; but, as it lires usually on rocky ground, it goes to a distance and spawns in places abounding 25 in sea-weed, at a period later than the red mullet. The maenis spawns about the winter solstice. Of the others, such as are pelagic spawn for the most part in summer; which fact is proved by their not being caught by fishermen during this period.

Of ordinary fishes the most prolific is the sprat; of carzo tilaginous fishes, the fishing-frog. Specimens, however, of the fishing-frog are rare from the facility with which the young are destroyed, as the female lays her spawn all in a lump close in to shore. ${ }^{\circ}$ As a rule, cartilaginous fish are less prolific than other fish owing to their being viviparous: $571^{\mathrm{a}}$ and their young by reason of their sizc have a better chance of escaping destruction.

The so-called needle-fish (or pipe-fish) is late in spawning: and the greater portion of them are burst asunder by the eggs before spawning; and the eggs are not so many in number as large in size.? The young fish cluster round the 5 parent like so many young spiders, for the fish spawns on

1 H. A. v. 9. $543^{\mathrm{a}} 8$, I I. $543^{\mathrm{b}} 8$.

2 According to Cuvier, Serranus anthias, C.V. (Anthius sacer, Bloch). The description in Ael. xiii. 17 is of a much larger fish, which Cuvier takes to be Thymmus alalonga, the Albicore. According to Dorio $a p$. Athen. vii. $282^{\mathrm{c}}$, the fish is identical with $\kappa \alpha \lambda \lambda i x \theta u s, \kappa a \lambda-$ $\lambda_{\iota} \omega_{\nu} \nu \mu o s$ and $\epsilon^{\prime} \lambda o \psi$, but cf. ibid. $282^{\circ}$.

${ }^{3}$ H.A. v. I0. $543^{\text {b }} 3$.

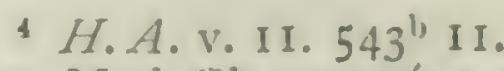

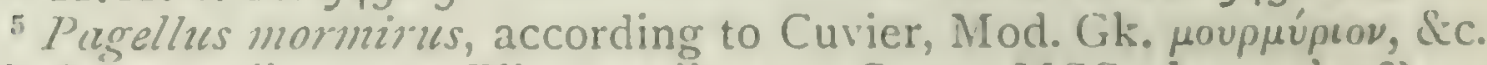
Cf. Athen. vii. 313; Plin. xxxii. 11. Some MSS. have ó $\sigma \mu \hat{u} \lambda o s$;

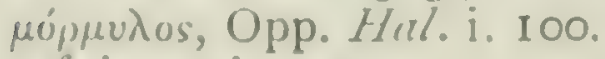
i. e. migrants.

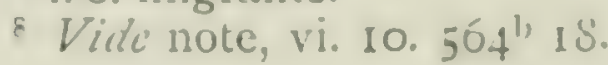

$$
\begin{gathered}
\text { i } 11.21 . v \cdot 9 \cdot 543^{i h} 5 \\
\text { Virte note, } 13 \cdot 567^{i}=2
\end{gathered}
$$


to herself; and, if any one touch the young, they swim away. The atherine spawns by rubbing its belly against the sand.

Tunny fish also burst asunder by reason of their fat. They live for two years $;^{1}$ and the fishermen infer this age from the circumstance that once when there was a failure of the young tunny fish for a year there was a failure of the 10 full-grown tunny the next summer. ${ }^{2}$ They are of opinion that the tunny is a fish a year older than the pelamyd. The tunny and the mackerel ${ }^{3}$ pair about the close of the month of Elaphebolion, ${ }^{4}$ and spawn about the commencement of the month of Hecatombaeon; ${ }^{5}$ they deposit their spawn in a sort of bag. ${ }^{6}$ The growth of the young tunny is rapid. After the females have spawned in the Euxine, there s. comes from the egg what some call scordylae, but what the Byzantines nickname the 'auxids' or 'growers', from their growing to a considerable size in a few days; these fish go out of the Pontus in autumn along with the young tunnies, and enter Pontus in the spring as pelamyds. Fishes as a rule take on growth with rapidity, ${ }^{7}$ but this is peculiarly 20 the case with all species of fish found in the Pontus; the growth, for instance, of the amia-tunny ${ }^{8}$ is quite visible from day to day.

To resume, we must bear in mind that the same fish in the same localities have not the same season for pairing, for conception, for parturition, or for favouring weather. The coracine, for instance, in some places spawns about wheatharvest. The statements here given pretend only to give the results of general observation.

The conger also spawns, but the fact is not equally obvious in all localitics, nor is the spawn plainly visible owing to the fat of the fish; for the spawn is lanky in shape as it is with serpents. However, if it be put on the fire it 30

1 Plin. ix. I5.

2 Sostrat. $a p$. Athen. vii. 303 .

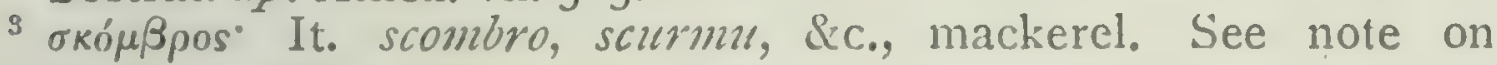

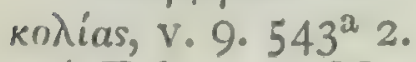

* February-March.

${ }^{6} H . A$. v. II. $543^{\mathrm{b}}$ I3, and note.

${ }^{5}$ June-July.

${ }^{8}$ For $\pi \circ \lambda u ́$ we should perhaps read $\pi \dot{u} v v$. Cf. Schn. Hist. litt. Pisc. p. 345 . 
shows its nature; for the fat evaporates and melts, while the eggs dance about and explode with a crack. Further, if you touch the substances and rub them with your fingers, the fat feels smooth and the egg rough. Some congers are $57 \mathrm{I}^{\mathrm{b}}$ provided with fat but not with any spawn, others are unprovided with fat but have egg-spawn as here described.

We have, then, treated pretty fully of the animals i 8 that fly in the air or swim in the water, and of such of those that walk on dry land as are oviparous, to wit of their 5 pairing, conception, and the like phenomena; it now remains to treat of the same phenomena in connexion with viviparous land animals and with man.

The statements made in regard to the pairing of the sexes apply partly to the particular kinds of animal and partly to all in general. It is common to all animals to be most excited by the desire of one sex for the other and by the so pleasure derived from copulation. The female is most cross-tempered just after parturition. the male during the time of pairing; for instance, stallions at this period bite one another, throw their riders, and chase them. Wild boars, ${ }^{1}$ though usually enfecbled at this time as the result of copulation, are now unusually fierce, and fight with one 15 another in an extraordinary way; clothing themselves with defensive armour, or in other words deliberately thickening their hide by rubbing against trees or by coating themselves repeatedly all over with mud and then drying themselves in the sun. They drive one another away from the swine 20 pastures, and fight with such fury that very often both combatants succumb. The case is similar with bulls, rams, and he-goats; for, though at ordinary times they herd together. at breeding time they hold aloof from and quarrel with one another. The male camel also is cross-tempered at pairing 25 time if either a man or a camel comes near him; as for a horse, ${ }^{2}$ a camel is ready to fight him at any time. It is the same with wild animals. The bear, the wolf, and the lion

I Antig. H. Mir. IO2 (I IO).

2 Herod. i. 80 ; Xen. Cyr. vi. 2. I8, vii. I. 27 ; Ael. iii. 7, xi. 36 ; Plin, viii, 26. 
are all at this time ferocious towards such as come in their way, but the males of these animals are less given to fight with one another from the fact that they are at no time gregarious. The she-bear is fierce after cubbing, and the 30 bitch after pupping.

Male elephants get savage about pairing time, and for this reason it is stated that men who have charge of elephants in India never allow the males to have intercourse with the females; on the ground that the males go wild at this time and turn topsy-turvy the dwellings of their keepers, $572^{\mathrm{a}}$ lightly constructed as they are, and commit all kinds of havoc. They also state that abundancy of food has a tendency to tame the males. ${ }^{1}$ They further introduce other elephants amongst the wild ones, and punish and break them in by setting on the new-comers to chastise the others.

Animals that pair frequently and not at a single specific 5 season, as for instance animals domesticated by man, such as swine and dogs, are found to indulge in such freaks to a lesser degree owing to the frequency of their sexual intercourse.

Of female animals the mare is the most sexually wanton, and next in order comes the cow. In fact, the mare is said to go a-horsing $;^{2}$ and the term derived from the habits of 10 this one animal serves as a term of abuse applicable to such females of the human species as are unbridled in the way of sexual appetite. This is the common phenomenon as observed in the sow when she is said to go a-boaring." The mare is said also about this time to get wind-impregnated if not impregnated by the stallion, ${ }^{4}$ and for this reason in

1 Cf. Ael. x. 10, xii. 14.

2 Ael. iv. I I cf. also G. A. iv. $5 \cdot 773^{\mathrm{b}} 25$.

3 I have transposed this sentence, which in the MSS. and edd. follows the next.

4 The fable of mares impregnated by the wind is widespread. Cf. Varro, R.R. ii. I 'In Lusitania ad Oceanum in ea regione ubi est oppidum Olysippo in monte sacro quaedam a vento concipiunt certo tempore equae, ut hic gallinae quoque solent quarum ova ínvé $\mu$ a appellant. Sed ex his equis qui nati pulli non plus triennio virunt.' See also Plin. viii. 67; Solin. xxiii. 43; Colum. vi. 27; August. de Civ. Dei, xxi. 5 'In Cappadocia vento equae concipiunt', \&c. Cf. Justin, xliv. 3 (ex Trogo) 'in Lusitanis iuxta fluvium Tagum, vento equas fetus 
Crete they never remove the stallion from the mares; for when the mare gets into this condition she runs away from 15 all other horses. The mares under these circumstances fly invariably either northwards or southwards, and never towards either east or west. When this complaint is on them they allow no one to approach, until either they are exhausted with fatigue ${ }^{1}$ or have reached the sca. Under either of these circumstances they discharge a certain sub20 stance called 'hippomanes', the title given to a growth on a new-born foal ${ }^{2}$ this resembles the sow-virus, and is in great request amongst women who deal in drugs and potions. About horsing time the mares huddle closer together, are continually switching their tails, their neigh is abnormal in 25 sound, and from the sexual organ there flows a liquid resembling genital sperm, but much thinner than the sperm of the male. It is this substance that some call hippomanes, instead of the growth found on the foal ; they say it is extremely difficult to get as it oozes out only in small drops at a time. Nares also, when in heat, discharge 30 urine frequently, and frisk with one another. Such are the phenomena connected with the horse.

Cows go a-bulling; and so completely are they under the influence of the sexual excitement that the herdsmen have no control over them and cannot catch hold of them

concipere multi auctores prodidere; quac fabulae exequarum fecunclitate et gregum multitudine natae sunt : qui tanti in (ialloecia et Lusitania, ac tam pernices visuntur ut non immerito vento ipso concepti videantur ${ }^{*}$ : Sil. Ital. iii. 381 (where the offspring are said to live for seven years). We may trace the fable back to the story of $I l . \mathrm{xx} .223$, the mares of

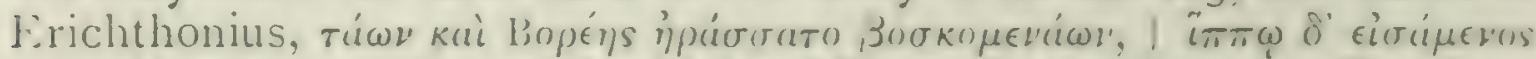

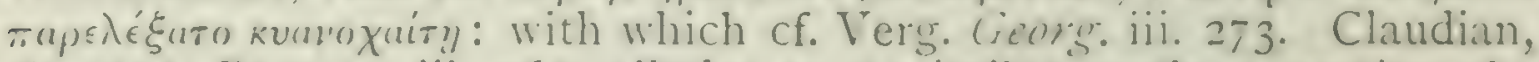
de rapt. I'rosupt. iii. 265 , alludes to a similar myth respecting the tiger. Cf. note on i $\pi \eta \nu \epsilon \epsilon u$, supra, 3, $559^{b} 30$.

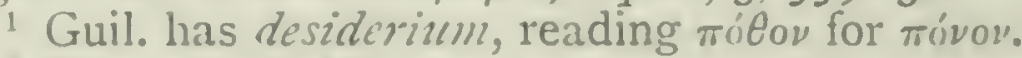

2 Plin. viii. $66^{\prime}$ Eit sane equis amoris innasci veneficium, hippomanes appellatum, in fronte. caricae magnitudine, colore nigro; quod statim edito partu devorat feta, aut partum ad ubera non admittit'. Cf.

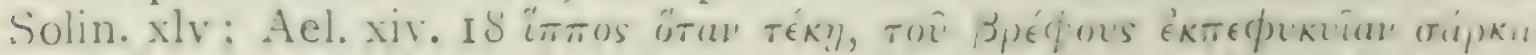

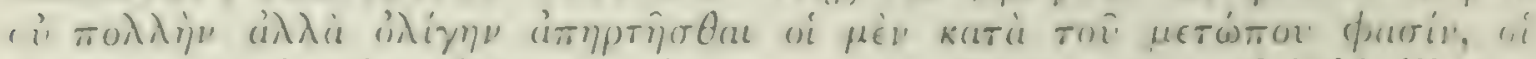

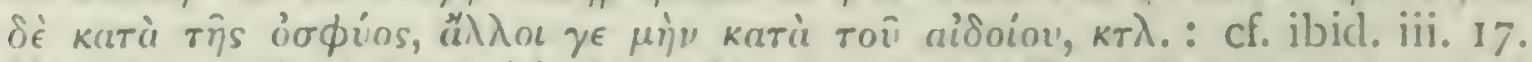
Vergil mentions buth kinds: Acm. iv. 515 'Quaeritur et nascentis equi de fronte revulsus, Et matri prereptus amor'; Georg. iii. 280 "Hic demum hippomanes vero yuod nomine dicunt Pastores lentum distillat ab inguine virus'. Cf. Tibull. ii. 4. 55 'Hippomanes cupidae stillat ab inguine equae'. Vide infra, viii. $24.605^{\circ} 2$. 
in the fields. Mares and kine alike, when in heat, indicate the fact by the upraising of their genital organs, and by continually voiding urine. Further, kine mount the bulls, follow them about, and keep standing beside them. The younger females both with horses and oxen are the first to 5 get in heat; and their sexual appetites are all the keener if the weather be warm and their bodily condition be healthy. Mares, when clipt of their coat, have the sexual feeling checked, and assume a downcast drooping appearance. ${ }^{1}$ The stallion recognizes by the scent the mares that form is his company, even though they have been together only a few days before breeding time : if they get mixed up with other mares, ${ }^{2}$ the stallion bites and drives away the interlopers. He feeds apart, accompanied by his own troop of mares. Each stallion has assigned to him about thirty mares or even somewhat more; when a strange stallion approaches, he huddles his mares into a close ring, runs 15 round them, then advances to the cncounter of the new. comer; if one of the mares malic a movement, he bites her and drives her back. The bull in brecding time begins to graze with the cows, and fights with other bulls (having hitherto grazed with them), which is termed by graziers 'herd-spurning':" Often in Epirus a bull disappears for three months together. In a general way one 20 may state that of male ${ }^{4}$ animals either none or few herd with their respective fcmales before breeding timc; but they keep separate after reaching maturity, and the two sexes feed apart. Sows, when they are moved by sexual desire, or are, as it is called, a-boaring, will attack eren human beings.

With bitches the same sexual condition is termed 25 'getting into heat'. The sexual organ rises at this time, and there is a moisture about the parts. Mares drip with a white liquid at this season.

Female animals are subject to menstrual discharges, but

1 Plin. viii. 66. Cf. Arist. ap. Ael. xi. I8. So also of the ass, Ael. xii. I6: cf. Boch. Hieroz. p. 120.

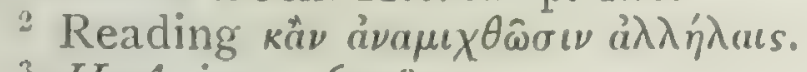

3 H. A. ix. 3. $6 \mathrm{II}^{2} 2$.

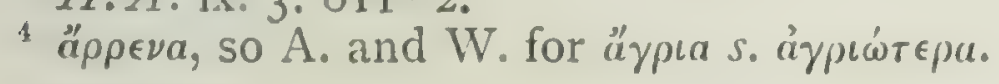

$A R . H . A$. 
30 never in such abundance as is the female of the human species. With cwes and she-goats there are signs of menstruation in breeding time, just before the time for submitting to the male; after copulation also the signs are manifest, and then cease for an interval until the period of $573^{\text {a }}$ parturition arrives; the process then supcrvenes, and it is by this supervention that the shepherd knows that such and such an ewe is about to bring forth. After parturition comes copious menstruation, not at first much tinged with blood, but deeply dyed with it by and by. With the cow, the she-ass, and the mare, the discharge is more copious 5 actually, owing to their greater bulk, but proportionally to the greater bulk it is far less copious. The cow, for instance, when in heat, cxhibits a small discharge to the extent of a quarter of a pint of liquid or a little less; and the time when this discharge takes place is the best time for her to be covered by the bull. Of all quadrupeds the mare is the most casily delivered of its young, exhibits the least 10 amount of discharge after parturition, and emits the least amount of blood; that is to say; of all animals in proportion to size. With line and mares menstruation usually. manifests itsclf at intervals of two, four, and six months ; ${ }^{\top}$ but, unless one be constantly attending to and thoroughly acpuainted with such animals, it is difficult to verify the circumstance, and the result is that many people are under the belief that the process never takes place with these animals at all.

15. With mules menstruation never takes place, but the urine of the female is thicker than the urine of the malc. As a general rule the discharge from the bladder in the case of guadrupeds is thiclier than it is in the human species, and this discharge with ewes and she-goats is thicker than with rams and he-goats; but the urine of the jackass is thicker so than the urine of the she-ass, and the urine of the bull is more pungent than the urine of the cow. After farturition the urine of all quadrupeds becomes thicker, especially with

1 Gaza translátes otherwise, 'Conceptus indicium maximum cum menses cessavcrint satio temporis trimestri,' \&c.; and Scaliger similarly. 
such animals as exhibit comparatively slight discharges. At breeding time the milk becomes purulent,' but after parturition it becomes wholesome. During pregnancy ewes 25 and she-goats get fatter and eat more; as is also the case with cows, and, indeed, with the females of all quadrupeds.

In general the sexual appetites of animals are keenest in spring-time; the time of pairing, however, is not the same for all, but is adapted so as to ensure the rearing of the young at a convenient season.

Domesticated swine carry their young for four months, and bring forth a litter of twenty at the utmost; and, by the way, if the litter be exceedingly numerous they cannot rear all the young. As the sow grows old she continues to bear, but grows indifferent to the boar; she conceives after a single copulation, but they have to put the boar to her repeatedly owing to her dropping after intercourse what is $573^{b}$ called the sow-virus." This incident befalls all sows, but some of them discharge the genital sperm as well. During conception any one of the litter that gets injured or dwarfed is called an after-pig or scut: ${ }^{3}$ such injury may occur at 5 any part of the womb. After littering the mother offers the foremost teat to the first-born. When the sow is in heat, she must not at once be put to the boar, but only after she lets her lugs drop, for otherwise she is apt to get into heat again; if she be put to the boar when in full condition of heat, one copulation, as has been said, is sufficient. It is as well to supply the boar at the period of copulation with 10 barley, and the sow at the time of parturition with boiled barley. Some swine give fine litters only at the beginning. with others the litters improve as the mothers grow in age and sizc. It is said that a sow, if she have one of her eyes knocked out, is almost sure to die soon afterwards. ${ }^{4}$ Swine 15 for the most part live for fifteen years, but some fall little short of the twenty.j

I9 Ewes conceive after three or four copulations with the

The so-called colostrum; vide note, iii. $20.522^{a}$ I.

Plin. viii. 51.

H.A. vi. 24. $577^{\mathrm{b}} 27$; G. A. ii. 8. $749^{\mathrm{a}}$ I, iv. $4.770^{\mathrm{b}} 7$, \&c.

* Antig. H.M. I10; Plin. viii. 51.

5 [ ] A. and W. Cf. v. 14. $546^{\mathrm{a}} 26$. 
ram. If rain falls after intercourse, the ram impregnates the ewe again: ${ }^{1}$ and it is the same with the she-goat. The 20 ewe bears usually two lambs, sometimes three or four. Both ewe and she-goat carry their young for five months; consequently wherever a district is sunny and the animals are used to comfort and well fed, they bear twice in the ycar. The goat lives for eight years and the sheep for ten, but in most cases not so long; the bell-wether, 25 however, lives to fifteen years. In every flock they train one of the rams for bell-wether. ${ }^{2}$ When he is called on by name by the shepherd, he takes the lead of the flock: and to this duty the creature is trained from its carliest years. Sheep in Ethiopia live for twelve or thirteen years, goats for ten or eleven." In the so case of the sheep and the goat the two sexes have intercourse all their lives long.

Twins with sheep and goats may be due to richness of pasturage, or to the fact that either the ram or the he-goat is a twin-begetter or that the ewe or the she-goat is a twinbearer. ${ }^{4}$ Of these animals some give birth to males and others to females; and the difference in this respect depends on the waters they drink and also on the sires. And if they submit to the male when north winds are blowing, they $574^{\text {a }}$ are apt to bear males; if when south winds are blowing. females. ${ }^{j}$ Such as bear females may get to bear males, duc regard being paid to their looking northwards when put to the malc. Eiwes accustomed to be put to the ram carly" will refuse him if he attempt to mount them late. Lambs s are born white and black according as white or black veins are under the ram's tongue: the lambs are white if the veins are whitc, and black if the veins are black, and white

1 àvakvíkel is doubtful: $\mathrm{cf}$. Dittm. at loc.

2 Il. vii. I 96.

3 Plin. viii. 75.

4Theocr. IA. i. 25, \&c.; Varro, R. R.ii.2. Cf. Lat. ambegnu, in Lex.

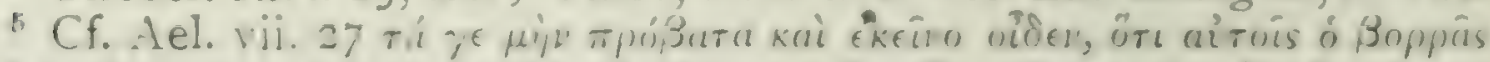

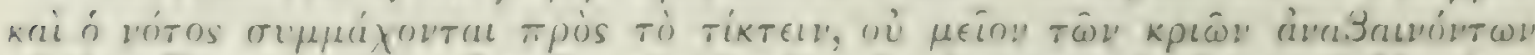

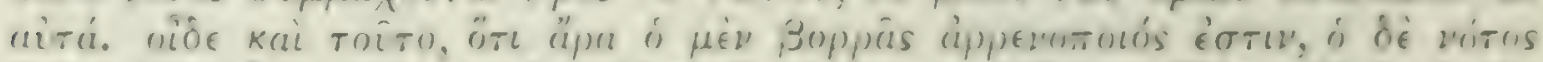

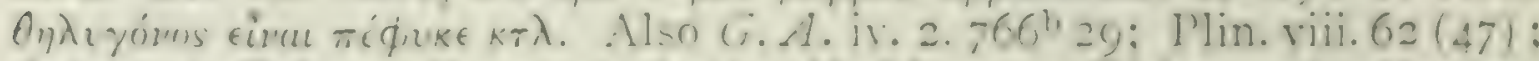

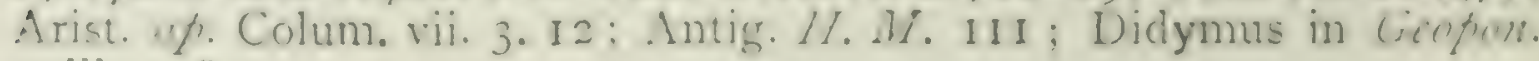
xviii. 3, \&c.

"i.e. in the morning, Gaza, Scal.; but in the season, Schn. 
and black if the veins are white and black; and red if the veins are red. ${ }^{1}$ The females that drink salted waters are the first to take the male; the water should be salted before and after parturition, and again in the spring-time. ${ }^{2}$ ro With goats the shepherds appoint no bell-wether, as the animal is not capable of repose but frisky and apt to ramble. If at the appointed season the elders of the flock are eager for intercourse, the shepherds say that it bodes well for the flock; "if the younger ones, that the flock is going to be bad.

20 Of dogs there are several breeds. Of these the Laconian hound of either sex is fit for breeding purposes when eight months old: at about the same age some dogs lift the leg when voiding urine. The bitch conceives with one lining; this is clearly seen in the case where a dog contrives to line a bitch by stealth, as they impregnate after mounting only 20 once. The Laconian bitch carries her young the sixth part of a year or sixty days: or more by one, two, or three, or less by one; " the pups are blind for twelve days after birth. After pupping, the bitch gets in heat again in six months, but not before. Some bitches carry their young for the fifth part of the year or for seventy-two days; and their pups are blind for fourteen days. Other bitches carry their young for 'a quarter of a year or for threc whole months; and the whelps of these are blind for seventeen days. ${ }^{6}$ The bitch appears to go in heat for the 30 same length of time. Menstruation continues for seven days, and a swelling of the genital organ occurs simultancously; it is not during this period that the bitch is disposed to submit to the dog, but in the seven days that follow. The bitch as a rule goes in heat for fourteen days, $574^{\text {b }}$ but occasionally for sixteen. The birth-discharge occurs

1 Cf. also Verg. G. iii. 387 ; Plin. viii. (47) 72 ; Varro, R. R. ii. 2. 4 ; Colum. vii. 3. I; Pallad. viii. 4. 2; Geopon. xviii. 6.

2 Cf. de Mirab. I jo; Plin. xxxi. 7.

3 A weather-prophecy, foreboding a hard or early winter, is the commoner deduction; cf. infra, 575 20 ; Arat. 336; Ael. vii. 8; Theoph. de Sign. Temp. pp. II3, 124 (Wimmer); Geopon. i. 4.2.

$\rightarrow$ Plin. x. 83.

- Plin.l.c.; Pollux, Onomast.v. 52. 
simultaneously with the delivery of the whelps, and the s substance of it is thick and mucous. [The falling-off in bulk on the part of the mother is not so great as might have been inferred from the size of her frame. $]^{1}$ The bitch is usually supplied with milk five days before parturition; some seven days previously, some four; and the io milk is serviceable immediately after birth. The Laconian bitch is supplied with milk thirty days after lining. The milk at first is thickish, but gets thinner by degrees; with the bitch the milk is thicker than with the female of any other animal cxcepting the sow and the hare. When the bitch arrives at full growth an indication is given of her capacity for the male: that is to say, just as occurs in the is female of the human species, a swelling takes place in the teats of the breasts, and the breasts take on gristle. ${ }^{2}$ This incident, however, it is difficult for any but an expert to detect, as the part that gives the indication is inconsiderable. The preceding statements relate to the female, and not one of them to the male. The male as a rule lifts his $20 \mathrm{leg}$ to roid urine when six months old; some at a later period, when eight months old, some before they reach six months. In a general way one may put it that they do so when they are out of puppyhood." The bitch squats down when she voids urine; it is a rare exception that she lifts 25 the leg to do so. The bitch bears twelve pups at the most, but usually five or six; occasionally a bitch will bear one only. The bitch of the Laconian breed generally bears eight. ${ }^{4}$ The two sexes have intercourse with each other at all periods of life." A very remarkable phenomenon is observed in the case of the Laconian hound: in other words, he is found to be more vigorous in commerce with

1 The rendering is conjectural. Schn. would read кaтi $\pi \lambda j \theta$ os, and tr. : purgationem de partu magis magisque tenuem et minus crassam. non minus copiosam. reddi'. Dittm. interprets rù $\pi \lambda \hat{\eta} \theta$ os rìs kutáporears.

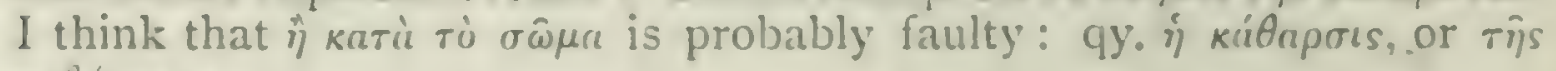
katipuresus.

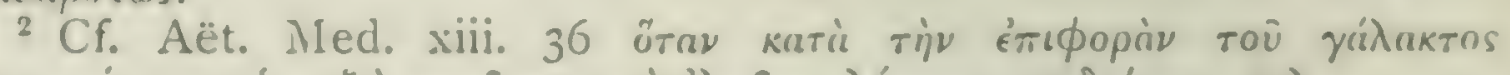

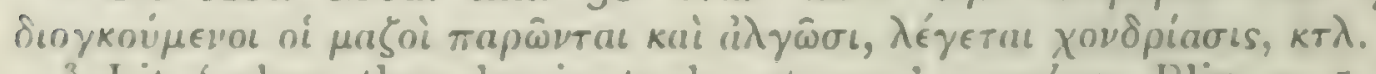

${ }^{3}$ Lit. 'when they begin to be strong'; a'alere, Plin. $x .5 .83$; for

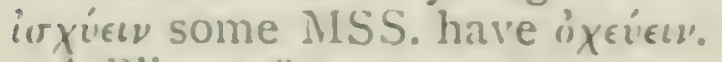

plin. x. $s_{3}$.

${ }^{5}$ But cf. H.A.v. 14. $546^{3} 2 S$. 
the female after being hard-worked than when allowed to live idle. ${ }^{1}$

The dog of the Laconian breed lives ten years, and the $3^{\circ}$ bitch twelve. The bitch of other breeds usually lives for fourteen or fifteen years, but some live to twenty; and for this reason certain critics consider that Homer did well in representing the dog of Ulysses as having died in his $575^{\mathrm{a}}$ twentieth year. ${ }^{2}$ With the Laconian hound, owing to the hardships to which the male is put, he is less long-lived than the female; with other breeds the distinction as to longevity is not very apparent, though as a general rule the male is the longer-lived.

The dog sheds no teeth except the so-called 'canines'; 5 these a dog of either sex sheds when four months old." As they shed these only, many people are in doubt as to the fact, and some people, owing to their shedding but two and its being hard to hit upon the time when they do so, fancy that the animal sheds no teeth at all ; others, after observing the shedding of two, come to the conclusion that the creature sheds the rest in due turn. Men discern the age io of a dog by inspection of its teeth; with young dogs the teeth are white and sharp pointed, with old dogs black and blunted. ${ }^{4}$

2I The bull impregnates the cow at a single mount, and mounts with such vigour as to weigh down the cow; if his effort be unsuccessful, the cow must be allowed an interval of twenty days before being again submitted." Bulls of 15 mature age decline to mount the same cow several times on one day, except, by the way, at considerable intervals. Young bulls by reason of their vigour are enabled to mount the same cow several times in one day, and a good many cows besides. The bull is the least salacious of male animals. ..." The victor among the bulls is the one 20

1 Plin. x. 83; Ael. iv. 40; Antig. H.M. II2. Plin. l.c. 'Propria in eo genere maribus laboris alacritas'; ubi Pintian. 'post laborem salacitas'.

2 Od. xvii. 326.

${ }^{4}$ Cf. $H . A$. ii. 2. 5 OI $^{\mathrm{b}}$ II.

3 Plin. xi. 63.

5 Plin. viii. 70.

"Here, apparently, is a lacuna. Dittm. would supply something 
that mounts the females; when he gets cxhausted by his amorous efforts, his beaten antagonist sets on him and very often gets the better of the conflict. The bull and the cow are about a year old when it is possible for them to have commerce with chance of offspring: as a rule, however, they are about twenty months old, but it is universally allowed that they are capable in this respect at the age of 25 two years. The cow goes with calf for nine months, and she calves in the tenth month; some maintain that they go in calf for ten months, to the very day. A calf delivered before the times here specified is an abortion and never lives, however little premature its birth may have becn, as its hooves are weak and imperfect. The cow as a rule bears 30 but one calf, very seldom two; she submits to the bull and bears as long as she lives.

Cows live for about fifteen years, and the bulls too, if they have been castrated; but some live for twenty years or even more, if their bodily constitutions be sound. The $575^{\mathrm{b}}$ herdsmen tame the castrated bulls, and give them an office in the herd analogous to the office of the bell-wether in a flock; and these bulls live to an exceptionally advanced age, owing to their exemption ${ }^{1}$ from hardship and to their browsing on pasture of good quality. The bull is in fullest vigour when five years old, which leads the critics to com5 mend Homer for applying to the bull the epithets' of 'flveyear-old', or 'of nine seasons', which epithets are alike in meaning. The ox sheds his teeth at the age of two ycars. not all together but just as the horse sheds his." Then the animal suffers from podagra it does not shed the hoof, but is subject to a painful swelling in the feet. The milk ro of the cow is scrviccable after parturition, and before parturition there is no milk at all. ${ }^{4}$ The milk that furst presents itself becomes as hard as stone when it clots; this result ensues unless it be previously diluted with water. Oxen younger than a year old do not copulate unless

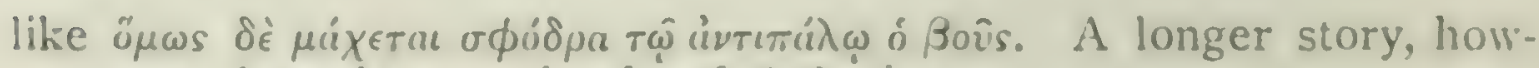
ever, may have been omitted; cf. Ael.vi. I.

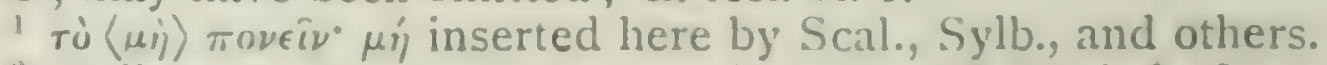

:Il. ii. 403, vii. 315; OA. x. 19, xix. 420. Cf. Hesiod, Op. 2.

"Plin. xi. 64.

+ Plin. xi. 96. 
under circumstances of an unnatural and portentous kind: instances have becn recorded of copulation in both sexes at the age of four ${ }^{1}$ months. Kine in general begin to submit to the male about the month of Thargelion or of 5 Scirophorion ${ }^{2}$ some, however, are capable of conception right on to the autumn. ${ }^{3}$ When kine in large numbers receive the bull and conceive, it is looked upon as prognostic of rain and stormy weather. ${ }^{4}$ Kine herd together like mares, but in lesser degree.

22 In the case of horses, the stallion and the mare are first fitted for breeding purposes when two years old. Instances, however, of such carly maturity are rare, and their young are exceptionally small and weak; the ordinary age for sexual maturity is three years, and from that age to twenty the two sexes go on improving in the quality of 25 their offspring:" The mare carries her foal for eleven months, and casts it in the twelfth. ${ }^{\circ}$ It is not a fixed number of days that the stallion takes to impregnate the mare; it may be one, two, three, or more. An ass in covering will impregnate more expeditiously than a stallion. The act of intercourse with horses is not laborious as it is 30 with oxen. In both sexes the horse is the most salacious of animals next after the human species. ${ }^{7}$ The breeding faculties of the younger horses may be stimulated beyond their years if they be supplied with good feeding in abundance. The mare as a rule bears only one foal; $76^{\text {a }}$ occasionally she has two, but never more. A mare has been known to cast two mules; but such a circumstance was regarded as unnatural and portentous.

The horse then is first fitted for breeding purposes at the age of two and a half years, but achieves full sexual maturity when it has ceased to shed teeth, except it be naturally infertile; it must be added, however, that some 5

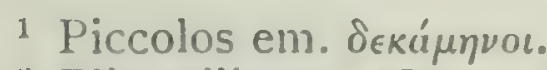

"Plin. viii. 70; Varro, R.R. ii. 5.

2 April to June.

4 Reff. are frequent to a similar prognostic in the case of sheep and goats: cf. note to $574^{2}$ I5.
H.A. v. 12.
${ }^{7}$ G. A. iv. $5.773^{\text {h }} 29$.
G. A. iv. Io. $777^{\text {b }}$ I2. 
horses have been known to impregnate the mare while the teeth were in process of shedding.

The horse has forty teeth. It sheds its first set of four, two from the upper jaw and two from the lower, when two and a half years old. After a year's interval, it sheds another set of four in like manner, and another set of four 10 after yet another year's interval; after arriving at the age of four years and six months it sheds no more. An instance has occurred where a horse shed all his teeth at once, and another instance of a horse shedding all his tecth with his last set of four ; but such instances are very rare. ${ }^{3}$ 15 It consequently happens that a horse when four and a half years old is in excellent condition for breeding purposes.

The older horscs, whether of the male or female. are the more generatively productive. Horses will cover mares from which they have been foaled and mares which they have begotten; " and, indeed, a troop of horses is 20 only considered perfect when such promiscuity of intercourse occurs. Scythians use pregnant mares for riding when the embryo has tumed rather soon in the womb. and they asscrt that thereby the mothers have all the easicr delivery. Quadrupeds as a rule lie down for parturition, and in consequence the young of them all come out of the womb sideways. The mare, however, when the time for 25 parturition arrives, stands crect and in that posture casts its foal. $0^{3}$

The horse in general lives for eighteen or twenty years; some horses live for twenty-five or cven thirty, ${ }^{4}$ and if a horse be treated with extreme care, it may last on to the age of fifty years; a horse, however, when it reaches thirty $56^{6}$ years is recarded as exceptionally old. The mare lives usually for twenty-five years, though instances have occurred of their attaining the age of forty. The male is less long-lived than the female by reason of the sexual service he is called on to render; and horses that are

1 Varro, R.R.ii. 7.2; Colum. vi. 29; Geropors. xvi.

${ }^{2}$ Cf. Ov. Met. x. 324 .

41. A. v. I $4.545^{\mathrm{b}}$ is.

Dittm. brackets the preceding sentence, which is in conflict with $545^{\circ}$ 1s'; cf. Plin. viii. 65. 
reared in a private stable live longer than such as are reared in troops. The mare attains her full length and height at five years old, the stallion at six; in another six years the 5 animal reaches its full bulk, and goes on improving until it is twenty years old. The female, then, reaches maturity more rapidly than the male, but in the womb the case is reversed, just as is observed in regard to the sexes of the human species $;^{1}$ and the same phenomenon is observed in the case of all animals that bear several young. ${ }^{2}$

The mare is said to suckle a mule-foal for six months, but not to allow its approach for any longer on account of the pain it is put to by the hard tugging " of the young; an ordinary foal it allows to suck for a longer period.

Horse and mule are at their best after the shedding of the teeth. After they have shed them all, it is not casy to distinguish their age; hence they are said to carry their mark before the shedding, but not after. However, even 15 after the shedding their age is pretty well recognized by the aid of the canines; for in the case of horses much ridden these teeth are worn away by attrition caused by the insertion of the bit; in the case of horses not ridden the teeth are large and detached, and in young horses they are sharp and small. ${ }^{4}$

The male of the horse will breed at all seasons and during 20 its whole life; the mare can take the horse all its life long, but is not thus ${ }^{5}$ ready to pair at all seasons unless it be held in check by a halter or some other compulsion be brought to bear. There is no fixed time at which intercourse of the two sexes cannot take place; and accordingly intercourse may chance to take place at a time that may

1 H. A. vii. 3. $583^{\mathrm{b}} 23 ; G \cdot$. A. iv. 6. $7 \overline{7} 5^{\mathrm{a}} 9$.

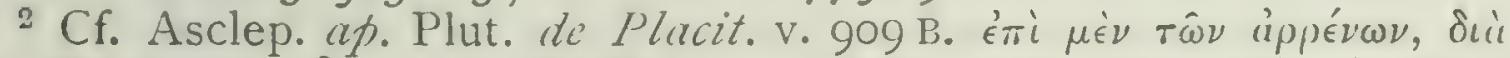

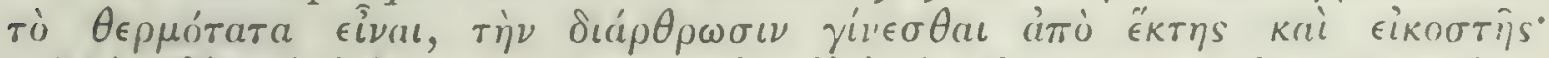

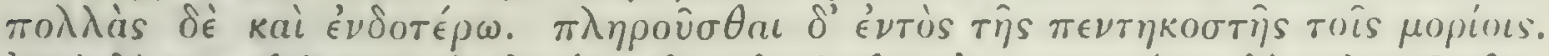

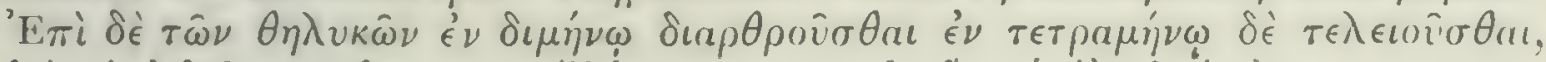

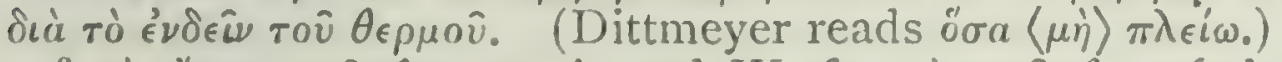

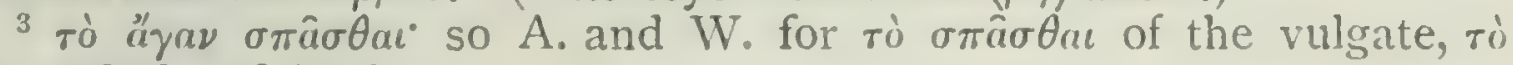

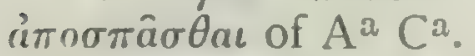

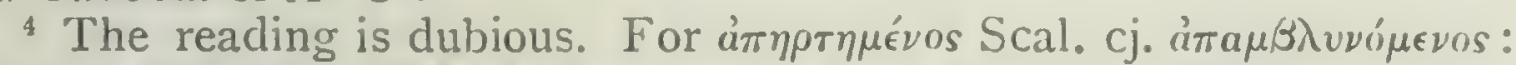

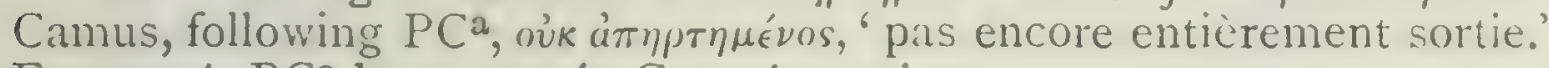

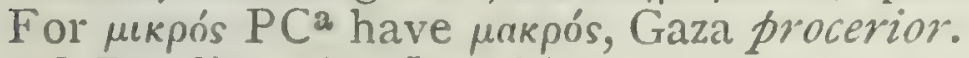

5 Reading oủ $\chi$ oũtws $\delta \epsilon ́$. 
25 render difficult the rearing of the future progeny. In a stable in Opus there was a stallion that used to serve mares when forty years old: ${ }^{1}$ his fore legs had to be lifted up for the operation.

Mares first take the horse in the spring-time. After a mare has foaled she does not get impregnated at once again, but only after a consiclerable interval; in fact, the foals will be all the better if the interval extend over four or five years. It is, at all events, absolutely necessary to $577^{\mathrm{a}}$ allow an interval of one year, and for that period to let her lic fallow. ${ }^{2} \Lambda$ mare, then, brecds at intervals; a she-ass breeds on and on without intermission. Of mares some are absolutely sterile, others are capable of conception but incapable of bringing the foal to full term; it is said to bc 5 an indication of this condition in a mare, that her foal if dissected is found to have other kidney-shaped substances round about its kidneys, presenting the appearance of having four kidneys."

After parturition the mare at once swallows the after-birth, and bites off the growth, ${ }^{4}$ called the 'hippomanes'; that is found on the forchead of the foal. This growth is someto what smaller than a dried fig; and in shape is broad and round, and in colour black. If any bystander gets possession of it "before the mare, and the mare gets a smell of it, she goes wild and frantic at the smell. ${ }^{i}$ And it is for this reason that venders of drugs and simples hold the substance in high request and include it among their stores.

If an ass cover a mare after the mare has been covered by a horse, the ass will destroy the previously formed embryo." 15. Horse-trainers do not appoint a horse as leader to a troop, as herdsmen appoint a bull as leader to a herd. and for this reason that the horse is not steady but quicktempered and skittish.]?

1 Plin. viii. 66.

2 Varro, R. R. ii. 7. I I.

s On fourfold kidneys in the stag cf. Plin. xi. S1; Ael. xi..40.

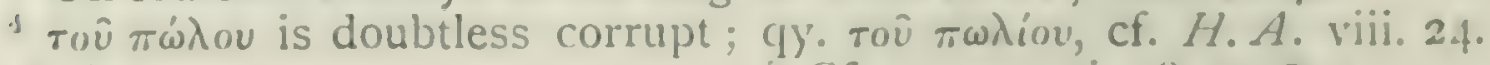
$605^{a} 6$.

Cf. note on vi. 1 S. $572^{i 2} 21$.

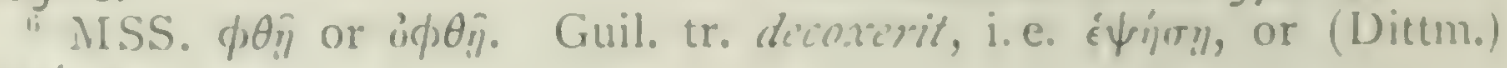
i.:i $\tau i, \pi ?$.

7 plin. $\%$.

$\because$ IA. and $11 \%$ : cf. $19.574^{2} 10$.

(i. A. ii. 8. $745^{\mathrm{a}} 33$. 
23 The ass of both sexes is capable of breeding, and sheds its first teeth at the age of two and a half years ${ }^{1}$ it sheds its second teeth within six months, its third within another six months, and the fourth after the like interval. These 20 fourth teeth are termed the gnomons or age-indicators.

A she-ass has been known to conceive when a year old, and the foal to be reared. ${ }^{2}$ Aftcr intercourse with the male it will discharge the genital sperm unless it be hindered, and for this reason it is usually beaten after such intercourse and chased about. ${ }^{3}$ It casts its young in the twelfth month. It usually bears but one foal, and that is its 25 natural number: occasionally however it bears twins. ${ }^{4}$ The ass if it cover a mare destroys, as has been said, the embryo previously begotten by the horse; but, after the mare has been covered by the ass, the horse supervening will not spoil the embryo. " The she-ass has milk in the tenth month of pregnancy. Seven days after casting a foal the she-ass submits to the male, and is almost sure to conceive if put to the male on this particular day; the same result, 30 however, is quite possible later on. The she-ass will refuse to cast her foal with any one looking on or in the daylight, $577^{\text {t }}$ and just before foaling she has to be led away into a dark place. If the she-ass has had young before the shedding of the index-teeth, she will bear all her life through; ${ }^{6}$ but if not, then she will neither conceive nor bear for the rest of her days. The ass lives for more than thirty years, and the she-ass lives longer than the male.

When there is a cross between a horse and a she-ass or a jackass and a mare, there is much greater chance of a miscarriage than where the commerce is normal. The period for gestation in the case of a cross depends on the male, and is just what it would have been if the male had had commerce with a female of his own kind. In regard to size, 10 looks, and vigour, the foal is more apt to resemble the mother than the sire. If such hybrid connexions be continued without intermittence, the female will soon go

\footnotetext{
H.A. v. I $4 \cdot 545^{\mathrm{b}} 20$.

G.A. ii. 8. $748^{a} 22$.

G.A. ii. 8. $748^{\text {i }} 33$; Plin. viii. 69.

${ }^{6}$ G.A. ii. 8. $748^{\text {b }} 9$; Plin. viii. 69.
}

2 Cf. $545^{\mathrm{b}} 22$.

1 Plin. viii. 68. 
sterile; ${ }^{1}$ and for this reason trainers always allow of inter15 vals between breeding times." A mare will not take the ass, nor a she-ass the horse, unless the ass or she-ass shall have been suckled by a mare; and for this reason trainers put foals of the she-ass under mares, which foals are technically spoken of as 'mare-suckled':" These asses, thus reared, mount the mares in the open pastures, mastering them by force as the stallions do.

A mule is fitted for commerce with the female after the 24 zo first shedding of its teeth, and at the age of scven will impregnate effectually; ${ }^{-1}$ and where connexion has taken place with a mare, a 'hinny' has been known to be produced. After the seventh year it has no further intercourse with the female." $\Lambda$ female mule has been known to be impregnated, but without the impregnation being followed up by parturition." In Syrophocnicia she-mules submit to the mule and bear young: ${ }^{7}$ but the breed, though it resembles 2.5 the ordinary one, is different and specific. The hinny or stunted mule is foaled by a mare when she has gone sick during gestation, ${ }^{8}$ and corresponds to the dwarf in the human species and to the after-pig or scut in swine; and, as is the case with dwarfs, the sexual organ of the hinny is abnormally large.

The mule lives for a number of years. There are on record cases of mulcs living to the age of eighty, as did one in 3 Athens at the time of the building of the temple: this mule

1 Colum. vi. 37. Io.

2 The translation is confirmed by Colum. l.c. 'Quae cum ex asino conceptum edidit, partum sequenti anno vacuat nutrit: id enim utilius cst quam quod (fidcan faciunt, ut et foetam nihilominus admisso equo impleant'.

3 Plin. viii. 69; Varro, R. R. ii. 8; Colum. vi. 37. S.

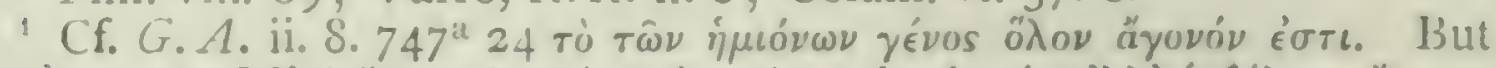

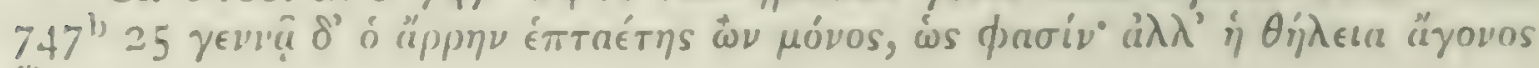
ó̀ $\lambda$ s.

Scal. interprets these words of the gimnus, 'sed is rursus non item coit.'

${ }^{6}$ Cf. Colum. vi. 37 for an account of mules bearing young in Africa.

7 Vide infrer, c. 36.

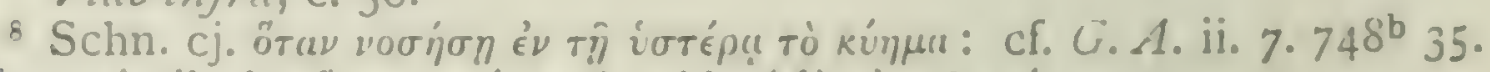

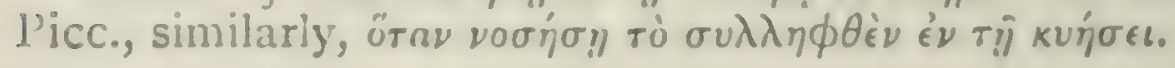


on account of its age was let go free, but continued to assist in dragging burdens, and would go side by side with the other draught-beasts and stimulate them to their work; and in consequence a public decree was passed forbidding any baker driving the creature away from his bread-tray. ${ }^{1} 578^{\text {a }}$ The she-mule grows old more slowly than the mule. Some assert that the she-mule menstruates by the act of voiding her urine, ${ }^{2}$ and that the mule owes the prematurity of his decay to his habit of smelling at the urine. So much for the modes of generation in connexion with these animals. 5

25 Breeders and trainers can distinguish between young and old quadrupeds. ${ }^{3}$ If, when drawn back from the jaw, the skin at once goes back to its place, the animal is young; if it remains long wrinkled up, the animal is old.

26 The camel carries its young for ten ${ }^{4}$ months, and bears 10 but one at a time and never more; the young camel is removed from the mother when a year old. The animal lives for a long period, more than fifty years. ${ }^{5}$ It bears in spring-time, ${ }^{i}$ and gives milk until the time of the next conception. Its flesh and milk are exceptionally palatable. ${ }^{\top}$ The milk is drunk mixed with water in the proportion of 15 either two to one or three to one.

27 The elephant of either sex is fitted for breeding before reaching the age of twenty. The female carries her young, according to some accounts, for two and a half years; according to others, for three ycars ${ }^{8}$ and the discrepancy in the assigned periods is due to the fact that there are 20 never human eyewitnesses to the commerce between the sexes. ${ }^{9}$ The female settles down on its rear to cast its young, and obviously suffers greatly during the process.

1 Ael. iv. 49; P'lut. de Sol. Anim. 970 A.; Plin. viii. 69; Hitpiatr. p. 4 .

${ }^{4}$ G. A. ii. 8. $748^{\text {a }} 24$.

Supra, v. 14, ¿ं $\delta \epsilon \kappa a$, which is correct.

5 Cf. viii. 9. $596^{\mathrm{a}} 9$.

7 Plin. xi. 96, xxviii. 33 ; Galen. vi. $486 \mathrm{~K}$. ; Diod. ii. 54.

8 But cf.v. I4. $546^{\mathrm{b}}$ II; G.A.iv. Io. $777^{\mathrm{l}}$ ' 15 ; de Mirab. $177.847^{\mathrm{b}} 5$;

Ael. iv. 31 ; Strabo xv. i. 43 ; Plin. viii. Io.

${ }^{9} H . A$. v. 2. $540^{a} 20$; Ael. viii. 17. 
The young one, immediately after birth, sucks the mother, not with its trunk but with the mouth $;^{1}$ and can walk about and see distinctly the moment it is born.

25 The wild sow submits to the boar at the beginning of 28 winter, and in the spring-time retreats for parturition to a lair in some district inaccessible to intrusion, hemmed in with sheer cliffs and chasms and overshadowed by trees. The boar usually remains by the sow for thirty days. The number of the litter and the period of gestation is the same 30 as in the case of the domesticated congener. The sound of the grunt also is similar: only that the sow grunts continually, and the boar but seldom. Of the wild boars such as are castrated grow to the largest size and become fiercest: $578^{\mathrm{b}}$ to which circumstance Ilomer alludes when he says :-

'He reared against him a wild castrated boar: it was not like a food-devouring brute, but like a forest-clad promontory." "

Wild boars become castrated owing to an itch befalling them in carly life in the region of the testicles, and the 5 castration is superinduced by their rubbing themselves against the trunks of trees.

The hind, as has been stated, submits to the stagy as a 29 rule only under compulsion," as she is unable to endure the male often owing to the rigidity of the penis. ${ }^{4}$ However, they do occasionally submit to the stag as the ewe submit: 10 to the ram: and when they are in heat the hinds avoid one another." The stag is not constant to one particular hind, but after a while quits one and mates with others." The brecding time is after the rising of Arcturus, cluring the months of Boedromion and Maimacterion. ${ }^{7}$ The period of gestation lasts for eight months. Conception comes on a

H.A.v. I4; Ael. iv. 3 I.

2 This interpretation of $x^{\lambda}+u^{\prime}{ }^{\prime}{ }^{\prime}$ is highly dubious, and the quotation is a travesty of $I l$. ix. 539 and Ot. ix. I90.

H. A. v. 2. $540^{\text {rl }} 5$.

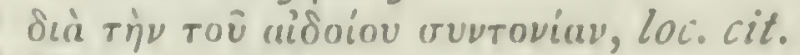

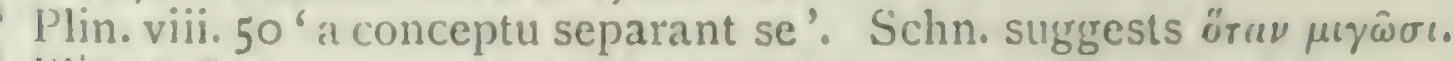
I'lin. x. 83 .

7 That is, in October'; cf. Plin. viii. 50. 
few days after intercourse; and a number of hinds can be impregnated by a single male. The hind, as a rule, bears is but one fawn, although instances have been known of her casting two. Out of dread of wild beasts she casts her young by the side of the high-road. ${ }^{1}$ The young fawn grows with rapidity. Menstruation occurs at no other time with the hind; it takes place only after parturition, and the substance is phlegm-like.

The hind leads the fawn to her lair; this is her place of refuge, a cave with a single inlet, inside which she shelters herself against attack. ${ }^{2}$

Fabulous stories are told concerning the longevity of the animal, but the stories have never been verified, and the brevity of the period of gestation and the rapidity of growth 25 in the fawn would not lead one to attribute extreme longevity to this creature.

In the mountain called Elaphoeis ${ }^{3}$ or Deer Mountain, which is in Arginussa in Asia Minor-the place, by the way, where Alcibiades was assassinated ${ }^{4}$-all the hinds have the ear split, so that, if they stray to a distance, they can be recognized by this mark; and the embryo actually has the mark while yet in the womb of the mother.

The hind has four teats like the cow. After the hinds have become pregnant, the males all segregate one by one, and in consequence of the violence of their sexual passions they keep each one to himself, dig a hole in the ground, $579^{a}$ and bellow from time to time; ${ }^{0}$ in all these particulars they resemble the goat, and their foreheads from getting wetted become black, ${ }^{7}$ as is also the case with the goat. In this

1 H. A. ix. 5. 6II $\mathrm{I}^{\mathrm{a}} \mathrm{I} 5$.

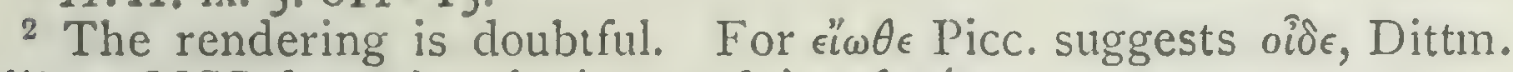

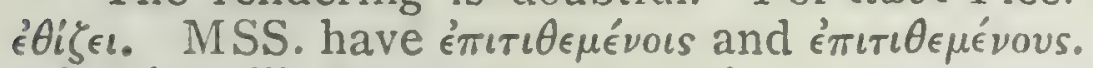

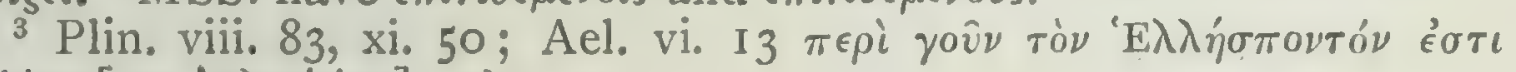
$\lambda o ́ \phi o s[q y . ~ ' E \lambda a \phi o ́ \epsilon t s], \kappa \tau \lambda$.

4 In Phrygia, Plut. $V$. Alcib. xxxix, C. Nepos, Alcib. x.

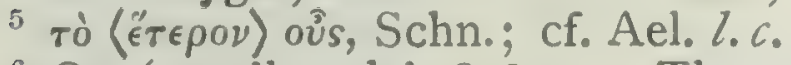

'Qy. 'smell rank', $\beta \rho \hat{\omega} \mu o s$. The word is not Attic.

7 The statement is unverified and the reading dubious. The underparts of the stag are known to grow darker in the breeding season, and

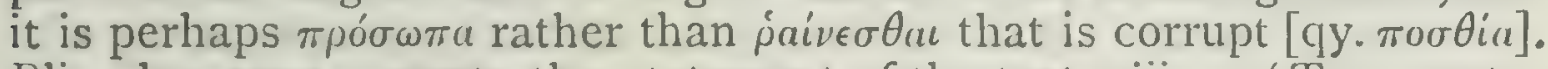
Plin., however, accepts the statement of the text, viii. 50 'Tunc rostra eorum nigrescunt, donec aliqui abluant imbres'. 
way they pass the time until the rain falls, after which time they turn to pasture. The animal acts in this way owing to 5 its sexual wantonness and also to its obesity; for in summertime it becomes so exceptionally fat as to be unable to run: in fact at this period they can be overtaken by the hunters that pursue them on foot in the second or third run; and, by the way, in consequence of the heat of the wcather and their getting out of breath they always make for water in their runs. ${ }^{1}$ In the rutting season, the flesh of the deer is 1o unsavoury and rank, like the flesh of the he-goat. In wintertime the deer becomes thin and weak, but towards the approach of the spring he is at his best for running. When on the run the decr keeps pausing from time to time, and waits until his pursuer draws upon him, whercupon he starts I 5 off again. This habit appears due to some internal pain : at all events, the gut is so slender and weak that, if you strike the animal ever so softly, it is apt to break asunder, though the hide of the animal remains sound and uninjured. ${ }^{2}$

Bears," as has been previously stated, do not copulate 30 with the male mounting the back of the female, but with the female lying down under the male. The she-bear goes 20 with young for thirty days. ${ }^{4}$ She brings forth sometimes one cub, sometimes two cubs, and at most five. Of all animals the newly born cub of the she-bear is the smallest in proportion to the size of the mother; that is to say, it is larger than a mouse but smaller than a weasel. It is also smooth and blind, and its legs and most of its organs are as yet inarticulate." Pairing takes place in the month of ${ }_{25}$ Elaphebolion, ${ }^{6}$ and parturition about the time for retiring into winter quarters; ${ }^{7}$ about this time the bear and the she-bear are at the fattest. After the she-bear has reared

1 Cf. Xen. Cynt. ix.

${ }^{3}$ H.A. v. 2. $539^{\mathrm{b}} 33$.

- Plin. viii. 54.

5 Cf. Ov. Met. xv. 379; Plin. viii. 36; Ael. ii. I9; Horap. ii. 79, SE.

- February-March.

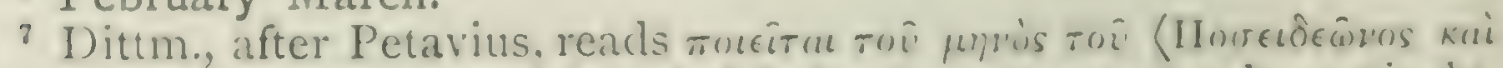

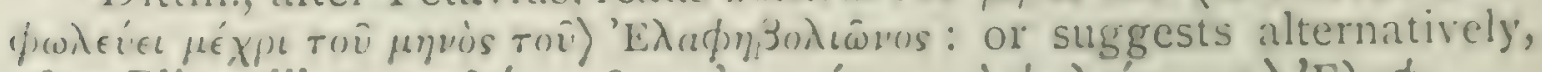

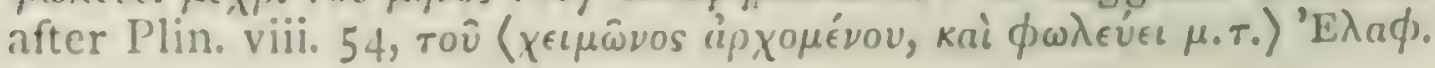


her young, she comes out of her winter lair in the third month, when it is already spring: ${ }^{1}$ The female porcupine, by the way, hibernates and goes with young the same number of days as the she-bear, and in all respects as to parturition resembles this animal. When a she-bear is with young, it is a very hard task to catch her.

3I It has already been stated that the lion and lioness copulate rearwards, ${ }^{2}$ and that these animals are opisthuretic. They do not copulate nor bring forth at all seasons indiscriminately, but once in the year only. The lioness brings forth in the spring, generally two cubs at a time, and six at $579^{\mathrm{b}}$ the very most; but sometimes only one. The story about the lioness discharging her womb in the act of parturition ${ }^{3}$ is a pure fable, and was merely invented to account for the scarcity of the animal; for the animal is, as is well known, 5 a rare animal, and is not found in many countries. In fact, in the whole of Europe it is only found in the strip between the rivers Achelous and Nessus. ${ }^{4}$ The cubs of the lioness when newly born are exceedingly small, and can scarcely walk when two months old. ${ }^{5}$ The Syrian lion bears cubs five times: five cubs at the first litter, then four, then three, ro then two, and lastly one; after this the lioness ceases to bear for the rest of her days. ${ }^{6}$ The lioness has no mane, but this appendage is peculiar to the lion. The lion sheds only the four so-called canines, ${ }^{7}$ two in the upper jaw and two in the lower; and it sheds them when it is six months old.

The hyena ${ }^{8}$ in colour resembles the wolf, ${ }^{9}$ but is more is

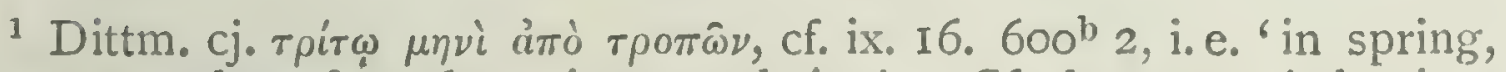
three months after the winter solstice'. Cf. however Ael. vi. 3

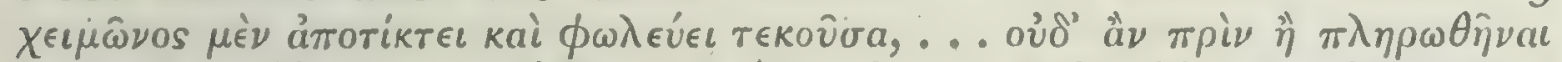

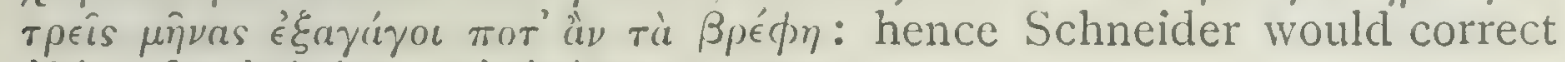

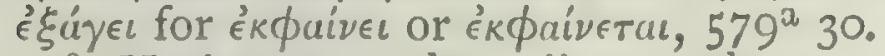

${ }^{2}$ H. A. v. 2. $539^{\mathrm{b}} 22$, ii. I. $500^{\mathrm{b}}$ I 5 .

3 Herod. iii. I08; Ael. iv. 34.

4 H.A. viii. 28; cf. Xen. Cyn. xi ; Herod. vii. I26; Pausan. vi. 5 ; Plin. viii. I7 (16).

5 Plin. l.c.; Ael. iv. 34.

${ }^{6} G$. A. iii. I. $750^{2} 32$; Plin. l.c.; Opp. Cynn. iii. 56.

7 Plin. xi. 63.

9 Guil. tr. 'quasi alba', reading $\lambda \epsilon v \kappa \omega ́ \delta \eta s$.

8 Plin. viii. 44 . 
shaggy, and is furnished with a mane running all along the spine. What is recounted concerning its genital organs, to the effect that every hyena is furnished with the organ both of the male and the female, is untrue. ${ }^{1}$ The fact is that the scxual organ of the male hycna resembles the same organ in the wolf and in the dog: the part rescmbling the female genital 20 organ lies underneath the tail, and does to some extent resemble the female organ, but it is unprovided with duct or passage, and the passage for the residuum comes underneath it. The female hyena has the part that resembles the organ of the male, and, as in the case of the male, has it underneath her tail, unprovided with duct or passage; and 25 after it the passage for the residuum, and underneath this the true female genital organ. The female hycna has a womb, like all other female animals of the same kind. It is an exceedingly rare circumstance to meet with a female hyena. At least a hunter said that out of eleven hyenas he had caught, only one was a female.

30 Hares copulate in a rearward posture, as has been 33 stated, ${ }^{2}$ for the animal is opisthuretic. They breed and bear at all seasons, superfoctate during pregnancy; ${ }^{2}$ and bear young every month. They do not give birth to their young ones all together at one time, but bring them $580^{a}$ forth at intervals over as many days as the circumstances of each case may require. The female is supplicd with milk before parturition; and after bearing submits immcdiately to the male, and is capable of conception while suckling her young. The milk in consistency resembles sow's milk. The young are born blind, as is the case with 5 the greater part of the fissipeds or toed animals. ${ }^{4}$

The fox mounts "the vixen in copulation, and the vixen 34 bears young like the she-bear: ${ }^{6}$ in fact, her young ones

1 G. A. iii. 6. $757^{a} 2$; Diod. xxxii; Ael. i. 25 ; Ov. Met. xv. 409.

2 H.A.v. 2. $539^{\mathrm{b}} 22$, ii. 1. $500^{\mathrm{b}} \mathrm{I} 5$.

G. A. iv. 5. $774^{\text {a }} 3$ I ; Herod. iii. I08.

G.A.iv. 6. $77 t^{\mathrm{b}}$ 10.

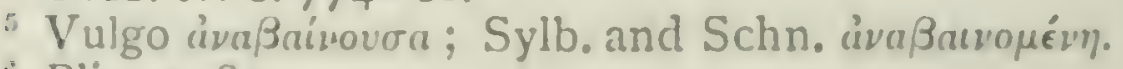

Plin. x. 83 . 
are even more inarticulately formed. Bcfore parturition she retires to sequestered places, so that it is a great rarity for a vixen to be caught while pregnant. After parturition she warms her young and gets them into shape by licking them. ${ }^{1}$ She bears four at most at a birth.

35 The wolf resembles the dog in regard to the time of conception and parturition, the number of the litter, and the blindness of the new-born young. The sexes couple at one special period, and the female brings forth at the beginning of the summer. There is an account given of the ${ }_{5} 5$ parturition of the she-wolf that borders on the fabulous, to the effect that she confines her lying-in to within twelve particular days of the year. ${ }^{2}$ And they give the reason for this in the form of a myth, viz. that when they transported Leto in so many days from the land of the Hyperboreans to the island of Delos, she assumed the form of a she-wolf to escape the anger of Here. Whether the account be correct or not 20 has not yet been verified; I give it merely as it is currently told. There is no more of truth in the current statement that the she-wolf bears once and only once in her lifetime.

The cat and the ichneumon bear as many young as the dog, and live on the same food; they live about six years. The cubs of the panther are born blind like those of the wolf, and the female bears four at the most at one 25 birth. The particulars of conception are the same for the thos, or civet, as for the dog; the cubs of the animal are born blind, and the female bears two, or three, or four at a birth. It is long in the body and low in stature; but notwithstanding the shortness of its legs it is excep- $3^{\circ}$ tionally fleet of foot, owing to the suppleness of its frame and its capacity for leaping.

36 There is found in Syria a so-called mulc. ${ }^{4}$ It is not the $580^{\mathrm{b}}$

1 The same is told of the she-bear, H. A. viii. I7; Plin. x. 83.

2 Ael. iv. 4; Antig. Mirab.6I; Schol. Apoll. Rh. ii. I23.

${ }^{3}$ Gaza has 'corpore longior et cauda porrectior, sed proceritate

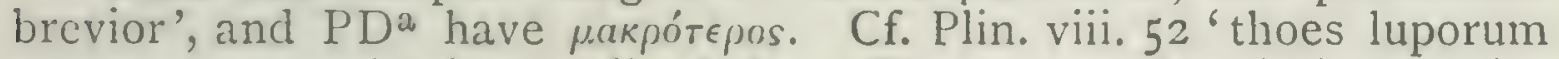
genus est procerius longitudine', \&c. The present description applies much better to the civet or genet, with which $\mathrm{A}$. and W. identify $\theta \dot{\omega} s$, than to the jackal, with which it is more commonly identified.

4 Equns onager or allied species. Cf. H.A. i. $6.49 I^{2} 2$, iv. 24. 
same as the cross between the horse and ass, but resembles it just as a wild ass resembles the domesticated congener, and derives its name from the resemblance. Like the wild 5 ass, this wild mule is remarkable for its spect. The animals of this species interbreed with one another; and a proof of this statement may be gathered from the fact that a certain number of them were brought into Phrygia in the time of Pharnaces, the father of Pharnabazus, and the animal is there still. The number originally introduced was nine, and there are three there at the present day.

ro The phenomena of generation in regard to the mouse 37 are the most astonishing both for the number of the young and for the rapidity of recurrence in the births. On one occasion a she-mouse in a state of pregnancy was shut up by accident in a jar containing millet-seed, and after a little while the lid of the jar was removed and upwards of one hundred and twenty mice were found inside it.

15 The rate of propagation of field mice in country places, and the destruction that they cause, are beyond all telling. In many places their number is so incalculable that but very little of the corn-crop is left to the farmer; and so rapid is their mode of proceeding that sometimes a small farmer will one day observe that it is time for reaping, and on the following morning, when he takes his reapers afield, zohe finds his entire crop devoured. ${ }^{1}$ Their disappearance is unaccountable: in a few days not a mouse will there be to be scen. And yet in the time before these few days men fail to keep down their numbers by fumigating ${ }^{2}$ and unearthing them, or by regularly hunting them and turning in swine upon them; for pigs, by the way, turn up the s5 mouse-holes by rooting with their snouts. Foxes also hunt

$577^{\mathrm{b}} 23$; cf. also de Mirat. 70. $835^{\mathrm{b}} 1$; II. ii. 852 ; Herod. iii. 151, I53, vii. 57; Plin. viii. 69; Mago ap. Varro, R.K. ii. I; Colum. vii. 37 , Sic. 1 I'lagues of tieli-mice or voles, Arvida gimthir, still occur in Thessaly, e.g. in I866 and I \&g2: see Report on a llague of FieldVoles in Scotland, 1893 (Cd. 943). A similar occurrence is alluded to in I Sam.v. 6, vi. I1.

${ }^{2}$ Cf. Pallad. i. 35. Io 'talfors fugat impletis fumo nucis [qy. picis] incensac cuniculis'; sce also Giopon. xiii. 7. 
them, and the wild ferrets in particular destroy them, but they make no way against the prolific qualities of the animal and the rapidity of its breeding. When they are superabundant, nothing succeeds in thinning them down except the rain; but after heavy rains they disappear rapidly.

In a certain district of Persia when a female mouse is 30 dissected the female embryos appear to be pregnant. ${ }^{1}$ Some people assert, and positively assert, that a female mouse by licking salt ${ }^{2}$ can become pregnant without the intervention $58 \mathrm{I}^{\mathrm{a}}$ of the male.

Mice in Egypt are covered with bristles like the hedgehog. ${ }^{3} \quad$ There is also a different breed of mice that walk on their two hind-legs; their front legs are small and their hind-legs long; ${ }^{4}$ the breed is exceedingly numerous. There are many other breeds of mice than are here referred to.

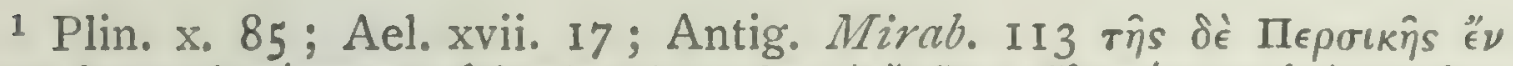

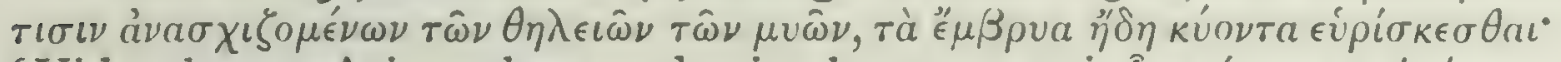

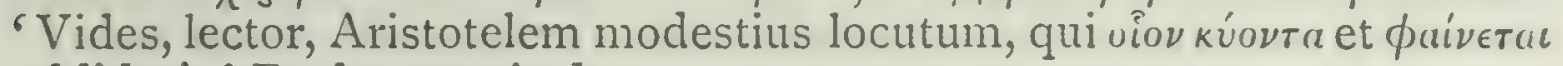
addiderit,' Beckmann in loc.

2 A. and W. cj. á $\lambda \lambda \dot{\eta} \lambda$ as $\lambda \epsilon i \chi \omega \sigma \iota \nu$ : but cf. Plin. x. 85 ; Ael. ix. 3.

3 The African genus Acanthomys or 'spiny mice'.

4 Dipus aegvptiacus, the jerboa; cf. Herod. iv. I92; H.A. viii. 28 ; Theoph. ap. Ael. xv. 26; Arist. de Mirab. 27; Plin. viii. 55, x. 85.

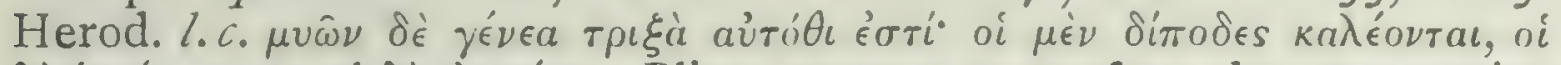

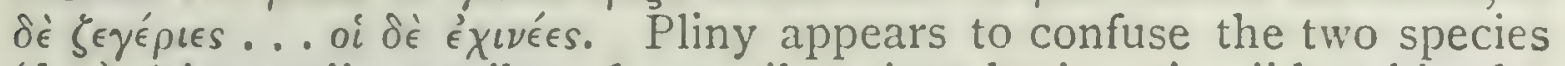
(l.c.), 'Aegyptiis muribus durus pilus sicut herinaceis: iidem bipedes ambulant, ceu alpini quoque.' 


\section{BOOK VII}

$5^{8 \mathrm{I}^{\mathrm{a}}} \quad{ }^{1}$ AS to MIan's growth, first within his mother's womb and I

ro afterward to old age, the course of nature, in so far as man is specially concerned, is after the following manner. And, by the way, the difference of male and female and of their respective organs has been dealt with heretofore. ${ }^{2}$ When twice seven years old, ${ }^{3}$ in the most of cases, the male begins to engender seed; and at the same time hair ${ }^{15}$ appears upon the pubes, ${ }^{4}$ in like manner, so Alcmaeon of Croton remarks, as plants first blossom and then sced. About the same time, the voice begins to alter, getting harsher and more uneven, neither shrill as formerly nor deep as afterward, nor yet of any cven tone, but like an 20 instrument whose strings are frayed and out of tune; and it is called, by way of by-word, the bleat of the billy-goat." Now this breaking of the voice is the more apparent in those who are making trial of their sexual powers; for in those who are prone to lustfulness the voice turns into the roice of a man, but not so in the continent. For if a lad strive diligently to hinder his voice from breaking, as some 25 do of those who devote themselves to music, the voice lasts

1 This book is of doubtful authenticity. Nearly one half of its contents may be closely paralleled with passages in the third and fourth books of the de Gen.; and much also appears to be drawn directly from the writings of the Hippocratic School. For the latter parallels see Littré (viii, p. 4 sec.) ; Kuhlewein, l'Wilologms, xlii, p. 127: Fr. Poschenrieder, 'Die naturw. Schr. des A. in ihrem Verh. zu den Büchern der Hippocr.-Sammlung,' Bamberg, I\$87, p. 33.

2 H.A. iii. I.

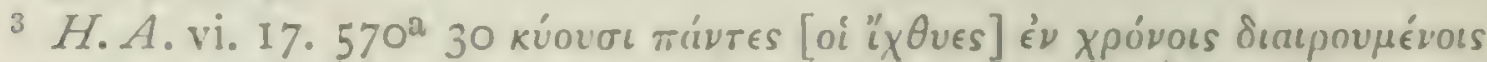

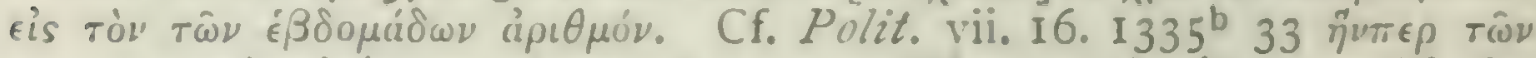

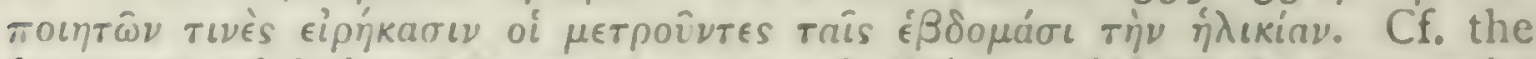
fragment of Solon (cincmiti $\mathrm{s}, 4$, ed. Boissonace) on the ten wecks of the life of man. Cf, also Hippocr. de Septemmadis, viii, p. $634 \mathrm{~L}$ 'Sic omnium mundi septinarium habent ordinem', \&c.

4H.A.v. 14. $544^{\mathrm{b}} 25$; Censorin. d. d. nat. 14; G. A. i. 20. $728^{\mathrm{b}}$

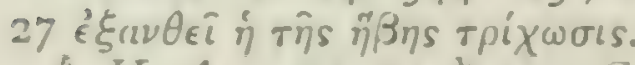

${ }^{5} H . A . v \cdot 14.544^{\mathrm{b}} 23 ; G . A$. iv. $8.77^{\mathrm{b}} 15 ; \mathrm{v} \cdot 7 \cdot 787^{\mathrm{b}} 31$.

Girquitallive, Censorin. 14; cf. Fest. ap. Paul. Diac., p. Iol (Muill.). 
a long while unbroken and may even persist with little change. And the breasts swell and likewise the private parts, altering in size and shape. (And by the way, at this time of life those who try by friction to provoke emission of seed ${ }^{1}$ are apt to experience pain as well as voluptuous 30 sensations.) At the same age in the female, the breasts swell and the so-called catamenia commence to flow; and $5^{81^{b}}$ this fluid resembles fresh blood. There is another discharge, a white one, by the way, which occurs in girls even at a very early age, more especially if their diet be largely of a fluid nature; and this malady causes arrest of growth and loss of flesh. ${ }^{2}$ In the majority of cases the catamenia are 5 noticed by the time the breasts have grown to the height of two fingers' breadth." In girls, too, about this time the voice changes to a deeper note; for while in general the woman's voice is higher than the man's, so also the voices of girls are pitched in a higher key than the elder women's, just as the boy's are higher than the men's; and the girls' 10 voices are shriller than the boys', and a maid's flute is tuned sharper than a lad's. ${ }^{4}$

Girls of this age have much need of surveillance. For then in particular they feel a natural impulse to make usage of the sexual faculties that are developing in them; so that unless they guard against any further impulse beyond that inevitable one which their bodily development of itself supplies, even in the case of those who abstain altogether ${ }_{15}$ from passionate indulgence, they contract habits which are apt to continue into later life. ${ }^{5}$ For girls who give way to wantonness grow more and more wanton; and the same is true of boys, unless they be safeguarded from one temptation and another; for the passages become dilated and set up a local flux or running, ${ }^{6}$ and besides this the 20 recollection of pleasure associated with former indulgence creates a longing for its repetition.

Some men are congenitally impotent owing to structural defect; and in like manner women also may suffer from

1 Ar.Vesp. 739.

3 G.A. i. 20. $728^{\mathrm{b}} 3 \mathrm{I}$.

5 Polit. vii. 16. $1334^{\text {b }} 26$.
${ }^{2} G$. A. ii. 4. $738^{a} 25$.

4 Athen. $176^{\mathrm{f}}$.

- Theophr. de Odore 50, de Sudore I9. 
congenital incapacity. Both men and women are liable to constitutional change, growing healthier or more sickly, or altering in the way of leanness, stoutness, and vigour; thus, after puberty some lads who were thin before grow stout and healthy, and the converse also happens; and the same is equally true of girls. For when in boy or girl the body 30 is loaded with superfluous matter, then, when such superfluities are got rid of in the spermatic or catamenial discharge, their bodies improve in health and condition owing $582^{a}$ to the removal of what had acted as an impediment to health and proper nutrition; but in such as are of opposite habit their bodies become emaciated and out of health, for then the spermatic discharge in the one case and the catamenial flow in the other take place at the cost of natural healthy conditions.

5 Furthermore, in the case of maidens the condition of the breasts is diverse in different individuals, for they are sometimes quite big and sometimes little; and as a general rule their size depends on whether or no the body was burthened in childhood with superfluous material. For when the signs of womanhood are nigh but not come, the ro more there be of moisture the more will it cause the breasts to swell, even to the bursting point; and the result is that the breasts remain during after-life of the bulk that they then acquired. And among men, the breasts grow more conspicuous and more like to those of women, both in young men and old, when the inclividual temperament is Is moist and sleck and the reverse of sinewy, and all the more among the dark-complexioned than the fair.

At the outset and till the age of one and twenty the spermatic discharge is devoid of fecundity; ${ }^{1}$ afterwards it becomes fertile, but young men and women produce undersizcd and imperfect progeny, as is the case also with the common run of animals." Young women conceive readily: 20 but, having conceived, their labour in childbed is apt to be difficult.

The frame fails of reaching its full development and

1 H. A. V. I $4 \cdot 544^{\mathrm{b}}$ I 5 .

2 Of the mare, H. A. vi. $22.575^{\mathrm{b}} 23$. 
ages quickly in men of intemperate lusts and in women who become mothers of many children; for it appears to be the case that growth ceases when the woman has given birth to three children. Women of a lascivious disposition 25 grow more sedate and virtuous after they have borne several children.

After the age of twenty-one women are fully ripe for child-bearing, but men go on increasing in vigour. When the spermatic fluid is of a thin consistency it is infertile; when granular it is fertile and likely to produce male 30 children, but when thin and unclotted it is apt to produce female offspring. And it is about this time of life that in men the beard makes its appearance.

2 The onset of the catamenia in women takes place towards the end of the month ${ }^{1}$ and on this account the wiseacres assert that the moon is feminine, because the discharge in $582^{\mathrm{b}}$ women and the waning of the moon happen at one and the same time, and after the wane and the discharge both one and the other grow whole again. [In some women the catamenia occur regularly but sparsely every month, and more abundantly every third month.] ${ }^{2}$ With those in whom the ailment lasts but a little while, two days or 5 three, recovery is easy; but where the duration is longer, the ailment is more troublesome. For women are ailing during these days; and sometimes the discharge is sudden and sometimes gradual, but in all cases alikc there is bodily distress until the attack be over. In many cases at the commencement of the attack, when the discharge is about to appear, there occur spasms and rumbling noises within ro the womb until such time as the discharge manifests itself.

Under natural conditions it is after recovery from these

${ }^{1}$ G. A. iv. 2. $767^{\mathrm{a}}$ 5, ii. $4.73^{\mathrm{a}}$ 20, iv. 2. $767^{\mathrm{a}}$ I. Cf. Hippocr. de

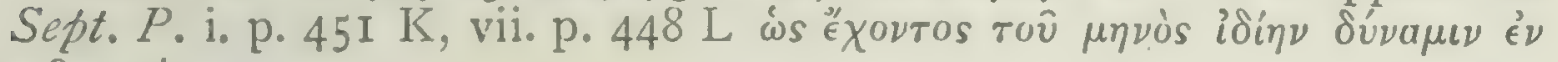

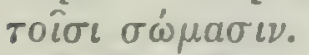

2 The MSS. are manifestly corrupt, and appear to mean that in some women the ailment occurs every month, but in the majority only every third month. The above conjectural rendering is based on

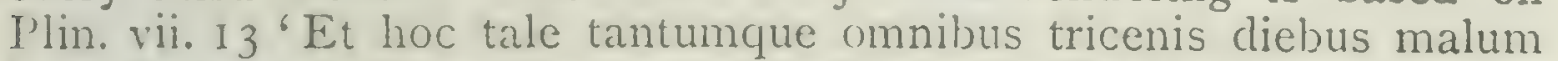
in muliere exsistit, et trimestri spatio largius'. But the sense may be, as $A$. and $W$. suspect, that the ailment may last more days or fewer, but usually three. 
symptoms that conception takes place in women, ${ }^{1}$ and women in whom the signs do not manifest themselves for the most part remain childless. But the rule is not without exception, ${ }^{2}$ for some conceive in spite of the absence of these symptoms; and these are cases in which a sccretion 15 accumulates, not in such a way as actually to issue forth," but in amount equal to the residuum left in the case of child-bearing women ${ }^{4}$ after the normal discharge has taken place. And some conceive while the signs are on but not afterwards, those namcly in whom the womb closes up immediately after the discharge. In some cases the menses 20 persist during pregnancy up to the very last; but the result in these cases is that the offspring are poor, and either fail to survive or grow up weakly.

In many cases, owing to excessive desire, arising either from youthful impetuosity or from lengthened abstinence, prolapsion of the womb takes place and the catamenia 25 appear repeatedly, thrice ${ }^{5}$ in the month, until conception occurs; and then the womb withdraws upwards again to its proper place. ...

As we have remarked above, the discharge is wont to be

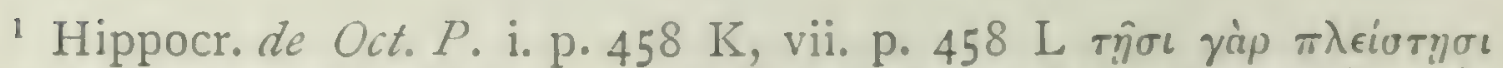

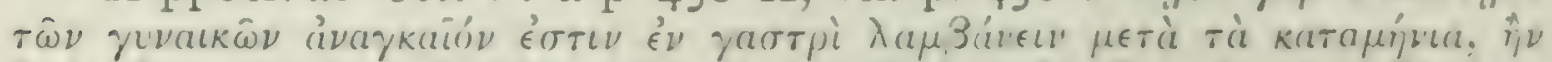

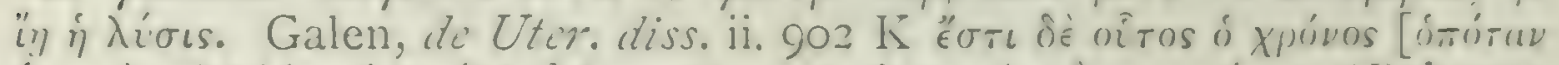

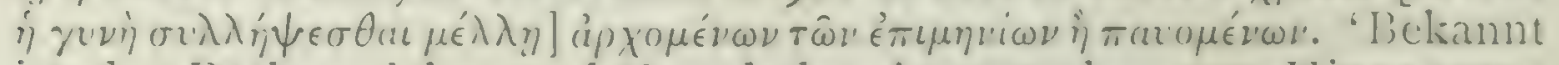
ist der Rath, welchen auf (irund des Ausspruches ron Hippocrates Fernel dem Gemahl der Catharina von Medici ertheilt haben soll':

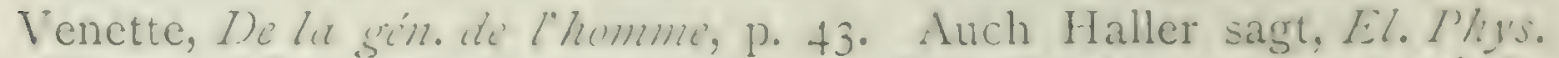

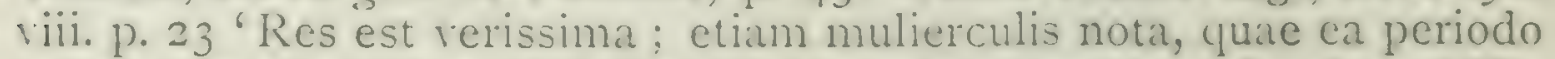
coire male metumnt, quoties non est e re earum concipere'. A. and II:, in G.A.i. 19. $\quad{ }^{2}$ G.A. i. 19. $727^{\mathrm{b}}$ I8, ii. $4.739^{\mathrm{a}}$ I3.

${ }^{3} \mathrm{Cf}$. A.s doctrine of conception by commixture of the seminal

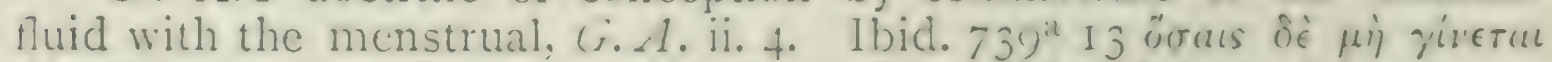

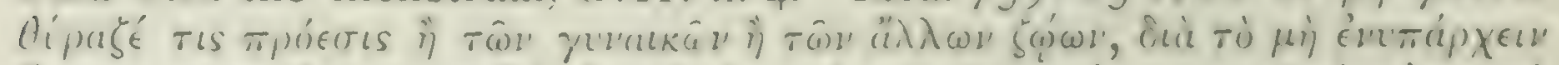

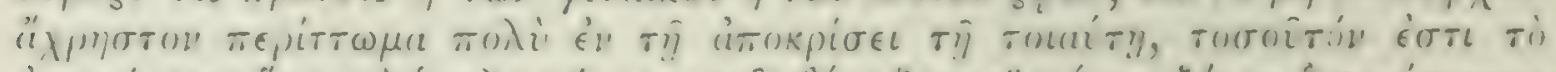

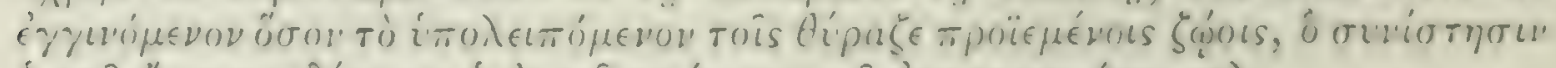

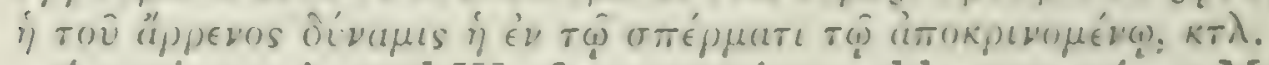

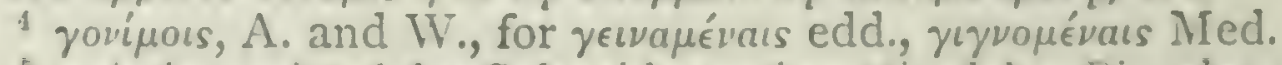

5 Tpis is omitted by Schneider, stigmatized by Piccolos: cf. G.A. iv. $5 \cdot 774^{a} 28$.

The meaning of the next sentence is unknown. Gaza tr. "etsi cactera bene se habet uterus'; Guil. 'etsi aliquando accidat habens':

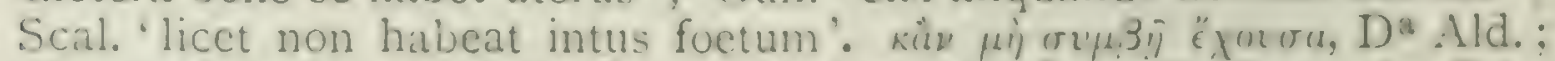

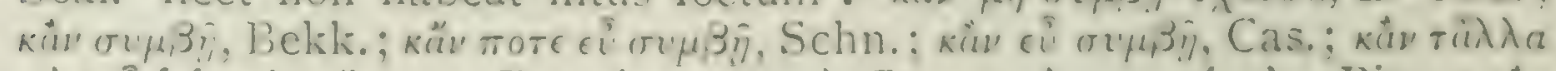

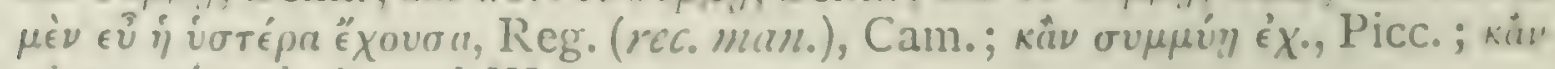
$\mu \eta \bar{\sigma} \sigma \nu \mu \mu i \eta, \mathrm{cj}$. A. and W. 
more abundant in women than in the females of any other animals. ${ }^{1}$ In creatures that do not bring forth their young 30 alive nothing of the sort manifests itself, this particular superfluity being converted into bodily substance; and by the way, in such animals the females are sometimes larger than the males; and moreover, the material is used up sometimes for scutes and sometimes for scales, and sometimes for the abundant covering of feathers, whereas in the vivipara possessed of limbs it is turned into hair and into bodily substance (for man alone among them is smooth- $583^{\text {a }}$ skinned), and into urine, for this excretion is in the majority of such animals thick and copious. Only in the case of women is the superfluity turned into a discharge instead of being utilized in these other ways.

There is something similar to be remarked of men: for in proportion to his size man emits more seminal fluid than 5 any other animal ${ }^{2}$ (for which reason man is the smoothest of animals), especially such men as are of a moist habit and not over corpulent, and fair men in greater degree than dark. It is likewise with women; for in the stout, great part of the excretion goes to nourish the body. In the act Io of intercourse, women of a fair complexion discharge a more plentiful secretion than the dark; ${ }^{3}$ and furthermore, a watery and pungent diet conduces to this phenomenon.

3 It is a sign of conception in women when the place is dry immediately after intercourse. ${ }^{4}$ If the lips of the 5 orifice be smooth conception is difficult, for the matter slips off; and if they be thick it is also difficult. But if on digital examination the lips feel somewhat rough and adherent, and if they be likewise thin, then the chances are in favour of conception. Accordingly, if conception be desired, we must bring the parts into such a condition as 20 we have just described; but if on the contrary we want to

${ }^{1}$ H.A. iii. 19. 52 I $^{\mathrm{a}}$, vi. 18. $572^{\mathrm{b}} ;$ G.A. i. $20.728^{\mathrm{b}}$.

${ }^{2}$ G.A.i. 19. $717^{\mathrm{a}}, 20.728^{\mathrm{b}}$, ii. $4.73^{\mathrm{b}}$.

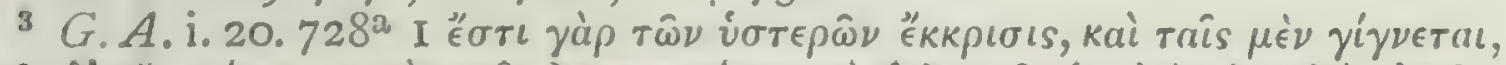

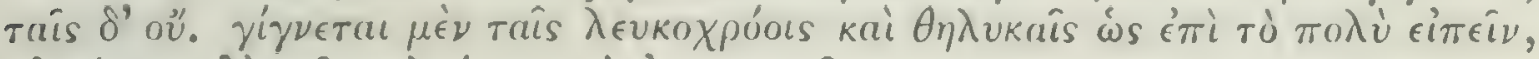

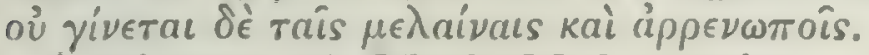

4 Hippocr. de Morb. Mul., passim. 
avoid conception then we must bring about a contrary disposition. Wherefore, since if the parts be smooth conception is prevented, some anoint that part of the womb on which the sced falls with oil of cedar, or with ointment of lead or with frankincense, commingled with olive oil. ${ }^{1}$ If the secd remain within for seven days then it is certain that conception has taken place; ${ }^{2}$ for it is cluring that period 25 that what is known as effluxion takes place.

In most cases the menstrual discharge recurs for soine time after conception has taken place, its duration being mostly thirty days in the case of a female and about forty days in the case of a male child. After parturition also it is common for the discharge to be withheld for an equal 30 number of days, but not in all cases with equal exactitude. After conception, and when the above-mentioned clays are past, the discharge no longer takes its natural course but finds its way to the breasts and turns to milk. The first appearance of milk in the breasts is scant in quantity and so to speak cobwebby or interspersed with little threads. And when conception has taken place, there is apt to be a sort of feeling in the region of the flanks, which in some $583^{\text {b }}$ cases quickly swell up a little, especially in thin persons, and also in the groin.

In the case of male children the first movement usually occurs on the right-hand side of the womb ${ }^{3}$ and about the fortieth day, but if the child be a female then on the left5 hand side and about the ninetieth day. However, we must by no means assume this to be an accurate statement of fact, for there are many exceptions, in which the movement is manifested on the right-hand side though a female child be coming, and on the left-hand side though the infant be a male. And in short, these and all suchlilie phenomena are usually subject to differences that may be summed up as differences of degree.

About this period the embryo begins to resolve into

${ }^{1}$ Cf. Hippocr. de Sterilit. MTul. iii. p. $38 \mathrm{~K}$, viii. p. $456 \mathrm{~L}$; also Aetii Sermon. 13, cit. Schneider, iii. p. 535.

2 Hippocr. de Sept. P. vii. p. 446 L, i. p. $451 \mathrm{~K}$.

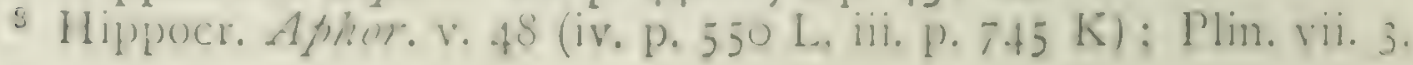


distinct parts, it having hitherto consisted of a fleshlike ro substance without distinction of parts.

What is called effluxion is a destruction of the embryo within the first week, while abortion occurs up to the fortieth day; and the greater number of such embryos as perish do so within the space of these forty days. ${ }^{1}$

In the case of a male embryo aborted at the fortieth day, if it be placed in cold water it holds together in a sort of membrane, but if it be placed in any other fluid it dissolves i 5 and disappears. If the membrane be pulled to bits the embryo is revealed, as big as one of the large kind of ants; and all the limbs are plain to see, including the penis, and the eyes also, which as in other animals are of great size. But the female embryo, if it suffer abortion during the first 20 three months, is as a rule found to be undifferentiated; if however it reach the fourth month it comes to be subdivided and quickly attains further differentiation. In short, while within the womb, ${ }^{2}$ the female infant accomplishes the whole development of its parts more slowly than the male, and more frequently than the man-child takes ten 25 months to come to perfection. ${ }^{3}$ But after birth, the females pass more quickly than the males through youth and maturity and age; and this is especially true of those that bear many children, as indeed I have already said.

4 When the womb has conceived the seed, straightway in the majority of cases it closes up until seven months are 30 fulfilled; but in the eight month it opens, and the embryo, if it be fertile, descends in the eighth month. ${ }^{4}$ But such embryos as are not fertile but are devoid of breath at eight months old, their mothers do not bring into the world by parturition at eight months, ${ }^{5}$ neither does the embryo descend within the womb at that period nor does the womb open. And it is a sign that the embryo is not capable of $584^{\text {n }}$

1 Hippocr. de Sept. P. i. pp. 447-8 K, vii. p. 442 L.

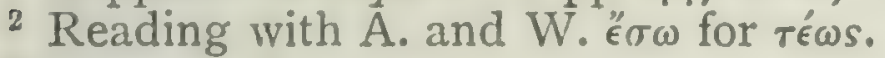

s Plin. vii. 3 .

4 Censorin. 7.

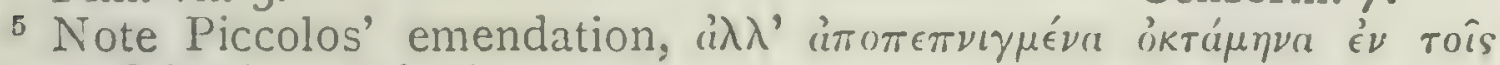

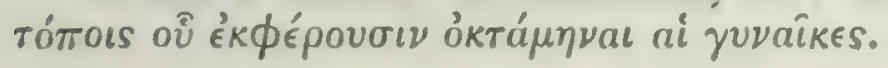


life if it be formed without the above-named circumstances taking place.

After conception women are prone to a fecling of heaviness in all parts of their bodies, ${ }^{1}$ and for instance they experience a sensation of darkness in front of the eyes and suffer also from headache. These symptoms appear sooner 5 or later, sometimes as early as the tenth day, according as the patient be more or less burthened with superfluous humours. Nausea also and sickness affect the most of women, and especially such as those that we have just now mentioned, after the menstrual discharge has ceased and before it is yet turned in the direction of the breasts.

Moreover, some women suffer most at the beginning of to their pregnancy and some at a later period when the embryo has had time to grow; and in some women it is a common occurrence to suffer from strangury towards the end of their time. As a general rule women who are pregnant of a male child escape comparatively easily and retain a comparatively healthy look, ${ }^{2}$ but it is otherwise with those whose infant is a female; for these latter look as a rule Is paler and suffer more pain, and in many cascs they are subject to swellings of the legs and eruptions on the body. Nevertheless the rule is subject to exceptions.

Women in pregnancy are a prey to all sorts of longings and to rapid changes of mood, and some folks call this the 'ivy-sickness';" and with the mothers of female 20 infants the longings are more acute, and they are less contented when they have got what they desired.

In a certain few cases the patient feels unusually well during pregnancy. The worst time of all is just when the child's hair is beginning to grow.

In pregnant women their own natural hair is inclined to grow thin and fall out, but on the other hand hair tends 25 to grow on parts of the body where it was not wont to be. As a general rule, a man-child is more prone to movement

1 Plin. vii. 5.

2 Plin. ibid.; Hippocr. Aphor.v. 42 (iii. p. 774 K, iv. p. 546 L).

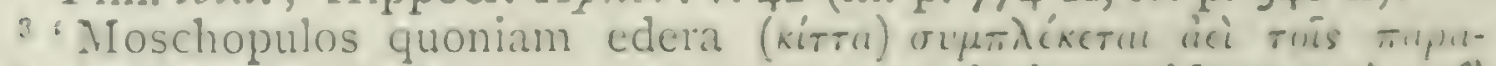

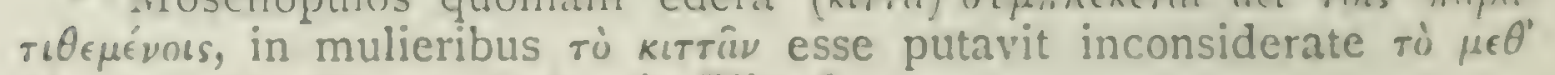

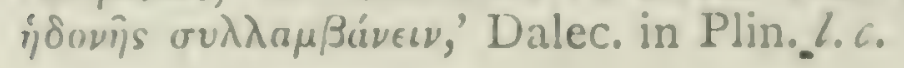


within its mother's womb than a female child, and it is usually born sooner. And labour in the case of female children is apt to be protracted and sluggish, while in the case of male children it is acute and by a long way more difficult. Women who have connexion with their husbands 30 shortly before childbirth are clelivered all the more quickly. ${ }^{1}$ Occasionally women seem to be in the pains of labour though labour has not in fact commenced, what seemed like the commencement of labour being really the result of the foetus turning its head.

Now all other animals bring the time of pregnancy to an end in a uniform way; in other words, one single term of pregnancy is defined for each of them. ${ }^{2}$ But in the case of 35 mankind alone of all animals the times are diverse; for pregnancy may be of seven months' duration, or of cight months or of nine, and still more commonly of ten [lunar] months, ${ }^{3}$ while some few women go even into the eleventh $584^{\text {b }}$ month. ${ }^{4}$

Children that come into the world before seven months can under no circumstances survive. ${ }^{5}$ The seven-months' children are the earliest that are capable of life, and most of them are weakly-for which reason, by the way, it is customary to swaddle them in wool,-and many of them are born with some of the orifices of the body imperforate, 5 for instance the ears or the nostrils. ${ }^{\circ}$ But as they get bigger they become more perfectly developed, and many of them grow up.

In Egypt, and in some other places where the women are fruitful and are wont to bear and bring forth many children

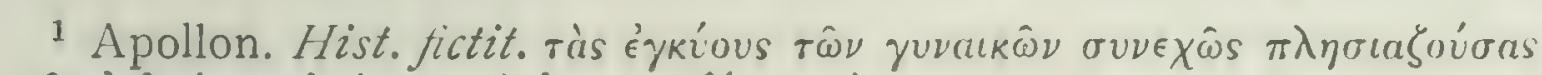

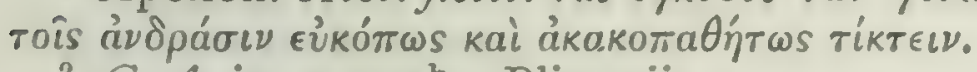

${ }^{2}$ G. A. iv. $3.772^{\mathrm{b}}$; Plin. vii. 4.

3 Sapient. vii. I, 2 'In ventre matris figuratus sum caro, decem mensium tempore'; Verg. Ecl. iv. 6I.

^ Aul. Gell. iii. I6 'Quamvis Decemviri in legibus duodecim tabularum, in decem mensibus gigni hominem non in undecimo scripsissent, I)ivum Hadrianum decrevisse in undecimo quoque mense partum edi posse'; Varro, ibi cit., '()uod si quis undecimo mense, кат' 'A

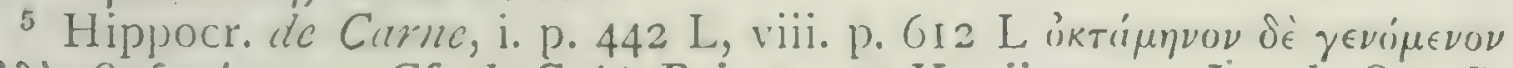

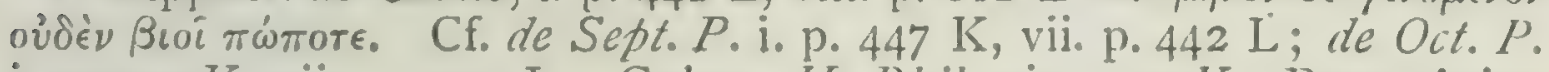
i. p. $455 \mathrm{~K}$, vii. p. $452 \mathrm{~L}$; Galen. H. Phil. xix. $332 \mathrm{~K}$; Rose, Arist. fr. p. 219.

${ }^{6} G .1$. iv. 6. $774^{\text {b). }}$ 
without difficulty, and where the children when born are capable of living ${ }^{1}$ even if they be born subject to deformity, ro in these places the eight-months' children live and are brought up, but in Grecce it is only a few of them that survive while most perish. ${ }^{2}$ And this being the general experience, when such a child does happen to survive the mother is apt to think that it was not an cight-months child after all, but that she had conceived at an carlier period without being aware of it.

r5 Women suffer most pain about the fourth and the eighth months, and if the foctus perishes in the fourth or in the eighth month the mother also succumbs as a general rule; so that not only do the eight-months' children not live, but when they die their mothers are in great clanger of their own lives. In like manner children that are apparently 20 born at a later term than eleven months" are held to be in doubtful case; inasmuch as with them also the beginning of conception may have escaped the notice of the mother. What I mean to say is that often the womb gets filled with wind, and then when at a later period connexion and conception take place, they think that the former circumstance was the beginning of conception from the similarity 2,5 of the symptoms that they experienced. ${ }^{4}$

Such then are the differences between mankind and other animals in regard to the many various modes ${ }^{5}$ of completion of the term of pregnancy." Furthermore, some animals produce one and some produce many at a birth, but the human species does sometimes the one and sometimes the other. As a general rule and among most 30 nations the women bear one child at a birth; but frequently and in many lands they bear twins, as for instance in Egypt cspecially.' Sometimes women bring forth three and even

1 Omit Dittmeyer's rá and oûv.

2 According to the mediacral astrologers the eighth month was under the rule of Saturn, and for this reason dangerous.

${ }^{3} \delta \epsilon ́ \kappa a \mu \eta \nu \hat{\omega} \nu$ A. and W., after Scotus, Alb. M., and D.

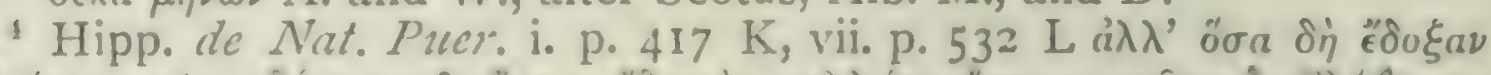

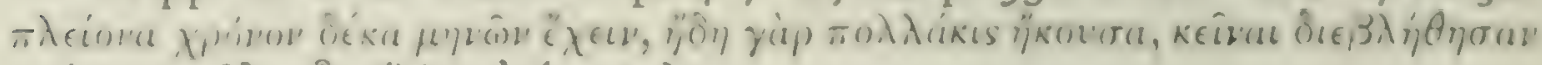

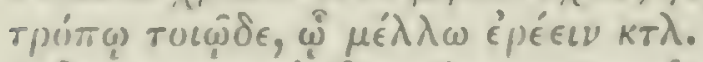

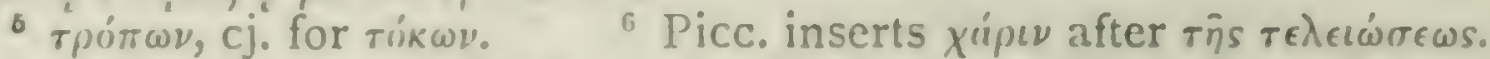

7 Antig. H. 11. I19; Phlegon 28; Gellius x. 2; Plin. vii. 3 ; Colum. R. R. iii. S; Seneca, 2. N. xiii. 25. 
four children, and especially in certain parts of the world, as has already been stated. The largest number ever brought forth is five, and such an occurrence has been witnessed on several occasions. There was once upon a time a certain woman who had twenty children at 35 four births; each time she had five, and most of them grew up.

Now among other animals, if a pair of twins happen to be male and female they have as good a chance of surviving as though both had been males or both females; ${ }^{1}$ but among mankind very few twins survive if one happen to be $585^{\mathrm{a}}$ a boy and the other a girl.

Of all animals the woman and the mare are most inclined to receive the commerce of the male during pregnancy; while all other animals when they are pregnant avoid the male, save those in which the phenomenon of superfoetation occurs, such as the hare. ${ }^{2}$ Unlike that 5 animal, the mare after once conceiving cannot be rendered pregnant again, but brings forth one foal only, at lcast as a general rule; in the human species cases of superfoetation are rare, but they do happen now and then.

An embryo conceived some considerable time after a previous conception does not come to perfection, but gives rise to pain and causes the destruction of the earlier embryo; and, by the way, a case has been known to occur 10 where owing to this destructive influence no less than twelve embryos conceived by superfoetation have been discharged. ${ }^{3}$ But if the second conception take place at a short interval, then the mother bears that which was later conceived, and brings forth the two children like actual twins, as happened, according to the legend, in the case of Iphicles and Hercules. ${ }^{4}$ The following also is a striking example: a certain woman, having committed ${ }_{15}$

1 Cf. John Hunter on Free Martins, Phil. Tr. vol. Ixix, p. 274.

2 H.A. vi. 33. $579^{\mathrm{b}} 32 ; G$. A. iv. 5. $773^{\mathrm{a}} 32$.

"A case of 'vesicular degeneration of the chorion', in which disease little bladders escape that may be mistaken for ova.

${ }^{1}$ Of whom the one was the son of Amphitryon and the other of Jupiter. Cf. Plin. vii. 9. 
adultery, brought forth the one child resembling her husband and the other resembling the adulterous lover.

The case has also occurred where a woman, being pregnant of twins, has subsequently conceived a third child: and in course of time she brought forth the twins perfect and at full term, but the third a five-months' child; and this last died there and then. And in another case it happened that the woman was first delivered of a seven20 months' child, and then of two which were of full term; and of these the first died and the other two survived.

Some also have been known to conceive while about to miscarry, and they have lost the one child and been delivered of the other.

If women while going with child cohabit after the eighth month the child is in most cases born covered over with 25 a slimy fluid. Often also the child is found to be replete with food of which the mother had partaken.

When women have partaken of salt in over-abundance their children are apt to be born destitute of nails. ${ }^{1}$

Milk that is produced carlicr than the serenth month 5 30 is unfit for use:"2 but as soon as the child is fit to live the milk is fit to use. The first of the milk is saltish, as it is likewise with sheep. Most women are sensibly affected by wine during pregnancy; for if they partake of it they grow relaxed and debilitated.

The beginning of child-bearing in women and of the capacity to procreate in men, and the cessation of these 3. functions in both cases, coincide in the one case with the emission of seed and in the other with the discharge of the catamenia: with this qualification that there is a lack of fertility at the commencement of these symptoms, and again towards their close when the emissions become scanty $585^{\mathrm{b}}$ and weak. The age at which the sexual powers begin has been related alrcady." As for their end, the menstrual discharge ceases in most women about their forticth year; but with those in whom it goes on longer it lasts cren to

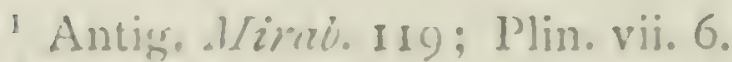

${ }^{2}$ G.A.iv. S. $776^{a} 23 ;$ P'lin. xi. $5, y 6$

3. $1 . \mathrm{V}$ I. 
the fiftieth year, and women of that age have been known to bear children. But beyond that age there is no case 5 on record.

6 Men in most cases continuc to be sexually competent until they are sixty years old, and if that limit be overpassed then until seventy years; and men have been actually known to procreate children at seventy years of age. With many men and many women it so happens that they are unable to produce children to one another, io while they are able to do so in union with other individuals. ${ }^{1}$ The same thing happens with regard to the production of male and female offspring; for sometimes men and women in union with one another produce male children or female, as the case may be, but children of the opposite sex when otherwise mated. And they are apt to change in this respect with advancing age: for sometimes a husband and wife while they are young produce female children and in later life male children; and in other cases is the very contrary occurs. And just the same thing is true in regard to the generative faculty: for some while young are childless, but have children when they grow older; and some have children to begin with, and later on no more.

There are certain women who conceive with difficulty, but if they do conceive, bring the child to maturity; 20 while others again conceive readily, but are unable to bring the child to birth. Furthermore, some men and some women produce female offspring and some male, as for instance in the story of Hercules, who among all his two and seventy children is said to have begotten but one girl. ${ }^{2}$ Those women who are unable to conceive, save with the help of medical treatment or some other adventitious ${ }_{25}$ circumstance, are as a general rule apt to bear female children rather than male.

It is a common thing with men to be at first sexually

1 G. A. iv. $2.767^{\mathrm{a}} 23$.

2 Macaria: Pausan. i. 326. Cf. Eurip. Heracl. 501 ; Schol. ad Ar. Lys. I I 4 I. 
competent and afterwards impotent, and then again to revert to their former powers.

From deformed parents come deformed children, lame 30 from lame and blind from blind, ${ }^{1}$ and, speaking generally, children often inherit anything that is peculiar in their parents and are born with similar marks, such as pimples or scars. Such things have been known to be handed down through three generations; ${ }^{2}$ for instance, a certain man had a mark on his arm which his son did not possess, but his grandson had it in the same spot though not very distinct. ${ }^{3}$

35 Such cases, however, are few ; for the children of cripples are mostly sound, and there is no hard and fast rule regarding them. While children mostly resemble their parents or $5^{86^{a}}$ their ancestors, it sometimes happens that no such rescmblance is to be traced. But parents may pass on resemblance after several generations, as in the case of the woman in Elis, ${ }^{4}$ who committed adultery with a negro; in this case it was not the woman's own daughter but the daughter's child that was a blackamoor.

As a rule the daughters have a tendency to take after 5 the mother, and the boys after the father; but sometimes it is the other way, the boys taking after the mother and the girls after the father. And they may resemble both parents in particular features. ${ }^{5}$

There have been known cases of twins that had no resemblance to one another, but they are alike as a general rule. There was once upon a time a woman who had 1o intercourse with her husband a week after giving birth to a child, and she conceived and bore a second child as like the first as any twin. Some women have a tendency to produce children that take after themselves, and others children that take after the husband: ${ }^{2}$ and this latter case

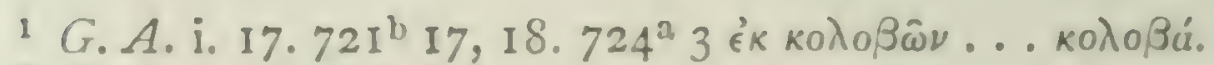

${ }^{2} G \cdot A \cdot$ i. 18. $722^{a} 8$.

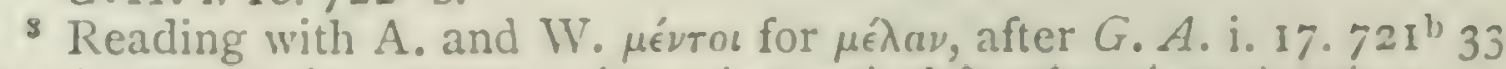

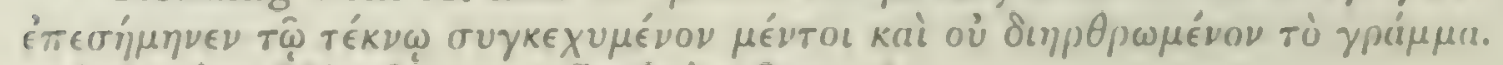

- Antig. Mirab. 122; G.A.i. 18. $722^{2} 9$.

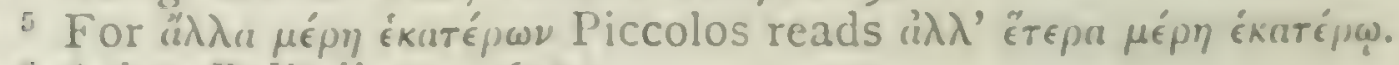

- Arist. Polit. ii. 3. $1262^{a} 2 \mathrm{I}$. 
is like that of the celebrated mare in Pharsalus, that got the name of the Honest Wife.

7 In the emission of sperm there is a preliminary discharge 15 of air, ${ }^{1}$ and the outflow is manifestly caused by a blast of air; for nothing is cast to a distance save by pneumatic pressure. After the seed reaches the womb and remains there for a while, a membrane forms around it; for when it happens to escape before it is distinctly formed, it looks like an egg enveloped in its membrane after removal of the 20 eggshell; and the membrane is full of veins.

All animals whatsoever, whether they fly or swim or walk upon dry land, whether they bring forth their young alive or in the egg, develop in the same way: save only that some have the navel attached to the womb, namely the viviparous animals, and some have it attached to the egs, and some to both parts alike, as in a certain sort of fishes. And in some cases membranous envelopes surround the egg, and 25 in other cases the chorion surrounds it. And first of all the animal develops within the innermost envelope, and then another membrane appears around the former one, which latter is for the most part attached to the womb, but is in part separated from it and contains fluid. In between is a watery or sanguineous fluid, which the women folk call the forewaters. ${ }^{2}$

8 All animals, or all such as have a navel, grow by the navel. ${ }^{3}$ And the navel is attached to the cotyledon in all such as possess cotyledons, and to the womb itself by a vein in all such as have the womb smooth. ${ }^{4}$ And as regards their shape within the womb, the four-footed animals all lie stretched out, and the footless animals lie on their sides, as for instance fishes; but two-legged animals lie in a bent $5^{86^{\mathrm{b}}}$ position, as for instance birds; ${ }^{5}$ and human embryos lie bent, with nose between the knees and eyes upon the knees, and the ears free at the sides.

1 Probl. xxx. I. $953^{\mathrm{b}} 33$.

2 This arcount is manifestly much inferior to that in Bk. vi. 3 and ro. Cf. also G.A. iii. 9; Hippocr. de Nat. Puer. i. pp. 386-7, 4I5-I6 K, vii. pp. $490,531 \mathrm{~L}$.
${ }^{3}$ G. A. ii. $7 \cdot 745^{\mathrm{b}} 22$.
${ }^{5} H . A$. vi. $3.561^{\mathrm{b}} 30 ;$ Plin. x. 84 .
4 H. A. iii. I. 5 I I $^{\mathrm{a}} 30$. 
All animals alike have the head upwards to begin with; but as they grow and approach the term of egress from the 5 womb they turn downwards, and birth in the natural course of things takes place in all animals head foremost ${ }^{1}$ but in abnormal cases it may take place in a bent position, or fect foremost.

The young of quadrupeds when they are near their full time contain excrements, both liquid and in the form of solid lumps, the latter in the lower part of the bowel and so the urine in the bladder.

In those animals that have cotyledons in the womb the cotyledons grow less as the cmbryo grows bigger, ${ }^{2}$ and at length they disappear altogether. The navel-string is a sheath wrapped about blood-vesscls which have their origin in the womb, from the cotyledons in those animals which possess them and from a blood-ressel in those which 15 do not. In the larger animals, such as the embryos of oxen, the vessels are four in number, and in smaller animals two; in the rery little ones, such as fowls, one vessel only."

Of the four vesscls that run into the embryo, two pass through the liver where the so-called gates or 'portac' 4 are, running in the dircetion of the great vein, and the 20 other two run in the direction of the aorta towards the point where it divides and becomes two vessels instead of one. Around each pair of blood-ressels are membranes, and surrounding these membranes is the navel-string itself, after the manner of a sheath. ${ }^{5}$ And as the embryo grows, the veins themselves tend more and more to dwindle in size. And also as the embryo matures it comes down into 25 the hollow of the womb and is obscrved to move here, and sometimes rolls over in the vicinity of the groin.

When women are in labour, their pains determine to- 9 wards many divers parts of the body, and in most cases

I G.A.iv. 9. $777^{2} 28$; Plin. x. I13.

2 Contra, Harvey, de Gen. p. 397.

3 See the much better account in $H$. A. vi. 3 .

${ }^{4}$ C. Plato, Tim. p. 390; Hippocr. de Morl. Vulg. iii. p. $456 \mathrm{~K}$, v. p. $123 \mathrm{~L}$; de Anat. viii. p. $538 \mathrm{~L}$.

G.A. ii. $4 \cdot 740^{2} 31,7 \cdot 745^{\circ}=6$. 
to one or other of the thighs. Those are the quickest to be delivered who experience severe pains in the region of 30 the belly; and parturition is difficult in those who begin by suffering pain in the loins, and speedy when the pain is abdominal. If the child about to be born be a malc, the preliminary flood is watery and palc in colour, but if a girl it is tinged with blood, though still watcry. In some cases of labour thesc latter phenomena do not occur, either one way or the other.

In other animals parturition is unaccompanied by pain, and the dam is plainly seen to suffer but moderate incon- $587^{\mathrm{a}}$ venience. In women, however, the pains are more severe, and this is especially the case in persons of sedentary habits, and in those who are weak-chested and short of breath. Labour is apt to be especially difficult if during the process the woman while exerting force with her breath fails to hold it in. ${ }^{1}$

First of all, when the embryo starts to move ${ }^{2}$ and the membranes burst, there issucs forth the watery flood; then afterwards comes the embryo, while the womb everts and the afterbirth comes out from within.

Io The cutting of the navel-string, which is the nurse's duty, is a matter calling for no little care and skill. For not only in cases of difficult labour must she be able to render assist- ro ance with skilful hand, but she must also have her wits about her in all contingencies, and especially in the operation of tying the cord. For if the afterbirth have come away, the navel is ligatured off from the afterbirth with a woollen thread and is then cut above the ligature; and at the place where it has been tied it heals up, and the remain- Is ing portion drops off. (If the ligature come loose the child dies from loss of blood.) ${ }^{4}$ But if the afterbirth has not yct come away, but remains after the child itself is extruded, it is cut away within ${ }^{5}$ after the ligaturing of the cord. ${ }^{6}$

3 Plin. vii. 5.

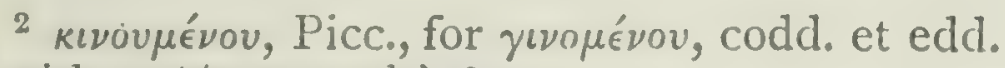

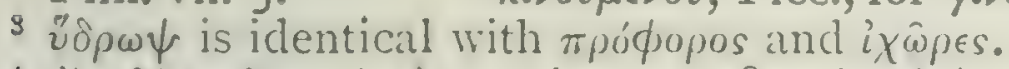

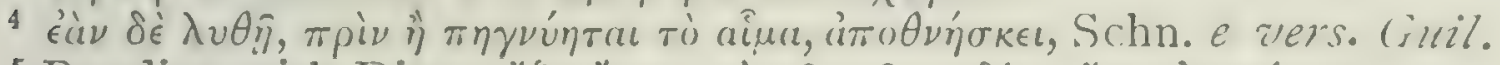

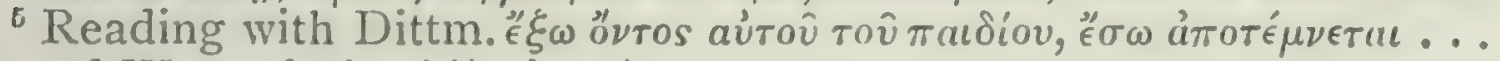

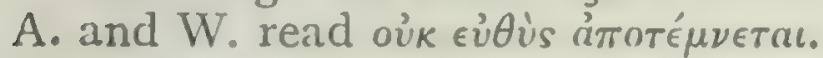

- $A$. and $I V$. reject the traditional reading on the ground that it 
It often happens that the child appears to have becn born dead when it is merely weak, and when, before the 20 umbilical cord has been ligatured, the blood has run out into the cord and its surroundings. But experienced midwives have been known to squecze back the blood into the child's body from the cord, and immediately the child that a moment before was bloodless came back to life again.

It is the natural rule, as we have mentioned above, for 25 all animals to come into the world head foremost, and children, moreover, have their hands stretched out by their sides. And the child gives a cry and puts its hands up to its mouth as soon as it issues forth.

Moreover the child voids excrement sometimes at once, sometimes a little later, but in all cases dirring the first day; and this excrement is unduly copious in comparison with 30 the size of the child; it is what the midwives call the meconium or 'poppy-juice'. In colour it resembles blood, extremely dark and pitch-like, but later on it becomes milky, for the child takes at once to the breast. Before birth the child makes no sound, eren though in difficult labour it put forth its head while the rest of the body remains within.

$5^{8} 7^{\mathrm{b}}$ In cases where flooding takes place rather before its time, it is apt to be followed by difficult parturition. But if discharge take place after birth in small quantity, and in cases where it only takes place at the beginning and does not continue till the forticth day, then in such cases women make a better recovery and are the sooner ready. 5 to conceive again.

Until the child is forty days old it neither laughs nor weeps during waking hours, but of nights it sometimes does both $;^{1}$ and for the most part it does not even notice being

prescribes identical treatment whether the placenta come away or not. 'Bei zurïkbleibender l'lacenta fürchtete man (wiewol grundlos) eine Ylutung der Mutter, und schnitt daher die Nabelschnur erst einige Zeit nach dem Iustritte des Kindes.' They accordingly reconstruct

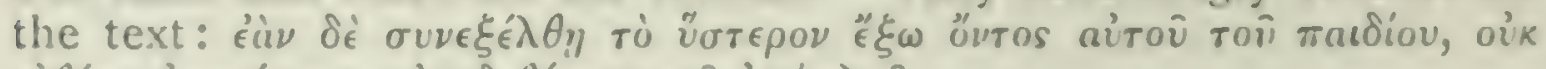

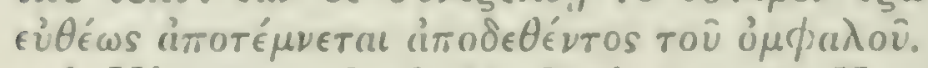

1 Hippocr. de Sept. P. i. p. 454 K, vii. p. 450 L Ëע te yìp toís

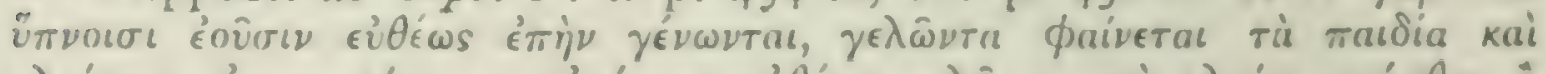

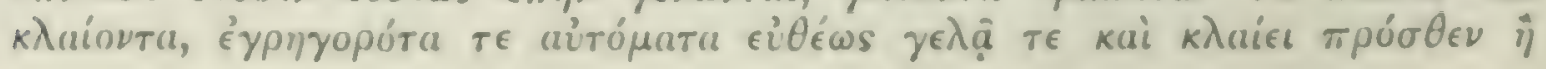


tickled, but passes most of its time in sleep. As it keeps on growing it gets more and more wakeful; and moreover it shows signs of dreaming, though it is long afterwards to before it remembers what it dreams.

In other animals there is no contrasting difference between one bone and another, but all are properly formed; but in children the front part of the head ${ }^{1}$ is soft and late of ossifying. And by the way, some animals are born with teeth, but children begin to cut their teeth in the seventh month $;^{2}$ and the front teeth are the first to come 15 through, sometimes the upper and sometimes the lower ones. And the warmer the nurses' milk so much the quicker are the children's teeth to come.

II After parturition and the cleansing flood the milk comes in plenty, and in some women it flows not only from the 20 nipples but at divers parts of the breasts, and in some cases even from the armpits. And for some time afterwards there continue to be certain indurated parts of the breast called strangalides, or 'knots', which occur when it so happens that the moisture is not concocted, ${ }^{3}$ or when it finds no outlet but accumulates within. ${ }^{4}$ For the whole breast is so spongy that if a woman in drinking happen to swallow a hair, she 25 gets a pain in her breast, which ailment is called 'trichia' ;" and the pain lasts till the hair either find its own way out or be sucked out with the milk. ${ }^{6}$ Women continue to have milk until their next conception; and then the milk stops coming and goes dry, alike in the human species and in the

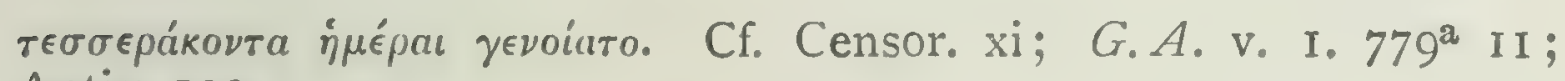
Antig. I23.

1 Or anterior fontanelle, which A. describes as a distinct bone H. A. i. 7. $491^{\mathrm{a}}$ 3 I; G.A. ii. 6. $744^{\mathrm{a}} 24$, v. $8.788^{\mathrm{b}}$.

2 (i. A. ii. 6. $745^{\mathrm{b}}$ 10; Plin. vii. 15, xi. 63; Hippocr. de S. P. i. p. $452 \mathrm{~K}$, vii. p. 448 L; Macrob. de S. Sc. i; Auson. in Monosyll. 'Indicat in pueris septennia prima novus dens'.

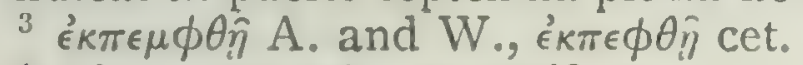

4 Picc. $\sigma \kappa \lambda \eta \rho \omega \theta \hat{\eta}, \pi \lambda \eta \rho \omega \theta \hat{\eta}$ cet.

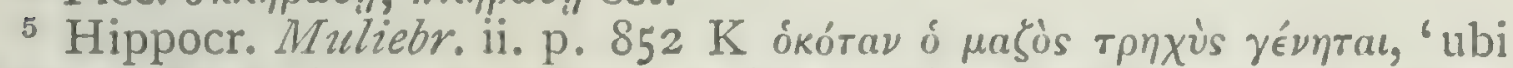

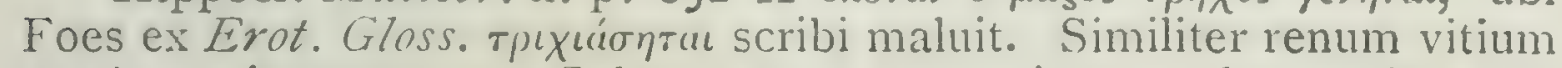
$\tau \rho \iota \chi^{\prime} \iota \sigma \iota \nu$ interpretatur Galenus cum per urinam velut capilli albi

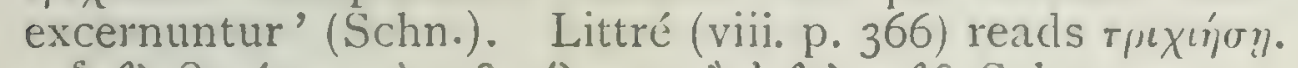

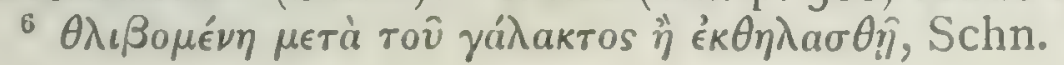


.0 quadrupedal vivipara. So long as there is a flow of milk the menstrual purgations do not take place: at least as a general rule, though the discharge has been known to occur during the period of suckling. For, speaking generally; a determination of moisture does not take place at one and the same time in several clirections; as for instance the menstrual purgations tend to be scanty in persons suffering from hacmorthoids. And in some women the like happens owing to their suffering from varices, ${ }^{2}$ when the fluids issue from the pelvic region before entering into the womb. And $598^{a}$ patients who during suppression of the menses happen to vomit blood are no whit the worse. ${ }^{3}$

Children are very commonly subject to convulsions, ${ }^{4}$ more 12 especially such of them as are more than ordinarily wellnourished on rich or'unusually plentiful milk from a stout 5 nurse. Wine is bad for infant., in that it tends to excite this malady; and red wine is worse than white, especially when taken undiluted; " and most things that tend to induce flatulency "are also bad, and constipation too is prejudicial. The majority of deaths in infancy occur before the child is a week old, hence it is customary to name the child at that age, from a belief that it has now a better chance of ro survival. This malady is worst at the full of the moon; ${ }^{s}$ and by the way, it is a dangerous symptom when the spasms begin in the child's back.?

1 H.A. iii. I9. $521^{a} 29 ; G \cdot A$. i. 19. $727^{a}$ I2.

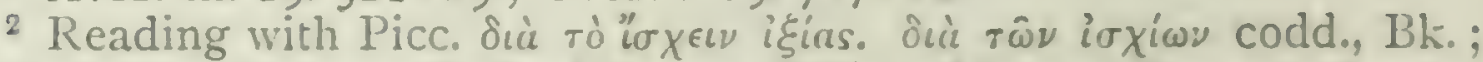

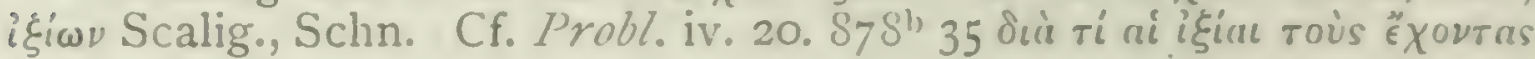

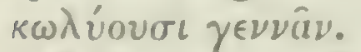

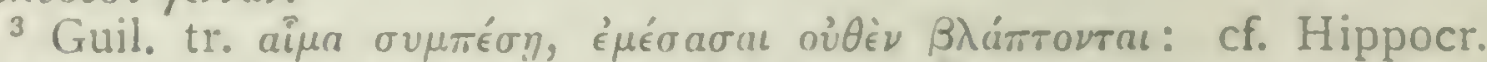

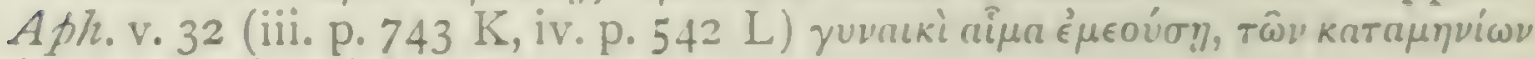

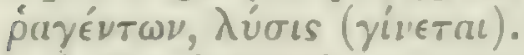

* On infantile convulsions see Hippocr. passim, e.g. ii. p. IS7, v. p. 607 , vi. p. $83 \mathrm{~L}$, \&.c.

Cf. de Somno et Vig. 3. $457^{\mathrm{a}}$ I 4 .

'A troublesome word, perhaps implying lentils, peas, or such-like regetables that grow in tods: cf. H. A. iii. $21.522^{b} 33$, viii. $7.595^{b} 6$.

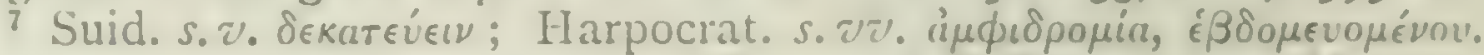
Lat. dies lustricus s. mominalis; cf. Festus up. P. Diac. p. I20; . Macrob. Saturn. i. I6; Suet. Nero 6.

Plin. vii. 5.

'A symptom of 'telumus nconutorum', a specific ailment arising by infection through an ill-dressed cord. 


\section{BOOK VIII}

I IVE have now discussed the physical characteristics of $588^{a}$ animals and their methods of generation. Their habits and their modes of living vary according to their character and their food.

${ }^{1}$ In the great majority of animals there are traces of psychical qualities or attitudes, ${ }^{2}$ which qualities are more markedly differentiated in the case of human beings. 20 For just as we pointed out resemblances in the physical organs, ${ }^{3}$ so in a number of animals we observe gentleness or fierceness, mildness or cross temper, courage or timidity, fear or confidence, high spirit or low cunning, and, with regard to intelligence, something equivalent to sagacity. Some of

1 Here A. deals with $\sigma v v^{\prime} \chi \in \epsilon l a$, the 'principle of continuity', fundamental in Biology and Psychology. Various analyses of the soul are dialectically possible (cf. Eth. Nii. I. I3. I I $2^{2} 28$, \& c. ), but the scientific account is found in the de Anima. There we arrive at a tripartite

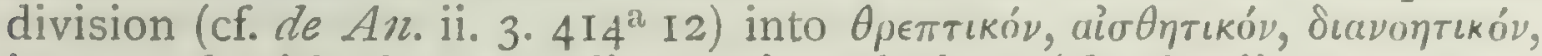
in accord with the ascending series of plant (de An. ii. 3. 4I $4^{2} 33$; G. A. ii. 4. $74^{\mathrm{a}} \mathrm{I}$ ), animal (de An. ii. 2. $4 \mathrm{I} 3^{\mathrm{b}} \mathrm{I} ; G \cdot A$. ii. $4 \cdot 74 \mathrm{I}^{\mathrm{a}} 2,3$. $736^{\mathrm{at}} 30 ; P . A$. iv. 5.678 2 ; de V.et $M .4 .469^{\mathrm{b}} 4$ ), and man (de An.

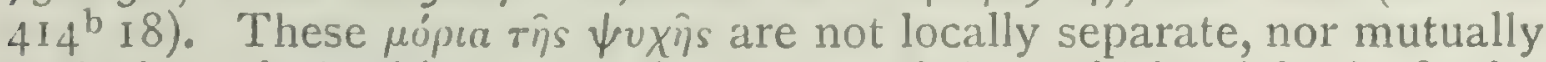

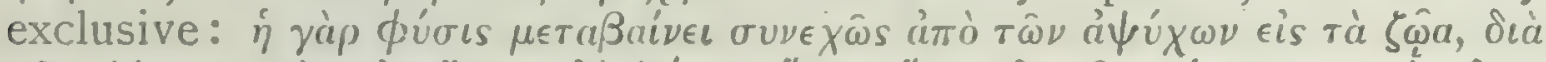

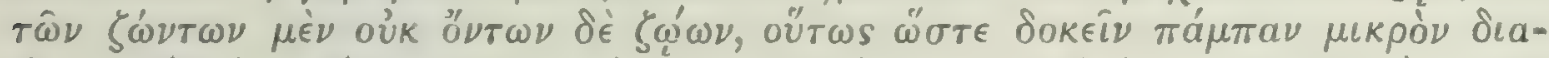

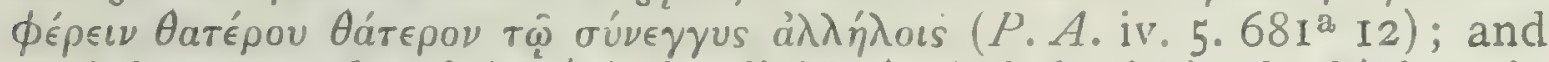
cach lower grade of $\psi u x \dot{y}$ is implicitly included within the higher. $\dot{\omega} s$

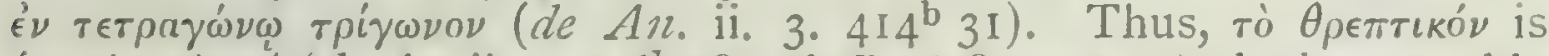

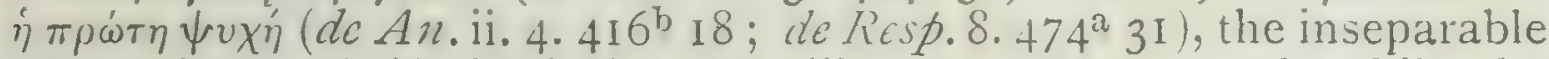
concomitant of life itself (de An. iii. I2. $434^{a} 22$ ); and, while the higher of the three physical stages retain the psychological qualities of the lower, so also do the lower exhibit adumbrations of the psychical

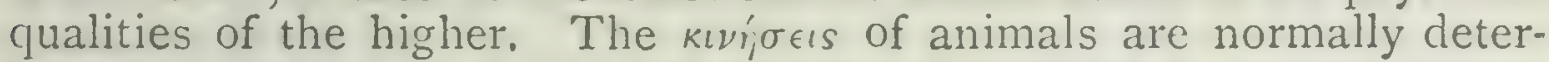
mined by $\dot{\epsilon} \pi \imath v \mu i_{a}$ or $\theta u \mu$ ós; but we have sometimes in animals traces

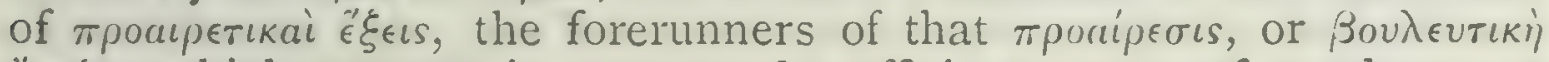
"of $f \dot{\xi} \iota s$, which appears in man as the efficient cause of goodness or

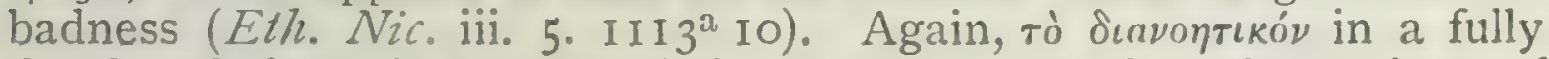
developed form is characteristic of man alone, but the actions of animals seem to exhibit it in a rudimentary form, just as even animals

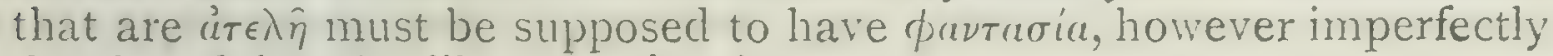
developed (de An. iii. II. $433^{\mathrm{b}}$ 3I).

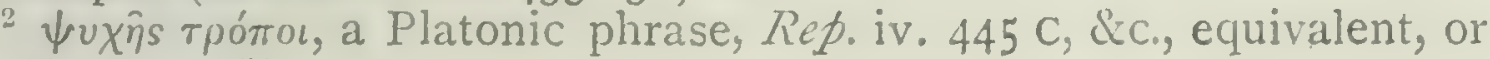
nearly so, to $\bar{\epsilon}^{\prime} \xi \epsilon$.

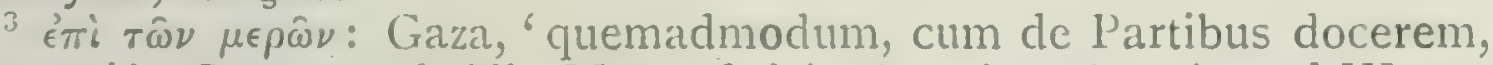
exposui'; Scotus and Alb. M. read $\epsilon \pi i t \tau \hat{\omega} \nu \mu \epsilon \lambda \iota \sigma \sigma \hat{\omega} \nu ; A$. and W. are inclined to transfer the clause to the following sentence, kutuitep rip. $\dot{\epsilon} \pi i \tau \hat{\omega} \nu \mu \epsilon \rho \hat{\omega} \nu \kappa \tau \lambda$. Dittm. refers to H. A. i. I. $488^{\mathrm{b}} \mathrm{I} 2$. 
25 these qualities in man, as compared with the corresponding qualitics in animals, differ only quantitatively: that is to say, a man has more or less of this quality, and an animal has more or less of some other; other qualitics in man are represented by analogous and not identical qualities: for instance, just as in man we find knowledge, wisdom, 30 and sagacity: ${ }^{1}$ so in certain animals there exists some other natural potentiality akin to these." The truth of this statement will be the more clearly apprehended if we have regard to the phenomena of childhood: for in children may be observed the traces and -seeds of what will one day $588^{\mathrm{b}}$ be settled psychological habits, though psychologically a child hardly differs for the time being from an animal; so that one is quite justified in saying that, as regards man and animals, certain psychical qualitics are identical with one another, whilst others resemble, and others are analogous to, each other.

Nature proceeds little by little from things lifeless to 5 animal life in such a way that it is impossible to determine the cxact line of demarcation, nor on which side thereof an intermediate form should lie." Thus, next after lifeless things in the upward scale comes the plant, and of plants one will differ from another as to its amount of apparent vitality; and, in a word, the whole genus of plants, whilst it is devoid of life as compared with an animal, is endowed ro with life as compared with other corporcal entitics." Indeed, as we just remarked, there is observed in plants a continuous scale of ascent towards the animal." So, in the sea, there are certain objects concerning which one would be at a loss to determine whether they be animai or vegetable. ${ }^{6}$ For instance. certain of these objects are

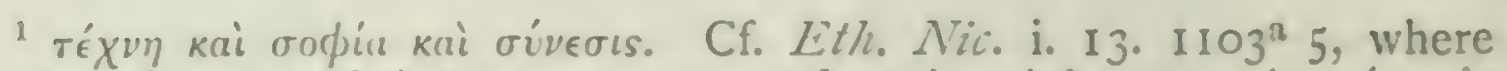

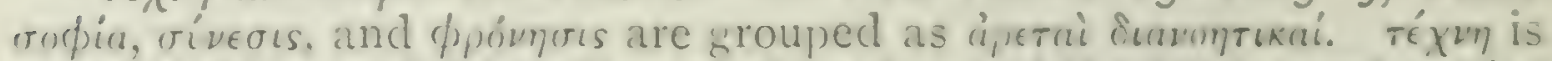

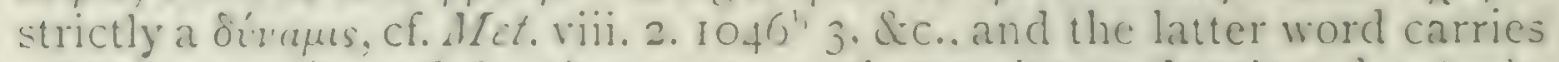

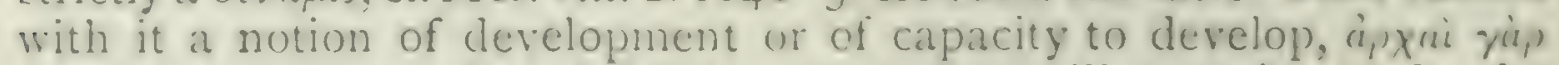

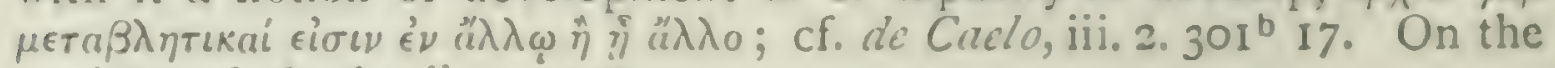

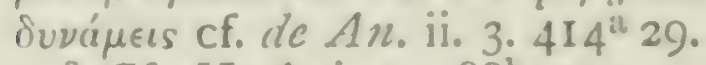

C C. H. A. i. I. $488^{\mathrm{b}}$ II.

(f. I. A. ii. $5.68 \mathrm{I}^{\mathrm{a}}$ I2.

1 Plat. Phacdr. 245 E; Arist. de A11. i. 2. $403^{\mathrm{b}} 25$, ii. $2.413^{\mathrm{a}} 25$; cf. Mctcor. iv. 12. 390 a , \&c.

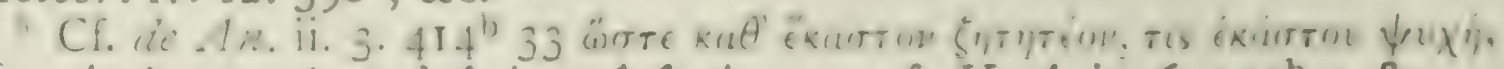

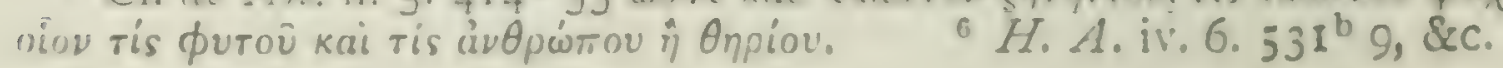


fairly rooted, ${ }^{1}$ and in several cases perish if detached; thus the pinna ${ }^{2}$ is rooted to a particular spot, and the ${ }_{15}$ solen (or razor-shell) cannot survive withdrawal from its burrow. ${ }^{3}$ Indeed, broadly speaking, the entire genus of testaceans have a resemblance to vegetables, if they be contrasted with such animals as are capable of progression.

In regard to sensibility, some animals give no indication whatsoever of it, whilst others indicate it but indistinctly. Further, the substance of some of these intermediate creatures is fleshlike, as is the case with the so-called tethya (or ascidians) and the acalephae (or sea-anemones); 20 but the sponge is in every respect like a vegetable. And so throughout the entire animal scale there is a graduated differentiation in amount of vitality and in capacity for motion.

A similar statement holds good with regard to habits of life. Thus of plants that spring from seed the one function seems to be the reproduction of their own particular species, 25 and the sphere of action with certain animals is similarly limited. The faculty of reproduction, then, is common to all alike. ${ }^{4}$ If sensibility be superadded, ${ }^{5}$ then their lives will differ from one another in respect to scxual intercourse through the varying amount of pleasure derived therefrom, and also in regard to modes of parturition and 30 ways of rearing their young. Some animals, like plants, simply procreate their own species at definite seasons; other animals busy themselves also in procuring food for their young, and after they are reared quit them and have no further dealings with them; other animals are more in- $589^{\text {a }}$ telligent and endowed with memory, and they live with their offspring for a longer period and on a more social footing.

1 H. A. i. I. $487^{\mathrm{b}} 8$, v. I6. $548^{\mathrm{b}} 5$, \&c.

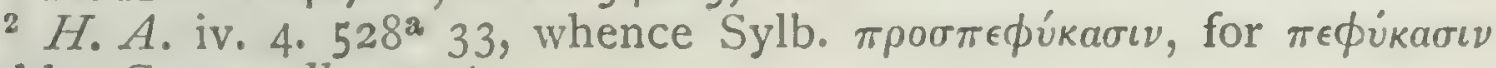
codd. Gaza, adhaerent.

${ }^{3}$ Note that it is by an iron rod or spike that the solen is withdrawn; cf. iv. 8. $535^{\mathrm{a}} 15$.

${ }^{4}$ H.A.v. I. $539^{\text {a }}$ I 5 ; Phys. i. 7. 190 ${ }^{\mathrm{b}}$ I, \&c.

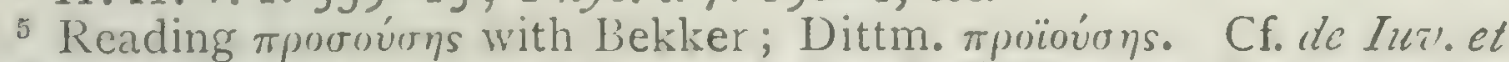

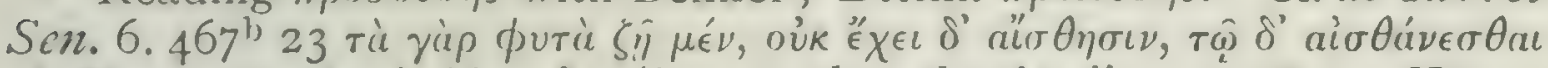

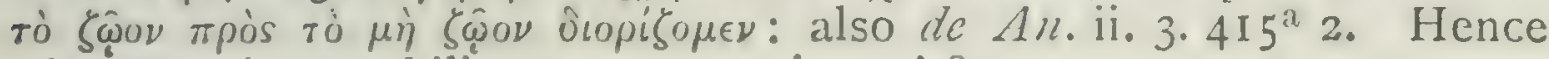
Linnaeus, 'vegetabilia crescunt et vivunt,' \&c. 
The life of animals, then, may be divided into two actsprocreation and feeding; for on these two acts all their 5 interests and life concentrate. Their food depends chiefly on the substance of which they are sererally constituted; for the source of their growth in all cases will be this substance. And whatsoever is in conformity with nature is pleasant, and all animals pursue pleasure in keeping with their nature.

Animals are also differentiated locally: that is to say, some live upon dry land, while others live in the water. And this differentiation may be interpreted in two ${ }^{1}$ different ways. Thus, some animals are termed terrestrial as inhaling air, and others aquatic as taking in water ; and there $1:$ are others which do not actually take in these elements, ${ }^{2}$ but nevertheless are constitutionally adapted to the cooling influence, so far as is needful to them, of one element or the other, and hence are called terrestrial or aquatic though they neither breathe air nor take in water. Again," other animals are so called from their finding their food and fixing their habitat on land or in water: for many animals, although they inhale air and breed on land, yet derive their food from the water, and 20 live in water for the greatcr part of their lives; and these

$1 \delta \iota \chi \omega \hat{s}$, MSS., Bekk., Picc.; $\tau \rho \iota \chi \omega ̄ s$, Scalig. after Gaza, A. and M., Dittm. ; cf. $590^{2}{ }^{1} 3$. I retain $\delta \iota \chi^{\omega} \omega$, thinking that $A$. started with two main dichotomies, one founded on respiration, the other upon habitation and diet. The thrst and fundamental distinction is, among blooded animals, between those possessed of a lung and those possessed of gills, those namely which take in air or water for respiration, or (as A. inderstoo(i it) for kuziqu $\xi$ s, the cooling of the blood (ut Resf. $10.475^{\circ}$ 18). Here a cognate but subsidiary distinction emerges, because bloodless animals can perform this function in a way sufficient for their necels likuas) through the cooling influence of the surrounding medium and without 'taking in' either water or air (cf. de liesp.9. $474^{\mathrm{b}} 26$; 10. $475^{\mathrm{b}} 5,15 ; 12.476^{\mathrm{b}}$ ). The second great distinction is that some animals live and feed on land, and some in water; and this is manifestly quite a different dichotomy to the first. $A$. is hampered throughout this discussion by his habitual reluctance to coin a new nomenclature or to abandon a popular classification embodied in current speech; he clings to the terms $\pi \epsilon \zeta i v$ and $\epsilon^{2} \nu v \delta p o \nu$ after they are shown to be unfit to connote the sought-for distinctions.

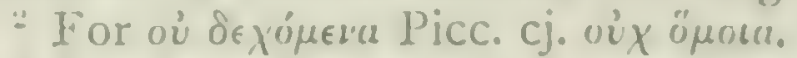

3 Kead ri $\delta \dot{\epsilon}$ ro with Schn., A. and 11. , and Ditm. For other variants in this difficult passage sce Schn., Jittm., and Piccolos. 
are the only animals to which as living in and on two elements the term 'amphibious' is applicable. There is no animal taking in water that is terrestrial or aerial or that derives its food from the land, whereas of the great number of land animals inhaling air many get their food from the water; moreover some are so peculiarly organized that if they be shut off altogether from the water they ${ }^{25}$ cannot possibly live, as for instance, the so.called seaturtle, the crocodile, the hippopotamus, the seal, and some of the smaller creatures, such as the fresh-water tortoise and the frog: now all these animals choke or drown if they do not from time to time breathe atmospheric air: they breed and rear their young on dry land, or near the 30 land, ${ }^{1}$ but they pass their lives in water.

But the dolphin 2 is equipped in the most remarkable way of all animals: the dolphin and other similar aquatic animals, including the other cetaceans which resemble it; that is to say, the whale, and all the other creatures that $589^{b}$ are furnished with a blow-hole. One can hardly allow that such an animal is terrestrial and terrestrial only, or aquatic and aquatic only, if by terrestrial we mean an animal that inhales air, and if by aquatic we mean an animal that takes in water. For the fact is the dolphin performs both these processes: he takes in water and discharges it by his 5 blow-hole, and he also inhales air into his lungs ; ${ }^{4}$ for, by the way, the creature is furnished with this organ and respires thereby, and accordingly, when caught in the nets, he is quickly suffocated for lack of air. He can also live for a considerable while out of the water, but all this while he keeps up a dull moaning sound corresponding to the noise made by air-breathing animals in general ${ }^{5}$ further- 10 more, when sleeping, the animal kecps his nose above water, and he cloes so that he may breathe the air. Now

1 P. omits $\tau a \grave{~} \delta \dot{\epsilon} \pi \rho \grave{s} \tau \hat{\omega} \hat{\xi} \eta \rho \hat{\varphi}$.

Cf. de Resp. I2. $476^{\mathrm{b}}$ i3.

$589^{a} 33$ omit kai after $\dot{\epsilon} \sigma \tau \iota$. Dittm. rejects as follows: [kai] $\tau \hat{\omega} \nu$

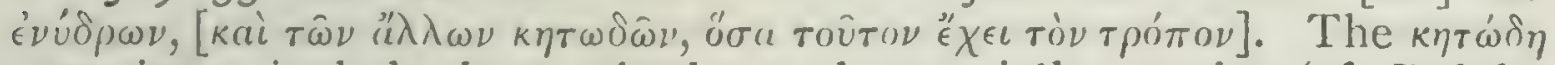
sometimes inclucle large sharks and especially tunnies (cf. Rohde, Thynnorum cupturet, \&c., p. II), and are accordingly more strictly defined here.
${ }^{4} P$. A. iv. I $3.697^{\mathrm{a}}$ I5.
AR. H.A.
${ }^{5}$ H. A. iv. $9 \cdot 535^{\mathrm{b}} 32$. 
it would be unreasonable to assign one and the same class of animals to both categories, terrestrial and aquatic, sceing that these categories are more or less exclusive of one another; we must accordingly supplement our definition of the term 'aquatic' or 'marine'. For the fact is, some aquatic animals take in water and discharge it again, for the same reason that leads air-breathing animals Is to inhale air: in other words, with the object of cooling the blood. Others take in water as incidental to their mode of feeding; for as they get their food in the water they cannot but take in water along with their food, and if they take in water they must be provided with some organ for clischarging it. ${ }^{1}$ Those blooded animals, then, that use water for a purpose analogous to respiration are provided with gills; and such as take in water when catching their 20 prey, with the blow-hole. Similar remarks are applicable to molluscs and crustaccans; for again it is by way of procuring food that these creatures take in water.

Aquatic in different ways, the differences depending on bodily relation to external temperature and on habit of life, are such animals on the one hand as take in air 25 but live in water, and such on the other hand as take in water ${ }^{2}$ and are furnished with gills but go upon dry land and get their living there." At present only one animal of the latter kind is known, the so-called cordylus or water-newt; this creature is furnished not with lungs but with gills, but for all that it is a quadruped and fitted for walking on dry land. ${ }^{4}$

In the case of all these animals their nature appears in so some lind of a way to have got warped, just as sume male animals get to resemble the female, and some femalc animals the male." The fact is that animals, if they be

\footnotetext{
1 de liesp. 12. $476^{\mathrm{b}} 23$.

" (ruil. has 'suscipiunt yuidem aerem humidum et habent branchias',

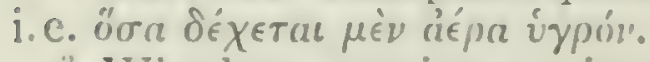

3 Whether genuine or interpolated, this passage is of the nature of an afterthought, modifying and correcting the statement of $589^{2} 23$.

"koputites is in all probubiluty some species of triton or newt, which,

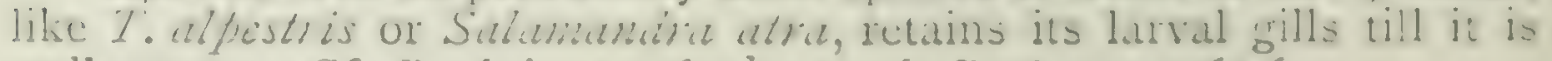
well grown. Cf. I. A. iv. 13. $695^{\mathrm{b}} 25$; de liesp. 10. $476^{\mathrm{a}} 6$.

(i. . 1. i. 2. $716^{\mathrm{i}} 3$.
} 
subjected to a modification in minute organs, are liable to immense modifications in their general configuration. This phenomenon may be observed in the case of gelded animals: only a minute organ of the animal is mutilated, $590^{\mathrm{a}}$ and the creature passes from the male to the female form. We may infer, then, that if in the primary conformation of the embryo an infinitesimally minute but absolutely essential organ sustain a change of magnitude one way or the other, the animal will in one case turn to male and in the other to female; and also that, if the said organ be obliterated altogether, the animal will be of neither one sex nor the other. And so by the occurrence of modification in minute organs it comes to pass that one animal is terrestrial and 5 another aquatic, in both senses of these terms. ${ }^{1}$ And, again, some animals are amphibious whilst other animals are not amphibious, owing to the circumstance that in their conformation while in the embryonic condition there got intermixed into them some portion of the matter of which their subsequent food is constituted; for, as was said above," what is in conformity with nature is to every ro single animal pleasant and agreeable.

Animals then have been categorized into terrestrial and aquatic in three ways, according to their assumption of air or of water, the temperament of their bodies, ${ }^{3}$ or the character of their food; and the mode of life of an animal 15 corresponds to the category in which it is found. That is to say, in some cases the animal depends for its terrestrial or aquatic nature on temperament and diet combined, as well as upon its method of respiration; and sometimes on temperament and habits alone.

1 With Dittm. we exclude as a gloss the succeeding words $\delta$ io

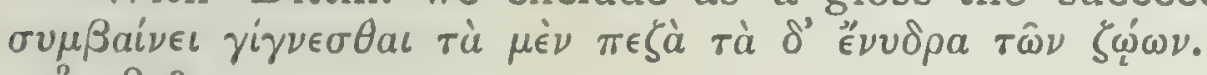

$589^{\mathrm{a}} 9$.

3 kpâoıs in this chapter means the interaction or interrelation between the organism and the surrounding medium by which the former is cooled (cf. $589^{a} \mathrm{I} 4,22 ; \dot{\eta} \kappa \rho$. той $\pi \epsilon \rho \iota \epsilon \sigma \tau \hat{\omega} \tau o s$ áépos, $G$. A. iv. 2. $767^{2} 30$; and the discussion of $\kappa a \tau a ́ \psi v u \xi$ is in de Resp. 10. $475^{\mathrm{b}}$ ). It so comes to mean, on the one hand, the temperument of the organism, in Galen's sense (cf. Probl.xx. I. $954^{\mathrm{b}} 8$ ), and, on the other, external temperature (e.g. Pl. Phaedo, I I l $)$, or climate (H.A. viii. $28.606^{\mathrm{b}} 3$;

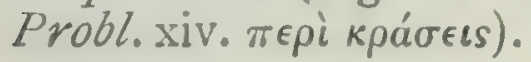


Of testaceans, ${ }^{1}$ some, that are incapable of motion, subsist on fresh water, for, as the sea water dissolves into its 20 constituents, the fresh water from its greater thinness percolates through the grosser parts; ${ }^{2}$ in fact, they live on fresh water just as they were originally engendered from the same. Now that fresh water is contained in the sea and can be strained off from it can be proved in a thoroughly practical way. Take a thin ressel of moulded

25 wax, attach a cord to it, and let it down quite empty into the sea: in twenty-four hours it will be found to contain a quantity of water, and the water will be fresh and drinkable."

Sea-anemones feed on such small fishes as come in their way. The mouth of this creature is in the middle of its body; and this fact may be clearly observed in the case 30 of the larger varieties. Like the oyster it has a cluct for the outlet of the residuum; and this duct is at the top of the animal." In other words, the sea-anemone corresponds to the inner fleshy part of the oyster; and the stone to which the one creature clings corresponds to the shell which encases the other.

The limpet detaches itself from the rock and groes about in quest of food. Of shell-fish that are mobile, some are $590^{\mathrm{b}}$ carnivorous and live on little fishes, as for instance, the

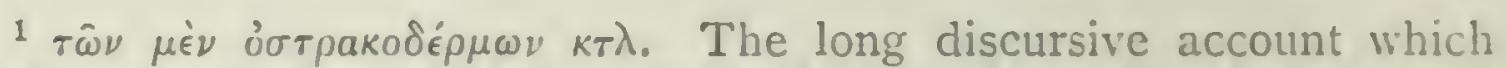
follows of the diet of animals seems to hark back to the end of Chap. I, the essay on aquatic and terrestrial life reading like a parenthetic interpolation.

${ }^{2}$ Cf. H.A.v.16.548 $27 ; P . A$. iv. $7.683^{\mathrm{b}} 29$. Aelian, ix. 64, attributes the doctrine to Democritus. Theophr. C.Pl.ii. 5.2 describes a straining or selective absorption of sea water by the roots of trees. As io

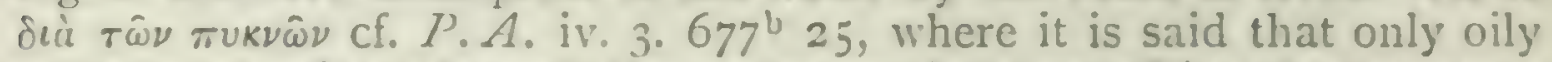
matters percolate through the omentum, because of its close texture.

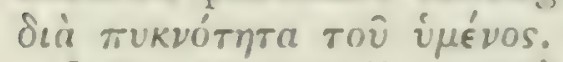

${ }^{3}$ Cf. Metcor. ii. 3. $35^{\circ} 35$; Ael. ix. 64; Plin. xxxi. 37. It is curious that the statement in the text is so often reprated; I have been at the pains to perform the cxperiment, but in vain. Dr. Ogle suggests кeprifum, for kiprwy; but the latter, though highly susplicious, is supported by the parallel passages: Aclian says explicitly ingeine

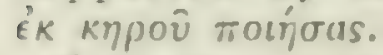

1 In the much better account, supra, iv. $6.53^{\mathrm{b}} 8$, we read $\pi \epsilon p i \tau \tau \omega \mu \mathrm{a}$

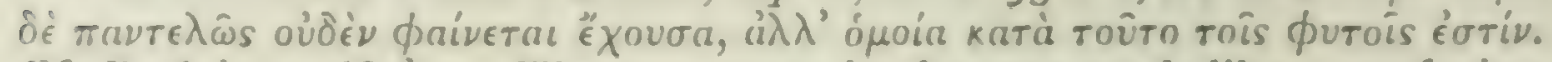
Cf. $P$. A.iv. $5.681^{b} 7$. The statement in the text reads like a confusion

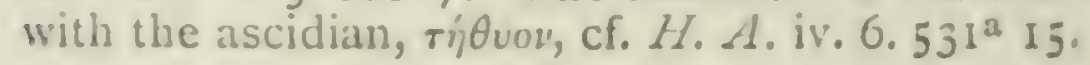


purple murex-and there can be no doubt that the purple murex is carnivorous, as it is caught by a bait of fish; others are carnivorous, but feed also on marine vegetation.

The sea-turtles feed on shell-fish-for, by the way, their mouths are extraordinarily hard; (whatever object it seizes, 5 stone or other, it crunches into bits, but when it leaves the water for dry land it browses on grass). ${ }^{1}$ These creatures suffer greatly, and oftentimes die when they lie on the surface of the water exposed to a scorching sun; for, when once they have risen to the surface, they find a difficulty in sinking again.

Crustaceans feed in like manner. They are omnivorous; ro that is to say, they live on stones, slime, sea-weed, and excrement-as for instance the rock-crab-and are also carnivorous. The crawfish or spiny-lobster can get the better of fishes even of the larger species, though in some of them it occasionally finds more than its match. Thus, this animal is so overmastered and cowed by the octopus that it dies of terror if it become aware of an octopus is in the same net with itself. ${ }^{2}$ The crawfish can master the conger-eel, ${ }^{3}$ for owing to the rough spines of the crawfish the eel cannot slip away and elude its hold. The congereel, however, devours the octopus, for owing to the slipperiness of its antagonist the octopus can make nothing of it. The crallfish feeds on little fish, capturing them 20 beside its hole or dwelling-place; for, by the way, it is found out at sea on rough and stony bottoms, and in such places it makes its den. Whatever it catches, it puts into its mouth with its pincer-like claws, ${ }^{4}$ like the common 25 crab. Its nature is to walk straight forward when it has

1 There is probably an interpolation here, as the construction indicates, on the part of some scribe negligent of the difference between the turtle and tortoise.

2 Very singularly, Horapollo, ii. I06, gives an opposite account:

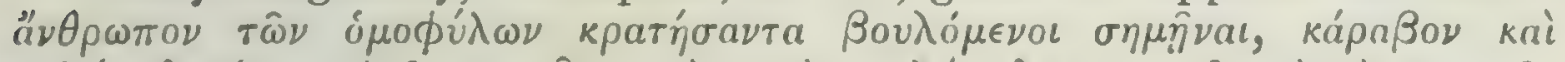

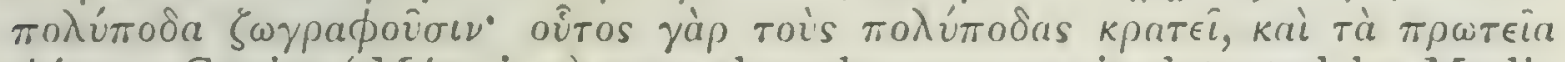

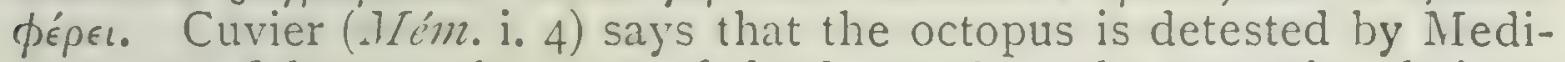
terranean fishermen because of the havoc it works upon the choicest lobsters and crabs: cf. Johnston, Introd. Conch. p. 315.

${ }^{3}$ Ael. i. 32, ix. 25, x. 38 ; Plin. ix. 88; Opp. Hal. ii. 389-4I8; Phile xxx; Plut. Sol. An. 27; Antig. Mirab. 99.

${ }^{4} H$. A. iv. 2. $526^{a}$ I3. 
nothing to fear, with its feclers hanging sicleways; if it be frightened, it makes its escape backwards, darting off to a great distance. These animals fight one another with their claws, just as rams fight with their horns, raising them and striking their opponents; ${ }^{1}$ they are often also 30 seen crowded together in herds. So much for the mode of life of the crustacean.

Molluscs ${ }^{2}$ are all carnivorous; and of molluscs the calamary and the sepia are more than a match for fishes $59 \mathrm{I}^{\mathrm{a}}$ even of the large species. The octopus for the most part gathers shell-fish. extracts the flesh, and feeds on that: in fact, fishermen recognize their holes by the number of shells lying about." Some say that the octopus devours its own species, ${ }^{4}$ but this statement is incorrect; it is doubtless founded on the fact that the creature is often 5 found with its tentacles removed, which tentacles have really been eaten off by the conger."

Fishes, all without exception, feed on spawn in the spawning scason; but in other respects the food varies with the varying species. Some fishes are exclusivcly carnivorous, as the cartilaginous genus, the conger, the ro channa or Scrramus, the tunny, the bass, the symorton or Dentex, the amia, the sea-perch, and the muracna. The red mullet is carnirorous, but feeds also on sca-weed, on shell-fish, and on mud. The grey mullet feeds on mud, the dascyllus" on mud and offal, the scarus or parrot-fish is and the melanurus ${ }^{i}$ on sea-reed, the saupe on offal and sea-recd;" the saupe fecels also on zostera," and is the

1 Ael. ix. 25.

2 This sentence we have transposed from 1.21 to this place in accordance with a suggestion of Scaliger that has the approval of Schneider and of $A$. and $W$.

${ }^{3}$ H. A. ix. $37.622^{n} 5$; Plin. ix. 48.

4 But Johnston has actually found in the stomachs of Loligo mulgaris the beaks of small individuals of its own species. Introd. to Conchnlogy, p. 314.

"Hes. Op. 522; Alcac. rr. ; Rhodig. xiii. 32; Opp. Hal. ii. 250; Acl. i. 27, xiv. 26; Plut. Sol. An. 9. 27; Antig. Mivab. 25; Plin. ix. 46 : Horap. ii. II 3 , Ec. Or by pupaiva, Ael. i. 32.

"ï $\ddot{\pi} \xi \lambda \in \gamma$.

"Oblata melammen, mod. Gk. $\mu \in \lambda$ anoûp. Cf. Arist.ap. Ath. vii. 3 I $3^{\prime \prime}$ : Ael. i. 41, xii. I7; Opp. Hal. i. 98, iii. 443, Sic.

Cf. Opp. Hal. iii. 4 I 4.

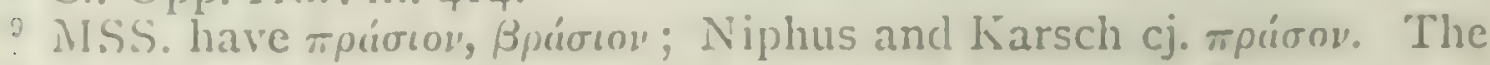


only fish that is captured with a gourd. ${ }^{1}$ All fishes devour their own species, with the single exception of the cestreus or mullet; and the conger is cspccially ravenous in this respect. The cephalus ${ }^{2}$ and the mullet in general are the only fish that eat no flesh ; ${ }^{3}$ this may be inferred from the facts that when caught they are never found with flesh 20 in their intestines, and that the bait used to catch them is not flesh but barley-cake.t Every fish of the mulletkind lives on sea-weed and sand. The cephalus, called by some the 'chelon', keeps near in to the shore, the peraeas ${ }^{j}$ keeps out at a distance from it, and feeds on a mucous substance exuding from itself, and consequently is always in a starved condition. " The cephalus lives in mud, and is 2.5 in consequence heavy and slimy; it never feeds on any other fish. As it lives in mud, it has every now and then

former means horchound ( $M(r) m b u m)$, and is accordingly inadmissible ; $\pi \rho a ́ \sigma o v$, besides its usual signification of garlic (Allium ', means also a marine plant, probably our Zostera: cf. Theophr. H. P. iv. 6 тov yà

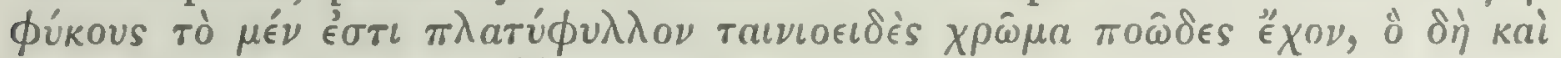

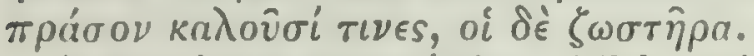

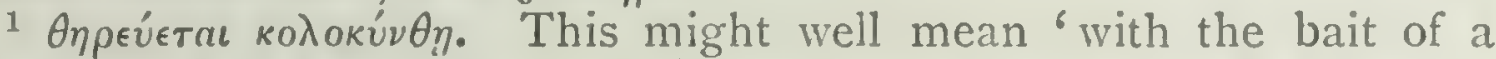
gherkin'; but Apostolides (p. 46) describes a peculiar mode of fishing

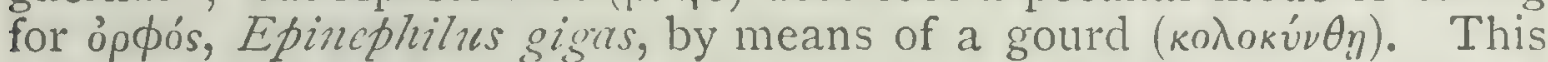
fish, on being hooked, retreats into its hole and holds on by dilating its spiny gill-covers; accordingly the practice is to attach the line in a peculiar way to a floating gourd, and to haul in the exhausted fish a couple of days later. Curiously cnough, Ap. states that the saupe (Box salpe), which is a worthless fish (Ovid, Hal. I22; Plin. ix. 32), is generally used to bait the line. I think it very possible that the present passage is faulty, and that i jopós has dropped out.

2 All the fishcs next described, $k \epsilon^{\prime} \phi u \lambda o s, k \epsilon \sigma \tau \rho \epsilon \dot{s} s$, and $\chi \epsilon \lambda \dot{\omega} \nu$, appear to be mullets or fish closely allied thereto. Cievolo and chelone are mod. Ital. for Mugil cephalus and chelo.

${ }^{3}$ Cf. Athen. vii. 307; Plut.Sol. Anim. ix. 'Mugil capito is the only fish of which I am able to express my belief that it usually selects for its food nothing that has life,' Couch.

${ }^{4} \mu \dot{a} \zeta \eta$. This was doubtless a poisoned cake or 'paste', the lateragna of the Neapolitan fishermen, who prepare it with the roots of Cyclamen hederaefolizm or C. neapolitamm, and use it especially for grey mullets, Cievoli: cf. Opp. Hal. iv. 647-93 ṕi̧av

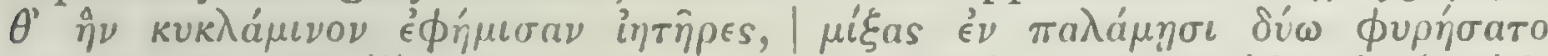

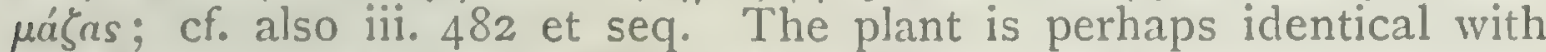
the Aristolochia rotunde of Plin. xxv. 54 'P'iscatores Campaniae radicem eam quae rotunda est venenum terrae vocant, coramque nobis contusam mixta calce in mare sparsere; advolant pisces cupiditate mira, statimque exanimati fluitant'. On poisons for fish see also $H$. A. viii. 20. $602^{\mathrm{b}} 3 \mathrm{I}$.

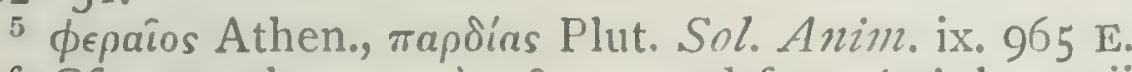

${ }^{6}$ Cf. proverb, $\kappa \epsilon \sigma \tau \rho \epsilon i s ~ \nu \bar{\eta} \sigma \tau \iota s$, and frr. ap. Athen. vii. 307. 
to make a leap upwards out of the mud so as to wash the slime from off its body. There is no creature known to prey upon the spawn of the cephalus, so that the species is excecdingly numerous; when, however, the fish is full30 grown it is preyed upon by a number of fishes, and $59 \mathrm{I}^{\mathrm{b}}$ especially by the acharnas ${ }^{1}$ or bass. Of all fishes the mullet " is the most voracious and insatiable, and in consequence its belly is kept at full stretch; whenever it is not starving, it may be considered as out of condition. When it is frightened, it hides its head in mud, under the notion that it is hiding its whole body." The synodon is car5 nivorous and feeds on molluscs. Very often the synodon and the channa cast up their stomachs ${ }^{4}$ while chasing smaller fishes; for, be it remembered, fishes have their stomachs close to the mouth, and are not furnished with a gullet. ${ }^{5}$

Some fishes then, as has been stated, are carnirorous, and carnivorous only, as the dolphin, the synodon, the giltro head, the selachians, and the molluscs." Other fishes feed habitually on mud or sea-weed or sca-moss or the so-called stalk-weed or growing plants; as for instance, the phycis, the goby, and the rock-fish; and, by the way, the only meat that the phycis will touch is that of prawns. Tery Is often, however, as has been stated, they devour one another, and especially do the larger ones devour the smaller. The proof of their being carnivorous is the fact that they can be caught with flesh for a bait. The mackercl, the tunny, and the bass are for the most part carnivorous, but they do occasionally feed on sea-weed. The sargue feeds on the leavings of the trigle or red mullet. The red mullet bur-

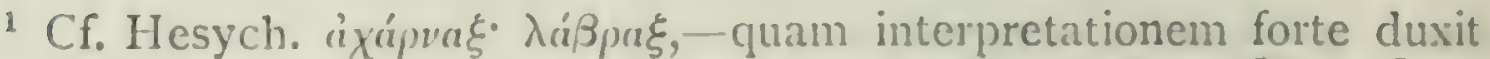
ex loco Aristotelis, unde Athen. vii. 307 excerpsit haec [Schn.] :-

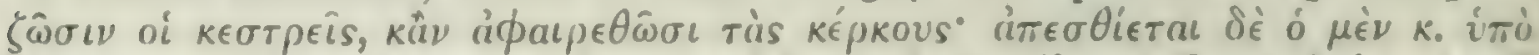
Ari3pakos. The statement is quoted by Athen. vii. 307 from Arist. '́n To

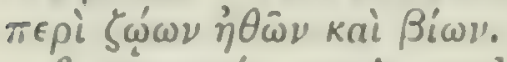

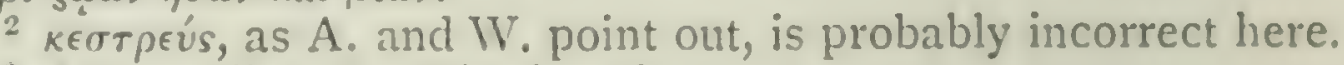

: Athen. vii. 308 ; Plin. ix. 26.

4 As Cuvier and others have noted, it is the swim-bladder and not the stomach that is apt to be everted as described.

5 Arist. $a p$. Galen. ii. $173 \mathrm{~K}$; H. A. ii. $17.507^{2} 26$.

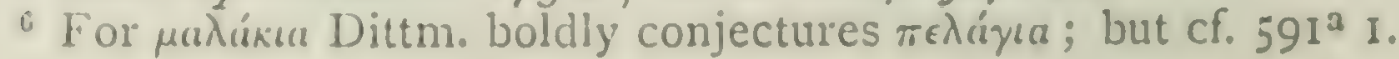


rows in the mud, and when it sets the mud in motion and 20 quits its haunt, the sargue settles down into the place and feeds on what is left behind, and prevents any smaller fish from settling in the immediate vicinity. ${ }^{1}$

Of all fishes the so-called scarus, or parrot-wrasse, is the only one known to chew the cud like a quadruped. ${ }^{2}$

As a general rule the larger fishes catch the smaller ones in their mouths whilst swimming straight after them in the ordinary position; but the selachians, ${ }^{3}$ the dolphin, and 25 all the cetacea ${ }^{4}$ must first turn over on their backs, as their mouths are placed down below; this allows a fair chance of escape to the smaller fishes, and, indced, if it were not so, there would be very few of the little fishes left, for the speed and voracity of the dolphin is something marvellous. ${ }^{5}$

Of eels ${ }^{6}$ a few here and there feed on mud and on chance morsels of food thrown to them; the greater part of them $592^{\mathrm{a}}$ subsist on fresh water. Eel-breeders are particularly careful to have the water kept perfectly clear, by its perpetually flowing on to flat slabs of stonc ${ }^{7}$ and then flowing off again ; sometimes they coat the eel-tanks with plaster. The fact is that the eel will soon choke if the water is not clear, 5 as his gills are peculiarly small. On this account, when fishing for eels, they disturb the water. In the river Strymon eel-fishing takes place at the rising of the Pleiads, because at this period the water is troubled and the mud raised up ${ }^{9}$ by contrary winds $;^{10}$ unless the water be in this condition, it is as well to leave the eels alone. When deacl the eel, unlike the majority of fishes, neither floats on nor to rises to the surface; and this is owing to the smallness

1 Plin. ix. 30.

${ }^{2}$ H. A. ii. 17. 508 b ix. 50; P. A. iii. 14. 675 3; Plin. ix. 29; Ov.

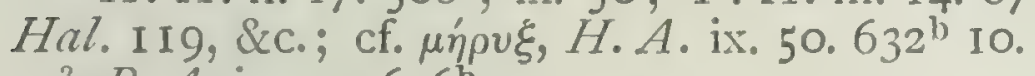

${ }^{3}$ P.A. iv. I $3.696^{\mathrm{b}}$ II.

${ }^{4} \mathrm{~A}$. and $\mathrm{W}$. stigmatize the words relating to the dolphin and other cetacea.

"H.A. ix. 48.63I 20 ; Plin. ix. 7.

Arist. ap. Athen. vii. 298.

7 Cf. Schol. ad Arat. Dios. 993, and many other reffo in Schneider's note.

${ }^{8}$ Ar. Eq. 864 .

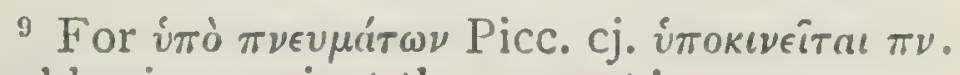

${ }^{10}$ Or ' by southerly winds blowing against the current'. 
of the stomach. A few ecls are supplied with fat, but the greater part have no fat whatsocver. When remored from the water they can live for five or six days $;^{1}$ for a longer period if north winds prevail, for a shorter if south winds." 15 If they are removed in summer from the pools to the tanks they will die; but not so if removed in the winter. They are not capable of holding out against any abrupt change: consequently they often die in large numbers when men engaged in transporting " them from one place to another dip them into water particularly cold. They will also dic of suffocation if they be kept in a scanty supply of 20 water. This same remark will hold good for fishes in general; for they are suffocated if they be long confined in a short supply of water, with the water kept unchangedjust as animals that respire are suffocated if they be shut up with a scanty supply of air. The eel in some cases lives for seven or eight years. The rirer-eel feeds on his 25 own species, on grass, or on roots, or on any chance food found in the mud." Their usual feeding-time is at night, and during the day-time they retreat into deep water. And so much for the food of fishes.

Of birds, such as have crooked talons are carnivorous 3 without exception, and cannot swallow corn or bread-food cren if it be put into their bills in tit-bits; as for instance, $592^{\mathrm{b}}$ the eagle of every varicty, the kite, the two species of hawks, to wit, the dorc-hawk and the sparrow-hawk-and, by the way, these two hawks differ greatly in size from one another-and the buzzard. The buzzard is of the same size as the kite, and is visible at all seasons of the year. ${ }^{5}$ 5 There is also the phene (or lïmmergeier) and the vulture. The phene is larger than the common cagle and is ashen in colour. Of the vulture there are two varieties: one small and whitsh, the other comparatively large and rather more ashen-coloured than white." Further, of birds that fly by

1 Plin. ix. $3 S$.

2 In other words, 'longer in cold weather than in warm.'

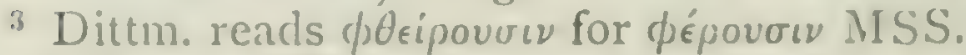

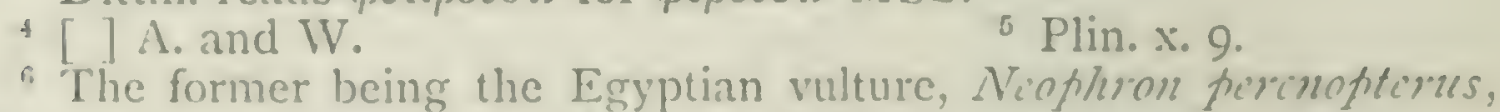
the latter including l'ultur fulturs and Gyps cincre'us. 
night, some have crooked talons, such as the night-raven, the owl, and the eagle-owl. The cagle-owl resembles the common owl in shape, but it is quite as large as the eagle. ro Again, there is the cleus, the Aegolian owl, and the little horned owl. Of these birds, the cleus is somewhat larger than the barn-door cock, and the Acgolian owl is of about the same size as the eleus, and both these birds hunt the jay; the little horned owl is smaller than the common owl. All these threc birds are alike in appearance, and all three are carnivorous.

Again, of birds that have not crooked talons some are carnivorous, such as the swallow. Others feed on grubs, such as the chaffinch, the sparrow, the 'batis', the green linnet, and the titmouse. Of the titmouse there are three varieties. The largest is the finch-titmouse-for it is about the size of a finch; the second has a long tail, and from its habitat is called the hill-titmouse; the third rescmbles the 20 other two in appearance, but is less in size than either of them. ${ }^{1}$ Then come the becca-fico, ${ }^{2}$ the black-cap, the bullfinch, the robin, the cpilais, the midget-bird, and the golden-crested wren. This wren is little larger than a locust, has a crest of bright red gold," and is in every way a beautiful and graceful little bird. Then the anthus, a 25 bird about the size of a finch; and the mountain-finch, which resembles a finch and is of much the same size, but its neck is bluc, ${ }^{+}$and it is named from its habitat; and lastly the wren and the rook. The above-enumcrated birds and the like of them feed either wholly or for the most part on grubs, but the following and the like feed on thistles; to wit, the linnet, the thraupis, and the goldfinch. All these birds feed on thistles, but never on grubs or any $593^{\text {a }}$ living thing whatever; they live and roost also on the plants from which they derive their food.

1 To wit, the great tit or ox-eye, the long-tailed or the penduline tit, and lastly the tomtit, coletit, and other allied species.

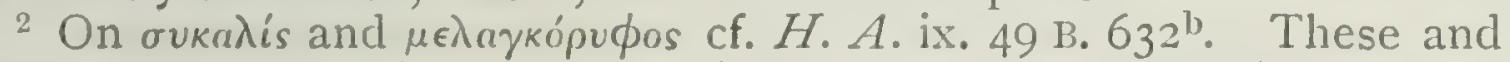
many of the other birds here mentioned are not to be identified.

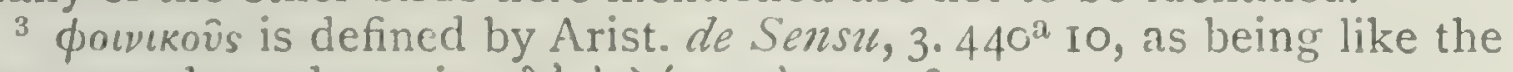

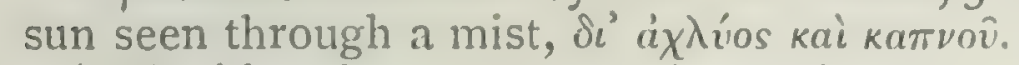

4 The blue-throat, Cyanecula suecica. 
There are other birds whose favourite food consists of insects found bencath the bark of trees; as for instance, 5 the great and the small pic, which are nicknamed the woodpeckers. These two birds resemble one another in plumage and in note, only that the note of the larger bird is the louder of the two; they both frequent the trunks of trees in quest of food. There is also the greenpic, a bird about the size of a turtle-dove, green-coloured all over, that pecks at the bark of trees with extraordinary vigour, lives generally ro on the branch of a trec, has a loud note, and is mostly found in the Peloponnese. There is another bird called the 'grubpicker' (or tree-creeper), about as small as the penduline titmouse, with speckled plumage of an ashen colour, and with a poor note; it is a variety of the woodpecker. ${ }^{1}$

There are other birds that live on fruit and herbage, In such as the wild pigeon or ring-dove, the common pigeon, the rock-dove, and the turtle-dove. The ring-dove and the common pigeon are visible at all scasons; the turtle-dove only in the summer, for in winter it lurks in some hole or other and is never secn. ${ }^{2}$ The rock-dove is chiefly visible in the autumn, and is caught at that season: it is larger 20 than the common pigeon but smaller than the wild one; it is gcnerally caught while drinking. ${ }^{4}$ These pigeons bring their young ones with them when they visit this country. All our other birds come to us in the early summer and build their nests here, and the greater part of them rear their young on animal food, ${ }^{5}$ with the sole exception of the pigeon and its varieties.

The whole genus of birds may be pretty well divided 25 into such as procure their food on dry land, such as frequent rivers and lakes, and such as live on or by the sea.

Of water-birds such as are web-fonted live actually on the water, while such as are split-footed live by the edge of

1 On the woodpecker cf. $H$. A. ix. 9. 6 I $^{3}$.

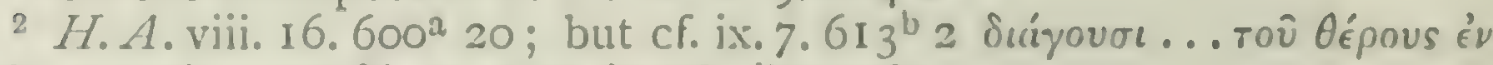

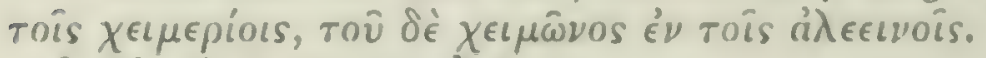

${ }^{3}$ H. A. V. I $3 \cdot 544^{\mathrm{b}} 2$.

4 That is to say. 'by means of a water-trap,' still in common use in [ta]y:

Ko'or is so translated by Scaliger, Schneider, and others; but the Greel may be questioned. 
it-and, by the way, water-birds that are not carnivorous live on water-plants, 〈but most of them live on fish〉, ${ }^{1}$ like the heron ${ }^{2}$ and the spoonbill that frequent the banks of $593^{\mathrm{b}}$ lakes and rivers; and the spoonbill, by the way, is less than the common heron, and has a long flat bill. There are furthermore the stork and the seamew; and the seamew, by the way, is ashen-coloured. There is also the schoenilus, the cinclus, and the white-rump. Of these smaller birds 5 the last mentioned is the largest, being about the size of the common thrush; all three may be described as 'wagtails'. Then there is the scalidris, with plumage ashengrey, but speckled. Moreover, the family of the halcyons or kingfishers live by the waterside. Of kingfishers there are two varieties; ${ }^{3}$ one that sits on reeds and sings; the 10 other, the larger of the two, is without a note. Both these varieties are blue on the back. There is also the trochilus (or sandpiper). The halcyon also, including a variety termed the cerylus, is found near the seaside. The crow also feeds on such animal life as is cast up on the beach, for the bird is omnivorous. There are also the white gull, the cepphus, the aethyia, and the charadrius.

Of web-footed birds, the larger species live on the banks of rivers and lakes; as the swan, the duck, the coot, the grebe, and the teal-a bird resembling the duck but less in size-and the water-raven or cormorant. This bird is the size of a stork, only that its legs are shorter; it is webfooted and is a good swimmer; its plumage is black. It 20 roosts on trees, ${ }^{4}$ and is the only one of all such birds as these that is found to build its nest in a tree. Further there is the large goose, the little gregarious goose, the vulpanser, the horned grebe, ${ }^{5}$ and the penelops. The sea-eagle lives in the neighbourhood of the sea and seeks its quarry in lagoons.

A great number of birds are omnivorous. Birds of prey 25 feed on any animal or bird, other than a bird of prey, that they may catch. These birds never touch one of their own

1 Cj. Dittm.

3 Plin. x. 47.

5 A conjectural translation of $a \ddot{\xi}$.
2 H. A. ix. $18.616^{\mathrm{b}} 33$.

1 Cf. Milton, P. L. iv. I 96. 
genus, whereas fishes often devour members actually of their own species.

Birds; as a rule, are very spare drinkers. In fact birds $594^{\text {a }}$ of prey never drink at all, excepting a very few, and these chink very rarely; and this last observation is peculiarly applicable to the kestrel. The kite has been seen to drink, but he certainly drinks very seldom.

Animals that are coated with tessellates-such as the 4 lizard and the other quadrupeds, and the serpents-are 5 omnivorous: at all events they are carnivorous and graminivorous; and serpents, by the way, are of all animals the greatest gluttons.

Tessellated animals are spare drinkers, as are also all such animals as have a spongy lung, ${ }^{2}$ and such a lung, scantily supplied with blood, is found in all oviparous animals. ${ }^{3}$ Serpents, by the by, have an insatiate appetite ro for wine; ${ }^{4}$ consequently, at times men hunt for snakes by pouring wine into saucers and putting them into the interstices of walls, and the creatures are caught when inebriated. Serpents are carnivorous, and whenever they catch an animal they extract all its juices and eject the creature whole. And, by the way, this is done by all other creatures of similar habits, as for instance the spider; only that the spider sucks out the juices of its prey outside, Is and the serpent does so in its belly. The serpent takes any food presented to him, eats birds and animals, and swallows eggs entire." But after taking his prey he stretches himself until he stands straight out to the very tip: ${ }^{6}$ and then he contracts and squeczes himself into little compass, so that the swallowed mass may pass down his 20 outstretched body: ${ }^{7}$ and this action on his part is due to the tenuity and length of his gullet. Spiders and snakes

$1 G$. A. iii. I. $750^{2} 7$.

2 P.A. iii. 6. $669^{a} 25$; de Resp. I0. $475^{\mathrm{b}} 24$.

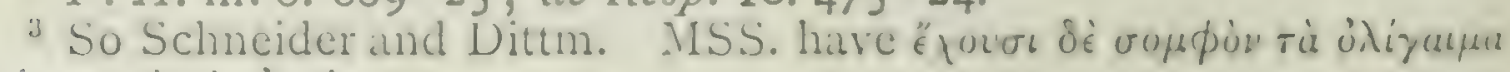

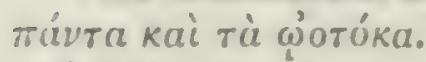

Plin. x. 93.

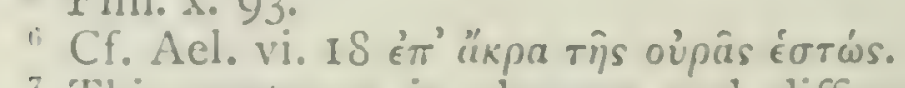

- Plin. x. 92.

7 This sentence is obscure and difficult, and has been variously translated, some making it the serpent and some the egg that is stood up $\epsilon \pi i$ ró äkpov. I suspect that some Egyptian story of the cobra underlies the statement. 
can both' go without food for a long time; and this remark may be verified by observation of specimens kept alive in the shops of the apothecaries.

5 Of viviparous quadrupeds such as are fierce and jag- 25 toothed are without exception carnivorous; though, by the way, it is stated of the wolf, but of no other animal, that in extremity of hunger it will eat a certain kind of earth. ${ }^{1}$ These carnivorous animals never eat grass except when they are sick, just as dogs bring on a vomit by eating grass and thereby purge themselves.

The solitary wolf is more apt to attack man than the $3^{\circ}$ wolf that goes with a pack. ${ }^{2}$

The animal called 'glanus' by some and 'hyaena' by others is as large as a wolf, with a mane like a horse, $594^{\mathrm{b}}$ only that the hair is stiffer and longer and extends over the entire length of the chine. It will lie in wait for a man and chase him, ${ }^{3}$ and will inveigle a dog within its reach by making a noise that resembles the retching noise of a man vomiting. ${ }^{4}$ It is exceedingly fond of putrefied flesh, and will burrow in a graveyard to gratify this propensity.

The bear is omnivorous. It eats fruit, and is enabled by 5 the suppleness of its body to climb a tree; it also eats vegetables, and it will brcak up a hive to get at the honey; it eats crabs and ants also, and is in a general way carnivorous. It is so powerful that it will attack not only the deer but the wild boar, if it can take it unawares, and also ro the bull. After coming to close quarters with the bull it falls on its back in front of the animal, and, when the bull proceeds to butt, the bear seizes hold of the bull's horns with its front paws, fastens its tceth into his shoulder, and drags him down to the ground. For a short time together is it can walk crect on its hind legs. All the flesh it eats it first allows to become carrion. ${ }^{6}$

1 Plin. x. 93.

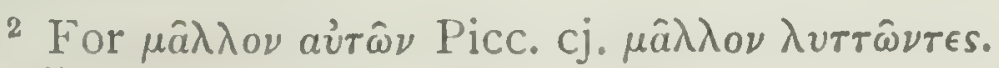

3 Plin. viii. 44 ; Ael. vii. 22.

4 Schn. quotes Political Magazine, I786, p. 65: 'This howl is very peculiar. Its beginning resembles a man moaning, and its latter part as if he were making a violent effort to vomit.' Dittm., however, believes the sentence to be wholly corrupt, and suggests such words as

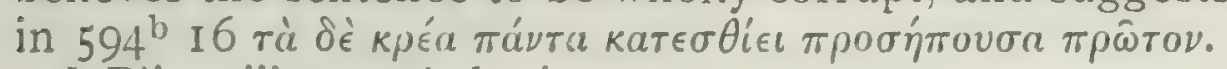

5 Plin. viii. 54 ; Ael. vi. 9.

${ }^{6} \mathrm{~A}$. and W. suggest that this clause may have become detached from 
The lion, like all other savage and jag-toothed animals, is carnivorous. It devours its food grecdily and fiercely, and often swallows its prey entire without rending it at all; it will then go fasting for two or three days 20 together, being rendered capable of this abstinence by its previous surfeit. It is a spare drinker. It discharges the solid residuum in small quantitics, about every other day or at irregular intervals, and the substance of it is hard and dry like the excrement of a clog. The wind discharged from off its stomach is pungent, and its urine cmits a strong odour, a phenomenon which, in the case of dogs, accounts 25 for their habit of sniffing at trees; $;$ for, by the way, the lion, like the dog, lifts its leg to void its urine. It infects the food it eats with a strong smell by breathing on it," and when the animal is cut open an overpowering vapour exhales from its inside.

Some wild quadrupeds feed in lakes and rivers; the seal 30 is the only one that gets its living on the sea. To the former class of animals belong the so-called castor, the satyrium, ${ }^{4}$ the otter, and the so-called latax, or beaver. The beaver is flatter than the otter and has strong teeth; $595^{\text {a }}$ it often at night-time emerges from the water and goes nibbling at the bark of the aspens that fringe the riversides. The otter will bite a man, and it is said that whenever it bites it will never let go until it hears a bone crack. The hair of the beaver is rough, intermediate in appearance 5 between the hair of the seal and the hair of the deer.

jag-toothed animals drink by lapping, as do also some 6 animals with teetl differently formed, as the mouse. Animals whose upper and lower tecth meet evenly ${ }^{5}$ drink by suction.

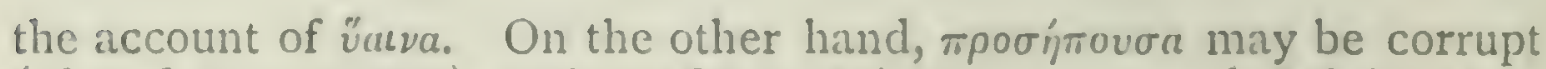

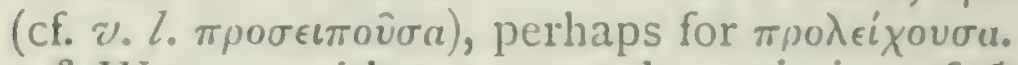

Ael. iv. 34.

2 We must either assume the omission of $\tilde{\omega} \sigma \pi \epsilon \rho$ after $\delta$ เót $\epsilon \rho$, or else suppose that the whole clause $\delta \iota^{\prime} \pi \epsilon \rho \ldots \delta^{\prime} \nu \delta \rho \omega \nu$ is parenthetical and loosely dependent on the suggestion of $\delta \sigma \mu \eta$.

3 Hence the story in Ael. v. 39 of how the lion, impregnating with his foul breath his reserves of food, secures them from molestation.

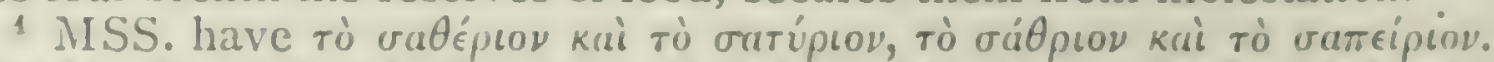

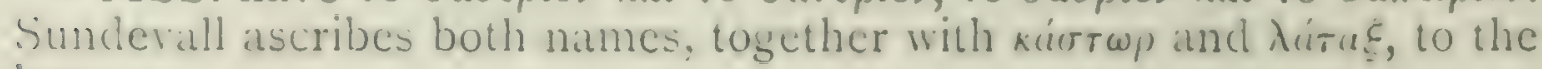
beatver.

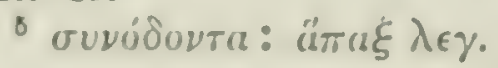


as the horse and the ox; the bear neither laps nor sucks, but gulps down his drink. Birds, as a rule, drink by io suction, but the long-necked birds stop and elevate their heads at intervals; the purple coot is the only one (of the long-necked birds) that swallows water by gulps.

Horned animals, domesticated or wild, and all such as are not jag-toothed, are all frugivorous and graminivorous, save under great stress of hunger. ${ }^{2}$ The pig $^{3}$ is an ex- ${ }^{5}$ ception; it cares little for grass or fruit, but of all animals it is the fondest of roots, owing to the fact that its snout is peculiarly adapted for digging them out of the ground ; it is also of all animals the most easily pleased in the matter of food. It takes on fat more rapidly in proportion to its size than any other animal; in fact, a pig can be 20 fattened for the market in sixty days. Pig-dealers can tell the amount of flesh taken on, by having first weighed the animal while it was being starved. Before the fattening process begins, the creature must be starved for three days ;" and, by the way, animals in general will take on fat if subjected previously to a course of starvation; after the three days of starvation, pig-breeders feed the animal lavishly. Breeders in Thrace, when fattening pigs, give them a drink on 25 the first day; then they miss one, and then two days, then three and four, until the interval extends over seven days. The pigs' meat used for fattening is composed of barley, millet, figs, acorns, wild pears, and cucumbers. ${ }^{6}$ These animals-and other animals that have warm bellies ${ }^{7}$ - are $3^{\circ}$ fattened by repose. [Pigs also fatten the better by being allowed to wallow in mud. ${ }^{8}$ They like to feed in batches of the same age. A pig will give battle even to a wolf. $]^{9} 595^{\mathrm{b}}$

1 Athen. ix. p. 398 ; Plin. x. 63.

2 Plin. x. 93.

3 Some MISS. have kuvós. The passage is apparently faulty, and

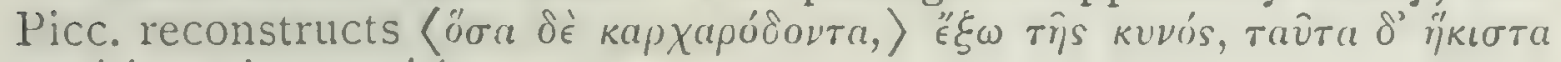

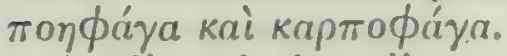

4 Plin. xi. 60, xii. 91. Cf. Alex. Aphr. Probl. i. I4I.

5 Plin. viii. 77.

- Cf. Hom. Od. x. 242; H. A. viii. $21.603^{\mathrm{b}} 27$; Varro, R. R. iv. 2.

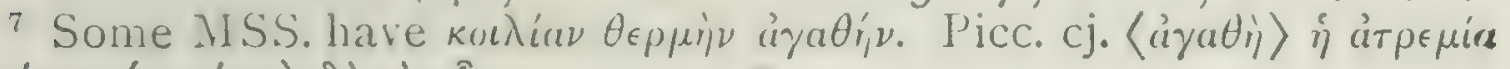

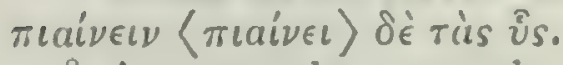

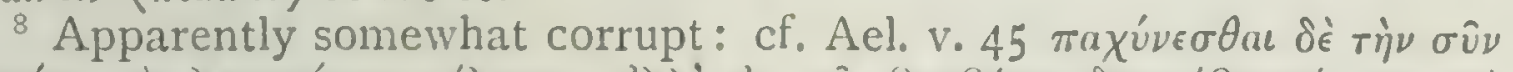

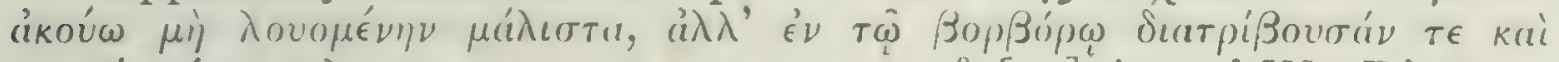
$\sigma \tau \rho \epsilon \phi о \mu \epsilon ́ \nu \eta \nu \kappa \tau \lambda$.

${ }^{9}$ [ ] A. and W., Dittm. 
If a pig be weighed when living, you may calculate that after cleath its flesh will weigh five-sixths of that weight, and the hair, the blood, and the rest will weigh the other sixth. When suckling their young, swine-like all other animals-get attenuated. So much for these animals.

$5 \quad$ Cattle ${ }^{1}$ feed on corn and grass, and fatten on regetables 7 that tend to cause flatulency, ${ }^{2}$ such as bitter vetch or bruised beans or bean-stalks. The older ones also will fatten if they be fed up after an incision has been made into their hide, and air blown thereinto." Cattle will fatten also on barley in its natural state or on barley finely ro winnowed, or on swect food, such as figs, or pulp from the wine-press, ${ }^{4}$ or on elm-leaves. But nothing is so fattening as the heat of the sun and wallowing in warm waters. If the horns of young cattle be smeared with hot wax, you may mould them to any shape you please," and cattle are less subject to disease of the hoof if you smear the horny parts ${ }^{6}$ Is with wax, pitch, or olive oil. Hercled cattle suffer more when they are forced to change their pasture-ground by frost than when snow is the cause of change. Cattle grow all the more in size when they are kept from sexual commerce over a number of years; and it is with a view to growth in size that in Epirus the so-called Pyrrhic kine ${ }^{7}$ are not allowed intercourse with the bull until they are nine years" old;

1 Plin. xviii. 30 .

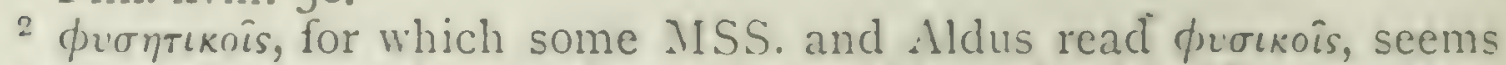

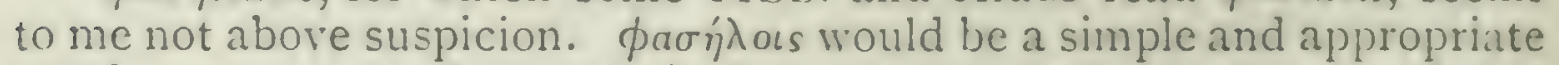

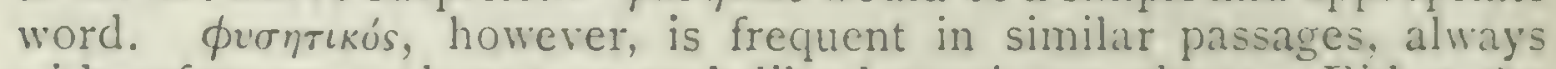
with reference to beans or such-like leguminous plants. Either the word itself or some other of which it is a corruption must; I think, have meant podded regetables, and has nothing to do with flatulency.

3 This also is stigmatized by $A$. and IV.; but cf. Plin. viii. 70.

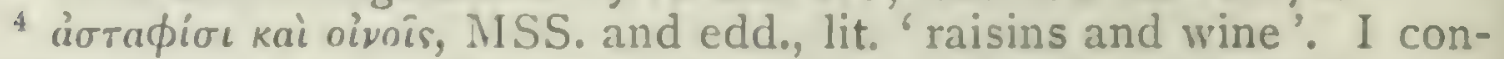
jecture $a . \tau o \hat{v}$ oivov, in the sense of $\sigma \tau \epsilon \dot{\mu} \phi v \lambda a$, Lat. vinacea, the 'marc', or crushed grapes from the wine-press; cf. Varro, R. R. ii. 2, iii. II; Colum. vi. 3, \&c.

5 Plin. xi. 45. Schn. quotes Itiner. Olufseni, i. p. 27 (a'ers. germ.), in witness of a similar practice in Iceland.

¿ ке́рата: lit. 'horns'; but cf. Cato, R. R. 72 'Boves ne pedes subternnt, pice liquida cornua infima unguito'. Cf. Colum. vi. 15; Verg. G. iii. 88, Sic.; Schn. and Picc. read kepúrın.

7 H. A. iii. 21. 522b 24 ; Ael. iii. 33; Plin. viii. 7o; Colum.vi. 1; Varro, R. R. ii. 5 .

${ }^{y}$ Plin.l.c. 'non ante quadrimatum', reading (as Dittm. shows) $\delta$ ' for $\theta$ '. 
from which circumstance they are nicknamed the 'unbulled' kine. Of these Pyrrhic cattle, by the way, they say that there are only about four hundred in the world, that they 20 are the private property of the Epirote royal family, that they cannot thrive out of Epirus, and that people elsewhere have tried to rear them, but without success.

8 Horses, mules, and asses feed on corn and grass, but are fattened chiefly by drink. Just in proportion as beasts of burden drink water, so will they more or less enjoy their food, and a place will give good or bad feeding according 25 as the water is good or bad. Green corn, while ripening, ${ }^{1}$ will give a smooth coat; but such corn is injurious if the spikes are too stiff and sharp. ${ }^{2}$ The first crop of clover is unwholesome, and so is clover over which ill-scented water runs; for the clover is sure to get the taint of the water. ${ }^{3}$ Cattle like clear water for drinking; ${ }^{4}$ but the horse 30 in this respect resembles the camel, for the camel likes turbid and thick water, and will never drink from a stream until he has trampled it into a turbid condition. ${ }^{5}$ And, by $596^{\text {a }}$ the way, the camel can go without water for as much as four days, but after that when he drinks, he drinks in immense quantities. ${ }^{6}$

9 The elephant ${ }^{7}$ at the most can eat nine Macedonian medimni of fodder ${ }^{8}$ at one meal; but so large an amount is unwholesome. As a general rule it can take six or seven 5 medimni of fodder, five medimni of wheat, and five mareis of wine-six cotylae going to the maris." An elephant has been known to drink right off fourteen Macedonian metretae of water, and another eight metretae later in the day.

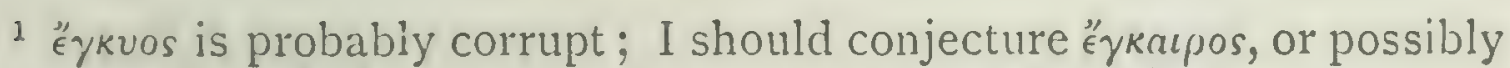

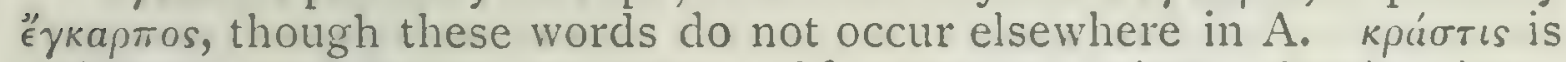

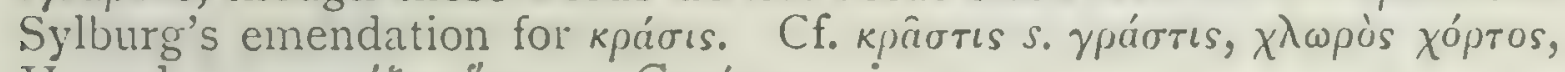

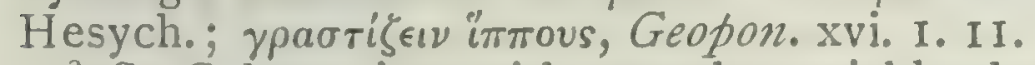

2 So Colum. vi. 3 , with regard to prickly shrubs.

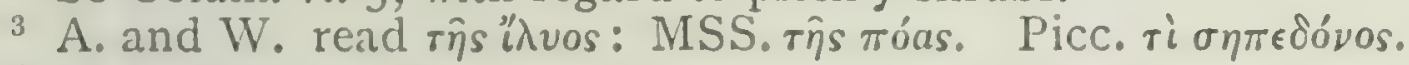

4 Cf. Colum. vi. 22.

5 Aelian xvii. 7 applies this statement to the elephant.

6 Plin. viii. 26. 7 Cit. Ael. xvii. 7.

8 Dittm., after Camus and Schn., inserts $\langle\kappa \rho \iota \theta \hat{\omega} \nu\rangle$, from Ael. l. $c_{0}$

9 Cit. Pollux, X. 47. 
Camels ${ }^{1}$ live for about thirty ${ }^{2}$ years; in some exro ceptional cases they live much longer, and instances have been known of their living to the age of a hundred. The clephant is said by some to live for about two hundred years; by others, for three hundred.

Sheep and goats are graminivorous, but shecp browse Io assiduously and steadily. whereas groats shift their ground rapidly, and browse only on the tips of the herbage. Is Sheep are much improved in condition by drinking, and accordingly they give the flocks salt " every five days in summer, to the extent of one medimnus to the hundred sheep, and this is found to render a flock healthier and fatter. In fact they mix salt ${ }^{4}$ with the greater part of their food; a large amount of salt is mixed into their 20 bran (for the reason that they drink more when thirsty), and in autumn they get cucumbers with a sprinkling of salt on them; this admixture of salt in their food tends also to increase the quantity of milk in the ewes. If shecp be kept on the move at midday they will drink more copiously towards evening; and if the ewes be fed with salted food as the lambing scason draws near they will get larger udders. Sheep are fattened by twigs of the 25 olive or of the olcaster, by vetch, and bran of every kind; and these articles of food fatten all the more if they be first sprinkled with brine. Sheep will take on flesh all the better if they be first put for three days through a process of starving. In autumn, water from the north is more wholesome for sheep than water from the south." Pasture grounds are all the better if they hare a westerly aspect.

Sheep will lose flesh if they be kept overmuch on the 30 move or be subjected to any harlship. In winter time

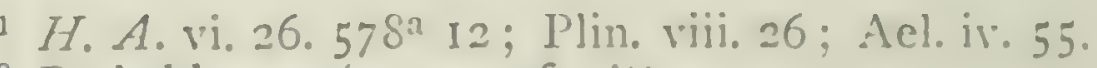

2 Probably $\pi \epsilon \nu \tau i j k \nu \pi a:$ cf. citt.

Eust. ad 11. p. 9I9; Colum. R. R. vi. 4.

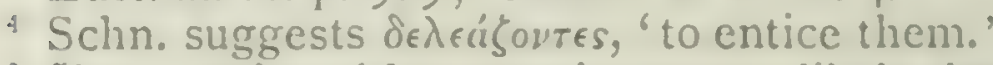

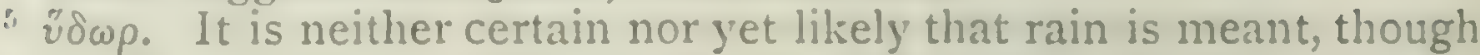
A. and W. take it so. Schn. suggests, with much probability, roù $\mu \dot{\prime}$ "

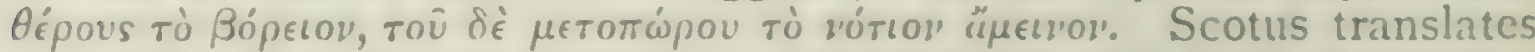
according to such a reading 'et in aestate valens est aqua septentrionalis frigida, et in autumno aqua meridionalis tepida '. 
shepherds can easily distinguish the vigorous sheep from the weakly; from the fact that the vigorous sheep are covered with hoar-frost while the weakly ones are quite free of it; the fact being that the weakly ones feeling $596^{\mathrm{b}}$ oppressed with the burden shake themselves and so get rid of it. The flesh of all quadrupeds deteriorates in marshy pastures, and is the better on high grounds. Sheep that have flat tails ${ }^{1}$ can stand the winter better ${ }^{2}$ than long-tailed sheep, and short-fleeced sheep than the shaggy- 5 fleeced; ${ }^{3}$ and sheep with crisp wool $^{4}$ stand the rigour of winter very poorly. Sheep are healthier than goats, but goats are stronger than sheep." [The fleeces and the wool of sheep that have been killed by wolves, as also the clothes made from them, are exceptionally infested with lice. $]^{6}$

II Of insects, such as have teeth are omnivorous; such as ro have a tongue feed on liquids only, extracting ${ }^{7}$ with that organ juices from all quarters. And of these latter some may be called omnivorous, inasmuch as they feed on every kind of juice, as for instance, the common fly; others are blood-suckers, such as the gadfly and the horse-fly, others again live on the juices of fruits and plants. The bee is the only insect that invariably eschews whatever is 15 rotten; 8 it will touch no article of food unless it have a sweet-tasting juice, and it is particularly fond of drinking

1 H. A. viii. $28.606^{2}$ I3.

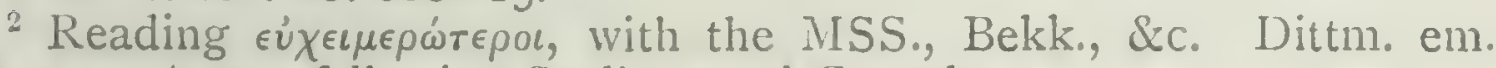
$\delta v \sigma \chi \epsilon \iota \mu \rho \omega^{\prime} \epsilon \epsilon_{0}$, following Scaliger and Casaubon.

3 On the various sorts of wool cf. Plin. viii. 73, Colum. vii. 4, \&c. As Schn. points out, the oies koגepai are such as the celebrated 'Apulae, breves villo', commonly called the Tarentine race, but originally Phrygian (Plin. xxix. 9; Strab. vi. 9.284, \&c.).

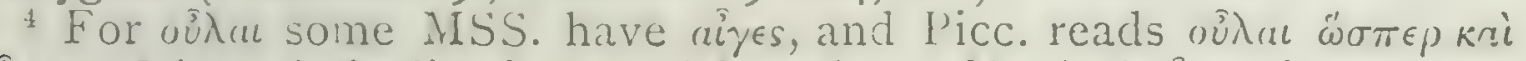

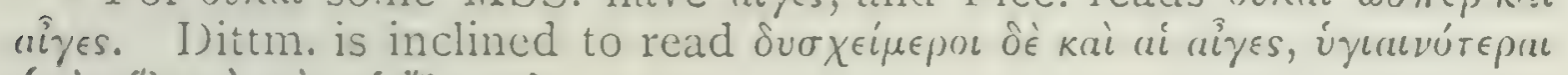

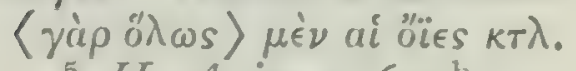

${ }_{5}$ H. A. ix. 3. $610^{\mathrm{b}} 33$.

6 Plin. xi. 39; Plut. Symp. ii. 9; Ael. i. 38 ; Geopon.xv. 1. 5 ; Phile. Videspread as this story is, it may well hare sprung from some simple

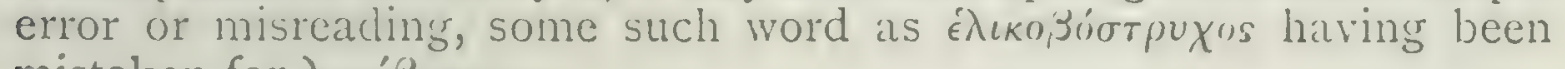

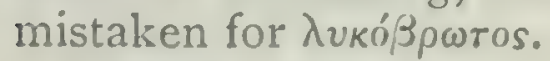

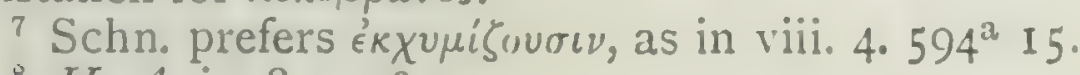

${ }^{8}$ H. A. iv. 8. $535^{2} 2$. 
water if it be found bubbling up clear from a spring underground.

So much for the food of animals of the leading genera.

20 The habits of animals are all connected with cither 12 breeding and the rearing of young, or with the procuring a due supply of food; and these habits are modified so as to suit cold and heat and the variations of the seasons. For all animals have an instinctive perception of the changes of tem25 perature, and, just as men seek shelter in houses in winter, or as men of great possessions ${ }^{1}$ spend their summer in cool places and their winter in sunny ones, so also all animals that can do so shift their habitat at various seasons.

Some creatures can make provision against change with30 out stirring from their ordinary haunts; others migrate, quitting Pontus and the cold countries after the autumnal $597^{\text {a }}$ equinox to avoid the approaching winter, and after the spring cquinox migrating from warm lands to cool lands to aroid the coming heat. In some cases they migrate from places near at hand, in others they may be said to come from the ends of the world, as in the case of the crane $:^{2}$ for these birds migrate from the steppes of Scythia 5 to the marshlands south of Egypt where the Nile has its source." And it is here, by the way, that they are said to fight with the pygmies; ${ }^{4}$ and the story is not fabulous, but there is in reality a race of dwarfish men, and the horses are little in proportion, and the men live in caves underground. Pelicans also migrate. and fly from the 10 Strymon to the Ister, and breed on the banks of this river. They depart in flocks, and the birds in front wait for those in the rear, owing to the fact that when the flock is passing over the intervening mountain range, the birds in the rear lose sight of their companions in the van.

I ishes also in a similar manner shift their habitat now out of

1 Not improbably referring to the I'ersian king's migrations between Susa and Ecbatana, as . Lelian (iii. 13), in his description of the crane, explicitly does.

Herod. ii. 22 ; Ael. ii. I, iii. I3; Plin. x. 30, \&c.

${ }^{3}$ C. . Melcor. i. I $3.350^{\circ}$ I4, and Ideler's note.

-11. iii. 6, \&c. See, for other reff, Gl. of Greck Birds, p. 43. 
the Euxine ${ }^{1}$ and now into it. In winter they move from the 15 outer sea in towards land in quest of heat; in summer they shift from shallow waters to the deep sea to escape the heat. ${ }^{2}$

Weakly birds in winter and in frosty weather come down to the plains for warmth, and in summer migrate to the hills for coolness. The more weakly an animal is the 20 greater hurry will it be in to migrate on account of extremes of temperature, either hot or cold; thus the mackerel migrates in advance of the tunnies, and the quail in advance of the cranes. The former migrates in the month of Boedromion, and the latter in the month of Maemacterion. ${ }^{3}$ All creatures are fatter in migrating from cold to 25 heat than in migrating from heat to cold; thus the quail is fatter when he emigrates in autumn than when he arrives in spring. The migration from cold countries is contemporaneous with the close of the hot season. Animals are in better trim for breeding purposes in spring-time, ${ }^{4}$ when they change from hot to cool lands.

Of birds, the crane, as has been said, migrates from one $3 \circ$ end of the world to the other; they fly against the wind. The story told about the stone is untrue: to wit, that the $597^{\mathrm{b}}$ bird, so the story goes, carries in its inside a stone by way of ballast, and that the stone when vomited up is a touchstone for gold. ${ }^{5}$

The cushat and the rock-dove migrate, and never winter in our country, as is the case also with the turtle-dove ${ }^{6}$; the common pigeon, however, stays behind. The quail 5 also migrates; only, by the way, a few quails and turtledoves may stay behind here and there in sunny districts. Cushats and turtle-doves flock together, both when they arrive and when the season for migration comes round again. When quails come to land, ${ }^{7}$ if it be fair weather or if a north wind is blowing, they will pair off and manage ro pretty comfortably; but if a southcrly wind prevail they

1 Perhaps 'from the open sea'. - 2 Ael. ix. 57.

Boeclromion, 22 August-22 September; Maemacterion,-22 October.

4 Here Dittm. rejects kai.

5 Ael. ii. I, iii. I3, \&c.

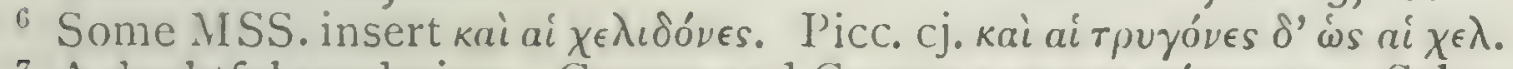

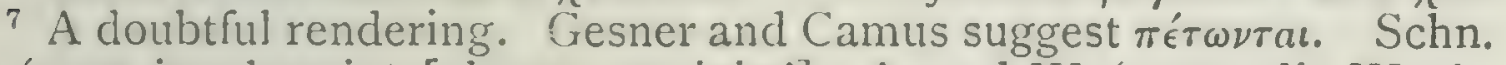
tr. 'cum incubuerint [alarum remigio']; A. and W. 'wenn die Wachteln einfallen'; Gaza, 'cum ceciderint.' 
are greatly distressed owing to the difficultics in the way of flight, ${ }^{1}$ for a southerly wind is wet and violent. For this reason bird-catchers are never on the alert for these birds during fine weather, but only during the prevalence of southerly winds, ${ }^{2}$ when the bird from the violence of the wind is unable to fly. And, by the way, it is owing to the distress occasioned by the bulkiness of its body that the bird always screams while flying: for the labour is is severe. When the quails come from abroad ${ }^{4}$ they have no leaders, but when they migrate hence, the glottis flits along with them, as does also the landrail, and the eared owl, and the comcrake.5 The corncrake calls them in the night, and when the bird-catchers hear the croak of the bird in the night-time they know that the quails are on 20 the move. The landrail is like a marsh bird, and the glottis has a tongue that can project far out of its beak. The cared owl is like an ordinary owl, only that it has feathers about its ears; by some it is called the nightraven. It is a great rogue of a bird, and is a capital mimic ; a bird-catcher will dance before it and, while the bird is mimicking his gestures, the accomplice comes behind and 25 catches it. ${ }^{6}$ The common owl is caught by a similar trick.

As a general rule all bircls with crooked talons are shortnecked, flat-tongued, and clisposed to mimicry. The Indian bird, the parrot, which is said to have a man's tongue, answers to this description: and, by the way, after drinking wine, the parrot becomes more saucy than ever.

Of birds, the following are migratory-the crane, the 30 swan, the pelican, and the lesser goose.

Of fishes, some; as has been ob-crved, inigrate from the I3 outer seas in towards shore, and from the shore towards $598^{\mathrm{a}}$ the outer seas, to avoid the extremes of cold and heat.

1 Plin. x. 33 ; Solin. xi.

2 Cf. Numbers xi. 3 I.

3 'Propter sui corporis pondus,' Gaza. Dittm. reads evioias $\delta$ ' oũ

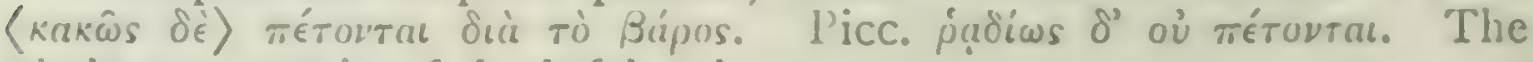
whole passage is of doubtful value.

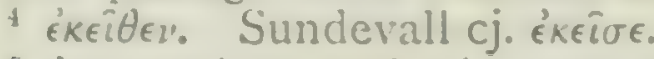

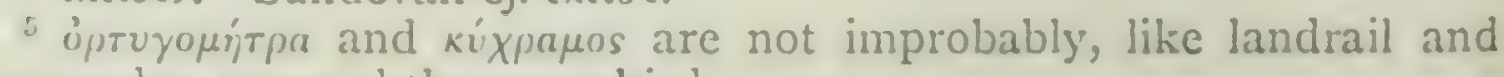
corncrake, one and the same bird.

1'lin. X. 33 ; Athen. ix. p. 390; Plut. Sol. Anim. 3.

${ }^{\prime}$ Plin. x. 58; Ctes. ap. Phot., Sic. 
Fish living near to the shore are better eating than deep-sea fish. The fact is they have morc abundant and better feeding, for wherever the sun's heat can reach vegetation is more abundant, better in quality, and more delicate, as is seen in any ordinary garden. Further, the black ${ }^{1}$ shore-weed grows near to shore; the other shore-weed 5 is like wild weed. ${ }^{2}$ Besides, the parts of the sea near to shore are subjected to a more equable temperature; and consequently the flesh of shallow-water fishes is firm and consistent, whereas the flesh of deep-water fishes is flaccid and watery.

The following fishes are found near into shore-the synodon, ${ }^{3}$ the black bream, ${ }^{4}$ the merou, the gilthead, the ro mullet, the red mullet, the wrasse, the weaver, ${ }^{6}$ the callionymus, the goby, ${ }^{7}$ and rock-fishes of all kinds. The following are deep-sea fishes - the trygon, the cartilaginous fishes, the white conger, the serranus, the erythrinus, and the glaucus. The braize, ${ }^{8}$ the sea-scorpion, the black

1 '́

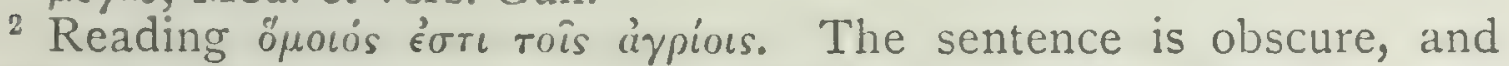

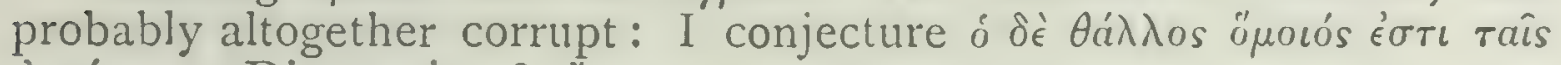
ảykúpats. Dittm. cj. тoîs "̈

${ }_{3} \sigma \iota \nu \omega \delta \delta \omega \nu, s . \sigma v v o \delta \delta \omega \%$. Some ichthyological writers have conjectured кuvóow", and take the name to be descriptive of Dentex vulgaris; cf. бvvaypis, ii. 13. $505^{2} 16$.

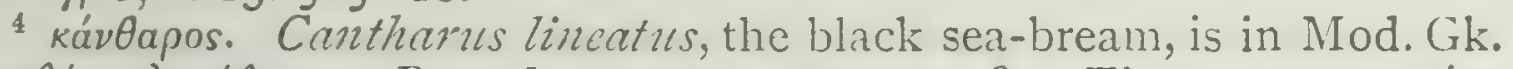

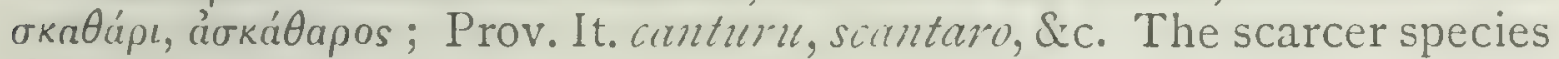
Scatharus graecus is confused with it. The former 'enters harbours and is frequently taken by anglers from rocks and pier-heads' (Yarrell).

${ }^{5}$ óphis. Probably the mérou, or great sea-perch, Serranus (Epineplielus) gigirs; Mod. Gk. óphós, pópos (Bory de St. Vincent, Apostolides): it spawns in shallow waters.

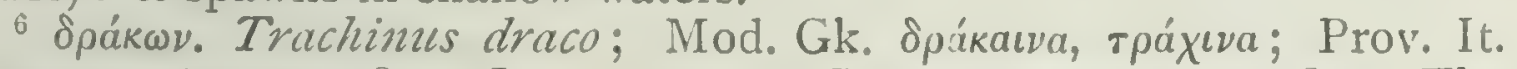
dragena, tragena, \&c.; Lat. araneus; Genoese pesce ragno, \&c. The name weever is said to be wyvern, i.e. dragon.

${ }^{7} \kappa \omega \beta$ ßós. Various species of Gobius are still called $\kappa \omega \beta$ ßús or $\gamma \omega \beta$ ßzós. $G$. niger is the commonest, and is caught in abundance in the lagoons of Missolonghi (Apostolides). Cf. Juv, xi. 57.

8 dáypos. Cf. Arist. $a p$. Athen. vii. $327^{\circ}$. Identified with Pagrus vulgaris, the braize or becker; Mod. Gk. dáypos, máypos, фíyoupos (Rond.), фáryape (Bory de St. V.); It. pagra, pagar, \&c. According to

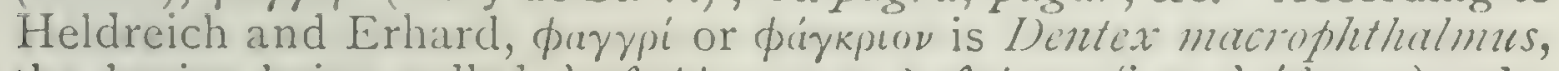

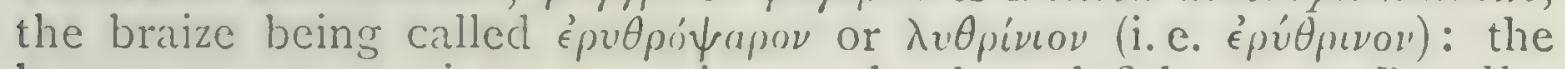
latter names are given to various red-coloured fishes, e. g. P'agellus erythrinus. Apostolides gives as the modern name of Pagrus r'ulgigris $\mu \in \rho \tau \zeta a ́ v \iota$, a Turkish equivalent of épútpivos. 
conger, ${ }^{1}$ the muraena, and the piper or sca-cuchoo are ${ }_{15}$ found alike in shallow and deep waters. These fishes, however, vary for various localities; for instance, the goby and all rock-fish are fat off the coast of Crete. Again, the tunny is out of season in summer, when it is being preyed on by its own peculiar louse-parasite, ${ }^{2}$ but after the rising of Arcturus, when the parasite has left it, it comes into 20 season again. A number of fish also are found in seaestuaries; such as the saupe, the gilthead, the red mullet, and, in point of fact, the greater part of the gregarious fishes. The bonito also is found in such waters," as, for instance, off the coast of Alopeconnesus; and most ${ }^{4}$ species of fishes are found in Lake Bistonis. ${ }^{5}$ The coly-mackerel ${ }^{6}$ as a rule does not enter the Euxine, but passes the summer in 25 the P'ropontis, where it spawns, and winters in the Aegean. ${ }^{7}$ The tumny proper, the pelamys, and the bonito penetrate into the Euxine in summer and pass the summer there; as do also the greater part of such fish as swim in shoals with the currents, or congregate in shoals together. And most fish congregate in shoals, and shoal-fishes in all cases have leaders.

30 Fish penetrate into the Euxine for two reasons, and firstly for food. For the feeding is more abundant and better in quality owing to the amount of fresh river-water that discharges into the sea, ${ }^{8}$ and moreover, the large fishes of this $598^{\mathrm{b}}$ inland sea are sinaller than the large fishes of the outer sea. In point of fact, there is no large fish in the Euxine cxcepting the dolphin and the porpoise," and the dolphin is a

1 This may be a dark variety of the common conger, distinguished as $C$ : niger by Risso; but there are also many other species of eels in the Mediterrancan.

$2 H . A \cdot$ v. 31. $557^{\text {a }} 27$, viii. 19. $602^{a} 25$.

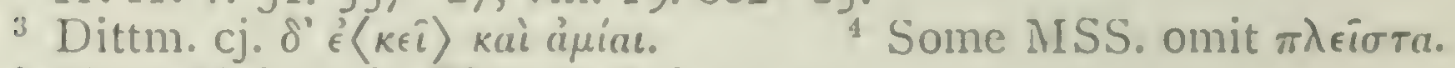

5 Near Abdera, in Thrace, Ael. xv. 25.

- According to Apostolides Scomber colicas is in Mod. Gk. koגıós, Sc. scomber бконßpi. The mackerels are the commonest fishes of the Black Sea. See note to v. 9. $543^{\mathrm{a}} 2$.

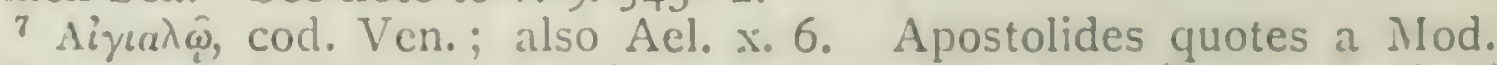
Gk. proverb: 'Everything in its season, and the kodıós in the month of August.?

3 Plin. ix. 19; Acl. ix. 64.

9 Plin. ix. 15; Ael. ix. 59; Plut. Sol. Anim. 9S1 D. The parallel passagres all give $\phi \dot{\kappa} \eta$ in place of фíканva. 
small variety; but as soon as you get into the outer sea the big fishes are on the big scale. Furthermore, fish penetrate into this sea for the purpose of breeding; for there are recesses there favourable for spawning, and the fresh and exceptionally sweet water has an invigorating 5 effect upon the spawn. After spawning, when the young fishes have attained some size, the parent fish swim out of the Euxine immediately after the rising of the Pleiads. If winter comes in with a southerly wind, they swim out with more or less of deliberation; but, if a north wind be blowing, they swim out with greater rapidity, from the fact that the breeze is favourable to their own course. And, by the way, the young fish are caught about this time in the neighbourhood of Byzantium very small in size, ro as might have been expected from the shortness of their sojourn in the Euxine. ${ }^{1}$ The shoals in general are visible both as they quit and enter the Euxine. The trichiae, ${ }^{2}$ however, only can be caught during their entry, but are never visible during their exit; in point of fact, when a trichia is caught running outwards in the neighbourhood of Byzantium, the fishermen are particularly careful to cleanse their nets, as the circumstance is so singular and exceptional. The way of accounting for this phenomenon ${ }_{5}$ is that this fish, and this one only, swims northwards into the Danube, and then at the point of its bifurcation swims down southwards into the Adriatic." And, as a proof that this theory is correct, the very opposite phenomenon presents itself in the Adriatic; that is to say, they are not

1 At the present day 'the fishermen maintain that these [autumn] shoals [of young tumnies] are composed of fishes of the same year: the uniformity of size is certainly very striking' (Ed. Forbes, op. cit., p. 206)].

${ }^{2} \tau \rho \iota x i a$ is usually taken to be an anchovy or some similar fish (vi. 15. $569^{\mathrm{b}} 26$ ), but the present account suggests the great shoals of lit tle atherines (see note on ápún, $569^{2} 31$ ), which migrate into the Black Sca in spring, and are equally abundant in the Adriatic. 'Having passed the Straits of Constantinople, the shoals turn northwards, keeping close in to avoid the current which sweeps down towards the outlet' (Ed. Forbes, op.cit. p. 204).

3 The Argonauts are said to have followed the same routc, Apoll. Rh. iv. 283 ; but its existence is denied by Strabo, i. p. I53, and Plin. iii. 18. In Plin. $\mathrm{ix} .20$ the fishes are said to reach the Adriatic 'subterraneis venis'. 
caught in that sea during their entry, but are caught during their exit.

Tunny-fish swim into the Euxine keeping the shore on 20 their right, and swim out of it with the shore upon their left. ${ }^{1} \quad$ It is stated that they do so as being naturally wcaksighted, and seeing better with the right eye. ${ }^{2}$

During the daytime shoal-fish continue on their way, but during the night they rest and feed." But if there be moonlight, they continue their journey without resting at all. Some people accustomed to sea-life assert that shoal25 fish at the perior of the winter solstice never move at all, but keep perfectly still wherever they may happen to have been overtaken by the solstice, and this lasts until the equinox.

The coly-mackerel is caught more frequently on entering than on quitting the Euxine. And in the Propontis the fish is at its best before the spawning season. Shoal-fish, as a rule, are caught in greatcr quantities as they leave the Euxine, and at that scason they are in the best condition. ${ }^{4}$ 30 At the time of their cntrance they are caught in very plump condition close to shore," but those are in comparatively poor condition that are caught farther out to sea. $599^{a}$ Very often, when the coly-mackerel and the mackerel are met by a south wind in their exit, there are better catches to the southward than in the neighbourhood of Byzantium. So much then for the phenomenon of migration of fishes.

Now the same phenomenon is observed in fishes as in 5 terrestrial animals in regard to hibemation: in other words. during winter fishes take to concealing themselves in out of the way places, and quit their places of concealment in the

1 Plin. ix. 20; Plut. Sol. Anim. 29; Athen. vii. p. 301; Ael. ix. 42 ; Solin. xii. All throush the Mecliterranean the routes of the tunny are minutely defined and seldom vary. Cf. P. Pavesi, Le migrazioni del tomo, Rendic. R. Ist. Lomb. (2), xx. p. 311 , Milano, 1887.

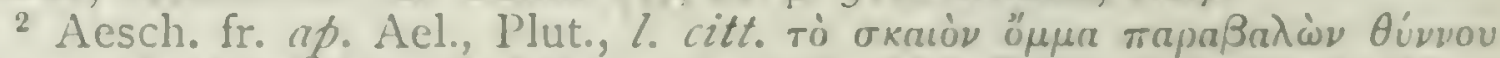
rikne: cf. also Arist. ap. Athen. vii. 301\%. MS. Canis. has simply piete

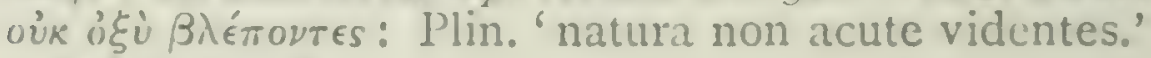

3 Acl. ix. 46.

+ "The fishermen profess to know the shoals as they pass back again, and can tell how much the fish have gained in weight in the course of the summer' (Ed. Forbes).

'Guil., Scotus, and Gaza all read roù Aiyaiov. 
warmer season. But, by the way, animals go into conccalment by way of refuge against extreme heat, as well as against extreme cold. Sometimes an entire genus will thus seek concealment; in other cases some species will do so and others will not. For instance, the shell-fish ro seek concealmont without exception, as is seen in the case of those dwelling in the sea, the purple murex, the ceryx, and all such like; but though in the case of the detached species the phenomenon is obvious--for they hide themselves, as is seen in the scallop, or they are provided with an operculum on the free surface, as in the case of land snails-in the case of the non-detached the con- 5 cealment is not so clearly observed. They do not go into hiding at one and the same season; but the snails go in winter; the purple murex and the ceryx for about thirty days at the rising of the Dog-star, and the scallop at about the same period. But for the most part they go into concealment when the weather is cither extremely cold or extremely hot.

I4 Insects almost all go into hiding, with the exception of 20 such of them as live in human habitations or perish before the completion of the year. They ${ }^{1}$ hide in the winter; some of them for several days, others for only the coldest days, as the bee. For the bee also goes into hiding: and the proof that it does so is that during a certain period 25 bees never touch the food set before them, and if a bee creeps out of the hive, it is quite transparent, ${ }^{2}$ with nothing whatsoever in its stomach; and the period of its rest and hiding lasts from the setting of the Pleiads until springtime.

Animals take their winter-slecp or summer-sleep by concealing themselves in warm places, or in places where they have been used to lie concealed.

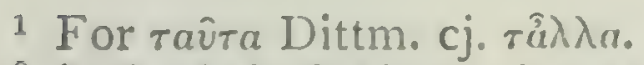

2 Sorфavís is clubious: it was suggested by Scaliger and adopted by Camus and Schneider from Med., Canis., and Gaza's tr. 'ventre trans-

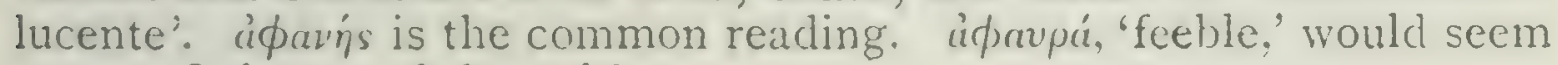
a more fitting word than either. 
30 Several blooded animals take this sleep, such as the I5 pholiclotes or tessellates, namely, the serpent, the lizard, the gecko, and the river-crocodile, all of which go into hiding for four months in the depth of winter, and during that $599^{\mathrm{b}}$ time eat nothing. Serpents in general burrow under ground for this purpose; the viper conceals itself under a stone.

A great number of fishes also take this slecp, ${ }^{1}$ and notably, the hippurus and coracinus in winter time; for, whereas fish in general may be caught at all periods of the year more or less, there is this singularity observed in these fishes, that they are caught within a ccrtain fixed period 5 of the year, and never by any chance out of it. The muracna also hides, and the orphus or sea-perch, and the conger. Rock-fish pair off, male and female, for hiding (just as for brecding); - as is observed in the case of the specics of wrasse called the thrush and the owzel," and in the perch.

The tunny also takes a sleep in winter in deep waters, ro and gets exccedingly fat after the slcep. The fishing season for the tunny begins at the rising of the P'leiads and lasts, at the longest, down to the setting of Arcturus: during the rest of the year they are hid and enjoying immunity. About the time of hibernation a few tumnics or other hibernating fishes are caught while swimming about, in particularly warm localities and in exceptionally fine Is weather; or on nights of full moon; for the fishes are induced (by the warmth or the light) to emerge for a while from their lair in quest of food.

Most fishes are at their best for the table during the summer or winter sleep.

The primas-tunny conceals itsclf in the mud; 'this may

1 Plin. ix. 24 ; Ael. ix. 57.

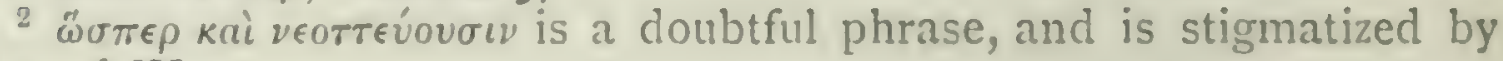
A. and $W$.

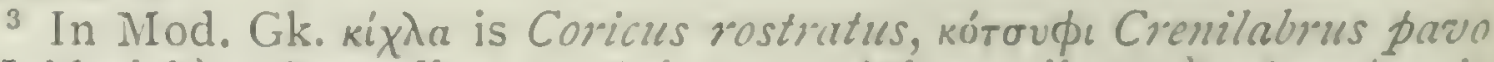
(Heldreich). According to Arist. ap. Athen. vii. $305^{\text {b }}$ kó $\sigma \sigma u \phi o s$ is $\mu \in \lambda$ unortatos, which would apply to several other species better than to c. purte. There are about twenty-four species of wrasse in the Meclitermean, and the name turdo in various forms is applied to most of them.

4 Hence the supposed derivation of $\pi \eta \lambda a \mu u$ s from $\pi \eta \lambda$ ós, Etym. .H.,

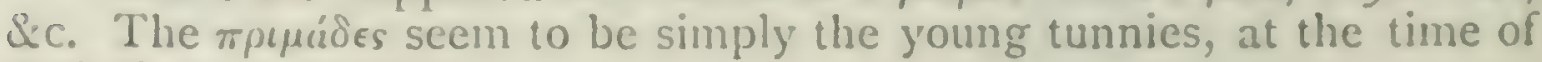
their first appearance. 
be inferred from the fact that during a particular period the fish is never caught, and that, when it is caught after that period, it is covered with mud and has its fins damaged. In the spring ${ }^{1}$ these tunnies get in motion and proceed 20 towards the coast, coupling and breeding, and the females are now caught full of spawn. At this time they are considered as in season, but in autumn and in winter as of inferior quality; at this time also the males are full of milt. When the spawn is small, the fish is hard to catch, but it is easily caught when the spawn gets large, 25 as the fish is then infested by its parasite. ${ }^{2}$ Some fish burrow for sleep in the sand and some in mud, just keeping their mouths outside.

Most fishes hide, then, during the winter only, but crustaceans, the rock-fish, the ray, and the cartilaginous species hide only during extremely severe weather, and this may be inferred from the fact that these fishes are never by any zo chance caught when the weather is extremely cold. Some fishes, however, hide during the summer, as the glaucus or grey-back; this fish hides in summer for about sixty days. ${ }^{3}$ The hake ${ }^{4}$ also and the gilthead hide; and we infer that the hake hides over a lengthened period from the fact $600^{a}$ that it is only caught at long intervals. We are led also to infer that fishes hide in summer from the circumstance that the takes of certain fish are made between the rise and setting of certain constellations: of the Dog-star in particular, the sea at this period being upturned from the lower clepths. ${ }^{5}$ This phenomenon may be observed to best advantage in the Bosporus; for the mud is there brought 5 up to the surface and the fish are brought up along with

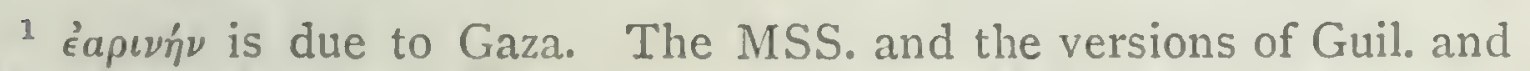
Scot. have $\epsilon_{i p \eta \mu \epsilon} \nu \eta \nu$. The latter reading would refer to the rising of the Pleiads, $599^{\mathrm{b}}$ II.

${ }^{2} H$. A. v. 31. $557^{a} 27$, viii. 19. $602^{a} 25$. Alb. M. tr. 'quoniam tunc moventur in desiderio coitus.'

3 Plin. ix. 25.

4 We follow tradition in translating övos 'hake'; cf the Mod. It.

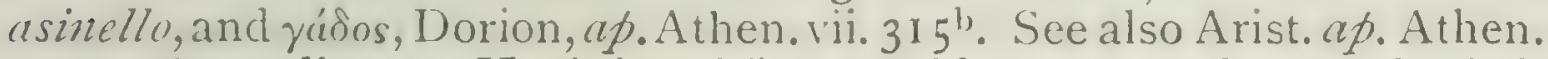
$315^{\circ}$. According to $H . A$. ix. 36 övos would appear to have a barbel, which the true hake has not, but which is present in l'hycis blennioides and $P$. mediterranea, the fork-beard and Mediterranean hakes.

${ }^{5}$ H. A. viii. 20. $602^{\text {h }} 22$, Plin. ix. 25 ; cf. ii. 40 , xii. 68. 
it. They say also that very often, when the sea-bottom is dredged, more fish will be caught by the sccond haul than by the first one. Furthermore, after very heavy rains numerous specimens become visible of creatures that at other times are never seen at all or secn only at intervals.

A great number of bircls also go into hiding; they do 16 not all migrate, as is generally supposed, to warmer countrics. Thus, certain birds (as the kite and the swallow) when they are not far off from places of this kind, in which they have their permanent abode, betake themselves thither; others, that arc at a clistance from such places, decline the trouble of migration and simply hide themselves where I5 they arc. Swallows, for instance, have been often found in holes, ${ }^{1}$ quite denuded of their feathers, and the kite on its first emergence from torpidity has been secn to fly from out some such hiding-place. And with regard to this phenomenon of periodic torpor there is no distinction observed, whether the talons of a bird be crooked or straight; for instance, the stork, the owzel, the turtle-dove, 20 and the lark, all go into hiding. The case of the turtledove is the most notorious of all, for we would defy any one to assert that he had anywhere scen a turtle-dove in winter-time; at the beginning of the hiding time it is exceedingly plump, and cluring this period it moults, but retains its plumpness. Some cushats hide; others, instead 25 of hiding, migrate at the same time as the swallow. The thrush and the starling hicle; and of birds with crooked talons the kite and the owl hide for a few days.

Of viviparous quadrupeds the porcupine and the bear ${ }^{2}$ I7 retire into concealment. The fact that the bear ${ }^{3}$ hides is well established, but there are doubts as to its motive for 30 so doing, whether it be by reason of the cold or from some

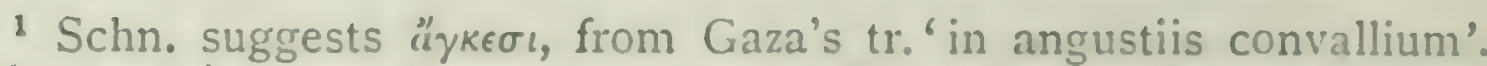

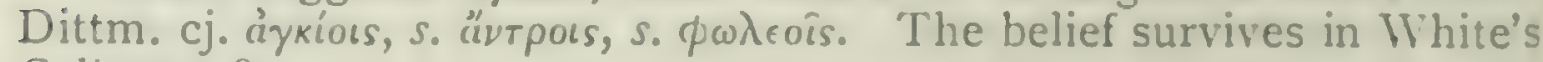
Selborne, \&c.

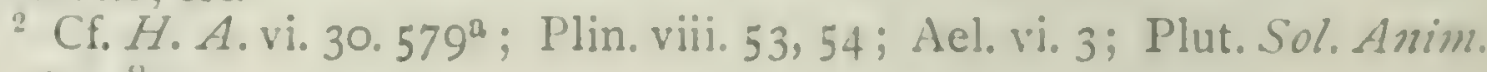
p. 974 , S.c.

"yptat a)кто, the epithet being otiose or spurious. 
other cause. About this period the male and the female become so fat as to be hardly capable of motion. The female brings forth her young at this time, and remains in concealment until it is time to bring the cubs out; and $600^{\mathrm{b}}$ she brings them out in spring, about three months after the winter solstice. The bear hides for at least forty days; during fourteen of these days it is said not to move at all, but during most of the subsequent days it moves, and from time 5 to time wakes up. A she-bear in pregnancy has either never been caught at all or has been caught very seldom. There can be no doubt but that during this period they eat nothing; for in the first place they never emerge from their hidingplace, and further, when they are caught, their belly and intestines are found to be quite empty. It is also said that from no food being taken the gut almost closes up, and Io that in consequence the animal on first emerging takes to eating arum ${ }^{1}$ with the view of opening up and distending the gut.

The dormouse actually hides in a tree, and gets very fat at that period; as does also the white mouse of Pontus.

[Of animals that hide or go torpid some slough off what ${ }^{5} 5$ is called their 'old-age'.2 This name is applied to the outermost skin, and to the casing that envelops the developing organism. $]^{3}$

In discussing the case of terrestrial vivipara we stated that the reason for the bear's seeking concealment is an open question. We now proceed to treat of the tessellates. The tessellates for the most part go into hiding, and if their skin is soft they slough off their 'old-age', but not 20 if the skin is shell-like, as is the shell of the tortoise-for, by the way, the tortoise and the freshwater tortoise belong to the tessellates. Thus, the old-age is sloughed off by the gecko, the lizard, and above all, by serpents; and they

1 H.A. ix.6.6ri ${ }^{a}$ 35. On this plant see Plin. xxiv. 92 ; Galen, Fac. Simpl. xi. 839 K; Diosc. ii. 157, \&c.

2 H.A. v. I7. $549^{\mathrm{b}} 26$.

3 The whole passage enclosed within brackets seems to have been oricrinally a note appended to explain xóptov, a few lines lower down, and to have got interpolated into the text. The last clause, kai...

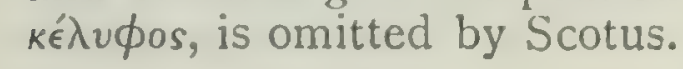

AR. H.A. 
slough off the skin in springtime when emerging from their 25 torpor, and again in the autumn. Vipers also slough off their skin both in spring and in autumn, and it is not the case, as some aver, that this species of the serpent family is exceptional in not sloughing. When the serpent begins to slough, the skin pecls off at first from the eyes, so that any one ignorant of the phenomenon would suppose the animal were going blind; after that it pecls off the head, and so on, until the creature presents to view only a white zo surface all over. ${ }^{1}$ The sloughing goes on for a day and a night, beginning with the head and ending with the tail. During the sloughing of the skin an inner layer comes to the surface, ${ }^{2}$ for the creature emerges just as the embryo $60 \mathrm{r}^{\mathrm{a}}$ from its afterbirth.

All insects that slough at all slough in the same way; as the silphe, ${ }^{3}$ and the empis or midge, ${ }^{4}$ and all the colcoptera, as for instance the cantharus-beetle. They all slough after the period of development; for just as the afterbirth breaks from off the young of the vivipara so the outer husk 5 breaks off from around the young of the vermipara, in the same way both with the bee and the grasshopper. The cicada the moment after issuing from the husk ${ }^{5}$ goes and sits upon an olive tree or a reed; after the breaking up of the husk the creature issues out, leaving a little moisture behind, and after a short interval flics up into the air and sets a-chirping.

Of marine animals the crawfish and the lobster ${ }^{6}$ slough

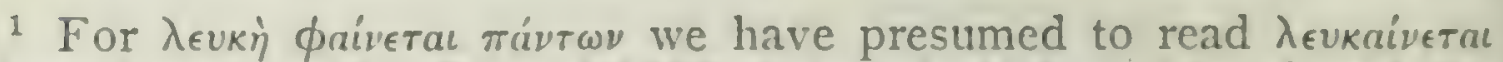

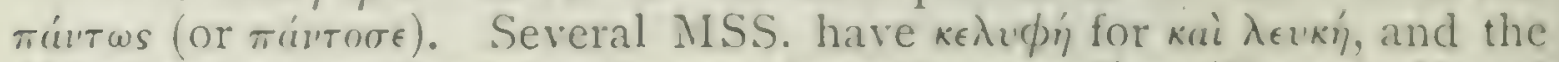
Marcian inserts the latter as an alternative reading (Camus, Not, $d$. IISS. v. p. 4521.

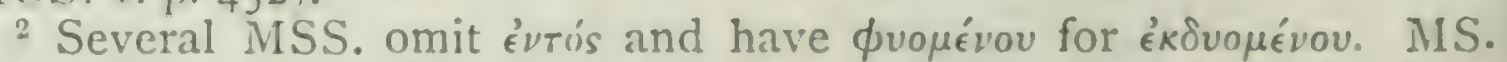

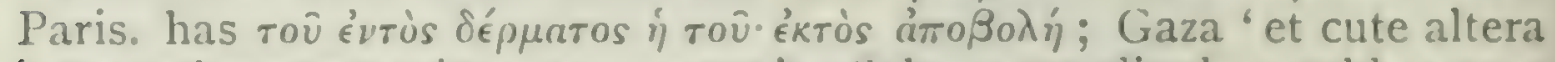
intus subnascente ipsa removetur'. Schn. accordingly would restore

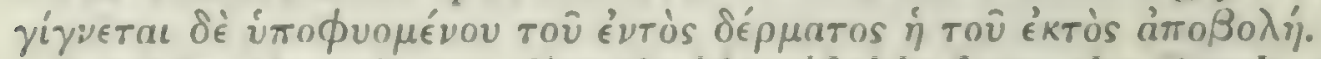

" rid $\phi \eta$, though not directly identifiable from the (ireck, appears to be identical with the Lat. blatta (Plin. xi. $28, \& c^{2}$ ), and that with the cockroach, e.g. Blatta germanica.

' $\epsilon$ ' $\mu$ is is properly a gnat or midge, cf. H.A.i. $5 \cdot 490^{\mathrm{a}} 2 \mathrm{I}, \mathrm{v} \cdot 19.5 \mathrm{I}^{\mathrm{b}} 27$; but that interpretation is inatpt here, as Sunclevall suggests rather one

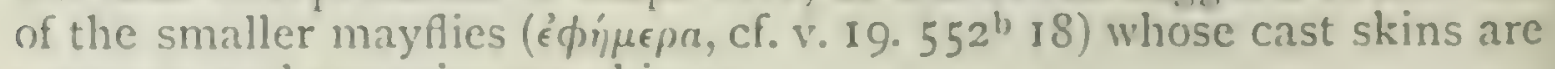
common and conspicuous objects.

H. A.v. 30. $556^{\mathrm{b}} 7$.

'H.A.v. 17. $549^{1 / 2} 25$; Artem. On. ii. I4. 
sometimes in the spring, and sometimes in autumn after parturition. Lobsters have been caught occasionally with the parts about the thorax soft, from the shell having there peeled off, and the lower parts hard, from the shell having. not yet peeled off there; for, by the way, they do not slough in the same manner as the serpent. The crawfish 15 hides for about five months. Crabs also slough off their old-age; this is generally allowed with regard to the softshelled crabs, and it is said to be the case with the testaceous kind, as for instance with the large 'granny' crab. ${ }^{1}$ When these animals slough their shell becomes soft all over, and as for the crab, it can scarcely crawl. These animals also do not cast their skins once and for all, but 20 over and over again.

So much for the animals that go into hiding or torpidity, for the times at which, and the ways in which, they go; and so much also for the animals that slough off their old-age, and for the times at which they undergo the process.

I8 Animals do not all thrive at the same seasons, nor do they thrive alike during all extremes of weather. Further, animals of diverse species are in a diverse way healthy or 25 sickly at certain seasons; and, in point of fact, some animals have ailments that are unknown to others. Birds thrive in times of drought, both in their general health and in regard to parturition, and this is especially the case with the cushat; ${ }^{2}$ fishes, however, with a few exceptions, thrive best in rainy weather; on the contrary, rainy seasons ${ }^{3}$ are bad for birds - and so by the way is much drinking - zo and drought is bad for fishes. ${ }^{4}$ Birds of prey, as has been already stated, may in a general way be said never to drink at all, ${ }^{5}$ though Hesiod ${ }^{6}$ appears to have been ignorant 6 o $^{\text {b }}$ of the fact, for in his story about the siege of Ninus he

$1 \mathrm{PE}^{\mathrm{a}}$ tàs $\mu$ aías tás te ypaûs.

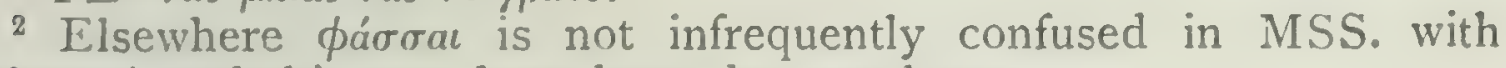
$\tau \iota \theta \kappa \sigma \sigma a i$, and this may have been the case here.

3 Some MSS. have '́tó $\mu \beta \rho \iota e^{\epsilon} \lambda \eta$.

4 The rest of the chapter is stigmatized by A. \& W.

5 H. A. viii. $3 \cdot 594^{a}$ I.

B Some MSS. have Herodotus, and Scotus gives Homer; the reference is unknown. 
represents the eagle that presided over the auguries as in the act of drinking; all other birds drink, but drink 5 sparingly, as is the case also with all other spongy-lunged oviparous animals. Sickness in birds may be diagnosed from their plumage, which is ruffled when they are sickly instead of lying smooth as when they are well.

The majority of fishes, as has been stated, thrive ${ }^{1}$ best I 9 ro in rainy seasons. Not only have they food in greater abundance at this time, but in a general way rain is wholesome for them just as it is for vegetation 2-for, by the way, kitchen vegetables, though artificially watered, derive benefit from rain; and the same remark applies even to I5 reeds that grow in marshes, as they hardly grow at all without a rainfall. ${ }^{3}$ That rain is good for fishes may be inferred from the fact that most fishes migrate to the Euxine for the summer; for owing to the number of the rivers that discharge into this sea its water is exceptionally fresh, and the rivers bring down a large supply of food. Besides, a great number of fishes, such as the bonito and 20 the mullet, swim up the rivers and thrive in the rivers and marshes. The sea-gudgeon also fattens in the rivers, and, as a rule, countrics abounding in lagoons furnish unusually excellent fish. While most fishes, then, are benefited by rain, they are chiefly benefited by summer rain; or we may state the case thus, that rain is good for 25 fishes in spring, summer, and autumn, and fine dry weather in winter. As a gencral rule what is good for men is good for fishes also.

Fishes do not thrive in cold places, and those fishes suffer 30 most in severe winters that have a stone in their head," as the chromis, the basse, the sciaena, and the braize;

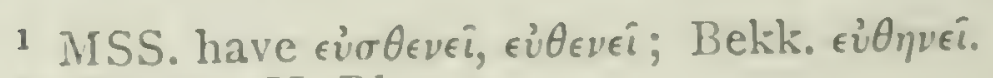

2 Theoph. H.Pl.v. 2.

4 H. A. vi. 14. $569^{\text {a }} 7$.

3 Plin. ix. 23.

5 Plin. ix. 24; Ael. ix. 7 .

" $\sigma$ kiaur is one of the three allied Sciaenidae, Sc. aquila, Umbrina cirrosa, and Corvina niger, to all of which the name ombra, umbrina, \&. ., is now applied. The last-named is called in Mod. Gk. okıós,

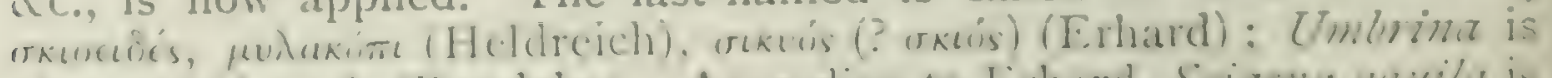

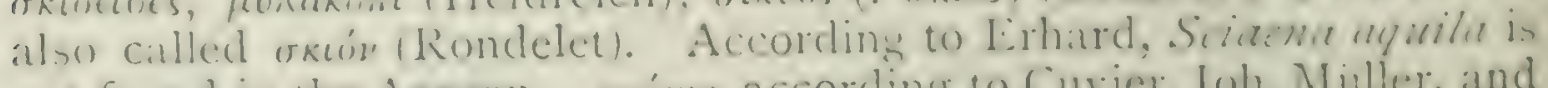
not found in the Aegean. Apripss, according to Curier, Joh. Misller, and others, is one of the same fishes. See notes to ir. $8.534^{2}$ IO, V. IO. $543^{1} 2$. 
for owing to the stone they get frozen with the cold, ${ }^{1}$ and are thrown up on shore. ${ }^{2}$

Whilst rain is wholesome for most fishes, it is, on the contrary, unwholesome for the mullet, the cephalus, and $602^{a}$ the so-called marinus, for rain superinduces blindness in most of these fishes, and all the more rapidly if the rainfall be superabundant. The cephalus is peculiarly subject to this malady in severe winters; their eyes grow white, and 5 when caught they are in poor condition, and eventually the disease kills them. It would appear that this disease is due to extreme cold even more than to an excessive rainfall; for instance, in many places and more especially in shallows off the coast of Nauplia, in the Argolid, a number of fishes have been known to be caught out at sea in ro seasons of severe cold. The gilthead also suffers in winter"; the acharnas ${ }^{3}$ suffers in summer, and loses condition. The coracine is exceptional among fishes in deriving benefit from drought, and this is due to the fact that heat and drought are apt to come together.

Particular places suit particular fishes; some are naturally i5 fishes of the shore, and some of the deep sea, and some are at home in one or the other of these regions, and others are common to the two and are at home in both. Some fishes will thrive in one particular spot, and in that spot only. As a general rule it may be said that places abounding in weeds are wholesome; at all events, fishes caught in such places are exceptionally fat: that is, such fishes as inhabit all sorts of localities as well. The fact is that weed-eating 20 fishes find abundance of their special food in such localities, and carnivorous fish find an unusually large number of smaller fish. It matters also whether the wind be from the north or south: the longer fish thrive better when a north wind prevails, and in summer at one and the same spot

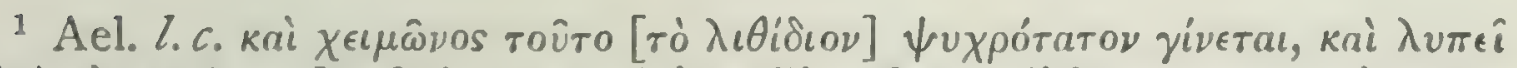

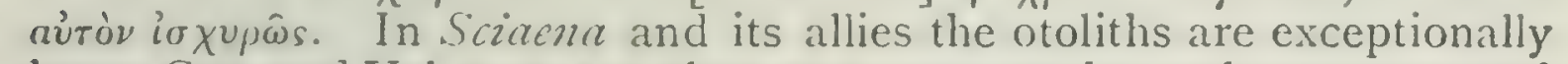
large, Cuv. and Val. v. p. 43: they were worn at the neck as a cure and prevention of colic, Belon, de Aquat. 1553, p. I 18 .

2 Or the verb may mean 'degenerate, fall off in condition'.

${ }^{3}$ Cf. viii. 2. $59 I^{\text {b }}$ I. 
25 more long fish will be caught than ${ }^{1}$ flat fish with a north wind blowing.

The tunny and the sword-fish are infested with a parasite about the rising of the Dog-star $;^{2}$ that is to say, about this time both these fishes have a grub beside their fins that is nicknamed the 'gadfly'. It resembles the scorpion in shape, and is about the size of the spider. So acute is the pain it inflicts that the sword-fish ${ }^{4}$ will often leap 30 as high out of the water as a dolphin; in fact, it sometimes leaps over the bulwarks of a vessel and falls back on the deck. The tunny delights more than any other fish in the heat of the sun. It will burrow for warmth in the sand $602^{\mathrm{b}}$ in shallow waters near to shore, or will, because it is warm, disport itself on the surface of the sea.

The fry of little fishes escape by being overlooked, for it is only the larger ones of the small species that fishes of the large species will pursue. The greater part of the spawn and the fry of fishes is destroyed by the heat of 5 the sun, ${ }^{5}$ for whatever of them the sun reaches it spoils.

Fishes are caught in greatest abundance before sunrise and after sunset, or, speaking gencrally, just about sunset and sunrise. ${ }^{6}$ Fishermen haul up their nets at these times, and speak of the hauls then made as the 'nick-oftime' hauls. The fact is, that at these times fishes are partiro cularly weaksighted; at night they are at rest, and as the light grows stronger they see comparatively well.

We know of no pestilential malady attacking fishes, such as those which attack man, and horses and oxen among the quadrupedal vivipara, and certain species of other genera,

1 kai MSS., Bekk. ; î Aldine, and most commentators.

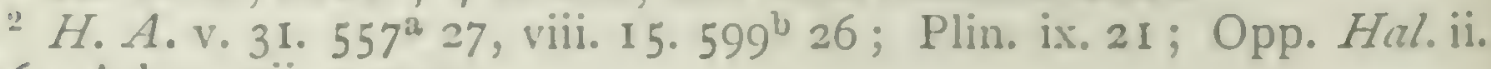
506 ; Athen. vii. p. 302.

3 These parasites are parasitic copepods; that of the sword-fish is I'enella filusa (L.), and to its elongated form the present description seems best to apply. The chief species infesting the tumny is brativilu thynni (Cuv.), but Cecrops Latreillii, Leach, is said also, by Milne Edwards, to infest that fish. Cf. Steenstrup and Lütken, $K$. Danshic Vid. Selsk. Sk\%. (5) v. 421, 186I.

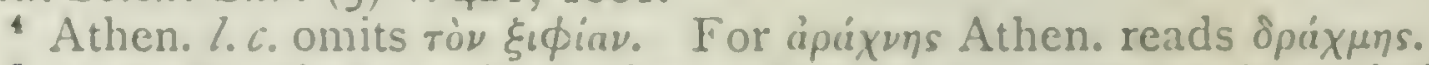

5 A. \& W. cj. $\delta$ ia roùs appévas. The whole sentence is probably corrupt: Gaza has translated a very different text, 'cum enim pisces desiderio teporis loca foeturate aleunt, ligmiunt quicquid attigerint.'

i Plin. ix. 23. 
domesticated and wild; but fishes do seem to suffer from I5 sickness; and fishermen infer this from the fact that at times fishes in poor condition, and looking as though they were sick, and of altered colour, are caught in a large haul of well-conditioned fish of their own species. So much for sea-fishes.

20 River-fish and lake-fish also are exempt from diseases of 20 a pestilential character, but certain species are subject to special and peculiar maladies. For instance, the sheat-fish ${ }^{1}$ just before the rising of the Dog-star, owing to its swimming near the surface of the water, is liable to sunstroke, and is paralysed by a loud peal of thunder. The carp is subject to the same eventualities, but in a lesser degree. The sheat-fish is destroyed in great quantities in shallow 25 waters by the serpent called the dragon. ${ }^{2}$ In the balerus and tilon ${ }^{3}$ a worm is engendered about the rising of the Dog-star, that sickens these fish and causes them to rise towards the surface, where they are killed by the excessive heat. The chalcis is subject to a very violent malady ; ${ }^{4}$ lice are engendered underneath their gills in great numbers, and cause destruction among them; but no other species $3 \circ$ of fish is subject to any such malady.

If mullein be introduced into water it will kill fish in its vicinity. ${ }^{\circ}$ It is used extensively for catching fish in rivers and ponds $;^{7}$ by the Phoenicians it is made use of also in the sea. $603^{\text {a }}$

There are two other methods employed for catching fish.

1 Plin. ix. 25.

2 Plin. l.c. 'silurus Caniculae exortu sideratur'. I am not aware of 'the dragon' being a mythical expression for thunder, though it is, in Semitic literature, for the earthquake (cf. Isa. xxi. 9), and I suspect that

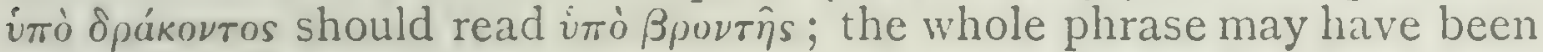
something like írò $\beta \rho$. $\tau \hat{\eta} \phi \lambda$ oyí.

${ }^{3}$ This is the curious word that Herodotus tells us belonged to the language of the Macedonian lake-dwellers. I suspect that it is a synonym of ydávis, or Silurus, and akin to the S. German Seile, a rame for the same fish. Cf. Kner, SB. Akad. Wien, 1864, p. 336.

${ }^{4}$ Plin. ix. 71 . As remarked under iv. $9.535^{11} 18$, this fish is conjectured to be the John Dory, Zeus faber. A parasitic copepod, Chondracanthus $z e i$, is very common and conspicuous on the gills of the fish, but is scarcely so conspicuous as to confirm the identification.

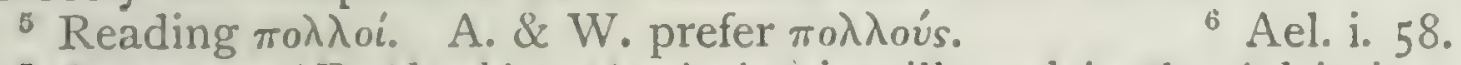

7 As spurge (Euphorbia cyparissias) is still used in the Adriatic and in Ireland; if indeed the same plant be not meant here also. 
It is a known fact that in winter fishes emerge from the decp parts of rivers - and, by the way, at all scasons fresh water is tolerably cold. A trench accordingly is dug 5 lcading into a river, and wattled at the river cnd with reeds and stones, an aperture being left in the wattling through which the river water flows into the trench; when the frost comes on the fish can be taken out of the trench in weels. Another method is adopted in summer and winter alike. They run across a stream a dam composed of brushwood ro and stones, leaving a small open space, and in this space they insert a weel; they then coop the fish in towards this place, and draw them up in the weel as they swim through the open space. ${ }^{1}$

Shell-fish, as a rule, are benefited by rainy weather. The purple murex is an exception; if it be placed on a shore near to where a river clischarges, it will die within a day I5 after tasting the fresh water. The murex lives for about fifty days after capture; during this period they feed off one another, ${ }^{2}$ as there grows on the shell a kind of seaweed or sea-moss; if any food is thrown to them during this period, it is said to be done not to keep them alive, but to make them weigh more.

To shell-fish in general drought is unwholesome." During 20 dry weather they decrease in size and degenerate in quality; and it is during such weather that the red scallop is found in more than usual abundance. ${ }^{4}$ In the Pyrrhacan Strait the clam was exterminated, partly by the dredging-machine used in their capture, and partly by long-continued droughts. Rainy weather is wholesome to the generality of shell-fish owing to the fact that the sca-water then 25 becomes exceptionally swect. In the Euxine, owing to the coldness of the climate, shell-fish are not found: nor yet in rivers, excepting a few bivalves here and there. Uni-

1 The original of this passage is very obscure, and the translation

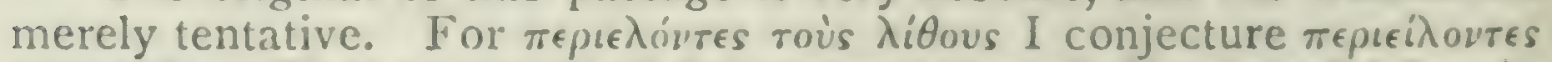
rois ixtis. Cf. the account of fish-weirs, 'serragli di grigiuoli,' $\mathcal{E}$. . in Faber's Fishes of the Adriatic, p. 123; the best fishing is at the time of the first frosts, and is known as fraima or frimas, i.e. hoar-frost (infra hiemem).

3 Xenocr. de Alim. xix; Diphil. ap. Athen. p. 90.

' Gaza tr. 'et quidem pectines tunc magis trahunt rufum colorem'. 
valves, by the way, are very apt to freeze to death in cxtremely cold weather. So much for animals that live in water.

2I ${ }^{1}$ To turn to quadrupeds, ${ }^{2}$ the pig suffers from three $3^{\circ}$ diseases, ${ }^{3}$ one of which is called branchos, ${ }^{4}$ a disease attended with swellings about the windpipe ${ }^{5}$ and the jaws. ${ }^{6}$ It may break out in any part of the body; very often it attacks $603^{\text {b }}$ the foot, and occasionally the ear; the neighbouring parts also soon rot, and the decay goes on until it reaches the lungs, when the animal succumbs. The disease develops with great rapidity, and the moment it sets in the animal gives up eating. The swincherds know but one way to 5 cure it, namely, by complete excision, when they detect the first signs of the disease. There are two other diseases, which are both alike termed craurus. ${ }^{7}$ The one is attended with pain and heaviness in the head, and this is the commoner of the two, the other with diarrhoea. The latter is incurable, the former is treated by applying wine fomenta- io tions to the snout and rinsing the nostrils with wine. Even

1 The following chapters on veterinary medicine, and indeed all the remainder of this eighth book, bear evidence of an alien hand.

${ }^{2}$ On the diseases of animals known to antiquity, see especially the Byzantine compilations known as the Hippiatrica (ed. Gryneus, 1537, \&c.) and Geoponica (ed. int. al. J. H. Niclas, 1781). See also A. Baranski, Thiermedicin im Alterthum, Wien, 1886).

${ }^{3}$ Verg. G. iii. 497 ; Plin. viii. 77 ; Colum. vii. 10.

4 Under $\beta \rho a ́ \gamma \chi^{\circ}$, two or more diseases appear to be confused. The inflammatory swellings about the windpipe and jaws, and the rapid and fatal course of the disease, correspond to the symptoms of anthrax. But the affection of the feet suggests more especially foot-and-mouth disease, or 'epizootic aphtha', in which the hooves tend to rot or slough away. This latter disease in most cases yields to treatment, and to it the subsequent and disconnected paragraph on $\beta_{p}$ áy refers.

${ }^{5}$ Note the use of $\beta p a ́ y x ı$ for windpipe, as in de Spiritu, 5. $483^{a} 22$, both passages being in all probability spurious.

${ }^{6}$ Verg. l.c. ' et quatit aegros Tussis anhela sues, ac faucibus angit obesis.'

7 The two varieties of xpaûpos cannot be identified with any approach to certainty. The drooping head is an early symptom of almost any disease. Diarrhoea is a common, but not invariable symptom, of the fatal malady known as swine fever. Suid., s. $v_{0}$ o oúppoı, describes

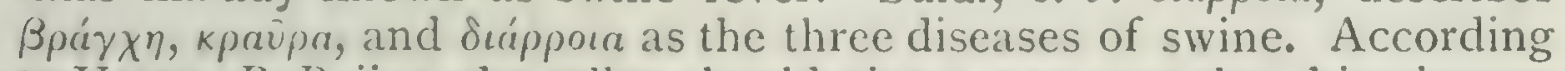
to Varro, R.R. ii. 4 , the seller should give a warranty that his pigs are 'a febri et a foria perfunctas', i. e. 'free from fever and from diarrhoea'. 
this disease is very hard to cure; it has been known to kill within three or four days. The animal is chiefly subject to branchos when it gets extremely fat, and when the heat has brought a good supply of figs. ${ }^{1}$ The treatment is to feed 15 on mashed mulberries, to give repeated warm baths, and to lance the under part of the tongue.

Pigs with flabby flesh are subject to measles ${ }^{2}$ about the legs, neck, and shoulders, for the pimples develop chiefly in these parts. ${ }^{3}$ If the pimples are few in number the flesh is comparatively sweet, but if they be numerous it gets 20 watery and flaccid. The symptoms of measles are obvious, for the pimples show chiefly on the under side of the tongue, and if you pluck the bristles off the chine the skin will appear suffused with blood, and further the animal will be unable to keep its hind-feet at rest. Pigs never 25 take this disease while they are mere sucklings. The pimples may be got rid of by feeding on a kind of spelt called tiphe; ${ }^{4}$ and this spelt, by the way, is very good for ordinary food. The best food for rearing and fattening pigs is chickpeas and figs, but the one thing essential is to vary the food as much as possible, for this animal, like 30 animals in general, delights in a change of diet; and it is said that one kind of food blows the animal out, that another superinduces flesh, and that another puts on fat, and that acorns, though liked by the animal, render the flesh flaccid. Besides, if a sow eats acoms in great quanti-

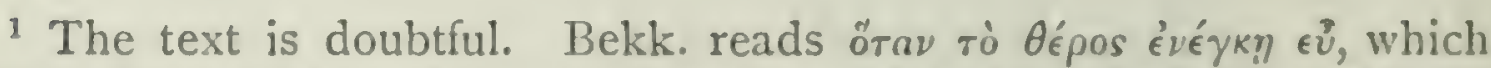
seems inacceptable: Picc. cj. єủкapтíav. Cf. Colum.R.R. vii. Io 'Solet etiam vitiosi splenis dolor eas infestare, quod accidit quum siccitas magna provenit, et, ut Bucolicum loquitur poema, Strata iacent fatssim sua quaeque sub arbore poma'.

2 'The 'measles' here alluded to are the cysticercus-cysts of the tape-worm. It is the case that the cysts or pimples are to be detected chiefly on, or rather under, the tongue, but 1 am not aware that there are symptoms of cutaneous suffusion. Indeed the statement as to this latter symptom is very possibly misplaced ; the symptom is mentioned by l'liny as a general sign of ill-health, or of the presence of anginu

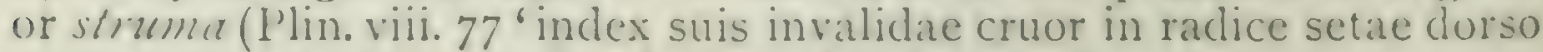
evulsae, caput obliquum [s. obstipum] in incessu').

${ }^{3}$ Ruf. Ephes. in Oribas. Collect. iv. 2. Cf. also Ar. Eq. 374 and Scholia.

1 Theophr. H.P. viii. i. I ; Plin. xviii. 19. Probably a sort of coarse wheat, Triticum monocoicum, L. Some MISS. have oтьфais. 
ties, it will miscarry, as is also the case with the ewe; and, indeed, the miscarriage is more certain in the case of the ewe than in the case of the sow. The pig is the only animal known to be subject to measles.

22 Dogs suffer from three diseases; rabies, quinsy, and sore feet. Rabies drives the animal mad, and any animal what- 5 ever, excepting man, will take the disease if bitten by a dog so afflicted; the disease is fatal to the dog itself, and to any animal it may bite, man excepted. ${ }^{1}$ Quinsy ${ }^{2}$ also is fatal to dogs; and only a few dogs recover from disease of the feet. The camel, like the dog, is subject to rabies. Io The elephant, which is reputed to enjoy immunity from all other illnesses, is occasionally subject to flatulency.

23 Cattle in herds are liable to two diseases, foot-sickness and craurus. ${ }^{4}$ In the former their feet suffer from eruptions, but the animal recovers from the disease without even the 15 loss of the hoof. It is found of service to smear the horny parts with warm pitch. ${ }^{5}$ In craurus, the breath comes warm at short intervals; in fact, craurus in cattle answers to fever in man. The symptoms of the disease are drooping of the ears and disinclination for food. The animal soon succumbs, 20 and when the carcase is opened the lungs are found to be rotten.

24 Horses out at pasture are free from all diseases excepting disease of the feet. From this disease they sometimes lose

${ }^{1} \pi \lambda \dot{\eta} \nu$ ả $\theta \rho \dot{\omega} \pi 0 v$ is absent from most MSS., and is rejected by Piccolos; but it is found in the version of Antigonus, cii. Pollux

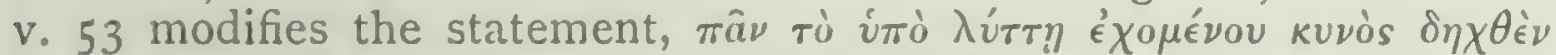

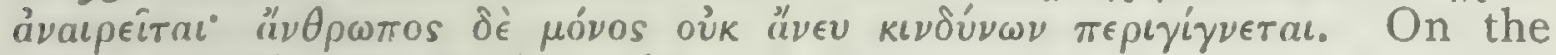
signs of rabies see Paul. Aegin. v. 3, Glycas Ann. p. 63. On lytta, the 'worm' in a dog's tongue removed (even to this day) to prevent rabies, see Plin. xxix. 5, Grat. Cyneg. 386, \&c.

2 This kuvaíy 7 may very possibly be 'distemper'.

${ }^{3}$ Cf. $26.605^{2} 23$.

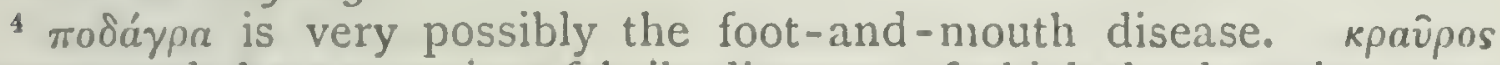
corresponds here to various febrile diseases, of which the drooping ears, loss of appetite, and laboured breathing are preliminary, rather than diagnostic symptoms; the cliseased lungs, however, suggest contagious pleuro-pneumonia, a malady which is usually fatal.

5 Cf. $7.595^{\mathrm{b}} 15$. 
25 their hooves: but after losing them they grow them soon again, for as one hoof is decaying it is being replaced by another. Symptoms of the malady are a sinking in and wrinkling of the lip in the middle under the nostrils, and in the case of the male, a twitching of the right testiclc. ${ }^{1}$

Stall-reared horses are subject to very numerous forms of discase. They are liable to a discase called 'eilcus'. $604^{\mathrm{b}}$ Under this disease the animal trails its hind-legs under its belly so far forward as almost to fall back on its haunches: if it goes without food for several days and turns rabid, ${ }^{2}$ it may be of service to draw blood, or to castrate the male." The animal is subject also to tetanus: the veins get rigid, 5 as also the head and neck, and the animal walks with its legs stretched out straight. The horse suffers also from abscesses. Another painful illness afflicts them called the 'barley-surfeit'. The symptoms are a softening of the palate and heat of the breath; ${ }^{4}$ the animal may recover through the strength of its own constitution, but no formal remedies are of any avail.

Io There is also a discase called nymphia, in which the

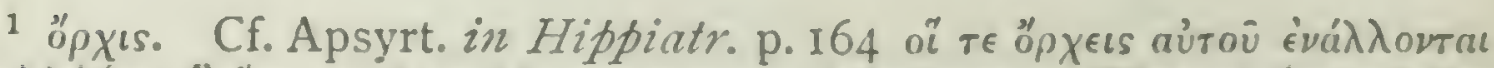

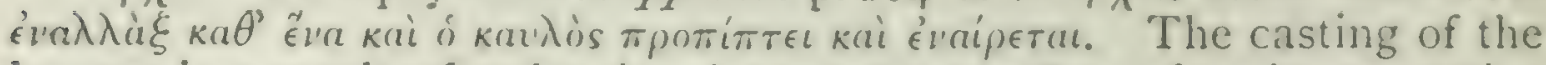
hooves is a result of poisoning by ergot, as well as of various eruptive diseases of the feet.

${ }^{2}$ Schn. points out that this sentence is somehow corrupt. I think that $\tau$ is $" \epsilon \mu \pi \rho \sigma \theta \epsilon \nu$ is interpolated by repetition from the line above;

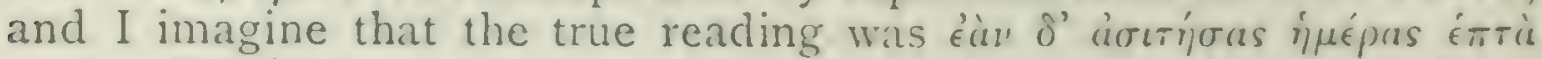

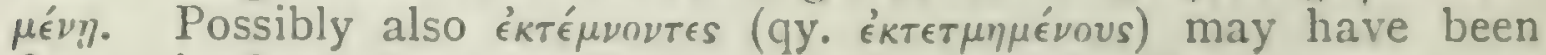
drawn in from the next clause; in other words, the statement may have been that lockjaw sometimes follows castration, as is indeed the case. On tetanus in horses cf. Hippiatr. p. I I 9.

${ }^{3} \epsilon^{\prime \prime} \lambda \in U s$ probably includes cases of ordinary colic; but the description further suggests the disease known as 'staggers', or coma somnolintum, much commoner in the south of Europe than with us, in which disease the legs are contorted into curious positions.

* Cf. Colum.vi. I4. 2 'Interdum et tumor palati cibos respuit crebrumque suspirium facit', \&c. In the account of $x$ setiurıs by Apsyrtus, in Hippiatr. i. c. 7, an oúpavioros $\mu \epsilon \tau \epsilon$ épos is spoken of in connexion with it, apparently from a notion connected with the doctrine of signatures. According to Vegetius, iii. 44, kpeluares is simply indigestion, or surfeit.

"The whole chapter is difficult, and this paragraph especially obscure.

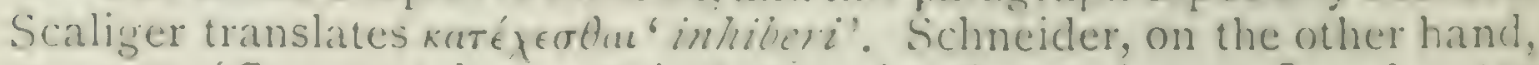

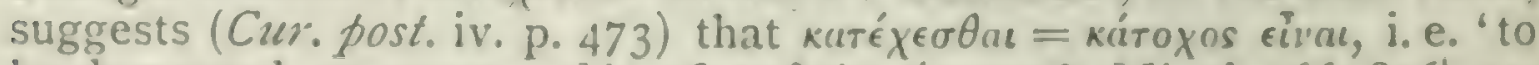

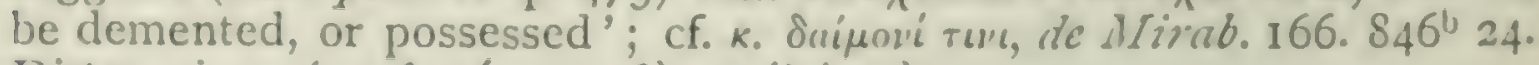

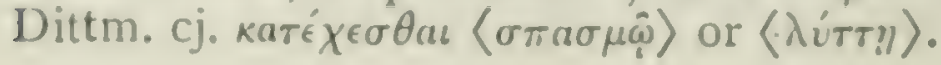


animal is said to stand still and droop its head on hearing flute-music; if during this ailment the horse be mounted, it will run off at a gallop until it is pulled. ${ }^{2}$ Even with this rabies in full force, it preserves a dejected spiritless appearance; some of the symptoms are a throwing back of the ears followed by a projection of them, great languor, and heavy ${ }^{2}$ breathing. Heart-ache ${ }^{3}$ also is incurable, of ${ }_{15}$ which the symptom is a drawing in of the flanks; ${ }^{4}$ and so is displacement of the bladder," which is accompanied by a retention of urine and a drawing up of the hooves and haunches. Neither is there any cure if the animal swallow the grape-beetle, which is about the size of the sphondyle or knuckle-beetle. ${ }^{6}$ The bite of the shrewmouse ${ }^{7}$ is dangerous to horses and other draught animals as well; 20 it is followed by boils. The bite is all the more dangerous if the mouse be pregnant when she bites, for the boils then burst, but do not burst otherwise. The cicigna ${ }^{8}$ - called 'chalcis' by some, and 'zignis' by others-either causes death by its bite or, at all events, intense pain; it is like a small lizard, with the colour of the blind snake. In point 25 of fact, according to experts, the horse and the sheep have pretty well as many ailments as the human species. The drug known under the name of 'sandarace' or realgar, is extremely injurious ${ }^{9}$ to a horse, and to all draught animals; it is given to the animal as a medicine in a solution of water, the liquid being filtered through a colander. The mare when pregnant is apt to miscarry when disturbed by $3 \circ$

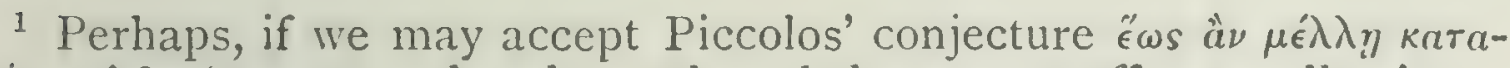
reivas $\theta \in i \nu$, ' runs round and round, and then starts off at a gallop.'

2 Picc. cj. каi $\langle\pi v \kappa \nu \dot{\nu}\rangle \pi \nu \epsilon \hat{\imath}$.

3 According to the usual interpretation of $P . A$. iv. $2.677^{\mathrm{b}} 4$ (cf. iii. 4. $667^{\mathrm{a}} 32$ ) the heart is subject to no diseases (cf. Daremberg, Galien, i. $40 \mathrm{I}$; Ogle, ad loc.).

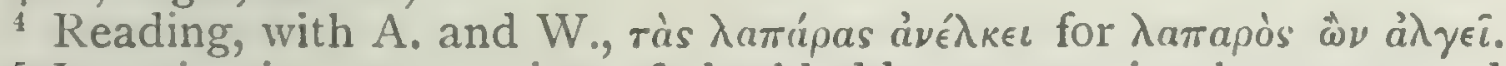

5 Invagination or eversion of the bladder occurs in the mare and the cow.

6 Hippiatr. p. 266.

7 Diosc. Theriac. c. viii.

8 The name Cicigna, for a lizard, is said to survive in Sardinia. Cf. Schol. Nicand. Ther. 817; Oken, Isis, I829, p. 623.

"The reading and the sense are very doubtful. If a preparation of arsenic (Plin. xxxiv. 54, Diosc.v. I22), it was doubtless given, as at present, to improve the animal's coat. Hence I think that

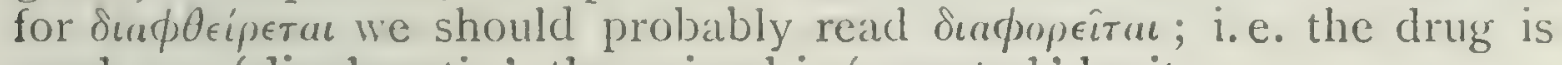
used as a 'diaphoretic', the animal is 'sweated' by it. 
the odour of an extinguished candle; ${ }^{1}$ and a similar $605^{\mathrm{a}}$ accident happens occasionally to women in their pregnancy. So much for the diseases of the horse.

The so-called hippomanes ${ }^{2}$ grows, as has been stated," on the foal, and the mare nibbles it off as she licks and cleans the foal. All the curious stories connected with the 5 hippomanes are due to old wives and to the venders of charms. What is called the 'polium' or foal's membrane, is, as all the accounts state, delivered by the mother before the foal appears.

A horse will recognize the neighing of any other horse with which it may have fought at any previous period. The horse delights in meadows and marshes, and likes to so drink muddy water; in fact, if water be clear, the horse ${ }^{4}$ will trample in it to make it turbid, will then drink it, and afterwards will wallow in it." The animal is fond of water in every way, whether for drinking or for bathing purposes; and this explains the peculiar constitution of the hippopotamus or river-horse. In regard to water the ox is the opposite of the horse; for if the water be impure or cold, or I5 mixed up with alien matter, it will refuse to drink it.

The ass suffers chiefly from one particular disease "i which 25 they call 'melis'. It arises first in the head, and a clammy humour runs down the nostrils, thick and red; if it stays in the head the animal may recover, but if it descends into the lungs the animal will die. Of all animals of its kind 20 it is the least capable of enduring extreme cold, which circumstance will account for the fact that the animal is not found on the shores of the Euxine, nor in Scythia.'

1 Arist. $x p$. Ael. ix. 54; Hierocl. in Hippiatr. p. 58 .

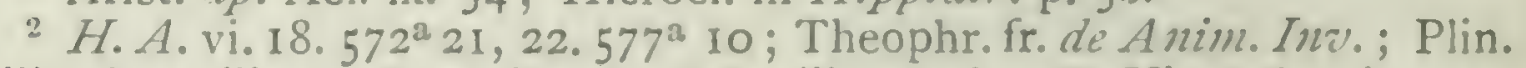
viii. 66, xxviii. 49; Juv.vi. I32; Ael. xiii. 17, xiv. I8; Virg. Aen. iv. 515.

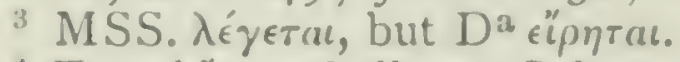

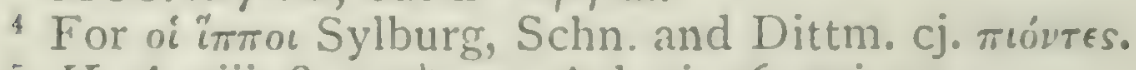

5H. A. viii. 8. 595' 30 ; Acl. xi. 36, xvi. 24.

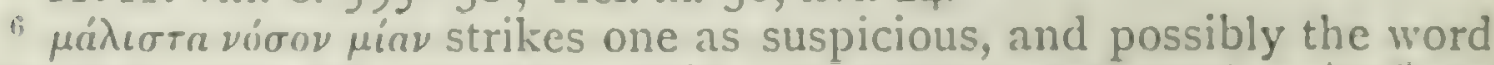

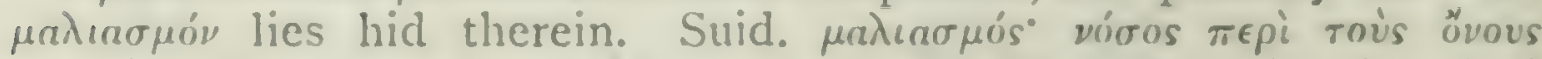

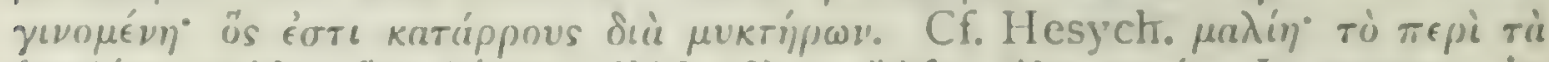

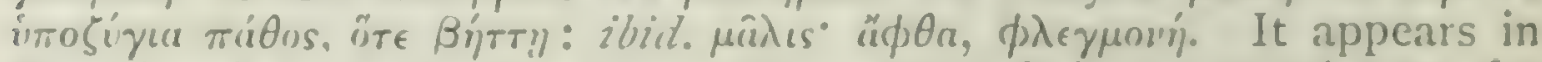
Vegetius, i. 10-20, in the form malleus, where it is a general term for the diseases of draught animals. As above described, the disease is probably "blanclers", which, however, is almost invariably fatal in the iss.

${ }^{7}$ G. A. ii. 8. $748^{2} 22$. 
26 Elephants suffer from flatulence, and when thus afflicted can void neither solid nor liquid residuum. ${ }^{1}$ If the elephant swallow earth-mould ${ }^{2}$ it suffers from relaxation; but if it 25 go on taking it steadily, it will experience no harm. From time to time it takes to swallowing stones. It suffers also from diarrhoea: in this case they administer draughts of lukewarm water or dip its fodder in honey, and either one or the other prescription will prove a costive. When they suffer from insomnia, they will be restored to health if their shoulders be rubbed with salt, olive-oil, and warm $3 \circ$ water; when they have aches in their shoulders they will derive great benefit from the application of roast pork. ${ }^{3} 605^{\mathrm{b}}$ Some elephants like olive-oil, and others do not. If there is a bit of iron in the inside of an elephant it is said that it will pass out if the animal takes a drink of olive-oil ${ }^{4}$ if the animal refuses olive-oil, they soak a root $^{5}$ in the oil and give it the root to swallow.

So much, then, for quadrupeds.

27 Insects, as a general rule, thrive best in the time of year in which they come into being, especially if the season be moist and warm, as in spring. ${ }^{6}$

1 Plin. viii. Io.

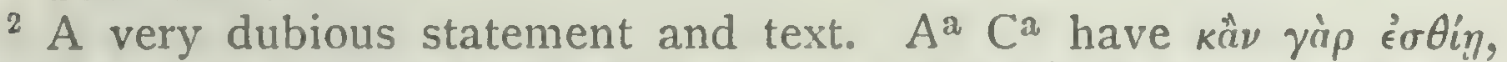
and if this be right $\mu a \lambda a \kappa i \zeta \epsilon \tau a l$ is wrong. We might suspect $\kappa a ̂ v$ yà $\epsilon^{\prime} \sigma \theta_{i} \eta \mu a \lambda a^{\prime} \chi \eta \nu$ (mallow), the laxative properties of which plant are mentioned by Plin. xx. 21, Diosc. ii. I 44, Mart. x. 48. 7, \&c.; and I should then be further tempted to suggest $a \lambda \theta$ ains for the unlikely $\lambda_{i} \theta$ ous of the next clause.

3 Arrian, Ind. xiv ; Ael. xiii. 7.

4 Cuvier (ad Plin. viii. Io, cf. Ael. ii. 18) notes the unlikelihood of this cure, and suspects that the olive oil was actually given as an anticlote to poison, and that in the original account drawn on by Aristotle and others there was a confusion between ios, a dirt, and iós, venom.

5 The MSS. are at variance, and our text is according to A. and W.'s

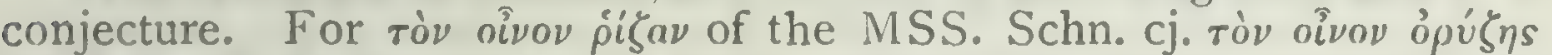
(cf. Ael. xiii. 8; Strabo xv. 53. 709); and this is highly probable, but the rest of the sentence is not correspondingly clear. It was wine according to Arrian and Aelian that was the usual medicine for elephants. Camus cites a Paris MS. of Gaza which gives 'qui autem oleum non bibunt, is radix tyrtami (? dyctami) decocta in vina datur'.

${ }^{6}$ Gaza tr., in accordance with an identical text, 'Insectorum maxima pars eo tempore valet quo gignitur; videlicet cum annus talis, quale ver, humidus et tepidus.' The text is not merely, as Scaliger puts it, 'paulo concisior' but, as A. and W. say, 'ganz ohne Sinn'; moreover, 
In bee-hives are found creatures that do great damage to so the combs; for instance, the grub that spins a web and ruins the honey-comb: ${ }^{1}$ it is called the 'cleros'. It engenders an insect like itself," of a spider-shape, and brings disease into the swarm. There is another insect resembling the moth, called by some the 'pyraustes', 3 that flics about a lighted candle: this creature engenders a brood full of ${ }_{5}$ a fine down. It is never stung by a bee, and can only be got out of a hive by fumigation. A caterpillar also is engendered in hives, of a species nicknamed the teredo, or 'borer', with which creature the bee never interferes. Bees suffer most when flowers are covered with mildew, or in seasons of drought.

All insects, without exception, die if they be smeared 20 over with oil $;^{4}$ and they die all the more rapidly if you smear their head ${ }^{5}$ with the oil and lay them out in the sun.

${ }^{6}$ Variety in animal life may be produced by variety of 28 locality: thus in one place an animal will not be found at all, in another it will be small, or short-lived, or will not 25 thrive. $^{7}$ Sometimes this sort of difference is observed in closely adjacent districts. Thus, in the territory of Miletus,

it is not in spring that insects are most plentiful. The sentence appears to be parallel to the opening one of c. 19, and there is a somewhat similar one in $P$. A. iv. $5.680^{2} 28$. I look with suspicion on $\epsilon^{2} y . j \pi \epsilon \rho$ $\tilde{\omega} p a$, and conjecture in place thereof $\mu \epsilon \tau 0 \pi \omega$ ' $p o u$; i.e. "insects cspecially' flourish and abound in autumn, when the season is moist, mild, and

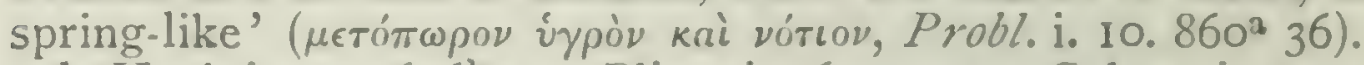

${ }^{1} H . A$. ix. 40. 626 15 ; Plin. xi. 16, 20, 2 I ; Colum. ix. 7. 13.

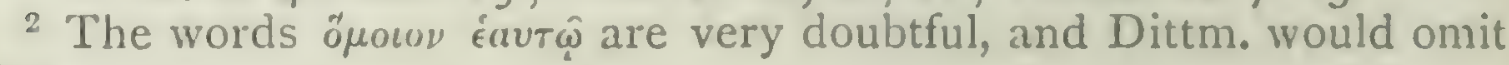
them.

3 'Transferred, according to Schneider's suggestion, from its usual

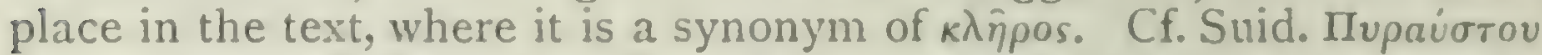

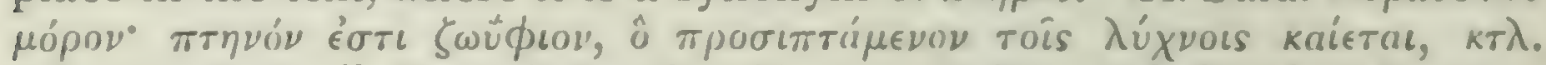
Cf. also Ael. xii. 8, and Aesch. ibi cit. Schn. and Sundevall agree that $\kappa \lambda \hat{\eta}$ pos is our 'Trichodes (Clerus) apiarius, a beetle; the 'moth' (papilio of Pliny, xi. 2 I, tinea of Vergil, G. iv. 246, and Colum. ix. 14) is the common 'wax-moth', Galleria cereana or mellonella; the caterpillars called $\tau \in$ profótes are the larvate of the last-named icf. I'lin. l. ..).

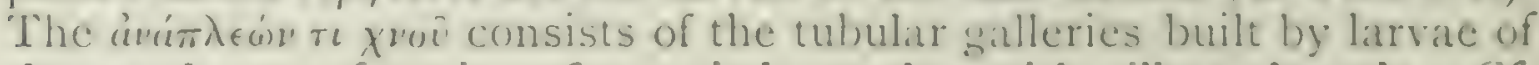
the moth out of grains of wax tied togrether with silken threads. Cf. Kirby and Spence, i. p. 465.

+ Plin. xi. 2 I; Ael. iv. IS.

"So Pliny, Albertus Mlagnus, and recent commentators. Nevertheless, there is evident ambiguity in rip $\kappa \epsilon ф u \lambda \eta \dot{\eta}$.

Dittm. considers this chapter to be derived from Theophrastus,

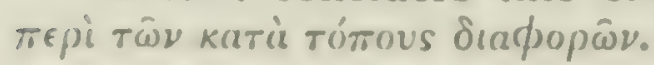

7 Plin. viii. 83 . 
in one district cicadas are found while there are none in the district close adjoining; and in Cephalenia there is a river on one side of which the cicada is found and not on the other. ${ }^{1}$ In Pordoselene there is a public road on one side of which the weasel is found but not on the other. ${ }^{2} 3^{\circ}$ In Boeotia the mole ${ }^{3}$ is found in great abundance in the neighbourhood of Orchomenus, but there are none in Lebadia though it is in the immediate vicinity, and if $606^{3}$. a mole be transported from the one district to the other it will refuse to burrow in the soil. The hare cannot live in Ithaca if introduced there; in fact it will be found dead, turned towards the point of the beach where it was landed. The horseman-ant ${ }^{4}$ is not found in Sicily; the croaking 5 frog has only recently appeared in the neighbourhood of Cyrene. ${ }^{5}$ In the whole of Libya ${ }^{6}$ there is neither wild boar, nor stag, nor wild goat; and in India, ${ }^{7}$ according to Ctesias-no very good authority, by the way-there are no swine, wild or tame, but animals that are devoid of blood and such as go into hiding or go torpid ${ }^{8}$ are all of immense size there. In the Euxine there are no small io molluscs nor testaceans, except a few here and there; but in the Red Sea all the testaceans are exceedingly large. ${ }^{9}$ In Syria ${ }^{10}$ the sheep have tails a cubit in breadth; the goats have ears a span and a palm long, and some have ears that flap down to the ground; ${ }^{11}$ and the cattle have ${ }_{15}$ humps ${ }^{12}$ on their shoulders, like the camel. ${ }^{13}$ In Lycia goats

1 Plin. xi. 32 ; Ael. v. 9 ; Antig. Mirab. 3: their absence, according to Pliny, being due to want of trees, cf. $H . A$. v. $30.556^{\mathrm{a}} 2 \mathrm{I}$.

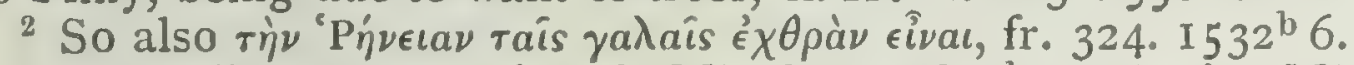

3 Ael. xvii. Io; Ps.-Arist. de Mirab. 124. $842^{\mathrm{b}} 3$; Antig. Mirab. I I.

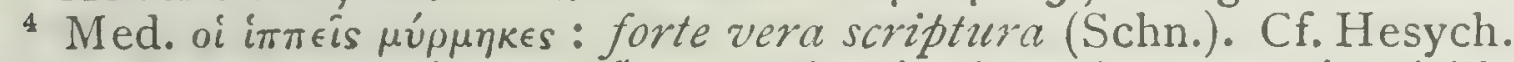

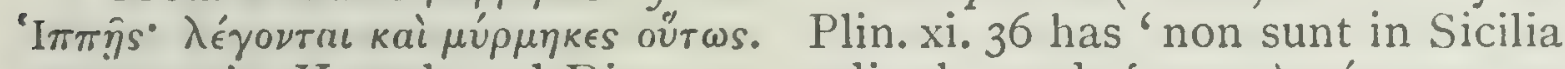
pennatae'; Karsch and Dittm. accordingly read oi $\pi r \eta \nu \circ i$ ú $\mu \mu \eta \kappa \epsilon s$, or oi $\pi \tau \epsilon \rho \omega \tau$ oì $\mu$ v́ $\rho \mu \eta \kappa \epsilon s$.

6 Herod. iv. I92; Ael. xvii. 10.

7 Ael. xvi. 37, cf. iii. 3; Ctes. ad Phot. xiii.

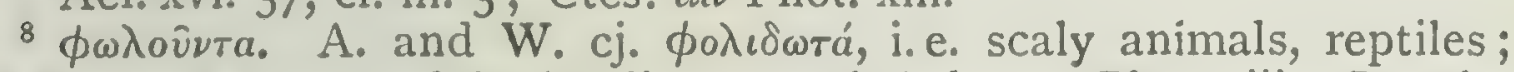
cf. Ctesias' account of the 'Indian worm', Ael. v. 3 ; Phot. xiii. But the mistake may have been as old as Aristotle.
${ }^{9}$ Ael. xvii. Io.
${ }_{10}$ H. A. ix. 10. $596^{\text {b }} 4$; Plin. viii. 75 .
11 Capra mambrica.

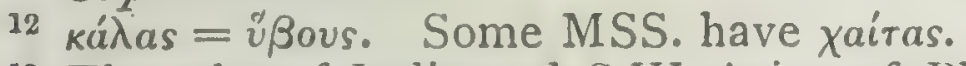

13 The zebu of India and S.W. Asia; cf. Plin. viii. 70 'Syriacis non sunt palearia, sed gibber in dorso'. 
are shorn for their fleece, just as sheep are in all other countries. ${ }^{1}$ In Libya the long-horned ram ${ }^{2}$ is born with horns, and not the ram only, as Homer ${ }^{3}$ words it, but the 20 ewe as well ${ }^{4}$ in Pontus, on the confines of Scythia, the ram is without horns.

In Egypt animals, as a rule, are larger than their congeners in Greece, ${ }^{5}$ as the cow and the sheep; but some are less, as the dog, the wolf, the hare, the fox, the raven, and the hawk; others are of pretty much the same size, as 25 the crow and the goat. The difference, where it cxists, is attributed to the food, as being abundant in one case and insufficient in another, for instance for the wolf and the hawk; for provision is scanty ${ }^{6}$ for the carnivorous animals, $606^{\mathrm{b}}$ small birds being scarce; food is scanty also for the hare and for all frugivorous animals, because neither the nuts nor the fruit last long. ${ }^{7}$

In many places the climate will account for peculiarities; thus in Illyria, Thrace, and Epirus the ass is small, and in 5 Gaul and in Scythia the ass is not found at all owing to the coldness of the climate of these countries. ${ }^{8}$ In Arabia the lizard is more than a cubit in length, ${ }^{9}$ and the mouse ${ }^{10}$ is

1 Callisth. ap. Ael. xvi. 30 ; Varro, R. R. ii. I I Plin. viii. 76.

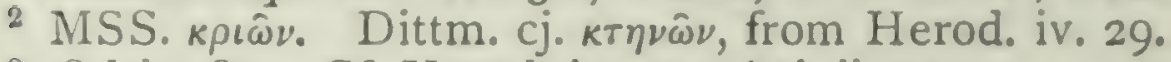

3 Od.iv. 85. Cf. Herod. iv. 29; Ael. ii. 53.

- MSS. have "upeves for apves, and it is not certain whether we are to take kai $\tau \hat{\imath} \lambda \lambda_{a}$ for 'the ewes also', as Gaza and Alb. MI. translate, perhaps reading $\tau$ ì $\theta i \lambda \in \in a$, or for 'other horned animals', which would be more in accord with Herodotus' account, who say's in general (l. c.) Év roiva

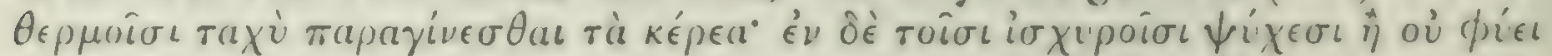

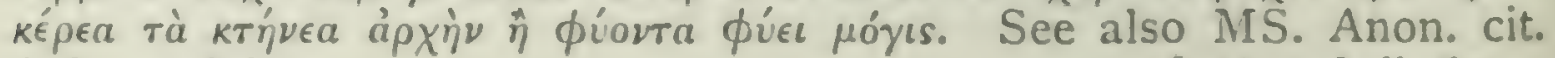
Schn. ad loc.

5 Herod. ii. 67.

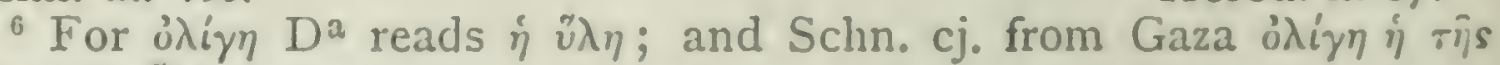

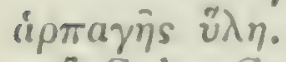

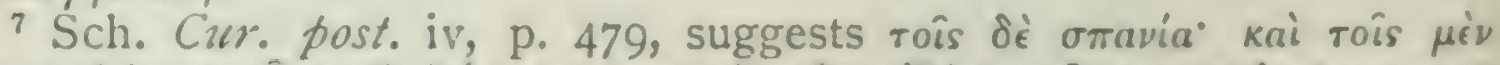

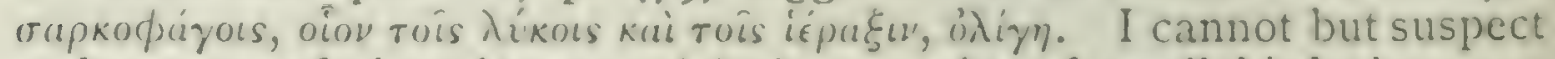
a deeper confusion, because (I) the scarcity of small birds is unexplained; (2) onaimor is somewhat singular when the word Angais is used immediately above; and (3) the hare, which ought to flourish where the ox and sheep do, has no direct comnexion with ikpropun or indipa, which latter are rather the food of the little birds. I conjecture some such statement in the original as the following: rois pit:

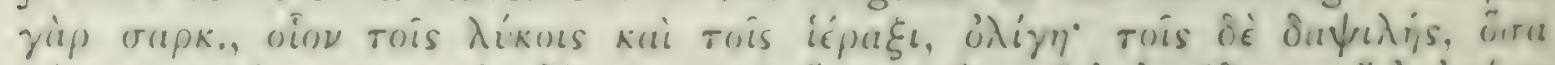

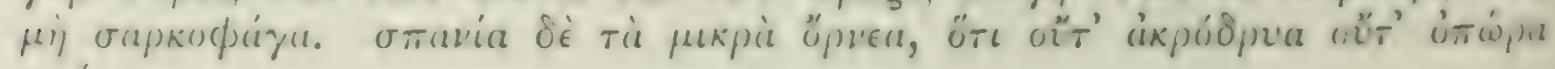
xpónos.

H. A. iii. 21. $522^{\mathrm{b}}$, viii. 25. $605^{\mathrm{a}} 20 ;$ G. A. ii. 8. $748^{\mathrm{a}} 25$.

'Cit. Ael. xvi. 41. 10 H. A.vi. 37. $581^{a} 3$; Ael. xv. 26. 
much larger than our field-mouse, with its hind-legs a span long and its front legs the length of the first finger-joint. ${ }^{1}$ In Libya, according to all accounts, the length of the serpents is something appalling; sailors spin a yarn to ro the effect that some crews once put ashore and saw the bones of a number of oxen, and that they were sure that the oxen had been devoured by serpents, for, just as they were putting out to sea, serpents came chasing their galleys at full speed and overturned one galley and set upon the crew. Again, lions are more numerous in Libya, ${ }^{2}$ and in that district of Europe that lies between the Achelous and I5 the Nessus ${ }^{3}$ the leopard is more abundant in Asia Minor, and is not found in Europe at all. As a general rule, wild animals are at their wildest in Asia, at their boldest in Europe, and most diverse in form in Libya ; in fact, there is an old saying, 'Always something fresh in Libya.' 4

It would appear that in that country animals of diverse species meet, on account of the rainless climate, at the watering-places, and there pair together; and that such pairs will often breed if they be nearly of the same size and have periods of gestation of the same length. For it is said that they are tamed down in their behaviour towards each other by extremity of thirst. And, by the way, unlike animals elsewhere, they require to drink more in winter-time than in summer: for they acquire the habit 25 of not drinking in summer, owing to the circumstance that there is usually no water then; and the mice, if they drink, die. ${ }^{5}$ Elsewhere also bastard-animals are born to hetero- $607^{\mathrm{a}}$ geneous pairs; thus in Cyrene the wolf and the bitch will

1 The jerboa, Dipus aegyptiacus or allied species. The text is

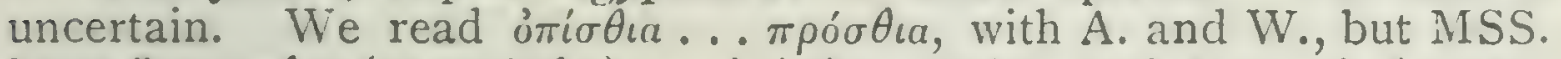

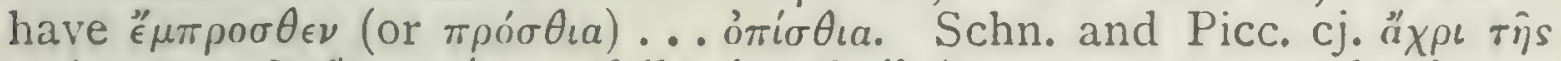
$\pi \rho \dot{\omega} \tau \eta s \kappa a \mu \pi \hat{\eta} s$ ö $\sigma o \nu \pi \dot{\eta} \chi \in \omega s$, following Guil. ' quantum usque ad primam iuncturam cubitorum?

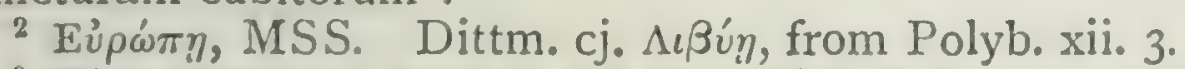

3 The statement rests on the authority of Herodotus, vii. I26, but the

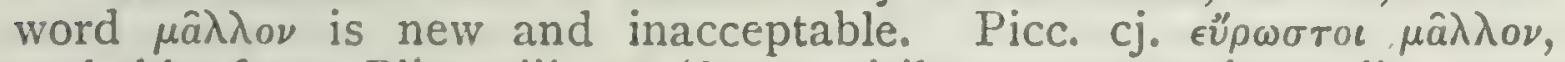
probably from Plin. viii. I7 'longe viribus praestantiores iis, quos Africa aut Syria gignant '. Cf. supra, vi. 31.579'b 5 ; Xen. Cyneg. II.

${ }^{4}$ G. A. ii. $7.746^{\mathrm{b}} 7$; Plin. viii. 17.

${ }_{5}$ Cf. 6. $595^{\mathrm{a}}$ 8. But Dittm. takes the statement here to apply only to the Libyan mice. 
couple and breed; ${ }^{1}$ and the Laconian hound is a cross between the fox and the dog." They say that the Indian dog is a cross between the tiger and the bitch, not the first 5 cross, but a cross in the third generation; for they say that the first cross is a savage creature. ${ }^{3}$ They take the bitch to a lonely spot and tie her up: if the tiger be in an amorous mood he will pair with her; if not he will eat her up, and this casualty is of frequent occurrence.

${ }^{4}$ Locality will differentiate habits also: for instance, rugged 29 ro highlands will not produce the same results as the soft lowlands. The animals of the highlands look fiercer and bolder, as is seen in the swine of Mount Athos; for a lowland boar is no match even for a mountain sow.

Again, locality is an important element in regard to the bite of an animal. Thus, in Pharos and other places, the I5 bite of the scorpion is not dangerous; elsewhere-in Caria, ${ }^{5}$ for instance,- where scorpions are venomous as well as plentiful and of large size, the sting is fatal to man or beast, even to the pig, and especially to a black pig, ${ }^{6}$ though the pig, by the way, is in general most singularly indifferent to the bite of any other creature. If a pis goes into water 2o after being struck by the scorpion of Caria," it will surely die.

There is great varicty in the effects produced by the bites of serpents. The asp is found in Libya ; the so-called 'septic' drug is made from the body of the animal, and is the only remedy known for the bite of the original. Among the silphium, also, a snake is found, for the bite of which a certain stone is said to be a cure : a stone that is brought 25 from the grave of an ancient king, which stone is put into

1 Plin. viii. 6r.

2 Ael.viii. I. Cf. G. A. ii. $7 \cdot 746^{a} 33$.

9 We translate according to Plin. l.c. 'Primo et secundo fetu nimis feroces putant gigni; tertio demum educant'.

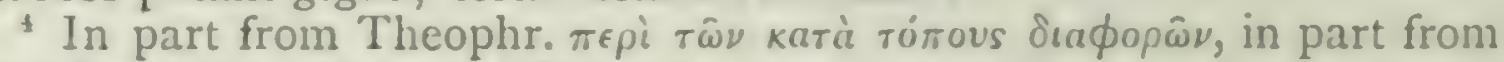

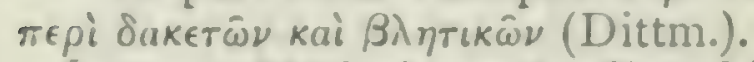

5 Some MSS. have Ekutia, which reading Pliny and Gaza follow: Nicand. Ther. 804 and Arist. fr. 562 (p. 1570 Rose) support Kinpia.

I'liny, xi. 3o, likewise speaks of the black pig. but elsewhere it is the scorpion that is black; cf. Nic. Ther. 775 fo de jocferists), and Ael. Pronot. (cit. Schn. ad loc. Nicandri).

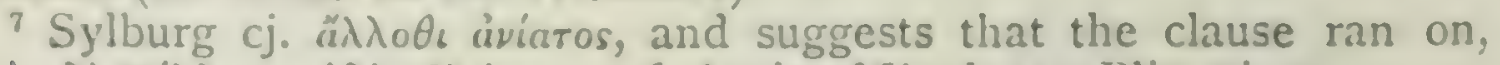

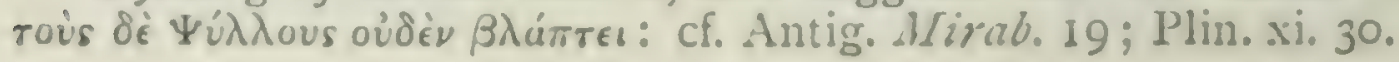


water and drunk off. In certain parts of Italy ${ }^{1}$ the bite of the gecko is fatal. But the deadliest of all bites of venomous creatures is when one venomous animal has bitten another; as, for instance, a viper's after it has bitten a scorpion. To the great majority of such creatures man's spittle is fatal. ${ }^{2}$ There is a very little snake, by some ${ }_{30}$ entitled the 'holy-snake', which is dreaded by even the largest serpents. ${ }^{3}$ It is about an ell long, and hairylooking; whenever it bites an animal, the flesh all round the wound will at once mortify. There is in India a small snake which is exceptional in this respect, that for its bite no specific whatever is known.

30 Animals also vary as to their condition of health in $607^{b}$ connexion with their pregnancy.

Testaceans, such as scallops and all the oyster-family, and crustaceans, such as the lobster-family, are best when with spawn. Even in the case of the testacean we speak ${ }^{4}$ of spawning (or pregnancy); but whereas the crustaceans may be seen coupling and laying their spawn, this is never the case with testaceans. ${ }^{\bar{D}}$ Molluscs are best in the breeding 5 time, as the calamary, the sepia, and the octopus.

Fishes, when they begin to breed, are nearly all good for the table; but after the female has gone long with spawn they are good in some cases, and in others are out of season. The maenis, for instance, is good at the breeding time. The female of this fish is round, the male longer and flatter; 10 ${ }^{6}$ when the female is beginning to breed the male turns black and mottled, ${ }^{7}$ and is quite unfit for the table; at this period he is nicknamed the 'goat'.

1 According to Theophrastus ap. Plin. viii. 49, it is in Greece that the creature's bite is fatal. Cf. Ps.-Arist. de Mirab. $148.845^{\text {b }} 4$; Plin. xxix. 28.

${ }^{2}$ Plin. vii. 2 ; Nic. Ther. 86.

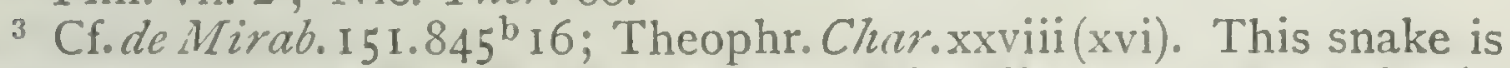
apparently the $\sigma \eta \pi \epsilon \delta \dot{\omega} \nu$ of Ael. xv. I 8 and Nic. Ther. 320. As to $\delta a \sigma u ́ s$, Nicander makes the more intelligible statement, $\dot{\eta} \delta \dot{\delta} \nu v \chi \rho \circ i \eta \mid$ oin

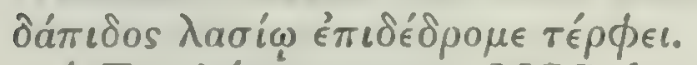

${ }^{4}$ For $\lambda \epsilon^{\prime} \gamma \epsilon \tau a l$ some MSS. have $\beta \lambda \epsilon \epsilon \epsilon \tau a \ell$.

${ }^{5}$ G. $A$. iii. I I. $763^{\mathrm{b}} 4$. Cf. $H$. $A$. iv. $4.529^{\mathrm{b}}$ I, v. 12. $544^{\mathrm{a}} 17$.

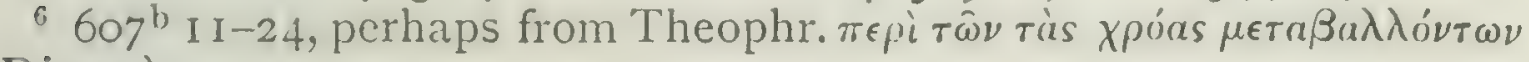
(Dittm.).

7 Plin. ix. 42 ; Ael. xii. 28 ; Opp. Hal. i. I07; Ovid ap. Plin. xxxii. 54. 
I5 The wrasses called the owzel and the thrush, and the smaris ${ }^{1}$ have different colours at different seasons, as is the case with the plumage of certain birds; that is to say, they become black in the spring and after the spring get white again. The phycis also changes its hue: in general it is white, but in spring it is mottled; it is the only sea-fish 20 which is said to make a bed for itself, and the female lays her spawn in this bed or nest. ${ }^{2}$ The maenis, as was obscrved, changes its colour as does the smaris, and in summer-time changes back from whitish to black, the change being especially marked about the fins and gills. The coracine, like the maenis, is in best condition at 25 breeding time; the mullet, the basse, and scaly" fishes in general are in bad condition at this period. ${ }^{+}$A few fish are in much the same condition at all times, whether with spawn or not, as the glaucus. Old fishes also are bad cating; the old tunny is unfit eren for pickling, as a great part of its flesh wastes away with age, and the same 30 wasting is observed in all old fishes. The age of a scaly fish may be told by the size and the hardness of its scales. An old tunny has been caught weighing fifteen talents," with the span of its tail two ${ }^{6}$ cubits and a palm broad.

River-fish and lake-fish are best after they have dis$608^{a}$ charged the spawn in the case of the female and the milt in the case of the male: that is, when they have fully recovered from the exhaustion of such discharge. Some are good in the breeding time, as the saperdis, ${ }^{7}$ and some bad, as the sheat-fish. As a general rule, the male fish is better eating than the female; but the reverse holds 5 good of the sheat-fish. The ecls that are called females are the best for the table: they look as though they were female, but they really are not so. ${ }^{8}$

1 kapis, a shrimp, of the MISS. and edd., is probably corrupt, and is absent from the list in Acl. xii. 2\$. I conjecture orpapis, which is coupled with $\mu a u v i s$, tpizos, \&c., Opp. Harl. i. I09. Schn. suggests kupis, s. kippis.

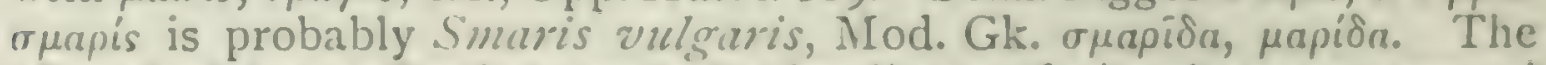
alleged change of colour probah!y implies confusion betwcen sereral allied species.

2 Plin. ix. 42 ; Ovid, Hal. 122; Plut. Sol. Anim. p. 981.

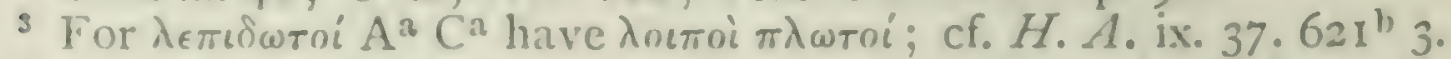

${ }^{4}$ Cf. supra, vi.13.567"19. "I'lin. ix. 17. "Some MSS. have tévte.

7 Unknown. According to Athen. vii. $30 S^{\mathrm{c}}=$ кnракizos, but the latter is a sea-fish.

8 H. A. iv. II. $53^{\mathrm{S}} 10$. 


\section{BOOK IX}

I OF the animals that are comparatively obscure and short- $608^{\mathrm{a}}$ lived the characters or dispositions ${ }^{1}$ are not so obvious to recognition as are those of animals that are longer-lived. These latter animals appear to have a natural capacity corresponding to each of the passions: to cunning or $\mathrm{I}_{5}$ simplicity, courage or timidity, to good temper or to bad, and to other similar dispositions of mind. ${ }^{2}$

Some also are capable of giving or receiving instructionof receiving it from one another or from man: those that have the faculty of hearing, for instance; and, not to limit the matter to audible sound, such as can differentiate the 20 suggested meanings of word and gesture. ${ }^{3}$

In all genera in which the distinction of male and female is found, Nature makes a similar differentiation in the mental characteristics of the two sexes. This differentiation

1 The $\ddot{\eta} \theta \eta$ are the natural dispositions or mental characters. On the $\eta^{\prime} \theta \eta$ of different animals cf. $H$. A. i. I. $488^{\mathrm{b}}$ 12, viii. I. $588^{\mathrm{a}}$ I 8 , ix. 3 . $610^{b} 20, \& c$.

2 In the beginning of the eighth book the psychological characteristics of animals are treated in a simple and elementary way. In certain passages of the ethical works, e.g. Eth. Eudem. ii. 2. 1220, the same characteristics are discussed in a more technical way, with a freer use of philosophical terms of definition. While here, in the opening of the ninth book, the subject is more briefly and less lucidly treated than in the eighth, yet we may remark the employment of a more refined terminology, to explain which we must have recourse to the passage in the Eth. Eudem. referred to above. There we are taught the distinction between the $\pi a \dot{\theta} \eta$ or $\pi a \theta \dot{\eta} \mu a \tau a \tau \eta \bar{\eta} s \psi \nu \chi \bar{\eta} s$, inherent 'accidents'

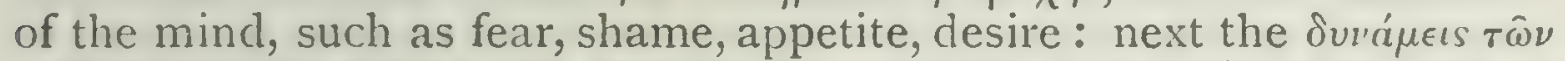
$\pi a \theta \eta \mu a r \omega \nu$, by which the former are brought into action and one is hungry or thirsty, afraid or ashamed: and lastly the " $\epsilon \xi \epsilon \iota s \pi \rho \dot{s} \tau \dot{\alpha} \pi \dot{\theta} \theta \eta$, the mental dispositions or inclinations, such as sobriety or intemperance, cowardice or courage, which, according to Aristotle, cause these duvámeis

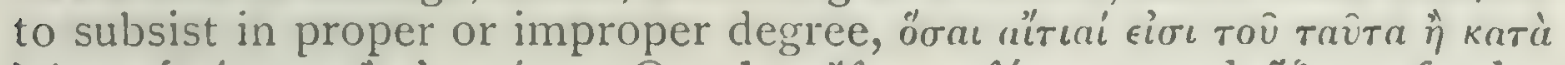

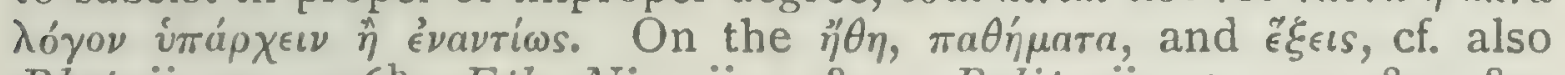
Rhet. ii. 22.1396" ; Eth. Nic. vii. I, \&c.; Polit. vii. 15. 1334, \&c., \&c.

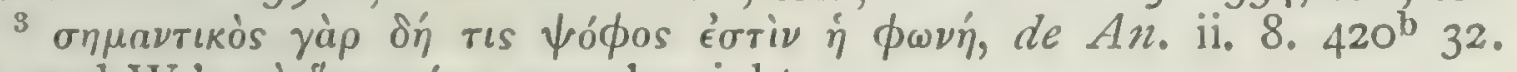

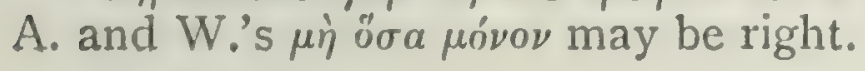


is the most obvious in the case of human kind and in that of the larger animals and the viviparous quadrupeds. In 25 the case of these latter the female is softer in character, is the sooner tamed, admits more readily of caressing, is more apt in the way of learning; as, for instance, in the Laconian breed of dogs the female is cleverer than the male. ${ }^{1}$ Of the Molossian breed of dogs, ${ }^{2}$ such as are cmployed in the chase are pretty much the same ${ }^{3}$ as those elsewhere; but 30 the sheep-dogs of this breed are superior to the others in size, and in the courage with which they face the attacks of wild animals. ${ }^{4}$

Dogs that are born of a mixed breed between these two kinds are remarkable for courage and endurance of hard labour.

In all cases, excepting those of the bear and lcopard," the female is less spirited than the male; in regard to the two exceptional cases, the superiority in courage rests with the femalc. With all other animals the female is softer $608^{\mathrm{b}}$ in disposition than the malc, is more mischicvous, less simple, more impulsive, and more attentive to the nurture of the young; the male, on the other hand, is more spirited than the female, more savage, more simple and less cunning. The traces of these differentiated characteristics are more or less visible crerywhere, but they are especially visible 5 where character is the more developed, and most of all in man.

The fact is, the nature of man is the most rounded off and complete, and consequently in man the qualities or capacities above referred to are found in their perfection.

${ }^{1}$ Cf. $H . A$. vi. 20. $574^{\mathrm{a}} \mathrm{I} 6$; Plin. x. 83 'propria in eo genere maribus laboris alacritas'.

- This passage is foreign to a context that deals with differences of

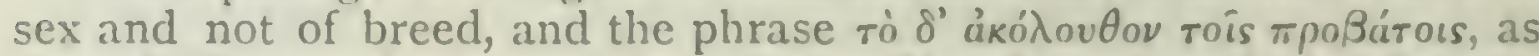
A. and W. remark, is not Aristotelian. We do not read elsewhere in Greek, though occasionally in Latin (e.g. Lucan iv. 440), of the Molossian breed as hunting-dogs, but only (cf. Suid. s. i.) as sheepdogs, nor of the cross between the Molossian and Laconian breeds.

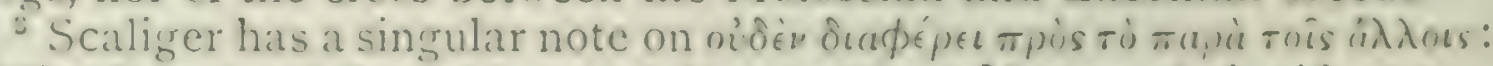
'Mira locutio philosophica. tó hic significat joos, wapo significat non substantiam sed accidens proprium inhaerens.' He is apparenty

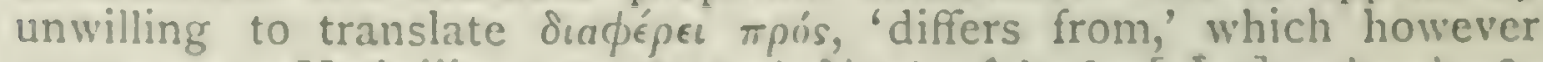

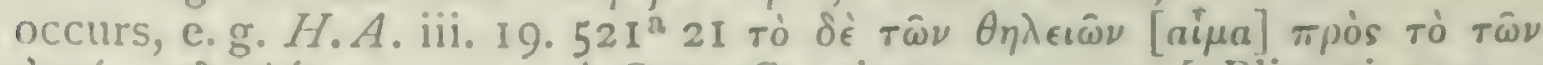

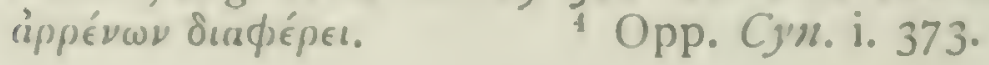

5 Plin. xi. 110. 
Hence woman is more compassionate than man, more easily moved to tears, at the same time is more jealous, more querulous, more apt to scold and to strike. She is, I5 furthermore, more prone to despondency and less hopeful than the man, more void of shame or self-respect, more false of speech, more deceptive, and of more retentive memory. She is also more wakeful, more shrinking, more difficult to rouse to action, and requires a smaller quantity of nutriment.

As was previously stated, the male is more courageous than the female, and more sympathetic in the way of standing by to help. Even in the case of molluscs, when the cuttle-fish is struck with the trident the male stands by to help the female; but when the male is struck the female runs away. ${ }^{1}$

There is enmity between such animals as dwell in the same localities or subsist on the same food. If the means 20 of subsistence run short, creatures of like kind will fight together. Thus it is said that seals which inhabit one and the same district will fight, male with male, and female with female, until one combatant kills the other, or one is driven away by the other; and their young do even in like manner.

All creatures are at enmity with the carnivores, and the carnivores with all the rest, for they all subsist on living creatures. Soothsayers take notice of cases where animals keep apart from one another, and cases where they congregate together; ${ }^{2}$ calling those that live at war with one another 'dissociates', and those that dwell in peace with one another 'associates'. One may go so far as to say that 30 if there were no lack or stint of food, then those animals that are now afraid of man or are wild by nature would be tame and familiar with him, and in like manner with one another. This is shown by the way animals are treated

1 Arist. $a p$. Athen, vii. $323 \mathrm{C}$.

2 We note again a similarity of language with the Eth. Eutcm.v.2.

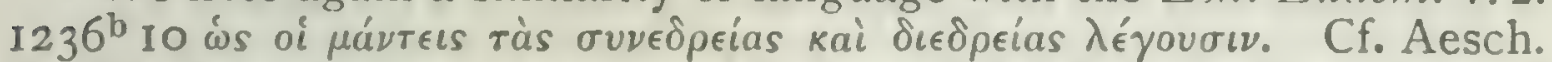

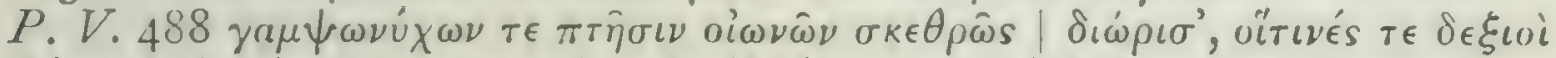

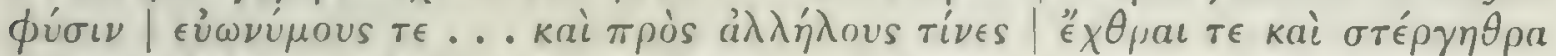

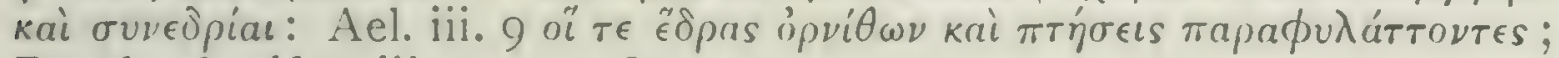
Porph. de Abst. iii, p. 243, \&c. 
in Egypt, for owing to the fact that food is constantly supplied to them the rery ficrcest creatures live peaceably together. The fact is they are tamed by kindness, and in $609^{\text {a }}$ some places crocodiles are tame to their priestly kecper from being fed by him. And elscwherc also the same phenomenon is to be observed. ${ }^{1}$

The eagle and the snake are encmies, ${ }^{2}$ for the eagle lives 5 on snakes; ${ }^{3}$ so are the ichneumon ${ }^{4}$ and the venom-spider, for the ichneumon preys upon the latter. In the case of birds, there is mutual enmity between the poecilis, the crested lark, the woodpecker (?); and the chloreus, for they devour one another's eggs; so also between the crow and the owl $;^{5}$ for, owing to the fact that the owl is dim-

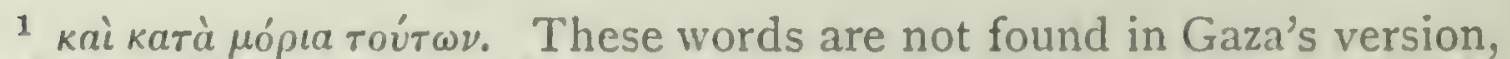
and $\mathrm{A}$. and $\mathrm{W}$. omit them from their translation. They are unintelligible as they stand, but we might perhaps link them with the following sentence, translating 'And now, of these (friendly or hostile) animals in detail'. What follows is largely fabulous, partly mystical, and apparently from another hand. For similar accounts of the fricndships or hostilities of animals see Ael. i. 32, iv. 5, v. 48, vi. 22 ; Plin. x. 95; Plut. de Od. et Inv.; Phile, 675-730, \&c.

2 Aristotle cites about forty instances of hostility between certain animals; of these forty about one-half are mentioned elsewhere, fourteen or fifteen by I'liny, nine or ten by I'hile, about as many by Aclian, and a few by Plutarch, Antoninus Liberalis, and other authors. From these authors together we may compile a list of nearly a hundred such instances. It is highly probable that these form a fragmentary

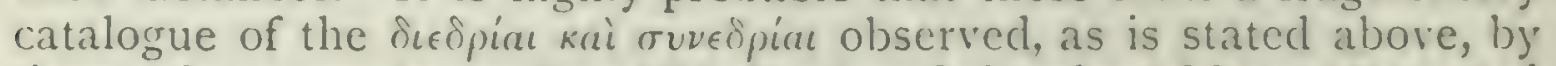
the soothsayers. In my ( $\mathrm{jl}$ of Gli. Birds and elsewhere I have attempted to trace in certain cases a correspondence between the animals referred to and the oppositions or juxtapositions of their stellar namesakes: if we are indeed dealing with a soothsayer's catalogue, it is all the more likely that such occisional astrological coincidences should exert their influence on it. In the Aristotelian list we have a very considerable number of names not mentioned elsewhere, of unknown meaning, and very possibly of foreign derivation.

${ }^{3}$ e.g. Circaëtus gallicus.

4 Not the Egyptian quadruped, but a species of wasp), c.g. I'omfilus or Calicurgus; cf. Fabre, Souv. Entom. 1882, p. 206; Plin. x. 95 (74) 'ichneumones vespae et phalangia aranei [dissident]'. Cf./1. A. Y.20: Plin. xi. 24 (2I). The name as applied to the insects (Sphegidue or I'omfilitue), which lay their eggs in the living borlies of other insects or of spiders, secms to be connected with an Esyptian fable of the true ichneumon told in Ael. x. 47 , to the effect that the animal is at once male and female, and that in combat the rictor compels his antagonist to bear and bring forth offspring to him: cf. Phile (98), 1739. On an ancient Chinese version, cf. Kumagusu Minakatu in Noture, 1, p. 30, 1894.

5 The fabled IVar of the Owls and Crows, of the Bird of Darkness and the bird of Light, of Night and Day, of sun and Moom, is one of 
sighted by day, the crow at midday preys upon the ro owl's eggs, and the owl at night upon the crow's, each having the whip-hand of the other, turn and turn about, night and day.

There is enmity also between the owl and the wren; ${ }^{1}$ for the latter also devours the owl's eggs. In the daytime all other little birds flutter round the owl-a practice which is popularly termed 'admiring him' 2-buffet him, and pluck out his feathers; in consequence of this habit, bird- I5 catchers use the owl as a decoy for catching little birds of all kinds.

The so-called presbys or 'old man' 3 is at war with the weasel and the crow, for they prey on her eggs and her brood; and so the turtle-dove with the pyrallis, for they live in the same districts and on the same food; and so with the green woodpecker and the libyus; and so with the kite and the raven, ${ }^{4}$ for, owing to his having the 20 advantage from stronger talons and more rapid flight the former can steal whatever the latter is holding, so that it is food also that makes enemies of these. In like manner there is war between birds that get their living from the

the chief tales of the Mahabharata; cf. Ind. Antiquary, March, I882, p. 87. Cf. also Ael. iii. 9, v. 48; Antig. Mirab. 57 (62); Plut. Od. et

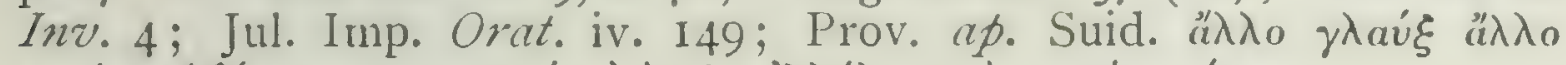

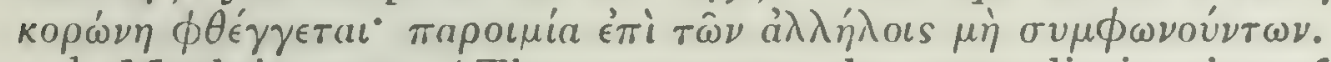

${ }_{1}$ Macb.iv. 2. 9: 'The poor wren, the most diminutive of birds, will fight, her young ones in the nest, against the owl.'

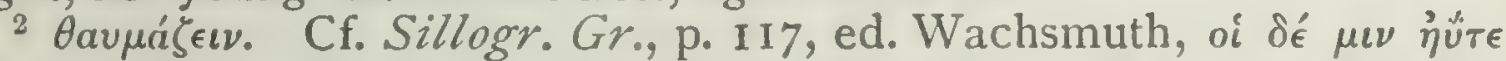

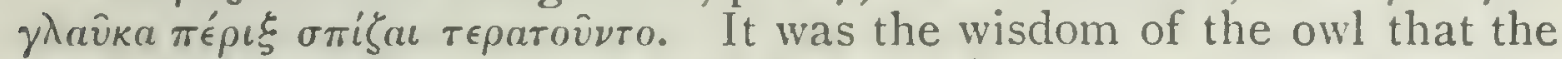
small birds wondered at; cf. Aes. Fab. 106 (Halm), crt Dion. Chrys. 82

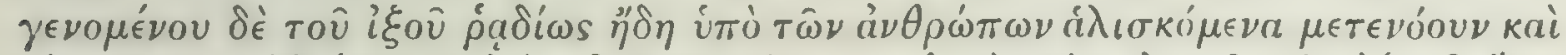

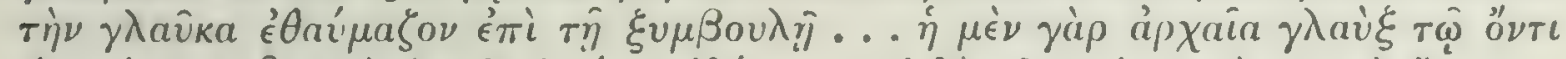

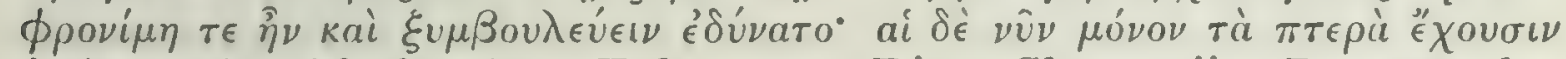

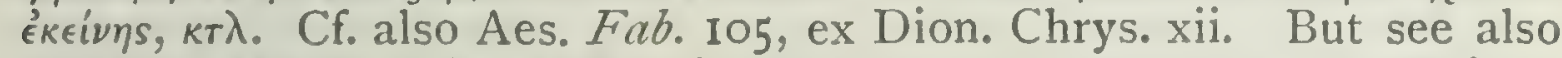

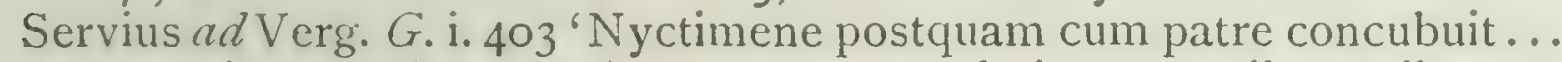
conversa in avem (noctuam), quae pro tanto facinore omnibus avibus est admirationi'. On bird-catching by help of the owl see Dion. de Avib. iii. 17; Dio Prus. Orat. 72 and 12 quoted in Schneider's Ecl. Phys. i. 48; Ael. i. 29; Phile 468; Diog. L. iv. 42 ; Timon ap. Hesych.; Horap. ii. 5 I.

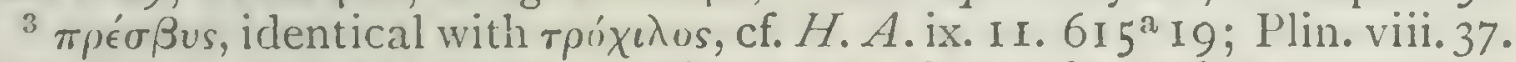
The text is probably faulty, a reference to the eagle having apparently

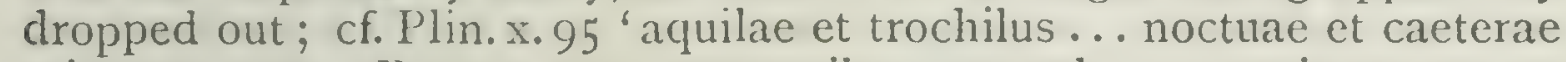
minores aves. Rursus cum terrestribus, mustela et cornix, turtur et pyralis.'

${ }^{4}$ Cic. Nat. Deor. ii. $49^{\prime}$ Milvo est quoddam bellum quasi naturale cum corvo. Ergo alter alterius, ubicunque nactus est, ova frangit.' 
sea, as between the brenthus, the gull, and the harpe ${ }^{1}$ and so between the buzzard on one side and the toad and snake on the other, for the buzzard preys upon the eggs of 25 the two others; and so between the turtle-dove and the chloreus; the chlorcus kilis the dove, and the crow kills the so-called drummer-bird. ${ }^{2}$

The aegolius, and birds of prey in general, prey upon the calaris, and consequently there is war between it and them; and so is there war between the gecko-lizard and the spider, for the former preys upon the latter; and so between 30 the woodpecker and the heron, for the former preys upon the eggs and brood of the latter." And so between the acgithus and the ass, owing to the fact that the ass, in passing a furze-bush, rubs its sore and itching parts against the prickles; by so doing, and all the more if it brays, it topples the eggs and the brood out of the nest, the young ones tumble out in fright, and the mother-bird, to avenge this wrong, flies at the beast and pecks at his sore place.:. ${ }^{4}$

$609^{b}$ The wolf is at war with the ass, the bull, and the fox, for as being a carnivore, he attacks these other animals; and so for the same reason with the fox and the circus, for the circus, being carnivorous and furnished with crooked talons, attacks and maims the animal. And so the raven is at 5 war with the bull and the ass, for it flies at them, and strikes them, and pecks at their eycs; ${ }^{5}$ and so with the eagle and the heron, for the former, having crooked talons, attacks the latter, and the latter usually succumbs to the attack; and so the merlin with the vulture; and the crex with the cleus-owl, the blackbird, and the oriole lof this

${ }^{\prime}$ Plin. x. 95 'Dissident aquaticae et gaviae; harpe et triorches accipiter'; ibid. 96 'Harpe et milvus contra triorchem'. 'Aristotelis locum vitio laborare praeposterae interpunctionis, ex Plinii contextu intelligimus', Harduin ait lec. P'ossibly the text in I'liny's hands read

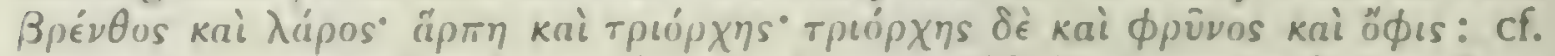
Schneider, iv, p. S. According to Tzetzes, Chiliad. v. 413 iktivos öpvrs

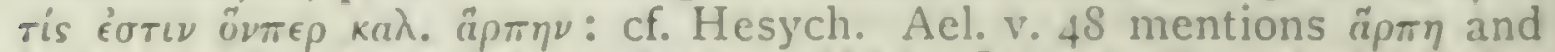

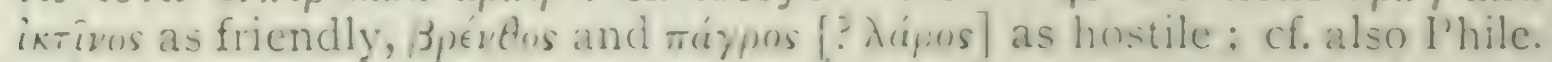

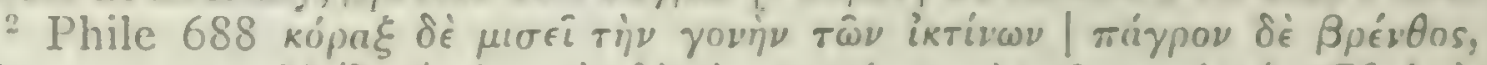

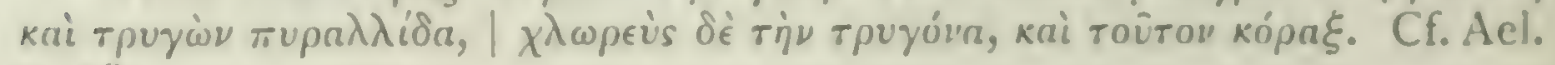
v. 48 .

${ }^{3}$ Nicander $a p$. Ant. Lib. xiv.

'Antig. Mirab. 58 (63); Ael. v. 48 ; Dion. de Ar'ib. i. 12; Phile 696; Plin. $x .95$.

5 Acl. 1.48 ; Phile 705. 
as it has crooked talons, it kills the animal's young. The raven and the fox are good friends, for the raven is at enmity with the merlin; and so when the merlin assails the fox the raven comes and helps the animal. The vulture and the merlin are mutual enemies, as being both furnished with crooked talons. The vulture fights with the $6 r 0^{a}$ eagle, and so, by the way, does the swan; and the swan is often victorious: moreover, of all birds swans are most prone to the killing of one another. ${ }^{1}$

In regard to wild creatures, some sets are at enmity with other sets at all times and under all circumstances; others, as in the case of man and man, at special times and under incidental circumstances. The ass and the acanthis are 5 enemies; for the bird lives on thistles, and the ass browses on thistles when they are young and tender. The anthus, the acanthis, and the aegithus are at enmity with one another; it is said that the blood of the anthus will not intercommingle with the blood of the aegithus. ${ }^{2}$ The crow and the heron are friends, as also are the sedge-bird and lark, the laedus and the celeus or green woodpecker; ${ }^{3}$ the woodpecker lives on the banks of rivers and beside brakes, ro the lacdus lives on rocks and hills, and is greatly attached to its nesting-place. The piphinx, ${ }^{4}$ the harpe, and the kite are friends; as are the fox and the snake, for both burrow underground; so also are the blackbird and the turtle-dove." The lion and the thos or civet ${ }^{6}$ are enemies, for both are carnivorous and live on the same food.

i5 Elephants fight fiercely with one another, and stab one another with their tusks; of two combatants the beaten one gets completely cowed, and clreads the sound of his conqueror's voice. These animals differ from one another

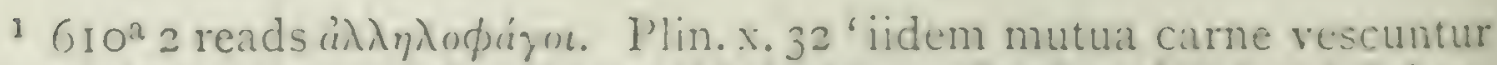
inter se', thus apparently reading a $\lambda \lambda \eta_{\eta}$. of piyou. On the other hand Athen.

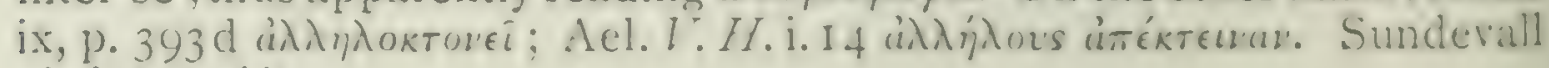

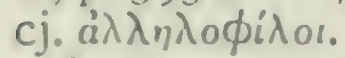

${ }^{2}$ Plin. x. 95 ; cf. Antig. Mirab. I14. Ael. x. 32 has äkav0os and

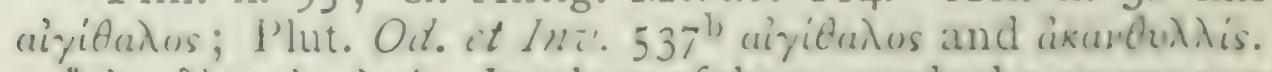

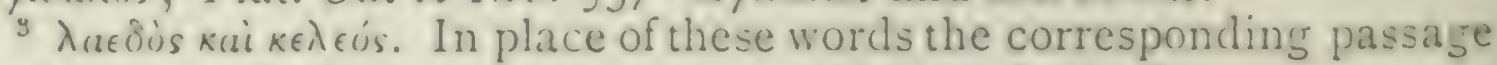

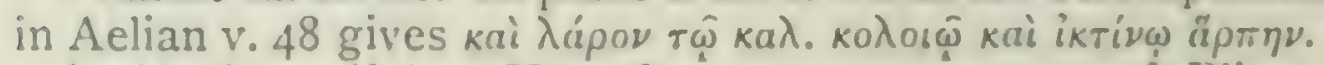

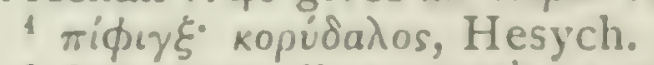

s. Plin. x. 95, 96.

' See notes, ii. $17.507^{1)} 17$, vi. $35 \cdot 5 \mathrm{SO}^{\mathrm{a}} 27$. 
to an extraordinary extent in the way of courage. ${ }^{1}$ Indians employ these animals for war purposes, irrespective of sex ; the females, however, are less in size and much inferior in 20 point of spirit. ${ }^{2}$ An elephant by pushing with his big tusks can batter down a wall, and will butt with his forehead at a palm until he brings it down, when he stamps on it and lays it in orderly fashion on the ground. ${ }^{3}$ Men hunt the elephant in the following way: they mount tame elephants of approved spirit and procecd in quest of wild 25 animals; when they come up with these they bid the tame brutes to beat the wild ones until they tire the latter completely. Hereupon the driver mounts a wild brute and guides him with the application of his metal prong; ${ }^{4}$ after this the creature soon becomes tame, and obeys guidance. Now when the driver is on their back they are all tractable, 30 but after he has dismounted, some are tame and others vicious; in the case of these latter, they tie their front-legs with ropes to keep them quiet. The animal is hunted whether young or full grown. ${ }^{5}$

Thus we see that in the case of the creatures above mentioned their mutual friendship or enmity is due to the food they feed on and the life they lead.

2 Of fishes, such as swim in shoals together are friendly to $610^{b}$ one another; such as do not so swim are enemies. Some fishes swarm during the spawning season; others after they have spawned. To state the matter comprehensively, we may say that the following are shoaling fish: the tunny, the maenis, the sea-gudgeon, the bogue, ${ }^{6}$ the horse-mackerel, ${ }^{7}$

1 Cf. Plin. vi. 24 'Onesicritus elephantos ibi (in insula Taprobane) maiores bellicosioresque quam in India gigni scripsit'; Ael. xvi. I8. That the African elephants (which are mentioned by A., de Caelo, ii. 14. 298 ) surpass the Indian in size and strength is stated by Plin. viii. 9 ; Liv. xxxvii. 39 ; Polyb. v. 84 , \&c.

3 Plin. viii. 8-Io; Ael.v. 55 ; Ctes. ap. Ael. xvii. 29.

$4 \rho \epsilon \pi a ́ \nu \omega:$ the elephant goad or ankus; å $\rho \pi \eta$, Ael. xiii. 9 and 22 ; ö $\rho \pi \eta$, àyóp $\pi \iota s$, Hesych.

5 On the capture and taming of elephants cf. Ael. x. IO, x. I 7, xii. 44 ; Plin. viii. 8 ; Strabo xv. I. 42.

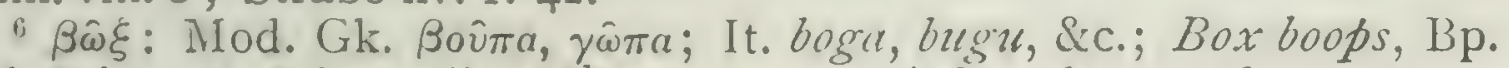
Cf. Arist. ap. Athen. vii. $286^{\text {b }} \nu \omega \tau$ ópartra: it has three or four narrow golden lines down its sides.

7 waupos, the horse-mackerel, Caranx trachurus: Lat. lacerta, Juv. xiv. I3 I ; Mart. x. 48 ; Cels. ii. I 8, \&c.; samrus, Plin. xxxii. 28 ; It.lacertu, sauriı; Mod. Gk. oaupíô. 
5 the coracine, the synodon or dentex, the red mullet, the sphyracna, the anthias, the eleginus, ${ }^{1}$ the atherine, the sarginus, the gar-fish, ${ }^{2}$ [the squid,] the rainbow-wrasse, ${ }^{3}$ the pelamyd, the mackerel, the coly-mackerel. Of these some not only swim in shoals, but go in pairs inside the shoal; the rest without exception swim in pairs, and only swim in shoals at certain periods: that is, as has been said, Io when they are heavy with spawn or after they have spawned.

The basse and the grey mullet are bitter enemies, but they swarm together at certain times; for at times not only do fishes of the same species swarm together, but also those whose feeding-grounds are identical or adjacent, if the food-supply be abundant. The grey mullet is often found I5 alive with its tail lopped off, and the conger with all that part of its body removed that lies to the rear of the vent ${ }^{4}$ in the case of the mullet the injury is wrought by the basse, in that of the conger-eel by the muracna. ${ }^{5}$ There is war between the larger and the lesser fishes: for the big fishes prey on the little ones. So much on the subject of marine animals.

20 The characters of animals, as has been observed, ${ }^{6}$ differ 3 in respect to timidity, to gentleness, to courage, to tameness, to intelligence, and to stupidity. ${ }^{7}$

The sheep is said to be naturally dull and stupid. ${ }^{s}$ Of all quadrupeds it is the most foolish : it will saunter away to lonely places with no object in view; oftentimes in

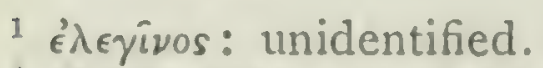

2While $\beta \in \lambda$ ou $^{\prime}$ in vi.12, \&c., is certainly the pipe-fish, syngmathus, here it may be assumed to mean liclone wius, the garfish: Nod. Cik.

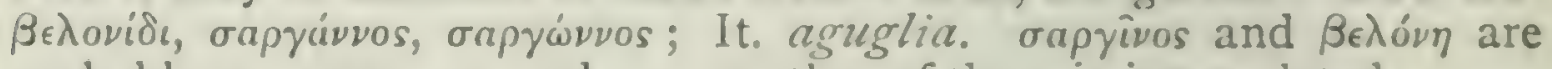
probably synonymous, and one or other of them is interpolated.

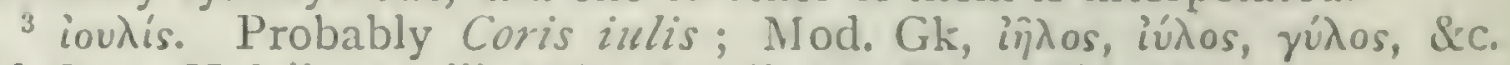
Cf. Opp. Hal. ii. 434, iii. I86 ; Ael. ii. 44 ; Marc. Sid. I5.

* Nigid. ap. Plin.ix. 88 .

6 H.A. ix. I. $608^{2}$ II.

7 The six qualities enumerated fall imperfectly into pairs. chypurnra is suggested by l'iccolos in place of ijpepirzra, and by A. and W. in place of $\pi$ puórytu. Gaza translates fortitudine, ignavia, mansuetudine, ferocitate, mente, dementia', and probably therefore read civopian xui

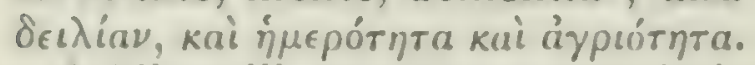

Plin. viii. 75 'Quam stultissima animalium lanata. Qua timuere ingredi, unum cornu raptum sequuntur.' 
stormy weather it will stray from shelter; if it be over- 25 taken by a snowstorm, it will stand still unless the shepherd sets it in motion; it will stay behind and perish unless the shepherd brings up the rams; it will then follow home.

If you catch hold of a goat's beard at the cxtremitythe beard is of a substance resembling hair-all the com- zo panion goats will stand stock still, staring at this particular goat in a kind of dumbfounderment.

You will have a warmer bed in amongst the goats than among the sheep, because the goats will be quietcr and will creep up towards you; for the goat is morc impaticnt of cold than the sheep. ${ }^{2}$

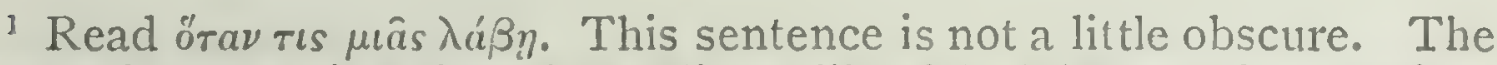
sense of the text is followed by Pliny, viii. 76 (50) ' Dependet omnium caprarum mento villus, quem aruncum vocant. Hoc si quis apprehensam ex grege unam trahat, ceterae stupentes spectant. Id etiam evenire, cum quandam herbam aliqua ex eis momorderit.' Arumcus does not occur elsewhere in Latin (spirillum is given as a goat's beard ap. Festus, p. 330, Muill.), and in Creek ïpuryos or iprizyov is elsewhere always the herb Goat's-beard. The expression in the text, "̈or $\iota \delta^{\prime}$ oi

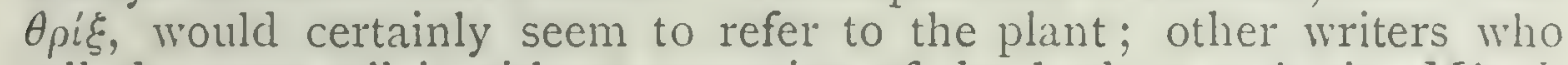
tell the story tell it without exception of the herb, e.g. Antig. Mirat.

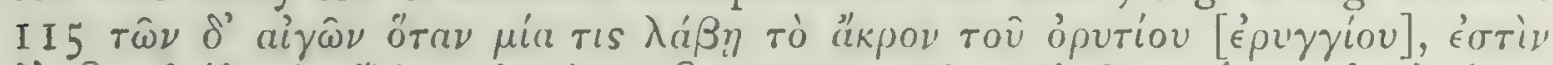

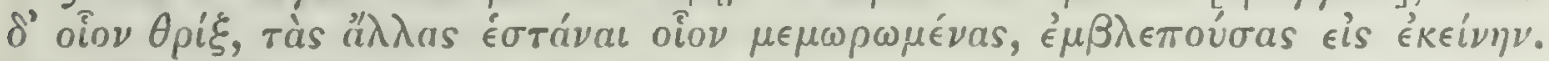
Cf. Theophr. fr. clxxv, ap. Phot. Bibl. 278. 8; Plut. Symp. Q. 700 C, de Sera mum. vind. $558 \mathrm{E}$; Schol. ad Nicand. Ther. 645. Salmas. de Homonym. p. 77 concludes that Aristotle was speaking of the plant, as does Beckmann in loc. Antig. It is very likely that this is indeed the case, also that Antigonus preserves so far the correct reading, and that Pliny's two separate statements are merely two interpretations of Aristotle's one. We may translate one way or the other,

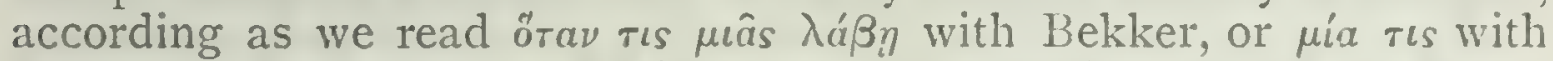
Salmasius, Beckmann, and Dittmeyer. The version of Guil. de Moerbeke, 'Caprarum autem cum unius cepit quis summitatem inflexionis tybiae, est autem velut palus,' is interesting for Schneider's most ingenious elucidation of it; after emending pilus for palus, Schn. shows that the reference to tibiae probably comes from a faulty sloss

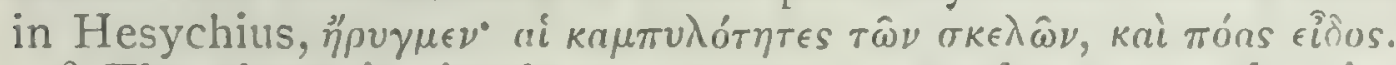

${ }_{2}$ The above is simply an attempt to render a text that is almost certainly corrupt, and whose original meaning was in all probability widely different. Many different versions have been given by former editors. De Moerbeke has, as in the present text, "in dormiendo

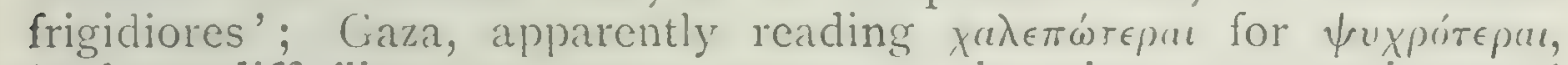
'cubant difficilius oves quam caprae, magis enim caprae quiescunt.'

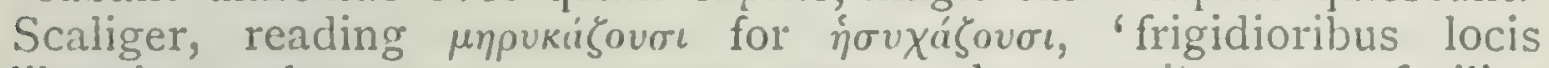
libentius cubant oves; caprae autem plus ruminant et facilius accedunt ad hominem, et aegrius ferunt frigus.' Albertus M. omits

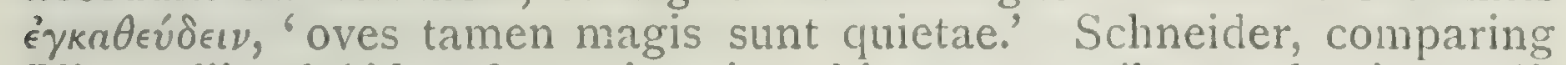
Pliny, viii. 76 'ideo fortassis anima his quam ovibus ardentior, cali- 
Shepherds train sheep to close in together at a clap of their hands, for if, when a thunderstorm comes on, ${ }^{1}$ a ewe stays behind without closing in, the storm will kill it if it $6 \mathrm{II}^{\mathrm{a}}$ be with young; consequently if a sudden clap or noise is made, they close in together within the sheepfold by reason of their training.

Even bulls, when they are roaming by themselves apart from the herd, are killed by wild animals. ${ }^{2}$

Sheep and goats lic crowded together, kin by kin. When 5 the sun turns carly towards its setting, the goats are said to lie no longer face to face, but back to back."

Cattle at pasture keep together in their accustomed 4 herds, and if one animal strays away the rest will follow; consequently if the herdsmen lose one particular animal, they keep close watch on all the rest. ${ }^{4}$

dioresque concubitus', and Varro, $R$.R. ii. 2, 3 'ovium semen tardius

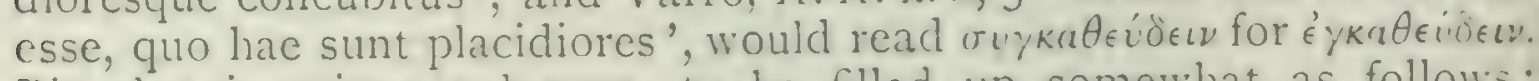
P'iccolos imagines a lacuna, to be filled up somewhat as follows:

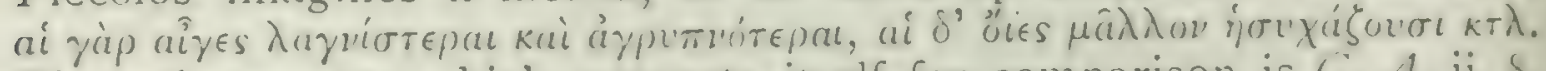
The only passage which suggests itself for comparison is $(r . A$. ii. $\delta$.

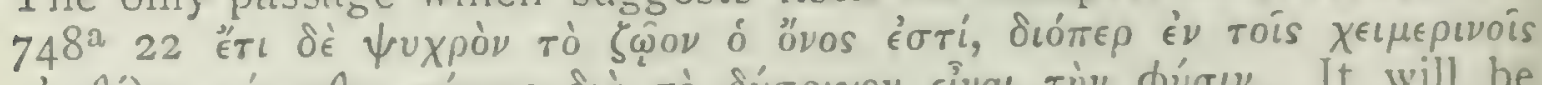

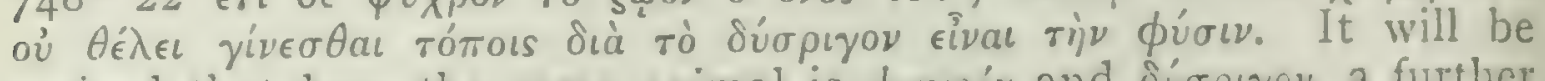

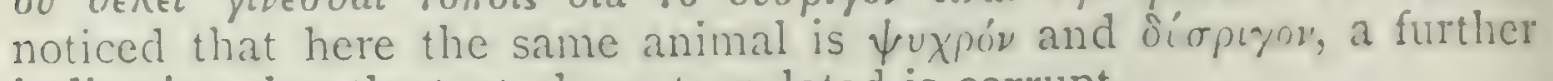
indication that the text above translated is corrupt.

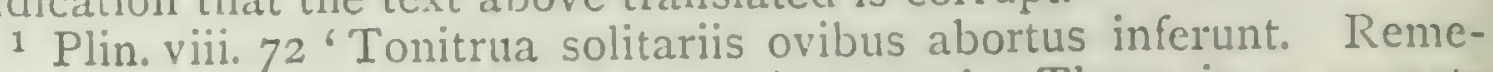
dium est congregare eas, ut coetu iuventur.' There is a cognate allusion in Ps. xxix. 9 "The voice of the Lord maketh the hinds to calve'.

2 ảт

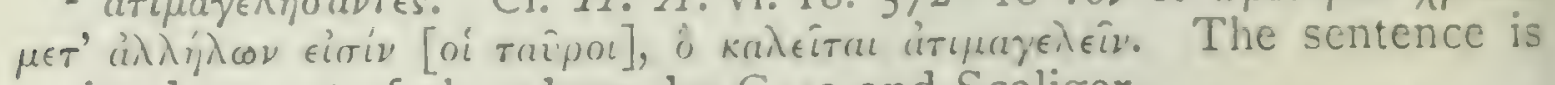
omitted, as out of place here, by Gaza and Scaliger.

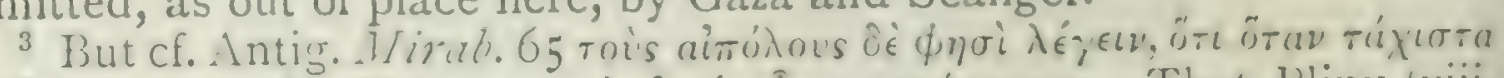

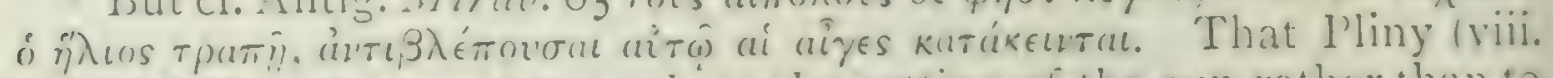
76) took this statement to apply to the setting of the sum rather than to the tropic does not prove that this interpretation is correct. The story is akin to the ligyptian fables of the goats and other animals that salue the heliacal rising of the doy-star, as the ary does undoubtedly salute the rising and setting sun; cf. Ael. vii. 8; Plut. Soll. Anim. 974 F; Antig. Mirab. c. 66.

4. The passage is obscure. Scal. translates I Icirco bubulci, mam si amiscrint, ommes practerea continuo pervestigant, adding the cxplana-

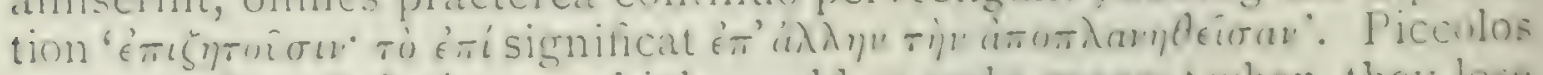

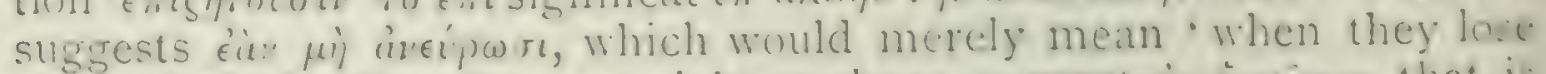

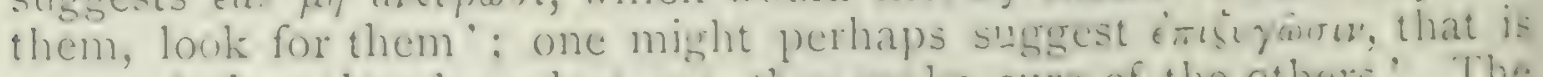
to say, "when they have lost one, they make sure of the others.' 'The

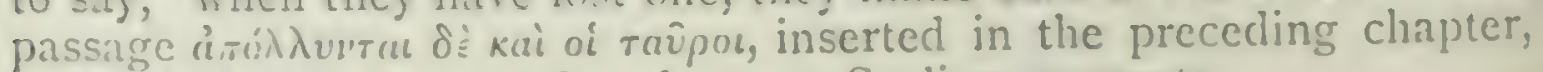
probably has its proper place here, as Scaliger suggests. 
When mares with their colts pasture together in the same field, if one dam dies the others will take up the ro rearing of the colt. In point of fact, the mare appears to be singularly prone by nature to maternal fondness; in proof whereof a barren mare will steal the foal from its dam, will tend it with all the solicitude of a mother, but, as it will be unprovided with mother's milk, its solicitude will prove fatal to its charge.

5 Among wild quadrupeds the hind appears to be pre- I5 eminently intelligent; for example, in its habit of bringing forth its young on the sides of public roads, where the fear of man forbids the approach of wild animals. ${ }^{1}$ Again, after parturition, it first swallows the afterbirth, ${ }^{2}$ then goes in quest of the seseli shrub, ${ }^{3}$ and after eating of it returns to its young. The mother takes its young betimes to her lair, so leading it to know its place of refuge in time of 20 danger ${ }^{4}$ this lair is a precipitous rock, with only one approach, and there it is said to hold its own against all comers. The male when it gets fat, which it does in a high degree in autumn, disappears, abandoning its usual resorts, apparently under an idea that its fatness facilitates its capture. ${ }^{5}$ They shed their horns in places difficult of 25 access or discovery, whence the proverbial expression of 'the place where the stag sheds his horns ' ${ }^{6}$ the fact being that, as having parted with their weapons, they take care

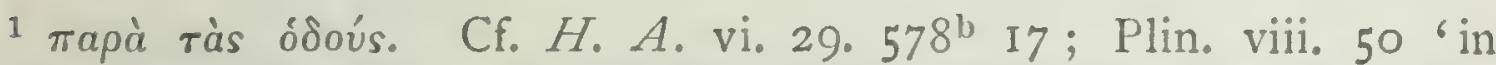
pariendo semitas minus cavent, humanis vestigiis tritas, quam secreta ac feris opportuna'. Cf. Plut. Soll. Anim.97 I E; Antig. Mirab. 35; Opp. Cyn. ii. 207. A somewhat confused account is given in Ael. vi. II.

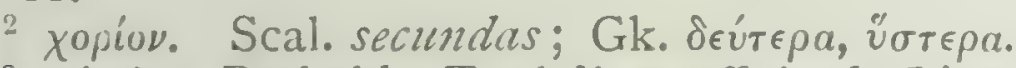

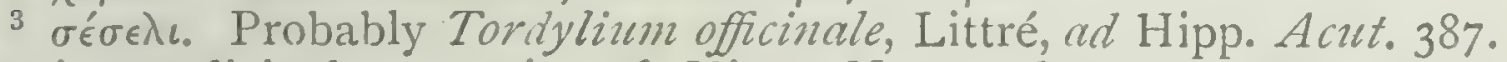
On its medicinal properties cf. Hipp. Nat. mulier. 572, 587, Morb. mul. i. 603" 626 ; Diosc. iii. 6o. Cf. Plin. viii. 50 'feminae ante partum purgantur herba quadam, quae seselis dicitur, faciliore ita utentes utero. A partu duas, quae aros (cf. Plin. xxiv. 9I) et seselis appellantur, pastae, redeunt ad fetum.' See also Ael. V. H. xiii. 35 (who speaks of $\sigma \epsilon ́ \lambda \iota \nu o \nu)$; Cic. de Nat. Deor. ii. 50 ; Plin. xx. 18, 87, xxv. 52.

4 Plin. viii. 50 has 'ad praerupta ducunt, saltumque demonstrant', and Solin. xix 'et assuescunt salire per abrupta'. Cf. H. A. vi. 29. $57^{\mathrm{b}} 2 \mathrm{r}$, Antig. Mirab. 35.

5 Plin.l.c.; Plut. Soll. Anim. 97 I F; Ael. vi. II.

G Zenob. Cent. v. 52 ; Suid. 
not to be seen. The saying is that no man has ever seen the animal's lcft horn; ${ }^{1}$ that the creature kecps it nut of ;o sight because it possesses some medicinal property.

In their first year stags grow no horns, but only an excrescence indicating where horns will be, this excrescence being short and thick. In their second year they grow their horns for the first time, straight in shape, like pegs for hanging clothes on; and on this account they have an appropriate nickname. ${ }^{2}$ In the third ycar the antlers are bifurcate; in the fourth year they grow trifurcate; ${ }^{3}$ and so they go on increasing in complexity until the creature is six $6 \mathrm{II}^{\mathrm{b}}$ ycars old: ${ }^{4}$ after this they grow their horns without any specific differentiation, so that you cannot by obscrvation of them tell the animal's age. But the patriarchs of the herd may be told chiefly by two signs; in the first place they have few teeth or none at all, and, in the second 5 place, they have ceased to grow the pointed tips to their antlers. The forward-pointing tips of the growing horns 〈that is to say the brow-antlers, with which the animal meets attack, are technically termed its 'defenders'; with these the patriarchs are unprovided, and their antlers merely grow straight upwards. Stags shed their horns annually, in or about the month of May; after shedding, they ro conceal themsclecs, it is said, during the daytime, and, to avoid the flies, hide in thick copses; during this time, until they have grown their horns, they feed at nighttime. The horns at first grow in a kind of skin enrelope,

1 The story is told by Plin. viii. 50; Theophr. fr. I75; Ael. iii. I7: Arist. de Mirab. 75. $835^{\mathrm{b}} 27$; Antig. Mirab. 24, according to all of whom it is the right horn that is not to be obtained. They all also use

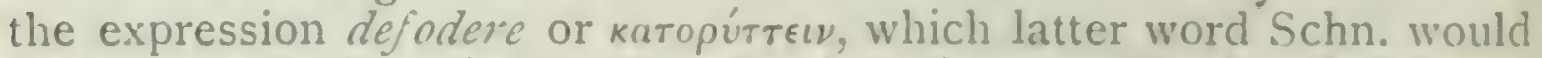

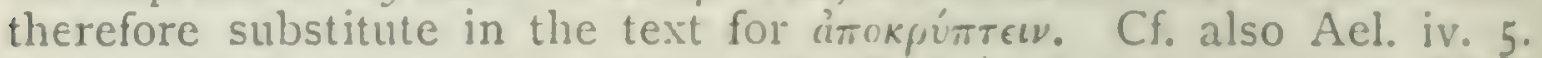
On the hart's horn and its virtues cf. H. A. iv. 8. 534; Nicand. Ther. 36; Phile 1245; Lithica, 242-56; Theophr. fir. cit., \&ic.

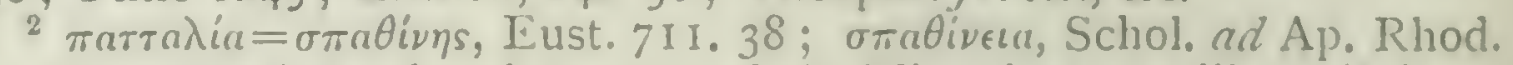
iv. 175 ; Anglicé, a brocket. L. subulo, Plin. xi. 45, xxviii. 53 (67)

3 трахи́тє⿻上丨 is, I think, obviously wrong. The word was probably

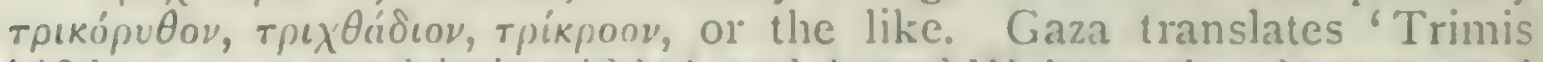
bifid exeunt, quadrimie trifila', and A. and W. have nheady suggested трекрайं.

1 l'lin. viii. 50 ; cf. Solin. xix.

${ }^{5}$ For $\mu v i u s$ Albertus M. has lupos. A. and IV. suggest cirnuis; cf.

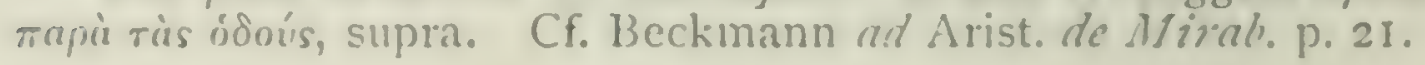


and get rough by degrees; ${ }^{1}$ when they reach thcir full size the animal basks in the sun, to mature and dry them. In When they need no longer rub them against tree-trunks they quit their hiding-places, from a sense of security based upon the possession of arms defensive and offensive. An Achaeine stag has been caught with a quantity of green ivy grown over its horns, ${ }^{2}$ it having grown apparently, as on fresh green wood, when the horns were young 20 and tender. When a stag is stung by a venom-spider or similar insect, it gathers crabs and eats them; ${ }^{3}$ it is said to be a good thing for man to drink the juice, but the taste is disagreeable. The hinds after parturition at once swallow the afterbirth, and it is impossible to secure it, for the hind catches it before it falls to the ground: now this ${ }^{25}$ substance is supposed to have medicinal properties. When hunted the creatures are caught by singing or pipe-playing on the part of the hunters; they are so pleased with the music that they lie down on the grass. ${ }^{4}$ If there be two ${ }^{1}$ H. A. ii. I. $5 \mathrm{co}^{\mathrm{a}} 9$; cf. iii. 9. $5 \mathrm{I}^{\mathrm{a}} 25$; Plin. viii. 50 ; Ael. vi. 5 ; Arist. de Mirab. 5 ; Theoph. Simoc. i. 5 , \&c.

${ }^{2}$ Cf. Athen. viii. p. 353; Theophr.C.P. ii. I7. The story is told more frequently than the interest of the simple fact would seem to warrant; probably a stag or fawn with the Dionysiac plant about its horns would be looked on as something portentous. By Antig. Mirab. 35 it is related

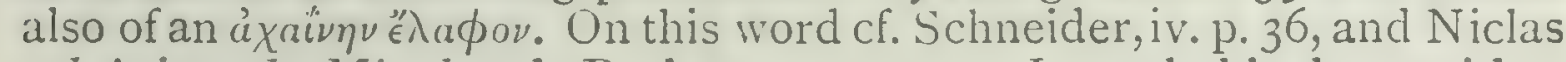
ad Arist. de Mirab., ed. Beckmann, p. 20. It probably has neither geographical nor specific significance. Cf. Hesych. ảxai $\nu \in \beta p \hat{\omega} \nu \epsilon^{\prime} \lambda \lambda^{\prime} \phi \omega \nu$

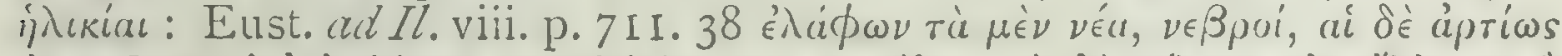

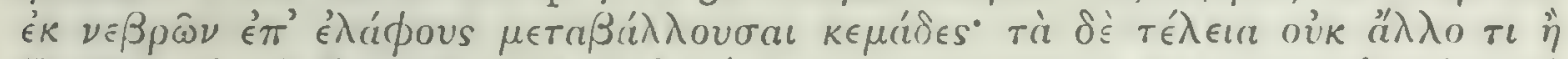

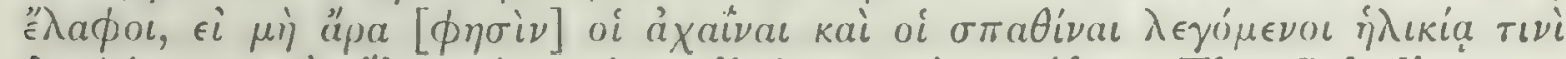

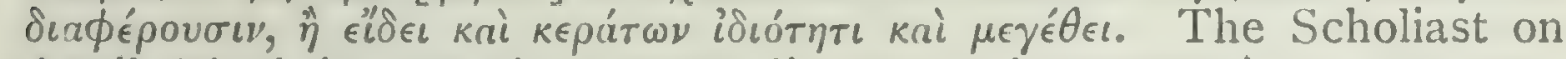
Apoll. Rhod. iv. 174 gives three discrepant interpretations, one geographical, one specific, and one relating to a particular age or period of growth. See also H. A. ii. I 5. 506 23 .

${ }_{3}$ The reading rois kapkivous seems dubious, though followed by Pliny viii. 4I, Ael. $V$. H. xiii. 35 : especially in view of the singular verb, which can scarcely refer to paxiyztov, in the next clause. The allusion to clittany in the next chapter is told of the stag by Pliny, l.c.; Solin. xix. 19; Apuleius, 72, \&c. Were we inclined to read here rò

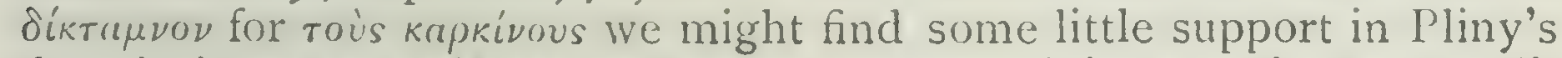

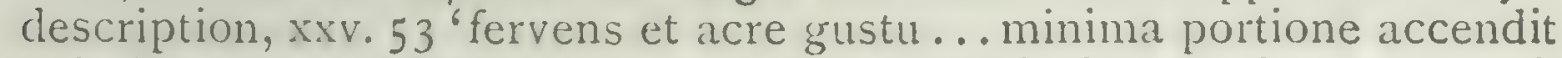
os'. Gaza has 'cancros edunt, quod idem homini etiam prodesse putatur'.

${ }^{2}$ Plin. viii. 50; Plut. Soll. Anim. 31 ; Xen. in Geopon. xix. 5; Antig.

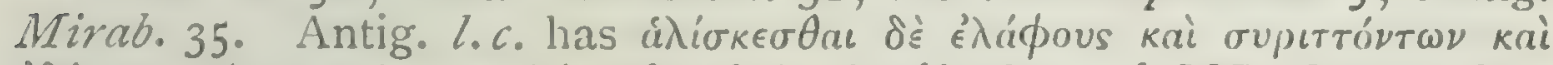

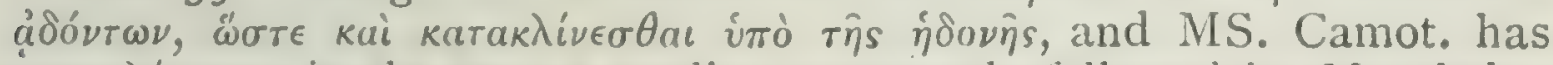

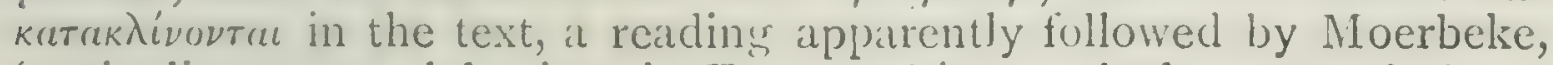

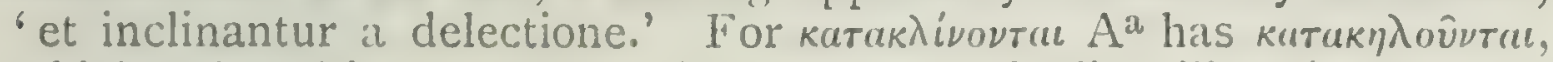
which Schn., Picc., and A. and W. accept; cf. Plin. viii. 50 'mulcentur fistulat pastorali'. 
hunters, one before their eyes sings or plays the pipe, the other keeps out of sight and shoots, at a signal given by 30 the confederate. ${ }^{1}$ If the animal has its ears cocked, it can hear well and you cannot cscape its ken; if its ears are down, you can.

When bears are running away from their pursuers they 6 push their cubs in front of them, or take them up and carry them; ${ }^{2}$ when they are being overtaken they climb up a tree. When emerging from their winter-den, they at once take to eating cuckoo-pint, as has been said, ${ }^{3}$ and $612^{2}$ chew sticks of wood as though they were cutting teeth.

Many other quadrupeds help themselves in clever ways. Wild goats in Crete are said, when wounded by arrows, to go in scarch of dittany, which is supposed to have the 5 property of ejecting arrows in the body. ${ }^{4}$ Dogs, when they are ill, eat some kind of grass and produce vomiting." The panther, after eating panther's-bane, tries to find some human excrement, which is said to heal its pain." This panther's-bane kills lions as well. Hunter's hang up human ro excrement in a ressel attached to the boughs of a trec. to keep the animal from straying to any clistance; the animal meets its end in leaping up to the branch and trying to get at the medicinc. They say that the panther has found out that wild animals are fond of the scent it cmits ${ }^{7}$ that, when it goes a-hunting, it hides itself; that the other animals come nearer and nearer, and that by this 15 stratagem it can catch even animals as swift of foot as stags.

The Egyptian ichneumon, when it sees the serpent called the asp, does not attack it until it has called in other

1 Plin. viii. 50.

${ }^{3}$ H. A. viii. 17. $600^{1}$ II ; Plin. viii. 54 .

${ }^{4}$ Verg. Aen. xii. $415^{6}$ non illa feris incognita capris Gramina, cum tergo volucres haesere sagittae'. Cf. Theophr. H.P. ix. 16; Antig. Mirab. 30 (36); Ps.-Arist.Mirab. 4. $830^{b} 20$; Plut. Soll. Anim. 974 D; Acl. $V . H$. i. IO. Of deer, Plin. viii. 41, xxv. 53; Apul. lxxiii. 3, \&ec.

- H. A. viii. 5. $594^{\text {a }}$ I8; Ael. v. 46, viii. 9; 1'lin. xxv. 5 r.

${ }^{6}$ Plin. viii. 4I, xx. 23, xxvii. 2; Ael.iv. 49; Ps.-Arist. Alirab.6.83I ${ }^{2} 4$; Cic. N. D. ii. 50 ; Xen. Cyneg. ii; Schol. ad Nic. Alex. 38.

7 Plin. viii. 23 , xxi. IS: Theophr. C: P. vi. 5. 2 ; Acl. V. 40 ; Arist. l'mell. xiij. 4 yo7' 35. 
ichneumons to help; to meet the blows and bites of their enemy the assailants beplaster themselves with mud, by first soaking in the river and then rolling on the ground. ${ }^{1}$

When the crocodile yawns, the trochilus" flies into his 20 mouth and cleans his teeth. The trochilus gets his food thereby, and the crocodile gets ease and comfort; it makes no attempt to injure its little friend, but, when it wants it to go, it shakes its neck:" in warning, lest it should accidentally bite the bird.

The tortoise, when it has partaken of a snake, eats marjoram; this action has been actually observed. ${ }^{4}$ A man 25 saw a tortoise perform this operation over and over again, and every time it plucked up some marjoram go back to partake of its prey; he thereupon pulled the marjoram up by the roots, and the consequence was the tortoise dicd. The weasel, when it fights with a snake, first eats ${ }^{j}$ wild rue, the smell of which is noxious to the snake. ${ }^{6}$ The dragon, when it eats fruit, swallows endive-juice $;^{7}$ it has $3^{\circ}$ been seen in the act. Dogs, when they suffer from worms, eat the standing corn. ${ }^{\checkmark}$ Storks, and all other birds, when they get a wound fighting, apply marjoram to the place injured. ${ }^{9}$

1 Plin. viii. 36; Ael.iii.22; Plut. Soll. Anim. 966 D ; Nicand. Ther. Igo; Antig. Mirab. 38; Phile, I33; Opp. Cyneg. iii. 407; Strabo, xvii. I. 39, 2. 4 .

2 The Egyptian plover, Pluviamus aegyptiacus, s. Charadrius melanocephalus, first identified by G. St. Hilaire, Desir. de l'Egypte (2), xxiv. p. 440, Mém. du Muséum, xv. p. 466; a recent writer, however, states that the true crocodile-bird is a somewhat larger species, the spur-winged plover, Hoplopterus spinosus (Ibis, I893, p. 277). Cf. Herod. ii. 68 ; Arist. Mirab. 7. 83 I I I Ammian. xxii. 15, I9; Antig. Mirab. 33; Ael. iii. I I, viii. 25; P'lut. Soll. Anim. 9830 D ; Phile 97 (82); Plin. viii. 37. According to Ael. xii. I 4, the

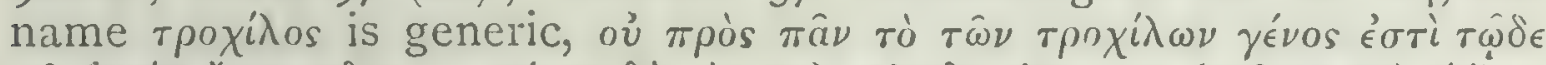

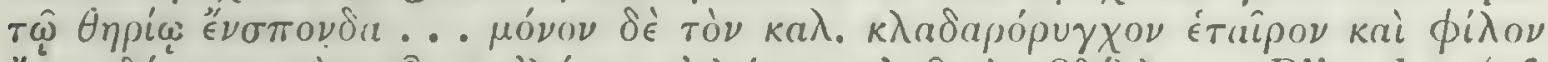

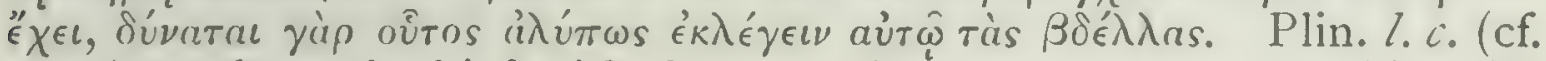
x. 95) confuses the bird with the wren, 'parva avis, quae trochilos ibi vocatur, rex avium in Italia.'

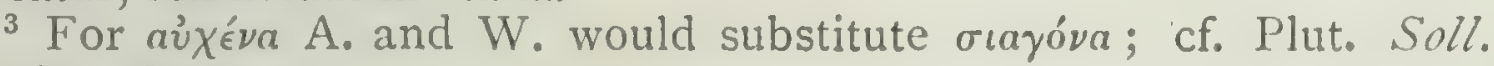
Anim. $980 \mathrm{~F}$.

* Plin. viii. 4I ; Antig. Mirab. 40; Arist. de Mirab. 10. 83I ${ }^{2} 27$; Plut. Q.Nat.918 c; Geop.xv. I ; Basil. Hex. ix. p. II 5; Ael.iii. 5, vi. I2; Nicand. Ther. 626.

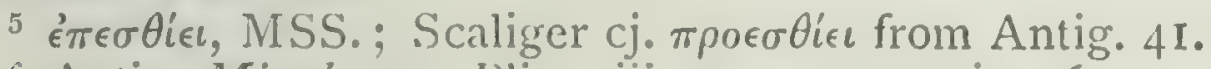

6 Antig. Mirab. $4 \mathrm{I}$; Plin. viii. 4I, xx. 5 I, xxix. I6.

7 Plin. viii. $4 \mathrm{I}$; Ael. vi. 4. ${ }_{8}$ Ael. v. $46 . \quad{ }^{9}$ Antig. Mirab. 42. 
Many have seen the locust, when fighting with the snalic get a tight hold of the snake by the neck. ${ }^{1}$ The weasel $612^{b}$ has a clever way of getting the better of birds; it tears their throats open, as wolves do with sheep. Weasels fight desperatcly with mice-catching snakes, as they both prey on the same animal. ${ }^{2}$

In regard to the instinct of hedgehogs, it has been 5 obscrved in many places that, when the wind is shifting from north to south, and from south to north, they shift the outlook of their earth-holes, and those that are kept in domestication shift over from one wall to the other." The story goes that a man in Byzantium got into high repute for foretelling a change of weather, all owing to his having noticed this habit of the hedgehog.

10 The polecat or marten ${ }^{*}$ is about as large as the smaller breed of Maltese dogs. ${ }^{5}$ In the thickness of its fur, in its look, in the white of its belly, and in its love of mischicf, it resembles the weasel; it is casily tamed; from its liking for honcy it is a plague to bec-hives; it preys on

1 'Aldina, Iuntina, Camotiana č $\sigma$ rióa nominant, Gazae vero versio et Thomae locustam. Scoti ct Alberti hoc membrum totun omisit' (Schn.).

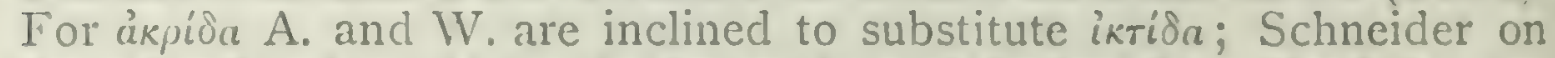
the other hand would justify the reading of the text from the following parallel passages: I'lin. xi. 35 (20) (de locustis) 'serpentem, quum libuit, necant singtilae, faucibus eius apprehensis mordicus'; I'hilo, de (ppif.

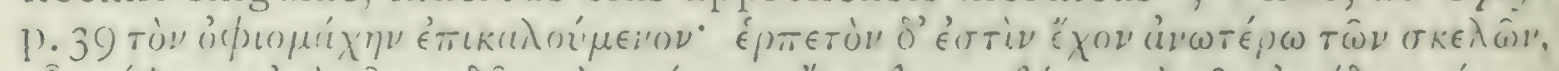

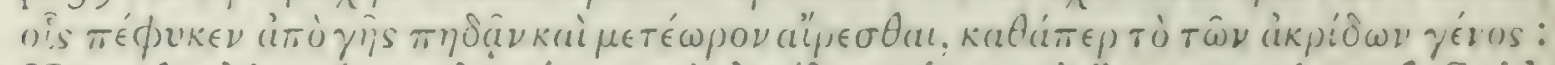

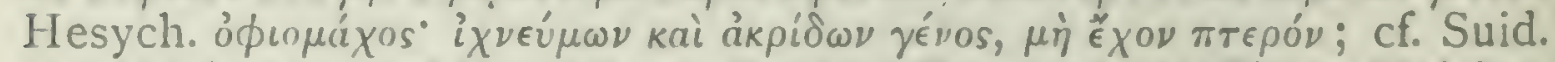
It is the a $\sigma \epsilon i_{i}$ akos of 1 iosc. ii. 57 . Bochart (ii. p. 449) cites Simon . Majolus, D) ialeg. x 'olitorem sumu ex agro renientem, locustam conspexisse, quace serpentem gutture apprehenderit, atyue ita citra pugnam interemerit'. The Vulgate renders by ophiomachus the Heb. חרגול, chargol (Levit.xi. 22), which, according to Lerysohn, Zool. d. Talmuet, p. 290, is Locusta viridissima; the name, as Bochart points out, is apparently identical with in, yolen, which suidas interprets as a species of serpent taken by Alexander from Aiges to Egypt for the purpose of

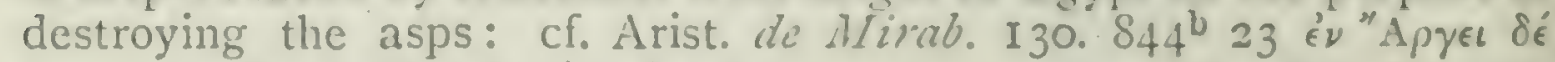

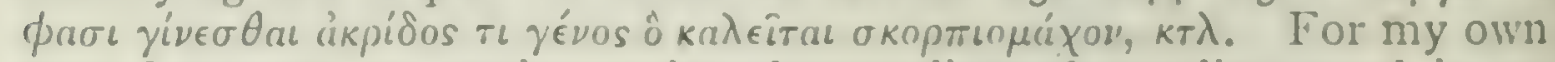
part I suspect an ancient misunderstanding of an alien word in an

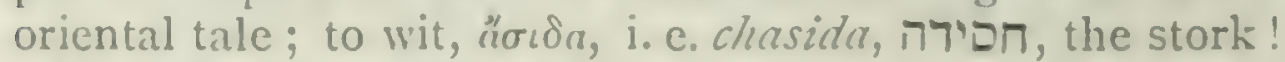

"H. A. vi. $37.580^{\text {") }} 26$.

3 Plut. Soll. Anim. 979 A; Plin. viii. 56 and (of squirrels) 58. Basil. Ilex. ix. p. II 5 .

'Plin. xxix. 4; Eust. ad 1l.x.335; Nic. The\%. 196. Probably Mustela lociamela, Cetti; cf. Martens, Arih.f. Naturg., I858, p. 121.

Cf. Probl. X. 12. Sozil I1, 21 . 
birds like the cat. Its genital organ, as has been said, 15 consists of bone: ${ }^{1}$ the organ of the male is supposed to be a cure for strangury; doctors scrape it into powder, and administer it in that form.

7 In a general way in the lives of animals many resemblances to human life may be observed. Pre-eminent intelligence will be seen more in small creatures than in 20 large ones, as is exemplified in the case of birds by the nest-building of the swallow. ${ }^{2}$ In the same way as men do, ${ }^{3}$ the bird mixes mud and chaff ${ }^{4}$ together; if it runs short of mud, it souses its body in water and rolls about in the dry dust with wet feathers; furthermore, just as man does, 25 it makes a bed of straw, putting hard material below for a foundation, and adapting all to suit its orvn size. Both parents co-operate in the rearing of the young; cach of the parents will detect, with practised eye, the young one that has had a helping, and will take care it is not helped twice over $;^{5}$ at first the parents will rid the nest of excrement, but, when the young are grown, they will teach their zo young to shift their position and let their excrement fall over the side of the nest. ${ }^{6}$

Pigeons exhibit other phenomena with a similar likeness to the ways of humankind. In pairing the same male and the same female liecp together; and the union is only broken by the death of one of the two parties. ${ }^{\top}$ At the time of parturition in the female the sympathetic attentions

1 H. A. ii. I. 500 24; Plin. xi. Io9; Antig. Mirab. 73 and II6; Ps.-Arist. de Mirab. I2. $83 \mathrm{I}^{\mathrm{b}} \mathrm{I}$.

2 Cf. Ael. iii. 24, 25 ; Antig. Mirab. 43; Plut. Soll. Anim. 996 D ; Ovid, F. i. I57; Basil. Hex. viii, p. 104. These descriptions all apply to the house-martin, Hirundo urbica; in Plin. x. 49 (33) the nest of that species and those of the swallow and the sand-martin are all described.

${ }^{3}$ Cf. Plin. vii. 57.

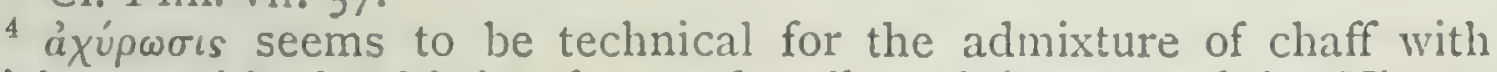
bricks or with the fabric of a mud-wall, and is so used by Vitruv. ii. I; cf. Tutum paleatum, Colum. v. 6, xii. 43, Plin. xv. I8; and lutum aceratum, Fest. ad Non. 5. 97.

5 Plin. x. 49; Ael. iii. 25 ; Antig. Mirab. 37, \&c.

- Plut. Soll. Anim. $962 \mathrm{~F}$; Symp. viii. 7.

7 J'lin. x. 52; Ael. iii. 44: Antig. 38 (44); Athen. ix. 394; Horap. i. 57 , ii. 33, \&c. 
of the male are extraordinary; if the female is afraid on account of the impending parturition to enter the nest, the male will beat her and force her to come in. When the young are born, he will take and masticate pieces of suitable food,' will open the beaks of the fledglings, and inject these pieces, thus preparing them betimes to take sfood. [When the male bird is about to expel the young ones from the nest, he cohabits with them all. ${ }^{2}$ ] As a general rule these birds show this conjugal fidelity, but occasionally a female will cohabit with other than her mate." These birds are combative, and quarrel with one another. and enter each other's nests, though this occurs but seldom; Io at a distance from their nests this quarrelsomeness is less marked, but in the close neighbourhood of their nests they will fight desperately. A peculiarity common to the tame pigcon, the ring-dove and the turtle-dove is that they do not lean the head back when they are in the act of drinking, ${ }^{4}$ but only when they have fully quenched their thirst. The turtle-dove and the ring-dove both have but one mate, 15 and let no other come nigh; both sexes co-operate in the process of incubation. It is difficult to distinguish between the sexes except by an examination of their interiors. Ring-doves are long-lived; cases have been known where such birds were twenty-five years old, thirty years old, and in some cases forty." As they grow old their claws increase 20 in size, and pigeon-fanciers cut the claws; as far as one can see, the birds suffer no other perceptible disfigurement by their increase in age. Turtle-doves and pigeons that

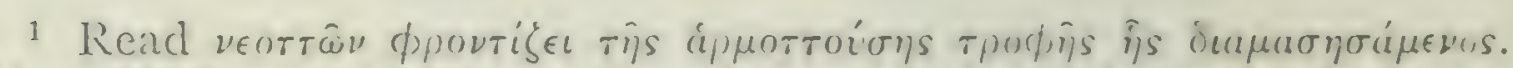

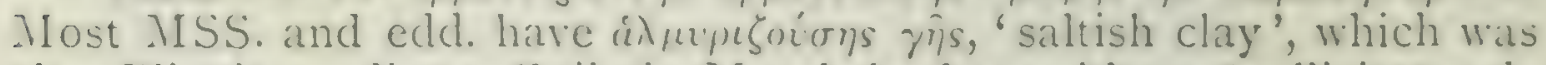
also I'liny's readinge: Guil. de Nocrbeke has, with us. "sollicitatur de opportuno alimento, qund cum masticavit, inspexit.' As an explana-

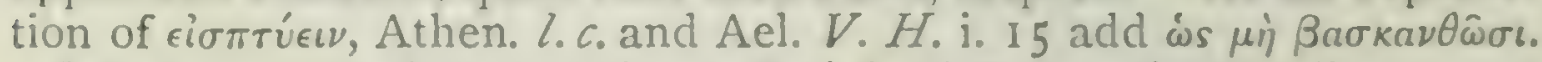

2 A fable told of the partridge, cf. vi. 8. $564^{a} 24$; alien to all accounts

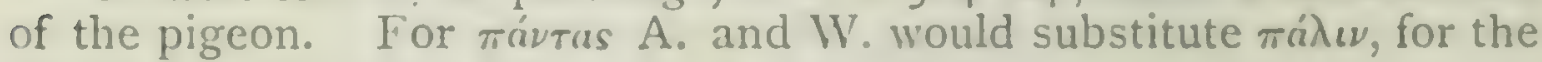
bird's reputation's sake.

3 No such exception to the pigeon's habitual chastity is mentioned clecwhere: unless incleed the phenomenon alluded to be that described

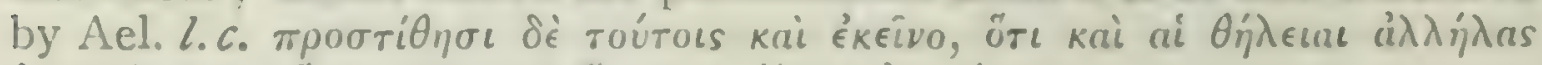

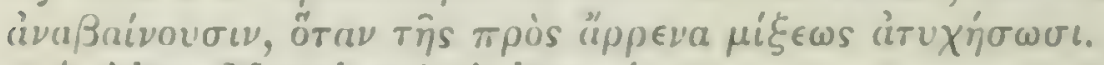

1 Alex. Mynd. ap. Athen. l.c.

5 H. 1. vi. +. $563^{\text {il }} 2$; Plin. x. 52; Achen. ix. 394 . 
are blinded by fanciers for use as decoys, live for cight years. Partridges live for about fifteen years. Ring-doves and turtle-doves always build their nests in the same 25 place ycar after year. The male, as a general rule, is morc long-lived than the female; but in the case of pigeons some assert that the male dies before the female, taking their inference from the statements of persons who kecp decoybirds in captivity. Some declare that the male sparrow lives only for a year, pointing to the fact that early in 30 spring the male sparrow has no black beard, but has one later on, as though the black-bearded birds of the last year had all died out; they also say that the females are the longer lived, on the grounds that they are caught in amongst the young birds and that their age is rendered $613^{\text {b }}$ manifest by the hardness about their beaks. Turtle-doves in summer live in cold places, 〈and in warm places during the winter $\rangle ;^{1}$ chaffinches affect warm habitations in summer, 5 and cold ones in winter.

8 Birds of a heavy build, such as quails, partridges, and the like, build no nests ; ${ }^{2}$ indeed, where they are incapable of flight, it would be of no use if they could do so. After scraping a hole on a level piece of ground-and it is only in such a place that they lay their eggs-they cover it over with thorns and sticks ${ }^{3}$ for security against hawks and 10 eagles, and there lay their egss and hatch them; after the hatching is over, ${ }^{4}$ they at once lead the young out from the nest, as they are not able to fly aficld for food for them. Quails and partridges, like barn-door hens, when they go to rest, gather their brood under their wings. Not 5 to be discovered, as might be the case if they stayed long in one spot, they do not hatch the eggs where they laid

1 〈 in the Aldine. Gaza 'hieme tepidis'.

2 H. A. vi. I. $55^{8 \mathrm{~b}} 3 \mathrm{I}$.

3 Plin. x. 5I; Ael. iii. 16, x. 35; Ov. Met. viii. 258.

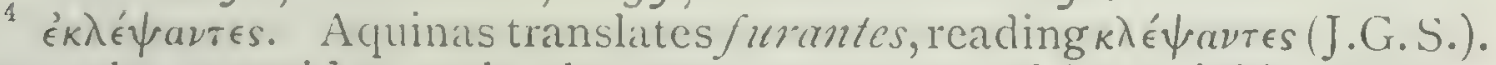
That the partrictge stole the egres or young of its neighbours was a common belief; see, for many reff., patristic, Arabic, \&.c., Bochart, Hicros. ii. 1. 84, \&ic. 
them.' When a man comes by chance upon a young brood, and tries to catch them, the hen-bird rolls in front of the hunter, pretending to be lame: ${ }^{2}$ the man every moment thinks he is on the point of catching her, and so zo she draws him on and on, until every one of her brood has had time to cscape; hercupon she returns to the nest and calls the young back. The partridge lays not less than ten eggs, and often lays as many as sixteen. As hits been observed, the bird has mischicvous and deceitful habits. In the spring-time, a noisy" scrimmage takes place, -5 out of which the male-birds emerge cach with a hen. Owing to the lecherous nature of the bird, and from a dislike to the hen sitting, the males, if they find any eggs, roll them over and over until they break them in pieces; to provide against this the female goes to a distance and lays the eggs, and often, under the stress of parturition, lays them in any chance spot that offers; ${ }^{4}$ if the male bird

so be near at hand," then to keep the eggs intact she refrains from visiting them. If she be seen by a man, then, just as with her fledged brood, she entices him off by showing herself close at his feet until she has drawn him to a clistance. When the females have run away and talien to sitting, the males $64^{\text {a }}$ in a pack take to screaming and fighting; when thus engaged, they have the nickname of "widowers'." The bird who is beaten follows his victor, and submits to be covered by him only; and the beaten bird is covered by a second one or by any other, only clandestinely without the victor's lnowledge: this is so, not at all times, but at a particular season of the 5ycar, and with quails as wcll as with partridges. ${ }^{i}$ A similar

${ }^{1}$ Cf. Plin. l.c. Alb. M. gives a loose, but possibly correct interpretation: 'Non habet nidum certum et stabilem per annos multos, sicut gallina, sed uno anno ovant in loco uno et in alio loco in alio, et hoc ideo faciunt ne venator cognoscat nidum eius.' The same story is

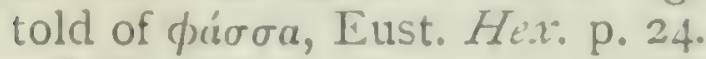

2 Plut. Soll. Anim.97 I C. Cf. Ar. Av. 768 and Schol.

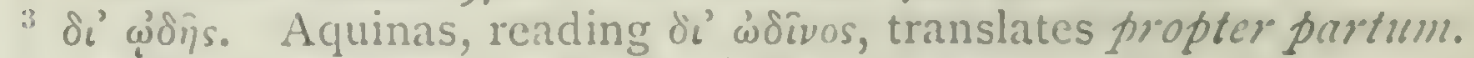

4 A different account in H. A. vi. 8. 564: 20.

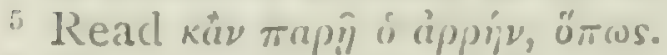

- There are traces of Egyptian influence in this and other stories

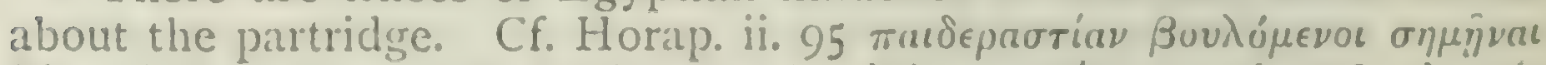

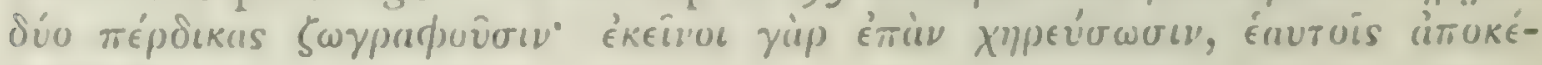
хрпитแ1.

Acl. iv. 16 . 
procecding takes place occasionally with barn-door cocks: for in temples, where cocks are set apart as dedicate without hens, ${ }^{1}$ they all as a matter of course tread any new-comer. Tame partridges tread wild birds, peck at their heads, ${ }^{2}$ and treat them with evcry possible outrage. The leader of the wild birds, with a counter-note of 10 challenge, ${ }^{3}$ pushes forward to attack the decoy-bird, ${ }^{4}$ and after he has been netted, ${ }^{5}$ another advances with a similar note. ${ }^{6}$ This is what is done if the decoy be a male; but if it be a female that is the decoy and gives the note, and the leader of the wild birds give a counter one, the rest of the males set upon him and chase him away from the $\mathrm{I}_{5}$ female for making advances to her instead of to them; in consequence of this the male often advances without uttcring any cry, so that no other may hear him and come and give him battle; and experienced fowlers assert that sometimes the male bird, when he approaches the female, makes her keep silence, to avoid having to give battle to 20 other males who might have heard him. The partridge has not only the note here referred to, but also a thin shrill cry and other notes.' Oftentimes the hen-bird rises from off her brood when she sees the male showing attentions to the female decoy; she will give the counter-note and remain still, so as to be trodden by him and divert him 25 from the decoy. The quail and the partridge are so intent upon sexual union that they often come right in the way

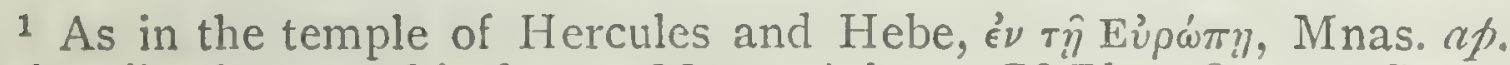
Ael. xvii. 46; or to this day on Mount Athos. Cf. Plut. Quaest. Symp. $696 \mathrm{E}$; Paus. ii. I 48.

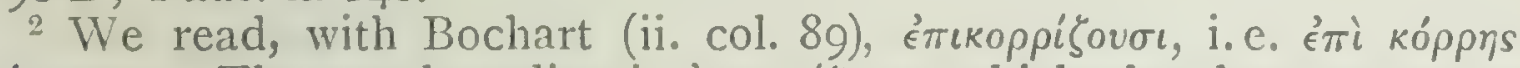

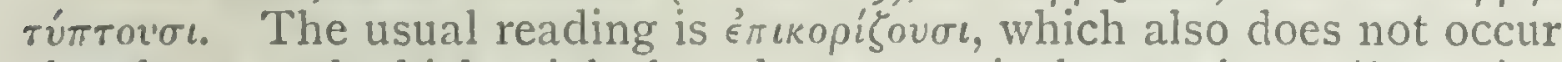

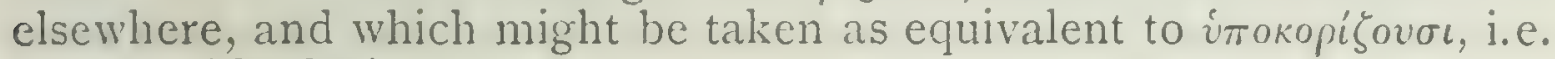
'pet' or 'fondle'.

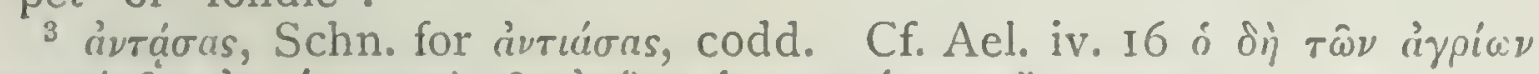

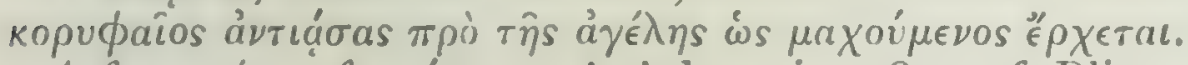

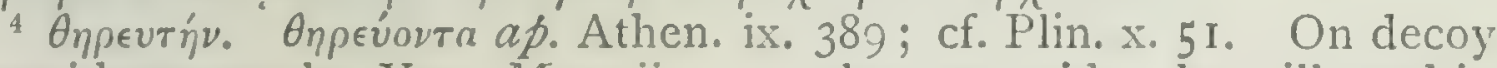
partridges see also Xen. Mem. ii. I. 4 ; they are said to be still used in Spain.

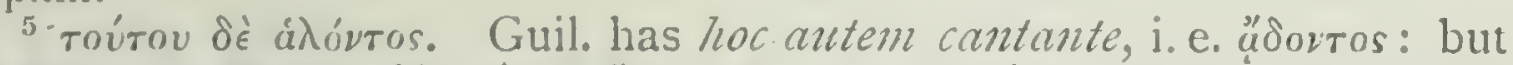

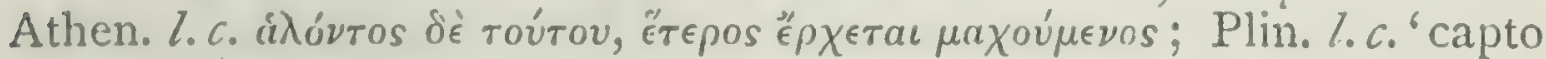

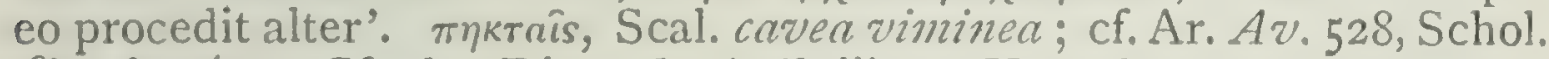

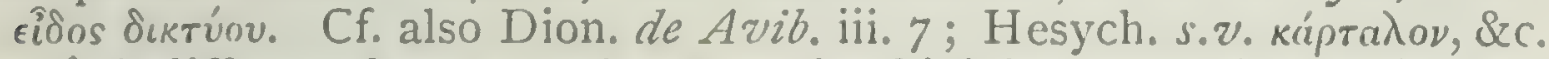

6 A different, but somewhat more intelligible account in Ael. iv. 6.

${ }^{7}$ H. A. iv. 9. 536 ${ }^{\text {b }}$ 4; Athen. ix. 390; Plut. Quaest. Symp. 727 D. 
of the decoy-bircls, and not seldom alight upon their heads. ${ }^{1}$ So much for the sexual proclivities of the par- tridge, for the way in which it is hunted, and the general 30 nasty habits of the bird.

As has been said: quails and partridges build their nests upon the ground, and so also do some of the birds that are capable of sustained flight. ${ }^{2}$ Further, for instance, of such birds, the lark and the woodcock, as well as the quail, do not perch on a branch, but squat upon the ground.

$64^{b}$ The woodpecker does not squat on the ground, but 9 pecks at the bark of trees to drive out from under it maggots and ginats; ${ }^{3}$ when they cmerge, it licks them up with its tongue, which is large and flat. ${ }^{4}$ It can run up and down a tree in any way, cren with the head downwards, like the gecko-lizard." For secure hold upon a tree, its 5 claws are better adapted than those of the daw; ${ }^{6}$ it makes its way by sticking these claws into the bark. One species of woodpecker ${ }^{\top}$ is smaller than a blackbird, and has small reddish speckles; a second species is larger than the blackbird. and a third is not much smaller than a barn-door to hen. ${ }^{8}$ It builds a nest on trees, ${ }^{9}$ as has been said, on olive trees amongst others. It feeds on the maggots and ants that are under the bark: it is so cager in the search for maggots that it is said sometimes to hollow a tree out to its downfall. A woodpecker once, in course of domestiIs cation, was secn to insert an almond into a hole in a piece of timber, so that it might remain steady under its

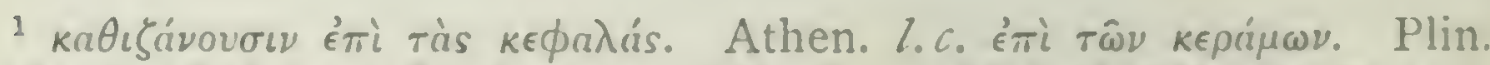
understands by rois Anpermoas. not the decoy-birds, but the sportsmen. 'ut in capite aucupantium saepe caecae metu sedeant.'

${ }^{2}$ Dittm. cj. $\tau \hat{\omega} \nu\langle\mu \dot{\eta}\rangle \pi \tau \eta \tau \iota \hat{\omega}^{2} \nu$; cf. H. A. vi. I. $558^{\mathrm{b}} 3$ I, ix. S. 6 I $3^{\mathrm{b}} 7$.

"Plin. x. 20; Ps.-Arist. Mirab. I3. 83 I" 5; Plut. Q. R. 269 A.

$4 \lambda$ areiur is inapplicable to the long, sharp tongue of the wood-

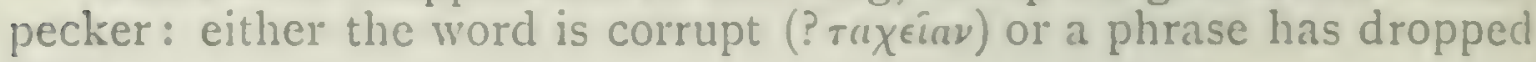
out.

Plin. l.c. has 'in subreptum [s. subrectum] felium modo :

"Schn. suggests $\kappa \circ \lambda \iota \hat{\imath} \nu, \mathrm{s}, \kappa \in \lambda \in \hat{\omega} \nu$.

ๆ $H \cdot$. A. viii. $3 \cdot 593^{\mathrm{a}} 5$.

\& Probably (I) the lesser and greater spotted woodpeckers, (2) the green woodpecker, and (3) the great black woodpecker.

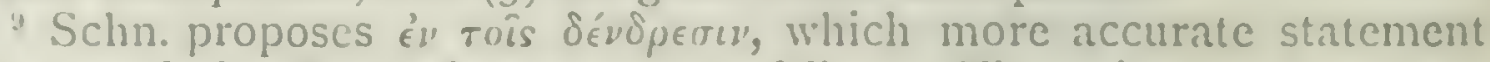
Gaza and de Moerbeke appear to follow. There is no passage to

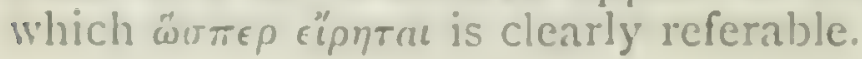


pecking; at the third peck it split the shell of the fruit, and then ate the kernel.

Io Many indications of high intelligence are given by cranes. They will fly to a great distance and high up in the air, to command an cxtensive view; if they see 20 clouds and signs of bad weather they fly down again and remain still. ${ }^{1}$ They, furthermore, have a leader in their flight, and patrols that scream on the confines of the flock so as to be heard by all. When they settle down, the main body go to sleep with their heads under their wing, standing first on one leg and then on the other, 25 while their leader, with his head uncovered, keeps a sharp look out, and when he sees anything of importance signals it with a cry.

Pelicans that live beside rivers ${ }^{2}$ swallow the large smooth mussel-shells : after cooking them inside the crop that precedes the stomach, they spit them out, so that, now when their shells are open, they may pick the flesh out and eat it. ${ }^{3}$

II Of wild birds, the nests are fashioned to meet the cxigencies of existence and ensure the security of the young. Some of these birds are fond of their young and take great care of them, others are quite the reverse; some are clever in procuring subsistence, others are not so. Some of these birds build in ravines and clefts, ${ }^{4}$ and on cliffs, as, for instance, the so-called charadrius, or stone-curlew; this bird 6r5 ${ }^{\text {a }}$ is in no way noteworthy for plumage or voice; it makes an appearance at night, but in the daytime kecps out of sight.

The hawk also builds in inaccessible places. Although a ravenous bird, it will never eat the heart of any bird it catches; " this has been obscrved in the case of the quail, 5

1 H. A. viii. 12. $597^{\mathrm{a}} 4$; Eurip. Hel. I478; Plin. x. 30; Ael. iii. I4, vii. 7 ; Cic. $N . D$. ii. 49 ; Horap. ii. 49, \&c.

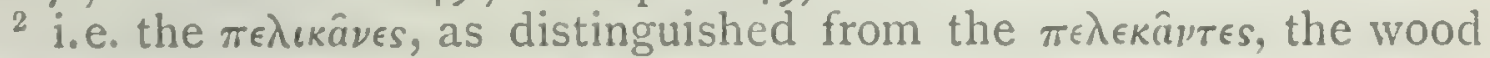
peckers; cf. Ar. A\%. II 55, \&c.

${ }^{3}$ Ael. iii. 23, v. 35 ; Ps.-Arist. Mirab. I4. $83^{\circledR 2}$ Io; Antig. 47 ; Dion. de Avib. ii. 6 ; Plin. x. 56 ; Cic. N.D. ii. 49.

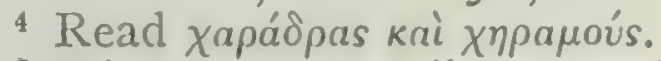

5 Plin. x. Io; Ael. ii. 42 ; an Egyptian myth. 
the thrush, and other birds. They modify betimes their method of hunting, ${ }^{1}$ for in summer they do not grab their prey as they do at other seasons. ${ }^{2}$

Of the vulture, it is said that no one has ever secn either its young or its nest;" on this account and on the ground that all of a sudden great numbers of them will appear without any one being able to tell from whence they come, Heroro dorus, the father of Bryson the sophist, says that it belongs to some distant and elevated ${ }^{*}$ land. The reason is that the bird has its nest on inaccessible crasss, and is found only in a few localities. The female lays one egg as a rule, and two at the most.

I5 Some birds live on mountains or in forests, as the hoopoc and the brenthus; " this latter bird finds his food with ease and has a musical voice. The wren lives in brakes and crevices; it is difficult of capture, kecps out of sight, is gentle of disposition, finds its food with ease, and is something of a mechanic. It goes by the nickname of 'old man' or 'king' $;{ }^{6}$ and the story goes that for this reason the eagle is at war with him. ${ }^{\top}$

Some birds live on the sea-shore, as the wagtail; the 12 bird is of a mischievous nature. hard to capture, but when

${ }^{1} \mu \epsilon \tau a \beta$ ai $\lambda \lambda \epsilon \nu$ is often used of the hawk, but always of its supposed metamorphosis with the cuckoo. The expression here is a singular one, and from the analogy of $H \cdot A \cdot v i \cdot 7 \cdot 563^{\mathrm{b}} 24$ we might suspect the true reading to be $\mu \in \tau \dot{x}$ rò $\theta$ '́́

2 Albertus M. 'aliam praedam capiunt in aestate et aliam in hieme'.

" That the vulture laid no eggs, but was impregnated by the east wind and brought forth her young alive and feathered, was an Egyptian myth, connected with the association of the bird with Maut, the goddess of maternity. For reff, see Gl. of Gl. Bircis, p. 48. The rest of the paragraph is an inaccurate transcript of $H . A$. vi. $5.563^{\mathrm{a}} 6$.

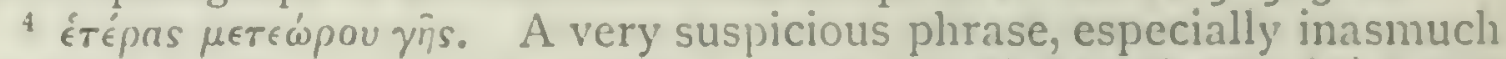
as what seems to be the parent passage (vi. 5) has simply a't 'érépas

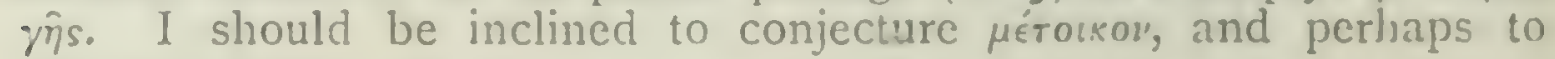
compare Acsch. $A g .57$.

Bpéveos. Hesych. kísordio: Cf. H. A. ix. I. $609^{2} 23$, where I suspect $\beta p$. to be an interpolation.

"In my Gl. of Gl. Birts (pp. 126, 171) I have hazarded the conjecture that rpoxinos is Egyptian, and further that in the likencsbetween Copt. oura, avis, and ouro, rex, may lie the comnexion between the bird and its appellation 'king'.

Cf. Plin. $x .95$. It is to the owl that "pxidos is said to be hostilc. H. A. ix. I. $609^{\mathrm{a}}$ I2. 
caught capable of complete domestication; it is a cripple, as being weak in its hinder quarters. ${ }^{1}$

Web-footed birds without exception live near the sea or rivers or pools, as they naturally resort to places 25 adapted to their structure. ${ }^{2}$ Several birds, however, with cloven toes live near pools or marshes, as, for instance, the anthus ${ }^{3}$ lives by the side of rivers; the plumage of this bird is pretty, and it finds its food with ease. The catarrhactes ${ }^{4}$ lives near the sea; when it makes a dive, it will keep under water for as long as it would take a man 30 to walk a furlong; it is less than the common hawk. Sivans are web-footed, and live near pools and marshes; they find their food with ease, are good-tempered, are fond of their young, and live to a green old age. If the eagle attacks them they will repel the attack and get the better $615^{\mathrm{b}}$ of their assailant, but they are never the first to attack. ${ }^{6}$ They are musical, and sing chiefly at the approach of death $;^{7}$ at this time they fly out to sea, and men, when sailing past the coast of Libya, have fallen in with many of them out at sea singing in mournful strains, and have 5 actually seen some of them dying.

The cymindis" is seldom scen, as it lives on mountains; it is black in colour, and about the size of the hawk called the 'dove-killer'; it is long and slender ${ }^{10}$ in form. The

1 ả

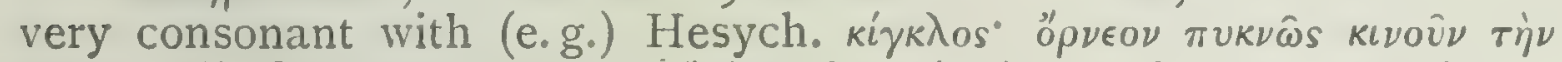

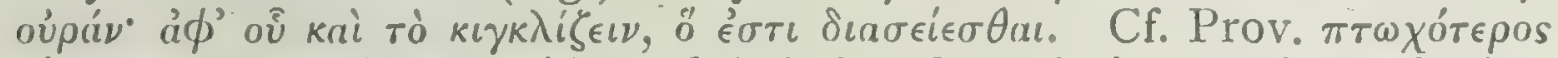

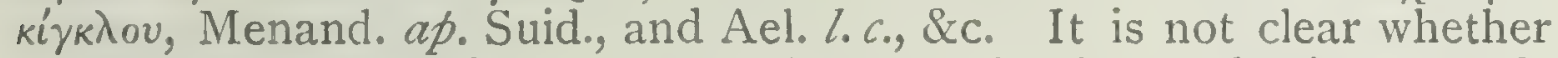
kík $\lambda$ os was a wagtail, or, as Sundevall and others take it, a sandpiper (cf. supra, viii. $4 \cdot 593^{\mathrm{b}}$ 5). There is a lurking unpleasantness in

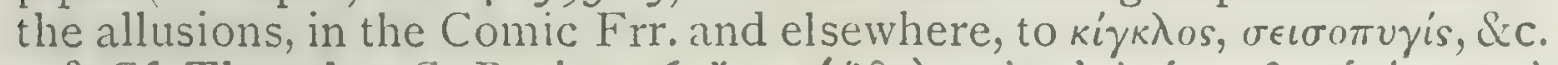

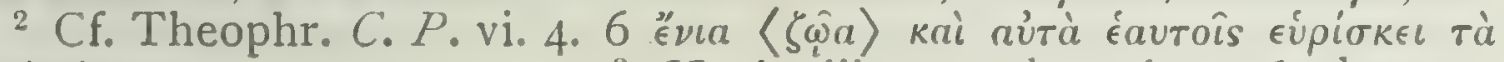
$\pi \rho \sigma^{\sigma} \sigma \phi \rho а$. H. A. viii. 3. $592^{\mathrm{b}} 25$, ix. I. $609^{\mathrm{b}}$ I 4 .

${ }^{4}$ H. A. ii. 17. $509^{\text {a }} 4$; Aristoph. H. A. Epit. i. 24 ; Dion. de Avib. ii. 2 ; Plin. x. 61 .

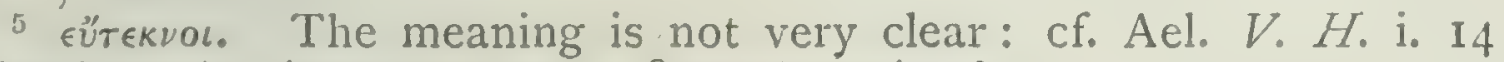

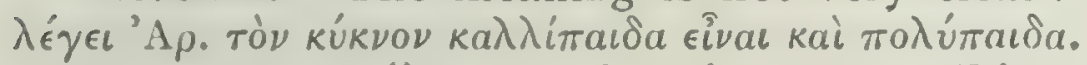

Ael. v. 34, xvii. 24; Athen. ix. p. 393; Dion. de Avib. ii. 19, \&c.

7 For the very numerous references to the swan's song see Gl. of Gk. Birds, pp. 106, 107.

8 Cit. $a p$. Ael. x. 36 .

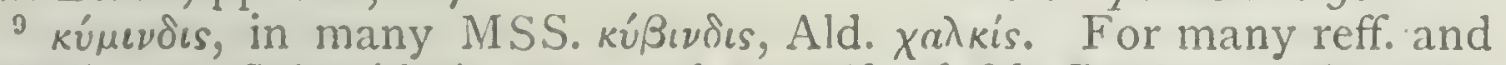
Scholia see Schneider's note and my Gil. of Gk. Birls, p. 108. The word is possibly alkin to the Indian govinda, a kite.

${ }^{10} \lambda \epsilon \pi$ rós. MSS. $\lambda \epsilon u k o ́ s . ~ S c h n$. and Picc. add, from Eustath. ad $1 /$.

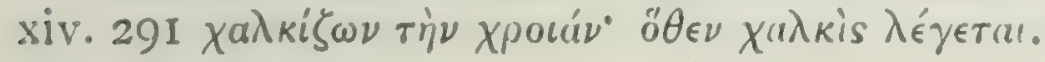

AR. II.A.

$\mathrm{D} d$ 
Ionians call the bird by this name; Homer in the Iliad mentions it in the line ${ }^{1}:-$

Chalcis its name with those of heav'nly birth, But called Cymindis by the sons of earth.

The hybris, said by some to be the same as the eagleowl is never scen by daylight, as it is dim-sighted, but during the night it hunts like the cagle ; ${ }^{2}$ it will fight the cagle " with such desperation that the two combatants are 15 often captured alive by shepherds: it lays two eggs, and, like others we have mentioned, it builds on rocks and in caverns. Cranes also fight so desperately among themselves as to be caught when fighting, for they will not leave off $;^{3}$ the crane lays two eggs.

The jay has a great variety of notes: indecd, one might 13 zo almost say it had a different note for every day in the year. ${ }^{4}$ It lays about nine eggs; builds its nest on trees, out of hair and tags of wool; when acorns are getting scarce, $^{5}$ it lays up a store of them in hiding.

It is a common story of the stork that the old birds are fed by their grateful progeny." Some tell a similar story 25 of the bee-eater, and declare that the parents are fed by their young not only when growing old, but at an carly period, as soon as the young are capable of feeding them : and the parent-birds stay inside the nest. ${ }^{i}$ The under part of the bird's wing is pale yellow; the upper part is dark

1 Il. xiv. $29 \mathrm{I}$.

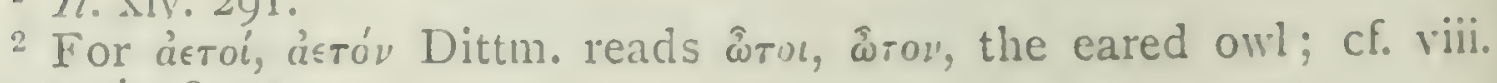
12. $597^{\mathrm{b}}$ I 8,22 .

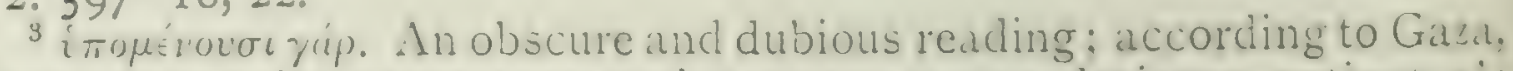
'hominem enim exspectare potius quam pugna ciesistere patiuntur': Scal. 'resistunt enim': Guil. 'ut et ambae capiantur viventes et ipsae a pastoribus pugnantes'. Hence Schneider conjectures that Guil.

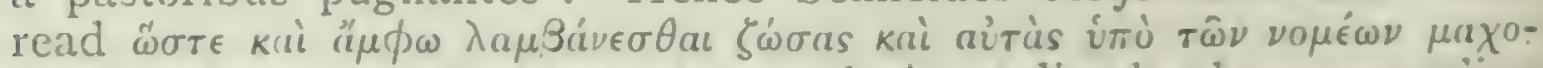
$\mu: u^{\prime}$, a statement similar to that made immediately aboic regariing the eagle.

Ael.vi. 19; Plut. Soll. An.973 C; Dion. de Avib. i. 18 ; Porph. de Abstin. iii. 4 .

5 ơ

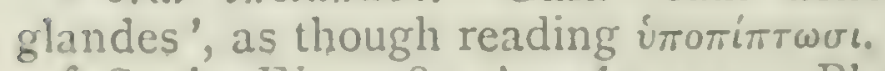

${ }^{6}$ Soph. El. 1058; Ar. Av. 1355; Plut. Alib. i. 135'; Ael. iii. 23 ; Acs. 100, 100') Babr. 13; Horap. ii. 55, Lic.

7 Plin. x. 51 ; Ael. xi. 30. 
blue, like that of the halcyon; the tips of the wings are red. ${ }^{1}$ About autumn-time ${ }^{2}$ it lays six or seven eggs, in $3 \circ$ overhanging banks where the soil is soft; there it burrows into the ground to a depth of six feet.

The greenfinch, so called from the colour of its belly, is as large as a lark; it lays four or five eggs, builds its nest out of the plant called comfrey, pulling it up $616^{a}$ by the roots, and makes an under-mattress to lie on of hair and wool. ${ }^{3}$ The blackbird and the jay build their nests after the same fashion. The nest of the penduline tit shows great mechanical skill; it has the appearance of a ball of 5 flax, and the hole for entry is very small. ${ }^{4}$

People who live where the bird comes from say that there exists a cinnamon bird which brings the cinnamon from some unknown localities, and builds its nest out of it; ${ }^{j}$ it builds on high trees on the slender top branches. They 10 say that the inhabitants attach leaden weights to the tips of their arrows and therewith bring down the nests, and from the intertexture collect the cinnamon sticks.

I4 The halcyon is not much larger than the sparrow. Its colour is dark blue, green, and light purple; the whole is body and wings, and especially parts about the neck, show these colours in a mixed way, without any colour being sharply defined; the beak is light green, long and slender: ${ }^{6}$ such, then, is the look of the bird. Its nest ${ }^{i}$ is like sea-

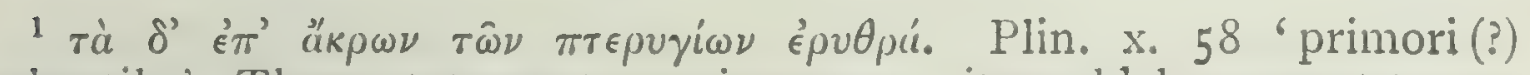
subrutilo.' These statements are incorrect: it would be correct to say

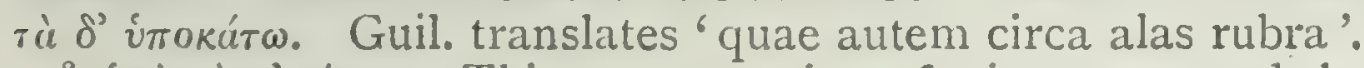

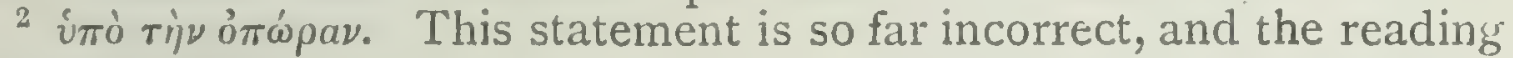

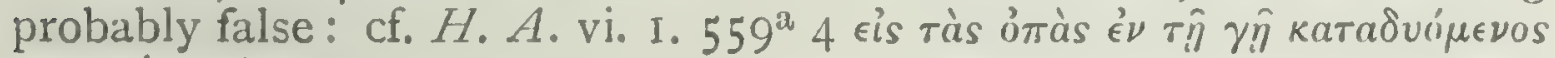

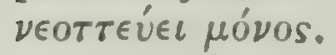

3 Ael. iv. 47. ${ }^{4}$ Plin. x. 50.

5 Herod. iii. I I ; Ael. ii. 34, xvii. 2 I; Antig. Mirab. 49; Plin. x. 50, xii. +2 ; Eust. ad Dionys. Perieget. $939,944,8 \mathrm{c}$. The bird is confused with the phoenix, Ov. Met.xv. 399; Stat. Silv. ii. 6.87, \&c. Bochart

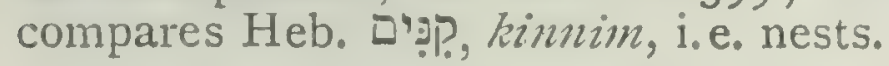

${ }^{6}$ Plin. x. (32) 47 gives what is probably an inaccurate translation: 'I Ipsa avis paulo amplior passere, colore cyaneo ex parte maiore, tantum purpureis et candidis (?) admixtis pennis, collo (?) gracili ac procero'.

$7 \dot{\eta} \delta \dot{\epsilon} \nu \in \tau_{\tau} u^{\prime}$. The nest of the kingfisher is a deep excavation, widening within, in a river-bank, and more or less filled with fishbones, the débris of food. It is impossible to understand why A. does not give a plain account of this nest (as he does of the somewhat

D d 2 
20 balls, i.e. the things that go by the name of halosachne ${ }^{1}$ or sea-foam, only the colour is not the same. The colour of the nest is light red, and the shape is that of the longnecked gourd. The nests are larger than the largest sponge, though they vary in size; they are roofed over, 25 and great part of them is solid and great part hollow. ${ }^{2}$ If you use a sharp knife it is not easy to cut the rest through ; but if you cut it, and at the same time bruise it with your hand, it will soon crumble to pieces, like the halosachne. The opening is small, just enough for a tiny entrance," so that even if the nest upset ${ }^{4}$ the sea does not enter in ; 30 the hollow channels are like those in sponges. It is not known for certain of what material the nest is constructed; it is possibly made of the backbones of the gar-fish; ${ }^{5}$ for, by the way, the bird lives on fish. Besides living on the

similar nest of $\left.\mu \epsilon^{\prime} p o \psi\right)$; nor is it easy to say whether we are dealingr with a connected account of some object totally cifferent, or with a corrupt passage, of which isolated phrases agree fairly well with the true character of the nest. The account in Aelian is similar, but wholly fabulous. That there was some religious mystery associated with the so-called nest is indicated by the conclusion of I'lutarch's

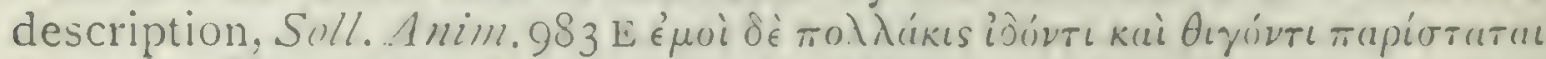

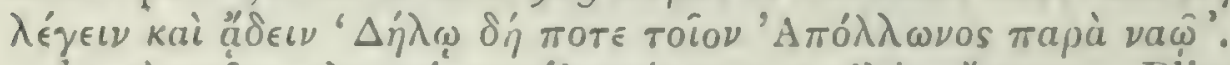

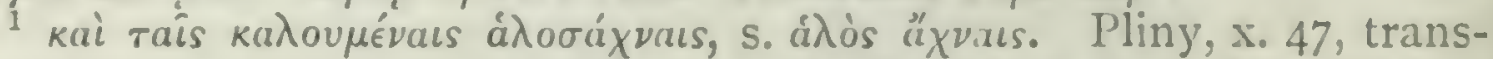
lates literally, 'ut spuma arida maris.' By others it is described as a special marine substance or organism; cf. Diosc. v. I36, Theophr. de Odor. iv. 8, \&c.

2 Gaza transl. 'crebro solido et cavo constant', and Scaliger adds 'Recte; iccirco spongiis assimilavit mox'. Scal. gives 'soliditate et Cavitate crebra constant'; and Schneider 'soliditate et raritate'. Nevertheless, the phrase is difficult, and one is tempted to think io ortprim at fault.

${ }^{3}$ Reading, with Casaubon and A. and W., ö $\sigma o \nu\langle\epsilon i s\rangle \epsilon i \sigma \delta v \sigma \nu$. Dittm.

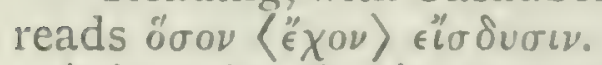

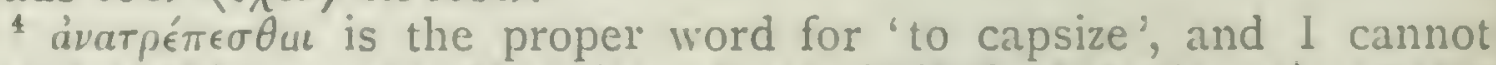
translate this passage othenwise. Ciaza similarly, "ut etiam si vertatur mare influere neyueat.' On the other hand, Scal. 'adeo, ubi subrortatur mare, ut ne tum quidem ingrediatur'; Schn. 'adeo, ubi subvertitur mare', Sc.: A. and W. 'so dass das Meerwasser nicht eindringt, auch wenn es höher steigt'. Whatever A. is actually describing, it is plainly something floating on the sea, and not the real nest of the kingfisher.

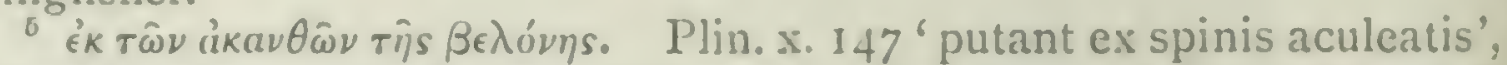
where Gronov. substitutes acularum, as in xxxii. II 'belonae, quos aculas vocamus' (Schn.). If we ask why of all fishes the $\beta \epsilon \lambda$ ov specified, it may be because the backbone of the gar-fish has a peculiar

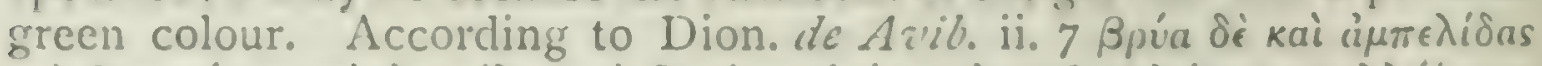

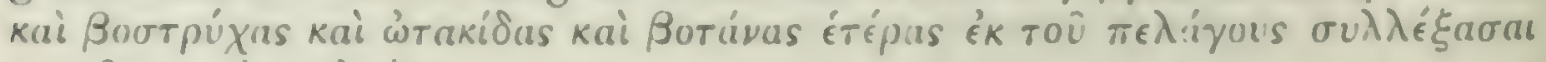

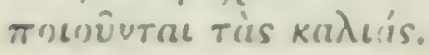


shore, it ascends fresh-ivater streams. It lays generally about five eggs, and lays eggs ${ }^{1}$ all its life long, beginning to do so at the age of four months.

\section{I5 The hoopoe usually constructs its nest out of human} excrement. $^{2}$ It changes its appearance ${ }^{3}$ in summer and $6_{1} 6^{b}$ in winter, as in fact do the great majority of wild birds. (The titmouse is said to lay a very large quantity of eggs: next to the ostrich the blackheaded tit is said by some to lay the largest number of eggs; seventeen eggs have been 5 seen; it lays, however, more than twenty; it is said always to lay an odd number. Like others we have mentioned, it builds in trees; it feeds on caterpillars.) A peculiarity of this bird and of the nightingale is that the outer extremity of the tongue is not sharp-pointed. ${ }^{4}$

The aegithus ${ }^{5}$ finds its food with ease, has many young, ro and walks with a limp. The golden oriole ${ }^{6}$ is apt at learning, is clever at making a living, but is awkward in flight and has an ugly plumage.

The reed-warbler makes its living as easily as any other bird, sits in summer in a shady spot facing the wind, in winter in a sunny and sheltered ${ }^{7}$ place among reeds in a $\mathrm{I}_{5}$ marsh; it is small in size, with a pleasant note. The

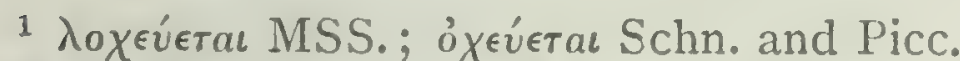

${ }^{2}$ Cf. H. A. vi. I. $559^{\text {a }} 8$; Ael. iii. 26. The nest is not made '́k кóm $\rho$ ov à $\theta \rho \omega \pi i \nu \eta s$, but has a very offensive odour arising from accumulated excrement, as well as from a peculiar secretion of the bird (cf. Arch. f. Naturgeschichte, i, p. II, 1852, \&c.): from this cause, and from the bird's seeking its food amidst dung ('avis obsceno pastu', Plin. $\mathrm{x} .44$ ), the hoopoe receives various characteristic epithets in countries where it abounds, e.g. Coq puant, Kothhahn, Mistvogel, Stinkvogel, \&c.

${ }^{3}$ Aesch. (?) fr. 297, ap. H. A. ix. 49 B. $633^{\text {a }}$ I9.

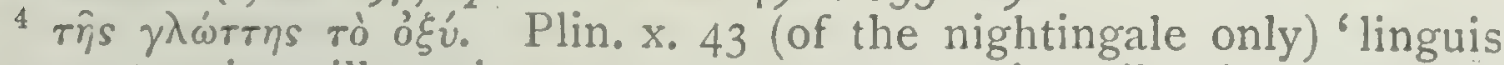
earum tenuitas illa prima non est quae ceteris avibus'. As Schn. points out, the remark here is an interpolation, and applies not to

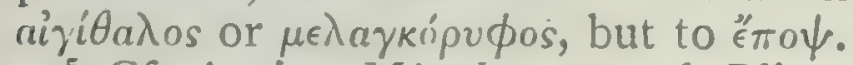

${ }_{5}$ Cf. Antig. Mirab. 2I, and Pliny, x. 9, who speaks of ali a hawk.

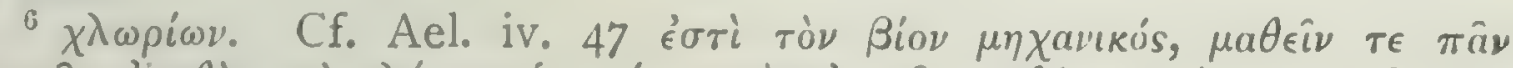

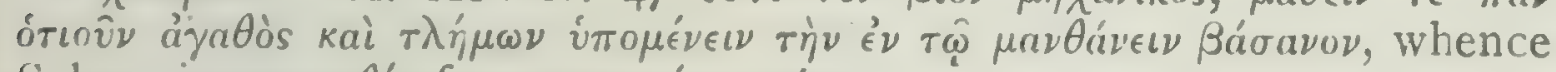
Sichn. сј. какотаӪ́s for каколєті́s, supra.

$7 \epsilon \pi \iota \sigma \kappa \epsilon \pi \epsilon \hat{\imath} \mathrm{Bk}$. Theophr. uses $\epsilon \hat{\imath} \sigma \kappa \epsilon \pi \dot{\eta} s$ in conjunction with $\epsilon \dot{i} \eta \dot{\lambda}$ เos

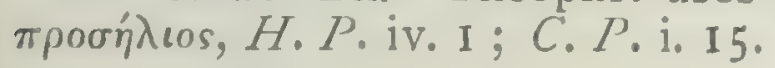


so-called chatterer has a pleasant note, beautiful plumage, makes a living cleverly, and is graceful in form; it appears to be alien to our country; at all events it is scldom seen at a distance from its own immediate home.

20 The crake ${ }^{1}$ is quarrelsome, clever at making a living, but ${ }^{7} 7$ in other ways an unlucky bird.2 The bird called sitta is quarrelsome, but clever and tidy, makes its living with case, and for its knowingness is regarded as uncanny: it has a numerous brood, of which it is fond, and lives by 2.5 pecking the bark of trecs. The aegolius-owl flics by night, is seldom seen by day; like others we lave mentioned, it lives on cliffs or in caverns; it feeds on two kinds of food; ${ }^{3}$ it has a strong hold on life and is full of resource. The tree-crecper is a little bird, of fearless disposition; it lives among trees, feeds on catcrpillars, makes a living with 30 case, and has a loud clear note. The acanthis finds its food with difficulty; its plumage is poor, but its note is musical.

Of the herons, the ashen-coloured one, as has been said, I8 unites with the female not without pain; ${ }^{4}$ it is full of resource, carries its food with it, is eager in the quest of it, and works by day; its plumage is poor, and its excrement $617^{\mathrm{a}}$ is always wet. Of the other two species-for there are three in all-the white heron has handsome plumage, unites

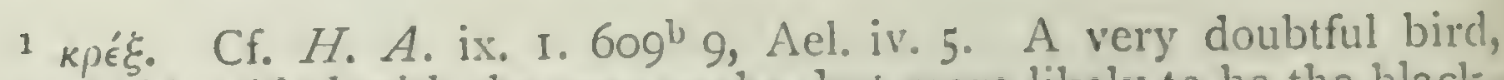
usually identified with the corn-crake, but more likely to be the blackwinged stilt, Ilimantopus rufipies, from its size, which is like that of the ibis (Herod. ii. 76$)$, and its rudimentary hind-toe $(P . A$. iv. I2. $\left.695^{\mathrm{a}} 21\right)$.

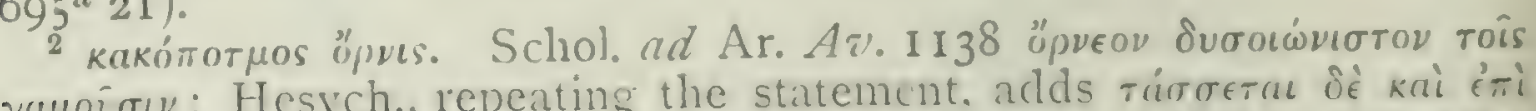

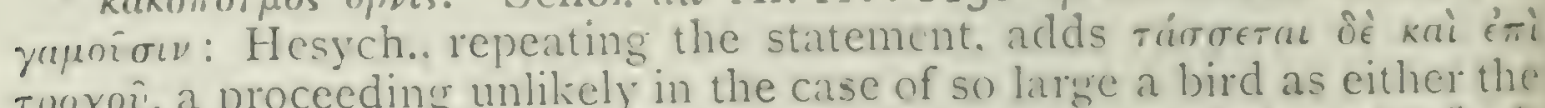
tproxor, a proceeding unlikely in the case of so large a bird as either the corn-cralic or the stilt, and apparently indicating a confusion with "u $z$. C.f. also I.ycophron 513. Where Helen is ôveriprayus kp'

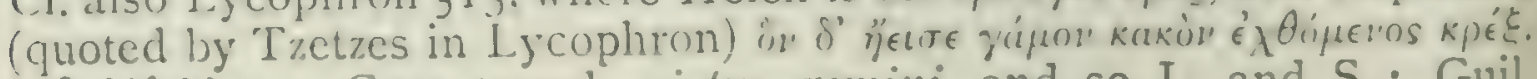

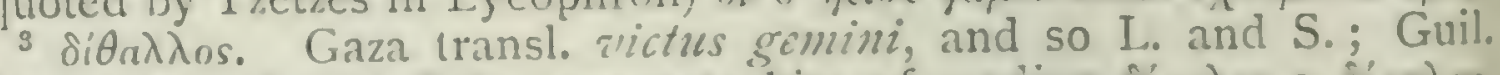
diz'mialu, whence Schn. suspects him of reading Cipados s. Fixplos.

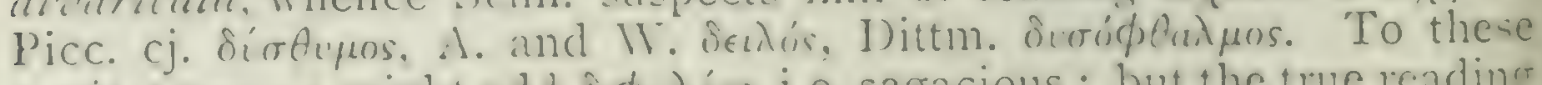

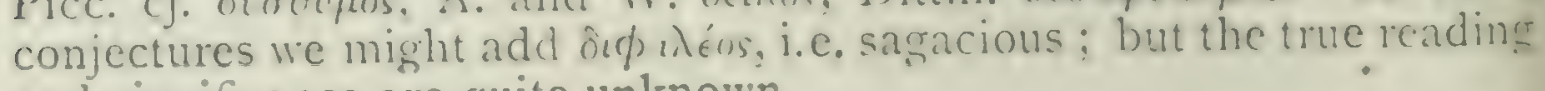
and significance are quite unknown.

${ }^{4}$ H. A. ix. 2. $609^{11} 21$; Callim. in Schol. Venet. 11. x. 274; cf. Schn. ii. p. $16 ; 0$. Schneider in Callim. ii. p. 296.

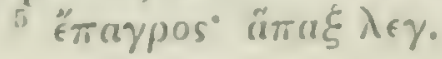


without harm to itself ${ }^{1}$ with the female, builds a nest and lays its eggs neatly ${ }^{2}$ in trees; it frequents marshes and lakes and plains and meadow land. The speckled heron, 5 which is nicknamed 'the skulker', is said in folklore storics to be of servile origin, and, as its nickname implies, it is the laziest bird of the three species. ${ }^{3}$ Such are the habits of herons. The bird that is called the poynx ${ }^{4}$ has this peculiarity, that it is more prone than any other bird to peck at the eyes of an assailant or its prey; it is at war so with the harpy; as the two birds live on the same food.

I9 There are two kinds of owsels; the one is black, and is found everywhere, the other is quite white, about the same size as the other, and with the same pipe. This latter is found on Cyllene in Arcadia, and is found nowhere else. The laius, ${ }^{,}$or blue-thrush, is like the black owsel, in only a little smaller; it lives on cliffs or on tile roofings; it has not a red beak as the black owsel has.

Of thrushes there are three spccies. ${ }^{7}$ One is the missclthrush; it feeds only on mistletoe and resin; it is about

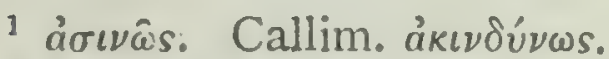

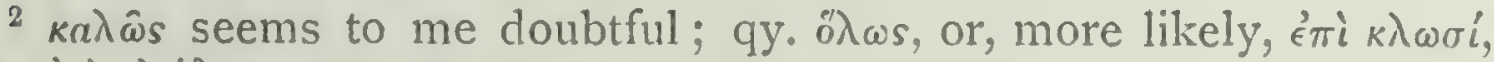

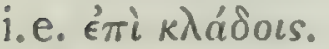

3 On the species of heron cf. Dion. de Avib. ii. 8. In Aristotle the

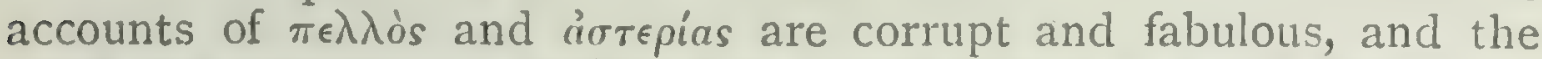
same two names occur conjoined as proper names in Apoll. Rh. i. I; 6 . The usual identification with the common heron and the bittern has a very slender basis in the supposed colour-significance of the names.

${ }^{4} \phi \hat{\omega} \ddot{v} \xi$. The glosses of Hesych., Suid. and Et. M. are unsatisfactory. The word is quite as likely to be a foreign word for heron as it is to be a more specific designation.

${ }^{5}$ Cf.Anton.Lib. 5; Ael.ii.47; Plin.x.45; Pausan.viii.I7.3; Sostrat.ap. Ael.v. 27; Ps.-Arist. de Mivab. I5.831 ${ }^{\mathrm{b}}$ I 4 , \&c. The story of the white blackbirds on Cyllene is widespread. Some authors state that all the blackbirds on Cyllene are white, and some that the white are not found elsewhere. Lindermeyer (Vögel (riechenlands, I 860, p. 86), mentioning a white blackbird shot near Athens, repeats the statement of their common occurrence on Cyllene. While white blackbirds occur occasionally everywhere, the permanent existence of a white race in a particular locality would be a remarkable and unparalleled occurrence. I am inclined to discredit the whole story, and to suspect an old blunder, dialectic misunderstanding, or play of words on the $\lambda$ evkis knpuфás of the mountain.

' $\lambda$ aıós. Guil. 'harum nigrae merulae est fuscus laios': 'is igitur iuxta nomen laii vocabulum фatós pro ßatós scriptum legit', Schn. Gaza appears to have read pacós or Broós alone 'est etiam ex hoc genere, quae similis nigrae sit, sed fusca colore'.

7 Arist. ap. Athen. ii. p. 65. 
20 the size of the jay. A second lind is the song-thrush; it has a sharp pipe, and is about the size of the owsel. There is another species called the Illas; ${ }^{1}$ it is the smallest species of the three, and is less variegated in plumage than the others.

There is a bird that lives on rocks, called the blue-bird 2I from its colour." It is comparatively common in Nisyros," 25 and is somewhat less than the owsel and a little bigger than the chaffinch. It has large claws, ${ }^{4}$ and climbs on the face of the rocks. It is steel-blue all over; its beak is long and slender; its legs are short, like those of the woodpecker.

The oriole" is yellow all over; it is not visible during 22 winter, but puts in an appearance about the time of the 30 summer solstice, and departs again at the rising of Arcturus: it is the size of the turtle-dove. The so-called soft-head (or shrike) always settles on one and the same branch, $617^{\mathrm{b}}$ where it falls a prey to the bird-catcher. Its head is big: and compoed of gristle; it is a little smaller than the thrush; its beak is strong, small, and round; it is ashencoloured all over; is flect of foot, but slow of wing. The " bird-catcher usually catches it by help of the ow.."

There is also the pardalus. As a rule, it is seen in flocks 23 and not singly; it is ashen-coloured all orer, and about the size of the birds last described; it is flect of foot and strong of wing. and its pipe is loud and high-pitched. The collyrion ro (or ficldfare) feeds on the same food as the owsel; is of the same size as the abore-mentioned birds; and is trapped usually in the winter. All these birds are found at all

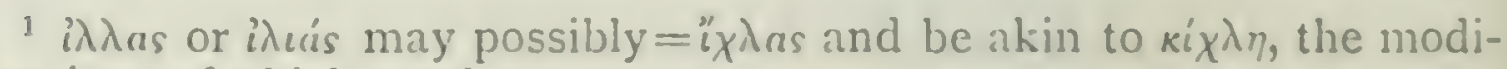
fications of which word are many.

2 The description of this little bird is unusually detailed. Save for kutuis ödos, which describes inadequately its brilliant colouring, the description agrees with the scarce and local wall-creeper, Tichodroma muraria. So Sundevall; but other commentators say the Blue-thrush, cf. Aruós.

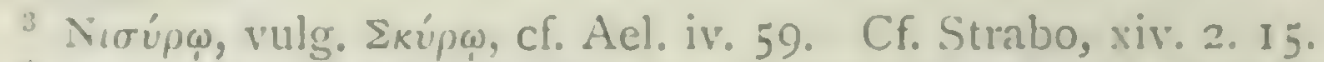

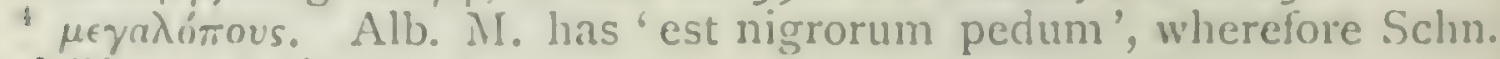
and Picc. substitute $\mu$ cinvórov's.
Plin. x. 45; Acl. ir. $4 \%$.
H. A. ix. $1.609^{2} 15$. 
times. ${ }^{1}$ Further, there arc the birds that live as a rule in towns, the raven and the crow. These also are visible at all seasons, never shift their place of abode, and never go into winter quarters.

24 Of daws there are three species. One is the chough; it is as large as the crow, but has a red beak. There is another, called the 'wolf' ${ }^{2}$ and further there is the little daw, called the 'railer'. There is another kind of daw found in Lydia and Phrygia, which is web-footed. ${ }^{3}$

25 Of larks there are two kinds. One lives on the ground 20 and has a crest on its head; ${ }^{t}$ the other is gregarious, and not sporadic like the first; it is, however, of the same coloured plumage, but is smaller, and has no crest; it is an article of human food.

26 The woodcock is caught with nets in gardens. It is about the size of a barn-door hen; it has a long beak, and 25 in plumage is like the francolin-partridge. It runs quickly, and is pretty easily domesticated. The starling is speckled; it is of the same size as the owsel.

27 Of the Egyptian ibis there are two kinds, the white and the black.5 The white ones are found all over Egypt, excepting in Pelusium; the black ones are found in 30 Pelusium, and nowhere else in Egypt.

28 Of the little horned owls ${ }^{6}$ there are two kinds, and one is

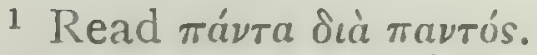

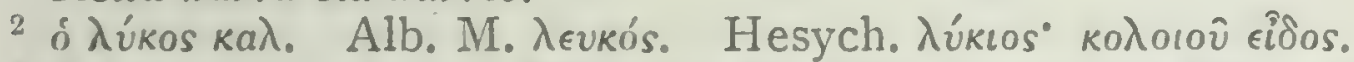

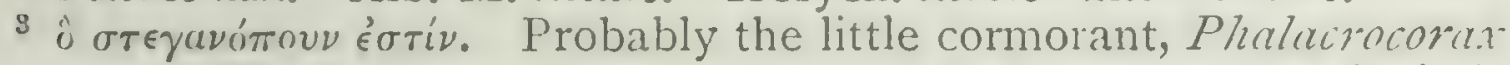
pygmacus. The large or common cormorant, I tal. corvo marino, is simi-

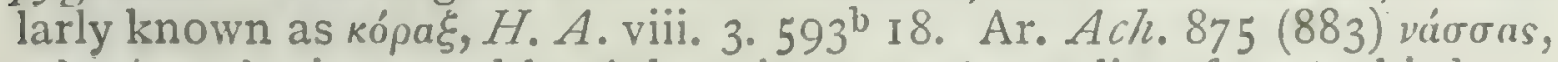

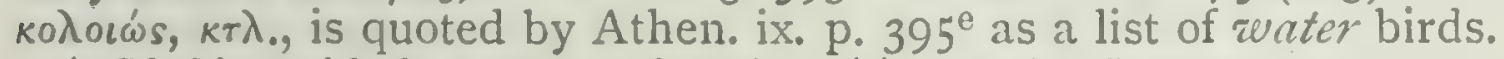

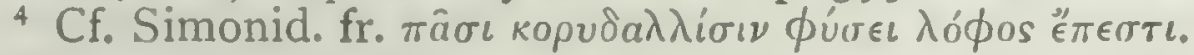

Herod. ii. 75 ; Plin. x. 40, 45 ; Strabo, xvii. 2. 4 ; Eust. ad Dionys. Perieg. 262; Ael. ii. 38. The white ibis (first recognized by Bruce) is Ibis religiosa, Cuv.; the black or glossy ibis is I. falcineilus, Temm. Cf. Cuv. Ann. du Muséum, iv. p. Ioz.

F. C. H.A.viii. 3.592 I 3. The description of Alexander Myndius (af. Athen. ix. 39I) is diagnostic of the little horned owl, liflialtes scops, L., and is an example of that writer's superiority in description to the present context; it is quoted by Ael. xv. 28, without ascription to Alexander. While Athene noctua ( $\gamma \lambda \alpha v \xi)$ is permanently resident in Greece, Ephirltes sceps is a migrant ; it breeds in Greece, but not abundantly, 
visible at all scasons, and for that reason has the nickname of 'all-the-ycar-round owl'; it is not sufficiently palatable $618^{a}$ to come to table; another species makes its appearance sometimes in the autumn, is scen for a single day or at the most for two days, and is regarded as a table delicacy: it scarcely differs from the first species save only in being 5 fatter; it has no note, but the other specics has. With regard to their origin, nothing is known from ocular obscrvation; the only fact known for certain is that they are first seen when a west wind is blowing.

The cuckon, ${ }^{1}$ as has been said elsewhere, makes no nest, 29 but deposits its eggs in an alien nest, generally in the ro nest of the ring-clove, or on the ground in the nest of the hypolais ${ }^{2}$ or lark, or on a tree in the nest of the green

and those pass through Greece that breed in Hungary and Gemany (Kriper, p. 18I). The Aristotelian account is not very clear: the birds of passage differ from the residents in more than their fatness. viz. in being mute instead of rocal; this (in spite of a lack of reference to the risible clistinction of the ear-tufts) would lead one to suppose

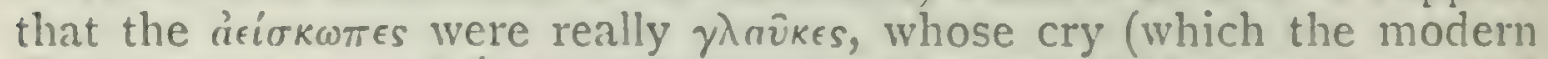
(ireek name koukou/ßum resembles) is persistent and characteristic, and I am not sure but what this is actually asserted by Callimachus ( $a p$. Athen. I.. ), from whom the Aristotelian passage is borrowed: K. Cé prier

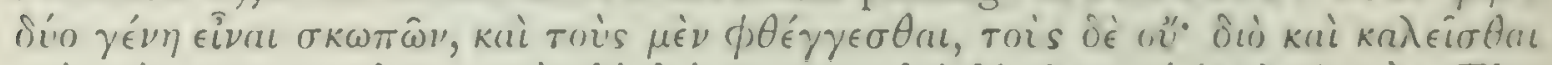

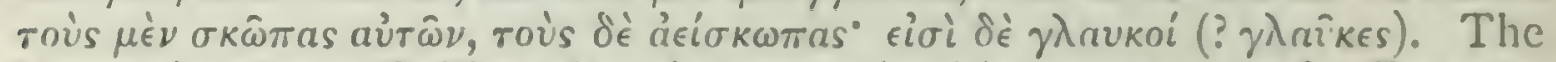
borrowing from Callimachus is patent in this passage, and affects, in all probability, much of the adjacent text.

${ }^{1} H . A \cdot$ vi. $7 \cdot 563^{\text {b }}$ I4.

$2 \epsilon^{\prime} \nu$ imodatios. This bird is frequently quoted as one of those in whose nest the cuckoo lays her egg, but in no other connexion whatsoever: cf. H. A. vi. $7.564^{a} 2$, Antig. Mirab. Ico (Iog), Theophr. C. $P$. ii. 17.9 . In a corresponding passage in Ael. iii. 30 , its place is taken by $\pi$ iimmos. The meaning of both alike is quite unknown. Sundevall's conjecture of the wheatear, which makes its nest under a stone, has no more grounds than the apparent connexion with $\lambda$ âas, which is more than doubtful. That the cuckoo lays in the nest of drit: or firtre (or $\pi$ cimmos), as stated in all the above passages (cf. also Ps.Arist. de Mirab.3. 830' I I, Plin. x. I I), is inexplicable. We may grope for a solution by supposing a confusion between $(i)$ motuis and rederis: or that the statement is of foreign origin and referred originally to some Oriental species; or that it is connected with eastern myths, such as are still current in China, where the dove and cuckoo are often confused, and the former is said to metamorphose into the hawk and to lay in the magpie's nest (cf. T. Watters, Clinese Notions about Pigeons and Dories, Tr. N. China Br., R. Asiat. Soc., iv. pp. 225-42. $1867)$. The orphean warbler is the bird in whose nest the cuclioo in Greece oftenest lays her egg, and this or an allied species is the Lat. curmou (cf. Juv. Sut. vi. 275 and Schol.). 
linnet. It lays only one egg ${ }^{1}$ and does not hatch it itself, but the mother-bird in whose nest it has deposited it hatches and rears it; and, as they say, this mother bird, when the young cuckoo has grown big, thrusts her own brood out of the nest and lets them perish; others say that this I5 mother-bird kills her own brood and gives them to the alien to devour, despising her own young owing to the beauty of the cuckoo.? Personal observers agree in telling most of these stories, but are not in agreement as to the destruction of the young. Some say that the mother-2o cuckoo comes and devours the brood of the rearing mothcr; others say that the young cuckoo from its superior size snaps up the food brought before the smaller brood have a chance, and that in conscquence the smaller brood clic of hunger; others say that, by its superior strength, it actually kills the other ones whilst it is being reared up with them. The cuckoo shows great sagacity in the dis- 25 posal of its progeny; the fact is, the mother-cuckoo is quite conscious of her own cowardice and of the fact that she could never help her young one in an emergency, and so, for the security of the young onc, she makes of him a supposititious child in an alien nest. The truth is, this bird is pre-eminent among birds in the way of cowardice; it allows itself to be pecked at by little birds, and flics away from their attacks.

30 It has already been stated that the footless bird, which some term the cypselus, ${ }^{3}$ resembles the swallow; indecd, it is not easy to distinguish between the two birds, excepting in the fact that the cypselus has feathers on the shank. These birds rear their young in long ${ }^{4}$ cells made of mud, and furnished with a hole just big enough for entry and

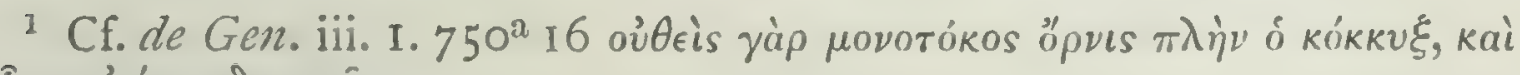

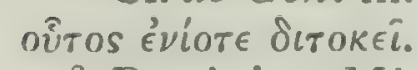

2 Ps.-Arist. Mirab. 3. $830^{\mathrm{b}}$ I I ; Plin. x. II.

${ }^{3}$ Cf. H.A. i. I. $487^{\mathrm{b}} 25$. The Aristotelian account, while inadequate for precise identification, inclines us rather to think of the sand-martin, which identification Sundevall adopts. Pliny, x. 55, on the other hand, describing the lengthy and continuous flight of the bircl, appears to be describing the swift, with which species his statement niaifirant in scopulis also agrees.

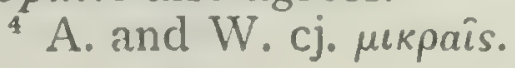


exit; they build under cover of some roofing-under a rock or in a carcrn - for protection against animals and mon.

The so-called goat-sucker lives on mountains; it is a little larger than the owsel, and less than the cuckoo; it lays two eggs, or three at the most, and is of a sluggish 5 disposition. It flies up to the she-goat and sucks its milk, from which habit it derives its name; it is said that, after it has sucked the teat of the animal, the teat drics up and the animal goes blind. ${ }^{1}$ It is clim-sighted in the day-time, but sees well enough by night.

In narrow circumscribed districts where the food would 31 ro be insufficient for more birds than two, ravens are only found in isolated pairs ; ${ }^{2}$ when their young are old enough to fly, the parent couple first eject them from the nest, and by and by chase them from the neighbourhood. The raven lays four or five eggs. About the time when the mercenarics under Medius" were slaughtered at Pharsalus. Is the districts about Athens and the Peloponnese were left destitute of ravens, from which it would appear that these bircls have some means of intercommunicating with one another: 4

Of eagles there are several species. ${ }^{5}$ One of them, called 32 'the white-tailed "i eagle', is found on low lands, in groves. 20 and in the neighbourhood of cities; some call it the 'heron-

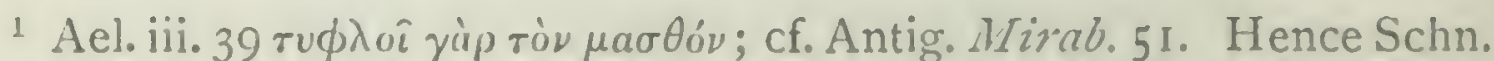

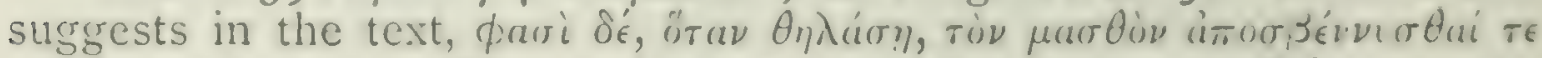

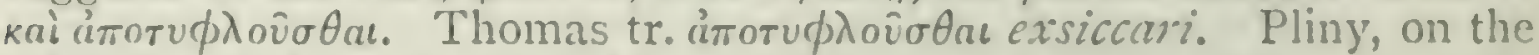
other hand, 'qua iniuria uber emoritur, caprisque caecitas, quas ita mulsere, oboritur,' an interpretation undoubtedly erroneous.

2 Ael. ii. 50; Plin. x. 15: Antig. Car. xi, \&c.

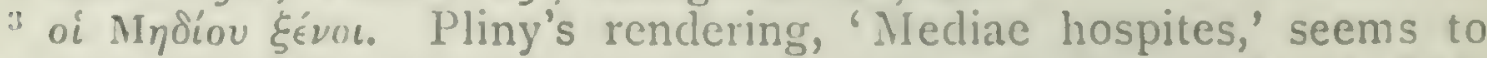
show a complete misconception; cf. Schn., in loc., and ad Xen. Hellen. ii. 3. 4, p. 87; also I)iod. xiv. 82.

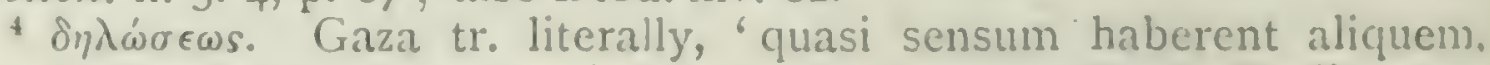
quo inter se rerum eventa significarent et moverentur.' Scaliger, on the other hand, "fuasi sensu guodam pereiperent rerum vicissitudines,

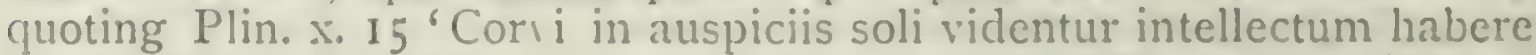
siguificationum suarum'. Scotus has 'quasi intelligerent nutibus et signis, et hoc fuerit signum desolationis illius loci'; and Alb. M. similarly; these two writers apparently, therefore, read sinjijows.

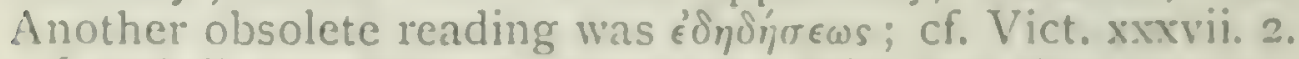

Acl. ii. 39; Plut. Amat.750 F; Plin. x. 3, dic.

- C. Aesch. Ag. 115. 
killer'. It is bold enough to fly to mountains and the interior of forests. The other eagles seldom visit groves or low-lying lands. There is another species called the 'plangus'; it ranks second in point of size and strength ; it lives in mountain combes and glens, and by marshy lakes, and goes by the name of 'duck-killer' and 'swart- 25 eagle'. It is mentioned by Homer ${ }^{2}$ in his account of the visit made by Priam to the tent of Achilles. There is another species with black plumage, the smallest but boldest of all the kinds. It dwells on mountains or in forests, and is called 'the black-cagle' or 'the hare-killer'; it is the only eagle that rears its young thoroughly and takes them out with it. It is swift of flight, is neat and tidy 30 in its habits, too proud for jealousy, fearless, quarrelsome; it is also silent, for it neither whimpers nor screams. There is another species, the percnopterus, very large, with white head, very short wings, long tail-feathers, in appearance like a vulture. It goes by the name of 'mountain-stork' or 'half-eagle'." It lives in groves; has all the bad qualities of the other species, and none of the good ones; for it lets itself be chased and caught by the raven and the other $619^{\text {a }}$ birds. It is clumsy in its movements, has difficulty in procuring its food, preys on dead animals, is always hungry, and at all times whining and screaming. There is another species, called the 'sea-eagle' or 'osprey'. This bird has a large thick neck, curved wings, and broad tail- 5 feathers; it lives near the sea, grasps its prey with its talons, and often, from inability to carry it, tumbles down into the water. There is another species called the 'truebred'; ${ }^{4}$ people say that these are the only true-bred birds to be found, that all other birds-eagles, hawks, and the smallest birds-are all spoilt by the interbreeding of ro different species. The true-bred eagle is the largest of all eagles; it is larger than the phene; is half as large again

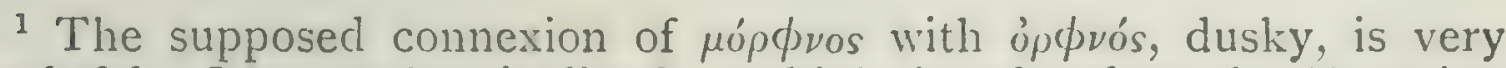
doubtful. I am rather inclined to think it related to the Eyyptian mer, a vulture; vide Brugsch, ii. $72 \mathrm{I}$.

2 Il. xxiv. 316 ; cf. Hes. Scut. I34.

3 Anton. Lib. xx.

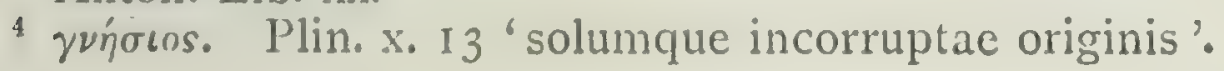


as the ordinary eagle, and has yellow plumage; ${ }^{1}$ it is seldom seen, as is the case with the so-called cymindis. The time for an cagle to be on the wing in search of prey 15 is from midday to evening; in the morning until the marliet-hour ${ }^{2}$ it remains on the nest. In old age the upper beak of the eagle grows gradually longer and more crooked, and the bird dies eventually of starvation; ${ }^{3}$ there is a folklore story that the eagle is thus punished because it once 20 was a man and refused entertainment to a stranger. The eagle puts aside its superfluous food for its young; for owing to the difficulty in procuring food day by day, it at times may come back to the nest with nothing. If it catch a man prowling about ${ }^{4}$ in the neighbourhood of its nest, it will strike him with its wings and scratch him with its talons." $\because$ The nest is built not on low ground but on an elevated spot, generally on an inaccessible ledge of a cliff; it does, however, build upon a tree. The young are fed until they can fly; hereupon the parent-birds topple them out of the nest, and chase them completely out of the locality. The fact is that a pair of eagles demands an extensive space for its 30 maintenance, and consequently cannot allow other birds to quarter themselves in close neighbourhood." They do not hunt in the vicinity of their nest, but go to a great distance to find their prey. When the cagle has captured a beast, it puts it down ' without attempting to carry it off at once; if on trial it finds the burden too heary, it will leave it. When it has spied a hare, it does not swoop on $6 \mathrm{rg}^{\mathrm{b}}$ it at once, but lets it go on into the open ground; neither does it descend to the ground at one swoop, but goes gradually down from higher flights to lower and lower:

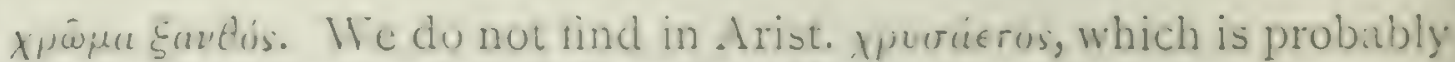
merely the 'golden hawk' of Ėgytian Horus.

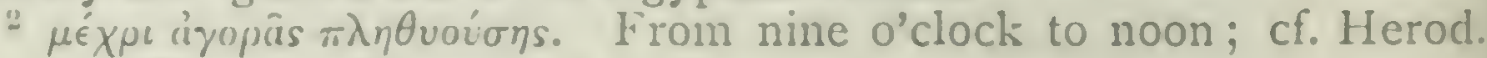
ii. I81, Theophr. Char. xiii (xi), \&c.

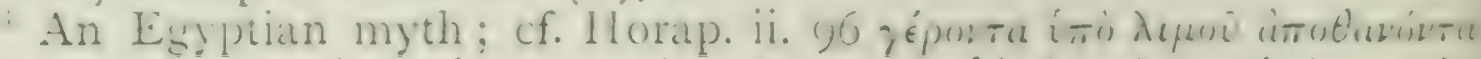

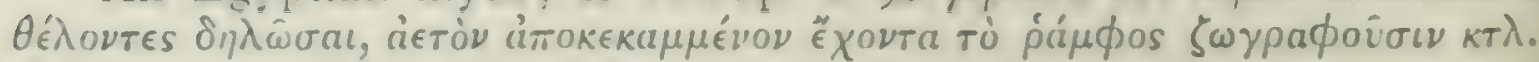
Cf. also Antig. Wivab. 52, Sc.

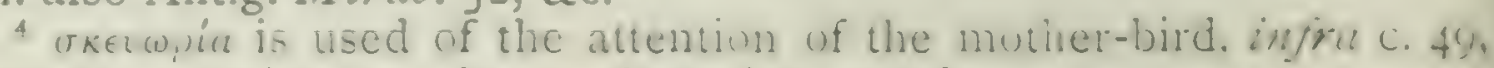
and the meaning here is not altogether certain.

5 Acl. ii. 40.

i Plin. x. 4; Ael. ii. 39.

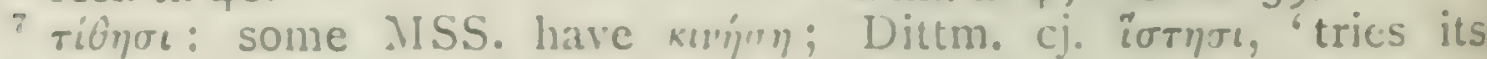
wcight.' 
these devices it adopts by way of security against the stratagem of the hunter. It alights on high places by reason of the difficulty it experiences in soaring up from 5 the level ground; it flies high in the air to have the more extensive view; from its high flight it is said to be the only bird that resembles the gods. ${ }^{1}$ Birds of prey, as a rule, seldom alight upon rock, as the crookedness of their talons prevents a stable footing on hard stone. The eagle huints hares, fawns, foxes, and in general all such animals 10 as he can master with ease. It is a long-lived bird, and this fact might be inferred from the length of time during which the same nest is maintained in its place.

33 In Scythia " there is tound a bird as large as the great bustard. The female lays two eggs, but does not hatch them, but hides them in the skin of a hare or fox and 15 leaves them there, and, when it is not in quest of prey, it keeps a watch on them on a high tree; if any man tries to climb the tree, it fights and strikes him with its wing, just as eagles do.

The owl and the night-raven and all the birds that see poorly in the daytime seek their prey in the night, but not 20 all the night through, but at evening and dawn." Their food consists of mice, lizards, chafers and the like little creatures. The so-called phene, or lämmergeier, is fond of its young, provides its food with ease, fetches food to its nest, ${ }^{4}$ and is of a kindly disposition. It rears its own young and those of the eagle as well; for when the eagle ejects its young 25 from the nest, this bird catches them up as they fall and feeds them. For the eagle, by the way, ejects the young birds prematurely; before they are able to feed themselves,"

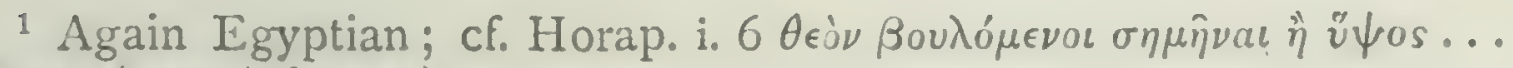

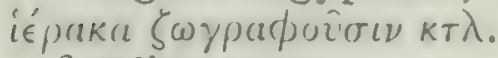

2 Plin. x. 50.

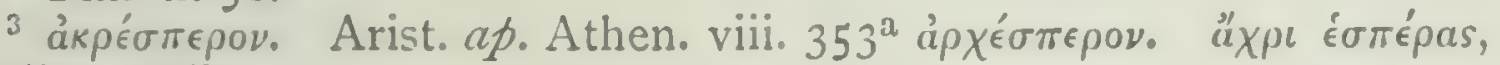
Aldine, Sylb.

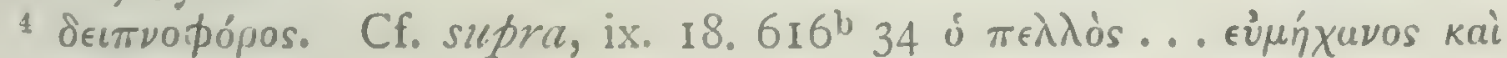
$\delta \epsilon \iota \pi \nu$ фópos.

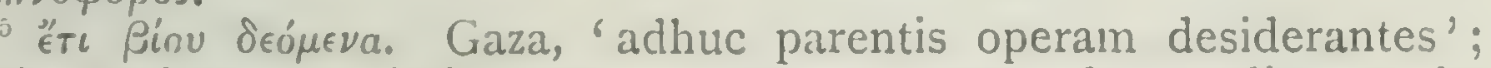
Guil. 'adhuc cura indigentes'. Schn. supposes the reading to be corrupt. 
or to fly. It appear's to do so from jealousy; for it is by nature jealous, and is so ravenous as to grab furiously at its 30 food: and when it does grab at its food, it grabs it in large morscls. It is accordingly jealous of the young birds as they approach maturity, since they are getting good appetites, and so it scratches them with its talons. The young birds fight also with one another, to secure a morsel of food or a comfortable position, whereupon the mother-bird beats them and ejects them from the nest; the young ones scream at this treatment, and the phene hearing them catches them $620^{\text {a }}$ as they fall. The phene has a film over its eyes and sees badly, but the sea-eagle is very keen-sighted, and before its young are fledged tries to make them stare at the sun, ${ }^{\prime}$ and beats the one that refuses to do so, and twists him back in the sun's direction; and if one of them gets watery cyes in 5 the process, it kills him, and rears the other. It lives near the sea, and feeds, as has been said, on sea-birds; ${ }^{2}$ when in pursuit of them it catches them one by one, watching the moment when the bird rises to the surface from its dive. When a sca-bird, emerging from the water, sees the seacagle, he in terror dives under, intending to rise again clsc10 where; the eagle. however, owing to its kecnness of vision, keeps flying after him until he either drowns the bird or catches him on the surface. The eagle never attaclis these birds when they are in a swarm, for they keep him off by raising a shower of water-drops with their wings.

The cepphus is caught by means of sea-foam;" the bird 35 snaps at the foam, and consequently fishermen catch it by sluicing with showers of sca-water. These birds grow to 15 be plump and fat; their flesh has a good odour, excepting the hinder quarters, which smell of shore-weed.

()f hawks, the strongest is the buzzard; the next in 36 point of courage is the merlin; and the circus ranks

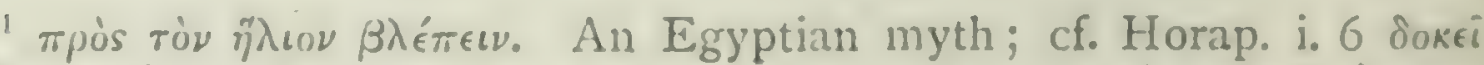

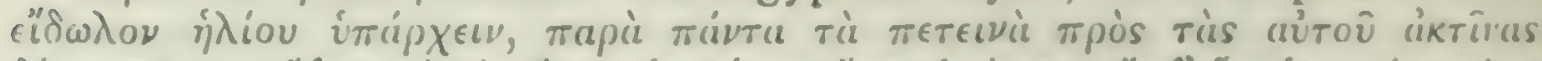
i.

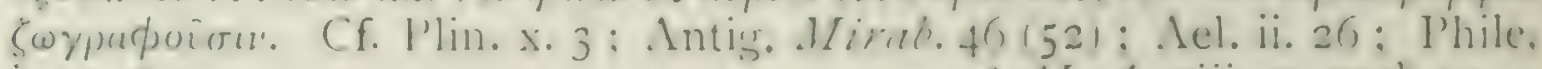
i. 14 , ilc.

Vicand. Alix: 165. Cf. T2. ent Lyc. 76. 
third; other diverse kinds are the asterias, the pigeonhawk, and the pternis ; the broader-winged ${ }^{1}$ hawk is called the half-buzzard; other's go by the name of hobby-hawk, 20 or sparrow-hawk, or 'smooth-feathered ', ' or 'toad-catcher'. Birds of this latter species find their food with very little difficulty, and flutter along the ground. Some say that there are ten species ${ }^{3}$ of hawks, all differing from one another. One hawk, they say, will strike and grab the pigeon as it rests on the ground, but never touch it while it 25 is in flight; another hawk attacks the pigeon when it is perched upon a tree or any elevation, but never touches it when it is on the ground or on the wing; other hawks attack their prey only when it is on the wing. They say that pigeons can distinguish the various species: so that, when a hawk is an assailant, if it be one that attacks its $3^{\circ}$ prey when the prey is on the wing, the pigeon will sit still; if it be one that attacks sitting prey, the pigeon will rise up and fly away.

In Thrace, in the district sometimes called that of Cedripolis, men hunt for little birds in the marshes with the aid of hawks. ${ }^{4}$ The men with sticks in their hands go beating at the reeds and brushwood to frighten the birds out, and the $620^{\mathrm{b}}$ hawks show themselves overhead and frighten them down. The men then strike them with their sticks and capture them. They give a portion of their booty to the hawks; that is, they throw some of the birds up in the air, and the hawks catch them.

In the neighbourhood of Lake Maeotis, it is said, wolves act in concert with the fishermen, and if the fishermen decline to share with them, they tear their nets in pieces as they lie drying on the shore of the lake.

$1 \pi \lambda a \tau \dot{\tau} \epsilon \rho o \iota$. Schn. cj. $\pi \lambda a \tau u ́ \pi \tau \epsilon \rho \circ$, cf. Guil. 'latarum autem alarum accipitres'.

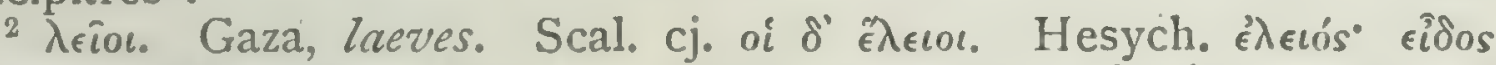
iépakos. Cf. cpileus, Plin.x. 9. Not improbably a foreign word, and here meaningless.

"Plin. x. 3 'accipitrum genera sedecim invenimus', where, according to Schn., Pintian corrects 'sunt decem, non minus': cf. Callim. fr.

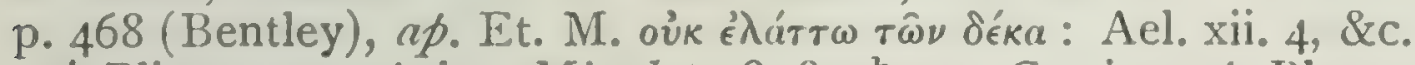

* Plin. x. Io; Arist. Mirab. I I8. $84 \mathrm{I}^{\mathrm{b}}$ I 5 ; Ctesias $a \not$. Phot. et Ael. iv. 26 ; Ael. ii. 42 ; Antig. Mirab. 28 (34).

$A R, H, A$.

$\mathrm{E}$ e 
So much for the habits of birds.

ro In marine creatures, also, one may observe many ingenious devices adapted to the circumstances of their lives. For the accounts commonly given of the so-called fishingfrog are quite true; as are also those given of the torpedo. The fishing-frog has a set of filaments that project in front of its eyes; ${ }^{2}$ they are long and thin like hairs, and are round I5 at the tips; they lie on either side, and are used as baits. Accordingly, when the animal stirs up a place full of sand and mud and conceals itself therein, it raises the filaments, and, when the little fish strike against them, it draws them in underneath into its mouth. The torpedo ${ }^{3}$ narcotizes the creatures that it wants to catch, overpowering them by the 20 power of shock ${ }^{4}$ that is resident in its body, and feeds upon them; it also hides in the sand and mud, and catches all the creatures that swim in its way and come under its narcotizing influence. This phenomenon has been actually observed in operation. The sting-ray also conceals itself, but not exactly in the same way.5 That the creatures get 25 their living by this means is obvious from the fact that, whereas they are peculiarly inactive, they are often caught

1 Ael. ix. 24; Antig. Mirab. lii; Cic. N.D.ii. 49; Plut. Soll. Anim. 978 B; Opp. Hal. ii. 86.

${ }^{2} \pi \rho \dot{\tau} \tau \hat{\omega} \nu$ ú $\phi \theta a \lambda \mu \hat{\omega} \nu$. More accurately in Aelian's description (ix. 24).

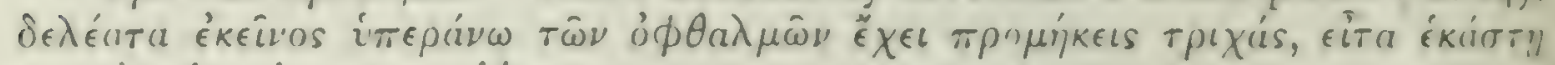

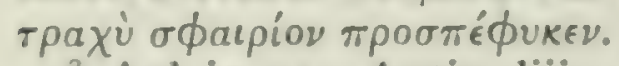

${ }^{3}$ Ael. ix. I4; Antig. liii ; Plin. ix. 67; Plut. Soll. Anim. 97 S B; Opp. Hal. ii. 62; Claudian, Id. iii. Cf. v. Olbers, Die Gattung Torpedo in ihr. naturh. u. antiq. bezichungen erliutert, Berlin, I 31 ; Lorenzini, Oss. int. alle Torpedini, Firenze, 1678. Sec. The torpedo's shock was first shown to be electrical by Walsh, Phil. Trans. I774.

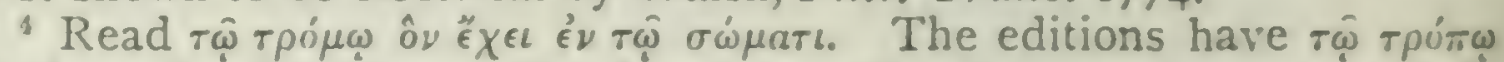

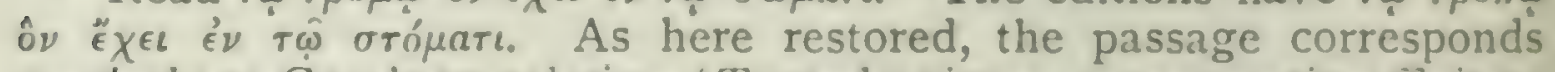
preclsely to Gaza's translation, "Torpedo pisces, quos appetit, afficit ea ipsa quam suo in corpore continet dicultate torpendi.' Piccolos had

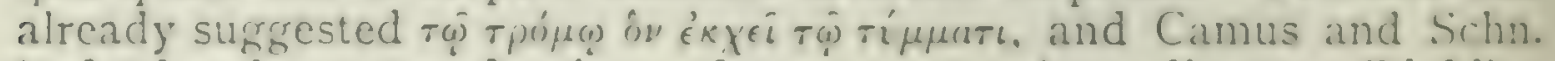
had already restored $\sigma \dot{\omega} \mu a \tau \iota$ for $\sigma \tau \cos _{\mu} \mathrm{r} \iota$. According to Diphilus

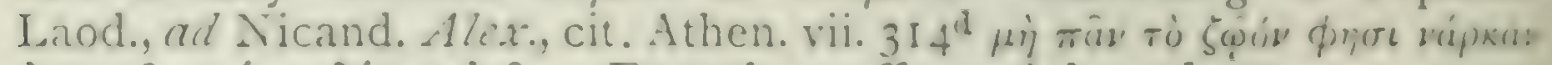

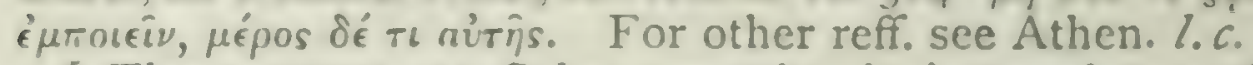

6 The account, as Schn. remarks, is incomplete: cf. Plin. ix. 67 'Nam pastinaca lairocinatur ex ncculto, transeuntes radio, quod telum est ei, figens. Argumenta solertiae huius. quod tardissimi piscium hi mugilem velocissimum omnium habentes in ventre reperiuntur.' The

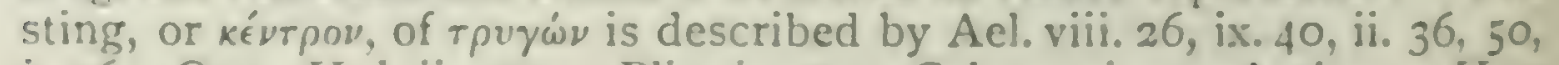
i. 56; Opp. Hal. ii. 470 ; Plin. ix. 72 ; Celsus, vi. 9; Ambros. Hex. ix. 48 . 
with mullets in their interior, the swiftest of fishes. Furthermore, the fishing-frog is unusually thin when he is caught after losing the tips of his filaments, and the torpedo is known to cause a numbness even in human beings. Again, the hake, the ray, the flat-fish, and the $3^{\circ}$ angel-fish burrow in the sand, and after concealing themselves angle with the filaments on their mouths, ${ }^{1}$ that fishermen call their fishing-rods, and the little creatures on which they feed swim up to the filaments taking them for bits of sea-weed, such as they feed upon.

Wherever an anthias-fish is seen, there will be no dangerous creatures in the vicinity, and sponge-divers will dive in security, and they call these signal-fishes 'holy-fish' ${ }^{2}$ It is 35 a sort of perpetual coincidence, like the fact that wherever snails are present you may be sure there is neither pig nor $62 \mathrm{I}^{\mathrm{a}}$ partridge in the neighbourhood; for both pig and partridge eat up the snails. ${ }^{3}$

The sea-serpent ${ }^{4}$ resembles the conger in colour and shape, but is of lesser bulk ${ }^{5}$ and more rapid in its movements. If it be caught and thrown away, ${ }^{6}$ it will bore

${ }^{1}{ }_{\epsilon}^{\prime} \nu \tau \hat{\omega} \sigma \tau \dot{\varphi} \mu a \tau \iota$. These words seem to me dubious; they are omitted by Plin. ix. 67 in the corresponding passage "Simili modo squatina [i.e. rhina, cf. xxxii. II] et rhombus abditi pinnas exsertas movent specie vermiculorum, itemque quae vocantur raiae'. The singular verb is also peculiar, and furthermore, unless perhaps övos be the forkbeard hake, none of these fishes have any barbels or oral tentacles. It is plain that the order of this and the foregoing sentences is very confused, and I rather think the statement applies only to Bárpaxos,

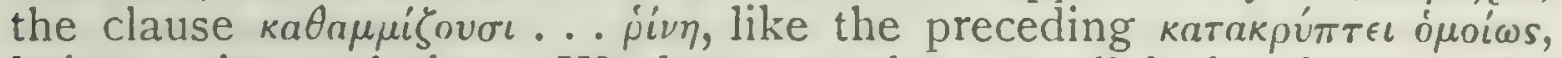
being an interpolation. We have no close parallel elsewhere to the present use of $\rho a \beta \delta i o \nu$, unless we may compare the radius of pastinaca, according to Pliny.

${ }^{2}$ Athen. vii. 282 ; Plut. Soll. An. 981 D; Plin. ix. 70 'certissima est securitas vidisse planos [Cuvier cj. anthias] pisces'. ${ }^{3}$ Ael. x. 5 .

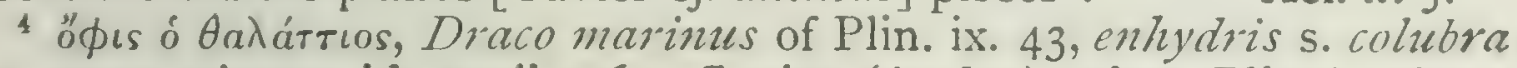
in aqua vivens, id. xxxii. 26. Cuvier (in loc.) takes Pliny's draco

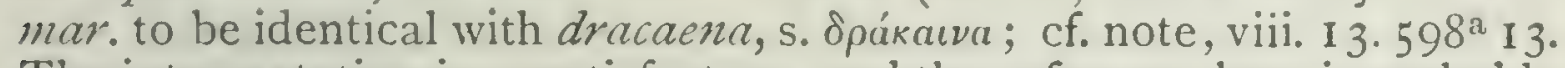
The interpretation is unsatisfactory, and the reference here is probably to some other species of eel, e.g. Ophisurus colubrinus. True sea-snakes are described by Ael. xvi. 8.

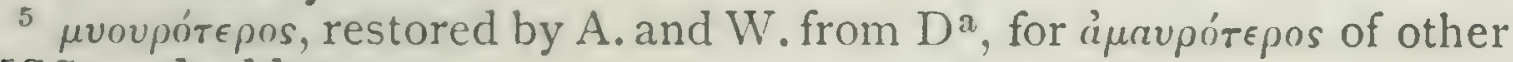
MSS. and edd.

${ }^{6} \epsilon^{\prime} \dot{a} \nu \delta \dot{\epsilon} \lambda \eta \phi \theta \hat{\eta}$. The Codd. and Ald. have $\phi \cap \beta \eta \theta \hat{\eta}$, which reading is adopted by A. and W. Camus and Schneider read $\lambda \eta \phi \theta \hat{\eta}$, following Gaza, 'si capta dimittatur foris.' $\lambda \eta \phi \theta \eta$ is supported by Plin. l.c. ' Rursus draco marinus, captus atque immissus in arenam cavernam sibi rostro mira celeritate excavat', where Harduin corrects 'captus atque missus'.

E e 2 
5 a hole with its snout and burrow rapidly in the sand; its snout, by the way, is sharper than that of ordinary serpents. The so-called 'sca-scolopendra, ${ }^{1}$ after swallowing the hook, turns itself inside out until it ejects it, and then it again turns itself outside in. The sea-scolopendra, like the land-scolopendra, will come to a savoury bait; the creature does not ro bite with its teeth, but stings by contact with its entire body, like the so-called sea-nettle. The so-called fox-shark," when it finds it has swallowed the hook, tries to get rid of it as the scolopendra does, but not in the same way; in other words, it runs up the fishing-line, and bites it off I5 short; it is caught in some districts in deep and rapid waters, with night-lines. ${ }^{3}$

The bonitos ${ }^{4}$ swarm together when they espy a dangerous crcature, and the largest of them swim round it, and if it touches one of the shoal they try to repel it; they have strong tecth." Amongst other large fish, a lamiaso shark, after falling in amongst a shoal, has been seen to be covered with wounds.

Of river-fish, the male of the sheat-fish ${ }^{6}$ is remarkably attentive to the young. The female after parturition goes away; the male stays and keeps on guard where the spawn is most abundant, contenting himself with keeping off all 25 other little fishes that might steal the spawn or fry, and this he does for forty or fifty days, until the young are sufficiently grown to make away from the other fishes

${ }^{1} \sigma \kappa o \lambda \dot{\pi} \epsilon \nu \delta \rho$. What animal is meant is unknown. Cuvier (ad Plin. ix. 67) supposes some annelid, e.g. a large Nereis, whose protrusible proboscis might have suggested a turning inside out, and O. F. Muiller and Schneider lean to the same opinion. These animals, however, have no urticating properties. Cf. Plut. S. Num. Vind. 567 D; Ael. vii. 35 ; Opp. Hal. ii. 424 ; Diosc. ii. 16.

${ }_{2}$ Plin. x. 67, xxxii. 53; Ael. V. H. i. 5; Plut. Sol. An. 977 в; Antig. Mirab. xxi ; Opp. Hal. iii. 144.

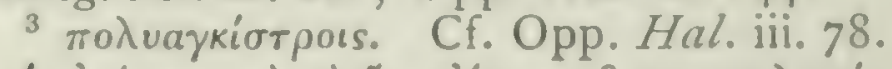

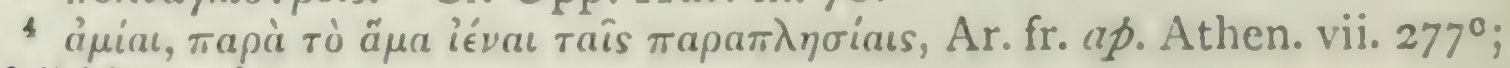
cf. ibid. $304^{\mathrm{d}}$.

5óoóvtas ioxupoús. Cf. Cuv. and Val. viii. p. I54'il y a dे chaque machoire une rangée de dents coniques. grêles, un peu comprimées. très pointues', \&c.; cf. also Cuv. ad Plin. ix. 19'solus e thynnis iste Scomber sarda dente pollet valido'; cf. Opp. Hal. ii. 553. Plut. Soll.

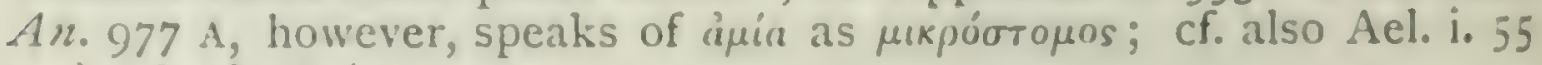

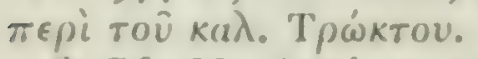

${ }^{6}$ Cf. H. A. vi. 4. $568^{2} 25$. 
for themselves. The fishermen can tell where he is on guard: for, in warding off the little fishes, he makes a rush in the water and gives utterance to a kind of muttering noise. He is so earnest in the performance of his parental duties that the fishermen at times, if the eggs be attached 30 to the roots of water-plants deep in the water, ${ }^{1}$ drag them into as shallow a place as possible; the male fish will still keep by the young, and, if it so happen, ${ }^{2}$ will be caught by the hook when snapping at the little fish that come by; if, however, he be sensible by experience of the danger of the hook, he will still keep by his charge, and with his $62 \mathrm{I}^{\mathrm{b}}$ extremely strong teeth will bite the hook in picces.

All fishes, both those that wander about and those that are stationary, occupy the districts where they were born or very similar places, for their natural food is found there. Carnivorous fish wander most; and all fish are carnivorous 5 with the exception of a few, such as the mullet, the saupe, the red mullet, and the chalcis. The so-called pholis ${ }^{3}$ gives out a mucous discharge, which envelops the creature in a kind of nest. Of shell-fish, and fish that are finless, the scallop moves with greatest force and to the greatest io distance, impelled along by some internal energy; the murex or purple-fish, and others that resemble it, move hardly at all. Out of the lagoon of Pyrrha ${ }^{4}$ all the fishes swim in winter-time, except the sea-gudgeon; they swim out owing to the cold, for the narrow waters are colder than the outer sea, and on the return of the early summer they all swim back again. In the lagoon no is scarus is found, nor thritta, ${ }^{5}$ nor any other species of the

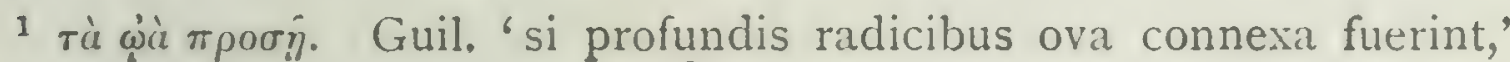
whence Schn. cj. $\tau \dot{a} \dot{\omega} \dot{a} a ̀ \pi \rho o \sigma \in \chi \hat{\eta} \hat{\eta}$.

${ }^{2}$ éà $\mu \dot{e} \nu$ rúx?. Gaza 'tunc, si minor sit natu, minusque usu exercitatus'; hence Camus and later editors insert $\nu$ éos, which is neither in the MSS., nor in the version of Guil.; neither does it appear to be necessary.

${ }^{3} \phi \omega \lambda$ is. This may be one of the nest-building fishes, Gobius (cf. $\phi \dot{v} k \eta s$, note to vi. 13. $567^{\mathrm{b}} 20$ ) or Gasterosteus.

4 The Pyrrhaean Euripus, in Lesbos, Strabo, xiii. 2.2.

- Apirta; traditionally identified with the shad, Alosa vulgaris. According to Hoffmann Opiora in Mod. Gk. is Sardinella aurita. Apiroa (Ael. vi. 32) or $\tau$ pexias (Arist. ap. Athen. vii. $328 \mathrm{f}$.) is said to delight in music, and the same has been reported of the shad in later times; cf. Schneider ad Ael. p. 197. 
spiny fish, no spotted dogfish, no spiny dogfish, no seacrawfish, no octopus either of the common or the musky kinds, and certain other fish are also absent; but of fish that are found in the lagoon the white gudgeon is not a marine fish. Of fishes the oviparous are in their 20 prime in the early summer until the spawning time; the viviparous in the autumn, as is also the case with the mullet, the red mullet, and all such fish. In the neighbourhood of Lcsbos, ${ }^{1}$ the fishes of the outer sca, or of the lagoon, bring forth their eggs or young in the lagoon; sexual union takes place in the autumn, and parturition in the spring. With fishes of the cartilaginous kind, the 25 males and females swarm together in the autumn for the sake of sexual union; in the early summer they come swimming in, and keep apart until after parturition; the two sexes are often taken linked together in sexual union.

Of molluses the sepia is the most cunning, and is the only species that employs its dark liquid for the sake of 30 concealment as well as from fear: the octopus and calamary make the discharge solely from fear. These creatures never discharge the pigment in its entirety; and after a discharge the pigment accumulates again. The sepia, as has been said, often uses its colouring pigment for concealment; it shows itself in front of the pigment and then $622^{\text {a }}$ retreats back into it; ${ }^{2}$ it also hunts with its long tentacles not only little fishes, but oftentimes even mullets. The octopus is a stupid creature, for it will approach a man's hand if it be lowered in the water; but it is neat and 5 thrifty in its habits: that is, it lays up stores in its nest, ${ }^{2}$ and, after eating up all that is eatable, it ejects the shells and sheaths of crabs and shell-fish, and the skeletons of little fishes. It secks its prey by so changing its colour ${ }^{4}$ as to render it like the colour of the stones adjacent to it; 10 it does so also when alarmed. By some the sepia is said to

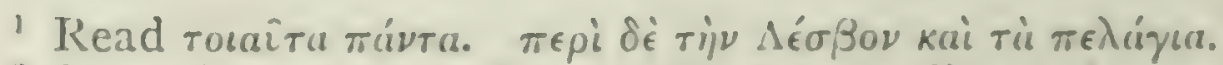

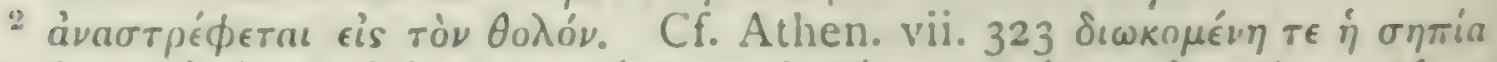

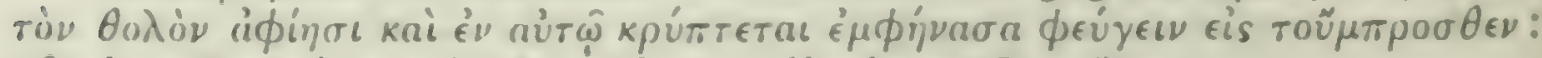
cf. also $P$. A. iv. 5. $679^{\AA}$ 5, Plut. Soll. An. 97 A, dic.

3 Plin. ix. 29; Antig. Mirab. lv.

- Theophr.fr. I7I-3; Athen.vii. 317; Plut. Soll. An. 978 D. 
perform the same trick; that is, they say it can change its colour so as to make it resemble the colour of its habitat. ${ }^{1}$ The only fish that can do this is the angel-fish, that is, it can change its colour like the octopus. The octopus as a rule does not live the year out. It has a I5 natural tendency to run off into liquid; for, if beaten and squeezed, ${ }^{2}$ it keeps losing substance and at last disappears. The female after parturition is peculiarly subject to this colliquefaction; it becomes stupid; if tossed about by waves, it submits impassively; ${ }^{3}$ a man, if he dived, could catch it with the hand; it gets covered over with slime, and 20 makes no effort to catch its wonted prey. The male becomes leathery and clammy. As a proof that they do not live into a second year there is the fact ${ }^{4}$ that, after the birth of the little octopuses in the late summer or beginning of autumn, it is seldom that a large-sized octopus is visible, whereas a little before this time of year the creature is 25 at its largest. After the eggs are laid, they say that both the male and the female grow so old and feeble ${ }^{5}$ that they are preyed upon by little fish, and with ease dragged from their holes; and that this could not have been done previously; they say also that this is not the case with the small and young octopus, but that the young creature 30 is much stronger than the grown-up one. Neither does the sepia live into a second year. The octopus is the only mollusc that ventures on to dry land; it walks by preference on rough ground; it is firm all over when you squeeze it, excepting in the neck. So much for the mollusca.

${ }^{6}$ It is also said that they make a thin rough shell about

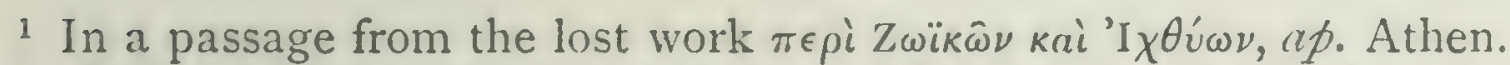

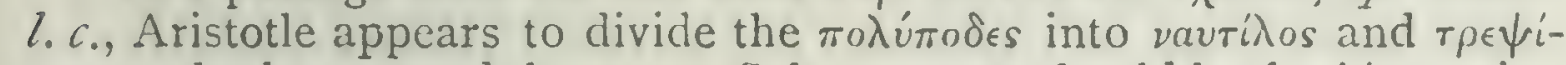
$\chi \rho \omega s$; the latter word, however, Schn. argues, should be $\theta \rho v \psi i x p \omega s$, i.e. soft-skinned, shell-less.

${ }^{2} \pi \iota \lambda$ ov́ $\mu \epsilon \nu$ s, i.e. to make it tender: cf. fr. ap. Suid. $\delta$ is $\epsilon \pi \tau \dot{a} \pi \lambda \eta \gamma$ ais

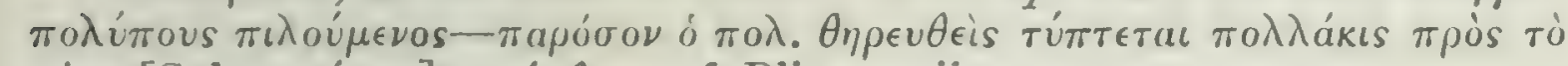
$\pi i \omega \nu$ [Schn. $\pi \epsilon ́ \pi \omega \nu]$ $\gamma \epsilon \nu \epsilon ́ \sigma \theta a \iota:$ cf. Plin. xxxii. 42.

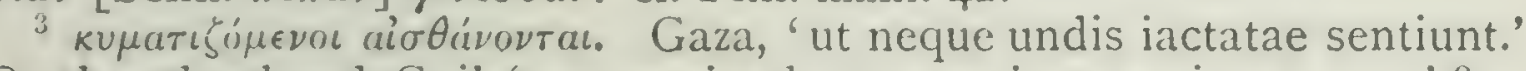
On the other hand, Guil. 'a cavernis eductae sentiunt, capique manu,' \&.c.

4 Plin. ix. 48 ; Ael.vi. 28.

5 Ael. ix. 45; Opp. Hal. i. 305, 535.

6 Tis $\delta \dot{\epsilon} \kappa \hat{\gamma} \chi \chi a s \kappa \tau \lambda$. There is either a lacuna here, as Schn. argues,

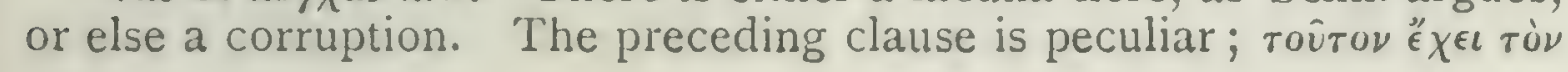


them like a hard sheath, and that this is macle larger and larger as the animal grows larger, and that it comes out of the sheath as though out of a den or dwelling-place. ${ }^{1}$

5 The nautilus (or argonaut) is a poulpe or octopus, but one peculiar both in its nature and its habits. ${ }^{2}$ It rises up from deep water and swims on the surface; it rises with its shell down-turned in order that it may rise the more easily and swim with it empty, but after reaching the surface it shifts the position of the shell. In between its feclers it has a ro certain amount of web-growth, ${ }^{3}$ resembling the substance between the toes of web-footed birds; only that with these latter the substance is thick, while with the nautilus it is thin and like a spider's web. It uses this structure, when a breeze is blowing, ${ }^{4}$ for a sail, and lets down some ${ }^{5}$ of its feelers alongside as rudder-oars." If it be frightened, I5 it fills its shell with water and sinks. With regard to the mode of generation and the growth of the shell knowledge from obscrvation is not yet satisfactory; the shell, however, does not appear to be there from the beginning, but to grow in their case as in that of other shell-fish; neither is it ascertained for certain whether the animal can live when stripped of the shell.

rpómov should have, or usually has, a nominative before it; moreover, we are not leaving the subject of the $\mu a \lambda$ cikı an aberrant member of the group. Furthermore, I cannot take, as

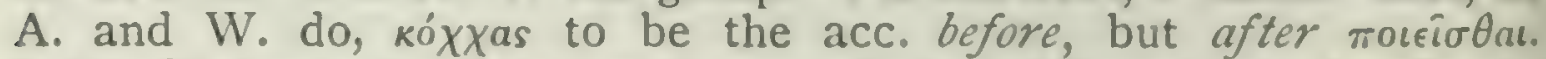
I should be inclined to read somewhat as follows: rì $\mu \dot{\epsilon} \nu$ oủv $\tau \hat{\omega}{ }^{\prime}$

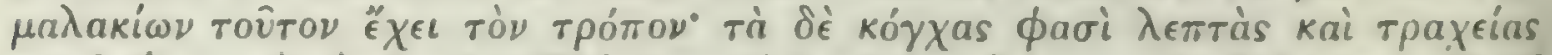

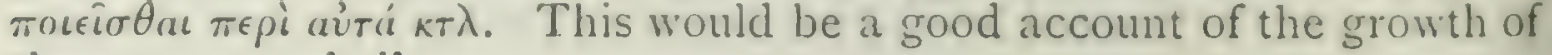
the argonaut-shell.

1 ì oikias. Guil. 'in latibulo quodam aut ventre.' 'Legit igitur

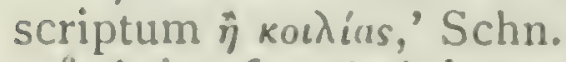

2 Arist. fr. $a p$. Athen. vii. 317 ; Plin. ix. 47; Antig. Car. 56; Opp. Hal. i. 338 ; Ael. ix. 34 .

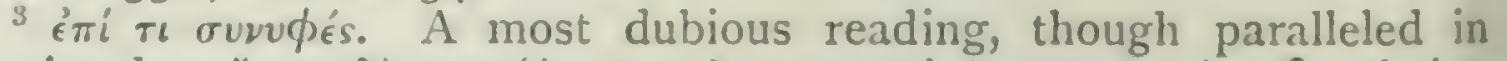

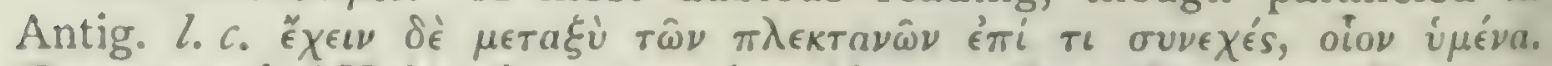
Gaza transl. "Habet inter sua brachia membranulam quandam an-

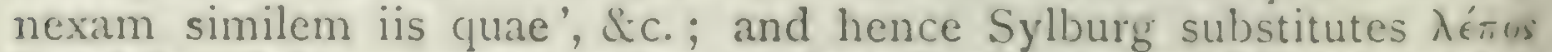
for $\epsilon \pi i$. Schn. sugrgests $\mu \epsilon_{\text {pos }} \tau$, but finally erases $\dot{\pi} \pi i$, comparing Guil. 'plectanarum quoddam contextum sicut steganopedibus'. Perhaps this is one of the many cases where e $\pi i$ has been substituted for "̈Tl.

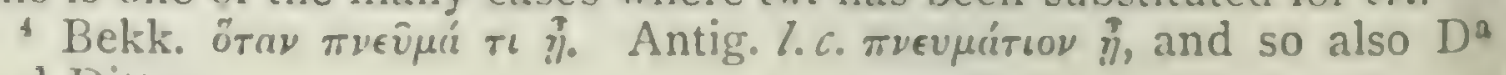
and Dittm.

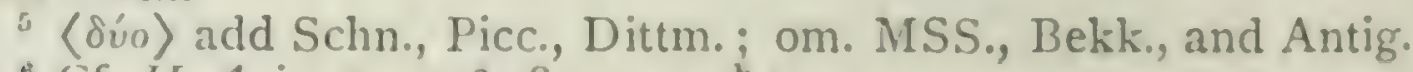

- Cf. H. A. iv. 7. $532^{\mathrm{a}} 28 ; 9.535^{\mathrm{b}}$ I2. 
38 Of all insects, one may also say of all living creatures, 20 the most industrious are the ant, the bee, the hornet, the wasp, and in point of fact all creatures akin to these; of spiders some are more skilful and more resourceful than others. ${ }^{1}$ The way in which ants work is open to ordinary observation; how they all march one after the other when 25 they are engaged in putting away and storing up their food ; all this may be seen, for they carry on their work even during bright moonlight nights. ${ }^{2}$

39 Of spiders ${ }^{3}$ and phalangia there are many species. Of the venomous phalangia there are two; one that resembles the so-called wolf-spider, small, speckled, and tapering 30 to a point; it moves with leaps, from which habit it is nicknamed 'the flea': the other kind is large, black in colour, with long front legs; it is heavy in its movements, walks slowly, is not very strong, and never leaps. (Of all the other species wherewith poison-vendors supply themselves, some give a weak bite, and others never bite at all. $623^{\mathrm{a}}$ There is another kind, comprising the so-called wolfspiders.) Of these spiders the small one weaves no web, and the large weaves a rude and poorly built one on the ground or on dry stone walls. ${ }^{4}$ It always builds its web over hollow places inside of which it keeps a watch on the end-threads, until some creature gets into the web and 5 begins to struggle, ${ }^{5}$ when out the spider pounces. The speckled kind makes a little shabby web under trees.

There is a third species of this animal, pre-eminently clever and artistic. ${ }^{6}$ It first weaves a thread stretching to

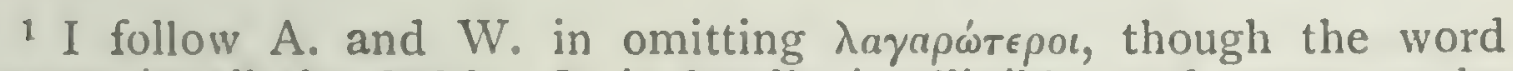
occurs in all the MSS. It is hardly intelligible, and seems to be a reduplication of $\gamma \lambda \alpha \phi v \rho \omega ́ \tau \epsilon \rho \iota_{\text {. }}$

2 Ael. iv. 43.

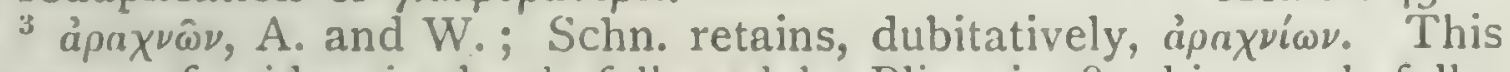
account of spiders is closely followed by Plin. xi. 28; his much fuller account in xxix. 27 is taken from Nicander, Ther. 715 et seq. Cf. H. A. v. $27 \cdot 555^{\mathrm{a}} 27$.

4 aipariais. Plin. 'cavernis'; Guil., more accurately, 'lapidum congeries'; Gaza, 'sepes.' (In Plin. for 'interna et cavernis exigua vestibula', read 'in terra'.)

5 Reading $\kappa \iota \nu \eta \hat{\eta}$. Gaza, Schn. and Picc. read $\kappa \iota \nu \dot{\eta} \sigma \eta$, 'sets it vibrating.'

6 A. now proceeds to describe the most perfect type of web, that of a 'geometric' spider, e.g. Epeira. 
ravenously, whereas at other times they are never observed to be so greedy, but apparently are thrifty and disposed to lay by for their future sustenance. ${ }^{1}$ They have also another food which is called bec-bread;" this is scarcer than honey and has a sweet fig-like taste; this they carry as they do 25 the wax on their legs.

Very remarkable diversity is observed in their methods of working and their general habits. When the hive has been delivered to them clean and empty, they build their waxen cells, ${ }^{3}$ bringing in the juice ${ }^{4}$ of all kinds of flowers and the 'tears' or exuding sap of trees, such as willows and elms and such others as are particularly given to the zo exudation of gum. With this material they besmear the ground-work, to provide against attacks of other creatures; the bee-keepers call this stuff 'stop-wax'. ${ }^{6}$ They also with the same material narrow by side-building the entrances to the hive if they are too wide. They first build cells for themselves; then for the so-called kings and the drones; ${ }^{7}$ $624^{a}$ for themselves they are always building, for the kings only when the brood of young is numerous, and cells for the drones they build if a superabundance of honey should suggest their doing so. They build the royal cells next to their own, ${ }^{8}$ and they are of small bulk; the drones' cells

1 Plin. xi. I5; Antig. Mivab. Ivii.

2 Plin. xi. 7; Varro, R. R. iii. I6. Cf. supra, v. I9.

3 Plin. xi. 5, xxiii. 3, xxiv. 32.

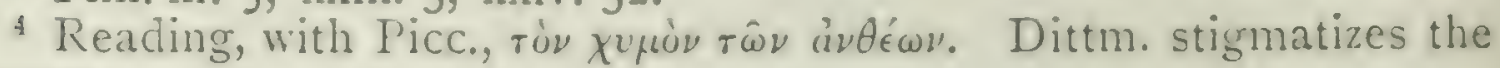
clause.

${ }^{3}$ Cf. Verg. G. iv. 40. It was the younger Huber who first discovered that wax is an exudation from the bee's body, secreted between the abdominal rings.

${ }^{6} \kappa \dot{\rho} \mu \omega \sigma \iota \nu$. Though A. and W., as well as Bekker, reject, in favour of kinow', this admirable conjecture of Schneider's, it seems to be substantiated (I) by Guil. sommosem (Lips. gemmoscm), (2) by

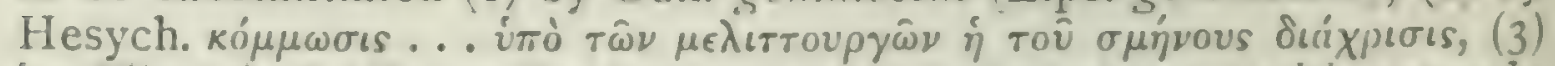
by J'lin. xi. 6 'Prima fundamenta commosin rocant periti, secunda pissoceron, \&c.... Commosis crusta est prima, saporis amari'. Cf. note to $624^{2} 18$, on next pare.

7 H.A.v. 21 ; cf. G. A. iii. 10; Plin. xi. 10; Colum. ix. I 5.

${ }^{8} \pi$ mòs rois aur $\hat{\omega} \nu$. These words, and great part of the context, are very obscure. The queen-cells are not the least, but the largest, and are not united in combs, but are more or less separate from the latter: cf. Plin. xi. 12 'Regias imperatoribus futuris in ima parte alvei exstruunt amplas, magnificas, separatas, tuberculo eminentes"; the drunes'

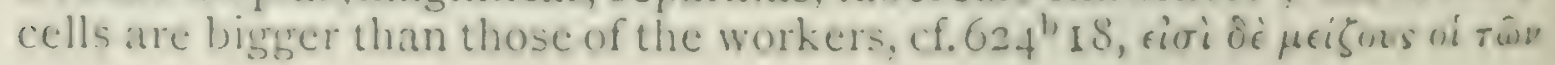


they build near by, and these latter are less in bulk than the bees' cells. They begin building the combs down- 5 wards from the top of the hive, and go down and down building many combs connected together until they reach the bottom. The cells, both those for the honey and those also for the grubs, are double-doored; for two cells are ranged about a single base, one pointing one way and one the other, after the manner of a double (or hour-glassshaped) goblet. The cells that lie at the commencement io of the combs and are attached to the hives, to the extent of two or three concentric circular rows, are small and devoid of honey; the cells that are well filled with honey are most thoroughly luted with wax. ${ }^{1}$ At the entry to the hive the aperture of the doorway is smeared with mitys; ${ }^{2}$ this substance is a deep black, and is a sort of dross or $1_{5}$ residual by-product of wax; it has a pungent odour, and is a cure for bruises and suppurating sores. The greasy stuff that comes next is pitch-wax; it has a less pungent odour and is less medicinal than the mitys. Some say that the drones construct combs by themselves in the same hive and in the same comb that they share with the bees; 20 but that they make no honey, but subsist, they and their grubs also, on the honey made by the bees. The drones, as a rule, keep inside the hive; when they go out of doors, they soar up in the air in a stream, ${ }^{3}$ whirling round and round in a kind of gymnastic exercise; when this is over, ${ }_{25}$ they come inside the hive and feed to repletion ravenously. ${ }^{4}$ The kings never quit the hive, except in conjunction with the entire swarm, either for food or for any other reason.

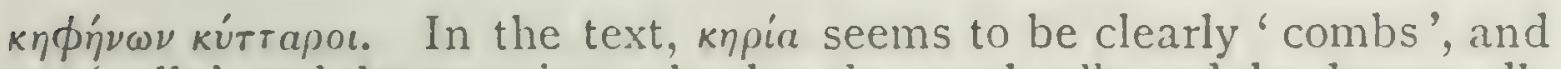
not 'cells', and the meaning to be that the royal cells and the drone-cells are collectively of little bulk. For $\mu \epsilon \lambda \iota \tau \tau i \omega \nu$ Picc. would read $\beta a \sigma \iota \lambda \epsilon i \omega \nu$.

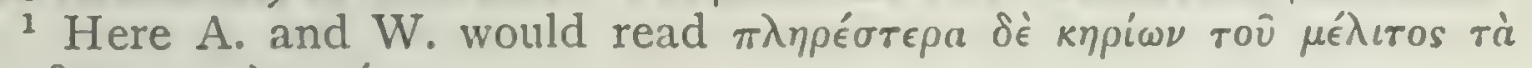

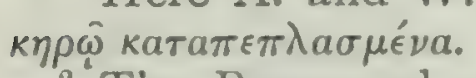

${ }_{2}$ The Parma ed. of Pliny has mytin for commosin in xi. 6. On

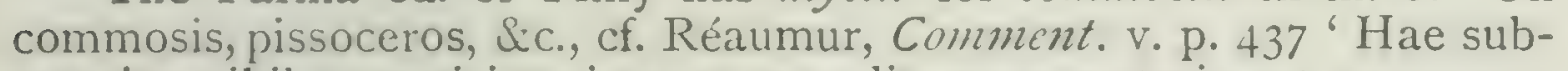
stantiae nihil sunt nisi varietates propolis, quae materia est gummosa, cerae dissimilis, qua apes utuntur ad alveorum supplendas rimas. Huic varii colores, varia soliditas.'

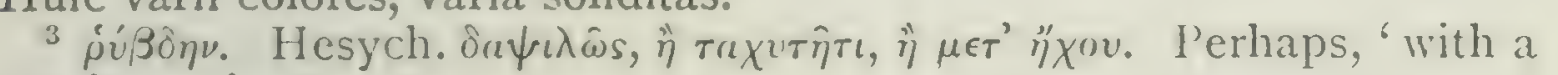
buzzing noise.'

* Plin. xi. 22.

5 Plin. xi. 17. 
They say that, if a young swarm go astray, it will turn back upon its route and by the aid of scent seek out its 30 leader. ${ }^{1}$ It is said that if he is unable to fly he is carried by the swarm, and that if he dies the swarm perishes; and that, if this swarm outlives the king for a while and constructs combs, no honey is produced and the bees soon die out. ${ }^{2}$ Bees scramble up the stalks of flowers and rapidly gather the becs-wax with their front legs; the $624^{\mathrm{b}}$ front legs wipe it off on to the middle legs, and these pass it on to the hollow curves of the hind-legs $;^{3}$ when thus laden, they fly away home, and one may sce plainly that their load is a heavy one. On each expedition the bee does not fly from a flower of one kind to a flower of 5 another, ${ }^{4}$ but flies from one violet, say, to another violet, and never meddles with another flower until it has got back to the hive; on reaching the hive they throw off their load, and each bee on his return is accompanied by three or four companions. ${ }^{5}$ One cannot well tell what is the substance they gather, nor the exact process of their work. Their mode of gathering wax has been obscrved on olive-trecs, ro as owing to the thickness of the leaves the bees remain stationary for a considerable while. After this work is over, they attend to the grubs. There is nothing to prevent grubs, honey, and drones being all found in one and the same comb. As long as the leader is alive, the drones are said to be produced apart by themselves; if he be no longer living, they are said to be reared by the bees in I5 their own cells, and under these circumstances to become more spirited: for this reason they are called 'sting-drones', not that they really have stings, but that they have the wish, without the power, to use such weapons. The cells for the drones are larger than the others; sometimes the bees construct cells for the drones apart, but usually they 20 put them in amongst their own; and when this is the case the bee-keepers cut the drone-cells out of the combs. There are several species of bees, as has becn said; two of 'kings',

Acl. vi. Io.

3 Plin. xi. ro.

5 Verg. G. iv. 167.
2 Ael. v. II.

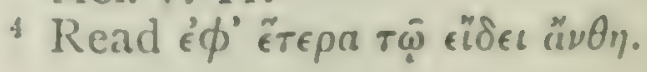


the better kind red, ${ }^{1}$ the other black and variegated, and twice as big as the working-bee. The best working-bee is small, round, and speckled : another kind is long and like an anthrene wasp; ${ }^{2}$ another kind is what is called the 25 robber-bee, black and flat-bellied ; ${ }^{3}$ then there is the drone, the largest of all, but devoid of sting, and lazy. There is a difference between the progeny of bees that inhabit cultivated land and of those from the mountains: the forestbees are more shaggy, smaller, more industrious and more 30 fierce. ${ }^{4}$ Working-bees make their combs all even, with the superficial covering quite smooth. Each comb is of one kind only: that is, it contains either bees only, or grubs only, or drones only; if it happen, however, that they make in one and the same comb all these kinds of cells, each separate kind will be built in a continuous row right through. ${ }^{5}$ The long bees build uneven combs, with the lids $625^{\text {a }}$ of the cells protuberant, like those of the anthrene; grubs and everything else have no fixed places, but are put anywhere; from these bees come inferior kings, a large quantity of drones, and the so-called robber-bee; they

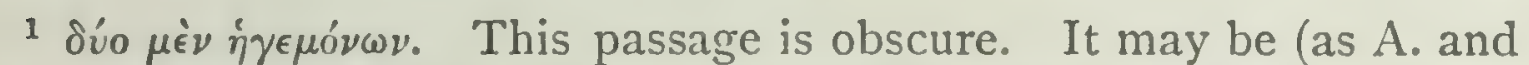
W. suppose) that A. alludes to the two well-marked varieties or species, the common and the Ligurian bee (Apis mellifica and ligustica); and we may note that Vergil speaks of the two sorts of kings having each their own people 'Ut binae regum facies, ita corpora plebis'. On the other hand, Kirby and Spence (Lect. xix) think that Vergil (and therefore Aristotle also) regarded the drone as one of the kings or leaders, 'Ille horridus alter Desidia latamque trahens inglorius alvum' ( $G$. iv. 93). 'It deserves to be mentioned that there seem actually to be two sorts of queens in the hive, a large one and a small. Needham was the first that observed the latter; and their existence, Mr. P. Huber tells us, has been confirmed by several observations of his father... They are of very rare occurrence' $\left(K\right.$. and S., l. $\left.c_{0}\right)$. With the description of A. and Vergil, cf. Plin. xi. 19 'Urbanarum duo genera: optimae breves variaeque, et in rotunditate compactiles: deteriores longae et quibus similitudo vesparum: etiamnum deterrimae ex is pilosae'. Varro, iii. I6, I8 'et ut quidam dicunt, tria genera cum sint ducum in apibus, niger, ruber et varius; ut Menecrates scribit, duo, niger et varius; qui ita, melior, ut expediat mellario ; cum duo sunt eadem alvo, interficere nigrum'. In these passages, especially in the last, we seem to discern a reference to the common, or black, and the Ligurian bees: but Pliny (xi.16) also describes, less intelligibly, the two varieties of 'kings'.

${ }^{2}$ H.A. v. $19.553^{\mathrm{b}} 8$.

${ }^{3}$ Plin. xi. 18; Varro, l.c.

${ }^{4}$ Plin. xi. 19; Varro, l.c.

${ }_{5}^{5}$ This is but a laboured attempt to translate an obscure and difficult

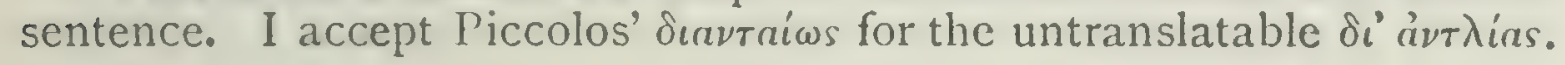


5 produce either no honey at all, or honey in very small quantities. Bees brood over the combs and so mature them; if they fail to do so, the combs are said to go bad and to get covered with a sort of spider's web. ${ }^{1}$ If they can keep brooding over the part undamaged, the damaged part simply eats itself away; if they cannot so brood, the ro entire comb perishes; in the damaged combs small worms are engendered, which take on wings and fly away. When the combs keep settling down, the bees restore the level surface, and put props underneath the combs to give themselves free passage-room ${ }^{2}$ for if such frce passage be lacking they cannot brood, and the cobwebs come on. When the robber-bee and the drone appear, not only do I5 they do no work themselves, but they actually damage the work of the other bees; if they are caught in the act, they are killed by the working-bees. These bees also kill without mercy most of their kings, and especially kings of the inferior sort ; ${ }^{3}$ and this they do for fear a multiplicity of kings should lead to a dismemberment of the hive. ${ }^{4}$ They kill them especially when the hive is deficient $20 \mathrm{in}$ grubs, and a swarm is not intended to take place; under these circumstances they destroy the cells of the kings if they have been prepared, on the ground that these kings are always ready to lead out swarms. They destroy also the combs of the drones if a failure in the honey supply be threatening and the hive runs short of provisions; under such circumstances they fight desperately with all who try 25 to take their honey, and cject from the hive all the resident drones; and oftentimes the drones are to be seen sitting apart in the hive. The little bees fight vigorously with the long kind, and try to banish them from the hives; if they succeed, the hive will be unusually productive, but if the bigger bees get left mistresses of the field they pass the 3o time in idleness, and do no good at all but dic out before the autumn. Whenever the working-bees kill an enemy they try to do so out of doors; ${ }^{5}$ and whenever one of

1 Plin. xi.16; Colum. R.R. ix. 13. Cf. H. A. viii. $27.605^{\mathrm{b}} 13$, and note; also ix. 40. 626" I8.

2 Plin. xi. 10.

:Cf. Huber, Obserr. i. p. 169 seqq.

3 Plin. xi. 16, 18.

5 Antig. Mirab. 57. 
their own body dies, they carry the dead bee out of doors also. The so-called robber-bees spoil their own combs, and, if they can do so unnoticed, enter and spoil the combs $625^{\mathrm{b}}$ of other bees; if they are caught in the act they are put to death. It is no easy task for them to escape detection, for there are sentinels on guard at every entry; and, even if they do escape detection on entering, afterwards from a surfeit of food they cannot fly, but go rolling about in 5 front of the hive, so that their chances of escape are small indeed. The kings are never themselves seen outside the hive except with a swarm in flight: during which time all the other bees cluster around them. When the flight of a swarm is imminent, a monotonous and quite peculiar sound made by all the bees is heard for several days, and for two or three days in advance a few bees are seen flying round ro the hive; it has never as yet been ascertained, owing to the difficulty of the observation, whether or no the king is among these. ${ }^{1}$ When they have swarmed, they fly away and separate off to each of the kings; if a small swarm happens to settle near to a large one, it will shift to join this large one, and if the king whom they have abandoned ${ }_{5}$ follows them, they put him to death. So much for the quitting of the hive and the swarm-flight. Separate detachments of bees are told off for diverse operations; that is, some carry flower-produce, others carry water, others smooth and arrange the combs. ${ }^{2}$ A bee carries water when it is 20 rearing grubs. No bee ever settles on the flesh of any creature, or ever eats animal food. They have no fixed date for commencing work; but when their provender is forthcoming and they are in comfortable trim, and by preference in summer, they set to work, and when the weather is fine they work incessantly. The bee, when quite young and in fact only three days old, after shedding its $₫ 5$ chrysalis-case, begins to work if it be well fed." When a swarm is settling, some bees detach themselves in search of food and return back to the swarm. In hives that are

1 Plin. xi. I7; Varro, iii. 16, 29.

2 Plin. xi. Io; Antig. Mirab. 47 ; Verg. G. iv. 54 ; Ael. v. Ir.

3 Plin. xi. 16.

AR. H.A. 
in good condition the production of young bees is discontinued only for the forty days that follow the winter 30 solsticc. ${ }^{1}$ When the grubs are grown, the bees put food beside them and cover them with a coating of wax; and, as soon as the grub is strong enough, he of his own accord breaks the lid and comes out. Creatures that make their appearance in hives and spoil the combs the working-bees clear out, but the other bees from sheer laziness look with indifference on damage done to their produce. When the $626^{a}$ bee-masters take out the combs, they leave enough food behind for winter use; if it be sufficient in quantity, the occupants of the hive will survive; if it be insufficient, then, if the weather be rough, they die on the spot, but if it be fair, they fly away and desert the hive. They feed on 5 honey summer and winter; but they store up another article of food resembling wax in hardness, which by some is called sandarace, or bee-bread. Their worst enemies" are wasps and the birds named titmice, and furthermore the swallow and the bee-eater. The frogs in the marsh also catch them if they come in their way by the ro water-side, and for this reason bee-keepers chase the frogs from the ponds from which the bees take water; they destroy also wasps' nests, and the nests of swallows, in the neighbourhood of the hives, and also the nests of bee-eaters. Bees have fear only of one another. They fight with one I5 another and with wasps. Away from the hive they attack neither their own species nor any other creature, but in the close proximity of the hive they kill whatever they get

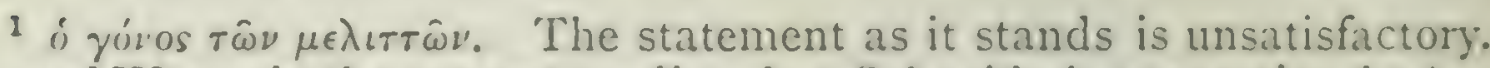
A. and W. retain the current reading, but Schneider's suggestion of rums is accepted by Piccolos. In support of the emendation Schn. quotes various parallels: Colum. ix. I4, 17' Post confectam brumam diebus fere $\mathrm{xl}$, quicquid est repositi mellis... consumunt', \&.c.; I'lin. xi. I5 'A bruma ad Arcturi exortum diebus $1 \mathrm{x}$ somno aluntur sine ullo

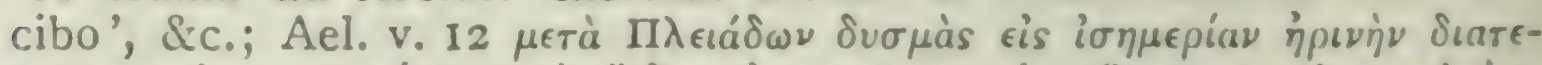
$\lambda$

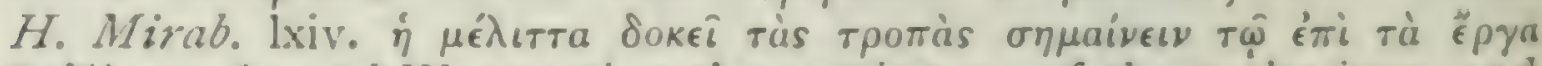
Brobifew. A. and $W$. question the pertinency of these citations, and

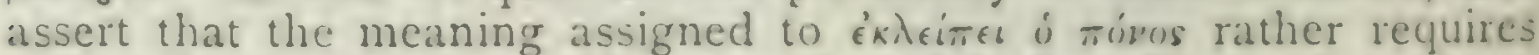
mavesu if epravia. I myself suspect the original reading to have been

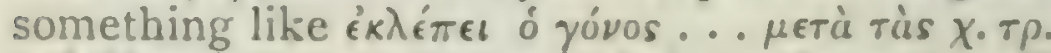

2 Verg. G. iv. 13, 245; Acl. i. 58, v. II; Phile 650; Geopon. xv. 2, \&.C. 
hold of. Bees that sting die from their inability to extract the sting ${ }^{1}$ without at the same time extracting their intestines. True, ${ }^{2}$ they often recover, if the person stung takes the trouble to press the sting out; but once it loses its sting 20 the bee must die. They can kill with their stings even large animals; in fact, a horse has been known to have been stung to death by them. ${ }^{3}$ The kings are the least disposed to show anger or to inflict a sting. Bees that die are removed from the hive, ${ }^{4}$ and in every way the creature is remarkable for its cleanly habits ; in point of fact, they 25 often fly away to a distance to void their excrement because it is malodorous; and, as has been said, they are annoyed by all bad smells and by the scent of perfumes, so much so that they sting people that use perfumes. ${ }^{5}$ They perish from a number of accidental causes, and when their kings become too numerous and try each to carry away a portion of the swarm. The toad also feeds on 30 bees; he comes to the doorway of the hive, puffs himself out as he sits on the watch, and devours the creatures as they come flying out; the bees can in no way retaliate, ${ }^{6}$ but the bee-keeper makes a point of killing him. As for $626^{b}$ the class of bee that has been spoken of as inferior or good-for-nothing; and as constructing its combs so roughly, some bee-keepers say that it is the young bees that act so from inexperience; and the bees of the current year are termed young. The young bees do not sting as the others 5 do; and it is for this reason that swarms may be safely carried, as it is of young bees that they are composed. When honey runs short they expel the drones, and the bee-keepers supply the bees with figs and sweet-tasting articles of food. ${ }^{7}$ The elder bees do the indoor work, and

${ }^{1}$ Plin. xi. 19: Verg. G. iv. 237; Apoll. H. M.xlv; Senec. de Clem. i. 19.

2 Dittm. adds $\left\langle\dot{a} \lambda \lambda^{\prime}\right.$ oúk áci〉 to the preceding clause. I have

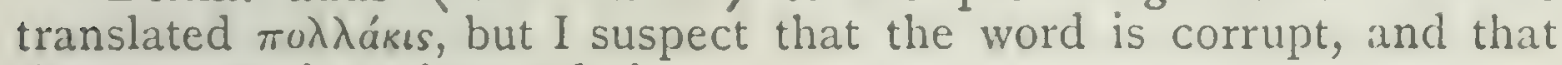
the sentence is an interpolation.

3 Plin. xi. 19; Ael.v. II. Cf. Scaliger in loc. ${ }^{4}$ Plin. xi. Io.

5 Plin. xi. I9; Antig. Ivii; Geopon.xv. 3 ; Ael. i. 58 ; Pallad. i. 37, \&c.; Theophr. C. P. vi. 4 .

${ }^{6}$ фpûvos. Guil. syrinis, Ael. i. 58 yúpıvos. Cf. Plin. l.c ' $\mathrm{Nec}$ sen. tire ictus apum ranae traduntur'.

7 Plin. xi. 12 ; Ael. i. II, v. I2, \&c. 
are rough and hairy from staying indoors; the young bees do the outer carrying, and are comparatively smooth. so They kill the drones also when in their work they are confined for room; the drones, by the way, live in the innermost recess of the hive. On one occasion, when a hive was in a poor condition, some of the occupants assailed a foreign hive; proving victorious in a combat they took to carrying off the honey ; ${ }^{1}$ when the bee-keeper tried to kill them, the other bees came out and tried to I5 beat off the encmy but made no attempt to sting the man. The diseases that chicfly attack prosperous hives are first of all the clerus ${ }^{2}$ - this consists in a growth of little worms on the floor, from which, as they develop, a kind of cobweb grows over the entire hive, and the combs decay; another diseased condition ${ }^{3}$ is indicated in a lassitude on the part 20 of the bees and in malodorousness of the hive. Bees feed on thyme $;^{4}$ and the white thyme is better than the red. ${ }^{5}$ In summer the place for the hive should be cool, and in winter warm. They are very apt to fall sick if the plant they are at work on be mildewed. In a high wind 25 they carry a stone by way of ballast to steady them. ${ }^{6}$ If a stream be near at hand, they drink from it and from it only, but before they drink they first deposit their load; if there be no water near at hand, they disgorge their honey as they drink ${ }^{7}$ elscwhere, and at once ${ }^{8}$ make off to work. There are two seasons for making honey, spring 30 and autumn; ${ }^{9}$ the spring honey is sweeter, whiter, and in every way better than the autumn honey. Superior honey comes from fresh comb, and from young shoots; the red honey is inferior, and owes its inferiority to the comb in

1 Plin. xi. I8; Ael.v. Ir.

${ }^{2}$ Cf. viii. $27.605^{\mathrm{b}} 13$, and note. See also Plin. xi. 20, 21 ; Colum. ix. 7,13 .

' 'Foul-brood'. Cf. H. A. viii. $27.605^{\mathrm{b}} 9$; Verg. G. iv. 251.

* Theophr. H.P. vi. 2, 3 .

- For a long list of flowers frequented by bees see Plin. xxi. 12, and cf. Verg. G. iv. 30 ; Varro iii. 9; Colum. ix. 8; Diosc. iii.123, \&.c. Cf. H. A. vi. 22. $554^{\text {a }}$ II .

6 Verg. G. iv. 194; Plin. xi. Io; Ael. v. 13.

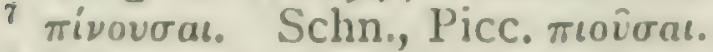

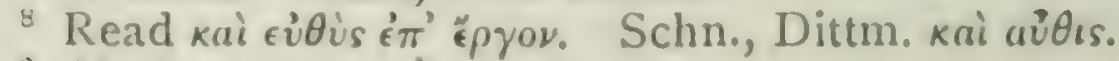

H.A.v. 22. $553^{\mathrm{b}} 25$. 
which it is deposited, just as wine is apt to be spoiled by its cask; consequently, one should have it looked to and dried. When the thyme is in flower and the $627^{\mathrm{a}}$ comb is full, the honey does not harden. ${ }^{1}$ The honey that is golden in hue is excellent. White honey does not come from thyme pure and simple; it is good as a salve for sore eyes and wounds. Poor honey always floats on the surface and should be skimmed off; the fine clear honey rests below. When the floral world is in full bloom, 5 then they make wax; consequently you must then take the wax out of the hive, for they go to work on new wax at once. The flowers from which, they gather honey are as follows: the spindle-trce, the melilot-clover, king'sspear, myrtle, flowering-reed, withy, ${ }^{2}$ and broom. ${ }^{3}$ When they work at thyme, they mix in water before sealing up 4 the comb. As has been already stated, they all either fly ro to a distance to discharge their excrement or make the discharge into one single comb. The little bees, as has been said, are more industrious than the big ones; their wings are battered; their colour is black, and they have a burnt-up aspect. Gaudy and showy bees, like gaudy and showy women, are good-for-nothings. Bees seem to ${ }_{5} 5$ take a pleasure in listening to a rattling noise; ${ }^{5}$ and consequently men say that they can muster them into a hive by rattling with crockery or stones ${ }^{6}$ it is uncertain, however, whether or no they can hear the noise at all, and also whether their procedure is due to pleasure or

1 Plin. xi. 15 ; cf. Dioph. in Geopon. xv. 7.

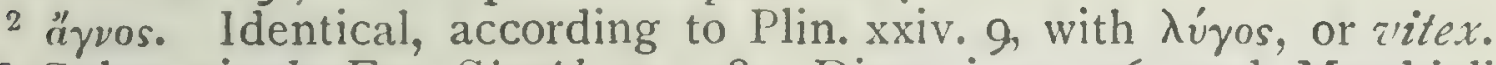
Cf. Galen. vi. de Fac. Simpl. p. 148 ; Diosc. i. p. 196, and Matthioli in loc., \&c.

${ }^{3}$ бrápтov. Plin. l. c. '[Genistae] flores apibus gratissimi. Dubito an haec sit quam Graeci auctores sparton appellavere.' Pliny's plant

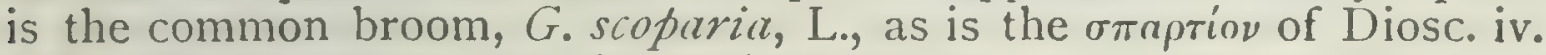

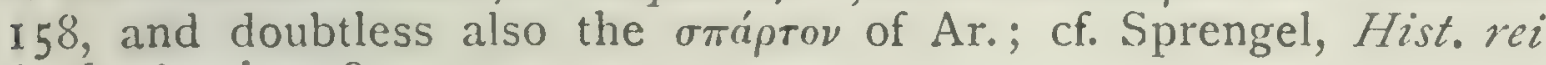
herbariae, i. p. 80.

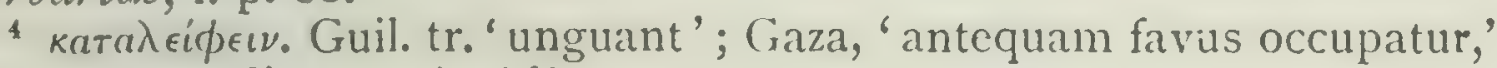
probably reading $\kappa a \tau a \lambda \eta \phi \theta \hat{\eta}$.

5 Verg. G. iv. 64 ; Plin. xi. 22; Varro, R. R. iii. I6.

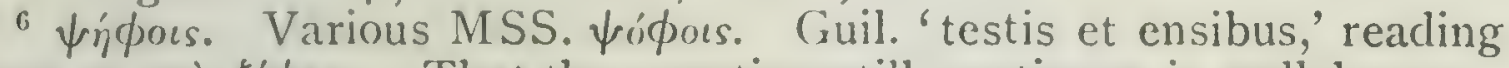

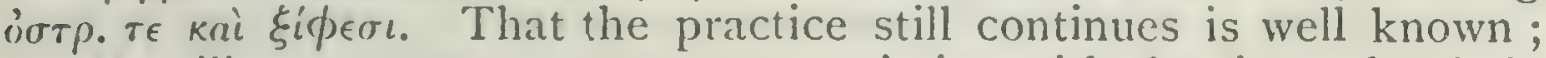
the Vergilian passage suggests an association with the rites of Cybele as its probable origin. 
alarm. They expel from the hive all idlers and unthrifts. 20 As has been said, they differentiate their work; some make wax, ${ }^{1}$ some make honey, some make bee-bread, some shape and mould combs, some bring water to the cells and mingle it with the honey, some engage in out-of-door work. At carly dawn they make no noise, until some one particular bee makes a buzzing noise two or three times and thercby awakes the rest; hereupon 25 they all fly in a body to work. By and by they return and at first are noisy; then the noise gradually decreases, until at last some one bee flies round about, making a buzzing noise, and apparently calling on the others to go to sleep; then all of a sudden there is a dead silence. ${ }^{2}$ The hive is known to be in good condition if the noise heard within it is loud, and if the bees make a flutter as they go out and in; for at this time they are constructing 30 brood-cells. They suffer most from hunger when they recommence work after winter. They become somewhat lazy if the bec-kecper, in robbing the hive, leave behind too much honey;" still one should leave cells numerous in proportion to the population, for the bees work in a $627^{\mathrm{b}}$ spiritless way if too few combs are left. They become idle also, as being dispirited, if the hive be too big. $A$ hive yiclds to the bee-lieeper six or nine pints of honey; a prosperous hive will yield twelve or fifteen pints, exceptionally good hives eighteen. Sheep ${ }^{4}$ and, as has been said, 5 wasps are enemies to the bees. ${ }^{5}$ Bee-kecpers entrap the latter, by putting a flat dish on the ground with pieces of meat on it; when a number of the wasps settle on it, they cover them with a lid and put the dish and its contents on the firc. It is a good thing to have a few drones in a hive. 10 as their presence increases the industry of the workers.

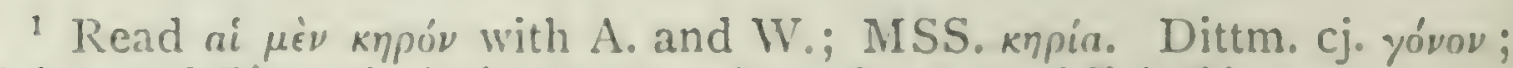

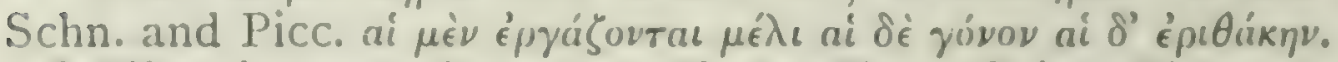

2 Plin. xi. 10; Ael.v. I1. Cf. also Verg. G. iv. 186-9o.

y Plin. xi. 14; Colum. ix. 15.

${ }^{4}$ mpóßarov, bracketed by A. and W., is amply supported by Plin. xi. I9) 'Inimicae et oves, dificile se a lanis earum explicantibus'. Schn. suggests, in like manner, ai öies for öpets in Ael. i. 5 S.

Ael. i. 58. 
Bees can tell the approach of rough weather or of rain; and the proof is that they will not fly away, but even while it is as yet fine they go fluttering about within a restricted space, and the bee-keeper knows from this that they are expecting bad weather. ${ }^{1}$ When the bees inside the hive hang clustering to one another, it is a sign that the swarm is intending to quit ; ${ }^{2}$ consequently, bee-keepers, on seeing I5 this, besprinkle the hive with sweet wine. It is advisable to plant about the hives pear-trees, beans, Median-grass, Syrian-grass, yellow pulse, myrtle, poppies, creeping-thyme, and almond-trees. Some bee-keepers sprinkle their bees with flour, and can distinguish them from others when they are at work out of doors. If the spring be late, or if there 20 be drought or blight, then grubs are all the fewer in the hives. ${ }^{3}$ So much for the habits of bees.

4I Of wasps, ${ }^{4}$ there are two kinds. Of these kinds one is wild ${ }^{5}$ and scarce, lives on the mountains, engenders grubs not underground but on oak-trees, is larger, longer, and 25 blacker than the other kind, is invariably speckled and furnished with a sting, and is remarkably courageous. The pain from its sting is more severe than that caused by the others, for the instrument that causes the pain is larger, in proportion to its own larger size. These wild wasps live over into a second year, and in winter time, when oaks $3 \circ$ have been in course of felling, they may be seen coming out and flying away. They lie concealed during the winter, and live in the interior of logs of wood. Some of them are mother-wasps and some are workers, as with the tamer kind; but it is by observation of the tame wasps that one may learn the varied characteristics of the mothers and the

1 Verg. G. iv. I9I ; Theophr. de Sign. fr.vi. 46; Plin. xi. 1o; Arat. Dios. 298 ;. Ael. i. I I, v. I3, \&c.

2 Varro, R. R. iii. I6. 29.

3 H. A. v. I9. $553^{\mathrm{b}} 20$.

${ }^{4} \sigma \phi \eta \hat{k} \epsilon s$, crabrones, Plin. xi. 24. $\sigma \phi \dot{\eta} \xi$ and $a \nu \theta \rho \dot{\eta} \nu \eta$ (cap. 42) are both wasps, but in our ignorance of the species inhabiting Greece it is impossible to identify the forms which Aristotle describes with manifest veracity.

5 'Crabronum silvestres in arborum cavernis degunt,' Plin.l.c. These are hornets, $V$. crabro, or a closely allied species. Cf. H.A. v. 23. $554^{\mathrm{b}} 22$, note. 
$628^{\mathrm{a}}$ workers. For in the case of the tame wasps also there are two kinds; one consists of leaders, who are called mothers, and the other of workers. The leaders are far larger and milder-tempered than the others. The workers do not live over into a second year, but all die when winter comes on; 5 and this can be proved, for at the commencement of winter the workers become drowsy, and about the time of the winter solstice they are never seen at all. The leaders, the so-called mothers, are seen all through the winter, and live in holes underground ; for men when ploughing or digging in winter have often come upon mother-wasps, but never ro upon workers. The mode of reproduction of wasps is as follows. At the approach of summer, when the leaders have found a sheltered ${ }^{1}$ spot, they take to moulding their combs, and construct the so-called sphecons, - little nests containing four cells ${ }^{2}$ or thereabouts, and in these are produced working-wasps but not mothers. When these I5 are grown up, then they construct other larger combs upon the first, and then again in like manner others; so that by the close of autumn there are numerous large combs, in which the leader, the so-called mother, engenders no longer working-wasps but mothers. These develop high up in the nest as large grubs, in cells that occur in groups 20 of four or rather more, pretty much in the same way as we have seen the grubs of the king-bees to be produced in their cells. ${ }^{3}$ After the birth of the working-grubs in the cells, the leaders do nothing and the workers have to supply them with nourishment; and this is inferred from

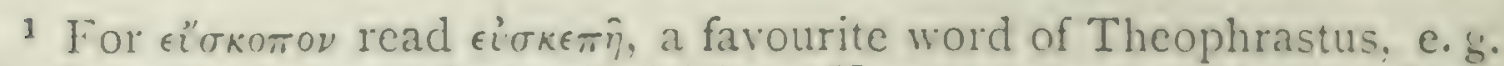

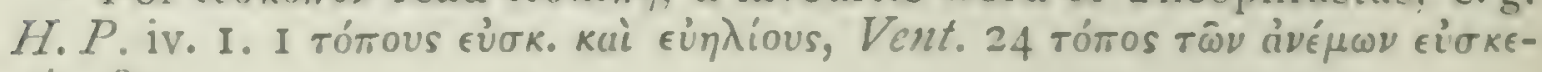
$\pi \dot{\eta} s, \mathbb{Q}$.

wow terpatipous. Whether this word be correct or not, the meaning is certainly 'containing four cells (Oupiôes)' and not 'provicled with four

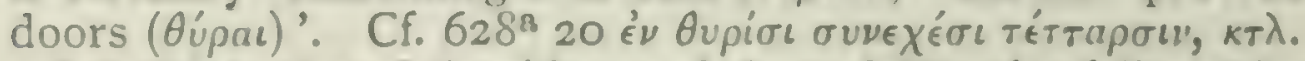

"I think that Schneider, and $\mathrm{A}$. and $\mathrm{W}$. who follow him, are right in attributing this comparison to the cells of the king-bee rather than to the original group of four cells that form the foundation

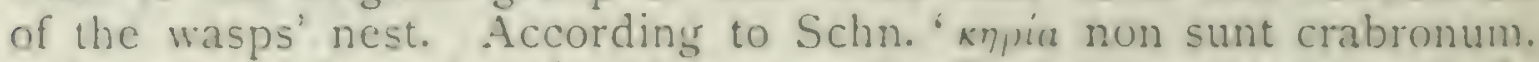
sed apum; igitur etiam ingexóres apum intelliguntur, et comparatio fit cellarum utriusque generis ducum'. It is the case that queens, and males also, are not developed until towards autumn, at which time larger cells are constructed for the reception of the eggs which are to produce them. 
the fact that the leaders [of the working-wasps] ${ }^{1}$ no longer fly out at this time, but rest quietly indoors. Whether the 25 leaders of last year after engendering new leaders are killed by the new brood, and whether this occurs invariably or whether they can live for a longer time, has not been ascertained by actual observation; neither can we speak with certainty, as from observation, as to the age attained by the mother-wasp or by the wild wasps, or as to any other similar phenomenon. The mother-wasp is broad and $3 \circ$ heavy, fatter and larger than the ordinary wasp, and from its weight not very strong on the wing; these wasps cannot fly far, and for this reason they always rest inside the nest, building and managing its indoor arrangements. The so-called mother-wasps are found in most of the nests $;^{2}$ it is a matter of doubt whether or no they are provided with $628^{\mathrm{b}}$ stings; in all probability, like the king-bees, they have stings, but never protrude them for offence. Of the ordinary wasps some are destitute of stings, like the drone-bees, and some are provided with them. Those unprovided therewith are smaller and less spirited and never fight, while 5 the others are big and courageous; and these latter, by some, are called males, and the stingless, females. ${ }^{3}$ At the approach of winter many of the wasps that have stings appear to lose them; but we have never met an eyewitness of this phenomenon. Wasps are more abundant in times of drought and in wild localities: They live underground; ${ }^{4}$ ro their combs they mould out of chips and earth, each comb from a single origin, like a kind of root. They feed on certain flowers and fruits, but for the most part ${ }^{5}$ on animal food. Some of the tame wasps have been observed when sexually united, but it was not determined whether both, or neither, had stings, or whether one had a sting and the ${ }_{15}$ other had not; wild wasps have been seen under similar circumstances, when one was seen to have a sting but the case of the other was left undetermined. The wasp-grub

${ }^{1} \tau \hat{\omega} \nu \epsilon^{\prime} \rho \gamma a \tau \hat{\omega} \nu$ is apparently corrupt, and is deleted by A. and W.

${ }^{2}$ Plin. l.c. $\quad{ }^{3}$ The stingless wasps are the males; cf. $628^{\mathrm{b}} 20$.

${ }^{4}$ Cf. V. rufa, germanica, \&c.

${ }^{5}$ Dittm. reads $\tau \dot{\eta} \nu \delta \dot{\epsilon} \pi \lambda \epsilon i \sigma \tau \eta \nu \nu\left\langle{ }^{\prime \prime} \chi 0 v \sigma \iota \nu\right\rangle . \quad \tau \hat{\eta} \delta \dot{\epsilon} \pi \lambda \epsilon i \sigma \tau \eta$ would seem the simplest reading. 
does not appear to come into existence by parturition, for at the outset the grub is too big to be the offspring of a wasp. If you take a wasp by the feet and let him buzz 20 with the vibration of his wings, wasps that have no stings will fly towards it, and wasps that have stings will not; ${ }^{1}$ from which fact it is inferred by some that one set are males and the other females. In holes in the ground in winter-time wasps are found, some with stings, and some without. Some build cells, small and few in number; 25 others build many and large ones. The so-called mothers are caught at the change of season, mostly on elm-trees, while gathering a substance sticky and gumlike. A large number of mother-wasps are found when in the previous year wasps have been numerous and the weather rainy; they are captured in precipitous places, or in vertical clefts 30 in the ground, and they all appeal to be furnished with stings.

So much for the habits of wasps.

Anthrenae ${ }^{2}$ do not subsist by culling from flowers as bees do, but for the most part on animal food: for this reason they hover about dung; for they chase the large flies, and after catching them lop off their heads and fly $629^{a}$ away with the rest of the carcases; they are furthermore fond of sweet fruits. Such is their food. They have also kings or leaders ${ }^{3}$ like bees and wasps; and their leaders 5 are larger in proportion to themselves than are wasp-kings to wasps or bec-kings to bees. The anthrena-king, like the wasp-king, lives indoors. Anthrenae build their nests

1 Antig. Mirab. lvii.

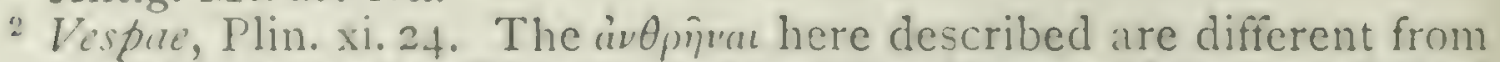
those of $H . A . Y .20$. The present species is strongly suggestive of Bembex rostrata, a large wasp of southern Europe, which bites off the heards of large gadflies, carries their bodies home hugged to its breast, and burrows rapidly in sandy soil. Bembex, however, is solitary: accordingly, the Aristotelian account of the colony and nest must either be based on investigation of an unknown species or may have become inaccurate through confusing the large underground nest of Pispo rufa or some similar common species with that of Bembex itself.

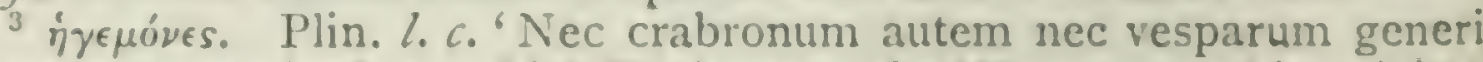
reges aut examina', on which Cuvier remarks 'Non monarchica civitas vesparum ; plures simul mares, plures feminae? 
underground, scraping out the soil like ants; for neither anthrenae nor wasps go off in swarms as bees do, but successive layers of young anthrenae keep to the same ro habitat, and go on enlarging their nest by scraping out more and more of soil. The nest accordingly attains a great size; in fact, from a particularly prosperous nest have been removed three and even four baskets full of combs. They do not, like bees, store up food, but pass the winter in a torpid condition; the greater part of them die in the 15 winter, but it is uncertain whether that can be said of them all. In the hives of bees several kings are found and they lead off detachments in swarms, but in the anthrena's nest only one king is found. When individual anthrenae have strayed from their nest, they cluster on a tree and construct combs, ${ }^{1}$ as may be often seen above-ground, and in this 20 nest they produce a king; when the king is full-grown, ${ }^{2}$ he leads them away and settles them along with himself in a hive or nest. With regard to their sexual unions, ${ }^{3}$ and the method of their reproduction, nothing is known from actual observation. Among bees both the drones and the kings are stingless, and so are certain wasps, as has been said; 25 but anthrenae appear to be all furnished with stings: though, by the way, it would well be worth while to carry out investigation as to whether the anthrena-king has a sting or not.

43 Humble-bees ${ }^{4}$ produce their young under a stone, right on the ground, in a couple of cells or little more; in these cells is found an attempt at honey, of a poor description. 30 The tenthredon 5 is like the anthrena, but speckled, and about as broad as a bee. Being epicures as to their food, they fly, one at a time, into kitchens and on to slices of

1 This would seem to refer to a different species.

${ }^{2}$ Guil. 'iste autem cum creverit, egrediens abducit accipiens', whence

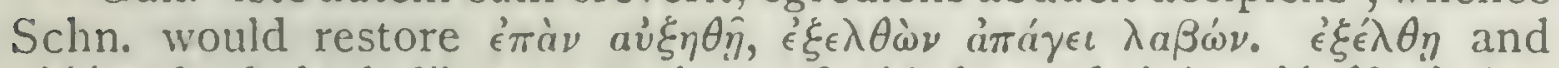

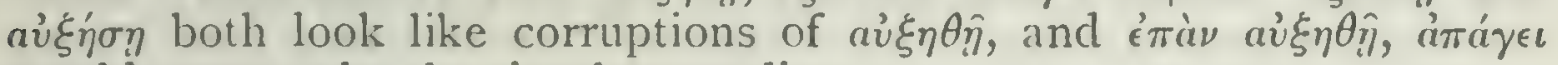
would seem to be the simplest reading.

${ }^{3}$ de Gen. iii. Io. 761 ${ }^{2} 2$.

${ }^{4} H . A . v .23 \cdot 554^{\mathrm{b}} 22$.

- A species of wasp, unidentified; probably one of the species already alluded to under $\sigma \phi \eta \dot{\xi} \xi$. Sundevall considers the passage to be an interpolation. 
fish and the like dainties. The tenthredon brings forth, like the wasp, underground, and is very prolific; its nest $629^{\mathrm{b}}$ is much bigger and longer than that of the wasp. So much for the methods of working and the habits of life of the bee, the wasp, and all the other similar insects.

5 A.s regards the disposition or temper of animals, as has 44 been previously observed, ${ }^{1}$ one may detect great differences in respect to courage and timidity, as also, even among wild animals, in regard to tameness and wildness. The lion, while he is eating, ${ }^{2}$ is most ferocious; but when he is not hungry and has had a good meal, he is quite gentle. ro He is totally devoid of suspicion or hervous fear, is fond of romping with animals that have been reared along with him and to whom he is accustomed, and manifests great affection towards them. In the chase, ${ }^{3}$ as long as he is in view, he makes no attempt to run and shows no fear, but even if he be compelled by the multitude of the hunters to retreat, he withdraws deliberately, step by step, every now 15 and thent turning his head to regard his pursuers. If, however, he reach wooded cover, then he runs at full speed, until he comes to open ground, when he resumes his leisurely retreat. When, in the open, he is forced by the number of the hunters to run while in full view, he does run at the top of his speed, but without leaping and bounding. This running of his is evenly and continuously kept up like the running of a dog; but when he is in 20 pursuit of his prey and is close behind, he makes a sudden pounce upon it. The two statements made regarding him are quite true; the one that he is especially afraid of fire. as Homer pictures him in the line-' and glowing torches,

1 H. A. viii. I. $588^{\mathrm{a}}$ 14, ix. $3.610^{\mathrm{b}} 20$.

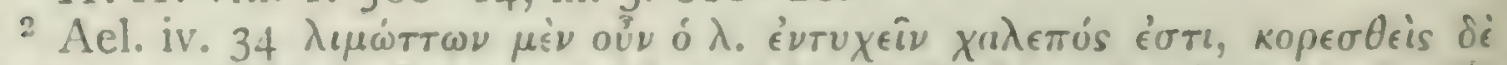

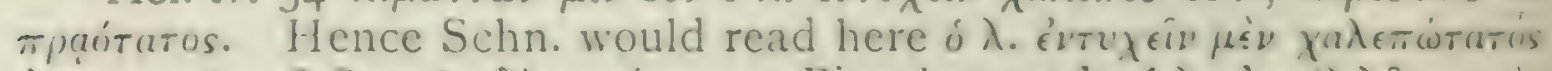

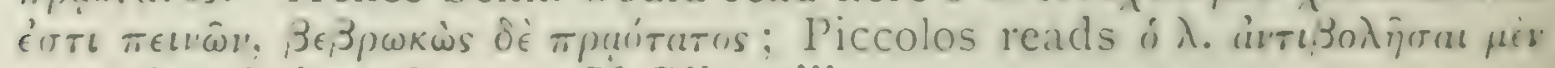

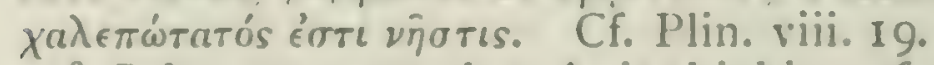

${ }^{3}$ Schn. suggests that A. is thinking of 11 . xi. 545 (within a few lines

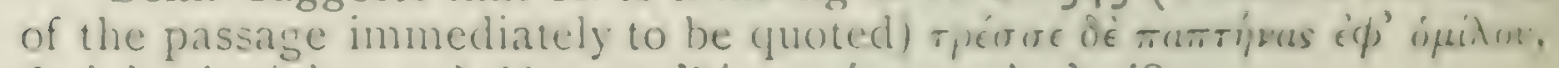

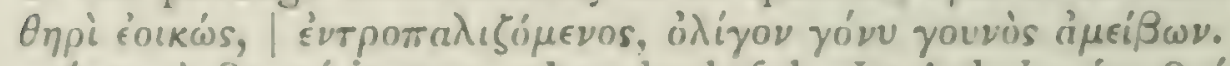

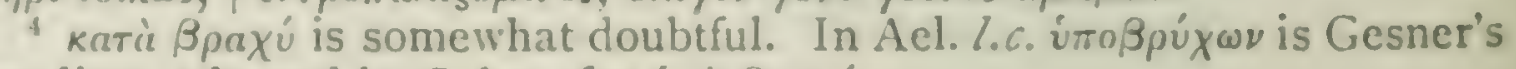
reading, adopted by Schn., for írò $\beta \rho a \chi u ́$. 
flows from the wounded parts suppurating matter, quite yellow, and not to be stanched by bandage or sponge; the treatment for such a wound is the same as that for the bite of a dog.

The thos, or civet, is fond of man's company $;^{1}$ it does him to no harm and is not much afraid of him, but it is an enemy to the dog and the lion, and consequently is not found in the same habitat with them. The little ones are the best. Some say that there are two species of the animal, and some say, three; there are probably not more than three, but, as is the case with certain of the-fishes, birds, and quadrupeds, 15 this animal changes in appearance with the change of scason. His colour in winter is not the same as it is in summer $;^{2}$ in summer the animal is smooth-haired, in winter he is clothed in fur.

The bison is found in Paeonia on Mount Messapium, 4 which separates Paeonia from Maedica; and the Paeonians 20 call it the monapos. ${ }^{3}$ It is the size of a bull, but stouter in build, and not long in the body; its skin, stretched tight on a frame, would give sitting room for seven people. In general it resembles the ox in appearance, except that it has a mane that reaches down to the point of the shoulder, as that of the horse reaches down to its withers; but the 25 hair in its mane is softer than the hair in the horse's mane, and clings more closely. The colour of the hair is brownyellow; the mane reaches down to the eyes, and is deep and thick. The colour of the body ${ }^{4}$ is half red, half ashengrey, like ${ }^{5}$ that of the so-called chestnut horse, but rougher. It has an undercoat of woolly hair. The animal is not 3o found either very black or very red. It has the bellow of a bull. Its horns are crooked, turned inwards towards each other and uscless for purposes of self-defence; they are a span broad, or a little more, and in volume each horn

${ }^{1}$ Ael. i. 7. Cf. notes, ii. 17. $507^{\mathrm{b}}$ 17, vi. 35.580a 27.2 Ael. xii. 28.

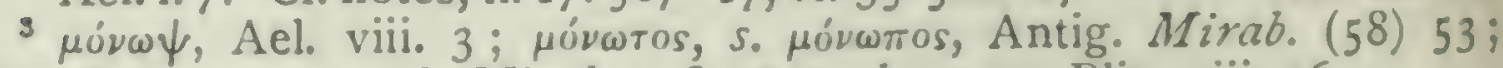

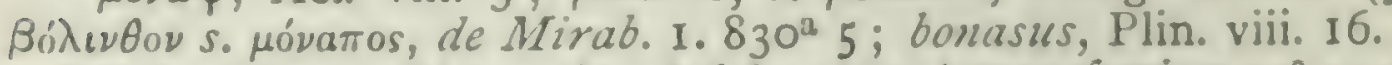

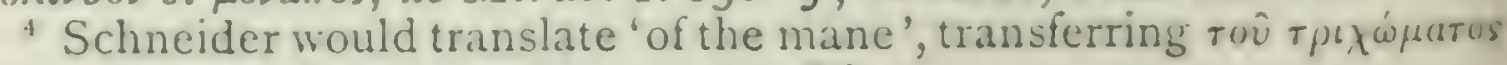
from the preceding sentence; so also Dittm.

'MSS. have oix wiv. A. and W. and Dittm., following Gesner and the early translators, omit oux. 
would hold about three pints of liquid; the black colour of the horn is beautiful and bright. The tuft of hair on the forehead reaches down to the eyes, so that the animal sees ${ }^{1} 630^{b}$ objects on either flank better than objects right in front. It has no upper teeth, as is the case also with kine and all other horned animals. Its legs are hairy; it is clovenfooted, and the tail, which resembles that of the ox, seems not big enough for the size of its body. It tosses up dust 5 and scoops out the ground with its hooves, like the bull. Its skin is impervious to blows. Owing to the savour of its flesh it is sought for in the chase. When it is wounded it runs away, and stops only when thoroughly exhausted. It defends itself against an assailant by kicking and projecting its excrement to a distance of eight yards; this device it can easily adopt over and over again, and the ro excrement is so pungent that the hair of hunting-dogs is burnt off by it. It is only when the animal is disturbed or alarmed that the dung has this property; when the animal is undisturbed it has no blistering effect. So much for the shape and habits of the animal. When the season comes for parturition the mothers give birth to their young in troops upon the mountains. Before dropping their young is they scatter their dung in all directions, making a kind of circular rampart around them; for the animal has the faculty of ejecting excrement in most extraordinary quantities.

46 Of all wild animals the most easily tamed and the gentlest is the elephant. It can be taught a number of tricks, the drift and meaning of which it understands; as, for instance, it can be taught to kneel in presence of the 20 king. ${ }^{2} \quad$ It is very sensitive, and possessed of an intelligence superior to that of other animals. When the male has had sexual union with the female, and the female has conceived, the male has no further intercourse with her. ${ }^{3}$

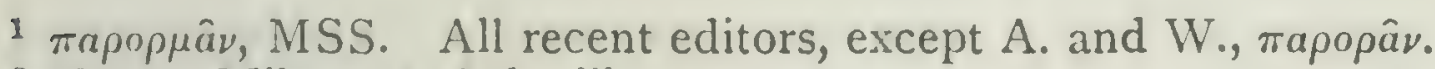

2. Hecat. Miles, $a p$. Ael, xiii. 22.

${ }^{3}$ Cf. H. A. v. I $4 \cdot 546^{\text {b }}$ Io. Beckmann has pointed out that this clause is transferred by Antig. (l.c.) to the description of Bóvaosos. 
Some say that the elephant lives for two hundred years; others, for one hundred and twenty ${ }^{1}$ that the female lives nearly as long as the male; that they reach their prime 25 about the age of sixty, and that they are sensitive to inclement weather and frost. The elephant is found by the banks of rivers, but he is not a river animal; he can make his way through water, as long as the tip of his trunk can be above the surface, for he blows with his trunk and breathes through it. ${ }^{2}$ The animal is a poor swimmer owing to the 30 heavy weight of his body.

The male camel declines intercourse with its mother; 47 if his keeper tries compulsion, he evinces disinclination. On one occasion, when intercourse was being declined by the young male, the keeper covered over the mother and put the young male to her ; but, when after the intercourse ${ }^{3}$ the wrapping had been removed, though the operation was completed and could not be revoked, still by and by he bit $63^{2}$ his keeper to death. ${ }^{4}$ A story goes ${ }^{j}$ that the king of Scythia had a highly-bred mare, and that all her foals were splendid; that wishing to mate the best of the young males with the mother ${ }^{6}$ he had him brought to the stall for the purpose ; that the young horse declined; that, after the mother's head had been concealed in a wrapper he, in ignorance, had intercourse; and that, when immediately 5 afterwards the wrapper was removed and the head of the mare was rendered visible, the young horse ran away and hurled himself down a precipice.

Among the sea-fishes many stories are told about the 48 dolphin, indicative of his gentle and kindly nature, and of

${ }^{1}$ Plin. viii. Io 'Vivere ducentis annis, et quosdam trecentis': whence

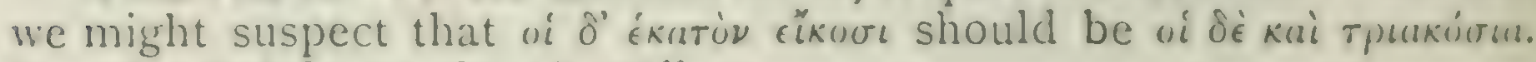
See also Ael. iv. 31, ix. 58, xvii. 7 .

2 H.A. ii. I. $497^{\mathrm{b}} 28 ;$ P. A. ii. 16. $659^{\mathrm{a}} 3 \mathrm{I}$; I'lin. viii. 10, 12 : A iv. 24 , vii. 15 .

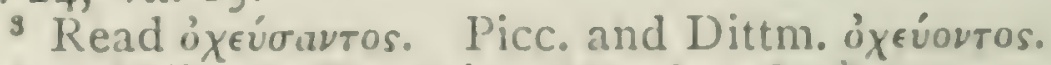

4 Ael. iii. 47 ; Ps. Arist. Mirab. 2. $830^{\mathrm{b}} 5$.

5 Ael.iv. 7; Antig. Mirab. 59; Plin. viii. (42) 64; Solin. 45; Varro, R. R. ii. 7, 9; Hierocles in Hippiatr., p. 173.

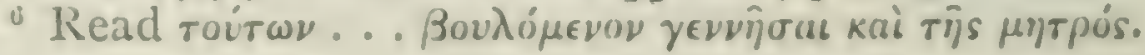


manifestations of passionate attachment to boys, ${ }^{1}$ in and about Tarentum, Caria, and other places. The story goes ${ }^{2}$ Io that, after a dolphin had been caught and wounded off the coast of Caria, a shoal of dolphins came into the harbour and stopped there until the fisherman let his captive go free; whereupon the shoal departed." A shoal of young dolphins is always, by way of protection, followed by a $\mathbf{I}_{5}$ large one. On one occasion a shoal of dolphins, large and small, was seen, and two dolphins at a little distance ${ }^{4}$ appeared swimming in underneath a little dcad dolphin when it was sinking, and supporting it on their backs, trying out of compassion to prevent its being devoured by some predaceous fish. Incredible stories are told regarding 20 the rapidity of movement of this creature. It appears to be the fleetest of all animals, marine and terrestrial, and it can leap over the masts of large vessels. ${ }^{5}$ This speed is chiefly manifested when they are pursuing a fish for food; then, if the fish endeavours to escape, they pursue him in 25 their ravenous hunger down to deep waters; but, when the necessary return swim is getting too long, they hold in their breath, as though calculating the length of it, and then draw themselves together ${ }^{6}$ for an effort and shoot up like arrows, trying to make the long ascent rapidly in order to breathe, and in the effort they spring right over a ship's masts if a ship be in the vicinity. This same 30 phenomenon is observed in divers, when they have plunged into deep water; that is, they pull themselves together and rise with a speed proportional to their strength. Dolphins $63^{\mathrm{b}}$ live together in pairs, male and femalc. It is not known for what reason they run themselves aground on dry land; at all events, it is said that they do so at times, and for no obvious reason.

1 Cf. Plin. ix. 8; Plin. (alt.) Ep. ix. 33; Solin. I2, \&c.

2 Plin. ix. Io; Ael.v. 6, xi. 12, xii.6; Antig. Mirab.6o, \&c.

3 Plin., loc. cit., begins the same story with 'Capto a rege Cariae alligatoque in portu'; Schn. adds 'Vides Plinium ridiculo crrore regem nominare ubi l'hilosophus ó ci $\lambda \iota \epsilon u ́ s$, quasi ó $\beta a \sigma \iota \lambda \epsilon u ́ s$ scriptum legrisset'.

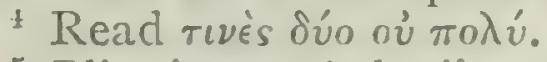

5 Plin. ix. 7; Ael. xii. I2.

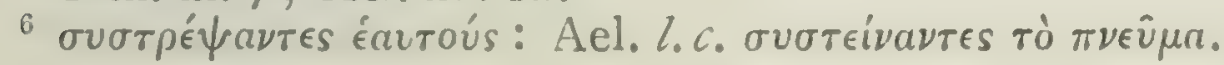
AR. $1 B . A$, $\mathrm{G} g$ 
5 Just as with all animals a change of action follows a 49 change of circumstance, so also a change of character follows a change of action, and often some portions of the physical frame undergo a change, as occurs in the case of birds. Hens, for instance, when they have beaten the cock in a fight, will crow like the cock and endeavour to tread to him: the crest rises up on their head and the tail-feathers on the rump, so that it becomes difficult to recognize that they are hens; in some cases there is a growth of small spurs. ${ }^{1}$ On the death of a hen a cock has becn scen to undertake the maternal duties, leading the chickens Is about and providing them with food, and so intent upon these duties as to cease crowing and inclulging his sexual propensitics. Some cocl-birds are congenitally so feminine that they will submit patiently to other males who attempt to tread them.

Some animals change their form and character, not only 50 20 at certain ages and at certain seasons, but in conseyuence of being castrated; and all animals possessed of testicles may be submitted to this opcration. Birds have their testicles inside, and oviparous quadrupeds close to the loins; and of viviparous animals that walk some have theni inside, and most have them outside, but all have them at 25 the lower end of the belly. Birds are castrated at the rump at the part where the two sexes unite in copulation. If you burn this twice or thrice with hot irons, then, if the bird be full-grown, his crest grows sallow, he ceases to crow, and foregoes sexual passion; but if you catuterize the bird when young, none of these male attributes or pro30 pensities will come to him as he grows up. The case is the same with men: if you mutilate them in boyhood, the

1 The hen that assumed the voice and plumage of the male was often referred to as an omen or portent, e. g. Terent. Phorm. iv. 4. 30 'gallina cecinit'; Liv. xli. 6'gallinam in gallum, gallum in gallinam versum': sec also Ael. v. 5. For an account of such superstition

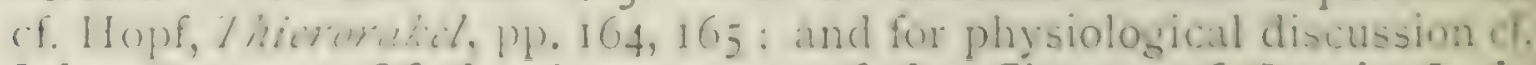
John Hunter, 'Of the Appearance of the Change of Sex in Lady 'Tynte's Peahen,' Phil. Trans. lxx, p. 534; G. St. Hilaire, Fimelle's du faisan ì plumage des mâles, Paris, 1826; Yarrell, On the Change of Plumage of some Hen Pheasunts, London, 1827 , \&.c. 
later-growing hair never comes, and the voice never changes but remains high-pitched; if they be mutilated in early $63^{a}$ manhood, the late growths of hair quit them except the growth on the groin, and that diminishes but does not entirely depart. The congenital growths of hair never fall out, for a eunuch never grows bald. In the case of all castrated or mutilated male quadrupeds the voice changes 5 to the feminine voice. All other quadrupeds when castrated, unless the operation be performed when they are young, invariably die; but in the case of boars, and in their case only, the age at which the operation is performed produces no difference. All animals, if operated on when they are young, become bigger and better looking than their unmutilated fellows; if they be mutilated when full-grown. they do not take on any increase of size. If stags be 10 mutilated when, by reason of their age, they have as yet no horns, they never grow horns at all; if they be mutilated when they have horns, the horns remain unchanged in size, and the animal does not lose them. Calves are mutilated when a year old; otherwise, they turn out uglier and smaller. Steers are mutilated in the following way: they $1 \%$ turn the animal over on its back, cut a little off the scrotum ${ }^{1}$ at the lower cnd, and squeeze out the testicles, then push back the roots of them as far as they can, and stop up the incision with hair to give an outlet to suppurating matter; if inflammation ensues, they cauterize the scrotum and put on a plaster. If a full-grown bull be -0 mutilated, he can still to all appearance unite sexually" with the cow. The ovaries of sows are excised with the view of quenching in them sexual appetites and of stimulating growth in size and fatness. The sow has first to be kept two days without food, and, after being hung up by the hind legs, it is operated on ; they cut the lower belly, about the place where the boars have their testicles, for it is there that the ovary grows, adhering to the two divisions 2: (or horns) of the womb; they cut off a little piece and stitch up the incision. Female camels are mutilated when they

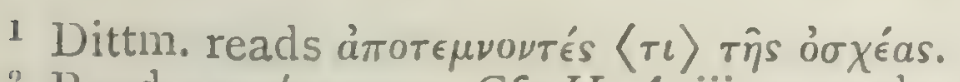

2 Read ougrivortur. Cf. H. A. iii. I. $510^{\mathrm{b}} 3 ;$ G. A. i. $4.717^{\mathrm{b}} 13$. 
are wanted for war purposes, and are mutilated to prevent their being got with young. Some of the inhabitants of Upper Asia have as many as three thousand camels: when they run, ${ }^{1}$ they run, in consequence of the length of their 30 stride, much quicker than the horses of Nisaca." As a general rulc, mutilated animals grow to a greater length than the unmutilated.

All animals that ruminate derive profit and pleasure from the process of rumination, as they do from the process $632^{\mathrm{b}}$ of cating. It is the animals that lack the upper tecth that ruminate, such as kine, sheep, and goats. In the case of wild animals no observation has been possible; save in the case of animals that are occasionally domesticated, such as the stag, and it, we know, chews the cud. All animals that ruminate generally do so when lying down on the 5 ground. They carry on the process to the greatest extent in winter, and stall-fed ruminants carry it on for about seven months in the year; beasts that go in herds, as they get their food out of cloors, ruminate to a lesser degree and over a lesser period. Some, also, of the animals that have weth in both jaws ruminate; as, for instance, the Pontic 10 mice, and the fish which from the habit is by some called 'the Ruminant', [as well as other fish].4

Long-limbed animals have loose faeces, and broadchested animals romit with comparative facility, and these remarks are, in a general way, applicable to quadrupeds, birds, and men.

A considerable number of birds change according to 49 15 scatson the colour of their plumage and their note: as, for instance, the owsel becomes yellow instead of black and its note gets altered, for in summer it has a musical note and in winter a discordant chatter: ${ }^{5}$ The thrush also changes its colour: about the throat it is marked in winter

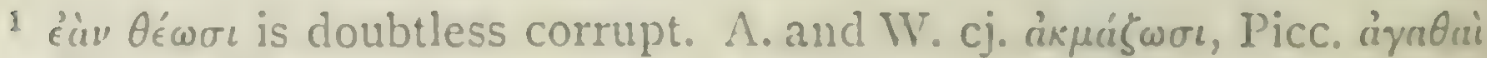

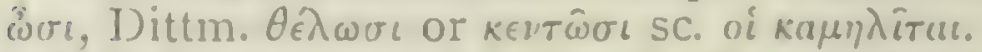

2 In Khorassan. Cf. Herod. vii. 40; Arrian, Exp. Alc. vii. I 3 , LE.

3 l'lin. viii. $82, x .73$.

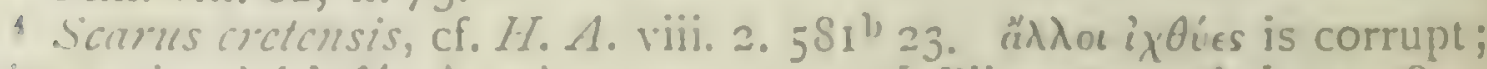
Dittm. cj. kai ó ix $\theta$ ís, ûn kai. 
with speckles like a starling, in summer distinctly spotted: however, it never alters its note. The nightingale, when 20 the hills are taking on verdure, sings continually for fiftcen days and fifteen nights; afterwards it sings, but not continuously. ${ }^{1}$ As summer advances it has a clifferent song, not so varied as before, nor so deep, nor so intricately modulated, but simple; it also changes its colour, and in 2.5 Italy about this season it goes by a different name. It goes into hiding, and is consequently visible only for a brief period. ${ }^{2}$

The erithacus (or redbreast) and the so-called redstart change into one another ;" the former is a winter bird, the latter a summer one, and the difference between them is practically limited to the coloration of their plumage. 30 In the same way with the beccafico and the blackcap; these change into one another. ${ }^{t}$ The beccafico appears about autumn, and the blackcap as soon as autumn has ended. These birds, also, differ from one another only in $633^{\text {a }}$ colour and note; that these birds, two in name, are one in reality is proved by the fact that at the period when the change is in progress each one has been seen with the change as yet incomplete. ${ }^{5}$ It is not so very strange that in these cases there is a change in note and in plumage, for eren the 5 ring-dove ceases to coo in winter, and recommences cooing when spring comes in; in winter, however, when fine weather has succeeded to very stormy weather, this bird has been known to give its cooing note, to the astonishment of such as were acquainted with its usual winter silence. As a general rule, birds sing most loudly and ro most diversely in the pairing season. The cuclioo changes its colour, and its note is not clearly heard for a short time previous to its departure. It departs about the rising of the Dog-star, and it reappears from springtime to the rising of the Dog-star. At the rise of this star the bird called by some ocnanthe disappears, and reappears when $r_{5}$

Plin. $x .43$.

Cf. Plin. x. 44 ; Geopon. xv. I. 22.

$2 H \cdot A \cdot v \cdot 9 \cdot 542^{\mathrm{b}} 27$.

Alex. Mynd. ap. Athen. ii. p. 65.

Read $\mu \in \tau a \beta \in \beta \lambda \eta \kappa o ́ \tau a$ and ö $\nu \tau a$. 
it is setting: ' thus keeping clear at one time of extreme cold, and at another time of extreme heat. The hoopoe also changes its colour and appearance, ${ }^{2}$ as Aeschylus has represented in the following lines ${ }^{3}$ :--

The Hoopoe, witness to his own distress,

Is clad by Zeus in variable dress :-

Now a gay mountain-bird, with knightly crest,

Now in the white hawk's silver plumage drest;

For, timely changing, on the hawk's white wing

He greets the apparition of the Spring.

Thus twofold form and colour are conferred,

In youth and agc, upon the selfsame bird.

The spangled raiment marks his youthful days,

25 The argent his maturity displays ;

And when the fields are yellow with ripe corn

Again his particoloured plumes are worn.

But evermore, in sullen discontent,

He sceks the lonely hills, in self-sought banishment.

Of birds, some take a dust-bath by rolling in dust, some take a water-bath, and some take neither the one bath nor the other. ${ }^{4}$ Birds that do not fly but keep on the ground

$633^{\mathrm{b}}$ take the dust-bath, as for instance the hen, the partridge, the francolin, the crested lark, the pheasant; some of the straight-taloned birds, and such as live on the banks of a river, in marshes, or by the sea, take a water-bath; some birds take both the dust-bath and the water-bath, as for instance the pigeon and the sparrow; of the crooked-taloned 5 birds the greater part take neither the one bath nor the other. So much for the ways of the abore-mentioned,-but some birds have a peculiar habit of making a noise at their hinder quarters, as, for instance, the turtle-dore; ${ }^{5}$ and they make a riolent morement of their tails at the same time that they produce this peculiar sound.

1 Plin. x. 45, xviii. 69.

2 Jlin. x. 44 .

Nauck, fr. 297. For various readings see Schneider and the

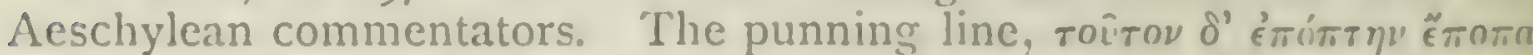

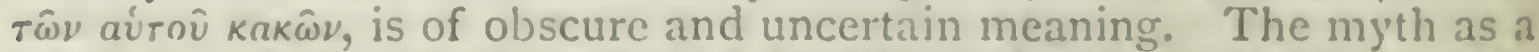
whole is subtle. complicated. and loubtless of greater antiquity. On the zonlogical side, it is based on the similarity of note in the hoopre and cuckoo, and on the hawk-like appenrance of the latter bird.

+ Athen. ix. p. 387.

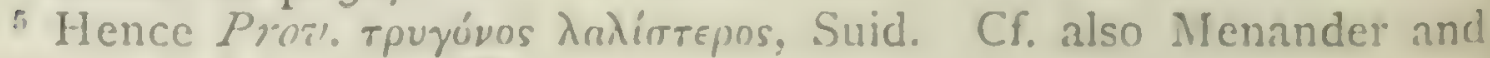
others, ap. Ael. xii. 10, Sc. 


\section{A LIST OF SUGGESTED TEXTUAL ALTERATIONS}

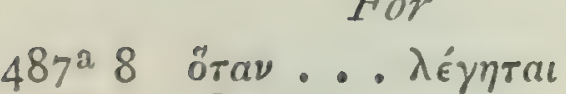

$488^{\mathrm{a}} 27$ oิ

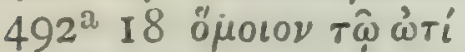

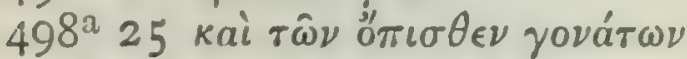

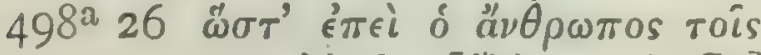

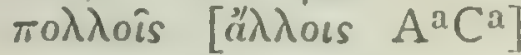

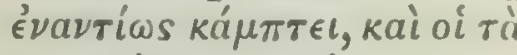

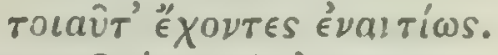

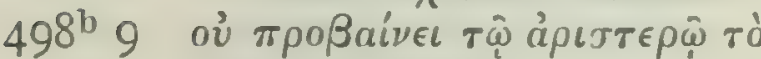

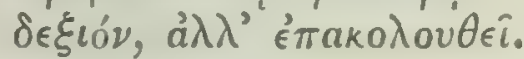

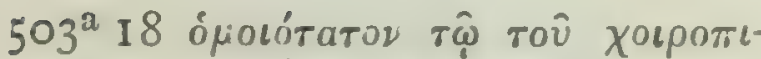

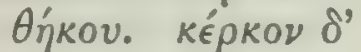

$507^{a} 20$ kai oi $\nu \in \phi \rho \circ$ roís ËX

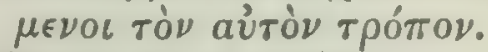

5I $3^{a} 2$ I $\tau \in \theta \nu \in \hat{\omega} \sigma \iota \tau \dot{o} \nu \in \nu \rho \hat{\omega} \delta \epsilon s$

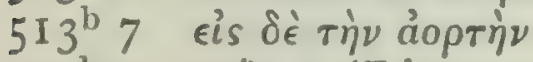

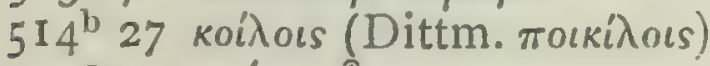

$515^{a} 24$ taútas ivas

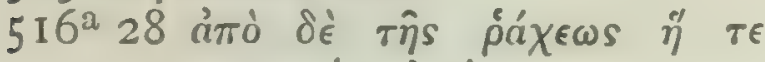

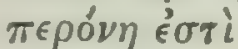

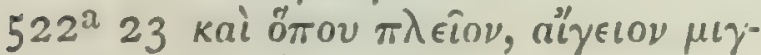

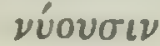

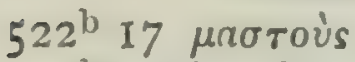

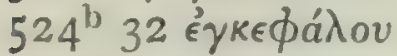

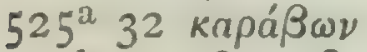

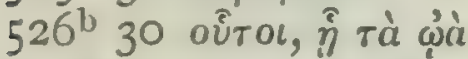

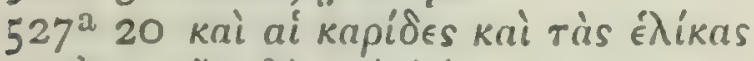

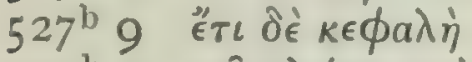

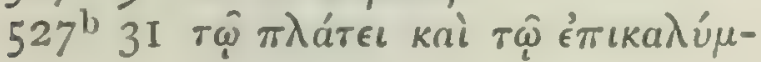

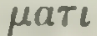

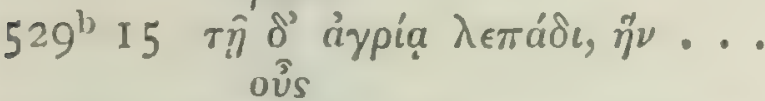

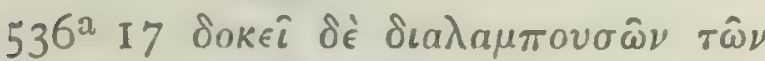

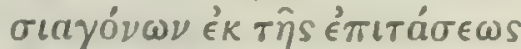

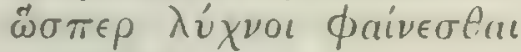
oi ỏ $\phi \theta a \lambda \mu o i ́$.

$537^{2} 5$ iोiбконтає

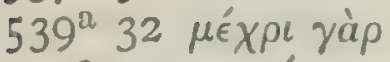

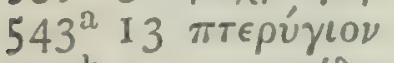

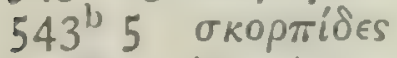

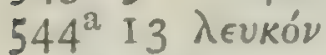

$545^{\circ} 27$ єैт

$54^{\mathrm{b}} 25$ Màं́a

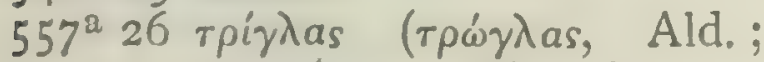

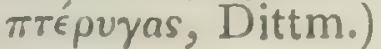

\section{Read}

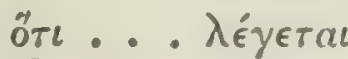

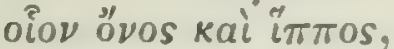

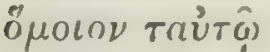

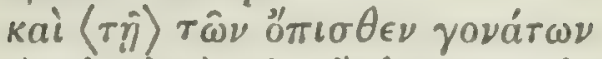

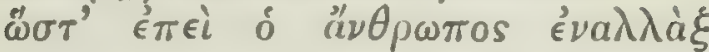

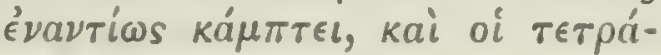

$\pi \circ \delta \in \mathcal{C}^{\epsilon} \nu a \nu \tau i \omega s$.

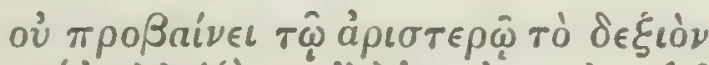

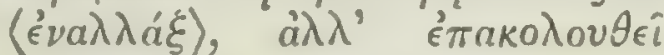
(s. $-\theta \omega s)$.

ó ке́ркор $\delta^{\prime}$

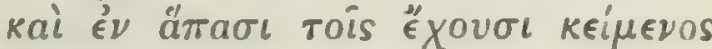

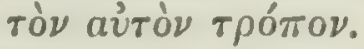

$\tau \in \theta \nu \in \hat{\omega} \sigma \iota \nu \stackrel{a}{\epsilon} \rho \hat{\omega} \delta \in S$

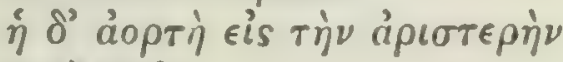

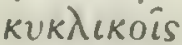

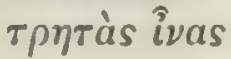

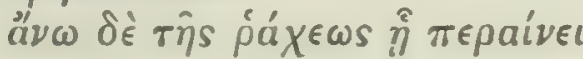

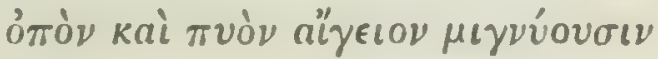

$\mu a \sigma \tau \in \dot{v} \sigma \epsilon \iota s$

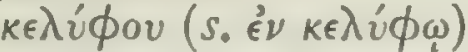

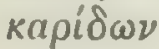

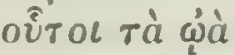

kaì oi kápaßoı kai oi ảotakoì

$\eta \tilde{\eta} \tau \in \kappa \in \phi a \lambda \dot{\eta}$

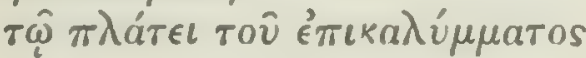

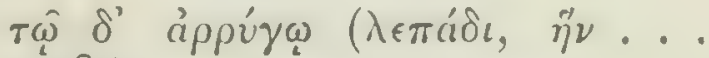
oủs).

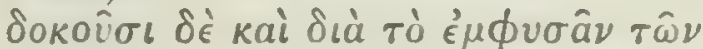

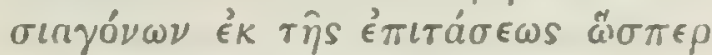

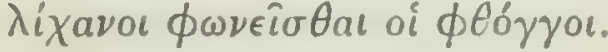

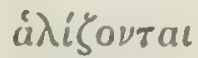

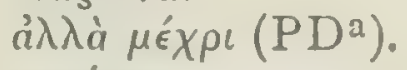

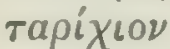

$\sigma \kappa о \mu \beta \rho i \delta \epsilon s$

$\lambda \in i \cap \nu$

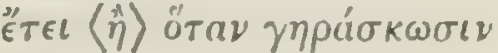

Ma入ía

Bprígxia 


\section{SUGGESTED TEXTUAL AITERATIONS}

\section{For}

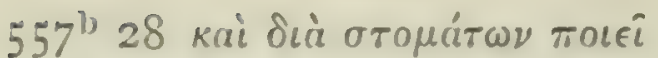
$560^{2} 28$ àp $\chi \hat{\eta}$

$56 \mathrm{I}^{\mathrm{a}}$ I6 $\lambda$ єUкоे

$567^{\mathrm{b}}$ I eis toùs tótrous eis oûs Ék-

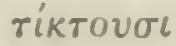

$57 I^{a} 22 \pi 0 \lambda \dot{v}$

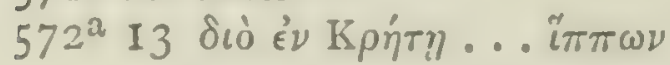

$577^{a} 8 \pi \dot{\omega} \lambda$ ov

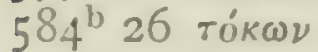

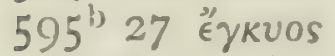

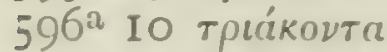

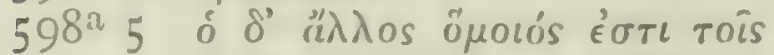

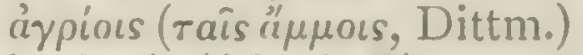

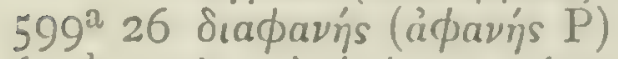

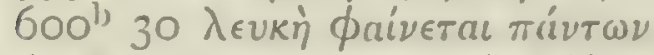

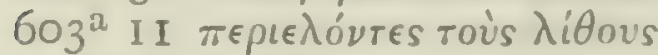

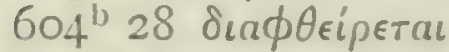

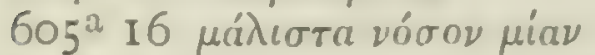

$605^{\mathrm{a}} 25$ ย่à

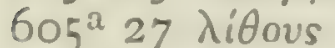

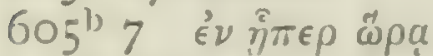

$606^{a} 26-606^{b} 2$ ót $2 . . x$ ро́vยcs

6o7") I5 kapis

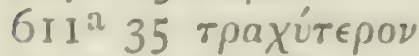

$612^{2} 34$ àkpíoa

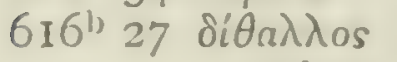

$617^{\mathrm{a}} 3 k a \lambda \hat{\omega} s$

$$
\text { Dittm.) }
$$

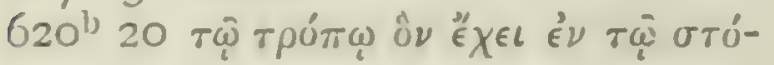
$\mu a \tau \iota$

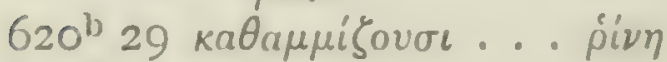

$622^{\text {b }}$ IO $\epsilon \pi i \tau i$

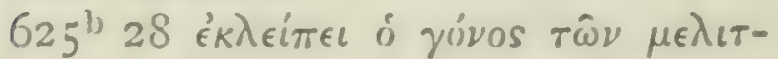

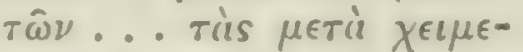

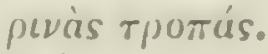

$626^{a}$ I9 $\pi 0 \lambda \lambda$ cíks

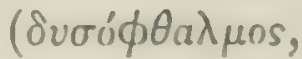

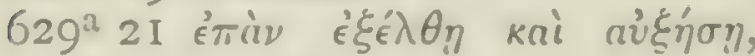

$629^{b} 27 \pi \dot{\lambda} \operatorname{sels}$ àmá $\gamma \in \iota$.

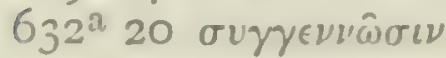

\section{Read}

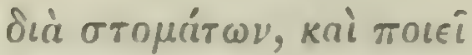

pa $\phi \bar{\eta}$

$\lambda \epsilon ́ K \iota \theta 0 \nu$

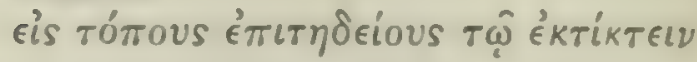

$\pi a ́ \nu v$

Transpose with following sentence.

$\pi \omega \lambda$ iov

тро́ $\pi \omega \nu$

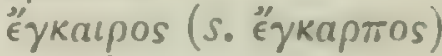

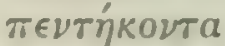

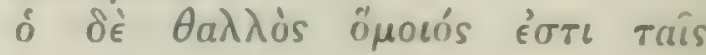
àykúpais

àфavpá

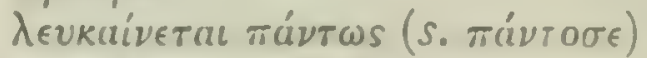

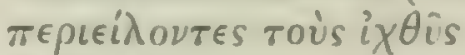

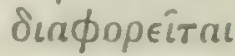

$\mu a \lambda\llcorner a \sigma \mu o ́ \nu$

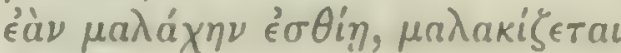

cìtrias

$\mu \in \tau o \pi \dot{\omega} \rho \circ v$

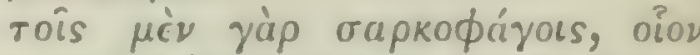
roís $\lambda$ úkois kai rois í́pa

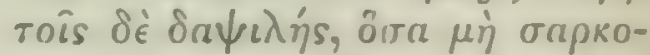

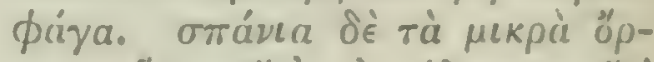

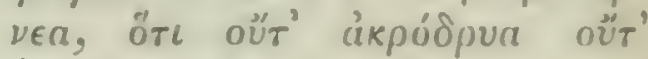
ỏm ́̀ pa xpónios.

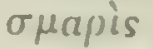

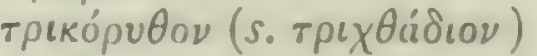

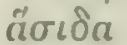

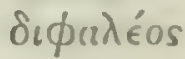

$\tilde{\delta} \lambda \omega s$

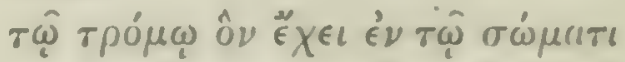

Omit.

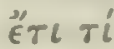

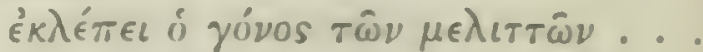

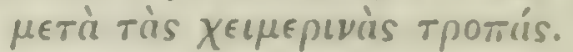

$\pi a \lambda \lambda a k o ́ s$

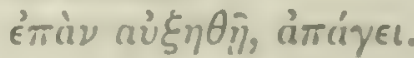

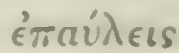

ovyrivovtai 


\section{INDEX}

Abdomen $493^{a}$ I 9.

Abomasum $507^{\mathrm{b}} 9$.

Abraxas $55^{\mathrm{b}} \mathrm{I}^{6}$ note.

Acalephae, or sea anemones, or sea-nettles $487^{\mathrm{a}} 26,^{\mathrm{b}}$ I $3,5^{58} 8^{\mathrm{b}}$ $20,590^{a} 27$; description $53^{\mathrm{I}}$ $32-\mathrm{b} 16$.

Acanthias $565^{\mathrm{a}} 29,{ }^{\mathrm{b}} 27,62 \mathrm{I}^{\mathrm{b}}$ I 7 . Acanthis, or linnet, diet of $592^{\mathrm{b}} 30$; habits of $616^{b} 31$; hostilities of $6 \mathrm{IO}^{\mathrm{a}} 4$.

Acanthomys $58 \mathrm{I}^{2} 33$ note.

Accident, or property $486^{\mathrm{b}} 5$.

Acetabulum $493^{2} 24$.

Achaeine stag $506^{\mathrm{a}} 23,6 \mathrm{II}^{\mathrm{b}}$ I8.

Acharnas, diet of $59 \mathrm{I}^{\mathrm{b}} \mathrm{I}$; seasons of $602^{2} \mathrm{I} 2$.

Achelous $535^{\mathrm{b}}$ I $8,579^{\mathrm{b}} 7,606^{\mathrm{b}}$ I 5 .

Achetes, or chirper $532^{\mathrm{b}} 17,556^{\mathrm{a}}$ 2 I.

Achilles, sponge of $54 \delta^{\mathrm{b}} \mathrm{I}, 2 \mathrm{O}$.

Acorns $603^{\mathrm{b}} 31,615^{\mathrm{b}} 22$.

Acorn-shell, see Barnacle.

Acquired characters, inheritance of $585^{\mathrm{b}} 29$.

Acridium peregrinum $555^{\mathrm{b}}$ i7 note.

Acris, see Grasshopper.

Adder, see Viper.

Adrian hens $55^{\mathrm{b}} \mathrm{1} 6$.

Adriatic $598^{\mathrm{b}} 16$ :

Aegean Sea $598^{\circ} 26$.

Aegithus, habits of $609^{a} 31,610^{a} 7$, 6 ז $6^{\mathrm{b}}$ IO

Aegocephalus, crop of $509^{a} 2$; gall of $506^{b} 23$; no spleen in $506^{2} 17$.

Aegolius owl $592^{\mathrm{b}}$ II ; eggs of $563^{2}$ 3I ; habits of $609^{2} 27$, $6 \mathrm{I}^{\mathrm{b}} 25$.

Aeschylus $633^{a}$ I0.

Aethyia, or Diver $487^{a} 23,593^{b}$ 17 ; eggs of $542^{\mathrm{b}} 19$.

Aetos, or Eagle-ray $540^{\mathrm{b}}$ I 8 .

After-pig, or scut $573^{\mathrm{b}} 6,577^{\mathrm{b}} 28$. Alcibiades $578^{\mathrm{b}} 29$.

Alcmaeon of Croton $492^{a} 14,581^{a}$ 16.
Alcman $557^{\circ} 2$.

Alimentary system $488^{\text {b }} 30$, \&c.

Allantoic artery $56 \mathrm{I}^{\mathrm{b}} 7$ note; fluid $562^{a}$ Io note; vein $561^{\mathrm{b}} 7$ note. Almond-tree $627^{\mathrm{b}}$ I 8 .

Alopecias vulpes $566^{a} 32$ note.

Alopeconnesus $59^{a} 22$.

Alosa vulgaris $62 \mathrm{I}^{\mathrm{b}}$ I 5 note.

Alvearius $553^{a} 32$ note.

Ambidextrous $497^{\mathrm{b}} 32$.

Amble $498^{\mathrm{b}} 9$.

Amia, see Bonito.

Amisus $554^{\mathrm{b}}$ I 5 .

Amphibious $566^{\mathrm{b}} 27,589^{\mathrm{a}} 2 \mathrm{I}$.

Analogy $486^{\mathrm{b}} 20,5^{16^{\mathrm{b}}} 29$.

Anatomy, Treatise on $497^{\mathrm{a}} 32$, $509^{b} 23,565^{a} 13$.

Anaxagoras $486^{\circ} 7$ note.

Anchovy $569^{\mathrm{b}} 28$.

Anemone, Sea-, see Acalephae.

Angel-fish, or Rhina, breeding of $540^{\mathrm{b}}$ I I, $543^{\mathrm{a}}$ I 4, b $9,566^{\mathrm{a}} 20$; habits of $620^{b} 30,622^{a} 13$; hybrid $566^{a} 27$; young of $565^{\text {b }}$. 25.

Animals, parts of $486^{2} 5$; diverse position of parts in $486^{\mathrm{b}} 25$; dwellings of $488^{a} 20$, \&c.; domesticated $488^{\mathrm{a}} 30, \& \mathrm{c}$.

Ankle $494^{\mathrm{a}}$ IO, $516^{\mathrm{b}}$ I.

Annelid worms $505^{\mathrm{b}}$ I2 note.

Anomalous organisms $532^{\mathrm{b}}$ I8.

Ant $5^{8} 3^{\mathrm{b}} 19,614^{\mathrm{b}} 12$; breeding of $555^{\mathrm{a}} 19$; destruction of $534^{\mathrm{b}} 22$; eaten by bears $594^{\mathrm{b}} 9$; habits of $488^{\mathrm{a}}$ IO, $2 \mathrm{I}, 542^{\mathrm{b}} 30,622^{\mathrm{b}} 20$, $623^{\mathrm{b}}$ I3; 'horseman' $606^{\mathrm{a}} 5$.

Antandria $519^{2} 16$.

Antelope, blood of 5 I $5^{\mathrm{b}} 34$.

Anthias $610^{\mathrm{b}} 5,620^{\mathrm{b}} 33$; spawning of $570^{\mathrm{b}} 19$.

Anthrene $55 \mathrm{I}^{\mathrm{a}} 30,553^{\mathrm{b}} 9,622^{\mathrm{b}}$ $21,623^{\mathrm{b}}$ I0, $624^{\mathrm{b}} 25,625^{\mathrm{a}} 2$; description of $554^{\mathrm{b}} 22-555^{\mathrm{a}}$ I2, $628^{\mathrm{b}} 32-629^{\mathrm{a}} 28$.

Anthus $592^{\mathrm{b}} 25,609^{\mathrm{b}}$ I4, $610^{\mathrm{a}} 6$, $615^{2} 27$.

Antilochus $513^{\mathrm{b}} 26$. 


\section{INDEX}

Antlers $5 I^{a} 24,6 I^{2} 34$.

Aorta $495^{\mathrm{b}} 7,510^{\mathrm{q}}$ I 5, $513^{\mathrm{b}} 5,20$, 5 I $4^{\mathrm{a}} 24, \& \mathrm{c}$.

Ape $502^{\mathrm{a}} 17, \mathrm{~b} 24$.

Apis ligustica and mellifica $624^{\text {b }}$ 22 note.

Aplysia $549^{2} 4$.

Apollonia, Diogenes of $5 \mathrm{II}^{\mathrm{b}} 30$.

Aporrhais $530^{2}$ I 7 note.

Apus, or Cypselus, or Swift, description of $487^{\mathrm{b}} 25,29$; nesting of $6 \mathrm{I} \delta^{\mathrm{a}} 3 \mathrm{I}-\mathrm{b}^{\mathrm{b}} 2$.

Aquatic and terrestrial animals $487^{a} 15^{-b}$ I $8,589^{a} 12-590^{a}$ I5, \&c.

Arabia $606^{\mathrm{b}} 6$; camels in $498^{\mathrm{b}} 8$, $499^{\mathrm{a}} 15,546^{\mathrm{b}} 2$.

Arachotae $499^{\circ} 4$.

Arcadia $617^{a} 14$.

Arcturus $549^{\mathrm{b}}$ I I, $569^{\mathrm{b}} 4: 598^{\mathrm{a}}$ 18, $599^{\mathrm{b}}$ II, $617^{\mathrm{a}} 31$.

Arctus, see Bear-crab.

Argeia $602^{a} 8$.

Arginussa $57^{\text {b }}$. 29.

Argonaut, or nautilus $53^{\mathrm{a}} 35$ note; habits of $525^{\mathrm{a}} 20-29$, $622^{\mathrm{b}} 5$.

Aristotle's lantern $53 \mathrm{I}^{\mathrm{a}} 35$ note.

Arms $491^{\mathrm{a}} 29,493^{\mathrm{b}} 24,497^{\mathrm{b}}$ I8.

Arsenic $604^{\text {b }} 27$.

Artery, see Blood-vessels.

Arum $600^{\mathrm{b}}$ I 2, 6II 35 .

Arvicola giuntheri $580^{\circ} 20$ note.

Ascalaphus, caeca of $509^{a} 22$.

Ascarids, or blood-worms $55 \mathrm{I}^{\mathrm{b}}$ $27-552^{a}$ I 5 ; intestinal worms so called $55 \mathrm{I}^{\mathrm{a}} \mathrm{IO}$.

Ascidians, or Tethya $528^{\mathrm{a}} 20$, $547^{\mathrm{b}} 21,588^{\mathrm{b}} 20$; description of $53 I^{2} 9-3 I$.

Asia Minor $569^{a}$ 20, $578^{\text {b }} 29$; leopard in $606^{\mathrm{b}} 16,18$.

Asp $607^{a} 22,612^{a} 16$.

Aspen $595^{\mathrm{a}} \mathrm{I}$.

Ass $49 I^{i b} 2,502^{a}$ I3; age of maturity in $545^{\mathrm{b}} 20$; blood of $521^{\mathrm{a}}$ 5 ; diet of $595^{\mathrm{b}} 23$; diseases of $605^{2} 16-22$; in Epirus, \&c., $522^{\mathrm{b}} 20,606^{\mathrm{b}} 4$; hostilities of $609^{a} 31-^{b} 5,29,610^{a} 4$; gallbladder absent in $505^{\mathrm{a}} 23$; milk of $521^{\mathrm{b}} 33$; pairing of $575^{\mathrm{b}} 30$, $577^{a} 3,15$; tail of $499^{b} 17$; teeth of $501^{b} 3$.

Associate animals $608^{\mathrm{b}} 30$.

Assyritis $519^{\mathrm{a}} \mathrm{I} 5$.

Astarus, see Lobster.
Asterias, a hawk $620^{a}$ I 8 ; a kind of heron, or bittern, $609^{\text {h }} 22$; fable of $617^{2} 5$.

Astragalus $499^{\circ} 20$; see also Huckle-bone.

Athene noctur 617 31 note.

Athens $559^{\mathrm{a}} 13,569^{\mathrm{b}}$ II $, 27,577^{\mathrm{b}}$ $3 \mathrm{I}, 618^{\mathrm{b}}$ I 5 .

Atherina hepsetus $570^{\mathrm{b}}$ I4 note.

Atherine $6 \mathrm{IO}^{\mathrm{b}} 6$; $^{\mathrm{s}}$ spawning of $570^{\mathrm{b}} 16,57 \mathrm{I}^{\mathrm{a}} 6$.

Athos, Mount $549^{\mathrm{b}}$ I7, $607^{\mathrm{a}}$ 12, $614^{a} 7$ note.

Attelabus, or locust $550^{\mathrm{b}} 32$; breeding of $556^{\mathrm{a}} 9^{-\mathrm{b}} \mathrm{I}$.

Aulopias, spawning of $570^{\mathrm{b}} 20$.

Auxids 57 I $^{\mathrm{a}}$ I 8.

Auxis vulgaris $543^{\mathrm{b}}$ I4 note.

Baboon $502^{\mathrm{a}}$ I $8,503^{\mathrm{a}}$ I9.

Back $493^{\text {b }}$ II ; hairier than belly $498^{\mathrm{b}} 20$.

Bactrian camel $498^{\mathrm{b}} 8,499^{\mathrm{a}}$ I 4 .

Balagrus, a fish of neuter sex $538^{\circ}$ I 5 .

Baldness $518^{a} 27,632^{2} 3$.

Baleros, spawning of $568^{\mathrm{b}} 28$, $602^{\mathrm{b}} 26$.

Barley-surfeit, in horses $604^{\mathrm{b}} \%$.

Barnacle $547^{b} 22$; senses of $535^{2}$ 25.

Basse, or Labrax, capture of $537^{2}$ 28 ; diet of $591^{2}$ II, $59 I^{\text {b }} 18$; ear of $534^{\mathrm{a}} 9$; fins of $489^{\mathrm{b}} 26$; senses of $607^{\mathrm{b}} 26$; spawning of $543^{a} 3, b 4$, I I, $567^{a}$ 19, $570^{\text {ln }}$ 21 ; stone in head of $6 \mathrm{OI}^{\mathrm{b}} 30$; see also 610 10, I6.

Bastard animals $607^{a} \mathrm{I}$.

Bat, feet of $587^{\mathrm{b}} 23$; nocturnal habits of $488^{2} 25$; wings of $490^{3}$ 8 ; womb of $5 \mathrm{II}^{2} 3 \mathrm{I}$; see also Flying Fox.

Batis, a bird so called $592^{1}$ I 17 : see also Ray.

Batrachus, see Fishing-frog.

Beak, of birds $486^{\mathrm{b}} 10,504^{\mathrm{a}} 20$, 5 I $7^{n} 9$, dic.

Beans $522^{\mathrm{l}} 34,561^{\mathrm{a}} 30,595^{\mathrm{b}} \delta$, $627^{\mathrm{b}} 17$.

Bear, breasts of $500^{2} 23$; diet of $594^{\mathrm{b}} 5-16$; drinking of $595^{\mathrm{a}} 10$; foot of $498^{a} 34,499^{a} 29$; hair of $49 S^{\text {b }} 27$; habits, breeding. hibernation, \&c. $539^{\mathrm{b}} 33,579^{\mathrm{a}}$ Is $-30,580^{a} 7,600^{a} 3 I^{-b}$ I $_{3}, 6$ I I $^{\text {l }}$ $32-612^{3}, 1$; stomach of $507^{11} 20$; 


\section{INDEX}

teeth of $507^{\mathrm{b}} \mathrm{I} 6$; temper of $57 \mathrm{I}^{\mathrm{b}} 2$ \%, $608^{\mathrm{a}} 32$.

Bear-crab, or Arctus $549^{\mathrm{b}} 23$.

Beard, of hippelaphus $499^{2} \mathrm{I}$; in women $518^{\mathrm{a}} 34$.

Beaver $594^{\mathrm{b}} 32-595^{\mathrm{a}} 7$; feet of $487^{2} 22$.

Becca-fico $592^{\mathrm{b}} 22,632^{\mathrm{b}} 32$.

Bee, diet of $488^{\mathrm{a}} 16,596^{\mathrm{b}} \mathrm{I6}$; diseases of $605^{\mathrm{b}} 9,622^{\mathrm{b}} \mathrm{I} 6$; feet of $489^{\mathrm{b}} 22$; generation of $55 \mathrm{I}^{\mathrm{a}}$ $29,553^{\mathrm{a}} 17-554^{\mathrm{b}} 2 \mathrm{I}, 601^{\mathrm{a}} 6$; hibernation of $599^{\mathrm{a}} 24$; hum of $535^{\mathrm{b}} 6$, IO ; senses of $534^{\mathrm{b}}$ 19, $535^{\mathrm{a}} 2$; sleep of $537^{\mathrm{b}} 8$; sting of $532^{\mathrm{a}} \mathrm{I} 6$; species and habits of $553^{\mathrm{b}} 9,623^{\mathrm{b}} 7-627^{\mathrm{b}} 22$; wings of $490^{a} 7,519^{a} 27,52^{a}$ 24 ; see also $487^{\mathrm{a}} 32, \mathrm{~b}_{1} 9,488^{\mathrm{a}}$ 9, 2I, $489^{\mathrm{a}} 32,523^{\mathrm{b}} \mathrm{I} 9,53^{\mathrm{b}} 22$, $53^{a^{a}} \cdot 24,554^{b} 27,30,555^{a} 5$, $596^{\mathrm{b}} \mathrm{I} 6,601^{\mathrm{a}} 6,622^{\mathrm{b}} 21$.

Bee-bread $623^{\mathrm{b}} 23$.

Bee-eater, filial love of $615^{\mathrm{b}} 25$; hostile to bees $626^{a} 9$; nest of $559^{\mathrm{a}} 4$.

Bee-keeper $554^{a} 2,623^{b} 19,31$.

Bees-wax $553^{\mathrm{b}} 28$.

Beetle, see Cantharus, Carabus, Scarabaeus.

Belone, or Needle-fish, (I) the Pipe-fish(Syngnathus), breeding of $567^{\mathrm{b}} 23,57 \mathrm{1}^{\mathrm{a}} 3-5 ;(2)$ probably the Garfish (Belone acus) $506^{b}$ Io, $543^{\mathrm{b}}$ II, 6 IO $^{\mathrm{b}}$ 9, 6I $6^{\mathrm{a}}$ 32.

Bembex rostrata $628^{\text {l' }} 32$ note.

Bichat $486^{a} 7$ note.

Bile 5 I I $^{\mathrm{b}}$ Io, \&c.

Biped $489^{a} 32,490^{a}$ Io, $498^{a} 29$; \&c.

Birds, breeding of $55^{\mathrm{b}}$ Io ; colour of $519^{a} \mathrm{I}$; diet of $592^{\mathrm{a}} 28$; eggs of $55^{\mathrm{b}}$ 10; gall of $506^{\mathrm{b}} 20$; genus and definition of $490^{\circ}$ I $2^{-b} 8,505^{b} 29$; hibernation of $600^{2}$ Io; limbs of $498^{2} 29$; see also $486^{\mathrm{a}} 23,487^{\mathrm{b}} 19,503^{\mathrm{b}} 29$, \&c.

Bison $498^{\mathrm{b}} 3 \mathrm{I}, 5 \mathrm{c} 6^{\mathrm{b}} 3 \mathrm{I}$; habitat of $500^{\mathrm{a}} \mathrm{I}$; description of $630^{\mathrm{a}}$ 19-b I8.

Bistonis, Lake $598^{\circ} 23$.

Bitch, gestation of $542^{a} 29$; temper of $571^{\mathrm{W}} 3 \mathrm{I}$; see also Dog.

Bittern, see Asterias.

Bivalves $528^{\mathrm{b}} 2$, II .
Blackbird, or Owzel 61 $8^{\mathrm{b}} 3$; breeding of $544^{a} 27$; hibernation of $600^{2} 20$; hostilities of 609k 9, 610? I 3; metamorphosis of $632^{\mathrm{b}} 16$; nest of $616^{\mathrm{a}} 3$; varieties of 6 I $7^{\mathrm{a}}$ II-25.

Black-cap, or blackheaded tit $592^{\mathrm{b}} 22$; eggs of $616^{\mathrm{b}} 4-9$; metamorphosis of $632^{\mathrm{b}} 31$.

Black formations, in sea-urchins, \&c. $529^{\mathrm{a}} 22$.

Bladder $489^{a} 5,497^{a} 17,506^{b} 25$, $519^{\mathrm{b}} 13$; ducts of $514^{\mathrm{b}} 34$; stone in $519^{\mathrm{b}} 20$; veins of $515^{\mathrm{a}} 4$.

Blastophaga grossorm $557^{\mathrm{b}} 3 \mathrm{I}$ note.

Blindness, in fishes $602^{a} 2$.

Blind-snake, spawning of $567^{\mathrm{b}} 26$.

Blister-beetle, see Cantharis.

Blood $487^{\mathrm{a}} 3,489^{\mathrm{a}} 22,30,5 \mathrm{I} \mathrm{I}^{\mathrm{b}} 2$, $52^{\mathrm{b}} 9,52 \mathrm{O}^{\mathrm{b}}$ IO, $52 \mathrm{1}^{\mathrm{b}} 3$; of fishes $505^{\mathrm{b}} \mathrm{I}$; in heart $496^{\mathrm{b}}$, 8 ; blooded and bloodless animals $490^{\circ} 2 \mathrm{I}$, $496^{\mathrm{b}} 3,502^{\mathrm{b}} 28, \& \mathrm{c}$.

Blood-letting $514^{\mathrm{b}} 3$.

Blood-vessels $489^{a} \quad 22,495^{a} 5$, $496^{\mathrm{a}} 4,497^{\mathrm{a}} 5,5 \mathrm{II}^{\mathrm{b}} \mathrm{I}-515^{\mathrm{a}} 25$, $\& c$.

Blood-worm, see Ascarids.

Blow-hole, of Cetacea $489^{\mathrm{b}} 4$, $537^{\mathrm{b}}$ I, $589^{\mathrm{b}} \mathrm{I}$; of cuttlefish $54 \mathrm{I}^{\mathrm{b}}$ I 5 .

Blue-bird, or wallcreeper $617^{a}$ 23-8.

Blue-thrush, or Laius $617^{a}$ I 5 .

Boar $546^{\mathrm{a}} 7$; castration of $578^{\mathrm{b}} \mathrm{I}$, $632^{\mathrm{a}} 8$; temper of $573^{\mathrm{b}}$ II ; tusks of $501^{\mathrm{a}} \mathrm{I} 5$; see also Pig.

Boar, Wild $488^{\mathrm{a}} 30,{ }^{\mathrm{b}} \mathrm{I} 5,499^{\mathrm{a}} 5$, $594^{\mathrm{b}}$ 10; habits of $57 \mathrm{I}^{\mathrm{b}} \mathrm{I} 3-2 \mathrm{I}$, $578^{\mathrm{a}} 25^{\mathrm{b}} 6$; penis of $500^{\mathrm{b}} 6$; absent from Libya $606^{\mathrm{a}} \%$.

Boar-fish, or Caprus, gills of $505^{a}$ I3; voice of $535^{\text {b }} 18$.

Boedromion $578^{\mathrm{b}}$ I $4,597^{\mathrm{a}} 24$.

Boeotia $559^{\mathrm{a}} 4,605^{\mathrm{b}} 3 \mathrm{I}$.

Bogue $610^{\mathrm{b}} 4$.

Bolbe, Lake $507^{a}$ I 7 .

Bolbidia $525^{a}$ I 9 .

Bolitaina $525^{\mathrm{a}} 19,26,62 \mathrm{I}^{\mathrm{b}} \mathrm{I} 7$.

Bombyx mori 55 'b II note.

Bone $511^{b} 6-516^{b} 30,517^{a}$ Io, $519^{\text {b }} 27$, \&c.; of heart $506^{\mathrm{a}} 9$; of limbs $493^{\mathrm{a}}$ I2 ; of penis $500^{\mathrm{h}}$ $24,612^{\mathrm{b}} 15$; of skull $49 \mathrm{I}^{\mathrm{a}} 32$.

Bonito, or Amia 488 7 ; diet of $591^{\mathrm{a}} \mathrm{I},{ }^{\mathrm{b}} \mathrm{I} 8$; gall of $506^{\mathrm{b}} \mathrm{J} 3$; 


\section{INDEX}

growth of $517^{2} 23$; habitat of $59^{a} 23,60 I^{b} 21$; habits of $62 I^{a}$ I7.

Bos, see Ox-ray.

Bosporus $600^{2} 5$; Cimmerian $552^{\mathrm{b}}$ I8.

Bostrychus $55 \mathrm{I}^{\mathrm{b}} 26$.

Bowel $489^{2} 7$.

Box boops $6 \mathrm{Io}^{\mathrm{b}} 4$ note.

Box salpa $534^{2} 8$ note.

Brain $494^{\mathrm{b}} 25$; fat of $520^{\mathrm{a}} 26$; membranes of $495^{a} 7,519^{b} 2$; veins of $514^{2} 15$.

Braize, habitat of $598^{2} \mathrm{I} 3$; stone in head of $6 \mathrm{OI}^{\mathrm{b}} 3 \mathrm{I}$.

Branchos, in pigs $603^{2} 31$.

Bream, black, habitat of $598^{\mathrm{a}} \mathrm{IO}$.

Breasts $493^{\mathrm{a}} \mathrm{I} 2,497^{\mathrm{b}} 35,500^{\mathrm{a}} \mathrm{I} 4$, \&c.

Bregma, or sinciput $491^{a} 31,495^{a}$ I0.

Brenthus 6o9a 23, 61 $5^{a}$ I6.

Brimstone $534^{\mathrm{b}} 2 \mathrm{O}$.

Broom $627^{a} 9$.

Brow-antlers 6 I I $^{\text {b }} 6$.

Bryson the Sophist $563^{a} 7,615^{a}$ I3.

Bryssus 530 5 .

Bubalis $515^{\mathrm{b}} 34$ note, $516^{\mathrm{a}} 5$.

Budbane, or orsodacna $52^{\text {il }} 30$.

Buffalo $499^{\text {a }} 5$ note.

Bugs 556 $23-27$.

Bull, age at maturity $575^{\mathrm{a}} 22$; blood of $520^{\mathrm{b}} 26,52 \mathrm{I}^{\mathrm{a}} 5$; castration of $5 \mathrm{IO}^{\mathrm{b}} 3$; combat with bear $594^{\mathrm{b}}$ I I-I 5 ; habits of $540^{\mathrm{a}}$ $6,571^{\mathrm{b}} 21,572^{\mathrm{b}} 4,17,575^{\mathrm{a}} \mathrm{I} 7$, $6 \mathrm{II}^{\mathrm{a}} 2$; hostilities of $609^{\mathrm{b}} \mathrm{I}, 5$; horn of $538^{b}$ 23. See also Cattle.

Bullfinch $592^{\mathrm{b}} 22$.

Bull-frog, voice of $536^{a}$ I 5 .

Bushy-tailed animals $49 I^{\mathrm{a}} \mathrm{I}, 495^{\mathrm{a}}$ $4,501^{2} 6$.

Bustard $619^{\text {b }} 13$; caeca of $509^{a}$ 33 ; crop of $509^{a} 4$; incubation of $563^{\mathrm{a}} 29$; pairing of $539^{\mathrm{b}} 30$.

Butterfly $532^{a} 27,551^{\text {il }} 14$.

Buttocks $499^{\mathrm{b}}$ I.

Buzzard $592^{b} 3,609^{a} 24,620^{a} 17$.

Byssus $547^{\mathrm{b}}$ is 5 note.

Byzantium $57 \mathrm{I}^{\mathrm{a}} 18,598^{\mathrm{b}} 10,599^{\mathrm{n}}$ $3,612^{b} 8$.

Cabbage, or Crambe $55 \mathrm{I}^{2} \mathrm{I} 6, \mathrm{~b}^{\mathrm{b}} \mathrm{I9}$, $552^{: 13} 32$.

Cabbage-worm 551' 19.
Caeca, intestinal $507^{\mathrm{b}} 34,508^{\mathrm{b}}$ I 5 ; in birds $509^{a} 17$.

Calamary, including Teuthus and Teuthis; age and sex of $550^{\text {b }}$ I2-I7; arms and suckers of $523^{\mathrm{b}} 3 \mathrm{I}$; diet of $590^{\mathrm{b}} 33$; ink of $62 \mathrm{I}^{\mathrm{b}} 30$; pairing of $54 \mathrm{I}^{\mathrm{b}} \mathrm{I}$; pen or 'sword' of $524^{\text {b }} 23,27$; seasons of $607^{\mathrm{b}} 7$; species of $490^{\mathrm{b}} 14,524^{\mathrm{a}} 25,31$; swimming of $490^{a} \mathrm{I}$.

Calappa $527^{\mathrm{b}}$ I 3 note.

Calaris 609a 27.

Calf, of leg $499^{\mathrm{b}} 5$.

Calicurgus, or Pompilus $609^{\mathrm{a}} 5$ note.

Callimachus $61 \eta^{b} 31$ note.

Callionymus, gall of $506^{\mathrm{b}}$ Io ; habitat of $598^{\mathrm{a}}$ II.

Callyntrum $553^{\mathrm{a}} 20$.

Caloptenus italicus $555^{\mathrm{b}}$ I 7 note.

Camel, age of $596^{\mathrm{a}} 10$; castrated $632^{a} 27$; cloven feet of $499^{a} 22$; copulation of $540^{2}$ I3-19; description of $499^{a}$ 13-30, $578^{a}$ II-I7; diseases of $604^{\mathrm{a}}$ IO; drinking of $595^{\mathrm{b}} 2-596^{\mathrm{a}} 3$; gait of $498^{\mathrm{b}} 8$; habits of $630^{\mathrm{b}} 32-36$; hump of $499^{a} 13,606^{a}$ I6 ; milk of $52 \mathrm{I}^{\mathrm{b}} 32$; penis of $500^{\mathrm{b}} 23$; retromingent $500^{\mathrm{b}} \mathrm{I} 6,546^{\mathrm{b}} \mathrm{I}$; teats of $500^{23} 29$; teeth of $499^{\text {: }}$ 23 ; temper of $57 \mathrm{I}^{\mathrm{b}} 24$.

Canine teeth $501^{\mathrm{b}} 6,17$; in $\operatorname{cog}$ $575^{a} 5$.

Cantharis $53 \mathrm{I}^{\mathrm{b}} 24,542^{\mathrm{a}} 9,552^{\mathrm{b}} 3 \mathrm{I}$ note.

Cantharus-beetle, or Dungbeetle, or Scarabaeus $490^{\circ} 15,17$; hatching of $552^{2} 17,601^{2} 4$.

Cantharus lineatus 59 S $^{2}$ note. Capon-fish, or epitragiae $53 \mathrm{~S}^{\mathrm{al}}$ I 4 . Caprification $557^{\mathrm{b}} 31$ note.

Caprus, see Boar-fish.

Carabus, or stag-beetle $53 \mathrm{I}^{\mathrm{b}}=4$, $532^{a} 27$.

Caranx trachurus $610^{\mathrm{b}} 35$ note.

Carcharias glaucus, or Circharn. don rondeletii $540^{\circ} 17$ note.

Carcinium, sec Hermit-crab.

Caria $547^{a} 6,548^{a} 14,63 I^{a}$ II; priestesses of $5 \mathrm{IS}^{\mathrm{a}} 35$.

Carid, or Prawn $525^{\mathrm{a}} 33$, b $^{2}, 33$, $527^{\mathrm{a}} 9\left(607^{\mathrm{b}} 15\right)$; caten by phycis $591^{\mathrm{b}} 15$; gut of $526^{\mathrm{l}} 27$; gestation of $549^{\text {b }}$ 12; parasite $547^{\prime \prime} 17$. 
Carnivorous animals $488^{a} 14,556^{b}$ $21,563^{a} 12, \& c$.

Carp, gills of $505^{\mathrm{a}} 17$; maladies of $602^{\mathrm{b}} 24$; of neuter $\operatorname{sex} 53^{\mathrm{a}}$ I 5 note; spawning of $568^{\mathrm{b}}$ I 8 , $28,569^{a} 5$; tongue of $533^{a} 29$.

Carrion-crow, see Crow.

Carthamus tinctorius $550^{\mathrm{b}} 25$ note.

Cartilage 5 I $6^{\mathrm{b}} 3 \mathrm{I}$.

Cartilaginous fishes, generation of $564^{\mathrm{b}}$ I6; see also Selachia.

Caruncula $49 \mathrm{I}^{\mathrm{b}} 25$ note.

Castor $594^{\mathrm{b}} 3 \mathrm{I}$.

Castration $510^{\mathrm{b}} 2,5 \mathrm{I}^{\mathrm{a}} 26,518^{\mathrm{a}}$ $3 \mathrm{I}, 545^{\mathrm{a}} 2 \mathrm{O}, 589^{\mathrm{b}} 34,63 \mathrm{I}^{\mathrm{b}} 2 \mathrm{O}$.

Cat, habits of $580^{a} 24,612^{b}$ I 5 ; pairing of $540^{a} \mathrm{IO}$.

Catamenia, see Menstruation.

Catarrhactes $509^{a} 4,615^{a} 28$.

Catfishes $568^{a} 21$ note.

Cattle, age of $575^{\mathrm{a}} 3 \mathrm{I}$; diet of $522^{\mathrm{b}} 2 \mathrm{I}-523^{\mathrm{a}} 8,596^{\mathrm{b}} 6-3 \mathrm{I}$; dreaming of $536^{\mathrm{b}} 29$; drinking of $595^{\mathrm{a}}$ IO, $605^{\mathrm{a}}$ I4; embryo of $586^{\mathrm{b}}$ I 7 ; feet of $499^{\mathrm{b}} \mathrm{I} 7$; heart of $506^{a} 9$; horns of $500^{a}$ IO, $538^{\mathrm{b}} 24$; kidneys of $506^{\mathrm{b}} 29$; lice on $557^{\mathrm{a}} 16$; maladies of $602^{b} 14,604^{a}$ I 5-2I; rennet in $522^{\mathrm{b}} 9$; reproduction, sex, \&c. $540^{\mathrm{a}} 6,572^{\mathrm{a}} 33^{-\mathrm{b}} 7,573^{\mathrm{a}} 27$, $575^{\mathrm{a}} \mathrm{I}^{-\mathrm{b}} 20$; rumination in $632^{\mathrm{b}} 3$; teats of $499^{\mathrm{a}} 19,500^{\mathrm{a}}$ $25,578^{\mathrm{b}} 33$; teeth of $5 \mathrm{OI}^{\mathrm{a}} \mathrm{I} 8$; temper of $488^{\mathrm{b}}$ I4; urine of $573^{\mathrm{a}} 2 \mathrm{I}$; voice of $53^{8 \mathrm{~b}}$ I4; womb of 5 IOb $^{\mathrm{b}}$ I8. Varieties of : wild and tame $488^{a} 30$; wild, or buffalos $499^{2} 4$; humped in Syria 606 15 ; large in Egypt, $606^{\mathrm{a}} 22$; Epirote $522^{\mathrm{b}} 16,595^{\mathrm{b}}$ 18 ; with mobile horns 5 I $^{\mathrm{a}} 29$. See also Bull.

Caul, or omentum $519^{\mathrm{b}} 7$.

Cautery $515^{\mathrm{b}} \mathrm{I} 7$.

Cavities of heart $496^{a} 4,20$.

Cavolini $526^{\mathrm{b}} 28,527^{\mathrm{a}}$ I I, b 2 I notes.

Cecrops latreillii $602^{\mathrm{b}} 28$ note.

Cedar, oil of $583^{a} 24$.

Cedripolis $620^{2} 33$.

Celeus, or green woodpecker, claws of $504^{\mathrm{a}} \cdot 19$; description of $593^{a} 8$; friendships, \&c., of $609^{2} 19,610^{2} 9$.
Centipede, or Scolopendra $489^{k}$ $22,523^{b}$ I $8,532^{a} 5,62 I^{a} 9$.

Cephallenia $605^{\mathrm{b}} 27$.

Cephalopods, or 'Mollusca' $487^{\mathrm{W}}$ 16, $523^{\mathrm{b}} 20$ notes. See also Argonaut, Calamary, Octopus, Sepia.

Cephalus, or Mullet, blindness in $602^{\mathrm{a}} 4$ : diet and habitat of $59 \mathrm{I}^{\mathrm{a}} \mathrm{I} 3, \mathrm{I} 8-25, \mathrm{~b} 3$; maladies of $602^{\mathrm{a}} 4$; spawning of $543^{\mathrm{b}} 16$, $567^{\mathrm{a}} 20, \mathrm{~b} 2 \mathrm{O}, 57 \mathrm{o}^{\mathrm{b}} \mathrm{I} 6$; see also Mullet.

Cepphus $593^{\mathrm{b}} \mathrm{I7}, 620^{\mathrm{a}} \mathrm{I} 3$.

Cerastes aegyptiacus $500^{a} 4$ note.

Ceratia, of womb $510^{b}$ I9.

Cerebellum $494^{b} 32$.

Cerithium $528^{a}$ Io note.

Cerylus $593^{\mathrm{b}} \mathrm{I} 2$.

Ceryx, or Trumpet shell, anatomy of $529^{\mathrm{a}} 7,547^{\mathrm{b}}$ 2-I I ; breeding of $544^{\mathrm{a}}$ I 5 ; capture of $528^{\mathrm{b}} 30$; hermit-crab in $548^{\circ} 19$; hibernation of $599^{\text {a }} 12$; 'mecon' of $527^{\mathrm{a}} 24,529^{\mathrm{a}} 7,530^{\mathrm{a}}$ I4; shell of $524^{\mathrm{b}}$ I2, $528^{\mathrm{a}}$ I0, $24,530^{\mathrm{a}} 5$; spat of $546^{\mathrm{b}} 26$.

Cestreus, see Mullet.

Cetacea $489^{\mathrm{b}} 2,490^{\mathrm{b}} 8,505^{\mathrm{b}} 28$, $566^{\mathrm{b}} 3$; diet of $59 \mathrm{I}^{\mathrm{b}} 27$; pairing of $540^{\mathrm{b}} 22$; respiration of $589^{\mathrm{a}}$ 33 ; teats of $52 \mathrm{I}^{\mathrm{b}} 24$, \&c. Sec also Dolphin, Porpoise, Whale.

Cetonia aurata $552^{a} 16$ note.

Chafer $619^{\mathrm{b}} 22$.

Chaffinch $504^{\mathrm{a}} 12,617^{\mathrm{a}} 25$; diet of $592^{\mathrm{b}} 16$; migration of $613^{\mathrm{b}} 5$.

Chalcidice, Euboean $496^{\mathrm{b}} 26$; Thracian $519^{2}$ I 4 .

Chalcis $53 \mathrm{I}^{\mathrm{b}} \mathrm{I}$ I.

Chalcis, a fish so called, breeding of $543^{a} 2,568^{a} 18,{ }^{b} 24$; diet of $62 \mathrm{I}^{\mathrm{b}} 6$; maladies of $602^{\mathrm{b}} 28$; voice of $535^{\mathrm{b}}$ I9; see also Cicigna.

Chalicodroma muraria $555^{\mathrm{a}}$ I I note.

Chameleon, description of $503^{a}$ $\mathrm{I} 5^{-\mathrm{b}} 28$.

Channa, or Serranus, diet of $591^{\text {a }}$ Io, b 6 ; habitat of $598^{\mathrm{a}}$ I3 ; hermaphrodite sex of $538^{a} 21$, $567^{a} 27$.

Characters, or dispositions, of animals $488^{\mathrm{b}} \mathrm{I} 2,588^{\mathrm{a}} \mathrm{I} 8,608^{\mathrm{a}} \mathrm{I}$, $610^{b} 20, \& c$. 


\section{INDEX}

Charadrius $593^{\mathrm{b}} 15,615^{\mathrm{a}} 1 ; C$. melanocephalus $612^{a} 20$ note.

Chastity, in animals $488^{\mathrm{b}} 5$.

Cheek $492^{\mathrm{b}} 22$.

Cheese $521^{b} 27,522^{a} 24$; Phrygian $522^{\mathrm{il}} 29$.

Chelifer cancroides $532^{\text {a }} 17,557^{\mathrm{l}}$ Io notes.

Chelon, a kind of mullet, diet of $591^{\mathrm{a}} 23$; spawning of $543^{\mathrm{b}} 15$, $570^{\mathrm{b}} 2$.

Chest $497^{\text {b }} 33$.

Chia $499^{\mathrm{b}} 29$.

Chick, development of $561^{\text {a }} 6$ $562^{i \mathrm{l}} 20$.

Chick-peas $546^{\text {b }} 21,603^{\mathrm{b}} 27$.

Childhood $588^{i 2} 32$, \&c.

Chin $492^{b} 22$.

Chironomins $487^{b} 5,552^{a b} 6$ notes.

Chirper, or achetes $532^{\mathrm{b}}$ I 5 .

Chloreus, hostilities of $609^{a} 7,25$, 26.

Chondracanthus aei $602^{b} 28$ note.

Chough $617^{\mathrm{b}} 16$.

Chremps, ear of $534^{\text {in }} 8$.

Chromis, or Sciaena, breeding of $543^{\text {a }} 2$; ear of $534^{\text {a }} 9$; stone in head of $601^{b} 30$; voice of $535^{\mathrm{b}}$ 17; C. castanea, $543^{\text {il }} 31$ note.

Chrysalis $55^{I^{\text {al }}} 19,26,557^{\text {b }} 23$.

Chrysophrys, sce Gilthead.

Cicada, or tettix, description of $55^{\mathrm{a}} 15-{ }^{\mathrm{b}} 20$; diet and tongue of $532^{\mathrm{b}}$ II; habits of $605^{\mathrm{l}} 27$; hatching of $5 \mathrm{OI}^{\mathrm{a}} 7$; sce also $550^{\mathrm{b}} 32$.

Cicadelle, or tettigonium $532^{\mathrm{b}} \mathrm{I} 8$, $55^{\text {il }} 21$.

Cicigna, or Chalcis, or 'Zignis $604^{\text {" }}$ 24.

Cimmerian Bosphorus $55^{\mathrm{b}}$ I 8 .

Cinclus, or Wagtail (?) $593^{\mathrm{b}} 6$, $615^{i l} 21$.

Cinnamon bird, fable of $616^{a} 6$.

Circaetus gallicus $609^{a} 5$ note.

Circus, a hawk so called $620^{a} 18$; hostile to fox $609^{\mathrm{b}} 3$; nest of $559^{2}$ II.

Citharus, caeca of $508^{\mathrm{b}} 17$.

Civet, or Thos $537^{\mathrm{b}} 17$; description $580^{a} 27,630^{a}$ IO-IS; hostilities of $610^{\mathrm{a}} 14$.

Clam, or Cockle 528a $24-26,547^{b}$ 13, $548^{a} 5,622^{b} 2$.

Claws $486^{b} 20,517^{a} 8,518^{b} 35$.

Cleros $605^{\mathrm{b}} 11,626^{\mathrm{b}} 17$.

Climate $490^{a} 25$; influence on hair $517^{b} 17$, and on feathers $519^{a} 3$, and on animals generally $606^{\mathrm{b}} 2$.

Clothes-moth, or Ses $557^{\mathrm{b}} 3$.

Cloven-footed animals $499^{\mathrm{a}} 2,23$, b I $4,502^{a} 10,630^{b} 4$.

Clover $595^{\mathrm{b}} 27$.

Cnecus $550^{\mathrm{b}} 27$.

Cnidos $569^{a}$ I 4 .

Cnips $593^{a} 4,614^{b} 1$; senses of $534^{\mathrm{b}} 19$.

Coa $499^{\mathrm{b}} 29$.

Coagulation of blood $515^{\mathrm{b}} 33$; of milk $62 \mathrm{I}^{\mathrm{b}} 27$.

Cobweb, see Spider.

Cocalia $528^{a} 9$.

Cock $592^{\mathrm{b}} 12$; caeca of $509^{\mathrm{a}} 2 \mathrm{I}$; comb of $504^{\mathrm{b}}$ I I ; crop of $508^{\mathrm{b}}$ 28 ; crow of $536^{\mathrm{a}} 28$; eggs in $559^{\mathrm{b}}$ I 8 ; pairing of $488^{\mathrm{b}} 4,539^{\mathrm{b}}$ $30,564^{\mathrm{b}} 12$; in temples $614^{\mathrm{a}} 7$.

Cockchafer $552^{\mathrm{a}} 16$ note, $523^{\mathrm{b}} 19$, 25 ; wings of $490^{a} 15,532^{i} 23$.

Cockle $528^{\mathrm{a}} 22$ note; sce also Clam, Shellfish.

Cocoon $55 \mathrm{I}^{\mathrm{b}} \mathrm{I} 3$.

Coleoptera $490^{2} \quad 14,552^{b} 30$; hatching of $6 \mathrm{OI}^{\mathrm{a}} 3$.

Collar-bone $516^{a} 28$.

Collyrion, or field-fare $617^{6} 9$.

Colostrum $573^{a} 22$ note.

Colotes, or lizard $609^{\mathrm{b}} 20$.

Colour of eyes $492^{2} 1$; of horn, dic. $517^{a} 13$; of chameleon $503^{b} 2$.

Coly-mackerel, breeding of $543^{\text {it }} 2$ note; habitat of $598^{2} 24$; migration of $598^{\mathrm{b}} 27,610^{\mathrm{b}} 7$.

Comfrey $616^{2} 1$.

Conception, signs of $583^{\text {i }} 14, \mathrm{Sic}$.

Conger $621^{a} 3$; dict of $591^{a} 6,9$; fins of $489^{\mathrm{b}} 28$; gall of $506^{\mathrm{b}}$ is ; gills of $505^{a} 15 ;$ gullet of $507^{a}$ II ; head of $505^{\mathrm{b}}$ IO; hibernation of $599^{\mathrm{b}} 6$; and mullet $610^{\mathrm{b}}$ I5; and octopus $590^{\mathrm{b}} 18$; roe of $517^{\mathrm{b}} 7$; shin of $505^{\mathrm{a}} 27$; spawning of $57 \mathrm{I}^{\mathrm{a}} 27-\mathrm{b} 2$; varieties of $598^{2} 12$.

Conops, or gnat, scuses of $535^{\text {at }} 3$; sting of $532^{a} 14$; or Vinegar-tly $552^{b} 4$.

Consonantal sounds $535^{a} 31$.

Consumption $518^{\mathrm{b}} 22$.

Convulsions, in infants $588^{\mathrm{a}} 2$.

Coot $593^{\mathrm{b}} 16$; Purple, sec l'orphyrio.

Copper ore $552^{\mathrm{b}} 10$. 


\section{INDEX}

Copulation $539^{\mathrm{d}} \mathrm{I6}-546^{\mathrm{a}} \mathrm{I} 4$, \&c.

Coracine, or crow-fish $610^{\mathrm{b}} 5$; hibernation of $599^{\mathrm{b}} 3$; seasons of $602^{\mathrm{b}} 12,607^{\mathrm{b}} 24$; spawning of $543^{\mathrm{a}} 3 \mathrm{I}, 570^{\mathrm{b}} 23,57 \mathrm{I}^{\mathrm{a}} 26$.

Cordylus, see Newt.

Coricus rostratus $599^{\mathrm{b}} 35$ note.

Cormorant $593^{\mathrm{b}} \mathrm{I} 8$.

Corncrake, migrations of $597^{\mathrm{b}}$ I 8 note.

Corvina nigra $543^{\mathrm{a}} 31,601^{\mathrm{b}} 31$ notes.

Coryphaena lippurus $543^{\mathrm{a}} 22$ note.

Cos, woman of $55^{\mathrm{b}}$ I5.

Cottus, or bull-head, hearing of $534^{2} 2$.

Cotyledons, in crawfish $527^{\mathrm{a}} 25$; of womb $5 \mathrm{II}^{\mathrm{a}} 30,586^{\mathrm{a}} 3 \mathrm{I}$.

Couch-grass $552^{2} 15$.

Cow, see Cattle.

Crab, description of $527^{b} 4-33$; copulation of $54 \mathrm{I}^{\mathrm{b}} 25-33$; claws of $590^{b} 26$; eyes of $526^{a}$ Io, $529^{\mathrm{b}} 29$; eaten by bears $594^{\mathrm{b}} 9$, and by octopus $622^{a} 7$; freshwater movements of $487^{\mathrm{b}} 17$; respiration of $526^{\mathrm{b}} 20,527^{\mathrm{b}} 16$; sloughing of $549^{\mathrm{b}} 27,601^{\mathrm{a}}$ I7 ; species of $525^{\mathrm{b}} \mathrm{I}-10$ : tail of $526^{\mathrm{b}} 28$; teeth of $527^{\mathrm{a}} 10,{ }^{\mathrm{b}} \mathrm{I} 4$; see also $490^{b} 13,523^{b} 8,525^{a} 34$.

Crake, or Crex, habits and hostilities $609^{b} 9,616^{b} 20$.

Crambe, or cabbage $55^{\text {a }}$ I 5 .

Crane, colour of $519^{a} 2$; filial love of $615^{\mathrm{b}} 16$; gregarious and social $488^{\mathrm{a}} 4$, I0; intelligence of $614^{\mathrm{b}} 18-26$; migrations of $597^{\mathrm{a}} 4^{-\mathrm{b}} 33$; pairing of $539^{\mathrm{b}} 3 \mathrm{I}$.

Crangon, or Squilla $525^{\mathrm{b}} 2,22$ note, 29.

Craurus, a malady of pigs $603^{\mathrm{b}} 7$; of cattle $604^{2}$ I4.

Crawfish $487^{\mathrm{b}} 16,489^{\mathrm{a}} 33,523^{\mathrm{b}} 8$, $525^{\mathrm{a}} 30,529^{\mathrm{b}} 22,541^{\mathrm{b}} 19,621^{\mathrm{b}}$ I7; antennae of $526^{\mathrm{a}} 3 \mathrm{I}$; capture of $534^{\mathrm{b}} 26$; description of $525^{\mathrm{b}} 33^{-526^{\mathrm{a}}}$ Io; in fresh water $530^{\mathrm{a}} 29$; diet of $590^{\mathrm{b}} \mathrm{I} 3-2 \mathrm{I}$; eyes and rostrum of $526^{\mathrm{b}} 2-4$; feet of $525^{a} 15$; gut of $526^{b} 25$, $527^{\mathrm{a}}$ I-9; mouth of $527^{\mathrm{b}} 16$; sexes of $526^{\mathrm{a}} 1,527^{\mathrm{b}} 33$; sleep of $537^{\text {in }} 1$; sloughing of $601^{\text {at }}$ IO; spawning of $529^{\text {ib }} 19,549^{\text {i }}$ $15^{-b} 28$; swimming of $490^{a} 3$.
Creeping-thyme $627^{\mathrm{b}}$ I8.

Crenilabrus pavo $599^{\mathrm{b}} 35$ note.

Crests, of birds $486^{\mathrm{b}} \mathrm{I2}, 504^{\mathrm{b}} 10$.

Crete $572^{a} 14,598^{a} 16,612^{a} 3$.

Crex, see Crake.

Crocodile $503^{\mathrm{a}} 3 \mathrm{I}, 505^{\mathrm{b}} 32,55^{\mathrm{a}}$ I8; amphibious $589^{\text {a }} 27$; colour of $503^{\mathrm{b}} 4$; eggs of $55^{8^{\mathrm{a}}} \mathrm{I} 5-18$; habits of $503^{\mathrm{a}}$ 9-I4; jaw of $492^{\mathrm{b}} 24,516^{\mathrm{a}} 24$; limbs of $487^{\mathrm{a}} 22,498^{\mathrm{a}}$ I3; hibernation of $599^{a} 32$; no tongue in $503^{a} 1$; spleen of $506^{2} 20$; stomach of $508^{a} 6$; tame, in Egypt $609^{a} 1$; testicles of $509^{\mathrm{b}} 9$; and trochilus, or crocodile-bird $612^{a}$ 20-24.

Croton $58 \mathrm{I}^{\mathrm{a}} \mathrm{I} 6$.

Crow $609^{a} 8$, I I, 17, 26 ; breeding of $564^{a} I 6$; care of young of $563^{\mathrm{b}}$ II ; chastity of $488^{\mathrm{b}} 5$; diet of $593^{b} 15$; in Egypt $66^{a}$ 25 ; friendships of $610^{2} 8$.

Crowfish, see Coracine.

Crustacea, or Malacostraca $487^{\mathrm{b}}$ I6, $490^{\mathrm{b}}$ II $, 523^{\mathrm{b}} 5,525^{\mathrm{a}} 3 \mathrm{O}$, $528^{\mathrm{a}} 3$; diet of $590^{\mathrm{b}} 10$; gums of $523^{\mathrm{b}} 5,534^{\mathrm{b}} 14$; hibernation of $599^{b} 29$; reproduction of $541^{\mathrm{b}}$ I $9,549^{\mathrm{a}} \mathrm{I} 4^{-\mathrm{b}} 30,550^{\mathrm{a}} 32$; respiration of $589^{\mathrm{b}} 20$; seasons of $607^{\mathrm{b}} 3$; sleep of $537^{\mathrm{b}} \mathrm{I}$; species of $525^{\mathrm{a}} 30$; swimming of $490^{a} \mathrm{I}$; voice absent in $535^{\mathrm{b}}$ I 4 .

Ctenilabrus rostratus $505^{\mathrm{a}} 16$ note.

Ctesias $501^{\mathrm{a}} 25,523^{\mathrm{a}} 26,66^{\mathrm{a}} 8$.

Cuckoo $618^{\mathrm{b}} 4$; habits of $563^{\mathrm{b}} 14$, $618^{\mathrm{a}} 8-30$; migration of $597^{\mathrm{b}} 3$, $633^{\mathrm{a}}$ I I ; voice of $535^{\mathrm{b}} 20,536^{\mathrm{b}}$ I9 note.

Cuckoo-fish, habitat of $598^{\mathrm{a}}$ I4; voice of $535^{\mathrm{b}} 20$.

Cuckoo-pint 6 I I $^{\mathrm{b}} 35$.

Curd, or cheese $507^{\mathrm{a}} 36,52 \mathrm{I}^{\mathrm{b}} 27$.

Currant-moth $55^{\mathrm{I}} \mathrm{b} 6$ note.

Cushat, or Ringdove, crop of $508^{\mathrm{b}} 28$; cuckoo in nest of $563^{\mathrm{b}}$ $32,618^{a} 10$; drinking of $613^{a}$ I2; habits of $488^{b} 2,593^{a} 16$, $601^{2} 30,613^{a} 14-21$; migration of $597^{\mathrm{b}} 4,8$; nesting and reproduction of $510^{\mathrm{a}} 5,55^{\mathrm{b}} \mathrm{22}$, $562^{b} 3-563^{a} 2,613^{a} 25$; note of $633^{2} 7$; specific character of $544^{\mathrm{b}} 6$. 


\section{INDEX}

Cuttlefish, see Sepia.

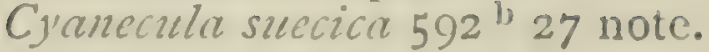

Cyclamen $59 I^{i 2} 21$ note.

Cyllarus $530^{i 2}$ I 2 .

Cyllene, white blackbirds on $617^{a}$ 14.

Cymindis 61 $15^{\mathrm{b}} 6-10,619^{\mathrm{a}}$ I4.

Cymips psen $557^{\text {b }} 31$ note.

Cynnonycteris $490^{a} 6$ note.

Cynoroestes $557^{\circ} 18$.

Cynosura $560^{2} 5$.

Cynthia papillosa $53 \mathrm{I}^{\mathrm{a}} 30$ note.

Cyphae, or hunchbacks $525^{\mathrm{l}} 2$, Is, $28,31,549^{\mathrm{b}} 12$.

Cyprus $552^{b}$ 10; Syennesis of $5 \mathrm{II}^{\mathrm{b}} 24$.

Cyrene $556^{\mathrm{a}} 23, \mathrm{~b} 2,557^{\mathrm{a}} 30,606^{\mathrm{a}}$ $6,607^{a} 2$.

Cytisus $522^{b} 28$.

\section{Dictylopterus $535^{\mathrm{b}} 37$ note.}

Danube, or Ister $598^{\mathrm{b}} 16$.

Dascyllus, diet of $591^{2}$ I4.

Dasypod, see Hare.

Daw $614^{\mathrm{b}} 5,617^{\mathrm{b}} 16$; crop of $509^{a} 1$.

Decoy-birds $560^{\text {il }}$ I 5 .

Deer $490^{\text {b }} 33,499^{\text {a }} 3$; antlers of $500^{a} 6,517^{2} 25,538^{i} 19$; blood of $515^{\mathrm{b}} 34,516^{\mathrm{a}} \mathrm{I}, 520^{\mathrm{b}} 24$; castrated $632^{\text {il }}$ II ; copulation of $500^{\mathrm{b}} 23,540^{\mathrm{a}} 5,8,578^{\mathrm{b}} 6$; foot of $499^{\mathrm{b}}$ I $7,499^{\mathrm{b}}$ 10; gallbladder absent in $506^{\mathrm{a}} 22,32$; habits of $578^{b} 6-579^{a}$ Is, $6 I^{a}$ $15^{-1)} 31$; rumination in $632^{\mathrm{b}} 4$; swiftness of $501^{a} 34,62^{\text {a }} 15$; tail of $498^{\mathrm{l}}$ I 4 ; temper of $488^{\mathrm{b}}$ I 5 ; voice of $545^{\circ} \mathrm{I}$; attacked by bear $594^{\text {b }}$ Io; absent from Libya $606^{2} 7$.

1) efect, or excess $486^{\mathrm{b}}$ I 7 .

Delos $580^{2}$ is 8 .

Delphys, or hystera $510^{\mathrm{b}} 14$.

Deltoid muscle $515^{\mathrm{b}}$ io note.

Democritus $590^{i 2} 21$ note, $623^{i n} 32$.

Dentex, or Symodon $610^{b} 5$; diet of $59 I^{a}$ II, b 5 , IO ; D. macrophithatmins $59^{\text {a }}$ I 3 note; 1$)$. aulgaris $505^{2} 15$ note.

Dentition, symmetrical $507^{13} 30$. See also Teeth.

Development of chick $56 \mathrm{I}^{\mathrm{a}} 4$ $562^{a} 21$; of fish $564^{\text {il }} 26,602^{\text {b }}$ $20, \& c$.

Diagonal movement 49 s. $^{\mathrm{b}} 5$.
Diaphragm $496^{1)} 12,506^{a} 5,514^{a}$ 35.

Diarrhoea $522^{\text {b }}$ II.

Dicaea $586^{\text {il }}$ I 5 .

Diogenes of Apollonia 5 I I 30 , 5 I $2^{b} 12$.

Diptcrous insects $490^{a}$ 16-20, $532^{\mathrm{a}} 20$.

Dipus aegyptiacus $606^{6} 8$ note.

Diseases of bees $605^{\mathrm{b}} 9-10,626^{\mathrm{l}}$ I6; of birds $626^{1}$ I6; of fish $602^{\mathrm{b}} 12-30$; of ass $605^{\mathrm{a}} 15^{-22}$; of dogs $604^{a} 4-12$; of cattle $604^{\text {a }}$ I3-2I; of elephant $604^{\mathrm{a}}$ II, $608^{a} 24^{-b} 5$; of horse $604^{a}$ $22-605^{a} 15$; of pigs $603^{\mathrm{a}} 30-$ $604^{i} 3$.

Dispositions, or characters, of animals $488^{\mathrm{b}} 12,608^{\mathrm{a}}$ I \& $S$. .

Dissection $5 \mathrm{II}^{\mathrm{b}} 2 \mathrm{I}$.

Dissociates $608^{\mathrm{b}} 29$.

Dittany $611^{1 / 2} 21$ note, $612^{27} 4$.

Diver, see Aethyia.

$\operatorname{Dog} 488^{a} 31,489^{b} 22,450^{b} 24$, $497^{b} 17,501^{2} 4,629^{b} 20$; age of maturity in $545^{\mathrm{b}} 3$; breeding of $580^{a} 11$; breeds of $574^{a} 17$; diseases of $604^{2} 4-10,612^{a} 6$, 31; dreaming of $536^{b} 29$; Egyptian 606 23; Epirote $522^{\text {l) }} 20$; foot of $499^{\text {l) }} 8$; habits of $488^{\mathrm{a}} 24,574^{\mathrm{a}} 17-575^{\mathrm{b}} 13$, $594^{\mathrm{b}} 23$; hair of $498^{\mathrm{b}} 27$; hostile to Thos $630^{a}$ II ; hybrid $607^{a} 2$; Indian $607^{\mathrm{a}} 4$; intelligence of $608^{a} 27-33$; Laconian $574^{a} 18$, 22, b $10,27,31,575^{\mathrm{a}} 2,608^{\prime} 27$, 33 ; lice on $557^{\mathrm{a}} 18$; Molossian $608^{\mathrm{a}} 28,32$; mouth of $502^{\mathrm{a}} 7$; pairing of $540^{\prime \prime} 25$, ' $15,546^{\text {: }}$ $28-34,572^{13} 26$; skull of $516^{\text {a }}$ I7; stomach of $507^{\mathrm{b}} 22,50 \mathrm{~S}^{\mathrm{a}} 8$, 29 ; teats of $500^{2} 27$; teeth of $501^{\mathrm{a}} 17, \mathrm{~b} 5,507^{\mathrm{b}}$ I 5 ; temper of $488^{\mathrm{b}} 22,572^{\mathrm{a}} 7$; voice of $545^{\mathrm{a}} 5$; vomiting in $594^{\mathrm{a}} 29$, $612^{\mathrm{a}} 31$; womb of $510^{13} 17$.

Dogfish, or Sharks $540^{\circ}$ 19; breeding of $543^{2} 16,566^{2} 16$, $3 \mathrm{I}$; cacca of (?) $50 \mathrm{~S}^{\mathrm{b}} \mathrm{I} 7$; egg of $565^{\mathrm{a}} 21$; gall of $506^{\mathrm{b}} \mathrm{S}^{\mathrm{S}}$; gills of $489^{1} 6,505^{2} 5$; liver of $507^{\text {:t }} 15 ;$ sexes of $540^{b} 27$; womb of $511^{\text {at }} 4$; dappled $565^{\mathrm{a}} 27$; little $566^{\mathrm{a}} 20$; smooth $565^{\mathrm{b}} 2$; spotted, or starry $543^{\mathrm{a}}$ I7, $566^{*} 17$. 
Dog-rose $552^{b} 2$.

Dogstar $547^{a}$ I $4,566^{\mathrm{b}} 2 \mathrm{I}, 569^{\mathrm{a}}$ I $5,599^{2} 17,600^{a} 5,602^{a} 26$, $633^{2} 16$.

Dolium galea $530^{2}$ I 4 note.

Dolphin, blowhole of $566^{b} 2,589^{a}$ 32 ; bones of $516^{b}$ I2 ; copulation of $540^{\mathrm{b}} 22$; diet of $59 \mathrm{I}^{\mathrm{b}} 9$, 25 ; habits and fables of $63 \mathrm{I}^{\mathrm{a}}$ $9^{-\mathrm{b}} 4$; hearing of $533^{\mathrm{b}} 10,539^{\mathrm{b}}$ 7 ; in Euxine $598^{\mathrm{b}} 2$; gall of $506^{\mathrm{b}} 5$; mouth of $59 \mathrm{I}^{\mathrm{b}} 25$; sleep of $537^{\mathrm{a}} 32$; teats of $52 \mathrm{I}^{\mathrm{b}}$ $24,540^{\mathrm{b}} 22$; testicles of $500^{\mathrm{b}} \mathrm{I}$, $509^{\mathrm{b}}$ 10, $510^{\mathrm{a}} 8$; viviparous $489^{\mathrm{b}} 2$; voice of $535^{\mathrm{b}} 32$.

Dolphin-hunter, stratagem of $533^{\mathrm{b}}$ 22.

Dolphin's louse, fish so called $557^{2} 31$.

Donax $528^{a}$ I 7 note.

Dorado, see Gilthead.

Dormouse, hibernation of $600^{b}$ I3. Dory $535^{\mathrm{b}}$ I 7 note.

Dove, see Ringdove, Rock-pigeon, Turtle-dove.

Dove-hawk, or Dovekiller $592^{\mathrm{b}} 2$, $615^{\mathrm{b}} 7,620^{\mathrm{a}} 18$.

Dragon.612 30 .

Drone, development and nature of $553^{a} 23,30,{ }^{b}$ I, $554^{a} 22,24$, b $4,624^{\mathrm{b}}$ I $3-27,625^{\mathrm{a}} 4$; habits of $624^{\mathrm{a}} 19-22,654^{\mathrm{b}} 4$; massacre of $625^{\mathrm{a}} 14,23$; stingless $553^{\mathrm{a}} 5$, I I, 628" 4 ; useful to hive $627^{\text {b }}$ 8 ; see also Bee.

Duck, gut and caeca of $509^{\mathrm{a}} 3$, 22 ; habitat of $593^{\mathrm{b}} 16$.

Duck-killer 6 I 8 b 25 .

Eagle $592^{\mathrm{b}}$ I, 61 $3^{\mathrm{b}}$ I I ; black $563^{\mathrm{b}}$ 6 ; claws of $517^{\mathrm{b}} 2$; drinking $601^{b} 3$; eggs of $563^{a} 17$; habits and species of $618^{b} 18,619^{13} 12$; hostilities of $609^{a} 4, b 7,12,26$, $610^{a} 1,615^{a} 19,33, b 13$; treatment of young $619^{b} 25-620^{a} \mathrm{I}$; wings of $490^{2} 7$; true-bred $619^{a}$ 8-14; white-tailed $563^{\mathrm{b}} 5,618^{\mathrm{b}}$ $19-619$ I2.

Eagle-owl 592b 9, 61 5 $5^{\text {b }}$ I2.

Eagle-ray, or Aetos $540^{\mathrm{b}}$ I 8 .

Ear $492^{a} 13$.

Earth's guts $570^{a} 16$.

Earthworm $570^{2}$ I8.

Echeneï, or ship-holder 505" 1922.

AR. H.A.

$\mathrm{Hh}$
Echinometra 530" 6.

Echinus, see Sea-urchin.

Echimus esculentus $530^{\text {b }} 8$ note.

Echinus, or 'manyplies', of ruminants $507^{\mathrm{b}} 7$.

Eel $487^{a} 20$ note; breeding of $592^{a}$ I-27 ; capture of $534^{a} 20$; fat of $520^{a} 24$; fins of $489^{b} 28$, $504^{\mathrm{b}} 3 \mathrm{I}$; diet of $59 \mathrm{I}^{\mathrm{b}} 3 \mathrm{I}$; gall of $506^{b} 9$; gills of $505^{a} 16$; gullet of $507^{\mathrm{a}}$ II ; sex and reproduction of $517^{\mathrm{b}} 8,538^{\mathrm{a}} 3$, I I, $567^{a} 21,569^{a} 6,570^{a} 3-25$, $608^{\mathrm{a}} 5$; skin of $505^{\mathrm{a}} 28$.

Egg $489^{\mathrm{b}} 6$; of birds $55^{\mathrm{b}}$ 10, \&c.; of fishes $564^{\mathrm{b}} 29$, \& c.

Egypt $502^{\mathrm{a}} 9,557^{\mathrm{a}} 31,562^{\mathrm{b}} 26$, $581^{\mathrm{a}} 2,597^{\mathrm{a}} 6,612^{\mathrm{a}} 16,617^{\mathrm{b}} 27$; animals of $606^{\mathrm{a}} 21,608^{\mathrm{b}} 33$; childbirth in $584^{\mathrm{b}} 7$; crocodile in $503^{a} \mathrm{I}$; hatching of eggs in $559^{\mathrm{b}} \mathrm{r}$.

Eileus, in horses $604^{2} 30$.

Elaphebolion $571^{a} 13,579^{a} 27$.

Elaphoeis $578^{\mathrm{b}} 28$.

Electric ray, see Torpedo.

Eledone $5^{2} 3^{\text {b }} 27$ note ; E. Aldrovandi $525^{a}$ I 7 note.

Eleginus $610^{\mathrm{b}} 6$.

Elephant, age of $596^{\mathrm{a}} 3-13,630^{\mathrm{b}}$ I9-3I ; breasts of $49^{a}$ I, $500^{a}$ I 7 ; breeding of $540^{\mathrm{a}} 20,546^{\mathrm{b}}$ $7,578^{a} 18-25$; capture of $610^{a}$ I 5-34; diet of $596^{\mathrm{a}} 3$; diseases of $604^{\mathrm{a}}$ II, $605^{\mathrm{a}} 23^{-\mathrm{b}} 5$; driver of $497^{\mathrm{b}} 27,6 \mathrm{IO}^{\mathrm{a}} 27$; feet of $497^{b} 23,517^{a} 31$; gall of $506^{\mathrm{b}} \mathrm{I}$; genitals of $500^{\mathrm{b}} 6-19$, $509^{\mathrm{b}}$ II ; habits of $630^{\mathrm{b}}$ I9-3I ; hair of $499^{a} 9$; limbs of $497^{b} 22$; sleep of $498^{a} 9$; skull of $507^{\text {b }}$ 35 ; sperm of $523^{a} 27$; temper of $488^{\mathrm{a}} 28 \mathrm{-}^{\mathrm{b}} 22$; teeth of $50 \mathrm{I}^{\mathrm{b}}$ $30,502^{\mathrm{a}} 2$; trunk of $492^{\mathrm{b}} 17$, $497^{\mathrm{b}} 23-31$; voice of $536^{\mathrm{b}} 22$.

Eleus-owl $592^{\mathrm{b}}$ i $\mathrm{I}, 609^{\mathrm{b}} 9$.

Elm $595^{\text {b }}$ i I, $628^{\mathrm{b}} 26$.

Elops $570^{\mathrm{b}} 20$ note; gall-bladder of $506^{\mathrm{b}} 16$; gills of $505^{a} 16$.

Empis, or Gnat, or Midge, development of $55 \mathrm{I}^{\mathrm{b}} 27-552^{\mathrm{a}} 8$; hatching of $60 I^{a} 3$; sting of $490^{2} 21$.

Encrasicholus, or Anchovy 569 27.

Endive $612^{a} 30$.

Enystrum 507" 9 . 


\section{INDEX}

Epeira $623^{a} 8$ note.

Ephemeron $490^{a} 34,552^{b} 18-23$ note.

Ephialtes scops 6I I $^{\text {l) }} 3$ I note.

Epididymis $510^{\text {b }} 22$ note.

Epiglottis $492^{\mathrm{b}} 35,495^{\mathrm{a}} 29,504^{\mathrm{b}} 4$. Epilais $592^{15} 23$.

Epinephelus gigas $547^{\mathrm{b}} 33$ note, $591^{2}$ I6 note.

Epirus $522^{\mathrm{b}} 16,20,572^{\mathrm{b}} 20,595^{\mathrm{b}}$ I8, $606^{\mathrm{b}} 4$.

Epitonos 5 $15^{\mathrm{b}}$ IO.

Epitragiae, or Capon-fish $53^{8}$ I4.

Epomis $493^{a} 9$.

Equns onager 580' 32 note.

Ergot, in horses $604^{\mathrm{a}} 28$ note.

Erithacus, or red-breast $592^{\text {b }} 22$, $632^{\mathrm{b}} 28$.

Erratic animals $487^{\text {b }} 6$.

Erythrinus, habitat of $598^{a}$ I3: hermaphrodite sex of $538^{a} 21$, $567^{a} 27$.

Etelis, spawn of $567^{a} 20$.

Etesian winds $559^{\text {b }} 29$ note.

Ethiopia, serpents in $490^{\circ}$ II sheep in $573^{\text {b }} 29$.

Ethiopians $517^{a} 19,523^{a} 18,586^{a}$ 4 ; sperm of $523^{a} 18$.

Euboea, sheep in $496^{\mathrm{b}} 25$.

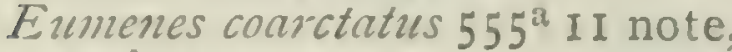
$623^{\mathrm{b}}$ i I note.

Eunuch $632^{2} 4$.

Euphorbia cyparissias $602^{\mathrm{b}} 32$ note.

Euripus $544^{a} 21,547^{a} 6,54^{a}$, $603^{\mathrm{a}} 21,621^{\mathrm{b}} 12$.

Europe $579^{\mathrm{b}} 6,606^{\mathrm{b}}$ I 5-I8.

Euxine, fishes of $567^{\mathrm{b}} \mathrm{I} 6,597^{\mathrm{a}} \mathrm{I} 4$, $598^{2} 24-29$, b 10 ; porpoise in $566^{\mathrm{b}}$ IO, $598^{\mathrm{b}} 2$; purging of $568^{a} 5$; shellfish absent from $603^{\mathrm{a}} 25$; tunny in $543^{\mathrm{b}} 3,57 \mathrm{I}^{\mathrm{a}}$ $16,598^{\mathrm{b}} 29$.

Ewe, breeding of $573^{\mathrm{b}} 7$; diet of $522^{\mathrm{b}} 34$; miscarriage in $604^{\mathrm{a}} \mathrm{I}$ : see also Sheep.

Excess, or defect $486^{\mathrm{b}} 17$.

Excretions $487^{\mathrm{a}} 5,5 \mathrm{II}^{\mathrm{b}} \mathrm{9}$.

Exhalation $487^{a} 29,492^{b} 9$.

Eye $491^{\mathrm{b}} 18,495^{\mathrm{a}}$ II, $503^{\mathrm{a}} 3 \mathrm{I}$, $520^{\mathrm{b}} 4,533^{\mathrm{a}}$ 19; colour of

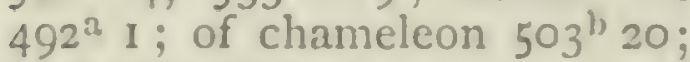
of fishes $505^{2} 32$.

Eyebrow $491^{b} 15,518^{b} 6$.

Eyelash $49 \mathrm{I}^{\mathrm{b}} 20,49^{\mathrm{b}} 22,5 \mathrm{IS}^{\mathrm{b}} 10$; absent in birds $504^{2} 24$.
Eyelid $493^{a} 29,518^{a} 2$; of apes $502^{a} 31$.

Face $49 I^{\mathrm{b}} 9$.

Faggot-bearer 557' 13.

Falcon, see Hawk.

Fascinations $560^{1 / 7} 7$ note.

Fat 5 II $^{\mathrm{b}} 9,520^{\mathrm{a}} 6,52 \mathrm{I}^{\mathrm{b}} \mathrm{IO}$.

Fawn 6ig" Io.

Fawn-killer $618^{\mathrm{b}} 20$.

Feather $486^{\mathrm{b}} 10,21,504^{\mathrm{a}} 30, \mathrm{Sc}$.

Female sex $489^{a}$ II, \&c.

Ferret $580^{\mathrm{b}} 26$.

Fibre $489^{a} 23,5$ I $^{b} 4,515^{b} 24$; of blood $520^{b} 26$.

Fieldfare, or collyrion $6 \mathrm{I} 7^{\mathrm{b}} 9$.

Fieldmouse $580^{\mathrm{b}} 20$ note, $606^{\mathrm{b}} 7$.

Fig $522^{\mathrm{b}} 2,541^{\mathrm{b}} 24,552^{\mathrm{b}} 1,577^{\mathrm{a}}$ II, $595^{\mathrm{a}} 29$ - b $^{\mathrm{l}} \mathrm{I}, 603^{\mathrm{b}} 14,27$, $626^{\text {b) }} 8$; wild $554^{a} 15$.

Fig district $507^{2} 17$.

Fig-wasp, or psen $557^{\text {l) }} 26$.

Finch, mountain $592^{\mathrm{b}}$ I 8 .

Finch-titmouse $592^{\mathrm{b}} 18$.

Fins, of fishes $489^{\mathrm{b}} 24,504^{\mathrm{b}} 30$, S.C.

Fir-tree $552^{\mathrm{b}} 2$.

Fish $486^{\mathrm{a}} 23,487^{\mathrm{l}} 16,490^{\mathrm{b}} 8$, $505^{\mathrm{b}} 28$; association of $610^{\mathrm{ll}} \mathrm{I}$; blindness in $602^{a} 3$; development of $564^{\mathrm{b}} 26$; diseases of $602^{\mathrm{b}} 12$; generation of $564^{\mathrm{b}}$ 15 ; heart of $507^{a} 2$; localities favourable to $60 \mathrm{I}^{\mathrm{b}}$ I 5 ; lice on $537^{a} 5$; migrations of $597^{a} 14$, 31 ; reproductive organs of $509^{\mathrm{b}} 16,540^{\mathrm{b}} 30$; ruminant $632^{\mathrm{b}} 10$, sce also Scarus; seasons of $601^{a} 28,607^{b} 6$; sense-organs of $505^{a} 32$; stomach of $507^{a} 29$; tail of $504^{\mathrm{b}} 16$; tongue of $503^{\mathrm{a}}$ I ; voice of $535^{\mathrm{b}}$ I5; $\mathrm{Sc}$.

Fish-bone $486^{\mathrm{b}} 20,5 \mathrm{II}^{\mathrm{b}} 7$.

Fish-eating animals $488^{2}$ I9.

Fish-glue $5 \mathrm{I} 7^{\mathrm{b}} 3 \mathrm{I}$.

Fishing, methods of $603^{\mathrm{a}} 2, \mathrm{Sic}$.

Fishing-frog, or Batrachus $508^{\text {h }}$ 24 note, $540^{\mathrm{b}}$ I8, 564 ${ }^{\mathrm{b}}$ I9 note; fins of $489^{b} 33$; gall of $506^{b} 16$; gills of $505^{a} 6$; habits of $620^{\text {l }}$ II-28; spawning of $505^{1} 4$, $570^{\mathrm{b}} 32$; young of $565^{\mathrm{b}} 29$.

Fissurellar $529^{\mathrm{b}}$ is note.

Flamingo $509^{\text {i }}$ is note.

Flat-fish, sce P'setta.

Flea, spontancous generation of $539^{\text {b) }} 12,556^{\text {b }} 23$; diet of $556^{\text {b }}$ 
22 ; sea-lice so called $537^{2} 6$; spider so called $622^{\mathrm{b}} 3 \mathrm{I}$.

Fleabane $534^{\mathrm{b}} 28$.

Flesh $487^{\mathrm{a}} 4,5 \mathrm{II}^{\mathrm{b}} 5,519^{\mathrm{b}} 25$.

Flexion of limbs $494^{\mathrm{b}} 3,498^{\mathrm{a}} 2$ ${ }^{b} 4$; in birds $503^{b} 32$; in camel $499^{a} 20$.

Flies $488^{\mathrm{a}}$ I $8,535^{\mathrm{b}} \cdot 9,539^{\mathrm{b}}$ I I , $542^{\mathrm{b}} 30,552^{\mathrm{b}}$ I $2,628^{\mathrm{b}} 36$; development of $552^{\mathrm{a}} 21$; diet of $596^{\mathrm{b}} 14$; dropsy of $553^{\mathrm{a}}$ I 5 ; pairing of $542^{\mathrm{a}}$ IO; sting of $490^{\mathrm{a}} 20, \quad 528^{\mathrm{b}} 29, \quad 532^{\mathrm{a}} 13$; wings of $532^{a} 21$.

Flowering reed $627^{a} 9$.

Flying animals $490^{\circ} 6$, \&c.

Flying-fish, flight of $535^{\mathrm{b}} 28$.

Flying Fox, wings of $490^{a} 8$.

Foot, cloven $499^{\mathrm{b}} 7$, \&c.

Foot-and-mouth disease $604^{\mathrm{a}}$ I3 note.

Forewaters $5^{86^{\mathrm{a}}} 30$.

Foul-brood, in bees $626^{\mathrm{b}}$ Ig note.

Fowl, see Cock, Hen.

Fox $619^{b} 10,15$; breeding of $580^{a} 6$; destruction of mice by $580^{\mathrm{b}} 25$; hostilities of $609^{\mathrm{b}} \mathrm{I}-32$, $610^{a} 12$; in Egypt $606^{\circ} 24$; hybrid $607^{a} 3$; penis of $500^{b}$ 23 ; temper of $488^{\mathrm{b}} 20$.

Fox-shark $565^{\mathrm{b}}$ I, $566^{\mathrm{a}} 3 \mathrm{I}, 621^{\mathrm{a}}$ I 2.

Francolin $617^{\mathrm{b}} 25,633^{\mathrm{b}} \mathrm{I}$.

Frenum $493^{\mathrm{a}} 30$.

Freshwater, in sea-water $590^{\circ} 22$.

Frog, amphibious $589^{a} 29$; black formations in $530^{\mathrm{b}} 34$; copulation of $540^{a} 31$; croaking $606^{a}$ 6 ; habitat of $487^{a} 28$; hostilities of $626^{a} 9$; sexes of $53^{a} 28$; spleen of $506^{a} 20$; spawn of $568^{a} 24$; tongue of $536^{a} 8$; voice of $536^{2} 8-19$; womb of $510^{b} 35$, \&c.; see also Fishingfrog.

Froth, or fry, of fishes $569^{\mathrm{b}} 30-^{\mathrm{b}} 28$, $602^{\mathrm{b}} 2$.

Fruit-bat $490^{b} 6$ note.

Function $488^{\mathrm{b}} 29$ note, \&c.

Gadfly, development and larva of $487^{\mathrm{b}} 6,506^{\mathrm{a}} 27$ note, $55^{\mathrm{b}}$ 22 ; diet of $596^{\mathrm{b}}$ I 5 ; proboscis or sting of $490^{\mathrm{a}} 2 \mathrm{I}, 528^{\mathrm{b}} 3 \mathrm{I}$, $532^{a}$ Io; of Tunny $557^{a} 28$, $602^{a} 28$.

Galeodes, or Sharks, see Dogfish.
Galeos, see Dogfish; $G$. canis $566^{a} 21$ note.

Gall $487^{a} 4$, \& c.

Gall-bladder $5^{0} 6^{\mathrm{a}} 2 \mathrm{I}$, \& $\mathrm{c}$.

Gallinaceous birds $504^{\mathrm{a}} 24$; see also Cock, Hen.

Gangrene $520^{b}$ I9.

Garfish, see Belone.

Garlic 591 ${ }^{a}$ I6 note.

Gastrocnemia 499" 5 .

Gustropteron meckelii $532^{b} 26$ note.

Gaul $606^{\mathrm{b}} 5$.

Gazelle, horns of $499^{a} 9$.

Gecko $6 \operatorname{6og}^{a} 28,614^{b} 4$; bite of $607^{a} 27$; habits of $614^{b} 4$; hibernation of $599^{a} 31$; hostilities of $607^{a} 27 ;$ sexes of $53^{a}$ 28 ; sloughing of $600^{\mathrm{b}} 23$.

Genera $486^{\mathrm{a}} 23,490^{\mathrm{b}} 7,497^{\mathrm{b}} 6$, $505^{\mathrm{b}} 26,527^{\mathrm{b}} 2,534^{\mathrm{b}} \mathrm{I} 4$, \&c.

Generation $489^{b}$ I8, $509^{a} 30,534^{b}$

I4; from egg $56 I^{2} 4$, \&c.; or gans of $509^{a} 1-5 I^{2} 34$; in man $497^{2} 24$; \&c.

Genet $580^{a} 28$ note.

Genista scoparia $627^{a} 8$ note.

Geometridae $55^{\text {I }} 6$ note.

Gills $489^{\mathrm{b}} 3,504^{\mathrm{b}} 28,506^{\mathrm{a}} 8,507^{\mathrm{a}}$ $5,524^{\mathrm{b}} 22$ note; of lobster $526^{\mathrm{a}}$ 26, \&c.

Gilthead, or Chrysophrys 508b 20 note; diet of $59 \mathrm{I}^{\mathrm{b}}$ IO ; fins of $489^{\mathrm{b}} 26$; habitat of $598^{\mathrm{a}}$ 10; hibernation of $599^{\mathrm{b}} 34$; seasons of $602^{\mathrm{a}}$ II ; sleep of $537^{\mathrm{a}} 29$; spawning of $543^{\mathrm{b}} 4,570^{\mathrm{b}} 2 \mathrm{I}$.

Giraffe $498^{\mathrm{b}} 33$ note.

Gizzard, of birds $508^{\mathrm{b}} 34$.

Glanders $605^{a} 16$ note.

Glanis, see Sheattish.

Glans $493^{a} 27$.

Glanus, or Hyaena $594^{a} 31$.

Glaucus, or greyback, caeca of $508^{\mathrm{b}} 20$; habitat of $598^{\mathrm{a}} \mathrm{I} 3$; hibernation of $599^{\mathrm{b}} 32$; seasons of $607^{\mathrm{b}} 27$.

Glottis, or corncrake, migration of $597^{\mathrm{b}} \mathrm{I} 7,2 \mathrm{I}$.

Glow-worm $523^{\mathrm{b}} 2 \mathrm{I}, 55^{\mathrm{b}} 25$.

Glue $517^{\mathrm{b}} 30$.

Gnat, or conops $535^{a} 3$; sting of $532^{\mathrm{a}}$ I4; the Vinegar-fly $552^{\mathrm{b}}$ 4 ; see also Empis.

Goat, age of, at maturity $545^{a} 24$; beard of $6 \mathrm{ro}^{\mathrm{b}} 29$; breeding of $567^{a} 5,572^{b} 32,573^{b} 20$; diet 


\section{INDEX}

of $522^{\text {b }} 34,596^{a} 14$; dreaming of $536^{\mathrm{b}} 30$; eyes of $492^{\mathrm{a}} 14$; foot of $499^{\text {b }}$ 10, 18; Egyptian $606^{\mathrm{a}} 25$; habits of $574^{\mathrm{a}} \mathrm{II}-15$, $596^{\mathrm{b}} 6,6 \mathrm{II}^{\mathrm{a}} 4$; Libyan $500^{\mathrm{a}} 16$ note; lice on $557^{\mathrm{a}} 16$; milk of $522^{a} 23,28,30,618^{b}$; (in hegoat) $522^{a} 8,14$; rumination in $632^{\mathrm{b}} 3$; Syrian $606^{\mathrm{a}} 16$; temper of $571^{\mathrm{b}} 21$; urine of $573^{\mathrm{a}} 19$; voice of $536^{a} 15$; wild $488^{a} 31$, $612^{a} 3 ;$ absent from Libya $606^{2} 7$.

Goat, fish so called $607^{\mathrm{b}}$ I2 ; sponge so called $548^{\text {l }} 5$.

Goat-sucker 61 $8^{\mathrm{b}} 2$.

Goby, or Gudgeon, caeca of $508^{\mathrm{b}}$ I 7 ; diet of $591^{\mathrm{b}} 14$; habitat of $598^{a}$ II note, I6, $601^{b} 22,610^{b}$ $4,62 \mathrm{I}^{\mathrm{b}} \mathrm{I} 3$; spaivn of $567^{\mathrm{b}} \mathrm{I} 2$, $569^{\mathrm{b}} 24$; black, or phycis, spawn of $567^{\text {l) }}$ I 9 note; white $62 I^{b}$ I9.

Golden-crested wren 592" 24 .

Golden oriole $616^{\mathrm{b}}$ 11, $617^{\mathrm{a}} 28$; fable of $609^{\mathrm{b}}$ 10.

Goldfinch $593^{\mathrm{a}}$ I.

Goose $593^{\mathrm{b}} 22$; caeca of $509^{\mathrm{a}} 22$; crop of $509^{a} 3$; foot of $499^{a} 28$; gregarious $593^{\mathrm{b}} 22,597^{\mathrm{l}} 31$; habits of $560^{\mathrm{b}} 10$; incubation of $563^{a} 29,564^{a}$ Io; penis of $509^{\mathrm{b}} 3 \mathrm{I}$; temper of $488^{\mathrm{b}} 23$; wind eggs in $559^{\mathrm{b}} 23,29$.

Govinda, a kite 6 I $5^{\mathrm{b}} 6^{2}$ note.

Graminivorous animals $488^{a}$ I5, \&.c.

Granny-crab, or Maia $525^{\mathrm{b}} 5$, $527^{\mathrm{b}} 13,691^{\mathrm{a}} 19$.

Grape-beetle 604' Is.

Grapes 550 1 I, 29.

Grapsus 527l 13 note.

Grasshopper, or Acris 550" 32 , $612^{\mathrm{a}} 34\left(\right.$ ?); gut of $532^{\mathrm{b}}$ II ; habits and breeding of $555^{\mathrm{b}}$ 10, $18-55^{a} 8,601^{n} 7$; hum of $535^{\text {l' }}$ II.

Grebe $487^{\mathrm{a}} 22,593^{\prime \prime} 19$; horned $593^{\text {l) }} 23$.

Grecce, animals in $606^{a} 22$; childbirth in $584^{\mathrm{b}}$ I 1 .

Greenfinch, or Green Linnet, diet of $592^{1)}$ I 7 ; nest of $615^{b} 32$ : cuckoo in nest of $6 \mathrm{Ig}^{\mathrm{a}}$ II.

Greenpie, or Green Woolpecker, see Celeus.

Greyback, see Glaucus.
Gristle, or cartilage $487^{2} 6,5 I^{1}$ 9, 5 I $^{\text {l) }} 31$.

Grubs $489^{\text {lb }} 9,16,539^{\mathrm{b}} 12,550^{\text {l) }} 26$.

Gudgeon, see Goby.

Guinea-fowl, eggs of $559^{2} 25$.

Gull, or Seamew $593^{b} 4,14,609^{2}$ 24 ; crop of $509^{a} 4$; eggs of $542^{\text {b }}$ I 7, I 9.

Gums $493^{a} 2$.

Gurnard, voice of $535^{\mathrm{b}}$ I6 note.

Gyrinus $55^{\mathrm{l}} \mathrm{b} 23$ note.

Haemorrhoid, or aporrhais $530^{\circ}$ 19, 25.

Haemorrhoids $52 I^{a}$ I $9,29,587^{b} 34$.

Hail-stones, of egg $560^{2} 28$.

Hair $487^{a} 6,51^{b} 8,517^{b} 3$; grey $518^{\mathrm{a}} 6$; partings of $491^{\mathrm{b}} 5$.

Hair-coated animals $490^{\text {l }} 22$. $498^{\mathrm{b}} 16$, \&c.

Hairy-growths, or gills, of scallop $529^{a} 34$.

Hake, habits of $620^{\prime \prime} 30$; hibernation of $599^{\mathrm{b}} 33$.

Halcyon, or Kingfisher, colour of

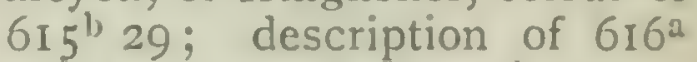
14-34; legend of $542^{11} 4-25$; species of $593^{\mathrm{b}}$ 10.

Halcyon days $542^{\mathrm{b}} 6,18$.

Half-buzzard $620^{\mathrm{a}}$ I 9 .

Half-eagle $618^{\mathrm{b}} 34$.

Haliotis $529^{\mathrm{b}}$ i 5 note.

Halosachne $616^{n} 20,28$.

Haltica oleracea $522^{\mathrm{b}} 3 \mathrm{I}$ note.

Hand $486^{\mathrm{b}} 20,502^{\mathrm{l}} \mathrm{S}$; of apes $502^{\mathrm{b}} 6$.

Hare $619^{a} 35,{ }^{b} 9,15$; blood of $516^{a} 2$; breeding of $579^{b} 31-$ $580^{a} 5$; copulation of $539^{\mathrm{b}} 22$ : in Egypt $606^{a} 24,{ }^{b} I$; in Ithaca $606^{a} 2$; liver of $507^{a} 16$; mouth and feet of $519^{2} 22$; rennet of $522^{\mathrm{b}} 9$; retromingent $500^{\mathrm{l}} 16$; superfoetation in $542^{1} 31,585^{a}$ 6 ; temper of $488^{\text {b }} 16$; womb of $5 I^{\mathrm{a}} 3 \mathrm{I}$.

Hare-killer 6 I $8^{b} 28$.

Harpe $609^{2} 24,610^{2} 11,617^{n}$ Io.

Hart's horn $534^{\text {b }} 24$.

Haunch-bone $516^{\mathrm{n}} 35$; of birds $504^{\mathrm{a}}$.

Hawk $490^{a} 7,613^{\text {b }}$ 10, 61 $5^{10} 7$; confused with cuckoo $563^{11}$ $14-28$; in Egypt $606^{2} 24$; gall of $506^{\mathrm{b}} 24$; habits of $615^{\mathrm{a}} 4-8$; hostilities of $613^{\text {" } 10 \text {; incubation }}$ of $503^{a} 30$ : interbreeding of 


\section{INDEX}

$619^{2}$ II ; nesting of $564^{2} 4$; species of $592^{\mathrm{b}} \mathrm{I}, 620^{\mathrm{a}} \mathrm{I} 7-32$; spleen of $506^{\mathrm{a}} 16$.

Hawking in Thrace $620^{\mathrm{a}} 32-^{\mathrm{b}} 5$.

Head $49 I^{\text {il }} 28,498^{b}$ I 8 , \&c.

Hearing $532^{\mathrm{b}} 33$; see also Ear.

Heart $506^{\mathrm{a}} 5,507^{\mathrm{a}} \mathrm{I}, 5 \mathrm{II}^{\mathrm{b}}, 513^{\mathrm{b}}$ 28 ; blood in $520^{\mathrm{b}} \cdot 15,52 \mathrm{I}^{\mathrm{a}}$ IO ; cavities of $496^{\mathrm{a}} 2 \mathrm{I}$ note, $5 \mathrm{I} 3^{\mathrm{b}} \mathrm{I}$; of ox $506^{a} 8$; position of $506^{b}$ 33 ; sinews of $515^{\mathrm{a}} 28$.

Heat $572^{\mathrm{b}} 25$.

Hecatombaeon $543^{b} 12,549^{a} 16$, $571^{2} 14$.

Hectocotylus $524^{\mathrm{a}} 7$ note, $54^{\mathrm{b}} 9$.

Hedgehog $58 \mathrm{I}^{\mathrm{a}} 2$; copulation of $540^{a} 3$; cunning of $612^{b} 4$; spines of $490^{b} 29,517^{b} 24$; testicles of $509^{\mathrm{b}} 9$.

Heel, of apes $502^{b}$ I 9 .

He-goat, milk in $522^{\mathrm{a}} \mathrm{I} 4$.

Heledone, see Eledone.

Helix pomatia $529^{a} 34$ note.

Hellespont $548^{\mathrm{b}} 24,549^{\mathrm{b}}$ I $5,568^{\mathrm{a}}$ 6.

Helminthes, or intestinal worms $548^{\mathrm{b}}$ I $5,55 \mathrm{I}^{\mathrm{a}} 8,57 \mathrm{O}^{\mathrm{a}} \mathrm{I} 4,602^{\mathrm{b}}$ 26.

Hemioni $49 \mathrm{I}^{a} 3$; see also Mule.

Hemys, or freshwater tortoise, eggs of $55^{2} 8$; respiration of $589^{a} 29 ;$ shell of $600^{b} 23$; spleen of $506^{a} 19$.

Hen, Adrian $55^{\mathrm{b}} \mathrm{I} 8$; breeding, eggs, \&c., of $544^{\mathrm{a}} 3 \mathrm{I}, 55^{\mathrm{b}} \mathrm{I} 2^{-}$ $27,559^{\mathrm{a}} \mathrm{I} 7,560^{\mathrm{a}} \mathrm{I}, \mathrm{b} 3,19,613^{\mathrm{b}}$ I5; crowing $63 I^{\text {b }} 8$, development of $561^{a} 6-562^{b} 2$; dustbath of $633^{\mathrm{b}} \mathrm{I}$; habits of $56 \mathrm{o}^{\mathrm{b}}$ 7 ; peafowl reared under $564^{\mathrm{b}} 2$; size of $614^{\mathrm{b}} 10,617^{\mathrm{b}} 24$; windeggs in $559^{\circ} 23,28$.

Hepatitis, vein $512^{a} 5,30$.

Hepatus, caeca of $508^{\mathrm{b}} 20$.

Heracleotis, crabs of $525^{\mathrm{b}} 5,527^{\mathrm{b}}$ I2.

Hercules $585^{\mathrm{a}} 14, \mathrm{~b} 24$.

Herd-spurning $572^{\mathrm{b}} 19$.

Here $580^{a} 19$.

Heredity $539^{a} 26$.

Hermaphrodite duct $529^{2}$ I 6 note; fishes $538^{a} 20$ note.

Hermit-crab, or Carcinium $529^{a}$

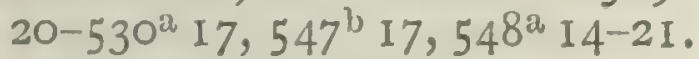

Herodorus $563^{a} 7,615^{a} 9$.

Herodotus $523^{a} 17$.

Heron, habitat of $593^{a} 28$; hostili- ties of $609^{a} 30,{ }^{b} 21,610^{a} 8$; species and habits of $609^{\mathrm{b}} 2 \mathrm{I}$, $616^{b} 33-617^{a} 8$; speckled, or Asterias $617^{\mathrm{a}} 5$; white $593^{\mathrm{b}} 3$. Hesiod $60 \mathrm{I}^{\mathrm{b}} 2$.

Himantopus rufipes $616^{\mathrm{b}} 20$ note. Hind $578^{\mathrm{b}} 7$.

Hinny $488^{\mathrm{a}} 27,491^{\mathrm{a}} 2,577^{\mathrm{b}} 2 \mathrm{I}$, 26, 29 ; see also Jennet.

Hip-socket $516^{\text {a }} 35$.

Hippelaphus $498^{b} 31-499^{a} 9$.

Hippomanes $572^{\mathrm{a}} 2 \mathrm{I}-30,577^{\mathrm{a}}$ IO, $605^{2} 2$.

Hippopotamus, aquatic habits of $589^{a} 28,605^{a} 13$; description of $502^{a}$ 9-I 5 ; feet of $499^{b}$ Io.

Hippurus, breeding of $543^{a} 22$; hibernation of $599^{\mathrm{b}} 3$.

Himendo urbica $6 \mathrm{I} 2^{\mathrm{b}} 2 \mathrm{I}$.

Hobbyhawk $620^{2} 20$.

Holothuria $487^{\mathrm{b}}$ I 5 .

Holy - fish $620^{\text {b }} 35$; see also Anthias.

Holy-snake $607^{a} 30$.

Homarus vulgaris $526^{\text {a }}$ I2 note; see also Lobster.

Homer $513^{\mathrm{b}} 27,519^{\mathrm{a}} 18,574^{\mathrm{b}} 34$, $575^{\mathrm{b}} 5,57^{\mathrm{b}} \mathrm{I}, 606^{\mathrm{a}} 20,615^{\mathrm{b}} 9$, $618^{\mathrm{b}} 25,629^{\mathrm{b}} 22$.

Homogeneous parts $486^{a} 5,487^{a} 2$, $489^{a} 26$.

Honest Wife, mare so called $586^{a}$ I4.

Honey $488^{\mathrm{a}} 18,553^{\mathrm{b}} 32,623^{\mathrm{b}} 24$, \&c.

Honeycomb $553^{b} 2,24,623^{b} 7,33$, \&c.; of Porphyra $546^{b} 20$.

Honeycomb bag, of ruminants $507^{\mathrm{b}} 4$.

Hooers $537^{\text {a }}$ I9 note.

Hoof $486^{b} 20,517^{a} 8$, \& 6 .

Hoopoe $615^{2} 16$; eggs and nest of $559^{a} 9,616^{a} 35$; habitat of $488^{b} 3$; metamorphosis of $633^{a}$ 18-29.

Hoplopterus spinosus $612^{a} 20$ note.

Horehound $59 I^{a}$ I6 note.

Horn $487^{a} 8,5 I 7^{a} 8,20$; of Bison $499^{\mathrm{b}} 32$; of deer $500^{\mathrm{a}} 6-1 \cdot 3$, $61^{a} 25$; \&c。

Horned animals $498^{b} 3 \mathrm{I}, 499^{\mathrm{a}} \mathrm{I}$, I $5,507^{a} 35$; diet of $595^{a} 14$; womb of $510^{b} 18$; \&c.

Hornet, see Anthrene.

Horse, age of maturity in $545^{\mathrm{b}}$ Io ; breeding of $575^{\mathrm{b}} 20$; colour of 


\section{INDEX}

$518^{a} 9$; diet of $595^{1 / 2} 23$; diseases of $602^{\mathrm{b}} 13,604^{\mathrm{a}} 22$; dreaming in $536^{\mathrm{b}} 29$; drinking $595^{\mathrm{a}} 9$; gall of $506^{a} 22$; genitals of $500^{a}$ $34,{ }^{b} 6$; habits of $605^{a} 8$; heart of $506^{a} 10$; hostilities of $609^{b}$ I4; killed by bees $626^{a} 21$; mane of $498^{\mathrm{b}} 30,502^{\mathrm{a}}$ 10 ; maternal resemblances in $500^{a}$ 32 ; neigh of $502^{\mathrm{a}} 12,544^{\mathrm{b}}$ 7 ; Nisaean $632^{a} 30$; senses of $533^{\mathrm{a}} 3 \mathrm{I}$; teats of $52 \mathrm{I}^{\mathrm{b}} 23$; teeth of $501^{a} 17, b^{b} 2,14,576^{a} 7$; temper of $57 \mathrm{I}^{\mathrm{b}} 25$; wild $438^{\mathrm{a}}$ 31 ; womb of $510^{15} 17$, \&c.

Horse-fly, or Myops, development of $552^{\mathrm{a}} 30$; diet of $596^{\mathrm{b}}$ I 5 ; proboscis or sting of $490^{2} 20$, $528^{\mathrm{b}} 31,532^{\mathrm{a}} 9$.

Horse-mackerel $6 \mathrm{Io}^{\mathrm{b}} 5$.

Horseman ant $606^{a} 5$; $\mathrm{crab} 525^{\mathrm{b}} 8$.

Huckle-bone $499^{\mathrm{b}}$ 20-31; of camel $499^{a} 21$; of hippopotamus $502^{\mathrm{a}}$ J I ; \&c.

Humble-bee $623^{\mathrm{b}}$ I 5 ; habits of $629^{a} 30$; nest of $555^{a} 13-19$.

Humming $535^{\circ} 6$.

Hump, of camel $499^{a}$ I 3 .

Hunchback crabs, or cyphae $525^{\mathrm{b}} 2$, I 8, 28, 3I, 549 $\mathrm{l}$ I2.

Hunter-wasp, see Ichneumon.

Hyaena, description of $579^{\mathrm{b}} 16-30$, $594^{a} 3 I^{-b} 5$.

Hybris 6 $5^{\mathrm{b}}$ 10.

Hypanis $552^{\mathrm{b}} 17$.

Hypera $55 I^{\mathrm{l}} 6$.

Hyperboreans $580^{2}$ I 8 .

Hypochondrium $493^{\text {a }} 20,496^{\text {b }} 13$.

Hypoglutis $493^{\mathrm{b}}$ Io.

Hypolais, or lark $564^{a} 2,618^{a} 10$.

Hypozoma $532^{\mathrm{b}} \mathrm{16}, 535^{\mathrm{b}} 8$.

Hystera, or delphys $510^{b} 14$.

Ibis, Egyptian 6I $7^{\text {l) }} 27$ note.

Ichneumon, craft of $612^{2} 16$; young of $580^{2} 24$; a species of wasp so called $552^{\text {b }} 26,552^{\text {b }} 26$ note, $609^{2} 5$.

Ichor $521^{\mathrm{a}}$ I 3,33 .

Idalia laciniosa $532^{\text {b }} 26$ note.

Iliad $615^{\mathrm{b}} 9$.

Illas $617^{\mathrm{a}} 22$.

Illyria $606^{b} 3$; swine in $499^{\text {l) }} 13$.

Incisors $499^{\circ} 23$ note.

India $501^{\mathrm{a}} 26,57 \mathrm{I}^{\mathrm{b}} 34,597^{\mathrm{l}} 27$, $605^{a} 8,607^{a} 34,610^{a} 19$.

Indian ass $499^{1 \text { l }} 19$.
Ines 5 I $5^{\text {l) }} 28$.

Inhalation $487^{a} 29,492^{1} 9$, \& c .

Insects $490^{\mathrm{b}} 14,523^{\mathrm{b}} 12,53 \mathrm{I}^{\mathrm{b}} \mathrm{I} 9$ $-532^{\mathrm{b}} 18,534^{\mathrm{b}} 15,550^{\mathrm{l}} 2-557^{\mathrm{l}}$ $31,601^{a} 1$; copulation of $542^{a}$ $35,550^{\mathrm{b}} 22$; definition of $487^{\mathrm{a}}$ 33 ; diet of $596^{\mathrm{b}} 10$; diseases of $605^{\mathrm{b}} 6$; hibernation of $599^{\mathrm{a}}$ 20 ; vitality of $531^{\mathrm{b}} 30$; \&c.

Intestine $489^{\mathrm{a}} 5,507^{\mathrm{b}} 3 \mathrm{I}$.

Inula coryza $534^{\mathrm{b}} 28$ note.

Inversio viscermm $507^{\mathrm{a}} 21$.

Ionia $615^{\mathrm{b}} 8$.

Iphicles $585^{\mathrm{a}}$ I4.

Ister, or Danube $597^{a}$ II, 598 ${ }^{b}$ I6.

Italy $607^{\mathrm{a}} 26,632^{\mathrm{b}} 26$.

Ithaca $606^{\mathrm{a}} 2$.

Iulus $523^{\mathrm{b}}$ I 8 .

Ixodes ricinus $557^{2}$ I6 note.

Jackal $580^{a} 28$ note.

Jaws $492^{\text {b }} 21$.

Jay $592^{1} 13,617^{2} 20$; description of $615^{\mathrm{b}} 19$; nest of $616^{\mathrm{a}} 3$.

Jennet $49 \mathrm{I}^{\mathrm{a}} 2$; see also Hinny.

Jerboa $58 \mathrm{I}^{\mathrm{a}} 34$ note.

John Dory $535^{\mathrm{b}}$ I 7 note.

Jugular veins $512^{a} 20,24,514^{a} 10$, 15 notes.

Keraiae $499^{\mathrm{b}} 29$.

Kestrel $594^{a} 2$; crop of $509^{a} 7$; eggs of $55^{8^{b}} 28,559^{a} 26$.

Kidneys $496^{\mathrm{b}} 34,506^{\mathrm{b}} 25,507^{\mathrm{a}} 20$, Sc.; fat of $520^{a} 27$; fourfold, in foal $577^{\mathrm{a}} 6$; of $\mathrm{Ox}$ and Turtle $506^{\mathrm{b}} 29$; veins of $514^{\mathrm{l}}$ I6, 36.

King, or Old Man, the wren so called $492^{b}$ i $8,609^{a} 17,615^{a} 19$.

King-bees $553^{a} 25,623^{b} 9$; cells for $623^{b} 34,624^{a} 1,3$; egg of $554^{\mathrm{a}} 24$; habits of $624^{\mathrm{a}} 26, \mathrm{~b} 6$, II-I 5 ; two kinds of $553^{1 \text { ) }} 14$.

Kingfisher, see Halcyon.

King's-spear $627^{\mathrm{a}} \mathrm{S}$.

Kissing, in pigeons $560^{\prime \prime} 25$.

Kite $592^{\text {l }} 1$; drinking of $594^{\text {i }} \approx$; gall of $506^{\text {' }} 24$; hibernation of $600^{2} 11,25$; hostilities of $609^{\text {a }}$ $20,610^{2} 11$; incubation of $563^{\text {th }}$ 30 ; spleen of $506^{\mathrm{a}} \mathrm{I} 6$.

Knee $494^{a} 5$, IS ; of camel $499^{2} 19$. Knuckle-beetle, or Sphondyle $542^{a} 11,604^{b} 19,619^{b} 22$.

Labour, in women $556^{\prime \prime} 27$. 


\section{INDEX}

Labrax, see Basse.

Labyrinth $499^{\text {b }} 25$.

Laconian hound, see Dog.

Laedus $610^{a} 9$.

Laius, or Blue-thrush $617^{a}$ I 5 .

Lake-fish, maladies of $602^{\mathrm{l}} 20$; seasons of $607^{\mathrm{b}} 34$.

Lamia, or Shark $540^{\mathrm{b}} 18,621^{\mathrm{a}} 20$.

Lammergeyer, see Phene.

Landrail, migration of $597^{\mathrm{b}} \mathrm{I} 7,20$ note; see also Corncrake.

Language $535^{a} 29,536^{b} 2$.

Lantern, of sea-urchin $531^{a} 5$.

Lard $487^{\mathrm{a}} 3$.

Lark $615^{\mathrm{b}} 33$; description of $617^{\mathrm{b}}$ $20-23$; habits of $614^{\mathrm{a}} 33,633^{\mathrm{b}}$ 2 ; hostilities of $609^{\mathrm{a}} 7, \mathrm{~b}_{27}$, $610^{2} 9$; hibernation of $600^{2} 21$; nest of $559^{a} 2,618^{a}$ IO.

Larus, see Gull.

Larynx $493^{a} 6$.

Latax, see Beaver.

Lateral sinus $514^{a}$ I 5 note.

Lebadia $606^{\mathrm{a}} \mathrm{I}$.

Lectum $547^{a} 5$.

Leek $55 \mathrm{I}^{\mathrm{b}} 20$.

Leekbane, or Prasocuris $55 \mathrm{I}^{\mathrm{b}} 20$.

Left-hand side, inferiority of $497^{\mathrm{b}}$ 22.

Leg $49 \mathrm{I}^{\mathrm{a}} 29,494^{\mathrm{a}} 3,502^{\mathrm{b}} \mathrm{I}, \& \mathrm{c}$.

Leguminous plants $522^{\mathrm{b}} 32$.

Lemnos $522^{a} 14,18$.

Leontini $520^{\mathrm{b}}$ I.

Leopard, Pard, or Panther, fable of $612^{a}$ IO-I 5 ; foot of $499^{b} 9$; habitat of $606^{\mathrm{l}} 16$; sexes of $608^{a} .32$; teats of $500^{2} 27$; teeth of $5 \mathrm{OI}^{\mathrm{a}} \mathrm{I7}$; temper of $488^{2} 27$.

Lesbos, fishes of $62 I^{b} 22$.

Leto $580^{2}$ I 8 .

Libya $606^{a} 7$, b $19,607^{a} 22,615^{b}$ 4 ; lions in $606^{\mathrm{b}} 9$; serpents in $606^{\mathrm{b}} 9$; Libyan sparrow, or ostrich $616^{\mathrm{b}} 5$; rams in $606^{\mathrm{a}} \mathrm{I} 9$.

Libyus $609^{2} 20$.

Lice, description of $556^{\mathrm{b}} 28-557^{\mathrm{a}}$ 28 ; diet of $556^{\mathrm{b}} 22$; reproduction of $539^{\mathrm{b}}$ 10; sea-lice $537^{\mathrm{a}} 5$, $602^{\mathrm{b}} 29$.

Ligaments 5 I $^{\text {l) }} 2 \mathrm{I}$ note; lig. muchae $5^{1} 5^{\mathrm{b}} 8$ note; lig. vesicae lateralia 5 I $4^{\mathrm{b}} 33$ note.

Limbs $486^{\circ}$ 9, \&c。

Limnostreae, or Lagoon oysters $528^{n} 23,30,547^{\text {b }}$ I I, 29 。

Limpet $528^{a} 14,529^{a} 31,530^{b} 21$; habits of $528^{a} 2,530^{a} 17,547^{b}$ $22,548^{a} 27,590^{a} 33$; wild $529^{b}$ I 5 .

Linnet, see. Acanthis; Green Linnet, see Greenfinch.

Ligyans, seven-ribbed $493^{\mathrm{b}}$ I 5 .

Lion, astragalus of $499^{b} 25$; bones of $51^{\mathrm{b}} 7,52 \mathrm{I}^{\mathrm{b}} 12$; breeding of $579^{\mathrm{a}} 33$; claws of $517^{\mathrm{b}} 1$; copulation of $539^{\mathrm{b}} 22$; description and habits of $579^{\mathrm{a}} 33^{-\mathrm{b}} 15,594^{\mathrm{b}}$ I $7-27,629^{b} 8-630^{a}$ Io ; foot of $499^{\mathrm{b}} 8$; gait of $498^{\mathrm{b}} 7$; hostilities of $610^{\mathrm{a}} 13$; in Libya $606^{\mathrm{b}}$ I4; mane of $498^{\mathrm{b}} 25$; neck of $497^{\mathrm{b}} 16$; poisoned by leopard's bane $612^{a} 9$; retromingent $500^{b}$ I 5 ; stomach of $507^{\mathrm{b}} 22$; teats of lioness $500^{2} 29$; teeth of $501^{\mathrm{a}} \mathrm{I} 6, \mathrm{~b} 6$ note, $507^{\mathrm{b}} \mathrm{I} 6$; species of $629^{\mathrm{b}} 33$; temper of $488^{\mathrm{b}} \mathrm{I} 7,57 \mathrm{I}^{\mathrm{b}} 27$.

Lips $492^{\mathrm{b}} 25$.

Lisping $492^{\mathrm{b}} 34$.

Liver $496^{\mathrm{b}} 17,30,506^{\mathrm{a}} 13,507^{\mathrm{a}}$ $\mathrm{I} 2,5 \mathrm{I} 4^{\mathrm{b}} 14,28,5^{\mathrm{b}} \mathrm{6} 6^{\mathrm{b}}$ I 8 .

Lizard $488^{\mathrm{a}} 23,489^{\mathrm{b}} 21,503^{\mathrm{b}} 12$, $619^{\mathrm{b}} 22,623^{\mathrm{a}} 34$; in Arabia $606^{\mathrm{b}} 6$; colour of $503^{\mathrm{b}} 5$; copulation of $540^{\mathrm{b}} 4$; diet of $594^{\mathrm{a}} 4$; eggs of $55^{\mathrm{a}}$ I 5 ; hibernation of $503^{\mathrm{b}} 28,599^{\mathrm{a}} 3 \mathrm{I}$; limbs of $498^{\mathrm{a}}$ $14,503^{a} 22$; scales of $504^{a} 28$; sloughing of $600^{\mathrm{b}} 23$; spleen of $506^{\mathrm{a}} 20,508^{\mathrm{a}} 35$; stomach of $508^{\mathrm{a}} 5$; tail of $508^{\mathrm{b}} 7$; testicles of $509^{\mathrm{b}} 8$; tongue of $508^{\mathrm{a}} 25$; womb of $5 \mathrm{ro}^{\mathrm{b}} 35$; see also Colotes, Gecko.

Lobster $490^{\mathrm{b}}$ I3, $525^{\mathrm{a}} 32$, b I I ; copulation of $54 \mathrm{I}^{\mathrm{b}} 20$; description of $526^{a} 1 I^{-b} 33$; freshwater $530^{\mathrm{a}} 28$; habitat of $549^{\mathrm{b}}$ I 5 ; seasons of $607^{\mathrm{b}} 4$; sloughing of $60{ }^{a} 11$.

Localus, caeca of, $509^{a} 22$.

Locust, see Attelabus and Grasshopper.

Locusta viridissima $612^{a} 34$ note.

Loligo vulgaris $524^{a} 26$ note.

Lopilizes piscatorius $564^{\mathrm{b}}$ I 8 note; see $\mathrm{F}$ ishing-frog.

Lota vulgaris, the burbot 508b I6 note.

Louse-disease $557^{2} 2$.

Lower and upper parts $494^{a} 27$.

Lucerne, see Median grass. 


\section{INDEX}

Luciola italica $55^{\mathrm{b}} 24$ note.

Lung $495^{\mathrm{a}} 31,496^{\mathrm{b}} \mathrm{I}, 506^{\mathrm{a}} \mathrm{I}$, $507^{a} 18,513^{b} 16,54^{a}$ I .

Lycia $548^{b} 20$; goats in $606^{a} 17$.

Lydia $617^{\mathrm{b}} 19$.

Lymph $489^{a} 23,5 I^{b} 3,515^{b} 29$.

Lynx, astragalus of $499^{b} 24$; copulation of $539^{\mathrm{b}} 22$; retromingent $500^{\mathrm{b}}$ I 5 .

Lyra, or Gurnard, voice of $535^{\mathrm{b}} \mathrm{I} 7$.

Lytta $604^{2} 7$ note.

Macedonia $596^{\mathrm{a}} 4,7$.

Mackerel, migrations of $597^{i 2} 22$, $599^{a} 2,610^{1} 7$; spawning of $571^{\text {a }} 13$; see also Coly-mack. erel.

Madrague $537^{\mathrm{a}}$ I9 note.

Maedica $500^{\circ} 2$.

Maemacterion $540^{\mathrm{b}} 3,5^{6} 6^{\mathrm{a}} \mathrm{I} 8$, $578^{b} 14,597^{a} 24$.

Maena vulgaris $569^{\mathrm{b}} 28$ note.

Maenis, abundance of $570^{\mathrm{b}} 28$; colour of $607^{b} 21$; fry of $569^{\text {al }}$ 19, b 28 ; seasons of $607^{1)} 21$; sexes of $607^{\mathrm{l}} \mathrm{ro}$.

Maeotis, Lake $620^{\mathrm{b}} 6$.

Maggots $614^{\text {b }} 2$; in stag's head $506^{a} 27$.

Maia squinado $525^{\mathrm{b}} 4$ note.

Malacocraneus $617^{\mathrm{a}} 32^{-1)} 5$.

Malacostraca, see Crustacea.

Male sex $489^{a}$ II, \&c.; teeth in $50 I^{b} 20$.

Malea, Cape $548^{1} 25$.

Males taking after mother $500^{2} 32$.

Mallow $605^{2} 23$ note.

Maltese dogs $612^{\text {b }}$ IO.

Man 486 $18,488^{a} 8,489^{b}$ I, \&ec. ; age of maturity in $545^{\mathrm{b}} 27$; anatomy of $491^{\text {il }} 20,494^{\text {l }} 22$; blood of $52 \mathrm{I}^{\mathrm{il}} 3$; breasts of $500^{a} 17,521^{\mathrm{b}} 23$; a genus $505^{\mathrm{b}}$ 28 ; hair of $498^{\text {b }} 16$; heart of $506^{\text {b }} 33$; gait in infancy $501^{\text {a }} 2$; mouth of $502^{\mathrm{a}} 34$; reproductive organs of $500^{a} 34,509^{1} 15$; stomach of $507^{\mathrm{b}} 2 \mathrm{I}$; skull of $516^{\text {a }} 17$; teeth of $501^{\text {b }} 2,507^{\text {b }} 16$; upper parts smaller than lower in $500^{\prime \prime} 26$.

Mane $498^{\text {l) }} 28$.

Manyplies $507^{\prime \prime} \%$

Marathon 569" 12.

Narc, of grapes $592^{\text {b }}$ II note.

Mare, maternal fondness of $6 \mathrm{II}^{\mathrm{a}}$ II ; impregnated by wind $572^{a}$
I4 note; milk of $522^{\mathrm{a}} 28$; in Pharsalus $586^{a} 14$; in Scythia $63 I^{a} 1$; wantonness of $572^{a} 8$; see also Horse.

Mare-suckled $577^{\mathrm{b}}$.

Marine animals $488^{\mathrm{b}} 7$, \&c.

Marinus, blindness in $602^{\mathrm{a}} \mathrm{I}$; gestation of $570^{a} 33$.

Marjoram 612 $25,27,28,34$; see also Origanum.

Marrow $487^{\mathrm{a}} 3,5^{16^{\mathrm{l}}} 6,517^{\mathrm{a}} 3$, $521^{13} 5$.

Marsh-fishes, spawn of $568^{a} 10$.

Marten, or Pole-cat, habits of $612^{1}$ 10-17; penis of $500^{b} 24$.

Martichoras $5 \mathrm{OI}^{\mathrm{a}} 25^{-\mathrm{b}} \mathrm{I}$.

Mayfly $552^{\mathrm{b}} 23,601^{\mathrm{a}} 34$ notes.

Meadow spider, eggs of $555^{\mathrm{b}} 7$.

Measles, in pigs $603^{\text {b }} 16$

Mecon $529^{2} 30$; of ascidians $531^{\text {a }}$ I6 ; of molluscs $529^{\text {a }}$ IO, $547^{a} 15$, \&c.

Meconium $587^{a} 30$.

Media $552^{15} 9$.

Median grass, or Lucerne $522^{b} 27$, $595^{\mathrm{b}} 29,627^{\mathrm{l}} 17$.

Medicago sativa $522^{\mathrm{b}} 30$ note.

Medius $618^{b}$ I4.

Melanurus, diet of $591^{a}$ I 5 .

Melilot-clover $627^{a} 8$.

Melis, a disease in asses $605^{\text {a }} 16$.

Melon-seed $55^{\mathrm{a}} \mathrm{I2}$.

Membrane 5 II $^{\mathrm{b}} 8,5 \mathrm{I} 9^{\mathrm{a}} 3 \mathrm{O}$, \&c.; of brain $514^{\mathrm{a}} \mathrm{I} 7$; of egg $56 \mathrm{I}^{\mathrm{b}} \mathrm{I} 6$.

Memory $488^{\mathrm{b}} 25$.

Meninx, see Membrane.

Menstruation $521^{\text {al }} 26,572^{\text {l }} 29$, $582^{a} 33,585^{1,} 2, \& c$.

Merlin $563^{\mathrm{b}} 25$ note, $620^{\mathrm{al}}$ IS: hostilities of $609^{b} 9,30-35$.

Merops, sec Bee-eater.

Merou, see Epinephelus.

Mesenteric arteries $514^{\text {b }} 24$ note.

Mesentery $495^{\text {b }} 32$.

Messapium, Mount $630^{2}$ I 9 .

Metageitnion $549^{\mathrm{a}}$ I 6 .

Metamorphosis of birds $632^{b} 24$.

Netra 5 IO $^{\text {l) }}$ I 5 .

Midge, see Empis.

Midget-bird, or Oestrus $592^{\mathrm{b}} 23$.

Midriff $506^{2} 5,507^{2} 26,509^{b} 26$, $514^{2} 30, b 35$.

Miletus, cicada in $605^{\mathrm{b}} 26$.

Milk $487^{a} 4,521^{b} 18,573^{a} 24$; of camel $578^{a} 14$; in women $585^{2}$ 29, $587^{\circ}$ 19, \&.c.

Milk-shells $52 S^{a} 23$. 


\section{INDEX}

Millet $551^{\mathrm{a}} 16,568^{\mathrm{b}} 24,580^{\mathrm{b}}$ I2, $595^{a} 29$.

Minnow, spawn of $567^{\mathrm{a}} 32,568^{\mathrm{a}}$ 22.

Mitys $624^{\mathrm{a}} 14$.

Moisture, in body $489^{\mathrm{a}} 20$.

Mole $488^{\mathrm{a}} 2 \mathrm{I}$; eye of $49 \mathrm{I}^{\mathrm{b}} 28$, $533^{\mathrm{a}} 3$; habitat of $605^{\mathrm{b}} 3 \mathrm{I}$.

Molluscs, see Cephalopods.

Molossian dogs, see Dog.

Monapus, or Bison $630^{\circ} 21$.

Monkey, description of $502^{a}$ I7- $^{-}$ b 26.

Moon, influence on menstruation $582^{a} 36$.

Mormyrus, spawning of $570^{b} 22$.

Morus alba $55^{\mathrm{b}} \mathrm{I} 6$ note.

Mosillus $535^{\text {a }} 3 \mathrm{I}$ note.

Moth, in beehives $605^{\mathrm{b}} 14$.

Motion, points of $490^{2} 26$.

Mountain-stork 61 $8^{\mathrm{b}} 33$.

Mouse $488^{\mathrm{a}} 21,579^{\mathrm{a}} 24$; drinking of $595^{\text {a }} 9$; multiplication of $580^{\mathrm{b}}$ IO- $58 \mathrm{I}^{\mathrm{a}} \mathrm{I}$; plague of $58 \mathrm{O}^{\mathrm{b}}$ 15 ; in Arabia (Jerboa) $606^{b} 6$; spiny in Egypt $581^{a} 2$; white, of Pontus $600^{\text {b }}$ I4.

Movements of animals $498^{\mathrm{b}} 5$, \&c. Mugil chelo $543^{\mathrm{b}}$ I4 note; $M$. saliens $570^{\mathrm{b}} 33$ note.

Mulberry $603^{\mathrm{b}} \mathrm{I} 4$.

Mule $488^{a} 27,49 I^{a} 2,498^{b} 30$, $499^{\mathrm{b}} \mathrm{I} 2$; breeding of $577^{\mathrm{b}} 5^{-}$ $578^{\mathrm{a}} 5$; diet of $595^{\mathrm{b}} 23$; gall absent in $506^{\mathrm{a}} 22$; menstruation in $573^{\mathrm{a}} 16,578^{\mathrm{a}} 2$; old mule, at Athens $577^{\mathrm{b}} 29$; teeth of $5 \mathrm{OI}^{\mathrm{b}} 3$; in Syria $580^{\mathrm{b}} \mathrm{I}$.

Mullein $602^{b} 32$.

Mullet, grey, or Cestreus, blindness in $602^{a} 1$; breeding of $543^{\mathrm{a}} 2, \mathrm{~b} 3,14$; capture of $541^{\mathrm{a}}$ 22 ; caeca of $508^{\mathrm{b}} \mathrm{I} 8$; and conger $610^{\mathrm{b}}$ II ; ear of $534^{\mathrm{a}} 8$; fry of $569^{b} 29$; habitat of $59^{a}$ Io, $601^{b} 21$; migration of $569^{a} 7$; seasons of $607^{\mathrm{b}} 25,62 \mathrm{I}^{\mathrm{b}} 2 \mathrm{I}$; sleep of $537^{a} 29$; spawn of $567^{a}$ I9, $570^{\mathrm{l}} 2$; swiftness of $620^{\mathrm{b}} 26$.

Mullet, red, or Trigle 610 5 ; breeding of $543^{\mathrm{a}} 5,570^{\mathrm{b}} 23-25$, $62 I^{\mathrm{b}} 2 \mathrm{I}$; caeca of $508^{\mathrm{b}} \mathrm{I} 7$; diet of $59 I^{a} 12,610^{b} 5,62 I^{b} 7$; habitat of $59 I^{\mathrm{l}} 20,598^{\mathrm{a}} \mathrm{IO}$, $610^{\mathrm{b}} 5$.

Munychium $543^{\text {b }} 7$.

Muraena, breeding of $543^{a} 20-29$; copulation of $540^{\mathrm{b}} \mathrm{I}$; diet of, $591^{\mathrm{a}} \mathrm{I} 2$; fins of $489^{\mathrm{b}} 28,504^{\mathrm{b}}$ 34 ; gall of $506^{\mathrm{b}} 17$; gills of $505^{a}$ I6; hábitat of $598^{a} 14$; hibernation of $599^{\mathrm{b}} 6$; hostility to conger $610^{\mathrm{b}} 17$; roe of $517^{\mathrm{b}} 7$; $M$. unicolor $543^{\text {a }} 26$ note

Murex, or Purple-shell $547^{\mathrm{b}} 3 \mathrm{I}$, 62 I $^{\mathrm{b}}$ II ; anatomy of $529^{\mathrm{a}} 6$, $530^{a} 5$; bait for $535^{a} 7$; diet of $568^{\mathrm{a}}$ II, $590^{\mathrm{b}} 2,603^{\mathrm{a}}$ I3-19; growth $547^{\mathrm{b}} 23$; habits, species, \& c. $547^{\mathrm{a}} 4-547^{\mathrm{b}}$ II ; hibernation of $599^{a}$ I I ; operculum of $530^{\mathrm{a}} 25$; proboscis of $528^{\mathrm{b}} 30$, $52^{a} 9$; shell of $528^{a} 10,530^{a} 5$; spawning of $546^{a} 18-547^{a} 4$; M. brandaris, \&c. $547^{a} 39$ note. Musaeus $563^{a}$ I 8 .

Mussel $528^{a} 15,22,29$; freshwater $6 \mathrm{I} 4^{\mathrm{b}} 28$; spat of $547^{\mathrm{b}}$ II.

Mustela boccamela $6 \mathrm{I} 2^{\mathrm{b}}$ Io note.

Mustelus laevis $565^{\mathrm{a}} 27,{ }^{\mathrm{b}} 6$ notes. Mutilation, effects of $589^{\mathrm{b}} 32$.

Myliobatis aquila $540^{b}$ I 8 note.

Myops, see Horse-fly.

Myrtle $550^{\mathrm{a}}$ Io, $627^{\mathrm{a}} 8$, b I 8 .

Mysticetus $519^{2} 23$ note.

Mytis $524^{\mathrm{b}} 15,526^{\mathrm{b}} 32$.

Myxon, or Smyxon, breeding of $543^{\mathrm{b}}$ I $5,570^{\mathrm{b}} 3$.

Nails $486^{b} 20,487^{a} 6,5 I^{b} 8,5 I^{a}$ $8,5 \mathrm{I} 8^{\mathrm{b}} 35$.

Narce, see Torpedo.

Naucrates ductor $557^{\text {a }} 30$ note.

Nauplia $602^{2} 8$.

Nautilus, see Argonaut.

Navel $586^{a} 30$; of apes $502^{b}$ I3, \&c.

Navel-string, ligature of $587^{a} 7$.

Naxos $496^{\circ} 26$.

Neck $491^{a} 28,493^{a} 5$; of lion, $497^{\mathrm{b}}$ I6.

Necydalus $55^{\mathrm{b}}$ I 2 .

Needle-fish, or Pipe-fish, see Belone.

Neritae, capture of $535^{\mathrm{a}} 19$; habits of $530^{a}$ I $8,547^{b} 23$; hermit$\mathrm{crab}$ in $53 \mathrm{O}^{\mathrm{a}} \mathrm{I} 2,27,548^{\mathrm{a}} \mathrm{I} 7$; shell of $530^{\mathrm{a}} 7$.

Nerves $515^{\mathrm{b}} 21$ note.

Nessus $579^{\mathrm{b}} 7, \mathrm{C06}^{\mathrm{l}} \mathrm{1} 15$.

Nests, of birds $559^{\mathrm{a}} \mathrm{I}-14,562^{\mathrm{b}} 2-$ $564^{\mathrm{b}}$ I $3,612^{\mathrm{b}}$ 18-620b 8 , pas sim ; of insects $552^{\mathrm{b}} 27-55^{\mathrm{b}} 5$, $622^{b} 9-629^{b} 2$; of octopus $544^{a}$ 


\section{INDEX}

$12,591^{\mathrm{a}} 2,622^{\mathrm{a}} 5$; of various animals $488^{a} 21$.

Newt, or Cordylus $487^{a} 28,490^{a}$ $4,589^{\text {l }} 26$.

Nictitating membrane $504^{\mathrm{a}} 26$ note.

Nightingale, breeding of $542^{\text {l }} 26$; song and habits of $536^{\mathrm{b}}$ I 8,29 , $632^{b} 21$; tongue of $536^{a} 29$.

Night-raven $509^{a} 22,592^{\text {b }} 9,597^{\text {b }}$ $23,619^{\mathrm{b}} 18$.

Nile $597^{a} 6$.

Ninus $6 \mathrm{OI}^{\mathrm{b}} 4$.

Nipple $493^{\mathrm{a}}$ I3.

Nisaea, horses of $632^{a} 31$.

Nisyros $617^{a} 24$.

Nits $539^{\mathrm{l}}$ I I , $55^{-6} \mathrm{l} 23$.

Nocturnal animals $488^{\text {a }} 25$; birds $592^{\text {l) }} 8$.

Nomad animals $488^{\mathrm{a}}$ I 4 .

Nonnati $569^{a} 30$ note.

Nose $492^{b} 5$; of elephant $497^{b} 25$, \&c.

Nostrils $533^{a} 23$.

Notidanus grisens $540^{\mathrm{b}}$ I 7 note.

Nuthatch, or Sitta $609^{\text {b }}$ II $616^{\text {b }}$ 22.

Nylghau 498' 32 note.

Nympha $55^{\mathrm{b}} 2,555^{\mathrm{a}} 3$.

Nymphia, or madness in horses $604^{\text {b }}$ Io.

Oblata melanura $59 \mathrm{I}^{\mathrm{a}}$ I3 note.

Occiput, hollow $49^{\text {a }} 33$, b I note.

Octopus, or Poulpe, as bait $534^{\mathrm{a}}$ 25 ; breeding of $534^{\mathrm{b}} 25,54 \mathrm{I}^{\mathrm{l}}$ I-I $S, 544^{a} \mathrm{I}-24 ;$ capture of $534^{\text {b }} 25$; description of $490^{2} \mathrm{I}$, $523^{\mathrm{b}} 29-524^{\mathrm{a}} 26,{ }^{\mathrm{b}} 27-525^{\mathrm{a}} 19$; diet of $59 \mathrm{I}^{\mathrm{a}} \mathrm{I}-6$; eaten by conger $590^{1} 18$; egg of $525^{a} 2$; habits of $490^{\mathrm{a}} \mathrm{I}, 53 \mathrm{I}^{\mathrm{b}} 2,62 \mathrm{I}^{\mathrm{l}} \mathrm{I}$ I, $30,622^{a} 3^{-1)} 18$; seasons of $607^{1)} 7$; spawn and development of $549^{\prime)} 31-550^{b} 21$.

Ocypondar cursor $525^{\text {b }} 8$ note.

Ocythoe tuberculate $525^{a} 29$ note.

Odour $492^{\text {b }}$ I 4.

Oenanthe $633^{2} 16$.

Ocnas, or Stock-dove $544^{\text {b }} 6,55^{\text {b }}$ $23,593^{a}$ I 5-2I.

Oesophagus $495^{\text {il }} 19,505^{\prime \prime} 32,507^{\mathrm{a}}$ 25 ; of fish $507^{\mathrm{a}} \mathrm{IO}$; veins of $514^{\mathrm{l}} 14$.

Oestrus, or Gaddly $506^{2} 27$ note : development of $487^{\prime \prime} 6(?), 551^{1)}$ 21 ; diet of $596^{\mathrm{b}} 15$; proboscis of $490^{a} 21,528^{a} 31,532^{a} 10$; a bird so called $592^{\mathrm{b}} 23$.

Oeta $522^{a} 7$.

Oil $605^{\mathrm{b}} \mathrm{I}, 20$.

Oinopota cellaris $55^{1)} 5$ note.

Old-age, or slough, of snakes $600^{\text {l) }}$ 2 I.

Old Man, see King.

Oleaster $596^{\mathrm{a}} 25$.

Olive $553^{\mathrm{a}} 21,55^{\mathrm{a}} 24,596^{\mathrm{a}} 25$, $601^{2} 7,624^{\text {b }}$ I I see Oil.

Omentum, or Caul $514^{\mathrm{b}} 10,519^{\mathrm{l}} 7$, $520^{\text {il } 24 .}$

Omnivorous animals $488^{a}$ I 5 .

Operculum, of fish $505^{\mathrm{a}} 2$; of shellfish $528^{\mathrm{b}} 8,530^{\mathrm{a}} 2 \mathrm{I}$.

Ophiomachus $612^{a} 34$ note.

Ophisurus colubrimus $621^{\mathrm{a}} 38$ note.

Opisthuretic animals 500' I 5 , $509^{\text {b }} 3,539^{\text {b }} 2 \mathrm{I}, 540^{\mathrm{a}} 24,546^{\mathrm{l}} \mathrm{I}$, $579^{\mathrm{a}} 33, \mathrm{~b} 32$.

Opus $576^{\mathrm{b}} 26$.

Oracle, of Lemnos $522^{a} 18$.

Orchomenus $605^{\mathrm{l}} 31$.

Orcys $543^{\mathrm{b}} 5$.

Origanum 534" 22 ; sce also Marjoram.

Oriole, see Golden oriole.

Orphean warbler 61 $8^{\mathrm{a}}$ I I note.

Orphic egg $559^{\mathrm{b}} 29$ note.

Orphus, or Sea-perch, diet of $591^{\mathrm{a}} 2$; growth of $543^{\mathrm{b}} 1$; habitat of $598^{\mathrm{a}}$ Io; hibernation of $599^{\text {l) }} 6$; see Perch.

Orsodacna, or Bud-bane $552^{\mathrm{a}} 30$.

Oryx $499^{\text {l) }} 20$.

Ostracoderms $490^{\text {b }}$ IO, 491 l) 27 , $523^{\text {b }} 9, \quad 527^{\text {b }} 35,590^{a} 1^{-b} \mathrm{I}$, $599^{\text {a }} 10-20$, \&c.

Ostrea cochlear $547^{1)}$ I2 note.

Ostrich 616 5 .

Otoliths 6 oI $^{\text {b }} 32$ note.

Otter, feet of $4 S 7^{i 2} 22$; habits of $594^{\prime \prime} 32-595^{\mathrm{a}} 4$.

Ourax, or Tetrix $559^{\mathrm{a}}$ I3.

Ovipara $489^{\mathrm{a}} 35,490^{\mathrm{l}} 22,502^{\mathrm{l}} 2 \delta$, $506^{\text {b }} 25,510^{\text {l) }} 35$, Sc.

Owl, bird-catching by means of $609^{\mathrm{a}} 15,617^{\mathrm{b}} 5$; caeca of $509^{\mathrm{a}}$ 22 ; capture of $597^{\prime \prime} 25$; crop of $509^{\mathrm{a}} 3$; eyclids of $504^{\mathrm{a}} 27$; fables of $609^{\text {in }} 8-16$; habits of $488^{a} 25,592^{11} 9,619^{11}$ IS -23 ; libernation of $600^{2} 28$; spleen of 506" I7; Ac grolian 592" II; eared, or horned 506 17 note, 


\section{INDEX}

$597^{\mathrm{b}} 18,617^{\mathrm{b}} 3 \mathrm{I}$; little horned $592^{\mathrm{b}}$ I I, I3, 6I $7^{\mathrm{b}} 3 \mathrm{I}$.

Owsel, see Blackbird; fish so called, colour of $607^{\mathrm{l}}$ I 5 ; hibernation of $599^{\mathrm{b}} 8$.

Ox, see Cattle.

Ox-ray, or Bos, disparity of sexes $540^{\mathrm{b}} 17$; viviparous $566^{\mathrm{b}} 4$.

Oyster $487^{\mathrm{a}} 26, \mathrm{~b} 9$, I $5,490^{\mathrm{b}}$ II, $523^{\mathrm{b}} 12,528^{\mathrm{a}} \mathrm{I}, 53 \mathrm{I}^{\mathrm{a}}$ I6, b 5 , $547^{\mathrm{b}} 20,54^{\mathrm{a}}$ I6, $568^{\mathrm{a}}$ 9, $590^{\mathrm{a}}$ $30,607^{\mathrm{b}} \mathrm{I}$; pool or lagoon oysters, or limnostreae $528^{a} 23$, $30,547^{\mathrm{b}}$ I I, 29.

Ozolis $525^{\mathrm{a}} 19$.

Pachytilus migratorius, \&c. $555^{\mathrm{b}}$ I7 note.

Paeonia $499^{\mathrm{b}}$ I $3,500^{\mathrm{a}}$ I, $630^{\mathrm{a}}$ I9.

Pagellus erythrinus 598a I 3 note; $P$. mormyrus $570^{\mathrm{b}} 2 \mathrm{I}$ note.

Pagrus vulgaris $58^{2}$ I 3 note.

Pagurus $525^{\mathrm{b}} 5 ; P$. bernhardus, \&c. $530^{a} 9$ note.

Palaemon, $525^{\mathrm{b}} 2$, 2 I notes; see also Carid.

Palm-tree $610^{2} 23$.

Palpitation $521^{2} 7$.

Pamphila $55^{\mathrm{b}} \mathrm{I} 6$.

Pancreas $5 \mathrm{I} 4^{\mathrm{b}} \mathrm{II}$.

Panther, see Leopard.

Panther's-bane $612^{\mathrm{a}} 7$.

Parasilurus aristotelis $568^{\mathrm{a}} 2 \mathrm{I}$ note.

Parasite, of tunny $557^{a} 28,598^{a}$ I8, $599^{\mathrm{b}} 26,602^{\mathrm{a}} 27$.

Pard, see Leopard.

Pardalus $617^{\mathrm{b}} 6$.

Pardion $498^{\mathrm{b}} 33$.

Parrot, $597^{\mathrm{l}} 28$.

Parrot-fish, see Scarus.

Partridge $488^{\mathrm{b}} 4$; age of $563^{\mathrm{a}} 2$, $613^{a} 24 ;$ caeca of $509^{a} 21$; conception in $54 \mathrm{I}^{\mathrm{a}} 27,56 \mathrm{o}^{\mathrm{b}} \mathrm{I} 3$; crop of $508^{\mathrm{b}} 28$; as decoys $614^{\mathrm{a}}$ 10; diet of $62 \mathrm{I}^{\mathrm{a}} \mathrm{I}$; eggs of $559^{\mathrm{a}} 23$; habits of $613^{\mathrm{b}} 6-614^{\mathrm{a}}$ $32,633^{b} \mathrm{I}$; nest of $559^{\mathrm{a}} \mathrm{I}, 564^{\mathrm{a}}$ $20-24$; temperament of $488^{\mathrm{b}} 4$, $564^{\mathrm{b}}$ 13; testicles of $510^{\mathrm{a}} 6$, $564^{\mathrm{b}}$ I2 ; voice of $536^{\mathrm{a}} 27$, " 14 , $614^{\mathrm{a}} 2$; wind-eggs in $559^{\mathrm{b}} 29$.

Parts of animals $49 I^{a} 14,497^{\mathrm{b}} 4$, \&c.

Paunch, of ruminants $507^{\mathrm{b}} \mathrm{I}$.

Peacock, and hen, description of $564^{a} 25^{-10} 9$; temperament of $488^{\mathrm{b}} 24$; wind-eggs in $559^{\mathrm{b}} 29$.

Pear-tree $552^{\mathrm{b}} \mathrm{I}, 627^{\mathrm{b}} 16$.

Pelamys $4^{8} 8^{a} 6,610^{b} 6$; breeding of $543^{\mathrm{b}} 2,57 \mathrm{I}^{\mathrm{a}} 20$; migration of $598^{a} 26$.

Peleias, see Rock-pigeon.

Pelican, diet of $614^{b} 27$; migrations of $597^{\mathrm{a}} 9-14,{ }^{\mathrm{b}} 30$.

Pelopaeus $552^{\mathrm{b}} 30$ note.

Peloponnese $593^{\mathrm{a}} 12,618^{\mathrm{b}} 15$.

Pelusium 6I $7^{\mathrm{b}} 30$.

Pelvis, $493^{a} 22$.

Penaens caramote, $525^{\mathrm{b}} 2$ I note.

Penduline titmouse $593^{\mathrm{a}} 12,616^{\mathrm{a}}$ 5 .

Penelops $593^{\mathrm{b}} 23$.

Penia $55 \mathrm{I}^{\mathrm{b}} 6$.

Penis $493^{a} 25,497^{a} 24,500^{b} 20$, $509^{a} 35,510^{a} 29$; of cuttlefish $54 \mathrm{I}^{\mathrm{b}} 8$.

Pennatula $532^{\mathrm{b}} 26$ note.

Pennella filosa $602^{a} 28$ note.

Peraeas, diet of $591^{2} 24$.

Perch, freshwater, $568^{a} 23$ note; caeca of $508^{\mathrm{b}}$ I7 ; gills of $505^{\mathrm{a}}$ I7; pairing of $599^{1 /} 8$; spawn of $568^{a} 23$.

Percnopterus $618^{\mathrm{b}} 32$.

Perineum $493^{\mathrm{b}} \mathrm{g}$.

Peristera, see Pigeon.

Persia $580^{\mathrm{b}} 29$.

Phalacrocorax pygmaeus 6r7 $7^{\text {b }}$ i9 note.

Phalangium, or Venom-spider $550^{\mathrm{a}} 5, \mathrm{~b} 3 \mathrm{I}, 522^{\mathrm{b}} 27,57 \mathrm{I}^{\mathrm{a}} 5$, $594^{a} 3^{2}$; copulation of $542^{\mathrm{a}}$ I II7; eggs of $555^{\mathrm{b}} \mathrm{I2}$; sexes of $538^{\mathrm{a}} 28$; species of $622^{\mathrm{b}} 28$; sting of $6 \mathrm{II}^{\mathrm{b}} 2 \mathrm{I}$.

Phaleric fry $569^{b} 24$.

Phallusia mammillata $53 \mathrm{I}^{\mathrm{a}} 30$ note.

Pharnabazus $580^{\mathrm{b}} 7$.

Pharnaces $580^{\mathrm{b}} 7$.

Pharos $607^{\mathrm{a}} \mathrm{I} 4$.

Pharsalus $586^{\mathrm{a}}$ I $5,618^{\mathrm{b}}$ I 4 .

Pharynx, $535^{a} 28$.

Phasis, cattle of $522^{\mathrm{b}}$ I 5 .

Phatta $544^{\mathrm{b}} 6$; see Cushat.

Pheasant, eggs of $559^{a} 25$; habits of $633^{\mathrm{b}} 2$; lice on $557^{\mathrm{a}} 12$.

Phene, or Lammergeyer $592^{\mathrm{b}} 5$, 6 I $^{a}$ I $3,{ }^{b} 23$; rears the eagle's young $563^{a} 27,619^{b} 34$.

Pherecydes $557^{a} 3$.

Philonexis catenulata $524^{2} 7$ note. 


\section{INDEX}

Phlegm $487^{a} 5,5$ II $^{\mathrm{b}}$ IO.

Phoenice, Phoenicia $525^{\mathrm{b}} 7,541^{\mathrm{a}}$ I $8,577^{b} 25,603^{a}$ I.

Pholidotes, or Tessellates $490^{\text {b }} 24$, $492^{i 2} 26, \& c$.

Pholis, nest of $62 \mathrm{I}^{\mathrm{b}} 8$.

Phoxinus, or Minnow, spawn of $567^{a} 32,568^{a} 22$.

Phrenic nerve $514^{\text {a }} 36$ note.

Phrygia $580^{\mathrm{b}} 7,617^{\mathrm{b}} 19$; cattle of $517^{\text {a }} 28$; cheese of $522^{\text {a }} 29$.

Phthiriasis $557^{\text {a }} 34$ note.

Phthirius inguinalis $557^{\text {a }} 34$ note.

Phycis, or Black Goby, colour of $607^{\mathrm{b}} \mathrm{I} 8$; diet of $59 \mathrm{I}^{\mathrm{l}} \mathrm{I} 3$; spawn of $567^{\mathrm{b}} 20$.

Phycis blennioides $599^{\mathrm{b}} 33$ note.

Phycus 568" 6, 10 note; see also Seaweed.

l'hysiognomy 491 $12-492^{\mathrm{il}}$ I2, $493^{b} 32,494^{a}$ I 5 .

pia mater $494^{\mathrm{b}} 30,519^{\mathrm{l}} 37$ notes.

Pickles, as bait $534^{\text {a }}$ I 8 .

Pig $609^{\mathrm{b}} 28,621^{\mathrm{a}} \mathrm{I}$; age of maturity in $545^{a} 28$; astragalus of $499^{\text {b }} 21$; brain of $520^{a} 27$; breeding and reproduction of $542^{a} 29,545^{\mathrm{b}}$ I, $546^{\mathrm{a}} \cdot 7-28,572^{\mathrm{a}}$ $7,573^{\mathrm{a}} 32^{-\mathrm{b}} 17,577^{\mathrm{b}} 28$; diet of $595^{a} 14^{-b} 5,62 I^{a} I$; diseases of $603^{a} 30-604^{a} 3$; flesh of $520^{a}$ 9 ; foot of $499^{\text {a }} 12$; gall, absent in $506^{\mathrm{a}} 23$; hair of $49^{\mathrm{l}} \mathrm{2} 27$;

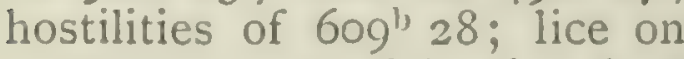
$557^{\mathrm{i}}$ I7 ; attacked by lion $630^{\text {il }}$ 2 ; mice destroyed by $580^{\mathrm{b}} 24$; mouth of $502^{i l} \mathrm{~S}$; marrow of $521^{1 /} 15$; and scorpion $607^{a} 18$; solid-hooved 499" 13 ; stomach of $507^{b} 20,508^{a r} 8$; teats of $500^{\text {al }}$ 27 ; teeth of $501^{1 "} 4,21,507^{1} 16$, $538^{\mathrm{b}} 2 \mathrm{I}$; tail of $502^{\mathrm{al}} 12$; testicles of $509^{\mathrm{b}} 14$; viscera of $507^{\mathrm{b}}$ 36 ; voice of $536^{\text {a }}$ I 5 ; womb of 510" I 7 ; see also l3oar.

Pigeon $633^{\mathrm{b}} 4$; breeding of $544^{\mathrm{b}}$ $8-12,562^{1)} 3-563^{a} 4 ;$ crop of $508^{\mathrm{b}} 28$; diet of $593^{\mathrm{a}} 16,24$; eggs of $558^{\text {b) }} 13-27,559^{\text {a }} 23$, $560^{\text {l) }} 21,562^{\text {l) }} 5$; gall of $506^{\text {b }} 21$; liabits of $488^{\text {: }} 5,560^{\text {l) }} 10,25$, $612^{b} 31-613^{a} 13,620^{a} 25,633^{b}$ 4 ; hatching of $564^{\text {in }} 8$; migrations of $597^{1} 5$; species of $544^{\text {b }}$ $1-8$; spleen of $506^{\text {: }} 16$; wind eggs in $559^{\circ} 29$; see also Oenas, Rock-pigeon, Turtle-dove.

Pinna $528^{a} 23,33,547^{b} 15,548^{a} 5$, $588^{\mathrm{b}}$ I 4 ; guard, or parasite, of $547^{\mathrm{b}}$ 16, 28, $548^{\mathrm{a}} 28$.

Pinnotheres pisum and $P$.veterum $547^{\mathrm{l}} \mathrm{I} 7,26$ note.

Pipe-fish, see Belone.

Piper, or Sea-cuckoo, see Cuckoofish.

Piphinx 610 11 .

Pitchwax $624^{a}$ I7.

Plangus $618^{\mathrm{b}} 23$.

Plants $539^{\mathrm{a}} \mathrm{I} 6$.

Plateus $55^{\mathrm{b}} \mathrm{I} 6$.

Plectrum 516 1 .

Pleiads $542^{\mathrm{b}}$ II $, 22,543^{\mathrm{a}}$ I $5,553^{\mathrm{b}}$ $31,566^{\mathrm{a}} 21,592^{\mathrm{a}} 7,598^{\mathrm{b}} 7,599^{\mathrm{a}}$ 28 , D I I.

Pluvianus aegyptiacus $6 \mathrm{I}^{\mathrm{a}} 20$ note.

Pneumatic pressure $586^{\mathrm{a}}$ I6.

Podagra $575^{\mathrm{b}} 8$.

Poduridae $552^{\mathrm{b}} 6$ note.

Poecilis 6ogi 6.

Points of motion $490^{\text {il }} 26$.

Poison for fish $602 \mathrm{~b} 31$.

Polecat, see Marten.

Polistes $554^{\text {b }} 24$ note.

Polium $605^{i} 6$.

Polybus $512^{\mathrm{b}} 12$.

Polypus' egg $525^{i 2} 22$; see Argo. naut.

Pompilus $609^{i} 5$ note.

Pontic mice $600^{b} 14,632^{b} 10$.

Pontilus, see Argonaut.

Pontonia tyrrhcna $547^{\text {b) }} 17$ note.

Pontus, ass absent from $605^{\text {il }} 22$ : bird migrants in $596^{\mathrm{b}} 32$; honey of $554^{\mathrm{b}} \mathrm{S}, 1 \mathrm{~S}$; ram, hornless in $606^{\text {a }}$ 10; see also Euxine.

Pool-oyster, see Oyster.

Poplar, white $549^{\mathrm{b}} 33$.

Poppy $627^{\mathrm{b}} 17$.

Porcupine, hibernation of $579^{: 4} 31$, $600^{i l} 29$; spines of $490^{1} 29,623^{i l}$ 33.

Pordoselene $605^{6} 29$

Porphyra, se'e Murex.

Porphyrio, or Purple Coot, crop of 509: II ; drinking of $595^{\text {: }} 13$.

Porpoise, habits of $566^{\mathrm{b}} 9-16$; in Euxine $59^{\circ}$ ' I ; teats of $521^{\prime \prime} 24$.

Portae, or portals, of liver $46^{\mathrm{b}} 32$, $586^{\mathrm{b}}$ Is.

Portal vein $514^{\mathrm{b}}$ i 5 note.

Poscidon $543^{\text {it }}$ II , I I $5,570^{\text {b }}$ I. 


\section{INDEX}

Poulpe, see Octopus.

Poynx $617^{2} 8$.

Prasocuris, or Leekbane $55 \mathrm{I}^{\mathrm{b}} 20$.

Prawn, see Carid.

Pregnancy, signs of $583^{\mathrm{b}} 30,60^{\mathrm{b}}$ I, \&c.

Prepuce $518^{a} 2$.

Presbys, see King or Old Man.

Priam $618^{b} 26$.

Priestesses, in Caria $518^{\mathrm{a}} 35$.

Primas-tunny, hibernation of $599^{\mathrm{b}}$ I8.

Propagation, modes of $539^{\mathrm{a}} \mathrm{I}$, \& c.

Property, or accident $486^{\mathrm{b}} 5$.

Propontis $598^{\mathrm{a}} 25,^{\mathrm{b}} 28$.

Psen, or Fig-wasp $557^{\mathrm{b}} 26$.

Psetta, or Flatfish, breeding of $543^{\mathrm{a}} 2$; habits of $620^{\mathrm{b}} 30$; hermaphrodite $538^{\mathrm{a}} 20$.

Pseudopus pallasii $567^{\mathrm{b}} 25$ note.

Psyche $557^{\mathrm{b}}$ I4 note.

Psyche, or Butterfly $53^{a} 27,550^{\mathrm{b}}$ $26,55^{\mathrm{a}} \mathrm{I} 4$.

Psychical qualities $588^{\mathrm{a}} 19, \& \mathrm{c}$.

Psychrus $519^{2} 15$.

Pternis $620^{2} 19$.

Pubes, hair on $498^{\mathrm{b}} 23$.

Pulmonary artery $513^{\mathrm{a}} 37$ note.

Pulse, vegetable $552^{\mathrm{a}} 19,627^{\mathrm{b}}$ I7.

Pupil, of eye $49 \mathrm{I}^{\mathrm{b}} 2 \mathrm{I}, 520^{\mathrm{b}} 3$.

Pus $52 \mathrm{I}^{2} 2 \mathrm{I}$.

Purple Coot, see Porphyrio.

Purple-fish, see Murex.

Purpura haemastoma $547^{a} 39$ note.

Pygmies $597^{a} 6$.

Pyrallis $609^{a} 19$.

Pyrrha $62 I^{b} 12$.

Pyrrhaean Euripus, or Lagoon $544^{a} \cdot 21,548^{a} 9,603^{a} 21$.

Pyrrhaustes $605^{\mathrm{b}}$ II.

Pyrrhic cattle $522^{\mathrm{b}} 24,595^{\mathrm{b}} \times 18$.

Pyrrhus $522^{\mathrm{b}} 26$.

Pythagoreans $497^{\mathrm{h}} 22$ note.

Quadruped $488^{a} 22,490^{a} 29, \& c$. \&c.

Quail, capture of $597^{\mathrm{b}}$ I I ; crop of $509^{\mathrm{a}} \mathrm{I}, 13$; fighting of $614^{\mathrm{a}}$ 6 ; gall of $506^{\mathrm{b}} 21$; heart of 6 I $5^{2} 6$; migration of $597^{a} 23,26$, b $6-20$; nesting of $559^{2} 1,613^{\text {b }} 7$, $614^{2} 31$; pairing of $614^{a} 26$; voice of $536^{a} 26$.

Rabies, in dogs $604^{a} 4$.
Rain, effect on fishes 60I" $11,32$.

Rainbow-twrasse $610^{\mathrm{b}} \%$.

Ram, long-horned, in Libya $606^{2}$ 19; temper of $57 \mathrm{I}^{\mathrm{b}} 2 \mathrm{I}$, \&c, ; see also Sheep.

Ranella $528^{2}$ Io note.

Raphanus $55^{\mathrm{a}}$ I 5 .

Raven, colour of $519^{2} 5$; crop of $509^{a} \mathrm{I}$; eggs of $563^{2} 32$; in Egypt $606^{a} 14,24$; gall of $506^{b}$ 21 ; habits of $617^{\mathrm{b}} 13,618^{\mathrm{b}} 9-16$; hostilities of $609^{\mathrm{a}} 20,{ }^{\mathrm{b}} 5,32$.

Ray $567^{2} 13$ note; breeding of, and development of $565^{a}$ I $5-29$, $565^{\mathrm{b}} 28,566^{\mathrm{a}} 32$; gall of $506^{\mathrm{b}}$ 8 ; gills of $489^{\mathrm{b}} 6,505^{\mathrm{a}} 4$; habits of $620^{b} 30$; hybrid, or Rhinobatus $566^{a} 27$; movements of $489^{\mathrm{b}} 32$.

Razor-fish, or Solen $528^{a}$ I 8, 547" I $3,548^{\mathrm{a}} 5,588^{\mathrm{b}} 15$; senses of $535^{\mathrm{a}} \mathrm{I} 4$.

Realgar, or 'Sandarace' $604^{\mathrm{b}} 28$.

Rectum $507^{\mathrm{a}} 33$.

Red Sea, testaceans in $606^{a}$ I I.

Redstart, or Phoenicurus $632^{\mathrm{b}} 28$.

Reed $553^{\mathrm{a}} 21,55^{\mathrm{b}} 3,5^{6} 8^{\mathrm{a}} 26,30$, $601^{\mathrm{b}} 14,620^{\mathrm{a}} 35$.

Reed-warbler 616 12.

Rennet $516^{\mathrm{a}} 4,522^{\mathrm{b}} 2$.

Residuum $489^{\mathrm{a}} \mathrm{I}$.

Respiration $492^{\mathrm{b}} 5,589^{\mathrm{a}} \mathrm{IO}^{\mathrm{b}} 28$; of cetacea $537^{\mathrm{b}} \mathrm{I}, 566^{\mathrm{b}} \mathrm{I} 3,589^{\mathrm{a}}$ $3 \mathrm{I}$; of goats $492^{\mathrm{a}} \mathrm{I} 4$.

Reticulum $507^{\mathrm{b}} 4$.

Rhina, see Angel-fish.

Rhinobatus $566^{\mathrm{a}} 28,566^{\mathrm{a}} 3 \mathrm{I}$ note; $R$. columnae $540^{b}$ Io, $566^{a} 31$ notes.

Rhinoceros $499^{\text {b }}$ I9 note.

Ribbon-fish $504^{\mathrm{b}} 33$.

Ribs $493^{\mathrm{b}} 14,516^{\mathrm{a}} 29$.

Right-hand side $497^{\text {" }} 22$.

Ringdove, see Cushat.

River-fish, maladies of $602^{\mathrm{b}} 20$; senses of $607^{\mathrm{b}} 34$, \& c.

River - worms, development of $487^{\mathrm{b}} 5$.

Robber-bee $553^{\mathrm{b}} 9,624^{\mathrm{b}} 25,625^{\mathrm{a}}$ 5,32 .

Robin, or Erithacus $592^{\mathrm{b}} 22,632^{\mathrm{b}}$ 28.

Rock-crab, diet of $590^{\circ}$ II.

Rock-fishes, breeding of $543^{a} 5$; diet of $548^{\mathrm{b}} 16,59 \mathrm{I}^{\mathrm{b}} \mathrm{I} 2$; habitat of $598^{\mathrm{a}}$ II ; hibernation of $599^{\mathrm{t}}$ 27 ; pairing of $599^{\mathrm{ll}} 7$. 


\section{INDEX}

Rock-pigeon, or Peleias 544 2 ; migration of $597^{\text {b }} 4$.

Roe, blood of $5 \mathrm{I} 5^{\mathrm{b}} 34,520^{\mathrm{b}} 24$; gall-bladder absent in $506^{\mathrm{a}} 22$.

Rostrum $526^{\mathrm{l}} 34$ note.

Round worm, see Ascards.

Rue $612^{\mathrm{a}} 28$.

Ruminants, fodder of $522^{\mathrm{b}} 26$; stomach of $507^{\mathrm{b}} \mathrm{I}, 519^{\mathrm{b}} \mathrm{I} 2$.

Rumination $507^{a} 35$; in fishes $508^{1 \prime} 12,591^{11} 23$.

Ryades, or 'Runners', breeding of $543^{\mathrm{b}}$ I $4,570^{\mathrm{b}} 2 \mathrm{I}$.

Salacious animals $488^{\mathrm{b}} 3$.

Salamander $522^{\mathrm{b}} \mathrm{I} 6$.

Salamis $569^{b} 12$.

Salpe, see Saupe.

Salt $596^{a}$ I 8 .

Sandals $499^{2} 30$.

Sandarace, or Bee-bread $626^{2} 7$; or Realgar $604^{\mathrm{b}} 27$.

Sandpiper, or Trochilus $593^{\mathrm{b}}$ II.

Saperdis $608^{\mathrm{a}} 2$.

Sarcoptes scabiei $557^{a}$ 3I note.

Sardine $543^{a} 38$ note.

Sardinella aurita $569^{\mathrm{b}} 27,62 \mathrm{I}^{\mathrm{b}} 25$ notes.

Sarginus $610^{\mathrm{l}} 6$.

Sargue, or Sargus, breeding of $543^{\mathrm{a}} 7,543^{\mathrm{b}} 8$, I5; diet of $591^{\mathrm{b}}$ 19; spawning of $570^{2} 33 ; S$. rondeletii and vulgaris $535^{\mathrm{b}} 8$, I7 notes.

Saturniae $55^{\mathrm{l}}{ }^{\mathrm{b}}$ I I note.

Satyrium $524^{\text {b }} 3$ I.

Saupe, or Salpe, breeding of $543^{\mathrm{a}}$ 8 ; diet of $59 \mathrm{I}^{\mathrm{a}} 15,62 \mathrm{I}^{\mathrm{b}} 7$; ear of $534^{a} 9$; habitat of $598^{a} 20$; spawning of $570^{\mathrm{b}} \mathrm{I} 9$.

Saw-fish, breeding of $566^{\mathrm{l}} 3$.

Saw-toothed animals $5 \mathrm{OI}^{\mathrm{a}} \mathrm{I} 6,5 \mathrm{O}^{\mathrm{i}}$ 8 ; fishes $505^{2} 28$, \&c.

Saxicola rubicola $564^{\mathrm{a}} 33$ note.

Scales $486^{\mathrm{b}} 2 \mathrm{I}, 490^{\mathrm{b}} 22,505^{\mathrm{a}} 25$, $517^{\mathrm{b}} 5, \& \mathrm{c}$.

Scalidris $593^{\text {b) }} 8$.

Scallop $525^{\mathrm{a}} 22,528^{\mathrm{a}} 15,25,53 \mathrm{I}^{\mathrm{b}}$

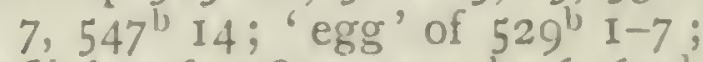
flight of $528^{a} 30,535^{\text {b }} 26,62 \mathrm{I}^{\text {b }}$ IO; gills of $524^{\mathrm{b}} 22$ note, $529^{\mathrm{a}}$ 30 ; growth of $547^{\text {" }} 24$; habits of $547^{\text {b }} 3 \mathrm{r}$; hibernation of $599^{\text {a }}$ I 4-1 8 ; pinna-guard in $547^{\prime \prime} 29$; seasons of $603^{\text {a }} 20$; senses of $535^{a} 17$; spawning of $607^{b} 2$.

Scamander $519^{2} 17,19$.
Scarabaeus, see Cantharus.

Scarabus, or Stag-beetle $55^{\mathrm{b}}$ I 7 ; see also Carabus.

Scarus, or Parrot-fish 505 $5^{\mathrm{a}} 14$, $632^{\mathrm{b}}$ I I notes; diet of $59 \mathrm{I}^{\mathrm{a}}$ I 5 ; gills of $505^{\mathrm{a}} 15$; habitat of $621^{\mathrm{b}}$ I5; stomach of $508^{\mathrm{b}}$ II ; teeth of $505^{\mathrm{a}} 28$.

Schoenilus $593^{\mathrm{b}} 6$.

Sciaena, or Chromis, breeding of $543^{\text {a }} 2$; ear of $534^{a} 9$; stone in head of $601^{\mathrm{b}} 30$; voice of $535^{\mathrm{l}}$ I7; S. aquila $534^{\mathrm{a}}$ 10, 601 b $^{\mathrm{b}} 30$ notes.

Scirrophorion $543^{\mathrm{b}} 7,549^{\mathrm{a}} 15$, $575^{\text {b) }} 16$.

Scolopendra, see Centipede ; Seascolopendra, description of $505^{\text {b }}$ I3-18; habits of, 62 $\mathrm{I}^{2} 7-10$.

Scomber colias and S. sarda 598 $24,62 I^{2}$ I 8 notes.

Scordylae $57 \mathrm{I}^{\mathrm{a}} \mathrm{I} 7$.

Scorpaena, or Sea-scorpion, breeding of $543^{a} 7$ note ; caeca of $508^{\mathrm{b}} 17$; habitat of $598^{\mathrm{a}} 3$; S. scrof a $543^{\text {a }} 8$ note.

Scorpion $557^{\mathrm{a}} 27$, b $10,602^{\mathrm{a}} 28$; breeding of $555^{a} 23-26$; sting of $532^{a} 16,607^{\mathrm{a}}$ I5-20, 29 ; tail of $50 I^{\mathrm{a}} 3 \mathrm{I}$.

Scorpis (?), breeding of $543^{\text {b }} 5$ note.

Sculptures, Assyrian, lion in 629" 33 note.

Scut, see After-pig.

Scyllium canicula and stellare $565^{\mathrm{a}}$ 16, 26 notes.

Scythia $597^{a} 5,605^{a} 21,606^{n} 20$ : Scythians $576^{2} 21,619^{1} 13$, $63 \mathrm{I}^{\mathrm{a}} \mathrm{I}$.

Sea-anemones, see Acalephae.

Sea-cuckoo, or Piper, habitat $598^{\mathrm{a}}$ I 4 ; voice of $535^{\mathrm{l}} \mathrm{2} 2 \mathrm{O}$

Sea-eagle, or Osprey, description of $619^{a} 4$; habitat of $593^{b} 23$; habits of $620^{2} \mathrm{I}-12$.

Sea-ear, or Haliotis $529^{\mathrm{b}}$ I 5 .

Sea-gudgeon, see Goby.

Sea-gull, or Sea-mew, see Gull.

Seal, $566^{\mathrm{b}} 27,567^{\mathrm{al}}$ 1 $4,589^{\mathrm{a}} 28$; combativeness of $608^{\mathrm{b}} 22$; copulation of $540^{a} 23-26$; description of $489^{\mathrm{b}} 11,566^{\mathrm{b}} 27-567^{\mathrm{a}} 14$; ears absent in $492^{\mathrm{a}} 26,29$; feet of $487^{b} 23,499^{a} 31^{-b} 4$; gallbladder absent in 506: 23 ; habitat of $594^{\text {l) }} 30$; kidney of 


\section{INDEX}

$497^{a} 7$; respiration of $589^{a} 28$; tail of $498^{\mathrm{b}} \mathrm{I} 4$; teeth of $5 \mathrm{OI}^{\mathrm{a}} 2 \mathrm{I}$; tongue of $508^{a} 27$.

Sea-nettle, see Acalephae.

Sea-perch, see Orphus.

Sea-scolopendra, see Scolopendra.

Sea-scorpion, see Scorpaena.

Sea-serpent $505^{\mathrm{b}} 8-12,621^{\mathrm{a}} 2$.

Sea-snails $528^{\circ} \mathrm{I}$.

Sea-swallow, or flying fish, flight of $535^{\mathrm{b}} 27$.

Sea-turtle, see Turtle.

Sea-urchin $528^{\mathrm{a}} 2,531^{\mathrm{b}} 7$; breeding of $544^{a}$ I $8-23$; description of $530^{2} 32-531^{2} 7$; senses of $535^{\mathrm{a}} 24$; species of $490^{\mathrm{b}} 30$.

Sea-weed $550^{\mathrm{b}} 7,552^{\mathrm{a}} 2,570^{\mathrm{a}} 25$, ${ }^{b} 26,590^{\mathrm{b}} 12,591^{\mathrm{l}} 12,19,603^{\mathrm{a}}$ $17,620^{\mathrm{b}} 33$.

Sedge-bird $610^{a} 8$.

Seed of plants $539^{a}$ I6, $581^{a}$ I6.

Selachia, or Cartilaginous fishes, bones of $516^{\mathrm{b}} 16,36$; caeca of $508^{\mathrm{b}} 23$; diet of $59 \mathrm{I}^{\mathrm{b}} 10,25$; habitat of $578^{a}$ I2 ; hibernation of $599^{\mathrm{b}} 30$; liver of $520^{\mathrm{a}} 17$; migrations of $566^{\mathrm{b}} 24$; operculum of $505^{2} 7$; pairing of $62 \mathrm{I}^{\mathrm{b}} 24$; reproduction and development of $489^{b} 16,540^{b} 6-20$, $565^{\mathrm{a}}$ I2-566 $\mathrm{a}$, I 5 ; sexual differences of $538^{a} 29,540^{b} 5,25$; sleep of $537^{\mathrm{a}} 31$; species of $489^{b} 30,540^{b} 5$, \&c. ; viviparous $489^{\mathrm{b}} 2, \quad 12,492^{\mathrm{a}} 28,564^{\mathrm{b}}$ I 5 , $570^{\mathrm{b}} 32, \& \mathrm{c}$. ; voice of $535^{\mathrm{b}} 24$; womb of $511^{\mathrm{a}} 4,564^{\mathrm{b}} 2 \mathrm{I}$; see also Dogfish, Shark, \&c.

Sense-organs $494^{b}$ I I, $499^{\text {b }}$ I I, $505^{a} 32, \& c$.

Senses $532^{\mathrm{b}} 29$, \&c.

Sensibility $588^{\mathrm{b}} 27$.

Sepia, or Cuttlefish $489^{a} 33,490^{\text {b }}$ I4; arms of $523^{\mathrm{b}} 30$; as bait $534^{\mathrm{a}} 23$; breeding and development of $525^{\mathrm{a}} 4,54 \mathrm{I}^{\mathrm{b}} \mathrm{I}-\mathrm{I} 8,544^{\mathrm{a}}$ $\mathrm{I}-6,549^{\mathrm{b}} 5,550^{\mathrm{a}} 16^{-\mathrm{b}} 9,567^{\mathrm{b}}$ $6-$ II ; capture of $534^{\mathrm{b}} 25,608^{\mathrm{b}}$ 17 ; change of colour in $622^{\mathrm{a}}$ I I ; diet of $590^{\text {b }} 33$; form of $524^{a} 25$; ink-sac of $524^{\mathrm{b}} 16,62 \mathrm{I}^{\mathrm{b}} 27$; length of life in $622^{2} 31$; seasons of $607^{b} 7$; size of $524^{a} 28$; swimming of $489^{\mathrm{b}} 36$.

Sepioteuthis $524^{2} 26$ note.

Sepium, or Cuttle-bone $524^{\mathrm{b}} 24$, $532^{11} 2$.
Septic drug $607^{2} 22$.

Serpent, or Snake $490^{\mathrm{b}} 24$; bite of $607^{a} 21-34$; bones of $516^{b} 20$; description and anatomy of $505^{\mathrm{b}} 5^{-22}, 3 \mathrm{I}, 508^{\mathrm{a}} 8-^{\mathrm{b}} 8$; diet of $594^{a} 4^{-24}$; flying $490^{a}$ II ; habitat of $488^{a} 23,509^{b} 5-18$; hibernation of $599^{a} 31$; hiss of $536^{a} 7$; horned, of Thebes $500^{a}$ 4 ; hostilities of $609^{a} 24,{ }^{b} 28$, $30,610^{2} 12,612^{\mathrm{a}} 29,35, \mathrm{~b} 3$; huge, in Libya $606^{\mathrm{b}} 9$; movements of $489^{b} 29,490^{a} 31,504^{a}$ I 8 ; reproduction of $5 \mathrm{II}^{\mathrm{a}} \mathrm{I} 4-22$, $540^{\mathrm{a}} 33^{-\mathrm{b}} 5,30,553^{\mathrm{a}} 25,57 \mathrm{I}^{\mathrm{a}} 3 \mathrm{I}^{\text {; }}$ sexes of $53^{\mathrm{a}} 28$; sloughing of $549^{\mathrm{b}} 26,600^{\mathrm{b}} 23-6 \mathrm{or}^{\mathrm{a}} \mathrm{I}$; temper of $488^{b} 16$; tongue of $504^{a} 15$.

Serranus anthias, Cabrilla, \&c. $53^{\mathrm{a}} 20,570^{\mathrm{b}}$ I8, $598^{\mathrm{a}}$ I0 notes; see Channa.

Serum $487^{a} 3,489^{a} 23$.

Ses, or Clothes-moth $557^{2} 2$.

Seseli 6 I I $^{\mathrm{a}}$ I 8 .

Setting sun 6 I I $^{2} 5$.

Sex $489^{\mathrm{b}}$ I I, $537^{\mathrm{b}} 22$, \&c.

Shark, Dappled, eggs of $565^{\mathrm{a}} 27$; Fox, breeding of $565^{\mathrm{b}} \mathrm{I}, 566^{\mathrm{a}} 3 \mathrm{I}$; cunning of $62 \mathrm{I}^{\mathrm{a}} \mathrm{II}$; Hammerheaded, gall of $506^{\mathrm{b}}$ Io ; Lamia $540^{\mathrm{b}}$ I 8, 62 $\mathrm{I}^{\mathrm{a}} 20$; see also Dogfish, Selachians, \&c.

Sheat-fish, or Glanis, care of young $568^{\mathrm{b}} 2 \mathrm{I}-569^{\mathrm{a}} 4,62 \mathrm{I}^{\mathrm{a}} 2 \mathrm{I}-$ ${ }^{b} 2$; as food $608^{a} 4$; gall of $506^{\mathrm{b}} 8$; gills of $505^{\mathrm{a}} 17$; maladies of $602^{\mathrm{b}} 22,24$; spawn of $568^{a} \cdot 23$; tail of $490^{a} 5$.

Sheath-winged insects, or Coleoptera $490^{a}$ I $4,55^{b} 30,601^{a} 3$.

Sheep, age of maturity in $545^{\mathrm{a}} 24$, b 31 ; blood of $516^{2} 6$; colour of, affected by water $519^{a} 13,17$; diet of $596^{\mathrm{a}}$ 12-b 9 ; dreaming of $536^{\mathrm{b}} 30$; fat of $520^{\mathrm{a}}$ IO ; foot of $499^{\mathrm{b}}$ IO ; habits of $573^{\mathrm{b}}$ I 8 $574^{\mathrm{a}}$ I6, 6I $1^{\mathrm{a}} 3$; hostile to bees $627^{\mathrm{b}} 5$; kidneys of $520^{\mathrm{a}} 32$; lice on $557^{2} 16$; maladies of $604^{\mathrm{a}} 2, \mathrm{~b} 27$; milk of $522^{\mathrm{b}} 34$, $523^{\mathrm{a}} 5,585^{\mathrm{a}} 32$; reproduction of $572^{\mathrm{b}} 3 \mathrm{I}, 573^{\mathrm{a}} 26,578^{\mathrm{b}}$ Io ; rumination in $632^{\mathrm{b}} 3$; teats of $500^{\mathrm{a}} 24$; teeth of $50 \mathrm{I}^{\mathrm{b}} 2 \mathrm{I}$; temperament of $6 \mathrm{IO}^{\mathrm{b}} 22-6 \mathrm{II}^{\mathrm{a}} 2$; in thunder $610^{\mathrm{b}} 33$; urine of $573^{\mathrm{a}}$ I9; voice of $536^{a}$ I 5 ; wild and 
tame $488^{a} 31$; in Egypt $606^{a} 22$; in Epirus $606^{\mathrm{a}} 13$; in Ethiopia $573^{1)} 29$; in Euboea $496^{\mathrm{b}} 26$; in Libya and in Pontus 605 19 ; flat-tailed in Syria $596^{\mathrm{b}} 6,606^{\mathrm{a}}$ I 2.

Shellfish, or Cockleshells, 5 I $^{\text {b }} 22$, $547^{\mathrm{b}} 7,622^{\mathrm{b}} 17$; food of Octopus $591^{a} 1,622^{a} 7$; and of Turtle $590^{\prime \prime} 4$.

Ship-holder, or Echeneis 505 b $19-$ 22.

Shoal-fishes, see Ryades.

Shoulder-blade $493^{\mathrm{b}} 12,5^{1} 6^{\mathrm{a}} 31$.

Shoulder-sinews $515^{\text {b }}$ Io.

Shrewmouse, bite of $604^{\text {b }} 19$.

Shrike, see Malacocraneus.

Shrimps $525^{\text {l) }} 2$.

Sicily $520^{\mathrm{b}} \mathrm{I}, 522^{\mathrm{a}} 23,606^{\mathrm{a}} 5$; Sicilian Seas $542^{\mathrm{b}} \mathrm{I} 6$.

Sigeum $547^{a} 5,549^{\mathrm{b}} 16$.

Sight $532^{1)} 33$.

Silk-worm $55^{\mathrm{b}}$ I 3 note.

Silphe, hatching of $6 \mathrm{OI}^{\mathrm{a}} 3$.

Silphium $607^{a} 23$.

Silurus $535^{!}$I 8, 568 2 I notes; see Sheat-fish.

Simonides $542^{\mathrm{b}} 7$.

Sinciput, or Bregma $495^{2} 10,491^{2}$ 3 I.

Sinew $487^{a} 6,5 I^{b} 8,5$ I $5^{a} 27$.

Siphae $504^{\text {b }} 32$.

Siren $623^{\text {b }}$ II.

Sitta, or Nuthatch, habits of $616^{1}$ 2 I ; hostilities of $609^{\text {b }}$ II.

Skate, see Ray.

Skin $487^{a} 6,5 I^{b} 8$; colour of $517^{2} 14, \& c$.

Skull 491 $30,516^{2} 14$; ossification of $587^{\text {l) }}$ I 3 .

Sleeping $536^{\mathrm{b}} 24$; of animals $599^{\mathrm{a}}$ 29 ; of fishes $537^{\mathrm{a}} 13$; of dolphin $537^{a} 32$, \&c.

Sloughing of skin $600^{\text {" }} 20$; of crustacea $549^{1 /} 25,601^{\mathrm{a}}$ 10-20 ; of insects $600^{2} \mathrm{I}-9$; of serpents $600^{b} 21$.

Smaris 607" I5 note; colour of $607^{\mathrm{b}} 22$.

Smell $532^{\mathrm{b}} 33,534^{\mathrm{a}} 12$, \&. .

Smooth-feathered hawk $620^{a} 20$.

Smooth skate, breeding of $566^{a} \mathrm{I}$.

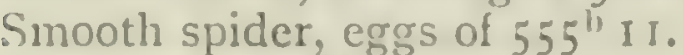

Smyraena, see Muraena.

Smyrus $543^{a} 24,26$.

Smyxon, see Myxon.

Snake, see Serpent.
Snail 523"1 II, 527 $35,528^{\mathrm{a}}$ I, 8 ; anatomy of $529^{a} 2-25$; eaten by partridges and pigs $621^{\mathrm{a}} \mathrm{I}$; hermit-crab in $530^{\circ} 27$; hibernation of $599^{a} 15$; operculum of $599^{a}$ I 5 ; seasons of $544^{a} 23$; shell of $525^{\mathrm{a}} 27,557^{\mathrm{b}}$ I8; teeth of $528^{\mathrm{b}} 28$.

Snow-fleas $552^{\text {b }} 7$ note, $55^{\text {l) }} 9$.

Social animals $488^{\mathrm{a}} 3$.

Soft-head, or Shrike, see Malacocraneus.

Solen, see Razor-shell.

Solid-hooved swine $499^{\text {b }} 13$.

Solitary animals $488^{a}$ I.

Song of birds $488^{\mathrm{b}} 1,536^{\mathrm{a}}$ I4-I 8 , \&c.

Sore feet, in dogs $604^{\mathrm{a}} 5$.

Sound $535^{a} 27$.

Sow, gestation of $542^{a} 29$; spayed $632^{\mathrm{a}} 21$; tuskless $538^{\mathrm{h}} 2 \mathrm{I}$; wild $578^{a} 25$; see also Pig.

Sow-virus $572^{a} 21$.

Spalax typhlus $533^{a} 35$ note.

Sparrow $616^{a} 4$; bathing of $633^{\mathrm{b}}$ 5 ; caeca of $509^{a} 24$; colour of $519^{2} 6$; crop of $509^{2} 9$; diet of $592^{\mathrm{b}}$ I 7 ; gall of $506^{\mathrm{b}} 22$; pairing of $539^{b} 33$; sexes of $613^{a} 29$. Sparrow-hawk $592^{\mathrm{b}} 2,620^{\mathrm{a}} 18,20$. Sparus, caeca of $508^{\mathrm{b}} 18$.

Spatangus $530^{\mathrm{b}} 4$.

Spears of hippopotamus hide $502^{2}$ I 4.

Species $486^{\mathrm{a}} 16,497^{\mathrm{b}} 12$, \&. .

Speech $488^{a} 33$.

Spelt $603^{\text {b }} 26$.

Sperm $487^{a} 3,489^{b}$ Io, $521^{\text {b }}$ is, $523^{a} 13,5^{2} 86^{a} 15$; of elephant $523^{\mathrm{a}} 26$.

Sphaerechinus 530" 8 note.

Sphecons 628 13.

Sphegidas $55^{\mathrm{b}} 30$ note.

Sphondyle, or Knuckle-beetle $542^{\text {? }}$ II, 604" I9, 619' 22.

Sphyraena 610' 5 .

Spider $529^{2} 26,557^{2} 30,602^{2} 29$, $605^{\text {l) }} 13$; diet of $488^{a} 16,594^{2} 14$, $623^{\text {b) }}$ I 4 ; habits, weaving, dic. $622^{\text {b }} 22,27-623^{\mathrm{b}} 2$; hostilities of $609^{\mathrm{a}} 29$; reproduction of $550^{\text {b }} 31,553^{\mathrm{a}} 9,555^{\mathrm{a}} 24,27-$ b I 7 ; web of $542^{\mathrm{a}} 13,548^{\mathrm{a}} 29$, $55^{\mathrm{a}} 21,552^{11} 25,554^{\mathrm{l}} 28$ (?), \&ic.

Spindle-tree $627^{2} \AA$

Spine $516^{\text {a }} 10$. 
Spiny dog-fish, absent from the lagoon $621^{b} 16$; eggs of $565^{a} 29$; young of $565^{\mathrm{b}} 26$.

Spirifex $55^{\mathrm{b}} 30$ note.

Spleen $496^{\mathrm{b}} 17,4^{8} 6^{\mathrm{b}} 2 \mathrm{I}, 5^{\circ} 6^{\mathrm{a}}$ I 4 , $26,507^{a} 19$.

Splenitis $512^{a} 5,30$.

Sponge $616^{a} 24,30,630^{a} 7$; description and species of $54^{\mathrm{a}} 28$ $549^{\mathrm{b}}$ I3 ; sensibility of $487^{\mathrm{b}}$ IO, $588^{\mathrm{b}} 20$.

Sponge-fishers $620^{\mathrm{b}} 34$.

Spontaneous generation, of eels $570^{a} 5$; of fishes $569^{a} 10$; of insects $539^{\mathrm{a}} 22$.

Spoonbill $593^{\mathrm{b}}$ I.

Sprat, see Maenis.

Spurge $602^{\mathrm{b}} 32$ note.

Spurs, of birds $486^{\mathrm{b}}$ I $2,504^{\mathrm{b}} 8$, $\& c$.

Squatina $540^{\mathrm{b}}$ Io, $566^{\mathrm{a}} 31$ notes.

Squid, see Calamary.

Squilla, see Crangon.

Squirrel $612^{\mathrm{b}} 7$ note.

Stag, see Deer.

Stag-beetle, see Carabus.

Stallion $57 \mathrm{I}^{\mathrm{b}} \mathrm{I} 2,572^{\mathrm{b}}$ IO; see Horse.

Star-fish $548^{a} 7$.

Starling, description of $6 \mathrm{I}^{\mathrm{b}} 26$; hibernation of $600^{2} 27$; metamorphosis of $632^{\mathrm{b}} 20$.

Stationary animals $487^{\mathrm{b}} 6$.

Stesichorus $542^{\mathrm{b}} 25$.

Sting-ray, see Trygon.

Stock-dove, see Oenas.

Stomach, of man $495^{\mathrm{b}} 24$; of fishes $507^{a} 29,520^{a} 24$; of ruminants $507^{b} \mathrm{I}$, \&C.

Stone-curlew, see Charadrius.

Stone, in bladder $519^{\mathrm{b}} 20$; in head of fishes $6 \mathrm{OI}^{\mathrm{b}} 30$; carried by Cranes $597^{\mathrm{b}} \mathrm{I}$.

Stop-wax $623^{\mathrm{b}} 31$.

Stork $593^{\mathrm{b}} 3,19,612^{\mathrm{a}} 34$ note; filial affection of $6 \mathrm{I} 5^{\mathrm{b}} 23$; hibernation of $600^{2} 21$; use of marjoram by $612^{a} 32$.

Strangalides $587^{\mathrm{b}}-23$.

Strangury $612^{\mathrm{b}} 17$.

Stromboids, or Spiral-shaped testaceans $492^{a}$ I $7, \quad 528^{a}$ II, $530^{\mathrm{b}} 2 \mathrm{I}$; anatomy of $528^{\mathrm{b}} 18$, $529^{a} 25,531^{a} I$; hermit-crab in $530^{a} 6,548^{a}$ I 8 ; movements of $528^{a} 33$; opercula of $528^{b} 5$, $530^{\mathrm{a}} 21,547^{\mathrm{b}} 4$.

AR. H.A.
Strongylocentrotus $530^{\mathrm{b}} 8$ note.

Strymon $597^{a}$ Io; eels in $592^{a} 7$.

Sturgeon $505^{a}$ I 5 note.

Styrax $534^{\mathrm{b}} 25$.

Subclavian arteries and veins $512^{a}$ $4,513^{\mathrm{b}} 35,514^{\mathrm{a}}$ Io notes.

Suet $487^{\mathrm{l}} 3,5 \mathrm{II}^{\mathrm{b}} 9,520^{\mathrm{a}} 6,52 \mathrm{I}^{\mathrm{b}}$ IO.

Superfoetation, in hare $542^{\mathrm{b}} 32$.

Superfluities, or excretions $487^{\mathrm{a}} 5$.

Sutures of skull $49 \mathrm{I}^{\mathrm{b}} 3,5 \mathrm{I} 6^{\mathrm{a}} \mathrm{I} 4$.

Swallow $487^{\mathrm{b}} 27,618^{\mathrm{a}} 32$; breeding of $544^{a} 26$; colour of $519^{a}$ 6 ; crop of $509^{a} 9$; diet of $592^{b}$ 16 ; gall of $506^{\mathrm{b}} 22$; hibernation, or migration of $600^{\mathrm{a}}$ I 4 , 17, 27 ; hostile to bees $626^{2}$ $8-12$; nesting of $559^{a} 6,563^{a}$ $13,612^{b} 21-31$.

Swallow-chicks, eyes of $508^{\mathrm{b}} 5$, $563^{a} 13$.

Sivan, caeca of $509^{2} 22$; habits of $488^{a} 7,593^{b} 16,615^{a} 31^{-b} 5$; hostilities of $610^{a} \mathrm{I}$; migration of $597^{\mathrm{b}} 3 \mathrm{o}$.

Swarming of bees $627^{a} 1$.

Swart-eagle $618^{\mathrm{b}} 25$.

Swift, Alpine $487^{\mathrm{b}} 26,28$; see also Apus.

Swimming $487^{b}$ I 5 , \&c.

Swine, see Pig.

Sword-fish, gall of $506^{b} 17$; gills of $505^{\mathrm{a}} 19$; parasite of $602^{\mathrm{a}}$ 26-30.

Sword of cuttle-fish, or Sepium $524^{\mathrm{b}} 25$.

Syennesis 5 I I $^{\mathrm{b}} 24,512^{\mathrm{b}} \mathrm{I2}$.

Sylvia orphea $564^{\mathrm{a}} 33$ note.

Synagris $623^{\mathrm{b}}$ I I note; gall of $506^{\mathrm{b}} 16$; gills of $505^{\mathrm{a}} 16$.

Syngnathus $567^{\mathrm{b}} 24, \quad 610^{\mathrm{b}} 6$ notes; see Belone.

Synodon, see Dentex.

Syracuse $559^{\mathrm{b}} 2$.

Syria, lions in $579^{\mathrm{b}} 9$; mules in $491^{\mathrm{a}} 2,577^{\mathrm{b}} 24,580^{\mathrm{b}} 1$; sheep in $606^{a} 13$.

Syrian-grass $627^{\mathrm{b}} \mathrm{I} 7$.

Syrophoenicia $577^{b} 24$.

Syrphus, or Strationys 55 1' 23 note.

Tabanus $55^{\mathrm{b}} 23$ note, $552^{\mathrm{a}} 29$ note; $T$. caecutiens $553^{\text {a }}$ I 5 note.

Tadpoles $568^{\mathrm{a}}$ I, 35 note.

Taenia $55 \mathrm{I}^{\mathrm{a}}$ II note. 


\section{INDEX}

Tail $498^{\mathrm{b}} \mathrm{I} 3$; of birds $504^{\mathrm{a}} 3 \mathrm{I}$; of camel $499^{a} 18$; of fish $504^{b}$ I6: restoration of in lizards $508^{\mathrm{b}} 7$.

Talpa caeca and europaea 49I ${ }^{\mathrm{b}}$ 29 note.

Tame animals $488^{a} 27$.

Tape-worm $603^{\mathrm{b}}$ I 6 note.

Tarentum $63 \mathrm{I}^{\mathrm{a}} \mathrm{I} \mathrm{I}$.

Taste, sense of $492^{\mathrm{b}} 27,532^{\mathrm{b}} 33$, S.c.

Teal $593^{\mathrm{b}} \cdot 19$.

Teats of apes $502^{\mathrm{a}} 34$; of camel $499^{\mathrm{a}} \mathrm{I7}$; of cow $500^{\mathrm{a}} 25$, \& $\mathrm{E}$.

Teeth $493^{\mathrm{a}} 2,501^{\mathrm{a}} 9,516^{\mathrm{a}} 25$; cutting of $587^{\mathrm{b}} \mathrm{I} 4$; of fishes $505^{a} 28$; of horned animals $507^{a} 35$; of horses $576^{a} 7$; of lobster $526^{\mathrm{a}} 30$, \&c.

Temperament of animals 488 12 ,

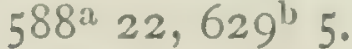

Tenthredo $623^{\mathrm{b}}$ I I, $629^{\mathrm{a}} 3 \mathrm{O}$.

Teredo $605^{\mathrm{b}} \mathrm{I} 6$.

Terrestrial and aquatic animals $487^{a}$ I 5, 589 $13,590^{a}$ I, \&c.

Tessellates, or Pholidotes $490^{b} 24$, $492^{a} 26,503^{a} 8,504^{a} 28,508^{a}$ II, 5 I $7^{\mathrm{b}}$ I $5,594^{\mathrm{a}} 4,599^{\mathrm{a}} 3 \mathrm{I}$, $600^{b} 21$.

Testaceans, see Ostracoderms.

Testicles $497^{\mathrm{a}} 27,493^{\mathrm{a}} 33,500^{\mathrm{l}}$ $4,509^{a} 32, \& c$.

Tetanus, in horses $604^{\mathrm{b}} 4$.

Tethya, see Ascidians.

Tetraptera $490^{\mathrm{a}} 16,532^{\mathrm{a}} 21$.

Tetrix, nest of $559^{\mathrm{a}} 3$.

Tettigometra $556^{\mathrm{b}} 7$.

Tettigonium, or Cicadelle $532^{\mathrm{b}} 18$, $556^{\text {il }} 21$.

Tettix, see Cicada.

Teuthis, see Calamary.

Thargelion $543^{\mathrm{b}} 7,575^{\mathrm{b}}$ 16, 61 $1^{\mathrm{b}}$ 9.

Thasos 549"1 16.

Thebes 500: 4 .

Thelphusa $527^{\mathrm{b}}$ i3 note.

Themiscyra $554^{\circ} \mathrm{g}$.

Themistocles $569^{\text {l. }} 12$.

Thermodon 554" $10,567^{\text {l) }} 17$.

Thespiae $504^{b} 32$ note.

'Thigh 504: 1 .

Thistles $593^{\mathrm{a}} \mathrm{I}, 610^{\mathrm{n}} 5$.

Thoön $5^{13} 3^{\mathrm{b}} 26$.

Thorax 49I" 39.

Thos, see Civet.

Thrace $519^{a} 4,595^{a} 26,606^{\text {b }} 3$, $620^{: 3} 33$.
Thraupis $592^{\mathrm{b}} 30$.

Thritta $62 \mathrm{I}^{\mathrm{b}} \mathrm{I} 6$.

Thrush $593^{\mathrm{b}} 6-617^{\mathrm{b}} 2$; heart of $615^{a} 6$; hibernation of $600^{a} 27$; metamorphosis of $632^{\mathrm{b}} 19$; nest of $559^{a} 5$; species of $617^{a} 18-$ 23.

Thrush, or Wrasse, colour of $607^{\mathrm{b}}$ I 5 ; gills of $505^{\mathrm{a}} 17$; habitat of $598^{\mathrm{a}}$ I I ; pairing of $599^{\mathrm{b}} 8$.

Thunderstorm and sheep $610^{\mathrm{b}} 34$. Thyme $554^{\mathrm{a}}$ IO $626^{\mathrm{b}} 2 \mathrm{I}$.

Thynmus alalonga $570^{\mathrm{b}}$ I 8 note.

Tichodroma muraria $617^{2} 24$ note.

Tick $552^{a}$ I 5 .

Tiger $5 \mathrm{OI}^{\mathrm{a}} 25,3 \mathrm{I}$ notes; hybrid $607^{a} 4$.

Tilon $568^{\mathrm{b}} 26, \quad 602^{\mathrm{b}} 26$; see Sheat-fish.

Tinea $557^{\mathrm{b}} 33$ note.

Tipha $504^{\mathrm{b}} 32$ note.

Tiphe, or Spelt $603^{b} 26$.

Tissues $486^{2} 7$ note.

Titmouse, eggs of $616^{\mathrm{b}} 3$; hostile to bees $626^{\mathrm{a}} 8$; species of $592^{\mathrm{b}}$ I 7-2I.

Toad, black formations in $530^{\mathrm{b}}$ 34 ; hostilities of $609^{a} 24,626^{a}$ 31 ; spleen of $506^{\mathrm{a}} 19$.

Toad-catchers $620^{a} 21$.

Todarodes sagittatus $524^{2} 26,{ }^{\text {b }}$ I2 notes.

Tongue $492^{\mathrm{b}} 27,502^{\mathrm{b}} 35,533^{\mathrm{a}} 24$, \&c.; of birds $504^{a} 35$; of crocodile $503^{a} 1$; of elephant $502^{\mathrm{a}} 3$; of fishes $505^{\mathrm{a}} 29$; of serpent $508^{\mathrm{a}} 22$; of wryneck $504^{\text {il }} 14$.

Tonsils $493^{a} \mathrm{I}$.

Tordylium officinale 6 I I ${ }^{2}$ I 8 note.

Torone $523^{a} 7,530^{b}$ IO, $548^{b} 15$.

Torpedo, or electric ray $540^{\mathrm{b}}$ is ; breeding of $543^{\mathrm{b}} 9,566^{\mathrm{a}} 23,32$; electric shock of $620^{\mathrm{b}}$ 19-29; gall-bladder of $506^{\mathrm{b}} 9$; gills of $505^{\mathrm{a}} 4$; young of $565^{\mathrm{b}} 25$.

Tortoise, bladder of $519^{\mathrm{b}} 15,54^{\mathrm{it}}$ 19-12; black formations in $529^{\mathrm{a}} 23,530^{\text {b }} 34$; copulation of $540^{a} 29$; eggs of $55^{a} 4-7$; gut of $50^{\mathrm{a}} 5$; hiss of $536^{\mathrm{at}} \mathrm{8}$; movements of $503^{\mathrm{b}} 9$; slough of $600^{b} 22$; spleen of $506^{\mathrm{a}} 19$; testicles of $509^{\mathrm{b}} \mathrm{S}$; woml of $510^{b} 35$.

Tortoise, freshwater $600^{1)} 23$; 


\section{INDEX}

breeding of $55 \mathrm{~g}^{\mathrm{a}} 8$; respiration of $589^{a} 29$; spleen of $506^{a}$ I 9 .

Touch $489^{a} 18,24,532^{b} 34$.

Trachinus draco $598^{\mathrm{a}}$ I I note.

Treadles, or Chalazae $560^{a} 28$.

Treatise on Anatomy $497^{2} 32$, $509^{b} 23,525^{a} 8,529^{b} 19,530^{a}$ $31,566^{a}$ I4; on Botany $539^{a}$ 20.

Tree-creeper $593^{\mathrm{a}} 12,616^{\mathrm{b}} 28$.

Tremoctopus $524^{\mathrm{a}} 7$ note.

Trichia, ailment so called $587^{\mathrm{b}}$ 25.

Trichias, breeding of $543^{\mathrm{a}} 5,569^{\mathrm{b}}$ 25 ; migration of $598^{\mathrm{b}} \mathrm{I}$.

Trichis $569^{\mathrm{b}} 26$.

Trichodes (Clerus) alvearius $553^{a}$ 32 note.

Trigle, see Mullet, Red.

Triticum monococcum $603^{\mathrm{b}} 26$ note.

Triton $589^{\mathrm{b}} 28$ note; see Newt.

Tritonium $528^{a}$ Io note.

Trochilus, or Sandpiper $593^{\mathrm{b}} \mathrm{I} 3$; or Crocodile-bird $612^{2} 21$.

Trochus $528^{\mathrm{a}}$ IO note; $530^{\mathrm{a}}$ I4 note.

Trumpet-shell, see Ceryx.

Trunk, of elephant $497^{\mathrm{b}} 25$.

Trygon, or Sting-ray, breeding of $540^{\mathrm{a}} 3 \mathrm{I}, 540^{\mathrm{b}} 8,566^{\mathrm{b}} \mathrm{I}$; fins of $489^{\mathrm{b}} 32$; habitat of $598^{\mathrm{a}}$ I2 ; habits of $620^{\mathrm{b}} 24$; young of $565^{\mathrm{b}} 28$.

Tunny $505^{\mathrm{a}}$ I 5 note, $506^{\mathrm{b}}$ Io note; age and size $607^{\mathrm{b}} 28$; as bait $533^{\mathrm{a}} 33$; breeding of $543^{\mathrm{a}} \mathrm{I}-12$, ${ }^{b} 2,5,12,57 \mathrm{I}^{\mathrm{a}} 8$; diet of $59 \mathrm{I}^{\mathrm{a}}$ II, $59 \mathrm{I}^{\mathrm{b}} \mathrm{I} 8$; eyes of $598^{\mathrm{b}} 2 \mathrm{I}$; fishery of $537^{\mathrm{a}} 20$; growth of $571^{a}$ IO-22; habits of $4^{8} 8^{a} 6$, $598^{\mathrm{a}} 17,602^{\mathrm{a}} 3 \mathrm{I}, 61 \mathrm{1}^{\mathrm{b}} 4$; hibernation of $599^{b} 9$; migration of $597^{\mathrm{a}} 23,598^{\mathrm{a}} 26$, b 19 ; parasite of $557^{\mathrm{a}} 28,602^{\mathrm{b}} 25$; skin of $505^{a} 27$.

Turtle, amphibious $589^{a} 27$; bladder of $506^{\mathrm{b}} 27$; copulation in $540^{a} 29$; diet of $590^{\circ} 4-10$; eggs of $55^{\mathrm{a}}$ II $-\mathrm{I} 4$; stomach of $568^{a} 5$.

Turtle-dove $544^{\mathrm{b}} 7,593^{\mathrm{a}} 9,617^{\mathrm{a}}$ 32 ; breeding of $558^{\mathrm{b}} 23,562^{\mathrm{b}} 4$, $28,613^{a} 14-25$; decoys $613^{a} 22$; diet of $593^{a} 16$; habitat of $613^{b}$ 2 ; habits of $613^{a} 13$; hibernation of $600^{2} 20-25$; hostilities of $609^{a} 18,25,610^{a} 13$; migration of $593^{\mathrm{a}} 17,597^{\mathrm{b}} 5-8,600^{\mathrm{a}}$ $20-25$; noise of $633^{\mathrm{b}} 7$.

Tusks $501^{\mathrm{a}}$ I 5 ; of elephants $50 \mathrm{I}^{\mathrm{b}}$ 32.

Twin eggs $562^{2} 24$.

Twins $584^{\mathrm{b}} 30,586^{\mathrm{a}} 8$, \&c.

Typton spongicola $54^{8^{a}} 28$ note.

Ulysses $575^{\mathrm{a}} \mathrm{I}$.

Umbrina cirrosa $543^{\mathrm{a}} 3 \mathrm{I}, 60 \mathrm{I}^{\mathrm{b}} 3 \mathrm{I}$ notes.

Unbulled kine $595^{\mathrm{b}}$ I 8 .

Univalves $528^{\mathrm{a}} 12,529^{\mathrm{a}} 25^{-\mathrm{b}} 6$, $603^{a} 27$.

Upper and lower parts $494^{\mathrm{a}} 27$.

Uranoscopus scaber $506^{\mathrm{b}}$ Io nate.

Urchin, see Sea-urchin.

Ureters $497^{\mathrm{a}}$ I3.

Urethra $493^{\mathrm{b}} 4$.

Uria $560^{2} 5$; see Wind-eggs.

Urine of animals $573^{\mathrm{a}} \mathrm{I} 5$, \& .

Uvula $493^{a} 3$.

Varicose veins $518^{\mathrm{b}} 26,52 \mathrm{I}^{\mathrm{a}} 20$, $29,587^{\mathrm{b}} 35$.

Veins $487^{\mathrm{a}} 6,489^{\mathrm{a}} 22,5$ II $^{\mathrm{b}}$ II $5 \mathrm{I} 5^{\mathrm{a}} 25,52 \mathrm{O}^{\mathrm{b}} \mathrm{IO}-52 \mathrm{I}^{\mathrm{b}} 2$, \&c.

Venom spider, see Phalangium.

Vermilion $559^{2} 25$.

Vermiparous animals $489^{\mathrm{a}} 35,53^{\mathrm{a}}$ $26,60 I^{2} 5$.

Vertebrae $516^{a}$ II.

Vespa crabro, \&c., $554^{\mathrm{b}} 2 \mathrm{I}, 627^{\mathrm{b}}$ $24,628^{\mathrm{b}} 32$ notes.

Vetch $552^{\mathrm{b}} 29,568^{\mathrm{b}} 23,595^{\mathrm{b}} \cdot 7$, $59^{\mathrm{a}} 26$.

Vine $546^{\mathrm{a}} 2,549^{\mathrm{b}} 33,55^{\mathrm{b}} 3$; tendril of $549^{2} 24,50^{\mathrm{a}}$ I I, 28 .

Vinegar $552^{\mathrm{b}} 5$; vinegar-fly $535^{\mathrm{a}}$ 3 I note.

Viper, hibernation of $599^{\mathrm{b}} \mathrm{I}$; sloughing of $600^{\mathrm{b}} 26$; venom of $607^{\mathrm{a}} 29,6 \mathrm{I} 2^{\mathrm{a}} 24$; viviparous $490^{\mathrm{b}} 25,5$ I I $^{\mathrm{a}} \mathrm{I} 6,55^{\mathrm{a}} 25^{\mathrm{b}} 4$.

Vitelline artery and vein $56 \mathrm{I}^{\mathrm{b}} 6$ note.

Viviparous animals $489^{a} 35$, b II, \&.

Vocal animals $488^{a} 34$.

Voice $535^{\mathrm{a}} 27$; change of $544^{\mathrm{b}} 22$, $581^{\mathrm{a}}$ I7; after castration $632^{\mathrm{a}}$ 5 ; of fishes $535^{\mathrm{b}} \mathrm{I} 4$; \&c.

Vowels $535^{2} 31$.

Vulpanser, or Chenalopex $593^{\mathrm{b}} 25$; wind-eggs in $559^{\mathrm{b}} 29$.

Vulture, hostilities of $609^{\mathrm{b}} 9,34$, 


\section{INDEX}

$610^{a} 1$; nest of $563^{a} 5-12,615^{a}$ $8-14$; species of $592^{\mathrm{b}} 5$.

Wagtail 593 $5,615^{a} 20$.

Waking and sleeping $536^{\mathrm{b}} 24$.

Wasp $487^{a} 22,488^{a} 10,489^{a} 33$, $523^{\mathrm{b}}$ I $9,53 \mathrm{I}^{\mathrm{b}} 22,552^{\mathrm{b}} 27,622^{\mathrm{b}}$ $22,623^{\mathrm{b}} 10$; breeding of $55 \mathrm{I}^{\mathrm{a}}$ $30,554^{b} 22-555^{a} 12,628^{a} 1-b 32$; hostile to bees $626^{a} 8,15,627^{b}$ 5 ; species and habits $627^{\mathrm{b}} 23^{-}$ $35,629^{a} 3^{-26}$; sting of $532^{a} 16$, $628^{\mathrm{b}} 3-24,629^{\mathrm{a}} 26$; vitality of 53 I' 3 I; see also Anthrene, Ichneumon.

Watchmen, or hooers, in tunnyfishery $537^{2} \cdot 19$.

Water, effect on colour of lambs $519^{a} 10$.

Water-bath $633^{a} 29$.

Water-newt, see Newt.

Water-raven, or Cormorant $593^{\mathrm{b}}$ I 8.

Water-snake $487^{\mathrm{a}} 23,508^{\mathrm{b}} \mathrm{I}$.

Wax $623^{\mathrm{b}} 25$.

Weasel $579^{a} 23$; hostile to birds and to snakes $609^{a} 17,{ }^{b} 28,612^{a}$ $28, \mathrm{~b}$ I ; penis of $500^{\mathrm{b}} 24$; at Pordoselene $605^{\mathrm{b}} 30$.

Weaver-fish, habitat of $598^{\mathrm{a}}$ II.

Web-footed birds $504^{\mathrm{a}} 7,32,593^{\mathrm{a}}$ $27,{ }^{b} 17,615^{a} 24,32$.

Whale, blowhole of $489^{\mathrm{b}} 4,566^{\mathrm{b}} 2$; reproduction of $566^{\mathrm{b}} 2-7$; respiration of $589^{\text {b }} 2$; sleep of $537^{\mathrm{a}} 32$; teats of $52 \mathrm{I}^{\mathrm{b}} 24$.

Whey $521^{\mathrm{b}} 27$.

Whitebait $569^{a} 21$.

White-rump $593^{\mathrm{b}} 6$.

White-sickness 5 I $8^{\mathrm{a}}$ I2.

Wild and tame animals $488^{2} 27$.

Wild boar $488^{\mathrm{a}} 30,{ }^{\mathrm{b}}$ I $5,499^{\mathrm{a}} 5$, $57 I^{b}$ I $3-21,578^{a} 26-b 6,594^{b}$ IO.

Wild cattle, or Buffaloes $499^{2} 5$.

Wild-fig $554^{\mathrm{a}} \mathrm{I} 5,557^{\mathrm{b}} 25-3 \mathrm{I}$.

Wild-limpet $529^{\mathrm{b}} 15$.

Wild-louse $557^{\mathrm{a}} 5$.

Wind-eggs $539^{a} 31,559^{b} 21-560^{\text {b }}$ I 8 .

Windpipe $492^{\mathrm{b}}$ I I, $493^{\mathrm{a}} 7,495^{\mathrm{a}} \mathrm{2}$, $496^{a} 29,505^{b} 33.507^{a} 24$.

winds, influence on breeding of sheep $573^{\mathrm{b}} 34$; Etesian $559^{\mathrm{b}} 30$ note.

Wine $588^{a} 5$.

Winglets or fins $489^{b} 24$, \&c.

Wings $487^{\mathrm{b}} 19,490^{\mathrm{a}} 6,503^{\mathrm{b}} 33$, \&. . ; leathern $487^{\mathrm{b}} 23,490^{\mathrm{a}} 8$.

Wisdom-teeth $50 \mathrm{I}^{\mathrm{b}} 24$.

Withy $627^{a} 9$.

Wolf $579^{\mathrm{b}}$ I 5 ; breeding of $540^{\mathrm{a}} 9$, $580^{a}$ II-23; diet of $594^{a} 26-31$; in Egypt $606^{a} 23,26$; friendly to fishermen $620^{\mathrm{b}} 6$; hostilities of $595^{\mathrm{b}} \mathrm{I}, 609^{\mathrm{b}} \mathrm{I}$; hybrid $607^{\mathrm{a}}$ 2 ; penis of $500^{\mathrm{b}} 24$; and sheep $596^{\mathrm{b}} 8,612^{\mathrm{b}} 2$; teeth of $507^{\mathrm{b}} 17$; temper of $488^{\mathrm{a}} 28,571^{\mathrm{b}} 27$.

Wolf, a jackdaw so called $617^{\mathrm{b}} \mathrm{I} 7$.

Wolf-spider $622^{\mathrm{b}} 30$.

Womb $489^{b} 12,493^{a} 24,497^{a} 34$, $510^{\mathrm{b}} 6, \& \mathrm{c}$.

Wood cock $614^{2} 33,617^{\mathrm{b}} 23$.

Wood-lice $557^{\mathrm{a}} 24$.

Woodpecker $617^{2} 27$; description and species $593^{a} 3-14$; habits of $614^{\text {b }} 1-18$; hostilities of $609^{\text {a }}$ 8, 30; Green, or Celeus, claw's of $504^{\mathrm{a}} 19$; description of $593^{\mathrm{il}}$ 8 ; hostilities of $609^{a} 19,610^{a} 9$.

Vorms, intestinal, or Helminthes $551^{\mathrm{a}} 8$; parasitic in fish $602^{\mathrm{b}} 26$; in dogs $612^{a} 32$.

Wrasse $505^{a} 16$ note; colour and species of $607^{\mathrm{b}} 15$; see also Owzel, Thrush. Parrot-wrasse $505^{\text {a }}$ I 4 note; see also Scarus.

Wren, $612^{a} 20$ note; habits of $615^{a}$ 17 ; hostilities of $609^{\mathrm{a}} 12,{ }^{\mathrm{b}} 12$; golden-crested $592^{\mathrm{b}} 23$.

Wrist $494^{a} 2$.

Wryncck, or Yunx, description of $504^{23} 12-19$.

Xanthus 5 I $9^{a} 19$.

Yellow River, or Scamander $519^{a}$ 10.

Yolk of egg $560^{2} 20$, Sc.

Yunx, sie I'ry'neck.

Zephyr-eggs $560^{2} 6$; see Windexgs.

Zeus faber $535^{\mathrm{b}}$ i $7,602^{\mathrm{b}} 2 \mathrm{~S}$ notes.

Zignis 604" 24 .

Zostera $591^{3} 16$.

Oxford: I'rinted at the Clarendon l'ress by Horace Hant, M.A. . 


UNIVERSITY OF ILLINOIS-URBANA

590AR41910

$\mathrm{CO01}$

HISTORIA ANIMALIUMS OXFORD

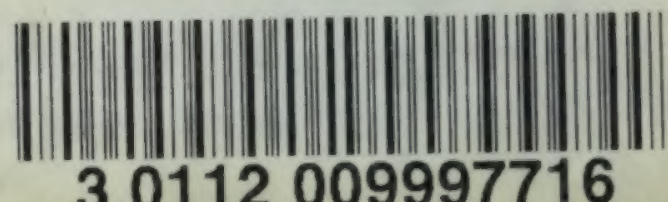

